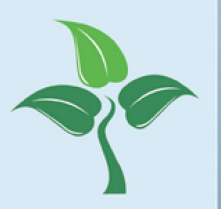

\title{
sustainability
}

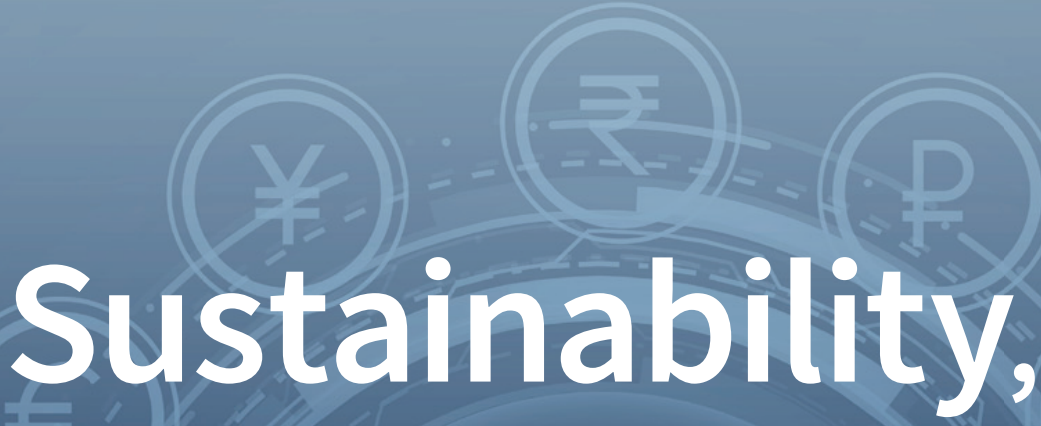

Digital

Eransformation

and Fintech

The New Challenges of the Banking Industry

Edited by Andrea Pérez

Printed Edition of the Special Issue Published in Sustainability 


\section{Sustainability, Digital Transformation and Fintech: The New Challenges of the Banking Industry}





\section{Sustainability, Digital Transformation and Fintech: The New Challenges of the Banking Industry}

Editor

Andrea Pérez 
Editor

Andrea Pérez

University of Cantabria

Spain

\section{Editorial Office}

MDPI

St. Alban-Anlage 66

4052 Basel, Switzerland

This is a reprint of articles from the Special Issue published online in the open access journal Sustainability (ISSN 2071-1050) (available at: https://www.mdpi.com/journal/sustainability/ special_issues/sustainability_digital_transformation_fintech_banking_industry).

For citation purposes, cite each article independently as indicated on the article page online and as indicated below:

LastName, A.A.; LastName, B.B.; LastName, C.C. Article Title. Journal Name Year, Volume Number, Page Range.

ISBN 978-3-0365-2740-6 (Hbk)

ISBN 978-3-0365-2740-6 (PDF)

(C) 2021 by the authors. Articles in this book are Open Access and distributed under the Creative Commons Attribution (CC BY) license, which allows users to download, copy and build upon published articles, as long as the author and publisher are properly credited, which ensures maximum dissemination and a wider impact of our publications.

The book as a whole is distributed by MDPI under the terms and conditions of the Creative Commons license CC BY-NC-ND. 


\section{Contents}

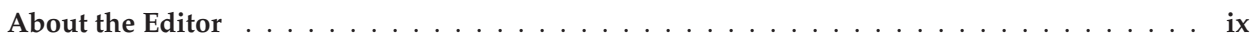

Preface to "Sustainability, Digital Transformation and Fintech: The New Challenges of the

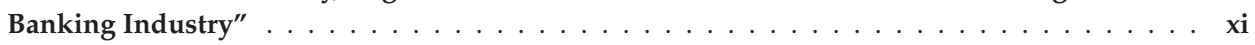

Marc Sanchez-Roger and Esther Puyol-Antón

Digital Bank Runs: A Deep Neural Network Approach

Reprinted from: Sustainability 2021, 13, 1513, doi:10.3390/su13031513 . . . . . . . . . . . . . 1

Beniamino Callegari and Ranvir S. Rai

Blending in: A Case Study of Transitional Ambidexterity in the Financial Sector

Reprinted from: Sustainability 2021, 13, 1690, doi:10.3390/su13041690 . . . . . . . . . . . . . 19

Florian Diener and Miroslav Špaček

Digital Transformation in Banking: A Managerial Perspective on Barriers to Change

Reprinted from: Sustainability 2021, 13, 2032, doi:10.3390/su13042032 . . . . . . . . . . . . . 37

Su-Chang Chen, Kuo Cheng Chung and Ming Yueh Tsai

How to Achieve Sustainable Development of Mobile Payment through Customer Satisfaction-The SOR Model

Reprinted from: Sustainability 2019, 11, 6314, doi:10.3390/su11226314 . . . . . . . . . . . . 63

Komlan Gbongli, Yongan Xu, Komi Mawugbe Amedjonekou and Levente Kovács

Evaluation and Classification of Mobile Financial Services Sustainability Using Structural

Equation Modeling and Multiple Criteria Decision-Making Methods

Reprinted from: Sustainability 2020, 12, 1288, doi:10.3390/su12041288 . . . . . . . . . . . . . 79

Alfonso Siano, Lukman Raimi, Maria Palazzo and Mirela Clementina Panait

Mobile Banking: An Innovative Solution for Increasing Financial Inclusion in Sub-Saharan

African Countries: Evidence from Nigeria

Reprinted from: Sustainability 2020, 12, 10130, doi:10.3390/su122310130 . . . . . . . . . . . 113

HaeOk Choi and KwangHo Lee

Micro-Operating Mechanism Approach for Regulatory Sandbox Policy Focused on Fintech

Reprinted from: Sustainability 2020, 12, 8126, doi:10.3390/su12198126 . . . . . . . . . . . . . 137

Jelena Kabulova and Jelena Stankevičienè

Valuation of FinTech Innovation Based on Patent Applications

Reprinted from: Sustainability 2020, 12, 10158, doi:10.3390/su122310158 _ . . . . . . . . . . . 149

Jinpei Liu, Mengdi Fang, Feifei Jin, Chengsong Wu and Huayou Chen

Multi-Attribute Decision Making Based on Stochastic DEA Cross-Efficiency with Ordinal

Variable and Its Application to Evaluation of Banks' Sustainable Development

Reprinted from: Sustainability 2020, 12, 2375, doi:10.3390/su12062375 . . . . . . . . . . . . . 165

Xue Wang and Guangwen He

Digital Financial Inclusion and Farmers' Vulnerability to Poverty: Evidence from Rural China

Reprinted from: Sustainability 2020, 12, 1668, doi:10.3390/su12041668 . . . . . . . . . . . . 181 
Juan Camilo Mejia-Escobar, Juan David González-Ruiz and Eduardo Duque-Grisales Sustainable Financial Products in the Latin America Banking Industry: Current Status and Insights

Reprinted from: Sustainability 2020, 12, 5648, doi:10.3390/su12145648 . . . . . . . . . . . . . . 199

Sergio Luis Náñez Alonso, Javier Jorge-Vazquez and Ricardo Francisco Reier Forradellas

Detection of Financial Inclusion Vulnerable Rural Areas through an Access to Cash Index:

Solutions Based on the Pharmacy Network and a CBDC. Evidence Based on Ávila (Spain)

Reprinted from: Sustainability 2020, 12, 7480, doi:10.3390/su12187480 . . . . . . . . . . . . . 225

Andrea Pérez, María del Mar García de los Salmones and Elisa Baraibar-Diez

Effects of the Type of CSR Discourse for Utilitarian and Hedonic Services

Reprinted from: Sustainability 2020, 12, 4821, doi:10.3390/su12124821 . . . . . . . . . . . . . 259

Naveed Ahmad, Rana Tahir Naveed, Miklas Scholz, Muhammad Irfan, Muhammad Usman and Ilyas Ahmad

CSR Communication through Social Media: A Litmus Test for Banking Consumers' Loyalty

Reprinted from: Sustainability 2021, 13, 2319, doi:10.3390/su13042319 . . . . . . . . . . . . . . . 281

Zia Ur Rehman, Muhammad Zahid, Haseeb Ur Rahman, Muhammad Asif, Majed Alharthi, Muhammad Irfan and Adam Glowacz

Do Corporate Social Responsibility Disclosures Improve Financial Performance? A Perspective of the Islamic Banking Industry in Pakistan

Reprinted from: Sustainability 2020, 12, 3302, doi:10.3390/su12083302 . . . . . . . . . . . . . 297

Francesco Manta, Annunziata Tarulli, Domenico Morrone and Pierluigi Toma

Toward a Quadruple Bottom Line: Social Disclosure and Financial Performance in the Banking Sector

Reprinted from: Sustainability 2020, 12, 4038, doi:10.3390/su12104038 - . . . . . . . . . . . 315

Esther Ortiz-Martínez and Salvador Marín-Hernández

European Financial Services SMEs: Language in Their Sustainability Reporting

Reprinted from: Sustainability 2020, 12, 8377, doi:10.3390/su12208377 . . . . . . . . . . . . . 333

Begoña Torre Olmo, María Cantero Saiz and Sergio Sanfilippo Azofra

Sustainable Banking, Market Power, and Efficiency: Effects on Banks' Profitability and Risk

Reprinted from: Sustainability 2021, 13, 1298, doi:10.3390/su13031298 . . . . . . . . . . . . . 353

Luning Shao, Jianxin You, Tao Xu and Yilei Shao

Non-Parametric Model for Evaluating the Performance of Chinese Commercial Banks'

Product Innovation

Reprinted from: Sustainability 2020, 12, 1523, doi:10.3390/su12041523 . . . . . . . . . . . . . . 377

\section{Sang-Giun Yim}

The Influence of IFRS Adoption on Banks' Cost of Equity: Evidence from European Banks

Reprinted from: Sustainability 2020, 12, 3535, doi:10.3390/su12093535 . . . . . . . . . . . . . 393

Jooyong Jun and Eunjung Yeo

Peer-to-Peer Lending and Bank Risks: A Closer Look

Reprinted from: Sustainability 2020, 12, 6107, doi:10.3390/su12156107 . . . . . . . . . . . . . 409

\section{Xiaofeng Hui and Aoran Zhang}

Construction and Empirical Research on the Dynamic Provisioning Model of China's Banking

Sector under the Macro-Prudential Framework

Reprinted from: Sustainability 2020, 12, 8527, doi:10.3390/su12208527 . . . . . . . . . . . . . . . 427 
Changjun Zheng, Probir Kumar Bhowmik and Niluthpaul Sarker

Industry-Specific and Macroeconomic Determinants of Non-Performing Loans: A Comparative Analysis of ARDL and VECM

Reprinted from: Sustainability 2020, 12, 325, doi:10.3390/su12010325

Li Liu, Yu-Min Liu, Jong-Min Kim, Rui Zhong and Guang-Qian Ren

Analysis of Tail Dependence between Sovereign Debt Distress and Bank Non-Performing Loans

Reprinted from: Sustainability 2020, 12, 747, doi:10.3390/su12020747 . . . . . . . . . . . . . . . 471

Teodor Hada, Nicoleta Bărbuță-Mișu, Iulia Cristina Iuga and Dorin Wainberg

Macroeconomic Determinants of Nonperforming Loans of Romanian Banks

Reprinted from: Sustainability 2020, 12, 7533, doi:10.3390/su12187533 . . . . . . . . . . . . . . . 491

Ha Nam Khanh Giao, Bui Nhat Vuong, Dao Duy Huan, Hasanuzzaman Tushar and Tran Nhu

Quan

The Effect of Emotional Intelligence on Turnover Intention and the Moderating Role of Perceived Organizational Support: Evidence from the Banking Industry of Vietnam

Reprinted from: Sustainability 2020, 12, 1857, doi:10.3390/su12051857 . . . . . . . . . . . . . . 511

Di Johnson, John Rodwell and Thomas Hendry

Analyzing the Impacts of Financial Services Regulation to Make the Case That Buy-Now-Pay-Later Regulation Is Failing

Reprinted from: Sustainability 2021, 13, 1992, doi:10.3390/su13041992 ․ . . . . . . . . . . . . 537

Ana Alvarenga, Florinda Matos, Radu Godina and João C. O. Matias

Digital Transformation and Knowledge Management in the Public Sector

Reprinted from: Sustainability 2020, 12, 5824, doi:10.3390/su12145824 . . . . . . . . . . . . . . . 557 



\section{About the Editor}

Andrea Pérez is an Assistant Professor who teaches in the areas of strategic marketing, distribution channels, and marketing communications. Her research interests focus on corporate social responsibility, consumer behavior, and corporate marketing in the banking and tourism industries. She has published more than 70 articles in international journals of recognized prestige. She has participated in numerous scientific congresses and has participated in the elaboration of several books/chapters in the field of corporate marketing and corporate social responsibility. She has held teaching and research stays at several international universities and research centers such as the Center for Business Ethics (Bentley University, USA) and the Center for Business, Organizations and Society (University of Bath, UK), among others. 



\section{Preface to "Sustainability, Digital Transformation and Fintech: The New Challenges of the Banking Industry"}

The banking industry in the XXI century faces an increasingly competitive, complex, and fast moving business scenario. Financial and banking institutions must contend with multiple challenges tied to new regulations, legacy systems, disruptive models, new technologies, new competitors, and a restive customer base, while pursuing revolutionary strategies for sustainable growth. Banking institutions that can address these emerging challenges and opportunities to effectively balance long-term goals with short-term performance pressures will amply stakeholder rewards, as well as the market. Along this line, this book tries to assist banking industry researchers and practitioners to identify current concerns and relevant topics for an equilibrium between banking business needs and the needs of the society where these institutions are embedded. These needs are closely linked to sustainability, corporate social responsibility (CSR), financial inclusion, and banking literacy. For this purpose, the book comprises a selection of papers addressing some of the most relevant challenges and opportunities for the sustainability of international banking institutions. Papers in this collection cover the most recent lines of banking research and are all novel propositions that deepen the analysis of business strategies in the banking industry. In total, a selection of 28 papers form this book, covering topics such as the digital transformation of the banking industry and its effect on sustainability, the emergence of new competitors such as FinTech companies, the role of mobile banking in the industry, the connections between sustainability and financial performance, and other general sustainability and CSR topics related to the banking industry, such as social disclosure and online communication through social media. Contributors to the book represent a wide spectrum of nationalities from all over the globe. Papers come from the United States, Australia, the United Kingdom, China, Sweden, Russia, Spain, the Czech Republic, Italy, Norway, Lithuania, Nigeria, Romania, Korea, Portugal, Colombia, Saudi Arabia, Poland, Vietnam, Bangladesh, Thailand, Hungary, and Taiwan. Therefore, this book provides an unprecedented opportunity to reflect upon the most current research of the banking industry from an enriched multicultural perspective. The book is a Special Issue of the MDPI journal Sustainability, which has been sponsored by the Santander Financial Institute (SANFI), a Spanish research and training institution created as a collaboration between Santander Bank and the University of Cantabria. SANFI works to identify, develop, support, and promote knowledge, study, talent, and innovation in the financial sector.

Andrea Pérez

Editor 



\title{
Digital Bank Runs: A Deep Neural Network Approach
}

\author{
Marc Sanchez-Roger ${ }^{1, *}$ and Esther Puyol-Antón ${ }^{2}$ \\ 1 Independent Researcher, London, UK \\ 2 School of Biomedical Engineering \& Imaging Sciences, King's College London, London SE1 7EH, UK; \\ esther.puyol_anton@kcl.ac.uk \\ * Correspondence: marc.sanchez.roger@gmail.com
}

Citation: Sanchez-Roger, M.; Puyol-Antón, E. Digital Bank Runs: A Deep Neural Network Approach. Sustainability 2021, 13, 1513. https:// doi.org/10.3390/su13031513

Academic Editors: Andrea Pérez and Hirofumi Fukuyama

Received: 31 December 2020

Accepted: 28 January 2021

Published: 1 February 2021

Publisher's Note: MDPI stays neutral with regard to jurisdictional claims in published maps and institutional affiliations.

Copyright: (c) 2021 by the authors. Licensee MDPI, Basel, Switzerland. This article is an open access article distributed under the terms and conditions of the Creative Commons Attribution (CC BY) license (https:// creativecommons.org/licenses/by/ $4.0 /)$.

\begin{abstract}
The introduction of Central Bank Digital Currency (CBDC) could represent a deep structural change to the financial sector, and in particular to the banking sector. This paper proposes a Deep Neural Network (DNN) design to model the introduction of CBDC and its potential impact on commercial banks' deposits. The model proposed forecasts the likelihood of the occurrence of bank runs as a function of the system characteristics and of the intrinsic features of CBDC. The success rate of $C B D C$ and the impact on the banking sector is highly dependent on its design. Whether CBDC should carry any form of interest, if the amount of CBDC should be capped by account or if convertibility from banks' deposits should be guaranteed by commercial banks are important features to consider. Further, the design of CBDC needs to contribute to enhancing the sustainability of the financial system, hence a CBDC design that promotes financial inclusion is paramount. The model is initially calibrated with Euro area system data. Results show that an increase in the financial system risk perception would trigger a significant transfer of wealth from bank deposits to CBDC, while the wealth transfer to CBDC is to a lesser extent also sensitive to its interest rate.
\end{abstract}

Keywords: CBDC; digital currency; bank run; banking; central bank

\section{Introduction}

Central Bank Digital Currency (CBDC) can be understood as a new form of central bank money that is different from the two types of money currently issued by central banks, which are physical cash and reserves. CBDC would represent a digital form of money, denominated in the national unit of account that is a direct liability of the central bank and intended to serve as legal tender [1,2].

The concept of public access to Central Bank deposit accounts is not by any means new, with the first public bank in Europe being the Taula de Canvi de Barcelona in 1401 which offered the possibility of opening deposit accounts to the population [3]. A walk through the first types of central bank money suggests that broadly accessible central bank deposits were the original form of central bank monetary liabilities. Neither banknotes nor commercial bank deposits were the common form of money over the last centuries, with the current limitation for the general population to access central bank accounts being introduced less than a century ago [4].

The introduction of CBDC could have important implications regarding the sustainability of the financial system, and in particular about financial inclusion. Indeed, Central Banks seem to consider financial inclusion as one of the most relevant reasons which support the introduction of CBDC [5]. This shows the strong link between CBDC and sustainability and leads us to consider financial inclusion as a key parameter when designing a CBDC.

We note that several countries and regions have concluded or are currently engaged in experiments and pilot tests to better understand the implications of introducing CBDC, including Ecuador, Ukraine, Uruguay, Bahamas, Cambodia, China, the Eastern Caribbean Currency Union, Korea, and Sweden [6]. In particular, the experiment to introduce CBDC 
in Uruguay was part of a financial inclusion program [5], which shows again the relevance for Central Banks of developing a CBDC which contributes to promoting the sustainability of the financial system. In the case of Bahamas, CBDC was officially launched in October 2020 as announced by the Bahamas Central Bank [7].

In this paper, we assume that the introduction of $\mathrm{CBDC}$ does not eradicate the fractional reserve system, with commercial banks still offering deposits [8]. However, other authors claim that the direction of travel is to fully phase-out commercial banks' deposits into CBDC, hence leading to an economy based on "public money", also known as sovereign money [9]. It is out of the scope of this paper to analyze the trade-offs of allowing CBDC to coexist with commercial banks' deposits versus fully phasing-out banks' deposits.

The issuance of CBDC only accessible to a subset of the economy has been also explored by the current literature, including the concepts of "retail CBDC" which could be used by households and non-financial businesses, and/or "wholesale CBDC" designed to be used by financial corporations [10]. In this paper, we embrace the comprehensive version of CBDC, which could be understood as a universal CBDC accessible by the general public, including households and non-financial businesses, as well as financial corporations.

Differences in the structure of legal claims and the Central Bank's records are also important features. As per the current literature, we can identify three potential CDBC architectures, including indirect $\mathrm{CBDC}$, direct $\mathrm{CDBC}$, and hybrid $\mathrm{CDBC}$ [11]. In the case of indirect or synthetic $\mathrm{CDBC}$, the claim is not on the Central Bank, and this form of CBDC could be understood as private sector financial corporations or e-money providers, issuing liabilities matched by funds held at the central bank [12]. In the case of Direct CBDC, the claim is on the Central Bank, while the Central Bank also handles the payments. Hybrid CBDC provides a direct claim on Central Bank; however, there are intermediaries to handle the payments.

The CBDC infrastructure is also a relevant issue to address [11]. As the authors of that paper describe, conventional infrastructures store data several times in separate physical locations, with data stored in multiple nodes and controlled by one authoritative entity. On the other hand, DLT-based infrastructures differ from conventional infrastructures given that the ledger is managed by different entities, without an authoritative entity, and in a decentralized model. The analysis of the potential tradeoffs is out of the scope of this paper. Note that this paper focuses on studying a system where the CBDC is introduced under the form of deposit based CBDC, disregarding a digital token currency.

The literature on CBDC covers a wide range of topics, from monetary policy or financial system stability to technology and computer science [13-17]. In particular, the current literature on CBDC shows a significant number of papers produced by institutions such as Central Banks, the International Monetary Fund (IMF), or the Bank for International Settlements (BIS), while a strong contribution from mainstream academia is also increasing. This highlights the relevance of the topic and the potential system-changing implications of CBDC for the entire financial and economic system.

Despite the interest in researching the uses and advantages of $\mathrm{CBDC}$, the new form of money is not exempt from criticism. While one could perceive some central banks more inclined to consider the acceptance of CBDC in the future, other central banks consider that its introduction would not represent a substantial improvement [18]. In particular, the authors of that report [18] highlight that (i) it is difficult to see what CBDC would be able to contribute that it is not yet covered by the payment systems already in place, (ii) issuing CBDC would make a National Central Bank a competitor to commercial banks in some areas, and (iii) the introduction on CBDC would lead to risks to the financial stability including an increase of systemic bank runs.

Other literature suggests that the introduction of CBDC does not need to have a negative impact on banks' lending rates and that a well-designed CBDC will not threaten financial stability $[19,20]$. However, the literature analyzing the impacts of CBDC on the banking sector is still at its early stages. Despite the relatively limited number of 
academic articles on the subject, a passionate debate is building up between defendants and opponents to the introduction of CBDC. This paper focuses on the implications of CBDC for the banking sector, and in particular, it focuses on bank runs.

The traditional banking business model, in which maturity transformation is at the core of its activity, is intrinsically fragile due to the threat of a sudden and significant number of deposit withdrawals taking place in a short time frame, which could lead to a shortfall in liquidity deriving into insolvency [21]. This mechanism, known as a bank run, has been widely studied in academic literature [22-24].

This work explores the concept of Digital Bank Run, understood as a bank run that takes place in a commercial bank where depositors (retail and wholesale) withdraw their deposits and place them in digital currencies. In particular, this work focuses on the different designs that could shape CBDC to understand and minimize the risks for the financial sector. The design of CBDC is still under discussion, and the final characteristics of it will determine its failure or success. In line with this, the literature has identified several important features of CBDC that is worth exploring, such as (i) adding limits to the amount of CBDC that could be stored by account, (ii) allowing CBDC to carry positive or negative interest rates, and (iii) warranting commercial banks' services to offer full convertibility from banks' deposits to CBDC, amongst others [25]. In this paper, we explore the likelihood of digital bank runs, testing different CBDC designs, varying its interest rates and under different levels of systemic risk.

In line with the above, understanding the potential effects of each of these features is paramount in assessing the impact of the introduction of CBDC on the financial sector. This work contributes to this complex task by designing a scalable Neural Network framework based on Deep Learning techniques initially calibrated with system-wide Euro area data. To the best of the authors' knowledge, this work represents an innovative approach to assessing how the different designs of CBDC could impact the banking sector.

We note that the ultimate goal of this work is to show the adequacy of Deep Neural Networks (DNN) as a tool to analyze the impact of the introduction of CBDC, rather than obtaining numeric conclusions from the specific scenario under analysis in the results section.

After this brief introduction, this paper is organised as follows. Section 2 comments on the impacts of CBDC on the banking sector, focusing particularly on the phenomena of bank runs. Section 3 presents the Deep Learning Neural Network model and describes the different scenarios and data used to calibrate the model. Section 4 presents the results, followed by the discussion section. Finally, Section 6 concludes.

\section{Theoretical Background}

Understandably, the introduction of CBDC could entail significant structural changes in the banking sector, which will vary very much depending on the features and the design of the CBDC.

The introduction of CBDC could lead to a disciplining effect on banks, which means that banks would be under the constant threat of bank runs [8]. In line with this, it could be understood that CBDC will have an impact on commercial bank business models, with expected flows of commercial bank deposits into CBDC. This could lead banks to prevent a loss of deposits by increasing interest rates offered in customer deposits, which could lead banks to seek alternatives to maintain profitability such as raising lending costs and increasing fees, ultimately leading to a reduction on banks' balance sheets [2]. The introduction of CBDC could facilitate the transfer of deposits from commercial banks to Central Banks since CBDC could be perceived as a risk-free option to store and protect wealth in economic stressed scenarios [26].

The current literature has briefly explored the steps that could be taken to limit the risk of bank runs as a result of the introduction of CBDC by adding frictions discouraging large amounts of deposit transfers from commercial banks to Central Banks. These frictions include limiting or capping the maximum amount to be deposited in CBDC accounts, 
adopting a flexible approach with different tiers regarding the interest paid on CBDC deposits, or imposing fees on large amounts deposited in CBDC accounts [27]. Other proposals include limitations such as removing the requirement for banks to convert deposits to CBDC [25]. The authors of that paper suggest a set of core principles for CBDC, including (i) CBDC paying an adjustable interest rate, (ii) $\mathrm{CBDC}$ and reserves to be distinct and not convertible to one another, (iii) no guaranteed on-demand convertibility of bank deposits into CBDC, and (iv) central bank can only issue CBDC against eligible securities such a government bond. The authors suggest that by following these principles the introduction of CBDC should not necessarily impact neither banks' provision of credit to borrowers nor banks' provision of liquidity to depositors.

Next, we briefly describe some of the key features of CBDC. The model proposed in this paper allows the simulation of the potential impact of the different combination of features and its potential impact on the distribution of wealth between cash, commercial bank deposits, other financial assets and CBDC. In other words, the DNN proposed in this work allows us to understand the transfer of funds from commercial bank deposits to CBDC under different scenarios, and hence to assess the likelihood of a bank run depending on the design of the CBDC.

- Interest on CBDC: We could see CBDC without interest as a partial substitute of cash, while a CBDC with interest could be rather seen as a substitute of commercial bank deposits. However, in times of economic stress, we could expect depositors to convert commercial bank deposits into CBDC even if CBDC rate is set at zero (or negative). This differs from depositors converting their commercial bank deposits into cash, since holding significant amounts of cash entails non-negligible storage risks (or costs). One of the hypotheses of this work is the use of CBDC interest (positive, zero, or negative) to counterbalance the increased risks linked to bank runs. This hypothesis has been tested and the results are shown and discussed in Section 5 of this paper.

- Limit the amount of CBDC per account: The limit on holdings of CBDC by account could potentially limit the value and number of transactions that could be made using CBDC, and hence, reduce the effectiveness of CBDC as a payment system [18] However, limiting the holdings of CBDC would, to some extent, potentially mitigate the risk of digital bank run. This feature can be easily integrated into the proposed model by just capping the CBDC output to a given value. This is also discussed later in Section 5.

- Convertibility of bank deposits into CBDC: Focusing on a new system where CBDC will coexist with commercial bank deposits and cash, [25] consider the no guaranteed on-demand convertibility of commercial bank deposits into CBDC as one of the key features of CBDC. As the authors describe, making the conversion credible even in stressed situations would involve the central bank also guaranteeing convertibility, which would lead the central bank to provide CBDC against bank commercial deposits. Kumhof and Noone consider that as long as there is a market where commercial bank deposits can be traded against CBDC and CBDC eligible securities (such as government bonds), there would be no need to force commercial banks to accept a guaranteed convertibility of bank deposits into CBDC. However, this proposal has been criticized by other authors, who suggest that this goes against one of the basic principles of CBDC to safeguard the confidence in commercial banks' deposits and the financial system itself, hence potentially having spillover effects to the wider economy [13,27]. This could be implemented in the model proposed in this paper by adding a new input for each financial asset which would model the degree of convertibility. These inputs would equal 1 if commercial banks are required to fully convert deposits into CBDC on demand, while will decline as the difficulty to convert a financial asset into CBDC (and vice-versa) increases.

- Full migration of commercial bank deposits into CBDC: Some researchers propose the phase-out of all commercial bank deposits into CBDC, or what is known as sovereign money [28]. The model proposed in this work could also introduce this variant by 
phasing-out (or switching instantly) commercial bank deposits into CBDC. However, this paper does not go down this route since the matter of full migration of commercial bank deposits into CBDC is out of the scope of this analysis.

Our work concurs with most of the current academic literature in the field of CBDC stressing the importance of the design and features of the CBDC $[25,29]$. Academic literature shows that prediction algorithms based on artificial intelligence have a wide range of applications and generally the results obtained are superior to those obtained through traditional statistical methods when applied to financial analyses [30,31]. In order to allow testing of the different CBDC features in a safe environment, this work presents an artificial intelligence model, based on deep learning, that allows the development of this task. The next section briefly explains the methodology applied and describes the different scenarios.

\section{Materials and Methods}

Financial prediction analyses are of great practical and theoretical interest. However, they are notoriously difficult, primarily driven by the non-linear and complex interactions in the data. Most of the mathematical techniques used in the field of computational finance for financial prediction use parametric and non-parametric statistical techniques [32]. An important limiting factor in the performance of statistics-based techniques in computational finance is the uncertainty inherent in any financial transaction, which leads to less accurate statistics-based financial models.

During the past few years, DNNs have achieved enormous success in many data prediction fields such as speech recognition, computer vision, or natural language processing, to name but a few. In this paper, we apply deep learning methods to forecast the likelihood of the occurrence of bank runs as a function of the intrinsic features of CBDC and also external factors such as systemic risk. The proposed deep learning-based model has several advantages over traditional statistical methods, which include (i) input data can be expanded to include all items of possible relevance to the predictor model; (ii) fewer assumptions than statistical models, which allow the model to be more generalizable; and (iii) non-linearities and complex interactions among input data are modelled by the deep learning models, which can help increase in-sample fit versus traditional models.

\subsection{Method: Deep Neural Network Architecture}

In this section, we describe the details of the Deep Neural Network (DNN) model we train to assess the likelihood of bank run when the CBDC is introduced. First, we provide the details of the DNN model and then we provide the details of the training and evaluation.

A DNN consists of multiple fully-connected (FC) layers: an input layer, one or multiple hidden layers, and a single output layer [33]. DNNs have a single input layer and a single output layer, and the number of neurons (also referred as units) in the input layer equals the number of input variables in the data being processed. The number of neurons in the output layer equals the number of outputs associated with each input.

In a FC layer, all output activations are composed of a weighted sum of all input activations (i.e., all outputs are connected to all inputs). More specifically, for each hidden unit $\mathrm{k}$, a non-linear activation function $f(\cdot)$ is used to map all inputs from the lower layer, $x_{k}$, to a scalar state, $y_{k}$, which is then fed to the upper layer $y_{k}=f\left(x_{k}\right)$, where $x_{k}=b_{k}+\sum_{i} y_{i} w_{i k}$ and $b_{k}$ is the bias unit $k, i$ is the unit index of the lower layer and $w_{i k}$ is the weight of the connection between the unit $\mathrm{k}$ and $\mathrm{i}$ in the layer below. In this work, we select the leaky rectified linear unit (ReLU) as the activation function $f(\cdot)$ for the hidden layers and the Softmax function for the output layer:

$$
f_{\text {leaky } \operatorname{ReLU}}(x)=\left\{\begin{array}{c}
x \text { if } x>0 \\
0.01 x \text { otherwise }
\end{array} \text { and } f_{\text {Sotmax }}\left(x_{i}\right)=\frac{e^{x_{i}}}{\sum_{j} e^{x_{j}}}\right.
$$


The neurons of the network jointly implement a complex non-linear mapping from the input to the output. This mapping is learned from the data by adapting the weights of each neuron using the back-propagation algorithm.

In this study, DNN is used as a multivariate regression model to learn the mapping function between the input vector, which in our case is composed of the interest and risk parameters of each one of the financial assets, and the output vector, which are the final weights or amounts allocated to each one of the financial assets given the interest-risk pairs for each asset. Figures 1-6 show an example of the proposed architectures. Color code used in the figures below is black for Cash, blue for Deposits, red for CBDC and green for other Financial Assets.

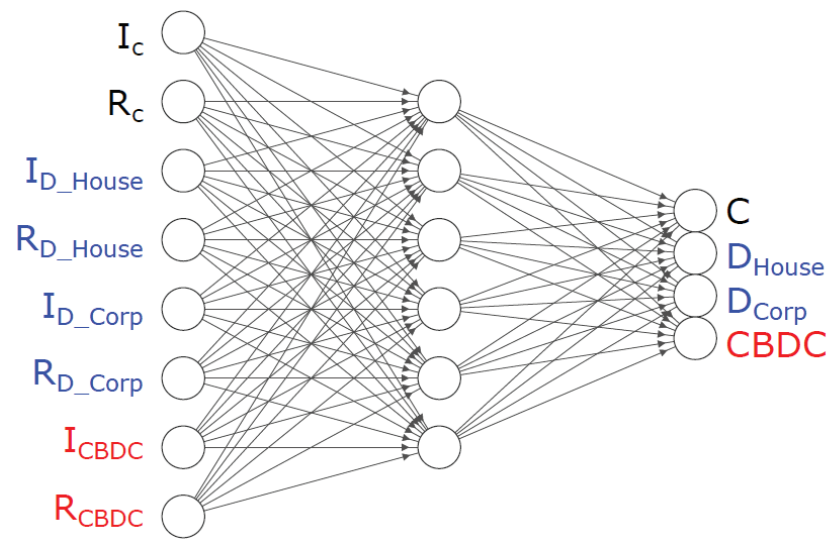

Figure 1. Deep Neural Network modeling the introduction of Central Bank Digital Currency (CBDC).

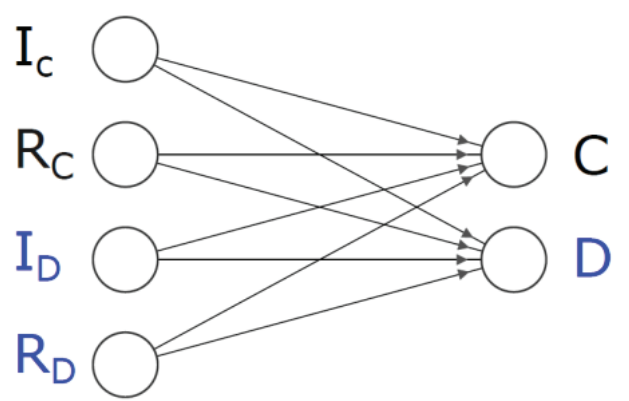

\section{Input Layer $\in \mathbb{R}^{4} \quad$ Output Layer $\in \mathbb{R}^{2}$}

Figure 2. Scenario 1. 


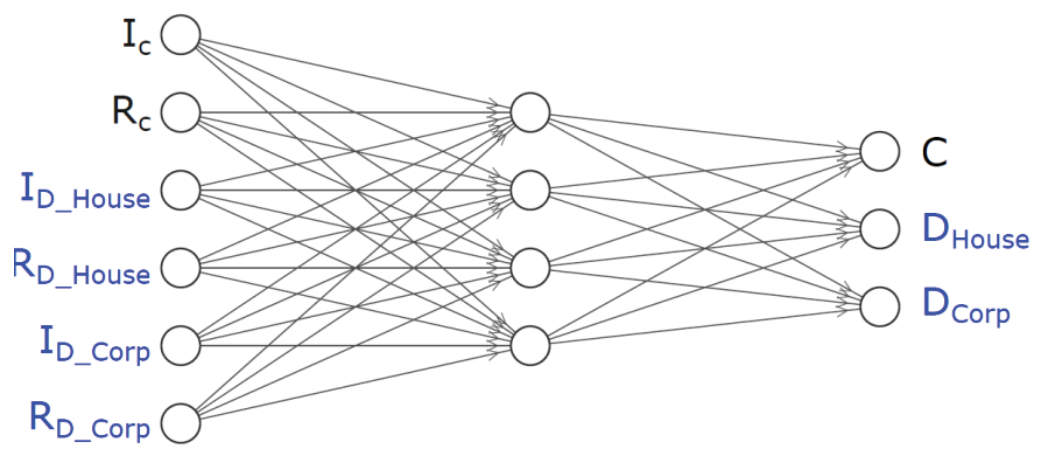

Input Layer $\in \mathbb{R}^{6}$

Hidden Layer $\in \mathbb{R}^{4}$

Output Layer $\in \mathbb{R}^{3}$

Figure 3. Scenario 2.

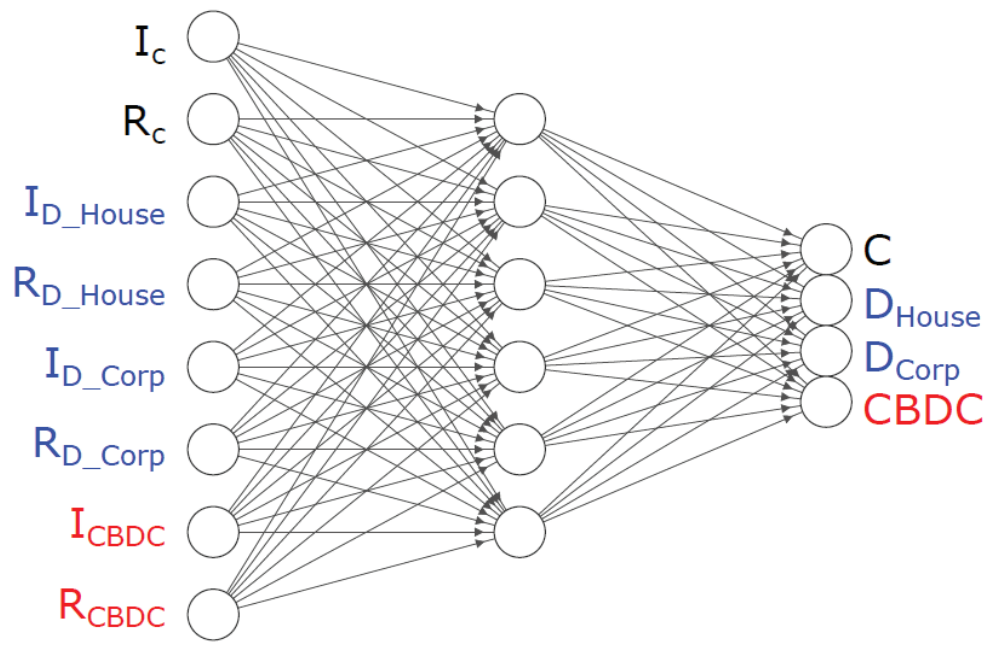

Input Layer $\in \mathbb{R}^{8} \quad$ Hidden Layer $\in \mathbb{R}^{6} \quad$ Output Layer $\in \mathbb{R}^{4}$

Figure 4. Scenario 3. 


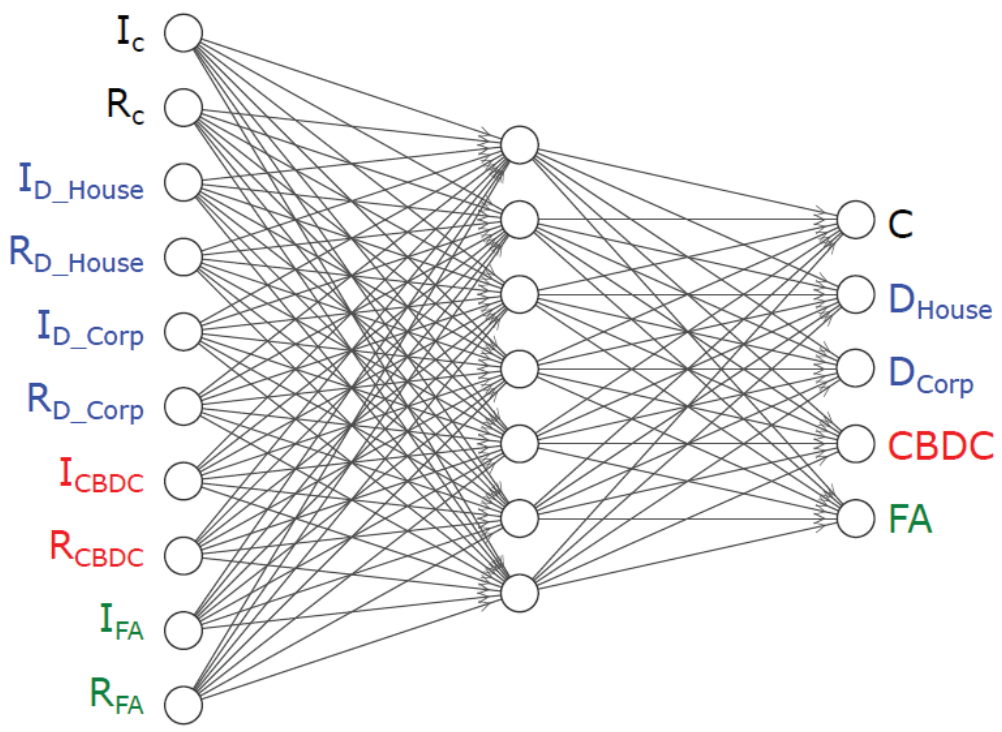

$$
\text { Input Layer } \in \mathbb{R}^{10} \quad \text { Hidden Layer } \in \mathbb{R}^{7} \quad \text { Output Layer } \in \mathbb{R}^{5}
$$

Figure 5. Scenario 4 .

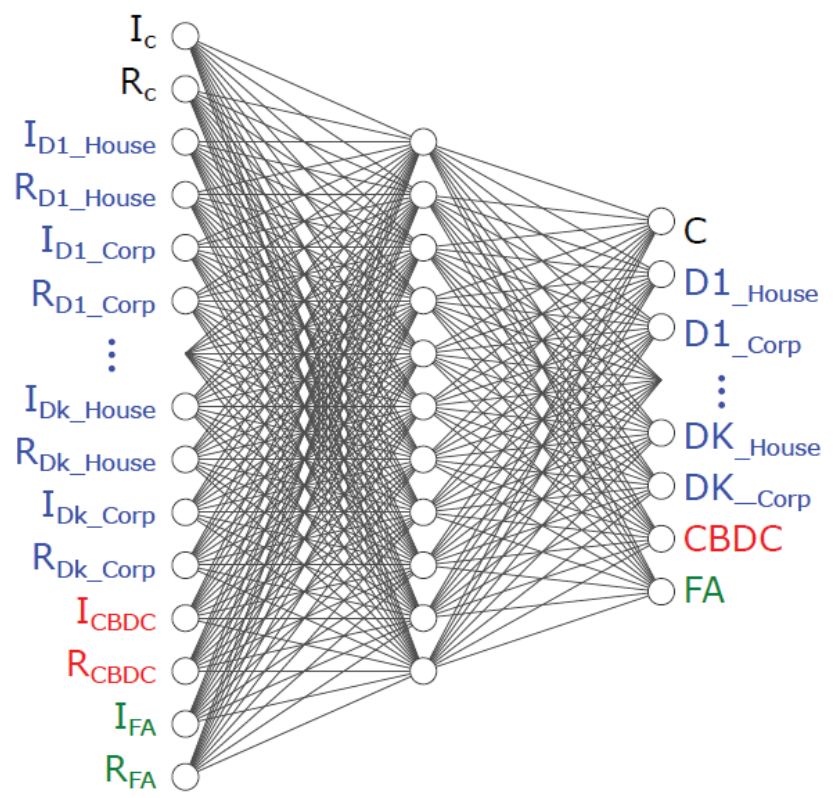

Input Layer $\in \mathbb{R}^{\mathrm{I}} \quad$ Hidden Layer $\in \mathbb{R}^{\mathrm{H}}$ Output Layer $\in \mathbb{R}^{\mathrm{O}}$

Figure 6. Scenario 5. Note: This model can also be expanded to include a broader number of financial assets, including holdings of debt instruments or stocks amongst others. For the sake simplicity we have not included such additional financial assets in this paper, and we focus on the transfer of wealth after the introduction of CBDC amongst: (i) Cash, (ii) Household commercial bank deposits, (iii) Corporate commercial bank deposits, and (iv) CBDC. 
Regarding the initialization of weights, to prevent the layer activation outputs from exploding or vanishing during a forward pass through a deep neural network, all weights and biases have been initialized using the Kaiming initialization [34].

Regarding the loss function, in regression problems, the typical loss function used is the L2 norm of the residual, which during backpropagation produces a gradient whose magnitude is linearly proportional to this difference [35]. This means that estimated values that are close to the ground-truth (i.e., inliers) have little influence during backpropagation, but on the other hand, estimated values that are far from the ground truth (i.e., outliers) can bias the whole training process given the high magnitude of their gradient. To overcome this limitation, we used the Huber's loss function, which is a robust loss function that behaves quadratically for small residuals and linearly for large residuals [36].

Next, we briefly describe the training and validation processes followed. We split the data set into three subsets: (i) training, (ii) validation, and (iii) test. The training set is used to adjust the weights of the network. The validation set is used to minimize overfitting and relates to the architecture design (i.e., the selection of hidden layers and neurons). Finally, the test set is used to assess the actual predictive power of the DNN. For all experiments, we used five-fold cross validation to obtain the optimal model and a grid search strategy to optimize the hyper-parameters, including the learning rate, and the number of hidden layers.

Finally, the mean squared error (MSE), the mean absolute error (MAE), the mean absolute percentage error (MAPE), and the coefficient of determination (R2) were calculated and tabulated to evaluate the performance of the model.

\subsection{Data}

The model has been trained using Euro area aggregate data. Data has been obtained directly from Euro area databases, in particular from the European Central Bank Statistical Data Warehouse. Monthly data from January 2003 until October 2020 has been used to train, validate and test the model.

Regarding the inputs, for each element, an interest-risk pair has been defined. Initially, the following levels for each input have been set:

$\mathbf{I}_{\mathbf{C}}$ : The interest rate of cash has been set at $0 \%$.

$\mathbf{R}_{\mathbf{C}}$ : Risk perception of cash has been set at 0 . Note that for simplicity reasons, storage risks are not considered.

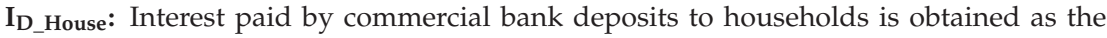
average interest paid for sight and term household deposits across European countries.

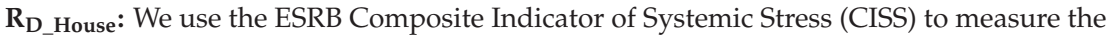
risk perception linked to commercial bank deposits (households). In particular, the CISS measures the level of stress in the financial system as a whole [37]. However, any other risk perception metric could be used instead.

I $_{\text {D_corp: }}$ Interest paid to corporate deposits is obtained as the average interest paid for sight and term corporate deposits across European countries.

$\mathbf{R}_{\mathbf{D} \_ \text {corp }}$ : Risk perception linked to commercial bank deposits (corporates). We use the same risk indicator as for household deposits (CISS).

I $_{\text {CBDC: }}$ Interest CBDC, which can be set at zero, negative, or positive rates.

$\mathbf{R}_{\text {CBDC: }}$ Risk perception of CBDC, which is set at zero in this work.

Regarding the outputs, the following magnitudes are used:

C: an estimate of the total amount of cash hold as a store of value. Citizens do also hold cash as a store of value. Studies from the European Central Bank show that on average $24 \%$ of European citizens hold cash outside a bank account as a precautionary reserve, based on a large sample of European respondents during 2015 and 2016 [38]. Estimating the share of cash used as a store of value is not an easy task, and a significant number of assumptions need to be made. By assuming that the holdings of cash as a store of value is the total amount of cash in circulation with the amount being used for transaction purposes deducted, held by financial institutions or held abroad, the European Central 
Bank estimates that more than one-third of the total Euro banknotes in circulation may be in use as a store of value [39]. The total amount of banknotes in circulation amounted to $€ 1,394$ bn as of October 2020, while the amount of coins totaled $€ 30$ bn as per ECB Statistical Data Warehouse. Assuming a third is being held as a store of value, in line with the ECB findings, this leads to an amount of c. $€ 430 \mathrm{bn}$. A similar study was conducted in Germany, where the main reasons for storing cash were analysed, these being (i) low-interest rate level, (ii) most common means of payment, (iii) cash works even if technology fails, (iv) no fees, and (v) anonymity [40].

$D_{\text {House }}$ : the total amount of household bank deposits in the Euro area. Household total deposits in Euro area commercial banks amounted to $€ 8,210$ bn as of October 2020 .

$D_{\text {Corp }}$ : the total amount of corporate bank deposits in the Euro area. Corporate deposits in Euro area commercial banks amounted to $€ 3,120$ bn as of October 2020.

CBDC: when CBDC is included in the model (from Model 3 onwards) and given that no real data regarding holdings of $C B D C$ exist, we have trained the model using different initial cases leading to a wide range of CBDC values, allowing us to simulate several scenarios. The DNN proposed in this paper will allow users to modify the CBDC inflow hypothesis easily.

As of October 2020, the split between cash, household deposits and corporate deposits was as follows: (i) cash 3.6\%, (ii) Household deposits $69.8 \%$, and (iii) Corporate deposits $26.5 \%$. According to the methodology described, this has been used as an output. Regarding the inputs, as of October 2020 the $I_{C}$ and $R_{C}$ were set at zero, the $I_{D}$ House was $0.14 \%$ while the $\mathrm{I}_{\mathrm{D} \_ \text {Corp }}$ was $-0.01 \%$. The $\mathrm{R}_{\mathrm{D} \_ \text {House }}$ and $\mathrm{R}_{\mathrm{D} \_ \text {Corp }}$ were set at 0.11 according to the ESRB Composite Indicator of Systemic Stress. This inputs-outputs combination was only one of the 315 samples used to train and test the model. In particular, the model has been trained using 251 samples which correspond to monthly values of the different series, while it has been tested using 64 samples. Both the CBDC inputs and expected outputs have been set across a wide range of scenarios as shown in the results section. The methodology proposed allows us to analyze a high number of different cases which should allow policymakers and other relevant authorities to assess the strengths and weaknesses of the different potential designs of CBDC.

\subsection{Model Description and Scenarios}

The model proposed is composed of four elements: (i) Cash, (ii) Household commercial bank deposits, (iii) Corporate commercial bank deposits, and (iv) CBDC. This model uses two key characteristics of a financial asset as inputs: (i) Interest (or expected yield), and (ii) Risk (or expected volatility), while the outputs represent the allocation of the total wealth of a closed economy between the different elements or financial assets mentioned above. The elements of the model and the number of inputs per element can be easily expanded following the same logic as presented later in this work. The model assumes a closed economy, with citizens and businesses having direct claims against the Central Bank when holding CBDC. Figure 1 shows a visual representation of the model, assuming only one commercial bank in the system, where the outputs are:

C: Total wealth amount or percentage allocated in cash as a store of value.

$\mathrm{D}_{\text {House }}$ : Total wealth amount or percentage allocated to household commercial bank deposits.

D $_{\text {Corp }}$ : Total wealth amount or percentage allocated to corporate commercial bank deposits. CBDC: Total wealth amount or percentage allocated to CBDC.

Note that when the outputs are expressed as percentages, the following expression is true.

$$
\sum \mathbf{C}+\mathbf{D}_{\text {House }}+\mathbf{D}_{\text {Corp }}+\mathbf{C B D C}=100 \%
$$
where

Regarding the inputs, we assign an interest and a risk level to each financial asset, $\mathbf{I}_{\mathbf{C}}$ : Interest paid by cash. 
$\mathbf{R}_{\mathrm{C}}$ : Risk perception of cash.

I __House: Interest paid by commercial bank deposits to households.

$\mathbf{R}_{\mathbf{D} \_ \text {House: }}$ Risk perception linked to commercial bank deposits (households).

I D_Corp: Interest paid by commercial bank deposits to corporates.

$\mathbf{R}_{\mathrm{D}_{-} \text {Corp }}$ : Risk perception linked to commercial bank deposits (corporates).

$I_{\text {CBDC: }}$ Interest paid by CBDC, which can be set at zero, negative, or positive rates.

$\mathbf{R}_{\mathrm{CBDC}}$ : Risk perception of CBDC.

As described above, we assign an interest and a risk level to each financial asset, while the outputs represent the allocation of the total wealth of a closed economy between the different financial assets.

Next, we briefly describe the different scenarios that lead to the design of the DNN proposed in this paper, while also showing the block approach followed, which suggests that it is relatively straightforward to add new elements to the model if data to calibrate the new inputs/outputs is available.

Figure 2 presents a simplification of the system, where cash and commercial bank deposits are the only available financial assets to store wealth. In this model, there is no distinction between household and corporate deposits, and the system is set up with a generic commercial bank that centralizes the total customer deposits outstanding. In this scenario, only cash competes with commercial bank deposits.

Next, we make a distinction between corporate and household deposits, which increases the granularity. Further, when increasing the number of inputs/ outputs we added a hidden layer in the design of the DNN. This model enables a simplified representation of a closed economy where the options for customers remain limited to cash or commercial bank deposits. In this system, changes in the risk perception and interest rates could lead to transfers of commercial bank deposits into cash, and vice-versa. This model was calibrated and trained with Euro area aggregate data, which allowed us to understand the sensitivities of the different types of depositors and cash to interest rates and systemic risk perception. These results are not included in this paper, since the focus of this work is to analyze the impact linked to the introduction of CBDC. However, the DNN used in Scenario 2 and trained with the abovementioned data is available upon request by contacting the authors of this paper.

The next step is the introduction of $\mathrm{CBDC}$, which represents a disruptive event in the system. Figure 4 represents a simple framework to analyze the wealth transfer amongst financial assets when introducing CBDC. This system allows the testing of different CBDC designs including interest rate set at positive, negative or zero levels as well as potential limits to the holdings of CBDC per account. In particular, the difference between the previous model and this one is the introduction of the element CBDC, which is represented by two new inputs and a new output. The DNN is designed with eight inputs, a hidden layer composed of six nodes and four outputs. This is the scenario that has been used as an example in the results section, as we describe later.

Despite the empirical work of this paper focusing on Scenario 3, the next step could be to add a new element defined as Financial Asset (FA), which represents households and corporations' holdings of bonds, equities and/or other financial assets. The introduction of FA opens the door to several substitutes of commercial bank deposits, ranging from cash to CBDC or financial assets. The design of the DNN proposed in this work makes it relatively simple to add new elements as mentioned above.

Figure 6 represents a generalization of the model developed in this paper, where competition amongst banks has been introduced. This model allows banks to set different deposit rates, and each bank to have a different risk perception level. This model would therefore simulate both systemic bank runs, and also idiosyncratic bank runs with the presence of CBDC. 


\section{Results}

In this section, we disclose and discuss the results of this analysis. As mentioned in the previous section, this paper focuses on Scenario 3. This experiment focuses on understanding the sensitivity of depositors to switch from commercial bank deposits into CBDC under different CBDC designs and system configurations. In particular, we analyze the impact of designing CBDC with positive, negative or zero interest rates. We also analyze the wealth transfer from deposits to CBDC under different levels of systemic risk.

Python 3.6+, PyTorch 1.7+ and scikit-learn 0.22+ are used to perform the analyses. To optimize the loss function we used the Adam optimizer, with the momentum set to 0.9 and the learning rate to 0.07 . The models were trained for 200 iterations on an NVIDIA GeForce GTX TITAN GPU and the model with the lowest MAE (on the validation set) was selected. The network training required 2 min per epoch on average and it took 0.52 milliseconds on average to process a case during testing. The source code is available at https:/ / github.com/estherpuyol/CBDC_model.git.

With regard to the validation results, the MSE, MAE, MAPE and R2 are provided in Figure 7. The loss change during training is shown in Figure 8. The system has a low MAE and MAPE, with also a strong regression coefficient R2.

\begin{tabular}{ccccc} 
& MSE & MAE & MAPE (\%) & $\mathbf{R}^{2}(\%)$ \\
\hline \hline DNN with CBDC & 0.000028 & 0.0023 & 0.0144 & 0.97
\end{tabular}

Figure 7. Mean squared error (MSE), mean absolute error (MAE), mean absolute percentage error (MAPE), and the coefficient of determination (R2).

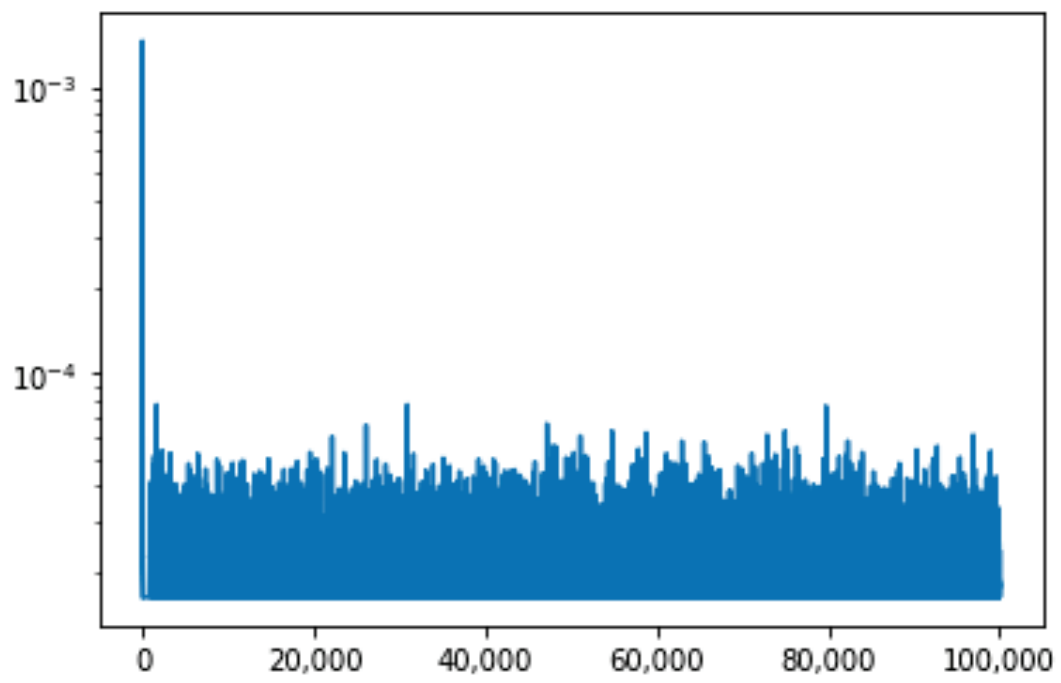

Figure 8. Loss change during training.

Once the model has been successfully calibrated, we used the DNN to simulate how the wealth distribution amongst the different financial assets would change with the introduction of CBDC. In particular, Figure 9 shows depositors' sensitivity to CBDC interest rate under three scenarios: (i) zero interest rate on CBDC, (ii) positive CBDC interest rate set at $0.5 \%$, and (iii) positive CBDC interest rate set at $1.0 \%$. The first two rows represent the October 2020 wealth distribution in the Euro area, and the average values since January 2003 respectively. October 2020 Euro area data has been used in all cases, while for CBDC since data is not available, the risk was set at zero and the output followed the hypothesis 
that increases in systemic risk would lead to an increase in CBDC demand in line with the current literature [41].

\begin{tabular}{lllll}
\multicolumn{10}{c}{ Interest Rate CBDC Change } \\
\cline { 2 - 13 }
\end{tabular}

Figure 9. Wealth transfer sensitivity to changes in CBDC interest rate. Blue numbers represent the model inputs.

Figure 10 shows depositor's sensitivity to changes in the financial system risk under three scenarios: (i) CISS set at 0.11 and in line with October 2020 data, (ii) CISS set at 0.5 representing a medium-high systemic risk, and (iii) CISS set at 0.9 representing an extremely high systemic risk. Similar to the previous table, the first two rows represent the October 2020 wealth distribution in the Euro area, and the average values since January 2003 , respectively. It is particularly interesting to note the redistribution of wealth in Case 1 vs. the October 2020 scenario.

\begin{tabular}{|c|c|c|c|c|c|c|c|c|c|c|c|c|}
\hline & \multicolumn{12}{|c|}{ Financial System Risk Change } \\
\hline & & & & & Inputs & & & & & & tputs & \\
\hline & I_CASH & IIDEP_HOUSE & I_DEP_CORP & I_CBDC & R_CASH & R_DEP_HOUSE & R_DEP_CORP F & R_CBDC & $\mathrm{CASH}$ & DEP_HOUSE & DEP_CORP & CBDC \\
\hline Oct-20 & 0 & 0.14 & -0.01 & - & 0 & 0.11 & 0.11 & & $3.6 \%$ & $69.8 \%$ & $26.5 \%$ & - \\
\hline Mean & 0 & 1.32 & 0.97 & - & 0 & 0.19 & 0.19 & & $3.3 \%$ & $74.6 \%$ & $22.1 \%$ & - \\
\hline Case 1 & 0 & 0.14 & -0.01 & 0 & 0 & 0.11 & 0.11 & 0 & $3.1 \%$ & $66.0 \%$ & $14.5 \%$ & $16.4 \%$ \\
\hline Case 2 & 0 & 0.14 & -0.01 & 0 & 0 & 0.5 & 0.5 & 0 & $5.6 \%$ & $29.3 \%$ & $13.2 \%$ & $51.9 \%$ \\
\hline Case 3 & 0 & 0.14 & -0.01 & 0 & 0 & 0.9 & 0.9 & 0 & $5.0 \%$ & $6.2 \%$ & $5.8 \%$ & $83.0 \%$ \\
\hline
\end{tabular}

Figure 10. Wealth transfer sensibility to changes in financial system risk Blue numbers represent the model inputs.

Finally, Figure 11 shows the transfer, mainly of commercial bank deposits given that cash remained broadly unchanged, to CBDC. The results shown in the matrix below represent the total volume of CBDC as a percentage of the total wealth. The colour code also shows the risk of a digital bank run, given that in some scenarios the total holdings of CBDC could reach as high as ca. $80 \%$ of the total.

\begin{tabular}{|c|c|c|c|c|c|c|c|c|c|c|}
\hline \multirow{10}{*}{ 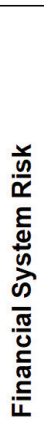 } & \multicolumn{10}{|c|}{ Interest CBDC } \\
\hline & & $-0.5 \%$ & $-0.25 \%$ & $0.00 \%$ & $0.25 \%$ & $0.50 \%$ & $0.75 \%$ & $1.00 \%$ & $1.25 \%$ & $1.50 \%$ \\
\hline & 0.1 & $18.5 \%$ & $17.4 \%$ & $16.4 \%$ & $16.4 \%$ & $17.1 \%$ & $17.8 \%$ & $18.5 \%$ & $19.2 \%$ & $19.8 \%$ \\
\hline & 0.2 & $20.9 \%$ & $21.8 \%$ & $22.7 \%$ & $23.6 \%$ & $24.4 \%$ & $25.2 \%$ & $26.0 \%$ & $26.7 \%$ & $27.3 \%$ \\
\hline & 0.3 & $29.4 \%$ & $30.5 \%$ & $31.5 \%$ & $32.4 \%$ & $33.3 \%$ & $34.1 \%$ & $34.9 \%$ & $35.5 \%$ & $36.1 \%$ \\
\hline & 0.4 & $39.4 \%$ & $40.5 \%$ & $41.5 \%$ & $42.4 \%$ & $43.2 \%$ & $43.9 \%$ & $44.6 \%$ & $45.1 \%$ & $45.5 \%$ \\
\hline & 0.5 & $50.1 \%$ & $51.1 \%$ & $51.9 \%$ & $52.7 \%$ & $53.3 \%$ & $53.8 \%$ & $54.2 \%$ & $54.6 \%$ & $54.8 \%$ \\
\hline & 0.6 & $60.5 \%$ & $61.2 \%$ & $61.8 \%$ & $62.3 \%$ & $62.7 \%$ & $63.0 \%$ & $63.2 \%$ & $63.3 \%$ & $63.3 \%$ \\
\hline & 0.7 & $69.6 \%$ & $70.1 \%$ & $70.5 \%$ & $70.7 \%$ & $70.9 \%$ & $71.0 \%$ & $70.9 \%$ & $70.8 \%$ & $70.6 \%$ \\
\hline & 0.8 & $77.1 \%$ & $77.4 \%$ & $77.5 \%$ & $77.6 \%$ & $77.5 \%$ & $77.4 \%$ & $77.3 \%$ & $77.0 \%$ & $76.7 \%$ \\
\hline & 0.9 & $82.9 \%$ & $83.0 \%$ & $83.0 \%$ & $82.9 \%$ & $82.7 \%$ & $82.5 \%$ & $82.3 \%$ & $81.9 \%$ & $81.5 \%$ \\
\hline
\end{tabular}

Figure 11. Wealth distribution sensitivity to CBDC interest rate and Financial System Risk.

\section{Discussion}

The results show that the introduction of CBDC would lead to an initial transfer of wealth from commercial bank deposits to CBDC. Figure 9, Case 1 simulates a simple scenario where the transfer of wealth from cash and commercial bank deposits to CBDC takes place when CBDC is introduced for the first time with CBDC interest rate and risk perception set at zero and the rest of the inputs set as at October 2020 levels. It is 
interesting to observe that cash would be slightly reduced from $3.6 \%$ to $3.1 \%$, while both household deposits and corporate deposits declined by 3.8 percentage points (pp) and $12 \mathrm{pp}$ respectively, leading to a CBDC amounting to c. $16.4 \%$ of the total wealth of the system. We also note that an increase in CBDC interest rates of 50bps (Figure 9, Case 2) and 100 bps (Figure 9, Case 3) leads to a moderate increase of total CBDC outstanding at c. $17.8 \%$ and $19.2 \%$ respectively. The sensitivity of deposit outflows to CBDC interest rates seems moderate, with c. 2.3 pp of deposit outflows per 50bps of CBDC interest rate increase. However, we note that deposit outflows sensitivity to CBDC is not linear as we show in Figure 11.

Figure 10 shows that an increase in systemic risk could lead to digital bank runs. In particular, the results show that a systemic risk indicator increasing from 0.11 to 0.5 would lead to significant deposit outflows, increasing the total wealth stored in CBDC from $16.4 \%$ to $51.9 \%$. In an extreme scenario, with systemic risk as high as 0.9 , over $80 \%$ of the total wealth would be stored in CBDC, leading to a system-wide digital bank run. We note that deposit outflow sensitivity to systemic risk is very high, which is in line with the majority of the literature on the topic as we highlight in the introduction and theoretical background sections of this document.

Figure 11 shows that deposit outflow sensitivity to financial system risk and CBDC interest rate is non-linear. In particular, sensitivity to CBDC interest rate is moderate when the systemic risk is at low or medium-high levels (with CISS ranging from 0.2 to 0.6 ), while there is no sensitivity to CBDC interest rate with high or very high systemic risk levels (with CISS ranging from 0.7 to 0.9 ). This suggests that under a stressed financial scenario, a commercial bank deposit outflow would not be stopped by lowering the interest rate of CBDC.

Furthermore, the results suggest that a maximum amount of CBDC per account set at $30 \%$ or $40 \%$ of total wealth per account would limit more effectively the potential deposit outflows in the case of system-wide financial stress. Adding caps to the design of CBDC could be somewhat seen as the physic limits that cash entails. In theory, the holdings of cash are only limited by the total wealth of an individual, however, in practical terms, holdings of cash are "virtually capped" by the storage and transport risks. Since CBDC would not entail any storage or transport risks, it could be deemed appropriate to add certain limits to the holdings of CBDC, particularly during the early stages of the introduction of CBDC. However, this remains to be tested and further analyses on that point would add significant value to the CBDC implementation debate.

In line with the above, some authors consider that a cap on CBDC would reduce the effectiveness of it [18]. Somewhat linked to that point, new questions regarding the scope of CBDC would need to be explored at some stage, including whether the introduction of CBDC would represent just a first stage before moving into a financial system embracing the concept of "sovereign money", whether it should be designed to compete with commercial bank deposits, or if it should be conceived as just a mere substitute of cash.

\section{Limitations and Future Lines of Research}

This methodology is not without limitations, with the lack of CBDC data being the most notable. As described above, the model has been initially trained using real Euro area aggregate data for all components but CBDC. In the case of CBDC, different assumptions have been made, which leads to a certain degree of subjectivity. On the other hand, the model proposed allows other researchers to modify such hypotheses concerning CBDC initial calibration.

Next, we discuss some of the potential implications of CBDC for the banking sector. The following points constitute hypotheses to be tested and do not express the authors' views on the subject. The goal of the remainder of this section is to stimulate the debate regarding the introduction of CBDC and the potential impact on the banking sector and on bank runs in particular. 
In the scenario described in this work, commercial banks would compete for deposits with Central Bank, leading banks to increase interest on customer deposits, hence eroding its margins. After the introduction of CBDC, and as per the results obtained in Figures 9-11, banks would need to reduce their balance sheet and increase lending rates, potentially tightening the access to credit. However, under this hypothetical scenario banks could use several strategies, including cross-selling techniques to retain deposits, and other measures such as offering lower loan rates to corporate clients holding deposits in the bank, or lower mortgage rates to retail customers using banks' deposits and payment services. Exploring this area would help to measure the impact on banks' accounts and indirectly the potential spillover effects on the availability of new credit.

Furthermore, banks would try to replace some deposits lost with other forms of funding, such as wholesale funding, leading to a higher cost of funding. In turn, higher wholesale funding reliance, and depositors' choice to transfer funds to CBDC could lead to higher market discipline in the banking sector. Some authors question whether the need for a deposit guarantee scheme would still be justified after the introduction of CBDC [42]. As described on the European Commission website, a fundamental principle underlying the Deposit Guarantee Scheme (DGS) is that they are funded entirely by banks and that no taxpayer funds are used. In line with this, a DGS would in part mitigate digital bank runs under stressed scenarios.

This work uses Euro area data to train, validate, and test the model. The authors would like to suggest the development of similar analyses with data from different geographic areas and regions as an interesting future line of research. Results obtained from Euro area data could differ from results in regions where there is not just a common monetary policy, but also a single fiscal policy.

The study uses a model based on a closed economy where only domestic use of CBDC was possible. However, we would encourage other researchers to elaborate on the subject of whether CBDC should be used exclusively in the national territory or whether the CBDC should be open to international use too.

As described in the introduction of this work, designing a CBDC that contributes to the sustainability of the financial system is relevant. In particular, some authors consider that features enhancing financial inclusion could limit the effectiveness of CBDC as a system of payments [43]. The relatively scarce literature on CBDC and financial inclusion suggests that further empiric analysis on that topic would be relevant for the current literature on CBDC.

So far, the literature is strongly focused on the impact on banks' funding costs, which as highlighted by many authors, could lead to disintermediation of the banking sector. However, it would be interesting to explore further whether the Loss Given Default of debt instruments and banks' cost of equity should remain unchanged or increase/decrease after the introduction of CBDC and the potential spillover effects mentioned above. Moreover, macroprudential and policymakers' options remain in place to contain a potential increase in banks' funding costs. Such options could include banks' debt being eligible for quantitative easing programs launched by central banks. Furthermore, it could be understood that in a hypothetical scenario where the public has the option to keep money in the form of CBDC at the Central Bank, the need for strict regulation over the sector declines. Capital, liquidity and loss absorption requirements could be loosened, leading to lower regulatory costs for banks, particularly on the funding side.

In line with the above, another question to explore under the hypothesis of CBDC introduction is whether banks should need to maintain a capital structure in line with Basel III, and complying with bank-specific capital and loss absorption requirements such as SREP (Supervisory Review and Evaluation Process), MREL (Minimum Requirement for own funds and Eligible Liabilities), or TLAC (Total Loss Absorbing Capacity).

It is also particularly important to design a solid transitional framework should CBDC be introduced. The transfer of significant amounts of commercial bank deposits to CBDC would add additional pressure to the stability of the banking system, hence raising the 
questions of whether and under which conditions the Central Bank may temporarily replace commercial banks' deposits lost with Central Bank lending. A phase-out calendar matching the maturity of the outstanding loans in the balance sheet could be adopted, with Central Bank lending in place during the phase-out period.

\section{Conclusions}

This paper develops a Deep Neural Network (DNN) design to assess the potential impact of the introduction of CBDC on the banking sector, and in particular, focuses on the link between CBDC and the bank run phenomena. This work represents an innovative method to assess the implications of the introduction of $\mathrm{CBDC}$, allowing the simulation of the transfer of wealth between different financial assets depending on the design of a CBDC. The transfer of flows from one asset class to another can be used as a proxy to understand the dynamics that one could expect in the event of CBDC introduction. Below we conclude by highlighting some of the findings or relevant points highlighted in this work:

First, this paper describes the use of a DNN design, representing a multivariate regression model that learns the mapping function between the input vector, which represents the interest and risk for a sample of financial assets, and output vector which represents the wealth allocation into the different financial assets available. Several scenarios are described, and the model is finally calibrated using 315 real data samples corresponding to Euro area aggregate data including cash and loans volumes, interest rates and systemic risk metrics. The calibration of CBDC to be used in the training phase of the algorithm represents an important limitation linked to this type of technique. On the other hand, using different hypotheses vis-à-vis the calibration of CBDC data allowed the authors to draw conclusions on the impact of CBDC in a financial system.

This work considers that different designs of CBDC would lead to a wide range of outputs in terms of success and acceptance of CBDC, and the ability to increase financial inclusion through the deployment of CBDC is, by all means, one of the characteristics that this new form of money should pursue.

Second, the results point out that the introduction of CBDC would lead to an outflow of commercial bank deposits into CBDC, particularly given the "risk-free" nature of CBDC, while commercial bank deposits have an inherent (low) risk perception. Interest rates on CBDC are an important but not leading factor when analyzing the risk of commercial bank deposit outflows, as per the results shown in Section 4. However, as discussed, it is highly likely that the outflows from commercial bank deposits to CBDC would become barely interest-sensitive in the event of severe financial distress. The likelihood of digital bank runs seems strongly driven by the overall financial risk perception, modelled through the CISS indicator in this work. Other levers such as the full guaranteed convertibility of bank deposits into CBDC or limits on the CBDC accounts could be used to limit bank runs at this stage with potentially higher success rates. However, the higher the number of frictions introduced in the CBDC design, the lower the utility of it. Further research would be required to fully understand the trade-offs of suboptimal CBDC designs to partially protect the banking sector.

Third, the DNN architecture used in this paper to model the introduction of CBDC is highly scalable, allowing us to build a series of different blocs or new elements on top of the basic system analysed in this work. The authors would like to invite other scholars to continue assessing the implications of the potential introduction of CBDC through Deep Neural Network designs. The authors consider that after proving that DNN constitutes an adequate and valuable method to analyze the potential different designs of CBDC and its implications not just for the banking sector, but for the broader economy, this technique could be used more frequently for analyzing problems of a similar nature.

Finally, the potential introduction of CBDC could represent one of the most disruptive changes introduced in the financial system in a long time. Hence, a scrupulous analysis of the trade-offs derived from introducing CBDC is paramount. This paper contributes to the research in the segment of the interaction of CBDC with the banking sector by proposing 
an innovative method to assess the likelihood of a sudden and significant transfer of funds from commercial bank deposits to CBDC. This is a relatively new concept to most of us but threatening to be a source of intense debate and concern in the years to come: Digital Bank Runs.

Author Contributions: Conceptualization, M.S.-R. and E.P.-A.; methodology, M.S.-R. and E.P.-A.; software, E.P.-A.; validation, M.S.-R. and E.P.-A.; formal analysis, M.S.-R. and E.P.-A.; data curation, M.S.-R. and E.P.-A.; writing-original draft preparation, M.S.-R.; writing—review and editing, M.S.-R. and E.P.-A. All authors have read and agreed to the published version of the manuscript.

Funding: This research received no external funding.

Institutional Review Board Statement: Not applicable.

Informed Consent Statement: Not applicable.

Data Availability Statement: The database and the code used for this study is freely available at https://github.com/estherpuyol/CBDC_model.git.

Acknowledgments: This research has been conducted using a GPU generously donated by NVIDIA Corporation.

Conflicts of Interest: The authors declare no conflict of interest.

\section{References}

1. Bank of International Settlements. Central Bank Digital Currencies: Foundational Principles and Core Feature; No. 1, 26; Bank of International Settlements: Basel, Switzerland, 2020.

2. Mancini-Griffoli, T.; Peria, M.S.M.; Agur, I.; Ari, A.; Kiff, J.; Popescu, A.; Rochon, C. Casting Light on Central Bank Digital Currency. IMF Staff Discuss. Note 2018, 18, 8. [CrossRef]

3. Riu, M. Banking and Society in Late Medieval and Early Modern Aragon. In The Dawn of Mediaeval Banking; Center for Mediaeval and Rennaissance Studies; University of California: Los Angeles, CA, USA; Yale University Press: New Haven, CT, USA, 1979.

4. Bindseil, U. Central Bank Digital Currency: Financial System Implications and Control. Int. J. Political Econ. 2019, 48, $303-335$. [CrossRef]

5. Barotini, C.; Holden, H. Proceeding with Caution-A Survey on Central Bank Digital Currency. Bank Int. Settl. 2019, 101, 1-15.

6. Auer, R.; Cornelli, G.; Frost, J. Rise of the Central Bank Digital Currencies: Drivers, Approaches and Technologies. In BIS Working Papers; No. 880; Centre for Economic Policy Research: London, UK, 2020.

7. Central Bank of The Bahamas. The Sand Dollar Is on Schedule for Gradual National Release to The Bahamas in Mid-October 2020; Central Bank of The Bahamas: Nassau, Bahamas, 2020.

8. Berentsen, A.; Schär, F. The Case for Central Bank Electronic Money and the Non-Case for Central Bank Cryptocurrencies. Fed. Reserve Bank St. Louis Rev. 2018, 100, 97-106. [CrossRef]

9. Ordóñez, M.F. Adiós a Los Bancos; Taurus: Georgia, GA, USA, 2020.

10. Bech, M.; Garratt, R. Central Bank Cryptocurrencies. In BIS Quarterly Review; Bank of International Settlements: Basel, Switzerland, 2017; pp. 55-70.

11. Auer, R.; Böhme, R. The Technology of Retail Central Bank Digital Currency. In BIS Quarterly Review; Bank of International Settlements: Basel, Switzerland, 2020; pp. 85-100.

12. Adrian, T.; Mancini-griffoli, T. The Rise of Digital Money; IMF: Washington, DC, USA, 2019; pp. 1-16.

13. Meaning, J.; Dyson, B.; Barker, J.; Clayton, E. Broadening Narrow Money: Monetary Policy with a Central Bank Digital Currency. No. 724. SSRN Electron. J. 2018. [CrossRef]

14. Engert, W.; Fung, B.S.C. Central Bank Digital Currency: Motivations and Implications. In Bank of Canada Staff Discussion Paper; Bank of Canada: Ottawa, ON, Canada, 2017; pp. 1-30.

15. Raskin, M.; Yermack, D. Digital Currencies, Decentralized Ledgers, and the Future of Central Banking; National Bureau of Economic Research: Cambridge, MA, USA, 2016.

16. Allen, S.; Čapkun, S.; Eyal, I.; Fanti, G.; Ford, B.A.; Grimmelmann, J.; Juels, A.; Kostiainen, K.; Meiklejohn, S.; Miller, A.; et al. Design Choices for Central Bank Digital Currency: Policy and Technical Considerations; National Bureau of Economic Research: Cambridge, MA, USA, 2020; Volume 53.

17. Alonso, S.L.N.; Fernández, M.Á.E.; Bas, D.S.; Kaczmarek, J. Reasons Fostering or Discouraging the Implementation of Central Bank-Backed Digital Currency: A Review. Economies 2020, 8, 41. [CrossRef]

18. Gürtler, K.; Nielsen, S.T.; Rasmussen, K.; Spange, M. Central Bank Digital Currency in Denmark? Danmarks Nationalbank: Copenhagen, Denmark, 2017.

19. Andolfatto, D. Assessing the Impact of Central Bank Digital Currency on Private Banks. Econ. J. 2020. [CrossRef]

20. Sveriges Riksbank. E-Krona: Part 2; No. October; Sveriges Riksbank: Stockholm, Sweden, 2018. 
21. Sanchez-Roger, M.; Oliver-Alfonso, M.D.; Sanchis-Pedregosa, C. Bail-In: A Sustainable Mechanism for Rescuing Banks. Sustainability 2018, 10, 3789. [CrossRef]

22. Shin, H.S. Reflections on Northern Rock: The Bank Run That Heralded the Global Financial Crisis. J. Econ. Perspect. 2009, 23, 101-119. [CrossRef]

23. Calvo, G.A. Financial Crises and Liquidity Shocks: A Bank-Run Perspective; National Bureau of Economic Research: Cambridge, MA, USA, 2009.

24. Engert, W.; Fung, B.S.C.; Hendry, S. Is a Cashless Society Problematic. In Bank of Canada Staff Discussion Paper; No. 2018-12; Bank of Canada: Ottawa, ON, Canada, 2018; pp. 12-18.

25. Kumhof, M.; Noone, C. Central Bank Digital Currencies-Design Principles and Balance Sheet Implications; No. 725. SSRN Electron. J. 2018. [CrossRef]

26. CPMI-MC. Committee on Payments and Market Infrastructures Markets Committee Central Bank Digital Currencies; CPMI-MC: Basel, Switzerland, 2018.

27. Ward, O.; Rochemont, S. An Addendum to "A Cashless Society-Benefits, Risks and Issues (Interim Paper)" Understanding Central Bank Digital Currencies (CBDC); Institute and Faculty of Actuaries: London, UK, 2019.

28. Dyson, B.; Hodgson, G.; Van Lerven, F. Sovereign Money: An Introduction; Positive Money: London, UK, 2016.

29. Bank of England. Central Bank Digital Currency Opportunities, Challenges and Design; No. March; Bank of England: London, UK, 2020; pp. 77-82.

30. Bousono-Calzon, C.; Bustarviejo-Munoz, J.; Aceituno-Aceituno, P.; Escudero-Garzas, J.J. On the Economic Significance of Stock Market Prediction and the No Free Lunch Theorem. IEEE Access 2019, 7, 75177-75188. [CrossRef]

31. Bahrammirzaee, A. A Comparative Survey of Artificial Intelligence Applications in Finance: Artificial Neural Networks, Expert System and Hybrid Intelligent Systems. Neural Comput. Appl. 2010, 19, 1165-1195. [CrossRef]

32. Sheskin, D.J. Handbook of Parametric and Non-Parametric Statistical Procedures; CRC Press: Boca Raton, FL, USA, 2020 ; Volume 46. [CrossRef]

33. Deng, L.; Yu, D. Deep Learning: Methods and Applications. Found. Trends Signal Process. 2014. [CrossRef]

34. He, K.; Zhang, X.; Ren, S.; Sun, J. Delving Deep into Rectifiers: Surpassing Human-Level Performance on ImageNet Classification. In Proceedings of the IEEE International Conference on Computer Vision; IEEE Computer Society: Washingto, DC, USA, 2014; pp. 1026-1034.

35. Belagiannis, V.; Rupprecht, C.; Carneiro, G.; Navab, N. Robust Optimization for Deep Regression. In Proceedings of the IEEE International Conference on Computer Vision, Santiago, Chile, 7-13 December 2015; pp. 2830-2838. [CrossRef]

36. Huber, P.J. Robust Estimation of a Location Parameter; Springer: New York, NY, USA, 1992. [CrossRef]

37. Holló, D.; Kremer, M.; Lo Duca, M. A Composite Indicator of Systemic Stress in the Financial System; Macroprudential Research Network: Frankfurt, Germany, 2012.

38. Esselink, H.; Hernández, L. Occasional Paper Series the Use of Cash by Households in the Euro Area; European Central Bank (ECB): Frankfurt, Germany, 2017.

39. Lalouette, L.; Esselink, H. Trends and Developments in the Use of Euro Cash over the Past Ten Years; ECB Economic Bulletin, European Central Bank (ECB): Frankfurt, Germany, 2018.

40. Bundesbank, D. Cash Hoarding by German Households-How Much Cash Do They Store and Why? Deutsche Bundesbank: Frankfurt, Germany, 2020.

41. Mersch, Y. Virtual or Virtueless? The Evolution of Money in the Digital Age; In Lecture at the Official Monetary and Financial Institutions Forum: London, UK, 2018.

42. Institute of International Finance. Money Redesigned; Institute of International Finance: Washington, WA, USA, 2020.

43. Maniff, J.L. Motives Matter: Examining Potential Tension in Central Bank Digital Currency Designs; Federal Reserve Bank of Kansas City: Omaha, NE, USA, 2020. 


\title{
Blending in: A Case Study of Transitional Ambidexterity in the Financial Sector
}

\author{
Beniamino Callegari and Ranvir S. Rai *
}

Citation: Callegari, B.; Rai, R.S Blending in: A Case Study of Transitional Ambidexterity in the Financial Sector. Sustainability 2021, 13, 1690. https://doi.org/ $10.3390 /$ su13041690

Academic Editor: Andrea Pérez Received: 31 December 2020 Accepted: 2 February 2021 Published: 4 February 2021

Publisher's Note: MDPI stays neutral with regard to jurisdictional claims in published maps and institutional affiliations.

Copyright: () 2021 by the authors Licensee MDPI, Basel, Switzerland. This article is an open access article distributed under the terms and conditions of the Creative Commons Attribution (CC BY) license (https:// creativecommons.org/licenses/by/ $4.0 /)$.

\author{
School of Economics, Innovation, and Technology, Kristiania University College, Oslo 0107, Norway; \\ Ben.Callegari@kristiania.no \\ * Correspondence: Ranvir.Rai@kristiania.no
}

\begin{abstract}
Organizational ambidexterity is widely recognized as necessary for the economic sustainability of firms operating in the financial sector. While the management literature has recognized several forms of ambidexterity, the relationship between them and their relative merits remain unclear. By studying a process of implementation of ambidextrous capabilities within a large Scandinavian financial firm, we explore the role of top-down reforms and bottom-up reactions in determining the development of sector-specific innovative capabilities. We find that blended ambidexterity follows naturally from the attempt to correct the tensions arising from harmonic ambidextrous blueprints. The resulting blended practice appears to be closely related to the reciprocal model of ambidexterity, which appears to be a necessity rather than a choice, for large firms attempting to develop innovative capabilities. Consequently, we suggest to re-interpret current taxonomies of ambidexterity not as alternative blueprints, but rather as stages in a long-term process of transition.
\end{abstract}

Keywords: economic sustainability; organizational ambidexterity; blended ambidexterity; innovation process

\section{Introduction}

Organizational ambidexterity has gained considerable attention in management literature since it was first introduced by Robert Duncan in 1976. Originally referring to the ability to use both hands adroitly, the term has been increasingly used in reference to organizations attempting to simultaneously manage both exploitation and exploration to ensure long-term sustainability and competitiveness. Exploitation extends upon current knowledge, seeking greater efficiency and incremental innovation. Exploration, on the other hand, entails the development of new knowledge, experimenting and reaching for more radical innovation [1]. Pursuing and maintaining such opposing business logics and concurrently alleviating related tensions is at the very core of organizational ambidexterity.

The relevance of ambidexterity has been further highlighted by present demands for a transition towards more sustainable business practices. While entirely novel business models can be pioneered by new entrants, spinoffs, and other dedicated experimental market niches, meeting the sustainability challenge also requires incumbents to gradually transform their activities. Such transformation, however, must be conducted while simultaneously maintaining their operations functional and their customers satisfied; while more sustainable options must be explored, exploitation of current opportunities must similarly continue. In other words, from an incumbent perspective, the sustainability transition implies the development and application of ambidexterity.

Extant literature suggests multiple paths to ambidexterity; structural [2], contextual [3] and sequential $[4,5]$ —usually treated as mutually exclusive pathways. However, as recently proposed by Foss and Kirkegaard [6] and as evident from this case study, various modes of ambidexterity may be present at once-ambidexterity can be "blended". Blended ambidexterity may portray a messier yet more realistic picture of "ambidexterity in the 
happening" as companies attempt to lessen some of the negative aspects inherent to any specific ambidexterity mode.

In our study, we focus on the dynamic issues related to the implementation of blended ambidexterity at a large financial organization. More specifically, we examine the issue through a case study of a Norwegian bank-currently undergoing a digital transformation towards becoming a technology-based provider of financial services. In line with previous research $[7,8]$, we investigate how the organization is transitioning between different ambidexterity modes over time in accordance with various challenges and opportunities facing the firm. Our objective is to highlight the unique implementation challenges faced by a top-management team using blended ambidexterity. In particular our theoretical framework leads us to believe that the organization will suffer from significant tensions and paradoxes as they transition from different modes of ambidexterity over time. Our empirical study focuses on exploring the evidence relevant to these transitional changes, and the relative managerial response. We find evidence of a specific transitional trajectory of ambidexterity accompanying the implementation of new practices. The transitional trajectory, and the factors underpinning its course are examined and discussed as part of a transformational strategy for the organization. Additionally, the emergence of specific ambidextrous practices through time have implications for the question of the sustainability of banking business models in the long term.

The article is organized as follows. After this introduction, Section 2 describes our theoretical framework of reference. Section 3 illustrates our methodology. Section 4 contains our findings, which are discussed in Section 5. Finally, Section 6 concludes.

\section{Literature Review}

Smith and Lewis [9] have argued that sustainability is indissolubly linked with the concept of ambidexterity, the ability to balance activities dedicated to exploiting current opportunities and to exploring new methods, business models, and resources, an ability that appears to be vital for the long-term survival of firms [8,10-13]. A successful, sustainable firm is one able to exploit current opportunities and efficiently manage today's demands while also being open to the exploration of new possibilities [13]; to pursue new knowledge while using existing knowledge optimally [12]. In short, a successful firm is more and more commonly described as ambidextrous [4,14-16]. However, not only are there significant differences within the academic community regarding the conceptualization of ambidexterity and its antecedents, there is also substantial heterogeneity in its practical implementation within actual firms.

The various positions can be classified along two main axes. The first regards the understanding of explorative and exploitative activities as either complementary or opposite. The differentiation view argues that explorative and exploitative processes compete for the same resources, their simultaneous implementation involving significant trade-offs $[8,17]$. The integration view argues instead for the presence of significant complementary benefits between the two processes $[3,18,19]$. Consequently, the differentiation view supports implementation strategies based on separate exploration and exploitation activities across business units, while the integration view argues that the processes can, and should, coexist within the same unit. The second axis relates to the temporal dimension of ambidexterity. Exploitation can follow exploration in a more or less rigid alternating sequence [20] or the two activities may always be available for managers and employees to decide when to pursue them [3,21].

Combining these two axes, Simsek et al. [20] propose a classification of ambidexterity in four categories: harmonic, partitional, cyclical, and reciprocal. Harmonic ambidexterity refers to the simultaneous pursuit of exploitation and exploration within a business unit, resulting in processes or systems enabling individual employees and managers to autonomously decide about how to divide their time between conflicting demands [3]. Cyclical ambidexterity, based on the literature on "punctuated equilibrium", refers to the sequential pursuit of exploitation and exploration within a business unit, alternating between 
long periods of exploitation and short bursts of exploration. Partitional ambidexterity refers instead to the simultaneous pursuit of exploitation and exploration across business units, what is commonly referred to in the literature as structural ambidexterity [8]. Finally, reciprocal ambidexterity refers to the sequential pursuit of exploitation and exploration within and across business units.

The latter configuration is certainly the most complex, requiring the establishment of structurally independent units characterized by different, and differently evolving, strategies, structures, and cultures [22]. While each unit operates at least partially independently, they are interdependent with respect to the achievement of ambidexterity. In this reciprocal context, the outputs of exploitation from one unit become the inputs for exploration activities conducted by other units, and vice versa [23]. Such complex configuration implies ongoing information exchange processes, collaborative problem solving activities and resource flows between middle management and the senior management team [24], requiring the presence of a clear shared vision at all operative levels shared vision [25].

While the categorization proposed by Simsek at al. [20] is comprehensive and clear, it is not surprising that empirical realities can be messier. Studying the operation of two business units operating under the William Demant Holding corporate umbrella, Foss and Kirkegaard [6] find evidence of "blending" modes of ambidexterity: the co-presence of structural and contextual ambidexterity, or harmonic and partitional, following Simsek et al. [20] classifications scheme. Specialized organizational units coexist and cooperate with units pursuing both exploitative and explorative activities. Foss and Kirkegaard argue that such configuration is not the result of muddled strategies or faulty implementation processes, but rather the outcome of intentional attempts to mitigate some of the negative aspects inherent to any specific ambidexterity mode, such as the potential loss of specialization advantages under contextual ambidexterity and the problem of diffusing the results of the explorative units activities within exploitative units under structural ambidexterity [14]. The resulting blended approach could also alleviate paradoxical pressures created by the demands of contextual ambidexterity on the individual, through the creation of dedicated supporting units.

An additional issue regarding the classification of ambidexterity regards its evolution over time. The question of how transitions between exploration and exploitation occur in contexts of sequential ambidexterity is still open [19]. Furthermore, due to the limitations linked with any specific approach to ambidexterity, Nosella et al. [7] and O'Reilly and Tushman [8] argue that the most advantageous strategy would involve systematically shifting between ambidexterity modes over time, according to current challenges and opportunities facing the firm. The possibility of blended ambidexterity further muddles the issue, as it is possible that empirical reality could be more correctly described as a shifting mix of ambidexterity regimes, morphing through time. However, the factors dominating the evolutionary shift of the ambidexterity mix through time are yet to be explored.

The link between ambidexterity and sustainability is in evidence within the corporate sustainability discussion that started in management literature in the mid-90s [26], gaining progressively more focus and attention since then [27-29]. In general, corporate sustainability refers to the ability of the firm to both make optimal use of environmental, physical, human, and organizational resources in relation to current knowledge and the existing set of opportunities and constraints as determined by the relevant constellation of stakeholders, while simultaneously cultivating their development over time; a description close to that of the ambidextrous firm [30]. Only through ambidexterity can the sustainable firm guarantee its continued survival by generating value and improving the lives of its stakeholders through time.

In their theoretical review, Sulphey and Alkahtani [31] argue that there is substantial overlapping between corporate ambidexterity and sustainability. The two are argued to complement each other, with sustainability providing the aims and general perspective, and ambidexterity the means and practices. The argument is similar to the one developed by Hahn et al. [32] in regard to the relationship between ambidexterity and corporate social 
performance. Ciasullo et al. [33] provide empirical evidence for structural ambidexterity as a key factor for the realization of sustainability among Chinese multinational firms. Similarly, Gomes et al. [34] illustrate how ambidexterity is an important determinant of environmentally sustainable production in the area of quality management. Using a qualitative approach, instead, Minatogawa et al. [35] come to the same conclusions in their study of a small e-commerce company.

The relevance of the topics of sustainability and ambidexterity in the banking industry context is well known. Financial services offered by banks can be considered transformative services [36], indispensable components of the social infrastructure, whose changes and development over time can trigger wide-range socioeconomic change. On a macroeconomic scale, the composition of their investment portfolios affects both the pace and composition of economic development, while the development of new financial instruments can either support or undermine financial stability. Technological changes, such as digitalization, can also bring substantial social consequences. Wang and He [37] illustrate how digital access to banking services decrease the vulnerability to risk of poor farmers in China, while Yeo and Jun [38] show how P2P lending is changing credit conditions for borrowers with low-to-mid credit ratings.

As service firms, banks rely on intangible assets and knowledge to provide a superior customer experience [39]. Innovative activity is required for the economic sustainability of banks and the maintenance of their competitive advantage [40]. The banking industry has witnessed fundamental changes and greater instability that heighten the importance of successfully attaining ambidexterity to increase their performance [41]. Following the intensified competition brought by the gradual process of deregulation that has taken place in the last decades, bank units are expected to constantly improve existing products while also reducing costs by optimizing current operations. To meet these challenges, banks have integrated advances in information and communication technologies to introduce process technologies, increasing internal efficiency and improving productivity. The need to merge digital innovation with banking operations, however, have led to the emergence of new challenges for the development of ambidexterity in banking.

Studying the implementation of sustainable business models in banking, Yip and Bocken [42] notice the practical relevance of short-termism: the tendency to evaluate innovative projects predominantly on their ability to generate value in the short-term. In this sense, digitalization is often preferred because of its potentially calculable benefits, and its relative quick scalability. However, Marabelli et al. [43] document how large banks, with activities dispersed over large territories, facing the challenge to conjugate the need for innovation with the constraints of the short term, are likely to adapt ambitious ambidextrous organizational approaches, despite the additional managerial and organizational costs involved. Ambidexterity is found to require a managerial approach based on trust and decentralization in boundary activities, confirming the importance of managerial leadership [44,45] and a trust-based culture [21,46] as antecedents. Although somewhat animated by short-term considerations, the digitalization process is also promoting the development of ambidextrous capabilities, thus improving the general ability of financial firms to engage in the transformation processes required by sustainability (new references mentioned before). Thus, although superficially separated, the development of ambidexterity can be understood as an intermediate step in the gradual transformation of financial services towards more sustainable configurations.

In conclusion, the literature reviewed reveals that sustainability in the banking industry requires the integration of ambidextrous business models. The questions of which type of ambidexterity is preferable and how should it be implemented remain open, however. Furthermore, actual implementation of new operational routines and innovationsupporting tools appears particularly challenging in the heavily regulated and risk-averse environment of large-scale banking. As low-interest rates persist and digital-based innovative competitors enter the market; however, the challenge of ambidexterity must be met if traditional banking is to retain its central position within the global financial infrastructure. 


\section{Methods}

This paper introduces a study of an on-going digital transformation in a large Norwegian bank. More specifically, we examine the issue through a case study of a large financial organization-DNB - currently transitioning from a traditional bank business model towards a technology-based provider of financial services. DNB is Norway's largest financial services group and one of the largest in the Nordic region in terms of market capitalization. They offer services to corporate, retail, and securities markets as well as the public sector. In addition to being a world leader in shipping, the bank has a strong position in the energy sector and seafood industries, reflecting traditional Norwegian economic strengths. As one of the largest financial institutions in the Nordic region, our case company is an excellent exemplar of an incumbent undergoing digital transformation while intending to retain its dominant market position.

We conducted semi-structured interviews with key stakeholders across operations to gain in-depth insight into organizational members' reasoning and reflections. This allowed us to comprehend the logic through which they viewed the world [47]. Furthermore, indepth interviews provide an effective means of obtaining rich insights into the phenomenon of interest, as they provide access to detailed contextual information and individual insight that cannot be obtained from surveys [48]. The informants were identified first through expert sampling, and then through snowball sampling, ensuring that all protagonists of the process have been interviewed, and their perspective integrated.

The respondents consisted of 12 managers directly involved in the company's innovation initiatives. They ranged from VP-level to middle management responsible for strategic innovation projects or programs across all DNB areas: New Business (5 respondents), Corporate Market (1 respondent), Consumer Market (2 respondents), Key Accounts (1 respondent), and IT (3 respondents). Within these areas, there are several divisions-referred to as "Innovation divisions" in New Business, "IT divisions" in IT, and "Business divisions" in the remaining areas.

Interviews were conducted until information redundancy was achieved [49]. We used semi-structured interview guides (see Appendix A), allowing for deviation from the sequence in order to follow interesting lines of inquiry and go deeper into relevant, emerging, topics. The approach was deemed particularly appropriate to this case study, since the company was undergoing a complex transformation process, leaving many informants to face significant, persistent uncertainty, which showed in their difficulties to engage directly with our questions. The questions covered the company's existing practices at the time of interview, personal experiences with and interpretations of innovation capabilities and tools, processes and resources, culture and values related to innovation initiatives. Interviews lasted for 45 to $60 \mathrm{~min}$; they were digitally recorded and transcribed verbatim.

To structure respondent explanations and interpretations, we inductively examined our data by following the procedure suggested by Gioia and co-authors [50,51], a method considered particularly appropriate for research on strategic change and sensemaking [52]. In the first stage, we developed "open" codes by uncovering initial concepts from respondents' statements. Then, we confronted our results and integrated them, prioritizing adherence to the respondents' opinions in order to solve controversies. In the second stage, we classified these into higher order themes through axial coding based on the relationships among the initial first-order codes, translating the empirical results into relevant theoretical constructs. Finally, we gathered similar themes into aggregate dimensions that provided an overall structure to our narrative. We performed this procedure iteratively, going back and forth between codes and data until consensus among the authors emerged. Figure 1 shows the final data structure. The vertical order of the aggregate dimensions offers a broad timeline of the process of implementation of ambidexterity capabilities, starting from original situation and the initial plan, moving gradually towards a blended approach directed towards a reciprocal outcome. This narrative emerged during reflexive discussion between the authors and was subsequent used to organize the exposition of empirical 
results. The following discussion provides a reconstruction and a potential explanation of the phenomenon in theoretical terms, illustrating which elements are consistent with existing literature, and which ones can be interpreted as an original contribution.

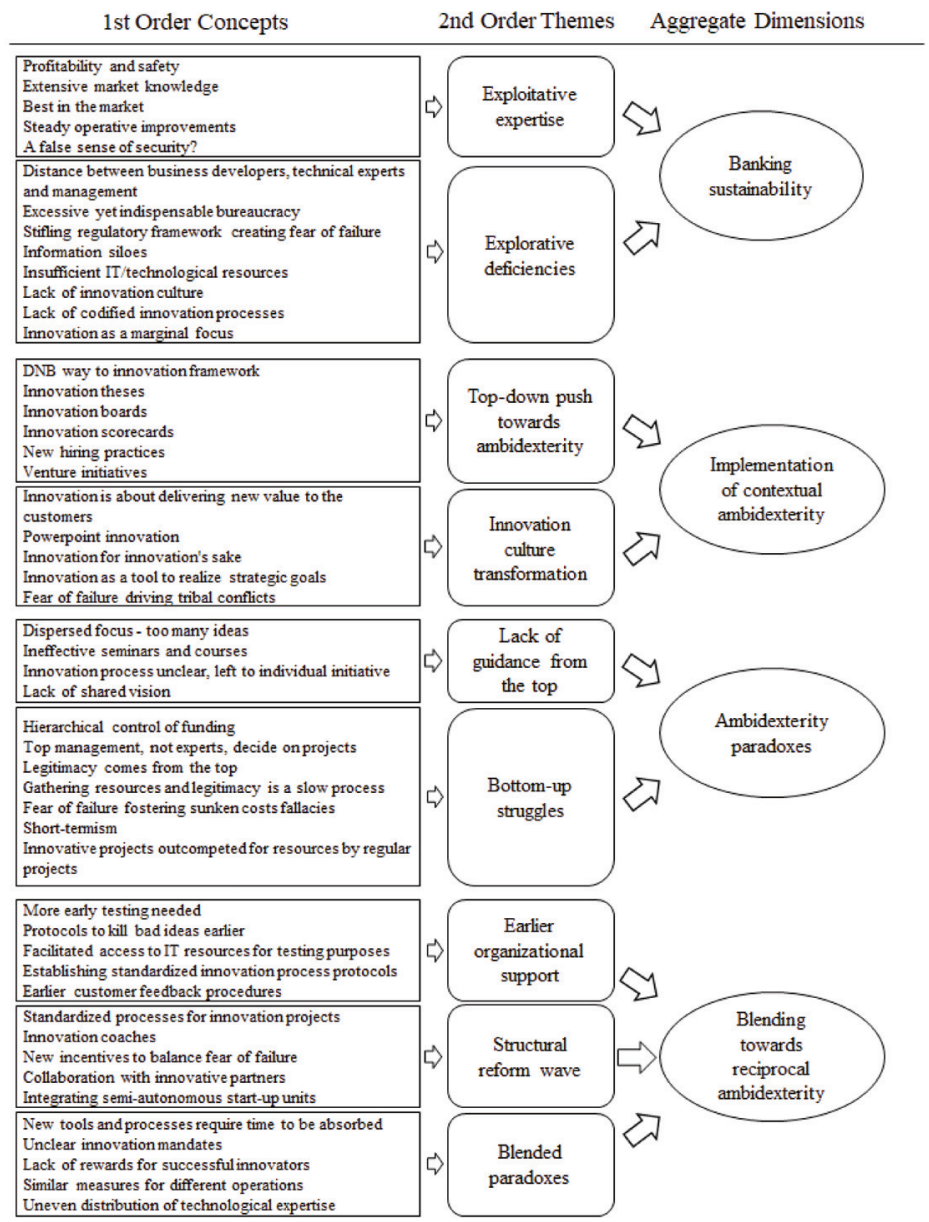

Figure 1. Data structure.

\section{Results}

\subsection{Banking Sustainability}

Most respondents contextualized the current organizational reform process affecting DNB as a reaction to a situation of complacency. The secure oligopolistic position held by DNB within the Norwegian financial market ensures comfortable profit margins, superior to most European counterparts, margins that are not currently under significant threat from the local competition. The management however is conscious of the fact that such rosy situation is unlikely to last indefinitely:

"I don't think we're going to be out-competed, but I probably think the margins within some of our most profitable business models is going to come under increasing pressure then in the years to come, and that requires us to innovate our existing business models, we need to become more efficient in streamlining our operations." - Division Director IT Division. 
Lack of profitability pressures and steady profits have led to somewhat underdeveloped innovative capabilities:

"We are lacking some parts of what I would call innovation competence, such as pure business model innovation, experiment design and execution. We have some individuals, but not enough for a company of this size. When you look at traditional business development, how to treat an idea, how to actually build up partnerships, how to build services and products, we have that in house, but using it for innovation is a different issue." - Leader, Digital Innovation, B2C.

Furthermore, innovative resources and competences are not only relatively scarce, but also unevenly distributed and isolated:

"Our innovation capabilities are kind of spread between business developers with different types of roles. And then you have other sides of the innovation capabilities, IT and people of operations in different service roles, like service designers or literally IT architects." - Senior innovation coach.

The interviews underlined how DNB lacked company-wide systems for knowledge integration and sharing [53]. Respondents reported how they often struggled to access and share specialized knowledge across departments in an effective manner:

"DNB actually does have a lot of insight, but we have difficulties in terms of access across divisions (because we are legally not allowed to) and the systems that we use." - Senior innovation coach.

In addition to knowledge, all managers interviewed have described IT resources as similarly scarce and difficult to mobilize, mostly tied up in the maintenance of inherited old IT systems. The challenge appears to be particularly pronounced in connection to innovative activities:

"Our IT department is at all times $100 \%$ sold out and over capacity, so that IT with today's setup does not have any capacity to assist in innovation work at all. It is due to the management model, and partly because IT has a rather heavy responsibility related to security, compliance, the Financial Supervisory Authority and other things." - IT Division Director.

\subsection{Implementation of Contextual Ambidexterity}

In reaction to these and other commonly perceived shortcomings, DNB has developed the "DNB Way of Innovation" strategy, in order to develop harmonic ambidexterity capabilities across the entire organization. This aim has been pursued through a series of top down reforms, supported by attempts directed towards a comprehensive organizational innovation culture transformation. Several top-down initiatives have been implemented on a company-wide level in order to become more innovative through the integration of more explorative methods, tools, and processes:

"I can't really say that we have a clearly defined innovation framework or strategy, but we do have some new initiatives (innovation boards). Moreover, we have something called 'The DNB Way of Innovation' with certain practices and tools that our innovation coaches should master quite well." —-Section Leader, New Business Payments.

DNB is on a transformation journey from being a sheltered, oligopolistic financial institution to a global competitor in the digital innovation arena. This means that DNB must become more forward-looking and able to embrace failure as part of becoming more innovative. However, such a mindset shift is entirely at odds with traditional banking, a business model well-known for its conservative approach and strongly institutionalized aversion to failure. One of the informants reflected on this: 
"We are supposed to depart from a culture in which we make 'safe' decisions towards a culture where failure is allowed, and initiative is rewarded." - Section Leader, New Business Payments.

Although the aim is clear, the path remains challenging, however, with significant tensions emerging within and between departments [54]:

"There are a lot of people at the IT department at DNB who do not dare to fail, because there has been no room for failure in the past. It has been a fear-based culture. Even though our CEO says we should dare to fail the organization is rigged towards risk aversion." —-Leader, Accelerate Innovation-New Business.

\subsection{Ambidexterity Paradoxes}

Since DNB has only recently developed an innovation focus, with most of the processes still to be fully implemented, few employees have actual experience with innovation management practices. As many new tools and processes for innovation are introduced "from above", many informants still feel like their innovation projects are outcompeted on resources against regular projects. One of the respondents commented:

"Some of us are supposed to think innovative according to our scorecards yet we often get tied up to existing projects. I tell my employees to spend twothirds of their time on existing projects and one-third of their time on thinking forwards, but this is not how it works out in reality." —Section Leader New Business Payments.

The lack of dedicated resources and structures supporting innovative efforts from the bottom-up hampered the first attempts to apply the new strategy:

"I think the greatest potential for DNB is to innovate more on the things that we already have. We have a lot of new initiatives [... ] Yet, with few resources, time and capacity on continuous improvement there is a need for a better balance." -New Business, Accelerate Innovation.

One of the respondents reflected further on this part:

"We are often saying that 'hey, we would like to explore some of these opportunities' but then when you look how we invest, everything is core [...] that is not necessarily the problem, but if you say that you don't want to just do that, and then you do it, that might be a problem." - Senior innovation coach.

In response to these and other challenges, the company has established a new division called "New Business". This division works as a support department for the entire DNB Group, contributing its innovation expertise to other divisions focusing on traditional business areas. Furthermore, dedicated innovation coaches have been hired, to provide support to bottom-up innovation processes. The collaboration, however, is more difficult than expected, as the divide between those who innovates and those who do not becomes more pronounced:

"you sit with one foot on the gas and one on the brake. So, then I kind of think it's either go or no go. Either you feel that you are allowed to work with innovation as an employee, or you are one of those who feel that you are hired to make sure things do not go wrong." - Division Director of Innovation Division.

\subsection{Blending Towards Reciprocal Ambidexterity}

In order to alleviate some of the tensions described above, DNB is currently undergoing a second reform wave. One of the informants noted:

"The competence in innovation in the bank is still extremely low [...] That is why we have started this enterprise innovation program and created a separate division for design and innovation." - IT Division Director. 
Another solution to the lack of competence has been to prioritize external relationships. Explorative units engage in comprehensive collaborations with universities, other financial organizations, digital startups, and talented young programmers. Exploitative units absorb the knowledge so attained through internal training and seminars. By collaborating with innovative partners, introducing innovation coaches, and launching more standardized exploration processes, DNB is supporting the implementation of its Way of Innovation with decidedly structural changes. DNB has purchased "Luca Lab" to bolster the innovative capabilities of its DNB Accounting business unit. In addition, DNB has partnered with "11: FS" to develop a consumer finance solution ("Foundry").

The data reveals that, despite the initial harmonic plans, during the process of implementation the organization has blended different modes of ambidexterity [6], introducing structural solutions both within and across departments. The co-presence of various ambidexterity modes resulting in distinct management challenges and paradoxes across units and departments. The company struggles to obtain mechanisms for linking and integrating different modes of operation. In this regard, previous studies [22] have emphasized that separate units may embody distinct strategies and operating logics and even cultures, yet need to be coordinated through a shared vision animating the senior management team's actions:

"We notice that in very many of the discussions we have, there is a cultural difference. I believe in creating a common culture, common goals and a common understanding. So, even if someone is working with an agile approach and others are doing more waterfall-type work that it is perfectly fine as long as we are working towards some common organizational goals." - Leader, Digital Innovation, B2C.

Achieving such synergistic fusion, however, necessitates that different units work interdependently in terms of ambidexterity:

"There is a gap in terms of implementing that innovation strategy and framework and process in the organization. My impression is that there is little awareness of the innovation strategy amongst managers and employees in general in the organization at large." —IT Division Director.

According to most respondents, the main challenge currently faced by DNB in the process to further develop its innovative capabilities lies in the fact that significant amounts of resources are spent on the idea generation and early development phases of new products and services, before any attempts towards validation are made, resulting in significant sunk costs.

"Now, people have a thousand ideas, and everyone works with them for a year, and then you come to the IT team and do not get the resources to make it. We need to become much better at prioritizing in early stages of projects and say no to others, so that the things we actually choose to do we do properly with the right resources." -Division Director, Open Banking.

This has led to the implementation of practices aimed at earlier idea selection:

"One of the things that we try to work with in the innovation team is the number of ideas we are able to kill, the so-called 'kill-index', which is quite important. We have to teach the business areas that bad ideas are bad quicker." - New Business, Accelerate Innovation.

The reform involves the creation of dedicated testing units and resource pools, accompanied by a concerted effort to promote a testing culture: "So we are really pushing the testing culture in the whole of DNB, building up a testing environment where you can actually, everyone and I am not talking about Private Market only, but that all DNB, IT, everyone is using the same platform, in terms of sharing their learnings."-Section Leader, Private Market-Digital Sales. 
The informants have also mentioned the lack of a rewards system for innovation efforts: current incentives in the bank follow traditional practices. In this regard, O'Reilly and Tushman [55] emphasize the importance of rewarding cross-unit accomplishments tied to growth targets instead of specific unit goals. As incentive structures and operative realities drift further apart, the opportunities for new paradoxes to arise increase.

These findings suggest that DNB is transitioning towards reciprocal ambidexterity, with different units operating partially independent-attempting to obtain the synergistic fusion of complementary streams of exploitation and exploration as depicted by Simsek et al. [20]. According to Brix [19], the main difference between reciprocal ambidexterity and partitional ambidexterity is that reciprocal ambidexterity is characterized by processes of transferring knowledge back and forth between two separate units. Simsek et al. [20] assert that this type of ambidexterity is more likely to emerge in complex environments-which certainly is descriptive for DNB as an organization.

By transitioning between multiple modes of ambidexterity several paradoxes have appeared to the surface. Structural reforms and company-wide change processes take time to complete, and unforeseen challenges are almost inevitable in a large an organization as DNB. Unclear mandates for innovation, uneven distribution of resources, especially IT, and the lack of a distinct reward system for innovation exemplify some of the paradoxes and inconsistencies that have emerged in a transitional ambidexterity process. We illustrate the trajectory path of transitional ambidexterity at DNB in Figure 2.

\section{Structural dimension}

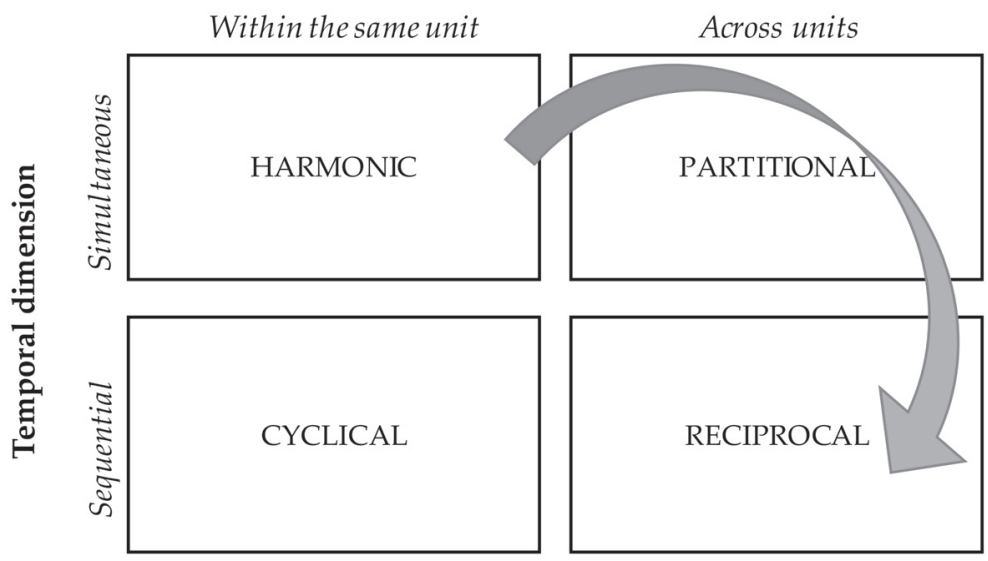

Figure 2. Suggested trajectory of transitional ambidexterity at DNB; from harmonic to reciprocal. The figure is an adapted version of organizational ambidexterity typology, as introduced by Simsek et al. [20] (p. 868).

\section{Discussion}

The implementation of the DNB Way of Innovation strategy is ongoing and, given the experimental, reflexive, and flexible approach undertaken by the top management in its realization, its long-term results cannot be fully appreciated today. What the DNB case can teach us, however, is how, while ambidextrous capabilities can be developed and an ambidexterity strategy planned, its implementation will confront management with certain realities imposing a specific direction to organizational reform, no matter the original intentions. Not only are these findings relevant for our understanding of the development of ambidexterity through time, it also matters for our analytical application of the various types of ambidexterity discussed in the literature. The emergence of specific ambidextrous practices through time have also important implications for the question of the sustainability of banking business models in the long term. 
In this regard, it is notable how neither present profitability, nor a strong market position, have blinded DNB management to the need for developing an ambidextrous stance in order to ensure long-term economic sustainability. All our informants, no matter how critical of the bank or its strategies, agreed on this point. A similar consensus was obtained in regard to the satisfactory performance of the exploitative activities of the firm, and its much less adequate explorative capabilities. Consequently, to achieve an ambidextrous stance, a comprehensive reform of the innovation processes of DNB was needed; this is what the DNB Way of Innovation is attempting to deliver.

The key aim of the new model is to achieve higher organizational explorative capabilities by fostering the development of individual innovative ability among the general workforce and, over time, within every business unit [56]. Employees are asked to devote an increasing amount of their time and attention to explorative activities in addition to routine exploitative tasks. Management is asked to support this shift by integrating a variety of new tools and processes developed to support bottom-up innovation processes, by allocating resources to such initiatives and by supporting the gradual diffusion of innovative expertise and an innovation-friendly culture. While digital technologies are involved in most innovative projects, the strategy itself is agnostic regarding content: any proposal able to satisfy the requirements defined by the strategy and to gain the relevant managerial support is welcome. The aim is to improve the general explorative capabilities of the firm, rather than achieving a specific technological or market objective; a choice not without consequences.

Although not labeled as such, the initial strategy has clearly been one of fostering contextual, or harmonic, ambidexterity among several business units. This aim has been pursued through the implementation of new practices and instruments, meant to both support the development of existing innovative projects and ideas, and to foster a more general shift toward an organizational culture more supportive of innovative individual initiatives. The chosen approach reveals an understanding on part of the reformers of the importance of a supporting organizational culture for contextual ambidexterity to be successfully developed, as argued by Wang and Rafiq [21]. However, the implementation of this consistent and theoretically sound plan reveals some inherent limitations.

Contextual ambidexterity encourages bottom-up innovation initiatives. However, especially in the initial phases of a transition towards a more established ambidextrous modus operandi, the burden of such efforts falls almost entirely on the shoulders of the innovative individuals involved. The paradox of ambidexterity highlighted here is that, while individual initiative is encouraged, it is only rewarded in case of success, if at all. The rate of success of innovative projects, however, is always very low; in a context in which explorative capabilities are lacking, and new instruments still being experimented with, the probabilities of success can be described as abysmal. Thus, those individuals open to innovation, receptive to encouragement, and hard-working and risk-tolerant enough to try and kickstart an innovative idea while still keeping up with their daily routine, are likely to encounter uncertainty, frustrations, and, ultimately, failure [57].

This undesirable outcome can be managed, but not entirely avoided. Establishing instruments, practices, and cultural norms able to support reiterated individual failure is a necessary goal on the road of establishing contextual ambidexterity capabilities. In the initial stages, however, the goal of fostering bottom-up initiatives in order to test the approach overrides any other concern, leading, in the best-case scenario, to a proliferation of ideas and new projects to be managed. The newly established and still experimental practices and tools are unlikely to be successful in providing sufficient support to all of them. Selection is necessary and yet, paradoxically, undesirable [58]. Employees are already asked to promote innovative ideas in addition to their normal tasks: to push severe requirements on such ideas is likely to result in very few projects being generated. While the low number of projects may very well be in line with initial managerial capabilities, an optimal outcome even, it may also delegitimize the ambidexterity reform, undermining 
the proponents in the eyes of top management. Better to let a hundred flowers bloom; the cruel harvest may come later.

Other paradoxes emerge in regard to the issue of organizational culture. If individual employees are to be free to pursue explorative activities, their managers must be willing and able to support such decisions. This requires the adoption of a perspective favorable to contextual/harmonic ambidexterity, and the acceptance of the organizational value of the new tools and practices which such approach entails. However, different business units will have different perspectives on the relative importance of bottom-up innovation processes for the sustainability of their operations. Thus, the single innovation vision promoted from the top will shatter into several different interpretations during the process of implementation. The understanding of what innovation is, how it should be pursued, and what it could achieve was extremely heterogeneous across organizational lines. This is not simply a matter of opinions: the role of management in supporting contextual/harmonic ambidexterity is key [59]. While new tools, practices, and lingo can be adopted as a result of a push from the top, their effectiveness will vary greatly according to the actual support that local management is willing to offer to the new innovative projects, a key factor in the tender early stages of the process.

However, these cultural differences are not created by reform attempts, but rather brought to light. The resulting discussions and attrition play two constructive roles. First, they promote a debate that, in the long term, can lead to a more homogeneous organizational culture. Second, managerial criticism may reveal flaws and limitations of the original strategy, either specific to a given business area or general, an input that, if constructively received, can lead to general improvements in ambidexterity capabilities. The paradox lies in the fact that, in the short term, attempts to foster a homogenous innovation culture will highlight the fractured condition of the organization [60].

Ultimately, these tensions will lead to a struggle for resources, the practical embodiment of the conflict between exploitative and explorative activities [61]. The initial push supporting bottom-up initiative provides enterprising employees with the possibility to allocate some of their work time to ideating an innovative project. Any serious development, however, would require additional resources; however, under contextual/harmonic ambidexterity, resources are not specifically allocated to exploration or exploitation, they are flexibility redistributed according to needs. This means that bottom-up initiatives must constantly leverage their resources into access to more resources, climbing the managerial pole one meeting at a time. While the initial competition will be with other innovative initiatives, eventually explorative and exploitative needs will come to a clash. From an organizational perspective, this conflict is both inevitable and desirable: the ability to constructively and efficiently solve such conflicts is contextual ambidexterity. It is clearly an unfair fight, as the necessity and benefits of exploitation are well known, while the gains of exploration are by nature uncertain. Furthermore, resources for innovative projects often must be gathered across organizational lines, with the resulting organizational culture differences further stacking the deck against the explorative alternative.

The situation is worsened by the early tolerance necessary for the testing phase to begin in earnest. A hundred flowers bloom, but very few give fruit: the early impression of vigor later gives rise to disappointment among the would-be innovators and a general perception of wasted time, efforts, and resources among all involved. Two solutions to this problem can be adopted; in our case, both roads have been travelled. The first is providing more support to the innovators, to allow them to fight more effectively for the resources they need. The second is to create resource pools dedicated exclusively to explorative purposes, thus alleviating the need to compete with exploitative activities. These solutions to the quintessential contextual ambidexterity issue, however, are clearly structural in nature [62]. The former implies the creation of groups and organizational divisions dedicated entirely to explorative support; the latter makes the critical allocation of resources decision an ex ante managerial prerogative, coming from the top rather than being endogenously defined by bottom-up initiatives. While such an organizational response is not necessary, the issues 
it addresses are implied by any contextual/harmonic strategy. The choice appears to be either to accept the paradoxes of contextual ambidexterity, and the organizational costs they imply, or to try and fix the situation by blending in structural solutions.

The contextual/structural axis is not the only one that begins to blur, however. Integrating a time perspective, it is possible to see that the DNB Way of Innovation intended to pursue a harmonic strategy, integrating exploration as a continuous focus over time [63]. However, the bottom-up, decentralized nature of contextual ambidexterity, combined with the broad integration of such practices over all business units, implies that the actual ratio of resources engaged in exploration vs. exploitation cannot be planned for in advance. Since most initiatives can be expected to fail in their early stages, most resources can be expected to be spent on exploitative routines. However, exceptional projects will arise from time to time, commanding a significant amount of internal resources. To be realized, such projects will eventually need to access resources across business units' lines, forcing other units to play a supporting role. At the same time, other units will have to pick up the exploitative slack, covering for the missing input for the temporarily explorative unit. Furthermore, as the innovation process develops, the initial unit may de-escalate its involvement, as other units with different capabilities and responsibilities take over the lead.

From a theoretical perspective, this description can be summarized in the following proposition: the implementation of a harmonic ambidexterity strategy within a large organization will lead to reciprocal ambidexterity in practice. The process will be supported by a gradual blending of contextual and structural elements, the latter introduced to diffuse the tensions emerging from the former. The argument can be seen as an extension of Andriopolous and Lewis' [64] argument in favor of a multilevel approach: structural and contextual ambidexterity are complementary strategies, covering each other's limitations. This does not mean that the resulting blend is devoid of paradoxes and tensions: our results already reveal several emergent issues. It is likely that such issues will drive further changes in the strategy. This reinforces our argument further: implementation challenges, and their solutions, drive the development of ambidexterity capabilities, in an evolutionary, path-dependent process illustrated in Figure 3, in which teleology can play only the role of trigger [65]. However, does this process ensure corporate sustainability?

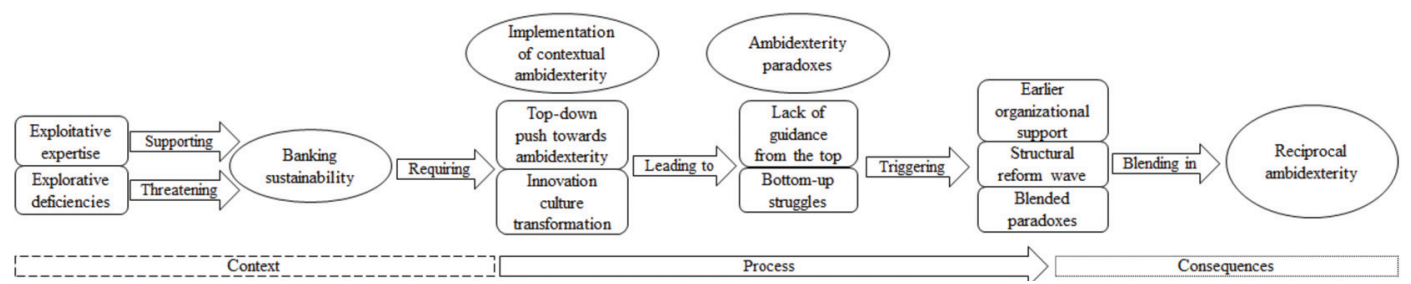

Figure 3. Transitioning from harmonic to reciprocal ambidexterity.

Of the various components of the corporate sustainability construct, economic, environmental, social, operational, and strategic, all are involved within the process under study, with one key exception. Strategic sustainability can be seen as the main aim of developing ambidexterity capabilities. Economic sustainability is improved by ensuring that a concern for maintaining the competitive advantage over time is diffused among all organizational units and levels. Operational sustainability is supported by the reflexive practices supporting the development of innovative capabilities. Social sustainability is also improved, through expansion of collaborative explorative initiatives involving external firms and organizations and by integrating customer feedback in the early stages of the innovation process. What remains outside this process, however, is environmental sustainability. The ongoing digitalization effort will have some modest positive consequences on the environmental blueprint of the immediate bank activities, but this is accidental: as discussed above, the ambidexterity process is technologically agnostic. We have found 
no evidence of significant environmental sustainability concerns at any organizational level, nor was the issue mentioned as particularly significant for the future of the firm at large. This blind spot will need to be addressed in the future, as the relevance of the environmental aspects of sustainability will come to play an increasingly larger role in the future [66].

\section{Conclusions}

The literature on ambidexterity has identified a number of alternative solutions to the need of the firm to simultaneously engage in exploitative and explorative tasks in order to secure its sustainability. Recent research has suggested that these solutions may not be alternatives, but they can be in fact simultaneously pursued, in different mixes. We add to this result by supporting the hypothesis that the limitations inherent in a specific ambidextrous solution, namely, contextual ambidexterity, create conditions that both invite and facilitate the introduction of structural solutions. Thus, a reflexive process of implementation is likely to result in blending harmonic and partitional approaches. Furthermore, we have provided evidence suggesting that, over time, the same process of addressing emerging practical issues may lead to the emergence of reciprocal ambidexterity, the most complex configuration identified by the literature.

Our research contributes to the existing literature by adding a temporal dimension to the analysis of blended ambidexterity, and by integrating the dynamic concept of blending with the static conceptual taxonomies of the ambidexterity construct. From a practical perspective, we argue that, in dealing with an inherently paradoxical phenomenon such as ambidexterity, internal consistency in planning should be sacrificed to operational flexibility and the emerging need revealed by the process of implementation: the resulting hybrid may well be more successful than its theoretical pure counterpart. From a theoretical perspective, we analyze the phenomenon of blending over time, and its consequences for our conceptualization of the phenomenon of ambidexterity. Furthermore, we question the analytical validity of imposing dualistic structure to a phenomenon that appears to be empirically dominated by crossed lines.

The research is characterized by a number of limitations. Firstly, we did not interview lower level employees; A more comprehensive approach in the gathering of data would strengthen the research and open new vistas on the bottom up struggles that characterize any attempt at fostering contextual ambidexterity. Secondly, although clear reciprocal signs are in evidence, the stability of this configuration cannot be taken for granted. On the basis of current evidence, we believe that such configuration may be reasonably assumed to be the final form that ambidexterity will take in DNB, at least in the medium-term. The validity of such assumption should however be tested by future research. Third, while the role of ambidexterity as an antecedent of sustainability is in our view sufficiently established, the actual mechanisms linking ambidextrous capabilities with the development of sustainable business practices should be subject to more direct investigation, something we were prevented from doing by the presently modest attention dedicated by the subject of our study to these concerns.

Author Contributions: Conceptualization, B.C. and R.S.R.; methodology, R.S.R; formal analysis, B.C. and R.S.R.; data curation, R.S.R.; writing - original draft preparation, B.C. and R.S.R; writing-review and editing, B.C. and R.S.R.; visualization, B.C. and R.S.R; supervision, B.C.; project administration, R.S.R.; All authors have read and agreed to the published version of the manuscript.

Funding: This research received no external funding.

Institutional Review Board Statement: Not applicable.

Informed Consent Statement: Informed consent was obtained from all subjects involved in the study.

Acknowledgments: We would like to thank Amir Saed Ali, Arman Muzaffar, and Rehan Yousaf for their help with data collection.

Conflicts of Interest: The authors declare no conflict of interest. 


\section{Appendix A. Interview Guide}

Resources: People and competence

How is the composition of people and competence in your division/section when it comes to innovation?

Time and resource allocation

What are your views on how time and other resources are allocated to activities related to innovation, exploration, reflection and problem solving, in your division?

Tools and frameworks

Are there any tools or frameworks available to manage and evaluate innovation?

Understanding of innovation

Do you perceive that DNB and your division understand what innovation is, its significance and how to work on it?

\section{Competition and market position}

Does DNB, and your division, know how the market is structured and how to compete in it?

\section{Processes}

Do you perceive that your division is making sufficient efforts to explore new business or technological possibilities?

\section{Incubation}

Are there effective ways to incorporate new ideas or solutions into the organization and subsequently implement them in products or customer offerings?

Learning and unlearning

Has the divisions worked to promote, rearrange or change the competence and capabilites in the organization to become competitive in a changing market?

\section{Bureaucracy}

Do you perceive that the inherent organizational bureaucracy is inhibiting how you work with innovation?

\section{Innovation strategy}

Do you perceive that there is a clear strategy for innovation, and is it known among the employees?

\section{Strategy vs. operational}

Do you feel that the innovation activity in your divisions is derived from or linked to one common innovation strategy in the organization?

\section{Culture for creativity}

Are creative solutions or unconventional ideas encouraged—and are they explored or implemented by your division?

\section{Organizational dependencies}

How does your division handle issues of being relevant both technologically and business wise-and how do you consider future opportunities?

Decision basis and rules for innovation

Do you perceive rules for decision making and evaluation of new ideas to be clear and suitable for enabling innovation?

\section{External relations}

How does how your division collaborate with or evaluate external actors to enable innovation?

Clear decisions and division of responsibilities

Is it clear and appropriate how the mandate and responsibilities for innovation are assigned in our division?

In general

What do you think are the most important factors that enable/inhibit innovation in your division?

\section{References}

1. Atuahene-Gima, K. Resolving the Capability-Rigidity Paradox in New Product Innovation. J. Mark. 2005, 69, 61-83. [CrossRef] 
2. Gupta, A.K.; Smith, K.G.; Shalley, C.E. The Interplay Between Exploration and Exploitation. Acad. Manag. J. 2006, 49, 693-706. [CrossRef]

3. Gibson, C.B.; Birkinshaw, J. The antecedents, consequences, and mediating role of organizational ambidexterity. Acad. Manag. J. 2004, 47, 209-226.

4. Duncan, R.B. The ambidextrous organization: Designing dual structures for innovation. Manag. Organiz. 1976, 1, 167-188.

5. Nickerson, J.; Zenger, T.R. Being Efficiently Fickle: A Dynamic Theory of Organizational Choice. Organ. Sci. 2002, 13, 547-566. [CrossRef]

6. Foss, N.J.; Kirkegaard, M.F. Blended ambidexterity: The copresence of modes of ambidexterity in William Demant Holding. Long Range Plan. 2020, 53, 102049. [CrossRef]

7. Nosella, A.; Cantarello, S.; Filippini, R. The intellectual structure of organizational ambidexterity: A bibliographic investigation into the state of the art. Strat. Organ. 2012, 10, 450-465. [CrossRef]

8. O’Reilly, C.A., III; Tushman, M.L. Organizational ambidexterity: Past, present, and future. Acad. Manag. Perspect. 2013, 27, 324-338. [CrossRef]

9. Smith, W.K.; Lewis, M.W. Toward a theory of paradox: A dynamic equilibrium model of organizing. Acad. Manag. Rev. 2011, 36, 381-403.

10. Hill, S.A.; Birkinshaw, J. Ambidexterity and Survival in Corporate Venture Units. J. Manag. 2014, 40, 1899-1931. [CrossRef]

11. Khan, Z.; Lew, Y.K. Post-entry survival of developing economy international new ventures: A dynamic capability perspective. Int. Bus. Rev. 2018, 27, 149-160. [CrossRef]

12. Levinthal, D.A.; March, J.G. The myopia of learning. Strat. Manag. J. 1993, 14, 95-112. [CrossRef]

13. March, J.G. Exploration and Exploitation in Organizational Learning. Organ. Sci. 1991, 2, 71-87. [CrossRef]

14. Tushman, M.L.; O’Reilly, C.A., III. Ambidextrous organizations: Managing evolutionary and revolutionary change. Calif. Manag. Rev. 1996, 38, 8-29. [CrossRef]

15. Adler, P.S.; Goldoftas, B.; Levine, D.I. Flexibility Versus Efficiency? A Case Study of Model Changeovers in the Toyota Production System. Organ. Sci. 1999, 10, 43-68. [CrossRef]

16. Raisch, S.; Birkinshaw, J. Organizational Ambidexterity: Antecedents, Outcomes, and Moderators. J. Manag. 2008, 34, 375-409. [CrossRef]

17. Smith, W.K.; Tushman, M.L. Managing Strategic Contradictions: A Top Management Model for Managing Innovation Streams. Organ. Sci. 2005, 16, 522-536. [CrossRef]

18. Caniëls, M.C.; Neghina, C.; Schaetsaert, N. Ambidexterity of employees: The role of empowerment and knowledge sharing. J. Knowl. Manag. 2017, 21, 1098-1119. [CrossRef]

19. Brix, J. Ambidexterity and organizational learning: Revisiting and reconnecting the literatures. Learn. Organ. 2019, 26, 337-351. [CrossRef]

20. Simsek, Z.; Heavey, C.; Veiga, J.F.; Souder, D. A typology for aligning organizational ambidexterity's conceptualizations, ante-cedents, and outcomes. J. Manag. Stud. 2009, 46, 864-894. [CrossRef]

21. Wang, C.L.; Rafiq, M. Ambidextrous Organizational Culture, Contextual Ambidexterity and New Product Innovation: A Comparative Study of UK and Chinese High-tech Firms. Br. J. Manag. 2012, 25, 58-76. [CrossRef]

22. Benner, M.J.; Tushman, M.L. Exploitation, Exploration, and Process Management: The Productivity Dilemma Revisited. Acad. Manag. Rev. 2003, 28, 238. [CrossRef]

23. Thompson, J.D. Organizations in Action: Social Science Bases of Administration Theory; McGraw-Hill: New York, NY, USA, 1967.

24. O'Reilly, C.A., III; Tushman, M.L. Ambidexterity as a dynamic capability: Resolving the innovator's dilemma. Res. Organ. Behav. 2008, 28, 185-206. [CrossRef]

25. Jansen, J.J.; George, G.; Van den Bosch, F.A.; Volberda, H.W. Senior team attributes and organizational ambidexterity: The moderating role of transformational leadership. J. Manag. Stud. 2008, 45, 982-1007. [CrossRef]

26. Dyllick, T.; Hockerts, K. Beyond the business case for corporate sustainability. Bus. Strat. Environ. 2002, 11, 130-141. [CrossRef]

27. Moneva, J.M.; Archel, P.; Correa, C. GRI and the camouflaging of corporate unsustainability. Account. Forum 2006, $30,121-137$. [CrossRef]

28. Moneva, J.M.; Ortas, E. Corporate environmental and financial performance: A multivariate approach. Ind. Manag. Data Syst. 2010, 110, 193-210. [CrossRef]

29. Schaltegger, S.; Burritt, R. Corporate sustainability. In The International Yearbook of Environmental and Resource Economics 2005/2006A Survey of Current Issues; Folmer, H., Tietenberg, T., Eds.; Edward Elgar: Cheltenham, UK, 2005.

30. Smith, J.; Haniffa, R.; Fairbrass, J. A conceptual framework for investigating 'capture' in corporate sustainability reporting as-surance. J. Bus. Ethics 2011, 99, 425-439. [CrossRef]

31. Sulphey, M.; Alkahtani, N.S. Organizational ambidexterity as a prelude to corporate sustainability. J. Secur. Sustain. Issues $\mathbf{2 0 1 7}, 7$. [CrossRef]

32. Hahn, T.; Pinkse, J.; Preuss, L.; Figge, F. Ambidexterity for Corporate Social Performance. Organ. Stud. 2015, 37, 213-235. [CrossRef]

33. Ciasullo, M.V.; Montera, R.; Cucari, N.; Polese, F. How an international ambidexterity strategy can address the paradox perspective on corporate sustainability: Evidence from Chinese emerging market multinationals. Bus. Strat. Environ. 2020, 29, $2110-2129$. [CrossRef] 
34. Gomes, P.J.; Silva, G.M.; Sarkis, J. Exploring the relationship between quality ambidexterity and sustainable production. Int. J. Prod. Econ. 2020, 224, 107560. [CrossRef]

35. Minatogawa, V.; Franco, M.; Durán, O.; Quadros, R.; Holgado, M.; Batocchio, A. Carving out New Business Models in a Small Company through Contextual Ambidexterity: The Case of a Sustainable Company. Sustainability 2020, 12, 2337. [CrossRef]

36. Anderson, L.; Ostrom, A.L.; Corus, C.; Fisk, R.P.; Gallan, A.S.; Giraldo, M.; Mende, M.; Mulder, M.; Rayburn, S.W.; Rosenbaum, M.S.; et al. Transformative service research: An agenda for the future. J. Bus. Res. 2013, 66, 1203-1210. [CrossRef]

37. Wang, X.; He, G. Digital Financial Inclusion and Farmers' Vulnerability to Poverty: Evidence from Rural China. Sustainability 2020, 12, 1668. [CrossRef]

38. Yeo, E.; Jun, J. Peer-to-Peer Lending and Bank Risks: A Closer Look. Sustainability 2020, 12, 6107. [CrossRef]

39. Junni, P.; Sarala, R.M.; Taras, V.; Tarba, S.Y. Organizational Ambidexterity and Performance: A Meta-Analysis. Acad. Manag. Perspect. 2013, 27, 299-312. [CrossRef]

40. Roberts, P.W.; Amit, R. The Dynamics of Innovative Activity and Competitive Advantage: The Case of Australian Retail Banking, 1981 to 1995. Organ. Sci. 2003, 14, 107-122. [CrossRef]

41. Jansen, J.J.; Simsek, Z.; Cao, Q. Ambidexterity and performance in multiunit contexts: Cross-level moderating effects of structural and resource attributes. Strat. Manag. J. 2012, 33, 1286-1303. [CrossRef]

42. Yip, A.W.; Bocken, N.M. Sustainable business model archetypes for the banking industry. J. Clean. Prod. 2018, 174, 150-169. [CrossRef]

43. Marabelli, M.; Frigerio, C.; Rajola, F. Ambidexterity in Service Organizations: Reference Models from the Banking Industry. Ind. Innov. 2012, 19, 109-126. [CrossRef]

44. Beckman, C.M. The Influence of Founding Team Company Affiliations on Firm Behavior. Acad. Manag. J. 2006, 49, 741-758. [CrossRef]

45. Lubatkin, M.H.; Simsek, Z.; Ling, Y.; Veiga, J.F. Ambidexterity and Performance in Small-to Medium-Sized Firms: The Pivotal Role of Top Management Team Behavioral Integration. J. Manag. 2006, 32, 646-672. [CrossRef]

46. Cegarra-Navarro, J.-G.; Jimenez-Jimenez, D.; Garcia-Perez, A. An Integrative View of Knowledge Processes and a Learning Culture for Ambidexterity: Toward Improved Organizational Performance in the Banking Sector. IEEE Trans. Eng. Manag. 2019, 1-10. [CrossRef]

47. McCracken, G. The Long Interview; SAGE Publications, Inc.: Newbury Park, CA, USA, 1988.

48. Gwinner, K.P.; Gremler, D.D.; Bitner, M.J. Relational Benefits in Services Industries: The Customer's Perspective. J. Acad. Mark. Sci. 1998, 26, 101-114. [CrossRef]

49. Lincoln, Y.S.; Guba, E.G. Naturalistic Inquiry; Sage: Newbury Park, CA, USA, 1985.

50. Corley, K.G.; Gioia, D.A. Identity ambiguity and change in the wake of a corporate spin-off. Adm. Sci. Q. 2004, 49, 173-208.

51. Gioia, D.A.; Price, K.N.; Hamilton, A.L.; Thomas, J.B. Forging an Identity: An Insider-outsider Study of Processes Involved in the Formation of Organizational Identity. Adm. Sci. Q. 2010, 55, 1-46. [CrossRef]

52. Langley, A.; Abdallah, C. Templates and Turns in Qualitative Studies of Strategy and Management. In Building Methodological Bridges; Emerald: Bingley, UK, 2011; Volume 6, pp. 201-235.

53. Tiwana, A. Do bridging ties complement strong ties? An empirical examination of alliance ambidexterity. Strat. Manag. J. 2008, 29, 251-272. [CrossRef]

54. Papachroni, A.; Heracleous, L.; Paroutis, S. In pursuit of ambidexterity: Managerial reactions to innovation-Efficiency tensions. Hum. Relat. 2016, 69, 1791-1822. [CrossRef]

55. O'Reilly, C.A., III; Tushman, M.L. The ambidextrous organization. Harv. Bus. Rev. 2004, 82, 74. [PubMed]

56. Ahammad, M.F.; Lee, S.M.; Malul, M.; Shoham, A. Behavioral ambidexterity: The impact of incentive schemes on productivity, motivation, and performance of employees in commercial banks. Hum. Resour. Manag. 2015, 54 (Suppl. S1), s45-s62. [CrossRef]

57. Hansen, E.G.; Wicki, S.; Schaltegger, S. Structural ambidexterity, transition processes, and integration trade-offs: A longitudinal study of failed exploration. RED Manag. 2018, 49, 484-508. [CrossRef]

58. Smith, S.M. Organizational Ambidexterity: Welcome to Paradox City. Hum. Resour. Manag. Int. Dig. 2017, 25, 1-3. [CrossRef]

59. Havermans, L.A.; Hartog, D.N.D.; Keegan, A.; Uhl-Bien, M. Exploring the Role of Leadership in Enabling Contextual Ambidexterity. Hum. Resour. Manag. 2015, 54, s179-s200. [CrossRef]

60. Pelagio Rodriguez, R.; Hechanova, M.; Regina, M. A study of culture dimensions, organizational ambidexterity, and perceived innovation in teams. J. Technol. Manag. Innov. 2014, 9, 21-33. [CrossRef]

61. Schreuders, J.; Legesse, A. Organizational ambidexterity: How small technology firms balance innovation and support. Technol. Innov. Manag. Rev. 2012, 2. [CrossRef]

62. Blindenbach-Driessen, F.; Ende, J.V.D. The Locus of Innovation: The Effect of a Separate Innovation Unit on Exploration, Exploitation, and Ambidexterity in Manufacturing and Service Firms. J. Prod. Innov. Manag. 2014, 31, 1089-1105. [CrossRef]

63. Chen, Y. Dynamic ambidexterity: How innovators manage exploration and exploitation. Bus. Horiz. 2017, 60, 385-394. [CrossRef]

64. Andriopoulos, C.; Lewis, M.W. Exploitation-Exploration Tensions and Organizational Ambidexterity: Managing Paradoxes of Innovation. Organ. Sci. 2009, 20, 696-717. [CrossRef]

65. Van de Ven, A.H.; Poole, M.S. Explaining development and change in organizations. Acad. Manag. Rev. 1995, 20, 510-540. [CrossRef] 
66. Nizam, E.; Ng, A.; Dewandaru, G.; Nagayev, R.; Nkoba, M.A. The impact of social and environmental sustainability on financial performance: A global analysis of the banking sector. J. Multinatl. Financial Manag. 2019, 49, 35-53. [CrossRef] 


\title{
Digital Transformation in Banking: A Managerial Perspective on Barriers to Change
}

\author{
Florian Diener * and Miroslav Špaček
}

Citation: Diener, F.; Špaček, M. Digital Transformation in Banking: A Managerial Perspective on Barriers to Change. Sustainability 2021, 13, 2032. https://doi.org/10.3390/su13042032

Academic Editor: Andrea Pérez Received: 28 December 2020

Accepted: 4 February 2021

Published: 13 February 2021

Publisher's Note: MDPI stays neutral with regard to jurisdictional claims in published maps and institutional affiliations.

Copyright: (c) 2021 by the authors. Licensee MDPI, Basel, Switzerland. This article is an open access article distributed under the terms and conditions of the Creative Commons Attribution (CC BY) license (https:// creativecommons.org/licenses/by/ $4.0 /)$.

\author{
Department of Entrepreneurship, Faculty of Business Administration, Prague University of Economics and \\ Business, 13700 Prague, Czech Republic; miroslav.spacek@vse.cz \\ * Correspondence: florian.diener@vse.cz; Tel.: +49-(0)151-4053-2978
}

\begin{abstract}
The digitalisation of banks is seen as the omnipresent challenge which the banking industry is currently facing. In this digital change process, banks are facing disruptive innovation that requires adaptation of almost all cooperative processes. Digital transformation in the financial industry is associated with obstacles that seem to hinder smooth implementation of digital approaches. This issue has not been adequately addressed in the current academic literature. The main purpose of this qualitative exploratory study is to identify the main perceived obstacles to digital transformation in both the private and commercial banking sectors from a managerial point of view and to analyse them accordingly. The methodology is based on a methodological approach using a combination of contextual interviews with German board members of banks, inductive content analysis, and the exploration of best-practice approaches. The findings revealed that elements of strategy and management, technology and regulation, customers, and employees receive a high level of attention within the digital transformation. The other main barriers can be found in the areas of market knowledge and products, employee and customer participation, and public benefit. Each main barrier is characterised by several sub-barriers of varying importance for the digital transformation of banks and is described in detail.
\end{abstract}

Keywords: bank; barriers; digitalisation; management; perception; transformation

\section{Introduction}

Over the past several years, digital transformation has received considerable attention in the areas of management, business, information systems, information technology, and marketing. The developments in information and communication technologies in the digital age have significant and varying effects on organisations. Changes in traditional business ecosystems have created new business environments called "digital business ecosystems". Changes in the business ecosystems affect the strategic decisions of the organisations related to the internal and external environment. The size and frequency of these changes are the parameters that make the concept of change more meaningful [1]. The rapid development of technology, as well as a great variety of changes in today's global marketplace, have led to the intensification of a new cooperative adaptation process. This digital transformation and the adoption of new technologies raise a growing number of questions about the changes that traditional companies, strategies, and management practices need to implement in order to respond to them [2]. This response involves the creation of new, innovative business models and/or changes and improvements to the existing business models with the help of digital technologies [3]. The application of these new technologies and their appropriate implementations to improve business performance is an important issue for companies [4,5]. Today, complex transformations affect many dimensions, including strategic direction, competitiveness, business model, decision-making, innovation itself, entrepreneurship, productivity, and customers [6-8]. Based on further continuous development and ever-increasing digitalisation of lifestyles and changes in 
customer behaviour [9-12], the world has become more and more informed, transparent, and efficient. Thus, new sales and service markets are coming into being, with continuous changes in technology and customer behaviour [9-12]. As a result, traditional business models in multiple industries are not just competing with each other, but also with new models that are external to their business fields [13]. To satisfy these market-based changes, enterprises have to adjust by reconsidering and reforming their traditional base [14,15].

Industrial companies, various administrations, educational institutions, the financial sector, etc., are all undergoing digital changes, which have a noticeable impact on them. One of the main drivers of digital economy development is the financial sector, which takes the second position, just behind telecommunication [16]. The key underlying process is the digital transformation of financial service systems through financial technology (FinTech)-disruptive innovations by new market entrants that challenge the position of mainstream financial institutions [17]. In particular, retail banks have been at the forefront of technological revolution, characterised by rapid deployment and innovation of digital services, exponential pace of change, and innovative breakthroughs that alter conventional banking practice [18].

The main problem in banking seems to be that traditional financial service providers have not yet implemented comprehensive digitalisation [19-22]. As a result, they often offer an incomplete range of services and are confronted with both strategic and operational barriers within the digital transformation process. In contrast to established service providers, there are new, innovative competitors with new concepts, products, and services [23] - and, above all, with a modern multi-channel approach in terms of distribution, communication and marketing, which approaches customers in a variety of ways. As a result, multi-channel business models have gained substantial market shares, as, for example, in the case of the German company N26 [24]. Recent research confirms the growing and prospective influence of these business models on the finance industry [25]. As traditional companies and their industries adapt slowly and ineffectively to the modern changing markets, there is a high risk of disruption caused by new technologies and business models [26,27]. "If such changes are missed by system-relevant financial institutions, such as large banks or groups of smaller ones, then financial services and the whole economic system will be endangered" [28]. Many existing financial service providers have already recognised the need for basic changes in their business model, and have started to rethink, or rather reform, their approaches $[29,30]$.

This aspect of market-driven technological change, in particular, raises the overall question of how new entrepreneurial approaches, management behaviour, and technology changes in the world of banking, a long-established financial system, as well as how they influence and change banking adjustment, thus leading to the following two research questions (RQ):

RQ1: What are the main barriers to smooth implementation of digitalisation in banking?

RQ2: What are the "best practices" that are applicable in the implementation of the digitalisation process?

Due to a complex adjustment process within the financial system and its all-encompassing entrepreneurial influence, the identification and analysis of obstacles that hinder digital adaptation in the context of an all-encompassing digitalisation is of great institutional importance. For this reason, this paper contributes to the issue of digital bank transformation and identifies obstacles to digital transformation in the sector from the perspective of the management, as the management is ultimately responsible for appropriate bank development and long-term business success. In line with this research objective, the present study identifies and analyses implementation barriers to digitalisation using a methodological approach based on a combination of contextual interviews with bank executives, inductive content analysis, and exploration of multiple best-practice approaches. 


\section{Literature Review}

Digital transformation is a holistic concept that includes technologies, as well as organisational and strategic changes [31]. Moreover, it is the process that an organisation goes through when it changes from an outdated approach to new ways of working and thinking by using digital, social, mobile, and new technologies [32]. It is driven by the advancement in technology, the appearance of new business models, and changes in expectations of the customer [33]. Several additional definitions of the term "digitalisation" are now commonly accepted. According to Gartner [34], digitalisation represents improvement of existing business models, creation of new revenues, and value-adding opportunities with the help of digital technologies. It can be understood as a complex issue that encompasses several areas like (i) shifts in thinking, (ii) changes in leadership, (iii) technology adoption, (iv) digitalisation of resources, and (v) acceptance of innovation [35]. As became apparent from the preceding classification, the term "digitalisation" should be distinguished from the similar term, "digitisation"; the former rather addresses the impact of digital technologies on the organization, while the latter represents the shift from an analogous solution to a digital one. Digitalisation is organizational renewal through new information and communication technologies [36]. According to Matt et al., digital transformation is a complex issue that proceeds within a framework that includes (i) changes in value creation, (ii) structural changes, and (iii) use of technologies and financial aspects [31]. It is no surprise that digital transformation seems to be blocked by a set of barriers that may hamper or even collapse the whole process of transformation. Digital transformation is considered a driving factor that offers a solution to the challenges currently faced by the banks. The core digital transformation practices, such as leadership, digital trends, digital transformation skills, digital strategies, implementation of digital technologies, and a customer-centric approach, are seen as influences brought to bear on digital maturity levels [37].

The term digital transformation (sometimes nicknamed digital entrepreneurship) is often misunderstood as a straightforward deployment of the latest information and communication technologies. In practice, technological investments entail not only risk, but also require an understanding of the relationship between technological and organisational culture and institutional change within certain boundaries of regulatory frameworks. Digital transformation is far from simple, certain, or predictable. Moreover, it is likely to be disruptive or transformative, with immutable impacts upon associated organisational outcomes related to technical capabilities and behaviours [18].

In the face of the established regulatory standards known as Basel III, banks aim to embark upon new technology standards, like Regulatory Technology (RegTech), which may facilitate digital transition. RegTech is an emerging technological trend that leverages information technology and digital innovations that can greatly assist with a bank's regulatory management process. It is advisable to incorporate RegTech into the digital transformation strategy of a management function, such as a treasury. Integrated adoption would mean that the digital platform can be deployed to support both strategic management activities and enhanced regulatory processes within the treasury. With this arrangement, commercial and prudential objectives are put in alignment [38].

Digitalisation plays a major role in contributing towards the United Nations Sustainable Development Goals. Without transformation of existing businesses, both economic and environmental challenges of the future cannot be solved sustainably [39]. Digital transformations will produce new social groups-partly human, semi-human, or nonhuman — some of which already exist, and some which can be foreseen by extrapolating from recent developments in the field of brain wearables, robotics, and software engineering. Growing dependency on digital services and tools may pose problems for both individuals and organisations [40]. Forcadell et al. [41] argue that digitalisation entails challenges that can hinder the potential benefits and compromise their survival. That is why corporate sustainability plays a significant role in enforcing digitalisation. It may compensate for drawbacks of digitalisation. In particular, the combination of corporate sustainability and digitalisation helps transform the organisational nature of banks by 
simultaneously narrowing their boundaries and expanding their scope. El Hilali et al. [42] drew attention to possible ways of reaching sustainability during digital transformation processes. They found that the companies achieved sustainability when effectively mastering customers, data processing, and innovation. On the other hand, they did not prove that the competition played a significant role in enhancing the companies' commitment to sustainability. This opinion was partly endorsed by Ordieres-Meré et al. [43], who confirmed the positive effects of knowledge creation facilitated by direct or indirect application of digitalisation. Technology is reported to disrupt the financial industry, solve friction points for consumers and businesses, and make the overall business more resilient and sustainable. Sustainable financial technology may contribute to the overall stability of the financial system as well [44]. Established technology-based business models can act as a sustainability catalyst to trigger collaborative innovations between traditional financial and banking institutions [45].

Effective risk management, including its diversification, is also ranked among the contributors to sustainable bank development in the global economy [46]. Examination of risk-mitigation strategies in Southeast Asia proved that the banks had become more sustainable when implementing viable risk-mitigation strategies [47].

Nevertheless, when it comes to the barriers to change in the implementation of digitalisation in the banking sector, few resources can be found in the literature. It is evident that the banking sector is changing and institutions have to adapt to new technological developments and customer behaviour. This trend is particularly evident in the increasingly digital user behaviour, as mentioned in Table 1, to which bank executives have to respond.

Table 1. Share of payment instruments in Germany.

\begin{tabular}{|c|c|c|c|c|c|c|c|c|c|}
\hline & \multicolumn{2}{|c|}{ Revenue 2008} & \multicolumn{2}{|c|}{ Revenue 2011} & \multicolumn{2}{|c|}{ Revenue 2014} & \multicolumn{2}{|c|}{ Revenue 2017} & \multirow{2}{*}{ CAGR $^{3}$} \\
\hline & $€$ & $\%$ & $€$ & $\%$ & $€$ & $\%$ & $€$ & $\%$ & \\
\hline cash & 405,486 & $57.89 \%$ & 317,137 & $53.10 \%$ & 267,249 & $53.18 \%$ & 297,901 & $47.58 \%$ & $-2.16 \%$ \\
\hline debit card & 178,829 & $25.53 \%$ & 169,093 & $28.31 \%$ & 147,592 & $29.37 \%$ & 212,576 & $33.95 \%$ & $3.22 \%$ \\
\hline credit card & 25,538 & $3.65 \%$ & 44,369 & $7.43 \%$ & 19,582 & $3.90 \%$ & 27,578 & $4.40 \%$ & $2.12 \%$ \\
\hline contactless payment & - & - & 318 & $0.05 \%$ & 386 & $0.08 \%$ & 7103 & $1.13 \%$ & $66.50 \%{ }^{1}$ \\
\hline other cards & 5127 & $0.73 \%$ & 815 & $0.14 \%$ & 486 & $0.10 \%$ & 676 & $0.11 \%$ & $-19.16 \%$ \\
\hline bank transfer & 62,199 & $8.88 \%$ & 49,181 & $8.23 \%$ & 26,405 & $5.25 \%$ & 34,749 & $5.55 \%$ & $-5.09 \%$ \\
\hline direct debit & 13,024 & $1.86 \%$ & 4268 & $0.71 \%$ & 14,881 & $2.96 \%$ & 15,181 & $2.42 \%$ & $2.99 \%$ \\
\hline online payment & 1939 & $0.28 \%$ & 10,115 & $1.69 \%$ & 13,986 & $2.78 \%$ & 23,258 & $3.71 \%$ & $33.45 \%$ \\
\hline mobile payment & - & - & - & - & 77 & $0.02 \%$ & 124 & $0.02 \%$ & $8.63 \%{ }^{2}$ \\
\hline other techniques & 8297 & $1.18 \%$ & 1984 & $0.33 \%$ & 11,900 & $2.37 \%$ & 6955 & $1.11 \%$ & $-0.71 \%$ \\
\hline$\sum$ & 700,439 & $100 \%$ & 597,280 & $100 \%$ & 502,544 & $100 \%$ & 626,102 & $100 \%$ & \\
\hline
\end{tabular}

Note: ${ }^{1}$ CAGR (Compound Annual Growth Rate) calculated for 2011-2017. ${ }^{2}$ CAGR calculated for 2014-2017. ${ }^{3}$ Possibility of bias due to different sample sizes $(n)$ and individual transaction levels. Source: Authors' own representation based on Deutsche Bundesbank [9-12].

Financial technology (companies called FinTech(s)) plays an essential role here. It is an industry composed of diversified firms that combine financial services with innovation technologies offered to financial service providers [44]. Shin and Choi [48] define FinTechs as platforms for the development of sustainable economic growth as well as a prompter of the fourth industrial revolution. These types of companies have several advantages over traditional banks. Typically, FinTechs may also provide a solution for sustainable finance through microfinance or crowdfunding, among others. Moreover, some FinTechs distribute insurance and other financial instruments or provide third-party services. FinTechs promise to disrupt and reshape the financial industry by cutting costs, improving the quality of financial services, and creating a more diverse and stabler financial landscape. Their existence is driven by sharing and the circular economy, as well as favourable regulation, and information technology [44]. FinTechs have the potential to unbundle core activities of the banking sector: clearing and settling payments, performing maturity transformations, sharing risks, validating trust, and allocating capital. They have also 
created a new paradigm in which information technology represents a meaningful driving force that gives rise to innovation [44].

Hereby, banks are under massive pressure to transform their approaches and business models to a more customer-centric approach in order to remain competitive. The traditional institution has felt the disruption and is working towards changing its business model from product-centric to customer-centric [37]. Similarly Mărăcine et al. [49] suggest that five main areas exist where FinTechs can provide improvements in business models for the banks: introducing specialized platforms, covering neglected customer segments, improving customer selection, reduction of the operating costs of the banks, and optimisation of the business processes of the banks. As digital banking offerings have matured and cost pressures have increased, it has become inevitable to make changes to the operating models of banks. Driven by the sub-optimum performance of the existing business model, the "digital" concept has evolved into more than a channel for accessing services. One of the outcomes was a full-fledged branchless digital bank [50] or challenger bank. A challenger bank stands for a financial institution that can be presented in the plain form of an information-communication system [16].

Sadigov et al. [51] have proved that FinTech development contributes to economic growth by increasing the GDP generated in the financial sector, and indirectly does so by increasing e-commerce turnover and real sector financing, particularly by creating more favourable lending conditions for small and medium-sized businesses.

As has become evident, business models adopted by FinTechs differ from those applied by traditional banks. Nevertheless, these differences do not mean that both types of banks may eventually converge towards a common market by exploiting co-operation strategies. Their business model is intangibly driven, combining e-finance, internet technologies, social networking, artificial intelligence, blockchains, and big data analytics. Moreover, their revenue model is much more scalable than that of a typical bank [44].

Given the lack of literature on banking and existing research that followed a similar approach to identifying implementation barriers, those by Chan [52], Chan [53], Vikneswaran and Anantharajah [54], Kamalulariffin et al. [55], and Yusof and Jamaludin [56] have to be considered; barriers arise in connection with the implementation of new strategies and management approaches. Given that these authors have already properly elaborated and investigated the barriers to the implementation of new strategies, it is important to take their research approaches into account.

In addition, the questionnaires they used have already been partially validated and can, therefore, be a sound basis for this study. For some barriers, however, their questionnaires need to be reformulated or reworded, as they only allow a theoretical approach and do not fully correspond to the specific terminology needed for this work. For example, the study by Kamalulariffin et al. [55] focussed on environmental management in the hotel sector; a closer look at the research findings revealed that this industry is facing a situation similar to that which financial institutes are facing today, with new strategies and business models being pursued internally and by competitors. In particular, new business models are being developed that have never been established in their market before, thus satisfying customer needs in the latest way and, at the same time, endangering traditional business models.

Chan [52,53] already considered internal and external barriers, which he repeatedly validated through his work. These findings can be summarised as (a) implementation and maintenance costs, (b) lack of knowledge and skills, (c) lack of a sense of urgency, (d) the ambiguity of modern banking, (e) lack of qualified consultants, (f) lack of motivation and professional advice, (g) conflicting guidance, (h) outcome uncertainty, and (i) inconsistent support.

Kamalulariffin et al. [55] mentioned the barriers of (a) regulation and government, (b) customer demand, (c) level of competition, (d) cost of greenness at the organisational level, and (e) attitude toward change. Vikneswaran and Anantharajah [54] referred to (a) high maintenance and implementation costs, (b) lack of sufficient knowledge, (c) lack 
of resources (time, manpower, equipment, and money), (d) lack of momentum from the company owners, (e) lack of a sense of urgency and ambiguity of guidelines, (f) lack of qualified verifiers or consultants, (g) conflicting guidance, and (h) lack of government regulations and enforcement, as well as (i) difficulty in operating an entity (difficult to balance the quality of service performance). From the content analysis of all the related literature, in summary, 12 pertinent barriers were identified by Yusof and Jamaludin [56]. Chan et al. $[57,58]$ confirmed and extended these results again, which can also be interpreted in relation to banking, the associated digitalisation, and FinTech. Due to the more appropriate and transparent approach of Yusof and Jamaludin [56], their analysis is not considered holistically in this elaboration.

Due to the holistic nature of these works, these results served as a textual foundation for the preparation of the interview questions; consequently, they were derived mainly from the proven works of Chan [52], Chan [53], Vikneswaran and Anantharajah [54], Kamalulariffin et al. [55], and Yusof and Jamaludin [56], which are considered reliable and valid.

\section{Methodology}

\subsection{Data}

Due to their strong market positioning, the German savings banks and cooperative banks were the focus of this study and, thus, the focus of the data collection process. Both types of banks are equally ranked among the good service providers. They provide the majority of regional and supra-regional branches in retail banking and are the most strongly represented group in banking from a personnel point of view [59-63]. In addition, they offer an almost identical product range to their customers. Although they differ only marginally in their products and services, they differ on an organisational and structural level with regard to their business model [64].

\subsubsection{Interview Process}

In total, for this study, 34 interviews were conducted with German bank managersmore precisely, bank executives. Two of them had to be disregarded, as they did not fit into the relevant target group; thus, 32 interviews, with an average interview duration of $34 \mathrm{~min}$, were considered for further evaluation. The valid interviews lasted between $22 \mathrm{~min}$ in the shortest case and $1 \mathrm{~h}$ and $7 \mathrm{~min}$ in the longest case; the total length of the interviews was $17 \mathrm{~h}$ and $53 \mathrm{~min}$. Two of the 32 valid interviews were interrupted, either due to technical problems or due to interruptions in the person's environment, so in these cases, several recording files were created for each interview; however, this does not affect the validity and substance of the discussions.

These were determined as Table 2. 
Table 2. Numerical interview data description.

\begin{tabular}{|c|c|c|c|c|c|}
\hline \multirow{2}{*}{ Interview } & Duration & Bank Experience & \multirow{2}{*}{ Gender } & \multirow{2}{*}{ Validity } & \\
\hline & (mm:ss) & (In Years) & & & \\
\hline 1. & $27: 57$ & 20 & $\mathrm{M}$ & $\checkmark$ & \\
\hline 2. & $31: 25$ & 5 & M & $\checkmark$ & \\
\hline 3. & $24: 15$ & 42 & M & $\checkmark$ & \\
\hline 4. & $38: 57$ & 9 & M & $\checkmark$ & \\
\hline 5. & $23: 02$ & 17 & M & $\checkmark$ & \\
\hline 6. & $23: 48$ & 33 & M & $\checkmark$ & \\
\hline 7. & $13: 12$ & 25 & M & $x$ & \\
\hline 8. & $39: 39$ & 32 & M & $\checkmark$ & \\
\hline 9. & 29:04 & 7 & M & $\checkmark$ & \\
\hline 10. & $25: 24$ & 20 & M & $\checkmark$ & \\
\hline 11. & $28: 05$ & 17 & M & $\checkmark$ & \\
\hline 12. & $34: 19$ & 8 & M & $\checkmark$ & \\
\hline 13. & $27: 03$ & 27 & M & $\checkmark$ & \\
\hline 14. & $34: 46$ & 34 & M & $\checkmark$ & \\
\hline 15. & $27: 13$ & 11 & M & $\checkmark$ & \\
\hline 16. & $66: 58$ & 22 & M & $\checkmark$ & \\
\hline 17. & $46: 48$ & 19 & M & $\checkmark$ & \\
\hline 18. & $25: 57$ & 28 & M & $\checkmark$ & \\
\hline 19. & $34: 48$ & 12 & M & $\checkmark$ & \\
\hline 20. & $31: 49$ & 26 & M & $\checkmark$ & \\
\hline 21. & $35: 18$ & 30 & M & $\checkmark$ & \\
\hline 22. & $38: 02$ & 17 & M & $\checkmark$ & \\
\hline 23. & $35: 59$ & 28 & M & $\checkmark$ & \\
\hline 24. & $22: 54$ & 23 & M & $\checkmark$ & \\
\hline 25. & $52: 55$ & 20 & M & $\checkmark$ & \\
\hline 26. & $46: 59$ & 10 & M & $\checkmark$ & \\
\hline $27 . / 28 .^{*}$ & $54: 05$ & $44 / 11$ & M & $\checkmark$ & \\
\hline 29. & $37: 31$ & 25 & M & $x$ & \\
\hline 30. & $28: 43$ & 30 & M & $\checkmark$ & \\
\hline 31. & $33: 31$ & 20 & M & $\checkmark$ & \\
\hline 32. & $35: 14$ & 27 & M & $\checkmark$ & Duration (hh:mm:ss) \\
\hline 33. & $37: 02$ & 20 & M & $\checkmark$ & $\sum$ (total) $18: 43: 56$ \\
\hline 34. & $31: 14$ & 25 & M & $\checkmark$ & $\sum$ (valid) $17: 53: 13$ \\
\hline
\end{tabular}

Source: Authors' own representation.

\subsubsection{Data Preparation}

The data were prepared by transcription according to "simple rules", whereby the audio recordings were transcribed word by word, but not repetitions, word deletions, or non-verbal utterances. Signals of understanding or confirmation, such as "mhm, aha, yes, exactly", etc., were not transcribed. The form of the transcription was based on Kuckartz [65] and Dresing and Pehl [66]. The interviews were transcribed verbatim, but dialectal variants were not transcribed, and slight dialectal utterances were translated in the standard language. Colloquial language was retained. The sentence form, definite and indefinite articles, etc. were retained, even if they contained errors.

\subsection{Analysis Procedure}

By means of an explorative interview framework [67], the main goal of this study was to generate impulses for an individual narrative of implementation barriers in digital transformation. In guided interviews, pre-defined questions were asked, but these could be answered very openly by interviewees; the procedure was less strict than in other interview methods. In a semi-structured interview, also called a guided interview, the interviewees are not given specific answers; they can report, comment, and explain freely. The advantage of this method is that, although the interviewer asks concrete questions by means of his or 
her questionnaire, the interviewee can answer openly and possibly focus the interview on new aspects and expand the entire interview.

Following Mayring [68], a theory-based analysis model was set up for the analysis, which was carried out by summarising and through inductive category formation. The selection of interviewees, as well as the number and scope of the answers given, is of crucial importance in the interview method [69]. As is the case in similar work on expert knowledge, the quality depends crucially on the selection of so-called experts-in this case, the interview participants [69]. Experts are understood to be individuals to whom knowledge of the surveyed topic area is attributed due to their activity and resulting practical expertise, as well as their specific educational qualifications [70]. This usually exceeds the knowledge of people who are unfamiliar with the topic being surveyed [71]. According to Chan [52], these are the managers and executives of an industry. For this study, interviewees are bank experts who are the actual decision-makers (the executive management) of a bank, with budget and personnel responsibility, as well as bank experts with specific knowledge and professional experience in the fields of banking, digitalisation, entrepreneurship, finance, financial technology and innovation, and many more.

A larger sample often leads to more confident and more reliable statements on what to look for [69]. The size of the samples for qualitative analyses is usually smaller than for quantitative analyses. Frequently, more accurate and more representative inferences about the population can be made in the case of large sample proportions; however, interviews will only be carried out as long as new information is perceived. In principle, the sample sizes should be large enough to obtain sufficient data to adequately describe a phenomenon of interest and to enable the research questions to be answered. The aim of this and all other qualitative studies is to obtain saturation of the sample; saturation occurs when the inclusion of additional participants does not lead to new perspectives or information. Glaser and Strauss [72] suggested the concept of saturation in order to achieve an appropriate sample size in qualitative studies. A number of guidelines have been developed for this purpose. Morse [73] suggested about 30-50 interviewees in ethnography for grounded theory. Creswell [74], in contrast, suggested only 20-30, and possibly as few as 5-25 for phenomenological studies, and Morse [73] suggested at least six.

The population is understood to mean the total regional savings and cooperative, and private banks. It can be assumed that at least one decision-maker/expert can be assigned to a bank. However, it may also be assumed that the actual population is much greater, as banks are not authoritarian institutions and their decisions are not made by one person alone; the prevailing ownership and organisation structures have an additional impact on a bank's business orientation.

In the context of explorative inductive content analysis with category formation, one can rely on work that has already been done. According to Mayring [75], the basic principle of inductive content analysis is that categories are derived directly from the respective research material in a generalisation process, without referring to previously formed theoretical concepts. When the terms "categories" and "barriers" are used in the following, they are synonymous and refer to the hurdles of digitalisation. Within the qualitative approaches, the inductive approach has great importance [76]. Its objective is to capture a naturalistic, object-like representation of the investigation material without distortion through presuppositions. This approach is a central process within "Grounded Theory" and is called "open coding" [75]. Within the analysis, this category-building process can be described as systematic, using a step-by-step and line-by-line approach. In this logic, the topic of category formation must first be determined on the basis of theory; i.e., a selection criterion is introduced that determines which material is intended to be the basis for further category definition. Insignificant contents are thus excluded from the analysis. The thematic question of the study is of great importance and in accordance with the main question of this study; it defines the focus of the content. Likewise, within this approach, the category dimensions and the level of detail have to be defined in advance, as well as the analysis units [68]. 
These were determined as Table 3 .

Table 3. Category dimensions.

\begin{tabular}{cc}
\hline Evaluation question & $\begin{array}{r}\text { What obstacles do banks face when implementing digital banking } \\
\text { approaches according to the respondents? }\end{array}$ \\
\hline Category definition & $\begin{array}{r}\text { Subjective as well as objective assessments and perceptions of } \\
\text { decision-makers and experts on the topic of digitalisation and the } \\
\text { associated implementation barriers. All related issues affecting the } \\
\text { industry and the specific situations of individual institutions in the } \\
\text { banking sector. }\end{array}$ \\
\hline Abstraction level & $\begin{array}{r}\text { Concrete content on the subject of digitalisation for people, } \\
\text { departments, companies, customers, and the market. }\end{array}$ \\
\hline Coding unit & $\begin{array}{r}\text { Clear and meaningful elements in the context of digitalisation in } \\
\text { banking and general financial services. }\end{array}$ \\
\hline Context unit & The whole interview with a person-verbatim transcription. \\
\hline Analysis unit & All valid research material from the 32 interviews.
\end{tabular}

The analysis approach to inductive content analysis with category formation follows a predefined process model, which is outlined in Figure 1.

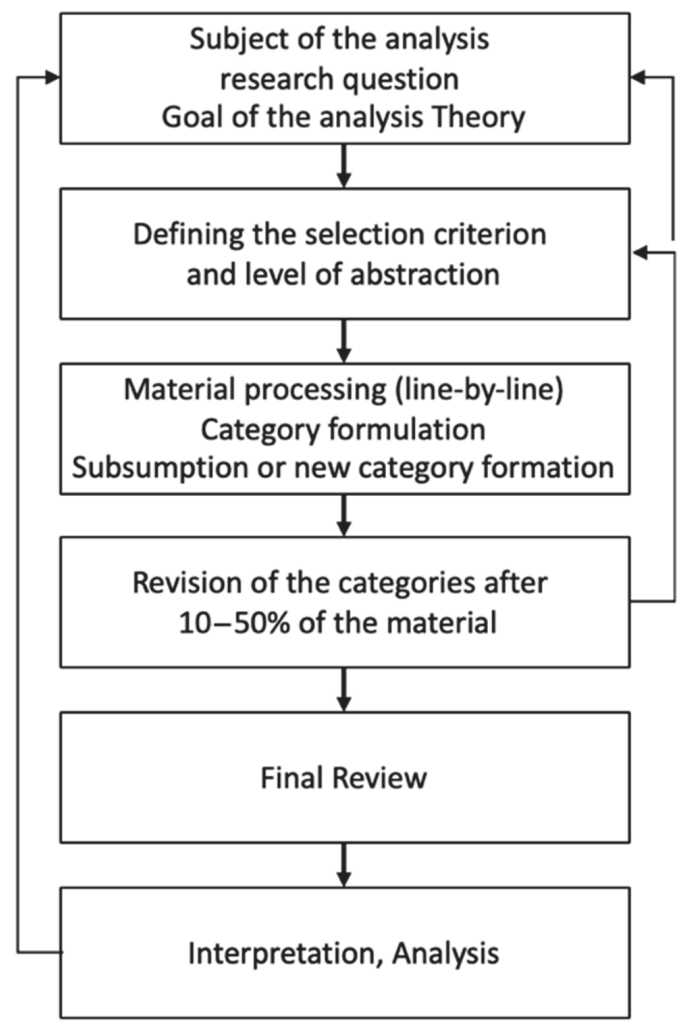

Figure 1. Sequences of inductive content analysis with category formation to illustrate the method of qualitative analysis according to Mayring $[68,75]$. 
In the analysis, taking into account the level of abstraction and the category definition, a suitable text passage is identified in the test material during the analysis, and a category is constructed. A term or phrase that comes as close as possible to the material is then used as the category name. Whenever a new passage is found in the further course of the text analysis that matches the selection criterion and category, it is also assigned to the same category. This is also referred to as "subsumption". However, if it turns out that no assignment to already existing categories is possible, a new category is inductively formulated from the specific material [75].

After a certain percentage of the material (often at 10 percent to 50 percent), when almost no new categories can be created, this is the moment for revision of the category system [68]. It is then necessary to check whether or not the logic is clear and the degree of abstraction fits the object and the question posed.

In the course of this qualitative analysis, the coded text passages are first paraphrased, then generalized, and finally form the actual category. The result of this process is a series of categories assigned to a specific topic and corresponding text passages in the research material. In the further course of the process, the interpretation is then made with regard to the overarching research question, taking into account the present approach and its findings. Due to the complexity of the interview topic, the respondents preferred to conduct the interviews in their first language. Given the availability of information, the generalised statements of the interviews were first formulated in German and later translated into English for this work. Thus, the internationality of the results is taken into account. In order to ensure the overall consistency of the generalisation, as well as the equivalence of the translations, a re-translation procedure was applied [77], carried out by a professional bilingual translator.

\subsection{Structure of the Interview Guideline}

The semi-structured interview guide was divided into a German and an English approach, depending on the interviewee. Both were based on previously extracted theoretical findings, which were used accordingly to interview decision-makers at banks. The barriers mentioned in Section 2 were fully taken into account. Furthermore, due to the different perspectives of the individual respondents, the guidelines were also adapted to each individual situation. They therefore differed slightly and were divided into two categories: banks and financial service providers. However, the basic structure of the interview guide was not changed. First, the interview topic was introduced and introductory questions about the person were asked. In the first section of the interview, the interviewees placed themselves in their respective positions in the company and described their level of knowledge on the topic of digitalisation in banking. This was to determine the suitability of each interview partner in advance. In the further course of the interview, questions regarding the banking sector and digitalisation were asked in detail, taking into account the findings of Chan [52], Chan [53], Vikneswaran and Anantharajah [54], Kamalulariffin et al. [55], and Yusof and Jamaludin [56].

\subsection{Conducting the Survey}

The guideline survey focused on interviews with decision-makers at banks. These were identified through personal contacts in the financial and banking industry and active approaches toward banking associations and local banks, as this is where access problems appear to be the lowest [70]. Furthermore, recommendations played an important role in the acquisition of interview partners. Consequently, further contacts with experts were established. Due to the geographical distance from the respective interview partners, the interviews were not exclusively conducted in person, but also via telephone or video conferencing [70].

In order to ensure the clarity of the individual questions, a pre-test with three test subjects was carried out in advance. As a result, the interview framework was confirmed, and no further adjustments had to be made. In order to comply with the applicable 
provisions of the General Data Protection Regulation (GDPR), respondents were required to sign a consent form. The interviews conducted were recorded using the memo function of a smartphone. Here, it is important to mention that all respondents were interviewed regardless of ethnic and social origin, age, gender, sexual identity, religion, ideology, or other ethically questionable aspects [78]. Furthermore, all of these interviews were voluntary and the participants consented to the GDPR.

\section{Qualitative Evaluation}

\subsection{Consistency of Coding}

In quantitative content analysis, the term "inter-rater reliability" is generally understood to refer explicitly to the quantitative quality criterion of reliability. The term is connected to measurement theory and claims to be replicable. Here, a distinction has to be made between a possible agreement in the formation or direct application of an existing category system. Since the formation of inductive categories according to Mayring [68,75,76] is the result of a construction process, the formation of a category system cannot be claimed to be consistent [65]. A coefficient that measures the agreement between two category systems created by two or more different coders using the same data material says little about the quality of the category system. Rather, it could measure something that was not intended to be measured [65]—-for example, the logic by which people create category systems. Accordingly, Kuckartz [65] concludes that the demand for agreement among coders thus refers primarily to the application of categories, i.e., the coding of data. However, the classical quality criteria for determining reliability in quantitative content analysis cannot be transferred to qualitative content analysis. Kuckartz [65] justifies this with the fact that, in quantitative content analysis, the coding units are defined before coding. In this quantitative case, relative matches and coefficients, such as Cohen's Kappa, Krippendorff's Alpha, or Scott's Pi would then be calculated [65]. In qualitative content analysis, the material is usually not segmented in advance, which is why Kuckartz sees two ways of identifying the concordance between coders, according to which the present study is oriented:

1. A qualitative path by means of the joint checking of codings, called consensual coding, and

2. a quantitative path by calculating percentage agreement and, under certain circumstances, a suitable coefficient [65].

\subsection{Consensus Coding}

Subjective assessment is understood by Kuckartz [65], referring to Guest, MacQueen, and Namey [79], as a situation in which two coders encode a text independently and then compare it subsequently. This process is also called consensual coding $[65,80]$. Here, the second coder notes questions and problems that arise in the process and discusses them at the end of the individual coding session. Using the formulated category definitions of disputed codes, a coding is agreed in the best case and, if necessary, the category definition is revised. If no consensus can be reached, another person is consulted, who then decides on the controversial case [65].

Since the qualitative data collection resulted in a total of 32 valid interviews, the second coder was provided with a selection of interviews. Due to the large amount of interview material, a complete second coding seemed unreasonable for an external coder. It was agreed that at least 10 to 30 percent of the interviews should be independently coded a second time, as this seemed to be feasible in terms of the time and motivation required. In order to ensure an independent selection of interviews, the principle of drawing random numbers (1 to 34 ) was applied with the help of a random number generator from Random.org. Interviews 7 and 29 were omitted; the respondents did not fit the target group because their business model was different from that of banks. Thus, a total of six interviews $(4,13,20,24,27 / 28,31)$ were coded by the second coder, which means that about 19 percent of the entire data material was used to verify the 
results. Furthermore, based on the sum of valid interviews, one is at least within the methodological revision range of 10 to 50 percent of the categories, which is consistent with Mayring's approach $[68,75,76]$.

Within the coding process, the second coder was first introduced to the developed coding system and the category set, including all sub-categories. For better interview analysis, MAXQDA Analytics Pro 2020 (Release 20.0.8), a qualitative analysis software, was used for the actual coding process.

In a personal meeting, classifications were discussed and definitional assignments were reconsidered. During this process, all six interviews were discussed step by step, or coding by coding. It is worth mentioning that the already provided coding set did not require any improvements and could be used by the second coder without additional modifications, or interpretation difficulties. In addition, there were no problems with the coding. Based on the fact that the second coder experienced the coding system as quite complex during familiarisation with the topic and approach, the first two coded interviews were revised a second time at the end of the coding process to increase reliability. At this stage of the qualitative evaluation, no numerical analysis of coders' agreement was carried out, since the interviews as a whole, rather than individual sections, were the subject of discussion and appropriate review.

\subsection{Calculation of Inter-Rater Reliability}

Inter-rater reliability (IRR) is a measure of the level of agreement between the independent coding choices of two (or more) coders [81-83]. Of course, it is expected that the allocation is not arbitrary, but that it is done in such a way that a certain reliability is achieved. In qualitative research, it is important to improve the agreement and to discuss together where there are differences in coding and why these differences exist. The MAXQDA Intercoder Matching function enables comparison of the codings of two persons coding independently of each other. It supports determination of the consistency of coding and can be used to establish the deviation of a coder's choices from the ideal or "true codes" ("true codes" are those that garner general consensus among multiple coders). There are a variety of statistics that can communicate a measure of inter-rater reliability, but one of the most common (and most appropriate for the study in question) is Cohen's kappa coefficient [84]. Cohen's kappa is considered one of the most robust measures of IRR and is used widely in science [85]. It is calculated based on the percentage of consistency between two or more coding collections and accounts for the possibility of chance consistency.

For further investigation, it is recommendable to define in advance the segments or citations to be coded. In the present analysis, due to the large amount of data, the selection refers to entire interviews and not to individual segments in order to ensure a holistic approach. Interviews were selected randomly, i.e., six interviews (4, 13, 20, 24, 27/28, 31). Only if this is the case does it make sense to calculate a coefficient to determine the concordance [65]. Based on the selected interviews, the evaluation checked whether the two coders matched in the coding of the individual segments and whether conclusions could be made regarding the reliability of the overall coding. The IRR approach is the comprehensive and typical variant of qualitative coding [84]. Since texts in qualitative evaluation procedures are often not divided into fixed text units, the verification of conformity is carried out by default for each segment encoded by the two coders (evaluation: segments of both documents). A percentage value was defined when two coded segments were considered to be a match. The default value was 90 percent. For this study, the value was set at 60 percent due to the high level of detail of the code set and the number of possible codings, as this allowed for more precise evaluations during the later discussion of the results with Coder 2. With this approach, at the end of the evaluation, for every 60 percent overlapping coded segment, there is a match that can be used for further analysis.

To interpret the Kappa values, ranges from 0.61 to 0.8 are considered acceptable agreement, and from 0.8 upwards, almost perfect agreement [65,86-88]. Further analysis of the relative number of matching codes was also carried out (see Table 4). The "Percent- 
age" column shows the percentage of matches per interview. This resulted in an overall percentage agreement of 84.66 percent. It was calculated as follows: Matches/(matches + non matches). In the "Kappa (RK)" column, the result table gives a randomly corrected value for the percentage match [83]. This takes into account the probability of two people randomly selecting the same codes in a document (if they would simply select codes randomly without considering the data material). The calculation only makes sense if the option "Unassigned codes as matches" is selected, which is the case here [83].

Table 4. Code consistency between documents.

\begin{tabular}{ccccc}
\hline File & Match & Non-Match & Percentage & Kappa (RK) \\
\hline Interview 4 & 57 & 6 & 90.48 & 0.90 \\
Interview 13 & 56 & 7 & 88.89 & 0.89 \\
Interview 20 & 53 & 10 & 84.13 & 0.84 \\
Interview 24 & 54 & 9 & 85.71 & 0.86 \\
Interviews 27 and 28 & 46 & 17 & 73.02 & 0.73 \\
Interview 31 & 54 & 9 & 85.71 & 0.86 \\
<Total> & 320 & 58 & 84.66 & \\
\hline
\end{tabular}

Source: Authors' own representation based on MAXQDA.

In determining the kappa coefficient, "P observed" represents the simple percentage of agreement. The calculation of "P chance", the random match, is based on the calculation by Brennan and Prediger [89], who have intensively studied the optimal application of Cohen's kappa and its problems with unequal marginal sum distributions. Using this calculation method, the random match is determined by the number of different categories used by both coders. This corresponds to the number of codes in the "code specific result table". The calculation of Cohen's kappa of the randomly selected interviews resulted in a value of 0.68 after a renewed review of the coded sequences with Coder 2, which can be regarded as a substantial agreement and supports the code set (Figure 2).

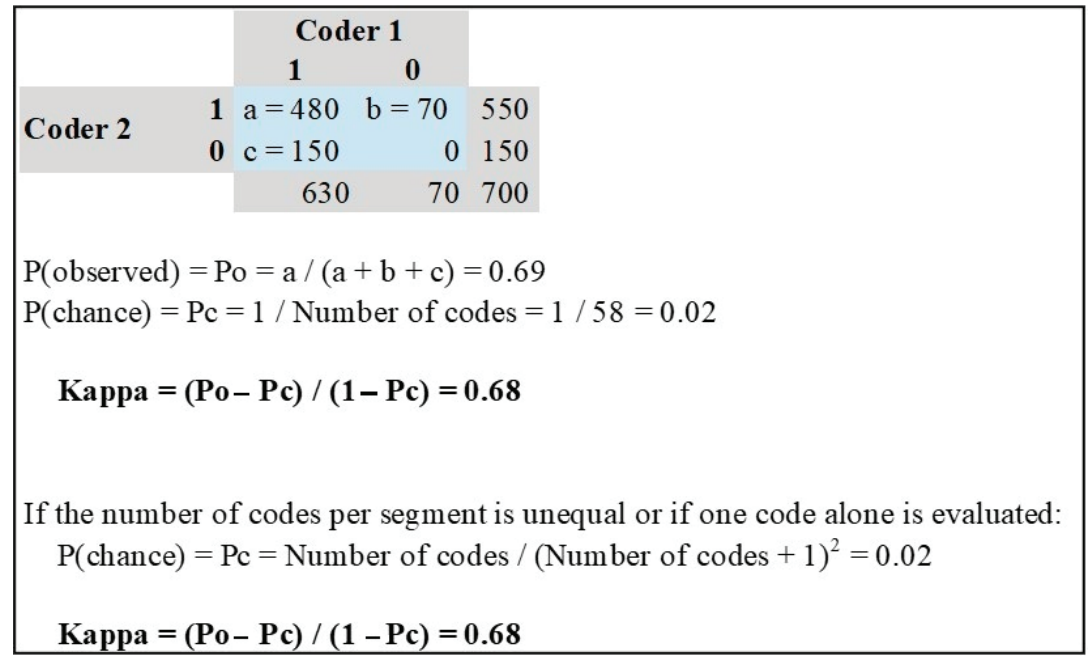

Figure 2. Calculation of the overall kappa coefficient values based on MAXQDA, representing results by Coder 1 and 2 .

When classifying the resulting characteristics of the IRR, it should be taken into account that the second coding was carried out under honorary conditions of a scientific research assistant to a professor and not under the conditions of a paid scientific research group. 
Against this background and the fact that six interviews were double-coded holistically and not just isolated sections, the reported results appear significant for further interpretation.

\section{Results}

The analytical approach enabled us to answer the two research questions formulated above, which are answered in more detail in this chapter. The first RQ referred to the contribution to theory, while the second referred to the contribution to practice.

\subsection{Contributions to Theory}

RQ1: What are the main barriers to smooth implementation of digitalisation in banking?

From December 2019 to March 2020, a total of 32 semi-structured interviews were conducted with board members in banking. This study contributes to the literary expansion and the first definition of barriers to implementation of digitalisation in the banking market, which can be used for further research. A total of 63 codes were worked out according to Mayring's method, which form the preliminary main category set (see Appendix A). Due to the complexity of the analytical approach, only the steps following the generalisation of Mayring's method can be presented in the Appendix A. Detailed representations are not feasible due to graphical limitations. Corresponding definitions for the respective sub-barriers enable interpretation for future analyses. Main categories represent the superordinate classification level of the respective sub-category set, but are not characterised by an independent definition. Table 5 presents a summary of the set of categories that represent the main barriers to smooth implementation of digitalisation in banks, with respect to savings and the cooperative bank sector.

Table 5. Category summary.

\begin{tabular}{cc}
\hline Main Category & Number of Sub-Categories \\
\hline Benefits & 1 \\
Customer & 11 \\
Employee & 8 \\
Knowledge and Product & 4 \\
Market & 4 \\
Participation & 2 \\
Strategy and Management & 25 \\
Technology and Regulation & 8 \\
\hline
\end{tabular}

Source: Authors' own representation.

\subsection{Contributions to Practice}

RQ2: What are the "best practices" that are applicable in the implementation of digitalisation process?

For this study, 34 interviews were conducted with bank executives on the topic of digitalisation in the banking sector, with emphasis on the digitalisation of their own banks. A total of 32 interviews were identified as valid for the case-analytical approach in this chapter and were used accordingly for the practical interpretation of the study results. A similar approach to interpreting interviews had already been followed in an earlier publication by Diener and Špaček [90]. The bank managers were not asked about the problems they encountered in practice, but rather about their best-practice approaches to digital transformation. All interview partners were asked the same question for reasons of consistency.

What concrete measures have you/has your bank taken in the past to keep pace with digital competition and the changing pace of digitalisation? (Interview Question 10)

This question was deliberately kept general in order to give respondents the greatest possible scope for answering it. As this is also highly sensitive information, data protection had to be guaranteed and data protection rules had to be respected. In particular, the respondents insisted on anonymity. Due to their professional status, the interviewees 
quoted in this chapter explicitly stressed the wish not to be named or quoted in person. The same applies to their banks. Official interview material would require explicit permission by the bank before publication, which is not feasible in the context of this scientific analysis and would lead to biased answers. For this reason, the original transcripts of the interviews were used for this study and the respondents were only mentioned anonymously. The interviewees are therefore only referred to as "Interviewee" in the following.

The analysis of the interviews showed that all decision-makers were generally aware of digital change in banking and particularly aware of digital changes and the issue of digitalisation in their own banks. Banks are even hiring a board member specifically focused on digitalisation. "[ . . ] many banks are now hiring a Chief Digital Officer. There is a new position that was actually created" (Interviewee 20-Section 49).

This move towards more digital orientation and new approaches to customer service may lead to a complete shift in personnel structures in some departments. As a result, employees no longer work in the bank branches that have been known for decades, but are now able to offer a full range of services independently of their geographical location. This development takes into account the efficiency concept of the branch and the increasing competition, which, according to the assessment of the interviewees, will lead to farreaching structural changes within the banking sector in the future. However, with constant digital development, the question arises how a branch without customer traffic can be physically maintained in the future and what justifies the maintenance of cost-intensive branches. These descriptions from the interviewees indicate that they actively try to react to corresponding market developments within the scope of what is economically feasible and to develop further. One interviewee confirmed that his bank is actively addressing new trends and issues in order to take them into account in its corporate focus. "In particular, we are very active in the field of trend scouting and in identifying and evaluating the strategic relevance of various trends and technologies. [ . . . ] We have an innovation lab where we do trend scouting and observe about 170 trends and technology duration" (Interviewee 26-Section 29). Another manager emphasised that the integration of employees into the thinking process of change is fundamental and that this should be secured and promoted by the necessary freedom of thought and continuous exchange between employees and management. "[ . . ] we have set up a room of ideas where every employee, from trainee to board member, can say: 'I have a cool idea and would like to present it.' There is a group of supporters who-for example, when trainees come, are perhaps not yet very good at presenting-support the employees in creating a small presentation. And then they can present directly to the board of directors" (Interviewee 14-Section 139).

The interviews also revealed that cooperation with external partners plays an important role in the further development of banks and that cooperation within the banking association is fundamental, but also leads to a slow-down due to increased structural complexity. Banks today cooperate with partners such as university institutions, which support them in the further and new development of applications, as well as future strategies, and provide them with the necessary know-how for digital corporate transformation. In particular, the participation of the target group at the university level, such as the actual developers of the applications, helps to align and develop the bank's range of products and services to the needs of the customer, which contributes to a tailor-made fit of banking solutions-at least for the younger generation of customers. One interviewee mentioned: "In two years we have made a lot of progress in this area, and in the meantime we have widened the channels. In other words, we have provided a chat solution to improve customer contact. At the same time, a video service consulting branch is also starting this year. This means a branch in which there are no employees any more, but the branch is looked after centrally from the customer dialogue centre with extended service times from 08:00 to 18:00. [ . . . What we have achieved for ourselves is to work together with universities, often here in the region, to design things in a way that is appropriate for the target group. [...] Together with a university, we have developed an app in the youth market" (Interviewee 17-Section 79).

The digital transformation in banking is progressing at an ever-increasing pace. Far away from interface requirements forced by regulatory laws, just a few institutions are 
creating application interfaces on their own initiative, which enable them to integrate innovative business models and/or products. "We also support via the Banking-API (Application Programming Interface) such innovations as Google Assistant or Alexa and many other things" (Interviewee 21-Section 14). However, the main focus is still on realising stronger networking, which ultimately benefits both the banks themselves and the bank customers. It enables a more comprehensive range of products and services. Digitalisation, in this context, implies not only the development of internal approaches and ideas, but also the intended cooperation with other credit institutions, external partners, and FinTechs, which is to be enabled and realised via application programming interfaces " [ . . ] so that we can also integrate our technical processes, which we have for product closures and transactions, into third-party platforms in order to network more closely with each other" (Interviewee 21Section 14). It seems obvious that the management has recognised digital transformation and is focusing on it accordingly in its banking activities.

In order to adopt and pursue new digital approaches, far from merely perceiving trends, managers are responding by elaborating in detail practical approaches that will facilitate and fundamentally enable future digital implementation. This process, however, requires the availability of appropriate resources, as implementation is ultimately only made possible by making them available. On this point, a large discrepancy is evident between small, medium, and large banking institutions-major challenges of a possible holistic digitalisation can be advanced together in a more targeted way. For a small bank, topics such as "quantum computing", which could be highly important within the next 10 to 15 years, simply cannot be tackled today from a financial point of view, since the costs exceed the available resources. It is crucial, though, that banks, regardless of their size, systematically address tomorrow's digital issues today, so that they can "have the necessary know-how to deal with them proactively at the appropriate time. There is no doubt that banks definitely want to know what is happening and have a clear opinion on it" (Interviewee 26-Section 29). Knowledge and the ability to react are important here; " [ . . ] one has to be familiar with the complex issues in good times, otherwise one cannot react accordingly" (Interviewee 26-Section 33).

Today's bank management attributes an important role model to the employees, as they implement digitalisation in the company in a targeted manner and bring it closer to the customer. It is, therefore, essential that employees are informed regarding technological applications and know how to apply them properly and safely. Employees and customers have to be taken along and introduced to the technology. Since this has to be done holistically and not only for specific target groups of customers and employees, it is important to differentiate between individual groups of both customers and employees and their individual age structures to introduce them to the technology in a targeted manner. Specific educational programmes and events for customers and employees are being introduced in banks to facilitate the implementation of digital approaches and, ultimately, bank digitalisation, as well as to enhance the acceptance and integration of employees and customers. "Not long ago, we held a digitalisation fair just for our employees. [...] It cost a lot of money. So we did it professionally, with professional providers. Just to show our employees what's available. There were various stands with different focal points. So that you have topics that you can understand. Online brokers were there. There were $3 D$ glasses where you can look at a house that we sell. And things like that. A multitude of things. And for us it is just important to take the employees with us. They know that digitalisation is destroying jobs [...] the trade fair has certainly contributed to the fact that the mood in our company is quite good at the moment. So the employees are going with us. One of the main problems is that some of our employees don't deal with things privately" (Interviewee 27/28-Section 47).

According to the executive management, internal experts prove to be of great value, as they can deal with a specific digitalisation topic, communicate it to the respective individuals, and support them accordingly. "For example, we have set up a programme with other partners, called Digital-Tiger, where we have specially trained one employee in each market area as a Digital-Tiger (an expert). He then serves as a multiplier, which also serves to encourage 
the employees more [ ... W We actually have seven experts in the entire company, e.g., in the corporate customer area and real estate centre. There is an expert in every branch office who is regularly trained. Then, in turn, he transfers the already existing knowledge and new knowledge or new products to the employees" (Interviewee 13-Section 45). This development indicates that the relevance of a topic is becoming increasingly important and that the necessary financial and humanitarian resources are being mobilised in order to pursue and promote topics internally. However, this is, without question, highly dependent on the individual perception, understanding, and acceptance of the management on the topic as well as on the general financial situation of each individual bank. It also depends on the availability of trained employees, the actual specialists, as people have to be mobilised for (change) projects and show the will to change and participate. In addition, the respective corporate "change culture" within the bank is crucial, as employees also have to be prepared to be led by specialists and managers and should not be completely opposed to new methods and change. Only through such a culture can new topics or digitalisation be realised. New topics and, ultimately, digitalisation can only be realised holistically and effectively if these framework conditions are met. "In a traditional company like ours, with people who are very security-oriented and very conservative in their attitudes, this is a challenge in itself. That means accompanying this human resource development or mentality development culture, development process" (Interviewee 17-Section 29).

Furthermore, the technological framework conditions have to be in place for digital change and have to meet certain prerequisites, but this still fails because of problems such as IT infrastructure, both on the bank side and on the side of the infrastructure provided by the state. "You first have to create the basis [...] so there's a big hurdle of servers and WLAN or LAN speed. You first have to create this for every branch in principle, for every stationary location [...]. And that is a big challenge, all the more in rural areas. [...] The wires have not been laid in the past. Twenty years ago, no one needed a strong internet connection. So now the question is: Is it possible from a constructional and technical point of view? What does it cost? In principle, that's where it starts" (Interviewee 10-Section 49). In order to be able to address a complex topic such as digitalisation in an individually customer-oriented way, banks are currently still very much dependent on the cooperative associations and linked to them on a technological level. There is less focus on independent in-house innovation development, which could enable a more tailored transformation on its own. Nevertheless, there are banks that have dedicated themselves to the topic. "We started a few years ago, for example, to set up an Innovation Lab in our company. [...] Then, of course, we also started to adopt the new technologies and implement agile concepts in our company. This led to the fact that at some point people said that we wanted to create a whole programme and ultimately digitalise the whole company" (Interviewee 31-Section 57). This approach presupposes the availability of the resources necessary for implementation, but supports the independent development of the corporate identity and can, ideally, address the needs of customers and employees in a precise manner at the same time.

The approaches discussed above represent a variety of elements that, from a managerial perspective, are or can be seen as fundamental for a holistic, fast, and tailor-made digital transformation and at least promote it significantly.

Multiple measures are being taken to promote digital transformation within banks. These include, in particular, measures to introduce employees and customers to new digital processes and technology in general in order to integrate these two groups into the process of transformation. However, funding that is sustainable at the technological level and that leads to a faster technological transformation cycle or to the reduction of regulatory research or its process-optimised (over)fulfilment is only addressed in a limited, global manner and does not address specific issues.

The measures currently taken and the managers' descriptions indicate that technological integration itself seems to be the most effective tool for successful change. This way of thinking is shared by large and small banking institutions alike. It is apparent, however, that small banks expect membership in an association to be the factor that determines 
success in further development, and that technological solutions should primarily be made available centrally. However, independent development and implementation of digital approaches are hardly taken into account in small-to-medium-sized institutions (SMEs), and are sometimes not even considered for reasons such as affiliation with an association or the requirement for excessive expenditure. This goes against the self-development approach of applications based on open-source solutions, which can now be realised at low cost and could be used, at least regionally, if an appropriate interface were provided.

These considerations, therefore, contrast with the understanding of management and their arguments against self-development. "Simple issues have to be implemented quickly and directly. Of course, this currently overwhelms many employees. But this will change slowly and continuously in three or four years. Open source, for example, now offers so many possibilities that you can virtually develop software in a very short time. The cost driver has to be assessed quite differently today than 15 years ago. The reason for this is that IT development is now possible in days, weeks, and months and no longer in years. Until then, banks often had three- to five-year development plans" (Interviewee 33-Section 20).

If one considers the prevailing view of the current management, however, it is primarily the situation of a resource-related discrepancy between small and large banks that weakens rural banking structures and increasingly drives these small banks into an association structure and, thus, into increased dependency. Nevertheless, this view cannot be supported on the basis of the above-mentioned low-cost technological approaches, such as open-source technologies and an ever more widespread API and interface structure.

Measures such as staff and customer fairs on technology topics, specially trained staff who supervise digital topics, creative rooms, and innovation labs are approaches that can be implemented efficiently and in a resource-saving manner within banks and can contribute to direct development. The innovation lab, admittedly, is associated with volatile costs, depending on the particular use and programmatic design, which should be carefully examined. However, the increasingly standardised interface programming, APIs, and open-source approaches can also improve and optimise the entire internal bank process structure, as an accelerated and targeted integration of applications of new offers is ultimately made possible. The first approaches mentioned are, from a creative point of view and a resource-conscious leadership approach by the management, especially easy to implement and equally easy to realize.

With regard to the findings on "Complex technology and increased regulation", there is a need for banks to catch up in order to implement digitalisation in a competitive and sustainable way so that they can become even more digital in the future. A few individual approaches by banks demonstrate that there are technologies that allow developments to take place at low cost. "Open source offers many new potentials" (Interviewee 33-Section 60). The only thing that needs to be done is to find and attract the appropriate IT staff who are specifically trained to deal with these issues. "In order to develop digital business models that represent a unique selling proposition, not only central but also decentralised IT know-how is needed. Central IT development alone will not be sufficient in the future" (Interviewee 33-Section 17).

\section{Conclusions and Further Research}

In this study, qualitative findings were combined with best-practice approaches from the banking sector with regard to digitalisation and the barriers that arise in this context. Here, for the first time, qualitative derivations were made that require further investigation. The interest of the interview participants, as well as their voluntary and open-minded participation in the study, once again underlines the importance of this explorative approach. The results also show a wide-ranging, still-young field of research, which needs further attention. This is underlined by the problematic nature of the literature analysis and the need to draw on derivations from sectors with similar challenges. Based on the present results, it is suggested that the identified transformation/implementation barriers and the reasons for a prevailing discrepancy between perceived and actual responses to digitalisation should be analysed and scrutinised in detail in further research. It could be 
the case that the large number of barriers identified limits the possibilities for interpretation, so a further reduction of the subcategories could be considered. There is also the possibility that other influencing variables can be identified.

In addition, management perceptions of the scale of barriers could be studied in more detail and practical transformation approaches could be analysed in more depth. Studies could also focus on examining banks and their management more deeply in terms of their approaches to digital transformation and identify further best-practice approaches. Furthermore, it is recommended that, in future studies, the results should be examined with a larger number of participants in all methodological approaches to maximise the possibility that further recommendations can be derived on the basis of existing bank structures or their business models. The differences between individual banks could provide insights to obtain more detailed results on barriers to implementing digitalisation.

The development of a comprehensive normative model for scientific and sectoral enrichment would be desirable. It would also be advisable to quantitatively record individual correlations between main and sub-barriers and to implement sustainable aspects in the research approach. An additional topic for further research is the study of the impact of digital transformation on the sustainable growth of banking organisations. This topic does not seem to be addressed in sufficient depth; a thorough investigation of the preconditions for digital transformation, which are prerequisites for sustainable development, is crucial. The development of a questionnaire is indispensable for the implementation of further quantitative studies so that analyses at the main barrier level or even studies of sub-barriers can be enabled. These further approaches could lead to the enrichment of not only the investigation of digital transformation, but also the banking sector in general, and could enable further industry studies, including in other industry sectors.

Author Contributions: Conceptualization, F.D.; methodology, F.D.; formal analysis, F.D.; investigation, F.D.; resources, F.D.; data curation, F.D.; writing-original draft preparation, F.D.; writingreview and editing, F.D.; supervision, M.Š. All authors have read and agreed to the published version of the manuscript.

Funding: No external funding.

Institutional Review Board Statement: Not applicable.

Informed Consent Statement: Informed consent was obtained from all subjects involved in the study.

Acknowledgments: We would like to thank all interview partners for their open participation.

Conflicts of Interest: The authors declare no conflict of interest.

\section{Appendix A}

\begin{tabular}{|c|c|c|c|}
\hline Main Category & Sub-Code & Code Description & $\begin{array}{l}\text { Number of } \\
\text { Sub-Codes }\end{array}$ \\
\hline Benefits & $\begin{array}{l}\text { No public } \\
\text { funding }\end{array}$ & $\begin{array}{l}\text { No public funding is known or available for the (further) development of } \\
\text { banking technologies. It is assumed that banks have the necessary financial } \\
\text { resources to implement digital transformation themselves and, therefore, do } \\
\text { not need support. }\end{array}$ & 27 \\
\hline \multirow{5}{*}{ Customer } & Customer & Customers have concerns and reject digitalisation in general. & 1 \\
\hline & Acceptance & $\begin{array}{l}\text { Customer acceptance and trust in the application/technology varies from person } \\
\text { to person and is an essential factor that has to be created and considered. }\end{array}$ & 18 \\
\hline & State of the art & $\begin{array}{l}\text { More and more is expected from and offered to the customer. However, } \\
\text { customers are not always able to use the technology to its full extent. }\end{array}$ & 6 \\
\hline & Age structure & $\begin{array}{l}\text { Based on their different ages, customers have different knowledge and } \\
\text { expectations towards digital technology and possibilities to use it. }\end{array}$ & 13 \\
\hline & $\begin{array}{c}\text { Usage } \\
\text { behaviour }\end{array}$ & $\begin{array}{l}\text { The customer's behaviour is changing in the sense that he/she is evolving } \\
\text { from an analogue to a digital customer. Services, especially digital ones, } \\
\text { should be available at all times, but old services should be retained as well. }\end{array}$ & 12 \\
\hline
\end{tabular}




\begin{tabular}{|c|c|c|c|}
\hline Main Category & Sub-Code & Code Description & $\begin{array}{l}\text { Number of } \\
\text { Sub-Codes }\end{array}$ \\
\hline \multirow{6}{*}{ Customer } & Expectations & $\begin{array}{l}\text { Customer expectations are very diverse. On the one hand, some } \\
\text { expect the permanent availability of technology and, at the same } \\
\text { time, the possibility to continue to use personal consultants. On the } \\
\text { other hand, others do not expect multi-channel offers. Both, } \\
\text { however, are characterized by the expectation of security. }\end{array}$ & 28 \\
\hline & Knowledge & $\begin{array}{c}\text { Today's customers are often well informed, but this knowledge as } \\
\text { a whole is very heterogeneous, though increasing. }\end{array}$ & 3 \\
\hline & $\begin{array}{l}\text { Non-existing } \\
\text { knowledge }\end{array}$ & $\begin{array}{l}\text { Customers are not informed about the existing possibilities and } \\
\text { are not familiar with banking and technology issues. }\end{array}$ & 5 \\
\hline & Existing knowledge & $\begin{array}{l}\text { The customers have knowledge and are well informed. Knowledge is } \\
\text { acquired online. For certain topics, no consultants will be needed in } \\
\text { the future. }\end{array}$ & 2 \\
\hline & Customer proximity & $\begin{array}{l}\text { Digitalisation and the resulting consequences of branch closures } \\
\text { lead to a minimization of personal customer contact. }\end{array}$ & 12 \\
\hline & Switching behaviour & $\begin{array}{l}\text { Digitalisation leads to a reduction in customer retention and } \\
\text { loyalty. Customers become more open-minded for new things and } \\
\text { "everything from one single source" is less important than before. }\end{array}$ & 9 \\
\hline \multirow{8}{*}{ Employee } & Employee & $\begin{array}{l}\text { Employees will be needed less in the future. However, digital } \\
\text { transformation is not possible without a minimum number of } \\
\text { employees, who, in turn, can only be maintained with appropriate } \\
\text { compensation (war for talents). Existential worries, fears, and } \\
\text { inhibitions arise, which are individually pronounced for } \\
\text { each employee. }\end{array}$ & 14 \\
\hline & Flexibility & $\begin{array}{l}\text { Employees are often overwhelmed by digitalisation and reach } \\
\text { their limits. In the future, they need to be flexible and fast enough } \\
\text { to adapt to and deal with new developments. }\end{array}$ & 9 \\
\hline & Acceptance & $\begin{array}{l}\text { Employees do not show acceptance at the beginning of a change } \\
\text { and often reject the new at first. Employees have to be involved in } \\
\text { the change process and learn how to deal with digitalisation and } \\
\text { corresponding innovations. It is fundamental that employees } \\
\text { should use software and hardware themselves. }\end{array}$ & 20 \\
\hline & Qualification & $\begin{array}{l}\text { Relevant qualifications for employees are not sufficiently available, } \\
\text { and this turns out to be a disadvantage for the implementation of } \\
\text { complex digital topics and the general digital change in banks. } \\
\text { Qualifications will have to be adapted in the future. }\end{array}$ & 16 \\
\hline & Availability & $\begin{array}{l}\text { There are not enough people on the market to fill open IT } \\
\text { vacancies for a decent salary and, ultimately, to work on digital } \\
\text { issues and enable digital transformation. }\end{array}$ & 15 \\
\hline & Friendliness & Employee friendliness could be improved. & 1 \\
\hline & Age structure & $\begin{array}{l}\text { The age structure in banks will change in the future. Increasingly } \\
\text { obsolete employees will lead to the need for digitalisation. It is } \\
\text { assumed that the majority of predominantly older employees will } \\
\text { slow down or even prevent change. Young people, on the other } \\
\text { hand, will not, as they have grown up with digital media } \\
\text { and processes. }\end{array}$ & 10 \\
\hline & Transparency & $\begin{array}{l}\text { Digitalisation leads to increased employee and process } \\
\text { transparency, which, in turn, is feared by employees. }\end{array}$ & 3 \\
\hline \multirow{3}{*}{$\begin{array}{l}\text { Knowledge and } \\
\text { Product }\end{array}$} & $\begin{array}{l}\text { Product and Bank } \\
\text { complexity }\end{array}$ & $\begin{array}{l}\text { The banking world and its range of products and services is } \\
\text { becoming increasingly complex. Here, the complexity of the offer } \\
\text { determines whether analogue or digital consulting services are } \\
\text { used. Customers often obtain information online and then contact } \\
\text { their bank offline. Complex topics can currently only be digitally } \\
\text { modelled to a limited extent. However, numerous simple } \\
\text { processes are also still offered exclusively in analogue form. }\end{array}$ & 9 \\
\hline & $\begin{array}{l}\text { Human uncertainty } \\
\text { factor }\end{array}$ & $\begin{array}{l}\text { Man-made mistakes lead to widespread effects in a centrally } \\
\text { organized (IT) infrastructure. Digitalisation can increase } \\
\text { transparency and minimise error, but it can also promote them } \\
\text { and create uncertainty. }\end{array}$ & 2 \\
\hline & $\begin{array}{l}\text { Experts } \\
\text { (internal) }\end{array}$ & $\begin{array}{l}\text { Experts on digital issues are (still) available internally to a certain } \\
\text { extent and are fundamental for digital transformation in banking. } \\
\text { Decentralised digitalisation will require more qualified personnel } \\
\text { in the future. }\end{array}$ & 19 \\
\hline
\end{tabular}




\begin{tabular}{|c|c|c|c|}
\hline Main Category & Sub-Code & Code Description & $\begin{array}{l}\text { Number of } \\
\text { Sub-Codes }\end{array}$ \\
\hline $\begin{array}{l}\text { Knowledge and } \\
\text { Product }\end{array}$ & $\begin{array}{l}\text { Experts } \\
\text { (external) }\end{array}$ & $\begin{array}{l}\text { External (digital) experts/consultants are available to banks in } \\
\text { large numbers. Universities also support banks. Both are available } \\
\text { to banks for digitalisation projects if required. External } \\
\text { consultants usually charge high costs. }\end{array}$ & 23 \\
\hline \multirow{4}{*}{ Market } & Market situation & $\begin{array}{l}\text { Investments in digitalisation require capital. The current market } \\
\text { situation poses challenges for banks: Only lower earnings are } \\
\text { being generated due to the interest rate policy. }\end{array}$ & 8 \\
\hline & Market uncertainty & $\begin{array}{l}\text { The results of the digitalisation process cannot be measured yet. } \\
\text { Future market developments and uncertain success are } \\
\text { determined by the customer. Banks are concerned about the right } \\
\text { corporate positioning, as there are few sustainable approaches. }\end{array}$ & 11 \\
\hline & Market power & $\begin{array}{l}\text { The current market situation poses challenges for banks. With } \\
\text { their increased market power, they can block competitors and thus } \\
\text { defend their position. }\end{array}$ & 2 \\
\hline & $\begin{array}{c}\text { Market/competitive } \\
\text { pressure }\end{array}$ & $\begin{array}{l}\text { The increased competitive pressure due to technical and } \\
\text { market-driven developments will increase in the future, not only } \\
\text { between FinTechs and banks, but also between banks themselves. }\end{array}$ & 22 \\
\hline \multirow[t]{2}{*}{ Participation } & Employee involvement & $\begin{array}{l}\text { Employees are actively involved in digitalisation issues by } \\
\text { management and are encouraged to develop and implement their } \\
\text { own ideas. The management creates the appropriate space for this. } \\
\text { In the end, they can (better) identify themselves with the } \\
\text { transformation and become a part of it. It is fundamental that } \\
\text { employees should apply the technology themselves. }\end{array}$ & 18 \\
\hline & Customer integration & $\begin{array}{l}\text { Customers are seen as partners. They are actively involved in } \\
\text { development and in ongoing processes. By involving them at an } \\
\text { early stage, their needs can be taken into account and they can } \\
\text { actively participate in shaping the process. }\end{array}$ & 15 \\
\hline \multirow{9}{*}{$\begin{array}{c}\text { Strategy/ } \\
\text { Management }\end{array}$} & $\begin{array}{c}\text { FinTechs } \\
\text { (partners/ } \\
\text { (non-)competitors) }\end{array}$ & FinTechs can be both partners and competitors. & 5 \\
\hline & FinTech (partners) & $\begin{array}{c}\text { FinTechs have become much more like partnership-based } \\
\text { companies (partners) that want to advance their own ideas } \\
\text { through cooperation and are looking for banks to support them } \\
\text { in this. }\end{array}$ & 8 \\
\hline & $\begin{array}{c}\text { FinTech } \\
\text { (non-competitors) }\end{array}$ & $\begin{array}{l}\text { Banks will continue to exist in the future and will be increasingly } \\
\text { digitalised through constant development. FinTechs should be } \\
\text { seen as a complementary approach and not as a competitor that } \\
\text { poses a threat to banks. }\end{array}$ & 10 \\
\hline & FinTech (competitors) & $\begin{array}{l}\text { Competition is increasing in the financial industry and FinTechs } \\
\text { are now seen as competitors, forcing banks to react and bring their } \\
\text { own digital solutions to the market. }\end{array}$ & 22 \\
\hline & $\begin{array}{l}\text { Banks want to } \\
\text { cooperate }\end{array}$ & $\begin{array}{l}\text { Banks seek proximity to external FinTechs or try to become active } \\
\text { themselves in the FinTech sector with their own developments. } \\
\text { These young companies very often offer innovative solutions: } \\
\text { Accordingly, banks would like to cooperate with them in order to } \\
\text { develop themselves further. }\end{array}$ & 23 \\
\hline & $\begin{array}{l}\text { Banks will not/cannot } \\
\text { cooperate }\end{array}$ & $\begin{array}{l}\text { Banks are unwilling or unable to cooperate with FinTechs for } \\
\text { organisational or interface reasons. The dominant positioning of } \\
\text { banks is intended to make market access more difficult } \\
\text { for FinTechs. }\end{array}$ & 6 \\
\hline & $\begin{array}{l}\text { Dependence on } \\
\text { providers }\end{array}$ & $\begin{array}{l}\text { Banks and FinTechs need customers and their data. There is a risk } \\
\text { of dependence on external providers and loss of control over their } \\
\text { own business. Only in exceptional cases is cooperation favoured. }\end{array}$ & 5 \\
\hline & $\begin{array}{l}\text { Reaction to } \\
\text { market } \\
\text { development }\end{array}$ & $\begin{array}{l}\text { Banks are reacting to market and competitive situations and are } \\
\text { trying to keep up with the latest developments in analogue and } \\
\text { digital services. They rely on systematic development, which is } \\
\text { implemented with the help of internal innovation management. } \\
\text { This approach is embedded in their strategy. }\end{array}$ & 26 \\
\hline & $\begin{array}{l}\text { Complex corporate } \\
\text { structure and multiple } \\
\text { interests }\end{array}$ & $\begin{array}{l}\text { In a large and differentiated corporate structure, banks have to } \\
\text { meet multiple and often complex customer needs of different age } \\
\text { groups. Expectations of permanent analogue and simultaneous } \\
\text { digital accessibility increase the complexity of today's } \\
\text { banking business. }\end{array}$ & 16 \\
\hline
\end{tabular}




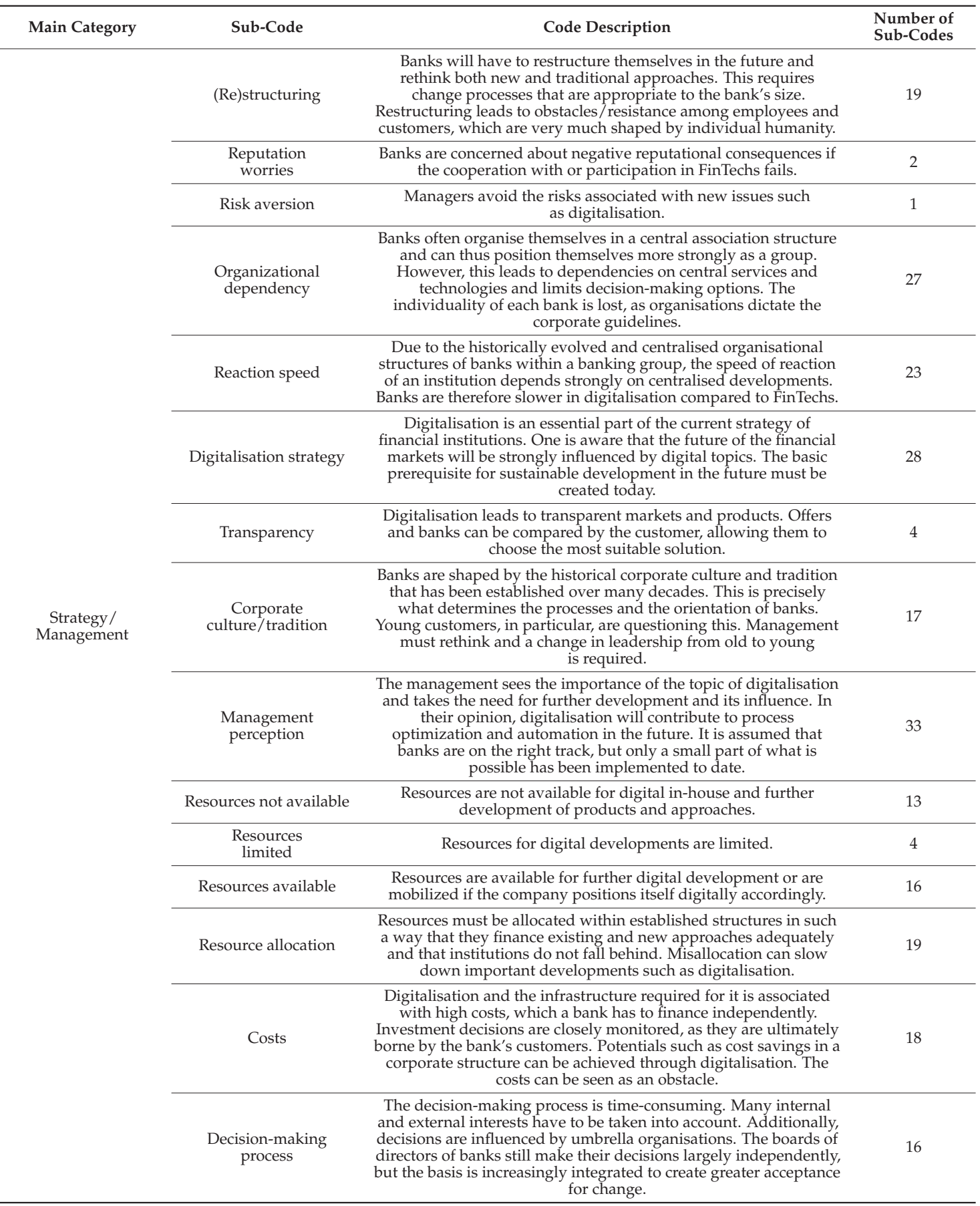




\begin{tabular}{|c|c|c|c|}
\hline Main Category & Sub-Code & Code Description & $\begin{array}{l}\text { Number of } \\
\text { Sub-Codes }\end{array}$ \\
\hline $\begin{array}{l}\text { Strategy/ } \\
\text { Management }\end{array}$ & Disruption & $\begin{array}{l}\text { Banks face technological developments and the associated risk of } \\
\text { disruption in an increasingly fast and competitive market. They } \\
\text { have to adapt to technologies and, at the same time, to the pace of } \\
\text { digitalisation, without losing their own identity, in order to } \\
\text { survive and remain competitive. }\end{array}$ & 15 \\
\hline \multirow{8}{*}{$\begin{array}{l}\text { Technology and } \\
\text { Regulation }\end{array}$} & Useability & $\begin{array}{l}\text { Usability is essential for customers in digital applications. } \\
\text { Customers must be taken into account-for certain customer } \\
\text { groups, usability is not a given. }\end{array}$ & 3 \\
\hline & Technical effort & $\begin{array}{l}\text { The technical and cost-related expenditures for banks for the new } \\
\text { and further development and adaptation of solutions are very } \\
\text { high. This makes digitalisation more difficult, which ultimately } \\
\text { becomes an obstacle. }\end{array}$ & 13 \\
\hline & $\begin{array}{l}\text { Regulatory } \\
\text { obstacles }\end{array}$ & $\begin{array}{l}\text { Regulatory requirements must be met by banks by law. This } \\
\text { confronts them, from an internal and external perspective of } \\
\text { further development, with major obstacles that slow } \\
\text { down digitalisation. }\end{array}$ & 21 \\
\hline & $\begin{array}{l}\text { Data } \\
\text { protection/security and } \\
\text { integrity }\end{array}$ & $\begin{array}{l}\text { Banks and FinTechs are becoming more and more networked, and } \\
\text { customers are becoming more and more transparent, particularly } \\
\text { through free access and exchange of data. In this context, data are } \\
\text { subject to special protection requirements, which poses a } \\
\text { challenge for both banks and FinTechs. This is slowing down } \\
\text { digitalisation. Banks are subjectively more strongly monitored } \\
\text { and are more in public focus than FinTechs. }\end{array}$ & 18 \\
\hline & $\begin{array}{l}\text { Implementation } \\
\text { difficulties }\end{array}$ & $\begin{array}{c}\text { The implementation of new processes and technologies in banks, } \\
\text { taking into account legal requirements and the growing IT } \\
\text { infrastructure, causes implementation problems of digital } \\
\text { approaches and slows down or even completely inhibits } \\
\text { digitalisation in banking. }\end{array}$ & 13 \\
\hline & Public infrastructure & $\begin{array}{l}\text { The public infrastructure does not meet the requirements for } \\
\text { comprehensive digitalisation of banks. }\end{array}$ & 6 \\
\hline & $\begin{array}{l}\text { Outdated IT } \\
\text { infrastructure }\end{array}$ & $\begin{array}{c}\text { The demands on banking IT are increasing together with the } \\
\text { speed of technology cycles and the associated technological } \\
\text { developments. Banks will never be able to keep up with the latest } \\
\text { developments. Legacy IT infrastructures place limits on } \\
\text { digitalisation in banks. }\end{array}$ & 7 \\
\hline & $\begin{array}{l}\text { State of the } \\
\text { art/integration (today) }\end{array}$ & $\begin{array}{c}\text { Centrally provided technology and corresponding interfaces are } \\
\text { not sufficiently developed to allow technical approaches to be } \\
\text { integrated into banks without problems and to enable } \\
\text { holistic digitalisation. }\end{array}$ & 11 \\
\hline
\end{tabular}

\section{References}

1. Türkmen, E.; Soyer, A. The Effects of Digital Transformation on Organizations. In Handbook of Research on Strategic Fit and Design in Business Ecosystems: Advances in E-Business Research; IGI Global: Hershey, PA, USA, 2020; pp. 259-288. [CrossRef]

2. Hess, T.; Matt, C.; Benlian, A.; Wiesböck, F. Options for Formulating a Digital Transformation Strategy. MIS Q. Exec. 2016, 15, 123-139.

3. Ivančić, L.; Stjepic, A.-M.; Vugec, D.S. Mastering digital transformation through business process management: Investigating alignments, goals, orchestration, and roles. J. Entrep. Manag. Innov. 2020, 16, 41-73. [CrossRef]

4. Ismail, M.H.; Khater, M.; Zaki, M. Digital Business Transformation and Strategy: What Do We Know So Far? Working Paper University of Cambridge; University of Cambridge: Cambridge, UK, 2018.

5. Westerman, G.; Bonnet, D.; McAfee, A. The Nine Elements of Digital Transformation. MIT Sloan Manag. Rev. 2014, 55, 1-6.

6. Aydalot, P.; Keeble, D. High Technology Industry and Innovative Environments, 1st ed.; Routledge: London, UK, 2018.

7. Cohen, B.; Amorós, J.E.; Lundy, L. The generative potential of emerging technology to support startups and new ecosystems. Bus. Horiz. 2017, 60. [CrossRef]

8. Li, L.; Su, F.; Zhang, W.; Mao, J.-Y. Digital transformation by SME entrepreneurs: A capability perspective. Inf. Syst. J. 2017, 28, 1-29. [CrossRef]

9. Deutsche Bundesbank. Zahlungsverhalten in Deutschland-Eine empirische Studie über die Auswahl und Verwendung von Zahlungsinstrumenten in der Bundesrepublik Deutschland. 2009. Available online: https://www.bundesbank.de/ resource/blob/599956/4d15527da87c104926f9ad8c5a53707a/mL/zahlungsverhalten-in-deutschland-2009-data.pdf (accessed on 10 September 2019).

10. Deutsche Bundesbank. Zahlungsverhalten in Deutschland 2011-Eine empirische Studie über die Verwendung von Bargeld und unbaren Zahlungsinstrumenten. 2012. Available online: https://www.bundesbank.de/resource/blob/663302/8b1c7f5a6407b2 1aac71dd41cef8bbd2/mL/zahlungsverhalten-in-deutschland-2011-data.pdf (accessed on 10 September 2019). 
11. Deutsche Bundesbank. Zahlungsverhalten in Deutschland 2014-Dritte Studie über die Verwendung von Bargeldund unbaren Zahlungsinstrumenten. 2015. Available online: https://www.bundesbank.de/resource/blob/599406/8deaa2563cb837cb33d2 d38edef6c4d6/mL/zahlungsverhalten-in-deutschland-2014-data.pdf (accessed on 10 September 2019).

12. Deutsche Bundesbank. Zahlungsverhalten in Deutschland 2017-Vierte Studie über die Verwendung von Bargeld und unbaren Zahlungsinstrumenten. 2018. Available online: https://www.bundesbank.de/resource/blob/634056/8e22ddcd69de76ff40078 b31119704db/mL/zahlungsverhalten-in-deutschland-2017-data.pdf (accessed on 10 September 2019).

13. Lee, I.; Shin, Y.J. Fintech: Ecosystem, business models, investment decisions, and challenges. Bus. Horiz. 2018, 61, 35-46. [CrossRef]

14. Chen, M.A.; Wu, Q.; Yang, B. How Valuable Is FinTech Innovation? Rev. Financ. Stud. 2019, 32, 2062-2106. [CrossRef]

15. Gomber, P.; Kaufmann, R.J.; Parker, C.; Weber, B.W. On the Fintech Revolution: Interpreting the Forces of Innovation, Disruption, and Transformation in Financial Services. J. Manag. Inf. Syst. 2017, 35, 220-265. [CrossRef]

16. Schepinin, V.; Bataev, A. Digitalization of financial Sphere: Challenger banks efficiency estimation. In Proceedings of the International Scientific Conference “Digital Transformation on Manufacturing, Infrastructure and Service", Saint-Petersburg, Russia, 21-22 November 2019.

17. Breidbach, C.F.; Keating, B.W.; Lim, C. Fintech: Research Directions to Explore the Digital Transformation of Financial Service Systems. J. Serv. Theory Pract. 2020, 30, 79-102. [CrossRef]

18. Krasonikolakis, I.; Tsarbopoulos, M.; Eng, T.-Y. Are incumbent banks bygones in the face of digital transformation. J. Gen. Manag. 2020, 46, 60-69. [CrossRef]

19. Fernández-Portillo, A.; Hernández-Mogollón, R.; Sánchez-Escobedo, M.C.; Coca Pérez, J.L. Does the Performance of the Company Improve with the Digitalization and the Innovation? In Economy, Business and Uncertainty: New Ideas for a Euro-Mediterranean Industrial Policy. AEDEM 2017. Studies in Systems, Decision and Control; Gil-Lafuente, J., Marino, D., Morabito, F.C., Eds.; Springer: Cham, Switzerland, 2019; pp. 276-291. [CrossRef]

20. Groberg, M.; Vetter, H.-M.; Flatten, T.C. A measurement instrument for digitization: Scale development and impact on new product performance. In Academy of Management Proceedings 2016; Academy of Management: Briarcliff Manor, NY, USA, 2016. [CrossRef]

21. Kelchevskaya, N.R.; Shirinkina, E.V.; Strih, N.I. Estimation of interrelation of components of human capital and level of digitalization of industrial enterprises by method of modeling of structural equations. In Proceedings of the 1st International Scientific Conference "Modern Management Trends and the Digital Economy: From Regional Development to Global Economic Growth" (MTDE 2019); Atlantis Press: Cambridge, MA, USA, 2019.

22. Niemand, T.; Rigtering, J.P.C.; Kallmüzer, A.; Kraus, S.; Maalaoui, A. Digitalization in the financial industry: A contingency approach of entrepreneurial orientation and strategic vision on digitalization. Eur. Manag. J. 2020. [CrossRef]

23. Dorfleitner, G.; Hornuf, L.; Schmitt, M.; Weber, M. FinTech in Germany; Springer International Publishing: Cham, Switzerland, 2017.

24. Crunchbase. N26. 2019. Available online: https://www.crunchbase.com/organization/n26\#section-twitter (accessed on 4 May 2019).

25. Dorfleitner, G.; Hornuf, L. Fintech-Markt in Deutschland; Bundesministerium der Finanzen: Berlin, Germany, 2016.

26. Christensen, C.M.; Bower, J.L. Customer Power, Strategic Investment, and the Failure of Leading Firms. Strateg. Manag. J. 1996, 17, 197-218. [CrossRef]

27. Christensen, C.M.; Raynor, M.E.; Rory, M. What Is Disruptive Innovation? Harvard Business Review. December 2015 , pp. 44-53. Available online: https:/ /hbr.org/2015/12/what-is-disruptive-innovation (accessed on 12 February 2021).

28. Diener, F.; Špaček, M. The Role of “Digitalization” in German Sustainability Bank Reporting. Int. J. Financ. Stud. 2020, 8, 16. [CrossRef]

29. Braun, A. Deutsche Bank voll "Digital". 2016. Available online: http://boerse.ard.de/aktien/deutsche-bank-voll-digital100.html (accessed on 17 November 2018).

30. Mohan, D. How banks and FinTech startups are partnering for faster innovation. J. Digit. Bank. 2015, 1, $12-21$.

31. Matt, C.; Hess, T.; Benlian, A. Digital Transformation Strategies. Bus. Inf. Syst. Eng. 2015, 57, 339-343. [CrossRef]

32. Terrar, D. What is Digital Transformation? 2015. Available online: http://www.theagileelephant.com/what-is-digitaltransformation/ (accessed on 12 May 2020).

33. Valdez-de-Leon, O. A Digital Maturity Model for Telecommunications Service Providers. Technol. Innov. Manag. Rev. 2016, 6, 19-32. [CrossRef]

34. Gartner. Gartner IT Glossary-Digitization. 2020. Available online: https://www.gartner.com/en/information-technology/ glossary/digitization (accessed on 11 May 2020).

35. Francis, B.; Hasan, I.; Küllü, A.M.; Mingming, Z. Should banks diversify or focus? Know thyself: The role of abilities. Econ. Syst. 2018, 42, 106-118. [CrossRef]

36. Hensmans, M. How digital fantasy work induces organizational ideal reversal? Long-term conditioning and enactment of digital transformation fantasies at a large alternative bank (1963-2019). Organization 2020. [CrossRef]

37. Lotriet, R.A.; Dltshego, K.K. An assessment of perceptions concerning digital transformation at a South African commercial bank-A case of Anthropocene denial for the economy. Tydskrif vir Geesteswetenskappe 2020, 60, 687-707. [CrossRef]

38. Von Solms, J. Integrating Regulatory Technology (RegTech) into the digital transformation of a bank Treasury. J. Bank. Regul. 2020. [CrossRef] 
39. Bican, P.M.; Brem, A. Digital Business Model, Digital Transformation, Digital Entrepreneurship: Is There A Sustainable "Digital". Sustainability 2020, 12, 5239. [CrossRef]

40. Fekete, A.; Rhyner, J. Sustainable Digital Transformation of Disaster Risk-Integrating New Types of Digital Social Vulnerability and Interdependencies with Critical Infrastructure. Sustainability 2020, 12, 9324. [CrossRef]

41. Forcadell, F.J.; Aracil, E.; Ubeda, F. Using reputation for corporate sustainability to tackle banks digitalization challenges. Bus. Strategy Environ. 2020, 29, 2181-2193. [CrossRef]

42. El Hilali, W.; El Manouar, A.; Janati Idrissi, M.A. Reaching sustainability during a digital transformation: A PLS approach. Int. J. Innov. Sci. 2020, 12, 52-79. [CrossRef]

43. Ordieres-Meré, J.; Prieto Remón, T.; Rubio, J. Digitalization: An Opportunity for Contributing to Sustainability FROM Knowledge Creation. Sustainability 2020, 12, 1460. [CrossRef]

44. Moro-Visconti, R.; Cruz Rambaud, S.; López Pascual, J. Sustainability in FinTechs: An Explanation through Business Model Scalability and Market Valuation. Sustainability 2020, 12, 10316. [CrossRef]

45. Verhagen, T. Catalysing FinTech for Sustainability. Lessons from Multi-Sector Innovation. A Report of the BEI's Fintech Taskforce. Preprint. Available online: https://www.researchgate.net/publication/328345987_Catalysing_Fintech_for_Sustainability_ Lessons_from_multi-sector_innovation_A_report_of_the_BEI $\backslash T 1 \backslash$ textquoterights_Fintech_Taskforce/comments (accessed on 23 January 2021).

46. Aguayo, F.Z.; Ślusarczyk, B. Risks of Banking Services' Digitalization: The Practice of Diversification and Sustainable Development Goals. Sustainability 2020, 12, 4040. [CrossRef]

47. Moudud-Ul-Huq, S.; Ashraf, B.N.; Gupta, A.D.; Zheng, C. Does bank diversification heterogeneously affect performance and risk-taking in ASEAN emerging economies. Res. Int. Bus. Financ. 2018, 46, 342-362. [CrossRef]

48. Shin, Y.J.; Choi, Y. Feasibility of the Fintech Industry as an Innovation Platform for Sustainable Economic Growth in Korea. Sustainability 2019, 11, 5351. [CrossRef]

49. Mărăcine, V.; Voican, O.; Scarlat, E. The Digital Transformation and Disruption in Business Models of the Banks under the Impact of FinTech and BigTech. In Proceedings of the International Conference on Business Excellence; Walter de Gruyter GmbH: Berlin, Germany, 2020; pp. 294-305. [CrossRef]

50. Hough, J.; Chan, K.-Y. Factors influencing the acceptance of digital banking: An empirical study in South Africa based on the enhanced Technology Acceptance Model. In Proceedings of the 27th Annual Conference of the International Association for Management of Technology (IAMOT 2018), Birmingham, UK, 22-26 April 2018.

51. Sadigov, S.; Vasilyeva, T.; Rubanov, P. FinTech in Economic Growth: Cross-country Analysis. In Economic and Social Development: Book of Proceedings, Proceedings of the 55th International Scientific Conference on Economic and Social Development, Baku, Azerbaijan, 17-18 June 2020; Ismayilov, A., Aliyev, K., Benazic, M., Eds.; ProQuest: Ann Arbor, MI, USA, 2020; pp. 729-739.

52. Chan, E.S.W. Barriers to EMS in the hotel industry. Int. J. Hosp. Manag. 2008, 28, 187-196. [CrossRef]

53. Chan, E.S.W. Implementing Environmental Management Systems in Small- and Medium-Sized Hotels: Obstacles. J. Hosp. Tour. Res. 2011, 35, 3-23. [CrossRef]

54. Vikneswaran, N.; Anantharajah, S. A green makeover for our hotels? Q. DOE Update Environ. Dev. Sustain. 2012, 2, 10-12.

55. Kamalulariffin, N.S.; Nabiha, S.; Khalid, A.; Wahid, N.A. The barriers to the adoption of environmental management practices in the hotel industry: A study of Malaysian hotels. Bus. Strategy Ser. 2013, 14, 106-117. [CrossRef]

56. Yusof, Z.B.; Jamaludin, M. Barriers of Malaysian Green Hotels and Resorts. In Procedia-Social and Behavioral Sciences, Proceedings of the AMER International Conference on Quality of Life, AicQoL2014KotaKinabalu, The Pacific Sutera Hotel, Sutera Harbour, Kota Kinabalu, Sabah, Malaysia, 4-5 January 2014; Elsevier: Amsterdam, The Netherlands, 2014; pp. 501-509.

57. Chan, E.S.W.; Okumus, F.; Chan, W. What hinders hotels' adoption of environmental technologies: A quantitative study. Int. J. Hosp. Manag. 2020. to be published. [CrossRef]

58. Chan, E.S.W.; Okumus, F.; Chan, W. Barriers to Environmental Technology Adoption in Hotels. J. Hosp. Tour. Res. 2015, 42, 1-25. [CrossRef]

59. Deutsche Bundesbank. Bankenstatistik Januar 2015. Available online: https://www.bundesbank.de/resource/blob/693922/a2 4868217d3ad9478b920930e2226987/mL/2015-01-bankenstatistik-data.pdf (accessed on 9 April 2019).

60. Deutsche Bundesbank. Bankenstatistik Januar 2016. Available online: https://www.bundesbank.de/resource/blob/693932/2 8e421937f44e7c19fee43daf9266b0b/mL/2016-01-bankenstatistik-data.pdf (accessed on 9 April 2019).

61. Deutsche Bundesbank. Bankenstatistik Januar 2018. Available online: https://www.bundesbank.de/resource/blob/693982/7b3 c771cecbc6b44934c408310bbb35f/mL/2018-01-bankenstatistik-data.pdf (accessed on 9 April 2019).

62. Deutsche Bundesbank. Bankenstatistik Januar 2019. Available online: https://www.bundesbank.de/resource/blob/773438/048 ad3c478cd071493582c25ca847a8a/mL/2019-01-bankenstatistik-data.pdf (accessed on 9 April 2019).

63. Deutsche Bundesbank. Bankenstatistik Januar 2020. Available online: https://www.bundesbank.de/resource/blob/822138/b3 d37fcb3c2a65a40ea3ada27a0988d4/mL/2020-01-bankenstatistik-data.pdf (accessed on 9 January 2019).

64. Diener, F. Empirical Evidence of a Changing Operating Cost Structure and Its Impact on Banks' Operating Profit: The Case of Germany. J. Risk Financ. Manag. 2020, 13, 247. [CrossRef]

65. Kuckartz, U. Qualitative Inhaltsanalyse. Methoden, Praxis, Computerunterstützung, 3rd ed.; Beltz Juventa: Weinheim, Germany, 2016.

66. Dresing, T.; Pehl, T. Praxisbuch Interview, Transkription \& Analyse, 6th ed.; Dr. Dresing und Pehl: Marburg, Germany, 2015. 
67. Helfferich, C. Die Qualität Qualitativer Daten: Manual für die Durchführung Qualitativer Interviews, 5th ed.; Springer VS: New York, NY, USA, 2020.

68. Mayring, P. Qualitative Inhaltsanalyse: Grundlagen und Techniken, 12th ed.; Beltz: Weinheim, Germany, 2015.

69. Döring, N.; Bortz, J. Forschungsmethoden und Evaluation in den Sozial-und Humanwissenschaften, 5th ed.; Springer: Berlin/Heidelberg, Germany, 2016.

70. Gläser, J.; Laudel, G. Experteninterviews und Qualitative Inhaltsanalyse als Instrumente Rekonstruierender Untersuchungen, 4th ed.; VS Verlag für Sozialwissenschaften: Wiesbaden, Germany, 2010.

71. Bogner, A. Interviews mit Experten: Eine praxisorientierte Einführung, 2014 ed.; Springer VS: New York, NY, USA, 2014.

72. Glaser, B.G.; Strauss, A.L. The Discovery of Grounded Theory: Strategies for Qualitative Research; Aldine Transaction: Piscataway, NJ, USA, 1967.

73. Morse, J.M. Designing funded qualitative research. In Handbook of Qualitative Research; Denzin, N.K., Lincoln, Y.S., Eds.; Sage Publications: Thousand Oaks, CA, USA, 1994; pp. 220-235.

74. Creswell, J.W. Qualitative Inquiry E Research Design, 3rd ed.; Sage Publications: Thousand Oaks, CA, USA, 2012.

75. Mayring, P. Einführung in die Qualitative Sozialforschung, 6th ed.; Beltz: Weinheim, Germany, 2016.

76. Mayring, P. Einführung in Die Qualitative Sozialforschung. Eine Anleitung zu Qualitativem Denken, 5th ed.; Beltz: Weinheim, Germany, 2002.

77. Brislin, R.W. Translation and content analysis of oral and written materials. In Handbook of Cross-cultural Psychology; Triandis, H.C., Berry, J.W., Eds.; Allyn and Bacon: Boston, MA, USA, 1980; pp. 389-444.

78. Allmark, P.; Boote, J.; Chambers, E.; Clarke, A.; McDonnell, A.; Thompson, A.; Tod, A.M. Ethical Issues in the Use of In-Depth Interviews: Literature Review and Discussion. Res. Ethics 2009, 5, 48-54. [CrossRef]

79. Guest, G.; MacQueen, K.M.; Namey, E.E. Applied Thematic Analysis; SAGE Publications: Thousand Oaks, CA, USA, 2012.

80. Hopf, C.; Schmidt, C. Zum Verhältnis von Innerfamilialen Sozialen Erfahrungen, Persönlichkeitsentwicklung und Politischen Orientierungen: Dokumentation und Erörterung des Methodischen Vorgehens in Einer Studie zu Diesem Thema. Available online: https:/ /nbn-resolving.org/urn:nbn:de:0168-ssoar-456148 (accessed on 24 August 2020).

81. Fleiss, J.; Levin, B.; Paik, M.C. Statistical Methods for Rates and Proportions, 3rd ed.; John Wiley \& Sons: Hoboken, NJ, USA, 2003.

82. Hallgran, K. Computing Inter-Rater Reliability for Observational Data: An Overview and Tutorial. Tutor. Quant. Methods Psychol. 2012, 8, 23-24. [CrossRef] [PubMed]

83. Rädiker, S.; Kuckartz, U. Analyse qualitativer Daten mit MAXQDA; Springer VS: Wiesbaden, Germany, 2018.

84. Bajpai, S.; Bajpai, R.; Chaturvedi, H.K. Evaluation of Inter-Rater Agreement and Inter-Rater Reliability for Observational Data: An Overview of Concepts and Methods. J. Indian Acad. Appl. Psychol. 2015, 41, 20-27.

85. Carletta, J. Assessing agreement on classification statistics: The kappa statistic. ACL Anthol. 1996, 22, 249-254

86. Gewt, K.L. Kappa Statistic is not Satisfactory for Assessing the Extent of Agreement Between Raters. Stat. Methods Inter Rater Reliab. Assess. 2002, 1, 1-6.

87. Ishak, N.M.; Bakar, A.Y.A. Qualitative Data Management and Analysis using NVivo: An Approach used to Examine Leadership Qualities among Student Leaders. Educ. Res. J. 2012, 2, 94-103.

88. Landis, J.R.; Koch, G.G. The measurement of observer agreement for categorical data. Biometrics 1997, 33, 159-174. [CrossRef]

89. Brennan, R.L.; Prediger, D.J. Coefficient kappa: Some uses, misuses, and alternatives. Educational and Psychological Measurement. Educ. Psychol. Meas. 1981, 41, 687-699. [CrossRef]

90. Diener, F.; Špaček, M. The Awareness of Digitisation in Strategic Sustainability Reporting in Banking. In Innovation Management, Entrepreneurship and Sustainability 2019 (IMES 2019), Proceedings of the 7th International Conference, Prague, Czech Republic, 30-31 May 2019; Dvouletý, O., Lukeš, M., Mísař, J., Eds.; Prague University of Economics and Business: Prague, Czech Republic, 2019; pp. $137-150$. 


\title{
How to Achieve Sustainable Development of Mobile Payment through Customer Satisfaction-The SOR Model
}

\author{
Su-Chang Chen ${ }^{1}$, Kuo Cheng Chung ${ }^{1, *}$ and Ming Yueh Tsai ${ }^{2}$ \\ 1 Department of Marketing and Logistics Management, National Penghu University of Science and \\ Technology, Magong City, Penghu County 88046, Taiwan; csc@npu.edu.tw \\ 2 Land Bank of Taiwan, Taipei City 10047, Taiwan; a0989411830@gmail.com \\ * Correspondence: d9732004@gmail.com
}

Received: 15 October 2019; Accepted: 6 November 2019; Published: 11 November 2019

\begin{abstract}
In recent years, due to smartphones being more popular and the wireless network infrastructure improving, individuals are no longer constrained by the workflow on personal computers. Therefore, business operators are constantly launching new mobile application services for everyday life. This study mainly explores how mobile payment adopts the determinants, and adds utilitarian value, hedonic value and salesperson performance as antecedences to understand whether utilitarian value, hedonic value and salesperson behavior can affect satisfaction through determinants, as well as to understand consumers' mobile payment usage intention through the stimulus-response model. The research objectives of this study are mainly mobile payment users in Taiwan. 425 valid questionnaires were received. This study uses a structural equation model to analyze the data. This study's results indicate that utilitarian value, hedonic value and salesperson selling behaviors positively affects customers' satisfaction, which customers' satisfaction positively affects mobile payment usage intention. The research results could provide mobile payment operators with references in the design and implementation of the mobile payment and application process, thereby accelerating the popularization of mobile payment.
\end{abstract}

Keywords: stimulus-response model; utilitarian value; Hedonic value; salesperson selling behaviors; customer satisfaction

\section{Introduction}

Research Background and Motives

With the popularization of the $4 \mathrm{G}$ mobile network and the diversified development of smart phone applications, the time spent by Taiwanese on mobile phones is increasing year by year. According to the report of the Institute for Information Industry, $51.5 \%$ of the people belong to moderate users of mobile phones, while $28.1 \%$ spend more than $5 \mathrm{~h}$ on mobile phones every day, making them heavy users [1]. It is worth noting that entertainment content has become the focus of the use of these mobile phones.

Consumers can pay for things in stores by scanning the bar codes, or sensing through their mobile phones, as long as their mobile phones are bound to their credit cards, bank accounts or electronic wallets, sparing them the trouble of carrying credit cards and cash.

According to the estimation of Statista, an international research institute, global mobile payment transactions will grow from 391.4 billion USD in 2018 to 1 trillion USD in 2021 and 1.3 trillion USD in 2022, with an annual composite growth rate (CAGR) of $35.7 \%$, while the number of global mobile payment users is looking forward to growing up to $970,000,000$ by 2022 , which number was $530,000,000$ in 2018, and its annual composite growth rate is $16.2 \%$ [2]. Pursuant to the statistical data of the Institute for Information Industry, the penetration rate of mobile payment in 2017 is 39.7\%, which is a growth in multiple compared with 19\% in 2015. 
In response to consumers' willingness to use mobile payments, many studies suggest that strategies which improve the usability and ease of use of mobile payments enhance customer value, and the reduced perceived risks will increase the customers' willingness to use mobile payments. The survey of the Institute for Information Industry [3] finds that about 39.7\% of Taiwanese smart phone users used mobile payment in 2017, and consumers' perception of mobile payment increased from $84 \%$ in 2016 to $91 \%$ in 2017 . The above data show that consumers' experience and perception of mobile payment is significantly improved. However, the proportion of mobile payment is still low compared with other payment markets. Although the acceptance of mobile payment among the public is gradually increasing, mobile payment has not reached the expected popularity. With the advent of the Banking 4.0 era, the behavioral patterns of financial consumers changes dramatically. Key factors for progress include consumers' perceived value, as it can attract new consumers and retain the original consumers [4]. Cognition and emotion would affect consumers' willingness to use technology services [5]. From the perspective of system design, consumers' use of mobile payment seems to bring more convenience to their life and it deserves to be their preference. Lee et al. (2004) points out that personal anxiety about technology will affect users' willingness to use mobile payment [6]. So as to achieve the popularization of mobile payment, we should not only strengthen the demand side (the perceived value of consumers), but also consider the supply side (the willingness of stores to provide good mobile payment services, including the salesperson's behaviors). The main purpose of many companies launching mobile pay is to utilize the convenient consumption model to assist the integration of online and offline virtual channels, cultivating loyal member customers and also grasping the contours of consumers' behavior based on consumers' big data. Then they shall launch products that are closest to customers' needs and propose the marketing strategy, so that the company can grasp the customers' consumption trends and respond to the market environment.

In review of literatures on the research of mobile payment use intentions in recent years, Lee et al. (2009) studies the interaction between the mobile payment platform and customers, pointing out that consumers will have an impact on network externality [7]. Consumers tend to use mobile payment under peer influence, while their purchase decisions are not easily subject to the influences of web advertising and promotion. Through the analysis based on innovation diffusion theories, Sharma (1999) brings up that trust is the most significant factor in mobile payment [8]. Customers make decisions on the use of mobile payment mainly according to the reputation, convenience and specifications of the payment platform. In the past studies, there is rare research on the intention to use mobile payment from the point of view of customer demand, except for Wang (2008) from interviews with mobile payment users' switching behavior, based on the Push-Pull-Mooring Theory, which came to the finding that privacy concerns are the determinant on consumers' decisions about whether to use the mobile payment [9]. Our study aims to understand the impacts of environmental stimulus and internal psychological state on consumers' intentions to use mobile payment from the view of points of customer demand, in order to compensate for the lack of previous literature on mobile payment, and to achieve the goal of sustainable operation. This study uses a stimulus-response model to analyze customers' consumption psychology.

\section{Literature Review}

\subsection{Mobile Payment}

As of late, with the consistent innovation and developing of Internet technology and e-commerce, mobile devices have become an inseparable companion of people in their daily life. They can use smart devices in their hands for socializing, playing games, sending and receiving e-mails, browsing messages, taking photos, or even shopping. Among them, the payment method has changed from simple cash or credit to mobile payment. Therefore, more and more people worldwide are using mobile payment. According to EMarketer (2018) research, 34.9\% of smart phone users will pay through mobile phones in retail channels at least every six months [10]. Advances in mobile payment technology have 
reduced technology barriers to mobile payment, and coupled with the rise of financial service Apps and the expanding accessibility of mobile devices, we believe that mobile payment will become more common and simple in the future [11]. Consumers can apply to the credit card issuing bank for this e-wallet. The e-wallet stores users' profiles, facilitating consumers to use it online. The operating mechanism is that the buyer's credit information will be encrypted before transmitting it to the seller's server. After the bank receives the encrypted data, the confirmation message is also encrypted into the credit card data, and this then transmits to the relevant bank network. Mobile payment is to use a Smartphone as an electronic wallet, so that consumers can use several services and pay for physical goods without using coins or credit cards. There are five types of mobile payment methods: SMS-based transfer payments, mobile bill payments, wireless application protocol payments (WAP), application payments (APP) and Near-field communication payments (NFC).

Mobile payment can be divided into two different types: Remote payment and short-range payment. Remote payment allows consumers to access financial accounts remotely, and can remit money or get other online services by using mobile devices and mobile websites, including mobile banking, mobile network payment, and so on [12]; short-range payment is also known as MPOS payment, which refers to payments that occur when customers and merchants are very close. In this type of payment, the vouchers of transactions displayed on cell phones and traded over short distances uses barcode scanning or radio frequency identification (RFID) technology [13]. In other words, consumers and physical store owners must make transactions face to face. Commodity trade and services occur in adjacent fields, for example, paying for transport tolls, dinner or shopping payment services in physical stores. Offline physical transactions use mobile tools and the merchants' equipment to transmit data to complete the cash flow. At present, there are two common ways of information communication, namely NFC sensing and bar code scanning. Mobile payment with NFC sensing technology requires consumers to install the mobile payment App on their mobile devices and store a variety of payment tools. Businessmen must build POS terminals for NFC payment [14]. This study considers mobile payment as a kind of payment, with smart phones as the tools to complete the transaction for purchases in physical stores, by using non-cash financial instruments with certification steps through specific transmission technologies or devices.

\subsection{SOR (Stimulus-Organism-Response) Framework (Stimulas-Response Model)}

Mehrabian and Russell (1974) originally proposed Stimulus-Organism-Response (S-O-R) from environmental psychology [15]. In the S-O-R framework, it is assumed that stimulus has an impact on the emotional state of an individual. This internal processing involves the individual's cognitive and emotional responses, such as the perception of stimuli; response represents the individual's behavioral outcomes, which can show that SOR is a physical and intangible form [16]. SOR stimulates individual's emotional and cognitive state through environmental cues, leading to certain behavioral outcomes [17]. Using the SOR model in the study of consumer behavior is helpful to distinguish environmental stimuli from consumers' internal and external behavior. Therefore, this S-O-R framework is considered to be a popular psychological theory in consumer behavior research [18].

The target of this study is to scrutinize consumers' consumption behavior of mobile payment from their cognitive and emotional responses through the S-O-R framework, the Stimulus factors consumer's hedonic value and utilitarian value and salesperson selling behaviors during this study. The reason is that consumers are exposed to the situational stimulus in the use of mobile payment in physical stores. Organism refers to the users' emotional and cognitive state, including their views, experiences and evaluations, and its factor selected in this study is satisfaction. Finally, Response is the intention of use. The study of Hossain et al. (2018) using SOR for mobile payment is the only one that uses stimulus-organism-response (SOR) as the study framework to understand the customer's purchase intentions and satisfaction of using mobile payments [19]. 
On the whole, when consumers are using mobile payment, the stimulation of perceived value which comprises hedonic value and utilitarian value and salesperson selling behaviors will affect their inner cognitive state (satisfaction) and their behavioral response (intention to use mobile payment).

\subsection{Utilitarian Value}

Value can influence consumers' views and considerations in purchasing products. In the same shopping situation, consumers with different shopping values will show different consumption behaviors [20]. Perceived value has two consumption values: Hedonic value and utilitarian value [21]. These two levels of value gave a complete picture of consumers' values [22]. Babin et al. (1994) points out that the utilitarian value represents that the usefulness, functionality and cognition of the tools and tasks related to consumption are essentially means to achieve goals [21]. Overby and Lee (2006) argue that the utilitarian value is the consumer's assessment of the cost and substantial advantages of products, services and prices after considering their characteristics [23]. Lowe and Alpert (2015) point out that the consumers' product perceptions, such as concepts, technological novelty and comparative advantages, all affect their hedonic and utilitarian values [24]. Overby and Lee (2006) point out that consumers mostly consider rational factors, i.e., judgment of economic benefits in terms of money, convenience and time cost [23].

\subsection{Hedonic Value (HV)}

Jong et al. (2010) believe that consumers with hedonic motivation would give themselves reasons to indulge themselves in shopping, with reasons including the elements of fun, happiness, joy and excitement [25]. Hedonism is related to the desire to pursue happiness and self-realization. Babin et al. (1994) regards shopping as enjoyment, which can relax the mood, relieve the pressure in the real life, and arouse a happy response naturally in the inner heart [21].

Roy and $\mathrm{Ng}$ (2012) argue that hedonic value is the comparatively strong emotion that consumers usually have toward a product [26]. They would consider all kinds of feelings that a product can bring, and evaluate the costs they would pay and the experienced benefits they would get, such as the feelings of pleasure, enjoyment and escaping from reality [23]. Soman (2003) puts forward the concept of payment transparency and regards mobile payment as an intangible way of payment which indirectly reduces customers' pain in payment, and thus reduces their negative emotions, so that consumers may pay more attention to the benefits of purchasing products than to the costs of using mobile devices to pay for them [27-29]. In terms of the development of hedonic value, Chitturi et al. (2007) put forward the principle of "hedonic advantage", that is, when all products to be purchased meet or exceed the standard value of utility and hedonism, consumers will pay more attention to hedonic benefits when choosing products [30]. Chitturi et al. (2008) indicate that consumers' pleasure could be generated through the promotion activities of stores, or when the products themselves could satisfy consumers' hedonic demands [31].

\subsection{Salesperson Selling Behaviors}

In the retail environment, the interaction between salesperson and customers is an important behavioral relationship. Jones et al. (2005) point out that because of the rapid changes in information technology and customer preferences, consumers' requirements for products and services and their expectations for salespersons are getting higher and higher [32]. Some consumers like to interact with salespersons when shopping, thereby establishing business friendship between salesmen and consumers, which often involves emotional elements [33]. Many enterprises begin to emphasize the customer-oriented marketing concept. How to improve customer value, customer satisfaction, service quality and retain customers has become the direction that enterprises must think about [34].

Service behavior is defined as the behavior of a salesperson after the initial point of sale by Ahearne et al. (2007) [35]. This ongoing behavior aims at cultivating and developing exchange relationships, and identifies five aspects of the salesperson's service behavior: Diligence, information 
communication, induction, sportsmanship and empathy. Darian et al. (2005) defines salesperson selling behavior as the consumers' feelings brought by the interaction between the salesperson and consumers in the shopping procedure [36]. Salespersons assume a significant job in sales, as they contact and interact with customers on behalf of the manufacturers. The success of marketing strategy mainly depends on the salesperson [37]. For consumers, the friendliness of salespersons has an important impact on whether they could feel comfortable or stress-free during the shopping process. Rapp et al. (2014) interpret that a salesperson is like a knowledge broker, whose important job is to obtain information about their merchandise and industries, in order to explain and resolve customers' matters [38]. Therefore, salespeople should constantly enrich their knowledge about new products, so as to make an adequate product introduction to customers. Meanwhile, if the salesperson responds to the information needed by the customer in time, it will help the customer save time cost, and avoid negative emotions. Sharma (1999) points out that if retailers want to improve customer service, they should pay attention to the salesperson's selling behaviors, as when consumers feel the positive emotions conveyed by the salesperson, the message transmission and persuasion will be improved [8]. Lee and Dubinsky (2003) believe that not only the store environment will affect customers' purchasing mood, but the interaction between salespersons and customers will also promote the customers' purchasing mood [39]. With technological advances and rapid changes, consumers' unfamiliarity with the use of equipment may inhibit their adoption of the equipment. Friendly salespeople should use sales service technology to help inexperienced consumers to extend their consumer experience rather than to act as barriers.

\subsection{Mobile Payment Usage Intention}

The Rational Behavior Theory (TRA) proposed by Fishbein and Ajzen (1975) holds that we can predict individual behavior, and behavioral intention can also influence individual behavior, that is too say, the actual behaviors can be predicted through behavioral intention, which is a method of people's intention to engage in a particular behavior [40]. The key indicator in measuring the use of information technology is Behavioral intention, and it is the basis for developing information technology as well.

Behavioral intention is an individual's belief in what he wants to do in certain situations [41]. Zeithaml et al. (1996) divide behavioral intention into positive intention and negative intention. When consumers have positive intention, they will generate positive word-of-mouth, and then recommend products or services to their friends and relatives; if they have negative intention, they may choose to change products or reduce the number of purchases [42]. When behavioral intention is applied to the degree of an individual's willingness to use the technology information system in the future, that is, when an individual intends to use the system subjectively, he has generated the usage intention [43]. Consumers' usage intention is related to their experience of trying the products or services, as well as the continuous of consumers to use the products or services if they have positive usage experience [44].

A research on the usage intention of interactive information is proposed by Lin et al. (2008), and it states a model which shows that the usage intention is positively affected by satisfaction. Usage intention is usually considered to be as a prior variable for consumers' actual use of a mobile service $[45,46]$.

\section{Research Design}

\subsection{Research Structure}

This research is based on the S-O-R framework, supplemented by the two consumption values (hedonic value and utilitarian value) proposed by Babin et al. (1994), and combined with the external factor of salesperson selling behavior, which are integrated into the three main constructs of "utilitarian value", "hedonic value" and "salesperson selling behavior" as the external stimulus influencing 
individuals (stimulus), which further influences the consumers' mobile payment usage intention (response) by influencing customer satisfaction (organism) [21].

\subsection{Hypothesis Deduction}

Customers' perceived value originates from their personal experience and interaction with the products or services [47]. Understanding the value of products or services from a user's perspective is long considered a successful customer strategy, and is usually related to the overall business performance [48]. Terpstra and Verbeeten (2014) find that many studies show that the relevance between perceived value and customer satisfaction, along with customers' perceived service value, positively affects customer satisfaction [49]. According to the past literature, empirical studies of traditional retailers have confirmed that perceived value positively affects the customers' satisfaction in most cases, and similar conclusions have been drawn from researches on online shopping websites and e-commerce [50,51]. In light of the above literature, we deduce some hypotheses listed in the following on the mobile payment context in this study:

H1. Utilitarian value has a positive impact on customer satisfaction.

Although the relative importance of hedonic value and utilitarian value is different, hedonic value may be regarded as the user's psychological needs compared with the basic functional needs of utilitarian value [52]. Past literatures show that hedonic value is an important factor affecting satisfaction [12]. Yoo et al. (2010) also propose that in the interactive relationship between suppliers and purchasers, customers experience intimate relationships, making e-commerce users happier [53]. According to the above literature, our study deduces the following hypothesis in mobile payment context:

H2. Hedonic value has a positive impact on customer satisfaction.

Mobile payment is a new technology for Taiwanese consumers. Every new technology must be considered from a consumer perspective before its launch. Therefore, the salesperson assumes a significant job in the promotion. When the consumer uses the electronic wallet, all the personal data can be integrated on one mobile phone. However, there are many banks and telecommunications companies that are actively investing in how to make the most adhesive with consumers through the relationship between salespeople and customers. The salesperson's behavior and attitudes directly affect consumers' satisfaction [19]. The interaction between salespersons and consumers is very important. Compared with competitors, assuming that the salespersons can offer consumers with more merchandises' knowledge, they will create higher added value for customers, which will affect the performance of their retail stores [36].

Lee and Dubinsky (2003) hold that the reliability, professionalism, empathy, friendliness, enthusiasm, similarity and professionalism of salespersons all affect customers' mood and satisfaction in their consumption, and then affect their purchase intention [39]. Amyx and Bhuian (2009) find that the customer evaluation of salesperson selling behavior reflects customers' satisfaction of the service and brand loyalty [54]. In addition, scholars support the concept that adaptive sales could have distinctive customer satisfaction, for example, supplier satisfaction, and satisfaction with services/products [55,56]. In light of the above literature, this study deduces the following hypothesis in the mobile payment context:

H3. Salesperson selling behaviors have a positive impact on customer satisfaction.

Practical value and hedonic motivation are important factors affecting consumers' online shopping, and are also important for repeat purchasing intention [22,57]. In the past literature, some scholars propose that cognition and emotion would influence consumers' willingness to use technology services [5]. In terms of mobile services, Pihlstrom and Brush (2008) propose that money, convenience 
and emotional value would influence repurchase intention [58]. In light of the above literature, this study deduces the following hypotheses in the mobile payment context:

H4. Utilitarian value has a positive impact on mobile payment usage intention.

H5. Hedonic value has a positive impact on mobile payment usage intention.

The salespeople of electronic payment are very important to the consumer because they have usefulness, emotion and security [19]. In addition, they can also understand consumers' needs and deliver the opinions of consumers to the company. The salesperson's empathy (cognition and emotion) and professionalism (sales wisdom and communication ability) have an impact on product sales. Salesperson's characteristics will affect consumers' repurchase intention [59]. Kennedy et al. (2001) also believes that salesperson's professional ability and sales skills will affect customers' satisfaction with salesperson and repurchase [60]. Haas and Kenning (2014) hold that salespersons have influences in determining customers by providing information [61]. The salesperson is also an important factor influencing purchase intention [62]. In light of the above literature, this study deduces the following hypothesis in the mobile payment context:

H6. Salesperson behaviors have a positive impact on mobile payment usage intention.

Satisfaction means the comprehensive evaluation of a service or a product after consumption, which includes the satisfaction degree at the cognitive and emotional levels. The satisfaction degree serves as a basis for the judgment of the successive consumers' behavioral intentions [63]. Customer satisfaction can lead to subsequent behavioral intention, like repurchase intention and behavioral intention $[64,65]$. Expectation uncertainty theory is universally used to disclose customer satisfaction [66]. Satisfaction comes from the comparison between the performance and expectation perception. On the assumption that the performance meets customer expectations, it is satisfactory; otherwise, when performance is lower than customer expectations, it is unsatisfactory. In addition, Chen et al. (2012) mentions that the subject of expectation uncertainty theory is that repurchase behavior depends on satisfaction [67]. Satisfied customers often tend to make positive word-of-mouth, and have a strong intention to keep using the service [68]. The research structure is shown in Figure 1. This study deduces the following hypothesis, in light of the above literature:

H7. Customer satisfaction has a positive impact on mobile payment usage intention.

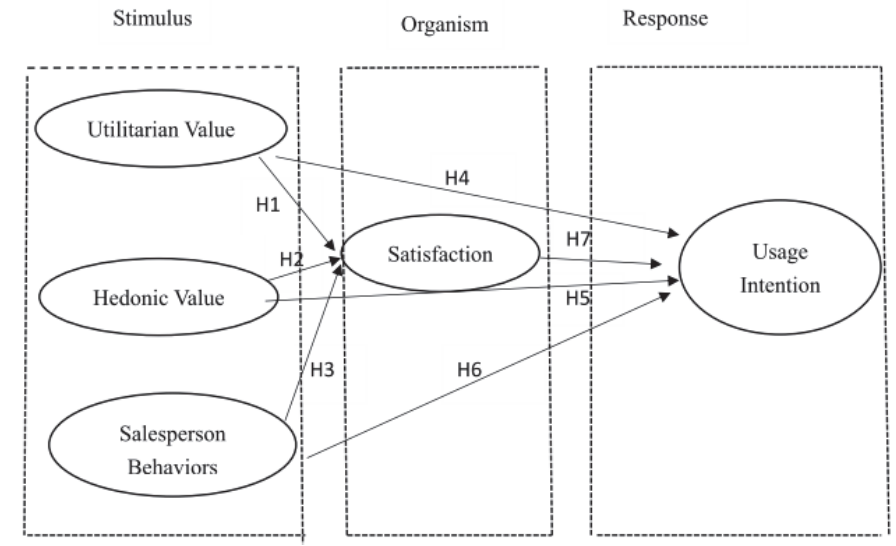

Figure 1. Research model. 


\subsection{Definition of Variables and Questionnaire Design}

The reason why we do this study is to scrutinize the relationship between the mobile payment users' satisfaction formed by their perceived utilitarian value, hedonic value and salesperson selling behaviors and their usage intention. This study adopts a method of investigation and research, and a structured questionnaire as the research tool. The subjects of this study are those who have experiences of using mobile payment in consumption in physical stores in Taiwan. Questionnaire data is received online. The content of the questionnaire was developed by collating the items of the scales already developed by experts and scholars that incorporate three segments: The initial segment is the experience of using mobile payment, the second segment consists of the questionnaire items, in order of utilitarian value, hedonic value and salesperson selling behaviors, customer satisfaction and mobile payment usage intention. Likert's 7-point scale was used as the measurement scale to quantify the data filled in by the respondents, ranging from 1 to 7 points, with 1 point representing "Strongly Disagree" and 7 points representing "Strongly agree", and finally, the third part is the basic data. Based on the research purpose and the need of research hypothesis, this study makes use of the operational characteristics of the structural equation model to measure the causal relationship between the measurement dimensions. The statistical software IBM SPSS AMOS 22 was used to make the model analysis and statistical software IBM SPSS Statistics 22 was used for statistical analysis of data (see Table 1).

Table 1. The demographic characteristics of the sample.

\begin{tabular}{ccc}
\hline & Frequency & Percentage \\
\hline Gender & 201 & \\
Female & 224 & 57.3 \\
Male & & 52.7 \\
Age & 5 & 1.2 \\
$20-$ & 47 & 11.1 \\
$21-30$ & 181 & 42.5 \\
$31-40$ & 124 & 29.2 \\
$41-50$ & 68 & 16.0 \\
$51+$ & & \\
Education & 35 & 8.2 \\
Diploma & 286 & 67.3 \\
Bachelor & 104 & 24.5 \\
Masters and Ph.D. & & \\
Income & 13 & 3.0 \\
20,000- & 47 & 11.1 \\
20,001-35,000 & 128 & 30.1 \\
35,001-50,000 & 110 & 25.9 \\
50,001-65,000 & 127 & 29.9 \\
65,001+ & & \\
\hline
\end{tabular}

\subsection{Sample Data}

In this study, samples were selected mainly from users who use mobile payment, mainly through an online questionnaire. The online questionnaires were mainly distributed through My Survey network platform. The questionnaires of this study were distributed in October 2018 and received in February 2019. The entire 526 questionnaires were received. After excluding 101 invalid questionnaires, there remained 425 valid questionnaires. The respondents of the questionnaires were consumers with experience in mobile payment in Taiwan in the past six months.

\subsection{Measurement}

In this study, analysis was made on five dimensions: Utilitarian value, hedonic value, salesperson selling behaviors, customer satisfaction and mobile payment usage intention by using Likert's 7-point Scale from 1 ("strong disagree") to 7 ("strong agreement"). The definition of utilitarian value is the 
consumers' assessment of the actual advantages and costs of using mobile payment services, with reference to [23]. The definition of Hedonic value is the degree to which consumers acquire emotional and sensory experience in using mobile payment services, with references to [68]. The salesperson selling behaviors are defined as the feelings brought to consumers by interaction between salesperson and consumer in the sales process, with reference to 36]. Customer satisfaction is the consumers' overall evaluation of use of the mobile payment service, with reference to [64]. Mobile payment usage intention is considered to be the willingness of people to pay through the mobile vehicle, with reference to $[69,70]$.

\section{Data Analysis}

\subsection{Reliability and Validity Analysis}

We use Harman's factor test method to conduct exploratory factor analysis (EFA) on all items in this study. Table 2 shows that five factors are extracted, and the explanatory power of the first factor is $34.265 \%$, which was less than $50 \%$. We can infer that there was no serious deviation in common method in the sample data of this study. In addition, we use single factor confirmatory factor analysis (CFA) for the test, which included all of the 25 items in the single-factor test. The results of the test indicate that the factor load level of 12 items exceeds 0.5 , and none of the items is significantly higher than the load level of 0.5 . The model values of this single factor validation analysis show that not all the constructional correlations in this study are derived from common method variations.

Table 2. Initial eigenvalues.

\begin{tabular}{cccc}
\hline Component & Eigenvalues & Variance (\%) & Cumulative Variance (\%) \\
\hline 1 & 8.566 & 34.265 & 34.265 \\
2 & 3.646 & 14.584 & 48.848 \\
3 & 3.003 & 12.012 & 60.860 \\
4 & 1.640 & 6.560 & 67.421 \\
5 & 1.408 & 5.630 & 73.051 \\
\hline
\end{tabular}

In terms of reliability, the combination reliability can be used as a test of internal consistency. It could be found through Table 3 that the values of combination reliability (CR) are from 0.846 to 0.9421, and all of them are larger than 0.6 , indicating that each dimension of the measurement model has a certain degree of reliability. Table 3 shows the measurement model. Among them, the values of average variance extracted (AVE) were between 0.599 and 0.699 , all larger than 0.5 . In addition, the values of AVE open root sign are also larger than the correlation coefficient of each construct, which means that each construct has discriminant validity. This study conducts verification of discriminant validity according to the two criteria put forward by Gaski and Nevin (1985): If (1) the correlation coefficient between two constructs is less than 1 ; (2) the correlation coefficient between two constructs is less than the individual reliability coefficients Cronbach's $\alpha$, and thus it indicates that the two constructs have discriminant validity. In addition, using Fornell and Larcker's (1981) method, we got the third criterion for verification of the discriminant validity: (3) If the correlation coefficient of the two constructs is less than the square root of AVE, it indicates that the two constructs have discriminant validity [71,72]. In addition, we use SPSS 22.0 and AMOS 22.0 to analyze the correlation coefficient matrix of measurement variables in this study, with the analysis data received in the table, all of which conform to the above three criteria for verification of the discriminant validity, showing a good validity of each dimension. In Table 4, all CR values of the structural model are greater than 0.7 , which verifies that the measurement items of each dimension have internal consistency, and all AVE values are larger than 0.5 . Therefore, the proposed framework has convergent validity and the measurement model of this study has good convergent validity, discriminant validity and reliability. 
Table 3. Main statistics.

\begin{tabular}{|c|c|c|c|c|}
\hline \multirow{2}{*}{ Constructs } & \multicolumn{2}{|c|}{ MLE Estimates } & \multirow{2}{*}{$\begin{array}{c}\text { Composite } \\
\text { Reliability (CR) }\end{array}$} & \multirow{2}{*}{$\begin{array}{c}\text { Average of } \\
\text { Variance Extracted } \\
\text { (AVE) }\end{array}$} \\
\hline & $\begin{array}{c}\text { Factor Loading } \\
\left(\lambda_{x} / \lambda_{y}\right)\end{array}$ & $\begin{array}{l}\text { Measurement } \\
(\delta / \varepsilon)\end{array}$ & & \\
\hline Utilitarian Value & & & 0.889 & 0.068 \\
\hline UV1 & $0.824^{* * *}$ & 0.321 & & \\
\hline UV2 & $0.846^{* * *}$ & 0.284 & & \\
\hline UV3 & $0.816^{* * *}$ & 0.334 & & \\
\hline UV4 & $0.781^{* * *}$ & 0.390 & & \\
\hline Hedonic Value & & & 0.936 & 0.678 \\
\hline HV1 & $0.849^{* * *}$ & 0.279 & & \\
\hline HV2 & $0.793^{* * *}$ & 0.371 & & \\
\hline HV3 & $0.822 * * *$ & 0.324 & & \\
\hline HV4 & $0.827 * * *$ & 0.316 & & \\
\hline HV5 & $0.821^{* * *}$ & 0.326 & & \\
\hline HV6 & $0.813^{* * *}$ & 0.339 & & \\
\hline HV7 & $0.839 * * *$ & 0.296 & & \\
\hline Salesperson Behaviors & & & 0.882 & 0.599 \\
\hline SB1 & $0.721 * * *$ & 0.480 & & \\
\hline SB2 & $0.800 * * *$ & 0.360 & & \\
\hline SB3 & $0.815^{* * *}$ & 0.336 & & \\
\hline SB4 & $0.753^{* * *}$ & 0.433 & & \\
\hline SB5 & $0.765 * * *$ & 0.415 & & \\
\hline Satisfaction & & & 0.874 & 0.636 \\
\hline Sat1 & $0.849 * * *$ & 0.279 & & \\
\hline Sat2 & $0.839 * * *$ & 0.296 & & \\
\hline Sat3 & $0.792 * * *$ & 0.373 & & \\
\hline Sat4 & $0.699 * * *$ & 0.511 & & \\
\hline Usage Intention & & & 0.920 & 0.699 \\
\hline UI1 & $0.856^{* * * *}$ & 0.267 & & \\
\hline UI2 & $0.775^{* * *}$ & 0.399 & & \\
\hline UI3 & $0.797 * * *$ & 0.365 & & \\
\hline UI4 & $0.856^{* * *}$ & 0.267 & & \\
\hline UI5 & $0.892 * * *$ & 0.204 & & \\
\hline
\end{tabular}

Note: UV: Utilitarian HV: Hedonic SB: Salesperson Behaviors US: Usage ***; $p<0.001$.

Table 4. Correlation matrix for measurement scales.

\begin{tabular}{cccccc}
\hline Constructs & Utilitarian Value & Hedonic Value & Salesperson Behaviors & Satisfaction & Usage Intention \\
\hline Utilitarian Value & 0.817 & & & & \\
Hedonic Value & 0.214 & 0.823 & & & \\
Salesperson & 0.132 & 0.166 & 0.773 & 0.797 & \\
Behaviors & 0.520 & 0.231 & 0.227 & 0.376 & 0.836 \\
Satisfaction & 0.356 & 0.572 & 0.284 & \\
Usage Intention &
\end{tabular}

\subsection{Model Fitness Analysis and Results}

The results of the basic fit criteria are that the error variance of the theoretical model is not negative, the load of standardization factors is not less than 0.50 or more than 0.95 , and all of them reach a significant level, and no higher standard errors are found (see Table 5). Therefore, the basic fitness of the research model should reach an acceptable level. The absolute fit measure index of the overall fitness of the model is as follows: $\chi^{2}=556.336$, d.f. $=265$, GFI $=0.908$, AGFI $=0.887$. Except that AGFI is slightly lower than the standard, various indices are in the criteria, and the index of incremental fit: NFI $=0.926, \mathrm{CFI}=0.908$, both within the acceptable range; the brief fit measurement index is: PNFI $=0.818$, PGFI $=0.740$, both within the acceptable range $(>0.500)$. On the whole, judging from all indices, in this study, the overall fitness of the theoretical model is good. 
The significance of the internal structural fitness of the model in evaluating this model's parameters, and the reliability of the indices and potential variables, can evaluated from whether the CR of the potential variables is above 0.70 , whether the AVE of the potential variables is above 0.5 , or whether the Individual Item Reliability is above the acceptable level of 0.5. Both the CR and AVE reach the standard value. On the whole, the evaluation results of the CR and AVE of potential variables show that this study's theoretical model has great fitness of internal structure.

Table 5. Standard coefficients and significance values.

\begin{tabular}{cccccc}
\hline & Paths & & Path Coefficients & Hypotheses & Test Results \\
\hline Utilitarian Value & $\rightarrow$ & Satisfaction & $0.624^{* * *}$ & H1 & Supported \\
Hedonic Value & $\rightarrow$ & Satisfaction & $0.136^{* *}$ & H2 & Supported \\
Salesperson Behaviors & $\rightarrow$ & Satisfaction & $0.320^{* * *}$ & H3 & Supported \\
Utilitarian Value & $\rightarrow$ & Usage Intention & $0.173^{* *}$ & H4 & Supported \\
Hedonic Value & $\rightarrow$ & Usage Intention & $0.528^{* *}$ & H5 & Supported \\
Salesperson Behaviors & $\rightarrow$ & Usage Intention & $0.245^{* *}$ & Hupported & H7 \\
Satisfaction & $\rightarrow$ & Usage Intention & $0.130^{* *}$ & & Supported \\
\hline & & Note: ${ }^{* *} ; p<0.001 ; * * ;<0.005$. & &
\end{tabular}

\subsection{Mediation Effect Analysis}

There are three mediating effects in this study. Customers' satisfaction has a mediating effect on the mobile payment usage intention and the utilitarian value. Customers' satisfaction has a mediating effect on hedonic value and mobile payment usage intention. Customers' satisfaction has a mediating effect on salesperson selling behaviors and mobile payment usage intention.

In this study, the results of the Sobel test show that the result of values of this Sobel test are all greater than 1.96 (Sobel, 1982), and that all 95\% confidence intervals for 5000 simulation analyses through Bootstrapping analysis did not include 0 (Efron and Tibshirani, 1993) [73,74]. The study indicates that customer satisfaction has significant impacts on utilitarian value, hedonic value, salesperson selling behaviors and mobile payment usage intention (see Table 6).

Table 6. Sobel test and bootstrapping confidence interval of mediator effects.

\begin{tabular}{cccccccc}
\hline \multirow{2}{*}{ IV } & \multirow{2}{*}{ M } & \multirow{2}{*}{ DV } & Sobel Test & \multicolumn{3}{c}{ Bootstrapping 95\%Confidence I } \\
\cline { 5 - 7 } & & & & Percentile CI & \multicolumn{2}{c}{ Biased Method CI } \\
\cline { 4 - 7 } & & & & Lower & Upper & Lower & Upper \\
\hline UV & PS & UI & 4.683 & 0.077 & 0.189 & 0.075 & 0.201 \\
HV & PS & UI & 3.898 & 0.032 & 0.0954 & 0.0351 & 0.117 \\
SSB & PS & UI & 3.9787 & 0.0516 & 0.1515 & 0.0548 & 0.513 \\
\hline
\end{tabular}

\section{Conclusions and Suggestions}

\subsection{Conclusions}

Empirical research shows that consumers' utilitarian value, hedonic value and salesperson selling behaviors positively affect customers' satisfaction, and Utilitarian value is considered to be an assessment of all the utilitarian costs and benefits. Hedonic value refers to the emotions about products, services and activities generated on the basis of hedonic activities, focusing on the experiences of the product purchasing process. For the first purpose, we can find that customer perceived value which comprises hedonic value and utilitarian value, also salesperson selling behaviors, all have positive impacts on customer satisfaction.

When people use mobile payment, they also enjoy the pleasure of consumption. The salesperson will explain the usage of mobile payment according to consumers' perception and will operate it to show to consumers. When consumers feel the behavior of the salesperson, their satisfaction will be 
relatively improved. Therefore, the perceived value which comprises hedonic value and utilitarian value and salesperson selling behavior has positively affected customers' satisfaction. In the part of customer satisfaction, this study finds that consumers' utilitarian value, hedonic value and salesperson selling behavior have positive impacts on customer satisfaction. This shows that customers tend to attach more importance to the acquisition of immediate benefits.

Many customers think that they will feel the existence of individual uniqueness at the moment of mobile payment, making them feel different from others, which will lead to the improvement of customer satisfaction. In terms of salesperson selling behavior, it can be clearly found that when consumption is made through mobile payment, the salesperson's introduction and assistance in actual operation will greatly improve customer satisfaction and will make the customers more likely to use mobile payment and consider mobile payment as one of the most critical options for payment. In short, when customers use the mobile payment function and consume through mobile payment, they will understand the satisfaction brought by mobile payment, and have relatively greater intention to use mobile payment. Consumer's perceived value, which comprises hedonic value and utilitarian value, comes from their perception. When consumers feel the convenience and happiness brought on by mobile payment, or feel the good performance of salesmen in the operation process, they will have greater intention to use mobile payment during consumption.

Therefore, operators can make use of the utilitarian value or hedonic value of mobile payment to create topics, encourage consumers to use mobile payment in consumption, and make use of the explanations of salesmen to make consumers more willing to use mobile payment. The mediating mechanism of customer satisfaction can assist the consumers' hedonic value and utilitarian value, the salesperson selling behaviors and the mobile payment usage intention.

The study finds that customer perceived value (utilitarian and hedonic) and salesperson selling behaviors can improve customer usage intention through customer satisfaction. It means that when promoting mobile payment products, the sellers shall first make customers free from vigilance towards the usage of mobile payment, so that customers can slowly tend towards mobile payment. In addition, they shall explain the mobile payment functions to customers. After trying the usage of mobile payment, customers can understand the convenience of mobile payment and experience the pleasant atmosphere brought by new payment means. In addition, if there is a salesperson to guide them, it can reduce customers' doubts about mobile payment and increase their mobile payment usage intention. Therefore, customer perceived value and salesperson selling behaviors can increase mobile payment usage intention through customer satisfaction.

\subsection{Suggestions}

1. Stores can share free Internet or WIFI and improve the security of mobile network transmission. Many consumers are less willing to use mobile payment because they do not have access to the Internet, or the signal is very weak during their consumption.

2. Business operators can adopt cross-industry alliances to provide more diversified and preferential promotion programs or lottery activities. Consumers will be more willing to use mobile payment if they can enjoy promotion programs together with lottery activities in consumption.

3. Business operators can strengthen the promotion and marketing of mobile payment through online social media. To popularize mobile payment, in addition to the cooperation and promotion of government policies, businesses operators can strengthen the promotion and marketing of mobile payment through online social media. The study finds that salesperson performance is significantly correlated with satisfaction. Because the mobile payment function is more reliable and faster, it is recommended that the company can regularly hold employee on-the-job training, so that employees can immediately operate it to reduce customers' waiting time. This study adopts the cross-section method, and that may be this study's main limitation, so it is only based on observing the data at a certain point in time as the basis for inference and verification. Therefore, it is impossible to understand 
the relationship between variables in the longitudinal section, and the inference and development of causality have limitations.

Author Contributions: Conceptualization and data curation: S.-C.C., formal analysis and methodology: K.C.C., writing-review and editing: M.Y.T.

Funding: This research received administrative and funding support from a project of Ministry of Education, R.O.C., Taiwan.

Conflicts of Interest: The authors declare no conflict of interest.

\section{References}

1. Institute for Information Industry. Taiwanese People Are More Sticky Phones! Nearly $80 \%$ of the People Use Mobile Phones Every Day for More Than 2 Hours. 2018. Available online: https://www.iii.org.tw/Press/ NewsDtl.aspx?nsp_sqno=2081\&fm_sqno=14 (accessed on 1 December 2018).

2. Statista. The Key to Mobile Payment and Electronic Payment. 2018. Available online: https://www.statista. com/study/39303mobile-payment-usage-worldwide/ (accessed on 2 December 2018).

3. Institute for Information Industry. Nearly $40 \%$ of Mobile Phone Users Have Used Mobile Payment Line Pay, Apple Pay Has the Highest Awareness. 2018. Available online: https://mic.iii.org.tw/news.aspx?id=486 (accessed on 1 December 2018).

4. Al-Sabbahy, H.Z.; Ekinci, Y.; Riley, M. An investigation of perceived value dimensions: Implications for hospitality research. J. Travel Res. 2004, 42, 226-234. [CrossRef]

5. Kulviwat, S.; Bruner, G.C.; Kumar, A.; Nasco, S.A.; Clark, T. Toward a unified theory of consumer acceptance technology. Psychol. Mark. 2007, 24, 1059-1084. [CrossRef]

6. Lee, C.P.; Warkentin, M.; Choi, H. The role of technological and social factors on the adoption of mobile payment technologies. In Proceedings of the 10th Americas Conference on Information Systems (AMCIS 2004), New York, NY, USA, 6-8 August 2004; pp. 2781-2786.

7. Lee, M.; Kim, Y.; Fairhurst, A. Shopping value in online auctions: Their antecedents and outcomes. J. Retail. Consum. Serv. 2009, 16, 75-82. [CrossRef]

8. Sharma, A. Does the salesperson like customers? A conceptual and empirical examination of the persuasive effect of perceptions of the salesperson's affect toward customers. Psychol. Mark. 1999, 16, 141-162. [CrossRef]

9. Wang, Y.S. Assessing e-commerce systems success: A respecification and validation of the DeLone and McLean model of IS success. Inf. Syst. J. 2008, 18, 529-557. [CrossRef]

10. Emarketer. 2018. Available online: https://www.emarketer.com/content/emarketer-releases-new-globalproximity-mobile-payment-figures (accessed on 1 December 2018).

11. Qin, Z.; Sun, J.; Wahaballa, A.; Zheng, W.; Xiong, H. A secure and privacy preserving mobile wallet with outsourced verification in cloud computing. Comput. Stand. Interfaces 2017, 54, 55-60. [CrossRef]

12. Kim, C.; Mirusmonov, M.; Lee, I. An empirical examination of factors influencing the intention to use mobile payment. Comput. Hum. Behav. 2010, 26, 310-322. [CrossRef]

13. Qasim, H.; Abu-Shanab, E. Drivers of mobile payment acceptance: The impact of network externalities. Inf. Syst. Front. 2015, 8, 1-14. [CrossRef]

14. Morosan, C.; DeFranco, A. It's about time: Revisiting UTAUT2 to examine consumers' intentions to use NFC mobile payments in hotels. Int. J. Hosp. Manag. 2016, 53, 17-29. [CrossRef]

15. Mehrabian, A.; Russell, J.A. An Approach to Environmental Psychology; MIT Press: Cambridge, MA, USA, 1974.

16. Jacoby, J. Stimulus-organism-response reconsidered: An evolutionary step in modeling (consumer) behavior. J. Consum. Psychol. 2002, 12, 51-57. [CrossRef]

17. Chan, T.K.; Cheung, C.M.; Lee, Z.W. The state of online impulse-buying research: A literature analysis. Inf. Manag. 2017, 54, 204-217. [CrossRef]

18. Chang, H.J.; Eckman, M.; Yan, R.N. Application of the stimulus-organism-response model to the retail environment: The role of hedonic motivation in impulse buying behavior. Int. Rev. Retail 2011, 21, 233-249. [CrossRef]

19. Hossain, M.S.; Zhou, X. Impact of m-payments on purchase intention and customer satisfaction: Perceived flow as mediator. Int. J. Sci. Bus. 2018, 2, 503-517.

20. Scarpi, D. Hedonic and utilitarian behaviour in specialty shops. Mark. Rev. 2005, 5, 31-44. [CrossRef] 
21. Babin, B.J.; Darden, W.R.; Griffin, M. Work and/or Fun: Measuring hedonic and utilitarian shopping value. J. Consum. Res. 1994, 20, 644-656. [CrossRef]

22. Ryu, K.; Han, H.; Jang, S. Relationships among hedonic and utilitarian values, satisfaction and behavioral intentions in the fast-casual restaurant industry. Int. J. Contemp. Hosp. Manag. 2010, 22, 416-432. [CrossRef]

23. Overby, J.W.; Lee, E.J. The effects of utilitarian and hedonic online shopping value on consumer preference and intentions. J. Bus. Res. 2006, 59, 1160-1166. [CrossRef]

24. Lowe, B.; Alpert, F. Forecasting consumer perception of innovativeness. Technovation 2015, 45-46, 1-14. [CrossRef]

25. Jong, U.K.; Woong, J.K.; Sang, C.P. Consumer perceptions on Web advertisements and motivation factors to purchase in the online shopping. Comput. Hum. Behav. 2010, 26, 1208-1222.

26. Roy, R.; Ng, S. Regulatory focus and preference reversal between hedonic and utilitarian consumption. J. Consum. Behav. 2012, 11, 81-88. [CrossRef]

27. Soman, D.T. The effect of payment transparency on consumption: Quasi-experiments from the field. Mark. Lett. 2003, 14, 173-183. [CrossRef]

28. Raghubir, P.; Srivastava, J. Monopoly money: The effect of payment coupling and form on spending behavior. J. Exp. Psychol. Appl. 2008, 14, 213-225. [CrossRef] [PubMed]

29. Chatterjee, P.; Rose, R.L. Do payment mechanisms change the way consumers perceive products? J. Consum. Res. 2012, 38, 1129-1139. [CrossRef]

30. Chitturi, R.; Raghunathan, R.; Mahajan, V. Form versus function: How the intensities of specific emotions evoked in functional versus hedonic trade-offs mediate product preferences. J. Mark. Res. 2007, 44, 702-714. [CrossRef]

31. Chitturi, R.; Raghunathan, R.; Mahajan, V. Delight by design: The role of hedonic versus utilitarian benefits. J. Mark. 2008, 72, 48-63. [CrossRef]

32. Jones, E.; Brown, S.P.; Zoltners, A.A.; Weitz, B.A. The changing environment of selling and sales management. J. Pers. Sell. Sales Manag. 2005, 25, 105-110.

33. Price, L.L.; Arnould, E.J.; Deibler, S.L. Consumers' emotional responses to service encounters: The influence of the service provider. Int. J. Serv. Ind. Manag. 1995, 6, 34-63. [CrossRef]

34. Siu, N.Y.M.; Cheung, J.T. A measure of retail service quality. Mark. Intell. Plan. 2001, 19, 88-97. [CrossRef]

35. Ahearne, M.; Jelinek, R.; Jones, E. Examining the effect of salesperson service behavior in a competitive context. J. Acad. Mark. Sci. 2007, 35, 603-616. [CrossRef]

36. Darian, J.C.; Wiman, A.R.; Tucci, L.A. Retail patronage intentions: The relative importance of perceived prices and salesperson service attributes. J. Retail. Consum. Serv. 2005, 12, 15-23. [CrossRef]

37. Johnson, M.S.; Sivadas, E.; Kashyap, V. Response bias in the measurement of salesperson orientations: The role of impression management. Ind. Mark. Manag. 2009, 38, 1014-1024. [CrossRef]

38. Rapp, A.; Bachrach, D.G.; Panagopoulos, N.; Ogilvie, J. Salespeople as knowledge brokers: A review and critique of the challenger sales model. J. Pers. Sell. Sales Manag. 2014, 34, 245-259. [CrossRef]

39. Lee, S.; Dubinsky, A. Influence of salesperson characteristics and customer emotion on retail dyadic relationships. Int. Rev. Retail Distrib. Consum. Res. 2003, 13, 23-36. [CrossRef]

40. Fishbein, M.; Ajzen, I. Belief, Attitude, Intention, and Behavior: An Introduction to Theory and Research; Addison-Wesley: Boston, MA, USA, 1975.

41. Fishbein, M.; Ajzen, I. Understanding Attitudes and Predicting Social Behavior; Prentice-Hall: Englewood Cliffs, NJ, USA, 1980.

42. Zeithaml, V.A.; Berry, L.L.; Parasuraman, A. The behavioral consequences of service quality. J. Mark. 1996, 60, 31-46. [CrossRef]

43. Taylor, S.; Todd, P.A. Understanding information technology usage: A test of competing models. Inf. Syst. Res. 1995, 6, 144-176. [CrossRef]

44. Zhang, X.; Prybutok, V.R. A consumer perspective of e-service quality. IEEE Trans. Eng. Manag. 2005, 52, 461-477. [CrossRef]

45. Lin, C.P.; Huang, H.N.; Joe, S.W.; Ma, H.C. Learning the determinants of satisfaction and usage intention of instant messaging. Cyber Psychol. Behav. 2008, 11, 262-267. [CrossRef] [PubMed]

46. Shin, D.H. Towards an understanding of the consumer acceptance of mobile wallet. Comput. Hum. Behav. 2009, 25, 1343-1354. [CrossRef] 
47. Turel, O.; Serenko, A.; Bontis, N. User acceptance of wireless short messaging services: Deconstructing perceived value. Inf. Manag. 2007, 44,63-73. [CrossRef]

48. DeSarbo, W.S.; Jedidi, K.; Sinha, I. Customer value analysis in a heterogeneous market. Strateg. Manag. J. 2001, 22, 845-857. [CrossRef]

49. Terpstra, M.; Verbeeten, F.H.M. Customer satisfaction: Cost driver or value driver? Empirical evidence from the financial services industry. Eur. Manag. J. 2014, 32, 499-508. [CrossRef]

50. Eggert, A.; Ulaga, W. Customer perceived value: A substitute for satisfaction in business markets. J. Bus. Ind. Mark. 2002, 17, 107-118. [CrossRef]

51. Hsu, H. An empirical study of web site quality, customer value, and customer satisfaction based on e-shop. Bus. Rev. 2006, 5, 190-193.

52. Oliver, R.L. Satisfaction: A Behavioral Perspective on the Consumer; Routledge: New York, NY, USA, 2014.

53. Yoo, W.S.; Lee, Y.; Park, J. The role of interactivity in e-tailing: Creating value and increasing satisfaction. J. Retail. Consum. Serv. 2010, 17, 89-96. [CrossRef]

54. Amyx, D.; Bhuian, S. Salesperf: The salesperson service performance scale. J. Pers. Sell. Scdes Manag. 2009, 29, 367-376. [CrossRef]

55. Román, S.; Juan Martín, P. Does the hierarchical position of the buyer make a difference? The influence of perceived adaptive selling on customer satisfaction and loyalty in a business-to-business context. J. Bus. Ind. Mark. 2014, 29, 364-373. [CrossRef]

56. Román, S.; Iacobucci, D. Antecedents and consequences of adaptive selling confidence and behavior: A dyadic analysis of salespeople and their customers. J. Acad. Mark. Sci. 2009, 38, 363-382. [CrossRef]

57. Bridges, E.; Florsheim, R. Hedonic and utilitarian shopping goals: The online experience. J. Bus. Res. 2008, 61, 309-314. [CrossRef]

58. Pihlstrom, M.; Brush, G.J. Comparing the perceived value of information and entertainment moible services. Psychol. Mark. 2008, 25, 732-755. [CrossRef]

59. Pilling, B.K.; Eroglu, S. An empirical examination of the impact of salesperson empathy and professionalism and merchandise slability on retail buyers evaluations. J. Pers. Sell. Sales Manag. 1994, 14, 45-58.

60. Kennedy, M.S.; Ferrell, L.K.; LeClair, D.T. Consumers' trust of salesperson and manufacturer: An empirical study. J. Bus. Res. 2001, 51, 73-86. [CrossRef]

61. Haas, A.; Kenning, P. Utilitaria and hedonic motivators of shoppers' decision to consult with salespeople. J. Retail. 2014, 90, 428-441. [CrossRef]

62. Sun, T.R.; Yazdanifard, R. Review of physical store factors that influence impulsive buying behavior. Int. J. Manag. Account. Econ. 2015, 2, 1048-1054.

63. Chea, S.; Luo, M.M. Post-adoption behaviors of e-service customers: The interplay of cognition and emotion. Int. J. Electron. Commer. 2008, 12, 29-56. [CrossRef]

64. Anderson, E.W.; Sullivan, M.W. The antecedents and consequences of customer satisfaction for firms. Mark. Sci. 1993, 12, 125-143. [CrossRef]

65. Gotlieb, J.B.; Grewal, D.; Brown, S.W. Consume. satisfaction and perceived quality: Complementary or divergent constructs? J. Appl. Psychol. 1994, 79, 875-885. [CrossRef]

66. Chou, S.W.; Min, H.T.; Chang, Y.C.; Lin, C.T. Understanding continuance intention of knowledge creation using extended expectation-confirmation theory: An empirical study of Taiwan and China online communities. Behav. Inf. Technol. 2010, 29, 557-570. [CrossRef]

67. Chen, S.C.; Yen, D.C.; Hwang, M.I. Factors influencing the continuance intention to the usage of Web 2.0. Comput. Hum. Behav. 2012, 28, 933-941. [CrossRef]

68. Chen, J.H.; Fu, J.R. On the effects of perceived value in the mobile moment. Electron. Commer. Res. Appl. 2018, 27, 118-128. [CrossRef]

69. Escobar-Rodríguez, T.; Carvajal-Trujillo, E. Online purchasing tickets for low cost carriers: An application of the unified theory of acceptance and use of technology (UTAUT) model. Tour. Manag. 2014, 43, 70-88. [CrossRef]

70. Schierz, P.G.; Schilke, O.; Wirtz, B.W. Understanding consumer acceptance of mobile payment services: An empirical analysis. Electron. Commer. Res. Appl. 2010, 9, 209-216. [CrossRef]

71. Gaski, J.F.; Nevin, J.R. The differential effects of exercised and unexercised power sources in a marketing channel. J. Mark. Res. 1985, 22, 130-142. [CrossRef] 
72. Fornell, C.R.; Larcker, F.F. Structural equation models with unobservable variables and measurement error. J. Mark. Res. 1981, 18, 39-51. [CrossRef]

73. Sobel, M.E. Asymptotic confidence intervals for indirect effects in structural equation models. Sociol. Methodol. 1982, 13, 290-312. [CrossRef]

74. Efron, B.; Tibshirani, R.J. An Introduction to the Bootstrap; Chapman and Hall: London, UK, 1993.

(c) (1) BY
(C) 2019 by the authors. Licensee MDPI, Basel, Switzerland. This article is an open access article distributed under the terms and conditions of the Creative Commons Attribution (CC BY) license (http://creativecommons.org/licenses/by/4.0/). 
Article

\title{
Evaluation and Classification of Mobile Financial Services Sustainability Using Structural Equation Modeling and Multiple Criteria Decision-Making Methods
}

\author{
Komlan Gbongli ${ }^{1, *}$, Yongan $\mathrm{Xu}{ }^{2, *}$, Komi Mawugbe Amedjonekou ${ }^{3}$ and Levente Kovács ${ }^{1}$ \\ 1 Institute of Finance and Accounting, Faculty of Economics, University of Miskolc, 3515 \\ Miskolc-Egyetemvaros, Hungary; kovacs.levente@uni-miskolc.hu \\ 2 School of International Business, Southwestern University of Finance and Economics, 55 Guanghuacun \\ Street, Qingyang District, Chengdu 610074, China \\ 3 Business School, York St John University, Lord Mayor's Walk, York Y031 7EX, UK; \\ komi.amedjonekou@yorksj.ac.uk \\ * Correspondence: samxp12@yahoo.fr or pzkgbong@uni-miskolc.hu (K.G.); xyan88@swufe.edu.cn (Y.X.)
}

Received: 23 December 2019; Accepted: 5 February 2020; Published: 11 February 2020

\begin{abstract}
Despite the fast emergent of smartphones in day-to-day activity, the sustainable development of mobile financial services (MFS) remains low partially due to online consumer's trust and perceived risk. This research broadens the trust and the perceived risk at the multi-dimensional for understanding and prioritizing alternatives of MFS decision. A combined methodology; structural equation modeling (SEM) with two multiple criteria decision-making (MCDM) methods such as a technique for order of preference by similarity to ideal solution (TOPSIS) and analytic hierarchy process (AHP) were applied for data analysis. The two steps SEM-TOPSIS techniques were adopted through a two-types survey on datasets consisting of 538 MFS users, and 74 both experienced MFS users and experts in Togo. The SEM is used for causal relationships and assigning weights for the TOPSIS input. TOPSIS was applied for providing MFS alternative classification, in which the results were compared with prior research using the SEM-AHP technique on the given population. The results via SEM revealed particularly strong support for the dispositional trust and perceived privacy risk. Trust has a negative relationship with perceived risk. Except for perceived time risk, all the antecedents of perceived risk and trust validated the proposed relationship. The findings of TOPSIS uncovered that mobile money transfer (MMT) remains the core application used, followed by mobile payment (MP) and mobile banking (MB) and, therefore, consistent with AHP. However, the TOPSIS technique is better suited to the problem of MFS selection for this study field. This research offers a novel and practical modeling and classification concept for researchers, companies' managers, and experts in the areas of information technology. The implications, limitations, and future research are provided.
\end{abstract}

Keywords: mobile financial services (MFS); trust; perceived risk; structural equation modeling (SEM); multiple-criteria decision-making (MCDM); technique for order preference by similarity to ideal solution (TOPSIS); analytic hierarchy process (AHP)

\section{Introduction}

As a part of the shift of technology in the financial business, mobile financial services have been exploring at an accelerate speed [1]. Innovations and technological expansion have emerged with significant advantages to the recent commercial market. Over the past few years, businesses have been redirecting their goals to making information system technology an essential part of their processes [2]. Therefore, more and more literature is diverted to the IS-related field [3]. The investigation of some 
existing studies which recommend integrating various theoretical models to understand the IT adoption has stressed that a comprehensive analysis in the context is required [2,4]. From these perspectives, an increasing number of researchers are focused on mobile financial services (MFS) considered as the development of the information system (IS) domain [5-8].

MFS refers to any financial transaction remotely conducted by the application of a mobile phone (e.g., smartphone or tablet) and mobile software (e.g., apps programs) either through banking service or network provider service $[9,10]$. MFS providers allow their consumers the flexibility to access their financial services (access information inquiry, bill payment, and money transfers) anywhere and anytime via a mobile phone, to support and improve service relationships by investing lots of resources using wireless Internet technology [11].

The studies of MFS that emphasized on electronic money transfer include three major mobile technologies-related fields of study, primarily mobile banking services (MB), mobile payment services (MP), and mobile money transfer (MMT) services [10]. MB remains part of the latest in a sequence of new mobile technological wonders [12]. Therefore, an expectation toward it should be for a significant impact on the market [13]. Payment today has now progressed to mobile devices (m-devices) identified as mobile financial services, particularly mobile payments [14]. Mobile money has appeared as a significant innovation with a potential expansion to financial inclusion in developing countries in various ways [15]. It is, therefore, growing access to financial services for a large number of people, who are entirely disregarded by banks because of longer travel distances or insufficient funds to fulfill the minimum deposit recommended for opening account in a bank [16,17], low-income population in developing countries [18], insofar, as it has several advantages $[15,19,20]$. In addition to the advantages granted to certain persons and companies, there are also advantages at the national economy level, primarily in emerging economies such as Hungary. The use of increasingly more accommodating tools may incentivize the suppressed use of cash, parallel to which, the countability of economic performance with statistical instruments continues to improve; meanwhile tax payment discipline also improves and the total social cost of payments decreases, etc., that is, overall the economy begins to whiten, leading to improved competitiveness [21].

While tremendous benefits are associated with adopting MFS as opposed to traditional payment methods, such as physical exchange notes, cheques, coins [18], the adoption rate is far from full utilization in many developing countries. This is characteristically the situation of West African Countries and particularly Togo. Given the statistical information on the Statista Portal (2016), the population using smartphones worldwide is predicted to be over five billion marks in 2019. Approximately $67 \%$ of the Togolese population subscribed to the mobile phone in 2015 , while users of mobile Internet doubled between 2014 and 2015. However, the percentage rate of users of banking services is less than 15\% [22] and, the rate of consumer acceptance of mobile banking remains trivial (around 1\%) when considering the expectation [23]. It is, therefore, leading to deduct that mobile money services should fill this lacuna by providing significant input to increase the acceptance of MFS. This hope is far from being the case. The experiences of more developed countries also suggest the same, not technological limitations were the primary obstacle of the extension of the innovative payment solutions [24]. Therefore, the motives for the successful evolution or not together with the causes and motives for mobile money adoption, remain not understood sufficiently, which infers that the technology has not been extensively adopted. These trends reveal partial knowledge regarding the motivators and inhibitors that impact the acceptance of this mobile service [25].

Understanding why it is worth to select to use MFS can help in strategy development and allow businesses to effectively communicate benefits to their customers [26,27]. Mobile financial service operators might increase their attractiveness and competitiveness if they were able to enhance their strategies to satisfy the demand of their consumers. Therefore, there is a necessity of understanding the various requirements of MFS users and the comparative weight of each factor or criteria that could affect the demand of consumers. One possible motive for the existence of a gap between these could be the perception of risk that limits consumers' capability to make informed decisions to partake 
the benefit of MFS technology in Togo [28]. This is particularly true for emerging nations, mainly in an unstable country where the consideration of the loss of privacy in the security system and the associated risk played a crucial part in adopting IT [29]. Moreover, the studies in the past revealed that once there are risk issue concerns, the demand for trust becomes a necessity, since trust and risk are interrelated facets $[28,30]$. Not only the developing countries facing the issue of e-business but also the reflection of the online risk has called for a considerable attention among the developed countries like Hungary, particularly in 2014 when the case of fraud risk in electronic payment transactions ascended in Hungary (the case was discussed in the work of Kovács and David in detail [31]).

Driven by studies toward the multiple scopes for risk and trust and the central research on trust in contrast to risk in novel information technology perspective [32], we suppose that initiating research into novel IT artifacts such as this research could enlighten how trust and perceived risk could influence the ultimate adoption of novel technologies in developing countries.

The goal of this study is to disclose mechanisms related to behavior associated with MFS adoption and sustainable development when decision-making involves multiple criteria issues. One main research question is to understand how multi-dimensional trust and multi-faceted perceived risk perceptions affect a new emerging information technology such as MFS adoption at the individual level in an unstable country. Our approach differs from most prior studies that assess trust and risk perception of individual behavior. Indeed, most of the research that investigated the acceptance and application of communicative IT has been done within stable, capitalist, and highly-developed communities. Moreover, the majority of research undertakes that individuals have freedom of speech, and safety of their lives, basic protection and business offered by the government. However, little has been known regarding the adoption of IT in emerging and dynamic societies [33,34]. Therefore, we explore the fundamental trust and risk allied with MFS technology usage in high poverty.

The majority of prior research typically tests trust as a single construct [35-37] or investigates trust constructs and risk dimensions disjointedly [27,38]. In other words, how to effectively assess trust and risk concerns concurrently remains a black box. Drawing on research in information technology [39,40], we stress that multi-dimensional trust and perceived risk concepts may jointly play an integral part in individual behavior with regard to adopting a novel MFS, and it is of paramount importance for this to be investigated, particularly in developing countries such as Togo.

Furthermore, a plethora of research has been done in order to fully understand the factors that affect MFS adoption and its significance. However, most prior studies in this perspective have emphasized the general factors regarding the adoption of MFS, using explanatory statistical analysis as the research method [41,42]. The beta coefficients gained in multiple regression techniques can be considered as the relative weights of the constructs, however, their values are obtained indirectly via the testing result. Additionally, a negative value of beta can be found, making it quite complex for the justification of the importance of the resultant value [43]. Making decisions has continually been an essential activity in day to day life. Therefore, using services such as MFS necessitates a careful decision from an individual so that he/she would not regret his/her decision, ever since decision-making has emerged as a mathematical science today [44]. From there, multiple criteria decision-making (MCDM) techniques constitute a critical framework through which companies focus on which strategy to implement to meet the needs of consumers, to acquire the appropriate income, and to prosper in the competitive milieu [45].

In order to advance current IS researches, Esearch and Koppius [46] stressed that there is a necessity to integrate decision modeling methods in IS research to generate data estimates as well as methods for assessing the analytical power of the result. Therefore, applying a combined analytic method stressed how integrating two or multiple data analysis techniques in either methodology or investigation can patronize the confidence and validity in the resulting outcome [15,47]. Additionally, most managers make strategic decisions based on a single goal or dimension, but strategic planning is impacted by many different factors and regarded from several perspectives [48]. As the traditional notion of strategic planning lacks multidimensional prominence, this paper integrates the structural 
equation modeling and technique for order preference by similarity to ideal solution (SEM-TOPSIS) method to construct the relationships between decision factors for MFS adoption, while classifying the alternative of MFS. It is a unique decision support technique grounded in structural modeling.

The primary objectives of this research are: To explore the influential antecedent of trust and risk perception at the multidimensional level regarding MFS adoption in Togo; to propose and validate model MFS acceptance using an SEM technique by employing data collected through experts of MFS and MFS experienced users; to develop an SEM-TOPSIS-based model for multi-criteria decision-making by selecting the appropriate MFS type for MFS, grounded in experts' view, and by prioritizing the operative trust-risk factors while exposing the veiled relationship among the factors that influence customers in the MFS. The present study has the following contributions.

Primarily, a growing number of recent studies link the multiple criteria decision-making (MCDM) techniques to financial decision making [49]. In the majority of cases, the traditional model of MCDM considers the criteria (factors) are independently and hierarchically organized. Nevertheless, problems are often organized by interdependent criteria and dimensions and might even reveal feedback-like effects [50]. TOPSIS is one of the most extensively adopted decision methodologies in technology, engineering, management, science, and business. TOPSIS approaches, as part of MCDM, have an impact on improving the quality of decisions by generating the development more efficient, rational, and explicit. However, previous works have not sufficiently kept pace. Thus, we believe that there is a necessity for the methodical integration of SEM-TOPSIS to merge a recent study performed in this field of study. This study incorporates a complex multi-criteria decision-making problem by assessing types of multidimensional trust and risk in MFS that have rarely been investigated and touched in past studies. As such, a literature review is conducted, and then SEM analysis is used to construct a hierarchical structure for trust and risk factors, which includes a total of ten sub-factors. According to the identified criteria and sub-criteria and by considering relationships among them, TOPSIS is adopted for selecting the appropriate types of MFS, based on the critical factors that influence customers' trust and risk. Hence, the study contributes by proposing a solution that could effectively enhance trust and mitigation-perceived risk measures through a multi-level approach considered as a new added concept to planning strategy from the MFS perspective.

Second, one of the contributions of this research is based on the comparison of the results of both TOPSIS and analytical hierarchical process (AHP) technique, for a given model, to inspect if there are, indeed, noteworthy differences. The result of AHP is derived from the earlier work of Gbongli [10] in which the SEM-AHP technique has been applied for assessing the issues of risk and trust using the specified population. Similarly, the main work is derived from previous work in which SEM-TOPSIS has been extensively adopted on the equal given population [51]. As a result, this study shows that both approaches achieved comparable results and were well consistent and, in general, agreed with each other. In other words, both methods classify mobile money services as the most important MFS used, followed by mobile payment as the second and mobile banking as the last. However, the TOPSIS method is better suited to the problem of MFS selection for this study area since AHP requires a long process of pairwise comparison, and the requirement of the consistency ratio should also be considered in the process. The paper provides a detailed methodology application that could provide very useful insights for managers and researchers for their specific application.

The remainder of this paper is structured as follows. In Section 2, we offer a succinct overview of the literature and theory review. For Section 3, we present the theoretical framework. In Section 4, the description of the research methodology and the procedure of this research are presented. Section 5 provides findings based on the research objectives. We conclude the work with discussions of the findings, implications, limitations, and future study suggestions. 


\section{Literature and Theory Review}

\subsection{Understanding Mobile Financial Services (MFS)}

The rapid adoption of mobile devices in developing countries [52], together with widespread mobile financial services, has recently drawn practitioners and academics' attention [53]. Since consumers are spending gradually more and more time in online and are "going mobile," financial digitalization is now driving banks and network companies' providers to undertake the most extensive transition in their history. Mobile financial services (MFS) denotes the financial services and financial transactions performed using the channel such as mobile devices [54].

MFS characterizes an area of innovation and strategic importance for global initiatives to counter poverty and mobile telecommunication providers [55]. It has been said to have carried about a positive shift in customers' perceptions in many countries. Mobile operators grasp MFS as an opportunity to engender revenue via an adjacent business (both basic payment and services) and recovery of cost and investments through enlarged data usage by consumers [56]. The goals of MFS are accompanied by various advantages for banks, such as the decreased use of cash, while cost-effectively serving the unbanked population, protecting current accounts and products. The major benefit of MFS regarding trade involves higher point-of-sale (PoS) throughput, real-time messaging to users, and fewer cost for cash handling. Accessing transaction information and ownership of the user interface are further viewed as an important perceived value of MFS. For the customer, MFS makes payments possible anytime, anywhere, and with the alleviated risk of theft (i.e., cash, particularly in underdeveloped communities) [55].

These advantages could be equally valid for Togo. Not much attention has been given to the empirical research on the adoption of MFS in Togo. Furthermore, in less affluent nations stricken with socio-political instability and vulnerability, MFS technologies may have different implications toward usage and are likely to impact the initial decisions to adopt $[57,58]$. The country of Togo sometimes encounters a kind of socio-political crisis. Given a negative socio-political and external influence such as the physical atmosphere of development and growth, policies, regulations, and social environment unsupportive of adoption are suggested to hinder innovation adoption [59]. MFS unavoidability might confront such challenges because of consumers' lack of trust in the novel wireless technology, and their risk perceptions. We thus stress that users' trust and risk perception may impact their adoption of MFS services.

\subsection{Theory and Past Research}

As an emergent service, mobile financial services (MFS) has not been widely adopted by users. Therefore, scholars have paid attention to assess the factors impacting their user adoption. Furthermore, technology adoption is one main area of focus for information systems (IS) researchers. A diversity of theoretical perspectives has been developed to study MFS adoption. More assertively toward another direction, the current literature on consumer behavior related to acceptance of IT, such as MFS, tends to elaborate on a theoretical model of technology adoption theories [60]. They often employ the traditional information system models to explain user adoption of IT like theory of reasoned action (TRA), motivational model, diffusion of innovation theory (DOI), technology acceptance model (TAM), innovation diffusion theory (IDT), theory of planned behavior (TPB), and unified theory of acceptance and use of technology (UTAUT). Numerous studies have employed these traditional frameworks to perform their researches, and the rest integrated either previous models or added new variables to construct models to carry out their study. They examine whether the models' theoretical constructs are likely to affect the consumer acceptance of an MFS [15,61-63] or assess whether consumers are ready to adopt m-payments grounded in the supposed factors [64].

The TRA model stipulates that a particular behavior is directed by the individual's intention to conduct that action, which itself hinges on the attitude to behavior and subjective norms [65]. For the TPB model, the perceived behavior was added to the attitude toward behavior and subjective norms 
that affect both the intentions of people's perceived behavior and actual behavior [66]. Past studies elucidated behavioral perception control as the degree to which one has control over launching a particular behavior as well as facing the circumstances, while the full volitional control over the behavior of interest is found limited [67]. Although their finding pinpointed the internal and external factors of perceived control, as an example, self-efficacy and facilitating condition, technology, and government sustenance, the utmost impact on the behavior is somehow associated with the type of innovation. The TAM model, as the extension to the TRA and TPB models, bears a significance of perceived usefulness and perceived ease of use factor to affect actual behavior geared toward innovation [68]. Based on the review of TAM literature, Marangunić and Granić [69] revealed seven past TAM-related studies. However, the goal of these works and the various analysis techniques adopted differ. For instance, Legris et al. [70] examine the question of whether the TAM explains actual use while Mortenson and Vidgen [71] conducted the review of TAM studies employing the computational literature review (CLR). Moreover, TAM [72] and its extended version has been used in various online milieu to assess the adoption of consumer's online-system [15,73-75].

The TRA model, however, has some drawbacks, comprising a major threat misleading between attitudes and norms because attitudes can commonly be viewed as norms and conversely. Similarly, further explanatory variables are required for TRA [76,77]. As such, TAM has then been successfully combined with TRA and TPB in parsimonious capability [78]. The theory of adoption, such as DOI theory [79], is a handy systemic background to define either adoption or non-adoption of new technology. The theory put forward is that people will be more likely to accept innovation grounded in the innovation facets and appearance of comparative benefit, compatibility, intricacy, trialability, and observability [80]. Regardless of the enlightened strength of this model, the weaknesses go a long way in decreasing its power. For instance, the relationship between attitude and espousal or rejection of innovation was restricted [81,82]; the innovation-decision process and the features of innovation remain unclear as well. The theory posits technology to pass via a linear stage; however, an intricate technology [83] has been perceived not on linear stages. Rendering to the critical review and meta-analysis of TAM [70], it was suggested as a useful model; although, it suffers from the trade-off of dropping information richness resulted from the investigation [84].

Despite the various advantages that might be incorporated into every theory or model, their competency in predicting and elucidating is due to the degree to which the predictor could get a sound proportion of variance explained in intention and usage behavior $[85,86]$. Even though the prevailing models are indicative of e-service or MFS acceptance behavior, many researchers believe that they are not sufficiently robust with regard to assessing all the aspects clients intend obviously throughout the various phases of their decision-making process and thus require further integration [87]. George's findings [88], after the review of previous information acceptance models, revealed that trust consideration could be a major laudatory and backup for an online vendor.

It is important to recall that trust and risk are interrelated facets [30], where the degree of importance of the situation depends on the impending outcome of risk. Given that the adoption of MFS becomes an important decision that consumers are required to make for a long-term impact, the function of risk is more likely to be vital. The extensive review of the literature revealed diverse antecedents to the adoption of mobile banking [27,89-92]. Studies were carried out in both developing and developed countries; however, a limited number have been conducted in Togo $[7,93]$. These outcomes are, therefore, insufficient to offer meaningful insights into predicting which multi-dimensional trust and risk influence customers' use of MFS in Togo while providing a strategy decision analysis framework for understanding the multiple factors that entail the decision of the acceptance. Moreover, many of these theories and models were used in developed countries, and their direct application in developing countries such as Togo might not be sufficiently robust for the economic situation of the country. Given that MFS belongs to information technology to which some adoption model might exist, it requires a distinctive conceptualization that might better pronounce the fact in emerging countries' situations. 
Regarding these ends, this study uses components from both trust and risk dimensionality literature. It proposes conceptual research to envisage consumer appraisal of MFS (mobile banking, mobile payment, and mobile money transfer) adoption in Togo while ranking their perspective.

\section{Theoretical Framework and Hypotheses}

\subsection{Antecedent of Trust}

The concept of trust remains an intricate, multi-dimensional, and context-dependent paradigm [94]. Past researchers emphasize the diverse aspects of trust, a fact that frequently leads to discrepancies between numerous studies outcomes. After the appeal from Gefen et al. [32] for additional new IT-related research on trust, there is a need to collectively assess the most crucial trust's dimension, such as a disposition to trust, technology trust, and vendor trust that seems to impact MFS.

Some scholars have proposed trust dispositional, trust belief, structural assurance [95]. From others' point of view, the interpersonal trust, the dispositional trust, and institutional trust are also essential constituents of the trust dimension [96]. Others found the dimension of trust to be trusting behavior, dispositional to trust, and institution-based trust [97]. Disposition to trust denotes the general susceptibility for a person to trust others [98]. It is grounded in the personality, which explains the reason why some of us have a tendency to either trust or mistrust and doubt others [99,100]. Disposition to trust is, therefore, crucial for the establishment of initial trust and subsequently accommodating to less importance in the presence of pre-existed trust belief [101].

Technology trust is considered as an antecedent of trust. It connotes the readiness of an individual, or individual's technological dependency, to achieve a designated task by the positive feature incorporated in the technology [102] and the benefit arises from the particular technology [103]. With this view, technology trust refers to the role of technology in building a trusting relationship with the user [104]. From the above perspective, when an MFS user considers the technologies that are being applied to be reliable and consistent, then the probability to assess the aggregate service seems more promising, and trust will increase. Although admitting that the three-fold technology aspect affects the environment of MFS (i.e., website, network, and mobile technology), the present study intends to treat them as a whole without separating them. As such, the user or potential user is called upon the strong level of comprehensive understanding purposively for MFS optimum usage. Past research has revealed much importance and many benefits of technological trust in the behavioral field of application [102,105-107].

Vendor trust denotes the extent to which the consumer sees and believes that the vendor will accomplish the designated transactional requirements in risky or ambiguous conditions [108]. Many situations can raise consumer's trust toward the vendor. An online consumer who perceives the vendor in presenting an opportunistic behavior can create a kind of reluctance within that particular consumer. Earlier studies have revealed a negative relationship between the online vendor's opportunism and online consumer's trust [109]. Trust, and in specific the confidence in the mobile vendor, plays an exceptionally important role in the digital environment [110-113]. For Roger C. Mayer et al. [114], vendor ability, integrity, and benevolence are crucial vendor trust features, although ability can also be regarded as vendor competence [115]. By relating that logic to the MFS environment, vendors with a good reputation/integrity will be less expected to bear unscrupulous behaviors and threaten their status. As a result, we posit the succeeding three assumptions to inspect the causal effect relationships between trust's antecedents and trust in the MFS perspective.

Hypothesis 1. The dispositional trust would significantly influence users' general trust in using MFS.

Hypothesis 2. The technological trust would significantly influence users' general trust in using MFS.

Hypothesis 3. The vendor trust would significantly influence users' general trust in using MFS. 


\subsection{Antecedent of Perceived Risk}

Perceived risk can denote a combination of uncertainty added to the severity of the consequence involved [116]. It is similarly taught as a kind of uncertainty and outcome [117]. In the psychological field, perceived risk is the emotional sensitivity and subjective thoughts of various objective risks. Although it is the derivative of the objectives risk, nevertheless, they are different from each other. From the perceptive of trust-risk relationship, prior researchers understood that the readiness to take risks is a general characteristic of all trust circumstances $[28,118,119]$. From this point, consumer trust could be noticed and subjected to the degree of the intricate risk presented in the situations [120]. Awkwardly perhaps, because of the complex nature of trust and risk variables, countless scholars have disregarded the function of risk perceptions [121]. E-commerce trust investigators have shown that, when trust increases, the trustee's perception of risk reduces and impacts their attitudes to the trustor, which successively, influences the readiness to procurement [122]. In the view of the risk management field, the risk is the construct associated with the cost of outcomes, empowering trust and risk as mirror images while both incorporate differing relationships [123]. The study focuses on the rapport among trust and risk [121], and the trust-related works and empirical confirmation predominantly emphasize on industrial relationships, nonetheless theoretical and empirical support encountered in MFS is limited. When people trust others, they believe that those they trust will act as anticipated, which diminishes the intricacy of the interaction. Understanding the high convolution of the relationship between trust and risk concept, and considering likewise the absence of scholarly unanimity that lack on how to account their relationship via model [124], this study takes the view of a mediating relationship [121] instead. On the mediating standpoint, if trust exists, then the risk perceived is reduced, which successively will impact the degree of decision-making to use MFS. Thus, higher trust in a technology would lower its perceived risk and consequently positively affect behavioral intention [125].

These ideas of risk and others will endure a detrimental dominance on the acceptance of MFS. For instance, Swaminathan et al. [126] revealed consumers' opposition to providing their credit card information through the Internet. With MFS, the consumers are required to entrust not only their credit card information but a whole account of information in most cases. Wide-ranging, trust ameliorates the consumer's conception toward online service and the related component, diminishing the level of the risk perception allied with the transaction process.

From the attribute of risk opinion, a plethora of researchers brought that studies on consumer's risk perception are a kind of a multi-facet concept [28,39,127], which becomes the root of the aggregate perceived risk. To date, perceived risk has been employed to elucidate both offline and online risk shopping behavior. The finding derived from the work of Featherman and Pavlou [127] on the consumer's adoption of e-services has been widely accepted, which classified perceived risk dimensions as an economic risk, social risk, time risk, functional risk, psychological risk, and privacy risk. Bellman et al. [128] informed regarding the prominence of time concerns and argued that it is a substantial predictor of online buying behavior. According to the finding, consumers in a hurry who have less time are more plausible to buy on the Internet. The perception of time risk can refer to the integration of time lost and determination expended in acquiring any item and service [129]. Grounded in this similar logic, the current study proposes that consumers are time-oriented, time-conscious, and therefore value the potential time they might spend in implementing, searching and learning the application process of the new MFS.

Security/privacy risk is categorized as an intrinsic loss undeviatingly to fraud, scam, or hacktivists haggling the security of the user of an e-service [130]. The security or privacy issues mostly arise when a customer is transferring money from his/her account or dealing with his/her secluded economic information, whereas others view this information without his/her consent. The perception of costs applied to the MFS application reveals fear among the consumers. Empirical evidence stressed that mobile banking acceptance is highly sustained by economic aspects such as beneficial fees regarding transaction service [131]. Alternatively, it is impeded by economic considerations (issues centered on basic 
fees for assessing mobile banking), like cost burden [132] or high payment incorporated in using mobile banking [133]. Therefore, the perception of cost risk tends to negate the adoption of mobile banking [134].

Centered on the work of Featherman and Pavlou [127] predominantly, and throughout the previous studies toward risk components so far; the present study deduces four important dimensions of risk perceived, which are expected to influence the consumer's overall risk concerning the MFS adoption. They are the perceived privacy risk, time, security, and financial risk in the form cost perceived. Hence, we can posit the following assumption based on the discussion being done under this section.

Hypothesis 4. Consumer's general trust would negatively associate with the perceived risk in MFS.

Hypothesis 5. Perceived privacy risk would significantly influence users' perception of risk of using MFS.

Hypothesis 6. The Perception of time risk would significantly influence users' perceived risk of MFS.

Hypothesis 7. Perception of security risk would significantly influence users' perceived risk of MFS.

Hypothesis 8. Cost perceived would significantly influence users' aggregate perceived risk of using MFS.

\subsection{Antecedents of MFS Adoption}

Under this section, three antecedents (dispositional trust, trust, perceived risk) of MFS adoption will be taken into consideration. Being part of a personality trait, a disposition to trust can denote an individual's predilection to show reliance on humanity and to support a trusting standpoint concerning others $[135,136]$. Many researchers hypothesize the disposition to trust as partaking a positive impact on trust toward online shopping websites [136]. This relationship was also supported in various IS research, particularly in e-commerce [94,137,138], and in mobile banking [139]. Accordingly, Gefen et al. [101] pointed out that disposition to trust is crucial, particularly for the development of early trust and befits less significant for established trust or pre-existing relationships trust beliefs. Once encountering people with trifling or no experience using the wireless Internet as a platform for financial transactions, a disposition to trust is predictable to affect their trusting perception on the Internet. People partaking high disposition to trust are more favorable to feel relaxed or secured when using wireless Internet for financial transactions [39]. Inferring from this lucidity to the MFS, we expect that consumers having a higher disposition to trust are more probable to espouse MFS than those with a lower disposition to trust.

The next antecedent of MFS adoption resides in risk perception. Since its application among consumer behavior literature [116], the conception of perceived risk has been reviewed from a multiplicity of viewpoints. The classical decision concept considers risk perception as a function of the distribution of probable outcomes of conduct, its likelihoods, and subjective values [140]. Accordingly, risk encompasses two dimensions: uncertainty and outcome, where there is the possibility of experiencing a loss as a consequence of a behavior and the significance accredited to the loss [141,142]. While various researchers have criticized this approach because of its strictness to apprehend a perceived risk variable equally to be ambiguous and indistinct [142], some others were heightened to this concept definition as expected utility theory $[143,144]$. Explicitly risk, therefore, carries on the subjectively driven expectancy of loss by the customer when denoting the perceived risk [145]. Internet banking and MFS, predominantly mobile banking, rely on a similar type of risk [146], only, the information media channels differ. Prior IS studies showed that the imperative attitudinal of perceived risks impact adoption behavior where much is based on the privacy risk and transaction security risk [6,147-150]. Preceding studies have equally supported the negative effect of the perceived risk of online usage and purchasing behavior [151-154]. Likewise, earlier researchers agreed that the more risk is perceived by someone in purchasing context, the less probable he/she will be resolved to buy [155]. Furthermore, the level of personal participation in the decision-making process exposes the degree of risk perceived 
combined with the significance attributed to the choice of the object while allowing for the desires, interest, and personal values of the individuals [156,157]. Based on the perception of risk assigned in past works as the main inhibitor elements of various IS arena; similarly, it is expected to affect the acceptance of MFS negatively.

Taking the antecedent of MFS from a different angle, the importance of trust has been revealed to be an extensive subject matter. Trust, combined with the previous definitions so far, denotes the readiness of one party to be exposed to the actions of another party deal with the hope that the other will accomplish the designated task needed to the trustor [30]. The empirical findings of Jarvenpaa and Tractinsky [158] revealed the trust element to influence the decision to purchase in various manifold cultures. The prominence of trust is so decisive that it may be extended to be viewed as the "wild wild west" of the 21st century [136]. The more MFS users or potential users believe and trust the services, the more they can develop an affirmative goal for its usage. User trust, which has been revealed to be an important adoption facilitator in many IS environments, lacks adequate inspection in the context of MFS as a whole. In line with the literature allied with the antecedent of adoption of MFS in this study, we can, therefore, posit as follows:

Hypothesis 9. Disposition to trust would have a positive effect on an individual' espousal of MFS.

Hypothesis 10. User aggregate risk perceived would have a negative impact on the adoption of MFS.

Hypothesis 11. User general trust will positively influence an individual's acceptance to use MFS.

\subsection{Conceptual Framework}

To assess how trust and risk perceptions at the multidimensional level affect the mobile financial services (MFS) acceptance in Togo, we propose a research model. Figure 1 summarizes the relationships described in the research hypotheses. The proposed model is used to identify several attributes as predictors of MFS. Based on the above discussion related to the suggested hypotheses, we considered three antecedents (dispositional trust, technology trust, and vendor trust) as a multi-dimensional trust for the general trust, four antecedents (privacy risk, time risk, security risk, and cost) regarded as multi-facet perceived risk for the aggregate perceived risk. The remaining three antecedents (dispositional trust, perceived aggregate, and general trust) are used for consumers' intention toward the adoption of mobile financial services. Demographic variables entailing age and education levels are included in the model as control variables.

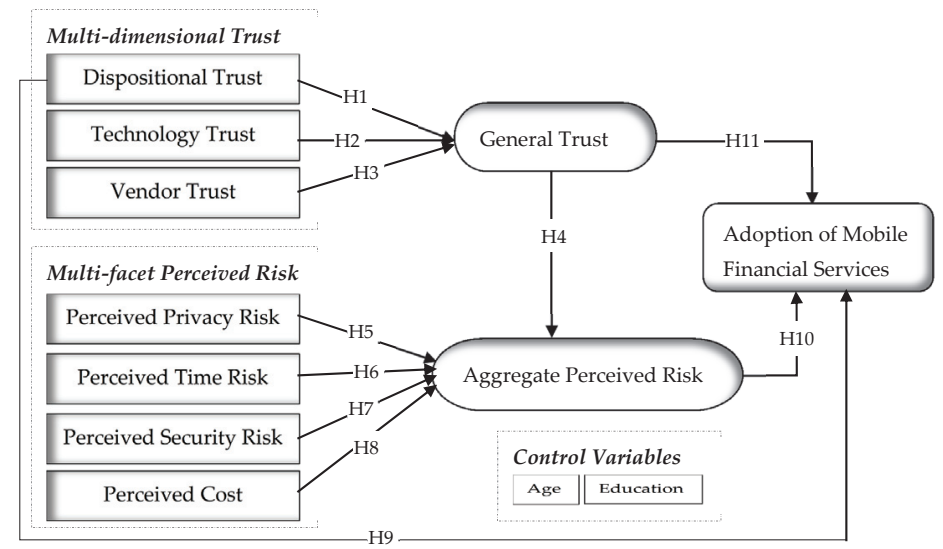

Figure 1. Proposed research model. 


\section{Research Methodology}

\subsection{Design and Data Collection}

Various schools of thought questioned how data collected would be executed as well as the content of the studies. Among them, Cooper and Schindler [159] have suggested two approaches of scrutinizing issues: One technique called observational approach is to gather data on people, event, situations, and behavior; while the next one, the so-called communication approach, has considered the attitudes, expectations intentions, and motivator aspect.

This research, as a result, used data collection via the communication approach, taking a form of the survey since the motive of the study turns to capture the influential factor of MFS adoption once testing the research model. A survey instrument was then established for indicators and criteria development, which primarily got ratified after revising the suitability of the constructs by the chosen experts of MFS. The preliminary draft of the questionnaire was prepared in English then translated into French (the official language of Togo) for its assessment as well. Both questionnaires in English and French have been retained as to avoid any confusion related to the scope, purpose, and content; so far, allowing the comparison of the versions for discrepancies concerns, steadfastness to be easily acknowledged and established. Following the advice and the opinion from the experts, redundant and confusing items were either improved or removed. As a result, new items were included in the questionnaire lastly, permitting the validity of the survey instrument employed. The research model embodies ten factors; each factor remains evaluated with multiple items. Also, all items were accommodated from existent literature to increase content validity [160]. There were two types of questionnaires. The first type (SEM questionnaire) was divided into two parts. The first part was distributed with bio-data of the sample, and the second part answered the MFS questions using the five-point Likert scale bounded from strongly disagree (1) to strongly agree (5). The final measurement scales, items, and their sources are listed in "Appendix A".

For the second type of questionnaire (TOPSIS questionnaire), we arbitrarily contacted users and potential users and questioned them whether they had mobile MFS usage experience to ensure their familiarity to some extent as recommended $[10,161]$. Thus, those with two or more MFS experience years were further invited to fill the TOPSIS questionnaire format.

The empirical study took almost three months of the span for data collection because of the delay in obtaining some participants' responses and an awkward time-period indicated by some of them. Data were collected at some of the busiest and most crowded places of the capital town Lomé (i.e., Assivito, Dekon, Be, and Université de Lomé) where potential users and currents users of mobile financial services (MFS) can relatively be found and inspected better than in other sectors. Literate people filled in their survey questionnaires themselves, whereas for illiterates, help was given. The questionnaire took almost 10-15 min to complete by a given participant. The estimated accessible population of Lomé is 837,437 [162]. Therefore, the estimated adjusted sample size for this research should have a minimum of $399.8090 \cong 400$ [163]. In the situation which involves minor participants, informed consent has been given by legal representatives together with the minor participants "assent" before partaking in a study. An exception to this procedure was when teenagers are employed and living on their own.

Once the data collection procedure was completed, we examined all questionnaires and discarded cases with too many missing and or rushed responses.

As such, 538 questionnaires, which fulfilled the minimum requirement, were both ready and yielded usable samples. Among them, 294 (54.6\%) were male and $244(45.4 \%)$ female. Seventy-five (13.9\%) respondents were aged below 18 years, 145 (27\%) aged between 19-24 years, 199 (37\%) aged between $25-30$ years, and 119 (22.1\%) aged above 31 years. Regarding educational qualifications, the majority of respondents (two hundred and sixty-seven) had a high school certificate or below, i.e., Baccalaureate (49.6\%), $203(37.7 \%)$ had a graduate degree, while $57(10.6 \%)$ had a master's degree. The remaining $11(2 \%)$ had a doctorate. Concerning MFS years of experiences, $187(34.8 \%)$ of respondents 
claimed to have no experience with MFS, 194 (36.1\%) used it for less than one year, 125 (23.2\%) MFS usage ranged from the 1-2 years, 26 (4.8\%) were found between 3-4 years of MFS experience. Only $6(1.1 \%)$ had MFS experience for more than five years. Hence, very few respondents had MFS experience above three years from the deduction. Moreover, they are those respondents engaged in MFS application at the early stage of its implementation (Most MFS companies in Togo started launching their activities in the year 2013) and dwell on it.

\subsection{Proposed Technique of Data Analysis: SEM-TOPSIS Methods}

The SEM-TOPSIS technique was employed to construct the MFS evaluation decision support system. Therefore, SEM was utilized to generate critical criteria and weights, whereas TOPSIS was used to engender the rank and score of alternatives as well permitted the fullness of the data, improved the data accuracy via group decision making.

SEM is suitable to estimate and test casual relationships by employing a combination of statistical data and qualitative assumptions $[15,164]$. It remains a second-generation multivariate technique that tolerates the simultaneous assessment of multiple equations, embraces multiple regression analysis, factor analysis, and path model analysis [165]. SEM incorporates the whole analysis of construct concurrently rather than separately [166], with this application being emergent in the social sciences [167]. Accordingly, it is the handiest method adapted for checking causative relations between predictors and adoption behavior $[168,169]$. It offers greater flexibility in matching a theoretical model with a data sample when compared with techniques like PCA and factor analysis [170].

TOPSIS: Technique for Order Preference by Similarity to Ideal Solution. The various process of TOPSIS will be explained in the analysis section.

\section{Data Analysis}

\subsection{Measurement and Hypotheses Testing with SEM Analysis}

We performed exploratory factor analysis (EFA) employing maximum likelihood estimation with Promax because of the large sample of data set $(n=538)$ and its intricacy related to the outcome's elucidation, which is trivial in resolving the correlated. The EFA reveals the output of KMO as 0.809 and Bartlet's test of sphericity to be significant at $\alpha=0.000$ with a Chi-square of $11,598.920$, indicating the relevance for performing exploratory factor analysis [171]. Besides, the communalities for each variable were sufficiently high (lowest was 0.343 , the majority were beyond 0.597 , and the greatest was 0.975 ), showing the evidence that these variables were effectively correlated for factor analysis. The ten-factor model obtained a total variance explained with more than $60 \%$ along with all extracted factors partaking eigenvalue beyond 1.0.

To continue assessing our quantitative model, we settled the subsequent analysis in two phases [167]: first, via confirmatory factor analysis (CFA), we appraised both reliability and discriminant validity of the ten constructs [172]. The outcomes will achieve validity unless the researchers employ constructs that diverge from another construct in a similar model [172]. From the second step, we valued the structural model then SEM for hypotheses testing. These last two steps are adopted from previous studies $[28,173]$. Hence, we estimated the reliability of each construct based on three indices, such as composite reliability (CR), average variance extracted (AVE), and Cronbach's alpha (CA). The suggested values for good measures were at least $0.70,0.50$, and 0.70 , respectively [174], (see Table 1). In patronage of convergent validity, the AVE found to be higher than 0.5 for all constructs, and all item factor loadings remain beyond the minimum threshold of 0.4 [175]. 
Table 1. Reliability and validity in confirmatory factor analysis (CFA).

\begin{tabular}{|c|c|c|c|c|c|c|c|c|c|c|c|c|c|c|}
\hline & CR & AVE & MSV & $\operatorname{MaxR}(\mathrm{H})$ & (1) & (2) & (3) & (4) & (5) & (6) & (7) & (8) & (9) & (10) \\
\hline (1) & 0.846 & 0.647 & 0.227 & 0.848 & 0.804 & & & & & & & & & \\
\hline (2) & 0.933 & 0.779 & 0.133 & 0.965 & 0.108 & 0.883 & & & & & & & & \\
\hline (3) & 0.904 & 0.704 & 0.087 & 0.975 & 0.216 & 0.067 & 0.839 & & & & & & & \\
\hline (4) & 0.860 & 0.609 & 0.057 & 0.979 & 0.168 & 0.157 & 0.155 & 0.780 & & & & & & \\
\hline (5) & 0.855 & 0.664 & 0.227 & 0.981 & 0.476 & 0.020 & 0.230 & 0.144 & 0.815 & & & & & \\
\hline (6) & 0.843 & 0.577 & 0.056 & 0.984 & 0.236 & 0.061 & 0.114 & 0.011 & 0.235 & 0.760 & & & & \\
\hline (7) & 0.856 & 0.600 & 0.133 & 0.985 & 0.041 & 0.365 & 0.044 & 0.238 & -0.022 & -0.072 & 0.775 & & & \\
\hline (8) & 0.811 & 0.594 & 0.065 & 0.987 & 0.127 & 0.155 & 0.113 & 0.232 & 0.091 & 0.035 & 0.255 & 0.771 & & \\
\hline (9) & 0.798 & 0.571 & 0.013 & 0.987 & 0.102 & 0.098 & 0.065 & -0.004 & -0.035 & 0.086 & 0.075 & 0.115 & 0.756 & \\
\hline (10) & 0.820 & 0.610 & 0.087 & 0.988 & 0.228 & 0.051 & 0.295 & 0.064 & 0.198 & 0.216 & -0.042 & 0.019 & 0.104 & 0.781 \\
\hline
\end{tabular}

Note: (1) DTrust: dispositional trust; (2) TTrust: technological trust; (3) Vtrust: vendor trust; (4) PPrivR: perceived privacy risk; (5) PTimeR: perceived time risk; (6) PSecurR: perceived security risk; (7) PCost: perceived cost; (8) PRisk: perceived risk; (9) AdMFS: adoption of MFS; (10) G-trust: general trust.

Moreover, all loadings of items arose in the corresponding construct, and no item loaded with the high value in another construct. This technique was espoused in past research $[15,176,177]$. As such, we established that our ten constructs displayed convergent validity (see Table 1 below).

We designed Table 2 to portray the goodness of fit of CFA and SEM. Apart from the goodness-of-fit index (GFI) for CFA slightly below the recommended, as this index is sensible to sample size, and in this study, we use large sample size $(n=538)$; for all indexes, our measurement model and structural model indicated sufficient goodness of fit.

Table 2. The goodness of fit (CFA and structural equation modeling (SEM)).

\begin{tabular}{ccccc}
\hline Indices & Abbreviation & CFA Value & SEM Value & Thresholds \\
\hline Chi square & $\mathrm{x}^{2}$ & 1068.904 & 30.445 & $p$ value $>0.05$ \\
\hline Normed chi square & $\mathrm{x}^{2} / \mathrm{DF}$ & 2.104 & 1.903 & $1<\mathrm{x}^{2} / \mathrm{df}<3$ \\
\hline Root mean square residual & RMS or RMR & 0.066 & 0.015 & $<0.08$ \\
\hline Goodness-of-fit index & GFI & 0.889 & 0.991 & $>0.90$ \\
\hline Adjusted GFI & AGFI & 0.862 & 0.955 & $>0.80$ \\
\hline Normed fit index & NFI & 0.900 & 0.941 & $>0.90$ \\
\hline Comparative fit index & CFI & 0.944 & 0.968 & $>0.93$ \\
\hline Tucker-Lewis index & TLI & 0.935 & 0.869 & $0<$ TLI $<1$ \\
\hline \multirow{2}{*}{ Root mean square error of approximation } & RMSEA & 0.045 & 0.041 & $<0.05$ excellent fit \\
\end{tabular}

Before the structural model, we conducted a common method bias. Since the data for the variable were led through a single method (survey), we performed a test to check if a common factor might have been impacted our outcomes. Hence, the test adopted was an unmeasured latent factor suggested by Podsakoff et al. [178] and Siemsen et al. [178] toward studies that do not obviously measure a common factor, mentioned as a common latent factor (CLF) method. The most prevailing and best method in checking the CMB is the zero-constrained test where the CLF is involved along with Marker if accessible [178]. This approach checks whether the shared variance across all variables differs significantly from zero. In a case it is, then there are bias issues. To proceed, we computed the chi-square difference test among the unconstrained model and the model per all paths regarding the CLF constrained to be zero. Since the result is markedly different from zero, we can conclude that method bias does occur in our measures. Thus, moving to the causal model based on the result, CLF was retained for our structural model (by imputing composites in AMOS in the presence of CLF), which provided CMB-adjusted values. 
We also check for invariance (configurable and metric) because of the presence of two groups, such as gender included in our data to see whether the factor and loading are adequately equivalent across groups. Davidov [179] has claimed that the assessment of path coefficients could only be useful if the invariance test has been done beforehand. The result signpost that the model fit of the unconstrained measurement models (per groups loaded distinctly) presented a sufficient fit $(\chi 2 / \mathrm{DF}=1.623, \mathrm{TLI}=0.928$, $\mathrm{CFI}=0.938, \mathrm{RMSEA}=0.034)$ when assessing a freely estimated model across genders. Grounded on the result, the model is configurally invariant. Once the model was constrained to be equal, the result of the chi-square difference test reveals the $p$-value $(0.226)$ to be nonsignificant. So, the measurement model satisfies the benchmarks criteria for metric invariance across gender as well. Then and there, we move on making the composite from this measurement model to build SEM for verification of hypotheses testing. The results of the structured model, together with parameters, were obtained while controlling for age and education. The standardized path coefficients, path significances, and explained variance $R^{2}$ of the structural model (see Figure 2).

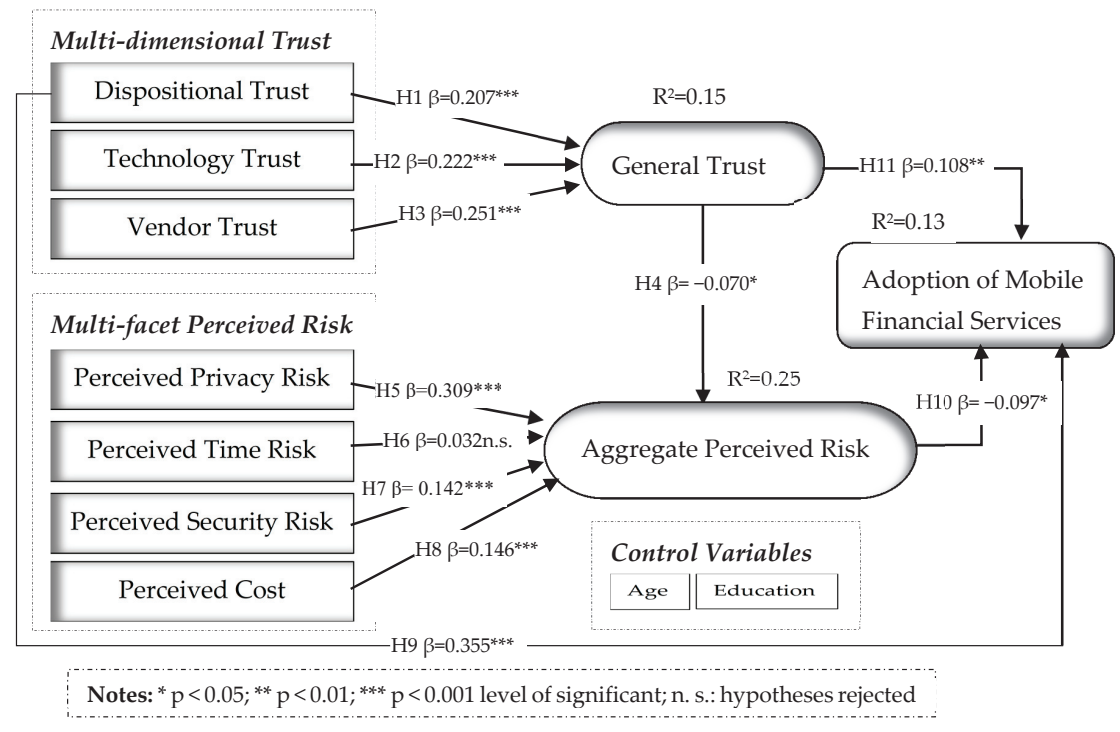

Figure 2. Final model after validation.

\subsection{TOPSIS Analysis}

The technique for order preference by similarity to ideal solution (TOPSIS) is a multiple criteria decision-making (MCDM) technique developed by Hwang and Yoon [180]. It is grounded in the criteria that the alternative should have the shortest distance from the positive ideal solution and the farthest from the negative ideal solution [181]. It has been extensively employed by researchers for the ranking of alternatives centered on different criteria $[7,161,164,182,183]$. When compared to other MCDM methods, TOPSIS necessitates limited subjective inputs from decision-makers [184] and remains a deterministic technique. It provides solution on both positive and negative way, which is beneficial for applications where there are considerations such as cost and benefits; and it is a rational method which works agreeably across various application areas [185]. Recall that the process of the SEM-TOPSIS can be characterized as follows. Primarily, SEM was applied to compute the hierarchical criteria and their relatives to ensure their significance. This is the reason why having the relative weightage obtained from SEM is reflected more valid than via any other method. The antecedent of trust and perceived risk given by the SEM model were deliberated for the relative weightage of the sub-criteria. 
The computation of TOPSIS methods grounded on Hwang and Yoon [180], Lin and Tsai [186], and predominantly the one required for grouping decision Shih et al. [187] were adopted and presented as followed:

Step 1: construction of decision matrix $\mathrm{D}^{\mathrm{k}}, k=1, \ldots, \mathrm{K}$ for each $\mathrm{DM}$. The matrix structure can be viewed below:

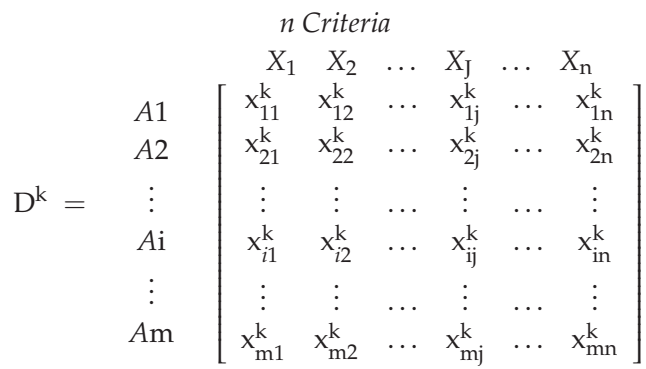

where $A_{i}$ refers to the likely alternatives of the decision process $i$ with $i=1, \ldots, m ; X_{j}$ denoting the attribute or criterion $j, j=1, \ldots, n$; with both quantitative and qualitative data. The value $x_{\mathrm{ij}}^{\mathrm{k}}$ remains, therefore, the performance score of alternative $A_{i}$ in relation to attribute $X_{j}$ by decision-maker $k, k=1, \ldots, K$, while $x_{i j}^{k}$ is the element of $\mathrm{D}^{\mathrm{k}}$. It is of importance to mention that there should be $K$ decision-maker matrices designed for $K$ participants of the group.

Step 2: the normalized decision matrix $\mathrm{R}^{k}, k=1, \ldots, K$ is generated for each $D M$. Vis-à-vis to any $D M k$, the vector normalization technique is used for computing the element $r_{i j}^{k}$ from the decision matrix $\mathrm{R}^{\mathrm{k}}$ which can take any linear-scale transformation to preserve $0 \leq r_{i j}^{k} \leq 1$ inequality. Since we consider the vector normalization operation, then $r_{i j}^{k}$ is given as:

$$
r_{i j}^{k}=\frac{x_{i j}^{k}}{{\sqrt{\sum_{\mathrm{j}=1}^{\mathrm{n}}\left(\mathrm{x}_{\mathrm{ij}}^{\mathrm{k}}\right)^{2}}}^{2}}
$$

where $i=1,2, \ldots, m ; j=1,2, \ldots, n$; and $k=1,2, \ldots, K$. It is also necessary to clue that the vector normalization method makes provision as to which one represents a cost criterion for additional management. Moreover, there is no need to directly assess the weighted normalized as per the case of the original TOPSIS [188].

Step 3. The positive ideal solution $V^{k+}$ (PIS), is made of all the best performance scores and the negative-ideal solution $V^{k-}$ (NIS) is made of all the worst performance scores at the measures in the weighted normalized decision matrix for each DM $k=1, \ldots, K$. For any given $D M k$, his/her PIS and NIS can be characterized in the form of

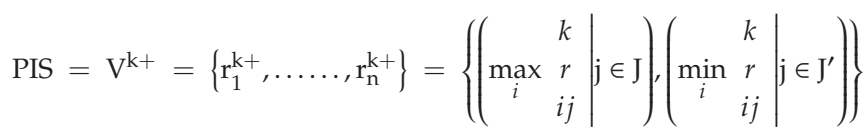

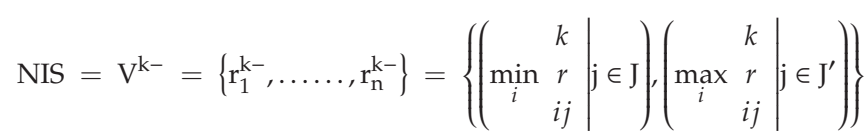

where $J$ is related to the benefit criteria and $J^{\prime}$ allied with the cost criteria, $i=1, \ldots, m ; j=1, \ldots, n$; and $k=1, \ldots, K$.

Step 4. A weigh vector $W$ is allocated to the attribute set for the group. Each DM will produce weights for attributes as $w_{j}^{k}$ where $j=1, \ldots, n$ and $\sum_{j=1}^{\mathrm{n}} w_{j}^{k}=1$; and for each DM $k=1, \ldots, K$. 
Each element of the weigh vector $\mathrm{W}$ will result from the operation of the corresponding components of the attributes' weights for every DM.

Step 5. Evaluate the separation measure through the positive ideal and the negative ideal solutions, $\overline{S_{I}^{+}}$and $\overline{S_{I}^{-}}$, relatively to the group. Because of the group decision with respect to this research, this step requires two sub-steps, where the initial one considers the distance measure for individuals while the next one aggregates the measure for the group.

Step 5a. Assessment of the measure from PIS and NIS individually. The n-dimensional Euclidean distance can compute the distance of an alternative $j$ to the ideal solution. Separation of each alternative from the positive ideal solution $S_{i}^{k+}$ is then provided by the Equation (5) below:

$$
\mathrm{S}_{\mathrm{i}}^{\mathrm{k}+}=\sqrt{\sum_{\mathrm{j}=1}^{\mathrm{n}} w_{j}^{k}\left(v_{i j}^{k}-v_{j}^{k+}\right)^{2}}, \text { for alternative } i, i=1, \ldots, m
$$

Similarly, separation from the negative ideal solution $S_{i}^{k-}$ is then given by

$$
S_{\mathrm{i}}^{\mathrm{k}-}=\sqrt{\sum_{\mathrm{j}=1}^{\mathrm{n}} w_{j}^{k}\left(v_{i j}^{k}-v_{j}^{k-}\right)^{2}}, \text { for alternative } i, i=1, \ldots, m .
$$

Step 5b. Assessment of the measure from PIS and NIS for the group. In this part, the individual group measure of each alternative is to be integrated via an operation $\otimes$ for all DMs, $k=1, \ldots, K$. As such, the two-fold measure of the PIS and NIS are presented below

$$
\begin{aligned}
& \overline{S_{i}^{+}}=\overline{S_{i}^{1+}} \otimes \cdots \otimes \overline{S_{i}^{K+}}, \text { for alternative } i, \\
& \overline{S_{i}^{-}}=\overline{S_{i}^{1-}} \otimes \cdots \otimes \overline{S_{i}^{K-}}, \text { for alternative } i .
\end{aligned}
$$

Though this operation can provide various choices like geometric mean, arithmetic means with their related extended; this study pondered only on the geometric one for the group computation. Its calculation's formulae are below shown for PIS and NIS (Equations (9) and (10))

$$
\begin{aligned}
& \overline{S_{i}^{+}}=\left(\prod_{k=1}^{K} S_{i}^{k+}\right)^{\frac{1}{K}}, \text { for alternative } i \\
& \overline{S_{i}^{-}}=\left(\prod_{k=1}^{K} S_{i}^{k-}\right)^{\frac{1}{K}}, \text { for alternative } i
\end{aligned}
$$

where $i=1, \ldots, m ; k=1, \ldots, K$.

Step 6: The ranking score $\overline{C_{i}^{*}}$ is computed as

$$
\overline{C_{I}^{*}}=\frac{\overline{S_{i}^{-}}}{S_{i}^{+}+S_{i}^{-}}, i=1, \ldots, m
$$

With $0 \leq \overline{C_{I}^{*}} \leq 1$. When $C_{I}^{*}$ is close to 1 , the alternative is considered as ideal; and when $C_{I}^{*}$ is close to 0 , the alternative is considered as non-ideal. The larger the index values, the higher the rank order, and so, the better the alternative' performance.

\subsection{Case Study Using Combined SEM-TOPSIS Techniques}

To establish the applicability of the suggested methodology (SEM-TOPSIS), a case study is carried out in this paper. The data examined were provided by respondents (74 MFS experienced 
users and experts) of mobile financial services, particularly for adopting the TOPSIS technique. The relative weightage is computed from the standardized total effect, normalized obtained from the SEM technique $[10,189]$, and presented in Table 3. The weightings showed the importance of each sub-criteria for the MFS companies.

Table 3. Relative weightage of sub-criteria.

\begin{tabular}{ccccccc}
\hline DTrust & TTrust & VTrust & PPrivR & PTimeR & PSecurR & PCost \\
\hline 0.265 & 0.128 & 0.177 & 0.200 & 0.021 & 0.109 & 0.101 \\
\hline
\end{tabular}

Note: (1) DTrust: dispositional trust; (2) TTrust: technological trust; (3) Vtrust: vendor trust; (4) PPrivR: perceived privacy risk; (5) PTimeR: perceived time risk; (6) PSecurR: perceived security risk; (7) PCost: perceived cost.

To compute the relative weightage of MFS alternatives to each sub-criteria toward the criteria (trust and risk), the decision matrix of alternative performance evaluation (Equation (1) step 1) was created. Moreover, the output of the qualitative attribute from each alternative can also be set as discrete value or linguistic values (referring to Table 4) intentionally that the quantitative values could be set in the decision matrix above. Participants were asked to provide a set of values within the range of one to nine for the sub-criteria using Table 4 as measurement scale.

Table 4. Transformation of linguistic scale into quantitative values.

\begin{tabular}{ccc}
\hline \multirow{2}{*}{ Linguistic Scale } & \multicolumn{2}{c}{ Quantitative Values } \\
\cline { 2 - 3 } & Benefit-Max & Cost-Min \\
\hline Very High & 9 & 1 \\
\hline High & 5 & 3 \\
\hline Average & 3 & 7 \\
\hline Low & 1 & 9 \\
\hline Very Low & \multicolumn{2}{c}{$(2,4,6,8)$} \\
\hline Intermediate values between the two-adjacent judgment:
\end{tabular}

Following the procedure of the TOPSIS method, through a TOPSIS algorithm built-in MATLAB technical computing tool, the relative weightage of MFS allied with each sub-criterion is calculated and shown in Table 5. After aggregating the individual PIS and NIS via geometric mean from the Step $5 \mathrm{~b}$ Equations (7) and (8), then the final score $\overline{C_{I}^{*}}$ is computed using Equation (11) of Step 6, followed by the ranking of the MFS alternatives as being portrayed in Figure 3 and Table 6 .

Table 5. Summary of the relative weightage of mobile financial services (MFS) to each sub-criterion.

\begin{tabular}{cccccccc}
\hline \multicolumn{7}{c}{ Relative Weightage of MFS to Each Sub-Criterion } \\
\hline Sub-criteria weightage & 0.265 & 0.128 & 0.177 & 0.200 & 0.021 & 0.109 & 0.101 \\
\hline Sub-criteria & DTrust & TTrust & VTrust & PPrivR & PTimeR & PSecurR & PCost \\
\hline MB & 5.40 & 4.78 & 6.23 & -3.56 & -7.53 & -4.20 & -6.50 \\
\hline MP & 8.50 & 5.40 & 4.43 & -2.34 & -8.20 & -5.00 & -7.00 \\
\hline MMT & 7.30 & 4.70 & 5.11 & -1.42 & -8.00 & -4.48 & -7.20 \\
\hline
\end{tabular}

Note: MB: mobile banking; MP: mobile payment; MMT: mobile money transfer. 


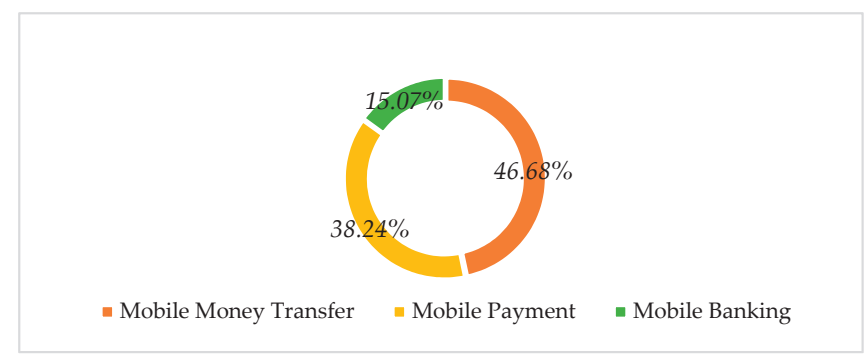

Figure 3. Classification of MFS alternatives using TOPSIS (\% representation).

Table 6. Results of three alternatives of MFS ranking using TOPSIS.

\begin{tabular}{cccc}
\hline MFS & $\overline{C_{I}^{*}}$ & Rank & \% Distribution of Coefficient \\
\hline MMT & 0.7454 & 1 & $46.68 \%$ \\
\hline MP & 0.6106 & 2 & $38.24 \%$ \\
\hline MB & 0.2407 & 3 & $15.07 \%$ \\
\hline
\end{tabular}

\section{Discussion}

New technology adoptions are impacted mainly by many factors, which may vary from technology concerns to the trust dimension, the perception of risk facets, and the behavior of users, to mention a few. The intricacy and significance related to the effort in elucidating the motives or reasons for users' adoption or rejection of new IT have led to the development of various concepts. Furthermore, there are a plethora of studies on the influence of trust and perceived risk with their determinant toward the adoption decision in an online environment.

Conversely to prior research works, this study scrutinizes the influence of critical variables such as multi-dimensional trust and perceived risk facets on the consumers' adoption behavior of MFS and incorporates each of them into the MFS alternative decision-making scenario. Some postulations were made toward the possible relationship among the factors. The findings are yet to be probed purposively to draw an important conclusion and implication. The result of the MFS structural model analysis regarded as a final model after validation is summarized and portrayed in Figure 2. To be specific, the discussion section is scheduled to be under two sections. The first section will be made with SEM methodology grounded on hypotheses results, which are comprised of three sets. First set: hypotheses associated with trust; second set: hypotheses associated with perceived risk; and third set: hypotheses associated with MFS adoption constructs. The last section of the discussion is booked for a succinct analysis of TOPSIS output obtained via the SEM-TOPSIS hybrid technique.

It should be mentioned that all hypotheses were tested when controlling for age and education. The reason for controlling variables is to support mitigating the unrelated effect. Moreover, its use contributes to improving the robustness and validity of the outcome. In terms of relationships, the study account for the $p$-value column allied with each variable where the related $p$-value of less than 0.05 indicates a significant relation associated. The results of the entire tested eleven hypotheses were statistically significant except for the relationship between perceived time risk (PTimeR) and perceived risk (PRisk, i.e., $\mathrm{H} 6$ as displayed from Figure 2).

The first set of hypotheses is related to trust, which was scrutinized by H1-H3. Empirical evidence is found to accept hypothesis H1 $(\beta=0.207, p<0.001)$, which refers to the positive effect the disposition to trust has on general trust in MFS. Payne and Clark [190] showed that the general disposition to trust exerts substantial control on the trust among senior managers in an industrial context. Moreover, consumers' disposition to trust has been revealed to maintain a strong influence on their trust in an e-vendor. Although most of the previous studies did not plainly define the direction of 
the impact, the present study ratifies that disposition to trust and trust are positively related in MFS. Such information comes to back the knowledge that consumers who unveil a greater disposition to trust will more willingly trust the e-vendor [137] compared to those who will require more info [191]. However, our results are contradicted by earlier e-services [110], particularly in mobile banking. The reason might be that when consumers are to encounter a choice within MFS perspectives (mobile banking, mobile payment, mobile money), their trust disposition significantly affects the general trust more or less that of the single type of MFS. As a result, companies dealing with MFS should be aware of this critical effect and prepare for any competitive advantage strategies in the marketplace.

$\mathrm{H} 2(\beta=0.222, p<0.001)$ tested the effect of trust in technology on trust in general, and the findings stressed that technology trust has a strong positive impact on trust. Given technological trust as a sole antecedent of trust whereby the object upon which the trust remained imparted when referring to the inert technology [192], then, our empirical results are in line with previous findings in the context of mobile banking [110]. Furthermore, previous works [193] implicitly incorporated the concept of trust technology to trust with its importance being emphasized as a facilitator of e-commerce adoption.

Trust in the vendor was also found to have a positive influence on general trust, which supports H3 $(\beta=0.251, p<0.001)$. The results of this research are reliable with the previous finding in which vendor trust has been defined as multi-dimensional and influential levers that the vendors could employ to build consumer trust [113]. Vendor trust remains so vital to promoting trust in changing a potential consumer from a curious viewer to one that will be ready to perform MFS. Thoughtful discerning of the essence and antecedents of consumer trust in MFS can support e-vendors with a set of controllable, strategic levers to develop such trust, which will encourage greater MFS acceptance and usage.

As a result, lack of consumer trust (trust disposition, technology trust, and vendor trust) in the overall online environment has been, and persists in being, a hamper to IS adoption [194] and thus to MFS. All these could serve as a clue to the concept that the consumers' espousal of MFS may be shaped accordingly.

The second set of hypotheses is associated with perceived risk. From this part, perceived risk has five antecedents, such as $\mathrm{H} 4$ and $\mathrm{H} 5-\mathrm{H} 8$. The investigation of the relationship between trust and perceived risk has been one of the main issues in the development of IS [195]. Our result shows that general trust has a negative influence on perceived risk, which supports $\mathrm{H} 4(\beta=-0.070, p<0.05)$. The literature offers supportive studies on the import of this relationship $[8,195]$. Various researchers have also contributed to the belief that trust mitigates consumers' perceived risk [196-198] as well as affecting perceived benefit in e-commerce [199]. Lots of incentives that increase trust are similar incentives that reduce perceived risk. This result clarifies to some extent, the doubt related to the direction of the causality between trust and risk, which were found deficient from the past literature [121]. From $\mathrm{H} 5-\mathrm{H} 8$, the empirical study found to patronize all the hypotheses at a different level of $p$-value mention that each dimension of perceived risk has a positive influence on the overall perceived risk except H6 (see Figure 2). At that point, the moderate to weak positive relationships between the perceived risk (aggregate) and the risk component offers further reinforcement that risk can be researched as a multidimensional phenomenon [200]. These results are also consistent with the work of Featherman and Pavlou [127], which validated a majority of these antecedents as a risk dimension; therefore, being the influential element of the aggregated risk. Again, the outcomes reveal the multidimensional nature of perceived risk in information technology, mainly MFS. Boksberger et al. [201] are supporters of these findings in the area of air travel. Again, the results show that perceived privacy risk H5 $(\beta=0.309$, $p<0.001)$ is indeed the predominant perceived risk dimension for the partakers of MFS, shadowed by the perceived cost H8 $(\beta=0.146, p<0.001)$ and perceived security risk H7 $(\beta=0.142, p<0.001)$. Moreover, this study confirms the positive effect of the perceived cost on the consumers' perceived risk, such as that the lower the cost, the more minor the perception of risk and the more the likelihood of MFS adoption. As such, the involvement aspect of the risk [202] is importantly observed when the price or cost is high, and the consumers risk losing money. 
This research reveals no statistical evidence to support the hypothesis $\mathrm{H} 6(\beta=0.032, p<0.342)$ that perceived time risk has a positive influence on the aggregate perceived. Although $\mathrm{H} 6$ is rejected; the expected direction of the relationship is kept just so that the $p$-value is not statistically significant at 0.05 . However, our findings are controverted by prior online payment research that has indicated a positive relationship between time risk and perceived risk [203]. It has stressed that consumers lack patience in waiting a long time because they are always delighted in pursuing new things [203]. Then, a longer waiting time for service delivery would deter the desire, impact their buying disposition or decision to adopt as well. In the view of this current study, the perceived risk dimension, such as perceived time risk, does not appear to impact the specific information technology acceptance, at least for the Togolese MFS investigated in this research. The reason may be related to the participants' (user and potential user) MFS experience. Since quite many of them lack experience in MFS, they might not be conscious regarding the real time needed for a service to be completed. This implies that the effect of time risk perceived is worthy of further development in future researches and MFS companies are encouraged to continue easing the transaction process of MFS in terms of time spent.

The third set of hypotheses is associated with the adoption of MFS. Among them, the hypothesis associated with the positive relationship that the dispositional trust has with MFS adoption was supported by the test result; hence, H9 $(\beta=0.355, p<0.001)$ is accepted (Figure 2$)$. This infers that when increasing the level of trust disposition, individuals tend to adopt MFS technologies without necessarily cogitating on the general trust. The finding is consistent with e-commerce adoption for SMEs [204]. Moreover, the scholars reported that indicators for the dispositional trust should be incorporated into empirical studies either as a moderating variable or as a precursor of trusting beliefs, intentions, and behaviors [205]. Being an antecedent of trust, a disposition to trust remains one of the most operative elements required during the launch phases of a relationship when parties are generally unacquainted with each other [206]. Given that MFS is still in the early stages of adoption in Togo, services providers are recommended to promote the variable that could increase the consumer's dispositional trust.

From Figure 3, perceived risk significantly negates the adoption and usage of MFS, rendering the support of H10 ( $\beta=-0.097, p<0.022)$. It is so crucial to signpost the feasibility of this outcome to be enlightened by the theory of consumer behavior [116] allied with risk perception. The importance of perceived risk in the study also confirms previous studies that demonstrate that consumers' perceived risk is more efficacious at clarifying purchasing or adoption behavior inasmuch as consumers are more recurrently driven to avert mistakes than to capitalize on utility in purchasing [207]. This output is also coherent with a recent report on mobile payment adoption, which underlines rapid technology innovation while stressing the importance of perceived risk in the form of security $[208,209]$.

Last but not least, the study entails and accepts the hypothesis H11 $(\beta=0.108, p<0.008)$ in which general trust has a positive influence on MFS adoption. Generally, trust remains a vital factor in various economic and social relations involving uncertainty and reliance [210,211], particularly those regarding important decisions [212] and new technologies [198] as an MFS perspective. Accordingly, our findings are sustained via the idea that trust in business rests on the pertinent and crucial stimulus of behavior in general [213-215], and the facilitator factors for MFS adoption and usage in particular.

Under this set, it can then be deduced that both improving trust and decreasing risk continue to raise the likelihood level of consumers' engagement in MFS transaction. Companies are required to take the necessary precaution to balance the trade-off.

SEM-TOPSIS: It is noteworthy to recall that the second section of discussion concerns the output of MFS alternatives computation. The overall result from the TOPSIS technique shows the preference of each alternative regarding the various sub-criteria. The relative closeness $\overline{C_{I}^{*}}$ results obtained satisfies the sine qua non-condition, i.e., $0 \leq \overline{C_{I}^{*}} \leq 1$. Furthermore, TOPSIS technique is grounded on the principle that the higher the value of $\overline{C_{T}^{*}}$, the high the rank order, and consequently, the more the chosen alternatives are favored over others. The final result reveals that mobile money transfer (MMT) is the most preferable MFS to adopt and use with $\overline{C_{I}^{*}}$ tantamount to 0.7454 signifying $46.68 \%$ compared to 
the last two remainings. Mobile payment (MP) with 0.6106 (38.24\%) was found to be the second MFS alternative used, whereas mobile banking (MB) adoption with 0.2407 (15.07\%) is considered minor. This finding is relatively supported by the prior study on mobile banking and mobile payment, where $82 \%$ of participants under 35 years old have made mobile payments as compared to $79 \%$ who used mobile banking [216]. A similar past study has further shown that mobile payment usage among USA millennials was higher than that of mobile banking generally. The likely motive of the MFS preference acknowledged in this study can be explained based on the significant issues of concern toward perceived privacy risk. Using mobile money transfer or mobile payment service does not necessarily involve consumers' personal information or an account that needs to be connected to a bank account. By that, lots of end-users would rather opt for mobile money transfer and mobile payment than for mobile banking accordingly.

Table 7 below compares the outputs of TOPSIS and AHP and reveals the same results for the choice of the alternative ranking of mobile financial services (MFS). It was found that the outcomes were well consistent and, in general, agreed with each other. Based on the results of the ranking of the two techniques, mobile money transfer (MMT) was chosen as the most appropriate among the mobile financial services followed by mobile payment and mobile banking. However, there are slight differences found in the percentage of coefficient distribution among the classification of their alternatives. For instance, AHP reveals that MFS consumers have a high preference in using mobile money services (i.e., the difference in the percentage of coefficient: $13.32 \%$ ) as compared to TOPSIS results. Contrarily, the TOPSIS result shows that consumers are more interested in using mobile payment when considering the difference in percentage sharing between the two techniques (i.e., the difference in the percentage of coefficient: $13.75 \%$ ).

Table 7. Comparison between TOPSIS and analytic hierarchy process (AHP) outputs.

\begin{tabular}{|c|c|c|c|c|c|}
\hline $\begin{array}{c}\text { MFS } \\
\text { Alternatives }\end{array}$ & $\begin{array}{c}\text { TOPSIS \% Distribution } \\
\text { of Coefficient }\end{array}$ & TOPSIS Rank & $\begin{array}{c}\text { AHP \% Distribution of } \\
\text { Coefficient }\end{array}$ & AHP Rank & $\begin{array}{l}\text { The Difference in the \% } \\
\text { Distribution Coefficient }\end{array}$ \\
\hline MMT & $46.68 \%$ & 1 & $60 \%$ & 1 & $13.32 \%$ \\
\hline MB & $15.07 \%$ & 3 & $15.26 \%$ & 3 & $0.19 \%$ \\
\hline
\end{tabular}

Note: The outputs of AHP are derived from the previous work of Gbongli [10].

However, the results regarding the difference in percentage distribution of coefficient between TOPSIS and AHP in terms of mobile banking selection remain trivial. These results stressed that MFS consumers would not prefer using mobile banking if they have a choice between the proposed mobile financial services (MFS).

The difference between the finding of TOPSIS and AHP in the choice of MFS depends on their strengths and weaknesses, which are thoroughly pronounced in the literature [161,217]. For instance, the core advantages of AHP over TOPSIS can be attributed to its intuitive appeal to decision-makers, and its ability to check inconsistencies. Furthermore, decision-makers find the pairwise comparison system of data input convenient and straightforward. However, the application of AHP leads to the decision problem being decomposed into numerous subsystems, which require a considerable number of pairwise comparisons to be completed. Therefore, it is a complex and time-consuming implementation. In the situation of TOPSIS, the non-linear relations between one-dimensional scores and distance ratios lead to the consideration of both negative and positive ideal solutions. Also, in the TOPSIS framework, we can use variables with different units of measurement. It is very simple and easy to implement so that it is adopted when the user prefers a simpler weighting approach. However, TOPSIS, in its standard and original form, is deterministic and does not embrace uncertainty in the calculations associated with final weightings. 


\section{Conclusions}

The objective of this study was to examine the influence of both multidimensional trust and perceived risk facets at the individual level concurrently on the acceptance of mobile financial services (MFS) when prioritizing the MFS perspective. This paper's goal is to illuminate, to some extent, the MFS accessibility in Togo allied with the potential facilitators or inhibitor factors. Also, to evaluate them based on the consumer's experience and experts through a benchmark robust SEM-TOPSIS methodology. A qualitative study in the context of the Togolese was performed together with a literature review to derive the most probable factors that might influence end-users' perception of MFS since there was a scarcity of research investigating general trust and perceived risk antecedents. A quantitative study was then propelled to test the hypotheses formulated through the collected information obtained.

Our research model efficaciously integrates these dimensions, such as trust (dispositional trust, technological trust, and vendor trust), perceived risk (privacy, time, security, and cost) viewed as complex multidimensional factors. The data support the underlying assumption of the study except for H6 (see Figure 2). Mainly, our study is partially similar to the recent study done in Ghana (neighboring country of Togo) in which the perceived risk found to be related to the customer's trust in service providers regarding the adoption of mobile money [218]. In this line, our study provides more information to the various role-players of MFS about the necessity to emphasize on the trust and risk at the multidimensional level while making strategic and multicriteria decision-making.

Among the MFS alternative, the ranking result revealed mobile money to be the preferable MFS type used, followed by mobile payment and mobile banking with a minor percentage. When the ranking of TOPSIS was compared with those obtained by the AHP techniques in a similar given population, the findings were well consistent and, in general, approved with each other. However, a slight difference was found between both techniques and therefore placing TOPSIS better suited to the problem of MFS classification for the study area.

\section{Implication}

\subsection{Implication for Practice}

The outcomes of this study expose and validate the factors that impact consumers' adoption of MFS. First, the relative level of the path coefficients in our analysis model recommended that disposition to trust (an antecedent of trust) be the most salient factor that facilitates either directly or indirectly the adoption of MFS. The perceived privacy risk (an antecedent of perceived risk) as the next influential factor, however, hinders MFS adoption. Given this trusting disposition is developed throughout a lifetime [206] and reveals social impact over broad periods [198], it implies that there might be a presence of a cross-cultural difference in trust. If so, MFS companies' providers must expect various levels of trust, and thus, different proportions of MFS adoption as well. As a deduction, companies are recommended to be acquainted with building trust-based tools and for instance, increasing awareness and firms' reputations by keeping their promises while treating the customer as individuals, mainly in societies that acknowledge exhibiting a lower level of trust. MFS service providers could meritoriously upsurge adoption behavior by publicizing the advantages of MFS to potential consumers, seeing that the findings supported trust with all of its antecedents.

Moreover, by modeling perceived risk with various facets, this study's finding imparts numerous risk effect concerns. From this perspective, when companies propagandize their MFS services to ease the adoption issues, they should realistically underline a neutralizer or counter step for those risks' perceptions. The prominence of privacy risk and financial risk in the form of perceived cost as confirmed by this study and others prior research [219] signposts that customers still have doubts about the security of virtual transactions. For instance, these companies may stimulate a privacy risk protection strategy and grant technological support and anti-fraud to guarantee potential end-users minimal security risk. It is typical in the practice of emerging and developed countries (and it should 
be considered in developing countries as well) for payment service providers to try and promote trust in mobile financial services, in payments in general, as well as in other banking services by improving the general financial literacy of the population and small and medium enterprises. This is important, as those individuals who are familiar with financial processes and concepts demonstrate more trust toward financial services and can assess their risks better [220]. An increasingly popular practice is for certain governments to aid this process through an appropriate strategy and programs that serve the execution of that strategy. Because perceived time risk did not hold statistical significance in Togo, this phenomenon pinpoints that using MFS has little to do with the time spent. As such, service providers should preserve those features that ease the MFS application in the time-frame.

Lastly, the outcome of TOPSIS through an SEM-TOPSIS integrated study specifies that mobile money transfer (MMT) is indeed the predominant mobile financial service (MFS) alternative used in Togo followed by mobile payment (MP), while mobile banking (MB) is reflected as trifling. In general, MFS companies should concede that consumer trust and risk with their antecedent create a tremendous barrier to MFS transactions. This study still demonstrates that among the MFS companies, mobile money transfer companies are not powerless. It provides a practical guideline toward mobile financial service companies compared to the prevailing competitors within the related field such as online banking and ATM, for constructing more trust-based strategies to manipulate favorable consumer attitudes certainly, actions, and eventual transaction behavior whereas mitigating the perceived risk factors. Regarding MFS, companies offering mobile money transfer are suggested to sustain the adoption growth, while those performing mobile payment, mobile banking predominantly, are to bear their target consumers at the core of the business model by diversifying market strategy.

With regard to the above, we cannot ignore the network nature of the payments market, an essential characteristic of which is that the market's dynamics (all the services provided and their prices) depend on the cooperation between many actors. Therefore the optimizing and maximizing effect of the traditional, individual competition on efficiency does not necessarily prevail by itself [24]. This may account for why collaboration between actors plays a positive and decisive role in improvements in the fields of trust and encountered risks.

\subsection{Implication for Methodology and Theory}

This research remains the first to assess the multi-dimensional trust and perceived risk facet concurrently toward consumers' adoption decisions in mobile financial services while ranking their perspective.

The result obtained will open doors for scholars to explore further trust and perceived risk antecedents. It will support the theory of trust and risk literature in general and IT in particular, since many prior studies lacked conclusive outcomes about the directivity of the causative relationship between trust and perceived risk $[30,121,211]$. Our finding acknowledges the trust to be the potential predictor of risk in technology adoption. The scale items employed were greatly adopted from the prevailing studies in developed countries that are allied with technology acceptance adoption behavior, trust, and perceived risk. This section provides a crucial methodological implication for the marketing scholar, who might require a hint to cross-cultural appraisal concerning the application of scales, like those established in the United States and their relevance or relatedness in Togo. Our study outcomes not only enhance the clarification of mobile financial services adoption via the effect of trust and perceived risk but also hold some strategic implications for the global expansion of managerial implementation decision tools. This study provides a benchmark integrated methodology based on an SEM-MCDM application, which found lacking in the adoption decision in general. The theoreticians and practitioners should comprehend that the prominence of the integrated SEM-TOPSIS is rooted in its robustness to test multifarious postulations made, combined with the high level in ranking the countless alternatives when multiple criteria issues arise in decision making. 


\section{Limitation and Future Research}

Notwithstanding some contributions to the literature, practical, theoretical, and methodological applications, all research unavoidably entails drawbacks that should be addressed. Our study outcomes are unique to Togo, although they are similar to IT in general and mobile financial transactions studies, predominantly. Preferably, a longitudinal study on our framework might need to gain a better understanding of how the variables relay over time. We expect future research will address these concerns. This research displays that time risk concerns are not significant antecedents of perceived risk. We hope that future research will further elucidate the relationship between time risk issues and adoption behavior in other populaces and circumstances. Emphasizing multi-dimensional trust and perceived risk influences; this research projected to offer a wide-ranging still parsimonious decision-making model for MFS acceptance. However, the present model expounds only $13.1 \%$ of the variance in behavior to adopt. Future studies can incorporate additional variables, such as usefulness, perceived ease of use, and familiarity, in an attempt to enhance the explanatory power. Based on the respondent's educational background, our distributed questionnaire appears to be limited to the more educated and technically competent elements of society, who would be more inclined to accept MFS applications. Therefore, researchers interested in MFS for adoption and sustainability should focus more on the underbanked population where illiterate people might be found in the majority. Comparison studies between statistical methods (regression or structural equation modeling (SEM)) and the MCDM method are welcome for future work.

Author Contributions: K.G. worked on the original idea, conducted the investigation and the conceptualization, coordinated the methodology, data analysis, and writing the research paper; Y.X. worked on the investigation and provided resources; K.M.A. provided support on the investigation; L.K. supervised the work. All authors have read and agreed to the published version of the manuscript.

Funding: This research received no external funding.

Conflicts of Interest: The authors declare no conflict of interest.

\section{Appendix A}

Table A1. Measurement scales and items.

\begin{tabular}{l}
\hline Measurement Scales \\
\hline General Trust (G-trust) [221] \\
\hline Mobile financial services are trustworthy (G-trust1) \\
\hline Mobile financial services keep their promises(G-trust2) \\
\hline Mobile financial services keep customers' interests first(G-trust3) \\
\hline Dispositional Trust (DTrust) [222] \\
\hline It is easy for me to trust a person/thing. (DTrust1) \\
\hline My tendency to trust a person/thing is high. (DTrust2) \\
\hline I tend to trust a person/thing even though I have little knowledge of it. (DTrust3) \\
\hline Trusting someone or something is not difficult. (DTrust4) \\
\hline Technology Trust (TTrust) [223] \\
\hline I think the application of the mobile device for financial products or services will improve my decision on the financial transaction. \\
(TTrust1) \\
\hline I would like to try financial products such as money transfer using mobile devices application. (TTrust2) \\
\hline I think there is no technical risk in using mobile phone technology to access financial products. (TTrust3) \\
\hline Vendor Trust (Vtrust) [224] \\
\hline The vendor can safeguard the interests of consumers. (Vtrust1) \\
\hline The vendor hopes to maintain a good reputation. (Vtrust2) \\
\hline Overall, the vendor is credible. (Vtrust3) \\
\hline Perceived Risk (PRisk) [127] \\
\hline Using MFS would expose me to any kind of risk perception. (PRisk1) \\
\hline
\end{tabular}


Table A1. Cont

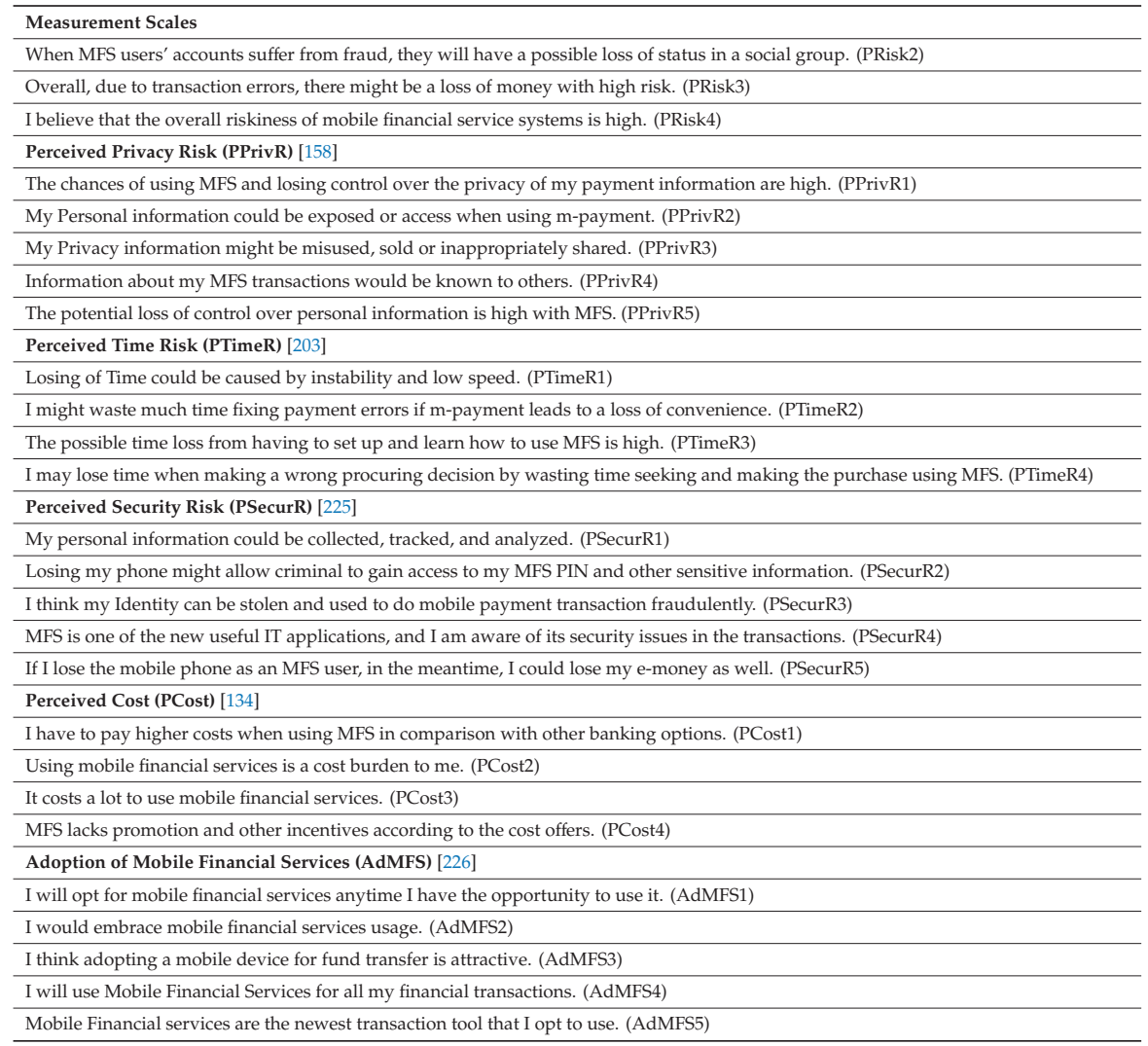

\section{References}

1. Hsu, C.L.; Wang, C.F.; Lin, J.C.C. Investigating customer adoption behaviours in Mobile Financial Services. Int. J. Mob. Commun. 2011, 9, 477. [CrossRef]

2. Oliveira, T.; Faria, M.; Thomas, M.A.; Popovič, A. Extending the understanding of mobile banking adoption: When UTAUT meets TTF and ITM. Int. J. Inf. Manag. 2014, 34, 689-703. [CrossRef]

3. Agarwal, R.; Prasad, J. Are individual differences germane to the acceptance of new information technologies? Decis. Sci. 1999, 30, 361-391. [CrossRef]

4. Afshan, S.; Sharif, A.; Waseem, N.; Frooghi, R. Internet banking in Pakistan: An extended technology acceptance perspective. Int. J. Bus. Inf. Syst. 2018, 27, 383. [CrossRef]

5. Al-Jabri, I.M.; Sohail, M.S. Mobile banking adoption: Application of diffusion of innovation theory. J. Electron. Commer. Res. 2012, 13, 379-391.

6. Abrahão, R.; Moriguchi, S.N.; Andrade, D.-F. Intention of Adoption of Mobile Payment: An analysis in the light of the Unified Theory of Acceptance and Use of Technology (UTAUT). Rev. Adm. Inov. 2016, 13, 221-230. [CrossRef]

7. Gbongli, K.; Dumor, K.; Kissi Mireku, K. MCDM technique to evaluating mobile banking adoption in the Togolese banking industry based on the perceived value: Perceived benefit and perceived sacrifice factors. Int. J. Data Min. Knowl. Manag. Process 2016, 6, 37-56.

8. Muñoz-Leiva, F.; Climent-Climent, S.; Liébana-Cabanillas, F. Determinants of Intention to Use The Mobile Banking Apps: An Extension of The Classic TAM Model. Span. J. Mark. 2017, 21, 25-38. [CrossRef] 
9. Yen, Y.S.; Wu, F.S. Predicting the adoption of mobile financial services: The impacts of perceived mobility and personal habit. Comput. Human Behav. 2016, 65, 31-42. [CrossRef]

10. Gbongli, K. A two-staged SEM-AHP technique for understanding and prioritizing mobile financial services perspectives adoption. Eur. J. Bus. Manag. 2017, 9, 107-120.

11. Lin, H.F. An empirical investigation of mobile banking adoption: The effect of innovation attributes and knowledge-based trust. Int. J. Inf. Manag. 2011, 31, 252-260. [CrossRef]

12. Mohammadi, H. A study of mobile banking loyalty in Iran. Comput. Human Behav. 2015, 44, 35-47. [CrossRef]

13. Safeena, R.; Date, H.; Kammani, A.; Hundewale, N. Technology Adoption and Indian Consumers: Study on Mobile Banking. Int. J. Comput. Theory Eng. 2012, 4, 1020-1024. [CrossRef]

14. Ooi, K.B.; Tan, G.W.H. Mobile technology acceptance model: An investigation using mobile users to explore smartphone credit card. Expert Syst. Appl. 2016, 59, 33-46. [CrossRef]

15. Gbongli, K.; Xu, Y.; Amedjonekou, K.M. Extended Technology Acceptance Model to Predict Mobile-Based Money Acceptance and Sustainability: A Multi-Analytical Structural Equation Modeling and Neural Network Approach. Sustainability 2019, 11, 3639. [CrossRef]

16. Jack, W.; Ray, A.; Suri, T. Transaction networks: Evidence from mobile money in Kenya. Am. Econ. Rev. 2013, 103, 356-361. [CrossRef]

17. Kikulwe, E.M.; Fischer, E.; Qaim, M. Mobile money, smallholder farmers, and household welfare in Kenya. PLoS ONE 2014, 9, e109804. [CrossRef]

18. Anderson, J. M-banking in developing markets: Competitive and regulatory implications. Info 2010, 12, 18-25. [CrossRef]

19. Assadi, D.; Cudi, A. Le potentiel d'inclusion financiere du Mobile Banking. Une etude exploratoire. Manag. Avenir 2011, 6, 227-243. [CrossRef]

20. Chaix, L.; Torre, D. Dominique Le double role du paiement mobile dans les pays en d'eveloppement. Rev. Econ. 2015, 66, 703-727.

21. MNB. National Bank of Hungary's Competitiveness Programme in 330 Points; Magyar Nemzeti Bank: Budapest, Hungary, 2019; ISBN 978-615-5318-26-9.

22. Couchoro, M.K. Challenges faced by MFIs in adopting Management information system during their growth phase: The case of Togo. Enterp. Dev. Microfinanc. 2016, 17, 115-131. [CrossRef]

23. Financial Afrik Faible Taux Du Mobile Banking Au Togo. Available online: http://news.alome.com/cc/24339. html (accessed on 14 March 2019).

24. Divéki, É.; Keszy-Harmath, Z.; Helmeczi, I. Innovative Payment Solutions, MNB Surveys No. 85; Magyar Nemzeti Bank: Budapest, Hungary, 2010; ISBN 1787-5293. (on-line).

25. Hassan Hosseini, M.; Fatemifar, A.; Rahimzadeh, M. Effective factors of the adoption of mobile banking services by customers. Kuwait Chapter Arab. J. Bus. Manag. Rev. 2015, 6, 1-13. [CrossRef]

26. Liébana-Cabanillas, F.; Sánchez-Fernández, J.; Muñoz-Leiva, F. Antecedents of the adoption of the new mobile payment systems: The moderating effect of age. Comput. Human Behav. 2014, 35, 464-478. [CrossRef]

27. Johnson, V.L.; Kiser, A.; Washington, R.; Torres, R. Limitations to the rapid adoption of M-payment services: Understanding the impact of privacy risk on M-Payment services. Comput. Human Behav. 2018, 79, 111-122. [CrossRef]

28. Gbongli, K.; Csordas, T.; Kissi Mireku, K. Impact of consumer multidimensional online trust-risk in adopting Togolese mobile money transfer services: Structural equation modelling approach. J. Econ. Manag. Trade 2017, 19, 1-17. [CrossRef]

29. Gbongli, K.; Peng, Y.; Ackah, O. Selection and ranking of perceived risk associated with mobile banking in West Africa: An AHP Approach from customers' perspective. Int. J. Sci. Eng. Res. 2016, 7, 80-86.

30. Mayer, R.C.; Davis, J.H.; Schoorman, F.D. An integrative model of organizational trust. Acad. Manag. Rev. 1995, 20, 709-734. [CrossRef]

31. Kovács, L.; David, S. Fraud risk in electronic payment transactions. J. Money Laund. Control. 2016, 19, 148-157. [CrossRef]

32. Gefen, D.; Benbasat, I.; Pavlou, P.A. A Research Agenda for Trust in Online Environments. J. Manag. Inf. Syst. 2008, 24, 275-286. [CrossRef]

33. Wells, J.D.; Campbell, D.E.; Valacich, J.S.; Featherman, M. The Effect of Perceived Novelty on the Adoption of Information Technology Innovations: A Risk/Reward Perspective. Decis. Sci. 2010, 41, 813-843. [CrossRef] 
34. Marett, K.; Pearson, A.W.; Pearson, R.A.; Bergiel, E. Using mobile devices in a high risk context: The role of risk and trust in an exploratory study in Afghanistan. Technol. Soc. 2015, 41, 54-64. [CrossRef]

35. Lee, K.C.; Chung, N. Understanding factors affecting trust in and satisfaction with mobile banking in Korea: A modified DeLone and McLean's model perspective. Interact. Comput. 2009, 21, 385-392. [CrossRef]

36. Gao, L.; Waechter, K.A. Examining the role of initial trust in user adoption of mobile payment services: An empirical investigation. Inf. Syst. Front. 2017, 19, 525-548. [CrossRef]

37. Alsaad, A.; Mohamad, R.; Ismail, N.A. The moderating role of trust in business to business electronic commerce (B2B EC) adoption. Comput. Human Behav. 2017, 68, 157-169. [CrossRef]

38. Lowry, P.B.; Vance, A.; Moody, G.; Beckman, B.; Read, A. Explaining and Predicting the Impact of Branding Alliances and Web Site Quality on Initial Consumer Trust of E-Commerce Web Sites. J. Manag. Inf. Syst. 2008, 24, 199-224. [CrossRef]

39. Luo, X.; Li, H.; Zhang, J.; Shim, J.P. Examining multi-dimensional trust and multi-faceted risk in initial acceptance of emerging technologies: An empirical study of mobile banking services. Decis. Support Syst. 2010, 49, 222-234. [CrossRef]

40. Park, S.; Tussyadiah, I.P. Multidimensional Facets of Perceived Risk in Mobile Travel Booking. J. Travel Res. 2017, 56, 854-867. [CrossRef]

41. Aktepe, A.; Ersöz, S.; Toklu, B. Customer satisfaction and loyalty analysis with classification algorithms and Structural Equation Modeling. Comput. Ind. Eng. 2015, 86, 95-106. [CrossRef]

42. Alzahrani, L.; Al-Karaghouli, W.; Weerakkody, V. Investigating the impact of citizens' trust toward the successful adoption of e-government: A multigroup analysis of gender, age, and internet experience. Inf. Syst. Manag. 2018, 35, 124-146. [CrossRef]

43. Shieh, L.F.; Chang, T.H.; Fu, H.P.; Lin, S.W.; Chen, Y.Y. Analyzing the factors that affect the adoption of mobile services in Taiwan. Technol. Forecast. Soc. Chang. 2014, 87, 80-88. [CrossRef]

44. Figueira, J.; Greco, S.; Ehrgott, M. Multiple criteria decision analysis: State of the art surveys. Mult. Criteria Decis. Anal. State Art Surv. 2005, 78, 859-890.

45. Valaskova, K.; Kramarova, K.; Bartosova, V. Multi Criteria Models Used in Slovak Consumer Market for Business Decision Making. Procedia Econ. Financ. 2015, 26, 174-182. [CrossRef]

46. Esearch, S.Y.R.; Koppius, O.R. Predictive Analytics in Information Systems Research. MIS Q. 2011, 35, 553-572.

47. Scott, J.E.; Walczak, S. Cognitive engagement with a multimedia ERP training tool: Assessing computer self-efficacy and technology acceptance. Inf. Manag. 2009, 46, 221-232. [CrossRef]

48. Hung, Y.H.; Chou, S.C.T.; Tzeng, G.H. Using MCDM methods to adopt and assess knowledge management. In Communications in Computer and Information Science; Springer: Berlin/Heidelberg, Germany, 2009; Volume 35, pp. 840-847.

49. Gupta, K.P.; Bhaskar, P.; Singh, S. Prioritization of factors influencing employee adoption of e-government using the analytic hierarchy process. J. Syst. Inf. Technol. 2017, 19, 116-137. [CrossRef]

50. Liou, J.J.H.; Tzeng, G.H. Comments on Multiple criteria decision making (MCDM) methods in economics: An overview. Technol. Econ. Dev. Econ. 2012, 18, 672-695. [CrossRef]

51. Gbongli, K.; Kovács, L. A Decision Analysis towards Mobile Financial Services Adoption and Sustainability in Togo: Structural Equation Modeling and TOPSIS Methodology. In Proceedings of the DSI 2019 Annual Meeting of Decision Sciences Institute, New Orleans, LA, USA, 23-25 November 2019; pp. 2080-2114.

52. Abu-Shanab, E.A.; Abu-Baker, A.N. Using and buying mobile phones in Jordan: Implications for future research and the Development of New Methodology. Technol. Soc. 2014, 38, 103-110. [CrossRef]

53. Laukkanen, T. Mobile banking. Int. J. Bank Mark. 2017, 35, 1042-1043. [CrossRef]

54. Hendricks, L.; Chidiac, S. Village Savings and Loans: A Pathway to Financial Inclusion for Africa's Poorest Households. Enterp. Dev. Microfinance 2011, 22, 134-146. [CrossRef]

55. Donovan, K. Mobile Money for Financial Inclusion. Inf. Commun. Dev. 2012, 61, 61-73. [CrossRef]

56. Dennehy, D.; Sammon, D. Trends in mobile payments research: A literature review. J. Innov. Manag. 2015, 3, 49-61. [CrossRef]

57. Lee, J.K.; Rao, H.R. Perceived risks, counter-beliefs, and intentions to use anti-/counter-terrorism websites: An exploratory study of government-citizens online interactions in a turbulent environment. Decis. Support Syst. 2007, 43, 1431-1449. [CrossRef] 
58. Li, H.; Sarathy, R.; Xu, H. The role of affect and cognition on online consumers' decision to disclose personal information to unfamiliar online vendors. Decis. Support Syst. 2011, 51, 434-445. [CrossRef]

59. Wisdom, J.P.; Chor, K.H.B.; Hoagwood, K.E.; Horwitz, S.M. Innovation adoption: A review of theories and constructs. Adm. Policy Ment. Health Ment. Health Serv. Res. 2014, 41, 480-502. [CrossRef]

60. Safeena, R.; Date, H.; Hundewale, N.; Kammani, A. Combination of TAM and TPB in Internet Banking Adoption. Int. J. Comput. Theory Eng. 2013, 5, 146-150. [CrossRef]

61. Yan, H.; Yang, Z. Examining mobile payment user adoption from the perspective of trust. Int. J. U E Serv. Sci. Technol. 2015, 8, 117-130. [CrossRef]

62. Slade, E.L.; Williams, M.D.; Dwivedi, Y.K. Mobile payment adoption: Classification and review of the extant literature. Mark. Rev. 2013, 13, 167-190. [CrossRef]

63. Tam, C.; Oliveira, T. Understanding mobile banking individual performance. Internet Res. 2017, 27, 538-562. [CrossRef]

64. Slade, E.; Williams, M.; Dwivedi, Y.; Piercy, N. Exploring consumer adoption of proximity mobile payments. J. Strateg. Mark. 2015, 23, 209-223. [CrossRef]

65. Fishbein, M.; Ajzen, I. Belief, Attitude, Intention and Behaviour: An Introduction to Theory and Research; Addison-Wesley: Reading, MA, USA, 1975. [CrossRef]

66. Ajzen, I. From intentions to action: A theory of planned behavior. In Action Control; Springer: Berlin/Heidelberg, Germany, 1985; pp. 11-39. ISBN 978-3-642-69746-3.

67. Barua, P. The Moderating Role of Perceived Behavioral Control: The Literature Criticism and Methodological Considerations. Int. J. Bus. Soc. Sci. 2013, 4, 57-59.

68. Davis, F.D.; Bagozzi, R.P.; Warshaw, P.R. User acceptance of computer technology: A comparison of two theoretical models. Manag. Sci. 1989, 35, 982-1003. [CrossRef]

69. Marangunić, N.; Granić, A. Technology acceptance model: A literature review from 1986 to 2013. Univers. Access Inf. Soc. 2015, 14, 81-95. [CrossRef]

70. Legris, P.; Ingham, J.; Collerette, P. Why do people use information technology? a critical review of the technology acceptance model. Inf. Manag. 2003, 40, 191-204. [CrossRef]

71. Mortenson, M.J.; Vidgen, R. A computational literature review of the technology acceptance model. Int. J. Inf. Manag. 2016, 36, 1248-1259. [CrossRef]

72. Davis, F. Perceived usefulness, perceived ease of use, and user acceptance of information technology. MIS Q. 1989, 13, 319-340. [CrossRef]

73. Gefen, D.; Straub, D.; Mack, J.; Distinguished, R. The relative importance of perceived ease of use in IS adoption: A study of e-commerce adoption. J. Assoc. Inf. Syst. 2000, 1, 1-30. [CrossRef]

74. Pavlou, P.A. Integrating trust in electronic commerce with the technology acceptance model: Model development and validation. In Proceedings of the Seventh Americas Conference in Information Systems AMCIS, Boston, MA, USA, 3-5 August 2001; pp. 816-822.

75. Waite, K.; Harrison, T. Online banking adoption: We should know better 20 years on. J. Financ. Serv. Mark. 2015, 20, 258-272. [CrossRef]

76. Thompson, R.L.; Higgins, C.A.; Howell, J.M. Personal Computing-Toward a Conceptual-Model of Utilization. MIS Q. 1991, 15, 125-143. [CrossRef]

77. Webster, J.; Martocchio, J.J. Microcomputer Playfulness: Development of a Measure with Workplace Implications. MIS Q. 1992, 16, 201. [CrossRef]

78. Suh, B.; Han, I. The Impact of Customer Trust and Perception ofSecurity Control on the Acceptance ofElectronic Commerce. Int. J. Electron. Commer. 2003, 7, 135-161.

79. Rogers, E.M. Diffusion of Innovations; Free Press of Glencoe: New York, NY, USA, 1962.

80. Plouffe, C.R.; Vandenbosch, M.; Hulland, J. Intermediating technologies and multi-group adoption: A comparison of consumer and merchant adoption intentions toward a new electronic payment system. J. Prod. Innov. Manag. 2001, 18, 65-81. [CrossRef]

81. Karahanna, E.; Straub, D.W.; Chervany, N.L.; Karahanna, E. Information technology adoption across time: A cross-sectional comparison of pre-adoption and post-adoption beliefs. MIS Q. 1999, 23, 183-213. [CrossRef]

82. Chen, L.-D.; Gillenson, M.L.; Sherrell, D.L. Enticing online consumers: An extended technology acceptance perspective. Inf. Manag. 2002, 39, 705-719. [CrossRef]

83. Lyytinen, K.; Damsgaard, J. What's Wrong with the diffusion of innovation theory? The case of a complex and networked technology. Reports Aalborg Univ. Dep. Comput. Sci. 2001, 187, 1-20. [CrossRef] 
84. Napaporn, K. Examining a Technology Acceptance Model of Internet Usage by Academics Within Thai Business Schools. Ph.D. Thesis, Victoria University, Melbourne, Australia, 2007.

85. Singleton, R.A.; Straits, B.C.; Straits, M.M. Approaches to Social Research, 2nd ed.; Oxford University Press: New York, NY, USA, 1993.

86. Taylor, S.; Todd, P.A. Understanding information technology usage: A test of competing models. Inf. Syst. Res. 1995, 6, 144-176. [CrossRef]

87. El-Kasheir, D.; Ashour, A.; Yacout, O. Factors affecting continued usage of internet banking among Egyptian customers. Commun. IBIMA 2009, 9, 252-263.

88. George, J.F. The theory of planned behavior and Internet purchasing. Internet Res. 2004, 14, 198-212. [CrossRef]

89. Aboelmaged, M.G.; Gebba, R.T. Mobile Banking Adoption: An Examination of Technology Acceptance Model and Theory of Planned Behavior. Int. J. Bus. Res. Dev. 2013, 2, 35-50. [CrossRef]

90. Shaikh, A.A.; Karjaluoto, H. Mobile banking adoption: A literature review. Telemat. Inform. 2014, 32, $129-142$. [CrossRef]

91. Narteh, B.; Mahmoud, M.A.; Amoh, S. Customer behavioural intentions towards mobile money services adoption in Ghana. Serv. Ind. J. 2017, 37, 426-447. [CrossRef]

92. Alalwan, A.A.; Dwivedi, Y.K.; Rana, N.P. Factors influencing adoption of mobile banking by Jordanian bank customers: Extending UTAUT2 with trust. Int. J. Inf. Manag. 2017, 37, 99-110. [CrossRef]

93. Afawubo, K.; Agbagla, M.; Couchoro, K.M.; Gbandi, T. Socioeconomic determinants of the mobile money adoption process: The case of Togo. Cah. Rech. 2017, 17, 1-23.

94. Gefen, D.; Straub, D. Managing User Trust in B2C e-Services. e-Serv. 2003, 2, 7-24. [CrossRef]

95. Mcknight, D.H.; Chervany, N.L. What trust means in e-commerce customer relationships: An interdisciplinary conceptual typology. Int. J. Electron. Commer. 2001, 6, 35-59. [CrossRef]

96. Tan, F.B.; Sutherland, P. Online Consumer Trust: A Multi-Dimensional Model. J. Electron. Commer. Organ. 2004, 2, 40-58. [CrossRef]

97. Vidotto, G.; Massidda, D.; Noventa, S.; Vicentini, M. Trusting beliefs: A functional measurement study. Psicologica 2012, 33, 575-590.

98. Nor, K.M.; Pearson, J.M. An Exploratory Study Into The Adoption of Internet Banking in a Developing Country: Malaysia. J. Internet Commer. 2008, 7, 29-73. [CrossRef]

99. Schoorman, F.D.; Mayer, R.C.; Davis, J.H. An Integrative Model of Organizational Trust: Past, Present, and Future. Acad. Manag. Rev. 2007, 32, 344-354. [CrossRef]

100. Hallikainen, H.; Laukkanen, T. National culture and consumer trust in e-commerce. Int. J. Inf. Manag. 2018, 38, 97-106. [CrossRef]

101. Gefen, D.; Karahanna, E.; Straub, D.W. Trust and TAM in online shopping: An integrated mode. MIS Q. 2003, 27, 51-90. [CrossRef]

102. Mcknight, D.H.; Carter, M.; Thatcher, J.B. Trust in a Specific Technology: An Investigation of Its Components and Measures Trust in a specific technology: An investigation of its components and measures. ACM Trans. Manag. Inform. Syst. 2011, 2, 1-25. [CrossRef]

103. Muir, B.M.; Moray, N. Trust in automation. Part II. Experimental studies of trust and human intervention in a process control simulation. Ergonomics 1996, 39, 429-460. [CrossRef] [PubMed]

104. Misiolek, N.; Zakaria, N.; Zhang, P. Trust in organizational acceptance of information technology: A conceptual model and preliminary evidence. In Proceedings of the Decision Sciences Institute 33rd Annual Meeting, San Diego, CA, USA, 23-26 November 2002; pp. 1-7.

105. Meng, D.; Min, Q.; Li, Y. Study on trust in mobile commerce adoption-A conceptual model. In Proceedings of the International Symposium on Electronic Commerce and Security, Guangzhou, China, 3-5 August 2008; pp. 246-249.

106. Min, Q.; Meng, D.; Zhong, Q. An empirical study on trust in mobile commerce adoption. In Proceedings of the 2008 IEEE International Conference on Service Operations and Logistics, and Informatics, Beijing, China, 12-15 October 2008; Volume 1, pp. 659-664.

107. Lankton, N.K.; Harrison McKnight, D.; Wright, R.T.; Thatcher, J.B. Using expectation disconfirmation theory and polynomial modeling to understand trust in technology. Inf. Syst. Res. 2016, 27, 197-213. [CrossRef]

108. Bailey, B.P.; Gurak, L.J.; Konstan, J. Trust in Cyberspace. In Human Factors and Web Development, 2nd ed.; Ratner, J., Ed.; Lawrence Erlbaum Associates: Mahwah, NJ, USA, 2002. 
109. Pavlou, P.A.; Liang, H.; Xue, Y. Understanding and Mitigating Uncertainty in Online Exchnge Relationships: A Principle-Agent Perspective. MIS Q. 2007, 31, 105-136. [CrossRef]

110. Liu, Z.; Min, Q.; Ji, S. An empirical study on mobile banking adoption: The role of trust. In Proceedings of the 2009 Second International Symposium on Electronic Commerce and Security, Nanchang, China, 22-24 May 2009; Volume 2, pp. 7-13.

111. Yang, S. Role of transfer-based and performance-based cues on initial trust in mobile shopping services: A cross-environment perspective. Inf. Syst. E-Bus. Manag. 2016, 14, 47-70. [CrossRef]

112. Yang, S.; Chen, Y.; Wei, J. Understanding consumers' web-mobile shopping extension behavior: A trust transfer perspective. J. Comput. Inf. Syst. 2015, 55, 78-87. [CrossRef]

113. Nilashi, M.; Ibrahim, O.; Reza Mirabi, V.; Ebrahimi, L.; Zare, M. The role of Security, Design and Content factors on customer trust in mobile commerce. J. Retail. Consum. Serv. 2015, 26, 57-69. [CrossRef]

114. Rogers, E.M. Diffusion of Innovations, 3rd ed.; Free Press: New York, NY, USA, 1983.

115. Bhattacherjee, A. Individual Trust in Online Firms: Scale Development and Initial test. J. Manag. Inf. Syst. 2002, 19, 211-242.

116. Bauer, R.A. Consumer behavior as risk taking. In Risk Taking and Information Handling in Consumer Behavior; Harvard University Press: Cambridge, MA, USA, 1960; pp. 389-398.

117. Cunningham, S.M. The Major Dimensions of Perceived Risk, in Risk Taking and Information Handling in Consumer Behavior; Harvard University: Cambridge, MA, USA, 1967; Volume 82-108.

118. Costigan, R.D.; Ilter, S.S.; Berman, J.J. A Multi-Dimensional Study of Trust in Organizations. J. Manag. 1998, 10, 303-316.

119. Johnson-George, C.; Swap, W.C. Measurement of specific interpersonal trust: Construction and validation of a scale to assess trust in a specific other. J. Personal. Soc. Psychol. 1982, 43, 1306-1317. [CrossRef]

120. Koller, M. Risk as a Determinant of Trust. Basic Appl. Soc. Psych. 1988, 9, 265-276. [CrossRef]

121. Gefen, D.; Srinivasan Rao, V.; Tractinsky, N. The conceptualization of trust, risk and their electronic commerce: The need for clarifications. In Proceedings of the 36th Annual Hawaii International Conference on System Sciences, HICSS 2003, Big Island, HI, USA, 6-9 January 2003.

122. Jarvenpaa, S.L.; Tractinsky, N.; Vitale, M. Consumer Trust in an Internet Store. Inf. Technol. Manag. 2000, 1, 45-71. [CrossRef]

123. Grandison, T.; Sloman, M. A survey of trust in internet applications. IEEE Commun. Surv. Tutor. 2000, 3, 2-16. [CrossRef]

124. Johnston, A.C.; Warkentin, M. The Online Consumer Trust Construct: A Web Merchant Practitioner Perspective. In Proceedings of the 7th Annual Conference of the Southern Association for Information Systems, Savannah, GA, USA, 27-28 February 2004; pp. 220-226.

125. Merhi, M.; Hone, K.; Tarhini, A. A cross-cultural study of the intention to use mobile banking between Lebanese and British consumers: Extending UTAUT2 with security, privacy and trust. Technol. Soc. 2019, 59, 101151. [CrossRef]

126. Swaminathan, V.; Lepkowska-White, E.; Rao, B.P. Browsers or Buyers in Cyberspace? An Investigation of Factors Influencing Electronic Exchange. J. Comput. Commun. 1999, 5. [CrossRef]

127. Featherman, M.S.; Pavlou, P.A. Predicting e-services adoption: A perceived risk facets perspective. Int. J. Hum. Comput. Stud. 2003, 59, 451-474. [CrossRef]

128. Bellman, S.; Lohse, G.L.; Johnson, E.J. Predictors of online buying behavior. Commun. ACM 1999, 42, 32-38. [CrossRef]

129. Murray, K.B.; Schlacter, J.L. The impact of services versus goods on consumers' assessment of perceived risk and variability. J. Acad. Mark. Sci. 1990, 18, 51-65. [CrossRef]

130. Lee, M.C. Predicting Behavioural Intention to Use Online Banking. In Proceedings of the 19th International Conference on Information Management, Taipei, Taiwan, 13-14 November 2008.

131. Yang, A.S. Exploring Adoption difficulties in mobile banking services. Can. J. Adm. Sci. 2009, 26, 136-149. [CrossRef]

132. Cruz, P.; Neto, L.B.F.; Muñoz-Gallego, P.; Laukkanen, T. Mobile banking rollout in emerging markets: Evidence from Brazil. Int. J. Bank Mark. 2010, 28, 342-371. [CrossRef]

133. Yao, H.; Zhong, C. The analysis of influencing factors and promotion strategy for the use of mobile banking/L'analyse d'influencer des facteurs et la stratégie de promotion pour l'usage des opérations bancaires mobiles. Can. Soc. Sci. 2011, 7, 60-63. 
134. Luarn, P.; Lin, H.-H. Toward an understanding of the behavioral intention to use mobile banking. Comput. Human Behav. 2005, 21, 873-891. [CrossRef]

135. McKnight, D.H.; Cummings, L.L.; Chervany, N.L. Initial trust formation in new organizational relationships. Acad. Manag. Rev. 1998, 23, 473-490. [CrossRef]

136. McKnight, D.H.; Choudhury, V.; Kacmar, C. Developing and validating trust measures for e-commerce: An integrative typology. Inf. Syst. Res. 2002, 13, 334-359. [CrossRef]

137. Gefen, D. E-commerce: The role of familiarity and trust. Omega 2000, 28, 725-737. [CrossRef]

138. Kim, K.K.; Prabhakar, B. Initial Trust and the Adoption of B2C e-Commerce: The Case of Internet Banking. ACM SIGMIS Database 2004, 35, 50-64. [CrossRef]

139. Guangming, Y.; Yuzhong, M. A research on the model of factors influencing consumer trust in mobile business. In Proceedings of the 2011 International Conference on E-Business and E-Government, Shanghai, China, 6-8 May 2011; pp. 1-5.

140. Pratt, J.W. Risk Aversion in the Small and in the Large. Econometrica 1964, 32, 122-136. [CrossRef]

141. Kogan, N.; Wallach, M.A. Risk-Taking: A Study in Cognition and Personality; Rhinehart \& Winston: New York, NY, USA, 1964.

142. Cox, D.F. Risk Taking and Information Handling in Consumer Behavior; Harvard University: Boston, MA, USA, 1967.

143. Bonoma, T.V.; Johnston, W.J. Decision making under uncertainty: A direct measurement approach. J. Consum. Res. 1979, 6, 177. [CrossRef]

144. Currim, I.S.; Sarin, R.K. A Procedure for Measuring and Estimating Consumer Preferences Under Uncertainty. J. Mark. Res. 1983, 20, 249-256. [CrossRef]

145. Cunningham, L.F.; Gerlach, J.H.; Harper, M.D.; Young, C.E. Perceived risk and the consumer buying process: Internet airline reservations. Int. J. Serv. Ind. Manag. 2005, 16, 357-372. [CrossRef]

146. Lee, M.S.Y.; McGoldrick, P.J.; Keeling, K.A.; Doherty, J. Using ZMET to explore barriers to the adoption of 3G mobile banking services. Int. J. Retail Distrib. Manag. 2003, 31, 340-348. [CrossRef]

147. Kim, K.K.; Prabhakar, B. Initial trust, perceived risk, and the adoption of internet banking. ICIS 2000 Proc. 2000, 55, 537-543.

148. Laforet, S.; Li, X. Consumers' attitudes towards online and mobile banking in China. Int. J. Bank Mark. 2005, 23, 362-380. [CrossRef]

149. Lee, E.; Kwon, K.; Schumann, D.W. Segmenting the non-adopter category in the diffusion of internet banking. Int. J. Bank Mark. 2005, 23, 414-437. [CrossRef]

150. Tan, M.; Teo, T.S.H. Factors Influencing the Adoption of Internet Banking. J. AIS 2000, 1, 1-42. [CrossRef]

151. Liang, T.-P.; Huang, J.-S. An empirical study on consumer acceptance of products in electronic markets: A transaction cost model. Decis. Support Syst. 1998, 24, 29-43. [CrossRef]

152. Liao, Z.; Cheung, M.T. Internet-based e-shopping and consumer attitudes: An empirical study. Inf. Manag. 2001, 38, 299-306. [CrossRef]

153. Kim, D.J.; Ferrin, D.L.; Rao, H.R. A trust-based consumer decision-making model in electronic commerce: The role of trust, perceived risk, and their antecedents. Decis. Support Syst. 2008, 44, 544-564. [CrossRef]

154. Pavlou, P.A. Consumer intentions to adopt electronic commerce-Incorporating trust and risk in the technology acceptance model. Int. J. Electron. Commer. 2003, 7, 101-134.

155. Dowling, G.R.; Staelin, R. A Model of Perceived Risk and Intended Risk-Handling Activity. J. Consum. Res. 1994, 21, 119. [CrossRef]

156. Assael, H. Consumer Behavior and Marketing Action, 6th ed.; South-Western College Publishing: Cincinnati, OH, USA, 1998.

157. Coulter, R.A.; Price, L.L.; Feick, L. Rethinking the Origins of invoivement and Brand Commitment: Insights from Postsociaiist Centrai Europe. J. Consum. Res. 2003, 30, 151-169. [CrossRef]

158. Jarvenpaa, S.L.; Tractinsky, N. Consumer trust in an Internet store: A cross cultural validation. J. Comput. Mediat. Commun. 1999, 5, 1-5. [CrossRef]

159. Cooper, D.R.; Schindler, P.S. Business Research Methods, 8th ed.; McGraw-Hill Irwin: Boston, MA, USA, 2003; ISBN 0199284989.

160. Straub, D.; Boudreau, M.; Gefen, D. Validation Guidelines for IS Positivist Validation Guidelines for IS Positivist. Commun. Assoc. Inf. Syst. 2004, 13, 380-427. 
161. Gbongli, K. Integrating AHP-TOPSIS approach on prioritizing self-service technology (SST) decision making in financial institution (Togo). Br. J. Math. Comput. Sci. 2016, 16, 1-22.

162. N'Guissan, Y. Résultats définitifs du 4ème recensement général (RGPH4) au Togo. Available online: http://www.stat-togo.org/index.php/rgph (accessed on 25 March 2018).

163. Yamane, T. Statistics: An introductory analysis. Harper Row 1967, 60, 886.

164. Kumar Mittal, V.; Singh Sangwan, K. Development of a structural model of environmentally conscious manufacturing drivers. J. Manuf. Technol. Manag. 2014, 25, 1195-1208. [CrossRef]

165. Hair, J.F.; Black, W.C.; Babin, B.J.; Anderson, R.E.; Tatham, R.L. Multivariate Data Analysis, 7th ed.; Pearson: New York, NY, USA, 2010; ISBN 9788577804023.

166. Chin, W. The partial least squares approach to structural equation modeling. Mod. Methods Bus. Res. 1998, 295, 295-336.

167. Anderson, J.C.; Gerbing, D.W. Structural equation modeling in practice: A review and recommended two-step approach. Psychol. Bull. 1988, 103, 411-423. [CrossRef]

168. Schumacher, R.E.; Lomax, R.G. A Beginner's Guide to Structural Equation Modeling; Lawrence Erlbaum Associates: Mahwah, NJ, USA, 1996.

169. Hair, J.F.; Black, W.; Babin, B.; Anderson, R.; Tatham, R. Multivariate Data Analysis, 6th ed.; Pearson Prentice Hall, Pearson Education, Inc.: Upper Saddle River, NJ, USA, 2006; Volume 6, ISBN 909003868X.

170. Aloini, D.; Martini, A.; Pellegrini, L. A structural equation model for continuous improvement: A test for capabilities, tools and performance. Prod. Plan. Control Manag. Oper. 2011, 22, 628-648. [CrossRef]

171. Kaiser, H.F. An index of factorial simplicity. Psychometrika 1974, 39, 31-36. [CrossRef]

172. Campbell, D.T.; Fiske, D.W. Convergent and discriminant validity by the multitrait-multimethod matrix. Psychol. Bull. 1959, 56, 81-105. [CrossRef] [PubMed]

173. Zhou, T. Examining mobile banking user adoption from the perspectives of trust and flow experience. Inf. Technol. Manag. 2012, 13, 27-37. [CrossRef]

174. Fornell, C.; Larcker, D.F. Structural Equation Models with Unobservable Variables and Measurement Error: Algebra and Statistics. J. Mark. Res. 1981, 18, 382-388. [CrossRef]

175. Hair, J.F.; Anderson, R.E.; Tatham, R.L.; Black, W.C. Multivariate Data Analysis, 7th ed.; Prentice Hall: Upper Saddle River, NJ, USA, 2010. [CrossRef]

176. Zhou, T.; Lu, Y.; Wang, B. Integrating TTF and UTAUT to explain mobile banking user adoption. Comput. Hum. Behav. 2010, 26, 760-767. [CrossRef]

177. Hwang, Y. User experience and personal innovativeness: An empirical study on the Enterprise Resource Planning systems. Comput. Human Behav. 2014, 34, 227-234. [CrossRef]

178. Podsakoff, P.M.; MacKenzie, S.B.; Lee, J.; Podsakoff, N.P. Common method biases in behavioral research: A critical review of the literature and recommended remedies. J. Appl. Psychol. 2003, 88, 879-903. [CrossRef]

179. Davidov, E. A cross-country and cross-time comparison of the human values measurements with the second round of the European social survey. Surv. Res. Methods 2008, 2, 33-46.

180. Hwang, C.-L.; Yoon, K. Multiple Attribute Decision Making: Methods and Applications: A State-of-the-Art Survey; Springer: Berlin, Germany; New York, NY, USA, 1981; Volume 259.

181. Patil, S.K.; Kant, R. A fuzzy AHP-TOPSIS framework for ranking the solutions of Knowledge Management adoption in Supply Chain to overcome its barriers. Expert Syst. Appl. 2014, 41, 679-693. [CrossRef]

182. Mahdevari, S.; Shahriar, K.; Esfahanipour, A. Human health and safety risks management in underground coal mines using fuzzy TOPSIS. Sci. Total Environ. 2014, 488, 85-99. [CrossRef]

183. Dhull, S.; Narwal, M.S. Prioritizing the Drivers of Green Supply Chain Management in Indian Manufacturing Industries Using Fuzzy TOPSIS Method: Government, Industry, Environment, and Public Perspectives. Process Integr. Optim. Sustain. 2018, 2, 47-60. [CrossRef]

184. Vinodh, S.; Prasanna, M.; Hari Prakash, N. Integrated Fuzzy AHP-TOPSIS for selecting the best plastic recycling method: A case study. Appl. Math. Model. 2014, 38, 4662-4672. [CrossRef]

185. Behzadian, M.; Khanmohammadi Otaghsara, S.; Yazdani, M.; Ignatius, J. A state-of the-art survey of TOPSIS applications. Expert Syst. Appl. 2012, 39, 13051-13069. [CrossRef]

186. Lin, C.T.; Tsai, M.C. Location choice for direct foreign investment in new hospitals in China by using ANP and TOPSIS. Qual. Quant. 2010, 44, 375-390. [CrossRef]

187. Shih, H.S.; Shyur, H.J.; Lee, E.S. An extension of TOPSIS for group decision making. Math. Comput. Model. 2007, 45, 801-813. [CrossRef] 
188. Shipley, M.F.; de Korvin, A.; Obid, R. A decision making model for multi-attribute problems incorporating uncertainty and bias measures. Comput. Oper. Res. 1991, 18, 335-342. [CrossRef]

189. Punniyamoorty, M.; Mathiyalagan, P.; Lakshmi, G. A combined application of structural equation modeling (SEM) and analytic hierarchy process (AHP) in supplier selection. Benchmarking An Int. J. 2012, 19, 70-92. [CrossRef]

190. Payne, R.; Clark, M. Dispositional and situational determinants of trust in two types of managers. Int. J. Hum. Resour. Manag. 2003, 14, 128-138. [CrossRef]

191. Salam, A.F.; Iyer, L.; Palvia, P.; Singh, R. Trust in e-commerce. Commun. ACM 2005, 48, 72-77. [CrossRef]

192. Lippert, S.K.; Forman, H. A supply chain study of technology trust and antecedents to technology internalization consequences. Int. J. Phys. Distrib. Logist. Manag. 2006, 36, 271-288. [CrossRef]

193. Pavlou, P.; Ratnasingam, P. Technology trust in B2B electronic commerce: Conceptual foundations. In Business Strategies for Information Technology Management; Kangas, K., Ed.; Idea Group Publishing: Hershey, PA, USA, 2001; pp. 200-215.

194. Aldridge, A.; White, M.; Forcht, K. Security considerations of doing business via the Internet: Cautions to be considered. Internet Res. 1997, 7, 9-15. [CrossRef]

195. Pavlou, A.P. Consumer acceptance of electronic commerce: Integrating trust and risk with the technology acceptance model. Int. J. Electron. Commer. 2003, 7, 69-103.

196. Cheung, C.; Lee, M.K.O. Trust in Internet Shopping: A Proposed Model and Measurement Instrument. In Americas Conference on Information Systems; AIS Electronic Library: Long Beach, CA, USA, 2000; pp. 680-689.

197. Kesharwani, A.; Bisht, S.S. The impact of trust and perceived risk on internet banking adoption in India: An extension of technology acceptance model. Int. J. Bank Mark. 2012, 30, 303-322. [CrossRef]

198. Fukuyama, F. Trust: The Social Virtues and the Creation of Prosperity. In Trust the Social Virtues and the Creation of Prosperity; Free Press: New York, NY, USA, 1995; p. 457. [CrossRef]

199. Ratnasingham, P.; Kumar, K. Trading partner trust in electronic commerce participation. ICIS 2000 Proc. 2000, 56, 544-552.

200. Zikmund, G.W.; Scott, E.J. A Multivariate Analysis of Perceived Risk Self-Confidence and Information Sources. N. Am. Adv. Consum. Res. 1974, 1, 406-416.

201. Boksberger, P.E.; Bieger, T.; Laesser, C. Multidimensional analysis of perceived risk in commercial air travel. J. Air Transp. Manag. 2007, 13, 90-96. [CrossRef]

202. Choffee, S.H.; McLeod, J.M. Consumer Decisions and Information Use; Ward, S., Robertson, T.S., Eds.; Consumer behavior: Theoretical sources; Prentice-Hall Inc.: Englewood Cliffs, NJ, USA, 1973.

203. Zhang, L.; Tan, W.; Xu, Y.; Tan, G. Dimensions of perceived risk and their influence on consumers' purchasing behavior in the overall process of B2C. In Engineering Education and Management; Zhang, L., Zhang, C., Eds.; Springer: Berlin/Heidelberg, Germany, 2012; Volume 111, pp. 1-11.

204. Chakuthip, A.; Brunetto, Y.; Rod, F.-W.; Sheryl, R. Trust, Social Network and Electronic Commerce Adoption. In Handbook of Research on Electronic Collaboration and Organizational Synergy; IGI Global: Hershey, NY, USA, 2007; pp. 452-471. [CrossRef]

205. Grabner-Kräuter, S.; Kaluscha, E.A. Empirical research in on-line trust: A review and critical assessment. Int. J. Hum. Comput. Stud. 2003, 58, 783-812. [CrossRef]

206. Rotter, J.B. Generalized expectancies for interpersonal trust. Am. Psychol. 1971, 26, 443-452. [CrossRef]

207. Mitchell, V. Consumer perceived risk: Conceptualisations and models. Eur. J. Mark. 1999, 33, $163-195$. [CrossRef]

208. Manchiraju, S.; Vudayagiri, G.; Garg, G. Capgemini Top 10 trends in payment in 2016. Available online: https://www.capgemini.com/resource-file-access/resource/pdf/payments_trends_2016.pdf (accessed on 20 September 2019).

209. De Fouchier, R.; Larduinat, X. Connected living: How technology could impact daily lives by 2025-An International Study of Consumers Expectations for the Future of Mobile Technology. Available online: http://www.gemalto.com/brochures-site/download-site/Documents/documentgating/telwp-connected-living-2025.pdf (accessed on 25 September 2019).

210. Hosmer, L.T. Trust: The connecting link between organizational theory and philosophical ethics. Acad. Manag. Rev. 1995, 20, 379-403. [CrossRef]

211. Rousseau, D.M.; Sitkin, S.B.; Burt, R.S.; Camerer, C. Not so different after all: A cross-discipline view of trust. Acad. Manag. Rev. 1998, 23, 393-404. [CrossRef] 
212. Luhmann, N. Trust and Power. Coop. Trust 1979, 8, 208. [CrossRef]

213. Konovsky, M.A.; Pugh, S.D. Citizenship behavior and social exchange. Acad. Manag. J. 1994, 37, 656-669.

214. Rossiter, C.M.; Barnett, P.W. Communicating Personally: A Theory of Interpersonal Communication and Human Relationships; The Bobbs-Merrill Company, Inc.: Indianapolis, IN, USA, 1975.

215. Schurr, P.H.; Ozanne, J.L. Influences on Exchange Processes: Buyers' Preconceptions of a Seller's Trustworthiness and Bargaining Toughness. J. Consum. Res. 1985, 11, 939. [CrossRef]

216. Fox, C.; Causey, E.; Cencula, D. Study of Mobile Banking \& Payments, 3rd ed.; First Annapolis Consulting, Inc.: Annapolis, MD, USA, 2016.

217. Gavade, R.K. Multi-Criteria Decision Making: An overview of different selection problems and methods. Int. J. Comput. Sci. Inf. Technol. 2014, 5, 5643-5646.

218. Abdul-Hamid, I.K.; Shaikh, A.A.; Boateng, H.; Hinson, R.E. Customers' Perceived Risk and Trust in Using Mobile Money Services—an Empirical Study of Ghana. Int. J. E-Bus. Res. 2019, 15, 1-19. [CrossRef]

219. José Liébana-Cabanillas, F.; Sánchez-Fernández, J.; Muñoz-Leiva, F. Role of gender on acceptance of mobile payment. Ind. Manag. Data Syst. 2014, 114, 220-240. [CrossRef]

220. Kovács, L.; Terták, E. Financial Literacy, Panacea or Placebo-A Central European Perspective; Verlag Dashöfer: Bratislava, Slovakia, 2016.

221. Zhou, T. An empirical examination of continuance intention of mobile payment services. Decis. Support Syst. 2013, 54, 1085-1091. [CrossRef]

222. Lee, M.K.O.; Turban, E.; Matthew, K.O.; Lee, E.T. A trust model for consumer internet shopping. Int. J. Electron. Commer. 2001, 6, 75-91. [CrossRef]

223. Cheng, X.; Macaulay, L. Exploring Individual Trust Factors in Computer Mediated Group Collaboration: A Case Study Approach. Gr. Decis. Negotiat. 2014, 23, 533-560. [CrossRef]

224. Fang, Y.; Qureshi, I.; Sun, H.; McCole, P.; Ramsey, E.; Lim, K.H. Trust, Satisfaction, and Online Repurchase Intention: The Moderating Role of Perceived Effectiveness of E-Commerce Institutional Mechanisms. MIS Q. 2014, 38, 407-427. [CrossRef]

225. Tsiakis, T. Consumers' issues and concerns of perceived risk of information security in online framework. The marketing strategies. Procedia Soc. Behav. Sci. 2012, 62, 1265-1270. [CrossRef]

226. Sharma, S.K.; Govindaluri, S.M.; Al-Muharrami, S.; Tarhini, A. Predicting mobile banking adoption: A neural network approach. J. Enterp. Inf. Manag. 2016, 29, 222-237.

(C) 2020 by the authors. Licensee MDPI, Basel, Switzerland. This article is an open access article distributed under the terms and conditions of the Creative Commons Attribution (CC BY) license (http://creativecommons.org/licenses/by/4.0/). 


\title{
Mobile Banking: An Innovative Solution for Increasing Financial Inclusion in Sub-Saharan African Countries: Evidence from Nigeria
}

\author{
Alfonso Siano ${ }^{1, *}$, Lukman Raimi ${ }^{2}$, Maria Palazzo ${ }^{1}$ and Mirela Clementina Panait ${ }^{3}$ \\ 1 Department of Political and Communication Sciences, University of Salerno, 84084 Salerno, Italy; \\ mpalazzo@unisa.it \\ 2 Department of Entrepreneurship and Management, American University of Nigeria, Lagos 23401, Nigeria; \\ lukman.raimi@aun.edu.ng \\ 3 Department of Cybernetics, Economic Informatics, Finance and Accounting, Petroleum-Gas University of Ploiesti, \\ 100680 Ploiesti, Romania; mirela.matei@upg-ploiesti.ro \\ * Correspondence: sianoalf@unisa.it
}

Received: 17 October 2020; Accepted: 29 November 2020; Published: 4 December 2020

\begin{abstract}
Purpose-This research discusses emerging trends in financial inclusion, barriers and factors influencing mobile banking as an innovative solution for increasing financial inclusion in sub-Saharan Africa (SSA) with a specific focus on Nigeria. Design/methodology/approach-Using a qualitative meta-synthesis (QMS), an interpretivist research paradigm, authors provide an analytical tool for understanding the subject of inquiry by integrating findings from previous studies and relevant data from the reports of the Central Bank of Nigeria on emerging trends in financial inclusion. Findings-Three major factors emerged as drivers of mobile banking in Nigeria: (a) the ease of using mobile devices for personal banking transactions including prompt information about users' financial transactions (savings and withdrawals) immediately through SMS (short message service) alert (easy management of my account); (b) the security/safety concerns of theft and cyber fraud; (c) social influence of friends, relatives, policy makers and social trends. Implications-In contextualizing mobile banking in SSA and in Nigeria in particular, this paper contributes to exploring the growth in the use of mobile banking by linking it with the "value in use" (VIU) perspective. This approach of the service dominant logic involves three sub-constructs (experience, personalization, and relationship), which all validate and support the proposed assertion that mobile banking is adopted by users because of utility expectancy (perceived usefulness), effort expectancy (perceived ease of use), and social influence expectancy (opinions of friends/relatives). Originality/value-This research, although qualitative in nature, validates information technology (IT) adoption theories/perspectives and enriches the "value in use" approach.
\end{abstract}

Keywords: financial inclusion; innovative solution; mobile banking; Nigeria; sub-Saharan Africa (SSA); qualitative meta-synthesis (QMS); banking industry; digital transformation; value in use approach

\section{Introduction}

The global economy faces extreme poverty, slower growth, climate change, widening inequalities, unemployment, and growing inconstant working conditions, but the plight of sub-Saharan Africa (SSA) is worse because more than 204 million people are unemployed, and the worsening unemployment situation provides breeding grounds for forced labour, slavery and human trafficking [1]. Additionally, the report of the World Bank from 2019 [2] identified extreme poverty, growing public debt/debt risk, slow growth of the labour market, rising labour force, and gender disparities as the critical inhibiting factors holding back economic growth and sustainable development in SSA. 
In the midst of the economic crisis explicated above, the people and businesses in the area, including Nigeria, suffer an extremely low level of financial inclusion [3,4]. Studies have explicated that the phenomenon of the lack of access (financial exclusion) to basic financial services is a global problem, but the problem is most pronounced in emerging economies including SSA $[5,6]$.

At the global level, financial inclusion has occupied the attention of international organisations especially the agendas of the millennium development goals (MDGs) and sustainable development goals (SDGs). Some of the targets of the expired MDGs alert the United Nations member countries to the pressing issue of financial inclusion and its complexity. Specifically, the goals of fighting extreme poverty foundationally (MDG1); achieving gender equality to promote equal opportunities for women to access employment, social protection, and training (MDG3); and forging a global partnership for development (MDG 8) directly address financial inclusion challenges. Similarly, the targets of the ongoing SDGs that directly impact on financial inclusion include: no poverty (SDG1), zero hunger (SDG2), good health and wellbeing (SDG3), quality education (SDG4), decent work and economic growth (SDG8), industry, innovation, and infrastructure (SDG9), reduced inequality (SDG10), peace, justice and strong institutions (SDG16) and partnerships for the goals (SDG17).

In Nigeria, several attempts have been made by the government to improve financial inclusion through a number of public-sector led credit schemes and poverty alleviation programmes such as National Economy Reconstruction Fund (NERFUND); the People's Bank, Community Banking Models, the Bank of Industry (BOI), the Microfinance Institutions (MFIs) the Small and Medium Enterprises Equity Investment Scheme (SMEEIS), National Poverty Eradication Programme, Youth Enterprise with Innovation in Nigeria (You Win) Programme, Subsidy Reinvestment and Empowerment Programme or SURE-P, National Enterprise Development Programme or NEDEP and several others [7,8]. In spite of the financial inclusion intervention schemes, the National Financial Inclusion Strategy (drafted in 2012 and revised in 2018) and the "cash-less Nigeria policy", the efforts failed because of the government's inability to properly nurture its development programmes, weak reward system, dysfunctional structures and endemic poor programme implementation [8-11]. In the early 2000s, mobile banking emerged as an information technology (IT)-driven innovative technology, which greatly improved the degree of financial inclusion in the continent [5,12-15]. Mobile banking provides virtual access for individuals and businesses to procure financial transactions such as savings, funds' transfer, and stock market deals with banks at any convenient time and place [16]. The receptiveness to mobile banking is impressive, as the majority of the banks in Nigeria have adopted and introduced mobile banking applications. Additionally, mobile banking has thrived because Nigeria has the fastest growing telecommunication infrastructure in Africa and the third in the world [17]. The benefit of IT infrastructure is supported by the population of over 150 million people [18]. Providing an enabling environment for better and improved financial inclusion, Nigeria justifies the adoption and introduction of mobile banking to strengthen local and international efforts towards financial inclusion (the timely introduction of mobile phone technology in the continent within the last 10 years resulted in $82 \%$ mobile banking penetration in Nigeria, the highest penetration of mobile banking across developing markets [19].

It is possible to state that research on financial inclusion in SSA is just emerging [20-22]. To enrich the body of knowledge in this important field of financial inclusion, there is a need to explore empirical evidence. Financial inclusion, in fact, has been delayed in the continent prior to the liberalization of the financial sector in the 1980s, because many African banks were owned, controlled and heavily regulated by the governments as monopolies, a situation that restricted the adoption of innovative technologies in banking operations $[3,6,23]$.

Thus, the purpose of this exploratory qualitative research is to critically discuss the emerging trends in financial inclusion, the barriers to financial inclusion and factors influencing mobile banking adoption as an innovative solution for increasing financial inclusion in SSA with a specific focus on Nigeria. 
There are several parts to this paper. The first part presents the introduction of the thematic issue of mobile banking and financial inclusion. The second part focuses on the definition of financial inclusion and mobile banking from both managerial and academic perspectives, examining barriers to financial inclusion and factors influencing adoption of mobile banking in Nigeria. Then, this paper discusses methodology and proposes findings and discussions of thematic issues. The concluding part discusses the implications and recommendations on the mobile banking agenda and direction in sub-Saharan Africa.

\section{Theoretical Background}

\subsection{Financial Inclusion: Definitions and Features}

The need to achieve the sustainable development goals brings to the attention of the authorities a pressing issue, namely the complexity of the phenomenon, the multitude of tools that could be used to achieve the set targets, the large number of stakeholders involved or that may be involved and the lack of financial funds [24-27]. For these reasons, financial inclusion has become important, both at the microeconomic and macroeconomic levels, as it can be a tool for promoting the principles of sustainable development [28-36]. Financial inclusion is not only a concern of financial institutions that are trying to attract more and more categories of consumers and have a responsible attitude towards them but also of public authorities [33,37-42]. In fact, there are specialists who consider financial inclusion, for some countries, even a catalyst for sustainable development, a tool for poverty reduction and a facilitator of economic growth [27,43-45]. Financial inclusion is a complex concept in a continuous evolution taking into account the transformations that are taking place worldwide from an economic, social and political point of view. Financial inclusion refers to "access to and usage of appropriate, affordable, and accessible financial services" [46]. Given the complexity of the phenomenon and the importance of national and regional characteristics on it, financial inclusion presents multiple definitions in the literature, which emphasize certain aspects such as financial innovation, microfinance and the use of mobile phones [47]. According to the World Bank, which is a main international financial institution with preoccupations in this field, financial inclusion is defined as "access to useful and affordable financial products and services that meet their needs-transactions, payments, savings, credit and insurance-delivered in a responsible and sustainable way" [43].

Apiors and Suzuki (2018) consider that financial inclusion supposes "the full range of services (payments, savings, credit, and insurance), to specific quality features of delivery (for example, stability and affordability), inclusiveness (with special focus on the poor), and choice (offer of service by a range of institutions)" [48].

The concept of social inclusion emerged as a solution to the phenomenon of social exclusion that has been identified by geographers who have observed limited access of certain categories of citizens to basic financial services [49]. After the emergence of the concept of social exclusion, the 90s were characterized by intense scientific concerns regarding citizens' access to financial services for payment, savings, and credit, but also to insurance services. Subsequently, the European Commission focused on this issue, considering that financial exclusion is a component of the phenomenon of social exclusion that affects, in various forms, important categories of citizens of the European Union [45]. Financial exclusion targets people that "encounter difficulties accessing and/or using financial services and products in the mainstream market that are appropriate to their needs and enable them to lead a normal social life in the society in which they belong." It must be highlighted that the phenomenon of financial exclusion affects both developed and developing countries, but the share of the non-banked population is different across the world, depending on the level of development of that country [45].

Although the concept of financial exclusion has emerged in the UK [50], the phenomenon mainly affects developing countries characterized by a precarious financial infrastructure from an institutional, technical, legislative, or social point of view. Given the manifestation of the phenomenon of financial exclusion predominantly in developing countries, more and more definitions and approaches [51,52] 
focus on: (i) citizens' access to the formal or semi-formal financial sector composed of commercial banks, development finance institutions, post offices, microfinance banks, credit unions and cooperatives, (ii) improving the process of saving but also accessing loans, (iii) enhancing risk management, (iv) developing innovative financial solutions, (v) protection of consumer rights.

The concerns of international financial institutions such as the World Bank, development agencies, national market supervisors and regulators have intensified [53] in order to attract an increasing number of citizens to gain access to products and services. As the financial inclusion is a multidimensional concept [47], various categories of stakeholders from supply and demand sides must be involved. Public authorities and financial institutions must offer sustainable alternatives to consumers, and citizens must make efforts to increase the degree of financial education by participating in programs conducted in this regard by various entities $[45,54-58]$. Given the multiple crises and scandals that have particularly affected the banking market, financial institutions need to substantially improve their behaviour so as to inspire consumer confidence. Therefore, consumers are also required to use the proper financial services according to their ability to understand financial phenomena or income level $[59,60]$. In addition, in certain particular situations, such as immigrants, financial consumers have to overcome certain language, cultural, and religious barriers $[45,48,61]$. Consumers must not only show responsibility when making financial decisions but must also have the ability to learn and adapt to the new conditions of the financial market generated by the digitization of operations. Achieving the objectives set at national level, usually by launching financial inclusion strategies, therefore requires sustained efforts both by the population and by the financial authorities and institutions.

Given the large number of definitions [47], three dimensions of financial inclusion have been established, namely access (refers to physical proximity and affordability), usage (refers to regularity, frequency, duration of time used) and quality (refers to products well-tailored to clients' needs and to appropriate segmentation to develop products for all income levels). To the three dimensions, other specialists $[44,62]$ added an additional dimension-choice (Figure 1).

\begin{tabular}{|c|c|}
\hline \multirow{4}{*}{$\begin{array}{l}\text { FINANCIAL- } \\
\text { INCLUSION }\end{array}$} & $\begin{array}{c}\text { ACCESS } \\
\text { physical-proximity } \cdot \text { and } \cdot \text { affordability } \cdot x\end{array}$ \\
\hline & $\begin{array}{c}\text { USAGE } \\
\text { regularity, frequency, duration.of.time'useds }\end{array}$ \\
\hline & 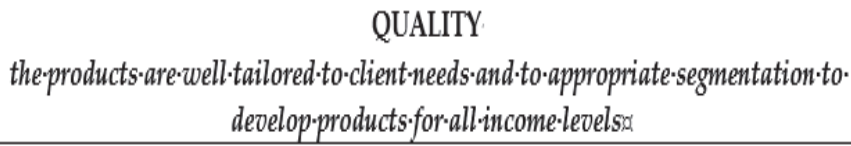 \\
\hline & $\begin{array}{c}\text { CHOICE } \\
\text { existence.of-similar.products.or-services } x\end{array}$ \\
\hline
\end{tabular}

Figure 1. Dimensions of Financial Inclusion. Source [47].

Mobile banking largely stimulates and promotes financial inclusion in developing economies, especially in sub-Saharan Africa [13], mobile penetration promotes financial inclusion, and significantly reduces the probability of a household becoming poor [63-69]. Having briefly synthesized this complex topic, this paper will focus on the analysis of financial inclusion, taking into consideration Nigeria. Nigeria is one of the leaders on the African continent along with Kenya in the process of increasing the degree of financial inclusion through the use of mobile banking. In addition, the successful experiences registered in these countries have been models for other countries in the areas of implementation and development of mobile banking systems. Despite the similarities between the two countries in terms of the level of development, the degree of financial exclusion penetration rates in mobile phone usage, the structure of the banking system and the approach to the need to increase financial inclusion were 
undertaken with different instruments. The reluctance of the Central Bank of Nigeria to use this model based on a mobile phone company monopoly, the structure of the mobile phone market and the late launch of initiative that coincided with the onset of the 2008 international financial crisis made the results modest. Therefore, the model of "bank-led" (or a non-MNO-led-mobile network operators-led) ecosystem used in Nigeria generates different network externalities compared to mobile network operator systems used in Kenya [70-73].

\subsection{Barriers to Financial Inclusion}

In developing countries, financial exclusion is fuelled by the country's economic structure (mainly agriculture), the location of the majority of the population is in the rural areas with poor banking intermediation and low spread of money deposit bank branches across different parts of the country due to the policy of commercial financial institutions [27]. Other factors that limit the financial inclusion of the population are bureaucracy, high costs of banking products and services and distance $[52,74,75]$.

Leveraging on past studies developed in Nigeria, Table 1 below clearly shows the degree of financial inclusion in the country measured in terms of five metrics, namely (a) \% of adult using formal payment systems, (b) \% of adult with savings accounts, (c) \% of adult with credit from the bank, (d) \% of adult with insurance policies, (e) \% of adult with pension schemes and (f) \% of adult financial exclusion.

Table 1. Access to financial services in Nigeria (2010-2018).

\begin{tabular}{ccccc}
\hline Focus Area & $\mathbf{2 0 1 0}$ & $\mathbf{2 0 1 2}$ & $\mathbf{2 0 1 4}$ & $\mathbf{2 0 1 6}$ \\
\hline \% of Adult using Formal Payments System & 22 & 20 & 24 & 38 \\
\% of Adult with Savings Accounts & 24 & 25 & 32 & 36 \\
\% of Adult enjoying Credits & 2 & 2 & 36 & 3 \\
\% of Adult with Insurance Policies & 1 & 3 & 1 & 2 \\
\% of Adult with Pension Schemes & 5 & 2 & 5 & 7 \\
\% of Adult Financial Exclusion & 46.3 & 39.7 & 39.5 & 41.6 \\
\hline
\end{tabular}

Source: [76].

The barrier of distance mentioned above is generated both by the weak representation in the territory of commercial banks, but also by the state of infrastructure that exacerbates the problem of moving citizens from rural areas to cities to make various financial operations [77]. Moreover, Table 2 below shows that weak representation of deposit money bank branches engenders the problem of financial inclusion in Nigeria. In fact, states in Northern Nigeria such as Adamawa, Jigawa, Bornu, Bauchi, and Kwara with a large population have very few bank branches, whereas smaller cosmopolitan states with a relatively low population have large bank branches.

Table 2. Number of deposit money bank branches in Nigeria by state 2010-2019.

\begin{tabular}{ccccccccccc}
\hline & $\mathbf{2 0 1 0}$ & $\mathbf{2 0 1 1}$ & $\mathbf{2 0 1 2}$ & $\mathbf{2 0 1 3}$ & $\mathbf{2 0 1 4}$ & $\mathbf{2 0 1 5}$ & $\mathbf{2 0 1 6}$ & $\mathbf{2 0 1 7}$ & $\mathbf{2 0 1 8}$ & $\mathbf{2 0 1 9}$ \\
\hline Number of Banks & 24 & 24 & 21 & 24 & 24 & 25 & 25 & 26 & 27 & 29 \\
Branches Abroad & 2 & 2 & 2 & 1 & 1 & 2 & 2 & 2 & 2 & 2 \\
Abia & 146 & 125 & 138 & 147 & 144 & 135 & 142 & 137 & 135 & 135 \\
Abuja (FCT) & 398 & 359 & 379 & 397 & 380 & 369 & 421 & 437 & 382 & 390 \\
Adamawa & 67 & 79 & 63 & 61 & 47 & 47 & 57 & 64 & 66 & 60 \\
Akwa-Ibom & 99 & 92 & 100 & 94 & 92 & 103 & 106 & 114 & 88 & 102 \\
Anambra & 237 & 222 & 228 & 224 & 219 & 218 & 219 & 214 & 209 & 227 \\
Bauchi & 53 & 50 & 46 & 46 & 47 & 48 & 50 & 47 & 55 & 47 \\
Bayelsa & 37 & 37 & 37 & 38 & 38 & 38 & 38 & 39 & 35 & 35 \\
Benue & 75 & 57 & 73 & 76 & 67 & 63 & 69 & 71 & 78 & 65 \\
Borno & 79 & 68 & 71 & 69 & 83 & 72 & 60 & 61 & 58 & 56 \\
\hline
\end{tabular}


Table 2. Cont.

\begin{tabular}{ccccccccccc}
\hline & $\mathbf{2 0 1 0}$ & $\mathbf{2 0 1 1}$ & $\mathbf{2 0 1 2}$ & $\mathbf{2 0 1 3}$ & $\mathbf{2 0 1 4}$ & $\mathbf{2 0 1 5}$ & $\mathbf{2 0 1 6}$ & $\mathbf{2 0 1 7}$ & $\mathbf{2 0 1 8}$ & $\mathbf{2 0 1 9}$ \\
\hline Cross-River & 79 & 76 & 76 & 80 & 79 & 74 & 78 & 79 & 72 & 75 \\
Delta & 198 & 177 & 194 & 198 & 178 & 180 & 200 & 205 & 183 & 183 \\
Ebonyi & 35 & 45 & 33 & 33 & 59 & 61 & 37 & 36 & 59 & 42 \\
Edo & 183 & 162 & 188 & 192 & 144 & 165 & 178 & 188 & 159 & 177 \\
Ekiti & 80 & 60 & 64 & 76 & 91 & 87 & 86 & 92 & 76 & 77 \\
Enugu & 141 & 116 & 142 & 147 & 158 & 151 & 159 & 162 & 127 & 148 \\
Gombe & 40 & 36 & 36 & 37 & 43 & 41 & 36 & 37 & 65 & 34 \\
Imo & 104 & 97 & 100 & 102 & 110 & 105 & 98 & 100 & 99 & 94 \\
Jigawa & 39 & 37 & 36 & 38 & 63 & 66 & 38 & 36 & 43 & 34 \\
Kaduna & 183 & 170 & 169 & 171 & 154 & 164 & 168 & 173 & 169 & 157 \\
Kano & 193 & 186 & 183 & 183 & 174 & 170 & 178 & 179 & 195 & 161 \\
Katsina & 62 & 55 & 58 & 59 & 73 & 78 & 56 & 55 & 52 & 47 \\
Kebbi & 40 & 40 & 37 & 38 & 95 & 37 & 37 & 35 & 49 & 61 \\
Kogi & 80 & 77 & 82 & 84 & 88 & 80 & 79 & 82 & 70 & 71 \\
Kwara & 79 & 139 & 75 & 79 & 104 & 101 & 78 & 84 & 100 & 85 \\
Lagos & 1766 & 1453 & 1692 & 1678 & 1443 & 1486 & 1645 & 1686 & 1478 & 1624 \\
Nasarawa & 58 & 51 & 49 & 48 & 68 & 69 & 49 & 49 & 67 & 52 \\
Niger & 80 & 76 & 79 & 82 & 67 & 65 & 78 & 86 & 64 & 71 \\
Ogun & 175 & 402 & 161 & 154 & 137 & 142 & 154 & 172 & 153 & 169 \\
Ondo & 121 & 109 & 110 & 119 & 106 & 101 & 113 & 120 & 120 & 112 \\
Osun & 105 & 118 & 101 & 104 & 101 & 99 & 106 & 108 & 86 & 99 \\
Oyo & 236 & 203 & 223 & 237 & 347 & 343 & 222 & 237 & 195 & 223 \\
Plateau & 79 & 72 & 77 & 75 & 75 & 71 & 70 & 67 & 75 & 83 \\
Rivers & 302 & 246 & 310 & 311 & 292 & 275 & 312 & 319 & 275 & 301 \\
Sokoto & 53 & 53 & 52 & 52 & 43 & 45 & 53 & 52 & 60 & 47 \\
Taraba & 37 & 41 & 35 & 35 & 40 & 40 & 34 & 27 & 39 & 30 \\
Yobe & 35 & 35 & 33 & 35 & 38 & 41 & 34 & 31 & 27 & 29 \\
Zamfara & 35 & 33 & 34 & 40 & 39 & 38 & 30 & 31 & 38 & 34 \\
TOTAL & 5809 & 5454 & 5564 & 5639 & 5526 & 5470 & 5570 & 5714 & 5301 & 5437 \\
\hline & & & & $50 u r c e: ~[78]$ & & & & & &
\end{tabular}

In addition, the rapid growth of the population in developing countries contributes to the deepening of the phenomenon of population impoverishment, and implicitly of social exclusion. Despite the efforts made by the public authorities in the banking sector and by the credit institutions, the population growth precedes the growth of the banked population, there are also multiple regional differences [45].

The ways of manifesting the phenomenon of financial inclusion and financial literacy differ depending on consumers' level of income and the development level of the countries $[44,77,79]$. In high-income countries, financial exclusion affects a small part of the population, and citizens have concerns about making sophisticated investments in the financial market and an investment plan for retirement [80]. In low-income countries, the concerns of financial authorities and institutions regarding financial inclusion are much more complex and lasting because they concern a considerable proportion of the population being attracted from the non-formal to the formal sector, and the causes of financial exclusion are generated by the economic situation, and not only the poor financial education of the population [80]. In these countries, citizens have problems when simply trying to open a bank account or purchase insurance.

In developing countries, the main cause of low financial inclusion is extreme poverty that affects a large part of the population. Citizens of these countries do not have bank accounts because they do not have enough money to save $[47,52]$. Studies conducted for African countries have revealed a positive link between per capita income and financial inclusion. Thus, the study conducted by Alenoghenain (2017) for 15 African countries for the period 2005-2014 showed that a high income per capita generates a higher financial inclusion [81]. 
Therefore, a phenomenon with multiple economic and social implications such as financial exclusion/inclusion has a complex of determining factors, and solving the problem requires a systemic approach and the involvement of several categories of stakeholders.

In addition, financial exclusion affects not only poor people and women but also migrants [44,82-84]. The trend of international migration has also generated financial problems, as migrants have to overcome certain psychological barriers generated by distrust in complex banking systems (compared to those in the country of origin), lack of financial education specific to developing countries or the time horizon (if the stay is prolonged, there is a change in attitude towards the banking system). The phenomenon of saving specific to migrants is followed by the periodic sending of large sums of money to the family in the country of origin, which is why having a bank account to make bank transfers is essential $[85,86]$. The frequency of remittances is different, being influenced by the needs of the family, the sex of the migrant, the prospects of opening a business in the country of origin or buying a home and by the intention to reunite the family in the destination country [61,87].

\subsection{Drivers of Mobile Banking}

The adoption of mobile banking has improved all aspects of financial transactions for both corporate and non-corporate customers of banks in Nigeria [21,88,89]. Conceptually, the term mobile banking is understood as the use of mobile devices for undertaking virtual financial transactions (especially savings, funds' transfer, and stock market transactions) with banks by customers at any convenient time and place [16]. Financial consumers are increasingly interested in achieving easy access to banking services and products, either to save money or to pay for goods or to send money to relatives or friends. In this sense, the statistical data provided by Global Findex [90] show the increase in the percentage of the population that makes domestic remittances. The intensification of the international migration process has also led to an increase in the frequency and value of the remittances sent by migrants to origin countries, mobile banking being a feasible solution that allows financial transfers but it also contributes to increasing the degree of financial education and financial inclusion in these countries. The feasibility of this method is also supported by the low costs generated by the intensification of competition between banks. From the consumers' perspective, the future of mobile banking depends on essentials such as ubiquity, instant connectivity, pro-active functionality, convenience, access to the service regardless of time and place, privacy, and savings in time and effort [91-93] (Singh 2012, Tiwari et al., 2016, Akturan and Tezcan, 2012). In addition, “The younger generations of the society seem to be fascinated by modern data and telecommunication services" [92]. The analysis of financial inclusion vis-à-vis mobile banking and information technology (IT) has to be embedded in IT adoption theories/perspectives. According to Bankole et al. (2011), the widely used theories in mobile banking [16] include the technology acceptance model (TAM), the extended technology acceptance model (TAM2), the theory of reasoned action (TRA), the theory of planned behavior (TPB) and the unified theory of use and acceptance of technology (UTAUT). Other specialists have focused on the task-technology fit (TTF) theory and the diffusion of innovation (DOI) in order to explain the determinants of the acceptance of mobile banking [94,95] (Munoz-Leiva et al. 2017, Sharma 2019). The technology acceptance model (TAM), the main influential model, focuses on two main issues-perceived usefulness and perceived ease of use- to explain the variance in users' intentions [96] (Luarn and Pin, 2005). According to Nasri and Charfeddine 2012, the "TPB suggests that in addition to attitudinal and normative influence, a third antecedent to the theory called perceived behavioral control, perceived behavioral (PBC), also influences behavioral intentions and actual behavior" [97]. Particularly, TAM and TPB were used by several researchers to investigate the factors influencing users' behavioural intentions towards mobile banking $[16,98]$. Summing up the insights from all the IT adoption theories, proponents argued that mobile banking is an off-shoot of IT that is adopted by users for financial transactions because of key factors, namely performance expectancy (perceived usefulness), effort expectancy (perceived ease of use), social influence (opinions of friends, 
relatives), facilitating conditions, trust and privacy, convenience and cost, user satisfaction and national culture [98-100].

Starting from these premises, the receptiveness of Nigerian customers towards mobile banking is impressive, as all banks have adopted and introduced mobile banking applications (the popular mobile banking apps in Nigeria include Diamond Mobile Banking, Stanbic IBTC Mobile Banking, First Bank Mobile Banking, Eco Bank Mobile Banking, Access Bank Mobile Banking, Fidelity Bank Mobile Banking and Sterling Bank Mobile Banking). Several factors have been identified by scholars as the determinants influencing mobile banking in the country. In a sequential order, the following are insights on factors influencing the adoption of mobile banking.

Anyasi and Otubu (2009) noted that mobile banking was adopted in Nigeria as a preferred means of accessing financial services with or without access to traditional banks, it also offers a way to lower the costs of transferring funds from place to place, while at the same time improving financial inclusion by bringing unbanked people into contact with the formal financial systems [101]. A decade ago, a result of the research of Oni et al. (2010) indicated that the e-banking system in Nigeria is widely adopted and preferred by customers because it is convenient, easy to use, time efficient, and appropriate for financial transactions. However, the users have concerns for the network security especially the privacy of transactions [102].

Moreover, Bankole et al. (2011) explained that utility expectancy and effort expectancy are major factors influencing behavioural intention to adopt mobile banking in Nigeria. Specifically, the ease of using a mobile device for personal banking transactions (easy management of accounts); the security and safety concerns of moving cash around regarding cyber fraud; and prompt information about users' financial transactions (savings and withdrawals) immediately through the SMS alert. However, the social influence of friends, relatives, colleagues at work and the service providers (banks) is not a major influence on mobile banking users in Nigeria [16].

Nevertheless, Aliyu et al. (2012) contended that the six critical success factors that influence the adoption of mobile banking in Nigeria include awareness, ease of use, security, cost, reduced reluctance to change and accessibility of mobile devices for undertaking financial transactions [103].

Furthermore, Balogun et al. (2013) affirmed that three factors largely influenced customers satisfaction with different aspects of e-banking in Nigeria, such as telephone banking, mobile banking, point of sale terminals, smart cards, and television banking. These factors are the quality services provided by banks through SMS alerts and e-mail alerts; the second factor is access to the option of electronically opening a bank account, and the third factor is availability of automated teller machines in strategic locations for making withdrawals when needed without going into the banks [104].

However, Adewoyein (2013) reported that the adoption of mobile banking by customers is premised on a number of factors such as transactional convenience, better turn-around time (saving time), quick transaction alert, reduction in service cost and overall customer satisfaction [105]. Similarly, Njoku and Odumeru (2013) opined that seven factors positively influence the adoption of mobile banking in Nigeria, these include relative advantage that mobile banking gives to bank customers; less complexity of mobile technology; compatibility of mobile banking with customers' norms, belief, existing values, and past experience; perceived trialability/ease of mobile banking when experimented with by the customers; perceived observability/visibility of the outcomes of mobile banking to customers; age of customers using mobile banking; and educational qualification of customers using mobile banking [7].

Moreover, Agwu and Carter (2014) noted that the use of mobile phones for mobile banking has fundamentally changed the way Nigerians (as individuals and businesses) conduct financial transactions [106]. Particularly, mobile banking is more established than internet banking and ATM (automated teller machine) services because it has wider reach than both internet banking and mobile banking (effort expectancy).

Three factors identified by Tarhini et al. (2015) as key drivers of mobile banking adoption [107] in Nigeria include: (a) functionality factor that consists of awareness, ease of use and accessibility; (b) risks 
factors that comprise trust, security and privacy; and (c) context factor that includes convenience. From the viewpoints of Agu et al. (2016), mobile banking became a prominent feature in banking operations in the country because it is an effective technology for providing the growing population of customers with fast, accessible, reliable and quality services. Secondly, as an innovative option, mobile banking enables users carry out banking transactions anywhere and anytime and it provides an easy platform for paying for goods or services [108].

In the view of Khan and Ejike (2017), widespread adoption of mobile banking is influenced by access to technological domains, which enhance good knowledge regarding mobile devices, but the degree of convenience and satisfaction of usage are very low [109]. Additionally, Bagudu et al. (2017) explained that the singular and most important success factor for the widespread adoption of mobile banking in the country is access to functional mobile technology, which makes it easy for customers to carry out financial transactions on their mobile handsets with ease [110].

In SSA, there has been an increase in both registration and usage of financial inclusion tools such as mobile banking and related systems. This fact is corroborated by Bille et al., (2018) who reported that as of 2018 there has been an encouraging improvement in financial inclusion because unbanked people and the small and medium-sized enterprises (have been well integrated into the financial landscape in sub-Saharan Africa as a result of improved access to financial inclusion tools, which have been made accessible by the financial service providers, especially banks, microfinance institutions, different mobile network operators and licensed payment service providers [111]. Particularly, the World Bank report indicated that financial inclusion has reached over seven million new financial services users across SSA, from Senegal to Tanzania, from Nigeria to Zambia [111] (Bille et al., 2018).

\section{Methodology}

In view of the exploratory nature of this research, a qualitative meta-synthesis (QMS), an interpretivist research paradigm, provides a rich analytical tool for this study.

The qualitative meta-synthesis was applied as a suitable approach and essential stage towards enlarging the research and setting the basis for analysing the contributions of this paper [112]. This step makes it easy to identify boundaries of the conceptual content of the field and contribute to theory advances [113]. In line with the qualitative research tradition, a qualitative meta-synthesis is an analytical approach that is widely used in meta study to integrate different findings from diverse studies on the same subject of inquiry from different contexts $[8,114]$.

The purpose of integrating findings and insights from groups of studies in a qualitative meta-synthesis is to develop an explanatory theory or model that explains the phenomenon being investigated better and richer [115]. With regard to steps involved in carrying out a sound QMS, Walsh and Downe (2005) proposed seven steps for using qualitative meta-synthesis in research [116].

(1) Framing a meta-synthesis exercise: our topic from the outset is framed for a qualitative meta-synthesis exercise.

(2) Locating relevant papers: we searched and located several papers on mobile banking within and outside SSA to gain richer insights on the subject of inquiry.

(3) Deciding what to include: after a literature audit of searched and located papers on mobile banking, we selected those related to mobile banking issues and financial inclusion in SSA in line with the qualitative meta-synthesis tradition.

(4) Appraising studies: the selected papers from SSA were then appraised to draw rich and meaningful information for making informed and evidence-based findings in line with the qualitative meta-synthesis tradition.

(5) Comparing and contrasting exercise: the findings in the selected papers from SSA were compared and contrasted.

(6) Reciprocating translation: we offered an explanation for the similar and opposing findings. 
(7) Synthesizing translation: the mixed findings extracted from different papers selected were then fused and synthesised to give a unique explanation for the trends and direction of mobile banking in relation to financial inclusion in SSA.

These steps were followed in the above study.

First of all, in order to manage the groundwork for the following QMS, and to identify emerging trends in financial inclusion, the key items were defined. In line with the mentioned definitions and features, but extending to related terms, "financial inclusion", "in-debtedness", "microfinance", "digital financial services", "mobile banking", and "Nigerian banks" were used for identifying related peer reviewed journal articles. The main reason for searching with these alternative items/terms was to ensure the comprehensive nature and content validity of our key terms.

The exploration for meaningful publications was conducted through databases such as Wiley, Elsevier, Scopus, Emerald, and Springer. The selection of these databases was based upon their use by academics in past systematic QMS in the fields of business, management, marketing, communication, and social sciences, along with the openness of the data for the analysis. In addition, the analysis was conducted by selecting only papers with a managerial/marketing perspective in peer-reviewed scientific journals published in the English language. Several papers in different languages or with a dissimilar focus were excluded. The list with articles used for this analysis is presented in Appendix A. The list of relevant papers was attained after removing duplicated articles and then exploring the filtered articles. Appendix A also refers to some relevant topics that are analysed in each paper, such as number of factors affecting mobile banking and type of specific factors affecting mobile banking.

Additionally, Appendices B and C show selected articles classified under several categories: number of research publications per year and classification based on number of determinants/factors able to influence mobile banking development. Moreover, for a meaningful selection of scholarly papers, a search for relevant articles on financial inclusion and mobile banking was carried out using a purposive sampling technique. Furthermore, 58 sampled articles that focused on Nigeria were systematically reviewed and synthesized with insights from the reports of the Central Bank of Nigeria to form integrated findings that explain the emerging trends in financial inclusion [117] and the barriers and factors influencing mobile banking in Nigeria.

The analysis and synthesis of papers aimed to reach two main objectives, first of all, briefly summarise existing research by identifying hot themes/matters; afterwards, contribute to shape the conceptual field of study. Obviously, the authors found it challenging to read everything about financial inclusion and mobile banking, especially if it is considered that the topic is not always called this label or the research is not always related to the selected country: Nigeria.

\section{Findings and Discussions}

Leveraging on the qualitative meta-synthesis, the findings that emerged could be classified into emerging trends on financial inclusion and the barriers and factors that influenced the adoption of mobile banking in Nigeria.

On the emerging trends of financial inclusion in connection with mobile banking, the research found that several attempts have been made by the government to improve financial inclusion in the country through a number of public-sector led credit schemes such National Economy Reconstruction Fund (NERFUND); the People's Bank, Community Banking Models, the Microfinance Institutions (MFIs), the Bank of Industry (BOI), the Small and Medium Enterprises Equity Investment Scheme (SMEEIS), National Poverty Eradication Programme, Youth Enterprise with Innovation in Nigeria (You Win) Programme, Subsidy Reinvestment and Empowerment Programme or SURE-P, National Enterprise Development Programme or NEDEP and several others (Table 3). 
Table 3. Emerging trends in financial inclusion and mobile banking.

\begin{tabular}{|c|c|c|c|}
\hline $\mathrm{SN}$ & Policies on Financial Inclusion & Governance Level & Target Audience \\
\hline 1 & $\begin{array}{c}\text { National Economy Reconstruction } \\
\text { Fund (NERFUND) }\end{array}$ & National & $\begin{array}{l}\text { Individuals and Businesses } \\
\text { across Nigeria }\end{array}$ \\
\hline 2 & People's Bank of Nigeria & National & $\begin{array}{c}\text { Individuals, petty traders, } \\
\text { artisans and small businesses } \\
\text { across Nigeria }\end{array}$ \\
\hline 3 & Community Banking Models & National & $\begin{array}{l}\text { Individuals, petty traders, } \\
\text { artisans and small businesses }\end{array}$ \\
\hline 4 & Microfinance Institutions (MFIs) & National & $\begin{array}{l}\text { Individuals, petty traders, } \\
\text { artisans and small businesses }\end{array}$ \\
\hline 5 & Bank of Industry (BOI) & National & $\begin{array}{l}\text { Corporate entities-SMEs } \\
\text { (small and medium-sized } \\
\text { enterprises) across Nigeria }\end{array}$ \\
\hline 6 & $\begin{array}{l}\text { Small and Medium Enterprises Equity } \\
\text { Investment Scheme (SMEEIS) }\end{array}$ & National & $\begin{array}{c}\text { Corporate entities-SMEs } \\
\text { across Nigeria }\end{array}$ \\
\hline 7 & $\begin{array}{l}\text { National Poverty Eradication } \\
\text { Programme (NAPEP) }\end{array}$ & National & $\begin{array}{l}\text { Individuals, petty traders, } \\
\text { artisans and small businesses }\end{array}$ \\
\hline 8 & $\begin{array}{l}\text { Youth Enterprise with Innovation in } \\
\text { Nigeria (You Win) Programme }\end{array}$ & National & $\begin{array}{l}\text { Individuals, petty traders, } \\
\text { artisans and small businesses }\end{array}$ \\
\hline 9 & $\begin{array}{c}\text { Subsidy Reinvestment \& } \\
\text { Empowerment Programme (SURE-P) }\end{array}$ & National & $\begin{array}{l}\text { Individuals, petty traders, } \\
\text { artisans and small businesses }\end{array}$ \\
\hline 10 & $\begin{array}{l}\text { Millennium Development Goals } \\
\text { (MDGs) }\end{array}$ & International & $\begin{array}{c}\text { National institutions, People } \\
\text { and businesses }\end{array}$ \\
\hline 11 & $\begin{array}{l}\text { Sustainable Development Goals } \\
\text { (SDGs) }\end{array}$ & International & $\begin{array}{c}\text { National institutions, People } \\
\text { and businesses }\end{array}$ \\
\hline
\end{tabular}

Source: authors, based on summary of reviewed literature on barriers to financial inclusion.

At the global level, financial inclusion has also occupied the attention of international organisations especially the agendas of the millennium development goals (MDGs) and sustainable development goals (SDGs). Some of the targets of the expired MDGs and SDGs alert the United Nations member countries to the pressing issue of financial inclusion and its complexity. Providing an enabling environment for better and improved financial inclusion in Nigeria justifies the introduction of mobile banking.

Considering the barriers to financial inclusion, this research identified a number of institutional and environmental barriers (Table 4). These barriers provided enabling grounds and springboards for the introduction of mobile banking in Nigeria. Financial inclusion intervention schemes failed because of the government's inability to properly nurture its development programmes, weak reward system, dysfunctional structures, and endemic poor programme implementation. Related to the barriers above are issues of bureaucracy of financial operations, high costs of banking products and services and distance of banks to the population.

With regard to drivers of mobile banking, this research identified three major factors as influencers of mobile banking in Nigeria; the ease of using a mobile device for personal banking transactions including prompt information about users' financial transactions (savings and withdrawals) immediately through the SMS alert (easy management of account); the security and safety concerns of moving cash around regarding cyber fraud; social influence of friends, relatives, policy makers and social trends. With regard to the contextualization of the findings, the three factors that emerged could be categorized as (a) utility expectancy (perceived usefulness), (b) effort expectancy (perceived ease of use), and (c) social influence expectancy (opinions of friends, relatives). Each of the three factors has specific elements assigned to them as shown in Table 5. 
Table 4. Barriers to financial inclusion (summary of reviewed literature on barriers to financial inclusion).

\begin{tabular}{ccc}
\hline SN & Nature of Barrier & Barrier Classification \\
\hline 1 & $\begin{array}{c}\text { Government's inability to properly nurture its financial } \\
\text { inclusion interventions and programmes }\end{array}$ & Institutional factor \\
\hline 2 & $\begin{array}{c}\text { Dysfunctional structures and endemic poor programme } \\
\text { implementation }\end{array}$ & Institutional factor \\
\hline 3 & Structure of the economy (Agriculture-based economy) & Institutional factor \\
\hline 4 & Location of the majority of the population & Environmental factor \\
\hline 5 & Bureaucracy of financial operations & Environmental factor \\
\hline 7 & High costs of banking products and services & Environmental factor \\
\hline 8 & Distance of banks to the population. & Environmental factor \\
\hline & Source: authors, based on summary of reviewed literature on barriers to financial inclusion.
\end{tabular}

Table 5. Contextualizing the factors influencing mobile banking (summary of reviewed literature on drivers of mobile banking).

\begin{tabular}{cccc}
\hline SN & $\begin{array}{c}\text { Value in Use } \\
\text { (VIU)Sub-Constructs }\end{array}$ & $\begin{array}{c}\text { Determinants/Drivers } \\
\text { of Mobile Banking }\end{array}$ & Main Specific Factor Elements \\
\hline 1 & Experience & Utility expectancy & $\begin{array}{c}\text { Prompt, transaction notification, Trust and } \\
\text { privacy, Satisfaction using mobile banking }\end{array}$ \\
\hline 2 & Personalization & Effort expectancy & $\begin{array}{c}\text { Convenience and cost, Ease of management, } \\
\text { personal banking transactions }\end{array}$ \\
\hline 3 & Relationship & $\begin{array}{c}\text { Social influence } \\
\text { expectancy }\end{array}$ & $\begin{array}{c}\text { Influence of advert, opinions of friends and } \\
\text { relatives, behavioural influence of people } \\
\text { on mobile banking, institutional policy on } \\
\text { cashless policy, other pressures }\end{array}$ \\
\hline
\end{tabular}

Source: authors, based on summary of reviewed literature on barriers to financial inclusion.

These three key factors seem to be in line with the complex perspective of the "value co-created in use", a very well-known facet of the service dominant logic (SDL) [118]. This approach considers value as co-created in use (VIU) because consumers assess and decide the value of a proposition based on their usage [119]. The VIU involves three sub-constructs: experience, personalization, and relationship.

Taking into consideration the first item, experience indicates an impressive, cognitive and/or emotional interface that creates essential value [118]. In our case, utility expectancy (perceived usefulness) can be perceived as a factor that is able to generate value for customers pushing them to use the banking sector's services as they are strongly based on setting a positive experience for these kind of potential clients through mobile banking.

On the other hand, personalization highlights the distinctiveness of the usage process, the value developed by individual needs [118]. In the current analysis, this is expressed by the effort expectancy (perceived ease of use). In fact, due to the fact that mobile banking is seen by customers as feasible and not too complicated, this also affects the perception that consumers have of banking services in general, before they were considered as misleading and problematic; nowadays, this trend is changing, setting the place for a new horizon in the sector.

Finally, relationship considers a mutual, continuing exchange and alliance not only among consumers, but also between the company and its clients, following an active communication setting [118]. The sub-construct of relationship, expressed in our study by the factor of social influence expectancy (opinions of friends, relatives), is able to empower current and potential consumers to resolve daily problems; thus, engendering mobile banking with a value that was not taken into account by people that until now decided to not use any kind of financial product [120]. 


\section{Implications, Limitations and Future Research}

This paper has the merit to deepen the understanding of current trends in financial inclusion. This topic can be considered nowadays as a catchphrase for banking specialists, researchers and other categories of stakeholders considering its implications on economic growth and achieving the SDGs $[51,88,121]$. Financial inclusion can be considered as an international challenge [122] but on the African continent, this issue is more stringent as there are high rates of financial exclusion and in addition, the heterogeneity generated by the specific economic situation, ethnic warfare, religious considerations and cultural perceptions is very high [123]. Little is known about emerging trends in financial inclusion and mobile banking, barriers to financial inclusion and factors influencing mobile banking especially in SSA and particularly in Nigeria. Exploring the trends, factors, barriers, and main items that impact on financial inclusion is essential, particularly in the African context where the level of financial inclusion is extremely low. Thus, this paper has contributed to the existing literature as it focuses on the importance of mobile banking as an innovative solution for increasing financial inclusion in a specific sub-Saharan African country: Nigeria.

Connecting back to previous conceptual research on VIU and SDL, a key theoretical contribution of this study lies in its extension of the boundary of this approach. Our study empirically illustrates the effects of VIU and of its variables in the field of mobile banking. In line with Ranjan and Read (2016) [118], our results empirically validate that consumers' VIU is due to personalized, memorable experiences and positive relationships with mobile banking features and applications. The three factors presented, in fact, not only increase consumers' propensity to continue to use mobile banking for the valuable services it provides to them but also nurtures a solid loyalty towards the banking sector that was never so developed before in the selected area.

From a managerial point of view, our findings regarding the applicability of SDL and the importance of VIU in mobile banking can be of special interest to managers and mobile app designers. Our results highlight that VIU is essential to boost financial inclusion towards banking services and financial products. From the VIU perspective, in fact, consumers are dynamically engaged in the value co-creation process, which relies on experience, personalization and relationship. This statement sets a challenge for managers and mobile app designers because for a client to play a role in the co-creation process, she/he have not only to download and utilize the app but log into the app for practitioners to attain her/his suggestions/comments/opinions. For instance, managers have to create more chances to co-create VIU with the client because the bank/financial institution needs to propose appropriate customized services and customer care that produce better experiences and set the basis for long term relationships with the customers. Additionally, leveraging on personalization is another key asset for managers, banks have to "push" clients to try new personalised financial services through mobile banking apps, offering to pioneer several incentives in order to reward their positive attitude towards the organisation and its services.

Moreover, this paper states that financial inclusion is a complex phenomenon and the solutions to reduce financial exclusion are economic, technical and social and have to be used in a mixed set up by public authorities and financial institutions.

For this reason, our work shows policy makers that the strategy of increasing financial inclusion must be based on the collaboration between different categories of stakeholders such as financial consumers, credit institutions, public authorities with supervisory and control attributions in financial markets, schools and universities.

From this perspective, this paper suggests that policy makers play an important role in creating online communities for consumers that use mobile banking. They could foster financial inclusion practices in virtual places, guiding users and acting as a reference point, or simply answer questions and solve doubts that consumers may have regarding using the financial products. In fact, policy makers should act as a "filter" between banks and users. This involves them being the first to catch customers' specific requests and needs and presenting them to banking managers. 
Additionally, they can be useful in explaining how to use more complex software to banking clients who are now choosing to employ only services with a low level of complexity; in this case, policy makers can show to users that a major degree of personalization in services is not going to harm them, instead it should be preferred as it can give them more benefits. Actually, if they are involved in presenting these new personalised services, users could be more interested in approaching them as they trust these kind of players more than employees or spokespersons who are directly paid by banks and other financial institutions.

Having said that, these individuals should be rewarded for their important contribution inside the community with tax incentives, financial benefits, easy-terms loan, soft financing, etc. Actually, feedback posted in online communities can be also appreciated by managers, who can follow the users' point of view to find new ways to increase the level of personalization of services offered through mobile banking.

In addition, public service announcements and other kinds of social advertising should be created by policy makers to communicate to the public that financial inclusion (spread thanks to mobile banking) can highly benefit not only the economy of a country but also the whole society's lifestyle and level of education.

On the other hand, it must be highlighted that our analysis shows several limitations that provide some precious opportunities to future researchers in this underestimated area of research.

We acknowledge that the highlighted features of financial inclusion, explored in this paper, do not represent a comprehensive list of factors expressing all the potentialities hidden inside this concept as we took into consideration a specific country and its peculiarities. This proposes opportunities for further analyses in this vast area employing other specific methodologies and context-related factors.

Each of the labels chosen to conduct the qualitative meta-synthesis are strictly linked with the concept of financial inclusion but, of course, they are not part of an exhaustive list. Therefore, an increase in the labels used may help in the future to better understand how the concept has evolved through the years. Given the different approaches of central banks in Nigeria and Kenya to mobile money services, one of the areas that future studies should investigate is the adequacy of existing financial regulations and policies in SSA regarding mobile banking, particularly because mobile banking is an interface between financial services and telecoms. Another important raging issue that should be explored in the future is the moderating effect of culture on the relationship between mobile banking and financial inclusion in developing countries. Finally, as the financial inclusion represents a challenging area of research that is continuously evolving, we were unable to include all features of this topic in our analysis. In fact, what is clear now is that the main characteristics of financial inclusion may vary over time as they are highly affected by other factors and by technological developments. Therefore, we encourage future researchers to conduct a longitudinal analysis by including a wider range of factors, especially those related to the online world. Considering the intensification of the financial innovation process and the increase in the standard of living, consumers are oriented towards more and more complex products and services. For this reason, a future direction of research may be towards mobile financial services as a tool for financial inclusion. Such efforts will surely further contribute to the theoretical development of this research area.

\section{Towards Conclusions}

This study discusses the emerging trends in financial inclusion and the barriers and factors influencing mobile banking as an innovative solution for increasing financial inclusion in SSA with a specific focus on Nigeria. After a qualitative meta-synthesis of the literature and other secondary materials, it was found that mobile banking was introduced by the government and adopted by major banks in the country to strengthen national and international efforts towards financial inclusion in spite of institutional and environmental barriers engendering financial inclusion. Three major factors emerged from the qualitative meta-synthesis as drivers of mobile banking in Nigeria. Firstly, the ease of using a mobile device for personal banking transactions including prompt information 
about users' financial transactions (savings and withdrawals) immediately through the SMS alert (easy management of account). Secondly, the security and safety concerns of theft and of cyber fraud. Thirdly, social influence of friends, relatives, policy makers and social trends.

In contextualizing mobile banking in sub-Saharan Africa in general and Nigeria in particular, it could be stated that the growth of the use of mobile banking is largely supported by the IT adoption theories/perspectives, such as the technology acceptance model (TAM) and the extended technology acceptance model (TAM2), which all validate and support the assertion that technology is adopted by users because of (a) utility expectancy (perceived usefulness), (b) effort expectancy (perceived ease of use), and (c) social influence expectancy (opinions of friends, relatives).

Author Contributions: Conceptualization, A.S., L.R., M.P., M.C.P., methodology, L.R.; formal analysis, A.S., L.R., M.P., M.C.P., resources, A.S., L.R., M.P., M.C.P.; data curation, L.R.; writing-original draft preparation, A.S., L.R., M.P., M.C.P.; writing-review and editing, A.S., L.R., M.P., M.C.P.; visualization, A.S., L.R., M.P., M.C.P.; supervision, A.S., L.R., M.P., M.C.P.; project administration, A.S. All authors have read and agreed to the published version of the manuscript.

Funding: This research received no external funding.

Acknowledgments: Although the views and ideas expressed in this article are those of Alfonso Siano, Lukman Raimi, Maria Palazzo and Mirela Clementina Panait; "Section 2.3" and "Section 3" are attributed to Lukman Raimi; "Section 2"; "Section 2.2" and "Section 4" are attributed to Mirela Clementina Panait; "Section 2.1" and "Section 5" are attributed to Maria Palazzo; while "Section 1" and "Section 6" is attributed to Alfonso Siano.

Conflicts of Interest: The authors declare no conflict of interest.

\section{Appendix A}

Table A1. Focus of Selected Paper.

\begin{tabular}{|c|c|c|c|c|c|}
\hline Article & Title & Author & Year & $\begin{array}{l}\text { Number of Factors } \\
\text { Affecting Mobile } \\
\text { Banking }\end{array}$ & $\begin{array}{c}\text { Type of Specific Factors } \\
\text { Affecting Mobile } \\
\text { Banking }\end{array}$ \\
\hline 1 & $\begin{array}{l}\text { Toward an Understanding of } \\
\text { Behavioural Intention to Use } \\
\text { Mobile Banking }\end{array}$ & Luarn \& Lin & 2005 & 3 & $\begin{array}{l}\text { Perceived credibility, } \\
\text { self-efficacy and } \\
\text { financial cost }\end{array}$ \\
\hline 2 & $\begin{array}{l}\text { M-Commerce Implementation in } \\
\text { Nigeria: Trends and Issues }\end{array}$ & $\begin{array}{l}\text { Ayo, Ekong, } \\
\text { Fatudimu \& Adebiyi }\end{array}$ & 2007 & 4 & $\begin{array}{l}\text { Patronage, quality of cell } \\
\text { phones, lack of basic } \\
\text { infrastructure and } \\
\text { security issues }\end{array}$ \\
\hline 3 & $\begin{array}{l}\text { Internet Diffusion in Nigeria: is } \\
\text { the 'Giant of Africa' waking up? }\end{array}$ & $\begin{array}{c}\text { Muganda, Bankole \& } \\
\text { Brown }\end{array}$ & 2008 & 1 & Infrastructure \\
\hline 4 & $\begin{array}{l}\text { Mobile Commerce User } \\
\text { Acceptance Study in China }\end{array}$ & $\operatorname{Min} \& Q u$ & 2008 & 7 & $\begin{array}{l}\text { Culture, user satisfaction, } \\
\text { trust, privacy protection, } \\
\text { quality, experience, } \\
\text { and cost }\end{array}$ \\
\hline 5 & $\begin{array}{c}\text { Mobile phone technology in } \\
\text { banking system: Its economic } \\
\text { effect }\end{array}$ & Anyasi \& Otubu & 2009 & 3 & $\begin{array}{l}\text { Convenience, } \\
\text { accessibility and } \\
\text { affordability. }\end{array}$ \\
\hline 6 & $\begin{array}{l}\text { An Empirical Investigation of the } \\
\text { Level of Users' Acceptance of } \\
\text { E-Banking in Nigeria. }\end{array}$ & $\begin{array}{l}\text { Oni, Aderonke \& } \\
\text { Ayo }\end{array}$ & 2010 & 6 & $\begin{array}{l}\text { Convenience, ease of use, } \\
\text { time saving, privacy, } \\
\text { appropriateness for their } \\
\text { transaction needs, } \\
\text { and network security }\end{array}$ \\
\hline 7 & $\begin{array}{l}\text { Mobile phones and economic } \\
\text { development in Africa }\end{array}$ & Aker \& Mbiti & 2010 & 3 & $\begin{array}{l}\text { Ease of use, fast services } \\
\text { and reduced } \\
\text { communication costs }\end{array}$ \\
\hline 8 & $\begin{array}{l}\text { Mobile banking adoption in } \\
\text { Nigeria }\end{array}$ & $\begin{array}{l}\text { Bankole, Bankole \& } \\
\text { Brown }\end{array}$ & 2011 & 1 & Cultural Values \\
\hline 9 & $\begin{array}{l}\text { An exploratory study on adoption } \\
\text { of electronic banking: underlying } \\
\text { consumer behaviour and critical } \\
\text { success factors: case of Nigeria }\end{array}$ & $\begin{array}{l}\text { Aliyu, Younus \& } \\
\text { Tasmin }\end{array}$ & 2012 & 6 & $\begin{array}{l}\text { Accessibility, reluctance } \\
\text { to change, cost/price, } \\
\text { security concern, ease of } \\
\text { use, and awareness }\end{array}$ \\
\hline
\end{tabular}


Table A1. Cont.

\begin{tabular}{|c|c|c|c|c|c|}
\hline Article & Title & Author & Year & $\begin{array}{l}\text { Number of Factors } \\
\text { Affecting Mobile } \\
\text { Banking }\end{array}$ & $\begin{array}{c}\text { Type of Specific Factors } \\
\text { Affecting Mobile } \\
\text { Banking }\end{array}$ \\
\hline 10 & $\begin{array}{l}\text { Going cashless: Adoption of } \\
\text { mobile banking in Nigeria }\end{array}$ & Njoku \& Odumeru & 2013 & 7 & $\begin{array}{c}\text { relative advantage, } \\
\text { complexity, } \\
\text { compatibility, } \\
\text { observability, trialability, } \\
\text { age and educational } \\
\text { background }\end{array}$ \\
\hline 11 & $\begin{array}{l}\text { Global financial development } \\
\text { report 2014: Financial inclusion }\end{array}$ & World Bank & 2013 & 2 & $\begin{array}{l}\text { Economic growth and } \\
\text { poverty alleviation }\end{array}$ \\
\hline 12 & $\begin{array}{l}\text { An investigative study on factors } \\
\text { influencing the customer } \\
\text { satisfaction with e-banking in } \\
\text { Nigeria }\end{array}$ & $\begin{array}{c}\text { Balogun, Ajiboye \& } \\
\text { Dunsin }\end{array}$ & 2013 & 1 & Quality of the service \\
\hline 13 & $\begin{array}{l}\text { Impact of mobile banking on } \\
\text { service delivery in the Nigerian } \\
\text { commercial banks. }\end{array}$ & Adewoye & 2013 & 4 & $\begin{array}{c}\text { Transactional } \\
\text { convenience, savings of } \\
\text { time, quick transaction } \\
\text { alert and save of service } \\
\text { cost }\end{array}$ \\
\hline 14 & Financial inclusion in Africa & Triki \& Faye & 2013 & & $\begin{array}{l}\text { Broadening access, } \\
\text { greater household } \\
\text { savings, capital for } \\
\text { investment, expansion of } \\
\text { class of entrepreneurs, } \\
\text { and human capital } \\
\text { investment }\end{array}$ \\
\hline 15 & $\begin{array}{l}\text { The opportunities of digitizing } \\
\text { payments }\end{array}$ & Klapper \& Singer & 2014 & 2 & Access and Participation \\
\hline 16 & $\begin{array}{c}\text { International remittances and } \\
\text { financial inclusion in Sub-Saharan } \\
\text { Africa }\end{array}$ & Aga \& Peria & 2014 & 1 & $\begin{array}{c}\text { Increases the probability } \\
\text { of households opening } \\
\text { bank accounts }\end{array}$ \\
\hline 17 & $\begin{array}{l}\text { Mobile phone banking in Nigeria: } \\
\text { benefits, problems and prospects }\end{array}$ & Agwu \& Carter & 2014 & 4 & $\begin{array}{l}\text { Cost of maintenance, } \\
\text { Users' education, } \\
\text { poverty and } \\
\text { infrastructure } \\
\text { availability. }\end{array}$ \\
\hline 18 & $\begin{array}{l}\text { Financial inclusion and } \\
\text { innovation in Africa }\end{array}$ & $\begin{array}{l}\text { Beck, Senbet \& } \\
\text { Simbanegavi }\end{array}$ & 2015 & 3 & $\begin{array}{c}\text { Inclusive growth, } \\
\text { financial deepening and } \\
\text { access }\end{array}$ \\
\hline 19 & $\begin{array}{l}\text { Financial Inclusion: Can It Meet } \\
\text { Multiple Macroeconomic Goals? }\end{array}$ & $\begin{array}{c}\text { Sahay, Cihak, M \& } \\
\text { N'Diaye }\end{array}$ & 2015 & 3 & $\begin{array}{l}\text { Access to credit, Savings } \\
\text { and Economic growth }\end{array}$ \\
\hline 20 & $\begin{array}{l}\text { Can Islamic Banking Increase } \\
\text { Financial Inclusion? }\end{array}$ & $\begin{array}{l}\text { Ben Naceur, Barajas } \\
\text { \& Massara }\end{array}$ & 2015 & 3 & $\begin{array}{l}\text { Access to Islamic } \\
\text { banking products, } \\
\text { improved savings, } \\
\text { investment }\end{array}$ \\
\hline 21 & $\begin{array}{l}\text { User adoption of online banking } \\
\text { in Nigeria: A qualitative study }\end{array}$ & $\begin{array}{l}\text { Tarhini, Mgbemena, } \\
\text { Trab \& Masa' Deh }\end{array}$ & 2015 & 3 & $\begin{array}{l}\text { Security, religion and } \\
\text { culture }\end{array}$ \\
\hline 22 & $\begin{array}{l}\text { The determinants of financial } \\
\text { inclusion in Africa }\end{array}$ & Zins \& Weill & 2016 & 4 & $\begin{array}{c}\text { Gender, economic status, } \\
\text { education and age } \\
\text { influence FI }\end{array}$ \\
\hline 23 & $\begin{array}{l}\text { Mobile banking-adoption and } \\
\text { challenges in Nigeria }\end{array}$ & $\begin{array}{l}\text { Agu, Simon \& } \\
\text { Onwuka }\end{array}$ & 2016 & 5 & $\begin{array}{l}\text { Handset operability, } \\
\text { Security, Scalability and } \\
\text { reliability, Geographic } \\
\text { distribution and Age }\end{array}$ \\
\hline 24 & $\begin{array}{l}\text { Financial inclusion in Africa: } \\
\text { evidence using dynamic panel } \\
\text { data analysis. }\end{array}$ & $\begin{array}{l}\text { Gebrehiwot \& } \\
\text { Makina }\end{array}$ & 2016 & 3 & $\begin{array}{l}\text { GDP per capita, mobile } \\
\text { infrastructure and } \\
\text { remoteness }\end{array}$ \\
\hline 25 & $\begin{array}{c}\text { Analysis of the determinants of } \\
\text { financial inclusion in Central and } \\
\text { West Africa }\end{array}$ & $\begin{array}{c}\text { Soumaré, } \\
\text { TchanaTchana \& } \\
\text { Kengne }\end{array}$ & 2016 & 9 & $\begin{array}{c}\text { Gender, education, age, } \\
\text { income, residence area, } \\
\text { employment status, } \\
\text { marital status, } \\
\text { household size and } \\
\text { degree of trust in } \\
\text { financial institutions }\end{array}$ \\
\hline 26 & $\begin{array}{l}\text { Is the rise of Pan-African banking } \\
\text { the next big thing in Sub-Saharan } \\
\text { Africa }\end{array}$ & PWC & 2017 & 2 & $\begin{array}{l}\text { Withdrawal of several } \\
\text { Western banks and } \\
\text { intra-regional trade } \\
\text { linkages }\end{array}$ \\
\hline
\end{tabular}


Table A1. Cont.

\begin{tabular}{|c|c|c|c|c|c|}
\hline Article & Title & Author & Year & $\begin{array}{l}\text { Number of Factors } \\
\text { Affecting Mobile } \\
\text { Banking }\end{array}$ & $\begin{array}{c}\text { Type of Specific Factors } \\
\text { Affecting Mobile } \\
\text { Banking }\end{array}$ \\
\hline 27 & $\begin{array}{l}\text { Mobile banking in Sub-Saharan } \\
\text { Africa: setting the way towards } \\
\text { financial development. }\end{array}$ & Rouse \&Verhoef & 2017 & 2 & $\begin{array}{l}\text { Extension of remote } \\
\text { rural locations and } \\
\text { introduction of } \\
\text { innovative products }\end{array}$ \\
\hline 28 & $\begin{array}{l}\text { What determines financial } \\
\text { inclusion in Sub-Saharan Africa? }\end{array}$ & Chikalipah & 2017 & 1 & $\begin{array}{l}\text { Illiteracy is the major } \\
\text { hindrance to FI }\end{array}$ \\
\hline 29 & $\begin{array}{c}\text { Financial inclusion, entry barriers, } \\
\text { and entrepreneurship: evidence } \\
\text { from China }\end{array}$ & Fan \& Zhang & 2017 & 3 & $\begin{array}{c}\text { Mitigation of credit } \\
\text { constraints, boosting } \\
\text { entrepreneurial activities } \\
\text { and reducing } \\
\text { information asymmetry } \\
\text { in financial transactions }\end{array}$ \\
\hline 30 & $\begin{array}{c}\text { Determinants of financial } \\
\text { inclusion in Sub-Sahara African } \\
\text { countries }\end{array}$ & $\begin{array}{l}\text { Oyelami, Saibu \& } \\
\text { Adekunle }\end{array}$ & 2017 & 2 & $\begin{array}{c}\text { Demand side factors } \\
\text { (level of income and } \\
\text { literacy) and Supply side } \\
\text { factors (Interest rate and } \\
\text { bank innovation proxy } \\
\text { by ATM usage). }\end{array}$ \\
\hline 31 & $\begin{array}{c}\text { An assessment of the impact of } \\
\text { mobile banking on traditional } \\
\text { banking in Nigeria }\end{array}$ & Khan \& Ejike & 2017 & 4 & $\begin{array}{c}\text { Good knowledge of } \\
\text { mobile devices, access to } \\
\text { mobile banking, } \\
\text { convenience and } \\
\text { satisfaction of usage }\end{array}$ \\
\hline 32 & $\begin{array}{c}\text { The effect of mobile banking on } \\
\text { the performance of commercial } \\
\text { banks in Nigeria }\end{array}$ & $\begin{array}{l}\text { Bagudu, Mohd Khan } \\
\text { \& Roslan }\end{array}$ & 2017 & 1 & $\begin{array}{l}\text { More access to mobile } \\
\text { handsets }\end{array}$ \\
\hline 33 & $\begin{array}{l}\text { Financial inclusion as a tool for } \\
\text { sustainable development }\end{array}$ & Voica & 2017 & 3 & $\begin{array}{c}\text { Sustainable } \\
\text { development, Consumer } \\
\text { protection and economic } \\
\text { literacy }\end{array}$ \\
\hline 34 & $\begin{array}{l}\text { The effect of financial inclusion on } \\
\text { welfare in sub-Saharan Africa: } \\
\text { Evidence from disaggregated data }\end{array}$ & Tita \& Aziakpono & 2017 & 3 & $\begin{array}{l}\text { Increase in formal } \\
\text { opening of bank } \\
\text { accounts, financial } \\
\text { infrastructure and } \\
\text { economic activities }\end{array}$ \\
\hline 35 & $\begin{array}{c}\text { Infrastructure deficiencies and } \\
\text { adoption of mobile money in } \\
\text { Sub-Saharan Africa }\end{array}$ & $\begin{array}{l}\text { Mothobi \& } \\
\text { Grzybowski }\end{array}$ & 2017 & 2 & $\begin{array}{l}\text { physical infrastructure } \\
\text { and level of income }\end{array}$ \\
\hline 36 & $\begin{array}{l}\text { Mobile Money and Financial } \\
\text { Inclusion in Sub-Saharan Africa: } \\
\text { the Moderating Role of Social } \\
\text { Networks }\end{array}$ & $\begin{array}{l}\text { Bongomin, Ntayi, } \\
\text { Munene \& Malinga }\end{array}$ & 2018 & 1 & $\begin{array}{c}\text { Existence of social } \\
\text { networks of strong and } \\
\text { weak ties among mobile } \\
\text { money users }\end{array}$ \\
\hline 37 & $\begin{array}{c}\text { Can mobile money help firms } \\
\text { mitigate the problem of access to } \\
\text { finance in Eastern sub-Saharan } \\
\text { Africa? }\end{array}$ & Gosavi & 2018 & 2 & $\begin{array}{l}\text { Access to finance, or } \\
\text { lines of credit }\end{array}$ \\
\hline 38 & $\begin{array}{c}\text { EFInA Access to Financial } \\
\text { Services in Nigeria 2010-2018 } \\
\text { survey }\end{array}$ & EFInA & 2018 & 4 & $\begin{array}{c}\text { Number of banked } \\
\text { population, awareness \& } \\
\text { knowledge, institutional } \\
\text { exclusion and } \\
\text { affordability }\end{array}$ \\
\hline 39 & $\begin{array}{l}\text { The Global Findex Database 2017: } \\
\text { Measuring financial inclusion and } \\
\text { the FinTech revolution }\end{array}$ & $\begin{array}{l}\text { Demirguc-Kunt, } \\
\text { Klapper, Singer, } \\
\text { Ansar \& Hess }\end{array}$ & 2018 & 0 & \\
\hline 40 & $\begin{array}{c}\text { Financial Inclusion and Per Capita } \\
\text { Income In Africa: Bayesian VAR } \\
\text { Estimates. }\end{array}$ & Alenoghena & 2019 & 3 & $\begin{array}{c}\text { Per capital incomes, } \\
\text { deposit interest rate and } \\
\text { the internet }\end{array}$ \\
\hline 41 & $\begin{array}{c}\text { M-PESA and Financial Inclusion } \\
\text { in Kenya: Of Paying Comes } \\
\text { Saving? }\end{array}$ & Van Hove \& Dubus & 2019 & 2 & $\begin{array}{c}\text { Phone owners, Better } \\
\text { educated }\end{array}$ \\
\hline 42 & $\begin{array}{l}\text { Migrant remittances and financial } \\
\text { inclusion among households in } \\
\text { Nigeria. }\end{array}$ & Ajefu \& Ogebe & 2019 & 2 & $\begin{array}{l}\text { Receipt of remittances } \\
\text { increases the use of } \\
\text { formal financial services } \\
\text { and migrant networks }\end{array}$ \\
\hline 43 & $\begin{array}{l}\text { The Impact of Mobile Money on } \\
\text { the Financial Performance of the } \\
\text { SMEs in Douala, Cameroon }\end{array}$ & Talom \& Tengeh & 2019 & 3 & $\begin{array}{l}\text { Access to the internet, } \\
\text { cost and efficiency }\end{array}$ \\
\hline
\end{tabular}


Table A1. Cont.

\begin{tabular}{|c|c|c|c|c|c|}
\hline Article & Title & Author & Year & $\begin{array}{l}\text { Number of Factors } \\
\text { Affecting Mobile } \\
\text { Banking }\end{array}$ & $\begin{array}{c}\text { Type of Specific Factors } \\
\text { Affecting Mobile } \\
\text { Banking }\end{array}$ \\
\hline 44 & $\begin{array}{c}\text { Digitising Financial Services: A } \\
\text { Tool for Financial Inclusion in } \\
\text { South Africa? }\end{array}$ & Shipalana & 2019 & 3 & $\begin{array}{c}\text { Tackle poverty, promote } \\
\text { inclusive development } \\
\text { and address the SDGs }\end{array}$ \\
\hline 45 & $\begin{array}{l}\text { See the best Nigerian mobile } \\
\text { banking apps in H1 } 2019\end{array}$ & Benson & 2019 & 2 & $\begin{array}{l}\text { Access to mobile device, } \\
\text { network connection }\end{array}$ \\
\hline 46 & $\begin{array}{c}\text { Financial Inclusion and } \\
\text { Achievements of Sustainable } \\
\text { Development Goals (SDGs) }\end{array}$ & Ma'ruf \&Aryani & 2019 & 2 & $\begin{array}{l}\text { Achievement of SGDs } \\
\text { and poverty alleviation }\end{array}$ \\
\hline 47 & $\begin{array}{c}\text { Financial inclusion and } \\
\text { sustainable development in } \\
\text { Nigeria. }\end{array}$ & $\begin{array}{c}\text { Soyemi, Olowofela \& } \\
\text { Yunusa }\end{array}$ & 2019 & 6 & $\begin{array}{l}\text { Accessibility, reluctance } \\
\text { to change, cost/price, } \\
\text { security concern, ease of } \\
\text { use, and awareness }\end{array}$ \\
\hline 48 & $\begin{array}{c}\text { Financial inclusion in sub-Saharan } \\
\text { Africa: Recent trends and } \\
\text { determinants }\end{array}$ & $\begin{array}{l}\text { Asuming, } \\
\text { Osei-Agyei, L.G. \& } \\
\text { Mohammed }\end{array}$ & 2019 & 6 & $\begin{array}{l}\text { Age, education, gender, } \\
\text { wealth, growth rate of } \\
\text { GDP and access to } \\
\text { financial institutions }\end{array}$ \\
\hline 49 & $\begin{array}{l}\text { Enhancing Financial Inclusion in } \\
\text { ASEAN: Identifying the Best } \\
\text { Growth Markets for Fintech }\end{array}$ & Loo & 2019 & 4 & $\begin{array}{l}\text { Commercial bank } \\
\text { branches, Demand } \\
\text { deposit from the rural } \\
\text { areas, loan to rural areas } \\
\text { and human capital } \\
\text { development }\end{array}$ \\
\hline 50 & $\begin{array}{l}\text { Social and Financial Inclusion } \\
\text { through Nonbanking Institutions: } \\
\text { A Model for Rural Romania. }\end{array}$ & $\begin{array}{l}\text { Yue, Cao, Duarte, } \\
\text { Shao \& Manta }\end{array}$ & 2019 & 3 & $\begin{array}{l}\text { Access to financial } \\
\text { services, communication } \\
\text { technologies, digital } \\
\text { mobile platforms }\end{array}$ \\
\hline 51 & $\begin{array}{l}\text { Do mobile phones, economic } \\
\text { growth, bank competition and } \\
\text { stability matter for financial } \\
\text { inclusion in Africa? }\end{array}$ & Chinoda \& Kwenda & 2019 & 4 & $\begin{array}{c}\text { Mobile phones, } \\
\text { economic growth, bank } \\
\text { competition and stability } \\
\text { impact financial } \\
\text { inclusion }\end{array}$ \\
\hline 52 & $\begin{array}{l}\text { Financial Inclusion Condition of } \\
\text { African Countries }\end{array}$ & Chinoda \& Kwenda & 2019 & 2 & $\begin{array}{l}\text { Access and usage factors } \\
\text { affect financial inclusion }\end{array}$ \\
\hline 53 & $\begin{array}{l}\text { Mobile telephony, financial } \\
\text { inclusion and inclusive growth }\end{array}$ & $\begin{array}{l}\text { Abor, Amidu \& } \\
\text { Issahaku }\end{array}$ & 2019 & 3 & $\begin{array}{l}\text { Mobile penetration, } \\
\text { pro-poor development } \\
\text { and improved } \\
\text { livelihoods }\end{array}$ \\
\hline 54 & $\begin{array}{l}\text { Financial Inclusion in Ethiopia: Is } \\
\text { It on the Right Track? }\end{array}$ & $\begin{array}{c}\text { Berhanu Lakew \& } \\
\text { Azadi }\end{array}$ & 2020 & 3 & $\begin{array}{l}\text { Barriers are preference } \\
\text { for informal saving club, } \\
\text { unemployment and low } \\
\text { income }\end{array}$ \\
\hline 55 & $\begin{array}{l}\text { Readiness for banking } \\
\text { technologies in developing } \\
\text { countries }\end{array}$ & $\begin{array}{l}\text { Berndt, Saunders \& } \\
\text { Petzer }\end{array}$ & 2020 & 2 & $\begin{array}{l}\text { Access to innovative } \\
\text { banking technologies } \\
\text { and technology } \\
\text { readiness of the people }\end{array}$ \\
\hline 56 & Financial Inclusion & World Bank & 2020 & 3 & $\begin{array}{l}\text { Quality of life, poverty } \\
\text { reduction, facilitating } \\
\text { investments in health, } \\
\text { education, } \\
\text { and businesses }\end{array}$ \\
\hline 57 & $\begin{array}{l}\text { Financial exclusion in OECD } \\
\text { countries: A scoping review }\end{array}$ & $\begin{array}{c}\text { Caplan, Birkenmaier } \\
\text { \& Bae }\end{array}$ & 2020 & 6 & $\begin{array}{c}\text { Dominant issues covered } \\
\text { in FI are } \\
\text { conceptualization, } \\
\text { contributors, } \\
\text { and impacts of FI. Less } \\
\text { covered are } \\
\text { measurement, } \\
\text { prevention, } \\
\text { and contemporary } \\
\text { practice trends in } \\
\text { financial exclusion. }\end{array}$ \\
\hline 58 & Financial inclusion-and the SDGs & $\begin{array}{c}\text { UN Capital } \\
\text { Development Fund }\end{array}$ & 2020 & 3 & $\begin{array}{l}\text { Promotes investment, } \\
\text { consumption and } \\
\text { resource mobilization }\end{array}$ \\
\hline
\end{tabular}

Source: authors, based on the summary of the reviewed literature. 
Appendix B. Year-Wise Distribution of Research Publications

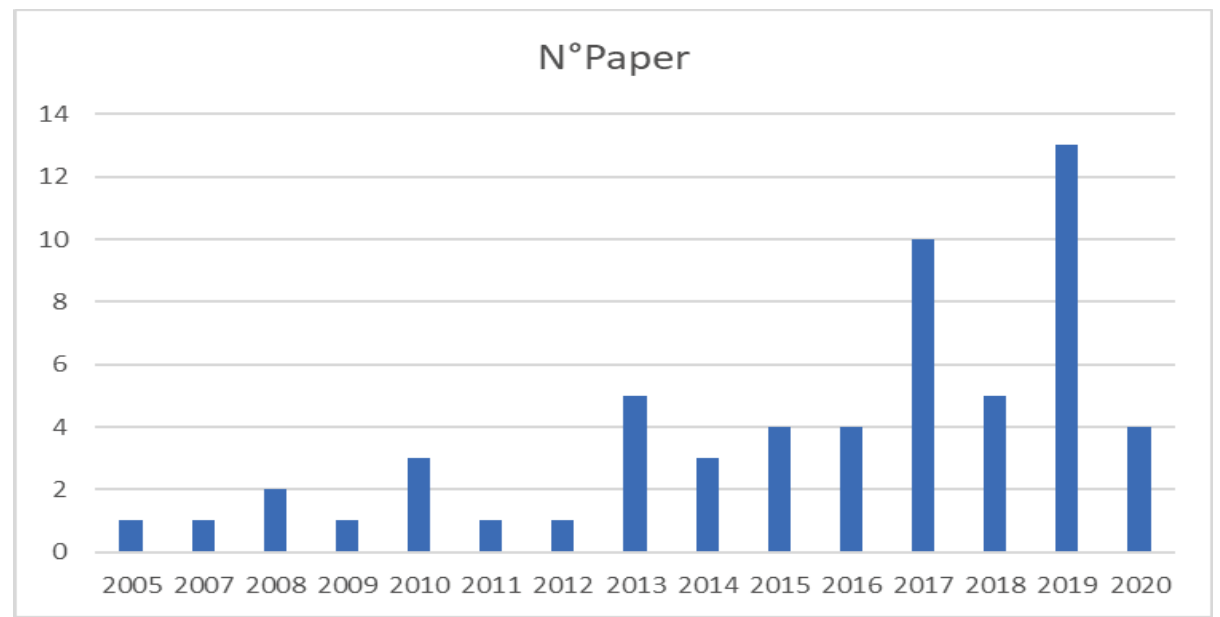

Figure A1. Source: authors, based on the summary of the reviewed literature.

Appendix C. Year-Wise Distribution of Specific Factors Affecting Mobile Banking Explored by Former Publications

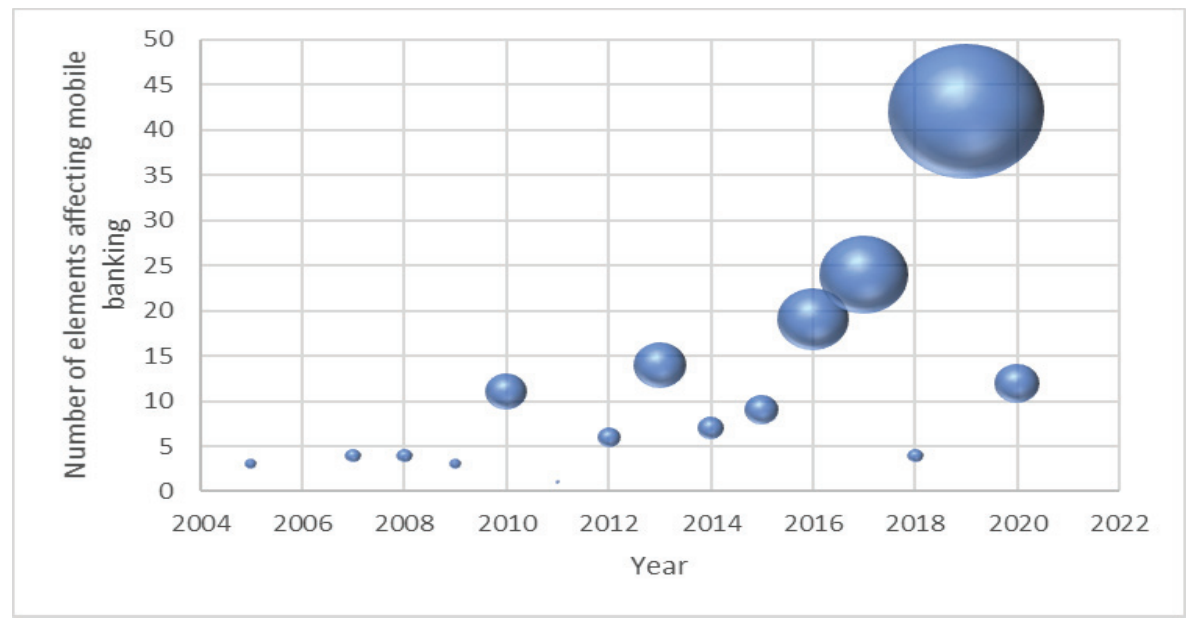

Figure A2. Source: authors, based on the summary of the reviewed literature.

\section{References}

1. United Nations Development Programme Goal 8: Decent Work and Economic Growth. 2020. Available online: https://www.undp.org/content/undp/en/home/sustainable-development-goals/goal-8-decent-workand-economic-growth.html (accessed on 24 February 2020).

2. World Bank The World Bank in Africa. 2019. Available online: https://www.worldbank.org/en/region/afr/ overview (accessed on 18 March 2020).

3. Amankwah-Amoah, J.; Boso, N.; Debrah, Y.A. Africa rising in an emerging world: An international marketing perspective. Int. Mark. Rev. 2018, 35, 550-559. [CrossRef] 
4. Amankwah-Amoah, J.; Egbetokun, A.; Osabutey, E.L. Meeting the 21st century challenges of doing business in Africa. Technol. Forecast. Soc. Chang. 2018, 131, 336-338. [CrossRef]

5. Aker, J.C.; Mbiti, I.M. Mobile phones and economic development in Africa. J. Econ. Perspect. 2010, 24, 207-232. [CrossRef]

6. Rouse, M.; Verhoef, G. Mobile Banking in Sub-Saharan Africa: Setting the Way Towards Financial Development. MPRA Paper No. 78006. 2017, pp. 1-21. Available online: https://mpra.ub.uni-muenchen.de/ 78006/1/MPRA_paper_78006.pdf (accessed on 15 April 2020).

7. Njoku, A.C.; Odumeru, J.A. Going cashless: Adoption of mobile banking in Nigeria. Niger. Chapter Arab. J. Bus. Manag. Rev. 2013, 62,1-9.

8. Raimi, L. Imperative of meta-study for research in the field of corporate social responsibility and emerging issues in corporate governance. In The Handbook of Research Methods on Corporate Social Responsibility; Crowther, D., Lauesen, L.M., Eds.; Handbook Series: Edgar Elgar, UK, 2017.

9. Amuda, Y.J.; Embi, N.A.C. Alleviation of Poverty among OIC Countries through Sadaqat, Cash Waqf and Public Funding. Int. J. Trade Econ. Finance 2013, 4, 405-407. [CrossRef]

10. Ihugba, O.A.; Odii, A.; Njoku, A. Theoretical Analysis of Entrepreneurship Challenges and Prospects in Nigeria. Int. Lett. Soc. Humanist. Sci. 2014, 5, 21-34. [CrossRef]

11. Rjoub, H.; Aga, M.; AbuAlRub, A.; Bein, M.A. Financial Reforms and Determinants of FDI: Evidence from Landlocked Countries in Sub-Saharan Africa. Economics 2017, 5, 1. [CrossRef]

12. Asuming, P.O.; Osei-Agyei, L.G.; Mohammed, J.I. Financial Inclusion in Sub-Saharan Africa: Recent Trends and Determinants. J. Afr. Bus. 2019, 20,112-134. [CrossRef]

13. Bongomin, G.O.C.; Ntayi, J.M.; Munene, J.C.; Malinga, C.A. Mobile Money and Financial Inclusion in Sub-Saharan Africa: The Moderating Role of Social Networks. J. Afr. Bus. 2018, 19, 361-384. [CrossRef]

14. Talom, F.S.G.; Tengeh, R.K. The Impact of Mobile Money on the Financial Performance of the SMEs in Douala, Cameroon. Sustainability 2019, 12, 183. [CrossRef]

15. Coffie, C.P.K.; Zhao, H.; Mensah, I.A. Panel Econometric Analysis on Mobile Payment Transactions and Traditional Banks Effort toward Financial Accessibility in Sub-Sahara Africa. Sustainability 2020, 12, 895. [CrossRef]

16. Bankole, F.O.; Bankole, O.O.; Brown, I. Mobile Banking Adoption in Nigeria. Electron. J. Inf. Syst. Dev. Ctries. 2011, 47, 1-23. [CrossRef]

17. Ayo, C.K.; Ekong, U.O.; Fatudimu, I.T.; Adebiyi, A.A. M-Commerce Implementation in Nigeria: Trends and Issues. J. Internet Bank. Commer. 2007, 12, 1-15.

18. Muganda, N.O.; Bankole, F.O.; Brown, I. Internet Diffusion in Nigeria: Is the 'Giant of Africa' waking up? In Proceedings of the 10th Annual Conference on World Wide Web Applications, Cape Town, South Africa, 3-5 September 2008.

19. Benson, E.A. See the Best Nigerian Mobile Banking Apps in H1 2019; Nairametrics Publication: Lagos, Nigeria, 2019; Available online: https://nairametrics.com/2019/07/17/the-best-mobile-banking-apps-innigeria/ (accessed on 20 April 2020).

20. Chikalipah, S. What determines financial inclusion in Sub-Saharan Africa? Afr. J. Econ. Manag. Stud. 2017, 8, 8-18. [CrossRef]

21. Mothobi, O.; Grzybowski, L. Infrastructure deficiencies and adoption of mobile money in Sub-Saharan Africa. Inf. Econ. Policy 2017, 40, 71-79. [CrossRef]

22. Gosavi, A. Can Mobile Money Help Firms Mitigate the Problem of Access to Finance in Eastern sub-Saharan Africa? J. Afr. Bus. 2018, 19, 343-360. [CrossRef]

23. Beck, T.; Senbet, L.; Simbanegavi, W. Financial Inclusion and Innovation in Africa: An Overview. J. Afr. Econ. 2015, 24, i3-i11. [CrossRef]

24. Gebrehiwot, K.G.; Makina, D. Financial inclusion in Africa: Evidence using dynamic panel data analysis. In Proceedings of the Conference on Inclusive Growth and Poverty Reduction in the IGAD Region, Addis Abeba, Ethiopia, 24-25 October 2016; p. 49.

25. Sahay, R.; Cihak, M.; N’Diaye, P.; Barajas, A.; Mitra, S.; Kyobe, A.; Mooi, Y.; Yousefi, R. Financial Inclusion: Can it Meet Multiple Macroeconomic Goals? Staff. Discuss. Notes 2015, 1-33. [CrossRef]

26. Ma'Ruf, A.; Aryani, F. Financial Inclusion and Achievements of Sustainable Development Goals (SDGs) in ASEAN. GATR J. Bus. Econ. Rev. 2019, 4, 147-155. [CrossRef] 
27. Soyemi, K.A.; Olowofela, O.E.; Yunusa, L.A. Financial inclusion and sustainable development in Nigeria. J. Econ. Manag. 2020, 39, 105-131. [CrossRef]

28. Ene, C. Current Issues Regarding the Protection of Retail Investors on the Capital Market within the European Union. USV Ann. Econ. Public Adm. 2017, 17, 35-44.

29. Fan, Z.; Zhang, R. Financial Inclusion, Entry Barriers, and Entrepreneurship: Evidence from China. Sustainability 2017, 9, 203. [CrossRef]

30. Grigorescu, A.; Cerchia, A.E.; Oachesu, M.M.; Udroiu, F. Enhancing Internet Banking-Solutions for Customer Relationship Management. Saudi J. Bus. Manag. Stud. 2017, 2, 38-43.

31. Voica, M.C. Financial inclusion as a tool for sustainable development. Rom. Econ. Rev. 2017, 44, 121-129.

32. Abor, J.Y.; Amidu, M.; Issahaku, H. Mobile Telephony, Financial Inclusion and Inclusive Growth. J. Afr. Bus. 2018, 19, 430-453. [CrossRef]

33. Iacovoiu, V.B. An Empirical Analysis of Some Factors Influencing Financial Literacy. Econ. Insights Trends Chall. 2018, VII, 23-31.

34. Loo, M.K.L. Enhancing Financial Inclusion in ASEAN: Identifying the Best Growth Markets for Fintech. J. Risk Financ. Manag. 2019, 12, 181. [CrossRef]

35. Yue, X.-G.; Cao, Y.; Duarte, N.; Shao, X.-F.; Manta, O.P. Social and Financial Inclusion through Nonbanking Institutions: A Model for Rural Romania. J. Risk Financ. Manag. 2019, 12, 166. [CrossRef]

36. Lakew, T.B.; Azadi, H. Financial Inclusion in Ethiopia: Is It on the Right Track? Int. J. Financ. Stud. 2020, 8, 28. [CrossRef]

37. Berndt, A.D.; Saunders, S.G.; Petzer, D.J. Readiness for banking technologies in developing countries. S. Afr. Bus. Rev. 2010, 14, 47-76.

38. Sapepa, K.; Roberts-Lombard, M.; Van Tonder, E. The Relationship between Selected Variables and Customer Loyalty within the Banking Environment of an Emerging Economy. J. Soc. Sci. 2015, 43, 115-123. [CrossRef]

39. Deigh, L.; Farquhar, J.; Palazzo, M.; Siano, A. Corporate social responsibility: Engaging the community. Qual. Mark. Res. Int. J. 2016, 19, 225-240. [CrossRef]

40. Deigh, G.L.A. Corporate Social Responsibility in the Banking Sector of a Developing Country: A Ghanaian Perspective. Ph.D. Thesis, University of Bedfordshire, Luton, UK, 2016.

41. Deigh, L.; Palazzo, M.; Farquhar, J.; Siano, A. Creating a national identity through community relations: The context of a developing country. In Proceedings of the 22nd International Conference on Corporate and Marketing Communications. CMC2017-Challenges of Marketing Communications in a Globalized World, Zaragoza, Spain, 4-5 May 2017.

42. Grigorescu, A.; Oprisan, O.; Condrea, E. Other economico-social factors of the saving process. HOLISTICA-J. Bus. Public Adm. 2017, 8, 41-48. [CrossRef]

43. World Bank. 2020. Available online: https://www.worldbank.org/en/topic/financialinclusion/overview (accessed on 20 March 2020).

44. Shipalana, P. Digitising Financial Services: A Tool for Financial Inclusion in South Africa? SAIIA. Occas. Pap. 2019, 31, 1-38.

45. Caplan, M.A.; Birkenmaier, J.; Bae, J. Financial exclusion in OECD countries: A scoping review*. Int. J. Soc. Welf. 2020, 1-14. [CrossRef]

46. Klapper, L.; Singer, D. The Opportunities of Digitizing Payments; The World Bank: Washington, DC, USA, 2014; pp. 1-33.

47. Triki, T.; Faye, I. Financial Inclusion in Africa; African Development Bank: Tunis, Tunisia, 2013; pp. 1-74.

48. Apiors, E.K.; Suzuki, A. Mobile money, individuals' payments, remittances, and investments: Evidence from the Ashanti Region, Ghana. Sustainability 2018, 10, 1409. [CrossRef]

49. Leyshon, A.; Thrift, N. The restructuring of the U.K. financial services industry in the 1990s: A reversal of fortune? J. Rural. Stud. 1993, 9, 223-241. [CrossRef]

50. Wilson, T.A. Supporting social enterprises to support vulnerable consumers: The example of community development finance institutions and financial exclusion. J. Consum. Policy 2012, 35, 197-213. [CrossRef]

51. Tita, A.F.; Aziakpono, M.J. The effect of financial inclusion on welfare in sub-Saharan Africa: Evidence from disaggregated data. Econ. Res. S. Afr. Work. Pap. 2017, 679, 1-29.

52. Soumaré, I.; Tchana, F.T.; Kengne, T.M. Analysis of the determinants of financial inclusion in Central and West Africa. Transnatl. Corp. Rev. 2016, 8, 231-249. [CrossRef]

53. Anghelache, C.; Niță, D.O.G. Analiza statistică aincluziunii financiare. Rom. Stat. Rev. Suppl. 2019, 9, 3. 
54. Lorena, I.P.; Florin, R.; Iuliana, T.A. Needs of local sustainable development. Ann. Fac. Econ. 2011, 1, 91-97.

55. Matei, M.; Voica, M.C. Social Responsibility in the Financial and Banking Sector. Econ. Insights-Trends Chall. 2013, 2, 115-123.

56. Ene, C.; Panait, M. The financial education-Part of corporate social responsibility for employees and customers. Rev. Romana Econ. 2017, 44, 145-154.

57. Brezoi, A.G. Ethics and Corporate Social Responsibility in the Current Geopolitical Context. Econ. Insights-Trends Chall. 2018, 7, 45-52.

58. Tăbîrcă, A.I.; Ivan, O.R.; Radu, F.; Djaouahdou, R. Qualitative Research in WoS of the Link between Corporate Social Responsibility and Corporate Financial Performance. Valahian J. Econ. Stud. 2019, 10, 107-118. [CrossRef]

59. Matei, M. Responsabilitatea socială a corporaţiilor şi instituţiilor şi dezvoltarea durabilă a României. Bucharest. Expert Publ. House 2013. Available online: https://www.amfiteatrueconomic.ro/temp/Articol_1014.pdf (accessed on 2 December 2020).

60. Iacovoiu, V.; Stancu, A. Competition and Consumer Protection in the Romanian Banking Sector. Amfiteatru Econ. 2017, 19, 381.

61. Kapur, D. Remittances: The new development mantra? Remit. Dev. Impact Future Prospect. 2005, 2, 331-360.

62. FinScope, 2015, FinScope South Africa 2015. Available online: http://www.finmark.org.za/wp-content/ uploads/2016/03/Broch_FinScopeSA2015_Consumersurvey_FNL.pdf (accessed on 17 April 2020).

63. Okello Candiya Bongomin, G.; Ntayi, J.M.; Munene, J.C.; Nabeta, I.N. Financial inclusion in rural Uganda: Testing interaction effect of financial literacy and networks. J. Afr. Bus. 2016, 17, 106-128. [CrossRef]

64. Klein, M.; Mayer, C. Mobile Banking and Financial Inclusion: The Regulatory Lessons; Frankfurt School of Finance and Management: Frankfurt, Germany, 2011; pp. 1-31.

65. Donovan, K. Mobile Money for Financial Inclusion. Inf. Commun. Dev. 2012, 61, 61-73.

66. Mago, S.; Chitokwindo, S. The Impact of Mobile Banking on Financial Inclusion in Zimbabwe: A Case for Masvingo Province. Mediterr. J. Soc. Sci. 2014, 5, 221.

67. Mutsune, T. No Kenyan left behind: The model of Financial Inclusion through Mobile banking. Rev. Bus. Financ. Stud. 2015, 6, 35-42.

68. Okello Candiya Bongomin, G.; Munene, J.C. Analyzing the Relationship between Mobile Money Adoption and Usage and Financial Inclusion of MSMEs in Developing Countries: Mediating Role of Cultural Norms in Uganda. J. Afr. Bus. 2019, 1-20. [CrossRef]

69. Ouma, S.A.; Odongo, T.M.; Were, M. Mobile financial services and financial inclusion: Is it a boon for savings mobilization? Rev. Dev. Financ. 2017, 7, 29-35. [CrossRef]

70. Bakari, I.H.; Idi, A.; Ibrahim, Y. Innovation determinants of financial inclusion in top ten African countries: A system GMM approach. Mark. Manag. Innov. 2018, 4, 99. [CrossRef]

71. Dafe, F. Ambiguity in international finance and the spread of financial norms: The localization of financial inclusion in Kenya and Nigeria. Rev. Int. Politi-Econ. 2020, 27, 500-524. [CrossRef]

72. Lepoutre, J.; Oguntoye, A. The (non-)emergence of mobile money systems in Sub-Saharan Africa: A comparative multilevel perspective of Kenya and Nigeria. Technol. Forecast. Soc. Chang. 2018, 131, 262-275. [CrossRef]

73. Williams, I. Regulatory frameworks and Implementation patterns for Mobile Money in Africa: The case of Kenya, Ghana and Nigeria. In Aalborg University Conference Paper; National Information Technology Agency: Accra, Ghana, 2013.

74. World Bank Group. Global Financial Development Report 2014: Financial Inclusion; World Bank Publications: Washington, DC, USA, 2013; Volume 2.

75. Prince, W.; Fantom, N. World Development Indicators 2014; The World Bank: Washington, DC, USA, 2014; pp. 1-137.

76. EFInA Access to Financial Services in Nigeria 2010-2018 Survey. Available online: https://www.efina.org.ng/ wp-content/uploads/2019/01/A2F-2018-Key-Findings-11_01_19.pdf (accessed on 24 February 2020).

77. Oyelami, L.O.; Saibu, O.M.; Adekunle, B.S. Determinants of financial inclusion in Sub-Sahara African countries. Covenant J. Bus. Soc. Sci. 2017, 8, 104-116.

78. Central Bank of Nigeria/Nigerian Deposit Insurance Corporation (2020). Available online: https://ndic.gov.ng/ (accessed on 24 February 2020). 
79. UN Capital Development Fund (UNCDF). Available online: https://www.uncdf.org/financial-inclusion-andthe-sdgs (accessed on 24 February 2020).

80. Demirguc-Kunt, A.; Klapper, L.; Singer, D.; Ansar, S.; Hess, J. The Global Findex Database 2017: Measuring Financial Inclusion and the Fintech Revolution; The World Bank: Washington, DC, USA, 2018.

81. Alenoghena, R.O. Financial Inclusion and Per Capita Income in Africa: Bayesian VAR Estimates. Acta Univ. Danub. Acon. 2017, 13, 201-221.

82. Conroy, K.; Goodman, A.R.; Kenward, S. Lessons from the Chars Livelihoods Programme, Bangladesh (2004-2010). In Proceedings of the CPRC International Conference, Manchester, UK, 8-10 September 2010.

83. Anghelache, C.; Partachi, I.; Anghel, M.G. Remittances, a factor for poverty reduction. Rom. Stat. Rev. Suppl. 2017, 65, 59-66.

84. Van Hove, L.; Dubus, A. M-PESA and Financial Inclusion in Kenya: Of Paying Comes Saving? Sustainability 2019, 11, 568. [CrossRef]

85. Aga, G.A.; Peria, M.S.M. International Remittances and Financial Inclusion in Sub-Saharan Africa; The World Bank: Washington, DC, USA, 2014

86. Ajefu, J.B.; Ogebe, J.O. Migrant remittances and financial inclusion among households in Nigeria. Oxf. Dev. Stud. 2019, 47, 319-335. [CrossRef]

87. Giuliano, P.; Ruiz-Arranz, M. Remittances, financial development, and growth. J. Dev. Econ. 2009, 90, 144-152. [CrossRef]

88. Zins, A.; Weill, L. The determinants of financial inclusion in Africa. Rev. Dev. Financ. 2016, 6, 46-57. [CrossRef]

89. PWC. Is the rise of Pan-African Banking the Next Big Thing in Sub-Saharan Africa? 2017. Available online: https://www.pwc.com/gx/en/issues/economy/global-economy-watch/rise-of-pan-african-banking. html (accessed on 1 September 2019).

90. World Bank, Global Findex Data. Available online: https://globalfindex.worldbank.org/ (accessed on 10 November 2020).

91. Singh, A.B. Mobile Banking Based Money Order for India Post: Feasible Model and Assessing Demand Potential. Procedia Soc. Behav. Sci. 2012, 37, 466-481. [CrossRef]

92. Tiwari, R.; Buse, S.; Herstatt, C. Customer on the move: Strategic implications of mobile banking for banks and financial enterprises. In Proceedings of the 8th IEEE International Conference on E-Commerce Technology, San Francisco, CA, USA, 26-29 June 2006; p. 81

93. Akturan, U.; Tezcan, N. Mobile banking adoption of the youth market. Mark. Intell. Plan. 2012, 30, 444-459. [CrossRef]

94. Munoz-Leiva, F.; Climent-Climent, S.; Liébana-Cabanillas, F. Determinants of intention to use the mobile banking apps: An extension of the classic TAM model. Span. J. Mark. ESIC 2017, 21, 25-38. [CrossRef]

95. Sharma, S.K. Integrating cognitive antecedents into TAM to explain mobile banking behavioral intention: A SEM-neural network modeling. Inf. Syst. Front. 2017, 21, 815-827. [CrossRef]

96. Luarn, P.; Lin, H.-H. Toward an understanding of the behavioral intention to use mobile banking. Comput. Hum. Behav. 2005, 21, 873-891. [CrossRef]

97. Nasri, W.; Charfeddine, L. Factors affecting the adoption of Internet banking in Tunisia: An integration theory of acceptance model and theory of planned behavior. J. High Technol. Manag. Res. 2012, 23, 1-14. [CrossRef]

98. Zhou, T.; Lu, Y.; Wang, B. Integrating TTF and UTAUT to explain mobile banking user adoption. Comput. Hum. Behav. 2010, 26, 760-767. [CrossRef]

99. Wang, Y.S.; Lin, H.H.; Luarn, P. Predicting consumer intention to use mobile service. Inf. Syst. J. 2006, 16, 157-179. [CrossRef]

100. Min, Q.; Ji, S.; Qu, G. Mobile commerce user acceptance study in China: A revised UTAUT model. Tsinghua Sci. Technol. 2008, 13, 257-264. [CrossRef]

101. Anyasi, F.I.; Otubu, P.A. Mobile phone technology in banking system: Its economic effect. Res. J. Inf. Technol. 2009, 1, 1-5.

102. Oni, A.A.; Ayo, C.K. An Empirical Investigation of the Level of Users' Acceptance of E-Banking in Nigeria. J. Internet Bank. Commer. 2010, 15, 1-13.

103. Aliyu, A.A.; Younus, S.; Tasmin, R.B.H.J. An exploratory study on adoption of electronic banking: Underlying consumer behaviour and critical success factors: Case of Nigeria. Bus. Manag. Rev. 2012, 2, 1-6.

104. Balogun, O.J.; Ajiboye, F.; Dunsin, A.T. An Investigative Study on Factors Influencing the Customer Satisfaction with E-Banking in Nigeria. Int. J. Acad. Res. Econ. Manag. Sci. 2013, 2, 64-73. 
105. Adewoye, J.O. Impact of mobile banking on service delivery in the Nigerian commercial banks. Int. Rev. Manag. Bus. Res. 2013, 2, 333-344.

106. Agwu, P.E.; Carter, A.L. Mobile phone banking in Nigeria: Benefits, problems and prospects. J. Internet Bank. Commer. 2014, 3, 50-70.

107. Tarhini, A.; Mgbemena, C.; Trab, M.S.A.; Masa'Deh, R. User adoption of online banking in Nigeria: A qualitative study. J. Internet Bank. Commer. 2015, 20, 132.

108. Agu, B.O.; Simon, N.P.N.; Onwuka, I.O. Mobile banking-adoption and challenges in Nigeria. Int. J. Innov. Soc. Sci. Humanit. Res. 2016, 4, 17-27.

109. Khan, H.U.; Ejike, A.C. An assessment of the impact of mobile banking on traditional banking in Nigeria. Int. J. Bus. Excell. 2017, 11, 446-463. [CrossRef]

110. Bagudu, H.D.; Khan, S.J.M.; Roslan, A.H. The Effect of Mobile Banking on the Performance of Commercial Banks in Nigeria. Int. Res. J. Manag. IT Soc. Sci. 2017, 4, 71-76.

111. Bille, F.S.; Buri, S.; Crenn, T.A.; Denyes, L.S.; Hassam, C.V.T.; Heitmann, S.; Martinez, M. Digital Access: The Future of Financial Inclusion in Africa; The World Bank: Washington, DC, USA, 2018; pp. 1-97.

112. Denyer, D.; Tranfield, D. Using qualitative research synthesis to build an actionable knowledge base. Manag. Decis. 2006, 44, 213-227. [CrossRef]

113. Lee, J. 10 year retrospect on stage models of e-Government: A qualitative meta-synthesis. Gov. Inf. Q. 2010, 27, 220-230. [CrossRef]

114. Raimi, L.; Uzodinma, I. Trends in Financing Programmes for the Development of Micro, Small and Medium Enterprises (MSMEs) in Nigeria: A Qualitative Meta-synthesis. In Contemporary Developments in Entrepreneurial Finance. FGF Studies in Small Business and Entrepreneurship; Moritz, A., Block, J., Golla, S., Werner, A., Eds.; Springer: Cham, Switzerland, 2020.

115. Finlayson, K.W.; Dixon, A. Qualitative meta-synthesis: A guide for the novice. Nurse Res. 2008, 15, 59-71. [CrossRef]

116. Walsh, D.; Downe, S. Meta-synthesis method for qualitative research: A literature review. Methodol. Issues Nurs. Res. 2005, 50, 204-211. [CrossRef]

117. Central Bank of Nigeria. Annual Statistical Bulletin. 2020. Available online: https://www.cbn.gov.ng/ documents/Statbulletin.asp (accessed on 24 February 2020).

118. Ranjan, K.R.; Read, S. Value co-creation: Concept and measurement. J. Acad. Mark. Sci. 2016, 44, 290-315. [CrossRef]

119. Vargo, S.L.; Lusch, R.F. Evolving to a new dominant logic for marketing. J. Mark. 2004, 68, 1-17. [CrossRef]

120. Bonsu, S.K.; Darmody, A. Co-creating second life: Market-Consumer cooperation in contemporary economy. J. Macromarket. 2008, 28, 355-368. [CrossRef]

121. Chinoda, T.; Kwenda, F.; McMillan, D. Do mobile phones, economic growth, bank competition and stability matter for financial inclusion in Africa? Cogent Econ. Financ. 2019, 7, 1622180. [CrossRef]

122. Chinoda, T.; Kwenda, F. Financial Inclusion Condition of African Countries. Acta Univ. Danub. Acon. 2019, 15, 242-266.

123. Ben Naceur, S.; Barajas, A.; Massara, A. Can Islamic Banking Increase Financial Inclusion? Int. Monet. Fund. 2015, 213-252. [CrossRef]

Publisher's Note: MDPI stays neutral with regard to jurisdictional claims in published maps and institutional affiliations.

(C) 2020 by the authors. Licensee MDPI, Basel, Switzerland. This article is an open access article distributed under the terms and conditions of the Creative Commons Attribution (CC BY) license (http://creativecommons.org/licenses/by/4.0/). 


\title{
Article \\ Micro-Operating Mechanism Approach for Regulatory Sandbox Policy Focused on Fintech
}

\author{
HaeOk Choi and KwangHo Lee ** \\ Science and Technology Policy Institute, 508 Building B, Sejong National Research Complex 370, \\ Sicheng-daero, Sejong 30147, Korea; hochoi@stepi.re.kr \\ * Correspondence: leekh@stepi.re.kr
}

Received: 15 September 2020; Accepted: 30 September 2020; Published: 1 October 2020

\begin{abstract}
To determine the micro-operating mechanism(MoM) of enterprises participating in the regulatory sandbox policy in fintech, this study analyzes the structure of enterprise innovation competencies and derives relevant implications. The results reveal that large, middle-standing, and small and medium-sized enterprises focus on security, infrastructure, and user-related technology development, respectively, to enhance their innovation competencies. The security-related issues considered by large enterprises entail relatively high costs in initial technology development and are closely related to infrastructure building. Large enterprises are focused on developing overall security-related technologies, whereas middle-standing enterprises are striving to develop infrastructure-related technologies, with particular emphasis on elementary technologies. Small and medium-sized enterprises are also making efforts to develop user-centered technologies that can directly be used in fintech. As a method to implement regulatory sandboxes tailored to the needs of participating enterprises in South Korea, this study will help to determine the MoM of such participants and establish strategies to support them sustainably in terms of evidence-based policy.
\end{abstract}

Keywords: MoM(micro-operating mechanism); regulatory sandbox; fintech; type by enterprise; innovation competencies; patents data; evidence-based policy

\section{Introduction}

Many countries around the world are implementing regulatory reform through regulatory sandboxes, which were first attempted in the fintech field as a way to create new technologies and services that have been blocked by regulations [1-3]. However, due to the side effects of being transplanted overseas, we have begun to recognize the need for an institutional transplant process tailored to different financial environments and characteristics at individual companies by countries. Until now, research on the regulatory sandbox itself has been limited because it has been dominated by government-oriented studies [4,5]. This study focuses on the innovation capabilities of Korean companies participating in the regulatory sandbox within the fintech sector and aims to help establish a tailored policy based on a company's characteristics. To evaluate these ideas, this research utilized semantic analysis focusing on the contents and titles of patents, which are unstructured data, to overcome the limitations of earlier studies [6,7]. The former research mainly focused on the frequency and regional distribution of patents, so there was a limitation to utilize (unstructured data) the contents of patent creation. So, this research tries to utilize the characteristics of each company occurring in actual innovation creation activities. The micro-operation mechanism implies that it is necessary to design policies suitable for each characteristic by analyzing micro-structural characteristics appearing in the process of actual system implementation.

The regulatory sandbox policy in fintech began with concerns about the weakening of global competitiveness due to limitations imposed by the government's regulatory policy on the ability 
to rapidly develop technology [8]. In particular, data collection and utilization have important value through the transition to the data economy; as data-based services are launched, the fintech industry is being activated [9]. As new technologies and services are developed, efforts are being made to overcome difficulties caused by institutional voids in government policies [10]. In particular, the fintech field has high initial infrastructure costs which means that they should often be conducted as a government-led business. In this process, government-led system design should preemptively respond to regulations by selecting the impeding factors of new industries and services due to likely issues, such as overregulation, system vacancy, and system duplication. The regulatory sandbox promotes policies that value speed as a means of regulatory reform.

This study is significant since it helps to analyze the innovation competencies of the enterprises participating [11-13] in the regulatory sandbox policy. It is implemented as part of regulatory innovation and uses these competencies as a reference that establish related tailored policies in the future in terms of evidence-based policy.

\section{Literature Review}

The micro-operation mechanisms' theoretical evolution comes from the rational selection system, policy network model, and policy advocacy coalition model. These items explain the system and describe the mechanism of the policy process centered on the constituent variables within each theory. Nevertheless, there was a limitation in being unable to explain the specific mechanism of the policy process by linking macro and micro variables. Therefore, in order to overcome the limitations of existing studies, this study utilized $\mathrm{ACI}$ as a basic theoretical framework for research on micro-operation mechanisms.

Examining regulatory sandboxes using MoM (micro-operating mechanism), actor-centered institutionalism (ACI), which can analyze regulatory policy with a focus on interactions among actors within the system, was considered suitable for this study. Furthermore, the study utilized a scientific analytical technique to analyze innovation competencies [14-16], as well as unstructured data that were the contents or titles of patent data for each type of enterprise; accordingly, enterprises were categorized into different types to clarify their structures and characteristics.

$\mathrm{ACI}$ is suitable for examining the complex mechanisms of policies as a single theory, rather than an integration of multiple theories. Proposed by Scharpf [17,18], ACI postulates that policies are produced because of interactions among actors in institutional settings. It is similar to the rational choice model in that it focuses on actors' preferences and strategic choices. It also takes the same stance as historical institutionalism in that it acknowledges institutional influence over actors. However, institutional influence over actors merely restricts the scope of actors' appropriate actions; the specific action to be taken within that scope is determined by the actors' preferences and strategic choices. In other words, active actors are postulated, which distinguishes ACI from historical institutionalism, which focuses on the passive role of actors. Moreover, since it enables the formation of actors' preferences and strategic choices in the institutional context, $\mathrm{ACI}$ is different from the rational choice model, which limits the actors' preference for specific economic interests. In other words, ACI is a model that combines the rational choice model, which emphasizes the strategic choice of actors, and historical institutionalism, which stresses institution.

To date, research on ACI has focused on how the actors influenced by an institution behave, rather than how the institution influences the actors. Institutional settings that affect actors' choices are the remote causes of policy outcomes, whereas the results of actors' interactions are the proximate causes of policy outcomes [18] (p. 3). Therefore, ACI assumes policies to be linked to constellations and modes of interactions comprising institutional settings, actors with capabilities and orientations, combinations of strategies, and appropriate payoff [17].

First, the institutional setting is a factor that restricts the behaviors of participating actors since it serves as a venue for interactions among the actors and determines the overall framework of the game. However, since these constraints are not decisive, the final policy outcome is determined by the interactions among actors. Second, actors are composite constructs characterized by capabilities 
and orientations (preferences and perceptions) [18] (pp. 43-44). Capabilities are behavioral resources that enable or limit competencies, as well as the right to participate, refrain from participating, or make autonomous decisions in the policy process. In other words, they refer to not only financial and human resources but also the actors' competencies and roles defined by the law and sustained relationships. Orientations indicate perceptions of and preferences for the maintenance of status quo, causes of problems, efficacy in the behavioral process, and the process' outcomes [18] (pp. 62-63). Perception is a subjective cognitive orientation regarding phenomena, including facts and causal relations, and the criteria for judgment are established under a theory or an institutional structure that make autonomous decisions in the policy process. Furthermore, preference is a concept that is classified into interests, norms, identities, and interaction orientations [18] (p. 64). Third, constellations refer to the static picture that appears in interactions and combines actors' characteristics (perceptions, preferences, and capabilities) with a combination of strategies, represented by the game matrix [18] (pp. 44-72). Constellations comprise players who participate in the specific game, their strategy options, outcomes of a combination of strategies, and the preferences of these outcomes. These game constellations do not individually affect interactions but affect them in a configurational manner; hence, various elements must all be considered in the analysis. Game constellations in interactions appear at the level of potential conflicts in actual policy interactions. Moreover, they are related to the type of game, as that determines different aspects of how the conflicts will be resolved and how the players will maximize their interests by adjusting their strategies or making decisions with others. Therefore, constellations are the appropriate measure to determine the choices of players among actual policy options [17] (p. 72).

Finally, the variable of interactions is a dynamic aspect within which conflicts are developed; the types of interactions include unilateral action, negotiated agreement, majority vote, and hierarchical direction. These are standardized interaction types that appear in combination in real life and are influenced by the institutional structure [17] (p. 47). This aspect of interactions is a key variable that affects the determination of the direction of final policy outcomes along with the institutional setting.

Therefore, this study used ACI as a theoretical framework to determine the MoM of enterprises. The use of ACI helped to structuralize various entangled factors and determine their characteristics. This study's analysis of enterprise structural characteristics has implications for the establishment of tailored policies through regulatory sandboxes in fintech.

To date, studies on regulatory sandboxes have mostly focused on the introduction of regulatory institutions in certain countries [3,5-13] or on the current state of such institutions implemented in certain fields $[1,14,15]$. However, these studies have been limited by their inability to adequately determine the MoM innovation capacities. Therefore, this study is significant in that it analyzes innovation competencies as the MoM of enterprises participating in the regulatory sandbox policy in fintech and discusses its implications.

\section{Methodology}

By using patent contents, this study examined the MoM of enterprises participating in the regulatory sandbox policy in fintech. The structural characteristics and innovation competencies of participating enterprises were analyzed by using MoM of regulatory sandboxes and the presented methods to apply them back to tailored policies $[19,20]$.

To do so, the study first adopted the regulatory sandbox policy as part of the regulatory innovation at the governmental level to create new industries and services that could overcome the difficulties caused by existing regulations. Accordingly, prior to analysis, this study conducted a literature review on the regulatory sandbox policy and examined various related trends.

Second, this study interviewed relevant experts (around 20 peoples between 1 April and 30 June 2020) to understand the innovation competencies of regulatory sandbox polices. 
Third, this study searched for credit information data using a list of participants limited to participants in the fintech sector of the regulatory sandbox and classified them by type of enterprise into large, middle-standing, and small and medium-sized enterprises.

To search for patent data, the names of the participating enterprises were converted into applicant codes by utilizing the Korea Intellectual Property Rights Information Service of the Korean Intellectual Property Office. Using these applicant codes and categories, patent data spanning 10 years (from 1 July 2011 to 1 July 2020) were collected. Among the types of patent-related attribute data that were collected, unstructured data pertaining to titles and contents were used to examine the MoM of enterprises.

Further, a group network analysis using NetMiner, a network analytical tool, was performed on the collected data. The results were used to process the data and confirm the ratio by organization and group, then derive conclusions (see Figure 1).

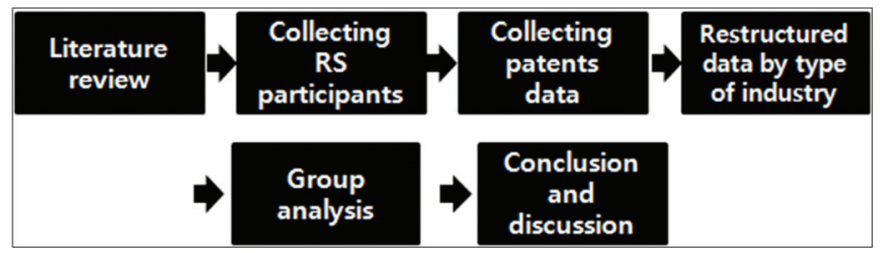

Figure 1. Research process.

\section{Results}

This study aimed to analyze the innovation competencies of enterprises participating in regulatory sandboxes in fintech. To clarify innovation competencies from a microscopic perspective, an analysis was conducted by classifying enterprises by type into large, middle-standing, and small and medium-sized enterprises based on patent data (see Figure 2).

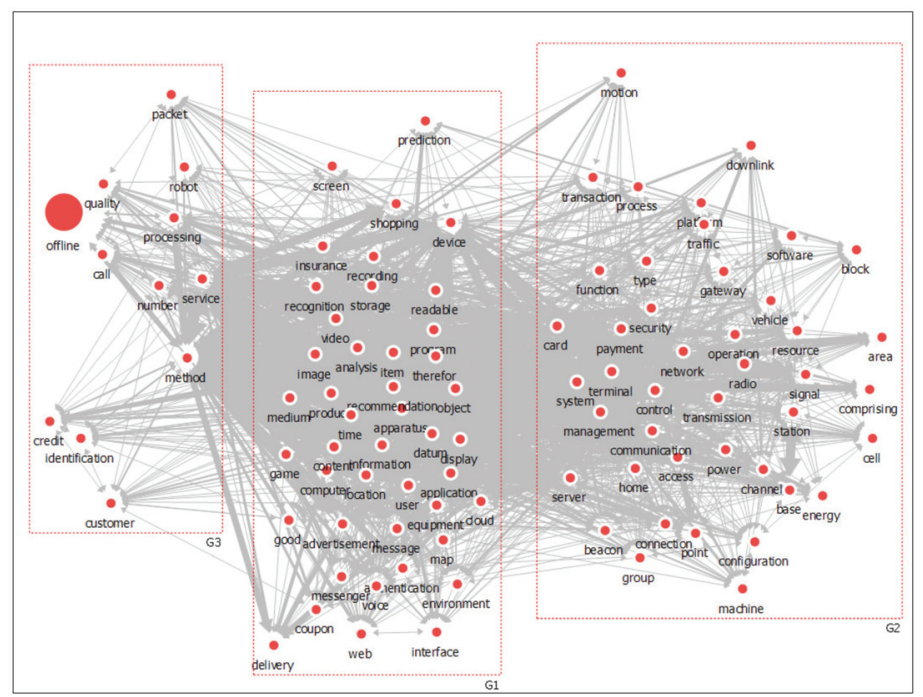

Figure 2. Results of group network analysis. Note: Nodes represent keywords, links show the relationship among nodes that appear as a result of analysis. The size of the nodes is related to their weight (the larger the node, the higher the frequency). Through semantic network analysis, the connection between nodes was visualized with the relationship frequencies. 
The following shows the main keywords, frequency, and centrality of each group from the cluster group analysis result. As a result of patent analysis, companies in the fintech field that participate in the regulatory sandbox can be divided into three groups. These can be labeled as infrastructure-related issues (G1), complementary issues (G2), and G3 (user-related issues).

First, infrastructure-related issues (indicated as G1) represented major issues related to the infrastructure of fintech; relevant keywords were apparatus, device, information, and computer. These issues revealed that the infrastructure-related innovation competencies that can support security in enterprise are enhanced by the application of new technology in fintech. It is important to build infrastructure that can safely manage and distribute users' funds. Furthermore, it was indicated that the industry developed because of the advancement of infrastructure-related technology to supplement funds.

Second, security-related issues (G2) included keywords such as system, server, network, control, payment, and security. The establishment of security technology in fintech enterprises helps to protect users when a financial company needs to prove that users permitted its transactions. Currently, the issues in developing technology for security are concentrated in systems, servers, and networks. This shows that security-related issues are closely related to the overall system operations of fintech, which are closely related to G1 (infrastructure-related issues). In particular, security-related issues involve the overall system, unlike infrastructure-related issues, whereas infrastructure represents detailed physical technical factors.

Third, user-related issues (G3) showed high frequencies for keywords such as method, service, call, processing, and credit. This indicates that technology related to stability in fintech transactions has been developed through credit guarantee in transactions. This shows that technology has been developed in terms of methods and services for credit guarantee, since there is an urgent need to establish safeguards for users with the development of fintech (see Table 1). 


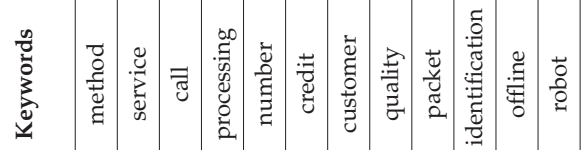

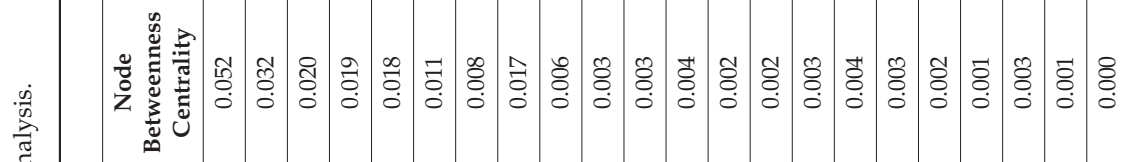

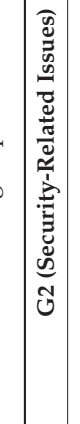

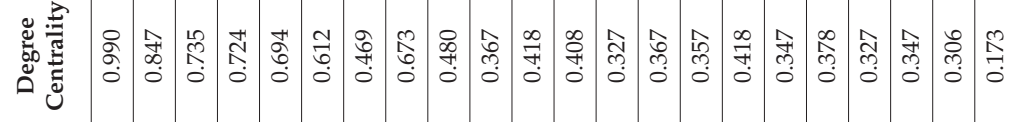

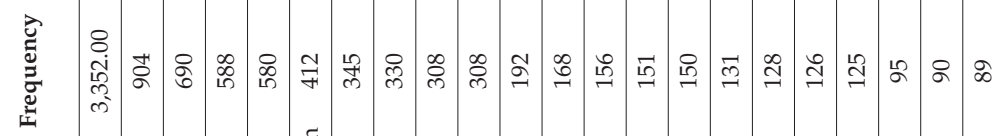

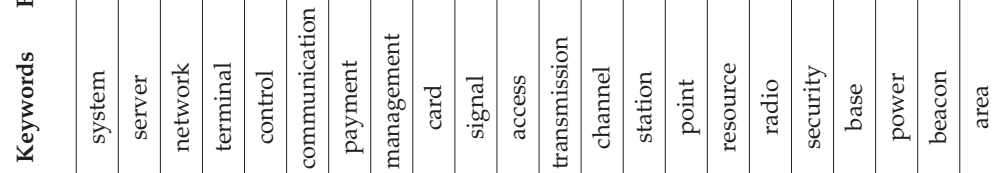
象

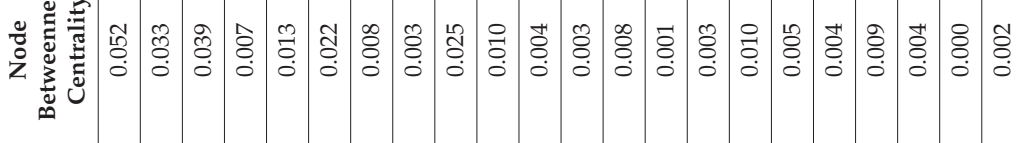

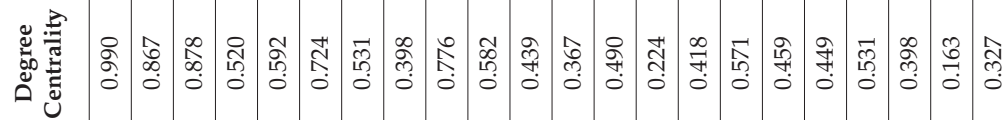

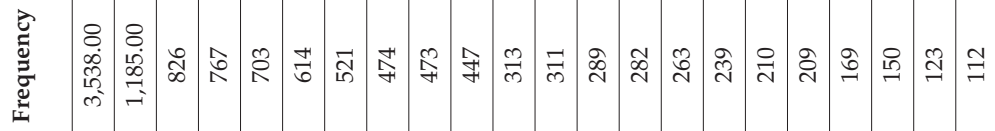

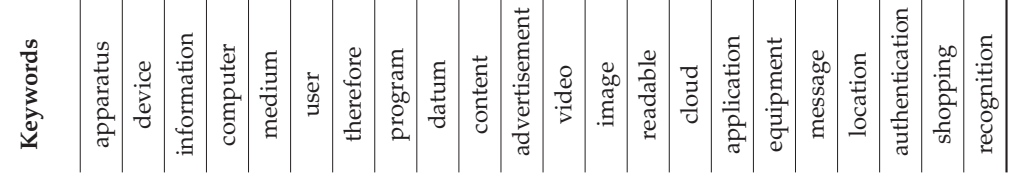




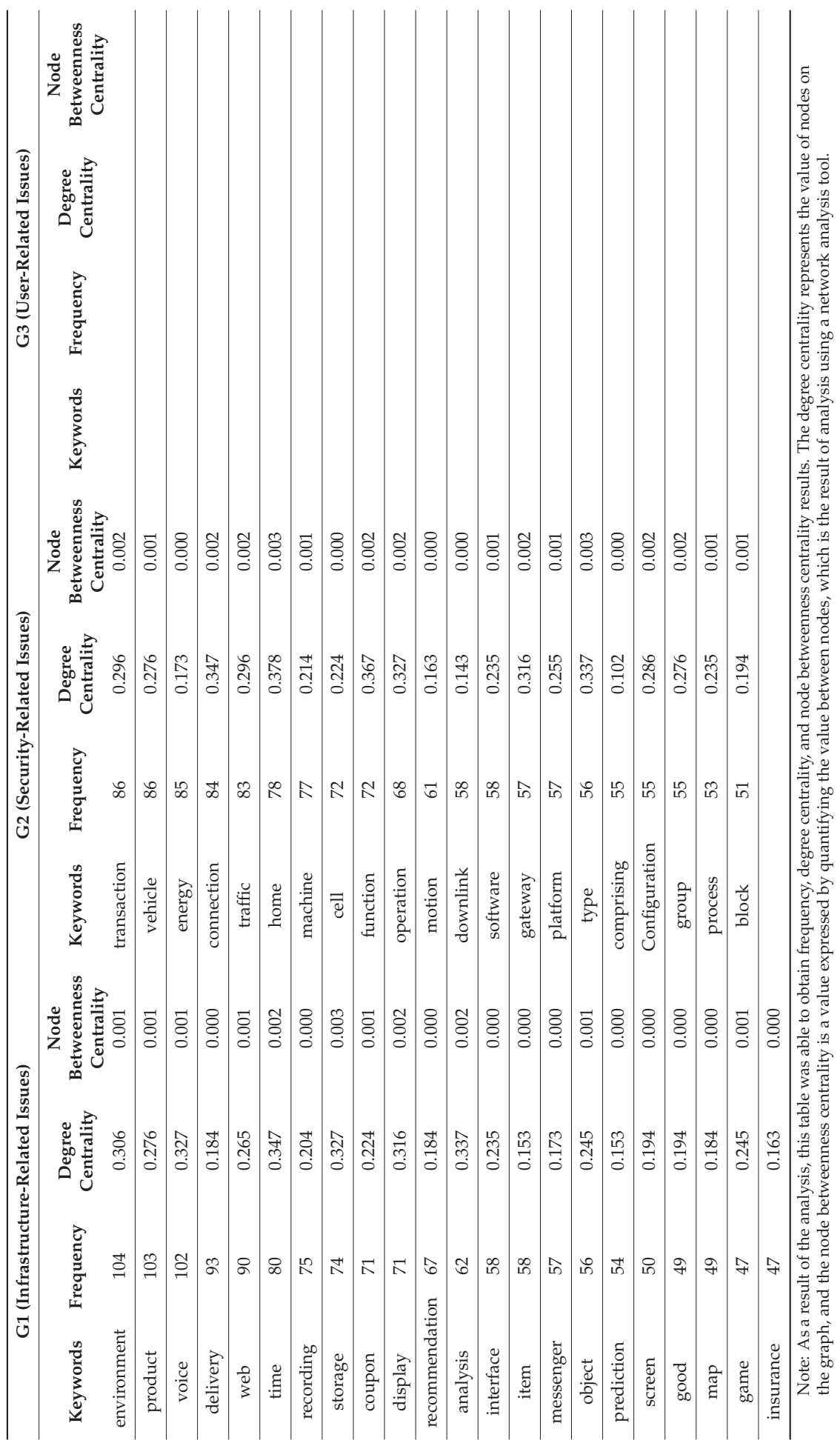


Subsequently, this study analyzed the structural characteristics of innovation competencies for each participant in a regulatory sandbox in finance. It was possible to understand the characteristics of each institution through the process of reclassifying the participants participating in the regulatory sandbox system in the fintech by institution.

First, large enterprises actively responded to security-related issues (G2) (35.3\%). Furthermore, infrastructure-related (G1) and user-related (G3) issues showed the same ratio (32.4\%).

Middle-standing enterprises showed the highest ratio of infrastructure-related issues (G1, 37.7\%), which were followed by user-related issues (G3, 33.2\%) and security-related issues (G2, 29.1\%). Furthermore, it was found that middle-standing enterprises were focusing on the development of infrastructure-related and user-related technologies in fintech.

Finally, small and medium-sized enterprises showed the highest ratio of user-related issues $(\mathrm{G} 3,37.1 \%)$, which were followed by infrastructure-related issues (G1, 34.6\%) and security-related issues (G2, 28.3\%). In other words, small companies were developing technologies with a focus on users. (see Table 2 ).

Table 2. Results of group network analysis by industry categorization.

\begin{tabular}{|c|c|c|c|c|c|c|c|}
\hline \multirow[t]{2}{*}{ Division } & \multicolumn{2}{|c|}{$\begin{array}{l}\text { Large-Sized } \\
\text { Company }\end{array}$} & \multicolumn{2}{|c|}{$\begin{array}{c}\text { Enterprise of } \\
\text { Middle-Standing }\end{array}$} & \multicolumn{2}{|c|}{$\begin{array}{l}\text { Small and } \\
\text { Medium-Sized } \\
\text { Enterprises }\end{array}$} & \multirow{2}{*}{$\begin{array}{l}\text { Total by } \\
\text { Group }\end{array}$} \\
\hline & Freq. & $\%$ & Freq. & $\%$ & Freq. & $\%$ & \\
\hline G1 (infrastructure-related issues) & 9290 & $32.4 \%$ & 693 & $37.7 \%$ & 275 & $34.6 \%$ & $104.6 \%$ \\
\hline G2 (security-related issues) & 10121 & $35.3 \%$ & 535 & $29.1 \%$ & 225 & $28.3 \%$ & $92.6 \%$ \\
\hline G3 (user-related issues) & 9297 & $32.4 \%$ & 611 & $33.2 \%$ & 295 & $37.1 \%$ & $102.7 \%$ \\
\hline Total & 28708 & $100 \%$ & 1839 & $100 \%$ & 795 & $100 \%$ & - \\
\hline
\end{tabular}

Regarding the characteristics of each participating enterprise, the results show that large enterprises are focusing on the development of security-related technologies, whereas middle-standing enterprises are focusing on infrastructure-related technologies and small and medium-sized enterprises on user-related innovation competencies. Furthermore, large enterprises are developing security technologies that require relatively high initial costs, which play a key role in infrastructure building for fintech.

Security technology is switching the direction from ex-post exposure to ex-ante prevention for the development of digital technology, which indicates the need to establish a system for risk management and relevant risk prevention. Middle-standing enterprises are improving efficiency and safety in fintech by developing infrastructure-related technologies. Although infrastructure-related technologies are closely related to security-related technologies, they are different in that the former are more focused on detail. An examination of such microscopic mechanisms indicates that it is necessary to establish policies suited to the characteristics of each enterprise type to facilitate institutional development in fintech. (see Figure 3). 


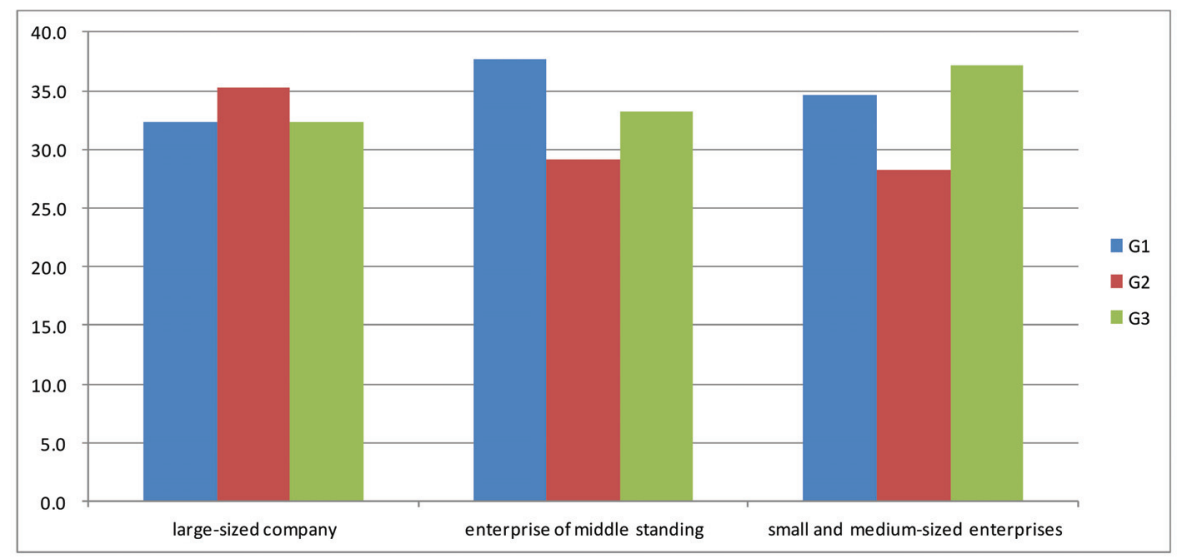

Figure 3. Group network analysis by industry categorization. Note: Data are classified by company and compared with the frequency of words belonging to each group.

\section{Discussion}

The current study analyzed the structural characteristics of the innovation competencies of participating enterprises after the implementation of the regulatory sandbox policy and helped use these characteristics to establish future policies in Korea. Furthermore, this study provides several implications for the development of a regulatory sandbox policy in terms of evidence-based policy.

To date, in the regulatory sandbox policy in Korea, a few policy makers have been effectively supplying policies that consider equity among participants. However, these policy makers have not made sufficient effort to determine the structure and characteristics of the innovation competencies of policy users in terms of the supply process [21-23] because policy makers do not have adequate time and funds to determine innovation competencies. Hence, the efficiency of user-centered policies can be improved by developing a scientific analysis method to analyze the competencies of policy users and including them in policies.

This study determined the MoM as a method to overcome policy failure by completely adopting the best practices implemented in other countries. The study results will help to implement regulatory sandbox policies tailored to the characteristics of South Korean participants to establish a differentiated system and establish strategies to support the participants' MoM.

To examine the MoM of regulatory sandboxes, this study used ACI, which analyzes policies focusing on interactions among actors. The application of ACI determines the institutional settings that affect the policies and examines how actors interact with different preferences and value systems under the constraints of institutional settings [19-24] to better explain the complicated aspects of the process of implementing regulatory sandboxes.

Future research projects can further explain the responses to regulations. For the successful execution of regulatory policies, it is necessary to obtain the compliance of subjects. Additional research using compliance theory must be conducted to explain the responses toward regulations [24-26].

This study has some limitations. It focuses on the innovation competencies of enterprises participating in the sandbox policy, rather than explaining the regulatory sandbox policy itself [27]. Therefore, in-depth discussions and considerations of the regulatory sandbox policy itself are necessary in the future.

\section{Conclusions}

This study focused on the structural characteristics of each type of enterprise participating in the regulatory sandbox policy and attempted to remove difficulties that new industries and services 
experiences during creation due to regulations. To examine the enterprises' MoM, this study collected and analyzed the patent data created by enterprises to analyze their characteristics and help design tailored policies in the future. The results of the analysis are as follows:

By analyzing the enterprise data by group, the innovation competencies of regulatory sandbox participants were classified into infrastructure-, security-, and user-related issues. Infrastructureand security-related issues were closely related, and user-related issues occurred in the development of technologies related to stability in fintech transactions. Furthermore, it was found that fintech technology was developed with a focus on credit guarantee. Previously in Korea, the fintech sector was fostered by the private sector, but the intention is to have the government foster the section. Since the existing regulatory issues can be solved by the government's policy, the government's efforts can have a great impact on the technology development in the fintech field.

The results of the analysis for each type of enterprise reveal that large enterprises are focusing on security, middle-standing enterprises on infrastructure, and small and medium-sized enterprises on user-related issues to develop their innovation competencies. In particular, the security-related issues considered by large enterprises involve relatively high costs in terms of initial technology development and are closely related to the construction of infrastructures. Contrarily, small and medium-sized enterprises are developing technologies and services in fintech with a focus on users. Since the infrastructure sector in the fintech sector in Korea is a sector that requires a high initial cost, it is the role of the government to establish an institutional foundation for well-equipped infrastructure. Therefore, the government's institutional support for each of the infrastructure and technology development sectors should be strengthened in future institutional design of the fintech sector in Korea.

This study can be used to formulate regulatory sandbox policies in the future by determining the MoM of enterprises. In particular, it can be used as a reference to establish policies tailored to the characteristics of each organization type by analyzing the innovation competencies of each enterprise. The regulatory sandbox system in Korea is progressing at a rapid pace with the aim of creating new industries and services in all industries. However, in the process of solving the issues arising in the actual system process behind the creation of results through this sense of speed, a process of transplanting the system suitable for the characteristics of Korea is necessary. Therefore, this research suggests that there is a need for a policy alternative to feedback that can identify the characteristics of companies participating in the regulatory sandbox in the fintech sector and reflect this in the policy.

Author Contributions: Conceptualization, H.C.; methodology, H.C.; validation, H.C.; formal analysis, H.C.; investigation, H.C.; data curation, H.C.; writing-original draft preparation, H.C. and K.L.; writing-review and editing, H.C. and K.L. supervision, H.C. and K.L.; All authors have read and agreed to the published version of the manuscript.

Funding: The publication fee for this manuscript is funded by the Science and Technology Policy Institute (project number: T0200600).

Acknowledgments: This research is supported by STEPI (project number: T0200600, title: Agenda setting research project for technological regulation reform (4th year)). Also, this research is related to "Planning and research to establish basic plan for new industry regulation" (project number: I0202500).

Conflicts of Interest: The authors declare no conflict of interest.

\section{References}

1. Piri, M.M. The changing landscapes of fintech and regtech: Why the United States should create a federal regulatory sandbox. Bus. Fin. L. Rev. 2018, 2, 233.

2. Van der Waal, E.C.; Das, A.M.; van der Schoor, T. Participatory experimentation with energy law: Digging in a 'regulatory sandbox' for local energy initiatives in the Netherlands. Energies 2020, 13, 458. [CrossRef]

3. Hapsari, R.A.; Maroni, M.; Satria, I.; Ariyani, N.D. The existence of regulatory sandbox to encourage the growth of financial technology in Indonesia. Fiat Justisia J. Ilmu Huk. 2019, 13, 271-288. [CrossRef]

4. Edler, J. Demand Oriented Innovation Policy. The Co-Evolution of Innovation Policy Encourage the Growth of Fina Systems and Governance; Working Report No. 99; Office of Technology Assessment at the German Bundestag, TAB: Berlin, Germany, 2006; pp. 1-32. 
5. Allen, H.J. Regulatory sandboxes. Geo. Wash. L. Rev. 2019, 87, 579.

6. Sun, Y. Spatial distribution of patents in China. Reg. Stud. 2000, 34, 441-445. [CrossRef]

7. Acs, Z.J.; Anselin, L.; Varga, A. Patents and innovation counts as measures of regional production of new knowledge. Res. Policy 2002, 31, 1069-1085. [CrossRef]

8. Jenik, I.; Lauer, K. Regulatory Sandboxes and Financial Inclusion; CGAP: Washington, DC, USA, 2017.

9. Zetzsche, D.A.; Buckley, R.P.; Barberis, J.N.; Arner, D.W. Regulating a revolution: From regulatory sandboxes to smart regulation. Fordham J. Corp. Fin. L. 2017, 23, 31. [CrossRef]

10. Grant, A. Proposed Historical Policy Analysis of Project Catalyst's Regulatory Sandbox. Ph.D. Thesis, California State University, Northridge, CA, USA, 2020.

11. Forsman, H. Innovation capacity and innovation development in small enterprises: A comparison between the manufacturing and service sectors. Res. Policy 2011, 40, 739-750. [CrossRef]

12. Lewis, J.M.; Ricard, L.M.; Klijn, E.H. How innovation drivers, networking and leadership shape public sector innovation capacity. Int. Rev. Adm. Sci. 2018, 84, 288-307. [CrossRef]

13. Mehrabani, S.E.; Shajari, M. Knowledge management and innovation capacity. Manag. Res. 2012, 4, 164. [CrossRef]

14. Thomas, L.G. The case for a federal regulatory sandbox for Fintech companies. NC Bank. Inst. 2018, $22,257$.

15. Buckley, R.P.; Arner, D.W.; Veidt, R.; Zetzsche, D.A. Building fintech ecosystems: Regulatory sandboxes, innovation hubs and beyond. UNSW Law Res. Pap. 2019, 19-72. [CrossRef]

16. Einav, L.; Levin, J. The data revolution and economic analysis. Innov. Policy Econ. 2014, 14, 1-24. [CrossRef]

17. Scharpf, F.W. Games Real Actors Play: Actor-Centered Institutionalism in Policy Research; Westview Press: Boulder, CO, USA, 1997; p. 44.

18. Scharpf, F. Institutions in comparative policy research. Comp. Political Stud. 2000, 33, 762-790. [CrossRef]

19. Rudolph, M. User-friendly and tailored policy administration points. In Proceedings of the 1st International Conference on Information Systems Security and Privacy (ICISSP) Doctoral Symposium, Angers, France, 9-11 February 2015.

20. Kim, S.S.; Rideout, C.; Han, H.W.; Lee, L.; Kwon, S.C. Implementing a targeted and culturally tailored policy, systems, and environmental nutrition strategy to reach Korean Americans. Prog. Commun. Health Partnersh. Res. Educ. Action 2018, 12. [CrossRef] [PubMed]

21. Prajogo, D.I.; Ahmed, P.K. Relationships between innovation stimulus, innovation capacity, and innovation performance. RED Manag. 2006, 36, 499-515. [CrossRef]

22. Jørgensen, F.; Ulhøi, J.P. Enhancing innovation capacity in SMEs through early network relationships. Creat. Innov. Manag. 2010, 19, 397-404. [CrossRef]

23. Etienne, J.; Schnyder, G. Improving the micro-foundations of actor-centered institutionalism. SSRN 2010. [CrossRef]

24. Etienne, J. Compliance theory: A goal framing approach. Law Policy 2011, 33, 305-333. [CrossRef]

25. Crick, T.; Mateos-Garcia, J.; Bakhshi, H.; Westlake, S. Innovation Policy-Making in the Big Data Era. In Proceedings of Data for Policy; Cambridge University Press: Cambridge, UK, 2015; pp. 1-4.

26. Kim, N.; Lee, H.; Kim, W.; Lee, H.; Suh, J.H. Dynamic patterns of industry convergence: Evidence from a large amount of unstructured data. Res. Policy 2015, 44, 1734-1748. [CrossRef]

27. Authority Financial Conduct. Regulatory Sandbox. Available online: https://www.fca.org.uk/publication/ research/regulatory-sandbox.pdf (accessed on 1 October 2016).

(C) 2020 by the authors. Licensee MDPI, Basel, Switzerland. This article is an open access article distributed under the terms and conditions of the Creative Commons Attribution (CC BY) license (http://creativecommons.org/licenses/by/4.0/). 



\title{
Valuation of FinTech Innovation Based on Patent Applications
}

\author{
Jelena Kabulova * and Jelena Stankevičienè \\ Faculty of Business Management, Vilnius Gediminas Technical University, Saulètekio al. 11, LT-10223 Vilnius, \\ Lithuania; jelena.stankeviciene@vgtu.lt \\ * Correspondence: jelena.kabulova@vgtu.lt
}

Received: 29 October 2020; Accepted: 2 December 2020; Published: 4 December 2020

\begin{abstract}
The financial services sector, perhaps more than any other, is being disrupted by advances in technology. The purpose of this study is to provide comprehensive data and evidence on value of the FinTech innovation event. First, a text-based filtering method for identifying FinTech patent applications is provided. Using machine learning applications, innovations are classified into major technology groups. The methodology for valuation of FinTech innovation is based on data of stock price changes. To assess the value impact, Poisson flow rates and stock price movements were combined. Further, to evaluate the effect of FinTech patents on the company's value, a combination of CAR of patent application and Poisson intensities were used. Research findings provide evidence that FinTech innovations bring significant value for innovators and Blockchain being especially valuable. Such innovations as blockchain, robo-advising and mobile transactions are the most valuable for the financial sector. On one side of the spectrum, the financial industry can be affected more negatively by the innovation of nonfinancial startups that carry disruptive technology at their core. However, on the other side of the spectrum, market leaders who make significant investments in their innovations can evade most of these negative effects. This helped to form an overall view of FinTech innovations.
\end{abstract}

Keywords: FinTech innovation; valuation; patent application

\section{Introduction}

Recent development of FinTech raised significant interest within the financial sector and beyond. This sudden evolution and development of financial technology was welcomed by many experts, claiming that FinTech has the potential to disrupt and transform the financial sector by making it more transparent, secure and less expensive [1-3]. For the past decade, sector leaders, represented by large financial institutions, have increased their interest along with investments in FinTech innovations [4,5]. The first two quarters of 2019 raised USD 37.9 billion of global investments in FinTech [6]. According to the Harvey Nash CIO Survey, in 2019, most competitive financial institutions considered FinTech to be their major investment [7].

Despite all of this, it is currently not entirely clear how this new and fast emerging technology can influence existing financial institutions and their business models; which emerging financial technologies will prove of bearing highest value to their creators. It is expected that with the help of FinTech innovations, financial institutions will be able to lower costs and increase customer inclusion that will lead to an increase in future profits [8]. At the moment, new sector entrants are already capitalizing on the growing demand for new, more customer-centric and digitally enabled services. With key technology continuing to evolve rapidly alongside changing consumer needs, industry leaders will be forced to compete with start-ups and tech companies for the new business models. It is difficult to properly asses the circumstances without systematic data analysis on FinTech innovations.

González, Gil, Cunill and Lindahl [9] state that financial innovations increase with increasing growth of volatility among sectors more dependent on external financing, as well as with higher 
non-stability (growth of instability) of banks, with higher volatility of bank incomes and higher losses of banks. Beck, Tao, Chen and Song [10] presented study based on data analysis of 32 countries over the period 1996-2010. Authors pioneer in assessing the relationship between financial innovation, at one end of the spectrum, and bank growth, as well as economic growth, on the other end. Minhua and Yu [11] use a well-established event study methodology to observe average positive market reactions to announcements of financial innovation regulations, thus implying positive impacts of regulations on company's operations and refer to such an impact as an 'innovation effect'. Lerner [12] studied patenting activities of investment banks and revealed a correlation with their size. Later, he tried to take into account the features of empirical research and the fact that granted patents were rarely used. Implemented analysis focused on organizations introducing financial innovations through the study of a number of hypotheses proposed in the literature. The results showed that the generation of innovation is inversely proportional to the size of the organization, emphasizing the failure of small companies to obtain their patent rights. Schmedders and Citanna [13], studied how the coefficient of incompleteness and structural changes in the financial market affect asset price volatility.

Summarizing the extensive theoretical literature on financial innovation and patenting, main areas of scientific research can be distinguished:

- Nature and design of financial innovation;

- Adoption of financial innovations and its motives;

- Conditions of the economic environment that stimulate financial innovation;

- Effects of financial innovation on profitability and economic well-being;

- Review of financial innovation.

However, key issues regarding the characteristics of financial innovations and their distribution remain unresolved. These issues relate to the nature of financial innovation, and the mathematical basis for assessing the impact of financial innovation in the financial market. In this regard, authors attempted to create a methodology for assessing the impact of financial innovations on the financial market. The proposed model is theoretical in nature and (since empirical studies for the totality of financial innovations are not possible) shows the relationship of the elements that affect the financial market.

The aim of study is to provide comprehensive data and evidence on the value of the FinTech innovation event. In search of a reliable set of innovative measures, some scholars show that researchers used various data collection tools, ranging from unstructured interviews, in which respondents were asked to list a number of measures (important for evaluating financial innovation), to structured interviews that required the respondent to list the list of measures affecting innovative strategies [14].

This paper builds upon a number of various articles and reports. Analysis of Fintech innovation value is based on the data of stock price changes linked with patent application disclosure. Results of the study can be used for further analysis of the reaction of financial sector to the innovation.

\section{Literature Review}

\subsection{Analysis of Key FinTech Innovations}

Financial technology or FinTech is a term used to describe the impact of new technologies on the financial services industry [15]. It covers a variety of products, processes, applications and business models that intend to transform the traditional understanding and way of providing financial services [16].

According to the Financial Stability Board FSB definition, "FinTech is technology-enabled innovation in financial services that could result in new business models, applications, processes or products with an associated material effect on the provision of financial services" [17].

From the point of view of procedures, FinTech refers to new applications, processes, products or business models in the field of financial services, consisting of one or more additional financial services, provided in whole or for the most part via the Internet. Services can be provided 
simultaneously by various independent service providers, typically including at least one licensed bank or insurance company [18].

Based on data analysis, different reports and scholars [15,17,19], the FinTech landscape can be mapped across four broad dimensions and technologies classified into major innovations groups that are ultimately developed for the purpose of application (present or future) in financial services (Table 1):

Table 1. Key FinTech innovations transforming financial services (source: elaborated by authors, based on articles, surveys and industry reports).

\begin{tabular}{|c|c|c|c|}
\hline \multirow{5}{*}{ Dimension } & & Technology Innovation & Financial Services \\
\hline & $\begin{array}{c}\text { Artificial intelligence (AI) } \\
\text { Big Data }\end{array}$ & $\begin{array}{l}\text { Machine learning (ML) } \\
\text { Predictive analytics } \\
\text { Data analytics }\end{array}$ & $\begin{array}{l}\text { Investment advice } \\
\text { (robo-advising) } \\
\text { Credit decisions } \\
\text { Asset Trading }\end{array}$ \\
\hline & Distributed computing & $\begin{array}{l}\text { Distributed ledger (DLT) } \\
\text { Blockchain }\end{array}$ & $\begin{array}{c}\text { Digital currencies } \\
\text { Back-office, recording } \\
\text { Settle payments }\end{array}$ \\
\hline & Cryptography & $\begin{array}{l}\text { Smart contracts } \\
\text { Biometrics } \\
\text { Cybersecurity }\end{array}$ & $\begin{array}{c}\text { Automatic transactions } \\
\text { Identity protection } \\
\text { Cybersecurity }\end{array}$ \\
\hline & Mobile access internet & $\begin{array}{c}\text { Digital wallets } \\
\text { Application programming } \\
\text { interfaces (APIs) } \\
\text { Mobile transactions } \\
\text { Internet of things (IoT) }\end{array}$ & $\begin{array}{c}\text { Crowd funding } \\
\text { person-to-person } \\
\text { transactions (P2P) } \\
\text { Smartphone wallets } \\
\text { Inter-operability and } \\
\text { expandability }\end{array}$ \\
\hline
\end{tabular}

Table 1 implies all the listed innovations should be considered FinTech as their implementation lies (or is intended for) in financial services.

The study presents how FinTech innovations in all four dimensions influence value from the point of view of individual traditional companies, i.e., market leaders and competitors. Theoretical discussion implies that disruptive innovations of potential market participants can be particularly unpleasant for industry leaders who struggle to adapt to changes and focus on customers. On the other hand, market leaders can benefit from disruption, because they have more financial resources and greater economies of scale for introducing new lines of business compared to competitors [20]. Empirical tests confirm the latest predictions that the amount of resources allocated to R\&D\&I can increase the agility of market leaders to damage from potential external disruptive innovations.

An analysis of the value of Fintech innovations requires reliable estimates (statistical data) of their value. Research on corporate innovation states that the reaction of stock prices to patent applications can be used to examine the valuation (value) of innovations [21]. However, it is less valuable that the reaction of price to a patent publication reflects an unexpected factor: market investors can anticipate a future event and partially include this expectation in the price of the firm's shares today. Without adjusting for the rational anticipation of the abnormal reaction of stock prices to a disclosed patent application, it will not give a rational assessment of innate value of financial innovation. Previously conducted research of stock price reactions to patent applications do not take into consideration the possible expectation of investors. However, in the study of Kogan, Papanikolaou, Seru, and Stoffman [22] the value of patents using pending adjusted price responses to patent grants was evaluated. Authors state that the market can expect several future financial innovations, but in this article, we focus on the Poisson distribution. 


\subsection{Classification of FinTech Innovations with Machine Learning}

The application of a machine-learning method was used for the purpose of classifying patent applications based on textual data. Method was applied in three steps: 1-processing of textual data of applications; 2-building sample unit; 3-training algorithm to single out categories of innovations.

Table 2 presents the results of a machine-learning method performance-neural networks (out-of-sample). Such measures as "accuracy", "precision", "recall", and a combination of the last two called "F1 score" are used to determine classification performance [23]. Neural networks method carries three layers with neurons: 1.124 in first, 286 in second and 42 in third.

Table 2. Performance of machine-learning method (source: author, based on [24]).

\begin{tabular}{cc}
\hline & Neural Network (\%) \\
\hline Accuracy & 94.7 \\
\hline Precision & 98.8 \\
\hline Recall & 97.4 \\
\hline F1 score & 98.1 \\
\hline
\end{tabular}

Table 3 reports performance scores of five main FinTech categories that were selected during text based filtering: (0) nonfinancial innovations, (1) blockchain, (2) cybersecurity, (3) mobile transactions, (4) robo-advising, (5) IoT.

Table 3. Performance of the neural network method for sample training (created by authors).

\begin{tabular}{cccccc}
\hline Category & Precision (\%) & Recall (\%) & $\begin{array}{c}\text { No. of } \\
\text { Applications } \\
\text { in Category }\end{array}$ & $\begin{array}{c}\text { No. of } \\
\text { Applications } \\
\text { in Predicted } \\
\text { Category }\end{array}$ & $\begin{array}{c}\text { No. of } \\
\text { Applications }\end{array}$ \\
\hline 0 & 98.9 & 97.2 & 517 & 514 & 44.916 \\
\hline 1 & 100.0 & 99.5 & 104 & 112 & 1.446 \\
\hline 2 & 97.9 & 97.4 & 269 & 264 & 5.127 \\
\hline 3 & 96.3 & 97.1 & 213 & 214 & 3.165 \\
\hline 4 & 97.8 & 97.7 & 91 & 91 & 1.512 \\
\hline 5 & 97.6 & 95.3 & 76 & 77 & 1.251 \\
\hline Total: & 98.1 & 97.4 & 1.270 & 1.270 & 59.417 \\
\hline
\end{tabular}

Performance of the used machine-learning method is summarized in Table 2. This algorithm has $98.8 \%$ precision and $97.4 \%$ of recall. Column of No. of Applications presents the text-filtered set of patent applications that were assigned into each of the five categories by the used algorithm. Created sample consists of $86 \%$ of nonfinancial innovations and $14 \%$ of FinTech patent applications

\section{Methodology and Data}

\subsection{Methodology for Assessing Worth Based on Values with Reactions of Stock Market}

The worth of FinTech innovations needs to be reliably estimated to be able to carry out empirical analysis. Lately, the research literature has acknowledged that new patent values can be studied on the basis of the fluctuations of the stock prices. However, there is a catch to it, as one must take into consideration the possibility of investors anticipation of the future patent case, that might correct the company's stock price prior the patent event itself. Consequently, to evade the biased estimation of the innovation value, a rational anticipation correction has to be implemented into the model. Most studies 
of the stock fluctuations do not take into consideration that possible future insight of the investors anticipating the possible patenting events.

Sometimes, more than one future innovation can be anticipated by the market. Thus, it is important to be able to evaluate the value of FinTech innovations, considering the possibility of multiple innovations. We created a method, that in itself was sufficiently general while giving a possibility to be used with a wide range of data count models (i.e., Poisson, negative binominal, etc.). To simplify the process, however, the focus was on the Poisson count distribution, which is used in many studies of patenting activity such as [25].

$V_{0}$ is the company value before the patent event, $V^{*}$ is the value increase caused by one patent event. The count of the patents $N$ that will happen over a period $(t, t+T)$ under our assumption is following a Poisson distribution:

$$
\operatorname{Price}\left(N=k \mid I_{t}\right)=\frac{\lambda^{k} e^{-\lambda}}{k !}, k=0,1,2, \ldots
$$

Here the information set of the participants in the market is marked by $I_{t}$, at specific point in time marked by $t$. The time $t+T$ change value for the company is $k V^{*}$ when the exact count of the patent events is $k$. We can express the value of the company before patent disclosure happens:

$$
\bar{V}_{i, 0}=V_{i, 0} \sum_{k=1}^{\infty} \frac{\lambda^{k} e^{-\lambda}}{k !}\left(k A V_{i}\right)+\lambda A V_{i}
$$

If we take independency of patent events as a constant, then the event of a patent produces a conditional distribution over further patents, which is a ZTP conditional Poisson distribution:

$$
\operatorname{Pr}\left(N=k \mid N \geq 1, I_{t}\right)=\frac{\lambda^{k} e^{-\lambda}}{\left(1-e^{-\lambda}\right) k !}, k=1,2, \ldots
$$

So we can express the actual value of the company after the patent disclosure happens:

$$
\bar{V}_{i, 0}=V_{i, 0}+\sum_{k=1}^{\infty} \operatorname{Pr}\left(N=k \mid N \geq 1, I_{t}\right) k A V_{i}=V_{i, 0} \sum_{k=1}^{\infty} \frac{\lambda^{k} e^{-\lambda}}{\left(1-e^{-\lambda}\right) k !} k A V_{i}=V_{i, 0}+\frac{\lambda}{1-e^{-\lambda}} A V_{i}
$$

Following Equations (2) and (4) we can express the value increase caused by one patent event as:

$$
A V_{i}=\frac{\Delta \bar{V}}{\frac{\lambda}{1-e^{-\lambda}}-\lambda}=\frac{e^{\lambda}-1}{\lambda} \Delta \bar{V}_{i}
$$

$\Delta \bar{V} \equiv \bar{V}_{1}+\bar{V}_{0}$ correspond to the company value change after the patent application disclosure. In Equation (5) we made an uncomplicated calculation of the increasing value of a patent $V^{*}$ using data of the observations. Mainly we could calculate the change of the market value $\Delta \bar{V}$ based on the irregular reactions of the stock prices. We could also calculate intensity parameter $\lambda$ using empirical models of the patent counts, for example Hausman et al. [25].

\subsection{Methodology of Assessing the Intensities of Innovations}

The innovation intensity parameter $\lambda$ has to be assessed as the time-variable value. To do that we used the innovator panel data from the patent filing counts and integrated it into the series of Poisson regressions. As there was a possibility of dependencies between the intensity of innovation and the specifics of the technology or the characteristics of the innovator, we constructed different combinations of the type of the technology and the innovator and we integrated them into the models separately. Total assessed count of the models was 18 , which included 5 FinTech categories (15 models) and 3 models for benchmarking financial innovations that were not FinTech. 
When evaluating public companies for a specific category of technology $k$, we used MLE (maximum likelihood estimation):

$$
\begin{aligned}
\log \left(\lambda_{i, k, t}\right)= & a+\beta_{1} \text { Asset }_{i, t}+\beta_{2} \text { R\&D\&I }_{i, t}+\beta_{3} R \& D \& I_{i, t-1}+\beta_{4} R \& D \& I_{i, t-2} \\
& +\beta_{5} \text { R\&D\&I I }_{i, t-3}+\beta_{5} \text { Age }_{i, t}+\beta_{6} \text { PreviousFinTech }_{i, t} \\
& +\beta_{6} \text { PreviousOther }_{i, t}+\beta_{7} \text { PreviousNonF }_{i, t}+\gamma_{i}+\delta_{t}+\varepsilon_{i, k, t}
\end{aligned}
$$

Here $t$ and $i$ are, respectively, year and innovating company. In this regression total assets are Asset $_{i, t} ; R \mathcal{E} D \mathcal{E} I$ spendings $n+1$ years before the present year are $R \mathcal{E} D \mathcal{E} I_{i, t-n}$; total age of the company since the founding is Age; the stock of company's FinTech applications before the $t$ year is PriorFinTech $h_{i t}$; the stock of the company's nonfinancial filings before the $t$ year is PriorNon $F_{i, t}$; the stock of company's non-FinTech financial applications before $t$ year is PriorOther $F_{i, t}$. Indexes $\gamma_{i}$ and $\delta_{t}$ are used to express the fixed effects of innovator and year and all other non-indicator controls are expressed in natural logarithm.

For private companies the following regression is assessed:

$$
\begin{aligned}
\log \left(\lambda_{i, k, t}\right)= & a+\beta_{1} \text { PreviousFinTech }_{i, t}+\beta_{2} \text { PreviousOther }_{i, t}+\beta_{3} \text { PreviousNon }_{i, t} \\
& +\gamma_{i}+\delta_{t}+\varepsilon_{i, k, t}
\end{aligned}
$$

Results of the Poisson regressions are represented in Table 6. As the table data suggests, more FinTech patent applications were completed by larger companies. Additionally, for the private companies, there were solid positive predictors of the innovations in FinTech in the form of company's age and amount of the prior non-FinTech applications. Further, for the individuals, the prior innovation experience in non-FinTech areas of finance was the most robust predictor of FinTech filing activity.

\subsection{FinTech Innovation Patenting Data}

Preparing data for the further analysis authors relied on various researches and data sources, such as open databases along with additional information processing and data matching. No commercial bulk data sources were used, therefore some limitations concerning data were necessary.

For the purpose of providing solid proof on the FinTech innovation event and value, a data set based on publically available patent applications was constructed. Patent applications were analyzed using publicly available data from World Intellectual Property Organization (WIPO) [26], European Patent Office (EPO) and Google Patents databases. This study was based on patent applications and not granted patents mainly for the reason that granting a patent takes years and FinTech is a relatively new field thus many of the patents were applied only recently.

We started by limiting the time span of patent application search to the period of 2015-2019. Which gave a search result of 1,511,546 applications. These applications were then limited to the

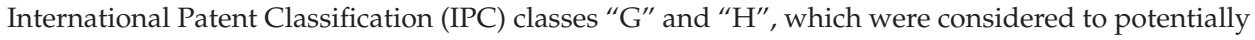
relate to FinTech [27]. It should be noted that not all developments relating to finance and business can be the subject of a patent [28].

Text in the abstract and description sections of patent application and information of assignees was used in order to distinguish assignees into groups of private/individual investors, private and public companies.

Due to the absence of clear and standard definitions of what explicit technologies FinTech covers, a list of terms related to finance was generated to pin down patent applications to those that represent financial services and products.

Table 4 shows main filtering (elimination) steps of applications to match specified criteria and the number of valid applications left for further analysis. 
Table 4. Creating a sample for filtering patent applications (created by authors).

\begin{tabular}{|c|c|c|c|}
\hline & Steps & Eliminated Applications & Valid Applications \\
\hline 1 & $\begin{array}{l}\text { Total number of patent } \\
\text { applications from } 2015 \text { to } \\
{ }^{1} 2019\end{array}$ & & $1,511,546$ \\
\hline 2 & $\begin{array}{l}\text { Eliminate applications } \\
\text { that do not fall under the } \\
\text { "G" or " } \mathrm{H} \text { " classes of } \\
\text { International Patent } \\
\text { Classification (IPC) }\end{array}$ & 790,631 & 720,915 \\
\hline 3 & $\begin{array}{l}\text { Eliminate nonfinancial } \\
\text { applications that do not } \\
\text { meet the definition based } \\
\text { on selected financial } \\
\text { terms }\end{array}$ & 731,214 & 59,417 \\
\hline 4 & $\begin{array}{l}\text { Eliminate applications } \\
\text { that fall under the } \\
\text { category on } \\
\text { "nonfinancial" after use } \\
\text { of machine-learning } \\
\text { algorithm }\end{array}$ & 39,709 & 19,708 \\
\hline 5 & $\begin{array}{l}\text { Eliminate applications } \\
\text { with incomplete } \\
\text { information }\end{array}$ & 8867 & 10,841 \\
\hline 6 & $\begin{array}{l}\text { Eliminate applications of } \\
\text { universities, research } \\
\text { institutes }\end{array}$ & 128 & 10,713 \\
\hline 7 & $\begin{array}{l}\text { Eliminate applications of } \\
\text { companies that don't } \\
\text { have public trading data }\end{array}$ & 5801 & 4912 \\
\hline 8 & $\begin{array}{l}\text { Patent applications left } \\
\text { in the set: }\end{array}$ & & 4912 \\
\hline 9 & $\begin{array}{l}\text { FinTech applications } \\
\text { where the applicant is: }\end{array}$ & & \\
\hline & Public company & & 1159 \\
\hline & Private company & & 2974 \\
\hline & Individual & & 779 \\
\hline
\end{tabular}

${ }^{1}$ Data from database was retrieved on November 2019. Therefore, not covering full year.

Total set of applications classified by machine learning method based on text filtering was 59,417, finance related was 19,708. From 19,708 applications, 8867 were eliminated as invalid, for the reason of missing necessary information (data). Finally, the data set was left with 4912 applications that were used for further analysis: 1159 on public companies; 2974 on private companies and 779 on individual innovators.

After application of machine learning algorithms to gathered data, the main innovations categories were distinguished: blockchain, mobile transactions, P2P, cybersecurity, IoT, data analytics and robo-advising.

In Table 5 applications are classified by different types of innovators. Data required for determining status, classification and dates were gathered from public sources. An interesting observation that can be drawn from this data is that private companies are most active and prevail in most of categories of 
FinTech innovations. Public companies bring substantial contributions to innovations in robo-advising, while individuals contribute more in cybersecurity.

Table 5. FinTech patent applications by innovations applicants' type (created by authors).

\begin{tabular}{lrrrr}
\hline \multicolumn{1}{c}{ Category } & Individual & Public Company & \multicolumn{2}{c}{ Private Company } \\
\hline blockchain & 5 & 94 & 109 \\
\hline cybersecurity & 514 & 931 & 1.271 \\
\hline mobile transactions & 162 & 88 & 993 \\
\hline robo-advising & 89 & 17 & 347 \\
\hline IoT & 9 & 29 & 254 \\
\hline & 779 & 1.159 & 2.974 \\
\hline
\end{tabular}

It can be stated that public companies (as a group) stimulated (promoted) the introduction of only a small number of Fintech innovations.

In order to determine the value of a FinTech innovation patent application to several publicly traded companies new methodology was developed. Stock market reaction to the event of patent publication was used as basis for valuation. To understand intrinsic value of every innovation for the company, predicted count intensity and stock price change of company needed to be combined.

Such an approach gives an opportunity to determine how much companies operating in the sector of financial services tend to profit from their own FinTech innovations. Overall study shows that blockchain, robo-advisors and cybersecurity are among the innovations carrying the largest value to the companies. The developed method allowed us to determine how innovation's value impacts the financial industry using stock price data, which means it is limited to measure the effect of publicly traded companies.

Among the listed categories of FinTech, cybersecurity and mobile transactions had the largest number of innovations over the period of the historical sampling. Blockchain as a category secured its position as the fastest growing innovation in the field of FinTech. To study the consequences of introducing FinTech innovations, a methodology for evaluating financial technologies in the financial market (based on the cost of patent applications for one or more companies traded on the stock exchange) was developed.

The valuation was based on the observed reaction of the stock market to the disclosure of patent applications. It is important to note that this approach took into account market expectations regarding various types of patent applications filed by different categories of entities. Initially, the intensity of innovation was assessed using a Poisson regression model, which takes into account factors such as the type of technology, time effects and previous experience of the patent applicant. Then, for each patent application, the predicted counting intensity was combined with the movement of company stock prices to determine the implicit value of innovation for the company. Applying this approach of valuation, we analyzed the number of companies in the financial market that have benefited from their own innovations in the field of financial technology. Calculations showed that the value of FinTech innovations (i.e., the value received by innovator) in general is positive.

Further study presents how value is influenced by FinTech innovations from the viewpoint of traditional companies, i.e., market leaders and their competitors. In different studies, the presented theoretical discussions imply that disruptive innovations presented by potential market participants might be particularly unpleasant for industry leaders who find it difficult to adapt to changes and focus on customers. At the same time, industrial disruption can be potentially beneficial to market leaders, as they usually have greater economies of scale and more financial resources for introducing new lines of business, compared with competitors. Empirical tests confirm the latest predictions that market leaders' ability to evade damage from disruptive external innovations is closely related to the sum total of resources allocated for their own R\&D\&I. 
This study complemented a significant number of studies that use patent data to study the innovative activities of companies [28,29]. Although the literature contains valuable information on innovation and corporate patenting in general, most of the previous research was based mostly on granted patent data and do not fully cover innovative activities in the field of FinTech, which actively has been carried out during recent years. Placing the main focus on patent applications in the field of FinTech innovation, we can mitigate problems of truncating data regarding patenting and provide more complete picture of the latest trends and models.

The developed model expanded on recognizing the nature of innovative events over time, which allowed us to more accurately assess the real value of such impact. In general, such approach of combining reactions of stock prices with predicted Poisson flow rates is helpful in exploring other different types of potentially recurring and to a certain extent expected phenomena, such as a reassessment of analyst estimates, the sequence of news releases by a company, or a wave of possible merges or bankruptcies.

Theoretical studies described in vast literature prove how external financial innovations can benefit or harm existing companies and how traditional companies can protect themselves from external threats by using their own innovations. It is rather difficult to test such theories because big samples of data about possible competitive threats from innovation are very difficult to obtain. This study used a new systematic data set in order to determine how innovations of potential participants can affect individual companies in the industry.

The approach presented in the article of FinTech patent applications identification and classification applying text analysis and machine learning contributes to literature that applies these methods to finance and economics. Machine learning algorithms that are used to classify texts are actually new to the financial field and can be used effectively to analyze a wide range of issues related to patent applications, legal documentation and other textual data.

\subsection{Assessing the Value of Own Patent Filings}

Further we evaluated the effect that owning FinTech patents has on the value of the publicly traded financial companies. To acquire this data, we used a combination of the cumulative (market-adjusted) abnormal returns (CAR) over the period of event of patent application with the Poisson intensities. We can use Equation (5)'s empirical analogue to assess the value of the innovation to the company:

$$
V_{i, j, k, t}^{f I N D}=\frac{e^{\lambda_{j, k, t}}-1}{\lambda_{j, k, t} \times n_{k, t}} C A R_{i, t} M_{i, t}
$$

Here the technology type of innovation is $\mathrm{k}$, the company is $i$ and the date of the publication of the innovation is $t$. $\lambda_{i, k, t}$ is the intensity of innovation from the Poisson regressions that was projected in Assessing the intensities of innovations Section; $n_{k, t}$ refers to a number of patents that have been disclosed on the date $t$ by a company $i ; C A R_{i, t}$ is a 4 day period calculation which starts 2 days prior the patent disclosure date $t ; M_{i, t}$ refers to a company's market capitalization 5 days before the disclosure date $t$.

\section{Results and Discussion}

\subsection{Results on Number of FinTech Innovation Events}

This Table 6 presents Poisson regression models calculation on the number of FinTech innovation events that occur in a given time period (2015-2019). Regression is calculated for every technology category separately. Research and Development and Innovation are the company's expenditures that it spends on R\&D\&I before the year of patent application event. FinTech previous applications are the number of company's previous Fintech patent applications. Nonfinancial previous applications are the number of company's previous nonfinancial patent applications. All applications are counted in the same IPC " $\mathrm{G}$ " and " $\mathrm{H}$ " classes. 
Table 6. Poisson count models calculated for FinTech innovations (created by authors).

\begin{tabular}{|c|c|c|c|c|c|}
\hline Public Companies & Blockchain & Cybersecurity & Mobile Transactions & Robo-Advising & Internet of Things \\
\hline Assets & $\begin{array}{l}0.943^{* * * *} \\
(-0.193)\end{array}$ & $\begin{array}{l}0.907 * * * \\
(-0.349)\end{array}$ & $\begin{array}{l}-1.277 * * \\
(-0.541)\end{array}$ & $\begin{array}{l}-35.903 * \\
(-20.399)\end{array}$ & $\begin{array}{l}-0.355 \\
(-0.486)\end{array}$ \\
\hline $\begin{array}{l}\text { Research and Development } \\
\text { and Innovation }\end{array}$ & $\begin{array}{l}0.073 \\
(-0.304)\end{array}$ & $\begin{array}{l}1.753 * * * \\
(-0.557)\end{array}$ & $\begin{array}{l}-0.172 \\
(-1.72)\end{array}$ & $\begin{array}{l}59.590^{* *} \\
(-29.945)\end{array}$ & $\begin{array}{l}1.988 \\
(-1.362)\end{array}$ \\
\hline $\begin{array}{l}\text { Research and Development } \\
\text { and Innovation } 1\end{array}$ & $\begin{array}{l}0.048 \\
(-0.3)\end{array}$ & $\begin{array}{l}-0.673 \\
(-0.66)\end{array}$ & $\begin{array}{l}1.908 \\
(-2.245)\end{array}$ & $\begin{array}{l}34.657^{* *} \\
(-16.662)\end{array}$ & $\begin{array}{l}3.738 \\
(-2.336)\end{array}$ \\
\hline $\begin{array}{l}\text { Research and Development } \\
\text { and Innovation } 2\end{array}$ & $\begin{array}{l}-0.236 \\
(-0.288)\end{array}$ & $\begin{array}{l}0.364 \\
(-0.662)\end{array}$ & $\begin{array}{l}0.287 \\
(-2.05)\end{array}$ & $\begin{array}{l}-22.221 * * \\
(-10.288)\end{array}$ & $\begin{array}{l}-7.361 * * * \\
(-2.344)\end{array}$ \\
\hline $\begin{array}{l}\text { Research and Development } \\
\text { and Innovation } 3\end{array}$ & $\begin{array}{l}-0.273 \\
(-0.248)\end{array}$ & $\begin{array}{l}-0.935^{*} \\
(-0.514)\end{array}$ & $\begin{array}{l}-1.241 \\
(-1.443)\end{array}$ & $\begin{array}{l}29.204 * * \\
(-14.246)\end{array}$ & $\begin{array}{l}2.111 * \\
(-1.129)\end{array}$ \\
\hline Age & $\begin{array}{l}-0.201 \\
(-0.591)\end{array}$ & $\begin{array}{l}-0.093 \\
(-1.329)\end{array}$ & $\begin{array}{l}-3.693 * * \\
(-1.514)\end{array}$ & $\begin{array}{l}37.648 \\
(-139.437)\end{array}$ & $\begin{array}{l}-0.295 \\
(-2.107)\end{array}$ \\
\hline $\begin{array}{l}\text { Fintech previous } \\
\text { applications }\end{array}$ & $\begin{array}{l}0.111 \\
(-0.11)\end{array}$ & $\begin{array}{l}-0.092 * \\
(-0.174)\end{array}$ & $\begin{array}{l}0.244 \\
(-0.309)\end{array}$ & $\begin{array}{l}-5.566 \\
(-3.711)\end{array}$ & $\begin{array}{l}-1.126 \text { *** } \\
(-0.339)\end{array}$ \\
\hline $\begin{array}{l}\text { Nonfinancial previous } \\
\text { applications }\end{array}$ & $\begin{array}{l}0.253 * * \\
(-0.101)\end{array}$ & $\begin{array}{l}0.197 \\
(-0.176)\end{array}$ & $\begin{array}{l}0.358 \\
(-0.278)\end{array}$ & $\begin{array}{l}27.971 \text { ** } \\
(-12.487)\end{array}$ & $\begin{array}{l}1.243 * * * \\
(-0.305)\end{array}$ \\
\hline \multicolumn{6}{|l|}{ Private Companies } \\
\hline Age & $\begin{array}{l}1.145^{* * *} \\
(-0.166)\end{array}$ & $\begin{array}{l}1.730 * * * \\
(-0.306)\end{array}$ & $\begin{array}{l}3.399 * * * \\
(-0.628)\end{array}$ & $\begin{array}{l}11.987 * * \\
(-5.55)\end{array}$ & $\begin{array}{l}3.547 * * * \\
(-0.725)\end{array}$ \\
\hline $\begin{array}{l}\text { Fintech previous } \\
\text { applications }\end{array}$ & $\begin{array}{l}-0.555^{* * *} \\
(-0.09)\end{array}$ & $\begin{array}{l}-1.103^{* * *} \\
(-0.137)\end{array}$ & $\begin{array}{l}-1.643^{* * *} \\
(-0.267)\end{array}$ & $\begin{array}{l}-2.790 * * \\
(-1.304)\end{array}$ & $\begin{array}{l}-1.105^{* * *} \\
(-0.27)\end{array}$ \\
\hline $\begin{array}{l}\text { Nonfinancial previous } \\
\text { applications }\end{array}$ & $\begin{array}{l}0.619 * * * \\
(-0.101)\end{array}$ & $\begin{array}{l}0.818 * * \\
(-0.174)\end{array}$ & $\begin{array}{l}0.966 * * * \\
(-0.281)\end{array}$ & $\begin{array}{l}8.111 * * * \\
(-2.982)\end{array}$ & $\begin{array}{l}0.867^{* *} \\
(-0.369)\end{array}$ \\
\hline
\end{tabular}

Data in parentheses represent robust standard errors. ${ }^{*} p<0.10 ;{ }^{* *} p<0.05 ;{ }^{* * *} p<0.01$.

In Table 7 we see a cumulative data for private innovation values across seven different categories and five major FinTech groups, FinTech innovations and non-FinTech financial innovations. CARs for each of the five categories are provided individually. The data prove that FinTech innovations lead to a notable value for the company. For the innovator value on average is $21.5 \mathrm{M}$ USD and the median reaches $41 \mathrm{M}$ USD. Comparing these values to innovations that fall under the category of non-FinTech financial, a substantially lower median value is created, that is USD $2.1 \mathrm{M}$, but the average value is still similar to the value FinTech innovations. In most of the innovation types the mean CAR values are positive. The fact that median and mean values in some innovation types have opposite signs, shows the degree of substantial asymmetry in the distributions. Mobile transactions have the only negative median value. Futher, the biggest values are seen in blockchain innovation, cybersecurity and robo-advising (USD 99.4 M, USD 56.3 M and USD 52.2 M, respectively).

We use bootstrapping to evaluate the importance of the median and mean values. Bootstrapped $p$ values for medians and means are presented in the Table 7 in parentheses. We have received results that show statistical difference of zero of the positive medians for blockchain, cybersecurity, robo-advising and IoT. Additionally, the positive median for all FinTech innovations shows high statistical significance. Thus, the statement, that FinTech innovations bear significant value to their innovators is supported by the $p$ values in Table 7 .

Table 7 presents data on the value effect for the company of selected FinTech innovation categories. Values, that are expressed in millions USD, from public company's abnormal stock returns (CAR) linked to their patent application event, are calculated according to Equation (8). CARs are calculated over the period of 2 days: starting one day before the news of patent application. Data in parentheses represent $p$-values for means and medians, and a bootstrapping method was used to calculate $p$-values. 
Table 7. FinTech innovation value for the company (created by authors).

\begin{tabular}{lllll}
\hline \multicolumn{1}{c}{ Innovation Category } & \multicolumn{1}{c}{ CAR (\%) } & \multicolumn{1}{c}{ Mean } & \multicolumn{1}{c}{ Median } & Standard Deviation \\
\hline Blockchain & 0.31 & $\begin{array}{l}62.5 \\
(0.431)\end{array}$ & $\begin{array}{l}\text { 99.4 } \\
(<0.001)\end{array}$ & 1768.50 \\
\hline Cybersecurity & 0.47 & $\begin{array}{l}49.2 \\
(0.456)\end{array}$ & $\begin{array}{l}56.3 \\
(0.083)\end{array}$ & 1021.73 \\
& & -89.7 & -18.4 & 1792.64 \\
\hline Mobile transactions & -0.36 & $(0.385)$ & $(0.089)$ & \\
& & -104.6 & 52.2 & 964.1 \\
\hline Robo-advising & 0.29 & $(0.455)$ & $(0.011)$ & \\
& & -31.4 & 2.2 & 817 \\
\hline IoT & -0.38 & $(0.611)$ & $(0.783)$ & 1548.80 \\
& & 21.5 & 41.0 & \\
\hline All FinTech Innovations & & $(0.483)$ & $(<0.001)$ & 3031.20 \\
& & 19.6 & 2.1 & \\
\hline Non FinTech Financial & & $(0.564)$ & $(0.482)$ & \\
Innovations & & & & \\
\hline
\end{tabular}

Further we evaluate the effect that underlying technologies have on the value of FinTech innovations. For this cause multivariate regressions are used. On the first stage the goal is a mitigation of skewness and outliers in the distribution of the value. For this cause, a logarithmic transformation is applied to the estimated values:

$$
V= \begin{cases}\log \left(1+V^{*}\right) ; & V^{*}>0 \\ -\log \left(1-V^{*}\right) ; & V^{*}<0\end{cases}
$$

Here, $V$ is a converted value that is later used in regressions as the dependent variable. $V^{*}$ is the estimated in Equation (8) value. Further, following form regressions are estimated:

$$
V_{i, k, t}^{f I N D}=\alpha_{i}+\beta^{\prime} T e c h D_{k}+\Gamma^{\prime} X_{i, k, t}+\varepsilon_{i, k, t}
$$

Here $V_{i}, O_{k},{ }_{t}{ }_{t}$ is the value (which is log transformed) of the patent application on a date $t$ of technology type $k$ to a company $i$. TechD are the binary variables and express categories of different FinTech. $X$ contains controls of company size, company age before FinTech applications, before applications in other financial areas and before nonfinancial applications in IPC " $\mathrm{G}$ " and " $\mathrm{H}$ ". Company and year fixed effects, patent breadth and quality controls are also included. Nonindicator controls are expressed in natural logarithm.

Table 8 presents regression results. According to the data, the most valuable innovation categories are blockchain followed by robo-advising. These types of innovation have much more significant value compared to mobile transactions baseline. However, it can be observed that other categories are not that significantly different from mobile transactions. These data show that, regarding future cost savings in financial services, there are big potential benefits offered by blockchain technology.

\subsection{Discussion}

In this analysis the value of FinTech innovation was presented through a patent lens. This is a tangible measure that proves that protecting the output of companies' investment can bear positive value effect. Being an essential source of competitive intelligence, patents can help companies to withstand introduction of disruptive innovation [30]. In this paper, the focus is put on patent applications rather than on granted patents which provides more of a complete analysis of recent trends in FinTech innovation. 
Table 8. Innovation category and company value of FinTech (created by authors).

\begin{tabular}{ll}
\hline \multicolumn{1}{c}{ Innovation Category } & \multicolumn{1}{c}{ Value } \\
\hline blockchain & $2.022^{* *}$ \\
& $(0.652)$ \\
\hline cybersecurity & 0.245 \\
& $(0.533)$ \\
\hline mobile transactions & $1.341 *$ \\
& $(0.731)$ \\
\hline robo-advising & $1.637 *$ \\
& $(0.731)$ \\
\hline IoT & 0.704 \\
& $(0.947)$ \\
\hline
\end{tabular}

The method that was developed complements other researchers that used stock prices to determine the value of innovation. Presented study extends and combines reactions of stock prices with Poisson innovation intensities. It can be used to analyze different types of recurring and partially anticipated events. Approach used in this paper to identify and classify FinTech innovations using machine learning and text analysis can contribute to the economic literature. The study demonstrates a correlation between financial innovations and impact or value on the financial market.

Despite the current widespread of FinTech, the fundamental challenge that was faced analyzing FinTech innovations is that there is currently no official definition or consensus about what FinTech is and of what exact technologies or services it comprises [31].

\subsection{Limitations}

Patenting FinTech inventions has a number of challenges and one of the limitations is that it reflects only part of financial sectors' innovation activities as not all of them can be subject to patenting [32]. While previous researchers have focused more on the analysis of granted patents [33,34], trends on machine learning technologies and applications [35,36], the presented study is based on patent applications, mainly for the reason that granting a patent takes years and FinTech is a relatively new field, thus many of the patents were applied only recently.

The other limitation is related to the complexity of companies R\&D\&I expenditures that makes it hard to determine exact investments. Further research is needed for a broader understanding of FinTech innovation impact on financial sector and society.

\section{Conclusions}

Such an increase of interest in FinTech-powered innovation during recent years brings out the need for a deeper understanding of a potential value that these new emerging technologies can bear to their inventors. There is an increase in general understanding that patents play an important part in an organization's innovation strategy. Different sectors adopt different strategies for generating value from innovations. Currently there is an obvious difference between how financial services and technology companies perceive patents.

Analysis of valuation of financial innovation presented in this paper was based on stock price data. The developed model expanded on recognizing the nature of innovative events over time, which allowed to assess value impact more accurately. For this purpose, Poisson flow rates and stock price movements were combined, which proved to be useful exploring other partially anticipated recurring phenomena such as the sequence of company news releases and wave of mergers or bankruptcies. 
The presented study provides evidence that FinTech innovations bring value to their inventors and generally are valuable to the whole financial sector. Most valuable FinTech innovations are blockchain innovation (USD 99.4 M), cybersecurity (USD 6.3 M) and robo-advising (USD 52.2 M).

On the other hand, some categories of FinTech innovation have a negative value effect on companies. Findings state that market leaders that invest in their own R\&D\&I, have tendency to avoid harm introduced by disruptive innovations.

For further research, the authors suggest to focus on a deeper analysis of the additional features of FinTech innovations and how they affect the value of companies in the financial sector. What is more, the conducted study can be used as basis for further research of social impact of FinTech innovation.

Author Contributions: Conceptualization, J.K.; data curation, J.K.; investigation, J.K.; resources, J.K.; writing - original draft preparation, J.K.; writing-review and editing, J.K. and J.S.; supervision, J.S. All authors have read and agreed to the published version of the manuscript.

Funding: This research received no external funding.

Conflicts of Interest: The authors declare no conflict of interest.

\section{References}

1. Buehler, K.; Chiarella, D.; Heidegger, H.; Lemerle, M.; Lal, A.; Moon, J. Beyond the Hype: Blockchains in Capital Markets; McKinsey \& Company: New York, NY, USA, 2015.

2. Harrist, M. How Fintech Is Powering The Global Economy. Forbes. 2017. Available online: https://www.forbes. com/sites/oracle/2017/03/14/how-fintech-is-powering-the-global-economy/ (accessed on 27 September 2020).

3. The Economist. The Fintech Revolution. A Wave of Startups Is Changing Finance for the Better. The Economist. 2015. Available online: https://www.economist.com/leaders/2015/05/09/the-fintech-revolution (accessed on 26 September 2020).

4. Nash, K.S. Big Banks Stake Fintech Claims with Patent Application Surge. Wall Street Journal. 2016. Available online: https://blogs.wsj.com/cio/2016/05/10/big-banks-stake-fintech-claims-with-patentapplication-surge/ (accessed on 2 September 2020).

5. Russo, C. Goldman and Google are among the most Active Blockchain Investors. Bloomberg. 2017. Available online: https://www.bloomberg.com/news/articles/2017-10-17/goldman-google-make-list-of-mostactive-blockchain-investors (accessed on 13 August 2020).

6. Pollari, I.; Ruddenklau, A. The Pulse of Fintech H1 2019. In 2019 bi-Annual Analysis of Global Investment Trends in the Fintech Sector; KPMG Global: Zurich, Switzerland, 2019.

7. Bates, S.; Ellis, A. A Changing Perspective. Harvey Nash CIO Survey 2019. Available online: https://home. kpmg/xx/en/home/insights/2019/06/harvey-nash-kpmg-cio-survey-2019.html (accessed on 21 August 2020).

8. Casey, M.; Crane, J.; Gensler, G.; Johnson, S.; Narula, N. The Impact of Blockchain Technology on Finance: A Catalyst for Change; Geneva Reports on the World Economy 21; International Center for Monetary and Banking Studies (ICMB): Geneva, Switzerland, 2019.

9. González, L.O.; Gil, L.I.R.; Cunill, O.M.; Lindahl, J.M.M. The effect of financial innovation on European banks' risk. J. Bus. Res. 2016, 69, 4781-4786. [CrossRef]

10. Beck, T.; Chen, T.; Lin, C.; Song, F. Financial innovation: The bright and the dark sides. J. Bank. Finance 2016, 72, 28-51. [CrossRef]

11. Yang, M.; He, Y. How does the stock market react to financial innovation regulations? Finance Res. Lett. 2019, 30, 259-265. [CrossRef]

12. Lerner, J. Patent protection and innovation over 150 years. Natl. Bur. Econ. Res. 2002, 97, 1-40.

13. Citanna, A.; Schmedders, K. Excess price volatility and financial innovation. Econ. Theory 2005, 26, 559-587. [CrossRef]

14. Council of Canadian Academies. Innovation Impacts: Measurement and Assessment. The Expert Panel on the Socio-Eco-Nomic Impacts of Innovation Investments, 1-148. 2015. Available online: https://cca-reports. ca/wp-content/uploads/2018/10/roi_fullreporten.pdf (accessed on 19 July 2020).

15. European Commission. What Is FinTech? 2019. Available online: https://ec.europa.eu/info/businesseconomy-euro/banking-and-finance/fintech_en (accessed on 5 November 2019). 
16. Chan, R. Asian Regulators Seek FinTech Balance. 2018. Available online: http://www.financeasia.com/News/ 401588, asian-regulators-seek-fintech-balance.aspx (accessed on 14 December 2019).

17. Financial Stability Board (FSB). Decentralised Financial Technologies: Report on Financial Stability, Regulatory and Governance Implications; Financial Stability Board: Basel, Switzerland, 2019.

18. European Commision. FinTech Action Plan: For a More Competitive and Innovative European Financial Sector. 2018. Available online: https://eur-lex.europa.eu/legal-content/EN/TXT/?uri=CELEX:52018DC0109 (accessed on 2 July 2020).

19. Lavender, J.; Pollari, I.; Raisbeck, M.; Hughes, B.; Speier, A. The Pulse of Fintech Q4 2017—Global Analysis of Investment in Fintech. Kpmg, (February), 1-80. 2017. Available online: https://assets.kpmg.com/content/ dam/kpmg/xx/pdf/2017/02/pulse-of-fintech-q4-2016.pdf (accessed on 12 September 2020).

20. Christensen, C.; Raynor, M. The Innovator's Solution: Creating and Sustaining Successful Growth; Harvard Business Review Press: Brighton, MA, USA, 2013.

21. Nicholas, T. Does Innovation Cause Stock Market Runups? Evidence from the Great Crash. Am. Econ. Rev. 2008, 98, 1370-1396. [CrossRef]

22. Kogan, L.; Papanikolaou, D.; Seru, A.; Stoffman, N. Technological Innovation, Resource Allocation, and Growth. Q. J. Econ. 2017, 132, 665-712. [CrossRef]

23. MS Azure. Understand Automated Machine Learning Results. 2019. Available online: https://docs.microsoft. com/en-us/azure/machine-learning/ (accessed on 19 September 2020).

24. Czakon, J. 24 Evaluation Metrics for Binary Classification (And When to Use Them). 2019. Available online: https://neptune.ai/blog/evaluation-metrics-binary-classification (accessed on 7 June 2020).

25. Hausman, J.; Hall, B.H.; Griliches, Z. Econometric Models for Count Data with an Application to the Patents-R \& D Relationship. Econometrica 1984, 52, 909-938. [CrossRef]

26. WIPO. PATENTSCOPE Database. 2019. Available online: https://www.wipo.int/patentscope/en/ (accessed on 17 October 2019).

27. European Patent Office (EPO). Espacenet Database. 2019. Available online: https://worldwide.espacenet.com/ (accessed on 17 October 2019).

28. Gardner, J.D. New Patent Office Guidelines and the Impact on the Patent Eligibility of Fintech Inventions. 2019. Available online: https://www.jdsupra.com/legalnews/new-patent-office-guidelines-and-the-34479/ (accessed on 19 May 2020).

29. Stankovic, M. Patentability of FinTech inventions. In FinTech: Law and Regulation; Madir, J., Ed.; Elgar Financial Law and Practice; Edward Elgar Publishing Ltd.: Geneva, Switzerland, 2019; p. 512.

30. Swycher, N.; Malek, M. Fintech-Understanding the Role of Patents. Available online: https://cipher.ai/wpcontent/uploads/Fintech-understanding-the-role-of-patnets.pdf (accessed on 25 May 2020).

31. Georges, A.D.; Korenchan, J.L. The Patent Landscape of Cryptocurrency and Blockchain. SNIPPETS, 1-16. 2018. Available online: https://www.mbhb.com/intelligence/snippets/the-patent-landscape-ofcryptocurrency-and-blockchain (accessed on 14 August 2020).

32. Fatás, A. The Economics of Fintech and Digital Currencies. 2019. Available online: https://voxeu.org/article/ economics-fintech-and-digital-currencies-new-ebook (accessed on 17 March 2020).

33. Bhatt, P.C.; Kumar, V.; Lu, T.-C.; Cho, R.L.-T.; Lai, K.K. Rise and Rise of Blockchain: A Patent Statistics Approach to Identify the Underlying Technologies. In Proceedings of the Intelligent Information and Database Systems, 12th Asian Conference, ACIIDS 2020, Phuket, Thailand, 23-26 March 2020. [CrossRef]

34. Unsal, O.; Rayfield, B. Trends in Financial Innovation: Evidence from Fintech Firms. Disruptive Innovation in Business and Finance in the Digital World. Int. Financ. Rev. 2019, 20, 15-25. [CrossRef] 
35. Chae, S.; Gim, J. A Study on Trend Analysis of Applicants Based on Patent Classification Systems. Information 2019, 10, 364. [CrossRef]

36. Zambetti, M.; Sala, R.; Russo, D.; Pezzotta, G.; Pinto, R. A Patent Review on Machine Learning Techniques and Applications: Depicting Main Players, Relations and Technology Landscapes. In Proceedings of the XXIII Summer School Francesco Turco, Palermo, Italy, 12-14 September 2018.

Publisher's Note: MDPI stays neutral with regard to jurisdictional claims in published maps and institutional affiliations.

(C) 2020 by the authors. Licensee MDPI, Basel, Switzerland. This article is an open access article distributed under the terms and conditions of the Creative Commons Attribution (CC BY) license (http://creativecommons.org/licenses/by/4.0/). 

Article

\title{
Multi-Attribute Decision Making Based on Stochastic DEA Cross-Efficiency with Ordinal Variable and Its Application to Evaluation of Banks' Sustainable Development
}

\author{
Jinpei Liu ${ }^{1,2}$, Mengdi Fang ${ }^{1}$, Feifei Jin ${ }^{1, *}$, Chengsong $\mathrm{Wu}^{1}$ and Huayou Chen ${ }^{3}$ \\ 1 School of Business, Anhui University, Hefei 230601, China; liujinpei@ahu.edu.cn (J.L.); \\ m18201053@stu.ahu.edu.cn (M.F.); 91027@ahu.edu.cn (C.W.) \\ 2 Department of Industrial and Systems Engineering, North Carolina State University, Raleigh, NC 27695, USA \\ 3 School of Mathematical Sciences, Anhui University, Hefei 230601, China; huayouc@ahu.edu.cn \\ * Correspondence: jinfeifei@ahu.edu.cn; Tel.: +86-1385-694-2010
}

Received: 14 February 2020; Accepted: 17 March 2020; Published: 18 March 2020

\begin{abstract}
Multi-attribute decision making (MADM) is a cognitive process for evaluating data with different attributes in order to select the optimal alternative from a finite number of alternatives. In the real world, a lot of MADM problems involve some random and ordinal variables. Therefore, in this paper, a MADM method based on stochastic data envelopment analysis (DEA) cross-efficiency with ordinal variable is proposed. First, we develop a stochastic DEA model with ordinal variable, which can derive self-efficiency and the optimal weight of each attribute for all decision making units (DMUs). To further improve its discrimination power, cross-efficiency as a significant extension is proposed, which utilizes peer DMUs' optimal weight to evaluate the relative efficiency of each alternative. Then, based on self-efficiency and cross-efficiency of all DMUs, we construct corresponding fuzzy preference relations (FPRs) and consistent fuzzy preference relations (FPRs). In addition, we obtain the priority weight vector of all DMUs by utilizing the row wise summation technique according to the consistent FPRs. Finally, we provide a numerical example for evaluating operation performance of sustainable development of 15 listed banks in China, which illustrates the feasibility and applicability of the proposed MADM method based on stochastic DEA cross-efficiency with ordinal variable.
\end{abstract}

Keywords: stochastic DEA; multi-attribute decision making; ordinal variable; cross-efficiency

\section{Introduction}

Sustainable development (SD) is a widely used phrase and idea, which firstly emerged in the context of environmental concerns [1-3]. However, with the development of society and economy, we gradually realized the significance of sustainable development of economy. To some extent, the operation performance of banks can reflect economic trends. Therefore, it is important to maintain the sustainable development of banks. Recently, sustainable development of banks has become a hotspot. Munir and Gallagher [4] proposed that optimizing the benefits and costs can improve sustainable development of banks. Xue et al. [5] considered that adjusting and optimizing the layout of the physical branches of commercial banks is crucial to its sustainable development. Jiang and Han [6] suggested that adopting diversification strategy is beneficial to achieving sustainable development of banks.

Multi-attribute decision making (MADM) is one of the most common and popular research fields in the theory of decision science [7]. It assumes that there exists a set of alternatives with multiple attributes which decision makers (DMs) need to evaluate. The purpose of MADM is to select the optimal one from a finite number of alternatives. Generally speaking, each MADM problem includes two parts: classifying and ranking. Classifying can be considered as the grouping of the alternatives 
based on the similarities of attributes. Ranking is defined as the rank of alternatives from the optimal to the worst [8]. In recent years, some methods have been proposed to handle MADM problems, such as total sum (TS) method [9], simple additive weighting (SAW) method [10], the analytic hierarchy process (AHP) method [11], multiplicative analytic hierarchy process (MAHP) method [12], the technique for order preference by similarity to ideal solution (TOPSIS) method [13], and data envelopment analysis (DEA) method [14].

In MADM problems, we need some decision making information including attribute values and attribute weights, which denote the characteristics of alternatives and relative importance of attributes, respectively [7]. Nevertheless, attribute values are known, so we have to obtain attribute weights by the aforementioned approaches. However, DEA is a nonparametric programming efficiency rating technique for evaluating the relative efficiency of DMUs with multiple inputs and outputs, whose evaluation results come from input and output data [15-17]. Compared with other methods, attribute weights derived by DEA is relatively objective. Therefore, DEA has been widely applied in many fields for different purposes [18-20], such as assessment of environmental sustainability [21,22], supplier selection [23-25], and evaluation of the influence of E-marketing on hotel performance [26].

Due to the inherent complexity and competition of the real world, MADM problems often involve some random and ordinal variables. However, previous DEA studies have been undertaken in a deterministic environment, which cannot solve the above situation. Therefore, it is necessary to incorporate the stochastic variable into DEA. Then, we propose the stochastic DEA model with ordinal variable. Recently, stochastic DEA has become the research hotspot. A well-known method to extend DEA to the case of random inputs and outputs is to utilize chance constrained programming (CCP) [27], which was proposed by Charnes and Cooper [28]. The CCP admits random data variations and permits constraint violations up to the specified probability limit. Khodabakhshi et al. [29] extended the super-efficiency DEA model to an input-oriented super-efficiency stochastic DEA model by CCP. The major contributions on the stochastic DEA may be attributed to the work of Sengupta [30]. A prominent characteristic of his study is that stochastic DEA is transformed into a deterministic equivalent [31]. In addition to Sengupta's work, Sueyoshi [31] proposed a DEA future analysis method that considered how to integrate future information into DEA, and then applied it to restructure strategy of a Japanese petroleum company. Wu et al. [32] followed the Cooper's approach to develop stochastic DEA model by considering undesirable outputs with weak disposability.

However, although stochastic DEA model can evaluate MADM problems with random and ordinal variables, the following disadvantages also exist. One is that DEA identifies many efficient alternatives where efficiency score is equivalent to one, and cannot further discriminate them. Another is that the ranking order of all alternatives cannot involve appraisal of peer DMUs and influences the accuracy and persuasion of evaluation results in MADM problems. Faced with these drawbacks, many researchers have taken efforts to modify DEA methods, including weight restriction, super-efficiency, cross-efficiency and so on [33]. The weight restriction methods commonly attach additional constrains to relative weights, including absolute weight restriction [34], common weights [35], and cone ratio restriction [36]. Nevertheless, all weight restriction approaches use priority information or predefined parameters, thus they are subjective to some extent. Andersen and Petersen [37] proposed a super efficiency method for ranking DMUs. The cross-efficiency evaluation method is an important extension, which is invented to utilize peer DMUs' optimal weights to appraise relative efficiency of each DMU [38-41]. Compared with the traditional DEA approach concentrating on self-efficiency evaluation, cross-efficiency evaluation method has the following main characteristics: (1) taking peer-evaluation of all alternatives into account and guaranteeing a unique ranking order for whole DMUs, (2) eliminating unrealistic weight schemes without predetermining any weight restrictions, and (3) effectively distinguishing better DMUs and poor DMUs [42]. Owing to these superiorities, cross-efficiency evaluation results can be more reasonable and acceptable. Therefore, cross-efficiency has been widely applied to diverse fields, including R\&D project selections and the ranking of universities' comprehensive ability. However, there are few DEA methods to handle the issue that 
MADM problems involve some random and ordinal variables. To further extend the application of DEA on aforementioned MADM problems, we develop a MADM method based on stochastic DEA cross-efficiency with ordinal variable.

The main purpose of this paper is to address the MADM problems with random and ordinal variables. Therefore, we propose a MADM method based on stochastic DEA cross-efficiency with ordinal variable. The major characteristics of this method are presented as follows. One is that both stochastic variable and ordinal variable are incorporated into DEA model, which is considerably consistent with the actual circumstance. The other is that it simultaneously considers the self-efficiency and cross-efficiency in evaluation process of MADM problems, and then constructs corresponding consistent FPRs. Subsequently, we calculate the priority weight vector of all alternatives by utilizing the row wise summation technique and derive the full ranking order of them.

The rest of this paper is organized as follows. In Section 2, we briefly introduce the traditional CCR model and its correlative properties. In Section 3, we develop a MADM method based on stochastic DEA cross-efficiency with ordinal variable. Section 4 gives a numerical example for evaluating operation performance of sustainable development of 15 listed banks in China, which illustrates the applicability of this proposed approach. Finally, some conclusions and future research work are presented in Section 5 .

\section{Preliminaries}

In this section, we briefly review some basic concepts of DEA model. DEA is a data-oriented methodology for identifying efficiency production frontiers and evaluating the relative efficiency of DMUs that multiple inputs of production factors produce certain amount outputs [43]. Suppose that there are n DMUs to be evaluated, where each DMU is characterized by its production process of consuming $\mathrm{m}$ inputs to generate $\mathrm{s}$ outputs. For convenience, the inputs and outputs of $\operatorname{DMU}_{j}(j=1,2, \cdots, n)$ are denoted as $x_{i j}(i=1,2, \cdots, m)$ and $y_{r j}(r=1,2, \cdots, s)$, respectively. To evaluate performance of specific $D M U_{k}$, Charnes et al. [44] proposed the following model to calculate its relative efficiency under the assumption of constant returns to scale (CRS).

$$
\begin{aligned}
& \min \theta_{k} \\
& \text { S.t } \sum_{j=1}^{n} \lambda_{j} y_{r j} \geq y_{r k}, r=1,2, \cdots, s, \\
& \sum_{j=1}^{n} \lambda_{j} x_{i j} \leq \theta_{k} x_{i k}, i=1,2, \cdots, m, \\
& \lambda_{j} \geq 0, j=1,2, \cdots, n .
\end{aligned}
$$

The above model is called input-oriented CCR model, where $\lambda_{j}$ are the nonnegative multipliers used to aggregate existing DMUs into a virtual one [45], $\theta_{k}$ is the relative efficiency score of $D M U_{k}$. To understand the CCR model clearly, we give the dual form of the CCR model:

$$
\begin{aligned}
& \max z=\sum_{r=1}^{s} \omega_{r} y_{r k} \\
& \text { S.t } \sum_{r=1}^{s} \omega_{r} y_{r j}-\sum_{i=1}^{m} \mu_{i} x_{i j} \leq 0, j=1,2, \cdots, n, \\
& \sum_{i=1}^{m} \mu_{i} x_{i k}=1, \\
& \omega_{r} \geq 0, r=1,2, \cdots, s ; \mu_{i} \geq 0, i=1,2, \cdots, m .
\end{aligned}
$$

where $x_{i j}$ and $y_{r j}$ are the inputs and outputs of $D M U_{j}(j=1,2, \cdots, n), \mu_{i}$ and $\omega_{r}$ are the input and output weights. $x_{i k}$ and $y_{r k}$ are the inputs and outputs of specific $D M U_{k}$, respectively. The optimal solution of the objective function is the relative efficiency of $D M U_{k}$. If the efficiency score of $D M U_{k}$ is less than one, the $D M U_{k}$ is defined as DEA inefficient. Conversely, if the efficiency score is equal to one, 
the $D M U_{k}$ is considered as DEA efficient. In the following, we extend the CCR model by incorporating discretionary variable, ordinal variable and stochastic variable. Then, we develop a MADM method.

\section{Multi-Attribute Decision Making Method}

Generally speaking, MADM is an evaluation process where the optimal alternative needs to be chosen from a finite number of feasible alternatives based on a set of attributes [8]. Owing to the inherent complexity and competition of real world, MADM problems often involve some random and ordinal variables. However, the traditional DEA approach assumes that all inputs and outputs are discretionary where they are under the control of management, thus it insufficiently addresses the above situation. Therefore, we propose a stochastic DEA model with ordinal variable, which constructs production frontiers that incorporate inefficiency and stochastic error [45].

\subsection{Stochastic DEA Model with Ordinal Variable}

The basic CCR model supposes that all inputs and outputs are deterministic. In other words, they are under the control of management [45]. However, in the real world, there are many situations where some inputs and outputs are out of the control of management. Hence, the aforementioned models need to be modified to adapt to these circumstances. First, we assume that $I$ denotes the set including all input variables, and then divide them into two categories: a set of discretionary inputs $I_{D}(i=1,2, \cdots, p)$, and a set of ordinal inputs $I_{O}(i=p+1, p+2, \cdots, m)$. We rewrite model (3) in a new form as follows:

$$
\begin{aligned}
& \max z=\sum_{r=1}^{s} \omega_{r} y_{r k} \\
& \text { S.t } \sum_{r=1}^{s} \omega_{r} y_{r j}-\sum_{i=1}^{p} \mu_{i}^{1} x_{i j}^{1}-\sum_{i=p+1}^{m} \mu_{i}^{2} x_{i j}^{2} \leq 0, \\
& \sum_{i=1}^{p} \mu_{i}^{1} x_{i k}^{1}+\sum_{i=p+1}^{m} \mu_{i}^{2} x_{i k}^{2}=1, \\
& \omega_{r} \geq 0, \mu_{i}^{1} \geq 0, \mu_{i}^{2} \geq 0, j=1,2, \cdots, n .
\end{aligned}
$$

The above model simultaneously considers discretionary and ordinal inputs. The model (3) is an output-oriented model in which we find the optimal output value on the condition that the input values are fixed. The optimal solution of the objective function of model (3) is the self-efficiency of the specific $D M U_{k}$. The symbols $\mu_{i}^{1}$ and $\mu_{i}^{2}$ represent weight multipliers of the discretionary inputs and ordinal inputs, respectively.

It is notable that this study pays attention to real situations where we can control the quantity of inputs, while being unable to control the outputs. The reason is that the quantity of outputs relies on many external factors such as economic factors, political factors and other social factors. Therefore, the output is commonly considered as stochastic variable. The traditional DEA model for performance evaluation is deterministic type, which does not take the random errors of output variable into account in production process. However, stochastic DEA constructs production frontiers that incorporate both inefficiency and stochastic error, which moves the frontiers closer to the bulk of the producing units [45]. Therefore, the measured technical efficiency of DMUs is improved comparing to the deterministic model. In this subsection, we introduce the stochastic outputs into model (3). Suppose that all stochastic outputs are denoted by $\widetilde{y}_{r j}(r=1,2, \cdots, s)$, and each $\widetilde{y}_{r j}$ has a certain probability distribution. The following model (4) is developed: 


$$
\begin{aligned}
& \max E\left(\sum_{r=1}^{s} \omega_{r} \widetilde{y}_{r k}\right) \\
& \text { S.t } \sum_{i=1}^{p} \mu_{i}^{1} x_{i k}^{1}+\sum_{i=p+1}^{m} \mu_{i}^{2} x_{i k}^{2}=1, \\
& \operatorname{Pr}\left(\frac{\sum_{r=1}^{s} \omega_{r} \widetilde{y}_{r j}}{\sum_{i=1}^{p} \mu_{i}^{1} x_{i j}^{1}+\sum_{i=p+1}^{m} \mu_{i}^{2} x_{i j}^{2}} \leq \beta_{j}\right) \geq 1-\alpha_{j}, \\
& \omega_{r} \geq 0, \mu_{i}^{1} \geq 0, \mu_{i}^{2} \geq 0, j=1,2, \cdots, n .
\end{aligned}
$$

The above model is designed to evaluate the expected efficiency of the specific $D M U_{k}$. The inequality constraint guarantees that the probability of the efficiency score of $D M U_{j}$ less than or equal to $\beta_{j}$ should be higher than $1-\alpha_{j}$. The symbols $\left(\omega_{r}, \mu_{i}^{1}, \mu_{i}^{2}\right)$ represent weight multipliers of stochastic outputs, discretionary inputs and ordinal inputs, respectively. Pr denotes a probability and the superscript " $\sim$ " expresses that $\widetilde{y}_{r j}$ is a stochastic variable. The other symbol $\beta_{j}$ is a predefined value whose range is between 0 and $1 . \beta_{j}$ stands for a desirable level of efficiency of $D M U_{j}$, which is determined by outside conditions including decision level of management or market circumstances [31]. Meanwhile, $\alpha_{j}$ is also a prescribed value whose range is between 0 and 1 . It is considered as an allowable risk level that violates the related constraints.

To obtain the computational feasibility, the stochastic DEA model should convert into the deterministic DEA model. In this paper, we utilize the CCP technique to transform the second constraint of model (4) into the following form.

$$
\operatorname{Pr}\left(\frac{\sum_{r=1}^{s} \omega_{r} \tilde{y}_{r j}-\sum_{r=1}^{s} \omega_{r} \bar{y}_{r j}}{\sqrt{U_{j}}} \leq \frac{\beta_{j}\left(\sum_{i=1}^{p} \mu_{i}^{1} x_{i j}^{1}+\sum_{i=p+1}^{m} \mu_{i}^{2} x_{i j}^{2}\right)-\sum_{r=1}^{s} \omega_{r} \bar{y}_{r j}}{\sqrt{U_{j}}}\right) \geq 1-\alpha_{j}, j=1,2, \cdots, n,
$$

where $\bar{y}_{r j}$ is the expected value of $\widetilde{y}_{r j}$ and

$$
U_{j}=\left(\begin{array}{llll}
\omega_{1} & \omega_{2} & \cdots & \omega_{s}
\end{array}\right) \times\left(\begin{array}{cccc}
V\left(\widetilde{y}_{1 j}\right) & \operatorname{Cov}\left(\widetilde{y}_{1 j}, \widetilde{y}_{2 j}\right) & \cdots & \operatorname{Cov}\left(\widetilde{y}_{1 j}, \widetilde{y}_{s j}\right) \\
\operatorname{Cov}\left(\widetilde{y}_{2 j}, \widetilde{y}_{1 j}\right) & V\left(\widetilde{y}_{2 j}\right) & \cdots & \operatorname{Cov}\left(\widetilde{y}_{2 j}, \widetilde{y}_{s j}\right) \\
\vdots & \vdots & \ddots & \vdots \\
\operatorname{Cov}\left(\widetilde{y}_{s j}, \widetilde{y}_{1 j}\right) & \operatorname{Cov}\left(\widetilde{y}_{s j}, \widetilde{y}_{2 j}\right) & \cdots & V\left(\widetilde{y}_{s j}\right)
\end{array}\right) \times\left(\begin{array}{c}
\omega_{1} \\
\omega_{2} \\
\vdots \\
\omega_{s}
\end{array}\right), j=1,2, \cdots, n .
$$

$U_{j}(j=1,2, \cdots, n)$ represents the variance-covariance matrix of the $D M U_{j}$ where the symbol " $V$ " stands for a variance and the symbol "Cov" denotes a covariance. To follow the CCP technique, this subsection introduces a new variable which follows the standard normal distribution with zero mean and unity variance.

$$
\widetilde{Z}_{j}=\frac{\sum_{r=1}^{s} \omega_{r} \widetilde{y}_{r j}-\sum_{r=1}^{s} \omega_{r} \bar{y}_{r j}}{\sqrt{U_{j}}}, j=1,2, \cdots, n .
$$

Therefore, the Formula (5) can be rewritten as follows:

$$
\operatorname{Pr}\left(\widetilde{Z}_{j} \leq \frac{\left.\beta_{j}\left(\sum_{i=1}^{p} \mu_{i}^{1} x_{i j}^{1}+\sum_{i=p+1}^{m} \mu_{i}^{2} x_{i j}^{2}\right)-\sum_{r=1}^{s} \omega_{r} \bar{y}_{r j}\right)}{\sqrt{U_{j}}}\right) \geq 1-\alpha_{j}, j=1,2, \cdots, n .
$$


After a simple transformation, we can obtain the following formula.

$$
\frac{\beta_{j}\left(\sum_{i=1}^{p} \mu_{i}^{1} x_{i j}^{1}+\sum_{i=p+1}^{m} \mu_{i}^{2} x_{i j}^{2}\right)-\sum_{r=1}^{s} \omega_{r} \bar{y}_{r j}}{\sqrt{U_{j}}} \geq \Phi^{-1}\left(1-\alpha_{j}\right), j=1,2, \cdots, n .
$$

where $\Phi$ represents a cumulative normal distribution function and $\Phi^{-1}$ denotes its inverse function. Based on Equation (9), the model (4) can be rewritten as follows:

$$
\begin{aligned}
& \max E\left(\sum_{r=1}^{s} \omega_{r} \widetilde{y}_{r k}\right) \\
& \text { S.t } \sum_{i=1}^{p} \mu_{i}^{1} x_{i k}^{1}+\sum_{i=p+1}^{m} \mu_{i}^{2} x_{i k}^{2}=1, \\
& \frac{\beta_{j}\left(\sum_{i=1}^{p} \mu_{i}^{1} x_{i j}^{1}+\sum_{i=p+1}^{m} \mu_{i}^{2} x_{i j}^{2}\right)-\sum_{r=1}^{s} \omega_{r} \bar{y}_{r j}}{\sqrt{U_{j}}} \geq \Phi^{-1}\left(1-\alpha_{j}\right), \\
& \omega_{r} \geq 0, \mu_{i}^{1} \geq 0, \mu_{i}^{2} \geq 0, j=1,2, \cdots, n .
\end{aligned}
$$

The second inequality constraint of model (10) includes quadratic expression and brings computational difficulty. To further simplify the computational process, we suppose that each stochastic output is denoted by $\widetilde{y}_{r j}=\bar{y}_{r j}+h_{r j} \delta(r=1,2, \cdots, s ; j=1,2, \cdots, n)$, where $\bar{y}_{r j}$ is the expected value of $\widetilde{y}_{r j}$ and $h_{r j}$ is its standard deviation. $\delta$ is assumed to follow a standard normal distribution $N(0,1) . B_{j}$ represents the covariance matrix of $D M U_{j}$. Under such an assumption, $B_{j}$ can be defined as follows:

$$
B_{j}=\left(\begin{array}{cccc}
h_{1 j}^{2} & h_{1 j} h_{2 j} & \cdots & h_{1 j} h_{s j} \\
h_{2 j} h_{1 j} & h_{2 j}^{2} & \cdots & h_{2 j} h_{s j} \\
\vdots & \vdots & \ddots & \vdots \\
h_{s j} h_{1 j} & h_{s j} h_{2 j} & \cdots & h_{s j}^{2}
\end{array}\right)
$$

Hence, $U_{j}$ can be rewritten as the following form,

$$
U_{j}=\left(\begin{array}{llll}
\omega_{1} & \omega_{2} & \cdots & \omega_{s}
\end{array}\right) \times\left(\begin{array}{cccc}
h_{1 j}^{2} & h_{1 j} h_{2 j} & \cdots & h_{1 j} h_{s j} \\
h_{2 j} h_{1 j} & h_{2 j}^{2} & \cdots & h_{2 j} h_{s j} \\
\vdots & \vdots & \ddots & \vdots \\
h_{s j} h_{1 j} & h_{s j} h_{2 j} & \cdots & h_{s j}^{2}
\end{array}\right) \times\left(\begin{array}{c}
\omega_{1} \\
\omega_{2} \\
\vdots \\
\omega_{s}
\end{array}\right)=\left(\sum_{r=1}^{s} \omega_{r} h_{r j}\right)^{2}, \forall r=1,2, \cdots, s ; j=1,2, \cdots, n .
$$

By incorporating Equation (12) into model (10), then the stochastic DEA model with ordinal variable can be transformed into the following equivalent linear programming:

$$
\begin{aligned}
& \max \sum_{r=1}^{s} \omega_{r} \bar{y}_{r k} \\
& \text { S.t } \sum_{i=1}^{p} \mu_{i}^{1} x_{i k}^{1}+\sum_{i=p+1}^{m} \mu_{i}^{2} x_{i k}^{2}=1, \\
& \beta_{j}\left(\sum_{i=1}^{p} \mu_{i}^{1} x_{i j}^{1}+\sum_{i=p+1}^{m} \mu_{i}^{2} x_{i j}^{2}\right)-\sum_{r=1}^{s} \omega_{r} \bar{y}_{r j} \geq \sum_{r=1}^{s} \omega_{r} h_{r j} \Phi^{-1}\left(1-\alpha_{j}\right), \\
& \omega_{r} \geq 0, \mu_{i}^{1} \geq 0, \mu_{i}^{2} \geq 0, j=1,2, \cdots, n .
\end{aligned}
$$


Here, the dual form of model (13) is presented as follows:

$$
\begin{aligned}
& \min \theta_{k} \\
& \text { S.t } \sum_{j=1}^{n} \lambda_{j}\left(\beta_{j} x_{i j}^{1}\right) \leq \theta_{k} x_{i k^{\prime}}^{1}, i=1,2, \cdots, p, \\
& \sum_{j=1}^{n} \lambda_{j}\left(\beta_{j} x_{i j}^{2}\right) \leq \theta_{k} x_{i k^{\prime}}^{2}, i=p+1, p+2, \cdots, m, \\
& \sum_{j=1}^{n} \lambda_{j}\left[\bar{y}_{r j}+h_{r j} \Phi^{-1}\left(1-\alpha_{j}\right)\right] \geq \bar{y}_{r k}, r=1,2, \cdots, s, \\
& \lambda_{j} \geq 0,0 \leq \alpha_{j} \leq 1,0 \leq \beta_{j} \leq 1, j=1,2, \cdots, n .
\end{aligned}
$$

We can derive the optimal weights $\left(\omega_{r}, \mu_{i}^{1}, \mu_{i}^{2}\right)$ of outputs and inputs by solving model (13). Based on the optimal weights of $D M U_{k}$, the cross-efficiency of $D M U_{j}$ is calculated by the following formula:

$$
E_{k j}=\frac{\sum_{r=1}^{s} \omega_{r k} \widetilde{y}_{r j}}{\sum_{i=1}^{p} \mu_{i k}^{1} x_{i j}^{1}+\sum_{i=p+1}^{m} \mu_{i k}^{2} x_{i j}^{2}}, k, j=1,2, \cdots, n, k \neq j .
$$

which is the peer evaluation of $D M U_{k}$ to $D M U_{j}$. Then, we obtain the cross-efficiency matrix.

$$
E=\left(\begin{array}{cccc}
E_{11} & E_{12} & \cdots & E_{1 n} \\
E_{21} & E_{22} & \cdots & E_{2 n} \\
\vdots & \vdots & \ddots & \vdots \\
E_{n 1} & E_{n 2} & \cdots & E_{n n}
\end{array}\right)
$$

However, we cannot derive priority weight vector of all DMUs by cross-efficiency matrix E. Therefore, we need to construct corresponding preference relations to yield the priority weight vector of whole alternatives.

\subsection{Constructing the Consistent Fuzzy Preference Relations for Ranking DMUs}

It is known that traditional ways to construct a preference relation are based on experts' subjective evaluation involving their professional knowledge and ideas, which lead to different preference information for different experts [46]. However, compared with traditional approaches, using the pairwise efficiency derived by DEA method to construct a preference relation is more objective. In this subsection, we present the following specific procedures of construction process. First, we can obtain the efficiency scores $E_{k k}, E_{k j}, E_{j k}, E_{j j}(k, j=1,2, \cdots, n)$ by solving model (13) and calculating Equation (15). Then, we construct corresponding fuzzy preference relations (FPRs) $R=\left(r_{k j}\right)_{n \times n^{\prime}}$ the element of R is defined as follows:

$$
r_{k j}=\frac{E_{k k}+E_{j k}}{E_{k k}+E_{k j}+E_{j k}+E_{j j}}, r_{j j}=0.5, j=1,2, \cdots, n .
$$

where $R=\left(r_{k j}\right)_{n \times n}$ is characterized by $r_{k j}+r_{j k}=1$ and $r_{j j}=0.5$. $r_{k j}$ represents the evaluation of unit $k$ over unit $j$. If $r_{k j}>0.5$, it denotes that unit $k$ is superior to unit $j$. Conversely, if $r_{k j}<0.5$, it stands for that unit $j$ is superior to unit $k$. Based on FPRs $R=\left(r_{k j}\right)_{n \times n^{\prime}}$, we can construct corresponding consistent FPRs $A=\left(a_{k j}\right)_{n \times n}$ by utilizing the following formulas.

$$
c_{k}=\sum_{j=1}^{n} r_{k j}=\sum_{j=1}^{n} \frac{E_{k k}+E_{j k}}{E_{k k}+E_{j k}+E_{j j}+E_{k j}}, k=1,2, \cdots, n .
$$




$$
a_{k j}=\frac{c_{k}-c_{j}}{2(n-1)}+0.5
$$

Based on the consistent FPRs $A=\left(a_{k j}\right)_{n \times n^{\prime}}$, we can derive the priority weight vector of all alternatives by using the row wise summation technique and obtain the whole ranking order. The priority weight vector $v_{k}(k=1,2, \cdots, n)$ of $D M U_{k}$ is calculated by the following equation,

$$
v_{k}=\frac{\sum_{j=1}^{n} a_{k j}}{\sum_{k=1}^{n} \sum_{j=1}^{n} a_{k j}}=\frac{\sum_{j=1}^{n} a_{k j}+\frac{n}{2}-1}{n(n-1)} .
$$

In summary, we show the detailed procedures of MADM method based on stochastic DEA cross-efficiency with ordinal variable.

Step 1: Solve model (13); we obtain the self-efficiency $E_{k k}(k=1,2, \cdots, n)$ and the optimal weights $\mu_{i}^{1 *}(i=1,2, \cdots, p), \mu_{i}^{2 *}(i=p+1, p+2, \cdots, m), \omega_{r}^{*}(r=1,2, \cdots, s)$.

Step 2: Utilize Formula (15) to calculate the cross-efficiency $E_{k j}(k \neq j, k, j=1,2, \cdots, n)$ by the optimal weights of other peer DMUs.

Step 3: Use Equation (17) to calculate the value of $r_{k j}(k, j=1,2, \cdots, n)$ and construct the FPRs $R=\left(r_{k j}\right)_{n \times n}$.

Step 4: Construct corresponding consistent FPRs $A=\left(a_{k j}\right)_{n \times n}$ based on the FPRs $R=\left(r_{k j}\right)_{n \times n}$ by utilizing Equations (18) and (19).

Step 5: Obtain the priority weight vector $v_{k}(k=1,2, \cdots, n)$ of $D M U_{k}$ by calculating the Formula (20).

Step 6: Rank all alternatives in accordance with the descending order of priority weight vector $v_{k}(k=1,2, \cdots, n)$ and select the optimal one.

\section{Example and Discussion}

With the development of society, we gradually realize the significance of sustainable development of economy. To some extent, the operation performance of banks can reflect the economic trend. Therefore, it is important to maintain sustainable development of banks. In this section, we provide a numerical example for evaluating operation performance of sustainable development of 15 listed banks in China, which illustrates practicability and validity of the proposed MADM method based on stochastic DEA cross-efficiency with ordinal variable. The 15 listed banks are Bank of China $\left(D M U_{1}\right)$, Construction Bank of China $\left(D M U_{2}\right)$, Industrial and Commercial Bank of China $\left(D M U_{3}\right)$, Agricultural Bank of China $\left(D M U_{4}\right)$, Industrial Bank Co., Ltd. $\left(D M U_{5}\right)$, Bank of Communications $\left(D M U_{6}\right)$, Shanghai Pudong Development Bank $\left(D M U_{7}\right)$, Ping An Bank Co., Ltd. $\left(D M U_{8}\right)$, China Minsheng Bank $\left(D M U_{9}\right)$, China Merchants Bank $\left(D M U_{10}\right)$, China Citic Bank $\left(D M U_{11}\right)$, China Everbright Bank $\left(D M U_{12}\right)$, Huaxia Bank $\left(D M U_{13}\right)$, Beijing Bank $\left(D M U_{14}\right)$ and Shanghai Bank $\left(D M U_{15}\right)$, respectively. Owing to operating similar business, these banks compete with each other. Then, we want to know the bank with the best performance under the same conditions. Therefore, we have to evaluate the relative performance of all listed banks by aforementioned method and obtain a full ranking of them. Here, we employ the intermediation approach to determine input and output factors of these banks. Compared with other approaches, this method is more suitable for evaluating the whole bank and superior in evaluating efficiency of bank's profitability. Then, it also reduces heavy computation and is considerably consistent with bank's daily operation. Therefore, based on the intermediation approach, we determine four input factors $(\mathrm{m}=4)$ and two output factors $(\mathrm{s}=2)$. The input factors consist of (i) fixed assets $\left(x_{1}\right)$, which stand for the capital value of tangible assets; (ii) labor costs $\left(x_{2}\right)$, which refer to the costs of the full-time employees; (iii) interest expense $\left(x_{3}\right)$ and the number of branches $\left(x_{4}\right)$. The output factors include the amount of the loan $\left(y_{1}\right)$ and the amount of deposit $\left(y_{2}\right)$. Among these six attributes, $x_{1}, x_{2}$ and $x_{3}$ are considered as the discretionary variables, $x_{4}$ is the ordinal variable, $y_{1}$ and $y_{2}$ are assumed 
as the stochastic variables. Our data come from the national Tai'an database. Table 1 gives a summary of the inputs and outputs. Table 2 gives order ranking for branches' number of all listed banks. Table 3 gives descriptive statistics of raw data.

Table 1. Input and output variables.

\begin{tabular}{cccc}
\hline Index & Sym & Item & Unit \\
\hline Input 1 & $\mathrm{X}_{1}$ & Fixed assets & 100-million CNY \\
Input 2 & $\mathrm{X}_{2}$ & Labor costs & 100-million CNY \\
Input 3 & $\mathrm{X}_{3}$ & Interest expense & 10-billion CNY \\
Input 4 & $\mathrm{X}_{4}$ & The number of branches & \\
Output 1 & $\mathrm{Y}_{1}$ & Loan & 100-billion CNY \\
Output 2 & $\mathrm{Y}_{2}$ & Deposit & 100-billion CNY \\
\hline
\end{tabular}

Table 2. Order ranking for branches' number of all listed banks.

\begin{tabular}{cccc}
\hline Banks & Rank & Banks & Rank \\
\hline Bank of China & 4 & China Minsheng Bank & 9 \\
Construction Bank of China & 3 & China Merchants Bank & 5 \\
Industrial and Commercial Bank of China & 2 & China Citic Bank & 7 \\
Agricultural Bank of China & 1 & China Everbright Bank & 9 \\
Industrial Bank Co., Ltd. & 6 & Huaxia Bank & 10 \\
Bank of Communications & 5 & Beijing Bank & 11 \\
Shanghai Pudong Development Bank & 7 & Shanghai Bank & 11 \\
Ping An Bank Co., Ltd. & 8 & & \\
\hline
\end{tabular}

Table 3. Descriptive statistics of raw data.

\begin{tabular}{ccccccc}
\hline Attribute & Fixed Assets & Labor Costs & $\begin{array}{c}\text { Interest } \\
\text { Expense }\end{array}$ & $\begin{array}{c}\text { Ranking of } \\
\text { Branches' Number }\end{array}$ & Loan & Deposit \\
\hline Average & 715.51 & 152.35 & 17.66 & 6.53 & 70.51 & 86.29 \\
Min & 43.95 & 27.62 & 4.59 & 1 & 6.43 & 9.24 \\
Max & 2161.56 & 402.22 & 37.56 & 11 & 198.93 & 232.26 \\
\hline
\end{tabular}

There are two parameters which are not part of the given database: $\alpha$ and $\beta$. We run the stochastic DEA model (13) in Matlab software with different values for these parameters to see the sensitivity of the result. Table 4 shows self-efficiency scores of 15 listed banks which are calculated with diverse combinations between $\alpha=\{0.05,0.1,0.2\}$ and $\beta=\{0.8,0.85,0.9,0.95,1\}$. It presents the values of three statistics of self-efficiency, including the minimum, maximum and the mean. As suggested by Sueyoshi [31], regular trends are found in Table 4. It is notable that the mean, the maximum and the minimum of the self-efficiency increase as $\alpha$ or $\beta$ increases. However, there are two cases that exist in Table 4 and cannot be viewed as exceptions. One is that an increase in $\beta$ from 0.95 to 1 decreases the maximum of self-efficiency from 1 to 0.9754 when $\alpha=0.1$. The other is that the maximum of self-efficiency has no variation between $\beta=0.95$ and $\beta=1$ under the condition of $\alpha=0.2$. It is obvious that there is smaller difference among self-efficiency scores under the condition that $\alpha$ or $\beta$ chooses diverse values. Therefore, we choose $\alpha=0.1$ and $\beta=0.95$ for the rest of the paper.

With the original data, we complete Step 1 of the developed method. In the following, we will accomplish Step 2 to 6 . In Step 2, we use the optimal attribute weights of each bank to calculate the cross-efficiency of the 15 listed banks by utilizing Formula (15) and the results are presented in Table 5 . In Table $5, E_{k j}(k=1,2, \cdots, 15)$ denotes the peer evaluation of $D M U_{k}$ to $D M U_{j}$. In Step 3, we utilize the Formula (17) to calculate the value of $r_{k j}(k, j=1,2, \cdots, 15)$ and construct corresponding FPRs $R=\left(r_{k j}\right)_{15 \times 15}$. Table 6 shows the values of the FPRs $R$. In Step 4, we construct the consistent FPRs $A=\left(a_{k j}\right)_{15 \times 15}$ by using Equations (18) and (19). Table 7 presents the values of the consistent FPRs $A$. In Step 5, we obtain the priority weight vector of each listed bank by utilizing Equation (20). In Step 6, 
we can select the optimal one by ranking all listed banks in accordance with the descending order of priority weight vector $v_{k}(k=1,2, \cdots, 15)$ and the result is documented in Table 8 .

Table 4. Self-efficiency under different $\alpha$ and $\beta$.

\begin{tabular}{ccccc}
\hline$\beta$ & $\alpha$ & $\min$ & $\max$ & mean \\
\hline 0.8 & 0.05 & 0.4142 & 0.7649 & 0.6470 \\
& 0.1 & 0.4528 & 0.8435 & 0.6791 \\
0.85 & 0.2 & 0.5171 & 0.8716 & 0.7064 \\
& 0.05 & 0.4401 & 0.8127 & 0.6874 \\
& 0.1 & 0.4811 & 0.8963 & 0.7215 \\
0.9 & 0.2 & 0.5494 & 0.9205 & 0.7502 \\
& 0.05 & 0.4660 & 0.8605 & 0.7278 \\
& 0.1 & 0.5094 & 0.9312 & 0.7576 \\
0.95 & 0.2 & 0.5817 & 0.9593 & 0.7933 \\
& 0.05 & 0.4919 & 0.9283 & 0.7696 \\
& 0.1 & 0.5377 & 1.0000 & 0.8212 \\
1 & 0.2 & 0.6141 & 1.0000 & 0.8365 \\
& 0.05 & 0.5178 & 0.9561 & 0.8087 \\
& 0.1 & 0.5660 & 0.9754 & 0.8434 \\
& 0.2 & 0.6464 & 1.0000 & 0.8770 \\
\hline
\end{tabular}

Table 5. Cross-efficiency and self-efficiency score.

\begin{tabular}{|c|c|c|c|c|c|c|c|c|}
\hline & $E_{1, j}$ & $E_{2, j}$ & $E_{3, j}$ & $E_{4, j}$ & $E_{5, j}$ & $E_{6, j}$ & $E_{7, j}$ & $E_{8, j}$ \\
\hline$E_{k, 1}$ & 0.9010 & 0.9493 & 0.9498 & 0.9507 & 0.9059 & 0.6197 & 0.8449 & 0.6523 \\
\hline $\mathbf{E}_{\mathbf{k}, 2}$ & 0.8762 & 1.0000 & 0.8815 & 0.8851 & 0.8317 & 0.5170 & 0.7675 & 0.6071 \\
\hline $\mathbf{E}_{\mathbf{k}, 3}$ & 0.9005 & 0.9246 & 0.9016 & 0.9259 & 0.8458 & 0.5912 & 0.7884 & 0.6076 \\
\hline $\mathrm{E}_{\mathbf{k}, 4}$ & 0.8961 & 0.9374 & 0.9272 & 0.8707 & 0.8361 & 0.4318 & 0.7651 & 0.6326 \\
\hline $\mathrm{E}_{\mathbf{k}, 5}$ & 0.7182 & 0.5316 & 0.5085 & 0.5325 & 0.8379 & 0.2974 & 0.7553 & 0.8421 \\
\hline $\mathrm{E}_{\mathbf{k}, 6}$ & 0.8000 & 0.7858 & 0.7684 & 0.7870 & 0.7827 & 1.0000 & 0.7508 & 0.6226 \\
\hline $\mathbf{E}_{\mathbf{k}, 7}$ & 0.6880 & 0.4986 & 0.5146 & 0.4992 & 0.8108 & 0.4244 & 0.8102 & 0.5327 \\
\hline $\mathrm{E}_{\mathbf{k}, 8}$ & 0.5317 & 0.3765 & 0.3377 & 0.3772 & 0.7480 & 0.3673 & 0.6536 & 0.8627 \\
\hline$E_{k, 9}$ & 0.5940 & 0.4900 & 0.4691 & 0.4908 & 0.6672 & 0.5191 & 0.6298 & 0.6017 \\
\hline$E_{k, 10}$ & 0.8565 & 0.8067 & 0.7437 & 0.8082 & 0.8942 & 0.9491 & 0.8380 & 0.9062 \\
\hline$E_{k, 11}$ & 0.7483 & 0.5406 & 0.5460 & 0.5413 & 0.9022 & 0.4473 & 0.8256 & 0.6656 \\
\hline$E_{k, 12}$ & 0.4792 & 0.3245 & 0.3215 & 0.3250 & 0.6325 & 0.3444 & 0.5905 & 0.5295 \\
\hline$E_{k, 13}$ & 0.3340 & 0.2141 & 0.2176 & 0.2144 & 0.4578 & 0.2772 & 0.4225 & 0.3466 \\
\hline$E_{k, 14}$ & 0.2555 & 0.1648 & 0.1631 & 0.1650 & 0.3608 & 0.4986 & 0.3379 & 0.3115 \\
\hline \multirow[t]{2}{*}{$E_{k, 15}$} & 0.2065 & 0.1279 & 0.1230 & 0.1281 & 0.3217 & 0.4377 & 0.2799 & 0.3316 \\
\hline & $E_{9, j}$ & $E_{10, j}$ & $E_{11, j}$ & $E_{12, j}$ & $E_{13, j}$ & $E_{14, j}$ & $E_{15, j}$ & \\
\hline $\mathrm{E}_{\mathbf{k}, 1}$ & 0.8543 & 0.6192 & 0.8056 & 0.7620 & 0.6979 & 0.7845 & 0.6618 & \\
\hline $\mathrm{E}_{\mathrm{k}, 2}$ & 0.7839 & 0.5166 & 0.7338 & 0.6950 & 0.6278 & 0.6723 & 0.5966 & \\
\hline $\mathbf{E}_{\mathbf{k}, 3}$ & 0.7981 & 0.5907 & 0.7465 & 0.7081 & 0.6484 & 0.7363 & 0.6161 & \\
\hline $\mathrm{E}_{\mathbf{k}, 4}$ & 0.8015 & 0.4315 & 0.7223 & 0.6923 & 0.6017 & 0.5903 & 0.5718 & \\
\hline $\mathrm{E}_{\mathbf{k}, 5}$ & 0.8082 & 0.2972 & 0.8971 & 0.8132 & 0.6871 & 0.4417 & 0.6563 & \\
\hline $\mathrm{E}_{\mathrm{k}, 6}$ & 0.7322 & 0.9484 & 0.7443 & 0.7046 & 0.7071 & 0.8947 & 0.6888 & \\
\hline $\mathrm{E}_{\mathbf{k}, 7}$ & 0.7309 & 0.4241 & 0.8104 & 0.7341 & 0.7082 & 0.7067 & 0.6541 & \\
\hline $\mathbf{E}_{\mathbf{k}, 8}$ & 0.6590 & 0.3670 & 0.9505 & 0.8461 & 0.8474 & 0.4468 & 0.8502 & \\
\hline$E_{k, 9}$ & 0.7477 & 0.5186 & 0.6937 & 0.6462 & 0.6509 & 0.6153 & 0.6363 & \\
\hline$E_{k, 10}$ & 0.8242 & 1.0000 & 0.9245 & 0.8610 & 0.8855 & 0.8809 & 0.8901 & \\
\hline$E_{k, 11}$ & 0.8133 & 0.4470 & 0.8555 & 0.8408 & 0.8092 & 0.7158 & 0.7597 & \\
\hline$E_{k, 12}$ & 0.5678 & 0.3441 & 0.7268 & 0.6991 & 0.6749 & 0.5365 & 0.6391 & \\
\hline$E_{k, 13}$ & 0.3933 & 0.2770 & 0.5495 & 0.4752 & 0.5377 & 0.4546 & 0.5040 & \\
\hline$E_{k, 14}$ & 0.2976 & 0.4982 & 0.4880 & 0.4076 & 0.5828 & 0.5987 & 0.5709 & \\
\hline$E_{k, 15}$ & 0.2401 & 0.4374 & 0.5198 & 0.3980 & 0.7339 & 0.5277 & 0.6945 & \\
\hline
\end{tabular}


Table 6. Fuzzy preference relations $R$.

\begin{tabular}{|c|c|c|c|c|c|c|c|c|}
\hline & $\mathbf{r}_{1, j}$ & $\mathbf{r}_{1, j}$ & $r_{3, j}$ & $\mathbf{r}_{4, j}$ & $\mathbf{r}_{5, j}$ & $r_{6, j}$ & $\mathbf{r}_{7, j}$ & $r_{8, j}$ \\
\hline$r_{k, 1}$ & 0.5000 & 0.5035 & 0.4933 & 0.4883 & 0.4627 & 0.5421 & 0.4618 & 0.4730 \\
\hline $\mathbf{r}_{k, 2}$ & 0.4965 & 0.5000 & 0.4925 & 0.4896 & 0.4278 & 0.5407 & 0.4254 & 0.4354 \\
\hline $\mathbf{r}_{k, 3}$ & 0.5067 & 0.5075 & 0.5000 & 0.4959 & 0.4352 & 0.5423 & 0.4394 & 0.4430 \\
\hline$r_{k, 4}$ & 0.5117 & 0.5104 & 0.5041 & 0.5000 & 0.4453 & 0.5784 & 0.4446 & 0.4520 \\
\hline$r_{k, 5}$ & 0.5373 & 0.5722 & 0.5648 & 0.5547 & 0.5000 & 0.6109 & 0.5043 & 0.4895 \\
\hline$r_{k, 6}$ & 0.4579 & 0.4593 & 0.4577 & 0.4216 & 0.3891 & 0.5000 & 0.4135 & 0.4312 \\
\hline $\mathbf{r}_{k, 7}$ & 0.5382 & 0.5746 & 0.5606 & 0.5554 & 0.4957 & 0.5865 & 0.5000 & 0.5303 \\
\hline $\mathbf{r}_{k, 8}$ & 0.5270 & 0.5646 & 0.5570 & 0.5480 & 0.5105 & 0.5688 & 0.4697 & 0.5000 \\
\hline$r_{k, 9}$ & 0.5668 & 0.5904 & 0.5828 & 0.5745 & 0.5378 & 0.5776 & 0.5280 & 0.5300 \\
\hline$r_{k, 10}$ & 0.4502 & 0.4564 & 0.4612 & 0.4187 & 0.3747 & 0.4999 & 0.4018 & 0.3921 \\
\hline$r_{k, 11}$ & 0.5155 & 0.5539 & 0.5404 & 0.5328 & 0.4968 & 0.5724 & 0.4908 & 0.5438 \\
\hline$r_{k, 12}$ & 0.5853 & 0.6235 & 0.6120 & 0.6042 & 0.5536 & 0.6203 & 0.5449 & 0.5817 \\
\hline $\mathbf{r}_{k, 13}$ & 0.6472 & 0.6841 & 0.6724 & 0.6619 & 0.6050 & 0.6769 & 0.6126 & 0.6592 \\
\hline $\mathrm{r}_{k, 14}$ & 0.6637 & 0.6866 & 0.6825 & 0.6567 & 0.5715 & 0.6333 & 0.6183 & 0.5899 \\
\hline \multirow[t]{2}{*}{$\mathbf{r}_{\mathrm{k}, 15}$} & 0.6343 & 0.6600 & 0.6499 & 0.6368 & 0.5952 & 0.5987 & 0.6004 & 0.6254 \\
\hline & $\mathbf{r}_{9, j}$ & $\mathbf{r}_{10, j}$ & $\mathbf{r}_{11, j}$ & $\mathbf{r}_{12, j}$ & $\mathbf{r}_{13, j}$ & $\mathbf{r}_{14, j}$ & $\mathbf{r}_{15, j}$ & \\
\hline $\mathbf{r}_{k, 1}$ & 0.4332 & 0.5498 & 0.4845 & 0.4147 & 0.3528 & 0.3363 & 0.3657 & \\
\hline$r_{k, 2}$ & 0.4096 & 0.5436 & 0.4461 & 0.3765 & 0.3159 & 0.3134 & 0.3400 & \\
\hline $\mathbf{r}_{k, 3}$ & 0.4172 & 0.5388 & 0.4478 & 0.3880 & 0.3276 & 0.3175 & 0.3501 & \\
\hline$r_{k, 4}$ & 0.4255 & 0.5813 & 0.4463 & 0.3958 & 0.3381 & 0.3433 & 0.3632 & \\
\hline$r_{k, 5}$ & 0.4622 & 0.6253 & 0.5032 & 0.4464 & 0.3950 & 0.4285 & 0.4048 & \\
\hline$r_{k, 6}$ & 0.4224 & 0.5001 & 0.4276 & 0.3797 & 0.3231 & 0.3667 & 0.4013 & \\
\hline $\mathbf{r}_{k, 7}$ & 0.4720 & 0.5982 & 0.5092 & 0.4551 & 0.3874 & 0.3817 & 0.3996 & \\
\hline $\mathbf{r}_{\mathbf{k}, 8}$ & 0.4700 & 0.6079 & 0.4562 & 0.4183 & 0.3408 & 0.4101 & 0.3746 & \\
\hline$r_{k, 9}$ & 0.5000 & 0.5903 & 0.5366 & 0.4761 & 0.3996 & 0.1792 & 0.4031 & \\
\hline$r_{k, 10}$ & 0.4097 & 0.5000 & 0.4036 & 0.3592 & 0.3017 & 0.3684 & 0.3746 & \\
\hline$r_{k, 11}$ & 0.4634 & 0.5964 & 0.5000 & 0.4567 & 0.3951 & 0.4088 & 0.4292 & \\
\hline$r_{k, 12}$ & 0.5239 & 0.6408 & 0.5433 & 0.5000 & 0.4244 & 0.4489 & 0.4495 & \\
\hline$r_{k, 13}$ & 0.6004 & 0.6983 & 0.6049 & 0.5756 & 0.5000 & 0.5435 & 0.5783 & \\
\hline$r_{k, 14}$ & 0.8208 & 0.6316 & 0.5912 & 0.5511 & 0.4565 & 0.5000 & 0.9109 & \\
\hline$r_{k, 15}$ & 0.5969 & 0.6254 & 0.5708 & 0.5505 & 0.4217 & 0.8717 & 0.5000 & \\
\hline
\end{tabular}

Table 7. Consistent fuzzy preference relations $A$.

\begin{tabular}{ccccccccc}
\hline & $\mathbf{a}_{\mathbf{1}, \mathbf{j}}$ & $\mathbf{a}_{\mathbf{2}, \mathbf{j}}$ & $\mathbf{a}_{\mathbf{3}, \mathbf{j}}$ & $\mathbf{a}_{\mathbf{4}, \mathbf{j}}$ & $\mathbf{a}_{\mathbf{5}, \mathbf{j}}$ & $\mathbf{a}_{\mathbf{6}, \mathbf{j}}$ & $\mathbf{a}_{\mathbf{7}, \mathbf{j}}$ & $\mathbf{a}_{\mathbf{8}, \mathbf{j}}$ \\
\hline $\mathbf{a}_{\mathbf{k}, \mathbf{1}}$ & 0.5000 & 0.5110 & 0.5069 & 0.5000 & 0.4737 & 0.5182 & 0.4756 & 0.4835 \\
$\mathbf{a}_{\mathbf{k}, \mathbf{2}}$ & 0.4890 & 0.5000 & 0.4959 & 0.4890 & 0.4626 & 0.5072 & 0.4646 & 0.4725 \\
$\mathbf{a}_{\mathbf{k}, \mathbf{3}}$ & 0.4931 & 0.5041 & 0.5000 & 0.4931 & 0.4668 & 0.5113 & 0.4687 & 0.4766 \\
$\mathbf{a}_{\mathbf{k}, \mathbf{4}}$ & 0.5000 & 0.5110 & 0.5069 & 0.5000 & 0.4736 & 0.5182 & 0.4756 & 0.4835 \\
$\mathbf{a}_{\mathbf{k}, \mathbf{5}}$ & 0.5263 & 0.5374 & 0.5332 & 0.5264 & 0.5000 & 0.5446 & 0.5020 & 0.5099 \\
$\mathbf{a}_{\mathbf{k}, \mathbf{6}}$ & 0.4818 & 0.4928 & 0.4887 & 0.4818 & 0.4554 & 0.5000 & 0.4574 & 0.4653 \\
$\mathbf{a}_{\mathbf{k}, \mathbf{7}}$ & 0.5244 & 0.5354 & 0.5313 & 0.5244 & 0.4980 & 0.5426 & 0.5000 & 0.5079 \\
$\mathbf{a}_{\mathbf{k}, \mathbf{8}}$ & 0.5165 & 0.5275 & 0.5234 & 0.5165 & 0.4902 & 0.5347 & 0.4921 & 0.5000 \\
$\mathbf{a}_{\mathbf{k}, \mathbf{9}}$ & 0.5254 & 0.5364 & 0.5323 & 0.5254 & 0.4991 & 0.5436 & 0.5010 & 0.5089 \\
$\mathbf{a}_{\mathbf{k} \mathbf{1 0}}$ & 0.4754 & 0.4864 & 0.4823 & 0.4754 & 0.4490 & 0.4936 & 0.4510 & 0.4589 \\
$\mathbf{a}_{\mathbf{k}, \mathbf{1 1}}$ & 0.5238 & 0.5348 & 0.5307 & 0.5239 & 0.4975 & 0.5421 & 0.4994 & 0.5073 \\
$\mathbf{a}_{\mathbf{k}, \mathbf{1 2}}$ & 0.5498 & 0.5608 & 0.5567 & 0.5498 & 0.5235 & 0.5680 & 0.5254 & 0.5333 \\
$\mathbf{a}_{\mathbf{k}, \mathbf{1 3}}$ & 0.5878 & 0.5988 & 0.5947 & 0.5878 & 0.5615 & 0.6060 & 0.5634 & 0.5713 \\
$\mathbf{a}_{\mathbf{k}, \mathbf{1 4}}$ & 0.5686 & 0.5796 & 0.5755 & 0.5686 & 0.5422 & 0.5868 & 0.5442 & 0.5521 \\
$\mathbf{a}_{\mathbf{k}, \mathbf{1 5}}$ & 0.5533 & 0.5644 & 0.5602 & 0.5534 & 0.5270 & 0.5716 & 0.5290 & 0.5369 \\
\hline
\end{tabular}


Table 7. Cont.

\begin{tabular}{cccccccc}
\hline & $\mathbf{a}_{\mathbf{9}, \mathbf{j}}$ & $\mathbf{a}_{\mathbf{1 0 , j}}$ & $\mathbf{a}_{\mathbf{1 1}, \mathbf{j}}$ & $\mathbf{a}_{\mathbf{1 2} \mathbf{j}}$ & $\mathbf{a}_{\mathbf{1 3 , j}}$ & $\mathbf{a}_{\mathbf{1 4}, \mathbf{j}}$ & $\mathbf{a}_{\mathbf{1 5}, \mathbf{j}}$ \\
\hline $\mathbf{a}_{\mathbf{k}, \mathbf{1}}$ & 0.4746 & 0.5246 & 0.4762 & 0.4502 & 0.4122 & 0.4314 & 0.4467 \\
$\mathbf{a}_{\mathbf{k}, \mathbf{2}}$ & 0.4636 & 0.5136 & 0.4652 & 0.4392 & 0.4012 & 0.4204 & 0.4356 \\
$\mathbf{a}_{\mathbf{k}, \mathbf{3}}$ & 0.4677 & 0.5177 & 0.4693 & 0.4433 & 0.4053 & 0.4245 & 0.4398 \\
$\mathbf{a}_{\mathbf{k}, \mathbf{4}}$ & 0.4746 & 0.5246 & 0.4762 & 0.4502 & 0.4122 & 0.4314 & 0.4466 \\
$\mathbf{a}_{\mathbf{k}, \mathbf{5}}$ & 0.5009 & 0.5510 & 0.5025 & 0.4765 & 0.4385 & 0.4578 & 0.4730 \\
$\mathbf{a}_{\mathbf{k}, \mathbf{6}}$ & 0.4564 & 0.5064 & 0.4579 & 0.4320 & 0.3940 & 0.4132 & 0.4284 \\
$\mathbf{a}_{\mathbf{k}, \mathbf{7}}$ & 0.4990 & 0.5490 & 0.5006 & 0.4746 & 0.4366 & 0.4558 & 0.4710 \\
$\mathbf{a}_{\mathbf{k}, \mathbf{8}}$ & 0.4911 & 0.5411 & 0.4927 & 0.4667 & 0.4287 & 0.4479 & 0.4631 \\
$\mathbf{a}_{\mathbf{k}, \mathbf{9}}$ & 0.5000 & 0.5500 & 0.5016 & 0.4756 & 0.4376 & 0.4568 & 0.4721 \\
$\mathbf{a}_{\mathbf{k}, \mathbf{1 0}}$ & 0.4500 & 0.5000 & 0.4515 & 0.4256 & 0.3876 & 0.4068 & 0.4220 \\
$\mathbf{a}_{\mathbf{k}, \mathbf{1 1}}$ & 0.4984 & 0.5485 & 0.5000 & 0.4740 & 0.4360 & 0.4552 & 0.4705 \\
$\mathbf{a}_{\mathbf{k}, \mathbf{1 2}}$ & 0.5244 & 0.5744 & 0.5260 & 0.5000 & 0.4620 & 0.4812 & 0.4965 \\
$\mathbf{a}_{\mathbf{k}, \mathbf{1 3}}$ & 0.5624 & 0.6124 & 0.5640 & 0.5380 & 0.5000 & 0.5192 & 0.5345 \\
$\mathbf{a}_{\mathbf{k}, \mathbf{1 4}}$ & 0.5432 & 0.5932 & 0.5448 & 0.5188 & 0.4808 & 0.5000 & 0.5152 \\
$\mathbf{a}_{\mathbf{k}, \mathbf{1 5}}$ & 0.5280 & 0.5780 & 0.5295 & 0.5035 & 0.4655 & 0.4848 & 0.5000 \\
\hline
\end{tabular}

Table 8. Ranking of 15 listed banks.

\begin{tabular}{ccc}
\hline Banks & Weight & Rank \\
\hline Bank of China & 0.0694683 & 6 \\
Construction Bank of China & 0.0709367 & 3 \\
Industrial and Commercial Bank of China & 0.0703883 & 4 \\
Agricultural Bank of China & 0.0694709 & 5 \\
Industrial Bank Co., Ltd & 0.0659563 & 11 \\
Bank of Communications & 0.0718976 & 2 \\
Shanghai Pudong Development Bank & 0.0662167 & 9 \\
Ping An Bank Co., Ltd & 0.0672700 & 7 \\
China Minsheng Bank & 0.0660825 & 10 \\
China Merchants Bank & 0.0727509 & 1 \\
China Citic Bank & 0.0662932 & 8 \\
China Everbright Bank & 0.0628283 & 12 \\
Huaxia Bank & 0.0577616 & 15 \\
Beijing Bank & 0.0603234 & 14 \\
Shanghai Bank & 0.0623554 & 13 \\
\hline
\end{tabular}

We can obtain the ranking of all listed banks:

$$
\begin{gathered}
D M U_{10}>D M U_{6}>D M U_{2}>D M U_{3}>D M U_{4}>D M U_{1}>D M U_{8}>D M U_{11} \\
>D M U_{7}>D M U_{9}>D M U_{5}>D M U_{12}>D M U_{15}>D M U_{14}>D M U_{13} .
\end{gathered}
$$

From the ranking in Table 7, we find that the optimal DMU is selected as $D M U_{10}$. It is obvious that China Merchants Bank is the listed bank with the best operation performance. However, according to self-efficiency of all listed banks, we derive the following ranking:

$$
\begin{gathered}
D M U_{10}=D M U_{6}=D M U_{2}>D M U_{3}>D M U_{1}>D M U_{4}>D M U_{8}>D M U_{11} \\
>D M U_{5}>D M U_{7}>D M U_{9}>D M U_{12}>D M U_{15}>D M U_{14}>D M U_{13} .
\end{gathered}
$$

We cannot select the best bank in accordance with the above ranking result. In addition, the ranking result obtained from the developed method is different from that derived by traditional DEA approach. The stochastic DEA cross-efficiency with ordinal variable method effectively distinguishes all listed banks and yields the whole ranking. Meanwhile, it can greatly avoid impact of subjectivity of experts and strengthen the discrimination power. Therefore, our proposed method is reliable and valid compared with the traditional DEA method. 


\section{Conclusions}

In this article, we proposed MADM method based on stochastic DEA cross-efficiency with ordinal variable and applied it to evaluating operation performance of sustainable development of 15 listed banks in China. First, we obtained self-efficiency scores of each bank and optimal attribute weights by solving stochastic DEA model. Then, we calculated cross-efficiency of all listed banks by utilizing the optimal attribute weights. Subsequently, according to self-efficiency and cross-efficiency of whole banks, we constructed corresponding FPRs and consistent FPRs. Finally, we used the row wise summation technique to derive the priority weight vector of all listed banks. Based on the unique ranking order of whole banks, we selected the best one.

In summary, the developed MADM method based on stochastic DEA cross-efficiency with ordinal variable is proved effective for evaluating MADM problems. The advantages of this approach are presented as follows. One is that it simultaneously incorporates stochastic variable and ordinal variable, which is considerably consistent with actual circumstances. The other is that it takes cross-efficiency into account in evaluation process of MADM problems and constructs corresponding FPRs, which guarantee the objectivity and persuasion of evaluation results. Furthermore, it requires no assumption of the functional relationships between multiple inputs and multiple outputs of alternatives, and all evaluation results come from original data. However, our method exists some limitations. One is that the stochastic output variable is assumed to follow standard normal distribution and directly applied to the stochastic DEA model. Standard normal distribution is one of the many probability distributions, we need to examine whether other distributions can be used for stochastic DEA model. Another is that the value of parameters $\alpha$ and $\beta$ is predefined. We have no mature approach to find the optimal value of parameters $\alpha$ and $\beta$.

In the future research, we intend to design an integrated method that combines DEA with multiplicative FPRs to handle performance evaluation of MADM problems. Another is that we need to consider the relation among different types of variables in MADM problems and extend existing DEA methods to address it.

Author Contributions: All of the authors contributed to this research. F.J. and J.L. provided case and idea. H.C. and M.F. were responsible for data collection and analysis. J.L. and C.W. provided revised advice. M.F. wrote the first draft of the article. All authors have read and agreed to the published version of the manuscript.

Funding: The work was supported by the National Natural Science Foundation of China (Nos. 71901001, 71501002, 71871001, 71771001), the Construction Fund for Scientific Research Conditions of Introducing Talents in Anhui University (No. S020118002/085), the Key Research Project of Humanities and Social Sciences in Colleges and Universities of Anhui Province (Nos. SK2019A0013, SK2018A0605), the Humanities and Social Sciences Planning Project of the Ministry of Education (No. 20YJAZH066), Project of Anhui Ecological and Economic Development Research Center, the Natural Science Foundation of Hefei University (No. 17ZR06ZDA), and the Natural Science Foundation for Distinguished Young Scholars of Anhui Province (No. 1908085J03).

Conflicts of Interest: The authors declare no conflicts of interest.

\section{References}

1. Hak, T.; Janoušková, S.; Moldan, B. Sustainable Development Goals: A need for relevant indicators. Ecol. Indic. 2016, 60, 565-573. [CrossRef]

2. Aleksic, A.; Braje, I.N.; Jelavić, S.R. Creating Sustainable Work Environments by Developing Cultures that Diminish Deviance. Sustain. 2019, 11, 7031. [CrossRef]

3. Goodland, R. Environmental sustainability in agriculture: Diet matters. Ecol. Econ. 1997, 23, 189-200. [CrossRef]

4. Munir, W.; Gallagher, K.P. Scaling Up for Sustainable Development: Benefits and Costs of Expanding and Optimizing Balance Sheet in the Multilateral Development Banks. J. Int. Dev. 2020, 32, 222-243. [CrossRef]

5. Xue, J.; Zhu, D.; Zhao, L.; Wang, C.; Li, H. Redundancy Identification and Optimization Scheme of Branches for Sustainable Operation of Commercial Banks. Sustain. 2019, 11, 4111. [CrossRef]

6. Jiang, H.; Han, L. Does Income Diversification Benefit the Sustainable Development of Chinese Listed Banks? Analysis Based on Entropy and the Herfindahl-Hirschman Index. Entropy 2018, 20, 255. [CrossRef] 
7. Xiao, P.; Wu, Q.; Li, H.; Zhou, L.; Tao, Z.; Liu, J. Novel Hesitant Fuzzy Linguistic Multi-Attribute Group Decision Making Method Based on Improved Supplementary Regulation and Operational Laws. IEEE Access 2019, 7, 32922-32940. [CrossRef]

8. Khameneh, A.Z.; Kılıçman, A.; Kılıçman, A. Multi-attribute decision-making based on soft set theory: A systematic review. Soft Comput. 2018, 23, 6899-6920. [CrossRef]

9. Bernroider, E.; Stix, V. A method using weight restrictions in data envelopment analysis for ranking and validity issues in decision making. Comput. Oper. Res. 2007, 34, 2637-2647. [CrossRef]

10. Yeh, C.H. The selection of multi-attribute decision making methods for scholarship student selection. Int. J. Sel. Assess. 2003, 11, 289-296. [CrossRef]

11. Kulak, O.; Kahraman, C. Fuzzy multi-attribute selection among transportation companies using axiomatic design and analytic hierarchy process. Inf. Sci. 2005, 170, 191-210. [CrossRef]

12. Barzilai, J.; Lootsma, F.A. Power relations and group aggregation in the multiplicative AHP and SMART. J. Multi-Criteria Decis. Anal. 1997, 6, 155-165. [CrossRef]

13. Xu, Z.; Zhang, X. Hesitant fuzzy multi-attribute decision making based on TOPSIS with incomplete weight information. Knowl.-Based Syst. 2013, 52, 53-64. [CrossRef]

14. Ho, W.; Xu, X.; Dey, P. Multi-criteria decision making approaches for supplier evaluation and selection: A literature review. Eur. J. Oper. Res. 2010, 202, 16-24. [CrossRef]

15. Liu, X.; Chu, J.; Yin, P.; Sun, J. DEA cross-efficiency evaluation considering undesirable output and ranking priority: A case study of eco-efficiency analysis of coal-fired power plants. J. Clean. Prod. 2017, 142, 877-885. [CrossRef]

16. Hatami-Marbini, A.; Tavana, M.; Agrell, P.J.; Lotfi, F.H.; Beigi, Z.G. A common-weights DEA model for centralized resource reduction and target setting. Comput. Ind. Eng. 2015, 79, 195-203. [CrossRef]

17. Li, Y.; Lei, X.; Dai, Q.; Liang, L. Performance evaluation of participating nations at the 2012 London Summer Olympics by a two-stage data envelopment analysis. Eur. J. Oper. Res. 2015, 243, 964-973. [CrossRef]

18. An, Q.; Chen, H.; Xiong, B.; Wu, J.; Liang, L. Target intermediate products setting in a two-stage system with fairness concern. Omega 2017, 73, 49-59. [CrossRef]

19. Emrouznejad, A.; Parker, B.R.; Tavares, G. Evaluation of research in efficiency and productivity: A survey and analysis of the first 30 years of scholarly literature in DEA. Socio-Econ. Plan. Sci. 2008, 42, 151-157. [CrossRef]

20. Karsak, E.E.; Dursun, M. An integrated supplier selection methodology incorporating QFD and DEA with imprecise data. Expert Syst. Appl. 2014, 41, 6995-7004. [CrossRef]

21. Jin, J.; Zhou, D.; Zhou, P. Measuring environmental performance with stochastic environmental DEA: The case of APEC economies. Econ. Model. 2014, 38, 80-86. [CrossRef]

22. Chen, L.; Lai, F.; Wang, Y.-M.; Huang, Y.; Wu, F.-M. A two-stage network data envelopment analysis approach for measuring and decomposing environmental efficiency. Comput. Ind. Eng. 2018, 119, 388-403. [CrossRef]

23. Toloo, M.; Nalchigar, S. A new DEA method for supplier selection in presence of both cardinal and ordinal data. Expert Syst. Appl. 2011, 38, 14726-14731. [CrossRef]

24. Dobos, I.; Vörösmarty, G. Inventory-related costs in green supplier selection problems with Data Envelopment Analysis (DEA). Int. J. Prod. Econ. 2019, 209, 374-380. [CrossRef]

25. Wu, M.-Q.; Zhang, C.-H.; Liu, X.-N.; Fan, J.-P. Green Supplier Selection Based on DEA Model in Interval-Valued Pythagorean Fuzzy Environment. IEEE Access 2019, 7, 108001-108013. [CrossRef]

26. Shuai, J.-J.; Wu, W.-W. Evaluating the influence of E-marketing on hotel performance by DEA and grey entropy. Expert Syst. Appl. 2011, 38, 8763-8769. [CrossRef]

27. Liu, W.; Wang, Y.-M.; Lyu, S. The upper and lower bound evaluation based on the quantile efficiency in stochastic data envelopment analysis. Expert Syst. Appl. 2017, 85, 14-24. [CrossRef]

28. Charnes, A.; Cooper, W.W. Deterministic Equivalents for Optimizing and Satisficing under Chance Constraints. Oper. Res. 1963, 11, 18-39. [CrossRef]

29. Khodabakhshi, M.; Asgharian, M.; Gregoriou, G.N. An input-oriented super-efficiency measure in stochastic data envelopment analysis: Evaluating chief executive officers of US public banks and thrifts. Expert Syst. Appl. 2010, 37, 2092-2097. [CrossRef]

30. Sengupta, J.K. Data envelopment analysis for efficiency measurement in the stochastic case. Comput. Oper. Res. 1987, 14, 117-129. [CrossRef]

31. Sueyoshi, T. Stochastic DEA for restructure strategy: An application to a Japanese petroleum company. Omega 2000, 28, 385-398. [CrossRef] 
32. Wu, C.; Li, Y.; Liu, Q.; Wang, K. A stochastic DEA model considering undesirable outputs with weak disposability. Math. Comput. Model. 2013, 58, 980-989. [CrossRef]

33. Li, F.; Zhu, Q.; Chen, Z.; Xue, H. A balanced data envelopment analysis cross-efficiency evaluation approach. Expert Syst. Appl. 2018, 106, 154-168. [CrossRef]

34. Roll, Y.; Cook, W.D.; Golany, B. Controlling Factor Weights in Data Envelopment Analysis. IIE Trans. 1991, 23, 2-9. [CrossRef]

35. Kao, C.; Hung, H.-T. Data envelopment analysis with common weights: The compromise solution approach. J. Oper. Res. Soc. 2005, 56, 1196-1203. [CrossRef]

36. Charnes, A.; Cooper, W.; Huang, Z.; Sun, D. Polyhedral Cone-Ratio DEA Models with an illustrative application to large commercial banks. J. Econ. 1990, 46, 73-91. [CrossRef]

37. Andersen, P.; Petersen, N.C. A Procedure for Ranking Efficient Units in Data Envelopment Analysis. Manag. Sci. 1993, 39, 1261-1264. [CrossRef]

38. Sexton, T.R.; Silkman, R.H.; Hogan, A.J. Data envelopment analysis: Critique and extensions. New Dir. Program Eval. 1986, 1986, 73-105. [CrossRef]

39. Doyle, J.; Green, R. Efficiency and cross-efficiency in DEA: Derivations, meanings and uses. J. Oper. Res. Soc. 1994, 45, 567-578. [CrossRef]

40. Liu, J.P.; Fang, S.C.; Chen, H.Y. Multiplicative data envelopment analysis cross-efficiency and stochastic weight space acceptability analysis for group decision making with interval multiplicative preference relations. Inf. Sci. 2020, 514, 319-332. [CrossRef]

41. Liu, J.; Song, J.; Xu, Q.; Tao, Z.; Chen, H. Group decision making based on DEA cross-efficiency with intuitionistic fuzzy preference relations. Fuzzy Optim. Decis. Mak. 2018, 18, 345-370. [CrossRef]

42. Liu, H.-H.; Song, Y.-Y.; Yang, G.-L. Cross-efficiency evaluation in data envelopment analysis based on prospect theory. Eur. J. Oper. Res. 2019, 273, 364-375. [CrossRef]

43. Jradi, S.; Ruggiero, J. Stochastic data envelopment analysis: A quantile regression approach to estimate the production frontier. Eur. J. Oper. Res. 2019, 278, 385-393. [CrossRef]

44. Charnes, A.; Cooper, W.; Rhodes, E. Measuring the efficiency of decision making units. Eur. J. Oper. Res. 1978, 2, 429-444. [CrossRef]

45. Wu, D.; Lee, C.-G. Stochastic DEA with ordinal data applied to a multi-attribute pricing problem. Eur. J. Oper. Res. 2010, 207, 1679-1688. [CrossRef]

46. Wu, D. Performance evaluation: An integrated method using data envelopment analysis and fuzzy preference relations. Eur. J. Oper. Res. 2009, 194, 227-235. [CrossRef]

(C) 2020 by the authors. Licensee MDPI, Basel, Switzerland. This article is an open access article distributed under the terms and conditions of the Creative Commons Attribution (CC BY) license (http://creativecommons.org/licenses/by/4.0/). 



\title{
Digital Financial Inclusion and Farmers' Vulnerability to Poverty: Evidence from Rural China
}

\author{
Xue Wang * and Guangwen He \\ College of Economics and Management, China Agricultural University, Beijing 100083, China; \\ hegwen@cau.edu.cn \\ * Correspondence: wangxue078@126.com; Tel.: +86-010-6273-8580 or +86-188-1170-5855
}

Received: 10 January 2020; Accepted: 17 February 2020; Published: 23 February 2020

\begin{abstract}
Access to finance is often cited as a key factor for sustainable poverty alleviation, but expanding access to the poor remains an important challenge for financial institutions. Much hope has, therefore, been placed in the transformative power of digital financial inclusion. However, evidence on the relationship between digital financial inclusion and poverty is limited. This paper is one of the first attempts to study the effects of digital financial inclusion on farmers' vulnerability to poverty in China, using survey data on 1900 rural households. Vulnerability to poverty, here defined as the likelihood of poverty in the future, is measured by the Asset-Based Vulnerability model. In our survey, the proportion of farmers using digital financial services is $35.63 \%$. Our estimations show that farmers' use of digital financial services have positive effects on reduction in their vulnerability. We also find that such effects rely mainly on improvement in farmers' ability to cope with risk, that is, alleviating their vulnerability induced by risk. Further investigation reveals that digital financial services provided by ICT companies have a larger impact on farmers' vulnerability than that provided by traditional banks. The lessons learned from China's digital financial inclusion is valuable for other developing countries where financial exclusion looms large.
\end{abstract}

Keywords: digital financial inclusion; risk-coping ability; vulnerability to poverty; instrumental variable estimation

\section{Introduction}

Expanding access to finance is often cited as one of the most important poverty alleviation policies [1]. However, it is well recognized that financial institutions face challenges in expanding access to the poor [2]. The government in China, as in many other developing counties, has actively employed numerous policies to improve financial services in rural areas [3], often with disappointing results [4]. Despite the variety of financial institutions—-such as Rural Commercial Banks, Agricultural Banks, Postal Savings Banks, Village and Township Banks, and Credit-Only Companies-in Chinese rural areas [5], as pointed out by He et al. [6], farmers remain underserved or excluded by the traditional banking sector because of the fundamental questions of high transaction cost, information asymmetry, and the shortage of collateral.

Much hope has, therefore, been placed in the growth of financial digital innovations. The term "digital financial inclusion", defined as digital access to and use of formal financial services by underserved and excluded populations [7], has attracted attention from many researchers and policy makers. In particular, in 2016, when China was the leader of the G20, the G20 Global Partnership for Financial Inclusion (GPFI) developed a set of High-Level Principles (HLPs) for digital financial inclusion that encourage governments to use digital technologies to foster inclusive finance. In this decade, successful business models for digital financial inclusion have emerged worldwide, following the introduction in Kenya in 2007 of M-Pesa, a key innovation initially developed for peer-to-peer (P2P) payment-mobile money. Using SMS, it is used mainly for money transfer and cash storage, 
primarily through mobile network operators [8]. The service was first expanded to Tanzania, and then to Afghanistan, South Africa, India, Romania, and most recently to Albania.

In China, digital financial inclusion differs in important ways, using a completely different model [9]. Unlike M-Pesa, mobile financial services in China are offered mainly by third-party payment platforms based on smartphone apps, such as those offered by Alipay or WeChat. In addition, digital financial inclusion is more than a payment innovation in China, which has a broad range of digital financial products and services, such as online banks, peer-to-peer (P2P) online lending, online fund sales, online crowdfunding, and online insurance [10].

Digital finance, also known as internet finance or FinTech, has experienced explosive development in China since 2013, when Yu'ebao (Yu'ebao is an online sales platform for money market funds, which was launched by Alibaba's Ant Financial Services in June 2013), an online fund sales platform was launched, and in 2016 the term "digital financial inclusion" began to draw attention when it was formally proposed in G20 HLPs. The providers of digital financial services in China can be divided into two groups-information and communication technologies (ICT) companies providing financial services, such as Alibaba or JD.com, and financial institutions applying ICT to their traditional services, such as the E-Housekeeper services of the Agricultural Bank [11], which are both crucial to financial inclusion goals [12]. In fact, providers of such financial services have actively expanded their business in rural China, including e-commerce platforms, P2P lending platforms and traditional financial institutions (see Appendix A Table A1). The Peking University Digital Finance Development Index (IFDI) shows the rapid development of digital finance at the county level across 30 provinces of China (see Appendix A Figure A1). The IFDI measures the growth in China's digital finance with rich data from Ant Financial Services. Several recent papers find a positive correlation between digital financial inclusion and rural economic activities, such as self-employment, income growth, and improvement in income distribution $[13,14]$.

However, evidence on the relationship between digital financial inclusion and poverty reduction remains limited, especially at the micro level. This paper is one of the first attempts to provide evidence from rural China regarding the impact of digital financial inclusion on farmers' vulnerability to poverty. Vulnerability to poverty, defined here as the possibility that a household will fall below the poverty line in the future, is an ex-ante poverty indicator, while poverty represents an ex-post welfare outcome. Vulnerability to poverty is a better indicator in China, given that its government has pledged to lift all people out of poverty by 2020 , when what really matters is vulnerability of a household, that is, poverty prevention is more important than alleviation. Using survey data on 1900 rural households, this paper first applies the Asset-Based Vulnerability model to measure farmers' vulnerability to poverty, then rely on an instrumental variable (IV) and two-stage least squares (2SLS) regression to study the effects of farmers' use of digital financial services on their vulnerability to poverty. We also examine the potential channels through which digital financial services may affect farmers' vulnerability to poverty.

The remainder of the paper is organized as follows. Section 2 first reviews the existing literature and then develops our hypothesis. Section 3 presents the research design. Section 4 reports the estimate results including the endogeneity tests. Section 5 presents additional robustness checks, and Section 6 concludes with a brief discussion of policy implications.

\section{Literature Review and Hypothesis Development}

\subsection{Literature Review for Vulnerability to Poverty}

The concept "vulnerability to poverty" was initially coined by the World Bank [15], which defined it as the possibility that a household will fall below the poverty line in the future. Poverty is an ex-post welfare condition, whereas vulnerability is an ex-ante poverty indicator of a household's ability to cope with risks $[16,17]$. In fact, the expanding literature on vulnerability has produced a multitude of definitions and corresponding approaches [18], including vulnerability as expected poverty (VEP), vulnerability as low expected utility (VEU), and vulnerability as uninsured exposure 
to risk (VER), among which the VEP approach is dominant [17-19]. However, as noted by Carter and Barrett [20], the VEP approach, as well as many other approaches, fails to unpack the nature and sources of vulnerability.

This paper thus adopts the Asset-Based Vulnerability approach developed by Chiwaula et al. [18], who combined the VEP approach and measured farmers' vulnerability based on their asset endowments. This approach allows us to decompose vulnerability into structural vulnerability and risk-induced vulnerability and thereby identify the sources of vulnerability. Structural vulnerability refers to a situation in which a household moves in and out of poverty in the future mainly because of changes in the level of assets (e.g., land endowment), while risk-induced vulnerability is when a household moves in and out of poverty because of positive or negative risk events [19], such as excessive rainfall or drought. It is important to distinguish structural from risk-induced vulnerability, which allows us to establish whether the farmers' vulnerability is driven by structural factors or risk events.

\subsection{Literature Review on Digital Financial Inclusion}

After the important stages of microcredit, microfinance and financial inclusion, the development of financial inclusion has arrived at a fourth stage: digital financial inclusion, which stresses the importance of ICT in expanding the scale and deepening the reach of financial services [7]. As the first stage, microcredit was coined initially to refer to institutions, such as the Grameen Bank of Bangladesh, that were founded to provide small loans to the poor [4]. By the early 1990s, the term "microcredit" was pushed to a much broader concept "microfinance," meaning the supply of a range of financial services, such as savings, mutual funds, insurance, loans, and so on [21]. Another important departure has involved the shift from "microfinance" to "financial inclusion," which was put forward by United Nations and CGAP in 2006. Historically, traditional financial institutions like Grameen Bank developed microcredit, microfinance and financial inclusion based on manual and field-based operation, a structure that weakened their efficiency in serving the poor [22]. Relying on ICT, the development of financial inclusion comes to a fourth stage: digital financial inclusion, a radical innovation that can be a changer for the population at the bottom of the pyramid [7,11]. As noted by Hart and Prahalad [22], doing business with population at the bottom of the pyramid requires radical innovations in technology and business models.

Digital financial inclusion refers broadly as digital access to and use of formal financial services by underserved and excluded populations [7]. This term began to attract attention mainly due to the success of M-PESA, a payment technology innovation introduced in Kenya in 2007 [8]. In Kenya, mobile money is used mainly for digital payments [23]. Several recent papers also provide some evidence on positive [8,24] or negative [23] correlations between this payment tool and economic activity. Digital financial inclusion in China, however, represents more than a payment instrument. It has been recognized as a new financial format, which includes three basic business: digital payments, digital investments, and digital financing.

The existing literature pointes out several important differences between traditional and digital financial inclusion. First, digital financial services greatly reduce transaction costs in rural areas because of their lower marginal cost $[10,12,25]$. Relying on ICT, such financial services need not establish physical outlets. Although new digital technologies often face higher initial costs to establish digital system, their marginal cost then tends toward zero with the increase of business volume $[25,26]$. Second, digital finance may overcome information asymmetry by developing ICT [27,28]. Online products and services, such as online shopping platforms and online social networks, produce a large amount of information on individuals [27], which will alleviate information asymmetry between individuals and financial institutions [13]. Finally, digital technology may improve access to credit for farmers who lack collateral [29]. Based on big data analysis, cloud computing, and other technologies, digital finance, such as P2P lending, uses new credit score mechanisms to create collateral-free loan products [25]. In summary, digital financial inclusion is considered a great method for alleviating financial constraints faced by farmers, especially those who are vulnerable [26]. In fact, the digital 
financial inclusion movement has made inroads around the world in the past decade. For instance, Grameen Bank, as the best-known microfinance institution, has broadly developed online business model to automate its operation [22].

\subsection{Hypotheses Development}

Based on the nature and sources of vulnerability to poverty, as mentioned above, the literature notes that farmers' vulnerability can be directly decomposed into two parts: structural vulnerability, in which households remain at a low level of consumption in the future because they have low asset endowments, and risk-induced vulnerability, in which households face consumption fluctuations in the future because of stochastic events. Figure 1 motivates our research by revealing these two channels through which digital financial inclusion affects farmers' vulnerability.

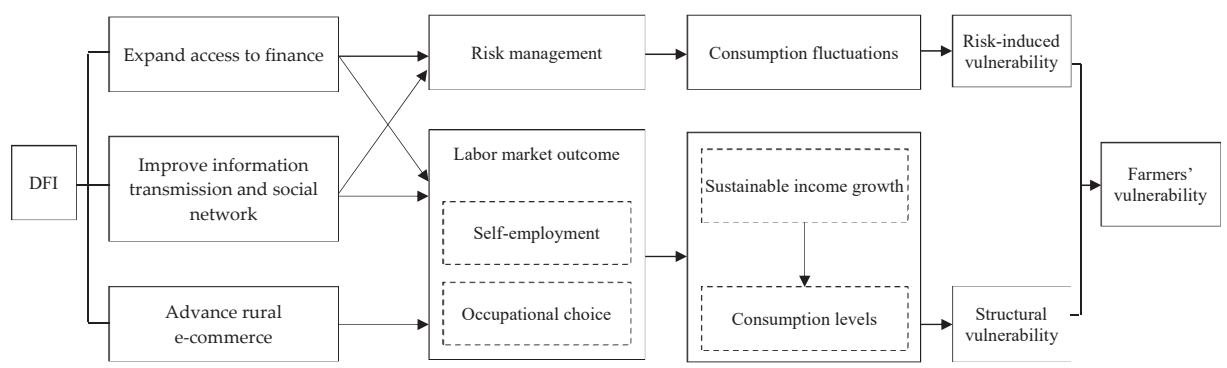

Figure 1. Logit Relationship between Digital Financial Inclusion (DFI) and Farmers' Vulnerability.

Access to digital financial services provides farmers with a more proactive way to cope with risks and thereby reduces fluctuations in their consumption and vulnerability. The intuition for this "primary impact channel" is first related to digital financing, through which farmers who lack collateral can expand access to formal loans based on big data analysis. Internet technology enables a rich information database to be established rapidly. The database in rural China includes three categories: direct credit data collected by traditional banks, information on individuals collected from online platforms, such as e-commerce platform and online social networks, and public information collected by governments, such as tax and social security records. Second, digital technology, as a way of lowering participation costs, makes it easier for farmers to manage their cash flows and savings and thereby improve their ability to cope with risk [30]. In addition, through associated internet-based financial services, farmers can draw on a wider network of social support in response to negative shocks, because they can receive more remittances more quickly from more people [31].

Farmers with higher use of digital finance are more likely to achieve sustainable income growth and consumption improvement through labor market outcomes, a "secondary impact channel". First, having a smaller asset endowment is often cited as the key reason the poor remain poor, especially small farmers. Thus, access to finance plays a fairly important role in both initial investment in production activities and their subsequent expansion [32]. Digital financing, as He and Li [14] noted, enables Chinese farmers to transform and expand their production activities. In addition, the use of digital financial services may improve information transmission and expand social networks, both of which are key factors for small farmers. Second, as the Klapper and Singer [31] reported, digital finance is a critical factor in advancing the expansion of e-commerce, which creates more opportunities and changes occupational choices. It allows farmers to move out of agriculture and into business and thereby obtain sustainable income growth [33].

Based on the theoretical analysis, our hypotheses can therefore be stated as follows:

H1: Farmers' use of digital financial services has positive effects on alleviating their vulnerability to poverty. 
H2a: Risk management is a potential channel through which digital financial services affect fluctuations in consumption and thereby alleviate farmers' vulnerability induced by risk events, that is, risk-induced vulnerability.

H2b: The labor market outcome is a potential channel through which digital financial services affect consumption levels and thereby alleviate farmers' vulnerability induced by structural factors, that is, structural vulnerability.

\section{Research Design}

\subsection{Sample and Data}

In this paper, we rely on the China Rural Financial Inclusion Survey Data 2018, conducted by the China Agricultural University, which includes a set of questions on the use of digital financial services. The data were collected through a stratified random sample survey of 1979 rural households through face-to-face interviews in July 2018. The survey was designed and conducted as follows: first, we selected Shandong, Henan and Guizhou provinces in the eastern, central, and western regions of China, respectively; second, in each province, we chose three counties based on their level of gross domestic product per capita; third, in each county, we chose three townships based on their level of economic development; and, fourth, in every township, we randomly chose two villages, in which the number of farm households is between 30 and 50. After deleting questionnaires with missing data, we ended up with 1900 valid samples for analysis (see Table 1).

Table 1. Districts studied and sample size.

\begin{tabular}{ccccc}
\hline Province & Shandong & Henan & Guizhou & Total \\
\hline Counties & 3 & 3 & 3 & 9 \\
Townships (three per county) & 9 & 9 & 9 & 27 \\
Villages (two per township) & 18 & 18 & 18 & 54 \\
Farmers in all villages & 666 & 691 & 543 & 1900 \\
\hline
\end{tabular}

\subsection{Variable Definition and Measurement}

\subsubsection{Measuring Farmers' Use of Digital Financial Services}

Payment, investment, and financing are key aspects of digital financial inclusion. Therefore, following Guo et al. [10] and He and Li [14], we measure farmers' use of digital financial services in terms of digital payments, digital investments, and digital financing. The corresponding survey questions are shown in Table 2.

Table 2. Questions and possible responses about the use of digital financial services.

\begin{tabular}{cl}
\hline Type & \multicolumn{1}{c}{ Questions and Possible Responses } \\
\hline \multirow{2}{*}{ Payment } & $\begin{array}{l}\text { Question 1: Which digital payment methods have you used? } \\
\text { a. online banking transfer; b. mobile banking transfer; c. Alipay; d. Wechat pay; e. other } \\
\text { digital payment methods; f. none }\end{array}$ \\
\hline \multirow{2}{*}{ Investment } & $\begin{array}{l}\text { Question 2: Have you invested in the following financial products? } \\
\text { a. bonds; b. funds; c. bank wealth management products; d. foreign assets; e. gold; f. } \\
\text { derivatives; g. stocks; h. online investment; i. online crowdfunding; j. none }\end{array}$ \\
\hline \multirow{2}{*}{ financing } & $\begin{array}{l}\text { Question 3: Have you ever used the internet to borrow money or to raise money? } \\
\text { a. yes; b. no }\end{array}$ \\
\hline
\end{tabular}

In Question 1, digital payment takes a value of 1 for any response other than $\mathrm{f}$, and 0, otherwise. In Question 2, digital investment takes a value of 1 for any response other than $\mathrm{i}$ or $\mathrm{j}$, and 0 , otherwise. In Question 3, digital financing takes a value of 1 if the response is a, and 0, otherwise. Digital financial 
services use here is a dummy variable that equals 1 if the value of digital payment, digital investment, or digital financing is 1 , which means that the respondent has used digital financial services, and 0 , otherwise.

In our sample, the proportion of farmers using digital financial services is $35.63 \%$. The proportion of farmers using digital payment instruments is $35.58 \%$. The proportion of farmers using digital investment and digital financing is $0.3 \%$ and $0.6 \%$, respectively, both of which are relatively low compared with digital payment. These results are similarly to those of a study on the Global Findex Database 2017 [9], which shows that in China 40\% of adults in rural and urban areas use digital payment.

\subsubsection{Measuring Farmers' Vulnerability to Poverty}

This paper applies the Asset-Based Vulnerability Approach, proposed by Chiwaula et al. [18], to measure farmers' vulnerability to poverty. Carter and Barrett [20] developed an Asset-Based Poverty Approach that established a functional relationship between assets and welfare indicators, such as consumption. The Asset-Based Vulnerability Approach introduces risk to the Asset-Based Poverty Approach by incorporating the variance of income or consumption [18]. Defined as the likelihood that a household will move into or out of poverty in the future, farmers' vulnerability can be calculated as

$$
V_{h}=\operatorname{Pr}\left(V_{h} \leq Z\right)=\left\{\begin{array}{cl}
0 & \text { if }\left[\hat{E}\left(C_{h}\right)-\sqrt{\left.\hat{V}\left(C_{h}\right)\right]} \geq Z\right. \\
\frac{Z-\left[\hat{E}\left(C_{h}\right)-\sqrt{\hat{V}\left(C_{h}\right)}\right]}{2 \sqrt{\hat{V}\left(C_{h}\right)}} & \text { if }\left[\hat{E}\left(C_{h}\right)-\sqrt{\hat{V}\left(C_{h}\right)}\right]<Z \leq\left[\hat{E}\left(C_{h}\right)+\sqrt{\hat{V}\left(C_{h}\right)}\right. \\
1 & \text { if }\left[\hat{E}\left(C_{h}\right)+\sqrt{\hat{V}\left(C_{h}\right)}\right] \leq Z
\end{array}\right.
$$

where $V_{h}$ is a household's vulnerability to poverty. $\operatorname{Pr}(\cdot)$ is the likelihood that household consumption will fall below the poverty line in the future. $Z$ is the poverty line, and $C_{h}$ is per capita consumption expenditure. $\hat{E}\left(C_{h}\right)$ of a given household is structural (or expected) consumption, and the approach assumes that this structural consumption is defined by the household stock of assets. $\sqrt{\hat{V}\left(C_{h}\right)}$ is the standard deviation of structural consumption. $\hat{E}\left(C_{h}\right)-\sqrt{\hat{V}\left(C_{h}\right)}$ is the lower consumption bound, and $\hat{E}\left(C_{h}\right)+\sqrt{\hat{V}\left(C_{h}\right)}$ is the upper consumption bound. In the presence of risk, household consumption has stochastic variations between the upper and lower bounds.

The approach applies model (1) to measure a specific household's vulnerability and uses a 50\% cut-off to identify the structural and risk-induced vulnerability to poverty. The different categories are defined as:

a. Structural vulnerability $\left(\operatorname{Stru} V_{h}\right)$, if $V_{h} \geq 0.5$

b. Risk-induced vulnerability $\left(\right.$ Risk $\left.V_{h}\right)$, if $0<V_{h} \leq 0.5$

c. Never poor, if $V_{h}=0$

Furthermore, the approach specifies an asset-based consumption Equation (2), which allows us to estimate expected consumption $\hat{E}\left(C_{h}\right)$ and variance in consumption $\hat{V}\left(C_{h}\right)$ using a three-step feasible generalized least squares (FGLS) procedure. (Following Chiwaula et al. [18], the first step of FGLS applies ordinary least squares (OLS) to estimate Equation (2). In the second step, the log of the squared residuals is regressed on the same variables as in the first step. The last step corrects for inefficiency of the OLS model by weighting it with the square root of the predicted values of the second step.) The equation is specified as follows:

$$
\ln \left(C_{h}\right)=\beta_{0}+\beta_{1} \text { Asset }_{h}+\beta_{2} X_{h}+e_{h}
$$

where $C_{h}$ is per capita consumption expenditure. Here, Asset $_{h}$ is understood to broadly include productive capital, human capital, financial capital, and social capital. $X_{h}$ represents a number of control variables. 
Using the FGLS estimation, this approach predicts $\hat{E}\left(C_{h}\right)$ and $\hat{V}\left(C_{h}\right)$, which we apply to estimate a household's vulnerability level.

We then calculate $V_{h}$, a household's vulnerability, using the Chinese poverty line of RMB 2300 and the international poverty line of \$1.90 USD, respectively. In our sample, based on the international poverty line, the average vulnerability is 0.03 , which is lower than 0.08 , the result derived by Wan et al. [33], who used the same approach to calculate Chinese farmers' vulnerability in 2004. The decomposition of the vulnerability in our study, as in theirs, shows that the proportion of farmers with structural vulnerability and risk-induced vulnerability is $0.79 \%$ and $12.37 \%$, respectively. The results-based poverty line of RMB 2300 remain unchanged.

\subsubsection{Control Variables}

This study includes three categories of control variables: household characteristics, household-head characteristics, and the ability to manage risk. Household characteristics include household size, labors, and land area. Household-head characteristics include age, education level, and financial literacy. The ability to manage risk includes job security, access to formal bank loans, and informal insurance networks. The definitions of these variables and descriptive statistics are in Table 3. To reduce noise in the data, we drop the top and bottom $0.05 \%$ outliers on the continuous variables.

Table 3. Definition and description of variables.

\begin{tabular}{|c|c|c|c|c|c|}
\hline Variable Labels & Definition of Variables & Mean & S.D. & Min & Max \\
\hline size & Household size & 4.319 & 1.767 & 1 & 10 \\
\hline labor & Proportion of labor in a household & 0.416 & 0.293 & 0 & 1 \\
\hline land & Land area (measured in $\mathrm{mu}^{\mathrm{a}}$ ) & 5.436 & 4.496 & 0 & 24.25 \\
\hline h_age & Age of household head & 51.330 & 12.360 & 21 & 77 \\
\hline$h \_a g e^{2}$ & Age of household head, squared & 2787 & 1240 & 441 & 5929 \\
\hline h_edu & $\begin{array}{c}\text { Education of household head }(1=0-8 \text { years of } \\
\text { education; } 2=9-15 \text { years of education; } 3=>15 \text { years } \\
\text { of education) }\end{array}$ & 1.614 & 0.535 & 1 & 3 \\
\hline$h \_$finknow & $\begin{array}{l}\text { Level of financial knowledge by household head } \\
\qquad(1=\text { lowest; } 2=\text { low; } 3=\text { high; } 4=\text { highest })\end{array}$ & 0.550 & 0870 & 0 & 4 \\
\hline worksecur & Number of migrant workers & 0.941 & 1.014 & 0 & 4 \\
\hline fincap & Having access to bank loans or not $(1=$ yes; $0=$ no $)$ & 0.800 & 0.400 & 0 & 1 \\
\hline socialcap & Number of relatives proving assistance & 7.771 & 8.118 & 0 & 40 \\
\hline
\end{tabular}

\subsection{Econometric Model}

To test H1, we construct the following Ordinary Least Squares (OLS) regression model:

$$
V_{h}=\alpha_{0}+\alpha_{1} D F I_{h}+\alpha_{2} X_{h}+\varepsilon_{h}
$$

where $h$ is a household. $V_{h}$ is farmers' vulnerability calculated on basis of the Chinese poverty line of RMB 2300 and the international poverty line of $\$ 1.90$, respectively; the range is $[0,1] . D F I_{h}$ equals 1 if a household uses digital financial services, and 0 , otherwise. $X_{h}$ represents additional control variables, and $\varepsilon_{h}$ is the error term.

The OLS estimate may be biased for various reasons, such as omitted-variable bias or reverse causality. In order to address these potential problems, we instrument the digital financial services use index with the average value of the digital financial services use index of the same age group in the same county. Following Bucher and Lusardi [34] and He and Li [14], we assume that famers are more likely to use digital financial services when they are exposed to an environment in which many other people use them (this is beyond the control of the respondent). The age groups are divided as follows: 18-30, 40-50, 50-60, and over 60. 
To test H2, we construct the following Logit regression model:

$$
\operatorname{Prob}\left(\text { Vtype }_{h}=k \mid D F I_{h}, X_{h}\right)=\frac{\exp \left(\alpha_{0}+\alpha_{1} D F I_{h}+\alpha_{2} X_{h}+\varepsilon_{h}\right)}{1+\sum_{k=1}^{K} \exp \left(\alpha_{0}+\alpha_{1} D F I_{h}+\alpha_{2} X_{h}+\varepsilon_{h}\right)}
$$

where $k$ takes a value of 0 if a household will never be poor, a value of 1 if a household has risk-induced vulnerability, and a value of 2 if a household has structural vulnerability. Other variables are the same as in model (3).

\section{Empirical Results}

\subsection{Does Digital Financial Inclusion Have an Effect on Farmers' Vulnerability?}

We first investigate the impact of farmers' use of digital financial services on their vulnerability to poverty. Table 4 presents the regression results of OLS. Columns (1) to (3) in Table 4 use farmers' vulnerability calculated on basis of the Chinese poverty line of RMB 2300 as dependent variables. All estimations control for county dummy variables. Column (1) shows the relationship without other control variables. In column (2), we gradually add the relatively exogenous control variables, such as household size, dependency ratio, land area, and age of household head. In column (3), we control for all variables. Similarly, columns (4) to (6) in Table 4 use vulnerability calculated according to the international poverty line of $\$ 1.90$ as dependent variables, which are also results of OLS regressions.

Table 4. Impacts of farmers' use of digital financial services on their vulnerability to poverty: OLS results.

\begin{tabular}{|c|c|c|c|c|c|c|}
\hline \multirow[t]{2}{*}{ Poverty line } & \multicolumn{3}{|c|}{ RMB 2300 a Year Per Capita } & \multicolumn{3}{|c|}{$\$ 1.90$ a Day Per Capita } \\
\hline & (1) & (2) & (3) & (4) & (5) & (6) \\
\hline$D F I$ & $\begin{array}{c}-0.032^{* * * *} \\
(0.003)\end{array}$ & $\begin{array}{c}-0.009 * * * \\
(0.003)\end{array}$ & $\begin{array}{c}-0.006^{* *} \\
(0.003)\end{array}$ & $\begin{array}{c}-0.032^{* * * *} \\
(0.003)\end{array}$ & $\begin{array}{c}-0.009 * * * \\
(0.003)\end{array}$ & $\begin{array}{c}-0.006 * \\
(0.003)\end{array}$ \\
\hline size & & $\begin{array}{c}0.018^{* * * *} \\
(0.002)\end{array}$ & $\begin{array}{c}0.019^{* * * *} \\
(0.002)\end{array}$ & & $\begin{array}{c}0.017^{* * *} \\
(0.002)\end{array}$ & $\begin{array}{c}0.019 * * * \\
(0.002)\end{array}$ \\
\hline labor & & $\begin{array}{c}0.028^{* * *} \\
(0.006)\end{array}$ & $\begin{array}{c}0.018^{* * *} \\
(0.006)\end{array}$ & & $\begin{array}{c}0.027^{* * *} \\
(0.006)\end{array}$ & $\begin{array}{c}0.018^{* * *} \\
(0.005)\end{array}$ \\
\hline land & & $\begin{array}{c}-0.001 * * * \\
(0.000)\end{array}$ & $\begin{array}{c}-0.001 * * * \\
(0.000)\end{array}$ & & $\begin{array}{c}-0.001 \text { *** } \\
(0.000)\end{array}$ & $\begin{array}{c}-0.001 * * * \\
(0.000)\end{array}$ \\
\hline h_age & & $\begin{array}{c}-0.006^{* * *} \\
(0.001)\end{array}$ & $\begin{array}{c}-0.006^{* * *} \\
(0.001)\end{array}$ & & $\begin{array}{c}-0.006^{* * *} \\
(0.001)\end{array}$ & $\begin{array}{c}-0.006^{* * *} \\
(0.001)\end{array}$ \\
\hline$h \_a g e^{2}$ & & $\begin{array}{c}0.000^{* * * *} \\
(0.000)\end{array}$ & $\begin{array}{c}0.000 * * * \\
(0.000)\end{array}$ & & $\begin{array}{c}0.000^{* * * *} \\
(0.000)\end{array}$ & $\begin{array}{c}0.000 * * * \\
(0.000)\end{array}$ \\
\hline h_edu & & & $\begin{array}{c}-0.015^{* * *} \\
(0.003)\end{array}$ & & & $\begin{array}{c}-0.015^{* * *} \\
(0.003)\end{array}$ \\
\hline$h_{-}$finknow & & & $\begin{array}{c}0.002 \\
(0.001)\end{array}$ & & & $\begin{array}{c}0.002 \\
(0.001)\end{array}$ \\
\hline worksecur & & & $\begin{array}{c}-0.006^{* * *} \\
(0.002)\end{array}$ & & & $\begin{array}{c}-0.006^{* * *} \\
(0.002)\end{array}$ \\
\hline fincap & & & $\begin{array}{c}-0.014 * * * \\
(0.005)\end{array}$ & & & $\begin{array}{c}-0.014 * * * \\
(0.005)\end{array}$ \\
\hline socialcap & & & $\begin{array}{l}-0.000 \\
(0.000)\end{array}$ & & & $\begin{array}{l}-0.000 \\
(0.000)\end{array}$ \\
\hline County & Yes & Yes & Yes & Yes & Yes & Yes \\
\hline Observations & 1900 & 1900 & 1900 & 1900 & 1900 & 1900 \\
\hline R-squared & 0.084 & 0.304 & 0.320 & 0.084 & 0.303 & 0.319 \\
\hline
\end{tabular}

Note: The poverty lines are adjusted according to purchasing power parity (PPP) according to the World Bank in 2015 and the Chinese consumer price index (CPI) of rural residents in 2017. Robust standard errors are in parentheses. ${ }^{* * *}, * *, *$ denote the significance at $1 \%, 5 \%$ and $10 \%$ level, respectively.

The results in Table 4 indicate that the use of digital financial services is likely to reduce farmers' vulnerability to poverty regardless of which poverty line is considered. In columns (1) to (3) in Table 4, 
the coefficients of DFI are significantly negative whether with or without control variables, suggesting that farmers' use of digital financial services have positive effects on reducing their vulnerability to poverty. Results in columns (4) to (6) in Table 4 show that the relationship between digital financial services use and farmers' vulnerability remains negative and statistically significant. Suri and Jack [24] obtain similar results, finding that using mobile money in Kenya has a significant impact on poverty reduction. Their analysis focuses mainly on digital payments, whereas ours considers digital payment as well as digital investment and digital financing.

Considering that the OLS regression may be biased, we further rely on an instrumental variable (IV) mentioned in Section 3 and two-stage least squares (2SLS) regression to deal with potential endogeneity. Table 5 presents both first- and second-stage 2SLS regression results. The 2SLS models here use vulnerability based on the poverty lines of RMB 2300 and \$1.90 USD, as in the OLS models in Table 4. At the same time, we also gradually added the controls variables in the 2SLS models. The first-stage regressions in columns (1) to (6) in Table 5 show that the Cragg-Donald F-statistics and Hansen J-statistics are significant, suggesting that our IV is valid. The second-stage regressions in columns (1) to (6) show that the coefficients of DFI are significantly negative, which confirms the relationship between digital finance and vulnerability while mitigating endogeneity concerns.

Table 5. Impacts of farmers' use of digital financial services on their vulnerability to poverty: 2SLS results.

\begin{tabular}{|c|c|c|c|c|c|c|}
\hline \multirow[t]{2}{*}{ Poverty Line } & \multicolumn{3}{|c|}{ RMB 2300 a Year Per Capita } & \multicolumn{3}{|c|}{$\$ 1.90$ a Day Per Capita } \\
\hline & (1) & (2) & (3) & (4) & (5) & (6) \\
\hline & \multicolumn{6}{|c|}{ 2SLS_Second Stage } \\
\hline \multirow{4}{*}{$\begin{array}{c}\text { Exogenous control variables } \\
\text { Potential endogenous control } \\
\text { variables }\end{array}$} & $-0.075^{* * *}$ & $-0.035^{* *}$ & $-0.032 *$ & $\underset{* * *}{-0.074}$ & $-0.035^{* *}$ & -0.032 * \\
\hline & $(0.007)$ & $(0.015)$ & $(0.018)$ & $(0.007)$ & $(0.015)$ & $(0.018)$ \\
\hline & & Yes & Yes & & Yes & Yes \\
\hline & \multicolumn{5}{|c|}{ Yes } & Yes \\
\hline County & Yes & Yes & Yes & Yes & Yes & Yes \\
\hline Observations & 1900 & 1900 & 1900 & 1900 & 1900 & 1900 \\
\hline \multirow[t]{2}{*}{ R-squared } & 0.031 & 0.291 & 0.308 & 0.031 & 0.290 & 0.307 \\
\hline & \multicolumn{6}{|c|}{ 2SLS_First Stage } \\
\hline $\begin{array}{l}\text { Average } D F I \text { of same age group } \\
\text { in the same township }\end{array}$ & $\begin{array}{c}1.000 * * * \\
(0.025)\end{array}$ & $\begin{array}{l}0.694^{* * *} \\
(0.068)\end{array}$ & $\begin{array}{l}0.543^{* * *} \\
(0.067)\end{array}$ & $\begin{array}{c}1.000^{* * *} \\
(0.025)\end{array}$ & $\begin{array}{l}0.694^{* * *} \\
(0.068)\end{array}$ & $\begin{array}{r}0.543^{* * *} \\
(0.067)\end{array}$ \\
\hline Cragg-Donald F-statistic & 929.735 & 115.223 & 73.174 & 929.735 & 115.223 & 73.174 \\
\hline Hansen $J$-statistic & 0.000 & 0.000 & 0.000 & 0.000 & 0.000 & 0.000 \\
\hline
\end{tabular}

Note: The poverty lines are adjusted according to purchasing power parity (PPP) according to the World Bank in 2015 and the Chinese consumer price index (CPI) of rural residents in 2017. Exogenous control variables and Potential endogenous control variables are the same as in Table 4. For more details on the impact of control variables on vulnerability, see Appendix A Table A2. Robust standard errors are in parentheses. ${ }^{* *},{ }^{* *}{ }^{*}$ denote the significance at $1 \%, 5 \%$ and $10 \%$ level, respectively.

\subsection{How Does Digital Financial Inclusion Affect Vulnerability: Structural or Risk-Induced?}

The regression results above show the positive impact of farmers' use of digital financial services on reduction in their vulnerability. In this section, we go one step further by investigating the channels through which digital financial services play a role in reducing farmers' vulnerability. We decompose vulnerability into structural vulnerability induced by the low asset endowments and risk-induced vulnerability due to stochastic events. Table 6 presents the Logit regression results for vulnerability with the poverty line of RMB 2300 in Panel A and \$1.90 USD in Panel B, respectively. 
Table 6. Impact Channels of Digital Financial Services on Farmers' Vulnerability.

\begin{tabular}{|c|c|c|c|c|c|c|}
\hline \multirow[t]{2}{*}{ Panel A } & \multicolumn{6}{|c|}{ RMB 2300 a Year Per Capita } \\
\hline & (1) & (2) & (3) & (4) & (5) & (6) \\
\hline & $R i s k V_{h}$ & $\operatorname{StruV}_{h}$ & $R i s k V_{h}$ & StruV $V_{h}$ & $R i s k V_{h}$ & $S t r u V_{h}$ \\
\hline$D F I$ & $\begin{array}{c}-2.314 * * * \\
(-8.150)\end{array}$ & $\begin{array}{l}-15.447 \\
(-0.020)\end{array}$ & $\begin{array}{c}-1.586^{* * * *} \\
(-3.960)\end{array}$ & $\begin{array}{l}-14.916 \\
(-0.030)\end{array}$ & $\begin{array}{c}-1.329 * * * \\
(-3.110)\end{array}$ & $\begin{array}{l}-15.038 \\
(-0.020)\end{array}$ \\
\hline Exogenous controls & & & Yes & Yes & Yes & Yes \\
\hline Possible endogenous controls & & & & & Yes & Yes \\
\hline County & Yes & Yes & Yes & Yes & Yes & Yes \\
\hline Observations & 190 & & 19 & & 1900 & 1900 \\
\hline \multirow[t]{3}{*}{ Panel B } & \multicolumn{6}{|c|}{ \$1.90 USD a Day Per Capita } \\
\hline & (1) & (2) & (3) & (4) & (5) & (6) \\
\hline & $R i s k V_{h}$ & StruV $V_{h}$ & RiskV $V_{h}$ & Stru $V_{h}$ & $R i s k V_{h}$ & StruV $V_{h}$ \\
\hline$D F I$ & $\begin{array}{c}-2.297^{* * *} \\
(-8.100)\end{array}$ & $\begin{array}{l}-15.682 \\
(-0.020)\end{array}$ & $\begin{array}{c}-1.564^{* * *} \\
(-3.910)\end{array}$ & $\begin{array}{l}-16.509 \\
(-0.020)\end{array}$ & $\begin{array}{c}-1.299 * * * \\
(-3.050)\end{array}$ & $\begin{array}{l}-14.998 \\
(-0.020)\end{array}$ \\
\hline Exogenous controls & & & Yes & Yes & Yes & Yes \\
\hline Possible endogenous controls & & & & & Yes & Yes \\
\hline County & Yes & Yes & Yes & Yes & Yes & Yes \\
\hline Observations & 1900 & 1900 & 1900 & 1900 & 1900 & 1900 \\
\hline
\end{tabular}

Note: For more details on the impact of control variables on vulnerability, see Appendix A Table A3. Robust standard errors are in parentheses. ${ }^{* * *}$ denotes the significance at $1 \%$ level.

The results in Table 6 indicate a significant and positive impact of digital financial services use on reducing risk-induced vulnerability, suggesting that digital financial inclusion may alleviate poverty vulnerability primarily through the channel of coping with risk. Panel A in Table 6 shows that the coefficients of DFI are negative and significant at the $1 \%$ level in columns (1), (3), and (5), while the coefficients of DFI are not significant in columns (2), (4), and (6). These results indicate that the use of digital financial services has a significant impact only on risk-induced vulnerability. The results in Panel B in Table 6 show that the coefficients of DFI are negative and significant at the $1 \%$ level only in columns (1), (3), and (5), which is consistent with the results in Panel A. Zhang and Yin [35] obtain similar results, finding that financially inclusive services provided by commercial banks have a greater impact on farmers' risk-induced vulnerability than on structural vulnerability.

\subsection{Further Analysis: Different Providers of Digital Financial Services}

The providers of digital financial services in China can be divided into two groups-ICT companies providing financial services, and financial institutions applying ICT to their traditional services $[11,36]$. Compared with traditional banks, the ICT companies have a comparative advantage in information technology and collection mechanisms. Having established that farmers' use of digital financial services has a positive effect on reducing their vulnerability to poverty, we further investigate whether digital financial services provided by ICT (DFI_ICT) have a larger impact than that provided by traditional banks (DFI_Bank). We measure DFI_ICT and DFI_Bank based on Question 1 in Table 3. In Question 1, DFI_ICT takes a value of 1 if the response is c or d, and 0, otherwise; DFI_Bank takes a value of 1 if the response is a or $\mathrm{d}$, and 0 , otherwise. At the same time, we also separately instrument the DFI_ICT and DFI_Bank index with the average value of the DFI_ICT and DFI_Bank index of the same age group in the same township.

We separately investigate the impact of DFI_ICT and DFI_Bank on farmers' vulnerability to poverty. Table 7 presents both OLS and second-stage 2SLS regression results. The Cragg-Donald F-statistics and Hansen J-statistics are significant, suggesting that our IV is valid. The results in Table 7 shows that the coefficients of DFI_ICT are significantly negative in Columns (2), (4), (6), and (8), while the coefficients of DFI_Bank are not significant in Columns (1), (3), (5), and (7). These results indicate 
that different providers of digital financial services result in a heterogeneous effect, and only DFI_ICT has a positive effect on reducing farmers' vulnerability to poverty.

Table 7. Impacts of different providers of digital financial services on farmers' vulnerability.

\begin{tabular}{|c|c|c|c|c|c|c|c|c|}
\hline \multirow[t]{3}{*}{ Poverty Line } & \multicolumn{4}{|c|}{ RMB 2300 a Year Per Capita } & \multicolumn{4}{|c|}{$\$ 1.90$ a Day Per Capita } \\
\hline & \multicolumn{2}{|c|}{ OLS } & \multicolumn{2}{|c|}{$\begin{array}{c}\text { 2SLS_Second } \\
\text { Stage }\end{array}$} & \multicolumn{2}{|c|}{ OLS } & \multicolumn{2}{|c|}{$\begin{array}{l}\text { 2SLS_Second } \\
\text { Stage }\end{array}$} \\
\hline & (1) & (2) & (3) & (4) & (5) & (6) & (7) & (8) \\
\hline DFI_Bank & $\begin{array}{c}0.003 \\
(0.003)\end{array}$ & & $\begin{array}{c}0.014 \\
(0.014)\end{array}$ & & $\begin{array}{c}0.003 \\
(0.003)\end{array}$ & & $\begin{array}{c}0.014 \\
(0.014)\end{array}$ & \\
\hline DFI_ICT & & $\begin{array}{l}-0.005 * \\
(0.003)\end{array}$ & & $\begin{array}{c}-0.037^{*} \\
(0.019)\end{array}$ & & $\begin{array}{l}-0.005^{*} \\
(0.003)\end{array}$ & & $\begin{array}{c}-0.037^{*} \\
(0.019)\end{array}$ \\
\hline Controls & Yes & Yes & Yes & Yes & Yes & Yes & Yes & Yes \\
\hline County & Yes & Yes & Yes & Yes & Yes & Yes & Yes & Yes \\
\hline Observations & 1900 & 1900 & 1900 & 1900 & 1900 & 1900 & 1900 & 1900 \\
\hline R-squared & 0.320 & 0.320 & 0.318 & 0.301 & 0.318 & 0.319 & 0.317 & 0.300 \\
\hline \multirow{2}{*}{\multicolumn{2}{|c|}{$\begin{array}{c}\text { Cragg-Donald F-statistic } \\
\text { Hansen } J \text {-statistic }\end{array}$}} & & 132.328 & 70.253 & & & 132.328 & 70.253 \\
\hline & & & 0.000 & 0.000 & & & 0.000 & 0.000 \\
\hline
\end{tabular}

\section{Additional Robustness Checks}

Our main results above show that farmers with higher use of digital finance are associated with lower vulnerability, a finding that is robust to the different choices of poverty line and to instrumental variable estimation. In this section, we present further robustness checks and these results further confirm the positive effect of digital financial inclusion on reduction in farmers' vulnerability to poverty.

First, we use an alternative variable to measure farmers' use of digital financial services in order to reduce the possibility of measurement error. Specially, we construct the frequency of farmers' use of digital payments (DP_Num) based on the following survey question.

Question 4: How often do you use the digital payment?

a. Never; b. Only once or twice; c. Sometimes; d. Often

In Question 4, DP_Num takes a value of 0 if the response is a, 1 if the response is b, 2 if the response is c, and 3 if the response is $\mathrm{d}$. We instrument the DP_Num index with the average value of the DP_Num index of the same age group in the same township. Results of OLS and 2SLS regressions in Table 8 show that DP_Num has a significant impact on farmers' vulnerability regardless of which poverty line is considered.

Table 8. Impacts of frequency of farmers' use of digital payments on their vulnerability.

\begin{tabular}{|c|c|c|c|c|c|c|}
\hline \multirow[t]{2}{*}{ Poverty Line } & \multicolumn{3}{|c|}{ RMB 2300 a Year Per Capita } & \multicolumn{3}{|c|}{$\$ 1.90$ USD a Day Per Capita } \\
\hline & OLS & 2SLS_First & 2SLS_Second & OLS & 2SLS_First & 2SLS_Second \\
\hline & (1) & (2) & (3) & (4) & (5) & (6) \\
\hline DP_Num & $-0.004^{* * *}$ & & $-0.036^{* * *}$ & $-0.004 * * *$ & & $-0.035^{* * *}$ \\
\hline & $(0.001)$ & & $(0.012)$ & $(0.001)$ & & $(0.012)$ \\
\hline Average DP_Num in same age & & $0.647^{* * *}$ & & & $0.647^{* * *}$ & \\
\hline group in the same township & & $(0.084)$ & & & $(0.084)$ & \\
\hline Controls & Yes & Yes & Yes & Yes & Yes & Yes \\
\hline County & Yes & Yes & Yes & Yes & Yes & Yes \\
\hline Observations & 1900 & 1900 & 1900 & 1900 & 1900 & 1900 \\
\hline R-squared & 0.321 & 0.269 & 0.261 & 0.319 & 0.269 & 0.260 \\
\hline Cragg-Donald F-statistic & & 67.401 & & & 67.401 & \\
\hline Hansen J-statistic & & 0.000 & & & 0.000 & \\
\hline
\end{tabular}

Note: Robust standard errors are in parentheses. ${ }^{* *}$ denotes the significance at $1 \%$ level. 
Second, we further calculate farmers' vulnerability according to a higher international poverty lines of \$3.20 USD, which is more typical of national poverty lines found in lower income economies. Results of OLS and 2SLS regressions in Table 9 show that the coefficients of DFI remain significantly negative while using the higher international poverty lines.

Table 9. Impacts of farmers' use of digital financial services on their vulnerability to poverty (poverty line: $\$ 3.20$ USD a day per capita).

\begin{tabular}{cccc}
\hline & OLS & 2SLS_First & 2SLS_Second \\
\hline DFI & $\mathbf{( 1 )}$ & $\mathbf{( 2 )}$ & $\mathbf{( 3 )}$ \\
\hline & $-0.033^{* * * *}$ & & $-0.107^{* *}$ \\
Average DFI of same age group & $(0.008)$ & & $(0.045)$ \\
in the same township & & $0.543^{* * *}$ & \\
Controls & Yes & $(0.067)$ & Yes \\
Counties & Yes & Yes & Yes \\
Observations & 1900 & 1900 & 1900 \\
R-squared & 0.575 & 0.417 & 0.561 \\
Cragg-Donald F-statistic & & 73.174 & \\
Hansen J-statistic & & 0.000 & \\
\hline
\end{tabular}

Note: Robust standard errors are in parentheses. ${ }^{* * *},{ }^{* *}$ denote the significance at $1 \%$ and $5 \%$ level, respectively.

\section{Conclusions and Policy Implication}

After the important stages of microcredit, microfinance, and financial inclusion, the development of financial inclusion has arrived at a fourth stage: digital financial inclusion, which has experienced explosive growth in China. However, evidence on the relationship between digital financial inclusion and poverty reduction remains limited, especially at the micro level. Using survey data on 1900 farmers in rural China, this paper sheds light on this relationship and its potential impact channels. The main conclusions are as follows.

First, farmers' broader participation in digital financial inclusion has a sizable positive effect on reduction in their vulnerability. Our empirical results show that farmers' vulnerability tends to be alleviated as a result of the use of digital financial services. Digital financial services are different from traditional financial services and have a great potential to expand farmers' access to finance. It also has a potential impact on information transmission, social networks and e-commerce.

Furthermore, the effect of digital financial services provided by ICT companies is more pronounced than that provided by traditional banks. We split the sample based on the provider types and the results show that digital financial services provided only by ICT companies have a statistically significant effect. Compared with traditional banks, the ICT companies have a comparative advantage in information technology and collection mechanisms, which further strengthens the potential impact of digital financial services on information transmission, social networks and e-commerce.

Second, our results shed a light on a channel through which digital financial inclusion reduces farmers' vulnerability. To investigate the potential impact channels, we decompose farmers' vulnerability into structural vulnerability induced by asset endowments and risk-induced vulnerability due to risk events. Our empirical results show that the use of digital financial services has a significant impact on risk-induced vulnerability but not on structural vulnerability. These results, as a theoretical prediction, highlight the channel of ability to cope with risk through which digital financial inclusion can reduce fluctuations in consumption and thereby alleviate farmers' vulnerability.

Our results have important policy implications. One direct policy implication is that farmers' access to and use of digital financial services, especially digital financing, should be expanded. First, more targeted efforts and programs may be needed to improve farmers' understanding of digital financing. According to our survey data, $80.76 \%$ of the respondents seemed unwilling to borrow money through the P2P platforms or online banks because they were unfamiliar with the tools or worried 
about security. Therefore, financial knowledge is as important as infrastructure, such as the internet penetration rate or smartphone, for expanding farmers' participation in digital financial inclusion. Second, a rich information database is one of the most important parts of the development of digital financial models. To improve information transmission and collection, policy makers should stimulate the development of rural e-commerce, which provides invaluable data about farmers' buying habits, as well as selling conditions. For instance, based on the rich data on buyers and sellers collected from the e-commerce platform, Ant Financial of the Alibaba Group established three digital financial products targeting farmers in rural areas. At the same time, local governments can support the availability of information by establishing a public information sharing system, including direct credit information, such as credit default records, and indirect information, such as tax and social security records.

In addition, paying attention to the effect of digital financial services on sustainable income growth is crucial if policy makers wish to reduce farmers' vulnerability through digital financial inclusion. Our results show that digital financial services have little impact on labor market outcomes which has a direct effect on structural vulnerability induced by lower asset endowments. This is consistent with the evidence showing that digital finance reduces the level of farmers' demand for credit for production but that increases their demand for credit for consumption [37]. Therefore, more targeted products and services for credit for production should be encouraged to expand in China's rural areas.

Author Contributions: Conceptualization, X.W. and G.H.; Formal analysis, X.W.; Investigation, X.W. and G.H.; Methodology, X.W.; Writing-original draft, X.W. and G.H.; Writing-review and editing, X.W. All authors have read and agreed to the published version of the manuscript.

Funding: This project is supported by The National Nature Science Fund of China (Grant Nos. 71873011), and The National Nature Science Fund of China (Grant Nos. 71603259).

Conflicts of Interest: The authors declare no conflict of interest.

\section{Appendix A}

Table A1. Key providers of digital financial services in rural areas in China.

\begin{tabular}{|c|c|c|}
\hline Types of Providers & Examples of Providers & Main Online Services \\
\hline e-commerce platforms & $\begin{array}{l}\text { Ant Financial Services }{ }^{a} \\
\text { JD.com }^{b}\end{array}$ & $\begin{array}{l}\text { Payment, Insurance, Lending } \\
\text { Investment, Crowdfunding, Lending }\end{array}$ \\
\hline P2P lending platforms & $\begin{array}{l}\text { CreditEase }{ }^{c} \\
\text { Yi Longdai }{ }^{d}\end{array}$ & $\begin{array}{l}\text { Lending } \\
\text { Lending }\end{array}$ \\
\hline Financial institutions & Agricultural Bank of China ${ }^{e}$ & $\begin{array}{l}\text { E-Housekeeper app including payment, } \\
\text { investment, lending, and other services }\end{array}$ \\
\hline
\end{tabular}

a Ant Financial Services of Alibaba group has produced three products for rural areas: Wangnong payment, Wangnong insurance, and Wangnong Lending, which have reached RMB 180 million, RMB 1.5 billion, and RMB 213 billion, respectively, at the end of June 2017. ' JD.com proposed "Finance to Country" strategy in 2015, since which its digital financial services have involved 1700 counties and 300,000 villages. ${ }^{c}$ CreditEase, as the largest P2P firm in the world, has a lending product targeting at farmers' financial demand for their production and entrepreneurship. d Yi Longdai is a P2P platform proving online lending primarily for rural areas. ${ }^{e}$ To develop digital finance in rural areas, this bank designed a smartphone app-E-Housekeeper-through which farmers can expand access to payment, investment, lending and other services without physical outlets. 


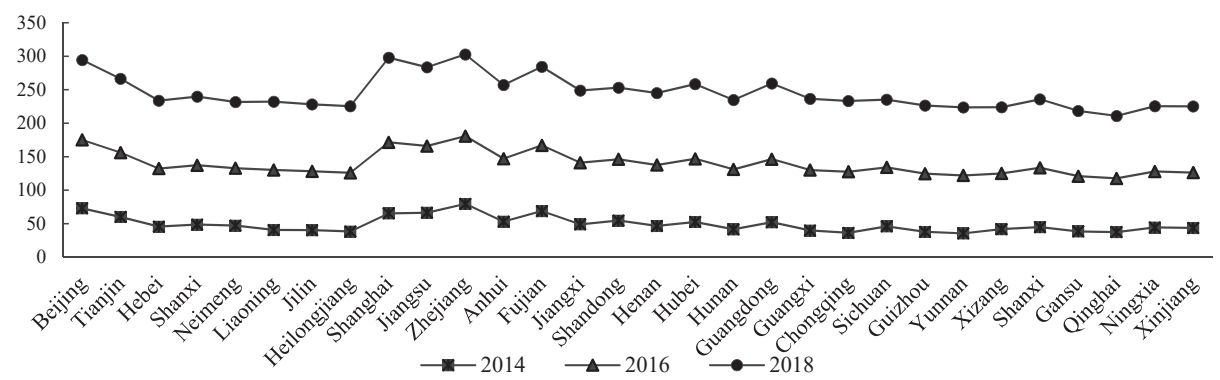

Figure A1. County-level digital finance development index across 30 provinces, 2014 to 2018. Source: authors' calculations based on the Peking University IFDI.

Table A2. Impacts of digital inclusive finance on vulnerability to poverty: 2SLS results.

\begin{tabular}{|c|c|c|c|c|c|c|}
\hline \multirow{2}{*}{$\begin{array}{l}\text { Poverty } \\
\text { Line }\end{array}$} & \multicolumn{3}{|c|}{ RMB 2300 a Year Per Capita } & \multicolumn{3}{|c|}{ \$1.90 USD a Day Per Capita } \\
\hline & (1) & (2) & (3) & (4) & (5) & (6) \\
\hline & \multicolumn{6}{|c|}{ 2SLS_second stage } \\
\hline$D F I$ & $\begin{array}{c}-0.075^{* * *} \\
(0.007)\end{array}$ & $\begin{array}{c}-0.035^{* *} \\
(0.015)\end{array}$ & $\begin{array}{c}-0.032 * \\
(0.018)\end{array}$ & $\begin{array}{c}-0.074^{* * *} \\
(0.007)\end{array}$ & $\begin{array}{c}-0.035^{* *} \\
(0.015)\end{array}$ & $\begin{array}{c}-0.032 * \\
(0.018)\end{array}$ \\
\hline size & & $\begin{array}{c}0.018^{* * *} \\
(0.002)\end{array}$ & $\begin{array}{c}0.020^{* * * *} \\
(0.002)\end{array}$ & & $\begin{array}{c}0.018^{* * *} \\
(0.002)\end{array}$ & $\begin{array}{c}0.019^{* * *} \\
(0.002)\end{array}$ \\
\hline labor & & $\begin{array}{c}0.027 * * * \\
(0.006)\end{array}$ & $\begin{array}{c}0.018^{* * * *} \\
(0.005)\end{array}$ & & $\begin{array}{c}0.027^{* * *} \\
(0.006)\end{array}$ & $\begin{array}{c}0.018^{* * *} \\
(0.005)\end{array}$ \\
\hline land & & $\begin{array}{c}-0.001 * * * \\
(0.000)\end{array}$ & $\begin{array}{c}-0.001 * * * * \\
(0.000)\end{array}$ & & $\begin{array}{c}-0.001^{* * *} \\
(0.000)\end{array}$ & $\begin{array}{c}-0.001 * * * \\
(0.000)\end{array}$ \\
\hline h_age & & $\begin{array}{c}-0.007^{* * * *} \\
(0.001)\end{array}$ & $\begin{array}{c}-0.007^{* * * *} \\
(0.001)\end{array}$ & & $\begin{array}{c}-0.007^{* * *} \\
(0.001)\end{array}$ & $\begin{array}{c}-0.007^{* * *} \\
(0.001)\end{array}$ \\
\hline$h \_a g e^{2}$ & & $\begin{array}{c}0.000 * * * \\
(0.000)\end{array}$ & $\begin{array}{c}0.000^{* * * *} \\
(0.000)\end{array}$ & & $\begin{array}{c}0.000^{* * * *} \\
(0.000)\end{array}$ & $\begin{array}{c}0.000 * * * \\
(0.000)\end{array}$ \\
\hline h_edu & & & $\begin{array}{c}-0.012 * * * \\
(0.004)\end{array}$ & & & $\begin{array}{c}-0.012 \text { *** } \\
(0.004)\end{array}$ \\
\hline$h_{-}$finknow & & & $\begin{array}{l}0.005^{*} \\
(0.002)\end{array}$ & & & $\begin{array}{l}0.005^{*} \\
(0.002)\end{array}$ \\
\hline worksecur & & & $\begin{array}{c}-0.007^{* * * *} \\
(0.002)\end{array}$ & & & $\begin{array}{c}-0.007^{* * *} \\
(0.002)\end{array}$ \\
\hline fincap & & & $\begin{array}{c}-0.013^{* * *} \\
(0.005)\end{array}$ & & & $\begin{array}{c}-0.013^{* * *} \\
(0.005)\end{array}$ \\
\hline socialcap & & & $\begin{array}{l}-0.000 \\
(0.000)\end{array}$ & & & $\begin{array}{l}-0.000 \\
(0.000)\end{array}$ \\
\hline County & Yes & Yes & Yes & Yes & Yes & Yes \\
\hline Observations & 1900 & 1900 & 1900 & 1900 & 1900 & 1900 \\
\hline \multirow[t]{2}{*}{ R-squared } & 0.031 & 0.291 & 0.308 & 0.031 & 0.291 & 0.307 \\
\hline & \multicolumn{6}{|c|}{ 2SLS_first stage } \\
\hline instrument & $\begin{array}{c}1.000^{* * *} \\
(0.025)\end{array}$ & $\begin{array}{c}0.694^{* * *} \\
(0.068)\end{array}$ & $\begin{array}{c}0.543^{* * *} \\
(0.067)\end{array}$ & $\begin{array}{c}1.000^{* * * *} \\
(0.025)\end{array}$ & $\begin{array}{c}0.694^{* * *} \\
(0.068)\end{array}$ & $\begin{array}{c}0.543^{* * *} \\
(0.067)\end{array}$ \\
\hline size & & $\begin{array}{c}0.004 \\
(0.005)\end{array}$ & $\begin{array}{c}0.008 \\
(0.005)\end{array}$ & & $\begin{array}{c}0.004 \\
(0.005)\end{array}$ & $\begin{array}{c}0.008 \\
(0.005)\end{array}$ \\
\hline labor & & $\begin{array}{l}-0.048 \\
(0.030)\end{array}$ & $\begin{array}{l}-0.026 \\
(0.030)\end{array}$ & & $\begin{array}{l}-0.048 \\
(0.030)\end{array}$ & $\begin{array}{l}-0.026 \\
(0.030)\end{array}$ \\
\hline land & & $\begin{array}{c}0.001 \\
(0.002)\end{array}$ & $\begin{array}{l}-0.001 \\
(0.002)\end{array}$ & & $\begin{array}{c}0.001 \\
(0.002)\end{array}$ & $\begin{array}{l}-0.001 \\
(0.002)\end{array}$ \\
\hline h_age & & $\begin{array}{c}-0.016^{* * * *} \\
(0.005)\end{array}$ & $\begin{array}{c}-0.015^{* * *} \\
(0.005)\end{array}$ & & $\begin{array}{c}-0.016^{* * *} \\
(0.005)\end{array}$ & $\begin{array}{c}-0.015^{* * *} \\
(0.005)\end{array}$ \\
\hline$h \_a g e^{2}$ & & $\begin{array}{l}0.000 \text { * } \\
(0.000)\end{array}$ & $\begin{array}{l}0.000 \text { * } \\
(0.000)\end{array}$ & & $\begin{array}{l}0.000 * \\
(0.000)\end{array}$ & $\begin{array}{l}0.000 * \\
(0.000)\end{array}$ \\
\hline
\end{tabular}


Table A2. Cont.

\begin{tabular}{|c|c|c|c|c|c|c|}
\hline \multirow{2}{*}{$\begin{array}{l}\text { Poverty } \\
\text { Line }\end{array}$} & \multicolumn{3}{|c|}{ RMB 2300 a Year Per Capita } & \multicolumn{3}{|c|}{$\$ 1.90$ USD a Day Per Capita } \\
\hline & (1) & (2) & (3) & (4) & (5) & (6) \\
\hline \multirow[t]{2}{*}{ h_edu } & & & $0.079^{* * *}$ & & & $0.079 * * *$ \\
\hline & & & $(0.018)$ & & & $(0.018)$ \\
\hline \multirow[t]{2}{*}{ h_finknow } & & & $0.097 * * *$ & & & $0.097^{* * *}$ \\
\hline & & & $(0.011)$ & & & $(0.011)$ \\
\hline \multirow[t]{2}{*}{ worksecur } & & & -0.014 & & & -0.014 \\
\hline & & & $(0.010)$ & & & $(0.010)$ \\
\hline \multirow[t]{2}{*}{ fincap } & & & $0.040 *$ & & & $0.040^{*}$ \\
\hline & & & $(0.021)$ & & & $(0.021)$ \\
\hline \multirow[t]{2}{*}{ socialcap } & & & $0.003^{* * *}$ & & & $0.003^{* * *}$ \\
\hline & & & $(0.001)$ & & & $(0.001)$ \\
\hline \multirow{2}{*}{$\begin{array}{c}\text { County } \\
\text { Cragg-Donald } \\
\text { F-statistic }\end{array}$} & Yes & Yes & Yes & Yes & Yes & Yes \\
\hline & 929.735 & 115.223 & 73.174 & 929.735 & 115.223 & 73.174 \\
\hline $\begin{array}{c}\text { Hansen } \\
J \text {-statistic }\end{array}$ & 0.000 & 0.000 & 0.000 & 0.000 & 0.000 & 0.000 \\
\hline
\end{tabular}

Note: Robust standard errors in parentheses: ${ }^{* * *}, * *, *$ denote the significance at $1 \%, 5 \%$ and $10 \%$ level, respectively.

Table A3. Impact mechanism of digital finance on vulnerability to poverty.

\begin{tabular}{|c|c|c|c|c|c|c|}
\hline \multirow{2}{*}{ Panel A } & \multicolumn{6}{|c|}{ RMB 2300 a Year Per Capita } \\
\hline & (1) & (2) & (3) & (4) & (5) & (6) \\
\hline & RiskV $V_{h}$ & $S t r u V_{h}$ & RiskV $V_{h}$ & StruV $V_{h}$ & RiskV $V_{h}$ & StruV $V_{h}$ \\
\hline$D F I$ & $\begin{array}{c}-2.314^{* * *} \\
(-8.150)\end{array}$ & $\begin{array}{l}-15.447 \\
(-0.020)\end{array}$ & $\begin{array}{c}-1.586^{* * *} \\
(-3.960)\end{array}$ & $\begin{array}{l}-14.916 \\
(-0.030)\end{array}$ & $\begin{array}{c}-1.329 * * * \\
(-3.110)\end{array}$ & $\begin{array}{l}-15.038 \\
(-0.020)\end{array}$ \\
\hline size & & & $\begin{array}{c}1.083^{* * *} \\
(0.080)\end{array}$ & $\begin{array}{c}2.276^{* * * *} \\
(0.286)\end{array}$ & $\begin{array}{c}1.272 * * * \\
(0.096)\end{array}$ & $\begin{array}{c}2.516^{* * *} \\
(0.342)\end{array}$ \\
\hline labor & & & $\begin{array}{c}4.084^{* * * *} \\
(0.521)\end{array}$ & $\begin{array}{c}17.734^{* * * *} \\
(3.633)\end{array}$ & $\begin{array}{c}3.874^{* * *} \\
(0.567)\end{array}$ & $\begin{array}{c}16.557^{* * * *} \\
(3.950)\end{array}$ \\
\hline land & & & $\begin{array}{c}-0.123^{* * *} \\
(0.029)\end{array}$ & $\begin{array}{c}-0.289^{* * *} \\
(0.135)\end{array}$ & $\begin{array}{c}-0.136^{* * *} \\
(0.031)\end{array}$ & $\begin{array}{c}-0.313^{* *} \\
(0.146)\end{array}$ \\
\hline h_age & & & $\begin{array}{l}0.202^{*} \\
(0.114)\end{array}$ & $\begin{array}{c}0.371 \\
(0.761)\end{array}$ & $\begin{array}{l}0.220 \text { * } \\
(0.122)\end{array}$ & $\begin{array}{c}0.173 \\
(0.825)\end{array}$ \\
\hline$h \_a g e^{2}$ & & & $\begin{array}{l}-0.000 \\
(0.001)\end{array}$ & $\begin{array}{l}-0.000 \\
(0.006)\end{array}$ & $\begin{array}{l}-0.001 \\
(0.001)\end{array}$ & $\begin{array}{c}0.001 \\
(0.006)\end{array}$ \\
\hline h_edu & & & & & $\begin{array}{c}-1.162^{* * *} \\
(0.240)\end{array}$ & $\begin{array}{c}-1.851 \text { * } \\
(1.026)\end{array}$ \\
\hline$h_{-}$finknow & & & & & $\begin{array}{c}-0.331 \text { * } \\
(0.196)\end{array}$ & $\begin{array}{l}-1.141 \\
(1.263)\end{array}$ \\
\hline worksecur & & & & & $\begin{array}{c}-0.316^{* *} \\
(0.127)\end{array}$ & $\begin{array}{l}-0.338 \\
(0.468)\end{array}$ \\
\hline finca & & & & & $\begin{array}{l}-0.351 \\
(0.258)\end{array}$ & $\begin{array}{c}-2.429 * * \\
(1.057)\end{array}$ \\
\hline socialcap & & & & & $\begin{array}{c}-0.037^{* *} \\
(0.018)\end{array}$ & $\begin{array}{c}0.089 \\
(0.102)\end{array}$ \\
\hline County & Yes & Yes & Yes & Yes & Yes & Yes \\
\hline Observations & 1900 & 1900 & 1900 & 1900 & 1900 & 1900 \\
\hline
\end{tabular}


Table A3. Cont.

\begin{tabular}{|c|c|c|c|c|c|c|}
\hline \multirow{2}{*}{ Panel B } & \multicolumn{6}{|c|}{ \$1.90 USD a Day Per Capita } \\
\hline & (1) & (2) & (3) & (4) & (5) & (6) \\
\hline & RiskV $V_{h}$ & StruV $V_{h}$ & $\operatorname{Risk} V_{h}$ & $\operatorname{StruV}_{h}$ & $R i s k V_{h}$ & StruV $V_{h}$ \\
\hline$D F I$ & $\begin{array}{c}-2.297^{* * *} \\
(-8.100)\end{array}$ & $\begin{array}{l}-15.682 \\
(-0.020)\end{array}$ & $\begin{array}{c}-1.564^{* * *} \\
(-3.910)\end{array}$ & $\begin{array}{l}-16.509 \\
(-0.020)\end{array}$ & $\begin{array}{c}-1.299 * * * \\
(-3.050)\end{array}$ & $\begin{array}{l}-14.998 \\
(-0.020)\end{array}$ \\
\hline size & & & $\begin{array}{c}1.083^{* * *} \\
(0.080)\end{array}$ & $\begin{array}{c}2.273^{* * *} \\
(0.286)\end{array}$ & $\begin{array}{c}1.264^{* * * *} \\
(0.095)\end{array}$ & $\begin{array}{c}2.504 * * * \\
(0.342)\end{array}$ \\
\hline labor & & & $\begin{array}{c}4.125 * * * \\
(0.523)\end{array}$ & $\begin{array}{c}17.775^{* * *} \\
(3.636)\end{array}$ & $\begin{array}{c}3.917^{* * * *} \\
(0.568)\end{array}$ & $\begin{array}{c}16.596^{* * *} \\
(3.954)\end{array}$ \\
\hline land & & & $\begin{array}{c}-0.120^{* * *} \\
(0.029)\end{array}$ & $\begin{array}{c}-0.286^{* *} \\
(0.134)\end{array}$ & $\begin{array}{c}-0.132 * * * \\
(0.031)\end{array}$ & $\begin{array}{c}-0.309^{* *} \\
(0.146)\end{array}$ \\
\hline h_age & & & $\begin{array}{l}0.193 * \\
(0.113)\end{array}$ & $\begin{array}{c}0.362 \\
(0.760)\end{array}$ & $\begin{array}{l}0.211 \text { * } \\
(0.121)\end{array}$ & $\begin{array}{c}0.161 \\
(0.825)\end{array}$ \\
\hline$h \_a g e^{2}$ & & & $\begin{array}{l}-0.000 \\
(0.001)\end{array}$ & $\begin{array}{l}-0.000 \\
(0.006)\end{array}$ & $\begin{array}{l}-0.000 \\
(0.001)\end{array}$ & $\begin{array}{c}0.002 \\
(0.006)\end{array}$ \\
\hline h_edu & & & & & $\begin{array}{c}-1.108^{* * *} \\
(0.238)\end{array}$ & $\begin{array}{c}-1.794 \text { * } \\
(1.024)\end{array}$ \\
\hline$h_{-}$finknow & & & & & $\begin{array}{c}-0.355^{*} \\
(0.196)\end{array}$ & $\begin{array}{l}-1.160 \\
(1.262)\end{array}$ \\
\hline worksecur & & & & & $\begin{array}{c}-0.311^{* *} \\
(0.127)\end{array}$ & $\begin{array}{l}-0.332 \\
(0.469)\end{array}$ \\
\hline fincap & & & & & $\begin{array}{l}-0.320 \\
(0.258)\end{array}$ & $\begin{array}{c}-2.398^{* *} \\
(1.056)\end{array}$ \\
\hline socialcap & & & & & $\begin{array}{c}-0.035^{*} \\
(0.018)\end{array}$ & $\begin{array}{c}0.091 \\
(0.102)\end{array}$ \\
\hline County & Yes & Yes & Yes & Yes & Yes & Yes \\
\hline Observations & 1900 & 1900 & 1900 & 1900 & 1900 & 1900 \\
\hline
\end{tabular}

Note: Robust standard errors in parentheses: ${ }^{* * *}, * *, *$ denote the significance at $1 \%, 5 \%$ and $10 \%$ level, respectively.

\section{References}

1. Bruhn, M.; Love, I. The Real Impact of Improved Access to Finance: Evidence from Mexico. J. Financ. 2014, 69, 1347-1376. [CrossRef]

2. Braverman, A.; Guasch, J.L. Rural Credit Markets and Institutions in Developing Countries: Lessons for Policy Analysis from Practice and Modern Theory. World Dev. 1986, 14, 1253-1267. [CrossRef]

3. Kochar, A. Branchless Banking: Evaluating the Doorstep Delivery of Financial Services in Rural India. J. Dev. Econ. 2018, 135, 160-175. [CrossRef]

4. Armendáriz, B.; Morduch, J. The Economics of Microfinance; MIT Press: Cambridge, MA, USA, 2010.

5. Wang, X.; He, G.W. The Banking Competition and Deepening of Financial Inclusion in Rural China: A Stratified Analysis between Poor and Non-poor Counties. Chin. Rural Econ. 2019, 4, 55-72. (In Chinese)

6. He, G.W.; He, J.; Guo, P. Rethinking the Credit Demand and Availability of Farm Household. Issues Agric. Econ. 2018, 2, 38-49. (In Chinese)

7. Lauer, K.; Lyman, T. Digital Financial Inclusion: Implications for Customers, Regulators, Supervisors, and Standard-Setting Bodies. In Consultative Group to Assist the Poor (CGAP) Brief; Consultative Group to Assist the Poor (CGAP): Washington, DC, USA, 2015.

8. Beck, T.; Pamuk, H.; Ramrattan, R.; Uras, B.R. Payment Instruments, Finance and Development. J. Dev. Econ. 2018, 133, 162-186. [CrossRef]

9. Demirguc-Kunt, A.; Klapper, L.; Singer, D.; Ansar, S.; Hess, J. The Global Findex Database 2017: Measuring Financial Inclusion and the Fintech Revolution; The World Bank: Washington, DC, USA, 2018.

10. Guo, F.; Kong, S.T.; Wang, J. General Patterns and Regional Disparity of Internet Finance Development in China: Evidence from the Peking University Internet Finance Development Index. China Econ. J. 2016, 9, 253-271. [CrossRef] 
11. Huang, Y.P.; Shen, Y.; Wang, J.Y.; Guo, F. Can the Internet Revolutionise finance in China? China's New Sources Econ. Growth 2016, 115. [CrossRef]

12. Huang, Y.P.; Wang, X. Building an Efficient Financial System in China: A need for stronger market discipline. Asian Econ. Policy Rev. 2017, 12, 188-205. [CrossRef]

13. Guo, F.; Wang, J.Y.; Wang, F.; Kong, T.; Zhang, X.; Cheng, Z.Y. Measuring China's Digital Financial Inclusion: Index Compilation and Spatial Characteristics; Working Paper; Institute of Digital Finance, Peking University: Beijing, China, 2019.

14. He, J.; Li, Q.H. Digital Finance and Farmers' Entrepreneurship. Chin. Rural Econ. 2019, 1, 112-126.

15. World Bank. World Development Report 2000/2001, Attacking Poverty; Oxford University Press: New York, NY, USA, 2001. (In Chinese)

16. Azeem, M.M.; Mugera, A.W.; Schilizzi, S.; Siddique, K.H. An Assessment of Vulnerability to Poverty in Punjab, Pakistan: Subjective Choices of Poverty Indicators. Soc. Indic. Res. 2017, 134, 117-152. [CrossRef]

17. Chaudhuri, S.; Jalan, J.; Suryahadi, A. Assessing Household Vulnerability to Poverty from Cross-Sectional Data: A Methodology and Estimates from Indonesia; Columbia University Discussion Paper No.0102-52; Columbia University: New York, NY, USA, 2002.

18. Chiwaula, L.S.; Witt, R.; Waibel, H. An Asset-Based Approach to Vulnerability: The Case of Small-Scale Fishing Areas in Cameroon and Nigeria. J. Dev. Stud. 2011, 47, 338-353. [CrossRef] [PubMed]

19. Günther, I.; Harttgen, K. Estimating Household's Vulnerability to Idiosyncratic and Covariate Shocks: A Novel Method Applied in Madagascar. World Dev. 2009, 37, 1222-1234. [CrossRef]

20. Carter, M.R.; Barrett, C.B. The Economics of Poverty Rraps and Persistent Poverty: An Asset-Based Approach. J. Dev. Stud. 2006, 42, 178-199. [CrossRef]

21. Karlan, D.; Morduch, J. Access to finance in Handbook of development economics. Elsevier 2010, 5, 4703-4784.

22. Hart, S.; Prahalad, C.K. The fortune at the bottom of the pyramid. Strategy Bus. 2002, 26, 54-67.

23. Hove, L.V.; Dubus, A. M-PESA and Financial Inclusion in Kenya: Of Paying Comes Saving? Sustainability 2019, 11, 568. [CrossRef]

24. Suri, T.; Jack, W. The Long-Run Poverty and Gender Impacts of Mobile Money. Science 2016, 354, 1288-1292. [CrossRef]

25. Liao, G.; Yao, D.; Hu, Z. The Spatial Effect of the Efficiency of Regional Financial Resource Allocation from the Perspective of Internet Finance: Evidence from Chinese Provinces. Emerg. Mark. Financ. Trade 2019, 1-13. [CrossRef]

26. Xie, P.; Zhou, C. Research on Internet-Based Finance Mode. J. Financ. Res. 2012, 12, 1211-1222. (In Chinese)

27. Mishkin, F.S.; Strahan, P.E. What will Technology Do to Financial Structure? Natl. Bur. Econ. Res. 1999. [CrossRef]

28. Gomber, P.; Koch, J.A.; Siering, M. Digital Finance and FinTech: Current Research and Future Research Directions. J. Bus. Econ. 2017, 87, 537-580. [CrossRef]

29. Bruett, T. How Disintermediation and the Internet are Changing Microfinance. Community Dev. Invest. Rev. 2007, 3, 44-50.

30. Apiors, E.; Suzuki, A. Mobile Money, Individuals' Payments, Remittances, and Investments: Evidence from the Ashanti Region, Ghana. Sustainability 2018, 10, 1409. [CrossRef]

31. Klapper, L.; Singer, D. The Opportunities of Digitizing Payments. Available online: https://www. openknowledge.worldbank.com/handle/10986/19917 (accessed on 11 October 2019).

32. Beck, T.; Lu, L.; Yang, R. Finance and Growth for Microenterprises: Evidence from Rural China. World Dev. 2015, 67, 38-56. [CrossRef]

33. Wan, G.H.; Liu, F.; Zhang, Y. Decomposition of Poverty Vulnerability from the Perspective of Assets: Based on China Empirical Analysis of Farmers' Panel Data. Chin. Rural Econ. 2014, 4, 4-19. (In Chinese)

34. Bucher-Koenen, T.; Lusardi, A. Financial Literacy and Retirement Planning in Germany. J. Pension Econ. Financ. 2011, 10, 565-584. [CrossRef]

35. Zhang, D.H.; Yin, Z.C. Financial Inclusion, Risk Coping and Rural Household Poverty. Chin. Rural Econ. 2018, 4, 54-73. (In Chinese) 
36. Xu, J. China's internet finance: A critical review. China World Econ. 2017, 4, 78-92. [CrossRef]

37. Fu, Q.Z.; Huang, Y.P. Digital Finance's Heterogeneous Effects on Rural Financial Demand: Evidence from China Household Finance Survey and Inclusive Digital Finance Index. J. Financ. Res. 2018, 11, 68-84. (In Chinese)

(c) BY
(C) 2020 by the authors. Licensee MDPI, Basel, Switzerland. This article is an open access article distributed under the terms and conditions of the Creative Commons Attribution (CC BY) license (http://creativecommons.org/licenses/by/4.0/). 


\title{
Article
}

\section{Sustainable Financial Products in the Latin America Banking Industry: Current Status and Insights}

\author{
Juan Camilo Mejia-Escobar ${ }^{1,2}$, Juan David González-Ruiz ${ }^{3, *}$ and Eduardo Duque-Grisales 4 \\ 1 Departamento de Ingeniería de la Organización, Facultad de Minas, Universidad Nacional de Colombia, \\ Avenida 80 No. 65-223 Medellín, Colombia; jcmejiae@unal.edu.co \\ 2 Facultad de Producción y Diseño, Institución Universitaria Pascual Bravo, Calle 73 No. 73A-226 Medellín, \\ Colombia \\ 3 Departamento de Economía, Facultad de Ciencias Humanas y Económicas, Universidad Nacional de \\ Colombia, Cra. 65 \#59a-110 Medellín, Colombia \\ 4 Facultad de Ingeniería, Institución Universitaria Pascual Bravo, Calle 73 No. 73A-226 Medellín, Colombia; \\ e.duque@pascualbravo.edu.co \\ * Correspondence: jdgonza3@unal.edu.co
}

Received: 9 June 2020; Accepted: 10 July 2020; Published: 14 July 2020

\begin{abstract}
The purpose of this study is to analyse the extant literature on sustainable financial products (SFP) with a comprehensive understanding of the status quo and research trends as well as characterise the existing SFP in the Latin America banking industry. In this way, research papers derived from Scopus as well as institutional reports such as main documents, sustainability reports, and product portfolios publicly available on webpages from public, private, and development banks are used to create a database of SFP where their main characteristics are included and classified. Based on the research trends identified, the results show the development of financial products focused on environmental, social, and government (ESG) matters, mainly from the credit side, of more sustainable financial markets and products under fintech ecosystems. The results show that because of regulatory and government support through mechanisms such as green protocols and social and environmental responsibility policies, private financial institutions of Brazil, Colombia, and Argentina have led the development of both social and green financial products. These study's findings may be used for several policymakers to broaden the opportunities available in sustainable financing and thus, provide a roadmap that researchers and practicing professionals can use to improve their understanding of SFP. Finally, the study presents the potential for further research in the field, both with a qualitative and a quantitative approach.
\end{abstract}

Keywords: sustainable finance; sustainable financial products; sustainable banking; SDGs; sustainable development; Latin America; ESG.

\section{Introduction}

Climate change is one of the greatest—if not the greatest—-threats to humanity. In order to avoid reaching critical levels, such as the one represented by an increase of $2^{\circ}$ Celsius above the levels before the pre-industrial era, sustainability would play a pivotal role [1]. Recent research suggests that, if this limit is exceeded, it could lead to continuous warming of the earth no matter what actions were taken by humans to reduce $\mathrm{CO}_{2}$ emissions [2]. On the other hand, global pressures determined by imbalances at the social and economic level, with vast inequalities between countries, accelerated population growth with limited access to primary resources, and more than 1 billion people considered multidimensionally poor demonstrate that commitment on the part of all actors is required, especially governments and private agents [3,4]. In this scenario, it is crucial to mobilise huge financial resources to achieve the relevant changes. Therefore, there is a substantial opportunity for the banking industry 
in developing financial products that favour the expansion of sustainable finance and thus, align their activities with a sustainable and green economy [5].

The concept of sustainability has ceased to be a matter merely focused on compliance with regulations or a move towards corporate reputation improvement with activities of merely a philanthropic type [6,7]. At present, it is also considered as an integral part of the business and generator of financial value [8,9]; in particular, green practices impact on both a company's future market value and its profitability [10].

Concepts such as Corporate Social Responsibility (CSR) or Environmental Management are part of the new sustainability perspective as a type of management oriented towards all stakeholders [11-14]. Moreover, a desirable paradigm to implement is Environmental, Social and Government Policy (ESG) throughout the business cycle as a strategy to take advantage of and unleash all the capacities that investors can contribute to reaching the Sustainable Development Goals (SDGs), whose central axis is sustainability [15]. ESG is considered as a strategic factor, which contributes to competitiveness by doing differentiation [16].

In the last decades, for the banking industry, both responsibility and climate concerns have been considered as the main drivers for developing new business models, mainly focused on sustainable banking [17-20]. Given its pivotal role as the leading financial intermediary and cornerstone in the granting of credits for the development of projects, business growth and the weighting of risks embedded therein, the effects that the incorporation of ESG criteria could have on the design of its products and financial services are extensive in the banking industry [21-24].

Since the banking industry is vital for economic growth, this has a considerable indirect impact on the environment and society. Thus, sustainable banks could help provide the estimated US $\$ 5$ to the US $\$ 7$ trillion per year needed for reaching the SDGs by 2030 [25]. In this sense, the responsible banking industry can be thought of as the appropriation of the industry of the broadest concept of sustainable finance, a term for which there is no single definition and coexists with others such as green finance or social finance and points to new sustainable business models [23,26,27]. However, despite the importance of banks in promoting a transition towards a more sustainable form of growth, the activities related to banks have received little to no attention from sustainable finance scholars [28].

According to [29], sustainable finance refers to financial products or services that integrate ESG criteria in business or investment decisions. This is how multiple initiatives focused on building sustainable banks have been promoted at different levels such as the Sustainable Banking Network (SBN), the International Developed Financial Club and Global Alliance for Banking on Values, and very recently the Principles for Responsible Banking [30] in an attempt to move sustainable banking into the mainstream [31]. For its part, green finance varies on its definition from institution to institution but despite these differences can be well declared as defined by [32] as "financing of investments that provide environmental benefits". Regarding social finance though, there is no consensus in the industry about its scope [33], as stated in [34] "it may be understood as a broad area wherein various forms of capital are structured in ways that consider and value both financial performance and social value creation". In the end, both are defined based on the orientation of their funds (environmental versus social) and by the fact that they both are covered under the umbrella of sustainable finance.

Despite being a relatively new trend, several studies have been conducted to aim at examining how the incorporation of ESG criteria can be carried out in the banking industry. Among them, analyses conducted by [35-38] have contributed to understanding how customer sustainability and financed activities can have an impact on financial performance, thus being a promoter of change towards a more responsible economy. However, the evidence shows some unawareness of the implications of an accurate administration focused on sustainability and impact on stakeholders [39]. Some studies argue that it is a trend that is due to solutions using market logic rather than ethics of the firm and shifts towards a private responsibility for the provision of welfare services and poverty treatment [33]. Studies conducted by [40] and [41] suggest measuring the performance and degree of sustainability of the banks through ratings that evaluate their commitments together with environmental and social 
indirect impacts generated by credit recipients. They also suggest the existence of two types of banks, and consequently, two different business models: Those of a reactive nature that only adopt certain sustainable banking practices due to regulatory pressures and others that truly recognise the importance of rethinking the business and pretend to be ahead of standards and regulations $[40,42,43]$.

Banks, meanwhile, by developing sustainable financial products (SFP) not only gain first-hand expertise but can also obtain benefits for their corporate image and reputation [44,45], as well as customer loyalty improvements $[43,46]$. Not to mention that seeing the implementation of more sustainable practices as a resounding alleviation to facing financial crises is something which diverse financial institutions agree upon $[23,47]$. Regarding profitability, previous research focused on Latin America (Latam) has shown that the performance of those SFP portfolios, particularly green ones, has a significantly better loan performance as well as high growth rates of about $50 \%$ year-on-year [48].

Moreover, these products demonstrate a real commitment to international voluntary initiatives to which they have joined and capitalise on an opportunity of a small business niche, but with significant growth. It is worth clarifying, however, that transparency and the real reach of banks that embark on such purposes can be questioned in several cases, as highlighted in [49-51]. Therefore, the inclusion of SFP strengthens overall sustainability performance, as explained by [23] and [52]. Despite this, very few studies have deepened in this specific field, and for the few inquiries that have been made, most have been carried out in European or North American countries, justifying a greater focus on emerging regions.

Thus, from researchers and practicing professionals' perspectives, little attention has been given to research on the SFP available in the market, which have ESG criteria, and what are the features and advantages that they offer to potential users of these products. For capital users, it is essential to know these types of products because obtaining financing through sustainable financial instruments offers companies and project developers a tangible benefit in terms of lower interest rates, which positively impacts on the cost of capital [53-55]. Also, benefits in the granting of loans such as longer terms, longer grace periods, and special guarantees provide valuable conditions to borrowers to comply with debt servicing [56]. The operative part of the projects that look for this type of financing is also favoured since they usually receive technical assistance and even have indirect operating cost reductions such as insurance premiums due to less exposure to ESG risks.

Furthermore, the value of SFP diversity relative to other financing products also lies in allowing green financing to be made available to the real economy and to actors (for example, individuals and SMEs) that do not have sufficiently large financing needs and/or the necessary experience to directly access the green bond market or be of interest to investment funds with climatic/sustainable criteria.

Studies conducted by the North American Task Force of the Finance Initiative of the United Nations Environment Programme [57] and [5] have aimed at mapping and providing a description of green financial products and identifying actors pushing the Italian financial sector to become increasingly greener, respectively. In the same way, studies conducted by $[58,59]$ have deepened the analysis and applications of SFP. However, to the best of the authors' knowledge, no elements in the current literature analyse research on SFP or the mapping of this type of products, especially in Latin America. Latam serves as an interesting and rather unique context for testing old theories and for generating new insights about SFP, and specifically for identifying the effect that these products have on the regional banking industry. It is important to emphasise that in the context of emerging economies, the social, cultural, and managerial practices are significantly and systematically different from developed economies, which could condition the development of effective SFPs.

To help bridge the identified knowledge gap, this study aims at analysing the extant literature on SFP with a comprehensive understanding of the status quo and research trends in this topic. Additionally, this study characterises the existing SFP in the Latam banking industry. This paper contributes to the literature in two ways. First, in order to have a better understanding of SFP, an in-depth review that allows for analysing the research areas, trending topics, and evolution in this arena is carried out. Secondly, the characterisation of the SFP allows having a road map of the offering 
of this type of products in the Latam bank industry. Thus, to achieve a greater understanding of the motivations of the banks in the incorporation of ESG criteria in their business model, the results obtained are compared with previous analyses on the archetypes adopted by them [22]. This study will help practitioners, consumers, and bank managers to expand their knowledge of the opportunities available in sustainable financing and build on the experience and advances of other banks. The results could be equally useful for policymakers and regulators in the design of public sustainability policies. Besides, the study presents the potential for further research in the field, both with a qualitative and a quantitative approach.

The paper is organised as follows: After this introduction, which provides a context on the main elements of the study, the methodology section is presented. Next, the literature review on sustainable banking and sustainable finance is provided, followed by the results and discussion. Finally, the last section summarises the conclusions and significance of this study, followed by further research topic recommendations.

\section{Methodology}

This study carried out a comprehensive, systematic, and holistic literature review covering all research papers published in leading journals in the fields related to sustainability, environmental studies, economics, finance, and management as well as categorising the leading development of SFP. In this way, research papers derived from the bibliographic database Scopus as well as main institutional documents such as annual reports, sustainability reports, and product portfolio summaries publicly available on webpages from public, private, and national development banks are used in order to create a database of SFP where its main characteristics are included and classified.

To have an in-depth understanding of SFP, a scientometric review that allows analysing the research areas, trending topics, and evolution in this arena is carried out. According to [60], Scopus is among the databases with the highest academic research reputation. For having concise results from the database, combinations based on these keywords are used: sustainable banking, sustainable finance, green financing, green loans, and SFP. Concerning scientometric analysis, [61] argue that this technique allows characterising specific scientific knowledge by identifying structural patterns and research trends by means of an illustrative map. To do this, VosViewer software is used. Given that this tool is substantially useful in mapping knowledge areas through illustrations with graphical maps, several studies such as [62-64] have used it. Figure 1 shows the general methodology of this research and is detailed below.
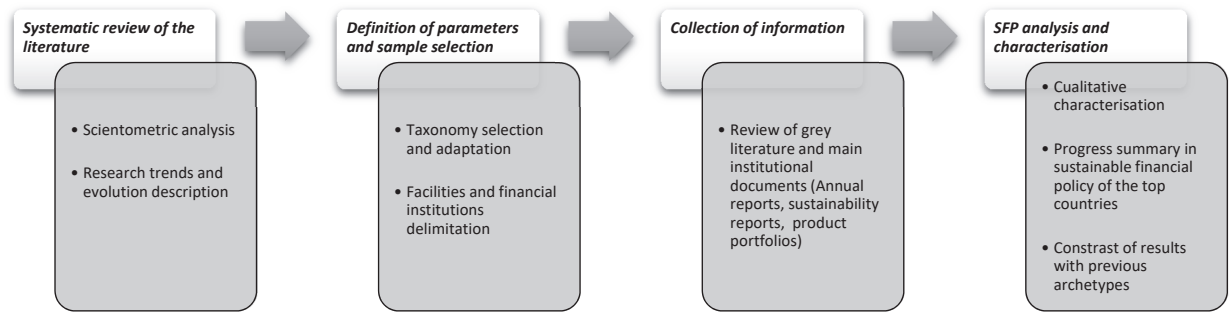

Figure 1. Overall methodology implemented.

For the searching, identifying, and conduction of this study, a broadly accepted set of sustainability-related guidelines were selected seeking despite lacking unified terms and concepts, the adoption of widespread categories and definitions related to SFP. Specifically, what can be understood as a green or social financial product, and some of the more meaningful taxonomies that cover SFP were sought. For this, the Green Loan Principles (GLP) [65] and the Social Bond Principles (SBP) [66] were chosen as referents for SFP, the former for those is more intended to bring mainly environmental benefits, and the latter for more socially-oriented products. These are both international voluntary 
forms of guidance that are the result of collaborative work between some of the main market actors, and which seek to foster the market development and guarantee the integrity of the products offered.

Although the GLP and SBP refer to different instruments and impacts (green versus social), both establish the same core components necessary to certify a green loan or social bond: the use of proceeds, the process for project evaluation and selection, management of proceeds, and reporting. For the analysis, SFP is considered to be any financial product existing in the market, whose only destination is the financing or refinancing, whether total or partial, of projects that bring environmental, social, or mixed benefits and that fall within the non-exhaustive categories of eligibility stated in the GLP or SBP.

It must be stressed that the last category in the green-oriented products sphere shown in Table 1-Multiple-does not belong to the original categories included in the GLP; however, it was added to better account for those products that encompass activities or projects related to two or more categories simultaneously, a possibility that the GLP also mentions.

Table 1. Taxonomies for Sustainable Financial Products (SFP).

\begin{tabular}{cc}
\hline Categories for Social-Oriented Products & Categories for Green-Oriented Products \\
\hline $\begin{array}{c}\text { Affordable basic infrastructure } \\
\text { Access to essential services } \\
\text { Affordable housing }\end{array}$ & $\begin{array}{c}\text { Renewable energy } \\
\text { Energy efficiency } \\
\text { Employment generation including through the } \\
\text { potential effect of (SME) financing and microfinance }\end{array}$ \\
Food security & $\begin{array}{c}\text { Pollution prevention and control } \\
\text { Environmentally sustainable management of living } \\
\text { natural resources and land use }\end{array}$ \\
$\begin{array}{c}\text { Terrestrial and aquatic biodiversity conservation } \\
\text { Clean transportation }\end{array}$ \\
Sustainable water and wastewater management \\
Eco-efficient and/or circular economy adapted \\
products, production technologies and processes \\
Green buildings \\
Multiple
\end{tabular}

The consideration of these taxonomies reflects the approach of sustainable finance adopted, which is not merely restricted to green categories as tends to be believed [67], and is in line with the recommendations of the G20 Sustainable Finance Study Group [25]. Additionally, this separation of products allows a more comprehensive analysis by having higher specificity regarding the use of funds.

On the other hand, the financial institutions considered were local financial institutions (LFI), which include private commercial banks and microfinance banking institutions, and public financial institutions (PFI) that comprise national development banks, state-owned commercial banks, special guarantee funds, or government trusts. The selection of institutions was made by including the banks that met the aforementioned characteristics and that belonged to one of the banking associations listed as active members of the Latin American Federation of Banks (FELABAN). FELABAN is an institution that groups banking associations from all over the continent and gathers more from 600 banks and financial institutions. The chosen associations by country and the number of financial institutions (FI) analysed are shown in Table 2.

Additionally, the SFP considered were limited to saving, credit, and grants-related products. This excluded insurance and investment products, mostly given that the institutions analysed were mainly commercial banks and because governments make the vast majority of clean economy investments, as well as corporations, private equity, and venture capital firms [68], which are outside of the scope of this study. This decision was made because the analysis of these kinds of products has been much more significant in the literature.

Besides, it should be noted that only products that explicitly indicated the sustainable purposes and/or categories of the facilities were considered. Therefore, several were either discarded or not considered given inaccuracies, or precarious disclosure in the media examined, which attends to the 
recommendations of the GLP and is consistent with the Climate Bonds Initiative (CBI) methodology for tracking of green bonds [69].

Table 2. Selected national banking associations. Source: Author's own research.

\begin{tabular}{ccc}
\hline Country & Member Association & FI \\
& Examined \\
\hline Argentina & Asociación de bancos de la Argentina & 62 \\
Bolivia & Asociación de Bancos Privados de Bolivia & 15 \\
Brazil & Federacao Brasileira de Bancos (FEBRABAN) & 79 \\
Chile & Asociación de Bancos e Instituciones Financieras de & 20 \\
& Chile A.G. & 32 \\
Colombia & Asociación Bancaria y de Entidades Financieras de & 14 \\
Costa Rica & Colombia (ASOBANCARIA) & 28 \\
Ecuador & Asociación Bancaria Costarricense & 13 \\
El Salvador & Asociación de Bancos Privados del Ecuador & 16 \\
Honduras & Asociación Bancaria Salvadoreña (ABANSA) & 54 \\
Mexico & Asociación Hondureña de Instituciones Bancarias & 18 \\
Guatemala & AHIBA) & 7 \\
Nicaragua & Asociación de Bancos de México & 44 \\
Panama & Asociación Bancaria de Guatemala & 15 \\
Paraguay & Asociación de Bancos Privados de Nicaragua & 20 \\
Peru & Asociación Bancaria de Panamá & 11 \\
Uruguay & Asociación de Bancos de Paraguay & \\
\hline & Asociación de Bancos del Perú & \\
\hline
\end{tabular}

With this in mind, together with the characterisation and analysis of the main SFP offered in the Latin American market, a catalogue of the main policies and regulations that have favoured the leadership and development of sustainable finances in the best-ranked countries is presented. Likewise, some progress indicators related to SFP provided by the SBN are evaluated. Its inclusion responds to its unique character as a global community that groups financial sector regulatory agencies and banking associations directed at emerging economies, and that in general seeks to provide a knowledge platform for the acceleration and commitment of these economies with the best international practices of sustainable finance [70]. Also, it is a major global player; SBN's 38 member countries are valued at $\$ 43$ trillion in total, which is around 85 per cent of emerging market banking assets, 11 of which are Latin American [70].

Finally, the results obtained in terms of categories are contrasted with the most relevant developments in terms of archetypes for the advancement of business models for sustainability in the banking industry exposed in [22].

\section{Literature Review}

Although the existing literature lack a common definition for it, SFP can be understood as the practical instrument of sustainable finance. Based on the previous definition of sustainable finance [29], SFP could be specified as financial instruments whose issues and whose deployment points to the allocation of funds to causes related to sustainability improvements, an approach that we consider most significant and will be adopted throughout the study. The above can take place both with totally new products and by adapting non-sustainable financial products, namely traditional ones.

In the most significant contributions to SFP, concepts such as sustainable development, corporate social responsibility, and impact investing have the most attention, while only recent and very few research studies have managed to identify an explicit and comprehensive approach to SFP [58,59,71-73].

Figure 2 presents the most relevant keywords obtained after refining the search with the words previously mentioned in the methodology. It allows observing a variety of terms among which, at least directly, it is not possible to observe SFP, responsible financial products, new financial instruments, or anything else that could be a synonym for SFP. All these terms appear in the universe of results; however, they are notably small, suggesting they are of relatively little relevance, highly novel, and poorly related 
to the rest of the resulting words. Such an outlook in the academy is consistent with [71] in exposing the incipient development of responsible financial products, especially in emerging market and developing countries, and which has only recently begun to emerge. In this context, three well-defined research development trends can be identified in the scientific literature.

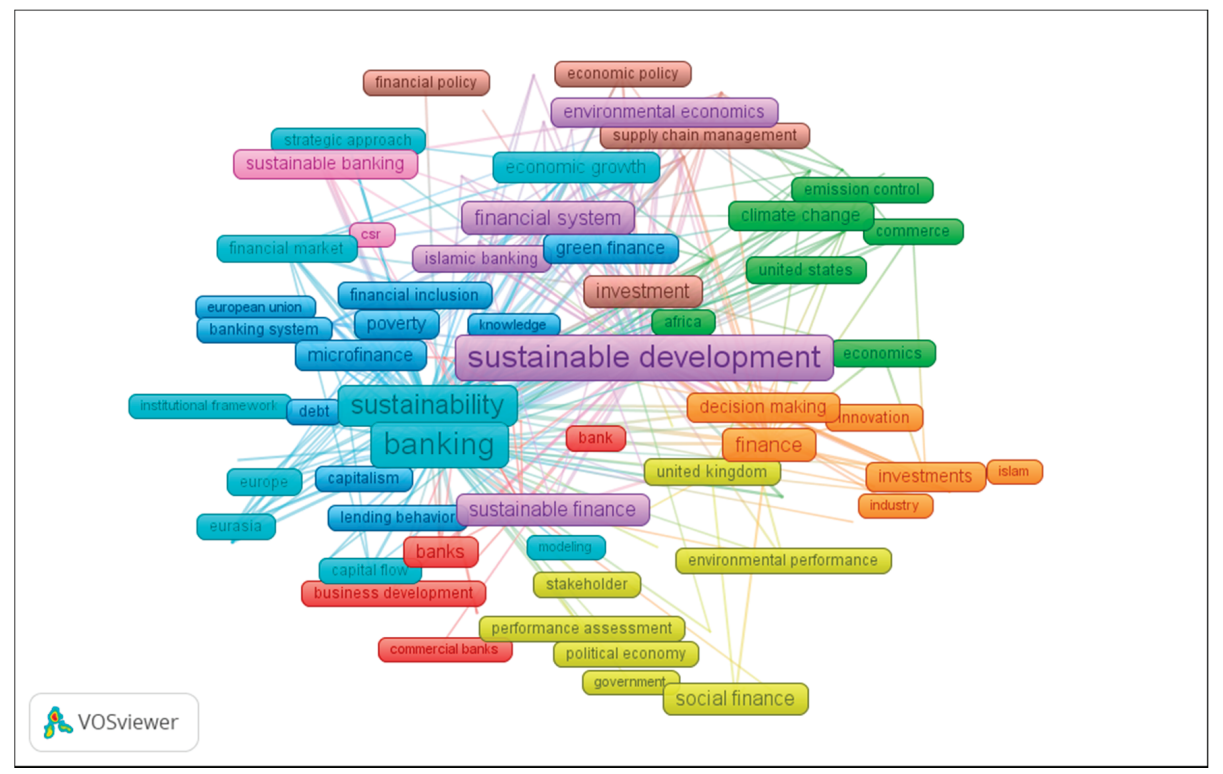

Figure 2. Most important keywords in the Sustainable Financial Products (SFP) research. Source: Author's own research.

A first research development trend focuses on a set of topics that cover risk management, sustainable banking practices, processes, environmental risks, and sustainability measurement as well as the business performance and sustainability relationship. Within this trend, the contributions conducted by $[35,74]$ stand out as referents in the field for rethinking the credit risk management process framed in terms of sustainability. In [74] the benefits for both parties of considering the sustainability profile in the granting of credit were analysed.

In this regard, the bank for its part reduces reputational, regulatory, and credit risks arising from an imprecise risk rating and borrowers can enhance their perceived solvency thanks to lower exposure to ESG risk with the improvement in the negotiating power that is highlighted by [35].

Likewise, there is evidence of the benefits of integrating ESG ratings on traditional credit risk ratings from obtaining improvements in the accuracy of default predictions of a loan, as shown by this author with a significant sample of credit assessments, which is extremely useful for loans to small to middle-sized enterprises (SME) whose qualification is a challenge. Furthermore, these results are complemented by [75] who through regression analysis of several different Chinese banks focused on the effects of China's green credit policy on their bank's credit risk, discovering that banks with a higher proportion of green loans are associated with a lower non-performance loans ratio. This trend is characterised by the connection between financial and sustainability performance. For example, [76] contributes to refuting the incompatibility paradigm between financial performance and sustainability efforts by identifying a two-way causality relationship between these two variables for Chinese banks. Meanwhile, the bidirectional nature of the relationship between financial results and sustainability performance of the organisation is also defended by [77], pointing this time to French banks using a regression panel model and a sample of 68 banks for this purpose. 
Within this research trend, assess sustainability risk is common among authors. [41] suggests a sustainability credit score system based on stages as a practical way to strengthen usual credit rating models in light of the sustainability considerations normally ignored in the banking industry. The authors of [78] for their part propose a framework to quantify, analyse, compare, and glimpse water risks by making investment decisions. The question about the actions taken to involve biodiversity in the bank's operations and the motivators for this purpose are addressed by [17]. The relations between a bank's CSR policies and the countries' peculiarities in developing countries have been conducted [12]; however, there is a scarcity of studies on these topics in Latam.

A second research development trend is about sustainable banking's evolution, which includes incorporated practices and the barriers, obstacles, and pitfalls faced as well as schemes and propositions of solutions. In this trend, studies on analysis at the institutional, sector, and macro regulatory level are common. Thus, the importance of banking industry in the mobilisation of resources towards sustainable finance is generally recognised; however, as is highlighted by $[48,56,79]$, the practical understanding of how to develop sustainable finance in their product portfolio is vague. In line with the above, [80] focuses on the approaches that seek to embody sustainable solutions in the bank's operation, arguing their usefulness to the extent that banks can impact the business models and strategic decisions of their clients given their potential to determine whether projects can obtain the requested capital or not based on sustainability considerations, which can be measured by ESG when considering the viability of a loan.

Although disparities regarding concepts of what can be classified as sustainable finance, diverse types of barriers for the development of financial innovations have been identified, as stated by [19]. These authors also examine the concept of financial eco-innovation and recompile several existing barriers to its expansion and the suggested instruments to undertake them. On the other hand, [81] analyses difficulties due to information gaps on social and environmental impacts and risks that transcend the purely monetary perspective as well as the widespread predilection for short-term returns and investments with relative security, asserting that the combination of both constitutes a crucial barrier that negatively affects financing for sustainable activities. The above is supported by [56], who focuses on fostering of green lending and acknowledges the incompatibility between the terms granted by traditional bank loans and the typical time horizon of benefits in sustainable projects.

Likewise, concerns relative to high costs associated with the development of departments dedicated to sustainable loans within banks, non-existent mechanisms for managing the risks of such loans, and the insufficient capacity for evaluation and segmentation once they are granted are addressed by [56] and [82]. To help sustainable lending get to gain traction among banks, [83] suggest considering certain minimum times being required before noticing an improvement in the return on assets, and differences on their magnitudes according to the degree of development of the financial market in question.

In this regard, [21] aims at considering monetary policies dedicated to easing lending conditions for the low-carbon firm, since nationally developed market schemes such as carbon pricing through carbon markets are insufficient to meet the imperative need for credit that sustainable activities entail, and also do not address the high capital costs associated with investments in clean technologies depicted in [84].

Hence, the insufficient disclosure and offers in the bank industry of SFP make it possible to identify a knowledge gap, particularly in having a better understanding of the existing SFP [16,22,85-87].

Finally, the third research development trend discusses new financing instruments, namely sustainable ones, the redevelopment of traditional products, and microfinance schemes. This trend is characterised by the fact that it contains research with a greater focus on SFP, or at least more directly related than the rest. For instance, [71] exposes the incipient development of responsible financial products, especially in emerging market and developing countries, which have only recently begun to develop. This study also highlights the role of SMEs as clear potential users of this type 
of products, particularly in the environmental area with feasible investments in renewable energy, resource efficiency, and pollution abatement, among others.

On the other hand, [73] conducted a study to identify investors' preferences regarding ESG criteria, their real-life investment needs, and the most relevant SFP in the Spanish market, with special focus on Socially Responsible Investing (SRI) funds, bonds, SR loans, and SR current accounts and savings. This study concludes there is a need to adapt the SRI products to those of the public investor's preferences, and, at the same time, to promote knowledge of the characteristics of these products, for instance, their risks and returns, to eliminate supply and demand's mismatch.

In this regard, [72] addresses the supply-demand discrepancy of SFP in Germany. Based on this, it is necessary to diversify, customise, and make known to current banking customers the existing SFP. This study also argues that new SFP can allow the growth of sustainable finance in risk-averse countries such as Germany, where the stock market stands as the principal sustainable investment alternative. Within this development trend, a study conducted by [58] delves into the understanding of the state-of-the-art in green leasing in theory and practice from a stakeholder perspective. In this way, [59] suggest a finance framework that serves the financing of environmentally friendly practices in EU agriculture through SFP. On this issue, a securitisation system that allows various sources of financing for farmers, for the most part obtained through public subsidies and improving efficiency in the placement of public resources, is outlined. On the other hand, in $[75,88]$, micro and social finance schemes are discussed. In the former, the case of a Canadian community credit institution dedicated to social finance and that is on the path to realising a $100 \%$ social finance portfolio is studied. In the latter, successes, errors, and recommendations are detailed based on a microfinance program in rural areas of Bangladesh [67].

Within these research development trends, the importance of SFP to support the expansion of the banking sector can be clearly observed. However, there is a scarcity of studies that allow having a better understanding of SFP since, although the research that addresses the concerns of massifying sustainable banking has abounded, it has focused mostly on the first two trends described and some other complementary issues, but has hardly delved into the third one. This scene is at least surprising and represents a conjunctural opportunity, since [22] proposes the SFP as one of the new archetypes to be adopted with the greatest potential to materialise sustainable finances towards bank users. In this sense, this gap can be noticed, especially in the Latam context. Therefore, it is necessary to analyse the evolution and characteristics of this type of products in the banking industry.

\section{Results and Discussion}

\subsection{Results by Countries}

In summary, 448 banks from 16 countries were analysed, with 267 of them with at least one SFP and thus obtaining a record of 1.709 SFP. The results show the number of SFP by countries, as shown in Figure 3. The top three (i.e., best-ranked) countries by offered SFP were Brazil, Colombia, and Argentina. Below are some of the main regulatory milestones that have contributed to their role as leaders in the region and the comparison with some indicators developed by the SBN to assess the performance and coverage of member countries with established national sustainable finance policies. After the selection of these indicators, the relevance of their scope was deemed to judge the progress in SFP. These countries are followed by Mexico and Ecuador that also show significant progress in sustainable finance, and that together account for $61.56 \%$ of all identified SFP. 


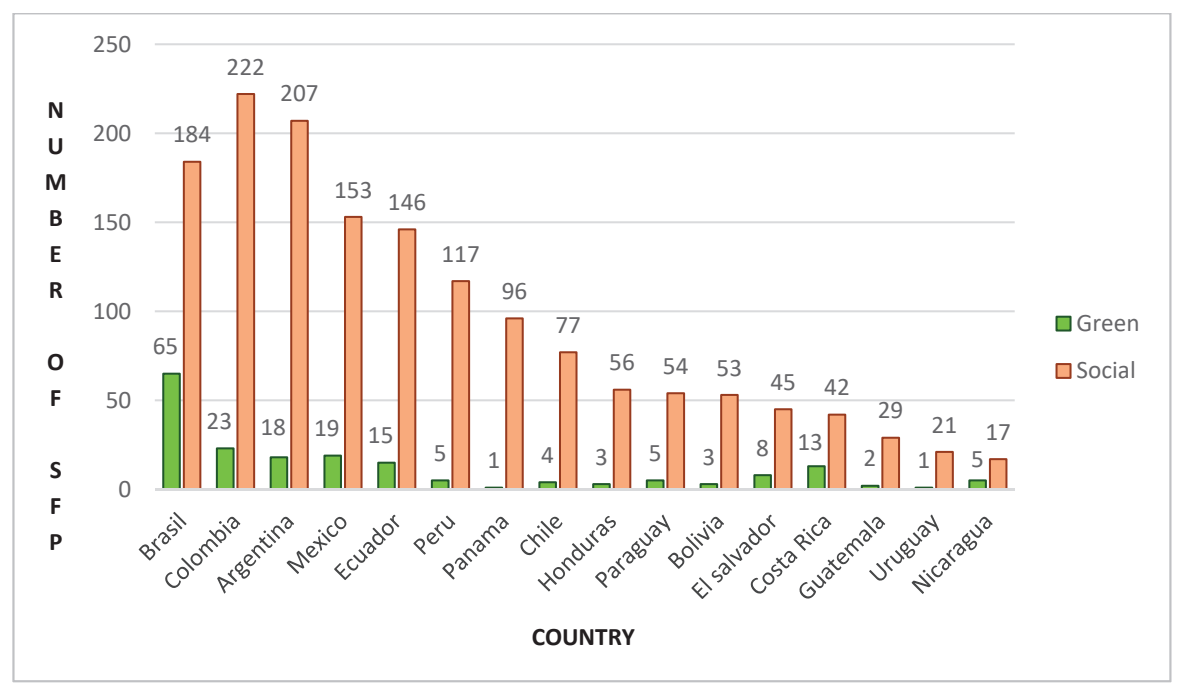

Figure 3. Sustainable financial products in Latin America. Source: Author's own research.

\subsubsection{Brazil}

Brazil is the most developed country in the region, working on the subject for more than a decade. In 2008, it established the green protocol and since 2013 it has been annually measuring financial resources for the green economy. In 2014, it established the framework for the creation and implementation of a social and environmental responsibility policy, and in 2016 it generated the guidelines for the issuance of green bonds. More recently, Brazil made progress in monitoring the environmental benefits of its banks' portfolios, while also beginning the creation of a methodology for calculating exposure to climate risks oriented to the national regulatory bodies. The country also has a great variety of national and regional state banks that are mainly active in the supply of SFP. For example, Banco Nacional de Desenvolvimento Econômico e Social is one of the largest banks with a vast number of products, which mark the development and supply of SFP nationwide and that place it above the rest of the relevant countries.

Another peculiar characteristic of Brazil is the special attention given to agricultural activity reflected in multiple products and services oriented to this sector by both PFI and LFI, although to a lesser extent for the latter. This scenario is logically clearly related to its role as a notable producer and exporter of many agricultural products, but it requires some restructuring and consolidation regarding PFI. That is, despite the positive nature of the existence of many programs to support sustainable agriculture, this favours a complex environment of financing that paradoxically hinders the understanding of available opportunities and ultimately hinders the proposed SFP disbursement objectives, as echoed in [69]. Finally, up to 2019, Brazil led investments in the fintech ecosystem, which necessarily drive the existence of a more significant number of SFP of a social nature oriented to financial inclusion and digitalisation of financial services.

The SBN framework contemplates two indicators to measure the progress in the sub pillar "Products and services", within the pillar "Climate and green finance" [70]. They are the indicators 4 and 5: "Defining sustainable assets and financial products" and "Green finance product guidelines", respectively. According to these indicators, Brazil has a 35\% gap in that Climate and green finance area, thus being above the regional and global average. This stands out from the framework that provides valuable definitions for green sectors and green bonds, which are in accordance with existing standards such as the Green Bond Principles or Climates Bond Standards. However, according to [89], for further 
improvement, there is a planned extension of guidelines for green financial assets that are different from green bonds; they also further detail the definitions and examples of social and sustainable assets.

\subsubsection{Colombia}

Colombia traces its first and most significant advance in the promotion of sustainable finance to the Green Protocol issued by Asobancaria in 2012, the same regulatory entity that issued general guidelines for the implementation of environmental and social risk analysis in 2016. This was then supported in 2017 by a roadmap of actions to launch a green bond market in Colombia. Recently, in 2018, the leading financial regulator (Superintendencia Financiera-SF-) has been striving to establish clear definitions of sustainable finance, and the scope of the Green Protocol has been extended to include other associations in the sector such as insurers and microfinance entities. Besides, Colombia is working on its national emission reduction objective aligned with the Sustainable Colombian Initiative framework (covering 2015-2030) as well as the National Decree on Climate Change. The above, together with its flourishing and diversified thematic bond market (that is, green, social, and sustainable bonds) led by financial institutions issuers augurs well for the expansion of other types of products and services within the spectrum of sustainable banking [69].

Concerning digital finance, Colombia ranks as the third largest fintech ecosystem in Latam behind Brazil and Mexico, favouring and urging on opportunities for innovation and financial inclusion from traditional banks, but there is still much to be done [90]. On the other hand, various support mechanisms used by the central government can only be granted to companies that meet the criteria established by the Mipyme Law in 2000 such as preferred credit lines for working capital, acquisition of productive assets and investment, guarantees to facilitate access to credits through the National Guarantee Fund, and diverse programs to support growth and innovation.

According to the SBN framework [91], within the pillar "climate and green finance", Colombia has a $60 \%$ gap in the sub pillar "products and services". However, it is above the regional and global average in the two indicators used. In this sense, national regulations define green assets, set targets to develop a green bond sector, and recommend the development of SFP to banks, yet, Colombia needs to develop a greater clarity through more specific taxonomies and more explicit definitions of social and sustainable assets. This is a task that is underway and according to the most updated information from $\mathrm{SF}$, is about to be completed very soon.

\subsubsection{Argentina}

In terms of sustainable banking, Argentina has been behind other countries in the region, including smaller or less developed financial markets. However, it has made several notable efforts beyond the stock market level. These actions include the development of environmental and social impact financing guidelines as well as the launching of a sustainable finance investor awareness campaign by the National Securities Commission, the first Argentinan sustainability index promoted by Bolsas $y$ Mercados Argentinos (BYMA) in cooperation with the Inter-American Development Bank, and the agreement between the Buenos Aires Stock Exchange and the Mexican Stock Exchange to work together on the development of environmental markets. Additionally, in June 2019, the Sustainable Finance Protocol of Argentina was launched, which will be the guide to bringing sustainability to the financial sector. Also, one of the strategic axes of this crucial protocol will be to create financial products and services to support the financing of projects with a positive environmental and social impact, so the outlook is positive.

Argentina, despite being a member of the SBN, does not have a national sustainable finance policy and was not subject to specific evaluation and therefore, there are no indicators related to SFP. This apparent contradiction suggests that despite the lack of a national policy that serves as a frame of reference, the concept does exist in the national banking market. At the same time, it has an important number of products that can be classified as SFP and in some cases products that are unintentionally related in some way to sustainability. This country also reveals great future potential once the recent 
sustainable finance protocol or similar initiatives are consolidated and implemented, as this would provide integrity to the SFP and promote collective learning among the actors involved. Nonetheless, it should be highlighted that greater political involvement with these initiatives and sectoral efforts is desirable.

\subsection{Results by Kind of Institution}

Regarding the kind of institutions analysed, only $18.08 \%$ were PFI, which in turn translates into approximately $38.27 \%$ of the total SFP compared to $61.73 \%$ of the LFI, as illustrated in Figure $4 a$,b. Although this does not represent a majority, it is an important number considering the low participation in the universe of registered financial institutions.

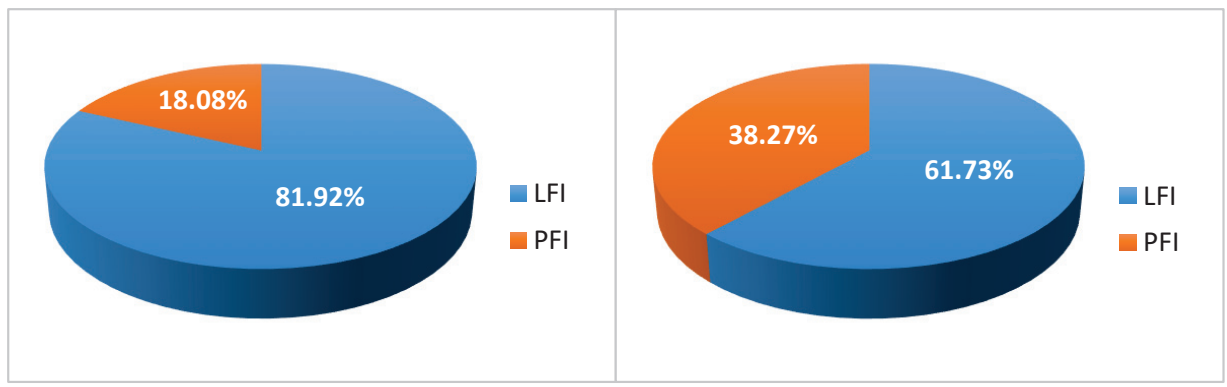

(a)

(b)

Figure 4. (a) Financial institutions examined; (b) Financial institutions offering SFP. Source: Author's own research.

Table 3 shows the first ten banks according to the number of SFP, with a predominance of banks in Colombia and Brazil, in addition to Argentina, Ecuador, and Chile. Although for this ranking the ratio of LFI versus PFI is the same, what is observed is that almost all of them are banks of considerable size and relative importance within the countries where they are located and that somehow gives indications of what has already been suggested about the bidirectional relationship between financial capacity and materialisation of strategies related to sustainability in its business model. In this sense, the average number of SFP per bank is approximately 6, which, however, is affected by the presence of large institutions with enough SFP in their portfolio. It is noteworthy that despite the financial institutions that have 1-4 SFP representing 50\%, that is, approximately 132 institutions, only 19 of them are PFI. Then, the best description of the variable number of SFP per institution is that of a distribution skewed to the right with a median of 5 and the most frequent value of SFP equal to 2 .

Table 3. Leading banks by the number of SFP. Source: Author's own research.

\begin{tabular}{|c|c|c|c|}
\hline Country & Financial Institution & Kind of Institution & No. of SFP Identified \\
\hline Brazil & $\begin{array}{c}\text { Banco Nacional de } \\
\text { Desenvolvimento Econômico e } \\
\text { Social }\end{array}$ & PFI & 48 \\
\hline Argentina & Banco de la Pampa & PFI & 30 \\
\hline Colombia & Davivienda & LFI & 29 \\
\hline Brazil & Banco do Nordeste do Brasil & PFI & 29 \\
\hline Chile & Banco del Estado de Chile & PFI & 27 \\
\hline Brazil & Banco Bradesco & LFI & 24 \\
\hline Colombia & Bancolombia & LFI & 23 \\
\hline Ecuador & Banco Pichincha & LFI & 22 \\
\hline Colombia & Banco Agrario de Colombia & PFI & 21 \\
\hline Colombia & Banco de Bogotá & LFI & 21 \\
\hline
\end{tabular}




\subsection{Results by Products}

All the products that are both social and green identified are part of the universe of sustainable finance and are some of the ways selected by financial institutions to adhere to this trend, that is to say, archetypes, but more precisely they are framed in the ways described by [22]. Analysing in depth the rationality on the part of financial institutions towards the offer of SFP is not the central focus of this study, but it is closely related. Thus, in addition to the aforementioned benefits derived from this, [22] has advanced a rigorous inspection of the motivations that drive them. That is why to shed light on this point, such archetypes were contrasted with the results, specifically four of them, which are: "Substitute with digital processes", "Inclusive value creation", "Resilience in loan granting", and "Sustainable financial products".

The main resulting categories for both social and green SFP indicate which are the archetypes of greater adoption in Latam and preliminarily suggest their pertinency in the region. Socially, the categories of SME financing and microfinance, access to essential services, socioeconomic development, empowerment, and even affordable housing account for the archetypes 'Substitute with digital processes' and 'Inclusive value creation'. There are associations that do not result in the reality of the region with emerging countries and multiple inequities and social problems, and that is evidenced for example in the low figures of financial inclusion. No less obvious is the predominance of informality in business and SMEs in regional economies, and so, by addressing these imbalances with SFP, financial institutions, as highlighted in [22], serve the most disadvantaged and generate opportunities in new markets. The other social categories also respond to a lesser extent to these archetypes.

As Figure 5 shows, products with a social focus are closely related to the unbanked population. These aim at creating opportunities for financial inclusion through microfinance, digital banking, and low-cost initiatives as well as financing of nascent enterprises to improve socio-economic conditions of disadvantaged communities. These products promote the development of SMEs as well as access to essential services.

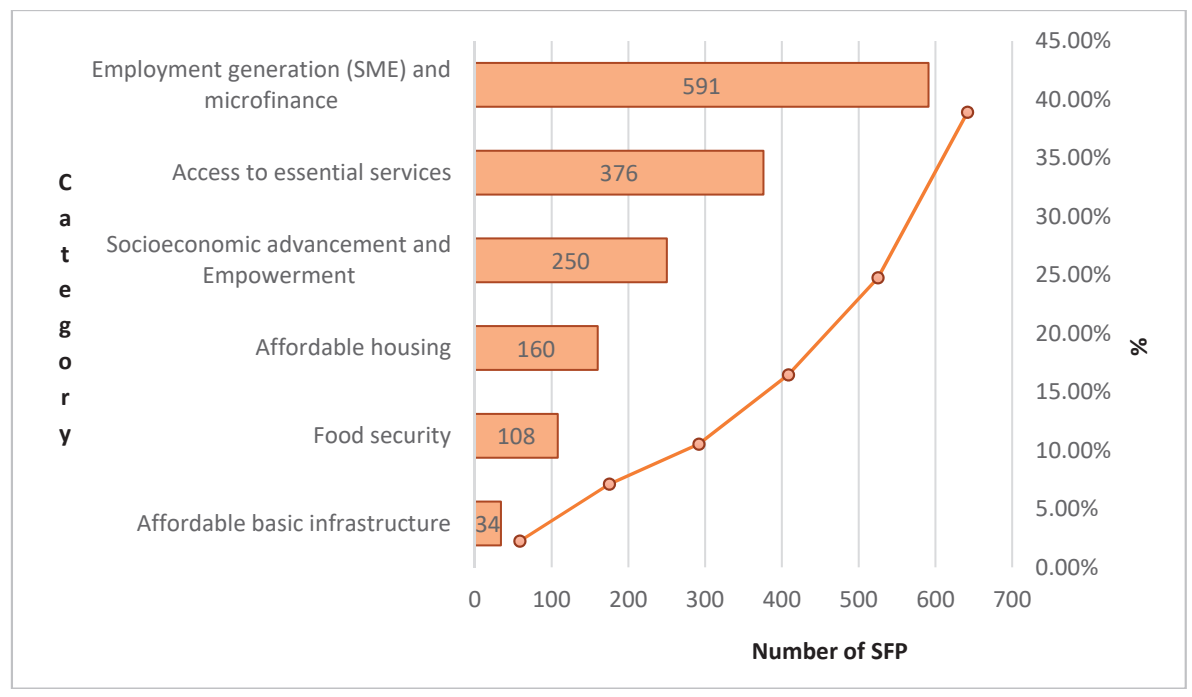

Figure 5. Results obtained for social-oriented SFP. Source: Author's own research.

It should also be noted that some of these institutions achieve their mission of sustainability using only one of those archetypes, such as a substitute with digital processes. In this sense, the results support what is stated by [22] regarding the persistence of institutions that prefer archetypes of high 
visibility and relatively easy and fast implementation over others, with more significant strategic and operational implications for their accomplishments. Once again, short-termism is present.

In products whose main sustainability benefit is environmental, in turn, the SFP, regardless of the category are framed in the archetype 'Sustainable financial products' and 'Resilience in loan granting'. As for green products, the generation of alternative energy, energy efficiency, and sustainable use of the land and its resources, or simply general environmental investments are the main focus of financial institutions as Figure 6 shows. In this sense, the results by categories are also consistent with previous analysis of green products and services in Latam [48,92].

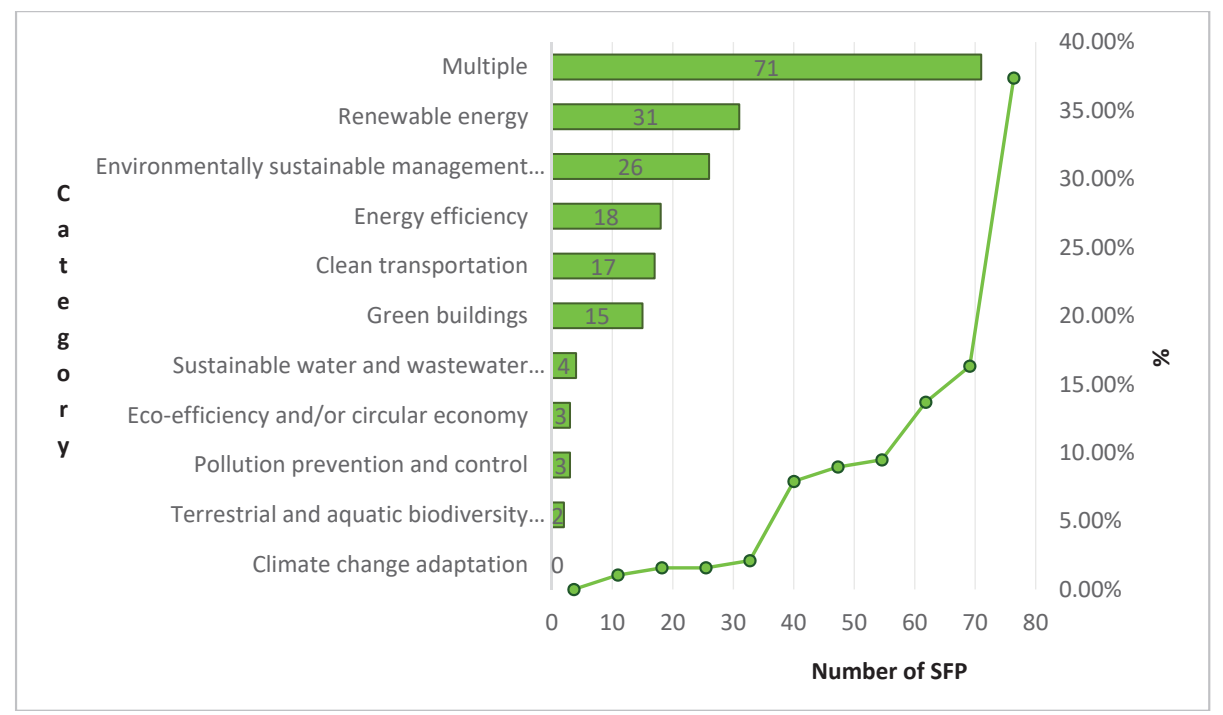

Figure 6. Results obtained for green-oriented SFP. Source: Author's own research.

On the other hand, the fact that the category 'Multiple' is by far the largest group of products identified with $38 \%$ of the total reflects that several financial institutions through their aim to include SFP develop general ecological products (regardless of the type of facility) that help potential clients to accomplish any activity that generates environmental benefits. The above is quite logical and may be explained by widely recognised barriers such as a lack of knowledge within the bank in terms of sustainability $[22,48,56,92]$, and thus, these types of products are the easiest to structure and practical to use to venture into the SFP.

Lastly, the importance of PFI in the promotion of SFP in Latam should be highlighted, not only for their role in encouraging LFI for the development of their own SFP, but also in a less commented aspect, that of their role in the adjustment and development of SFP according to the environmental and social needs, and economic vocation of the areas where they are located. Evidence of this may be that countries that have diverse state banks in their different regions were clear leaders in some key categories such as the case of Brazil in "Renewable energy" and "Environmentally sustainable management of living natural resources and land use", and to some extent Argentina in "Employment generation through SME financing and microfinance". SFP were characterised according to the category, type of facility, and features of the products identified in the financial institutions of Latam and are shown in Table 4. 


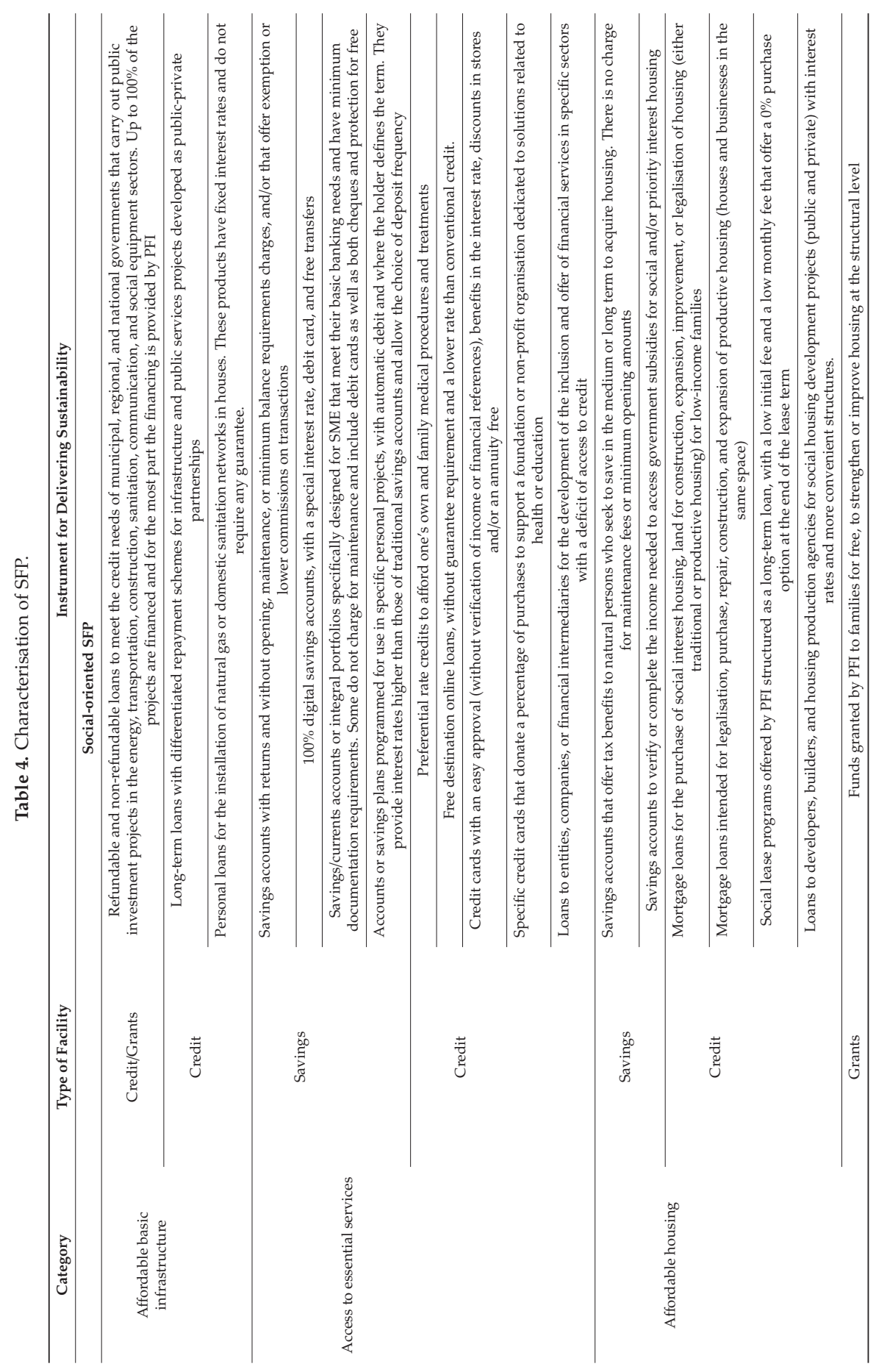




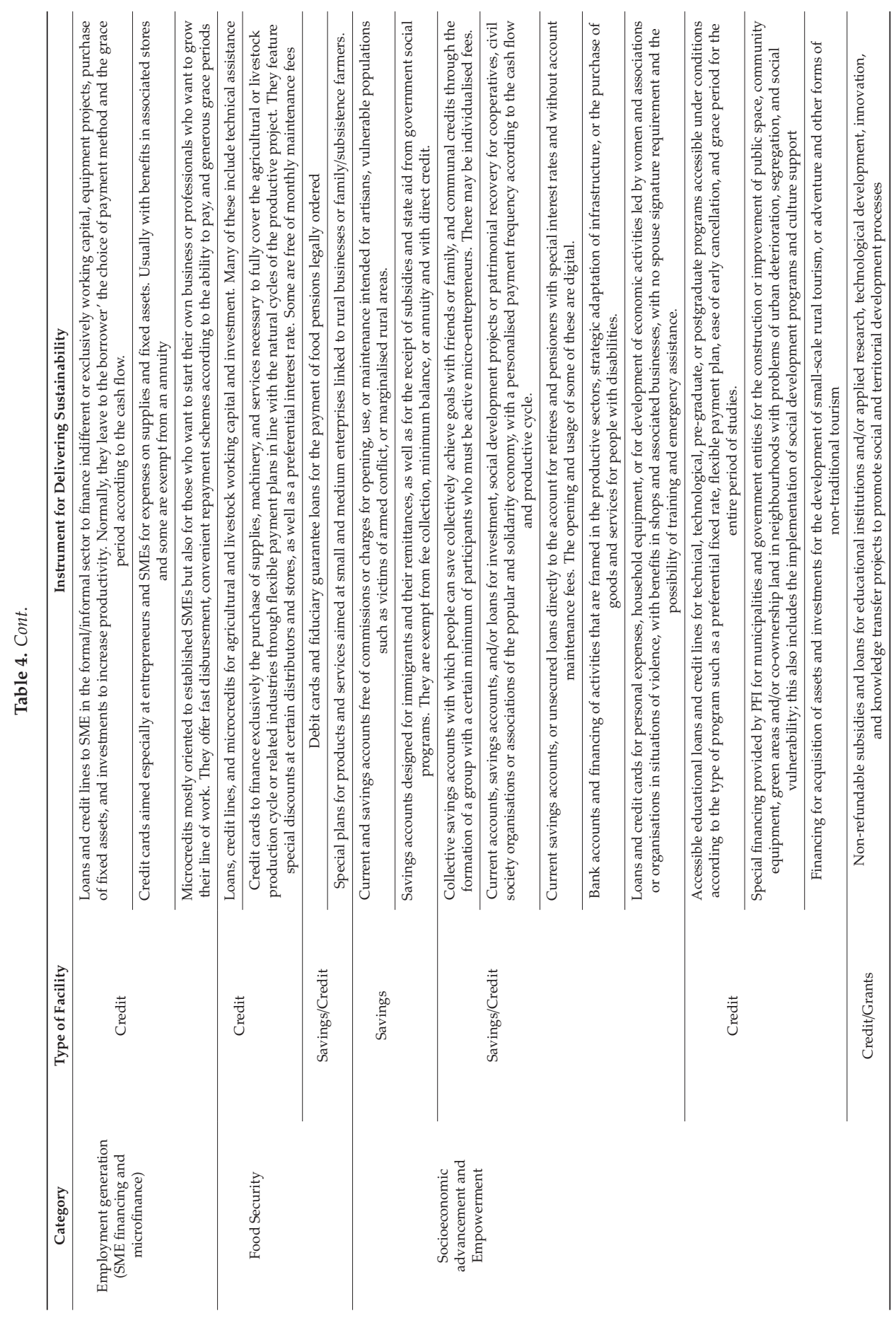




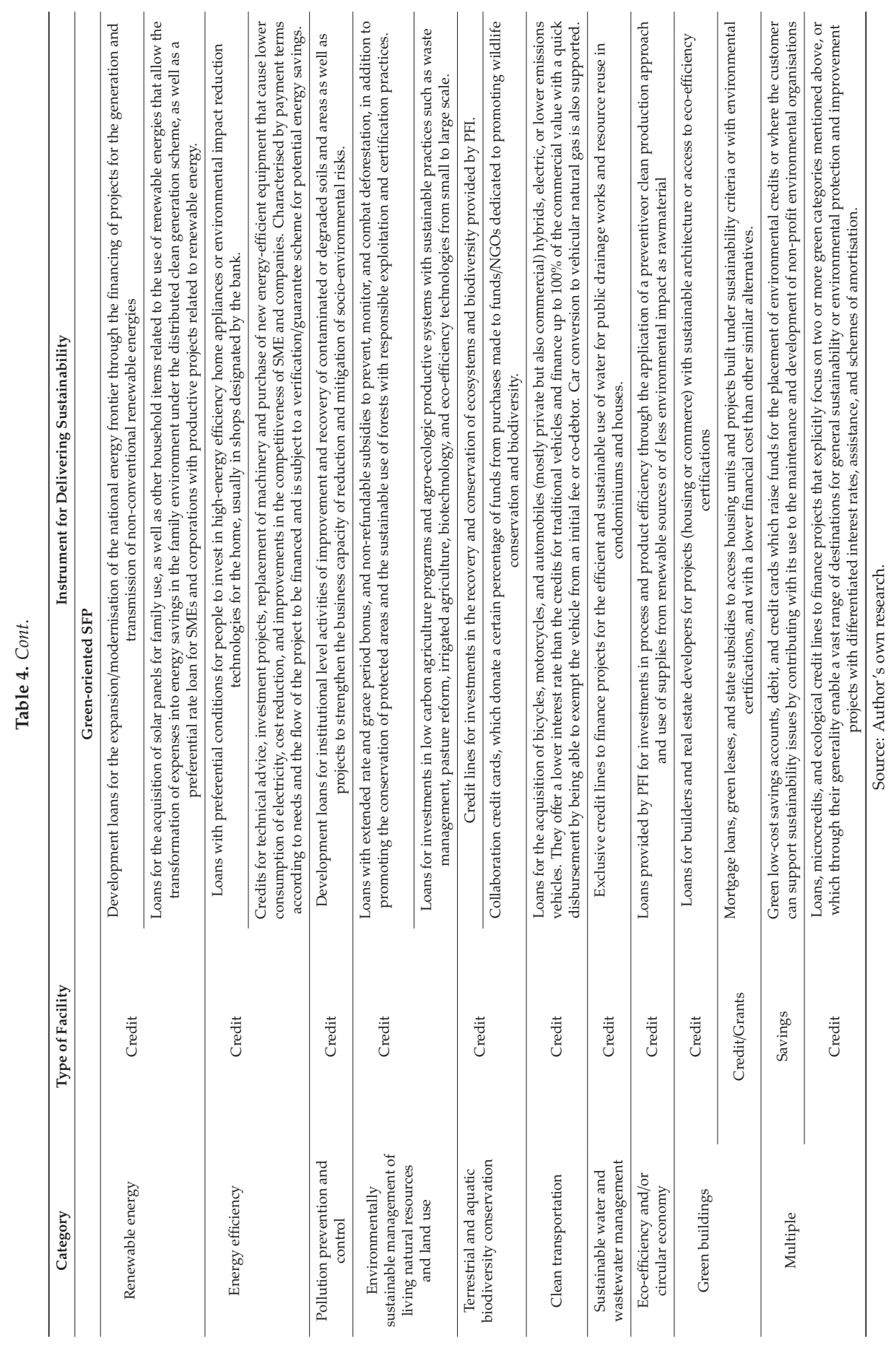




\subsection{Segments}

Individuals, SME, corporations, and government entities were considered as segments for SFP. These products can be directed to one or several segments at the same time. Thus, the records obtained are those observed in Figure 7. These show the relationship between projects and the categories associated with significant investment and projects with corporate segments and government entities. In this sense, credit products for infrastructure projects, public programs, and mega-investments in categories such as affordable basic infrastructure, energy renewable, affordable housing, green buildings, and access to essential services (other than financial) are most commonly offered to this segment. As for the segment of individuals, they are significant recipients of products of various modalities, especially in the social field within the categories of access to essential services, microfinance, affordable housing, and socioeconomic development and empowerment. In the environmental field, they have less prominence and the products they can access are focused on the acquisition of energy-efficient products, green buildings, renewable energy for domestic applications, or personal clean transportation solutions. Although SFP are offered to people in general, population groups with some vulnerability or degree of exclusion (e.g., ethnic minorities, disabled persons, or immigrants) are offered these SFPs more frequently by financial institutions.

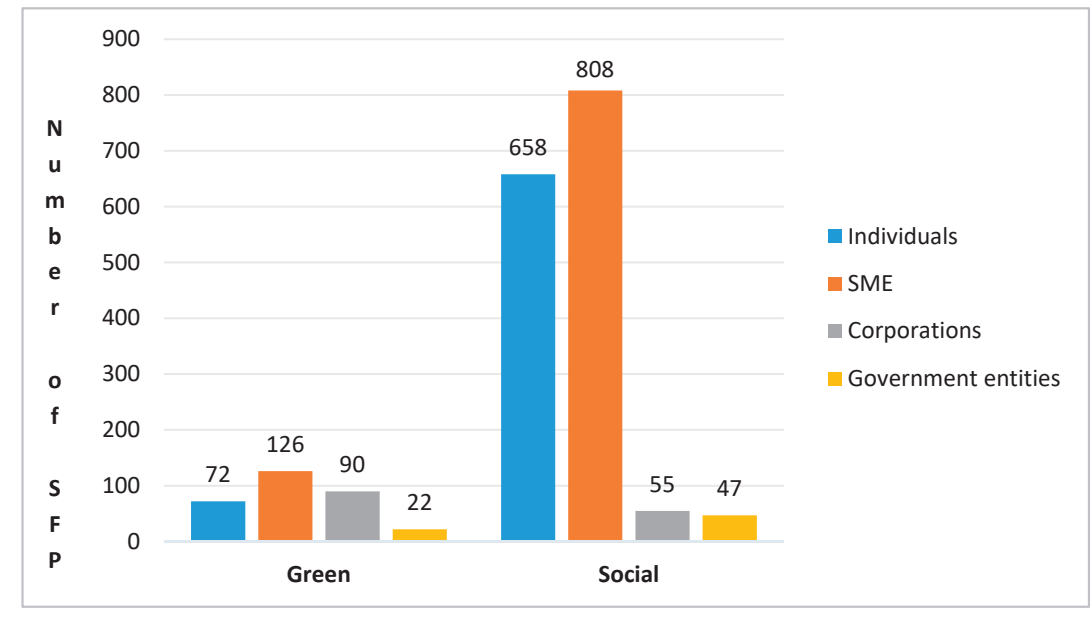

Figure 7. Target segments for SFP. Source: Author's own research.

Finally, the SME segment is the most versatile and attended, leading both the social and green ambits. The main categories are access to essential services (financial), food security, and employment generation through SME financing and microfinance. It is remarkable how attractive SMEs are to deploy SFP not only because the sector is a market of great size and potential, but also because of its recognition as high potential actors due to its mainly familiar nature, dynamism, and significant involvement with the communities that can help to achieve several of the social objectives framed in the different sustainability taxonomies and SDGs.

\subsection{Sustainability and Corporate Social Responsibility Reporting}

Along with the revision of the SFP, the existence and publication of sustainability reports or reports on socio-environmental policies on the websites of financial institutions was verified. Figure 8 shows that only $29.53 \%$ of the banks analysed report their efforts in terms of sustainability, which is eminently a really small part. It should be clarified that the fact that an institution has not been accounted for does not mean that it does not have SFP. It may have these products, but it has not developed adequate communication or does so insufficiently in the media examined. Besides, there is 
evidence of the confusion of sustainability strategies with solidarity and philanthropic activities in financial institutions that they recurrently advertise in so-called sustainability sections on web pages or annual reports but in many cases, this is nothing more than a compendium of donation activities, allied foundations, or occasional campaigns of volunteer activities within the institution. This alone does not meet the requirements of sustainable banking at all and instead provides a window-dressing practice for stakeholders, and therefore was not considered.

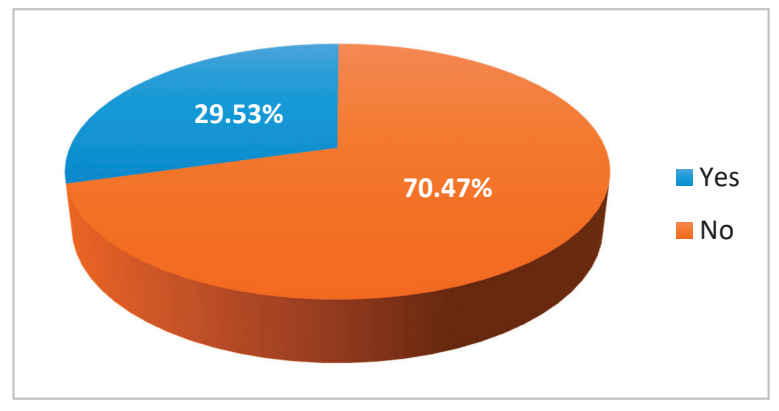

Figure 8. Financial institutions that communicate their sustainability management. Source: Author's own research.

Moreover, this may be one of the reasons why the levels of reporting observed are much lower than previous measurements in this regard in the region [92], in which the consideration of what is and what is not a report of sustainability efforts was solely the perception of financial institutions' managers.

The results are consistent with the previous descriptions of the precarious communication to the interest groups and particularly to the clients by the banks. What is beyond the report is evidence that even institutions with SFP in their portfolios do not promote them with the fortitude that one would expect in the most essential points of contact today, which are virtual channels [21]. The idea is not only to develop SFP, but they should also be promoted and even more privileged in marketing strategies. As echoed in [22,48], it is just as important to publicise the benefits and impact of sustainable banking with financial institutions and civil society in general, as it is to promote the demand for SFP. The faster and more integrated these efforts are, the greater will be the success in the consolidation of sustainable banking.

The SBN framework contemplates one indicator to measure the progress in the sub pillar "Climate and green investment reporting", within the pillar "Climate and green finance" [70]. It is the indicator: "Tracking and disclosure of climate \& green finance". According to this, Brazil has a 60\% coverage in that area, positioning itself well ahead of the regional and global average. Meanwhile, Colombia has not yet made any progress in this area, and the essential needs should be to compel reporting on climate / green financing flows and stimulate financial institutions to publicly report on green financing activities. This aspect is vital to address for the sake of standardising information that enables effective monitoring. Then, Colombia is called upon to work with its neighbor countries and build on its recognised experience.

\section{Conclusions and Further Research}

This paper analysed the extant literature on SFP with a comprehensive understanding of the status quo and research trends and, characterised the existing SFP in the Latam banking industry. In this way, this paper contributes to the body of knowledge and practice by being the first to characterise and analyse the SFP in the Latam banking industry. The results of the study show that Brazil, Colombia, and Argentina are the main countries involved in the development of SFP. Because of regulatory and government support such as through Green Protocols and social and environmental responsibility policies, these countries have led both social and green financial product development. 
The development of financial products focused on ESG, particularly from the credit side, is highlighted in the first research trend. It is important to highlight that Brazil has one of the most developed financial markets in the region and it has allowed the development and supply of SFP nationwide. Besides, it has a fintech ecosystem which has allowed it to have a greater financial inclusion and digitalisation of financial services, as well as agricultural activity reflected in multiple products and services oriented to this sector, developed by both PFI and LFI.

On the other hand, Colombia began its evolution towards sustainable finance with the Green Protocol issued by Asobancaria in 2012. Even though Colombia has had relevant advances in fintech, much still to be done to have greater financial inclusion as Brazil and Mexico have, though its ecosystem is highly promissory.

This result was in line with the SBN framework; the authors of [91] found that Colombia had a $60 \%$ gap in products and services. This suggests that both the public and private sector should develop strategies for boosting the development of SFP based on fintech. This would include greater clarity through more specific taxonomies and more explicit definitions of social and sustainable assets. Although Argentina has a small and less developed financial market, it has made several efforts towards developing SFP. At this point, campaigns in alliance with BYMA, the Inter-American Development Bank, and the Mexican Stock Exchange, as well as its very recently launched national sustainable finance policy have played a pivotal role and therefore, the outlook is positive.

Thus, barriers, obstacles, and pitfalls are being overcome aimed at developing a more sustainable financial system, which is line with the second research trend. Other relevant countries are Mexico and Ecuador, these five countries together account for $61.56 \%$ of all SFP identified in this study, which is certainly significant.

Concerning the rest of the Latin American countries, it is highly recommended that they deepen cooperative relationships with these five leaders, especially those that are in the basic stages of development respecting SFP. As it has already been demonstrated with countries in Latam and other regions, success is based on sharing experiences and building from the mistakes of others, which will undoubtedly help with the further development of SFP.

About the kind of institutions, the results show the tremendous importance of PFI, which obtained significant results with almost a $40 \%$ participation. The role of a promoter and at the same time as a persuader towards the LFI is confirmed, but it is also important to emphasise the work of PFI in matching regional needs with the potential SFP that address them.

The results also indicate a prominent relationship between SFP and the creation of opportunities for financial inclusion for the unbanked and vulnerable population, as well as with SME financing initiatives. These two factors were the main categories in the social-oriented SFP. On the other hand, in the green-oriented SFP, the main categories were occupied by products with multiple environmental destinations, renewable energies, and activities on sustainable management of natural resources and land use, sectors with huge investment opportunities in the region.

When evaluating the target audience of the different SFP, it can be seen that SME are the most flexible segment. These have the highest amount of SFP, both in the green and social spheres.

Regarding the kind of facilities granted, individuals are recipients of savings products such as checking accounts, savings, debit cards, and credit loans mainly to encourage their insertion into the formal financial system and healthy financial habits. Multiple ecological loans, which are another widespread practice, are the most practical and efficient option for financial institutions (regardless of type) to include in green products in the portfolios, which was raised in the second research trend.

At the same time, low levels of bank sustainability reporting expose the imperative need to improve the dissemination of efforts in this regard. Furthermore, in terms of promotion it is required that in addition to informing the details of traditional products, the banks report whether they have SFP, and if so, what are the mechanisms for evaluation and monitoring adopted.

Despite the contributions of the present study, limitations should be acknowledged. The most significant limitation of this study is the scarce information on SFP that financial institutions publish 
on websites. Also, there is a lack of homogeneity in the presentation of information as well as a low proportion of institutions that quantify and monitor the flows and performance of SFP if offered. Therefore, it is possible that additional elements not identified may be essential for establishing new features on SFP. This issue should be addressed in further research. Finally, this research is providing a roadmap to SFP in the Latam banking industry so researchers and practicing professionals can improve their understanding of the SFP and thus, they may use these study's findings to broaden the central aspects of this kind of financial products, as the third research trend indicated.

Based on the research trends and results, to go beyond this study, research on topics related to SFP will facilitate improve financial practices for the economic development based on ESG issues. From a practical and research perspective, further research may develop a framework in which each financial institution registers its SFP. It would allow us to determinate the real SFP offers. Likewise, the development of both new metrics for measuring financial leverage from ESG perspective as well as interest rates indexed by ESG issues is required. These issues could complement the sustainability credit score system proposed by $[41,74,80]$. Additional lines of further research may include:

- Comparing interest rates for similar SFP but in different countries.

- Developing a credit risk framework to measure how much money a sustainable project could borrow.

- Measuring if SFP could boost the generation of economic value added (EVA)

- Analysing the relation between green bonds and SFP in financial institutions.

- Appraising the participation of monetary flows destined to reach green and social loans in the financial markets at a regional level.

- Assessing the applicability of the archetypes established in [21] now for the banking industry in emerging economies.

- In order to have more understanding of the associations and factors determining the offering / not offering of SFP in Latam countries, an analysis by means of numeric analysis, statistic tests, or even econometric models when suitable.

Finally, since only $60 \%$ of the banks considered had at least one SFP, and because the average number of SFP among financial institutions is just two, the developing nature of this topic is corroborated. As a result, the topics above represent only a part of the great potential in the SFP research field with both a qualitative and quantitative focus. Thus, greater engagement of public/private agents and awareness-raising for potential users about existing opportunities are the preconditions for triggering a virtuous cycle.

Author Contributions: J.C.M.-E. wrote, reviewed, and analysed literature and data, J.D.G.-R. designed the research framework, conceptualised, wrote, reviewed and developed the manuscript, E.D.-G. analysed literature, and reviewed the paper. All authors have read and agreed to the published version of the manuscript.

Funding: This research received no external funding.

Acknowledgments: The authors thank the editor and two anonymous reviewers for their useful comments that allowed us to improve the quality and comprehension of the paper.

Conflicts of Interest: The authors declare no conflict of interest.

\section{References}

1. United Nations. United Nations Framework Convention on Climate Change. In Adoption of the Paris Agreement; United Nations: New York, NY, USA, 2015; p. 32.

2. Steffen, W.; Rockström, J.; Richardson, K.; Lenton, T.M.; Folke, C.; Liverman, D.; Summerhayes, C.P.; Barnosky, A.D.; Cornell, S.E.; Crucifix, M.; et al. Trajectories of the Earth System in the Anthropocene. Proc. Natl. Acad. Sci. USA 2018, 115, 8252-8259. [CrossRef] [PubMed]

3. Bassi, S.; Jennifer, E.; Lucas, T.; Leonardo, M.; Volkery, A. Briefing Green Economy—What Do We Mean by Green Economy? United Nations Environment Programme: Nairobi, Kenya, 2012. 
4. United Nations Development Programme and Oxford Poverty and Human Development Initiative. Global Multidimensional Poverty Index 2019 Illuminating Inequalities; United Nations: New York, NY, USA, 2019.

5. Falcone, P.M.; Morone, P.; Sica, E. Greening of the financial system and fuelling a sustainability transition: A discursive approach to assess landscape pressures on the Italian financial system. Technol. Forecast. Soc. Chang. 2018, 127, 23-37. [CrossRef]

6. Pinillos, A.A.; Fernández, J.L. De la RSC a la sostenibilidad corporativa: Una evolución necesaria para la creación de valor. Harvard Deusto Bus. Rev. 2011, 207, 4-21.

7. Masud, M.; Hossain, M.; Kim, J. Is Green Regulation Effective or a Failure: Comparative Analysis between Bangladesh Bank (BB) Green Guidelines and Global Reporting Initiative Guidelines. Sustainability 2018, 10, 1267. [CrossRef]

8. Zhang, D.; Zhang, Z.; Managi, S. A bibliometric analysis on green finance: Current status, development, and future directions. Financ. Res. Lett. 2019, 29, 425-430. [CrossRef]

9. González-Ruiz, J.D.; Arboleda, A.; Botero, S.; Rojo, J. Investment valuation model for sustainable infrastructure systems: Mezzanine debt for water projects. Eng. Constr. Archit. Manag. 2019, 26, 850-884. [CrossRef]

10. Miroshnychenko, I.; Barontini, R.; Testa, F. Green practices and financial performance: A global outlook. J. Clean. Prod. 2017, 147, 340-351. [CrossRef]

11. Kaufer, J. Social responsibility as a core business model in banking: A case study in the financial sector. J. Sustain. Financ. Invest. 2014, 4, 76-89. [CrossRef]

12. Hu, V.I.; Scholtens, B. Corporate social responsibility policies of commercial banks in developing countries. Sustain. Dev. 2014, 22, 276-288. [CrossRef]

13. Sarfraz, M.; Qun, W.; Hui, L.; Abdullah, M.I. Environmental Risk Management Strategies and the Moderating Role of Corporate Social Responsibility in Project Financing Decisions. Sustainability 2018, 8, 2771. [CrossRef]

14. Miralles-Quirós, M.M.; Miralles-Quirós, J.L.; Redondo Hernández, J. ESG Performance and Shareholder Value Creation in the Banking Industry: International Differences. Sustainability 2019, 11, 1404. [CrossRef]

15. United Nations. Transforming Our World: The 2030 Agenda For Sustainable Development United Nations. United Nations: New York, NY, USA, 2015.

16. Pomering, A.; Dolnicar, S. Assessing the prerequisite of successful CSR implementation: Are consumers aware of CSR initiatives? J. Bus. Ethics 2009, 85 (Suppl. 2), 285-301. [CrossRef]

17. Mulder, I.; Koellner, T. Hardwiring green: How banks account for biodiversity risks and opportunities. J. Financ. Invest. 2011, 1, 103-120.

18. Conley, M.; Williams, C.A. Global Banks as Global Sustainability Regulators? The Equator Principles. Law Policy 2011, 33, 542-575. [CrossRef]

19. González-Ruiz, J.D.; Botero-Botero, S.; Duque-Grisales, E. Financial Eco-Innovation as a Mechanism for Fostering the Development of Sustainable Infrastructure Systems. Sustainability 2018, 10, 4463. [CrossRef]

20. Stern, N. The Economics of Climate Change: The Stern Review; Cambridge University Press: Cambridge, UK, 2007.

21. Campiglio, E. Beyond carbon pricing: The role of banking and monetary policy in financing the transition to a low-carbon economy. Ecol. Econ. 2016, 121, 220-230. [CrossRef]

22. Yip, W.H.; Bocken, N.M.P. Sustainable business model archetypes for the banking industry. J. Clean. Prod 2018, 174, 150-169. [CrossRef]

23. Jeucken, H.A.; Bouma, J.J. The changing environment of banks. Greener Manag. Int. 1999, 27, $20-35$. [CrossRef]

24. Alexander, K. Stability and Sustainability in Banking Reform: Are Environmental Risks Missing in Basel III? Cambridge and Geneva: Geneva, Switzerland, 2014.

25. United Nations. Environment Programme, Sustainable Finance Progress Report; United Nations: Geneve, Switzerland, 2019.

26. Jeucken, M. Sustainable Finance and Banking: The Financial Sector and the Future of the Planet, 1st ed.; Routledge: London, UK, 2001.

27. Jeucken, M. Sustainability in Finance: Banking on the Planet; Eburon Academic Publishers: Delft, The Netherlands, 2004.

28. Urban, M.A.; Wójcik, D. Dirty Banking: Probing the Gap in Sustainable Finance. Sustainability 2019, $11,1745$. [CrossRef] 
29. Clarke, T.; Boersma, M. Sustainable Finance? A Critical Analysis of the Regulation, Policies, Strategies, Implementation and Reporting on Sustainability in International Finance; United Nations Environment Programme: Sydney, Australia, 2016.

30. United Nations. Environment Programme Finance Initiative, Principles for Responsible Banking: Key Steps to be Implemented by Signatories. United Nations: Washington, DC, USA, 2020.

31. Korslund, D.; Spengler, L. Financial Capital and Impact Metrics of Values Based Banking; Global Alliance for Banking on Values: Zeist, The Netherlands, 2012.

32. Bergedieck, L.; Maheshwari, A.; Avendano, F. Green Finance A Bottom-Up Approach to Track Existing Flows; International Finance Corporation: Washington, DC, USA, 2017.

33. Rosenman, E. The geographies of social finance: Poverty regulation through the 'invisible heart' of markets. Prog. Hum. Geogr. 2019, 43, 141-162. [CrossRef]

34. Emerson, J.; Freundlich, T.; Fruchterman, J.; Berlin, L.; Stevenson, K. Nothing Gained: Addressing the Critical Gaps in Risk-Taking Capital for Social Enterprise; Oxford University: Oxford, UK, 2007.

35. Weber, O.; Scholz, R.W.; Michalik, G. Incorporating sustainability criteria into credit risk management. Bus. Strateg. Environ. 2010, 19, 39-50. [CrossRef]

36. Fijałkowska, J.; Zyznarska-Dworczak, B.; Garsztka, P. Corporate social-environmental performance versus financial performance of banks in Central and Eastern European Countries. Sustainability 2018, 10, 772. [CrossRef]

37. Nizam, E.; Ng, A.; Dewandaru, G.; Nagayev, R.; Nkoba, M.A. The impact of social and environmental sustainability on financial performance: A global analysis of the banking sector. J. Multinatl. Financ. Manag. 2019, 49, 35-53. [CrossRef]

38. Jan, A.; Marimuthu, M.; Hassan, R. Sustainable business practices and firm's financial performance in islamic banking: Under the moderating role of islamic corporate governance. Sustainability 2019, 11, 6606. [CrossRef]

39. Paulet, E.; Parnaudeau, M.; Relano, F. Banking with Ethics: Strategic Moves and Structural Changes of the Banking Industry in the Aftermath of the Subprime Mortgage Crisis. J. Bus. Ethics 2015, 131, 199-207. [CrossRef]

40. Raut, R.; Cheikhrouhou, N.; Kharat, M.B. Sustainability in The Banking Industry: A Strategic Multi-Criterion Analysis. Bus. Strateg. Environ. 2017, 26, 550-568. [CrossRef]

41. Zeidan, R.; Boechat, C.; Fleury, A. Developing a Sustainability Credit Score System. J. Bus. Ethics 2015, 127, 283-296. [CrossRef]

42. Shum, K.; Yam, S.L. Ethics and Law: Guiding the Invisible Hand to Correct Corporate Social Responsibility Externalities. J. Bus. Ethics 2011, 98, 549-571. [CrossRef]

43. Igbudu, N.; Garanti, Z.; Popoola, T. Enhancing bank loyalty through sustainable banking practices: The mediating effect of corporate image. Sustainability 2018, 10, 4050. [CrossRef]

44. Dell'Atti, S.; Trotta, A.; Iannuzzi, A.P.; Demaria, F. Corporate Social Responsibility Engagement as a Determinant of Bank Reputation: An Empirical Analysis. Corp. Soc. Responsib. Environ. Manag. 2017, 24, 589-605. [CrossRef]

45. Ibe-Enwo, G.; Igbudu, N.; Garanti, Z.; Popoola, T. Assessing the Relevance of Green Banking Practice on Bank Loyalty: The Mediating Effect of Green Image and Bank Trust. Sustainability 2019, 11, 4651. [CrossRef]

46. Ferreira, F.A.; Jalali, M.S.; Meidutè-Kavaliauskienè, I.; Viana, B.A. A metacognitive decision making based-framework for bank customer loyalty measurement and management. Technol. Econ. Dev. Econ. 2015, 21, 280-300. [CrossRef]

47. Bossle, M.B.; de Barcellos, M.D.; Vieira, L.M.; Sauvée, L. The drivers for adoption of eco-innovation. J. Clean. Prod. 2016, 113, 861-872. [CrossRef]

48. International Finance Corporation. FELABAN, and EcoBusiness Fund, Green Finance Latin America 2017 Report: What is the Latin American Banking Sector Doing to Mitigate Climate Change? International Finance Corporation: Washington, DC, USA, 2017.

49. Dingwerth, K.; Eichinger, M. Tamed transparency: How information disclosure under the global reporting initiative fails to empower. Glob. Environ. Polit. 2010, 10, 74-96. [CrossRef]

50. Rasche, A. A Necessary Supplement: What the United Nations global compact is and is not. Bus. Soc. 2009, 48, 511-537. [CrossRef]

51. Windolph, S.E. Assessing Corporate Sustainability Through Ratings: Challenges and Their Causes. J. Environ. Sustain. 2011, 1, 1-22. [CrossRef] 
52. Scholtens, B. Corporate social responsibility in the international banking industry. J. Bus. Ethics 2009, 86, 159-175. [CrossRef]

53. Figge, F.; Hahn, T. The cost of sustainability capital and the creation of sustainable value by companies. J. Indust. Ecol. 2005, 9, 47-58. [CrossRef]

54. Ng, C.; Rezaee, Z. Business sustainability performance and cost of equity capital. J. Corp. Financ. 2015, 34, 128-149. [CrossRef]

55. Ruiz, J.G.; Arboleda, C.A.; Botero, S. A Proposal for Green Financing as a Mechanism to Increase Private Participation in Sustainable Water Infrastructure Systems: The Colombian Case. Procedia Eng. 2016, 145, 180-187. [CrossRef]

56. Shishlov, I.; Bajohr, T.; Deheza, M.; Cochran, I. Using Credit Lines to Foster Green Lending: Opportunities and Challenges; Institute for Climate Economics: Paris, France, 2017.

57. United Nations. Environment Programme Finance Initiative, Green Financial Products and Services Current Trends and Future Opportunities in North America; United Nations: Toronto, ON, Canada, 2007.

58. Collins, D. Green leases and green leasing in theory and in practice: A state of the art review. Facilities 2019, 37, 813-824. [CrossRef]

59. Migliorelli, M.; Dessertine, P. Time for new financing instruments? A market-oriented framework to finance environmentally friendly practices in EU agriculture. J. Sustain. Financ. Invest. 2018, 8, 1-25. [CrossRef]

60. Waltman, L. A review of the literature on citation impact indicators. J. Informetr. 2016, 10, 365-391. [CrossRef]

61. Olawumi, T.O.; Chan, D.W.M. A scientometric review of global research on sustainability and sustainable development. J. Clean. Prod. 2018, 183, 231-250. [CrossRef]

62. Dominko, M.; Verbič, M. The Economics of Subjective Well-Being: A Bibliometric Analysis. J. Happiness Stud. 2019, 20, 1973-1994. [CrossRef]

63. Ertz, M.; Leblanc-Proulx, S. Sustainability in the collaborative economy: A bibliometric analysis reveals emerging interest. J. Clean. Prod. 2018, 196, 1073-1085. [CrossRef]

64. Nájera-Sánchez, J. A Systematic Review of Sustainable Banking through a Co-Word Analysis. Sustainability 2019, 12, 278. [CrossRef]

65. Loan Market Association. Green Loan Principles, Supporting Environmentally Sustainable Economic Activity; Loan Market Association: London, UK, 2018.

66. International Capital Market Association. Social Bond Principles, Voluntary Process Guidelines for Issuing Social Bonds; International Capital Market Association: París, France, 2018.

67. Forstater, M.; Zhang, N. Definitions and Concepts: Background Note; United Nations Environmental Programme: Geneva, The Netherlands, 2016.

68. European Political Strategy Centre. Financing Sustainability: Triggering Investments for the Clean Economy. EPSC Strateg. Notes 2017, 25, 18.

69. Almeida, M.; Filkova, M. América Latina y el Caribe Estado Del Mercado De Las Finanzas Verdes; Climate Bonds Initiative: London, UK, 2019.

70. Sustainable Banking Network. Global Progress Report of the Sustainable Banking Network: Innovations in Policy and Industry Actions in Emerging Markets; Sustainable Banking Network: Washington, DC, USA, 2019.

71. Lindlein, P. Mainstreaming environmental finance into financial markets-Relevance, potential and obstacles. In Greening the Financial Sector: How to Mainstream Environmental Finance in Developing Countries; Springer: Heidelberg/Berlin, Germany, 2012; pp. 1-30.

72. Heinemann, K.; Zwergel, B.; Gold, S.; Seuring, S.; Klein, C. Exploring the supply-demand-discrepancy of sustainable financial products in Germany from a financial advisor's point of view. Sustainability 2018, 10, 944. [CrossRef]

73. Escrig-Olmedo, E.; Muñoz-Torres, M.J.; Fernández-Izquierdo, M.Á. Fernández-Izquierdo, Sustainable development and the financial system: Society's perceptions about socially responsible investing. Bus. Strateg. Environ. 2013, 22, 410-428. [CrossRef]

74. Weber, O.; Fenchel, M.; Scholz, R.W. Empirical analysis of the integration of environmental risks into the credit risk management process of European banks. Bus. Strateg. Environ. 2008, 17, 149-159. [CrossRef]

75. Geobey, S.; Weber, O. Lessons in operationalising social finance: The case of Vancouver City Savings Credit Union. J. Sustain. Financ. Invest. 2013, 3, 124-137. [CrossRef]

76. Weber, I. Corporate sustainability and financial performance of Chinese banks. Sustain. Account. Manag. Policy J. 2017, 8, 358-385. [CrossRef] 
77. Laguir, I.; Marais, M.; El Baz, J.; Stekelorum, R. Reversing the business rationale for environmental commitment in banking: Does financial performance lead to higher environmental performance? Manag. Decis. 2018, 56, 358-375. [CrossRef]

78. Nikolaou, I.E.; Kourouklaris, G.; Tsalis, T.A. A framework to assist the financial community in incorporating water risks into their investment decisions. J. Sustain. Financ. Invest. 2014, 4, 93-109. [CrossRef]

79. Zimmermann, S. Same same but different: How and why banks approach sustainability. Sustainability 2019, 11, 2267. [CrossRef]

80. Bowman, M. The Role of the Banking Industry in Facilitating Climate Change Mitigation and the Transition to a Low-Carbon Global Economy. Environ. Plan. Law J. 2010, 27, 448-468.

81. Clark, R.; Reed, J.; Sunderland, T. Bridging funding gaps for climate and sustainable development: Pitfalls, progress and potential of private finance. Land Use Policy 2018, 71, 335-346. [CrossRef]

82. Polzin, F. Mobilising private finance for low-carbon innovation-A systematic review of barriers and solutions. Renew. Sustain. Energy Rev. 2017, 77, 525-535. [CrossRef]

83. Jo, H.; Kim, H.; Park, K. Corporate Environmental Responsibility and Firm Performance in the Financial Services Sector. J. Bus. Ethics 2015, 131, 257-284. [CrossRef]

84. Steckel, C.; Jakob, M. The role of financing cost and de-risking strategies for clean energy investment. Int. Econ. 2018, 155, 19-28. [CrossRef]

85. Amin, A.L.; Dimsdale, T.; Jaramillo, M. Greening the Financial Sector-From Demonstration to Scale in Green Finance. In Designing Smart Green Finance Incentive Schemes: The Role of the Public Sector and Development Banks; E3G Working Paper; Third Generation Environmentalism: London, UK, 2014; p. 32.

86. Carolina Rezende de Carvalho Ferreira, M.; Amorim Sobreiro, V.; Kimura, H.; Luiz de Moraes Barboza, F. A systematic review of literature about finance and sustainability. J. Sustain. Financ. Invest. 2016, 6, 112-147. [CrossRef]

87. Sobhani, F.A.; Amran, A.; Zainuddin, Y. Sustainability disclosure in annual reports and websites: A study of the banking industry in Bangladesh. J. Clean. Prod. 2012, 23, 75-85. [CrossRef]

88. Rahman, A. Micro-Credit initiatives for equitable and sustainable development: Who pays? World Dev. 1999, 27, 67-82. [CrossRef]

89. Sustainable Banking Network. A Sustainable Banking Network (SBN) Brazil Flagship Report Addendum to SBN Global Progress Report; Sustainable Banking Network: Washington, DC, USA, 2019.

90. Inter-American Development Bank. Informe Fintech en América Latina 2018: Crecimiento y Consolidación; Inter-American Development Bank: Washington, DC, USA, 2018.

91. Sustainable Banking Network. A Sustainable Banking Network (SBN) Colombia Flagship Report Addendum to SBN Global Progress Report; Sustainable Banking Network: Washington, DC, USA, 2019.

92. United Nations. Environment Programme Finance Initiative, Integración de la Sostenibilidad en las Instituciones Financieras Latinoamericanas: Énfasis en los Aspectos Medio Ambientales; United Nations: Ginebra, Switzerland, 2012.

(C) 2020 by the authors. Licensee MDPI, Basel, Switzerland. This article is an open access article distributed under the terms and conditions of the Creative Commons Attribution (CC BY) license (http://creativecommons.org/licenses/by/4.0/). 

Article

\title{
Detection of Financial Inclusion Vulnerable Rural Areas through an Access to Cash Index: Solutions Based on the Pharmacy Network and a CBDC. Evidence Based on Ávila (Spain)
}

\author{
Sergio Luis Náñez Alonso *, Javier Jorge-Vazquez and Ricardo Francisco Reier Forradellas \\ Department of Economics-DEKIS Research Group, Catholic University of Ávila, Canteros St., \\ 05005 Ávila, Spain; Javier.jorge@ucavila.es (J.J.-V.); ricardo.reier@ucavila.es (R.F.R.F.) \\ * Correspondence: sergio.nanez@ucavila.es
}

Received: 20 July 2020; Accepted: 8 September 2020; Published: 11 September 2020

\begin{abstract}
The ability to access quality financial services and cash has been indicated by various organizations, such as the World Bank or UN, as a fundamental aspect to guarantee regional sustainable development. However, access to cash is not always guaranteed, especially in rural regions. The present study is based in the Ávila region of Spain. A parameter called the "access to cash index" is constructed here. It is used to detect rural areas where the ability to access cash and banking services is more difficult. Based on the "access to cash index", two sustainable solutions are proposed: The first (in the short term), based on extending access to cash, takes advantage of the existing pharmacy network. With this measure, a notable reduction of more than $55 \%$ of the average distance required to access this service is verified here. The second is based on the implementation of a central bank digital currency. Here, the results show an acceptance of $75 \%$. However, it is known that elderly people and those without relevant education and/or low incomes would reject its widespread use. Such a circumstance would require the development of training and information policies on the safety and effectiveness of this type of currency.
\end{abstract}

Keywords: financial inclusion; vulnerable rural areas; sustainable solutions; central bank digital currency; social sustainability; pharmacy network; sustainable development; sustainable access to cash

\section{Introduction}

In recent years, the fight against corruption and tax avoidance has been one of the most recurring pillars of the reformist agendas of most developed countries. A measure that has recently become popular to combat the shadow economy and minimize tax fraud has been the progressive elimination of cash payments. Recently, the Spanish government presented a non-law proposal for the "gradual elimination of cash payment, with the horizon of its final disappearance" in the bulletin of the Congress of Deputies [1]. However, the European Central Bank (ECB) quickly stepped up to remind the Spanish government that "ending cash could be a problem when there are failures in the underlying technical infrastructures used by payment service providers" and that "cash is appreciated as a payment instrument because it is accepted by all, fast and facilitates control over the payer's spending" The ECB added a reminder: "It is the only means of payment that allows citizens liquid and instant transactions without having to pay fees for their use". Also, Article 127 of the Treaty on the Functioning of the European Union [2] includes in its second section that it is the basic function of the European System of Central Banks (ESCB) "to define and execute the monetary policy of the Union [ ... ] and promote the proper functioning of payment systems". The destruction of jobs in the financial sector and the massive number of bank branch closures have 
increased the number of people without a bank branch in their municipality by $20 \%$, a form of financial exclusion that affects 1.13 million Spaniards in rural areas. The wave of mergers between financial institutions, which could extend to credit cooperatives, has led to the networks of offices in rural areas focusing on other activities. Likewise, the progressive digitization of the banking sector has multiplied the effects of the existing digital divide between urban and rural areas, also contributing to financial exclusion [3].

Furthermore, according to [4], Castile and León is the Spanish region that is most affected by financial exclusion, since $16 \%$ of the population (392,003 people) there does not have access to a bank branch in their municipality. Exclusion is even more pronounced in the provinces of Zamora, Segovia, and Ávila, where more than one-fifth of the inhabitants must move outside their locality to access a bank branch. In these three provinces, $29 \%, 37 \%$, and $40 \%$ of bank branches were closed, respectively, between 2008 and 2017.

As can be observed in Figure 1, Ávila has a population density of 19.9 inhabitants per square kilometer. This is much lower than the European average (108 inhabitants per square kilometer) and that of the Spanish average, which is 93 inhabitants per square kilometer [5]. Ávila, together with Teruel and Huesca (Aragon), Cuenca and Guadalajara (Castilla La Mancha), and Segovia, Soria Palencia, and Zamora (Castile and León) are the provinces with the lowest population density. This implies a greater dispersion of the resident population and therefore greater difficulty in accessing banking services. This was deduced considering the data previously provided for bank closures. This is the reason that the authors have chosen Ávila: It is a largely rural region in a developed country and has a low population density, with obvious difficulties in accessing banking services. Figures A1 and A2 in Appendix A show European regions that present a population density like those analyzed in our study region. On the one hand, Alentejo in Portugal, as well as Beira Baixa, stand out in southern Europe. In the case of France, the areas of the Alps, Lózere, and Creuse stand out. In Austria, Osttirol, Lungau, and Liezen have a similar population density to the study region considered here. In Greece, the areas of Fokida and Evrytaria are also noteworthy. Regarding northern Europe, practically all of Finland, Sweden, and Norway have a similar population density to the studied region here. Additionally, Estonia, Latvia, and Lithuania are similar, and the Scottish Highlands and surrounding islands are also similar in terms of their population density [6].

Beyond the entailing legal difficulties of the implementation of the proposal considered here, i.e., the legal difficulties of the elimination of cash, the authors propose to analyze the possible effect that this measure would have in a Spanish province, namely, Ávila. To this end, the entailing problems of elimination of cash will be analyzed from the perspective of financial inclusion, moreover, taking into account, as argued in [7], that an inclusive financial system "enhances efficiency and welfare by providing avenues for secure and safe saving practices and by facilitating a whole range of efficient financial services. Through efficient allocation of productive resources, an inclusive financial system increases investment, raises economic growth and promotes capital formation".

A map is prepared here that collates the areas with the greatest difficulty of accessing cash in Ávila, so that it can be used by the relevant authorities. An access to cash index in the province is designed here. One of the ideas shown by the authors here is to improve access to cash using the existing extensive network of pharmacies in the region. This idea is similar to the use of start-ups in Ecuador between 2014 and 2019, which consisted of establishing "transactional kiosks operating in remote and rural areas" and "the use of smartphones or tablets". In the case of Ecuador, $31.5 \%$ of the population lives in rural areas. Only $42 \%$ of people living in rural areas have access to cash due to the lack of financial services in these areas [8]. Finally, via a questionnaire, the use of cash and the acceptance of a central bank digital currency (CBDC) as a means of payment to replace cash is analyzed here. 


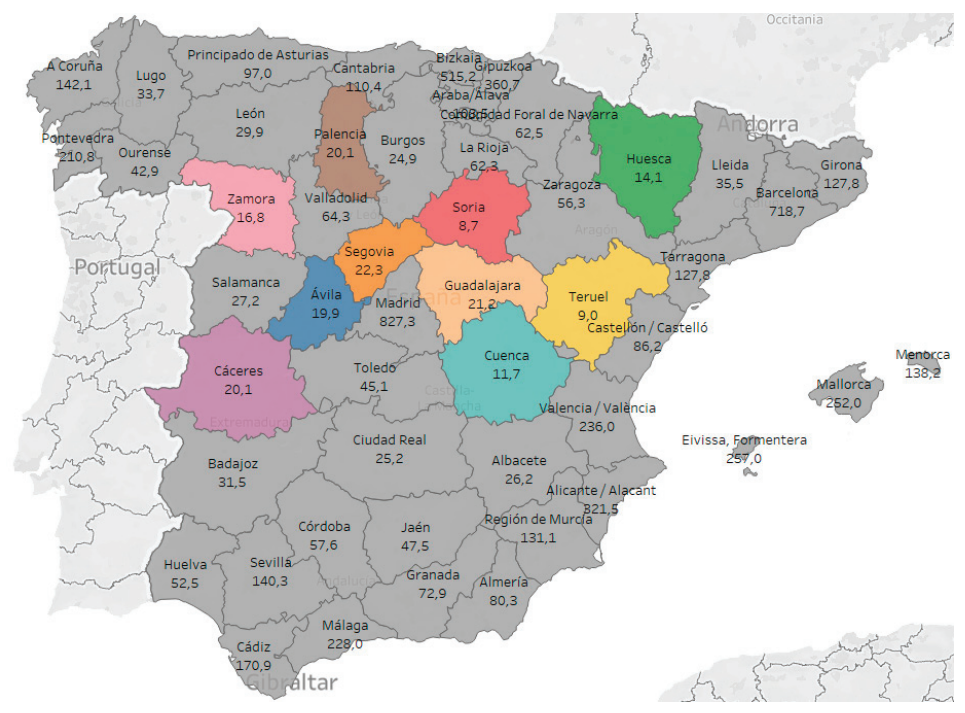

Figure 1. Population density (persons per square kilometer) in 2019 by Spanish province. Source: Author's elaboration based on data from Eurostat and Tableau Desktop Professional Edition.

The article has the following structure: The advantages and disadvantages derived from the elimination of cash, financial inclusion, and the use of cash are considered. For the methodology here, the detection of vulnerable areas regarding access to cash is carried out. This methodology section includes data collection, analyses, and cash access maps. An access to cash index is established and the detection of vulnerable areas is thus carried out. A proposal for sustainable solutions to increase the access to cash index in vulnerable areas is suggested. An expansion of cashback points with the existing pharmacy network and the implementation of a CBDC to increase access to cash are both highlighted. Finally, the results and conclusions of this work are discussed.

\section{Advantages and Disadvantages Derived from the Elimination of Cash}

A first approach to the problem of financial inclusion unquestionably requires its definition. In general terms, financial inclusion implies the need to provide the entire population with access to adequate financial services at an affordable cost according to three criteria: Justice, transparency, and equity [9-11]. In fact, according to the World Bank, financial inclusion means "access to useful and affordable financial products that meet the needs of people (transactions, payments, savings, credit and insurance) and is provided in a responsible and sustainable manner" [12]. Furthermore, financial inclusion has been declared by the World Bank itself and the UN as a factor that will help achieve 7 of the 17 Sustainable Development Goals (SDGs) [13]. The work in [14] identifies five different ways in which the phenomenon of financial exclusion materializes: Access exclusion, condition exclusion, price exclusion, marketing exclusion, and self-exclusion. In the present work, attention will be mainly focused on the first dimension, that is, on the exclusion of certain segments of population from the financial system, mainly for reasons of distance or demographic dispersion. In this way, the use of cash is configured as a fundamental pillar of financial inclusion. According to [15], "a cashless transaction refers to an economic setting whereby goods and services are transacted without cash".

At this point, a broad set of advantages and disadvantages can be identified as results of eliminating the use of cash.

As the elimination of cash is appreciable, it brings with it a set of advantages and disadvantages that have been widely analyzed in the economic literature. Thus, [16] has affirmed that a society without 
cash would pose a challenge for a central bank, where this challenge is related to financial stability. In turn, [17] has pointed out that this elimination of cash as a form of money would bring associated problems that may "compromise privacy" but also undoubted advantages, such as "crime reduction", pertaining to crimes related to money laundering or tax evasion, along with a possible lowering of taxes resulting from higher state collection. In [18], the transition costs of a society that changes from using cash to going without cash were analyzed, detecting that, depending on the type of transaction, cash was preferred over other means of payment.

In [19], it was argued that one of the advantages of eliminating cash would be a greater ease of applying monetary policy, as well as reducing the "cost of using cash (estimated to be at least $€ 50$ billion euros per year in the Euro system"), but this also points out the exclusion of certain groups as a great disadvantage, as "electronic money is a service usually connected to a bank account and the bank can and does exclude people from that service." In [20], it was pointed out that one of the advantages of implementing forms of payment other than cash is bringing advantages to areas where access to cash is difficult, especially if using contactless mobile or card payments; however, that can also pose problems for those people who do not handle this technology well. In [21] and [22], it was concluded that the main advantage of reducing or eliminating cash is the reduction in costs: "During this decade, many banks have fostered cashless payment methods in the hope of reducing overall payment costs". In [23], advantages derived from the elimination of cash were pointed out in their analysis, where one may "tax the underground economy, promote business efficiency and cover up criminal or lobbyist activities". In the investigations of [24-26], the main disadvantages of a cashless society were identified as "user privacy problems", as well as "hacking problems"; despite this, for these authors, the advantages were superior when noting that "there are major social and economic benefits to a cashless society, such as reduction in cash related crimes and monetary benefits [... ] cash is bulky and heavy to carry by the customer. A cashless solution, even a smart card, may well be smaller and lighter".

In [27], the advantage that "cashless payment might have a positive impact on economic activities" was indicated, while [28] pointed out "reduced policy control of the monetary system" as a disadvantage of the reduction or elimination of the use of cash and also the possible security problems derived from "cybercrime". In [29], it was affirmed in their study that a cashless society can pose a problem when applying monetary policy by the central bank, as well as highlighting dangers derived from personal data protection. At this point in the analysis, we can therefore indicate that there is no doubt that cash "is essential for the operation of a modern economy, but its nature has varied substantially over time" [30]. According to [31], the elimination of cash brings some advantages, such as the following: "Unlike traditional cash transactions, cashless payments discourage robbery and other cash related crimes".

In the study by [32], the fall in the use of cash in two countries was analyzed, namely, Canada and Sweden. The authors concluded that "cash does not play a significant role in monetary policy, and so its disappearance generally would have no material adverse effect on monetary policy", but that "the emergence of a cashless society could affect key concerns of a central bank, including seigniorage, monetary policy, payments and financial stability considerations". Also, Ref. [33] has argued that electronic money brings about privacy problems for users. In [34], advantages of a cashless society were pointed out, including "a great and rapid development of payment technology, a reduction of the shadow economy (with the consequent increase in revenue from the state), personal security by not having to carry cash "in your pocket"; and the reduction of crime". However, the same author identified "the financial exclusion of the poor and elderly), the difficulty of accessing banking services in rural areas, as well as the increase in cybercrime and the decrease in user privacy" as the main disadvantages. Along these same lines, Ref. [35] pointed out that Swedish merchants continue to accept cash but that cash will have surely disappeared in favor of other means of payment by 2023. Additionally, the aforementioned study identified positive factors derived from cash elimination pertaining to crime reduction and technological development; however, as disadvantages, it pointed to the exclusion of certain groups, such as the elderly, the disabled, or immigrants. In the study carried out by [36], it was concluded that "possible proposals that advocate the total elimination of cash in the eurozone should be carried out gradually and with strong public support for sectors of the population with lower levels 
of income and education", thus hinting at the disadvantage related to social inclusion. The European Central Bank issued a speech in February 2019 [37] (European Central Bank: "The possibility of paying in cash is still very important for certain social sectors that, for various and legitimate reasons, prefer to use cash instead of other means of payment. It is widely accepted and fast and allows the payer to control their expenses. In addition, it is a means of payment that allows citizens to settle operations instantly, and the only means of payment in money from the central bank and at its nominal value that does not entail the legal possibility of charging a commission for its use. Also, paying in cash does not require a functional technical infrastructure and can always be used, which is very important in case of interruption of electronic payments". Available at: https: //eurancla/legal-content/EN/TXT/PDF/?uri=CELEX:52019AB0004\&from=ES), in which it highlighted all the advantages that cash payments currently represent, especially for certain groups. The work of [38] confirmed that the use of cryptocurrencies as a means of payment (instead of cash) can help to increase the collection of the state since the "grey economy" is reduced. In [39], their study analyzed the effects of a "cashless" society on corruption and related crimes, concluding that the elimination of cash helps to reduce this type of crime. The work carried out in [40] pointed in the same direction, i.e., that a decrease in the use of cash and an increase in digital means of payment, alluding to a central bank digital currency (CBDC), could bring about the disadvantage of an increase in cybercrime, as well as consequences that are adverse to financial stability; however, on the other hand, it would allow some advantages to be achieved; among them, a reduction in the shadow economy and greater collection of the state, technological development, and an increase in speed of the application of monetary policy by the central bank. In [41], it was recently indicated that "central banks need to foster innovation to tackle current shortcomings in payments and ensure that households and businesses have access to a diverse set of safe and efficient payment methods".

As found in [42], the disadvantages derived from dependence solely on technology, as well as the risk of hacking, can be corrected by public campaigns that "enhance the adoption of mobile payment services" and that "service providers should focus on promoting the benefits." Another advantage derived from the elimination of cash was reinforced by [43], with "empirical evidence supporting this claim: Credit and debit card payments are negatively related to VAT evasion", where a CBDC would reinforce this situation and serve to increase collection from the state via taxes.

On the other hand, [44] pointed out that the elimination of cash can have a positive consequence, i.e., that "eliminating cash leads to inefficient investments"; however, they also pointed out that this would lead to certain social problems, such as the demand for illegal goods and their associated transactions, which would be carried out via more complex ways. However, the authors pointed out that "the move towards a cashless society has, no doubt, its positive effects". The position of these authors agrees with that maintained by [45], considering an Italian case that indicates that "the cashless society is the right direction and it is not far from achievement. Italy, by heading towards it, can give a stimulus to the economy and finally align to the other European countries that are benefiting from cashless transactions".

From this section, we can extract that, despite the advantages derived from the elimination of cash, there are other series of disadvantages that should not be ignored by governments and banking authorities; especially those related to financial inclusion. This article therefore contributes to continuing the open debate on whether to eliminate cash or not, and the corresponding effects are analyzed based on the current situation in an area of Spain where it is already difficult to access cash.

The advantages and disadvantages derived from the elimination of cash are summarized in Table 1. 
Table 1. Advantages and disadvantages derived from the elimination of cash.

\begin{tabular}{ll}
\hline \multicolumn{1}{c}{ Advantages of Eliminating Cash } & \multicolumn{1}{c}{ Disadvantages of Eliminating Cash } \\
\hline Greater ease of the central bank to apply monetary policy. & $\begin{array}{l}\text { Absolute dependence on electronic means for payments: } \\
\text { network outages, power outages etc. }\end{array}$ \\
\hline $\begin{array}{l}\text { Higher collection of the state, when "transactions" from the } \\
\text { underground economy emerge. }\end{array}$ & $\begin{array}{l}\text { Increase in inequality I: Exclusion of unprofitable clients for } \\
\text { financial institutions. }\end{array}$ \\
\hline $\begin{array}{l}\text { Crime reduction: Money laundering crimes, tax evasion } \\
\text { and other illegal activities such as drug or arms trafficking. }\end{array}$ & $\begin{array}{l}\text { Increase in inequality II: Difficulty in making transactions } \\
\text { on the part of the elderly, people with disabilities, poor } \\
\text { people with problems accessing bank accounts, etc. }\end{array}$ \\
\hline $\begin{array}{l}\text { Technological innovation: new means of payment and } \\
\text { official virtual currencies. }\end{array}$ & $\begin{array}{l}\text { Privacy problems: access to data and customer transactions } \\
\text { when everything is registered. }\end{array}$ \\
\hline $\begin{array}{l}\text { Greater physical security for businesses, avoiding robberies } \\
\text { since they do not have cash on their premises. }\end{array}$ & Security problems: Hacking and theft of customer data. \\
\hline Cost savings in issuing banknotes and coins. & Financial instability problems. \\
\hline \multicolumn{2}{c}{ Source: Author's elaboration. }
\end{tabular}

\section{Financial Inclusion and Use of Cash}

As stated in [12], "half of the world adult population (3.5 billion inhabitants) does not have a bank account in a financial institution". The way in which financial inclusion has traditionally been measured has been through instruments such as a multidimensional index of financial inclusion (MIFI), which is a harmonized index of financial inclusion that is comparable between countries and for the same country when analyzing different periods. A MIFI evaluates the use, access, and quality of a country's financial services using 18 World Bank indicators [46]. These 18 indicators are grouped into three blocks or components. First, we find the use, which in turn presents three indicators: The existence of financial, savings, and credit products. This information is provided by the World Bank through the Global Findex database [47]. Second, the quality. This is based on four indicators, which are the following: Trust in the financial system, the cost of financial services, access points, and the required documentation. Finally, and thirdly, there is access. This indicator measures the number of personal service points (bank branches and the like) and access to services through machines such as automated teller machines (ATMs) and the like. This information is obtained from studies such as the "International Monetary Fund's Financial Access Survey" (FAS), provided by the International Monetary Fund. According to [48], access is measured with four indicators: (1) The number of ATMs per 100,000 adults, (2) the number of bank branches for those 100,000 adults, (3) the number of bank branches for each 1000 square meters, and (4) the number of ATMs per 1000 square meters. In our study, focused on Spain and more specifically on the province of Ávila, we have carried out measurement by carrying out a more complete study through an index of access to cash, which is an analysis method that goes beyond these indicators.

Beyond the Global Findex database and the International Monetary Fund's Financial Access Survey, numerous scientific-economic studies have already been carried out on access to banking services, especially for access to cash, and the effects of the elimination of cash on certain areas and groups. Most of them have focused on less developed countries.

In all the previous studies (see Table 2), it was highlighted that access to cash, both in physical and digital formats, is very important for citizens and merchants, and in general for the economy. However, in many of these investigations, it was highlighted that the path to a cashless society needs to be carefully studied. Specifically, avoiding the exclusion of particularly vulnerable population groups, such as the elderly, the young, or the poor. In the case of the elderly, this relates to their mobility limitations (difficulty in getting around and getting cash) or difficulty in managing digital applications (technological gap). In the case of young people, this pertains to them not being profitable customers for the bank when considering that they must operate or maintain a digital account but do not generate enough business for the bank. Regarding the poor, this exclusion pertains to restrictions on access to 
financial channels and to the technological devices necessary to carry out transactions. Therefore, any policy that is taken regarding the elimination of cash and progress towards a "cashless society" must be made considering these factors.

Table 2. Studies on access to banking services and use/demand for cash.

\begin{tabular}{|c|c|c|c|c|}
\hline Study & Country & Year & Author/s & Results/Conclusions \\
\hline $\begin{array}{l}\text { Comparative Analysis of the Changes } \\
\text { in Cash Demand in Hungary. }\end{array}$ & Hungary & 2020 & [49] & $\begin{array}{l}\text { The realistic goal for Hungary should primarily be to } \\
\text { decelerate the expansion, as experiences show that a nominal } \\
\text { decrease in cash volume requires the long-term and } \\
\text { concurrent existence of several factors. }\end{array}$ \\
\hline $\begin{array}{l}\text { ¿Es la Eurozona un área óptima para } \\
\text { suprimir el efectivo? Un análisis } \\
\text { sobre la inclusión financiera y el uso } \\
\text { de efectivo. }\end{array}$ & Eurozone & 2019 & [36] & $\begin{array}{l}\text { Possible proposals that advocate the total elimination of cash } \\
\text { in the Eurozone should be carried out gradually and with } \\
\text { strong public support for sectors of the population with } \\
\text { lower levels of income and education. }\end{array}$ \\
\hline $\begin{array}{l}\text { The Acceptance Model toward } \\
\text { Cashless Society in Thailand. }\end{array}$ & Thailand & 2019 & [50] & $\begin{array}{l}\text { The acceptance of the cashless society in Thailand is high, } \\
\text { and the industry is encouraged to try to continue in } \\
\text { this direction. }\end{array}$ \\
\hline $\begin{array}{l}\text { Building a Cashless Society: The Swedish } \\
\text { Route to the Future of Cash Payments }\end{array}$ & Sweden & 2019 & [35] & $\begin{array}{l}\text { consumers [ ... ] are seemingly more interested in using } \\
\text { electronic services than cash. The laws and the system } \\
\text { governing cash handling stimulate a reduction of cash. } \\
\text { Demographics: Young people prefer electronic payments vs. } \\
\text { elderly, who have a higher tendency to use cash. The } \\
\text { alternatives to cash that are likely to become more attractive } \\
\text { for consumers. }\end{array}$ \\
\hline $\begin{array}{l}\text { A great leap of faith: The cashless } \\
\text { agenda in Digital India }\end{array}$ & India & 2019 & [51] & $\begin{array}{l}\text { The author shows concern about the rapid expansion of } \\
\text { electronic money and the effects it can have on society, } \\
\text { beyond the economic analysis of inclusion and use. }\end{array}$ \\
\hline $\begin{array}{l}\text { Influence of Cashless Society } \\
\text { Socialization toward Trust Transaction } \\
\text { Culture in Jakarta, Indonesia }\end{array}$ & Indonesia & 2018 & [52] & $\begin{array}{l}\text { People in Jakarta will not be too significant to trust the } \\
\text { non-cash transaction system. It can be found that the } \\
\text { heterogeneous Jakarta community with educational, } \\
\text { occupational, and social levels is the factor determining the } \\
\text { use of cash or not. }\end{array}$ \\
\hline Malaysia Towards Cashless Society. & Malaysia & 2018 & [53] & $\begin{array}{l}\text { Consumers these days trust more on the cashless } \\
\text { transaction. A cashless society, with all its benefits and } \\
\text { drawbacks, is undeniably maturing in Malaysia. }\end{array}$ \\
\hline $\begin{array}{l}\text { Prospects of Nigeria's ICT } \\
\text { Infrastructure for E-Commerce and } \\
\text { Cashless Economy. }\end{array}$ & Nigeria & 2016 & [56] & $\begin{array}{l}\text { Cashless policy needs to be fully implemented while } \\
\text { public-private sectors collaboration and partnership should } \\
\text { be strengthened especially at the national level. Education } \\
\text { should be inculcated in the school curriculum right from the } \\
\text { primary education to the tertiary institutions in order to } \\
\text { increase the knowledge base and develop human capacity of } \\
\text { the economy. }\end{array}$ \\
\hline $\begin{array}{l}\text { Mapping mobile money in Rwanda: } \\
\text { The Mvisa project. }\end{array}$ & Rwanda & 2016 & [57] & $\begin{array}{l}\text { The goal of mVISA is to meet the needs of underserved and } \\
\text { unbanked Rwandans by providing relevant, affordable and } \\
\text { accessible financial services. It will allow clients to easily } \\
\text { access their bank's account via their phone and encourage } \\
\text { non- account holders mainly rural folks to become bankable. } \\
\text { The general public needs to know where to find an mVisa } \\
\text { agent who can pay real cash withdrawn or transferred from } \\
\text { remote accounts. }\end{array}$ \\
\hline
\end{tabular}

Source: Author's elaboration based on referenced studies.

\section{Methodology: Detection of Vulnerable Areas of Access to Cash}

According to [48], access to cash is measured with four indicators: (1) The number of ATMs per 100,000 adults, (2) the number of bank branches per those 100,000 adults, (3) the number of bank branches per 1000 square meters, and (4) the number of ATMs per 1000 square meters. In the present study, the geographic scope of research is centered in the province of Ávila (Spain) as an example 
of an aging province with a low population density. Data extraction was carried out based on the methodology described below. However, once the data were collected, the construction of a specific "access to cash index" was carried out based on the methodologies proposed by [58], applied to the case of South Wales (United Kingdom), by [59], applied in the city of Bristol (United Kingdom), and by [60], applied in Australia, and following some questions have been dealt with by considering the methodologies of [61], which was applied in Sweden, or [62], which was applied in Portugal. However, variations have been introduced to adapt the methodology to the particularities in which the banking and savings system operates in Spain.

The method used here will allow identification of areas where citizens have easy access to cash and areas where access is more difficult. This will outline the areas that public authorities should influence if they intend to reduce cash, and where they should focus their efforts on improving the financial inclusion of their citizens, based on the experience of the province of Ávila, using the indicator methodology of the International Monetary Fund to collect data, combined with the proposed and analyzed access to cash index.

The construction of the access to cash index was carried out as follows:

1. All information related to banking services in the province of Ávila was analyzed and collected. This included bank offices, savings banks (this figure does not exist in the studies of the authors cited above), and ATMs that dispense cash. In this case, no distinction was made between free ATMs or fee-charging ATMs, and there was no penalty in the index, as other authors have included, when considering fee-charging ATMs (The reason for the non-differentiation was the following: In the Spanish banking system, clients of a bank can withdraw cash at ATMs of another bank or savings bank of which they are not clients with or without a commission, provided that the financial entity is part of the same means of payment system (for example, EURO 6000 or System 4B). However, if certain amounts are exceeded in the cash withdrawal (60, 80, or 100 euros), the client who withdraws money from a bank/savings bank of which he is not a client does not bear the commission. The cash withdrawal fee is borne by the customer's bank/cashier, and if it exceeds the previous figures, the fee is not passed on to the customer. This is the reason why the withdrawal of cash is "free" or without commission or cost). Postal mail offices were also taken into account, since they provide banking services to citizens, and, additionally, businesses that offer "cashback" services were included, although, it should be noted that this is not a mode that is widely used in Spain, unlike in Anglo-Saxon areas of the world. The appendix presents tables with the data collected for each of the categories (see Table A1).

2. Once all these data were collated, we proceeded to reflect them on a map. The territorial extension features the municipal term, which is the center of the population. This can be seen in the next section of results analysis.

3. Calculation of the access to cash index was carried out. Once the number of bank branches, ATMs, post offices, or cashback points found in each municipal term were quantified, we could calculate an index of access to cash in each of the municipalities in the province of Ávila.

For the construction of the index, the type of infrastructure (bank branches, ATM, etc.) was multiplied by a score established for each type of installation, depending on the cost and accessibility of withdrawing cash from that type of infrastructure. This is reflected in the following equation Equation (1):

Access to cash index $=\sum($ bank branch $\times 1)+($ ATM $\times 3)+($ post office $\times 2)+$ $($ cashback point $\times 1)$

The system that was developed to assign a score to each type of element (bank Branch, ATM, etc.) was based on the combination of three criteria: Temporary availability, universal availability, and the need to carry out or not carry out another type of transaction. These criteria were based on those used 
by [58], which was applied to the case of South Wales (UK), and by [59], applied to the city of Bristol (UK).

Regarding the temporary availability when assigning a score, this refers to how many hours said element is available for use by people who want to access the banking service. ATMs are available $24 \mathrm{~h}$ a day, 365 days a year, while post offices, bank branches, and cashback points are subject to time restrictions that are normally determined by business hours, as well as closing for some days of the week (banks and post offices are not open on Sundays).

Regarding universal availability, we referred to whether the user must bear some type of cost when accessing said service when they are not a customer of the entity that offers the service. In the case of ATMs, as we have already mentioned, in the Spanish banking system, customers of a bank can withdraw cash at ATMs of another bank or savings bank of which they are not customers, either with a commission or without it, provided that the entity they are interacting with is a part of the same system of means of payment (for example, EURO 6000 or System 4B). However, if certain amounts are exceeded in the cash withdrawal $(60,80$, or 100 euros), the client who withdraws money from a bank/savings bank of which he is not a client does not bear the commission. The commission for cash withdrawals is borne by the client's bank/savings bank, and if it exceeds the previous figures, the commission will not be passed on to the client, meaning that the cash withdrawal is "free" or without commission or cost. In any case, "it is important that reasonable access to cash services is maintained for people in regional or remote locations as long as such access is needed", and ATMs play a very important role in this regard [60]. In the case of "Correos", the state-owned postal service in Spain, there is no such limit, as it can operate with all banking companies, and in the case of cashback points, there are limits that depend on the agreement that the business/trade has with a certain financial institution. Here, this situation is similar to that in Australia [60], where "for many regional and remote communities, Australia Post's service is the only reasonably accessible cash deposit point".

In line with the use of this score, similar initiatives are being carried out in the United Kingdom through the "Community Access to Cash Pilots initiative" program [63]. According to [64], "the needs of local communities are critical. That is why we are supporting the Community Access to Cash Pilots initiative as an additional industry measure to improve access, helping local areas develop and support solutions". Regarding the need to carry out another type of transaction, we referred to whether it was necessary for another activity (e.g., purchase, refueling of gasoline, etc.) to be carried out by the user in order to obtain the banking service to withdraw cash. In this case, this circumstance does not occur with ATMs, and neither in bank nor post offices; only in cashback points. In the United Kingdom, cashback points are widely established and "the 2019 Local Shop Report shows that 62\% of convenience stores currently offer cashback services and $100 \%$ of the stores surveyed accepted cash as a method of payment" [65], and that "convenience stores are often the only local source for cash in communities". Therefore, they are a place that is widely used by local people to obtain cash, despite the limited operating hours.

Therefore, combining these explanations with the summary contained in Table 3, a score was obtained that was later used in Equations (1) and (2). In Equation (2), an additional score was inserted and this is explained in the corresponding section. 
Table 3. Multiplier coefficient depending on the type of infrastructure.

\begin{tabular}{ccl}
$\begin{array}{c}\text { Infrastructure that } \\
\text { Allows Access to Cash }\end{array}$ & $\begin{array}{c}\text { Score by Type of } \\
\text { Infrastructure Present } \\
\text { in the Municipality }\end{array}$ & \multicolumn{1}{c}{ Explanation of the Awarded Score } \\
\hline $\begin{array}{c}\text { Bank Branches/ } \\
\text { Savings bank }\end{array}$ & 1 & $\begin{array}{l}\text { Opening hours limit, they only deliver cash to clients of } \\
\text { the bank or cashier, generally with time limits for this } \\
\text { type of operations, in some cases with cost per operation } \\
\text { of cash and not to any client. }\end{array}$ \\
\hline ATM & 3 & $\begin{array}{l}\text { Available 24 h, available to anyone, not just customers. } \\
\text { No cost (withdrawal fee) for clients. When you are not a } \\
\text { customer of that entity, but you withdraw a certain } \\
\text { amount in cash or more, the cash withdrawal operation } \\
\text { is free (without commission). }\end{array}$ \\
\hline Post Office & 2 & $\begin{array}{l}\text { Opening hours limit. They operate with many entities. } \\
\text { Cash Back Point }\end{array}$ \\
\hline
\end{tabular}

Source: Own elaboration based on methodology proposed by Tischer, Evans, and Davies (2019), and Evans, Tischer, and Davies (2020) (Note that the methodology initially proposed by the authors was adapted to the Spanish case and to the operation of the Spanish banking system, where two items were eliminated, and it is specified here that cashback practices in Spain are not widespread).

\section{Data Collection and Analysis}

To collect the necessary data, primary sources of information were used. In this case, the sources of information were the webpages of the financial entities (to extract the data from bank branches and ATMs by municipality). In the case of post offices, the website of the state postal agency "Correos" was used, and in the case of cashback points, the website of the ING group and those of the businesses adhering to the cashback format that operate in the province of Ávila were used. Regarding the bank and savings bank branches, the province of Ávila has a total of 112 (The bank branches have been obtained by consulting the websites of the following entities: Bankia BFA, Banco Santander-Popular, Banco Sabadell, Bankinter, BBVA (Banco de Bilbao-Vizcaya), as well as the Bank of Spain (2020). Most municipalities do not have a bank branch $(86 \%)$, as seen in Table 4 , which is a factor that hinders access to cash. This means that if the inhabitants of these municipalities want to have cash, they must either use their private vehicle or use public transport. The opposite extreme includes only two municipalities (Ávila, the capital and, Arévalo, the second most populous municipality, with more than five branches).

Table 4. Scale of bank branches by municipality, and percentage of municipalities with bank branch.

\begin{tabular}{ccc}
\hline Number of Bank Branches & $\begin{array}{c}\text { Number of Municipalities } \\
\text { and Bank Branches }\end{array}$ & $\begin{array}{c}\text { \% of Municipalities } \\
\text { (with Bank Branches) }\end{array}$ \\
\hline 0 branches & 214 & 86.3 \\
1 branch & 17 & 6.9 \\
2 branches & 3 & 1.2 \\
3 branches & 5 & 2.0 \\
4 branches & 6 & 2.4 \\
5 branches & 3 & 1.2 \\
More than 5 branches & 2 & 0.8
\end{tabular}

Source: Own elaboration based on data extracted from Bankia BFA, Banco Santander-Popular, Banco Sabadell, Bankinter, BBVA (Banco de Bilbao-Vizcaya Argentaria), Caixabank, Unicaja Banco, ING Direct, Citibank, Deutsche Bank, Ibercaja, Cajamar and Caja rural de Salamanca.

In the case of automatic teller machines (ATMs) operational ATMs were obtained by consulting the webpages of the following entities: Bankia BFA, Banco Santander-Popular, Banco Sabadell, Bankinter, BBVA (Banco de Bilbao-Vizcaya Argentaria), Caixabank, Unicaja Banco, ING Direct, Citibank, Deutsche Bank, Ibercaja, Cajamar and Caja rural de Salamanca (last consultation date: July 2, 2020), There are 
150 ATMs in the province of Ávila. As can be seen, as in the case of bank branches, $87.5 \%$ of the municipalities lack access to an ATM, and this is a factor that again restricts access to cash (see Table 5). This means that for the inhabitants of these municipalities, when they want to obtain cash, must use their private vehicle or use public transport to move to another municipality. At the opposite extreme are four municipalities with more than five ATMs, and therefore access to cash is easier.

Table 5. Scale of automatic teller machines (ATMs) by municipality, and percentage of municipalities with ATMs.

\begin{tabular}{ccc}
\hline Number of ATMs & Number of Municipalities and ATMs & \% of Municipalities (ATMs) \\
\hline 0 ATMs & 217 & 87.5 \\
1 ATM & 13 & 5.2 \\
2 ATMs & 4 & 1.6 \\
3 ATMs & 4 & 1.6 \\
4 ATMs & 3 & 1.2 \\
5 ATMs & 3 & 1.2 \\
More than 5 ATMs & 4 & 1.6 \\
\hline
\end{tabular}

Source: Own elaboration based on data extracted from Bankia BFA, Banco Santander-Popular, Banco Sabadell, Bankinter, BBVA (Banco de Bilbao-Vizcaya Argentaria), Caixabank, Unicaja Banco, ING Direct, Citibank, Deutsche Bank, Ibercaja, Cajamar and Caja rural de Salamanca.

Regarding post offices, the dependencies existing in the province of Ávila of the state operator of Correos were included (see Table 6). There are a total of eight offices in the province of Ávila, distributed between Ávila (capital) and the most populated municipalities, such as Arévalo or Arenas de San Pedro. This means that access to cash through the banking service that Correos can provide is only available in $3.2 \%$ of the municipalities analyzed here, and that the rest, i.e., $96.8 \%$ of municipalities, cannot access cash through the post offices of Correos (The post offices were obtained by consulting the website of the state agency Correos (last consultation date: 2 July 2020)).

Table 6. Scale of post offices by municipality, and percentage of municipalities with post office.

\begin{tabular}{ccc}
\hline Number of Post Offices & Number of Municipalities and Post Offices & \% of Municipalities (Post Offices) \\
\hline 0 offices & 240 & 96.8 \\
1 or more offices & 8 & 3.2 \\
\hline
\end{tabular}

Source: Own elaboration from data extracted from the state postal agency "Correos".

Regarding access to cash through cashback points (All the points that offer cashback services in the province of Ávila were extracted by searching the web portals of bank operators regarding the following businesses: DIA supermarkets, SHELL gas stations, GALP gas stations, ONCE kiosks, tobacconists, and other small businesses (last consultation date: 2 July 2020)), it was found that the distribution is somewhat more consistent than other means, such as post offices (see Table 7). However, a similar situation was found with ATMs. Most municipalities also do not have access to cash through cashback services (89.1\%). This modality to obtain cash is also underdeveloped in Spain, contrary to what happens in other countries, such as the United Kingdom or Ireland [66].

Table 7. Scale of cash back points by municipality, and percentage of municipalities with cash back point.

\begin{tabular}{ccc}
\hline $\begin{array}{c}\text { Number of Points with Cash } \\
\text { Back }\end{array}$ & Number of Municipalities and Cash Back Points & \% of Municipalities (Cash Back) \\
\hline 0 cashback points & 221 & 89.1 \\
1 cashback point & 19 & 7.7 \\
2 cashback points & 4 & 1.6 \\
3 cashback points & 1 & 0.4 \\
4 cashback points & 0 & 0.0 \\
5 cashback points & 0 & 0.0 \\
More than 5 cashback points & 2 & 0.8 \\
\hline
\end{tabular}

Source: Own elaboration from data contained on the website of DIA Supermarkets, SHELL Gas Stations, GALP Gas Stations, ONCE Kiosks, Tobacconists and Other small businesses. 


\subsection{Cash Access Maps}

As indicated in the second section of the methodology, once all these data were obtained (banks, ATMs, post offices, and cashback points) they were reflected on maps. The extension of this is municipal term, which is the center of the population. These maps will allow us to find areas that have greater difficulty in accessing cash.

These maps should be given priority when looking for a solution where one wants to reduce or eliminate cash. The reason for this is that they highlight areas where there are no other banking services, such as a bank office or ATM to deposit money, make withdrawals, or check balances, among other operations.

These maps should be given priority when offering other alternatives, such as financial education to use electronic banking, mobile coverage in the event of starting a virtual currency with an electronic wallet, etc.

In addition, the sum of the data collection of all these combined maps allows us to elaborate on them in the following section, based on the described methodology, to evaluate the index of access to cash.

As we can see in Figure 2, the points of access to cash in the province of Ávila follow a well-defined pattern. They are concentrated in the nuclei with the largest populations and are also centralized at the ends of the province, e.g., in the north of Madrigal de las Altas Torres and Arévalo and in the southeast of Las Navas del Marqués, Cebreros, El Tiemblo, and la Adrada, mainly. In the southern area, only the municipality of Arenas de San Pedro was identified. In the southwest, the towns of Barco de Ávila and Piedrahíta were identified, and in the east (the border area with the province of Salamanca) we did not find any notable towns. Consequently, it is expected that there will be areas in which access to cash will be difficult, requiring travel by public or private transport in order to access banking services. In order to respond to this difficulty and define which areas would be more problematic when accessing cash and to be able to solve this, it is not enough to reflect the situation in the previous maps. It is necessary to take into account the different options together for access to cash (post offices, bank or savings bank branches, ATMs, and cashback points) but also to weigh the availability with a score based on various parameters, namely, the hourly availability, the need to be a customer or not, and the requirement to carry out other transactions, such as refueling or making a purchase, together with the necessary movement from one municipality to another. 


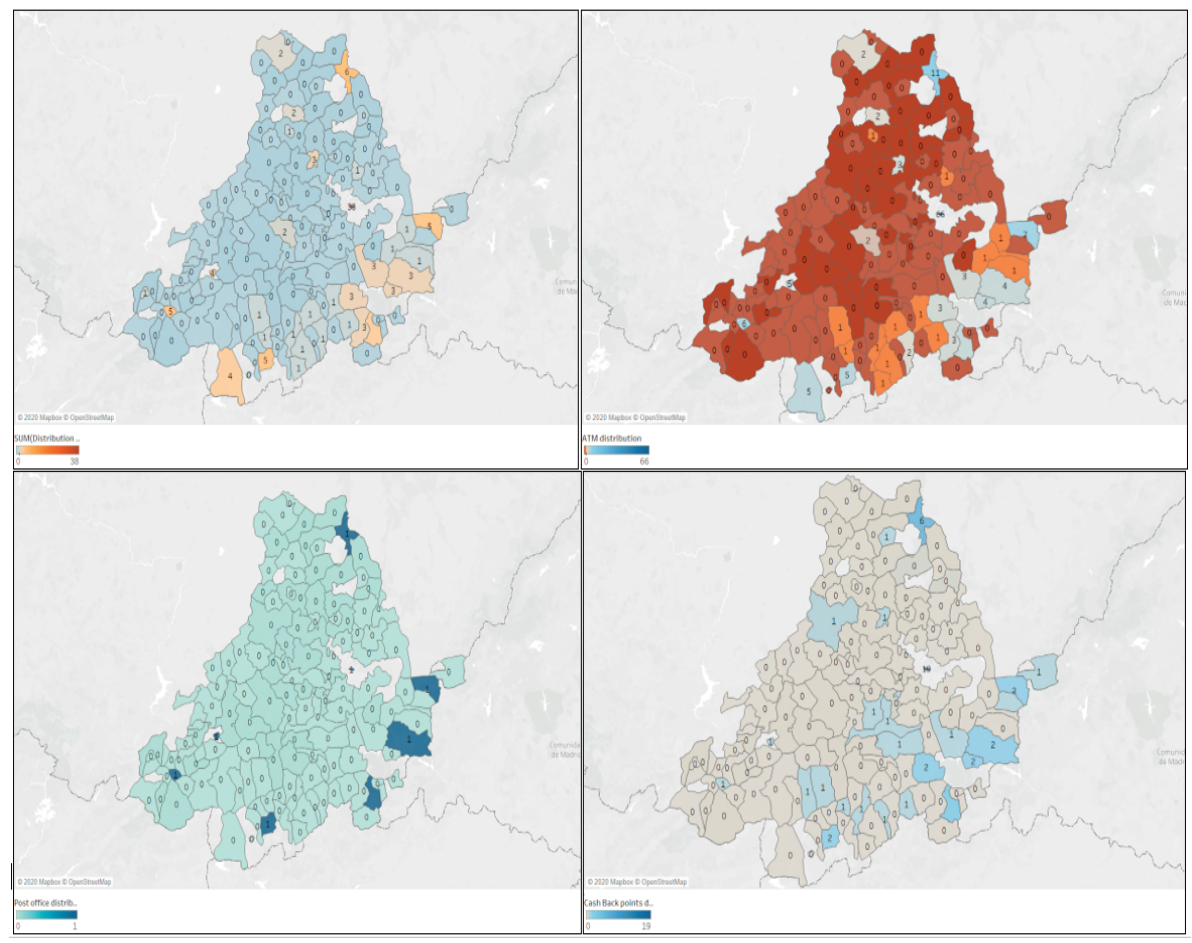

Figure 2. Distribution of bank branches, automated teller machines (ATMs), post offices, and cashback points. Source: Author's own elaboration using Tableau Desktop Professional Edition.

\subsection{Access to Cash Index and the Detection of Vulnerable Areas}

As already indicated in the previous section, in order to obtain greater accuracy regarding the existing facilities or restrictions in terms of access to cash from a territorial perspective, it is not enough just to graphically represent the points on the map. On the contrary, it is an essential requirement to weigh the point of access to cash in each municipality under study (considering post offices, bank or savings bank branches, ATMs, and cashback points) by a coefficient, i.e., that shown in Table 3 of the methodology section. Thus, applying Equation 1, the cash access index for each municipality was obtained. Additionally, it allows the detection of municipalities that are distant from points of access to cash, therefore, suggesting either no access point in the municipality, difficulties relating to having to travel by public or private transport to access banking services, time availability requirements, issues relating to whether it is necessary to be a customer or not, or the need to carry out other actions, such as refueling or making a purchase. The index results will show the most problematic areas regarding inability to access cash.

From Figure 3, it can be seen how both the capital, Ávila, and the northern area near Arévalo and the province of Valladolid, as well as the southeastern area of the province (El Tiemblo, Cebreros, Las Navas del Marqués, and La Adrada areas) present access to cash index values with optimal levels. There are municipalities with an index value of 0 , where areas within a few-kilometer radius would have an inability access to cash. However, as can be seen in Figure 3, some areas surrounding the capital are $22 \mathrm{~km}$ away from a cash access point. 


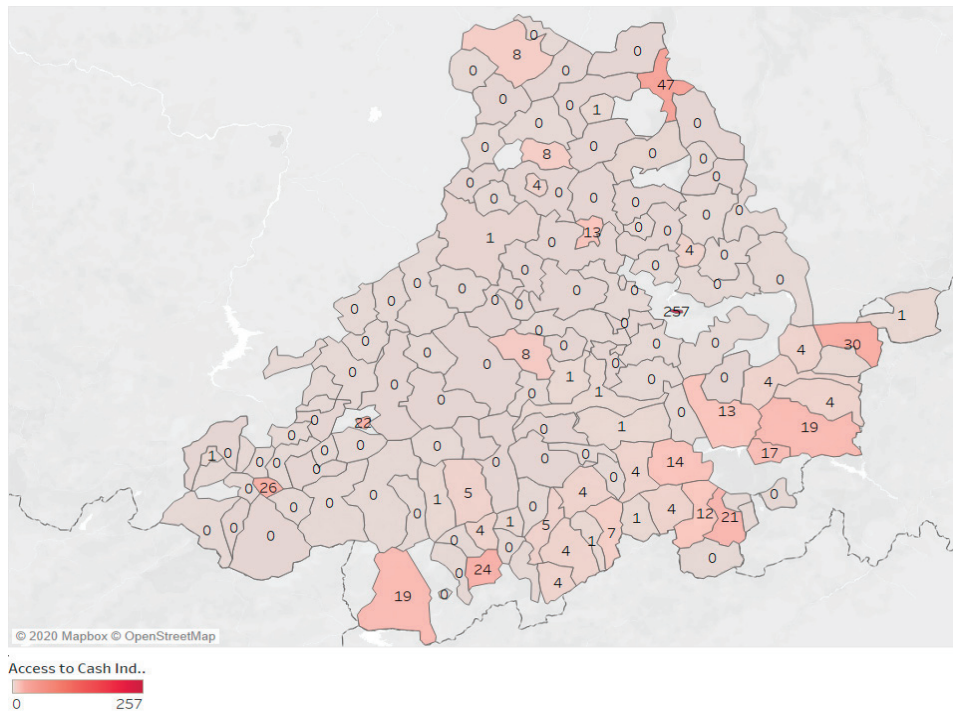

Figure 3. Access to cash index in the province of Ávila. Source: Own elaboration using Tableau Desktop Professional Edition.

In the central area of the province, the situation is like that of the surrounding area. In this case, the number of kilometers required to travel to access cash amounts to $26 \mathrm{~km}$. The southeast region is well served by cash access points and this is reflected in the index values for this region. Las Navas del Marqués, Cebreros, El Tiemblo, and La Adrada have acceptable cash access index values and this means that the distance to be traveled is lower than $15 \mathrm{~km}$, as shown in Figure 4. The southern part of the province (Arenas de San Pedro, Candeleda) and the southeast (Piedrahíta and Barco de Ávila) also have average distance values for access to cash of $14 \mathrm{~km}$. Regarding the northern area of the province and based on the calculated cash access index value, the area made up of Arévalo and Madrigal de las Altas Torres reflects that there will be an availability of access to cash in $11 \mathrm{~km}$ around the area. The area with the greatest difficulties in accessing cash, according to the proposed method, are in the west of the province and the entire southeast area bordering Salamanca Province. As we can see in Figure 4, the residents of this area may require trips of up to $30 \mathrm{~km}$ to find an access point for cash. If the average is prepared considering the capital and the four divisions made, as well as the central area, it can be extracted that inhabitants of this province will have access to cash within a radius of $19.6 \mathrm{~km}$ on average. 

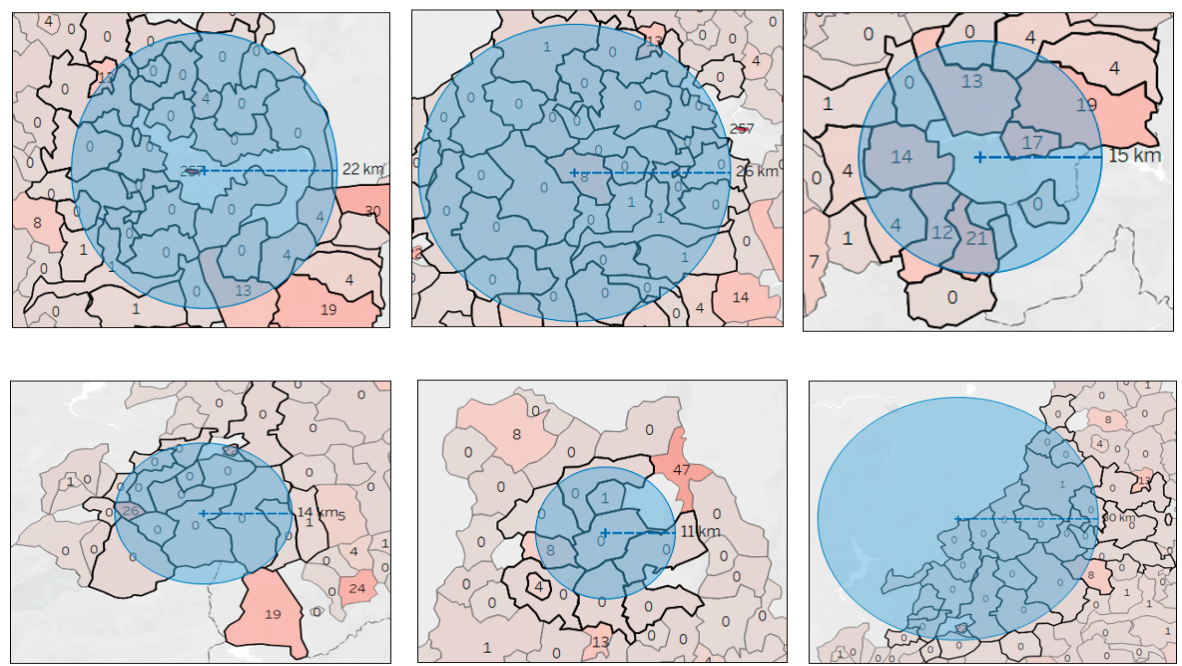

Figure 4. Distance necessary to access cash according to the geographical area of the province of Ávila (area around the capital of the province, central zone, southeast area, south zone, north zone, and west of the province). Source: Author's own elaboration using Tableau Desktop Professional Edition.

\section{Proposal for Sustainable Solutions to Increase the Access to Cash Index in Vulnerable Areas}

As [67] has pointed out, it is necessary that "governments should vigorously pursue financial inclusion goals by implementing regulatory and supervisory policies [ . . . ] by encouraging technology innovations that lower adoption costs and widen outreach, and by ensuring that systems take care of the concerns of consumers." As these authors have argued, such an intervention must be proactive and focus on issues such as the "proximity to financial services; extent of their dimension and coverage; product features and quality; promotion of usage; household financial capacity and expansion of financial literacy." Along these lines, the measures proposed below attempt to respond to the challenges associated with the problems of the proximity and scope of financial services in terms of size and coverage, as well as access to digital financial services. Precisely, expanding access points and digitizing payments are two of the objectives of the UFA2020 initiative of the World Bank (For more information, see: https://www.worldbank.org/en/topic/financialinclusion/brief/achieving-universal-financial-accessby-2020), which seeks to promote universal financial access.

At this point and having identified the difficulties in some areas for accessing cash, two solutions are proposed here to increase the rate of access to cash and thus guarantee an essential part of financial inclusion and access to banking services:

1. In the short term, we recommend using the Spanish pharmacy network to provide access points for cash, given the extensive presence of the network in the territory.

2. In the medium- to long-term, we recommend the possible implementation of a virtual currency backed by the Central Bank that is present on users' mobile phones, with which they can make payments using digital cash (Like the Chinese virtual currency (CBDC) that is already operating in tests).

\subsection{Expansion of Cashback Points through the Pharmacy Network}

Spain has "one of the most extensive pharmacy networks, not only in Spain, but in Europe; above countries like France or Germany" [68]. Thus, the proposal to minimize cash access difficulties that affect a large part of the resident population in areas with a low demographic density or those with a certain degree of isolation consists of taking advantage of the existing pharmacy network as a point of access to 
cash. In a simulation exercise, we proceeded to redefine Equation 1 with the incorporation of a new component (pharmacy), thus obtaining the following expression:

$$
\begin{gathered}
\text { Access to cash index }=\sum(\text { bank branch } \times 1)+(\text { ATM } \times 3)+(\text { post office } \times 2)+ \\
(\text { cashback point } \times 1)+(\text { pharmacy } \times 1) .
\end{gathered}
$$

The pharmacy component is assigned a coefficient of 1 in this case, given that it has a time limit and it may also be necessary to make a purchase in order to receive the cash, as is the case in some cashback points. Pharmacies have a time restriction, normally determined by business hours, as well as closing for some days of the week (i.e., the same assumption as bank branches and post offices, which are not open on Sundays). The full explanation of the scoring has carried out by explaining Equation (1). First, as we can see in Table 8, the percentage of municipalities without this possible point of access to cash is 20 points lower than in the case of the rest of the points collected in Equation 1 , so the access to cash index values would be significantly improved and the kilometers of travel required to obtain cash would be reduced with the addition of pharmacies as points of access to cash.

Table 8. Pharmacy scale by municipality, and percentage of municipalities with Pharmacy.

\begin{tabular}{ccc}
\hline Pharmacy & Number of Municipalities and Pharmacies & \% of Municipalities (Pharmacies) \\
\hline 0 pharmacies & 156 & 62.9 \\
1 pharmacy & 83 & 33.5 \\
2 pharmacies & 5 & 2.0 \\
3 or more pharmacies & 4 & 1.6 \\
\hline
\end{tabular}

Source: Own elaboration from data extracted from the Ávila Official College of Pharmacists.

The network of pharmacies in the province of Ávila is presented here as a solution to increase the rate of access to cash. Here, the pharmacy data have been extracted from the official website of the College of Pharmacists, with the most recent data available as of 22 June 2020. Each pharmacy is listed by municipality, as well as its current status (open or closed) and if it has any limits on the opening hours or opening days.

Nearly $40 \%$ of the territory has at least one pharmacy in its municipal area. Based on these data, a map of the pharmacy network in the province of Ávila can be drawn up. It can be clearly seen that these pharmacies are better distributed throughout the whole territory than the aforementioned areas for cash access (see Figure 5). In this way, if the pharmacy network served as an access point to cash, the access rate to cash (in this case, in the province of Ávila) would be significantly increased. Especially, access would increase in not only places where some point of access to cash already existed, but especially in places where there was no existing way to access cash, causing the displacement of citizens.

This can be easily verified in Figure 6, which shows how the access to cash index has changed after implementing this measure. 


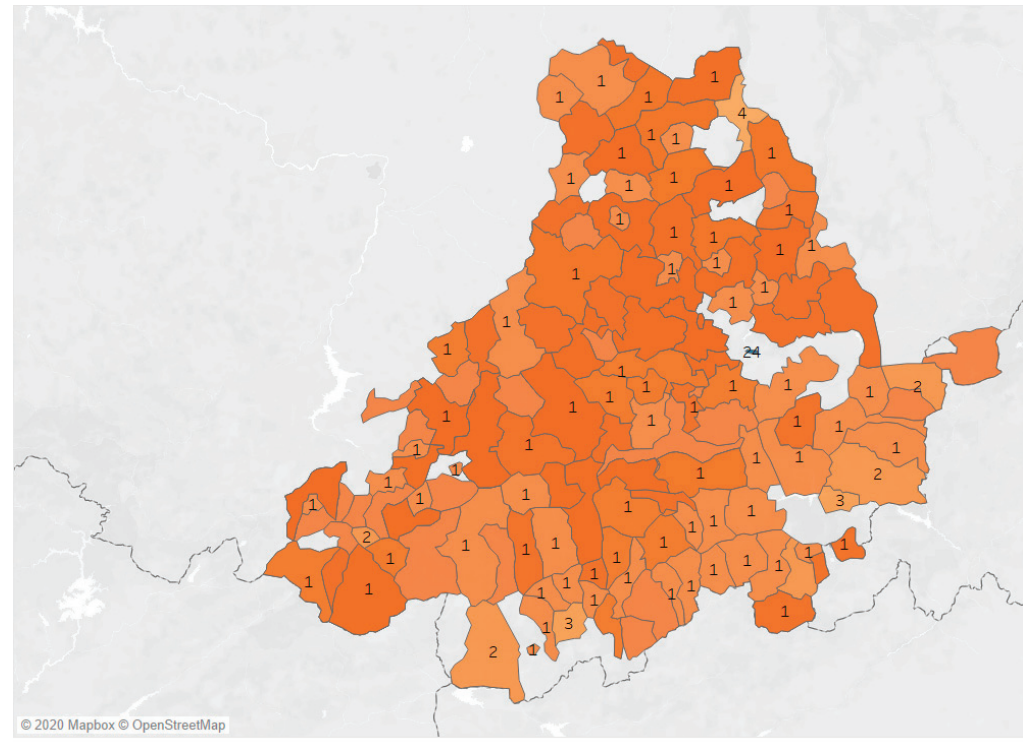

Distribution of the.

Figure 5. Distribution of the pharmacy network in the province of Ávila. Source: Author's own elaboration using Tableau Desktop Professional Edition.

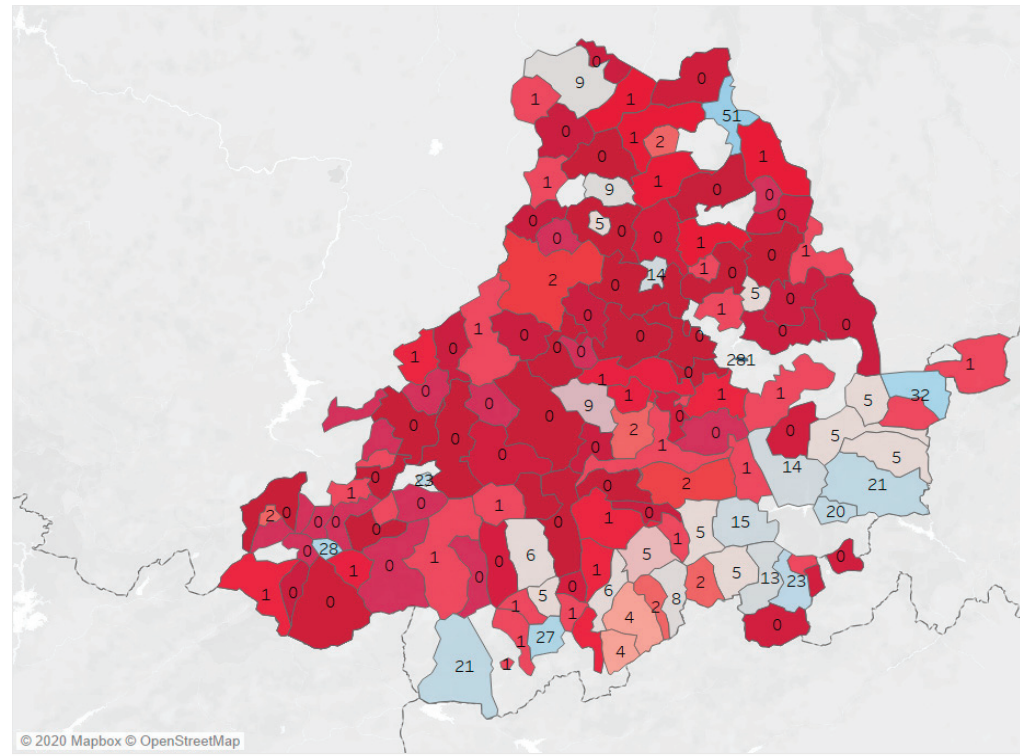

Access to cash Ind..

1

Figure 6. Access to cash index if the pharmacy network is used as a "cashback" point. Source: Author's own elaboration using Tableau Desktop Professional Edition. 
As can be seen, the access to cash index values of all the areas previously analyzed have significantly improved with the addition of pharmacies. Both the capital area, as well as the north of the province, the southeast, and south, and even the west area adjacent to Salamanca and the downtown area (which were the areas with the worst access to cash index values) show improvement.

As shown in Figure 7, the distance to travel around the capital to access cash has been reduced from the $22 \mathrm{~km}$ shown in Figure 3 to the $5 \mathrm{~km}$ shown in Figure 7. This denotes an improvement in the ability to access cash. The same can be said for the rest of the zones (i.e., comparing Figure 7 to Figure 4). The value of $26 \mathrm{~km}$ around the downtown area has decreased to $11 \mathrm{~km}$. In the southeast area, a reduction of $15 \mathrm{~km}$ to $10 \mathrm{~km}$ can be seen. In the southern area, a reduction of $14 \mathrm{~km}$ to $6.1 \mathrm{~km}$ can be seen. In the north zone, a reduction from $11 \mathrm{~km}$ to $6 \mathrm{~km}$ can be seen. However, the area showing great improvement is the western area. In Figure 3, the distance to be traveled to access a cash point was $30 \mathrm{~km}$. If the pharmacy network is incorporated, as proposed, as a solution, the distance is reduced, as we can see in Figure 7, to $14 \mathrm{~km}$. If the average is analyzed again, taking into consideration the pharmacy network, and again the capital and the four divisions made are taken into consideration, as well as the central area, the inhabitants of this province will have access to cash within $8.7 \mathrm{~km}$ on average (a notable reduction from the $19.6 \mathrm{~km}$ if the pharmacy network is not available).
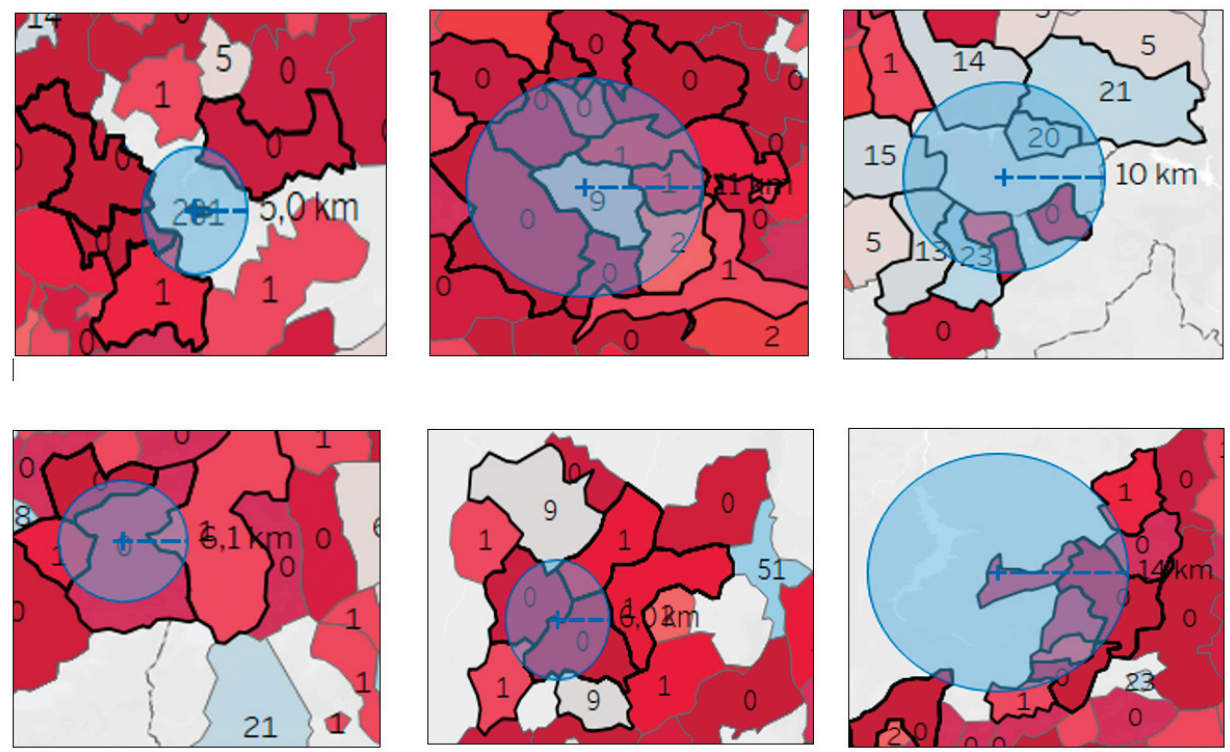

Figure 7. Distances necessary to access cash according to the geographical area of the province of Ávila after adding the pharmacy network as a cash source. Areas around the capital of the province, central zone, southeast area, south zone, north Zone, and west of the province are shown. Source: Author's own elaboration using Tableau Desktop Professional Edition.

\subsection{Implementation of a $C B D C$ to Increase Access to Cash}

As [69] pointed out, "the accelerated pace of development of digital infrastructure, together with increasingly rapid and widespread access and interconnection to networks among citizens, companies and institutions are shaping a digital ecosystem that drives numerous disruptive processes and transformation in all the productive sectors of the economy, to the point of envisioning an eminent change in business models and the pattern of economic growth", questioning the traditional forms and balances of economic and social organization [70]. In this favorable context for the development of digital financial services, another possible solution to increase access to cash could be 
the implementation of a CBDC (central bank digital currency). This, in any case, does not depend on the Spanish authorities, but on the European Central Bank. The implementation or not of a CBDC presents a series of advantages, such as "improving access to financial services when there is geographic dispersion, increasing the rate of bank penetration and access to financial services or as an alternative to the drop in the use of cash" [40]. This alternative, given the geographical dispersion and the difficulty of accessing cash in this province, could be a solution (at least in the medium- to long-term). Also, in order to implement a CBDC, other issues such as the one pointed out by [71] must be considered, since in the generation and maintenance of CBDCs it is necessary to "invest a large amount of electrical energy". Therefore, despite the advantages of saving in physical costs (paper money and metal) derived from the implementation of a CBDC, it is also possible that an environmental cost is incurred, derived from a greater increase in electricity required for the currency's generation and maintenance. An example of the latter is found in [72], where they pointed out that in 2014 that "bitcoin mining has consumed as much electric energy as Ireland required in 2014". Another problem brought about by CBDCs is the one pointed out by [73], since "there is concern about the tax evasion of those who use bitcoin instead of more traditional online payment methods", and some may derive its use for the "laundering of money", as suggested by [74].

However, as pointed out in [40], there are countries that have already carried out tests on the possible implementation of a CBDC and its effects, such as Uruguay with the "e-Peso" or the Bahamas with the "Project Sand Dollar". However, the country with the most weight in the world and the most advanced implementation of a CBDC is China, where "in January 2020, senior officials from the People's Bank of China confirmed that the bank has concluded the development and testing of China's sovereign digital currency" [75]. Each user will have a wallet on their mobile with which they can make payments through $\mathrm{QR}$ codes and this will also allow them to send or receive money and even initiate transactions by putting two mobile phones in contact. In the present study, in order to assess the possible acceptance of a CBDC as a solution to the difficulties of an inability access to cash, a survey was carried out with the inhabitants of the province of Ávila to find out if they would accept its implementation (see Table 9).

Table 9. Knowledge and acceptance of a central bank digital currency (CBDC) in the province of Ávila.

\begin{tabular}{lcc}
\hline 1. Do you Know What a Virtual Currency Is? & Frequency & Percentage \\
\hline No, I don't know what a digital currency is. & 172 & 33.6 \\
Yes, I know what a digital currency is. & 340 & 66.4 \\
2. If the European Central Bank launched a virtual & & \\
currency, would you continue to use traditional cash, & Frequency & Percentage \\
would you reduce it use in favor of digital or would & & 43 \\
you replace traditional cash with digital? & 220 & 25 \\
I Would reduce the use of traditional cash & 128 & 32 \\
I would continue to use traditional cash (coins and bills) & 164 & $\mathbf{1 0 0}$ \\
I would substitute traditional cash for digital cash & $\mathbf{5 1 2}$ & \\
Total & & \\
\hline
\end{tabular}

Source: Own elaboration from data collected via online survey.

In total, 512 people participated in the survey (see Tables A2-A7 in Appendix A) (The population of Ávila is made up of 158,930 people. Thus, with 50\% homogeneity, a 5\% margin of error, and a 95\% confidence level, at least 384 surveys would be necessary for the result to be representative. In our case, this number was far exceeded, as 512 people participated. Therefore, the sample is representative). The population was segmented according to sex, studies, job occupation, family income, and the size of the municipality. The two questions that were asked were the following: Do you know what a virtual currency is? If the European Central Bank launched a virtual currency, would you continue to use traditional cash, would you reduce cash use in favor of digital cash, or would you replace traditional cash with digital cash? See Tables A8 and A9 the in appendix for more details. All statistical data related to the variance, skewness, standard error of skewness, kurtosis, and kurtosis standard error can be found by consulting Table A10 in the appendix of this article. 
As can be seen from the data extracted from the survey carried out, first of all, $66 \%$ of those surveyed affirmed that they either know what a digital currency is or have heard something about this type of currency and, in short, answered the question affirmatively.

Second, but not least, regarding a scenario where a CBDC was implemented (the question stated that China is currently conducting a successful test), $32 \%$ of respondents said that they would replace traditional cash with digital cash. Next, $43 \%$ of respondents indicated that if a CBDC was introduced that they would reduce their use of traditional cash in favor of digital cash. Only one in four surveyed citizens ( $25 \%$ ) would continue to use traditional cash (coins and bills) instead of a CBDC. In this context, we proceeded to analyze the $25 \%$ of people who would pose difficulties when accepting a CBDC in order to analyze their profile.

The 128 people out of the 512 respondents who answered "I would continue to use traditional cash (coins and bills)" and therefore would not accept a CBDC were mostly men. Therefore, a CBDC would have more acceptance among women. Regarding the age range, we see a clear trend, where those under 18 would accept a CBDC (none preferred traditional cash) and as people get older, their rejection of CBDC grows, except in the 45 to 54 age range.

Therefore, new generations would be more willing to accept a CBDC while older people tend to prefer traditional cash (the 55-64 age range features the highest percentage of CBDC rejection). Regarding the level of education and studies, the trend is also clear, where only $1.6 \%$ of people with university studies rejected the CBDC, while people without an education or those with more basic studies (less education) preferred traditional cash. These results are reflected in Table 10.

Table 10. Sex, age, and level of education (studies) of people who would reject the use of a CBDC as a substitute for traditional cash in the province of Ávila.

\begin{tabular}{|c|c|c|c|c|c|c|c|c|}
\hline \multicolumn{3}{|c|}{ Sex } & \multicolumn{3}{|c|}{ Age } & \multicolumn{3}{|c|}{ Training Level (Studies) } \\
\hline Sex & Total & Percentage & $\begin{array}{c}\text { Age Range } \\
\text { (years) }\end{array}$ & Total & Percentage & $\begin{array}{l}\text { Training level } \\
\text { (studies) }\end{array}$ & Total & Percentage \\
\hline Man & 78 & 60.9 & $<18$ & 0 & 0 & Primary & 2 & 1.6 \\
\hline \multirow[t]{6}{*}{ Woman } & 48 & 37.5 & $18-24$ & 18 & 14.1 & High school & 30 & 23.4 \\
\hline & & & $25-34$ & 24 & 18.8 & University & 2 & 1.6 \\
\hline & & & $35-44$ & 26 & 20.3 & No studies & 92 & 71.9 \\
\hline & & & $45-54$ & 14 & 10.9 & $\begin{array}{c}\text { Do not know, } \\
\text { no answer }\end{array}$ & 2 & 1.6 \\
\hline & & & $55-64$ & 38 & 29.7 & & & \\
\hline & & & $>65$ & 8 & 6.3 & & & \\
\hline
\end{tabular}

Source: Own elaboration from data extracted from the survey.

From the data shown in Table 11 regarding the occupations of the interviewees, it can be seen that the vast majority of people who rejected the implementation of the CBDC and, therefore, prefer the use of cash, were active workers (people who currently have a job). Regarding income, for the vast majority of people who reject the use of a CBDC and prefer cash, it was observed that these results are concentrated in the lowest family income ranges (a total $62.5 \%$ between the two other defined ranges), indicating that there is a relationship between lower income and the rejection of a CBDC and inversely higher income and acceptance of it. In the case of the municipality of residence, the vast majority of respondents were concentrated in municipalities with more than 50,000 inhabitants. This is logical, given that most of the Ávila's population is concentrated in its capital. The results of the study are like those obtained by other authors. At a lower educational level and at a lower level of income, there is a greater use of cash. This same situation was shown by [76] in a study carried out in the United States of America. The same is true in the case of Canada, according to a study by [77], or in the case of [78], in their study in Germany. More recently, this also coincides with the results obtained by [36] in their study on the eurozone, indicating in their conclusions that "... it is observed that the probability of using cash is higher for individuals with lower levels of income and education" and also that "possible proposals that advocate the total elimination of cash in the eurozone should be carried out gradually and with strong public 
support for sectors of the population with lower levels of income and education". Also, in the recent study of [79], conclusions were reached in the same direction, where "digital financial inclusion reduces farmers' vulnerability" and "digital financial inclusion can reduce fluctuations in consumption and thereby alleviate farmers' vulnerability". In the study of [42], carried out in South Africa, it was indicated that the greatest beneficiaries of a "cashless society" would be women, where a "cashless society may enhance consumers' optimism levels towards new mobile payment services, but also reduce safety concerns as a result of carrying cash, especially for women." In our study, women show a very high level of acceptance (higher than men) for a CBDC (or in other words, a lower rejection). Finally, in the study carried out by [45] in Italy, a conclusion similar to ours was reached: "We expect a larger use of cashless payment from a population with a higher GDP" and therefore, a greater use of cash in people with minor a GPD.

Table 11. Socioeconomic characterization of the population that would reject the use of CBDC in the province of Ávila.

\begin{tabular}{|c|c|c|c|c|c|c|c|c|}
\hline \multicolumn{3}{|c|}{ Current Main Occupation } & \multicolumn{3}{|c|}{ Income of the Family Unit } & \multicolumn{3}{|c|}{ Size of the Municipality of Residence } \\
\hline & Total & Percentage & & Total & Percentage & & Total & Percentage \\
\hline $\begin{array}{l}\text { Active } \\
\text { worker }\end{array}$ & 74 & 57.8 & $<€ 14,000$ & 44 & 34.4 & $<1000$ & 20 & 15.6 \\
\hline Self-Worker & 12 & 9.4 & $€ 14,000,001-25,000$ & 36 & 28.1 & $1000-10,000$ & 6 & 4.7 \\
\hline Student & 18 & 14.1 & $€ 25,000.001-€ 35,000$ & 22 & 17.2 & $10,000.1-50,000$ & 26 & 20.3 \\
\hline Retired & 10 & 7.8 & $€ 35,000.001-€ 50,000$ & 14 & 10.9 & $50,000.1-100,000$ & 76 & 59.4 \\
\hline Unemployed & 6 & 4.7 & $€ 50,000.001-€ 100,000$ & 12 & 9.4 & & & \\
\hline $\begin{array}{l}\text { Others } \\
\text { Do not }\end{array}$ & 6 & 4.7 & $>€ 100,000$ & 0 & 0.0 & & & \\
\hline $\begin{array}{c}\text { know, no } \\
\text { answer }\end{array}$ & 2 & 1.6 & & & & & & \\
\hline
\end{tabular}

Source: Own elaboration from data extracted from the survey.

However, this measure to guarantee access to cash in the long term should be accompanied by others, such as encouraging sustainable means of transport in these areas, as indicated [80], and a series of tax incentives in the rural environment, as pointed out [81]. All this will contribute to improving access to "quality" banking services and reduce the shock of the depopulation situation experienced by large areas in the interior of Spain that are collectively referred to today as "depopulated Spain". Lastly, in [82], in an applied study in Canada, it was pointed out that "the public remains indifferent to the various bank deposit monies (media of exchange) [ ... ] in other words, the non-zero-sum nature of electronic methods of payment is not inconsistent with a uniform currency". Thus, a CBDC could have a perfect place in society.

\section{Discussion of Results}

This research has sought to contribute to the study of the problem of financial exclusion and the difficulties of an inability to access to cash that are suffered in Spain by the populations of certain areas characterized by low demographic densities and a high proportion of elderly people. For this purpose, the population residing in the province of Ávila has been taken as a study sample, whose interest is justified when considering the existence of a representative demographic structure that is characterized by an aging population that is dispersed throughout the territory in small urban centers. At the same time, this province constitutes evidence of the financial exclusion problems that have arisen from the recent restructuring process of the Spanish banking system that has led to the closure of $40 \%$ of the bank branches that operate in this territory. In recent years, European countries have launched numerous initiatives to combat corruption, money laundering, and tax fraud. Among them, the progressive elimination of cash through the limitation of payments through this means stands out. Despite this, cash and its use in day-to-day transactions continues to represent a very widespread form of payment for a large part of the population, and there are different international organizations, such as the BIS or the World Bank, which advocate its maintenance. The methodology proposed in this research goes beyond the measurements made by the "International Monetary Fund's Financial Access 
Survey" (FAS). The construction of an index of access to cash via the consideration of a diverse set of cash dispensing infrastructures that have been suitably weighted according to parameters, such as ease of access, has allowed the construction of maps that have detected and identified the most vulnerable areas at risk of financial exclusion. Consequently, this has facilitated the identification of territories where it would be recommended to implement public policies to guarantee equal access to cash for the entire population, or at least to minimize access costs. Even though the empirical data were collected from throughout the province of Ávila, a limitation exists, since the data were collected from one part of the country only. More studies are required to test and validate the results of the study in other regions (for example, those indicated in the introduction with a similar population density). On the one hand, this study has only been based on including the existing pharmacy network in order to increase the access to cash index. However, other possible solutions, e.g., the use of mobile ATMs (e.g., in a bus or van) that run through the area, have not been analyzed. On the other hand, this study has only investigated the moderating effect of gender, age, household income, education, and the size of the municipality of residence. Other variables could have been included (for example, if COVID-19 has affected the use of cash), so more research may be required in the future.

\section{Conclusions}

Beyond the multiple advantages that the reduction or elimination of cash could bring, such as cost savings, the greater effectiveness of monetary policy, or the reduction in crime, most studies have agreed on the advisability of analyzing any change that leads to a cash-free society in detail. In addition to the absolute dependence on electronic means for payments, the risk of financial exclusion of certain vulnerable groups (elderly, youth, people without resources, etc.) with difficulty in accessing new technologies and financial services necessarily requires that any initiative in this sense contemplates such risks.

In order to solve this problem, the present investigation has identified and analyzed the implications of two possible solutions: In the short term, it has been proposed to take advantage of the extensive network of pharmacies for use as access points to cash (as cashback facilities) and, in the medium and in the long term, the introduction of a CBDC as an alternative means of payment to cash.

In the application of the proposed methodology, it has been verified that the population residing in the province of Ávila, which is one of the Spanish provinces that has been most affected by financial exclusion, faces significant difficulties in accessing cash. In fact, $81.5 \%$ of the municipalities of the province of Ávila present a score of zero points in the access to cash index proposed here. Each inhabitant of this province must travel, on average, approximately $20 \mathrm{~km}$ to access a cash dispensing point. This problem is aggravated when considering the southwest quadrant of the province of Ávila, where the distance is increased to an average of $30 \mathrm{~km}$.

Taking advantage of the pharmacy network to provide cashback points would facilitate access to cash in the study population, who are currently at risk of financial exclusion. With this measure, a notable reduction in costs associated with accessing cash has been verified, as the average distance that would be necessary to access this service is reduced by more than $55 \%$ compared to other cash source locations. A reduction of more than 20 percentage points in the number of municipalities in Ávila with a score of zero in the access to cash index was also found here. Said improvement is possible when considering the extensive pharmacy network in the province, which, in the case of the province of Ávila, covers nearly $40 \%$ of the territory, with at least one pharmacy in each municipal area.

Finally, it has been verified that the implementation of a CBDC as an alternative means of payment to cash would enjoy good acceptance by the population under study here. Specifically, $75 \%$ of respondents said they would substitute digital money for cash or at least reduce their use of it. Conversely, one in four respondents, whose profile coincides with the elderly, uneducated, and/or low-income people, would reject its widespread use. Such a circumstance would require the development of training and information actions to raise awareness of the safety and effectiveness of this type of currency. 
Author Contributions: Conceptualization, S.L.N.A.; Data curation, S.L.N.A.; Formal analysis, S.L.N.A.; Funding acquisition, J.J.-V. and R.F.R.F.; Investigation, S.L.N.A. and J.J.-V.; Methodology, S.L.N.A.; Project administration, S.L.N.A. and J.J.-V.; Resources, J.J.-V. and R.F.R.F.; Software, S.L.N.A.; Supervision, J.J.-V. and R.F.R.F.; Validation, J.J.-V.; Visualization, R.F.R.F.; Writing—original draft, S.L.N.A.; Writing—review \& editing, J.J.-V. and R.F.R.F. All authors have read and agreed to the published version of the manuscript.

Funding: The APC was funded by the incentive granted to the authors by the "Asociación de Amigos de la $U C A V^{\prime \prime}$ - Catholic University of Ávila.

Acknowledgments: In this section we want to thank the "Asociación de Amigos de la UCAV"—Catholic University of Ávila, for the granted incentive that has served to pay the APC. Since this study is framed within a larger research project called "Depopulation and new technologies: the development of Smart Rural as an instrument to combat depopulation in Castilla y León", funded by the AAUCAV. Also, we want to thank Tableu Inc. for allowing us to use Tableau Desktop Professional Edition free of charge for scientific purposes.

Conflicts of Interest: The authors declare no conflict of interest.

\section{Appendix A}

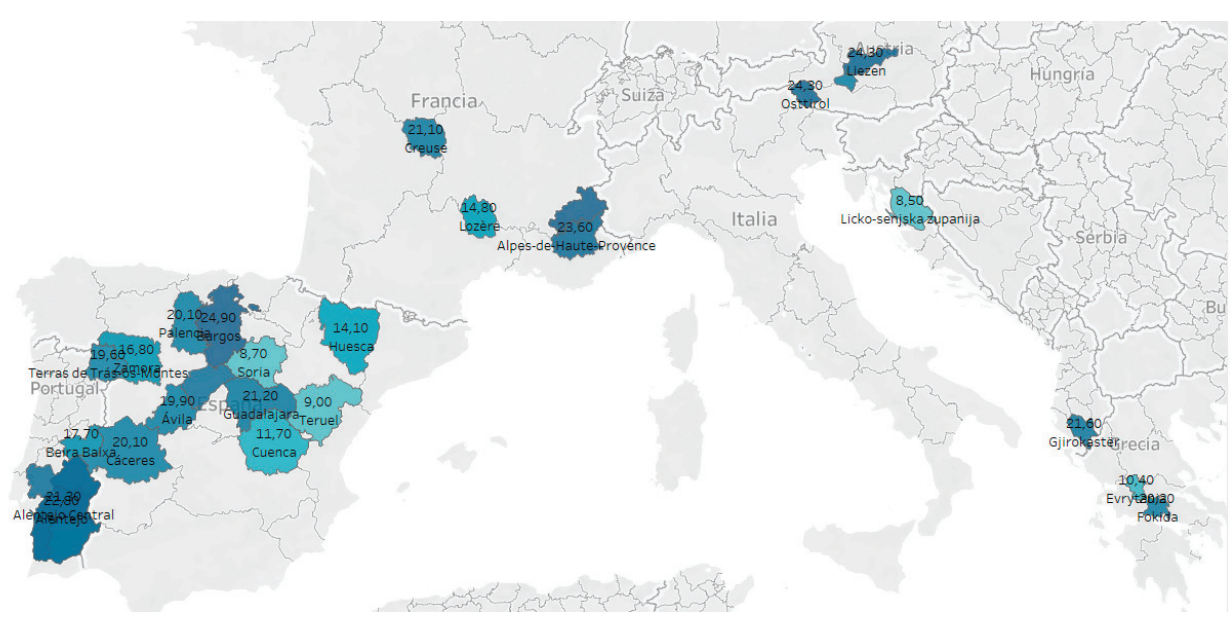

Figure A1. Population density (persons per square kilometer) in southern and central Europe. Source: Author's elaboration based on data from Eurostat (2019) and Tableau Desktop Professional Edition. 

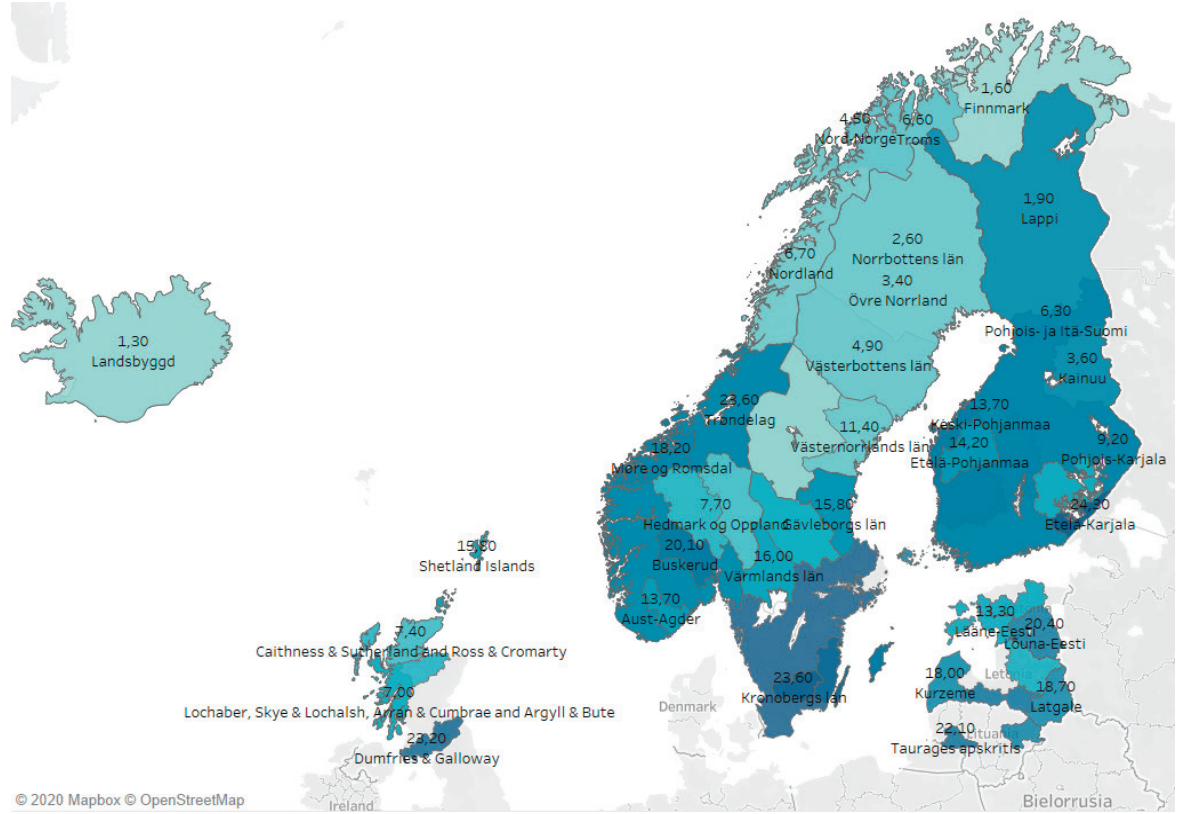

C 2020 Mapbox @ OpenStreetMap

Figure A2. Population density (persons per square kilometer) in northern and central Europe. Source: Author's elaboration based on data from Eurostat (2019) and Tableau Desktop Professional Edition.

Table A1. Bank branches, post offices, ATMs, cashback points, and pharmacies by municipality. Calculation of access to cash index.

\begin{tabular}{|c|c|c|c|c|c|c|c|}
\hline Municipality & Bank Branches & Post Offices & ATMs & Cash Back & Access Cash Index & Pharmacies & $\begin{array}{l}\text { Access Cash Index } \\
\text { (Pharmacies) }\end{array}$ \\
\hline Adanero & 0 & 0 & 0 & 0 & 0 & 1 & 1 \\
\hline La Adrada & 3 & 0 & 3 & 0 & 12 & 1 & 13 \\
\hline Albornos & 0 & 0 & 0 & 0 & 0 & & 0 \\
\hline Aldeanueva de Santa Cruz & 0 & 0 & 0 & 0 & 0 & & 0 \\
\hline Aldeaseca & 0 & 0 & 0 & 0 & 0 & 1 & 1 \\
\hline La Aldehuela & 0 & 0 & 0 & 0 & 0 & 1 & 1 \\
\hline Amavida & 0 & 0 & 0 & 0 & 0 & & 0 \\
\hline El Arenal & 1 & 0 & 1 & 0 & 4 & 1 & 5 \\
\hline Arenas de San Pedro & 5 & 1 & 5 & 2 & 24 & 3 & 27 \\
\hline Arevalillo & 0 & 0 & 0 & 0 & 0 & & 0 \\
\hline Arévalo & 6 & 1 & 11 & 6 & 47 & 4 & 51 \\
\hline Aveinte & 0 & 0 & 0 & 0 & 0 & & 0 \\
\hline Avellaneda & 0 & 0 & 0 & 0 & 0 & & 0 \\
\hline Ávila & 38 & 1 & 66 & 19 & 257 & 24 & 281 \\
\hline El Barco de Ávila & 5 & 1 & 6 & 1 & 26 & 2 & 28 \\
\hline El Barraco & 3 & 0 & 3 & 1 & 13 & 1 & 14 \\
\hline Barromán & 0 & 0 & 0 & 0 & 0 & 1 & 1 \\
\hline Becedas & 1 & 0 & 0 & 0 & 1 & 1 & 2 \\
\hline Becedillas & 0 & 0 & 0 & 0 & 0 & & 0 \\
\hline Bercial de Zapardiel & 0 & 0 & 0 & 0 & 0 & & 0 \\
\hline Las Berlanas & 0 & 0 & 0 & 0 & 0 & 1 & 1 \\
\hline Bernuy-Zapardiel & 0 & 0 & 0 & 0 & 0 & & 0 \\
\hline Berrocalejo de Aragona & 0 & 0 & 0 & 0 & 0 & & 0 \\
\hline Blascomillán & 0 & 0 & 0 & 0 & 0 & & 0 \\
\hline Blasconuño de Matacabras & 0 & 0 & 0 & 0 & 0 & & 0 \\
\hline Blascosancho & 0 & 0 & 0 & 0 & 0 & & 0 \\
\hline El Bohodón & 0 & 0 & 0 & 0 & 0 & & 0 \\
\hline Bohoyo & 0 & 0 & 0 & 0 & 0 & 1 & 1 \\
\hline Bonilla de la Sierra & 0 & 0 & 0 & 0 & 0 & & 0 \\
\hline Brabos & 0 & 0 & 0 & 0 & 0 & & 0 \\
\hline Bularros & 0 & 0 & 0 & 0 & 0 & & 0 \\
\hline Burgohondo & 1 & 0 & 1 & 0 & 4 & 1 & 5 \\
\hline Cabezas de Alambre & 0 & 0 & 0 & 0 & 0 & 1 & 1 \\
\hline Cabezas del Pozo & 0 & 0 & 0 & 0 & 0 & & 0 \\
\hline Cabezas del Villar & 0 & 0 & 0 & 0 & 0 & 1 & 1 \\
\hline
\end{tabular}


Table A1. Cont.

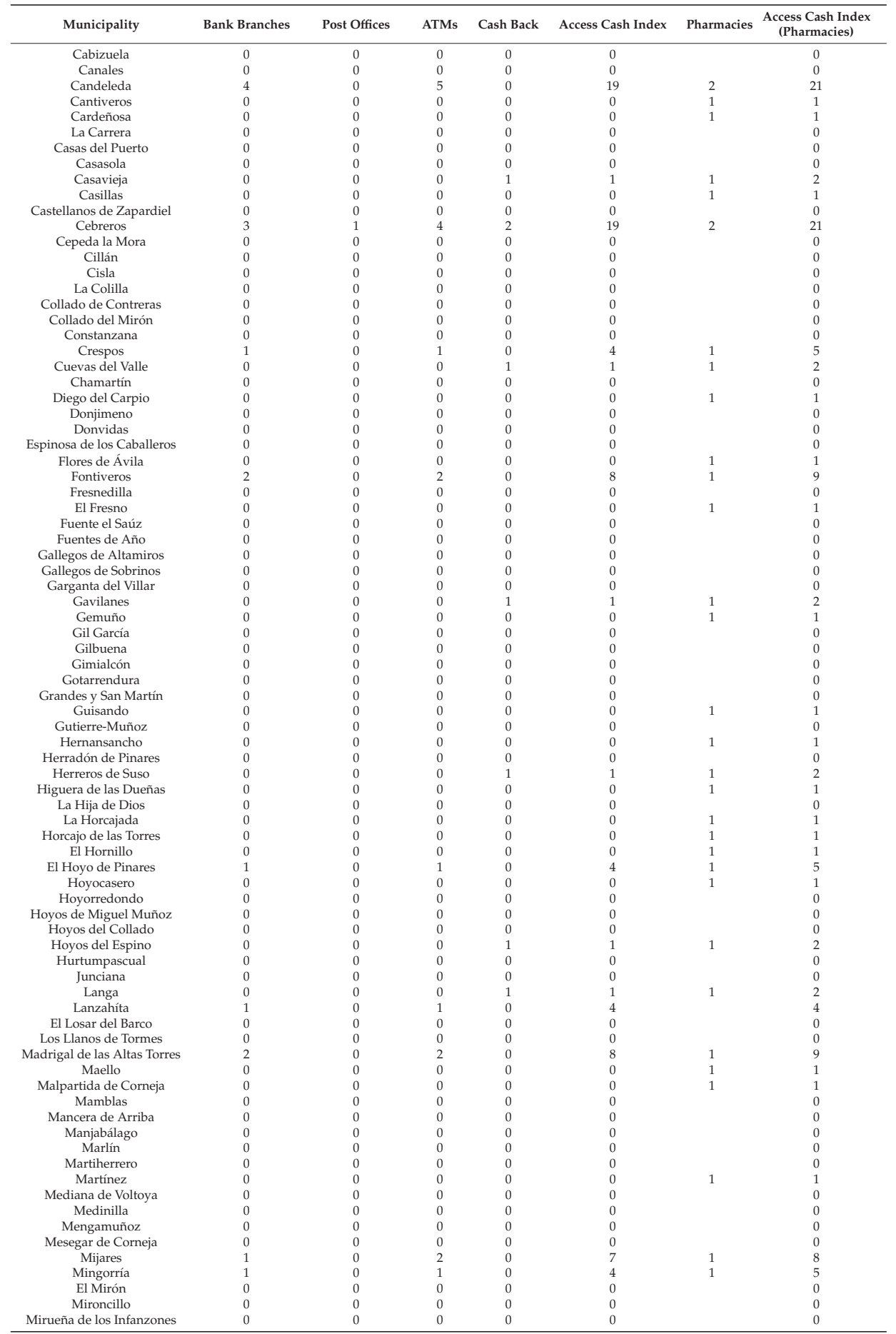


Table A1. Cont.

\begin{tabular}{|c|c|c|c|c|c|c|c|}
\hline Municipality & Bank Branches & Post Offices & ATMs & Cash Back & Access Cash Index & Pharmacies & $\begin{array}{c}\text { Access Cash Index } \\
\text { (Pharmacies) }\end{array}$ \\
\hline Mombeltrán & 0 & 0 & 0 & 0 & 0 & 1 & 1 \\
\hline Monsalupe & 0 & 0 & 0 & 0 & 0 & & 0 \\
\hline Moraleja de Matacabras & 0 & 0 & 0 & 0 & 0 & & 0 \\
\hline Muñana & 2 & 0 & 2 & 0 & 8 & 1 & 9 \\
\hline Muñico & 0 & 0 & 0 & 0 & 0 & & 0 \\
\hline Muñogalindo & 0 & 0 & 0 & 0 & 0 & 1 & 1 \\
\hline Muñogrande & 0 & 0 & 0 & 0 & 0 & & 0 \\
\hline Muñomer del Peco & 0 & 0 & 0 & 0 & 0 & & 0 \\
\hline Muñopepe & 0 & 0 & 0 & 0 & 0 & & 0 \\
\hline Muñosancho & 0 & 0 & 0 & 0 & 0 & & 0 \\
\hline Muñotello & 0 & 0 & 0 & 0 & 0 & & 0 \\
\hline Narrillos del Álamo & 0 & 0 & 0 & 0 & 0 & & 0 \\
\hline Narrillos del Rebollar & 0 & 0 & 0 & 0 & 0 & & 0 \\
\hline Narros de Saldueña & 0 & 0 & 0 & 0 & 0 & & 0 \\
\hline Narros del Castillo & 0 & 0 & 0 & 0 & 0 & & 0 \\
\hline Narros del Puerto & 0 & 0 & 0 & 0 & 0 & & 0 \\
\hline Nava de Arévalo & 0 & 0 & 0 & 0 & 0 & 1 & 1 \\
\hline Nava del Barco & 0 & 0 & 0 & 0 & 0 & & 0 \\
\hline Navacepedilla de Corneja & 0 & 0 & 0 & 0 & 0 & & 0 \\
\hline Navadijos & 0 & 0 & 0 & 0 & 0 & & 0 \\
\hline Navaescurial & 0 & 0 & 0 & 0 & 0 & & 0 \\
\hline Navahondilla & 0 & 0 & 0 & 0 & 0 & & 0 \\
\hline Navalacruz & 0 & 0 & 0 & 0 & 0 & & 0 \\
\hline Navalmoral de la Sierra & 0 & 0 & 0 & 1 & 1 & 1 & 2 \\
\hline Navalonguilla & 0 & 0 & 0 & 0 & 0 & 1 & 1 \\
\hline Navalosa & 0 & 0 & 0 & 0 & 0 & 1 & 1 \\
\hline Navalperal de Pinares & 1 & 0 & 1 & 0 & 4 & 1 & 5 \\
\hline Navalperal de Tormes & 0 & 0 & 0 & 0 & 0 & 1 & 1 \\
\hline Navaluenga & 3 & 0 & 3 & 2 & 14 & 1 & 15 \\
\hline Navaquesera & 0 & 0 & 0 & 0 & 0 & & 0 \\
\hline Navarredonda de Gredos & 1 & 0 & 1 & 1 & 5 & 1 & 6 \\
\hline Navarredondilla & 0 & 0 & 0 & 0 & 0 & 1 & 1 \\
\hline Navarrevisca & 1 & 0 & 1 & 0 & 4 & 1 & 5 \\
\hline Las Navas del Marqués & 5 & 1 & 7 & 2 & 30 & 2 & 32 \\
\hline Navatalgordo & 0 & 0 & 0 & 0 & 0 & & 0 \\
\hline Navatejares & 0 & 0 & 0 & 0 & 0 & & 0 \\
\hline Neila de San Miguel & 0 & 0 & 0 & 0 & 0 & & 0 \\
\hline Niharra & 0 & 0 & 0 & 1 & 1 & 1 & 2 \\
\hline Ojos-Albos & 0 & 0 & 0 & 0 & 0 & & 0 \\
\hline Orbita & 0 & 0 & 0 & 0 & 0 & & 0 \\
\hline El Oso & 0 & 0 & 0 & 0 & 0 & & 0 \\
\hline Padiernos & 0 & 0 & 0 & 0 & 0 & 1 & 1 \\
\hline Pajares de Adaja & 0 & 0 & 0 & 0 & 0 & & 0 \\
\hline Palacios de Goda & 0 & 0 & 0 & 0 & 0 & 1 & 1 \\
\hline Papatrigo & 1 & 0 & 0 & 0 & 1 & 1 & 2 \\
\hline El Parral & 0 & 0 & 0 & 0 & 0 & & 0 \\
\hline Pascualcobo & 0 & 0 & 0 & 0 & 0 & & 0 \\
\hline Pedro Bernardo & 1 & 0 & 1 & 0 & 4 & & 4 \\
\hline Pedro-Rodríguez & 0 & 0 & 0 & 0 & 0 & & 0 \\
\hline Peguerinos & 0 & 0 & 0 & 1 & 1 & & 1 \\
\hline Peñalba de Ávila & 0 & 0 & 0 & 0 & 0 & & 0 \\
\hline Piedrahíta & 4 & 1 & 5 & 1 & 22 & 1 & 23 \\
\hline Piedralaves & 1 & 0 & 1 & 0 & 4 & 1 & 5 \\
\hline Poveda & 0 & 0 & 0 & 0 & 0 & & 0 \\
\hline Poyales del Hoyo & 0 & 0 & 0 & 0 & 0 & 1 & 1 \\
\hline Pozanco & 0 & 0 & 0 & 0 & 0 & & 0 \\
\hline Pradosegar & 0 & 0 & 0 & 0 & 0 & & 0 \\
\hline Puerto Castilla & 0 & 0 & 0 & 0 & 0 & 1 & 1 \\
\hline Rasueros & 0 & 0 & 0 & 0 & 0 & & 0 \\
\hline Riocabado & 0 & 0 & 0 & 0 & 0 & & 0 \\
\hline Riofrío & 0 & 0 & 0 & 0 & 0 & & 0 \\
\hline Rivilla de Barajas & 0 & 0 & 0 & 0 & 0 & & 0 \\
\hline Salobral & 0 & 0 & 0 & 0 & 0 & & 0 \\
\hline Salvadiós & 0 & 0 & 0 & 0 & 0 & & 0 \\
\hline San Bartolomé de Béjar & 0 & 0 & 0 & 0 & 0 & & 0 \\
\hline San Bartolomé de Corneja & 0 & 0 & 0 & 0 & 0 & & 0 \\
\hline San Bartolomé de Pinares & 1 & 0 & 1 & 0 & 4 & 1 & 5 \\
\hline San Esteban de los Patos & 0 & 0 & 0 & 0 & 0 & & 0 \\
\hline San Esteban de Zapardiel & 0 & 0 & 0 & 0 & 0 & & 0 \\
\hline San Esteban del Valle & 1 & 0 & 1 & 1 & 5 & 1 & 6 \\
\hline San García de Ingelmos & 0 & 0 & 0 & 0 & 0 & & 0 \\
\hline San Juan de Gredos & 0 & 0 & 0 & 0 & 0 & & 0 \\
\hline San Juan de la Encinilla & 0 & 0 & 0 & 0 & 0 & & 0 \\
\hline San Juan de la Nava & 0 & 0 & 0 & 0 & 0 & 1 & 1 \\
\hline San Juan del Molinillo & 0 & 0 & 0 & 0 & 0 & & 0 \\
\hline San Juan del Olmo & 0 & 0 & 0 & 0 & 0 & & 0 \\
\hline San Lorenzo de Tormes & 0 & 0 & 0 & 0 & 0 & & 0 \\
\hline $\begin{array}{l}\text { San Martín de la Vega del } \\
\text { Alberche }\end{array}$ & 0 & 0 & 0 & 0 & 0 & 1 & 1 \\
\hline San Martín del Pimpollar & 0 & 0 & 0 & 0 & 0 & & 0 \\
\hline
\end{tabular}


Table A1. Cont.

\begin{tabular}{|c|c|c|c|c|c|c|c|}
\hline Municipality & Bank Branches & Post Offices & ATMs & Cash Back & Access Cash Index & Pharmacies & $\begin{array}{c}\text { Access Cash Index } \\
\text { (Pharmacies) }\end{array}$ \\
\hline San Miguel de Corneja & 0 & 0 & 0 & 0 & 0 & & 0 \\
\hline San Miguel de Serrezuela & 0 & 0 & 0 & 0 & 0 & & 0 \\
\hline San Pascual & 0 & 0 & 0 & 0 & 0 & & 0 \\
\hline San Pedro del Arroyo & 3 & 0 & 3 & 1 & 13 & 1 & 14 \\
\hline San Vicente de Arévalo & 0 & 0 & 0 & 0 & 0 & & 0 \\
\hline Sanchidrián & 0 & 0 & 0 & 1 & 1 & 1 & 2 \\
\hline Sanchorreja & 0 & 0 & 0 & 0 & 0 & & 0 \\
\hline Santa Cruz de Pinares & 0 & 0 & 0 & 0 & 0 & 1 & 1 \\
\hline Santa Cruz del Valle & 0 & 0 & 0 & 0 & 0 & 1 & 1 \\
\hline Santa María de los Caballeros & 0 & 0 & 0 & 0 & 0 & & 0 \\
\hline Santa María del Arroyo & 0 & 0 & 0 & 0 & 0 & & 0 \\
\hline Santa María del Berrocal & 0 & 0 & 0 & 0 & 0 & 1 & 1 \\
\hline Santa María del Cubillo & 0 & 0 & 0 & 0 & 0 & & 0 \\
\hline Santa María del Tiétar & 0 & 0 & 0 & 0 & 0 & 1 & 1 \\
\hline Santiago del Collado & 0 & 0 & 0 & 0 & 0 & & 0 \\
\hline Santiago de Tormes & 0 & 0 & 0 & 0 & 0 & & 0 \\
\hline $\begin{array}{l}\text { Santo Domingo de las } \\
\text { Posadas }\end{array}$ & 0 & 0 & 0 & 0 & 0 & & 0 \\
\hline Santo Tomé de Zabarcos & 0 & 0 & 0 & 0 & 0 & & 0 \\
\hline La Serrada & 0 & 0 & 0 & 0 & 0 & & 0 \\
\hline Serranillos & 0 & 0 & 0 & 0 & 0 & 1 & 1 \\
\hline Sigeres & 0 & 0 & 0 & 0 & 0 & & 0 \\
\hline Sinlabajos & 0 & 0 & 0 & 0 & 0 & & 0 \\
\hline Solana de Ávila & 0 & 0 & 0 & 0 & 0 & 1 & 1 \\
\hline Solana de Rioalmar & 0 & 0 & 0 & 0 & 0 & & 0 \\
\hline Solosancho & 0 & 0 & 0 & 1 & 1 & 1 & 2 \\
\hline Sotalbo & 0 & 0 & 0 & 1 & 1 & & 1 \\
\hline Sotillo de la Adrada & 4 & 1 & 4 & 3 & 21 & 2 & 23 \\
\hline El Tiemblo & 3 & 0 & 4 & 2 & 17 & 3 & 20 \\
\hline Tiñosillos & 1 & 0 & 0 & 1 & 2 & 1 & 3 \\
\hline Tolbaños & 0 & 0 & 0 & 0 & 0 & & 0 \\
\hline Tormellas & 0 & 0 & 0 & 0 & 0 & & 0 \\
\hline Tornadizos de Ávila & 0 & 0 & 0 & 0 & 0 & 1 & 1 \\
\hline La Torre & 0 & 0 & 0 & 0 & 0 & & 0 \\
\hline Tórtoles & 0 & 0 & 0 & 0 & 0 & & 0 \\
\hline Umbrías & 0 & 0 & 0 & 0 & 0 & & 0 \\
\hline Vadillo de la Sierra & 0 & 0 & 0 & 0 & 0 & & 0 \\
\hline Valdecasa & 0 & 0 & 0 & 0 & 0 & & 0 \\
\hline Vega de Santa María & 0 & 0 & 0 & 0 & 0 & & 0 \\
\hline Velayos & 0 & 0 & 0 & 0 & 0 & 1 & 1 \\
\hline Villaflor & 0 & 0 & 0 & 0 & 0 & & 0 \\
\hline Villafranca de la Sierra & 0 & 0 & 0 & 0 & 0 & 1 & 1 \\
\hline Villanueva de Ávila & 0 & 0 & 0 & 0 & 0 & 1 & 1 \\
\hline Villanueva de Gómez & 0 & 0 & 0 & 0 & 0 & & 0 \\
\hline Villanueva del Aceral & 0 & 0 & 0 & 0 & 0 & & 0 \\
\hline Villanueva del Campillo & 0 & 0 & 0 & 0 & 0 & & 0 \\
\hline Villar de Corneja & 0 & 0 & 0 & 0 & 0 & & 0 \\
\hline Villarejo del Valle & 0 & 0 & 0 & 0 & 0 & 1 & 1 \\
\hline Villatoro & 0 & 0 & 0 & 0 & 0 & 1 & 1 \\
\hline Viñegra de Moraña & 0 & 0 & 0 & 0 & 0 & & 0 \\
\hline Vita & 0 & 0 & 0 & 0 & 0 & & 0 \\
\hline Zapardiel de la Cañada & 0 & 0 & 0 & 0 & 0 & & 0 \\
\hline Zapardiel de la Ribera & 0 & 0 & 0 & 0 & 0 & & 0 \\
\hline
\end{tabular}

Source: Author's elaboration based on data from Bankia BFA, Banco Santander-Popular, Banco Sabadell, Bankinter, BBVA (Banco de Bilbao-Vizcaya Argentaria), Caixabank, Unicaja Banco, ING Direct, Citibank, Deutsche Bank, Ibercaja, Cajamar, Caja rural de Salamanca. The state postal agency "Correos" and the Ávila Official College of Pharmacists.

Table A2. Descriptive statistics of the survey carried out: Age.

\begin{tabular}{lcccc}
\hline Age & Frequency & Percentage & Valid Percentage & Accumulated Percentage \\
\hline$<18$ & 8 & 1.6 & 1.6 & 1.6 \\
$>65$ & 16 & 3.1 & 3.1 & 4.7 \\
$18-24$ & 68 & 13.3 & 13.3 & 18 \\
$25-34$ & 174 & 3.4 & 3.4 & 74.2 \\
$35-44$ & 114 & 22.3 & 22.3 & 85.9 \\
$45-54$ & 60 & 11.7 & 11.7 & 100 \\
$55-64$ & 72 & 14.1 & 14.1 & \\
Total & 512 & 100 & 100 & \\
\hline
\end{tabular}

Source: Author's elaboration based on data from an online survey. 
Table A3. Descriptive statistics of the survey carried out: Sex.

\begin{tabular}{lcccc}
\hline \multicolumn{1}{c}{ Sex } & Frequency & Percentage & Valid Percentage & Accumulated Percentage \\
\hline Man & 226 & 44.1 & 44.1 & 44.1 \\
Woman & 284 & 55.5 & 55.5 & 99.6 \\
I prefer not to & 2 & 0.4 & 0.4 & 100 \\
say & 512 & 100 & 100 & \\
Total & Source: Author's elaboration based on data from an online survey.
\end{tabular}

Table A4. Descriptive statistics of the survey carried out: Training level (studies).

\begin{tabular}{ccccc}
\hline Training Level (Studies) & Frequency & Percentage & Valid Percentage & Accumulated Percentage \\
\hline Do not know, no answer & 8 & 1.6 & 1.6 & 1.6 \\
Primary & 10 & 2 & 2 & 3.5 \\
High school & 80 & 15.6 & 15.6 & 19.1 \\
No studies & 2 & 0.4 & 0.4 & 19.5 \\
University & 412 & 80.4 & 80.4 & 100 \\
Total & 512 & 100 & 100 & \\
\hline
\end{tabular}

Source: Author's elaboration based on data from an online survey.

Table A5. Descriptive statistics of the survey carried out: Current main occupation.

\begin{tabular}{ccccc}
\hline Current Main Occupation & Frequency & Percentage & Valid Percentage & Accumulated Percentage \\
\hline Self-worker & 26 & 5.1 & 5.1 & 5.1 \\
Unemployed & 32 & 6.3 & 6.3 & 11.3 \\
Student & 66 & 12.9 & 12.9 & 24.2 \\
Retired & 22 & 4.3 & 4.3 & 28.5 \\
Do not know, no answer & 4 & 0.8 & 0.8 & 29.3 \\
Others & 22 & 4.3 & 4.3 & 33.6 \\
Active worker & 340 & 66.4 & 66.4 & \\
Total & 512 & 100 & 100 & \\
\hline
\end{tabular}

Table A6. Descriptive statistics of the survey carried out: Income of the family unit.

\begin{tabular}{ccccc}
\hline Income of the Family Unit & Frequency & Percentage & Valid Percentage & Accumulated Percentage \\
\hline$<€ 14,000$ & 88 & 17.2 & 17.2 & 17.2 \\
$€ 14,000,001-25,000$ & 4 & 0.8 & 0.8 & 18 \\
$€ 25,000.001-€ 35,000$ & 166 & 32.4 & 32.4 & 50.4 \\
$€ 35,000.001-€ 50,000$ & 104 & 20.3 & 20.3 & 70.7 \\
$€ 50,000.001-€ 100,000$ & 98 & 19.1 & 19.1 & 100 \\
$>€ 100,000$ & 52 & 10.2 & 10.2 & \\
Total & 512 & 100 & 100 & \\
\hline
\end{tabular}

Source: Author's elaboration based on data from an online survey.

Table A7. Descriptive statistics of the survey carried out: Size of the municipality of residence.

\begin{tabular}{ccccc}
\hline Size of the Municipality of Residence & Frequency & Percentage & Valid Percentage & Accumulated Percentage \\
\hline$<1000$ & 34 & 6.6 & 6.6 & 7 \\
$1000-10,000$ & 36 & 7 & 21.9 & 13.7 \\
$10,000.1-50,000$ & 112 & 21.9 & 64.5 & 35.5 \\
$50,000.1-100,000$ & 330 & 64.5 & 100 & 100 \\
Total & 512 & 100 & \\
\hline
\end{tabular}

Source: Author's elaboration based on data from an online survey. 
Table A8. Descriptive statistics of the survey carried out: Do you know what a virtual currency is?

\begin{tabular}{lcccc}
\hline Do you Know What a Virtual Currency Is? & Frequency & Percentage & Valid Percentage & Accumulated Percentage \\
\hline No, I don't know what a digital currency is. & 172 & 33.6 & 33.6 & 33.6 \\
Yes, I know what a digital currency is. & 340 & 66.4 & 66.4 & 100 \\
Total & 512 & 100 & 100 & \\
\hline
\end{tabular}

Source: Author's elaboration based on data from an online survey.

Table A9. Descriptive statistics of the survey carried out: If the European Central Bank launched a virtual currency, would you continue to use traditional cash, would you reduce it use in favor of digital or would you replace traditional cash with digital?

\begin{tabular}{|c|c|c|c|c|}
\hline $\begin{array}{l}\text { If the European Central Bank Launched a Virtual } \\
\text { Currency: }\end{array}$ & Frequency & Percentage & Valid Percentage & Accumulated Percentage \\
\hline I would reduce the use of traditional cash & 220 & 43 & 43 & 43 \\
\hline I would continue to use traditional cash (coins and bills) & 128 & 25 & 25 & 68 \\
\hline I would substitute traditional cash for digital cash & 164 & 32 & 32 & 100 \\
\hline Total & 512 & 100 & 100 & \\
\hline
\end{tabular}

Source: Author's elaboration based on data from an online survey.

Table A10. Variance, asymmetry, standard error of skewness, kurtosis, and kurtosis standard error.

\begin{tabular}{ccccccc}
\hline & Age & Sex & $\begin{array}{c}\text { Training Level } \\
\text { (Studies) }\end{array}$ & $\begin{array}{c}\text { Current Main } \\
\text { Occupation }\end{array}$ & $\begin{array}{c}\text { Income of the } \\
\text { Family Unit }\end{array}$ & $\begin{array}{c}\text { Size of the Municipality } \\
\text { of Residence }\end{array}$ \\
\hline Variance & 1859 & 0.260 & 0.216 & 1448 & 1574 & 1357 \\
Skewness & 0.421 & -0.077 & -2066 & 1910 & 0.363 & -0.511 \\
Standard error of skewness & 0.131 & 0.131 & 0.131 & 0.131 & 0.131 & 0.131 \\
Kurtosis & -0.546 & -1676 & 7086 & 3217 & -0.678 & 0.526 \\
Kurtosis standard error & 0.261 & 0.261 & 0.261 & 0.261 & 0.261 & 0.261 \\
\hline
\end{tabular}

Source: Author's elaboration based on data from an online survey and SPSS Statistics.

\section{References}

1. BOE-Boletín Oficial del Estado. Diario de sesión del Congreso de los Diputados de España, del día 24 de abril de 2020. 2020. Available online: http://www.congreso.es/public_oficiales/L14/CONG/BOCG/D/BOCG14-D-73.PDF (accessed on 2 June 2020).

2. BOE-Boletín Oficial del Estado. Tratado de Funcionamiento de la Unión Europea. 2020. Available online: https://www.boe.es/doue/2010/083/Z00047-00199.pdf (accessed on 2 June 2020).

3. European Parliament. Financial Exclusion in Rural Areas. 2020. Available online: https://www.europarl. europa.eu/doceo/document/E-8-2017-005311_ES.html (accessed on 8 August 2020).

4. Instituto Valenciano de Investigaciones Económicas. La Población Sin Acceso a Una Sucursal Bancaria en Su Municipio Aumenta un 34\% Desde 2008. 2020. Available online: https://www.ivie.es/es_ES/la-poblacion-sinacceso-una-sucursal-bancaria-municipio-aumenta-34-desde-2008/ (accessed on 3 July 2020).

5. Eurostat. Population Density by NUTS 3 Region: Spain. 2020. Available online: https://ec.europa.eu/ eurostat/web/products-datasets/-/demo_r_d3dens (accessed on 8 August 2020).

6. Eurostat. Population Density by NUTS 3 Region: Europe. 2020. Available online: https://appsso.eurostat.ec. europa.eu (accessed on 8 August 2020).

7. Sarma, M. Index of Financial Inclusion-A measure of financial sector inclusiveness. In Centre for International Trade and Development, School of International Studies Working Paper; Jawaharlal Nehru University: Delhi, India, 2012.

8. Citibank. Outstanding Leaders in Financial Inclusion: Ecuador. 2020. Available online: https://seepnetwork. org/files/galleries/1433_SPANISH-FINAL-RFR-compressed.pdf (accessed on 8 August 2020).

9. Solo, T.M. Financial exclusion in Latin America-or the social costs of not banking the urban poor. Environ. Urban 2008, 20, 47-66. [CrossRef]

10. Le, T.H.; Chuc, A.T.; Taghizadeh-Hesary, F. Financial inclusion and its impact on financial efficiency and sustainability: Empirical evidence from Asia. Borsa Istanb. Rev. 2019, 19, 310-322. [CrossRef]

11. Yin, X.; Xu, X.; Chen, Q.; Peng, J. The Sustainable Development of Financial Inclusion: How Can Monetary Policy and Economic Fundamental Interact with It Effectively? Sustainability 2019, 11, 2524. [CrossRef] 
12. World Bank. Inclusión Financiera Es Un Factor Clave Para Reducir la Pobreza e Impulsar la Prosperidad. 2020. Available online: https://www.bancomundial.org/es/topic/financialinclusion/overview (accessed on 1 July 2020).

13. United Nations. La Guía de los Vagos Para Salvar el Mundo. 2020. Available online: https://www.un.org/ sustainabledevelopment/es/takeaction/ (accessed on 3 June 2020).

14. Martin-Oliver, A. Financial exclusion and branch closures in Spain after the Great Recession. Reg. Stud. 2019, 53, 562-573. [CrossRef]

15. Akhalumeh, P.; Ohiokha, F. Nigeria's cashless economy: The imperatives. Int. J. Manag. Bus. Stud. 2012, 22, 31-36.

16. Storti, C.C.; De Grauwe, P. 13 Monetary policy in a cashless society. In Technology and Finance: Challenges for Financial Markets, Business Strategies and Policy Makers; Routledge: London, UK, 2003; Volume 17, p. 250.

17. Warwick, D.R. Toward a cashless society. Futurist 2004, 38, 38-42.

18. Garcia-Swartz, D.; Hahn, R.; Layne-Farrar, A. The Move Toward a Cashless Society: Calculating the Costs and Benefits. Rev. Netw. Econ. 2006, 5. [CrossRef]

19. Papadopoulos, G. Electronic Money and the Possibility of a Cashless Society. SSRN Electron. J. 2007. [CrossRef]

20. Khan, J.; Craig-Lees, M. "Cashless" Transactions: Perceptions of Money in Mobile Payments. Int. Bus. Econ. Rev. 2009, 1.

21. Lorenz, W. Moving Away from Cash. Card Technol. Today 2009, 21, 12-14. [CrossRef]

22. Bonhage, B. Eurocheque: Creating a 'Common Currency' European Infrastructure for the Cashless Mass Payments System. In Materializing Europe; Badenoch, A., Fickers, A., Eds.; Palgrave Macmillan: London, UK, 2010.

23. Parihar, M. 'Cashless Society'-A Financial 'Paradigm Shift' Through Social Networking. SSRN Electron. J. 2011. [CrossRef]

24. Alawiye-Adams, A. Evaluating the systemic transition to a cashless economy in Nigeria. SSRN Electron. J. 2012. [CrossRef]

25. Akinola, O.S. Cashless society, problems and prospects, data mining research potentials. Int. J. Comput. Sci. Telecommun. 2012, 3, 49-55.

26. Feige, E. The Myth of the Cashless Society: How Much of America's Currency Is Overseas? The Usage, Costs and Benefits of Cash: Theory and Evidence from Macro and Micro Data; MPRA Paper No. 42169; Deutsche Bundesbank, Eurosystem: Munich, Germany, 2012.

27. Hasan, I.; De Renzis, T.; Schmiedel, H. Retail Payments and Economic Growth. SSRN Electron. J. 2012, 1-37. [CrossRef]

28. Ezuwore-Obodoekwe, C.N.; Eyisi, A.S.; Emengini, S.E.; Chukwubuzo, A.F. A Critical Analysis of Cashless Banking Policy in Nigeria. IOSR J. Bus. Manag. 2014, 16, 30-42. [CrossRef]

29. Krüger, M.; Seitz, F. Costs and Benefits of Cash and Cashless Payment Instruments: Overview and Initial Estimates; Deutsche Bundesbank: Frankfurt, Germany, 2014.

30. McLeay, M.; Radia, A.; Thomas, R. El Dinero En La Economía Moderna: Una Introducción. Rev. Econ. Inst. 2015, 17, 333. [CrossRef]

31. Tee, H.; Ong, H. Cashless Payment and Economic Growth. Financ. Innov. 2016, 2, 16. [CrossRef]

32. Engert, W.; Fung, B.; Hendry, S. Is a Cashless Society Problematic? Staff DiscussionPaper/Document d'analysedu personnel2018-12; Bank of Canada: Ottawa, ON, Canada, 2018.

33. Masciandaro, D.; Cillo, A.; Borgonovo, E.; Caselli, S.; Rabitti, G. Cryptocurrencies, Central Bank Digital Cash, Traditional Money: Does Privacy Matter? SSRN Electron. J. 2018. [CrossRef]

34. Fabris, N. Cashless Society-The Future of Money or a Utopia? J. Cent. Bank. Theory Pract. 2019, 8, 53-66. [CrossRef]

35. Arvidsson, N. The Future of Cash in Sweden. In Building a Cashless Society; Springer: Berlin/Heidelberg, Germany, 2019; pp. 75-84. [CrossRef]

36. Gómez-Fernández, N.; Albert, J. ¿Es la Eurozona un área óptima para suprimir el efectivo? Un análisis sobre la inclusión financiera y el uso de efectivo. Cuad. Econ. 2019, 43. [CrossRef]

37. European Central Bank. Dictamen Sobre las Limitaciones a los Pagos en Efectivo, en Respuesta a la Solicitud del Banco de España, en Nombre de la Secretaría de Estado de Hacienda; European Central Bank: Frankfurt, France, $2019 ;$ p. 1. 
38. Náñez Alonso, S. Activities and Operations with Cryptocurrencies and Their Taxation Implications: The Spanish Case. Laws 2019, 8, 16. [CrossRef]

39. Goh, Y.Y.; Leong, S.H.; Pang, M.W.; Yew, S.K.; Yow, Z.L. The Effects of Cashless Payments on Corruption. Bachelor's Thesis, Universiti Tunku Abdul Rahmanutar, Kampar, Malaysia, April 2019.

40. Náñez Alonso, S.; Echarte Fernández, M.; Sanz Bas, D.; Kaczmarek, J. Reasons Fostering or Discouraging The Implementation Of Central Bank-Backed Digital Currency: A Review. Economies 2020, 8, 41. [CrossRef]

41. Bank for International Settlements. BIS Annual Economic Report, 24 June 2020; Werner Druck \& Medien AG: Basel, Switzerland, 2020.

42. Humbani, M.; Wiese, M. A cashless society for all: Determining consumers' readiness to adopt mobile payment services. J. Afr. Bus. 2018, 19, 409-429. [CrossRef]

43. Immordino, G.; Russo, F.F. Cashless payments and tax evasion. Eur. J. Political Econ. 2018, 55, 36-43. [CrossRef]

44. Cohen, N.; Rubinchik, A.; Shami, L. Towards a cashless economy: Economic and socio-political implications. Eur. J. Political Econ. 2020, 61, 101820. [CrossRef]

45. Lombardi, M. Italy: A Cashless Society? 2018. Available online: http://tesi.luiss.it/21905/1/204071_ LOMBARDI_MARIO_ITALY\%20CASHLESS\%20SOCIETY_\%20.pdf (accessed on 24 August 2020).

46. World Bank. How to Measure Financial Inclusion. 2020. Available online: https://www.worldbank.org/en/ topic/financialinclusion/brief/how-to-measure-financial-inclusion (accessed on 15 June 2020).

47. World Bank. Global Findex. 2020. Available online: https://globalfindex.worldbank.org/ (accessed on 15 June 2020).

48. International Monetary Fund. Financial Access Survey 2019. 2020. Available online: https://data.imf.org/ ?sk=E5DCAB7E-A5CA-4892-A6EA-598B5463A34C (accessed on 15 June 2020).

49. Végső, T. Comparative Analysis of the Changes in Cash Demand in Hungary. Financ. Econ. Rev. 2020, 19, 90-118. [CrossRef]

50. Chaveesuk, S.; Vanitchatchavan, P.; Wutthirong, P.; Nakwari, P.; Jaikua, M.; Chaiyasoonthorn, W. The Acceptance Model toward Cashless Society in Thailand. In Proceedings of the 9th International Conference on Information Communication and Management, Prague, Czech Republic, 23-26 August 2019; pp. 190-195.

51. Athique, A. A Great Leap of Faith: The Cashless Agenda in Digital India. New Media Soc. 2019, 21, 1697-1713. [CrossRef]

52. Hastomo, A.; Aras, M. Influence of Cashless Society Socialization toward Trust Transaction Culture in Jakarta, Indonesia. Humaniora 2018, 9, 1-13. [CrossRef]

53. Kadar, H.H.B.; Sameon, S.S.B.; Din, M.B.M.; Rafee, P.A.B.A. Malaysia towards Cashless Society. In International Symposium of Information and Internet Technology; Springer: Cham, Germany, 2018; pp. 34-42.

54. Gas, S. Mobile Money, Cashless Society and Financial Inclusion: Case Study on Somalia and Kenya. SSRN Electron. J. 2017. [CrossRef]

55. Moon, W. A Coinless Society as a Bridge to a Cashless Society: A Korean Experiment. In Cash in East Asia; Springer: Berlin/Heidelberg, Germany, 2017; pp. 101-105. [CrossRef]

56. Omotoso, K.; Muyiwa, A. Prospects of Nigeria's ICT infrastructure for e-commerce and cashless economy. Br. J. Econ. Manag. Trade 2016, 13, 1-10. [CrossRef]

57. Burikoko, T. Mapping Mobile Money in Rwanda: The Mvisa Project. In Proceedings of the International Conference "InterCarto/InterGIS", Braunschweig, Germany, 10-14 March 1997; Volume 1, p. 145. [CrossRef]

58. Evans, J.; Tischer, D.; Davies, S. Geographies of Access to Cash: Identifying Vulnerable Communities in a Case Study of South Wales; Personal Finance Research Centre (PFRC), University of Bristol: Bristol, UK, 2020.

59. Tischer, D.; Evans, J.; Davies, S. Mapping the Availability of Cash a Case Study of Bristol's Financial Infrastructure; Personal Finance Research Centre (PFRC), University of Bristol: Bristol, UK, 2019.

60. Delaney, L.; O’Hara, A.; Finlay, R.; Reserve Bank of Australia. Cash Withdrawal Symptoms. 2019. Available online: https://www.rba.gov.au/publications/bulletin/2019/jun/pdf/cash-withdrawal-symptoms. pdf (accessed on 24 August 2020).

61. Swedish Government. 'Secured Access to Cash', Media Release. 16 April 2020. Available online: https: //www.riksbank.se/en-gb/payments--cash/the-riksbanks-task-in-relation-to-payments/secure-access-tocash---report-from-the-riksbank-committee/ (accessed on 24 August 2020). 
62. Cadete de Matos, J.; D'Aguiar, L. Assessing Financial Inclusion in Portugal from the Central Bank's Perspective. In Proceedings of the Bank of Morocco-CEMLA-IFC Satellite Seminar at the ISI World Statistics Congress on "Financial Inclusion", Marrakech, Morocco, 14 July 2017; Available online: https: //www.bis.org/ifc/publ/ifcb47a.pdf (accessed on 24 August 2020).

63. Community Access to Cash Pilots. 2020. Available online: https://communityaccesstocashpilots.org/ (accessed on 24 August 2020).

64. Ceeney, N. UK Finance Responds to the Launch of the Community Access to Cash Pilots Initiative, UK Finance. 2020. Available online: https://www.ukfinance.org.uk/press/press-releases/uk-finance-respondslaunch-community-access-cash-pilots-initiative (accessed on 24 August 2020).

65. Lowman, J. Association of Convenience Stores Welcomes New Community Access to Cash Initiative. 2020. Available online: https://www.acs.org.uk/news/acs-welcomes-new-community-access-cash-initiative (accessed on 24 August 2020).

66. Vana, P.; Lambrecht, A.; Bertini, M. Cashback Is Cash Forward: Delaying a Discount to Entice Future Spending. J. Mark. Res. 2018, 55, 852-868. [CrossRef]

67. Datta, S.K.; Singh, K. Variation and determinants of financial inclusion and their association with human development: A cross-country analysis. IIMB Manag. Rev. 2019, 31, 336-349. [CrossRef]

68. Consulting, C. Acta Sanitaria: España Cuenta Con la Red de Farmacias Comunitarias Más Grande de Europa. 2020. Available online: https://www.actasanitaria.com/espana-cuenta-con-la-red-de-farmaciascomunitarias-mas-grande-de-europa/ (accessed on 15 June 2020).

69. Jorge, J.; Chivite, M.P.; Salinas, F. La transformación digital en el sector cooperativo agroalimentario español: Situación y perspectivas. CIRIEC España Rev. Econ. Pública Soc. Coop. 2019, 95, 39-70. [CrossRef]

70. Jorge Vázquez, J. La economía colaborativa en la era digital: Fundamentación teórica y alcance económico. In Economía Digital y Colaborativa: Cuestiones Económicas y Jurídicas; Náñez, S.L., Ed.; Università degli Studì Suor Orsola Benincasa: Naples, Italy, 2019.

71. Sánchez Cano, J. El Bitcoin y Su Demanda Exponencial de Energía. Panor. Econ. 2019, 14, 85. [CrossRef]

72. Dolader-Retamal, C.; Bel-Roig, J.; Muñoz-Tapia, J.L. La Blockchain: Fundamentos, Aplicaciones y Relación Con Otras Tecnologías Disruptivas. Econ. Ind. 2017, 405, 33-40.

73. Slattery, T. Taking a Bit Out of Crime: Bitcoin and Cross-Border Tax Evasion. Brooklyn J. Int. Law 2014, $39,829$.

74. Campbell-Verduyn, M. Bitcoin, Crypto-Coins, and Global Anti-Money Laundering Governance. Crime Law Soc. Chang. 2018, 69, 283-305. [CrossRef]

75. Diez de los Rios, A.; Zhu, Y. CBDC and Monetary Sovereignty, No 2020-5; Staff Analytical Notes from Bank of Canada; Bank of Canada: Ottawa, ON, Canada, 2020.

76. Schuh, S.; Stavins, J. Why are (Some) Consumers (Finally) Writing Fewer Checks? The Role of Payment Characteristics. SSRN Electron. J. 2009, 34, 1745-1758. [CrossRef]

77. Arango, C.; Huynh, K.; Sabetti, L. How Do You Pay? The Role of Incentives at the Point-of-Sale; Bank of Canada Working Paper 2011-23; Bank of Canada: Ottawa, ON, Canada, 2011.

78. Von Kalckreuth, U.; Schmidt, T.; Stix, H. Choosing and Using Payment Instruments: Evidence from German Microdata. Empir. Econ. 2013, 46, 1019-1055. [CrossRef]

79. Wang, X.; He, G. Digital Financial Inclusion and Farmers' Vulnerability to Poverty: Evidence from Rural China. Sustainability 2020, 12, 1668. [CrossRef] 
80. Náñez Alonso, S.L. The Tax Incentives in the IVTM and "Eco-Friendly Cars": The Spanish Case. Sustainability 2020, 12, 3398. [CrossRef]

81. Náñez Alonso, S.L.; Reier Forradellas, R. Tax Incentives in Rural Environment as Economic Policy and Population Fixation. Case study of Castilla-León Region. In Business, Economics and Science Common Challenges; Bernat, T., Duda, J., Eds.; Filodiritto Editore: Bologna, Italy, 2020; pp. 205-210. [CrossRef]

82. Engert, W.; Fung, B. A Uniform Currency in a Cashless Economy; Staff Analytical Note/Note Analytique du Personnel-2020-7; Bank of Canada: Ottawa, ON, Canada, 2020; p. 5.

(C) 2020 by the authors. Licensee MDPI, Basel, Switzerland. This article is an open access article distributed under the terms and conditions of the Creative Commons Attribution (CC BY) license (http://creativecommons.org/licenses/by/4.0/). 

Article

\title{
Effects of the Type of CSR Discourse for Utilitarian and Hedonic Services
}

\author{
Andrea Pérez *, María del Mar García de los Salmones and Elisa Baraibar-Diez \\ Business Administration Department, University of Cantabria, 39005 Santander, Spain; \\ mariadelmar.garcia@unican.es (M.d.M.G.d.1.S.); elisa.baraibar@unican.es (E.B.-D.) \\ * Correspondence: andrea.perezruiz@unican.es
}

Received: 25 May 2020; Accepted: 5 June 2020; Published: 12 June 2020

\begin{abstract}
In a context of corporate social responsibility (CSR) communication, we explore whether the use of expositive versus narrative discourses interacts with the type of service commercialized by the company (utilitarian vs. hedonic) to determine consumer perceptions and responses to corporate communication. Our main proposal is that, as representative examples of utilitarian services, banking companies would benefit significantly from communicating their CSR efforts with expositive discourses, whereas narrative discourses would be more adequate for hedonic services (e.g., catering). To test the research hypotheses, we use a 2 (expositive/narrative discourse) $\mathrm{x} 2$ (utilitarian/hedonic service) between-subjects experimental design where we expose 302 consumers to different combinations of CSR messages and we evaluate changes in their message attributions and internal and external responses to them. The findings show that the interaction effect is significant and it works in the expected direction for issue importance, CSR fit, and CSR attributions. However, for CSR impact, attitude, trust, purchase, and advocacy intentions, the findings suggest that narrative discourses work better than expositive discourses both for utilitarian and hedonic services. No significant differences between types of discourses are observed for CSR motives, CSR commitment, and $\mathrm{C}-\mathrm{C}$ identification and the interaction effect is also not significant for these variables.
\end{abstract}

Keywords: CSR; communication; discourse; exposition; narrative; storytelling; banking; catering; utilitarian service; hedonic service

\section{Introduction}

Since the 2008 Great Recession, increasing attention has been devoted to corporate social responsibility (CSR). Not only has the international community realized the importance of achieving sustainable economic, social, and environmental development for stability and progress in the world economy [1], but CSR has also become paramount for institutions and companies to recover credibility, trust, and reputation $[2,3]$.

Nonetheless, it is noticeable that the business returns to CSR are contingent on stakeholders' awareness of a company's CSR activities [4]. However, studies frequently report that CSR awareness is typically low, while stakeholders also demonstrate to be highly skeptical of the CSR motives behind companies that engage in CSR efforts [5]. These ideas highlight the necessity that companies have nowadays to design better communication strategies to reap strategic benefits from its CSR activities [4]. The way companies design their CSR communication strategies is crucial for the success of CSR and research should focus on this issue to provide companies with useful insight to design CSR and communication strategies more adequately.

For instance, an interesting line of research has focused on exploring the effect that different discourse strategies have on audiences when exposed to communication [6-8]. Scholars have frequently discussed the advantages and disadvantages of designing messages based on expositive (semantic or rational) or narrative (i.e., storytelling) discourses $[9,10]$. Based on the premises 
of the narrative paradigm theory (NPT) [11], scholars have mostly defended that discourse will always tell a story and insofar as it invites an audience to believe it or to act on it, the narrative paradigm and its attendant logic, narrative rationality, are available for (better) interpretation and assessment. Therefore, narrative discourses are expected to report better outcomes for companies than expositive discourses [12-14]. Nonetheless, the empirical evidence along this line of research is largely inconclusive [15], with studies alternatively demonstrating the superior performance of expositive [16] or narrative [15] discourses, or even showing mixed results within the same experiments [17].

Some scholars have suggested that the inconclusiveness of previous findings may be due to the existence of an interaction effect between the type of discourse strategy and the type of product/service context of the company [17-19]. More precisely, scholars suggest that the type of discourse chosen by the company in its communications should match their product/service type to be successful [15]. For instance, banking services are utilitarian services that, based on the premises of the elaboration likelihood model (ELM), would benefit from applying rational nonnarrative appeals to their communications [20]. On the contrary, catering services are hedonic services, which are focused on pleasing consumers and, consequently, would benefit more from emotional narrative discourses [20]. Nevertheless, support for this matching principle is again contradictory and little consensus has been reached yet. As an example, in her qualitative study, Mortimer (2008) observed that narrative discourses could be useful for both hedonic and utilitarian services and that the matching of the discourse strategy to the type of service context was not necessarily an adequate communication approach for companies [15].

Along this line of research, we have observed that the lack of conclusive findings on the matching principle between the type of discourse and the type of service is especially evident in the CSR communication literature, where very few studies have tested this interaction effect [21]. All the papers discussed above have explored the role of the type of discourse and/or the service context in conventional commercial advertising (i.e., communication focused on presenting the products and services that can solve a consumer's problem), whereas very little research has been implemented so far in the CSR context. Nonetheless, CSR communication differs from commercial advertising significantly because its main goal is not to "sell" products/services but to promote corporate sustainable development endeavors and define corporate values and personality [22]. It also differs from commercial advertising because of its normative or moralistic character. Therefore, the few conclusions (if any) that could be extracted from previous literature on the interaction effect between the type of discourse and the type of service could not be translated into the CSR literature straightforwardly and, as so, further research is needed in the context of CSR communication.

Based on these ideas, the research goal of the present paper is to explore whether the use of expositive versus narrative discourses interacts with the type of service (utilitarian vs. hedonic) to determine consumer perceptions and responses to CSR communication. To propose our research hypotheses, we base on the ELM [23] and the distinction between functional and self-congruity types of message processing $[15,18]$ to propose that utilitarian (banking) services would benefit significantly from communicating their CSR efforts with expositive discourses, whereas narrative discourses should be left for hedonic (catering) services that would achieve better results with them. To measure the consequences of the interaction effect, we evaluate changes in consumer message attributions and internal and external responses to a CSR message [4] in a $2 \times 2$ experimental context where consumers are exposed to different combinations of expositive vs. narrative messages in utilitarian vs. hedonic service contexts. In testing this proposal, the paper will contribute to previous literature in two ways. First, the paper will provide further insight into the discourse by service interaction effect that has reported inconclusive findings in previous literature. Second, it will do so in the context of CSR communication, where previous literature has largely neglected the possibility of an interaction effect between both conditions.

We structure the paper as follows. First, we revise literature on discourse and communication strategies and types of services to propose the research hypotheses of the study. Second, we describe 
the research method, paying special attention to its design, sample, and measurement scales. Third, we describe the main findings of the paper and we discuss them in the light of previous literature. We conclude by presenting the most relevant implications, limitations, and future lines of research derived from the study.

\section{Literature Review}

\subsection{Expositive and Narrative Discourses in Corporate Communication}

An extensive line of research in marketing and communication literature suggests that the success of corporate communication largely depends on the type of discourse used by companies in their public messages [6,8]. In this regard, designing a message that will be perceived as rational, emotional, or mixed in its discourse is a primary strategic consideration in corporate communication [24].

Along this line, companies have traditionally applied two opposite types of discourses to their corporate communications; they present messages that are mostly expositive or narrative in character $[9,10]$. Expositive (semantic, rational, or nonnarrative) perspectives on communication include "self-evident propositions, demonstrations, proofs, and verbal expressions of certain and probable knowing" [7]. Thus, exposition mainly bases on the description of rational arguments, statistics, numbers, names, and facts [12]. Expositive messages do not go any deeper into the reality behind those numbers and they avoid emotional connotations as much as possible [9]. In numerous occasions, this approach has been referred to as informational communication [15]. On the contrary, the narrative (storytelling) rationality implies that "facts need some narrative to bind them together to enhance their intelligibility" [7]. In narrative messages, companies may use storytelling, which refers to the art of telling emotional stories to engage with the audience. Corporate storytelling is the "practice of using narration from within the organization relating to its people, practices, policies and visions to effectively engage with staff (and external stakeholders)" [25]. Thus, narrative messages are aimed at generating emotional connections between stakeholders and companies $[26,27]$ by adding favorable and unique associations to companies through messages that can better embrace the core corporate values [27].

Based on the narrative paradigm theory (NPT) [11], previous research has mostly defended that people tend to think narratively more than paradigmatically or in an expositive way [20]. Therefore, narrative discourses are expected to lead to better audience responses than expositive discourses [12-14]. Consisting of a sequence of story — understanding — shared meaning, storytelling, materialized in a compelling story, gains access to the mind and sensations of those who are listening or watching, enriched in their learning and feelings. This connection provokes empathy and, therefore, it allows the audience to understand and be sensitive to the experience that they are being told about, which derives into better attitudes and allows the formation of stronger relationships and engagement [28].

Nonetheless, empirical evidence is inconclusive when it comes to corroborating the role of expositive and narrative discourses on consumers' message attributions and responses to corporate communication. For instance, Mortimer (2008) examined a sample of service advertisements that had been recognized for their success and she found that the majority of advertisements utilized emotional discourses [15]. On the contrary, in a study that explored retail services advertising, Stafford and Day (1995) found the main effect for discourse across industries, in which rational discourses led to more positive levels of attitude towards the ad than emotional discourses [16]. Hill et al. (2004) tested the hypothesis that a successful visualization advertising strategy (i.e., an ad based on a narrative discourse) evoked clear and vivid mental images of the service on consumers, thus making CSR communication more successful [17]. However, their findings only supported this hypothesis for some outcomes such as perceived informativity, service quality, and likelihood to use, but it was not supported for perceived uniqueness. 


\subsection{Interaction Effect between Discourse Strategy and Type of Service}

A plausible explanation for the inconclusiveness of previous literature is that responses to corporate communication do not only depend on the type of discourse adopted by the company, but also on the type of service context where the company operates [15-17,21]. Generally, in service literature, scholars differentiate between utilitarian and hedonic services $[16,20]$. For instance, banking services are utilitarian services that provide functional utilities, deliver cognitive benefits, and are characterized by low employee contact, moderate customization, an equipment-orientation, and direction toward things $[16,20]$. On the contrary, catering services are hedonic services that are consumed primarily for affective or sensory gratification purposes, provide consumers with emotions, and are characterized by high employee contact, considerable customization, and an orientation toward people, not things (i.e., they are more personal) $[16,20]$.

Based on the elaboration likelihood model (ELM) [23] and the functional congruity and self-congruity types of message processing [15,18], we propose that an expositive discourse is especially adequate for communicating about the CSR of banking (utilitarian) services, whereas narrative approaches would be more suitable for the CSR communication of catering (hedonic) services.

In this regard, banking services are high-involvement services for consumers [29] and, as such, the amount this audience type would think about a message coming from a banking company would be high. Um (2008) shows that elaboration is higher when the argument is relevant to the person (i.e., high involvement), and lower when the argument is irrelevant [30]. Therefore, in the case of a banking company, persuasion is most commonly achieved through central and functional processing routes $[15,24]$, which occur when the person who receives the information is likely to focus and process the finer points in the message (e.g., the quality of the argument) $[18,24]$. Therefore, for banking services, communicating CSR facts with a rational, expositive discourse would be more adequate than using a narrative, storytelling discourse because, as utilitarian services, the functional aspects of consumption are more important and rational decision is dominant over emotional responses [31]. Consumers evaluate utilitarian services using cognitive criteria [20]. This rationale matches the use of expositive discourses, which assume that consumers make rational decisions and, therefore, they prefer nonnarrative messages [21].

On the contrary, in catering services, the hedonic aspect of consumption is highly important and affective responses may overwhelm cognitive responses [31]. Catering services are value-expressive, which means that consumers will generally make their decisions to use the service based on the image that is associated to the company and the association that will be created between the company's image and his/her image [18]. Consumers are expected to be influenced by this type of hedonic service more at a personal level, making it difficult for them to disassociate themselves from the service and perceiving it as an extension of themselves [19]. Therefore, when the service is value-expressive, audience persuasion is influenced through an affective, peripheral, and self-congruity processing route [18], which occurs when the person focuses more lightly on source cues to form their attitudes [18] because these cues require little mental effort [24]. In this context, narrative discourses will be more adequate than expositive discourses. In this regard, "well-designed, well-told stories convey both information and emotion, both the explicit and the tacit, both the core and context" [32]. CSR stories have an ameliorative effect, enhancing the ability of audiences to exist more meaningfully and improve their mental models of others and themselves [33]. Thus, corporate storytelling generates an emotional connection between consumers and companies [26,27] and, consequently, it is expected to intensify consumer positive responses to CSR messages when they evaluate hedonic services.

\subsection{Message Attributions in CSR Communication}

To explore how the interaction between type of discourse and type of service affects consumer perceptions and responses to CSR communication, we test the differentiated effect of CSR messages on the prominent framework of CSR communication developed by Du et al. (2010) [4]. According to these authors, one key aspect to create stakeholder awareness and managing stakeholder 
perceptions of a company's CSR activities is the message content (i.e., the "what to communicate" question). Du et al. (2010) and subsequent researchers who have tested their conceptual framework empirically [34], defend that the content of a CSR message should emphasize: (a) the importance of the social issue, (b) the impact the company has on the cause, (c) the motives why it engages in the social cause, (d) the fit (i.e., congruence, similarity, compatibility) between the cause and the company, and (e) the company's long-term commitment to the cause.

Issue importance refers to the relevance of the social cause on a global scale. When companies include information about issue importance in the CSR message, they increase stakeholders' awareness of the cause, which will improve message diagnosticity, allow stakeholders to effectively process CSR appeals and, consequently, improve responses to the CSR message $[35,36]$.

CSR impact reflects the results of the collaboration between the company and the social cause, that is, the impact the company has achieved on the social cause over the time they have collaborated. Mentioning CSR impact gives the message an objective charge, it enhances its credibility, and it let stakeholders evaluate the true level of a company's CSR involvement and commitment to the social cause, which can lead to positive communication outcomes [4,37].

As for CSR motives, it is generally agreed that the perception of a company's intrinsic (altruistic) motives to collaborate with a social cause increases perceived sincerity and positive emotions, whereas a behavior attributed only to extrinsic (egoistic) motives is perceived as dishonest, opportunistic, and misleading for stakeholders, arousing negative feelings [38,39]. Literature also defends that perceptions of corporate altruistic motives lead stakeholders to understand the company's commitment to the social cause as more lasting and stable over time [40] because it derives from the company's value system directly [41].

CSR fit refers to the congruence between the social cause and the company, which can be functional (i.e., the congruence of the type of product/service marketed by the company, and the type of social cause supported) or based on image cues (i.e., the holistic, symbolic, and peripheral judgement of company identity and its relatedness and similarity to the cause identity) [42-44]. A good cause-company fit may minimize negative judgments about the company's motives to collaborate with the cause [45] and, therefore, it leads to better communication outcomes $[4,46]$. On the contrary, a low perceived fit is likely to increase cognitive elaboration and make egoistic motives more salient, arousing negative feelings toward CSR messages [44].

Finally, CSR commitment relates to the company's long-term commitment to the social cause. CSR commitment improves stakeholders' responses because a long-term commitment (versus a reactive, shorter-term CSR action) provides more time to learn about a company-cause collaboration [4]. It also reflects a genuine concern for increasing community welfare and, consequently, it improves attitudes towards the company [35].

As reported in the previous section of this paper, we expect that these consumer perceptions of the message content are dependent upon the interaction between type of discourse (expositive vs. narrative) and type of service (utilitarian vs. hedonic) $[15,16,18,21]$. Thus, we hypothesize that consumers will perceive the different components of the CSR message discussed by Du et al. (2010) differently in each industry depending on the type of CSR discourse used by companies. Based on this idea, this study tests the following research hypotheses:

H1: In a utilitarian service context, an expositive CSR discourse generates statistically significant higher perceptions of (a) issue importance, (b) CSR impact, (c) CSR motives, (d) CSR fit, and (e) CSR commitment than a narrative CSR discourse.

H2: In a hedonic service context, a narrative CSR discourse generates statistically significant higher perceptions of (a) issue importance, (b) CSR impact, (c) CSR motives, (d) CSR fit, and (e) CSR commitment than an expositive CSR discourse. 


\subsection{Consumer Responses to CSR Communication}

Then, message attributions generate internal and external outcomes among stakeholders, which refer respectively to their attitudinal and behavioral responses to the company's CSR communication strategy [4,34]. As stated by Du et al. (2010), when analyzing consumer responses specifically, internal outcomes mainly include CSR attributions, service brand attitude, consumer-company (C-C) identification, and trust, whereas external outcomes refer to purchase and advocacy intentions [4].

CSR communication makes consumers aware of such initiatives, then, it derives in positive CSR attributions [21]. Therefore, corporate communications are important in raising CSR attributions among consumers to induce positive attitudes and behavioral intentions. Without this sort of communication, consumers will purchase a similar service that does not have such CSR attributes [21].

Along with CSR awareness (i.e., associations), Keller (1998) considers that to gain consumer-based brand equity, the consumer should also hold brand associations that are strong, favorable, and unique in comparison to other brands offered in the same category [47]. These brand associations refer to service brand attitude as described by Du et al. (2010) [4]. A large component of Keller's (1998) model depicts various types of brand associations in the form of service-related and non-service-related attributes, such as CSR [48]. Improving brand attitude is important for companies because it is linked to the consumer intention to use the service directly [49].

C-C identification refers to the cognitive and affective state of connection that a consumer perceives between him/herself and a company because of the identification of substantial overlap between the consumer's perceptions of his/her identity and the perceptions of the company's identity [50]. A company that is skilled in meeting the consumer's needs for self-definition is also a company the consumer is satisfied with because $\mathrm{C}-\mathrm{C}$ identification provides a more favorable context for consumers to respond to corporate performance experiences as against to prior expectations. In addition, the higher C-C identification, the higher consumer loyalty and the wish to establish long-term relationships with the company [51].

Trust is understood as the existence of a bidirectional relationship where one exchange partner (consumer) believes in the other's (company) reliability and integrity [52]. Achieving consumer trust is especially important for companies because it serves as a key driver of consumer retention strategies, especially in retail service markets. Along this line, in numerous occasions, research has confirmed the link between trust and other relevant outcomes of corporate strategies such as perceived value, purchase, advocacy, and loyalty [53,54].

Purchase intentions refer to consumer commitment to buy goods or use services from a company over time [55]. Therefore, it reflects a deeply held commitment of consumers to repurchase from the company [56]. Purchase intentions have always been defended as the primary criteria used by companies to assess the adequacy of their consumer retention strategies [57].

Finally, advocacy intentions refer to consumer positive word-of-mouth, that is, informal communication directed at other consumers about products, services, and companies [58]. Advocacy has a large influence on people close to the consumer because it may encourage them to also show interest in the company and buy its products or services [55].

Based on the interaction effect suggested in this study, the following research hypotheses are proposed:

H3: In a utilitarian service context, an expositive CSR discourse generates a statistically significant higher level of (a) CSR attributions, (b) service brand attitude, (c) C-C identification, (d) trust, (e) purchase intentions, and $(f)$ advocacy intentions than a narrative CSR discourse.

H4: In a hedonic service context, a narrative CSR discourse generates a statistically significant higher level of (a) CSR attributions, (b) service brand attitude, (c) C-C identification, (d) trust, (e) purchase intentions, and $(f)$ advocacy intentions than an expositive CSR discourse. 


\section{Method}

\subsection{Research Design}

To test the research hypotheses, we used a 2 (expositive/narrative discourse) x 2 (utilitarian/hedonic service) between-subjects experimental design.

We collected data in a northern city in Spain (i.e., Santander, Cantabria) between April and July 2018, after we had properly trained research assistants for the task. Each research assistant was assigned randomly to collect data in one of the four experimental conditions. We used a convenience sampling procedure based on gender and age to select respondents and assign them to each scenario. In total, 302 participants took place in the experiment and they were distributed across scenarios as shown in Table 1. The sample comprised 49.7\% women and 50.3\% men. Participants' age ranged from 19 to 90. More precisely, $22.2 \%$ of the participants were younger than 35, 38.7\% were between 35 and 55, and $39.1 \%$ were older than 55. Sampling quotas were very similar in the four scenarios and they were representative of the population in the Spanish region where data was collected.

Table 1. Sample sizes.

\begin{tabular}{ccc}
\hline Service Type & Discourse Strategy & $\mathbf{n}$ \\
\hline Utilitarian (bank) & Expositive & 75 \\
& Narrative & 75 \\
\hline Hedonic (restaurant) & Expositive & 76 \\
& Narrative & 76 \\
\hline
\end{tabular}

For each scenario, research assistants gave short explanations to the participants before the procedure started. The explanations did not convey the real purpose of the study. Instead, participants were told that the purpose was to understand their level of interest in CSR activities. Participants became aware of a fictitious company and its CSR program by evaluating website content (Appendix A, Figures A1 and A2). The experiment contained stimuli from fictitious websites portraying information on the CSR activities implemented by the company over the last year, which were focused especially on the fight against childhood leukemia in two service contexts: a bank (utilitarian) and a restaurant (hedonic).

We purposely used fictitious stimuli to control for participants' knowledge, attitudes, and behavioral intentions concerning real companies, therefore avoiding their influence on the conceptual model proposed in this study [59]. We focused on the website for several reasons. First, website audiences generally perceive home pages primarily as an advertisement designed to entice them to experience the site [24]. Thus, communication theory matches this online context well. Second, a website is the most frequent medium used to engage in CSR communication because it provides a highly accessible but inexpensive medium to avoid accusations of spending more on communication than on the CSR activities themselves [38]. Third, websites are a preferred medium to communicate CSR commitment because of the richness of argumentation and opportunities for interactivity they provide [38]. We chose childhood leukemia as the social cause of our study based on previous studies that had considered health as a critical issue for CSR assessment [60].

To avoid potential confounding effects, all experimental website content used the same images and structure so that the only difference between them was the company itself and the discourse strategy used to present the information [61]. In the four treatments, information about key characteristics of the focal company and its CSR activities (e.g., numbers, figures) were kept constant. The website content conveyed that "Your Bank" (bank, utilitarian service) or "Ecofood" (restaurant, hedonic service) had invested " $x$ " amount of money to collaborate with the childhood leukemia cause and it had achieved " $x$ " results because of the collaboration during the last year. In the narrative treatments, the company's CSR activities were described through an emotional story that involved the son of a company's employee who suffered from childhood leukemia. In the expositive treatments, the same 
information was described, although this time it was presented objectively and in a rational way, with bullet points, only using facts, figures, and statistics, and without referring to the employee's son who suffered from the disease.

Participants were asked to read the fictitious information about the company and its CSR website at their own pace. After reading it, they had to complete a questionnaire that included manipulation and post-test measures. The experiment included a manipulation check to test for perceived differences between utilitarian and hedonic services in terms of competence (expert vs. inexperienced/competent vs. incompetent) [62] and attractiveness (attractive vs. unattractive/pleasant vs. unpleasant) [62]. Utilitarian services usually rate higher in functional components than emotional components of customer experience and companies offering this type of services tend to be perceived as more competent and experienced than companies providing hedonic services [63]. On the contrary, participants were expected to perceive hedonic services as more delightful, enjoyable, and attractive than utilitarian services [21]. A manipulation check to evaluate message authenticity (The information presented in the website seems able to occur in the real world/is authentic/provides an abundance of facts so that I believe it is authentic) [64] and participants' skepticism towards the information presented in the websites (Claims are exaggerated/are intended to mislead/are not believable/are not true) [65] tested for perceived differences between expositive and narrative discourses. Expositive discourses do not go deep into the reality behind the rational arguments, statistics, numbers, names, and facts that they provide [12]. On the contrary, CSR stories make social causes much more real to the audience and they make the messages more convincing and memorable [26]. Therefore, they are expected to be more authentic and elicit less skepticism than expositive discourses. Measurement of all items took place on seven-point Likert-type and semantic differential scales.

\subsection{Measurement Scales}

Seven-point Likert-type and semantic differential scales were used to evaluate post-test measures. We measured issue importance with the three-item scale proposed by Russell and Russell (2010) [66]. To measure CSR impact, we applied the five-item scale proposed by Connors et al. [67]. CSR motives were evaluated by adopting the three-item scale originally proposed by Becker-Olsen et al. [68]. The five-item scale used to measure CSR fit was adapted from Speed and Thompson (2000) and Skard and Thorbjornsen (2014) [69,70]. We measured CSR commitment using a five-item scale taken from Walton (2014) [71]. CSR attributions were measured with a three-item scale taken from Wagner et al. (2009) [72]. We evaluated service brand attitude with the four-item scale also proposed by Wagner et al. (2009) [72]. To measure C-C identification, we applied the five-item scale proposed by Currás (2007) [62]. To measure trust, we used the three-item scale proposed by Morgan and Hunt (1994) [52]. Finally, we evaluated purchase and advocacy intentions with two three-item scales adapted from the original proposals of Groza et al. (2011) and Romani et al. (2013), respectively $[73,74]$. Table 2 presents all the items.

When building the questionnaire, we also discussed sources of common method variance (CMV), such as social desirability bias, to refine the gathering of empirical data [75]. To avoid the transient mood state of the participants, we aimed at reducing evaluation apprehension by guaranteeing anonymity. For this purpose, we instructed the research assistants to assure the participants that their answers were anonymous and that there were no right or wrong answers. In doing so, the participants were encouraged to answer questions as honestly as possible [75]. After collecting data, we also applied statistical analyses to control for CMV. More precisely, we conducted Harman's single-factor test, which corroborated that all the scales items loaded on more than one single factor. Therefore, they were not concentrated in any one general factor, which corroborated that the correlation among variables was not influenced by their common source [75]. Thus, CMV did not influence the findings of our quantitative research significantly. 
Table 2. Measurement scales.

\begin{tabular}{c} 
Message Attributions \\
Items \\
\hline Factors \\
Issue importance $\quad \begin{array}{c}\text { IMPO1) The company transmits that this is an important cause; IMPO2) The } \\
\text { company transmits it is vital to tackle this cause; IMPO3) The company transmits that } \\
\text { companies have a responsibility to address this cause } \\
\text { The information presented on the website is ... }\end{array}$ \\
IMPA1) Abstract/Concrete; IMPA2) Ambiguous/Clear; IMPA3) Not \\
Impact \\
descriptive/Descriptive; IMPA4) Not vivid/Vivid; IMPA5) Not easy to imagine/Easy \\
to imagine \\
The motivations of the company to support the cause are ... \\
MOTI1) Self-interested/Community interested; MOTI2) \\
Fit \\
Firm-focused/Customer-focused; MOTI3) Profit-motivated/Socially-motivated \\
FIT1) The image of the cause and the image of the company are similar; FIT2) The \\
company and the cause fit together well; FIT3) The company and the cause stand for \\
similar things; FIT4) It makes sense to me that the company sponsors this cause; FIT5) \\
There is a logical connection between the cause and the company \\
COMM1) The company seems to feel strongly about helping the cause; COMM2) The \\
company demonstrates a real interest in making an impact to help the cause; \\
COMM3) The company is capable of long-lasting beneficial effects towards the cause; \\
COMM4) The company seems like they will support the cause for a long period; \\
COMM5) The company will more than likely make a large impact toward helping the \\
cause
\end{tabular}

\section{Consumer Responses}

Attributions

Attitude

Identification

Trust

Purchase

Advocacy
ATTR1) The company is socially responsible; ATTR2) The company is concerned to improve the well-being of society; ATTR3) The company follows high ethical standards

My general feeling towards the company is ..

ATTI1) Unfavorable/Favorable; ATTI2) Bad/Good; ATTI3) Unpleasant/Pleasant; ATTI4) Negative/Positive

IDEN1) My way of being sticks with what I perceive from the company; IDEN2) I look like what I think the company represents; IDEN3) I am similar to how I perceive the company; IDEN4) The image I have of the company matches the image I have of myself; IDEN5) The company's identity resembles my identity

TRUS1) The company can be trusted; TRUS2) The company can be counted on to do what is right; TRUS3) The company has high integrity

If the company existed, how likely would it be that you purchased its services?

?PURC1) Very unlikely/Very likely; PURC2) Improbable/Probable; PURC3) Impossible/Possible

ADVO1) I intend to say positive things about the company to friends, relatives and other people; ADVO2) I intend to mention favorable things about the company with my friends, relatives, or other people; ADVO3) I intend to recommend to purchase services of the company to my friends, relatives, and other people

\section{Findings}

\subsection{Manipulation Checks}

We performed two independent-samples t-tests on the manipulation check questions to verify if the participants rated corporate competence and attractiveness and message authenticity and skepticism differently in the alternative experimental conditions. As per expectations, the participants perceived the hedonic service to be more attractive (meanU $=5.090$, meanH $=5.880 ; t=4.983, p<0.050$ ) and pleasant $($ meanU $=5.190$, meanH $=5.970 ; t=5.369, p<0.050)$ than the utilitarian service, whereas there were no significant differences in the competence dimension (meanU $=5.050$, meanH $=5.303 ; \mathrm{t}=1.953$, $p>0.050$ ), where both types of services were perceived equally expert (meanU $=5.010$, meanH $=5.180$; $\mathrm{t}=1.268, p>0.050$ ). Although the test did not report significant differences concerning skepticism towards the message (meanE $=3.171$, meanN $=2.901 ; \mathrm{t}=1.808, p>0.050$ ), the narrative discourse was perceived to be more realistic (meanE $=5.170$, meanN $=5.480 ; \mathrm{t}=2.210, p<0.050$ ) and authentic (meanE $=4.890$, meanN $=5.300 ; t=2.822, p<0.050$ ) and to provide more abundance of authentic 
facts $($ meanE $=4.900$, meanN $=5.330 ; t=2.894, p<0.050)$ than the expositive message. Therefore, the results indicated that the experimental manipulation was successful because the different scenarios were perceived differently by the participants.

\subsection{Evaluation of the Measurement Scales}

We implemented a first-order confirmatory factor analysis (CFA) to analyze the psychometric properties of the measurement scales. To evaluate the quality of all the indicators that are explained in this section, we followed the recommendations of Hair et al. (2014) [76].

Table 3 shows the results of the analysis implemented with the scales that measured message attributions. The findings corroborated that all the comparative fit indexes were very close or exceeded the recommended value of 0.900 , thus corroborating the goodness of the model fit (NFI $=0.897$, $\mathrm{NNFI}=0.932, \mathrm{CFI}=0.943, \mathrm{IFI}=0.943)$. The root mean square error of approximation $(\mathrm{RMSEA})$ value was also below the maximum limit of 0.080 recommended in the literature (RMSEA $=0.060$ ). Additionally, scales yielded acceptable psychometric properties: factor loadings were greater than 0.500 , composite reliability (CR) indicators were greater than 0.700 , average variance extracted (AVE) indicators were greater than 0.500 , and these AVE indicators were also greater than the squared correlation with any other construct.

Table 3. Confirmatory factor analysis (CFA) message attributions $(n=302)$.

\begin{tabular}{|c|c|c|c|c|c|c|c|}
\hline Factors & Items & Mean & s.d. & $\lambda$ & $\mathbf{R} 2$ & CR & AVE \\
\hline \multirow{3}{*}{ Issue importance } & IMPO1 & 5.680 & 1.239 & 0.804 & 0.647 & \multirow{3}{*}{0.869} & \multirow{3}{*}{0.690} \\
\hline & IMPO2 & 5.520 & 1.296 & 0.904 & 0.817 & & \\
\hline & IMPO3 & 5.330 & 1.539 & 0.778 & 0.606 & & \\
\hline \multirow{5}{*}{ CSR impact } & IMPA1 & 5.320 & 1.245 & 0.816 & 0.666 & \multirow{5}{*}{0.875} & \multirow{5}{*}{0.584} \\
\hline & IMPA2 & 5.420 & 1.306 & 0.846 & 0.716 & & \\
\hline & IMPA3 & 4.940 & 1.376 & 0.757 & 0.573 & & \\
\hline & IMPA4 & 4.310 & 1.438 & 0.701 & 0.491 & & \\
\hline & IMPA5 & 5.010 & 1.396 & 0.689 & 0.475 & & \\
\hline \multirow{3}{*}{ CSR motives } & MOTI1 & 4.550 & 1.585 & 0.836 & 0.698 & \multirow{3}{*}{0.895} & \multirow{3}{*}{0.740} \\
\hline & MOTI2 & 4.640 & 1.548 & 0.812 & 0.659 & & \\
\hline & МOTI3 & 4.880 & 1.565 & 0.929 & 0.864 & & \\
\hline \multirow{5}{*}{ CSR fit } & FIT1 & 5.120 & 1.422 & 0.865 & 0.749 & \multirow{5}{*}{0.938} & \multirow{5}{*}{0.753} \\
\hline & FIT2 & 5.160 & 1.465 & 0.895 & 0.802 & & \\
\hline & FIT3 & 5.140 & 1.562 & 0.911 & 0.831 & & \\
\hline & FIT4 & 5.440 & 1.481 & 0.790 & 0.624 & & \\
\hline & FIT5 & 5.530 & 1.550 & 0.874 & 0.764 & & \\
\hline \multirow{5}{*}{ CSR commitment } & COMM1 & 5.350 & 1.285 & 0.633 & 0.400 & \multirow{5}{*}{0.869} & \multirow{5}{*}{0.574} \\
\hline & COMM2 & 5.240 & 1.295 & 0.705 & 0.497 & & \\
\hline & COMM3 & 4.830 & 1.309 & 0.763 & 0.582 & & \\
\hline & COMM4 & 4.800 & 1.404 & 0.830 & 0.689 & & \\
\hline & COMM5 & 5.070 & 1.370 & 0.836 & 0.699 & & \\
\hline
\end{tabular}

Model fit: S-B $\chi 2$ (d.f. $=176)=368.745(p<0.010) ; \mathrm{NFI}=0.897 ; \mathrm{NNFI}=0.932 ; \mathrm{CFI}=0.943 ; \mathrm{IFI}=0.943 ; \mathrm{RMSEA}=0.060$.

Similarly, Table 4 shows the results of the analysis implemented with the scales that measured consumer internal and external responses to CSR communication. These scales also reported acceptable psychometric properties in the analysis. 
Table 4. CFA consumer responses $(n=302)$.

\begin{tabular}{cccccccc}
\hline Factors & Items & Mean & s.d. & $\lambda$ & R2 & CR & AVE \\
\hline \multirow{5}{*}{ Attributions } & ATTR1 & 5.250 & 1.319 & 0.855 & 0.731 & & \\
& ATTR2 & 5.340 & 1.244 & 0.819 & 0.671 & 0.857 & 0.667 \\
& ATTR3 & 5.180 & 1.300 & 0.775 & 0.600 & & \\
\hline \multirow{5}{*}{ Attitude } & ATT1 & 5.360 & 1.246 & 0.880 & 0.774 & & \\
& ATTI2 & 5.540 & 1.331 & 0.910 & 0.828 & 0.951 & 0.828 \\
& ATT13 & 5.530 & 1.375 & 0.946 & 0.894 & & \\
& ATTI4 & 5.590 & 1.348 & 0.902 & 0.814 & & \\
\hline \multirow{5}{*}{ Identification } & IDEN1 & 4.750 & 1.375 & 0.802 & 0.643 & & \\
& IDEN2 & 4.620 & 1.373 & 0.892 & 0.795 & & \\
& IDEN3 & 4.540 & 1.475 & 0.934 & 0.873 & 0.945 & \\
& IDEN4 & 4.420 & 1.502 & 0.903 & 0.815 & & \\
& IDEN5 & 4.380 & 1.509 & 0.870 & 0.758 & & \\
\hline \multirow{5}{*}{ Trust } & TRUS1 & 4.630 & 1.318 & 0.852 & 0.726 & & \\
& TRUS2 & 4.900 & 1.210 & 0.875 & 0.766 & 0.894 & \\
& TRUS3 & 4.940 & 1.242 & 0.851 & 0.724 & & \\
\hline \multirow{5}{*}{ Purchase } & PURC1 & 4.750 & 1.412 & 0.859 & 0.738 & & \\
& PURC2 & 4.670 & 1.599 & 0.963 & 0.928 & 0.937 & 0.832 \\
& PURC3 & 4.770 & 1.613 & 0.912 & 0.832 & & \\
\hline \multirow{5}{*}{ Advocacy } & ADVO1 & 5.030 & 1.579 & 0.952 & 0.906 & & \\
& ADVO2 & 5.070 & 1.573 & 0.968 & 0.937 & 0.957 & 0.882 \\
& ADVO3 & 4.880 & 1.624 & 0.896 & 0.803 & & \\
\hline
\end{tabular}

Model fit: S-BX2(d.f. $=173)=353.142(p<0.010) ; \mathrm{NFI}=0.928 ; \mathrm{NNFI}=0.953 ; \mathrm{CFI}=0.962 ; \mathrm{IFI}=0.962 ; \mathrm{RMSEA}=0.059$.

\subsection{Hypotheses Testing}

We contrasted the hypotheses applying multivariate ANOVA (Table 5).

Table 5. Multivariate ANOVA.

\begin{tabular}{|c|c|c|c|c|c|c|c|}
\hline \multirow{2}{*}{ Factors } & \multicolumn{3}{|c|}{ Type of Service (S) } & \multicolumn{3}{|c|}{ Discourse Strategy (D) } & \multirow{2}{*}{$\begin{array}{l}\text { Interaction } \\
\quad(S \times D)\end{array}$} \\
\hline & Mean (U) & Mean (H) & $F(p)$ & Mean (E) & Mean (N) & $F(p)$ & \\
\hline $\begin{array}{c}\text { Issue } \\
\text { importance }\end{array}$ & 5.202 & 5.809 & $\begin{array}{l}21.258 \\
(0.000)\end{array}$ & 5.351 & 5.665 & $\begin{array}{c}5.579 \\
(0.019)\end{array}$ & $\begin{array}{c}8.228 \\
(0.004)\end{array}$ \\
\hline CSR impact & 4.845 & 5.155 & $\begin{array}{c}6.337 \\
(0.012)\end{array}$ & 4.744 & 5.258 & $\begin{array}{l}17.419 \\
(0.000)\end{array}$ & $\begin{array}{c}0.003 \\
(0.953)\end{array}$ \\
\hline CSR motives & 4.331 & 5.050 & $\begin{array}{l}20.861 \\
(0.000)\end{array}$ & 4.539 & 4.848 & $\begin{array}{c}3.884 \\
(0.059)\end{array}$ & $\begin{array}{c}1.624 \\
(0.203)\end{array}$ \\
\hline CSR fit & 4.785 & 5.758 & $\begin{array}{l}47.898 \\
(0.000)\end{array}$ & 5.099 & 5.450 & $\begin{array}{c}6.113 \\
(0.014)\end{array}$ & $\begin{array}{l}14.590 \\
(0.000)\end{array}$ \\
\hline $\begin{array}{c}\text { CSR } \\
\text { commitment }\end{array}$ & 4.812 & 5.303 & $\begin{array}{l}16.215 \\
(0.000) \\
\end{array}$ & 4.958 & 5.160 & $\begin{array}{c}2.762 \\
(0.098) \\
\end{array}$ & $\begin{array}{c}0.038 \\
(0.845) \\
\end{array}$ \\
\hline Attributions & 4.896 & 5.614 & $\begin{array}{l}34.802 \\
(0.000)\end{array}$ & 5.108 & 5.406 & $\begin{array}{c}5.903 \\
(0.016)\end{array}$ & $\begin{array}{c}6.823 \\
(0.009)\end{array}$ \\
\hline Attitude & 4.970 & 6.026 & $\begin{array}{l}68.856 \\
(0.000)\end{array}$ & 5.328 & 5.676 & $\begin{array}{c}7.414 \\
(0.007)\end{array}$ & $\begin{array}{c}1.579 \\
(0.210)\end{array}$ \\
\hline Identification & 4.311 & 4.766 & $\begin{array}{c}9.217 \\
(0.003)\end{array}$ & 4.522 & 4.558 & $\begin{array}{c}0.054 \\
(0.817)\end{array}$ & $\begin{array}{c}1.140 \\
(0.287)\end{array}$ \\
\hline Trust & 4.471 & 5.171 & $\begin{array}{l}33.888 \\
(0.000)\end{array}$ & 4.532 & 5.115 & $\begin{array}{l}23.363 \\
(0.000)\end{array}$ & $\begin{array}{c}4.098 \\
(0.044)\end{array}$ \\
\hline Purchase & 4.396 & 5.061 & $\begin{array}{l}16.998 \\
(0.000)\end{array}$ & 4.528 & 4.934 & $\begin{array}{c}6.313 \\
(0.013)\end{array}$ & $\begin{array}{c}0.134 \\
(0.715)\end{array}$ \\
\hline Advocacy & 4.433 & 5.548 & $\begin{array}{l}50.338 \\
(0.000)\end{array}$ & 4.620 & 5.369 & $\begin{array}{l}22.534 \\
(0.000)\end{array}$ & $\begin{array}{l}5.228 \\
(0.023)\end{array}$ \\
\hline
\end{tabular}

F-value (d.f. $=1), p$-values in parentheses, type of service (utilitarian vs. hedonic), CSR discourse (expositive vs. narrative). 
As shown in Table 5, the findings indicated that the type of service (S) had a significant influence over all message attributions and consumer responses to CSR, whereas the discourse strategy (D) also had some significant influence over issue importance, CSR impact, CSR fit, CSR attributions, service brand attitudes, trust, purchase intentions, and advocacy intentions, but not over CSR motives, CSR commitment, or C-C identification. These three variables had similar means in the expositive and the narrative scenarios.

As for the interaction effect between the type of discourse and the type of service over message attributions, multivariate ANOVA detected a significant interaction for issue importance $(\mathrm{F}=8.228$, $p<0.050$ ) (Figure 1): the expositive discourse outperformed the narrative discourse in the bank context, whereas the narrative discourse outperformed the expositive discourse in the restaurant context. These results supported the hypotheses H1a and H2a. Similarly, results revealed a significant interaction, in the expected direction, for CSR fit $(\mathrm{F}=14.590, p<0.050)$ (Figure 2). Therefore, the hypotheses H1d and H2d were supported. For CSR impact, CSR motives, and CSR commitment, multivariate ANOVA did not detect any significant interaction effect. However, as seen in Table 5, the discourse strategy had a significant effect over CSR impact, which was statistically higher for the narrative (vs. expositive) discourse (meanE $=4.744$, meanN $=5.258 ; \mathrm{F}=17.419, p<0.050$ ). Therefore, the hypothesis $\mathrm{H} 2 \mathrm{~b}$ was supported by the findings, whereas the hypotheses H1b, H1c, H1e, H2c, and H2e were not supported.

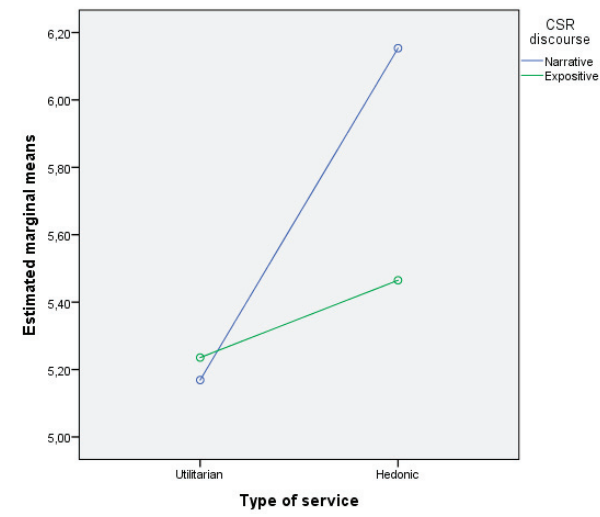

Figure 1. Effects of service type and discourse strategy on issue importance.

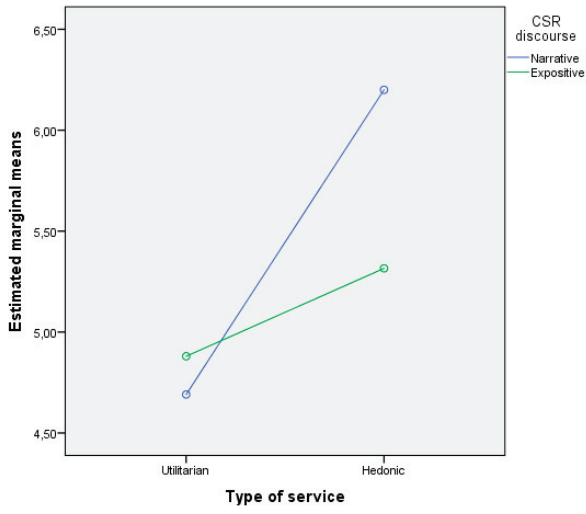

Figure 2. Effects of service type and discourse strategy on CSR fit. 
Concerning the interaction effect of discourse strategy and type of service over consumer responses to CSR, multivariate ANOVA results showed that a significant interaction existed for CSR attributions $(\mathrm{F}=6.823, p<0.050)$ (Figure 3): the expositive discourse outperformed the narrative discourse in the bank context, whereas the narrative discourse outperformed the expositive discourse in the restaurant context. These results supported the hypotheses H3a and H4a.

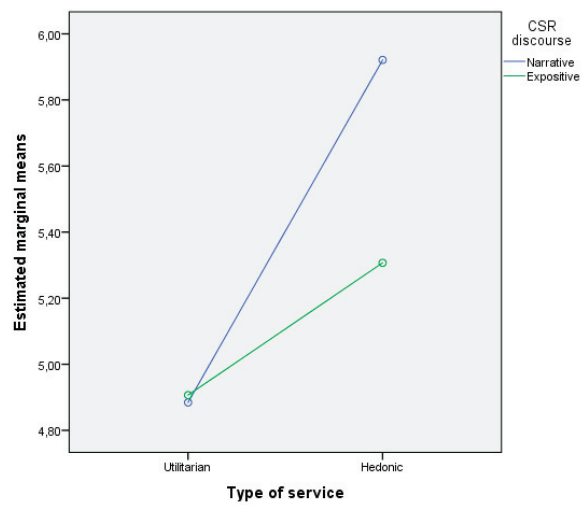

Figure 3. Effects of service type and discourse strategy on CSR attributions.

The analysis also detected interaction effects for trust $(\mathrm{F}=4.098, p<0.050)$ (Figure 4$)$ and advocacy intentions $(\mathrm{F}=5.228, p<0.050)$ (Figure 5). Nonetheless, in these two cases, the narrative discourse reported higher responses for both the utilitarian and the hedonic service. In these cases, the interaction effects highlighted that the difference in trust and advocacy intentions reported by the participants when exposed to the narrative (vs. expositive) discourse was statistically higher in the hedonic (vs. utilitarian) scenarios. Based on these results, then, the hypotheses H3d and H3f were not supported by the findings of the study, whereas the hypotheses H4d and H4f were supported.

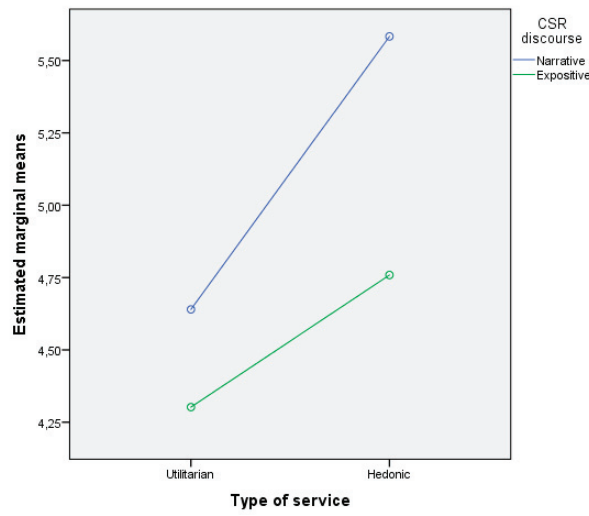

Figure 4. Effects of service type and discourse strategy on trust. 


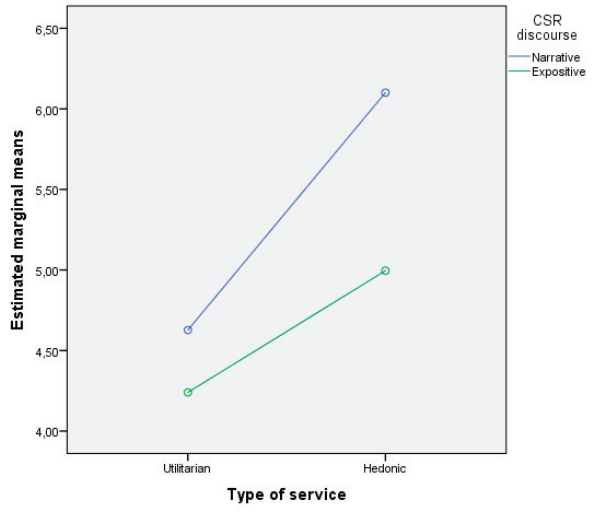

Figure 5. Effects of service type and discourse strategy on advocacy.

For service brand attitude, $\mathrm{C}-\mathrm{C}$ identification and purchase intentions, multivariate ANOVA did not detect any significant interaction effect. However, as seen in Table 5, the discourse strategy had a significant effect over service brand attitude (meanE $=5.328$, meanN $=5.676 ; \mathrm{F}=7.414, p<0.050$ ) and purchase intentions (meanE $=4.528$, meanN $=4.934 ; \mathrm{F}=6.313, p<0.050$ ), which were statistically higher for the narrative (vs. expositive) discourse. Therefore, the hypotheses H4b and H4e were supported by the findings, whereas the hypotheses $\mathrm{H} 3 \mathrm{~b}, \mathrm{H} 3 \mathrm{c}, \mathrm{H} 3 \mathrm{e}$, and $\mathrm{H} 4 \mathrm{c}$ were not supported.

\section{Discussion}

As a first interesting finding of this paper, the research shows that there were significant differences in message attributions and consumer responses across different types of services. In this regard, the catering service reported statistically significant higher valuations than the banking service for all the dependent variables in our conceptual model. This finding is not surprising as previous empirical literature in the services sector has already proved that hedonic services receive better outcomes from their communication strategies than utilitarian services $[16,17,77,78]$. Along this line, scholars have proposed that affect may provide a richer understanding of the experiential aspects of service consumption and such consumption emotion may even serve as a stronger motivator for purchase than utilitarian attributes [31]. Additionally, scholars also defend that experiential services are inherently more interesting to consumers than utilitarian services and, then, consumers are more involved with the category domain and more motivated to process promotional information [16,77]. Based on these ideas, research has mostly defended the superior role of hedonic services to generate more positive consumer responses [20], even to the point that several studies have demonstrated that, roughly speaking, any sort of corporate communication is frequently more effective for hedonic than utilitarian services $[16,17,77,78]$. Although this idea has been tested mostly in the context of conventional commercial communication, our paper contributes to this line of thought by corroborating the same finding in the context of CSR communication.

As for the effect of the type of discourse strategy on message attributions and consumer responses to CSR communication, our findings suggest that this is not as clear as the effect of the service type. On the contrary, here it is important to analyze the interaction effect between discourse strategy and type of service to get a better picture of the implications of choosing between an expositive and a narrative discourse when designing CSR communications. In this regard, our findings align with previous results in academic literature, as some empirical studies have also observed the difficulty to ascertain clear general conclusions derived from the application of different discourses [17].

For instance, there were no significant differences according to the type of discourse strategy for CSR motives, CSR commitment, and C-C identification. A possible explanation is that these three variables were among the lowest-rated attributes of CSR communication in the diverse scenarios 
explored in the study. Even though the two types of discourses evaluated in the study elicited positive outcomes in most of the message attributions and consumer responses, they were not able to transmit enough altruism nor enough long-term commitment on the part of the company to collaborate in the specific leukemia cause. This finding reinforces the arguments of previous scholars who have defended that consumers are highly skeptical of companies and their CSR activities [79], which undermines the power of CSR communication to transmit altruistic motives and long-term commitment for the company-cause collaboration, even if the company relies on narrative messages to communicate its CSR activities through storytelling. Similarly, C-C identification was the lowest-rated consumer response in both the expositive and narrative scenarios. This result may be explained by the utilization of fictitious information (companies and social cause) for the experiment. As it has happened in other studies, to feel identified with a company and its CSR efforts, consumers must cognitively categorize themselves as members of the company (i.e., actual customers). Awareness of belonging and connection to a company is a way for consumers to achieve a positive social identity and, as a consequence of this sense of connection, the company is psychologically accepted as part of that personal identity and the consumer feels identified with it [80]. However, when analyzing fictitious companies in experiments, participants do not have the time to develop a strong connection to the company and, as so, C-C identification ranks low.

The superiority of expositive (vs. narrative) discourses for utilitarian services was confirmed only for issue importance, CSR fit, and CSR attributions, whereas the superiority of narrative (vs. expositive) discourses for hedonic services was proved for issue importance, CSR impact, CSR fit, CSR attributions, service brand attitude, trust, purchase, and advocacy intentions. Indeed, in most cases, the results showed that, in both the banking and restaurant contexts, message attributions and responses to CSR communication were significantly higher when consumers were exposed to the narrative discourse. This was especially the case for CSR impact, service brand attitude, and purchase intentions, for which no interaction effect between discourse strategy and service type was observed. For the three variables, the narrative discourse always reported better results than the expositive discourse for both the utilitarian and the hedonic services. This finding was also corroborated for trust and advocacy intentions and the findings in these cases are especially worth mentioning. For trust and advocacy intentions, the interaction effect between discourse strategy and service type was significant but it worked in a different direction than our previous expectations. Consumers reported higher trust and advocacy intentions when exposed to the narrative discourse in banking and restaurant scenarios. Nonetheless, in these two cases, the difference between using an expositive and a narrative discourse was notably higher in the hedonic condition than in the utilitarian condition. This finding suggests that making a wrong decision when choosing the discourse strategy (i.e, selecting an expositive message instead of a narrative one) would be more damaging to a company commercializing hedonic services than utilitarian services. In doing so, hedonic services face the risk of losing a greater amount of trust and advocacy intentions than a company commercializing utilitarian services taking the same decision.

Although these findings do not fully align with the principles of the ELM defended in previous literature, an interesting explanation for them may be found in the arguments provided by Stafford (1996) concerning the use of documentation strategies for corporate communication [77]. A documentation strategy refers to the provision of facts and figures within corporate messages that explain or demonstrate the benefits, value, quality, or advantages of the information provided [17]. As reported in her study, using a documentation strategy has positive effects on consumer responses in hedonic settings, whereas it has no significant effects in terms of informativeness, uniqueness, perceived quality, or likelihood to use the service in utilitarian service contexts [77]. In our experiment, the expositive and narrative scenarios used the same documentation strategy (i.e., the same facts, numbers, etc.), while the findings reported that the matching principle fitted the narrative-hedonic combination much better than the expositive-utilitarian combination. More precisely, while 8 sub hypotheses of the 11 initially proposed were supported by our findings for the restaurant context, only 3 out of 11 sub hypotheses were supported for the banking service. Therefore, the findings seem to corroborate the more positive 
effect of documentation in the hedonic context. In this regard, Singh and Dalal (1999) defend that, regardless of their nature, all corporate messages 'inform' because they create awareness, impressions, knowledge, and beliefs about services, companies, and messages [24]. Thus, the difference in corporate communication depends largely on the emotional connection that it establishes between the company and consumers.

Under these premises, it is also easy to understand why the narrative discourse outperformed the expositive discourse in our study, even in the utilitarian conditions. It seems that, along with documentation features, adding visualization elements (e.g., narrative discourses based on storytelling) to corporate communication [17] generates a favorable general context for communication, which aligns with the principles of the NPT [11]. According to this theory, corporate stories activate narrative rationality, making the information contained in the message more salient, accessible, and intelligible for consumers to interpret and assess the message [7]. This theory suggests that well-designed and well-told stories not only convey information but they also convey emotion [32], which enhances the potential of the message to make its information more real to consumers, easier to remember and more convincing [12,81]. Not in vain, Mortimer (2008) showed how the majority of successful advertisements utilize emotional appeals for not only experiential but also utilitarian services [15]. Therefore, our findings align with those of Mortimer (2008), as she also detects that narrative discourses can be adequate for both utilitarian and hedonic services.

The superior performance of narrative over expositive discourses in our paper can also be justified by the communication context explored in the study. More precisely, we analyzed consumer responses to CSR communication that, in itself, is more affective and emotional than conventional commercial communications such as advertising. As opposed to commercial advertising, CSR communication does not directly seek to "sell" a product/service. CSR communication is institutional communication that mostly seeks to improve corporate image. Therefore, emotional elements in the message may be more important to the consumer than the functional, objective elements when evaluating CSR communication. This idea is supported by the insights provided by previous scholars such as Batra and Ahtola (1990) or Kempf (1999) [20,82]. More precisely, Batra and Ahtola (1990) showed that consumer attitudes are compounded of two distinct dimensions, hedonic and utilitarian attitudes, and that different service attributes contribute to each dimension differently [82]. For instance, experiential sensory attributes are closely associated with the hedonic component of attitude, whereas more functional attributes are associated with the utilitarian part of attitude [20]. Along this line, it can be argued that CSR is a hedonic attribute of the company, which especially affects the hedonic component of consumer responses and, as so, fits into the narrative-hedonic matching principle proposed in this paper much better than functional, rational attributes.

\section{Conclusions, Implications, Limitations, and Future Lines of Research}

The main goal of this paper has been to determine whether the use of expositive versus narrative discourses interacts with the type of service commercialized by a company to determine consumer perceptions and responses to CSR communication. For this purpose, we have developed a conceptual model based on the theoretical framework of CSR communication of Du et al. (2010) that we have tested empirically with a sample of consumers who have evaluated a fictitious CSR message coming from a banking and a catering company, respectively. In this regard, although research from diverse disciplines has defended an interaction effect between the discourse strategy and the service context, scholars have scarcely explored this idea in the CSR context, where a significant gap exists between the theory and practice of CSR communication. This scarcity of previous literature highlights the contribution of our paper.

The findings of the paper demonstrate that the matching principle suggested by the ELM does not apply as clearly to the context of CSR communication as it does to conventional commercial communication (e.g., advertising). As expected, it is confirmed that for hedonic services, narrative discourses outperform expositive discourses in terms of message attributions and consumer attitudinal 
(i.e., internal) and behavioral (i.e., external) responses to CSR communication. Nonetheless, and in accordance with the NPT, the use of narrative discourses can also be useful for utilitarian services as they also generate some better message attributions (i.e., CSR impact) and consumer responses (i.e., service brand attitude, trust, purchase, and advocacy intentions) than expositive discourses. Unfortunately, the findings also show that companies that commercialize utilitarian services, such as banking companies, do not profit from CSR communication as much as companies in the context of hedonic services. In our study, the bank reaped more modest responses to its CSR efforts than the restaurant. Along this line, the findings demonstrate that the choice between expositive and narrative discourses has a noticeably higher effect on consumer responses in hedonic than utilitarian contexts, indicating that the decision of the type of discourse strategy to follow is more strategic for hedonic than utilitarian services.

Based on these findings, we highlight some managerial implications that could help companies improve their CSR communication.

In this regard, the most significant implication of the study relates to the benefits that companies can gain by presenting CSR through attractive and compelling stories, especially in the context of hedonic services. CSR stories make social causes real to the audience, they reframe arguments in an easy-to-grasp and easy-to-remember format and they make messages memorable in multiple ways (visually, factually, and emotionally) [26]. In doing so, CSR storytelling generates an emotional connection between the audience and the company [26,27] and, consequently, it intensifies consumer positive attitudes and responses to CSR messages $[64,83]$. This way of presenting CSR information matches the characteristics of hedonic services especially well as hedonic services are characterized by affective gratification purposes [20] and they mostly provide consumers with emotions [31]. Therefore, we recommend that companies that commercialize hedonic services design CSR messages based on storytelling instead of using expositive discourses that lack emotional bases to engage consumers. Nonetheless, recent studies have identified that companies are missing opportunities to maximize the impact of narrative discourse strategies, especially in the online context $[15,81]$. More precisely, storytelling is a relatively unpopular form of communication in companies' websites, as very few companies and brands use it $[81,84,85]$. The scarcity of stories in corporate communication is especially evident in the context of CSR communication, where companies have only recently started to transmit messages through storytelling [86].

In the case of utilitarian services, companies should first decide the communication objectives they want to prioritize and, based on that, select the best discourse strategy to achieve those goals. If the objective is to improve the overall CSR image of the company (i.e., CSR attributions), or improve the visibility of the social cause (i.e., issue importance), companies such as banks should better use an expositive discourse. On the contrary, if they want to focus on consumer behavioral responses (i.e., purchase, advocacy), it is best to use a narrative discourse.

One additional implication, which can benefit both utilitarian and hedonic services, relates to the messages attributions that companies should try to improve in their future CSR communication. On the one hand, the findings of the present study demonstrate that CSR motives are the most poorly rated attributions in CSR communication. Consumers have demonstrated to be highly skeptical of corporate motives to relate to social causes; they have a natural tendency to perceive egoism behind company-cause connections [87]. Nonetheless, avoiding skepticism and improving motives attribution is key to success in CSR communication, as this variable relates closely to consumer behavior such as purchase, advocacy, and loyalty intentions [88]. Therefore, companies must focus their CSR messages on providing convincing reasoning for their motives to engage with social causes, which should be as altruistic as possible to reduce consumer skepticism and improve their support responses. On the other hand, companies should also focus on improving C-C identification, which rated notably low in all the conditions of our experiment. C-C identification has been proved to be an essential attitudinal response to CSR communication that derives in positive outcomes for companies, including trust, satisfaction and loyalty [50]. 
Finally, this study is not without limitations and future research should consider them to improve our knowledge of CSR communication. First, the use of fictitious companies and fictitious CSR messages can limit the generalization of our findings. Future studies should explore consumer responses to the CSR communication of real companies to determine whether our research findings also apply to CSR messages and consumers in real contexts. Second, future research should also focus on studying additional interaction effects between discourse strategy and other variables that may affect message attributions and consumer responses to CSR communication more intensively than the discourse-service match tested in this paper. For instance, an interesting interaction effect could emerge between discourse strategy and the CSR stimulus (i.e., social cause) chosen by the company as the focus of its CSR efforts [21]. Then, we suggest that future authors test our conceptual model for diverse social causes to corroborate (or not) our findings. In addition, previous research has suggested that the type of CSR support provided by companies (i.e., monetary vs. in-kind support) may affect consumer responses to CSR messages in CSR communication [89]. Consumers tend to react to in-kind support more favorably than to monetary support [89] and this fact may determine the effect of different discourse strategies. In testing these ideas, we suggest that scholars delve further into CSR literature to build their arguments. Given the differences between conventional commercial communication and CSR communication, we believe that scholars can develop hypotheses that are more accurate if they base their arguments on CSR theories instead of grounding them solely on communication and advertising literature.

Author Contributions: Conceptualization, A.P. and E.B.-D.; methodology, A.P. and M.d.M.G.d.1.S.; software, A.P.; validation, A.P., M.d.M.G.d.1.S. and E.B.-D.; writing-original draft preparation, A.P., M.d.M.G.d.l.S. and E.B.-D.; writing-review and editing, A.P., M.d.M.G.d.I.S. and E.B.-D. All authors have read and agreed to the published version of the manuscript.

Funding: This research received no external funding.

Conflicts of Interest: The authors declare no conflict of interest.

Appendix A. Website Stimuli Evaluated by the Participants
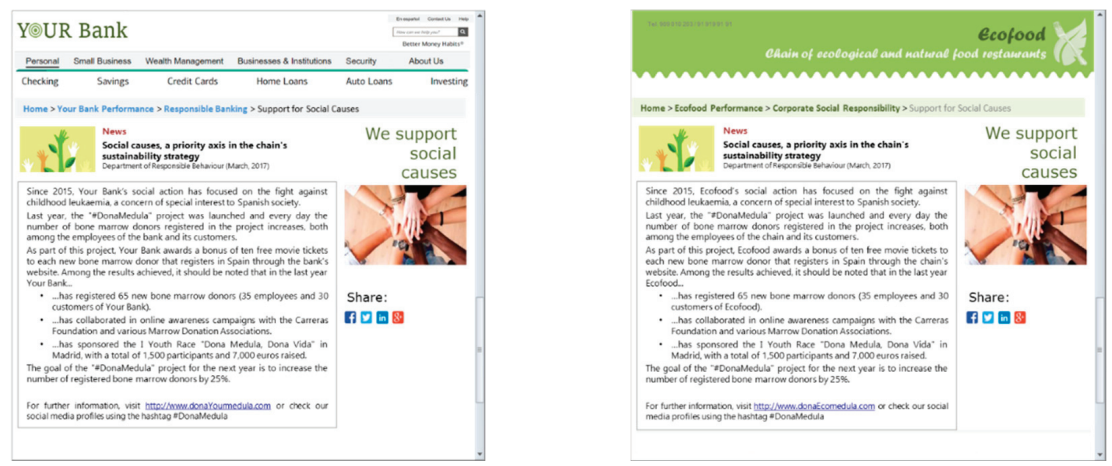

Figure A1. Expositive discourse strategy. Website A (utilitarian service), Website B (hedonic service). 

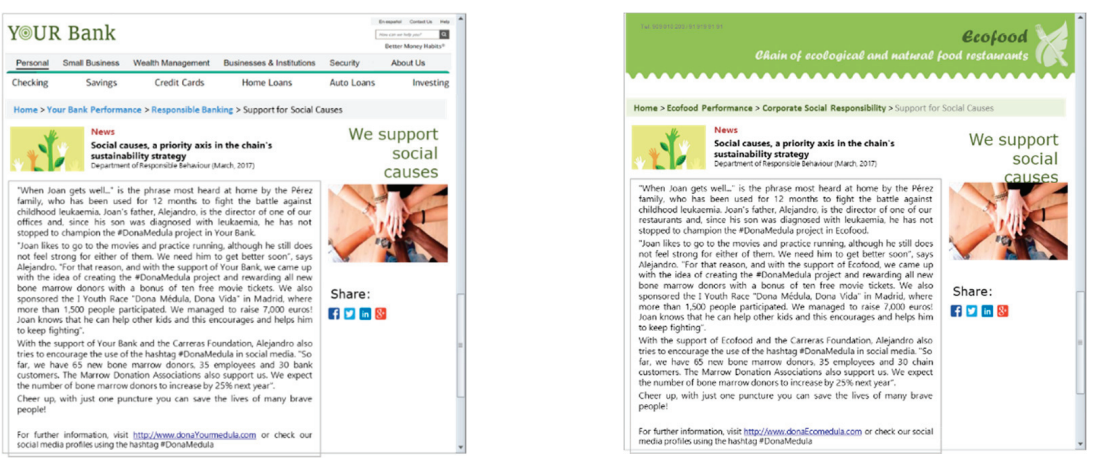

Figure A2. Narrative discourse strategy. Website C (utilitarian service), Website D (hedonic service).

\section{References}

1. Mason, C.; Simmons, J. Forward looking or looking unaffordable? Utilising academic perspectives on corporate social responsibility to assess the factors influencing its adoption by business. Bus. Ethics A Eur. Rev. 2011, 20, 159-176. [CrossRef]

2. Liang, X.; Hu, X.; Meng, H. Truly sustainability or hypocrisy: The effects of corporate sustainable orientation on consumers' quality perception and trust based on evidence from China. Sustainability 2020, 12, 2735. [CrossRef]

3. Ahmed, I.; Nazir, M.S.; Ali, I.; Nurunnabi, M.; Khalid, A.; Shaukat, M.Z. Investing in CSR pays you back in many ways! The case of perceptual, attitudinal and behavioral outcomes of customers. Sustainability 2020, 12, 1158. [CrossRef]

4. Du, S.; Bhattacharya, C.B.; Sen, S. Maximizing business returns to corporate social responsibility (CSR): The role of CSR communication. Int. J. Manag. Rev. 2010, 12, 8-19. [CrossRef]

5. Skarmeas, D.; Leonidou, C.N. When consumers doubt, watch out! The role of CSR skepticism. J. Bus. Res. 2012, 66, 1831-1838. [CrossRef]

6. Martin, J.; Powers, M. Organizational stories: More vivid and persuasive than quantitative data. In Psychological Foundations of Organizational Behavior; Foresman: Glenview, IL, USA, 1983; pp. 162-168.

7. Weick, K.E.; Browning, L.D. Argument and narration in organizational communication. J. Manag. 1986, 12, 243-259. [CrossRef]

8. Martin, J. Stories and scripts in organizational settings. In Cognitive Social Psychology; Elsevier: New York, NY, USA, 1982; pp. 255-305.

9. Lewis, N.; Sznitman, S.R. You brought it on yourself: The joint effects of message type, stigma, and responsibility attribution on attitudes toward medical cannabis. J. Commun. 2017, 67, 181-202. [CrossRef]

10. Murphy, S.T.; Frank, L.B.; Chatterjee, J.S.; Baezconde-Garbanati, L. Narrative versus nonnarrative: The role of identification, transportation and emotion in reducing health disparities. J. Commun. 2013, 63, 116-137. [CrossRef] [PubMed]

11. Fisher, W.R. The narrative paradigm: An elaboration. Commun. Monogr. 1985, 52, 347-367. [CrossRef]

12. Kaufman, B. Stories that sell, stories that tell. J. Bus. Strategy 2003, 24, 11-15. [CrossRef]

13. Woodside, A.G. Brand-consumer storytelling theory and research: Introduction to a Psychology \& Marketing speciall issue. Psychol. Mark. 2010, 27, 531-540.

14. Lundqvist, A.; Liljander, V.; Gummerus, J.; van Riel, A. The impact of storytelling on the consumer brand experience: The case of a firm-originated story. J. Brand Manag. 2013, 20, 283-297. [CrossRef]

15. Mortimer, K. Identifying the components of effective service advertisements. J. Serv. Mark. 2008, 22, $104-113$. [CrossRef]

16. Stafford, M.R.; Day, E. Retail services advertising: The effects of appeal, medium, and service. J. Advert. 1995, 24, 37-41. [CrossRef] 
17. Hill, D.J.; Blodgett, J.; Baer, R.; Wakefield, K. An investigation of visualization and documentation strategies in services advertising. J. Serv. Res. 2004, 7, 155-166. [CrossRef]

18. Johar, J.S.; Sirgy, M.J. Value-expressive versus utilitarian advertising appeals: When and why to use which appeal. J. Advert. 1991, 20, 23-33. [CrossRef]

19. Albers-Miller, N.D.; Stafford, M.R. International services advertising: An examination of variation in appeal use for experiential and utilitarian services. J. Serv. Mark. 1999, 13, 390-406. [CrossRef]

20. Kempf, D.S. Attitude formation from product trial: Distinct roles of cognition and affect for hedonic and functional products. Psychol. Mark. 1999, 16, 35-50. [CrossRef]

21. Andreu, L.; Casado-Díaz, A.B.; Mattila, A.S. Effects of message appeal and service type in CSR communication strategies. J. Bus. Res. 2015, 68, 1488-1495. [CrossRef]

22. Yang, C.-M.; Hsu, T.-F. Effects of skepticism about corporate social responsibility advertising on consumer attitude. Soc. Behav. Pers. 2017, 45, 453-468. [CrossRef]

23. Petty, R.E.; Cacioppo, J.T. Attitudes and Persuasion: Classic and Contemporary Approaches; William C. Brown: Dubuque, IO, USA, 1981.

24. Singh, S.N.; Dalal, N.P. Web home pages as advertisements. Commun. ACM 1999, 42, 91-98. [CrossRef]

25. Gill, R. An integrative review of storytelling: Using corporate stories to strengthen employee engagement and internal and external reputation. Prism 2011, 8, 1-16.

26. Escalas, J.E. Narrative processing: Building consumer connections to brands. J. Consum. Psychol. 2004, $14,168-180$.

27. Herskovitz, S.; Crystal, M. The essential brand persona: Storytelling and branding. J. Bus. Strategy 2010, 31, 21-28. [CrossRef]

28. Zak, P.J. Why your brain loves good storytelling. Harv. Bus. Rev. 2014, 28, 1-5.

29. Pérez, A.; del Mar García de los Salmones, M.; López-Gutiérrez, C. Corporate reputation in the Spanish context: An interaction between reporting to stakeholders and industry. J. Bus. Ethics 2015, 129, 733-746.

30. Um, N.H. Revisit elaboration likelihood model: How advertising appeals work on attitudinal and behavioural brand loyalty centering around low vs. high involvement product. Eur. J. Soc. Sci. 2008, 7, 126-139.

31. Jiang, Y.; Lu Wang, C. The impact of affect on service quality and satisfaction: The moderation of service contexts. J. Serv. Mark. 2006, 20, 211-218. [CrossRef]

32. Sole, D.; Wilson, D.G. Storytelling in Organizations: The Power and Traps of Using Stories to Share Knowledge in Organizations; Harvard Graduate School of Education: Cambridge, MA, USA, 2002.

33. Aldama, F.L. The Science of storytelling: Perspectives from cognitive science, neuroscience, and the humanities. Projections 2015, 9, 80-95. [CrossRef]

34. Pérez, A.; del Mar García de los Salmones, M.; Liu, M.T. Maximising business returns to corporate social responsibility communication: An empirical test. Bus. Ethics A Eur. Rev. 2019, 28, 275-289.

35. Pomering, A.; Johnson, L.W. Advertising corporate social responsibility initiatives to communicate corporate image: Inhibiting scepticism to enhance persuasion. Corp. Commun. An Int. J. 2009, 14, 420-439. [CrossRef]

36. Menon, S.; Kahn, B. Corporate sponsorships of philanthropic activities: When do they impact perception of sponsor brand? J. Consum. Psychol. 2003, 13, 316-327. [CrossRef]

37. Bhattacharya, C.B.; Korschun, D.; Sen, S. Strengthening stakeholder-company relationships through mutually beneficial corporate social responsibility initiatives. J. Bus. Ethics 2009, 85, 257-272. [CrossRef]

38. Parguel, B.; Benoit-Moreau, F.; Larceneux, F. How sustainability ratings might deter "greenwashing": A closer look at ethical corporate communication. J. Bus. Ethics 2011, 102, 15-28. [CrossRef]

39. García de los Salmones, M.M.; Pérez, A. Effectiveness of CSR advertising: The role of reputation, consumer attributions, and emotions. Corp. Soc. Responsib. Environ. Manag. 2018, 25, 194-208. [CrossRef]

40. van Rekom, J.; van Riel, C.B.M.; Wierenga, B. A methodology for assessing organizational core values. J. Manag. Stud. 2006, 43, 175-201. [CrossRef]

41. Maignan, I.; Ralston, D.A. Corporate social responsibility in Europe and the U.S.: Insights from businesses' self-presentations. J. Int. Bus. Stud. 2002, 33, 497-514. [CrossRef]

42. Lafferty, B.A.; Goldsmith, R.E.; Hult, G.T.M. The impact of the alliance on the partners: A look at cause-brand alliances. Psychol. Mark. 2004, 21, 509-531. [CrossRef]

43. Trimble, C.S.; Rifon, N.J. Consumer perceptions of compatibility in cause-related marketing messages. Int. J. Nonprofit Volunt. Sect. Mark. 2006, 11, 29-47. [CrossRef] 
44. Bigné, E.; Chumpitaz, R.; Currás, R. Alliances between brands and social causes: The influence of company credibility on social responsibility image. J. Bus. Ethics 2010, 96, 169-186.

45. Rifon, N.J.; Choi, S.M.; Trimble, C.S.; Li, H. Congruence effect in sponsorship: The mediating role of sponsor credibility and consumer attributions of sponsor motive. J. Advert. 2004, 33, 29-42. [CrossRef]

46. Benoit-Moreau, F.; Parguel, B. Building brand equity with environmental communication: An empirical investigation in France. EuroMed J. Bus. 2011, 6, 100-116. [CrossRef]

47. Keller, K.L. Strategic Brand Management; Prentice-Hall: Upper Saddle River, NJ, USA, 1998.

48. O'Cass, A.; Grace, D. Exploring consumer experiences with a service brand. J. Prod. Brand Manag. 2004, 13, 257-268. [CrossRef]

49. Bravo, R.; Matute, J.; Pina, J.M. Corporate social responsibility as a vehicle to reveal the corporate identity: A study focused on the websites of Spanish financial entities. J. Bus. Ethics 2012, 107, 129-146. [CrossRef]

50. Pérez, A.; del Mar García de los Salmones, M.; Rodríguez del Bosque, I. The effect of corporate associations on consumer behaviour. Eur. J. Mark. 2013, 47, 218-238.

51. Garcia de los Salmones, M.M.; Perez, A.; Rodriguez del Bosque, I. The social role of financial companies as a determinant of consumer behaviour. Int. J. Bank Mark. 2009, 27. [CrossRef]

52. Morgan, R.M.; Hunt, S.D. The commitment-trust theory of relationship marketing. J. Mark. 1994, 58, 20-38. [CrossRef]

53. Chiou, J.-S.; Droge, C. Service quality, trust, specific asset investment, and expertise: Direct and indirect effects in a satisfaction-loyalty framework. J. Acad. Mark. Sci. 2006, 34, 613-627. [CrossRef]

54. Lewis, B.R.; Soureli, M. The antecedents of consumer loyalty in retail banking. J. Consum. Behav. 2006, 5, 15-31. [CrossRef]

55. Oliver, R.L. Satisfaction: A Behavioral Perspective on the Consumer; McGraw-Hill: New York, NY, USA, 1997.

56. Oliver, R.L. Whence consumer loyalty? J. Mark. 1999, 63, 33-44. [CrossRef]

57. Khan, Z.; Ferguson, D.; Pérez, A. Customer responses to CSR in the Pakistani banking industry. Mark. Intell. Plan. 2015, 33. [CrossRef]

58. Westbrook, R.A. Product/consumption-based affective responses and postpurchase processes. J. Mark. Res. 1987, 24, 258-270. [CrossRef]

59. Kim, Y. Strategic communication of corporate social responsibility (CSR): Effects of stated motives and corporate reputation on stakeholder responses. Public Relat. Rev. 2014, 40, 838-840. [CrossRef]

60. Nan, X.; Heo, K. Consumer responses to Corporate Social Responsibility (CSR) initiatives: Examining the role of brand-cause fit in cause-related marketing. J. Advert. 2007, 36, 63-74. [CrossRef]

61. Alniacik, U.; Alniacik, E.; Genc, N. How corporate social responsibility information influences stakeholders' intentions. Corp. Soc. Responsib. Environ. Manag. 2011, 18, 234-245. [CrossRef]

62. Currás, R. Comunicación de la Responsabilidad Social Corporativa: Imagen e Identificación con la Empresa como Antecedentes del Comportamiento del Consumidor; Universitat de València: Valencia, Spain, 2007.

63. Ladhari, R.; Souiden, N.; Dufour, B. The role of emotions in utilitarian service settings: The effects of emotional satisfaction on product perception and behavioral intentions. J. Retail. Consum. Serv. 2017, 34, 10-18. [CrossRef]

64. Chiu, H.-C.; Hsieh, Y.-C.; Kuo, Y.-C. How to align your brand stories with your products. J. Retail. 2012, 88, 262-275. [CrossRef]

65. Mohr, L.A.; Eroğlu, D.; Ellen, P.S. The development and testing of a measure of skepticism toward environmental claims in marketers' communications. J. Consum. Aff. 1998, 32, 30-55. [CrossRef]

66. Russell, D.W.; Russell, C.A. Here or there? Consumer reactions to corporate social responsibility initiatives: Egocentric tendencies and their moderators. Mark. Lett. 2010, 21, 65-81. [CrossRef]

67. Connors, S.; Anderson-MacDonald, S.; Thomson, M. Overcoming the 'window dressing' effect: Mitigating the negative effects of inherent skepticism towards corporate social responsibility. J. Bus. Ethics 2017, 145, 599-621. [CrossRef]

68. Becker-Olsen, K.L.; Cudmore, B.A.; Hill, R.P. The impact of perceived corporate social responsibility on consumer behavior. J. Bus. Res. 2006, 59, 46-53. [CrossRef]

69. Speed, R.; Thompson, P. Determinants of sport sponsorship response. J. Acad. Mark. Sci. 2000, 28, $226-238$. [CrossRef]

70. Skard, S.; Thorbjørnsen, H. Is publicity always better than advertising? The role of brand reputation in communicating corporate social responsibility. J. Bus. Ethics 2014, 124, 149-160. [CrossRef] 
71. Walton, M.R. The PR in CSR: Assessing Perceptions of Partnerships Versus Donations in Corporate Social Responsibility Initiatives; Texas A\&M University: Canyon, TX, USA, 2014.

72. Wagner, T.; Lutz, R.J.; Weitz, B.A. Corporate hypocrisy: Overcoming the threat of inconsistent corporate social responsibility perceptions. J. Mark. 2009, 73, 77-91. [CrossRef]

73. Groza, M.D.; Pronschinske, M.R.; Walker, M. Perceived organizational motives and consumer responses to proactive and reactive CSR. J. Bus. Ethics 2011, 102, 639-652. [CrossRef]

74. Romani, S.; Grappi, S.; Bagozzi, R.P. Explaining consumer reactions to corporate social responsibility: The role of gratitude and altruistic values. J. Bus. Ethics 2013, 114, 193-206. [CrossRef]

75. Podsakoff, P.M.; MacKenzie, S.B.; Lee, J.Y.; Podsakoff, N.P. Common method biases in behavioral research: A critical review of the literature and recommended remedies. J. Appl. Psychol. 2003, 88, 879-903. [CrossRef]

76. Hair, J.F.; Black, W.C.; Babin, B.J.; Anderson, R.E. Multivariate Data Analysis, 7th ed.; Pearson Education Limited: Harlow, UK, 2014.

77. Stafford, M.R. Tangibility in services advertising: An investigation of verbal versus visual cues. J. Advert. 1996, 25, 13-28. [CrossRef]

78. Wakefield, K.L.; Inman, J.J. Situational price sensitivity: The role of consumption occasion, social context and income. J. Retail. 2003, 79, 199-212. [CrossRef]

79. Forehand, M.R.; Grier, S. When is honesty the best policy? The effect of stated company intent on consumer skepticism. J. Consum. Psychol. 2003, 13, 349-356.

80. Currás, R.; Bigné, E.; Alvarado, A. The role of self-definitional principles in consumer identification with a socially responsible company. J. Bus. Ethics 2009, 89, 547-564. [CrossRef]

81. Delgado-Ballester, E.; Fernández-Sabiote, E. Once upon a brand: Storytelling practices by Spanish brands. Spanish J. Mark.-ESIC 2016, 20, 115-131. [CrossRef]

82. Batra, R.; Ahtola, O.T. Measuring the hedonic and utilitarian sources of consumer attitudes. Mark. Lett. 1990, 2, 159-170. [CrossRef]

83. van Laer, T.; de Ruyter, K.; Visconti, L.M.; Wetzels, M. The extended transportation-imagery model: A meta-analysis of the antecedents and consequences of consumers' narrative transportation. J. Consum. Res. 2014, 40, 797-817. [CrossRef]

84. Spear, S.; Roper, S. Using corporate stories to build the corporate brand: An impression management perspective. J. Prod. Brand Manag. 2013, 22, 491-501. [CrossRef]

85. Du, S.; Vieira, E.T. Striving for legitimacy through corporate social responsibility: Insights from oil companies. J. Bus. Ethics 2012, 110, 413-427. [CrossRef]

86. Gill, R. Why the PR strategy of storytelling improves employee engagement and adds value to CSR: An integrated literature review. Public Relat. Rev. 2015, 41, 662-674. [CrossRef]

87. Bigné, E.; Currás, R.; Sánchez, I. Brand credibility in cause-related marketing: The moderating role of consumer values. J. Prod. Brand Manag. 2009, 18, 437-447. [CrossRef]

88. Pérez, A.; del Bosque, I.R. How customer support for corporate social responsibility influences the image of companies: Evidence from the banking industry. Corp. Soc. Responsib. Environ. Manag. 2015, 22. [CrossRef]

89. Hildebrand, D.; Demotta, Y.; Sen, S.; Valenzuela, A. Consumer responses to corporate social responsibility (CSR) contribution type. J. Consum. Res. 2017, 44, 738-758. [CrossRef]

(C) 2020 by the authors. Licensee MDPI, Basel, Switzerland. This article is an open access article distributed under the terms and conditions of the Creative Commons Attribution (CC BY) license (http://creativecommons.org/licenses/by/4.0/). 


\title{
CSR Communication through Social Media: A Litmus Test for Banking Consumers' Loyalty
}

\author{
Naveed Ahmad ${ }^{1, *}$, Rana Tahir Naveed ${ }^{2}$, Miklas Scholz ${ }^{3,4,5, *}$, Muhammad Irfan ${ }^{6}$, Muhammad Usman ${ }^{2}$ \\ and Ilyas Ahmad ${ }^{2}$ \\ 1 Faculty of Management Studies, University of Central Punjab, Lahore 54000, Pakistan \\ 2 Department of Economics and Business Administration, Art \& Social Sciences \\ Division, University of Education, Lahore 54000, Pakistan; tahir.naveed@ue.edu.pk (R.T.N.); \\ m.usman@ue.edu.pk (M.U.); ilyas.ahmad@ue.edu.pk (I.A.) \\ 3 Department of Building and Environmental Technology, Division of Water Resources Engineering, \\ Faculty of Engineering, Lund University, P.O. Box 118, 22100 Lund, Sweden \\ 4 Civil Engineering Research Group, School of Science, Engineering and Environment, \\ The University of Salford, Newton Building, Salford M5 4WT, UK \\ 5 Department of Town Planning, Engineering Networks and Systems, South Ural State University (National \\ Research University), 76, Lenin prospekt, 454080 Chelyabinsk, Russia \\ 6 Institute of Banking and Finance, Bahauddin Zakariya University, Multan 66000, Pakistan; \\ dr.mirfan@bzu.edu.pk \\ * Correspondence: naveeddgk2010@gmail.com (N.A.); miklas.scholz@tvrl.lth.se (M.S.)
}

Citation: Ahmad, N.; Naveed, R.T.; Scholz, M.; Irfan, M.; Usman, M.; Ahmad, I. CSR Communication through Social Media: A Litmus Test for Banking Consumers' Loyalty. Sustainability 2021, 13, 2319. https://doi.org/10.3390/su13042319

Academic Editor: Andrea Pérez

Received: 2 February 2021

Accepted: 13 February 2021

Published: 20 February 2021

Publisher's Note: MDPI stays neutral with regard to jurisdictional claims in published maps and institutional affiliations.

Copyright: (c) 2021 by the authors. Licensee MDPI, Basel, Switzerland. This article is an open access article distributed under the terms and conditions of the Creative Commons Attribution (CC BY) license (https:// creativecommons.org/licenses/by/ $4.0 /)$.
Abstract: Prior literature in the field of corporate social responsibility (CSR) has largely focused on investigating its relationship with organizational-related outcomes, whereas the impact of CSR on consumer behavior is largely ignored in the recent literature. Further, most of the prior studies have investigated CSR with a philanthropic viewpoint, but its importance in achieving marketing-related outcomes is something that is to date, underexplored. Hence, the aim of the present study is to investigate the impact of CSR communication through social media on consumer loyalty with the mediating effect of consumers' brand admiration in the banking sector of Pakistan. The banking sector was selected due to the reason that this sector is homogenized in nature and creating consumers' loyalty due to this homogenized character of this sector is challenging. The data of the present study were collected from different banking consumers through an adapted questionnaire on a five-point Likert scale. A total of 448 fully filled questionnaires were received which included 289 male and 159 female banking consumers. The results of the present study revealed that CSR communications through social media have a positive impact on consumer loyalty, and consumers' brand admiration partially mediates this relationship. The findings of the present study would help policymakers from banking institutions to use CSR strategy from the perspective of marketing which is undoubtedly very important for every organization in the current digital age.

Keywords: social media; CSR; admiration; consumer loyalty; sustainability

\section{Introduction}

The development in communication technologies has forced organizations to use new communication strategies to deliver their important messages to different stakeholders including consumers [1]. Research has long established that traditional communication channels and strategies are losing their effectiveness with the rise of social media in today's digital age. Thus, businesses are pushed to be involved in the conversation with consumers through social media. Social media offer organizations the opportunities to deliver their CSR messages and stories with different stakeholders [2]. The main advantage of social media includes its wide availability to diverse stakeholders in a short period of time through using different social media platforms, such as Twitter, Facebook, Instagram, YouTube and others. The organizations may share their stories and videos to convince the 
stakeholders about their contributions to the wellbeing of the consumers and their families, as well as to the lives of the consumers, the shareholders, the environment and the society as a whole. Another advantage of social media over traditional communication strategies is its ability to provide interactive communication to the organizations. The organizations can offer their services to the stakeholders and receive immediate feedback and can discuss with the stakeholders to establish better relationships [3].

According to stakeholder theory, not only do the organization's shareholders emphasize the importance of social responsibility for the sustainable growth of the organizations, but other stakeholders, including consumers, suppliers, governments, environmental organizations, non-governmental organizations and local communities also acknowledge its importance [4]. Freeman et al. [5] described the stakeholders as "a group and persons benefiting or harmed, as well as persons whose rights have been violated or respected due to the organizational business activities". This means that different people have their own positions in collective actions, so organizations must be accountable for satisfying their needs and rights in a socially responsible manner. Organizations are not only accountable to their shareholders, but they are also answerable to their stakeholders with diverse interests in the organization.

Social media have emerged as a powerful and effective tool for sustainable business communication [6]. Most of the people around the world use social media for communication and information sharing purpose. Hence, people can use such media to create content or express their opinions about corporate characteristics or ethics [7]. Social media are a source to share information that can be disseminated in a short time to a larger community. It is also used by the organizations to deliver their messages, as well as to attract various stakeholders and to maintain competition in the digital age [8]. Statistics show that about 3.6 billion individuals were using social media in 2020 [9]. Given the importance of the social media in modern communications, organizations communicate important messages through social media. It is claimed that media services produced by unpaid communities such as consumers have the potential to change the mindset of general audience and create a good brand image for a specific brand [10].

The organization's use of social media is also important to communicate corporate social responsibility (CSR) activities. Different studies have highlighted the importance of using social media for effective CSR communication because the communication from different social media platforms is considered to be more transparent and can better shape the behavior of consumers to support sustainability objectives of an organization [1,3]. By engaging in corporate social responsibility (CSR) activities, organizations not only provide feedback but also create supportive environment for different stakeholders [7]. Hence, the aim of the present study is to investigate the impact of CSR communication through social media on consumers' outcomes such as consumer loyalty and consumer brand admiration in the banking sector of Pakistan. The present study contends that CSR communication through social media develops positive emotions among consumers, in the shape of consumers' brand admiration, which in turn affects their loyalty towards a particular brand.

This is evident from the recent literature that businesses are required to incorporate CSR in their business decisions in order to meet the expectations of different stakeholders and to build a better brand image [11]. However, this perspective is largely ignored by contemporary CSR researchers as most of the studies related to CSR largely focused on firm-centric outcomes to be achieved through CSR initiatives [12,13]. Consumers prefer organizations that perform CSR functions, and modern organizations realize the importance of CSR communication to shaping consumer behavior positively. The ecology-related information to society and consumers via environmental advertising raises the awareness level of consumers and other stakeholders, and they urge organizations to practice sustainability in a real sense [14]. Moreover, sustainability has emerged as one of the most important concerns for modern businesses [15]. Likewise, Abbas et al. [16] noted the positive effect of CSR on consumer behavior. Therefore, a general link between CSR activities 
and consumer behavior is logical to consider, and different studies have also identified a positive link between CSR and consumer purchasing intentions [17,18]. Organizations with appropriate CSR policies have good consumer preferences. In relation to consumers, Brown and Dacin [19] identified two types of CSR activities which include association and participation. Association refers to consumers' understanding of corporate ethics in social matters, and participation speaks about the level at which they participate in the implementation of CSR plans with organizations. For example, Hur et al. [20] noted the importance of a socially responsible profile of an organization in defining consumer commitments and to achieve organizational objectives. This means that the higher the level of CSR engagement of an organization, the greater the willingness of consumers to contribute to the achievement of the sustainability goals of an organization. CSR collaboration and consumer services are critical for achieving community-based outcomes [21]. The development and maintenance of sustainable relationships between business and consumers through effective communication, identification, discussion and exchange processes, or a combination of these factors, are critical for achieving sustainable organizational objectives. Similarly, Zasuwa [22] analyzed the impact of CSR participation on consumer behavior and concluded that CSR activities increase the level of consumer involvement with the organization. Businesses that work to improve the well-being of consumers and their families have better relationships with their consumers, which in turn show a higher level of commitment with the organization. Shareholders and prospective investors also recognize the importance of the CSR [23]. The prior literature also acknowledged the association between CSR communication and favorable consumer behavior [24,25]. The main purpose of entrepreneurs' coverage of their CSR services on social media is to attract the attention of different stakeholders [26]. For example, if CSR initiatives are properly delivered to consumers, it is expected that such initiatives will positively impact consumer behavior [27]. The literature provides ample evidence to the positive impact of CSR initiatives on consumer behavior in different countries and in different business areas [28,29].

Prior studies on the topic of CSR have largely investigated the impact of CSR activities on financial outcomes of an organization [30,31] but the potential impact of CSR on consumer-centric outcomes, such as on loyalty and on positive emotions, has been largely missed by contemporary CSR researchers. These consumers-related outcomes of CSR are very important for any organization to base their competitive advantage on solid foundations [32]. Likewise, there have been some studies on the topic of CSR and consumer behavior [33,34], but how CSR is related to emotional outcomes (such brand admiration) and attitudinal outcomes (loyalty) is underexplored in recent literature.

The contributions of the present study are critical for existing CSR and consumer behavior literature for the following reasons. First, the prior literature has largely focused on cognitive aspect of consumer behavior [35-37], whereas the emotional side of consumer behavior has been rarely explored in existing literature. We, in this regard, argue that although cognitive side of consumer behavior is important, the emotional side of individuals is far more effective in shaping positive consumer behavior in comparison to the cognitive one. Hence, we build an argument in this study that well-planned CSR communications of an organization may generate a sense of brand admiration among consumers (emotional aspect of behavior) and they feel admiration for that organization that practices CSR proactively. This argument receives support from existing literature [38,39]. Ultimately these emotions (admiration) build a higher level of loyalty among consumers, which is very important for any organization.

Secondly, the banking sector of Pakistan is purposefully chosen for the present study because this sector is facing a high level of competition and retaining the existing consumers is of utmost importance to each bank in this sector $[40,41]$. However, the problem with the banking sector of Pakistan, as with other developing regions of the world, is that the character of the banking sector is homogenized in nature, where mostly banks offer, more or less, the same kinds of products/services to the consumers, which creates the challenge of how to hold the current share of consumers and how to uphold their loyalty level so that 
there is less likelihood of consumers' switching to other brands. In this connection, CSR may be a good strategy in the context of marketing objectives because CSR initiatives of a bank create positive emotions (admiration) in consumers to stay connected with a bank, which in turn takes them towards a higher level of loyalty.

Thirdly, different researchers in recent studies have argued that the phenomenon of CSR and consumer loyalty are complex to understand, and their relationship is better explained in the presence of moderator(s) and mediator(s) [42,43]. Hence, we have logically introduced the consumers' brand admiration as a mediating variable between the relationship of CSR communication through social media and consumer loyalty. Lastly, the majority of prior research studies have been conducted in developed countries [44,45]; we argue here that as the concept of CSR is contextual in nature and produces different results in different contexts, it will not be logical to generalize the results from developed countries in the context of developing countries. The remainder of this article is arranged as follows: the second part of the present study discusses the literature review, the third section is concerned with methodology, the fourth section is about results and the analysis phase, and finally the last section includes the discussion and implications of the present study.

\section{Theoretical Framework}

Over the years, CSR has emerged as one of the most popular strategies in the business world. CSR is defined as "an honest business practice that helps sustain economic development by working with employees, their families, local organizations and the general public to improve their living conditions" [46]. This research study defines CSR in line with the definition of founding father Carroll [47] in the field of CSR, who defines it as "CSR is the economic, legal, ethical and philanthropic obligation of a business towards society". In his definition, the first set (economic, legal) is required by society, and the second set (ethical, philanthropic) is expected by society.

CSR aims to reduce the environmental impact of organizations along with the wellbeing of employees, their families, consumers and society [48]. The main business principle in CSR is to effectively seek business opportunities, strengthen relationships with the community and solve common societal problems. In the recent era, businesses are facing social, political and economic changes that encourage the growth of a new culture in the organizations. Globalization along with technological development also contributes to the emergence of a new social model with new actors and behaviors. New questions and expectations about the management, communications and social responsibility have been emerging in the present era [49]. As a result, many companies in all industries understand the importance of their role in the society for developing a successful CSR model because they know the benefits of doing business in line with CSR philosophy. For example, companies can make significant profits from one of the CSR beneficiary groups, such as consumers [17].

In recent times, the concept of sustainability has emerged as a "new normal" for modern businesses [50] in which sustainable practices are not only concerned with the philanthropic orientation of an organization, but these practices are also important from a marketing point of view. For example, modern consumers are well aware of the importance of sustainability for a better and sustainable future, and they consider it while making purchase decisions [51]. Marketers need to realize the importance of sustainability for attaining consumer preferences towards their brand, and hence they need to incorporate this element of sustainability into their marketing communication objectives [52]. This argument of incorporating sustainability into marketing communication is also supported by Nyilasy et al. [53] who mentioned that green advertising enhances consumer purchase intentions.

The present study uses the lens of attribution theory as a grounding theory. The theory was originally proposed by Fritz [54] and further advanced by Kelley [55]; the theory investigates how people explain the causes of behaviors and events. Attribution theory has been heavily exercised in consumer behavior studies [56-58]. In the context 
of the present study, we argue that attribution process influence consumers' evaluation of a brand based on their CSR perceptions for that brand. Hence, the higher the level of consumers' evaluation of a brand to be labeled as a socially responsible brand, the greater the likelihood that consumer will prefer that brand over competitors [59]. By portraying the image of a socially responsible organization, businesses can increase loyal consumers by turning consumers into business ambassadors and advocating consultants due to their sense of admiration in response to well-planned CSR initiatives and communicating with stakeholders of an organization. For instance, this can lead to positive word-of-mouth communications for their admired organization, willingness to pay premium prices and less consideration of the rival brands [60]. It should be noted that CSR communication tools are very important in providing CSR messages and building the image of a socially responsible organization. In addition to company experience, in high-end products and models, socially responsible organizations receive empowerment from different stakeholders including consumers and reflect compliance with issues that are distinctive from the usual cultural norms. The main challenge in developing a CSR approach is to involve consumers and other stakeholders for reducing their uncertainty in achieving sustainable organizational goals [61].

Recent CSR research has shown that engaging stakeholders in CSR programs allows companies to build a strong image [62], strengthen consumer relationships [16] and improve the reputation of businesses [63]. Hence, CSR activities inculcate the feelings of admiration among consumers as they are admired being the customers of an organization that is socially responsible and actively contributes to uplift society and the environment [38]. Ultimately, this sense of admiration takes them towards a higher level of loyalty [64]. Providing accurate CSR information to stakeholders not only increases their participation in the organization, but also promotes the company's representation on different social media platforms [65]. Advances in technology have changed the way businesses use CSR planning and its implementation.

Social media platforms expand communication and collaboration between groups of individuals. It also promotes the quick dissemination of information, and it is a tool that allows people to express their ideas and communicate with others; people can come up with new ideas and use them to improve organizational approach in building a sustainable environment [66]. There have also been different studies highlighting the importance of CSR communication to the stakeholders using conventional media [67-69], acknowledging that CSR communication with stakeholders has positive outcomes for an organization. However, the rise of social media is the dawn of a new horizon in the field of marketing communication $[70,71]$. In particular, social media can be categorized into two categories, such as expressive and collaborative. Expressive social media include sites such as blogs, Twitter, YouTube, Facebook and Flickr, and collaborative social media include sites such as Wikipedia and Craigslist. Social media have changed the future of businesses due to its low cost, wider range and interactive environment which attracts companies to use it for advertising, consumer marketing or consumer company communication. Instead, the consumer role is changing with the rise of social media technologies [72]. Dwivedi et al. [73] contended that consumers' brand attachment on social media positively impacts consumerbased brand equity.

Consumers are no longer recognized as an isolated entity, as they are well-concerned and connected with the organizations from which they purchase their products or services. They not only have the knowledge needed to make a decision, but also provide important feedback to organizations for improving the overall performance of their products in line with the philosophy of sustainability [74]. Social media are a powerful communication tool for disseminating information on CSR-related activities, seeking strong links between socially responsible organization and consumers and attracting partners through in-depth reviews on products' performance [75]. In brief, social media are a powerful modern tool for informing consumers about CSR initiatives of an organization. 
The present study introduces the construct of consumer sense of brand admiration as a potential mediator between CSR communication on social media and consumer loyalty and defines this as "consumer brand admiration is the process that involves consumers with a brand personally through evoking positive emotions, trust, love and respect". This definition is also supported by eminent contemporary researchers such as Park et al. [76] and Trivedi and Sama [77]. The reason to think about consumer brand admiration as a potential mediator lies in the logic that when consumers are informed about the social responsibility of an organization they develop positive emotions on their part for that organization and start associating them with the brand positively, all this in turn takes consumers towards a higher level of loyalty. Further, the present study defines consumer loyalty in line with the definition of Oliver [78] who contends that consumer loyalty is a tendency of consumers to prefer a brand in the long run over its competitors.

Prior literature has also recognized that well-planned CSR plans in the context of the banking sector are associated with positive emotions of consumers [42,79]. It is also established in the recent literature that positive emotions, such as feelings of admiration, are positively related to consumer loyalty $[80,81]$. To summarize, we conclude that the rise of social media has changed the traditional business model that was a sort of one way communication model, as the emergence of social media has been highly acknowledged by the organizations and consumers due to its flexibility, broader range, quick dissemination of information and, above all, its interactive communicative options. The consumers, in this regard, behave like ambassadors of an organization through their positive word-ofmouth communications toward an admired organization; all such activities inculcate a higher level of loyalty in the consumers. Hence based upon above discussion, we argue that CSR activities directly and indirectly (through brand admiration) are associated with consumer loyalty. Therefore, the following set of hypotheses is framed. Further, the proposed relations of the studied variables are framed in Figure 1 for the readers.

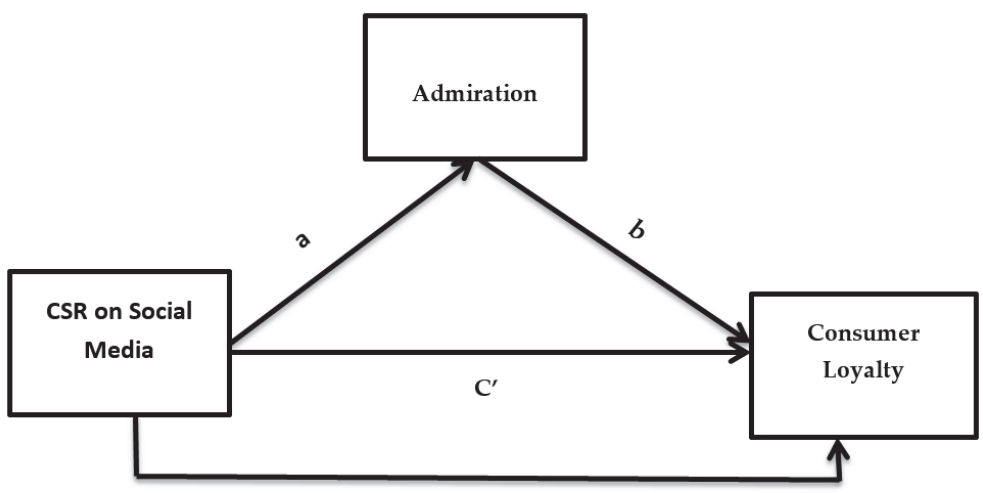

C

Figure 1. Proposed research model showing path directions for mediation. Where corporate social responsibility $(\mathrm{CSR})(\mathrm{X})=$ the independent variable, consumer loyalty $(\mathrm{Y})=$ the dependent variable, admiration $(M)=$ the mediating variable, $a * b=$ the indirect effect of the mediator on $Y$, and $C^{\prime}=$ indirect direct effect of $X$ on $Y$ with the effect of the mediator, $C=\operatorname{direct}$ effect of $\mathrm{X}$ on $\mathrm{Y}$ without mediator.

Hypothesis 1 (H1). CSR communications of a bank through social media are positively related to consumer loyalty.

Hypothesis 2 (H2). CSR communications of a bank through social media are positively related to consumers' brand admiration. 
Hypothesis 3 (H3). Consumers' brand admiration mediates the relationship between CSR communication through social media and consumer loyalty.

\section{The Data Collection and Measures}

The proposed model of the present study is intended to be tested on banking consumers. The banking sector for the present study was selected due to two specific reasons. First, due to the homogenized character of the banking industry, it is very difficult to differentiate the services of a bank from its competitors in order to gain consumers' attention. Second, the banking sector of Pakistan is facing a stiff competitive environment where the ordinary strategies for consumer retention might not be helpful, and hence some extraordinary thinking is necessary to address the situation on the part of policymakers and marketers from the banking institutions.

The rise of a second wave of the COVID-19 pandemic posed some serious challenges on the data collection phase of the present study due to smart lockdown in different regions of the country. Likewise, it was also not feasible for us to maintain physical contact with the consumers of different banks in order to invite them to participate in the survey. In this regard, an online survey was the only option that could work for the present study in the context of data collection. Before disseminating the questionnaire online, we carefully assessed the banking institutions of Pakistan which were actively involved in CSR initiatives. We came out with a list of four banks named Habib Bank Limited (HBL), United Bank Limited (UBL), MCB Bank Limited and Allied Bank Limited (ABL). The selection of these banks was made as these banks are the four largest banks in the country with widespread branches all over the country; furthermore, all these banks have their CSR presence on social media (Facebook, YouTube and Twitter, etc.). To start with the data collection phase, we prepared an online self-administered survey and sent it to different individuals through emails and WhatsApp. The online survey includes two screening questions regarding the CSR knowledge of the respondents and whether they have a bank account in any of these four banks. We initially floated 1000 surveys to different individuals for the purpose of data collection. As was expected, the online strategy of data collection resulted in a poor response rate as we received only 116 questionnaires from respondents; among those 116 surveys we had to discard 11 questionnaires because they were partially filled and could not be included into final dataset because these contained missing information on the part of respondent, and researchers were unable to address these kind of questionnaires. Thus, we deleted these questionnaires and recorded 105 questionnaires in our first phase of data collection. This strategy is in line with the guidelines of Ahmed et al. [82]. We started the second phase of the online survey using the same procedure as in the previous phase. This time, we received 118 filled questionnaires. Our repeated efforts and poor response rate pushed us to start another phase of data collection; this time, we invited our colleagues and peers to support us in data collection process by using their personal contacts. We sent the online questionnaire to our colleagues with this request to share it with their fellows through email and WhatsApp and asked them to fill in the questionnaire. This strategy eventually worked for us, and we were able to collect a feedback of 448 respondents (105 in the first phase, 118 in the second and 225 in the last phase). We used already established scales for measuring our study variables: for example, we adapted the items for CSR from the studies of van Asperen et al. [83] and Eisingerich et al. [84]. The scale consisted of five items; likewise, the items of brand admiration were adapted from Sweetman et al. [85]. This scale consisted of a total of five items. Lastly, the three-item scale of consumer loyalty was adapted from Dagger et al. [86]. We used a five-point Likert scale for recording the responses from respondents.

\section{Results}

\subsection{Common Method Bias, Sample Profile, Validity and Reliability}

As the data for all variables of the present study were collected from the same individuals, there is a likelihood for the presence of common method bias (CMB) in our data. 
In order to handle $\mathrm{CMB}$, we followed the guidelines of [81], and we performed a single factor confirmatory factor analysis in AMOS. The results revealed a poor model fit which means that there was no single dominating factor in our data. This is a positive symbol because it pushes away the fear of common method bias from our data. Hence, we took the data analysis phase at further levels. We in this regard, first of all presented the descriptive statistics of our sample (Table 1).

Table 1. Demographic profile.

\begin{tabular}{ccc}
\hline & Frequency & $\%$ \\
\hline Gender & 289 & \\
Male & 159 & 35.5 \\
Female & & \\
Age & 49 & 10.9 \\
$18-20$ & 169 & 37.7 \\
$21-30$ & 112 & 25.1 \\
$31-40$ & 76 & 17.0 \\
$41-45$ & 42 & 09.3 \\
Above 45 & 53 & 11.8 \\
Education & 129 & 28.8 \\
Intermediate & 176 & 39.3 \\
Graduate & 90 & 20.1 \\
Master & & \\
Higher & &
\end{tabular}

Next, we performed a factor analysis in order to observe whether all items of a variable have acceptable factor loadings greater than 0.5 (See Table 2). The empirical results revealed that all the items having factor loadings greater than the cut-off value of 0.5 ; hence, we established that all items are well-loaded onto their respective variable. Similarly, the results of standard deviation (SD) for all variables are also described in Table 2. All values for SD analysis are fewer than 1 and closer to 0 ; that means there is less variability in our data which is good as less variability means that our data are close to mean values.

Table 2. Correlations, validities and reliabilities.

\begin{tabular}{|c|c|c|c|c|c|c|c|}
\hline Variables & Mean & SD & CSR & $\mathrm{AD}$ & CL & MSV & ASV \\
\hline CSR & 3.41 & 0.51 & $(0.781)$ & $0.213 * *$ & $0.409^{* *}$ & 0.186 & 0.163 \\
\hline $\begin{array}{l}\text { Admiration } \\
\text { (AD) }\end{array}$ & 3.85 & 0.46 & & $(0.818)$ & $0.362 * *$ & 0.142 & 0.118 \\
\hline Loyalty (CL) & 3.79 & 0.38 & & & $(0.842)$ & 0.109 & 0.087 \\
\hline & Items & Loadings * & AVE & $\alpha$ & CR & Skewness & Kurtosis \\
\hline CSR & 5 & $0.65-0.77$ & 0.61 & 0.76 & 0.76 & -0.72 & 0.39 \\
\hline $\mathrm{AD}$ & 5 & $0.74-0.89$ & 0.67 & 0.82 & 0.83 & -0.33 & 0.28 \\
\hline $\mathrm{CL}$ & 3 & $0.63-0.81$ & 0.71 & 0.87 & 0.89 & -0.18 & 0.23 \\
\hline
\end{tabular}

Loadings *: Factor loading range (max: $\min ) ; \alpha$ : Cronbach's $\alpha$ coefficient; CR: composite reliability; AVE: average variance extracted; **: significant values of correlations; MSV: maximum shared variance; ASV: average shared variance. The bold diagonal values represent square root of AVE for a variable.

Next, we report the results of correlation analysis amongst the study variables. According to the results, all three variables are positively related to each other: for example, the value of correlation amongst CSR and brand admiration is $0.213^{* *}$, which is significant and positive, meaning that these two variables are correlated positively. The bold diagonal values in the table (Table 2) present the results of discriminant validity values; in doing so, we calculated the square root values of average variance extracted (AVE) for each variable and then compared it with the values of correlations of other variables. The rule of thumb is that if square root of AVE is greater than the correlation values, then it is established that 
the items of one variable discriminate with other variable items, and hence discriminant validity of the data is maintained. Table 2 also disuses the results of convergent validity for achieving convergent validity. We calculated AVE of each variable: the AVEs for each variable are larger than 0.5 , which means convergent validity is well-maintained for our instrument. The reliability values (alpha and composite reliabilities) are also reported in Table 2, which are more than 0.70 and prove that the reliability of our instrument is also fine. Lastly, we also reported the results of normality. We, in this regard, are in line with the recommendation of Brown [87], who recommended that the data normality is established when the values of standard deviation (SD) are in the range of \pm 1.5 , skewness \pm 3 and kurtosis \pm 10 . These results establish our confidence to state that there is no issue of data normality in our data. All these measures encourage the researchers to take the data analysis further for hypotheses testing.

In next step of data analysis, we tested model fit indices. Initially we tested model fit index values for each construct individually, which produced good results (CSR: $\chi^{2} / d f=2.81$ RMSEA $=0.054 \mathrm{NFI}=0.943, \mathrm{CFI}=0.949, \mathrm{GFI}=0.946$; Admiration: $\chi^{2} / d f=3.11$ RMSEA $=0.063$ $\mathrm{NFI}=0.928, \mathrm{CFI}=0.930 \mathrm{GFI}=0.928$; Loyalty: $\chi^{2} / d f=2.91=\mathrm{RMSEA}=0.058 \mathrm{NFI}=0.919$, $\mathrm{CFI}=0.927$ GFI $=0.922$ ) for each variable. Finally, we checked model fit results for our threefactor model that is our hypothesized model too. The model fit results for our three-factor model produced more appropriate results (see Table 3 ).

Table 3. Model fit indices.

\begin{tabular}{cc}
\hline Variable & Model Fit Indices \\
\hline CSR & $\chi^{2} / d f=2.81$, RMSEA $=0.054$, NFI $=0.943$, CFI $=0.949$, GFI $=0.946$ \\
Admiration & $\chi^{2} / d f=3.11$, RMSEA $=0.063, \mathrm{NFI}=0.928, \mathrm{CFI}=0.930 \mathrm{GFI}=0.928$ \\
Loyalty & $\chi^{2} / d f=2.91$, RMSEA $=0.058, \mathrm{NFI}=0.919, \mathrm{CFI}=0.927 \mathrm{GFI}=0.922$ \\
Overall model fit (three factor model); $\chi^{2} / d f=2.19$ RMSEA $=0.39, \mathrm{NFI}=0.972$, \\
$\mathrm{CFI}=0.981, \mathrm{GFI}=0.978$ \\
\hline
\end{tabular}

\subsection{Hypothesis Testing}

We used the structural equation modeling (SEM) technique for hypothesis testing. In this regard, we used AMOS software and we conducted our analysis in two steps. In the first step, we checked the results of direct effects, and in second step we checked the results of mediation analysis. We have reported these results in Table 4. According to these results, the direct effect model suggests that our hypotheses 1 and 2 are true $(\mathrm{H} 1 ; \beta=0.277 * *$, $\mathrm{LLCI}=0.193, \mathrm{ULCI}=0.374, p<0.05 \mathrm{H} 2 ; \beta=0.198 * *, \mathrm{LLCI}=0.490, \mathrm{ULCI}=0.832, p<0.05)$. Further, for testing the mediation results, we used the bootstrapping option in AMOS software by choosing a larger bootstrap sample of 2000. The results of the mediation analysis showed that the variable "brand admiration" is playing the role of a mediator between CSR and consumer loyalty $\left(\mathrm{H} 3 ; \beta=0.093^{* *}\right.$, LLCI $\left.=0.117, \mathrm{ULCI}=0.367, p<0.05\right)$. It is to be noted that the beta value is reduced from $0.198^{* *}$ (direct effect) to $0.093^{* *}$ (indirect effect) which means that there is partial mediation effect of brand admiration between CSR and consumer loyalty. 
Table 4. Hypothesis testing.

\begin{tabular}{|c|c|c|c|c|c|}
\hline Path & Beta Value & S.E & LLCI & ULCI & Decision \\
\hline & \multicolumn{5}{|c|}{ Model 1: Standardized direct effects } \\
\hline $\begin{array}{c}\mathrm{CSR} \rightarrow \\
\text { Admiration }\end{array}$ & $0.277^{* *}$ & 0.039 & 0.193 & 0.374 & Accepted \\
\hline CSR $\rightarrow$ Loyalty & \multicolumn{5}{|c|}{$\begin{array}{c}\left(\chi^{2} / d f=1.69, \text { RMSEA }=0.048, \mathrm{NFI}=0.969, \mathrm{CFI}=0.983, \mathrm{GFI}=0.982\right) * * * \\
\left(R^{2}=0.16^{*} \text { for } H 1, R^{2}=0.19^{*} \text { for } H 2\right) \\
* * * \text { model fit indices for direct effect model } \\
* * \text { beta value significant, }{ }^{*} R^{2} \text { value significant } \\
\text { Model 2: Standardized indirect effect (mediation model) }\end{array}$} \\
\hline \multirow{2}{*}{$\begin{array}{l}\mathrm{CSR} \rightarrow \\
\text { Admiration } \rightarrow \\
\quad \text { Loyalty }\end{array}$} & $0.093 * *$ & 0.018 & 0.117 & 0.367 & Accepted \\
\hline & \multicolumn{5}{|c|}{$\begin{array}{c}\left(\chi^{2} / d f=1.39, \text { RMSEA }=0.041, \mathrm{NFI}=0.986, \mathrm{CFI}=0.987, \mathrm{GFI}=0.985\right) * * * \\
\left(R^{2}=0.23 * \text { for } H 3\right) \\
* * * \text { model fit indices for mediated (three factor) model } \\
* * \text { beta value significant, }{ }^{*} R^{2} \text { value significant }\end{array}$} \\
\hline
\end{tabular}

CSR = corporate social responsibility, $\mathbf{S} . \mathbf{E}=$ standard error, $\mathbf{L L C I}=$ lower limit confidence interval, $\mathbf{U L C I}=$ upper limit confidence interval.

\section{Discussion and Implications}

The present study aims at investigating the impact of CSR communication through social media on consumer loyalty in the context of banking sector of Pakistan with the mediating effect of brand admiration. The results of the present study revealed that CSR initiatives directly and indirectly, via admiration, influence the banking consumers' loyalty. The results further affirmed that the involvement of a bank in CSR communication using social media produces better outcomes for building sustainable image of a bank. These results are also in line with the studies of Aramburu and Pescador [88] and Bediako [89]. When an organization uses social media to communicate its CSR activities with different stakeholders including the consumers, it creates positivity among consumers for that organization which ultimately increases their loyalty. The recent study of Bilgin [10] also acknowledged the importance of social media to enhance brand loyalty.

The rise of social media and information technology has brought a paradigm shift in business communication models. Traditionally, the business communication model was based on one-way communication, but with the rise of the digital age, this one-way communicative model is being replaced with an interactive communication model in which different stakeholders, including consumers, have their voice and say in the business decisions of an organization. Modern consumers are more informative and empowered due to the access of information and availability of different knowledge platforms. Our research affirmed that when consumers see that their bank is communicating its CSR activities on social media with them, it inculcates a sense of admiration among them for the bank, and this sense of admiration actually builds a higher level of loyalty in consumers. Hence the results confirmed that CSR initiatives are positively related with admiration; this finding is also supported by contemporary researchers in their studies [64,90]. Likewise, the mediating role of admiration between the relationship of CSR communication through social media and consumer loyalty is also an important factor in this relationship.

The present study has some important implications for theory and practice. For example, the present study adds to extant CSR literature in the context of consumers, whereas the majority of the previous studies have addressed CSR relation in the organizational context. Likewise, another important theoretical implication of the present study is that it introduces the novel construct of consumers' brand admiration as mediator between the relationship of CSR communication on social media and consumer loyalty. Likewise, the study adds to contemporary literature of CSR from a developing country context where this phenomenon is still underexplored. Further, the present study enriches the extant literature from the perspective of marketing by highlighting that CSR initiatives of an 
organization can be helpful in attaining marketing-related objectives of an organization, including consumer loyalty.

Likewise, the study has some important practical implications: for example, it highlights to the policymakers of banking institutions that looking at CSR from the perspective of marketing may generate better marketing-related outcomes in an industry which is labeled as homogenized and where differentiation of products and services is very difficult. Well-planned CSR activities of a bank may be a key resource that can build a competitive advantage for a specific bank. Currently, the majority of banking institutions of Pakistan are practicing CSR activities with a philanthropic mindset, and they intentionally or unintentionally have ignored the marketing aspect of CSR plans to enhance consumer loyalty. This is the time for the banking institutions of Pakistan to change their approach towards CSR initiatives and think of CSR in terms of consumer-related outcomes. Our study, in this regard, is a pioneering one which highlights the importance of CSR communication through social media for establishing consumer loyalty. Furthermore, the usage of social media for communicating CSR initiatives produces positive emotions on the part of consumer as they feel admiration for an organization that truly practices CSR activities and informs their stakeholders about such initiatives. Ultimately, the consumers become a strong advocate for such organizations and develop positive word-of-mouth communications on social media for the brand. It is noteworthy that when an organization is being promoted by the consumers, it produces better results as compared to advertising outcomes, because the feedback given by consumers to other potential consumers is considered to be honest and transparent. Our results further affirmed that CSR communication on social media is very important for consumer loyalty.

Traditional CSR communication can also affect consumers behavior as mentioned in prior studies $[67,91]$, but the point to note here is that social media are an interactive medium which provides the organizations with a platform to interactively communicate with different stakeholders. In this connection, CSR communication through social media works on the emotional aspects of consumer behavior, which is very strong as compared to the cognitive aspects, because once the consumers develop positive emotions (admiration), they are less price-sensitive and are even willing to pay a premium price to the bank for which they feel admiration. Likewise, such consumers are less likely to switch to the competing brands. The banking institutions are required to work on these new insights from this study in order to place the CSR initiatives as core to their business strategies, with the mindset that CSR is double edged sword as on one hand it addresses the social obligations of a bank towards society, and on the other hand it can create consumer-related outcomes by building higher levels of consumer loyalty and positive emotions.

\section{Limitations and Future Research Directions}

The present study also faces some limitations which may be considered a way forward for future researchers. The first limitation of our study lies in the fact that our target population was only the banking sector, which creates the question of generalizing the results of the present study into other service sectors. In order to address this issue, the future researchers are suggested to test our model in another service sector, such as the insurance and healthcare sectors for better generalizability. Secondly, the data for the present study were cross-sectional, which limits us in establishing any causation effect with confidence. One remedy to answer this issue in future research is to use longitudinal data which are able to provide historical information about the issue at hand, and hence are considered better for establishing causality. Thirdly, the present study only took the perception of consumers for CSR initiatives, whereas it has neglected the inputs from other stakeholder such as employees, who are equally important for an organization. Thus, for future researchers it is suggested examination of the effect of CSR initiatives on employees and assessment of whether properly planned CSR initiatives create positive emotions among employees. Fourthly, the study only considered the impact of CSR communication on consumer loyalty, whereas other important variables such as service quality, trust and 
brand image were not considered to predict banking consumer loyalty. Thus, the future researchers are encouraged to address this issue by considering these variables in our model as a mediator or moderator. Lastly, the influence of age, gender and income are not considered in this research. For future research, testing the possible impact of age, gender and income levels as moderators can be a meaningful extension of this research. Likewise, the present study has investigated the impact of CSR communication through social media on consumer loyalty; future researchers are encouraged to investigate further brand-related variables such as brand equity, which is one of the most cited variables in the field of marketing. It will be interesting for future researchers to investigate which brand equity, consumer based or finance based is the most affected though CSR activities.

Author Contributions: All of the authors contributed to conceptualization, formal analysis, investigation, methodology and writing and editing the original draft. All authors have read and agreed to the published version of the manuscript.

Funding: This research received no external funding.

Institutional Review Board Statement: Not applicable.

Informed Consent Statement: Informed consent was obtained from the respondents of the survey.

Data Availability Statement: The data will be made available on request from the corresponding author.

Acknowledgments: The authors acknowledge Andrijana Markovic for her support and efforts during the publication process of this manuscript.

Conflicts of Interest: The authors declare no conflict of interest.

\section{References}

1. Gomez, L.M. The State of Social Media Research in CSR Communication. The Palgrave Handbook of Corporate Social Responsibility; Springer: Berlin/Heidelberg, Germany, 2020; pp. 1-23.

2. Lund, N.F.; Cohen, S.A.; Scarles, C. The power of social media storytelling in destination branding. J. Destin. Mark. Manag. 2018, 8, 271-280. [CrossRef]

3. Hibbert, S. CSR engagement via social media: In theory and practice. In Communicating Corporate Social Responsibility in the Digital Era; Routledge: London, UK, 2017; pp. 3-16.

4. Waheed, A.; Zhang, Q. Effect of CSR and Ethical Practices on Sustainable Competitive Performance: A Case of Emerging Markets from Stakeholder Theory Perspective. J. Bus. Ethics 2020, 1-19. [CrossRef]

5. Freeman, R.E.; Harrison, J.S.; Wicks, A.C.; Parmar, B.L.; De Colle, S. Stakeholder Theory: The State of the Art; Cambridge University Press: Cambridge, UK, 2010.

6. Hussain, T.; Chen, S.; Nurunnabi, M. The role of social media for sustainable development in mountain region tourism in Pakistan. Int. J. Sustain. Dev. World Ecol. 2019, 26, 226-231. [CrossRef]

7. Wang, R.; Huang, Y. Communicating corporate social responsibility (CSR) on social media. Corp. Commun. Int. J. 2018, 23, 326-341. [CrossRef]

8. Liu, Y.; Jiang, C.; Zhao, H. Assessing product competitive advantages from the perspective of customers by mining user-generated content on social media. Decis. Support. Syst. 2019, 123, 113079. [CrossRef]

9. Statista. Most Popular Social Networks Worldwide as of October 2020, Ranked by Number of Active Users. Available online: https:/ / www.statista.com/statistics/272014/global-social-networks-ranked-by-number-of-users/ (accessed on 18 December 2020).

10. Bilgin, Y. The effect of social media marketing activities on brand awareness, brand image and brand loyalty. Bus. Manag. Stud. Int. J. 2018, 6, 128-148. [CrossRef]

11. Contini, M.; Annunziata, E.; Rizzi, F.; Frey, M. Exploring the influence of Corporate Social Responsibility (CSR) domains on consumers' loyalty: An experiment in BRICS countries. J. Clean. Prod. 2020, 247, 119158. [CrossRef]

12. Latif, K.F.; Sajjad, A.; Bashir, R.; Shaukat, M.B.; Khan, M.B.; Sahibzada, U.F. Revisiting the relationship between corporate social responsibility and organizational performance: The mediating role of team outcomes. Corp. Soc. Responsib. Environ. Manag. 2020, 27, 1630-1641. [CrossRef]

13. Sarkar, S.; Chatterjee, M.; Bhattacharjee, T. Does CSR disclosure enhance corporate brand performance in emerging economy? Evidence from India. J. Indian Bus. Res. 2021. [CrossRef]

14. Casado-Aranda, L.-A.; Martínez-Fiestas, M.; Sánchez-Fernández, J. Neural effects of environmental advertising: An fMRI analysis of voice age and temporal framing. J. Environ. Manag. 2018, 206, 664-675. [CrossRef] [PubMed]

15. Ahmad, N.; Mahmood, A.; Han, H.; Ariza-Montes, A.; Vega-Muñoz, A.; Din, M.u.; Iqbal Khan, G.; Ullah, Z. Sustainability as a "New Normal" for Modern Businesses: Are SMEs of Pakistan Ready to Adopt It? Sustainability 2021, 13, 1944. [CrossRef] 
16. Abbas, M.; Gao, Y.; Shah, S.S.H. CSR and customer outcomes: The mediating role of customer engagement. Sustainability 2018, 10, 4243. [CrossRef]

17. Sharma, V.; Jeannne, P.; Mohanta, S.; Liza, E. Influence of the dimensions of CSR activities on consumer purchase intention. Innov. Mark. 2018, 14, 23-32. [CrossRef]

18. Kim, J.S.; Song, H.; Lee, C.-K.; Lee, J.Y. The impact of four CSR dimensions on a gaming company's image and customers' revisit intentions. Int. J. Hosp. Manag. 2017, 61, 73-81. [CrossRef]

19. Brown, T.J.; Dacin, P.A. The company and the product: Corporate associations and consumer product responses. J. Mark. 1997, 61, 68-84. [CrossRef]

20. Hur, W.M.; Kim, H.; Kim, H.K. Does customer engagement in corporate social responsibility initiatives lead to customer citizenship behaviour? The mediating roles of customer-company identification and affective commitment. Corp. Soc. Responsib. Environ. Manag. 2018, 25, 1258-1269. [CrossRef]

21. Phillips, S.; Thai, V.V.; Halim, Z. Airline Value Chain Capabilities and CSR Performance: The Connection Between CSR Leadership and CSR Culture with CSR Performance, Customer Satisfaction and Financial Performance. Asian J. Shipp. Logist. 2019, 35, 30-40. [CrossRef]

22. Zasuwa, G. The role of company-cause fit and company involvement in consumer responses to CSR initiatives: A meta-analytic review. Sustainability 2017, 9, 1016. [CrossRef]

23. Kim, M.; Kim, Y. CSR and shareholder value in the restaurant industry: The roles of CSR communication through annual reports. Cornell Hosp. Q. 2019, 60, 69-76. [CrossRef]

24. Tarabashkina, L.; Tarabashkina, O.; Quester, P. Using numbers in CSR communication and their effects on motive attributions. J. Consum. Mark. 2020, 37, 855-868. [CrossRef]

25. Schramm-Klein, H.; Zentes, J.; Steinmann, S.; Swoboda, B.; Morschett, D. Retailer corporate social responsibility is relevant to consumer behavior. Bus. Soc. 2016, 55, 550-575. [CrossRef]

26. She, C.; Michelon, G. Managing stakeholder perceptions: Organized hypocrisy in CSR disclosures on Facebook. Crit. Perspect. Account. 2019, 61, 54-76. [CrossRef]

27. Dunn, K.; Harness, D. Communicating corporate social responsibility in a social world: The effects of company-generated and user-generated social media content on CSR attributions and scepticism. J. Mark. Manag. 2018, 34, 1503-1529. [CrossRef]

28. Kim, J.; Lacey, R.; Kim, H.-R.; Suh, J. How CSR serves as a preventive mechanism for coping with dysfunctional customer behavior. Serv. Bus. 2019, 13, 671-694. [CrossRef]

29. Karaosmanoglu, E.; Altinigne, N.; Isiksal, D.G. CSR motivation and customer extra-role behavior: Moderation of ethical corporate identity. J. Bus. Res. 2016, 69, 4161-4167. [CrossRef]

30. Karyawati, G.; Subroto, B.; Sutrisno, T.; Saraswati, E. Explaining the complexity relationship of CSR and financial performance using neo-institutional theory. J. Asian Bus. Econ. Stud. 2020, 27, 227-244.

31. Ramzan, M.; Amin, M.; Abbas, M. How does corporate social responsibility affect financial performance, financial stability, and financial inclusion in the banking sector? Evidence from Pakistan. Res. Int. Bus. Financ. 2021, 55, 101314. [CrossRef]

32. Ahmad, N.; Scholz, M.; Ullah, Z.; Arshad, M.Z.; Sabir, R.I.; Khan, W.A. The nexus of CSR and co-creation: A roadmap towards consumer loyalty. Sustainability 2021, 13, 523. [CrossRef]

33. Shah, S.S.A.; Khan, Z. Creating advocates: Understanding the roles of CSR and firm innovativeness. J. Financ. Serv. Mark. 2021, 1-12. [CrossRef]

34. Fatma, M.; Khan, I.; Rahman, Z. CSR and consumer behavioral responses: The role of customer-company identification. Asia Pac. J. Mark. Logist. 2018, 30, 460-477. [CrossRef]

35. Wang, T. Social identity dimensions and consumer behavior in social media. Asia Pac. Manag. Rev. 2017, 22, 45-51. [CrossRef]

36. Conner, S.L.; Reardon, J.; Miller, C.; Salciuviene, L.; Auruskeviciene, V. Cultural antecedents to the normative, affective, and cognitive effects of domestic versus foreign purchase behavior. J. Bus. Econ. Manag. 2017, 18, 100-115. [CrossRef]

37. Chen, C.-C.; Chen, C.-W.; Tung, Y.-C. Exploring the consumer behavior of intention to purchase green products in belt and road countries: An empirical analysis. Sustainability 2018, 10, 854. [CrossRef]

38. Castro-González, S.; Bande, B.; Fernández-Ferrín, P.; Kimura, T. Data to model the influence of CSR on consumer behaviors: A process approach. Data Brief 2019, 27, 104713. [CrossRef] [PubMed]

39. Linacre, S. Status symbols: How to win admiration and influence people. Ann. Soc. Responsib. 2019, 5, $2-4$.

40. Saleem, M.A.; Zahra, S.; Ahmad, R.; Ismail, H. Predictors of customer loyalty in the Pakistani banking industry: A moderatedmediation study. Int. J. Bank Mark. 2016, 34, 411-430. [CrossRef]

41. Rafay, A.; Franco, G.; Gilani, U. Measuring Competition in Banking Industry: Evidence from Latin American Economies. Pak. Bus. Rev. 2019, 21, 154-163.

42. Raza, A.; Saeed, A.; Iqbal, M.K.; Saeed, U.; Sadiq, I.; Faraz, N.A. Linking corporate social responsibility to customer loyalty through co-creation and customer company identification: Exploring sequential mediation mechanism. Sustainability 2020, 12, 2525. [CrossRef]

43. Sun, H.; Rabbani, M.R.; Ahmad, N.; Sial, M.S.; Cheng, G.; Zia-Ud-Din, M.; Fu, Q. CSR, Co-Creation and Green Consumer Loyalty: Are Green Banking Initiatives Important? A Moderated Mediation Approach from an Emerging Economy. Sustainability 2020, 12, 10688. [CrossRef]

44. Bagozzi, R.; Grappi, S.; Romani, S. Consumers Reactions to Admirable or Reprehensible Corporate Behavior. Proc. Eur. Mark. Acad. 2020, 49, 1-10. 
45. Castro-González, S.; Bande, B.; Fernández-Ferrín, P.; Kimura, T. Corporate social responsibility and consumer advocacy behaviors: The importance of emotions and moral virtues. J. Clean. Prod. 2019, 231, 846-855. [CrossRef]

46. Siltaoja, M.E. Value priorities as combining core factors between CSR and reputation-A qualitative study. J. Bus. Ethics 2006, 68, 91-111. [CrossRef]

47. Carroll, A.B. The pyramid of corporate social responsibility: Toward the moral management of organizational stakeholders. Bus. Horiz. 1991, 34, 39-48. [CrossRef]

48. Brondoni, S.M.; Bosetti, L.; Civera, C. Ouverture de 'CSR and Multi-Stakeholder Management'. Symph. Emerg. Issues Manag. 2019, 1,1-15. [CrossRef]

49. Chu, S.-C.; Chen, H.-T. Corporate social responsibility (CSR) communication in social media in china: The role of identification with the company and brand trust. In American Academy of Advertising. Conference. Proceedings (Online); American Academy of Advertising: Heathrow, FA, USA, 2017; p. 177.

50. Jose, R.; Ramakrishna, S. Comprehensiveness in the Research on Sustainability; Springer: Berlin/Heidelberg, Germany, 2021.

51. Li, M.; Hua, Y.; Zhu, J. From Interactivity to Brand Preference: The Role of Social Comparison and Perceived Value in a Virtual Brand Community. Sustainability 2021, 13, 625. [CrossRef]

52. Lee, Y.C. Communicating sustainable development: Effects of stakeholder-centric perceived sustainability. Corp. Soc. Responsib. Environ. Manag. 2020, 27, 1540-1551. [CrossRef]

53. Nyilasy, G.; Gangadharbatla, H.; Paladino, A. Perceived greenwashing: The interactive effects of green advertising and corporate environmental performance on consumer reactions. J. Bus. Ethics 2014, 125, 693-707. [CrossRef]

54. Fritz, H. The Psychology of Interpersonal Relations; John Wiley and Sons: New York, NY, USA, 1958.

55. Kelley, H.H. Attribution theory in social psychology. In Nebraska Symposium on Motivation; University of Nebraska Press: Lincoln, NE, USA, 1967.

56. Chakraborty, U.; Bhat, S. The effects of credible online reviews on brand equity dimensions and its consequence on consumer behavior. J. Promot. Manag. 2018, 24, 57-82. [CrossRef]

57. Jackson, M. Utilizing attribution theory to develop new insights into tourism experiences. J. Hosp. Tour. Manag. 2019, 38, 176-183. [CrossRef]

58. Sharma, T. What a Waste: Confronting Consumer Food Waste Behavior in Hospitality Settings. In Advances in Hospitality and Leisure; Emerald Publishing Limited: Bentley, UK, 2021.

59. Ginder, W.; Kwon, W.-S.; Byun, S.-E. Effects of Internal-External Congruence-Based CSR Positioning: An Attribution Theory Approach. J. Bus. Ethics 2019, 1-15. [CrossRef]

60. Chomvilailuk, R.; Butcher, K. Evaluating the effect of corporate social responsibility communication on mobile telephone customers. J. Retail. Consum. Serv. 2016, 33, 164-170. [CrossRef]

61. Lee, E.-M.; Yoon, S.-J. The effect of customer citizenship in corporate social responsibility (CSR) activities on purchase intention: The important role of the CSR image. Soc. Responsib. J. 2018, 14, 753-763. [CrossRef]

62. Ramesh, K.; Saha, R.; Goswami, S.; Dahiya, R. Consumer's response to CSR activities: Mediating role of brand image and brand attitude. Corp. Soc. Responsib. Environ. Manag. 2019, 26, 377-387. [CrossRef]

63. Tetrault Sirsly, C.-A.; Lvina, E. From doing good to looking even better: The dynamics of CSR and reputation. Bus. Soc. 2019, 58, 1234-1266. [CrossRef]

64. Mohammed, A.; Al-Swidi, A. The influence of CSR on perceived value, social media and loyalty in the hotel industry. Span. J. Mark. ESIC 2019, 23, 373-396. [CrossRef]

65. Dutot, V.; Galvez, E.L.; Versailles, D.W. CSR communications strategies through social media and influence on e-reputation. Manag. Decis. 2016, 54, 363-389. [CrossRef]

66. Reilly, A.H.; Hynan, K.A. Corporate communication, sustainability, and social media: It's not easy (really) being green. Bus. Horiz. 2014, 57, 747-758. [CrossRef]

67. Kim, S.; Ferguson, M. Public expectations of CSR communication: What and how to communicate CSR. Public Relat. J. 2014, 8, 1-22.

68. Andreu, L.; Casado-Díaz, A.B.; Mattila, A.S. Effects of message appeal and service type in CSR communication strategies. J. Bus. Res. 2015, 68, 1488-1495. [CrossRef]

69. Birth, G.; Illia, L.; Lurati, F.; Zamparini, A. Communicating CSR: Practices among Switzerland's top 300 companies. Corp. Commun. Int. J. 2008, 13, 182-196. [CrossRef]

70. Hogan, M.; Strasburger, V.C. Social media and new technology: A primer. Clin. Pediatrics 2018, 57, 1204-1215. [CrossRef]

71. Subramanian, K.R. Influence of social media in interpersonal communication. Int. J. Sci. Prog. Res. 2017, 38, 70-75.

72. Ketonen-Oksi, S.; Jussila, J.J.; Kärkkäinen, H. Social media based value creation and business models. Ind. Manag. Data Syst. 2016, 116, 1820-1838. [CrossRef]

73. Dwivedi, A.; Johnson, L.W.; Wilkie, D.C.; De Araujo-Gil, L. Consumer emotional brand attachment with social media brands and social media brand equity. Eur. J. Mark. 2019, 53, 1176-1204. [CrossRef]

74. He, W.; Zhang, W.; Tian, X.; Tao, R.; Akula, V. Identifying customer knowledge on social media through data analytics. J. Enterp. Inf. Manag. 2019, 32, 152-169. [CrossRef]

75. Quesenberry, K.A. Social Media Strategy: Marketing, Advertising, and Public Relations in the Consumer Revolution; Rowman \& Littlefield Publishers: Lanham, MA, USA, 2020. 
76. Park, C.W.; MacInnis, D.J.; Eisingerich, A.B. Brand Admiration: Building a Business People Love; John Wiley \& Sons: Hoboken, NJ, USA, 2016.

77. Trivedi, J.; Sama, R. The effect of influencer marketing on consumers' brand admiration and online purchase intentions: An emerging market perspective. J. Internet Commer. 2020, 19, 103-124. [CrossRef]

78. Oliver, R.L. Whence consumer loyalty? J. Mark. 1999, 63, 33-44. [CrossRef]

79. Pérez, A.; del Bosque, I.R. Personal traits and customer responses to CSR perceptions in the banking sector. Int. J. Bank Mark. 2017, 35, 128-146. [CrossRef]

80. Nasrah, R. The Effect Of Experiential Marketing Toward Customer Loyalty (Empirical Study Of Fast Food Restaurants In Padang City). Int. J. Manag. Bus. 2020, 1, 104-110.

81. Han, H.; Yu, J.; Kim, W. Environmental corporate social responsibility and the strategy to boost the airline's image and customer loyalty intentions. J. Travel Tour. Mark. 2019, 36, 371-383. [CrossRef]

82. Ahmed, M.A.; Jouhar, R.; Ahmed, N.; Adnan, S.; Aftab, M.; Zafar, M.S.; Khurshid, Z. Fear and practice modifications among dentists to combat novel coronavirus disease (COVID-19) outbreak. Int. J. Environ. Res. Public Health 2020, 17, 2821. [CrossRef] [PubMed]

83. van Asperen, M.; de Rooij, P.; Dijkmans, C. Engagement-based loyalty: The effects of social media engagement on customer loyalty in the travel industry. Int. J. Hosp. Tour. Adm. 2018, 19, 78-94. [CrossRef]

84. Eisingerich, A.B.; Rubera, G.; Seifert, M.; Bhardwaj, G. Doing good and doing better despite negative information?: The role of corporate social responsibility in consumer resistance to negative information. J. Serv. Res. 2011, 14, 60-75. [CrossRef]

85. Sweetman, J.; Spears, R.; Livingstone, A.G.; Manstead, A.S. Admiration regulates social hierarchy: Antecedents, dispositions, and effects on intergroup behavior. J. Exp. Soc. Psychol. 2013, 49, 534-542. [CrossRef]

86. Dagger, T.S.; David, M.E.; Ng, S. Do relationship benefits and maintenance drive commitment and loyalty? J. Serv. Mark. 2011, 25, 273-281. [CrossRef]

87. Brown, T.A. Confirmatory Factor Analysis for Applied Research; Guilford Publications: New York, NY, USA, 2015.

88. Aramburu, I.A.; Pescador, I.G. The effects of corporate social responsibility on customer loyalty: The mediating effect of reputation in cooperative banks versus commercial banks in the Basque country. J. Bus. Ethics 2019, 154, 701-719. [CrossRef]

89. Bediako, B. The impact of corporate social responsibility on customer loyalty. A case study of StanBed Tours ky. Bus. Econ. 2017. [CrossRef]

90. Mercadé-Melé, P.; Molinillo, S.; Fernández-Morales, A.; Porcu, L. CSR activities and consumer loyalty: The effect of the type of publicizing medium. J. Bus. Econ. Manag. 2018, 19, 431-455. [CrossRef]

91. Nielsen, A.E.; Thomsen, C. CSR communication in small and medium-sized enterprises. Corp. Commun. Int. J. 2009, 14, 176-189. [CrossRef] 

Article

\title{
Do Corporate Social Responsibility Disclosures Improve Financial Performance? A Perspective of the Islamic Banking Industry in Pakistan
}

\author{
Zia Ur Rehman ${ }^{1}$, Muhammad Zahid ${ }^{1, *}$, Haseeb Ur Rahman ${ }^{2}$, Muhammad Asif ${ }^{1}$, \\ Majed Alharthi ${ }^{3}$, Muhammad Irfan ${ }^{4, *}$ and Adam Glowacz ${ }^{5}$ \\ 1 Department of Management Sciences, City University of Science and IT, Peshawar 25000, Pakistan; \\ obaid3915@gmail.com (Z.U.R.); asifbaloch@cusit.edu.pk (M.A.) \\ 2 Institute of Management Sciences, University of Science and Technology, Bannu 28100, Pakistan; \\ drhaseeb@ustb.edu.pk \\ 3 Finance Department, College of Business, King Abdulaziz University, Rabigh 21911, Saudi Arabia; \\ mdalharthi@kau.edu.sa \\ 4 Electrical Engineering Department, College of Engineering, Najran University Saudi Arabia, \\ Najran 61441, Saudi Arabia \\ 5 Department of Automatic, Control and Robotics, AGH University of Science and Technology, \\ 30-059 Krakow, Poland; adglow@agh.edu.pl \\ * Correspondence: zahid@cusit.edu.pk (M.Z.); irfan16.uetian@gmail.com (M.I.)
}

Received: 20 March 2020; Accepted: 15 April 2020; Published: 18 April 2020

\begin{abstract}
This study aims to investigate the impact of corporate social responsibility disclosures (CSRD) on the financial performance of the Islamic banking industry of Pakistan. The study employed the method of content analysis for collecting the required data from annual reports of all four full-fledged Islamic banks operating in Pakistan from 2012 to 2017. The study developed a novel comprehensive CSRD index by using the "Global Reporting Initiative" (GRI) and "Accounting and Auditing Organization of Islamic Financial Institutions" (AAOIFI). This index consists of five dimensions and 105 sub-dimensions of CSRD. The use of Ordinary Least Squares (OLS), Panel Corrected Standard Errors (PCSEs), and Generalized Least Squares (GLS) using random-effect (RE) and fixed-effect (FE) estimators revealed a significant negative relationship between CSRD and the financial performance of the sample firms. Regarding separate dimensions, the relationship of the Environmental and Economic dimensions of CSRD is significantly positive with current performance, but it is insignificant for the relationships of Legal, Philanthropic, and Ethical dimensions of CSRD with the current financial performance. In addition to contributing to the scarce literature in the Islamic banking industry of a developing country like Pakistan, the study will also help the policymakers and other stakeholders, including the AAOIFI, to develop a comprehensive CSRD policy or index and further improve the already established standards for CSRD.
\end{abstract}

Keywords: corporate social responsibility disclosure (CSRD); financial performance; Islamic Banking Industry of Pakistan; GRI; AAOIFI; CSRD index

\section{Introduction}

Adam Smith noted in his book "The Theory of Moral Sentiments" that capitalism would not sustain if not based on integrity and honesty. He suggested that the self-interests of the owners and the managers could be countered by first establishing and then following the moral and ethical values [1]. Most of the recent studies in corporate governance have focused on certain specific issues like corporate fraud, the misuse of managerial powers, and social irresponsibility in business. In response to the changing and challenging market and managerial behavior, the business firms are compelled to take 
externalities into account. Business ethics and corporate social responsibilities (CSR) are now crucial for being competitive; firstly, these help firms to maintain excellent and trained staff, and secondly, these assist firms in addressing and meeting the customer's expectations [2]. CSR is a corporate move for the betterment of the whole society apart from the compulsions of law and the primary objective that firms are supposed to perform for the wellbeing of shareholders only [3]. Unlike the Western approach, the Islamic perception of CSR is different; it is considered a holy concept. Islam explains CSR in a more religious context that has its roots in both the Quran and Sunnah, which provides a better substitute or framework for the philosophy of the human's interaction with its fellow humans and nature as a whole. The ethical and the moral principles originating from the revelations are greatly eternal, enduring, and absolute; one can perform better by exercising the social and the business responsibilities simultaneously [4].

The Holy Quran has emphasized the CSR activities and declares these for those who are the believers, such as: "Ye cannot attain righteousness unless ye donate to charity from possessions ye love. What ye donate to charity, ALLAH is aware of" Quran, surah 3 Ayahs 92 [3:92]. The financial contributions under CSR are emphasized by the Holy Quran and the Sunnah in the shape of Sadqat and Zakat. Zakat means purification. It is a yearly contribution that is mandatory for the rich and paid to the poor, especially to the widows, orphans, and the elderly people who are no longer able to work or earn for themselves. Islam as a religion offers a complete code of life, including instructions about faith, ethics, morality, prayers, and belief in Allah in every walk of life, such as political, business, social, economic, and religious affairs [5]. The primary purpose of Islam is holistic welfare. The ethical and moral teachings of Islam produce complete and everlasting principles that set guidelines for individuals, society, and economic and business interactions [6].

However, in modern corporations, corporate social responsibility disclosure (CSRD) refers to the improvement of financial performance by bringing significant and positive outcomes through customers' loyalty and commitment to paying high prices and the reduction of the risk directed towards their reputation, especially in times of unfavorable economic conditions [7]. The journey towards CSR has started for the last few centuries and is still moving forward, with no signs of slowing down its pace $[8,9]$. CSR has much importance in the success of an organization, as customers prefer for the organizations to be responsible economically as well as socially. In Pakistan, the majority of the CSR activities are performed in the light of corporate philanthropy. Corporate financial contributions in the form of donations are considered an authentic tool to improve a corporation's image in an extremely competitive environment [10]. For the last few years, many financial institutions have started introducing CSR practices in their operational and organizational strategies. The banking industry is relatively different, especially regarding corporate governance and other reforms and regulations, including CSR. The banking industry has a central role in society due to its higher level of social interaction; therefore, banks are expected to be socially responsible [11]. Substantial research has examined the relationship between CSRD and the financial performance of conventional financial institutions, which produced inconsistent results. The majority of these studies used the global reporting initiative (GRI) as a benchmark for developing the CSRD index. Some studies on whether CSRD has any contribution towards the financial performance of Islamic banks have also been conducted throughout the world, bearing positive, negative, and neutral results. The majority of these studies relied on the standards established by the Accounting and Auditing Organization of Islamic Financial Institutions (AAOIFI) for developing the CSRD index. Therefore, the motivation of this study is to bridge the gap between these two standards by merging them and developing a more comprehensive index. The AAOIFI standards will help cover the issues related to Shariah compliance, such as Riba, Zakat and Sadqat, Qard-E-Hassana, Shariah Supervisory Board (SSB) approvals, attestation, and other ethical issues. The GRI standards will cover the issues related to conventional aspects, such as community, employees, environment, human rights, and other legal issues.

As far as the Islamic banking industry in Pakistan is concerned, minimal work has been done on the subject matter of CSRD. The Islamic banking industry has a good market share in the overall 
existing banking industry of Pakistan. Due to the increasing importance of CSR and its disclosures in the banking industry in general and in the Islamic banking industry in particular, it is vital to find out whether or not the increasing market share and financial performance have any relevance to CSR practices and their disclosures in Pakistan. Hence, this study aims to answer the research questions: What is the level of exposure of CSR of the Islamic banking industry in Pakistan? What is the impact of CSR disclosure on the financial performance of the Islamic banking industry in Pakistan? What are the impacts of dimensions of CSR disclosure on the financial performance of the Islamic banking industry in Pakistan?

After answering the above research questions, the study offers several theoretical, methodological, and practical contributions. Firstly, the study contributes to the literature on Islamic banking in Pakistan, as there were limited studies in the past $[9,12]$. Secondly, the study has a theoretical contribution in the application of the crux of stakeholder theory in the literature of Islamic banking, which may further assist the industry in understanding the demand of multiple stakeholders and legitimizing their license to operate on the larger canvas of the society [13-15]. Thirdly, the study extends the existing CSRD index, which is based on the Global Reporting Initiative (GRI) framework and "Accounting and Auditing Organization of Islamic Financial Institutions" (AAOIFI); it consists of five dimensions and 105 sub-dimensions of CSRD. The study claims that the novel index is more comprehensive than those of previous studies $[9,16]$ and has a methodological contribution in measuring CSRD in developing countries like Pakistan. Likewise, the study applied a panel data longitudinal analysis approach from 2012 to 2017, as the focus of the previous studies was limited in the period and dimensions of CSRD. The study period is important, as many environmental, social, and governance reforms (ESG), along with the concept of green banking, its regulations, and the codes of corporate governance of 2012 and 2017, were introduced during this time in Pakistan. Finally, this study provides practical implications for management and policymakers of the Islamic banking industry to understand the importance of CSRD reporting and its impact on overall firm performance. Furthermore, it would add to the systematic presentation of CSRD in developing an international attitude towards CSRD, especially in developing countries.

The rest of the paper consists of a literature review where the theoretical framework and hypothesis development followed by the conceptual framework are discussed. The data sample, measurement of financial performance and CSRD with the research model, and the estimations are discussed in the methodology section. Finally, the results and discussions with conclusions, limitations of the study, and future directions are reported.

\section{Literature Review}

\subsection{CSRD and Financial Performance of Islamic Banks}

Prior studies noted a positive and considerable association between firms' profitability and the magnitude of their CSRD $[9,17,18]$. Most profitable organizations disclose their CSR information to show their social role in the wellbeing of the community and ensure their survival in the industry. A study found a significant positive relationship between the practices of CSR disclosed in the annual reports and performance of the selected Islamic banks regarding the goodwill in Malaysia [19]. In another study, the possible link between CSRD and financial performance of the Islamic banks selected from different countries from 2010 to 2011 was investigated. The analyses indicated a significant positive relationship between the CSRD and financial performance [20]. Another study investigated the information that is crucial for ethical issues in Islamic business [21]. They designed a moral benchmark that is considered vital to differentiate Islamic banks from conventional banks. Using content analyses, they collected data from annual reports and noted a significant gap between the expected and actual disclosures. They concluded that the expected gap may have originated from the indifferent behavior of the stakeholders or the Arab culture where the sample banks were located. In the end, they summarized that if the Islamic banks intend to remain in competition with conventional 
banks, their communication should be even more useful to improve their overall reputation in the society in which they operate. Another dimension of the study examined the degree and the nature of CSRD and its impact on the firms' performance in a study of 90 Islamic banks from 13 countries for a period from 2010 to 2011 [20]. The study constructed a comprehensive CSRD index for the Islamic banks where the AAOIFI standard No. 7 was used to collect data. The study reported a direct link between CSRD, the financial performance of Islamic banks, and the level of CSRD for different countries. Among them, Indonesia stood first with the highest score of $54 \%$, while Pakistan was the last with the lowest score, i.e., 30.4\%. The researchers investigated CSRD in the Islamic banks of Malaysia and found that the volume and quantity of CSRD have improved with time [22]. Another study [23] noted a regular sequence in the CSRD in three phases in the Islamic banking industry of Bangladesh, i.e., the pre-1990s, 1990-2001, and post-2001. Similarly, they divided the moral and the ethical reporting of CSR into two categories, i.e., the particular style of reporting that is related to the Islamic banks, especially those practicing Shariah compliance, and the universal standards of reporting practices that mostly account for shareholders' communities, customers, and the employees. They noticed an overall positive increase in both the particular and the universal standards of disclosures over the corresponding period, but an upward shift in the universal disclosures after 2006. However, in contrast, some studies found a negative association between CSRD dimensions and financial performance. For example, a study found a negative impact of the environmental and social dimensions of CSRD on the financial performance of Malaysian Islamic banks [9].

\subsection{Theoretical Framework and Hypothesis Development}

The stakeholder's theory states that the main objective of organizations is the creation and maximization of stakeholders' value. Whenever the firms meet the expectations of more than a single stakeholder, they come into a position to improve their performance [13,24]. Given this, the theory that explains the disclosure of CSR and its impact on the firm's performance is the stakeholder theory. As per this theory, if an organization wants to be more efficient, it has to pay greater attention to all of the relationships, especially to those that affect or are affected by the organization's objectives. The stakeholder management assumption of the theory is a useful tool to gain the results which are already predicted, especially the profitability. This aspect of the said theory signals a link between the stakeholders and the performance of the corporation [13]. To summarize the stakeholders' theory, the stakeholders are assets and the managers are expected to manage them effectively. Similarly, the social responsibilities of the business organizations are to accomplish the needs of their stakeholders for which they are legally and socially responsible [25]. From a CSR perspective, society expects firms to run their operations responsibly regardless of their economic and commercial interests. The main crux of this theory is that the organization's goals must be in line with the goals of society. The theory further supports the goals of the Islamic banks to satisfy the demand of multiple stakeholders in the normative approach and avail instrumental benefits in the shape of better financial performance $[13,26]$. All of these arguments and assumptions are also compatible with the teachings of Islam regarding CSR. In addition to compliance with the governmental policies and reforms, Islam also necessitates the welfare of the individuals, society, environment, and all other creatures in the universe. Most of the prior empirical studies found a positive link between the individual dimension of CSRD and financial performance $[9,27]$. These positive impacts are mainly attributed to the competitive advantage, which improves customers' relations and retention and thus recognizes better financial performance. Competitive advantage is closely related to firms' financial performance. The conventional concept of competitiveness is widely used in a business strategy, which means that a firm becomes competitive when it gains higher financial returns than the average of its industry peers [28]. Similarly, the authors further argued that the individual dimension of the CSRD is equally important, as certain information may be lost while using the aggregate CSRD against financial performance. Thus, it is necessary to find a link between the individual dimensions of CSRD and financial performance. The detailed literature review and the previous discussion hint at a positive association of the particular dimensions 
of CSRD, i.e., Ethical, Legal, Environmental, Economic, and Philanthropic, with financial performance. Therefore, the following hypotheses are developed.

Hypothesis 1. The CSRD has a positive impact on the financial performance of the Islamic banking industry in Pakistan.

Hypothesis 2. The ethical dimension of CSRD has a positive impact on the financial performance of Islamic banks.

Hypothesis 3. The legal dimension of CSRD has a positive impact on the financial performance of Islamic banks in Pakistan.

Hypothesis 4. The economic dimension of CSRD has a positive impact on the financial performance of Islamic banks in Pakistan.

Hypothesis 5. The environmental dimension of CSRD has a positive impact on the financial performance of Islamic banks in Pakistan.

Hypothesis 6. The philanthropic dimension of CSRD has a positive impact on the financial performance of Islamic banks in Pakistan.

\subsection{Conceptual Framework}

The conceptual framework of the study is based on Carroll's CSR model and the two approaches, namely normative and instrumental, of the stakeholder theory. The Carroll CSR model supports the ethical, legal, economic, environmental, philanthropic, and financial performance [29]. The approaches of stakeholder theory further underpin the relationships among these variables; the Islamic banks try to satiate the demand of multiple stakeholders in the normative approach and avail instrumental benefits in the shape of better financial performance $[13,26]$. These relationships are depicted in Figure 1.

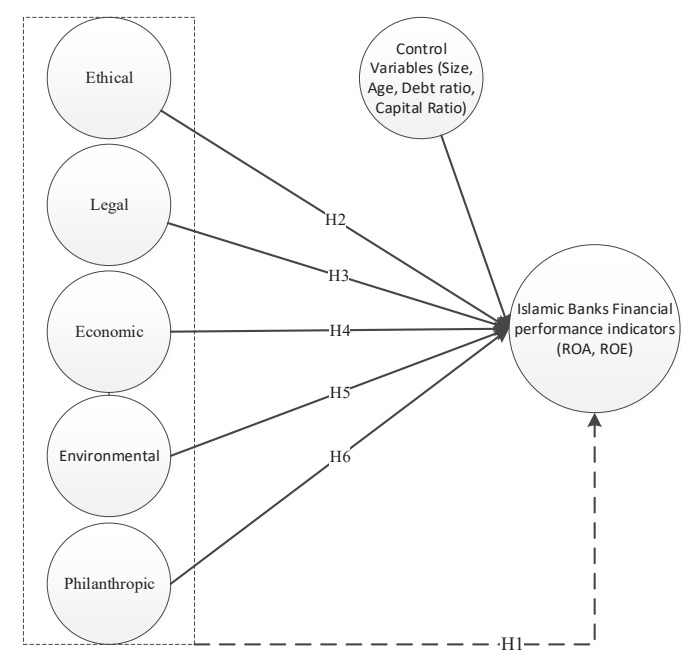

Figure 1. Conceptual framework. 


\section{Materials and Methods}

\subsection{Sample for the Research}

In Pakistan, the total population of Islamic Banks registered with the State Bank of Pakistan (SBP) was five banks, namely the MCB Islamic Bank Limited, Bank Al Meezan Limited, Bank Al Baraka Limited, Bank Islami Limited, and Dubai Islamic Bank Limited [30]. However, the study excluded MCB Bank Limited, as it operates in both the Islamic and conventional or commercial banking, and had no separate annual report on Islamic banking and CSRD. The study selects the data collection period from 2012 to 2017, as many reforms regarding the environment, society, and governance (ESG), along with the concept of green banking, its regulations in Pakistan, and the codes of corporate governance of 2012 and 2017, were introduced during this period.

\subsection{Measurement of Financial Performance}

Most of the previous studies that investigated the association between CSRD and financial performance mainly relied on the accounting aspect of firms' performance [31]. These studies used return on assets (ROA), which is a key indicator of the firms' financial performance showing managerial efficiency, ability, and competency to generate profits by using the assets of the banks. Some studies also used the accounting measure of Return on equity (ROE) for measuring firm performance as an additional indicator or robustness check. It is also necessary to mention that ROE is strongly linked with the ROA, and, therefore, it is important to use this ratio as an extra measure of a bank's performance. Hence, this study uses ROA to measure the financial performance of the Islamic banks and employs ROE for further validation of the results.

\subsection{Measurement of CSR Disclosure}

For data collection, the study relied on the annual reports of Islamic banks of Pakistan. The procedure of content analysis was adopted for data collection from the annual reports of the sample banks. The content analysis procedure is considered less expensive and unmistakable as compared to some other methods. Hence, it is frequently used in previous studies related to CSRD [32,33]. Following prior studies, an unweighted scoring method was applied to record the data for the CSRD index by using a dichotomous procedure, where disclosure is assigned a value of 1 if an item is disclosed in the report of a bank, and 0 otherwise [26,34]. The study used five dimensions of CSRD, namely Ethical, Legal, Environmental, Economic, and Philanthropic, which constitute composite CSRD. The sub-dimensions of each dimension are marked as 1 in the case that the sub-dimension is reported in the annual report, and 0 otherwise, by using the content analysis technique for the respective bank. Finally, adding these scores contributes to the total disclosure of CSRD for each sample bank. For each dimension of CSRD, this procedure is summarized by the equation as $\frac{\sum \mathrm{d} i}{N}$, where $\mathrm{d}=1$ if the CSRD exists and 0 if not, while $N$ is the total number of maximum possible disclosures for the given dimension. Similarly, the whole equation for the composite CSRD is given as:

$$
\text { CSRD }=\frac{\sum_{i=1}^{\mathrm{n}} X_{i k t}}{N}
$$

where the CSRD index ${ }_{k t}$ represents the disclosure index for dimension $k$ and time $t$, while $X$ is a variable starting from 1 to $\mathrm{n}(1 \ldots \mathrm{n})$ for the given dimension $k$ and the time $t$. 
ROA represents a return on assets, which is measured by dividing the net income by the total assets, while the CSRD is the total CSR disclosure score, which can be calculated as dividing the total disclosures of the sub-dimensions by the maximum number of sub-dimensions possibly reported by a bank. The CSR dimensions consist of the Ethical, Legal, Environmental, Economic, and Philanthropic dimensions, which compose the CSR aggregate, i.e., CSRD. The capital ratio, represented by Cap Ratio, is calculated as the equity capital divided by total assets for the respective year. Size represents the size of the bank, which will be calculated as the log of total assets. The debt ratio will be calculated as the ratio of long-term debt to the total assets. Similarly, the firm's age can be calculated by taking the years since the bank was registered or started its operations. Here, $\varepsilon$ represents the error factor, and $\alpha$ is the intercept in the regression model. Return on equity (ROE), used as a robustness check, is measured as the net income divided by shareholders' equity.

\subsection{Estimation}

The random-effect (RE) and fixed-effect (FE) models of Generalized Least Squares (GLS) were applied to the panel data to investigate the impact of CSRD on the financial performance of Islamic banks. In addition, the study used the Ordinary Least Squares (OLS) regression and Panel-Corrected Standard Errors (PCSEs) estimators for the robustness of the GLS estimations. However, the study claims the results of GLS, as these are more robust than other estimators for panel data analyses. The GLS random-effect model assumes the variation across the entities to be random and uncorrelated with the predictor or independent variables included in the model. In contrast, the fixed-effect model of GLS controls is for all of the time-invariant differences between the cross-sections; hence, the estimated coefficients of the fixed-effect models cannot be biased because of omitted time-invariant characteristics. The author explains the difference as "... the crucial distinction between fixed and random effects is whether the unobserved individual effect embodies elements that are correlated with the regressors in the model, whether these effects are stochastic or not" [35]. In GLS, the Hausman test was employed to decide between the random-effect and fixed-effect models. If the result of the Hausman test is significant (Chi 2, Prob. > Chi 2), then the fixed-effect model is appropriate; if not, then the random-effect model is selected. Most of the previous studies related to CSR and financial performance employed the same methodology [36,37]. The results of the Hausman test in this study are reported below. The research models are shown as follows.

Model I

$$
\begin{gathered}
\text { ROA }=\alpha+\beta 1 \text { CSRD }+\beta 2 \text { SIZE }+\beta 3 \text { Cap Ratio }+\beta 4 \text { Age }+\beta 5 \text { Debt Ratio }+\varepsilon \\
\text { Model II } \\
\text { ROA }=\alpha+\beta 1 \text { Dimensions }+\beta 2 \text { SIZE }+\beta 3 \text { Cap.ratio }+\beta 4 \text { Age }+\beta 5 \text { Debt Ratio }+\varepsilon
\end{gathered}
$$

\section{Results and Discussion}

The descriptive statistics with the Skewness and Kurtosis show that some variables were not normally distributed, which might be due to outliers. Thus, the data were normalized by using the Van der Waerden data distribution method. The Kurtosis statistics are in a range of \pm 3 and the Skewness in a range of \pm 1.96 [21], as reported in Table 1. In addition, the mean and the standard deviation, the minimum statistics, and the maximum statistics with the mean statistics are also reported in Table 1 . To check the heteroscedasticity, the Breusch-Pagan/Cook-Weisberg test and White's test were conducted on both the composite CSRD model and the dimension model. In both the models, there was no issue of heteroscedasticity, as the probability of both the tests (Breusch-Pagan/Cook-Weisberg and White's tests) was less than 0.5 . Therefore, the data are fit for regression.

The descriptive statistics for all of the variables of the study from the given sample of 24 observations over 6 years from all four full-fledged Islamic banks across the country are reported in Table 1 . The 
findings show that the lowest value is -0.140 and the highest value is 0.950 , with a standard deviation of 0.273 for ROA. The mean for ROA is 0.202 , which indicates that return on assets at the given period, i.e., 2012-2017, remained stable. However, as far as the CSRD index is concerned, the minimum statistic is 35 , while the maximum value is 78 , along with the mean value of 57.38 . These statistics indicate that the banks have increased their disclosures during the given period, which shows their confidence and belief in CSR practices and CSRD. This also provides a clear indication of the Islamic banks' commitment towards increasing their interaction with the customers and the investors, as well as the society at large, to reduce the communication gap and improve the overall image of the Islamic banking industry. The positive increase in the CSRD can be interpreted as: The banks consider socially responsible activities very crucial for shaping the public opinion in favor of the banks. The average size of the bank has a lowest value of 0.103 and a highest value of 11.81 , with a mean value of 8.46. This shows an overall expansion in the size of the banks and their assets over the given period. Similarly, the capital ratio has a lowest value of 0.035 and a highest statistic of 0.172 , with a mean value of 0.116 and a standard deviation of 0.033 . The lowest statistics for debt ratio are 2.780 , while the highest statistics are 20.580, with mean statistics of 11.59, which shows an increase in the level of debt. This indicates that banks increasingly dependent on debt to finance their operations. The firm's age has a minimum statistic of 2 and a maximum statistic is 14, with a mean value of 8.25 , showing that most of the sample banks have an average age of less than 10 years. The minimum statistic for the individual dimension of CSRD, i.e., the environmental dimension, is 2 , and the maximum is 10 , while the mean score is 5.21 . The minimum number for the legal dimension is 3 and the maximum is 9 , with a mean value of 6.71. The minimum statistic for the ethical dimension of CSRD is 2, while the maximum is 13 and the mean score is 7.88. The minimum value for the economic dimension of CSRD is 5 , while the maximum is 10 . The mean value is 7.04 with a standard deviation of 1.68 , which is pretty handsome, showing a strong and growing commitment of the banks towards the disclosure of this dimension. The minimum value for the philanthropic/social dimension of CSRD is 18 and the maximum value is 37 , with a mean score of 26.46 .

Table 1. Descriptive statistics.

\begin{tabular}{|c|c|c|c|c|c|c|c|c|}
\hline & \multirow{2}{*}{$\begin{array}{c}\text { Minimum } \\
\text { Statistic }\end{array}$} & \multirow{2}{*}{$\begin{array}{l}\text { Maximum } \\
\text { Statistic }\end{array}$} & \multirow{2}{*}{$\begin{array}{c}\text { Mean } \\
\text { Statistic }\end{array}$} & \multirow{2}{*}{$\begin{array}{c}\text { Std. Deviation } \\
\text { Statistic }\end{array}$} & \multicolumn{2}{|c|}{ Skewness } & \multicolumn{2}{|c|}{ Kurtosis } \\
\hline & & & & & Statistic & Std. Error & Statistic & Std. Error \\
\hline ROA & -0.14 & 0.95 & 0.20 & 0.27 & 1.21 & 0.47 & 0.93 & 0.91 \\
\hline Firm Size & 0.10 & 11.81 & 8.46 & 4.93 & -1.22 & 0.47 & -0.54 & 0.91 \\
\hline Capital ratio & 0.03 & 0.17 & 0.11 & 0.03 & -0.83 & 0.47 & 0.66 & 0.91 \\
\hline Debt ratio & 2.78 & 20.5 & 11.59 & 5.61 & -0.32 & 0.47 & -1.08 & 0.91 \\
\hline Environmental & 2 & 10 & 5.21 & 2.58 & 0.25 & 0.47 & -1.04 & 0.91 \\
\hline Legal & 3 & 9 & 6.71 & 1.45 & -0.26 & 0.47 & 0.37 & 0.91 \\
\hline Ethical & 2 & 13 & 7.88 & 3.71 & -0.37 & 0.47 & -1.33 & 0.91 \\
\hline Economic & 5 & 10 & 7.04 & 1.68 & 0.40 & 0.47 & -0.81 & 0.91 \\
\hline Philanthropic/social & 18 & 37 & 26.46 & 6.15 & 0.24 & 0.47 & -1.14 & 0.91 \\
\hline
\end{tabular}

From Table 2, as shown, the Pearson correlation matrix does not detect any multicollinearity, i.e., above 0.8 between two predictors. So, the predictors that are to be tested for regression are not highly correlated and are, therefore, fit for further analysis.

Figure 2 shows a relation between the average percentages for CSRD over the period 2012-2017. The figure indicates that the average CSRD in 2012, 2013, and 2014 is $49 \%$, while from 2015, there is an abrupt change in percentage, reaching a score of 53\%. It falls back to 51\% and $50.8 \%$ in 2016 and 2017, respectively. During the corresponding period, the average percentage score for the industry remained at $51 \%$. 
Table 2. Correlation matrix.

\begin{tabular}{|c|c|c|c|c|c|c|c|c|c|c|c|c|}
\hline & (1) & (2) & (3) & (4) & (5) & (6) & (7) & (8) & (9) & (10) & (11) & (12) \\
\hline ROA (1) & 1 & & & & & & & & & & & \\
\hline Size (2) & -0.03 & 1 & & & & & & & & & & \\
\hline Age (3) & -0.01 & $0.90 *$ & 1 & & & & & & & & & \\
\hline Capital Ratio (4) & -0.08 & 0.04 & -0.09 & 1 & & & & & & & & \\
\hline Debt Ratio (5) & -0.06 & $0.72 * *$ & $0.88^{* *}$ & 0.11 & 1 & & & & & & & \\
\hline Environment (6) & 0.02 & $0.80 *$ & $0.79 * *$ & -0.09 & 0.87 * & 1 & & & & & & \\
\hline Legal (7) & $-0.647 * *$ & 0.16 & 0.10 & 0.23 & 0.20 & 0.11 & 1 & & & & & \\
\hline Ethical (8) & $-0.70 *$ & 0.33 & 0.27 & 0.33 & 0.33 & 0.28 & $0.81 * *$ & 1 & & & & \\
\hline Economic (9) & 0.55 ** & 0.29 & 0.17 & 0.31 & 0.31 & 0.19 & $0.78 * *$ & $0.73 * *$ & 1 & & & \\
\hline Philanthropic (10) & $0.73 * *$ & 0.36 & 0.27 & 0.27 & 0.36 & 0.29 & $0.77^{* *}$ & $0.88^{* *}$ & $0.78^{* *}$ & 1 & & \\
\hline CSRD (11) & $0.56 * *$ & 0.33 & 0.31 & 0.10 & 0.26 & 0.33 & $0.80 * *$ & $0.81 * *$ & $0.63 * *$ & $0.68^{* *}$ & 1 & \\
\hline Lag ROA (12) & 0.41 & $0.89 * *$ & 0.10 & 0.04 & -0.11 & 0.09 & 0.06 & $0.63 * *$ & $0.69 * *$ & 0.61 ** & $0.78 * *$ & 1 \\
\hline
\end{tabular}

CSRD \% age score

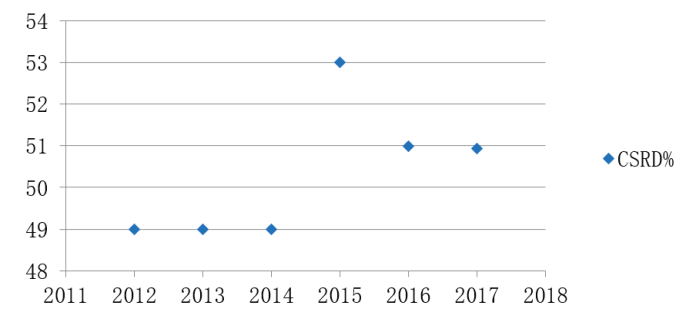

Figure 2. Trend of percentage corporate social responsibility disclosure (CSRD) score for the Islamic banking industry.

The results of the Hausman test for all of the models are reported at the ends of Tables 3 and 4 . In all of the models, the results indicated that the random-effect model was an appropriate choice, as it is believed that the omitted variables only vary over time or between cases. Likewise, when such a situation exists, the random-effect model can give relatively more robust results [38]. Furthermore, endorsing our results, it is also acknowledged that Islamic banks in Pakistan are limited in number; hence, they keep a close eye on each other, especially regarding CSR activities and market strategies for the satisfaction of multiple stakeholders. Table 3 explains $54.2 \%$ of the variation in ROA and $52.1 \%$ variation in ROE due to change in the predictors. The model is significant at $p<0.01$. The results indicate that CSRD has a significant negative relationship with financial performance (ROA) at $p<0.01$. These results, which endorse prior studies, noted a significant negative relationship between CSR and financial performance [31,39]; this may have a plausible explanation in that increases in CSR activities and their financial cost have negatively affected the financial performance of the banks by decreasing their profitability. However, these findings are contradictory to the first hypothesis, $\mathrm{H}_{1}$, of the study; thus, it is rejected. The significantly negative coefficient (instead of positive) for CSRD with financial performance is also contrary to the suppositions of the stakeholders. Nevertheless, the findings are consistent with the postulations of the tradeoff hypothesis presented by Friedman, that the firms' prime responsibility is to maximize the profits of the stakeholders [39]. Hence, managers and firms involved in social activities could cause extra costs to the firms that ultimately decrease their profits. In short, the theory suggests that the greater the level of CSRD, the smaller would be the financial performance of the firm $[37,40]$. 
Table 3. CSRD and financial performance.

\begin{tabular}{|c|c|c|c|c|c|c|}
\hline & (1) & (2) & (3) & (4) & (5) & (6) \\
\hline & $\begin{array}{l}\text { ROA } \\
\text { OLS }\end{array}$ & $\begin{array}{c}\text { ROA } \\
\text { GLS } \\
\text { Random }\end{array}$ & $\begin{array}{l}\text { ROA } \\
\text { GLS } \\
\text { Fixed }\end{array}$ & $\begin{array}{l}\text { ROE } \\
\text { OLS }\end{array}$ & $\begin{array}{c}\text { ROE } \\
\text { GLS } \\
\text { Random }\end{array}$ & $\begin{array}{l}\text { ROE } \\
\text { GLS } \\
\text { Fixed }\end{array}$ \\
\hline CSRD & $\begin{array}{c}-0.587^{* *} \\
(0.201)\end{array}$ & $\begin{array}{c}-0.587^{* * *} \\
(0.201)\end{array}$ & $\begin{array}{l}-0.053 \\
(0.286)\end{array}$ & $\begin{array}{c}0.022 \\
(0.146)\end{array}$ & $\begin{array}{c}0.022 \\
(0.146)\end{array}$ & $\begin{array}{c}0.009 \\
(0.109)\end{array}$ \\
\hline Firm size & $\begin{array}{l}-1.331 \\
(1.344)\end{array}$ & $\begin{array}{l}-1.331 \\
(1.344)\end{array}$ & $\begin{array}{c}0.396 \\
(1.341)\end{array}$ & $\begin{array}{c}0.667 \\
(0.740)\end{array}$ & $\begin{array}{c}0.667 \\
(0.740)\end{array}$ & $\begin{array}{l}1.094^{*} \\
(0.524)\end{array}$ \\
\hline Capital ratio & $\begin{array}{c}0.028 \\
(0.254)\end{array}$ & $\begin{array}{c}0.028 \\
(0.254)\end{array}$ & $\begin{array}{c}0.725 \\
(0.481)\end{array}$ & $\begin{array}{l}-0.050 \\
(0.136)\end{array}$ & $\begin{array}{l}-0.050 \\
(0.136)\end{array}$ & $\begin{array}{c}0.410^{* *} \\
(0.179)\end{array}$ \\
\hline Debt ratio & $\begin{array}{l}-0.502 \\
(0.492)\end{array}$ & $\begin{array}{l}-0.502 \\
(0.492)\end{array}$ & $\begin{array}{l}-0.331 \\
(0.514)\end{array}$ & $\begin{array}{l}-0.365 \\
(0.265)\end{array}$ & $\begin{array}{l}-0.365 \\
(0.265)\end{array}$ & $\begin{array}{l}-0.322 \\
(0.193)\end{array}$ \\
\hline Age & $\begin{array}{c}2.303 \\
(1.332)\end{array}$ & $\begin{array}{l}2.303 * \\
(1.332)\end{array}$ & $\begin{array}{c}0.876 \\
(3.792)\end{array}$ & $\begin{array}{l}-0.279 \\
(0.730)\end{array}$ & $\begin{array}{l}-0.279 \\
(0.730)\end{array}$ & $\begin{array}{l}-1.630 \\
(1.438)\end{array}$ \\
\hline Lag ROA & $\begin{array}{c}0.130 \\
(0.250)\end{array}$ & $\begin{array}{c}0.130 \\
(0.250)\end{array}$ & $\begin{array}{l}-0.067 \\
(0.261)\end{array}$ & - & - & - \\
\hline Years & $\begin{array}{c}-0.356 \text { * } \\
(0.184)\end{array}$ & $\begin{array}{c}-0.356^{*} \\
(0.184)\end{array}$ & $\begin{array}{l}-0.215 \\
(1.090)\end{array}$ & $\begin{array}{c}0.015 \\
(0.099)\end{array}$ & $\begin{array}{c}0.015 \\
(0.099)\end{array}$ & $\begin{array}{c}0.344 \\
(0.400)\end{array}$ \\
\hline Lag ROE & - & - & - & $\begin{array}{c}0.787^{* * *} \\
(0.144)\end{array}$ & $\begin{array}{c}0.787^{* * *} \\
(0.144)\end{array}$ & $\begin{array}{c}0.164 \\
(0.199)\end{array}$ \\
\hline _cons & $\begin{array}{l}716.232 * \\
(370.697) \\
\end{array}$ & $\begin{array}{l}716.232 * \\
(370.697) \\
\end{array}$ & $\begin{array}{c}433.129 \\
(2195.810) \\
\end{array}$ & $\begin{array}{c}-31.300 \\
(199.219) \\
\end{array}$ & $\begin{array}{c}-31.300 \\
(199.219) \\
\end{array}$ & $\begin{array}{l}-693.116 \\
(806.422) \\
\end{array}$ \\
\hline Obs. & 24 & 24 & 24 & 24 & 24 & 24 \\
\hline $\mathrm{R}$-squared & 0.542 & 0.542 & 0.344 & 0.837 & 0.837 & 0.521 \\
\hline Hausman Test (Chi2) & - & 8.3 & - & - & - & $34.82 * * *$ \\
\hline Prob. > Chi 2 & - & 0.307 & - & - & - & 0.000 \\
\hline
\end{tabular}

Note: Standard errors are in parentheses. ${ }^{* * *} p<0.01,{ }^{* *} p<0.05,{ }^{*} p<0.1$.

Figure 2 indicates that the Islamic banking industry has increased CSRD, but, still, the stakeholders' perception in this regard is not positive, which, on one hand, shows a strong commitment of the industry towards CSRD, but, on the other hand, a poor public or customer response. This might be due to the rationale that "Pakistanis are the most generous people. Pakistan's contribution to charity is almost $1 \%$ of its GDP, which distinguishes it in the list of top-ranked countries with respect to charitable activities, like the United Kingdom contributing 1.3\% of GDP and Canada contributing $1.2 \%$ of its GDP to charity; Pakistan gives about twice what India gives to charity" [41]. Despite all of these facts, the significantly negative coefficient of CSRD may also signal that the message of the Islamic banking industry has not been properly communicated to the stakeholders. As a plausible explanation for this, the annual reports published by Islamic banks are not well organized. Except for Bank Al Meezan Limited, the rest of these reports could not properly showcase the CSR-related information, which might affect the behavior of the potential customers. The average industrial age reveals that the Islamic banking industry is in the emerging stage; therefore, it would take time to acquire a stage of maturity. The country has also passed through an intense wave of terrorism and extremism starting from 2002 onward, which has affected business activities, the overall economy in general, and the banking industry in particular. However, the average CSRD shows a slight increase in the average CSRD for the last couple of years, while an average decrease has been reported in the financial performance (ROA). The findings for ROA are also consistent with those of ROE, which is used as an additional measure to gauge performance and validate the results.

The regression results reported in Table 4 explain $83 \%$ of the variation in ROA and $92.8 \%$ variation in ROE due to change in the predictors. These results show that all of the dimensions of CSRD are statistically insignificant with the firm's current financial performance (ROA), except the environmental and economic dimensions. These results also indicate that the ethical dimension of CSRD is insignificant with the firm's financial performance, which rejects hypothesis $\mathrm{H}_{2}$ of the study. It is to be noted that the ethical dimension of CSRD is statistically significant with the ROE at significance level $p<0.05$. The ROE, which is used as a robustness check throughout the analysis, is mostly associated with the owners of the banks. Therefore, the owners of the banks are comparatively more attracted to the 
ethical issues, as these are worthy of the goodwill of the banks without incurring any direct cost to them. Similarly, the legal dimension of CSRD is also statistically insignificant with the firm's financial performance, so hypothesis $\mathrm{H}_{3}$ is also rejected. These results endorse a previous study showing that most of the developing countries have a lower priority for the legal dimensions [42]. This does not necessarily mean that firms in the developing countries flaunt the laws, but they are under minor pressure to operate responsibly. In these countries, there are certain issues in the legal systems that do not pressure the firms to operate in full compliance with the relevant laws. These countries are also far behind the developed countries in practicing issues like human rights and others such as the CSR in their legislation [34].

Table 4. Dimensions of CSRD and financial performance.

\begin{tabular}{|c|c|c|c|c|c|c|}
\hline & (1) & (2) & (3) & (4) & (5) & (6) \\
\hline & ROA (OLS) & $\begin{array}{c}\text { ROA (GLS } \\
\text { Random) }\end{array}$ & $\begin{array}{c}\text { ROA } \\
\text { (GLS } \\
\text { Fixed) }\end{array}$ & $\begin{array}{l}\text { ROE } \\
\text { (OLS) }\end{array}$ & $\begin{array}{c}\text { ROE } \\
\text { (GLS } \\
\text { Random) }\end{array}$ & $\begin{array}{c}\text { ROE } \\
\text { (GLS } \\
\text { Fixed) }\end{array}$ \\
\hline Environmental & $\begin{array}{c}0.821 \text { ** } \\
(0.324)\end{array}$ & $\begin{array}{c}0.821 \text { ** } \\
(0.324)\end{array}$ & $\begin{array}{c}0.723 \\
(0.411)\end{array}$ & $\begin{array}{c}0.283 \\
(0.204)\end{array}$ & $\begin{array}{c}0.283 \\
(0.204)\end{array}$ & $\begin{array}{c}0.142 \\
(0.200)\end{array}$ \\
\hline Legal & $\begin{array}{l}-0.011 \\
(0.304)\end{array}$ & $\begin{array}{l}-0.011 \\
(0.304)\end{array}$ & $\begin{array}{c}0.364 \\
(0.394)\end{array}$ & $\begin{array}{l}-0.102 \\
(0.176)\end{array}$ & $\begin{array}{l}-0.102 \\
(0.176)\end{array}$ & $\begin{array}{c}0.364 \\
(0.205)\end{array}$ \\
\hline Ethical & $\begin{array}{l}-0.436 \\
(0.370)\end{array}$ & $\begin{array}{l}-0.436 \\
(0.370)\end{array}$ & $\begin{array}{c}-1.052 * \\
(0.548)\end{array}$ & $\begin{array}{c}0.472^{*} \\
(0.232)\end{array}$ & $\begin{array}{c}0.472 * * \\
(0.232)\end{array}$ & $\begin{array}{l}-0.347 \\
(0.320)\end{array}$ \\
\hline Economic & $\begin{array}{l}0.645 * \\
(0.339)\end{array}$ & $\begin{array}{l}0.645 * \\
(0.339)\end{array}$ & $\begin{array}{c}0.384 \\
(0.376)\end{array}$ & $\begin{array}{c}0.583 * * \\
(0.203)\end{array}$ & $\begin{array}{c}0.583 * * * \\
(0.203)\end{array}$ & $\begin{array}{c}0.062 \\
(0.222)\end{array}$ \\
\hline Philanthropic & $\begin{array}{l}-0.598 \\
(0.399)\end{array}$ & $\begin{array}{l}-0.598 \\
(0.399)\end{array}$ & $\begin{array}{l}-0.675 \\
(0.583)\end{array}$ & $\begin{array}{c}0.009 \\
(0.230)\end{array}$ & $\begin{array}{c}0.009 \\
(0.230)\end{array}$ & $\begin{array}{c}0.056 \\
(0.289)\end{array}$ \\
\hline Firm size & $\begin{array}{c}-0.799 \\
(1.067)\end{array}$ & $\begin{array}{r}-0.799 \\
(1.067)\end{array}$ & $\begin{array}{l}-0.287 \\
(1.181)\end{array}$ & $\begin{array}{c}0.556 \\
(0.631)\end{array}$ & $\begin{array}{c}0.556 \\
(0.631)\end{array}$ & $\begin{array}{l}1.244 \text { * } \\
(0.575)\end{array}$ \\
\hline Capital ratio & $\begin{array}{c}0.086 \\
(0.195)\end{array}$ & $\begin{array}{c}0.086 \\
(0.195)\end{array}$ & $\begin{array}{c}0.926 \\
(0.686)\end{array}$ & $\begin{array}{l}-0.238 \\
(0.157)\end{array}$ & $\begin{array}{l}-0.238 \\
(0.157)\end{array}$ & $\begin{array}{l}0.698 \text { * } \\
(0.356)\end{array}$ \\
\hline Debt ratio & $\begin{array}{c}0.005 \\
(0.371)\end{array}$ & $\begin{array}{c}0.005 \\
(0.371)\end{array}$ & $\begin{array}{c}0.325 \\
(0.487)\end{array}$ & $\begin{array}{l}-0.326 \\
(0.218)\end{array}$ & $\begin{array}{l}-0.326 \\
(0.218)\end{array}$ & $\begin{array}{l}-0.285 \\
(0.237)\end{array}$ \\
\hline Firm age & $\begin{array}{c}1.821 \\
0.821 \text { ** }\end{array}$ & $\begin{array}{c}1.821 * \\
0.821 \text { ** }\end{array}$ & $\begin{array}{l}3.936 \\
0.723\end{array}$ & $\begin{array}{l}0.119 \\
0.283\end{array}$ & $\begin{array}{l}0.119 \\
0.283\end{array}$ & $\begin{array}{c}-1.432 \\
0.142\end{array}$ \\
\hline Lag ROA & $\begin{array}{c}0.087 \\
(0.216)\end{array}$ & $\begin{array}{c}0.087 \\
(0.216)\end{array}$ & $\begin{array}{c}0.042 \\
(0.217)\end{array}$ & - & - & - \\
\hline Years & $\begin{array}{c}-0.509 \text { ** } \\
(0.186)\end{array}$ & $\begin{array}{c}-0.509 * * * \\
(0.186)\end{array}$ & $\begin{array}{l}-0.973 \\
(1.169)\end{array}$ & $\begin{array}{c}-0.269 * \\
(0.139)\end{array}$ & $\begin{array}{c}-0.269 * \\
(0.139)\end{array}$ & $\begin{array}{c}0.328 \\
(0.571)\end{array}$ \\
\hline Lag ROE & - & - & - & $\begin{array}{c}0.722^{* * *} \\
(0.203)\end{array}$ & $\begin{array}{c}0.722 * * * \\
(0.203)\end{array}$ & $\begin{array}{c}0.018 \\
(0.278)\end{array}$ \\
\hline _cons & $\begin{array}{c}1026.163 * * \\
(374.915)\end{array}$ & $\begin{array}{c}1026.163 * * * \\
(374.915)\end{array}$ & $\begin{array}{c}1959.252 \\
(2355.501)\end{array}$ & $\begin{array}{l}542.467 * \\
(279.282)\end{array}$ & $\begin{array}{l}542.467 * \\
(279.282)\end{array}$ & $\begin{array}{c}-660.113 \\
(1151.203)\end{array}$ \\
\hline Obs. & 24 & 24 & 24 & 24 & 24 & 23 \\
\hline R-squared (Overall) & 0.830 & 0.830 & 0.752 & 0.928 & 0.928 & 0.715 \\
\hline Hausman Test (Chi2) & - & 5.000 & - & - & 11.25 & - \\
\hline Prob. > Chi 2 & - & 0.931 & - & - & 0.423 & - \\
\hline
\end{tabular}

However, the environmental dimension of CSRD has a positive and significant relationship with the financial performance of the sample Islamic banks at a significance level of $p<0.05$. Therefore, the hypothesis $\mathrm{H}_{4}$ is accepted. This shows that the customers and other stakeholders pay greater attention to environmental issues. The previous studies indicate inconsistent results for the relationship between the environmental dimension and financial performance. Some of these studies found a negative or neutral association $[43,44]$. However, the results of the current study are in line with many previous studies showing a significant positive relationship between the environmental dimension of CSRD and the financial performance [31,45-48]. The economic dimension of CSRD has a positive and statistically significant relationship with the financial performance (ROA) at a significance level $p<0.10$, which confirms hypothesis $\mathrm{H}_{5}$ of the study. Similarly, the economic dimension of CSRD is also statistically significant and positive with the ROE at a significant level $p<0.01$. The findings which support $\mathrm{H}_{6}$ are compatible with a prior study showing a positive and significant relationship between the economic 
dimension of CSRD and financial performance [49]. The Islamic banking industry has flourished for the last couple of years, especially in Pakistan, with a high profit margin, based on Shariah; therefore, the customers are increasingly inclined towards Islamic banking due to the economic transparency and other benefits offered. The customers are attracted to the Islamic banking industry due to its operations based on the principles of profit and loss. As indicated by Figure 2, these banks are more inclined towards publicizing the economic information because, economically, they are considered to be more transparent, committed, and ethically responsible.

The philanthropic dimension of CSR also has an insignificant relationship with ROA, which rejects hypothesis $\mathrm{H}_{6}$ of the study. As we know, Islam has a social and legal code of conduct, which is its beauty. The philanthropic aspect of CSRD is what the customers expect from an Islamic bank. The negative and insignificant relationship of the philanthropic dimension with financial performance could be possibly explained in that Islam discourages disclosing the philanthropic efforts due to ethical considerations [50]. Islam discourages both individuals and groups from disclosing the philanthropic and social practices they carry, as this may hurt the ego, dignity, and self-esteem of those who receive Zakat, Sadqat, Qard-e-Hassana, donations, charity, etc. Islam also warns that the publicity of philanthropic activities may hurt the true sense of giving (or welfare), which affects its promised return in the eternal world. Hence, philanthropic practices are usually kept hidden and undisclosed in an Islamic society; if they are not, or are reported, the customers may perceive these negatively. In addition, the study also estimated all models through Panel-Corrected Standard Error (PCSE), which is considered an appropriate estimator for micro-panel datasets where $N$ is small and T is large [51-55]. The findings reported in Table 5 under the PCSEs are consistent with those of OLS and GLS, which further authenticates the accuracy and reliability of all of the estimations in the current study.

Table 5. Panel-Corrected Standard Errors.

\begin{tabular}{|c|c|c|c|c|}
\hline & (PCSEs) & (PCSEs) & (PCSEs) & (PCSEs) \\
\hline & ROA & ROE & ROA & ROE \\
\hline \multirow[t]{2}{*}{ CSRD } & $-0.587 * * *$ & 0.022 & - & - \\
\hline & $(0.198)$ & $(0.072)$ & - & - \\
\hline \multirow{2}{*}{ Firm size } & -1.331 & 0.667 & -0.799 & 0.556 \\
\hline & (1.017) & $(0.545)$ & $(0.869)$ & $(0.523)$ \\
\hline \multirow[t]{2}{*}{ Capital ratio } & 0.028 & -0.050 & 0.086 & $-0.238^{* *}$ \\
\hline & $(0.239)$ & $(0.104)$ & $(0.202)$ & $(0.119)$ \\
\hline \multirow[t]{2}{*}{ Debt ratio } & -0.502 & $-0.365^{* * *}$ & 0.005 & -0.326 ** \\
\hline & $(0.481)$ & $(0.132)$ & $(0.243)$ & $(0.159)$ \\
\hline \multirow[t]{2}{*}{ Firm age } & $2.303^{* *}$ & -0.279 & $1.821 * *$ & 0.119 \\
\hline & $(0.921)$ & $(0.494)$ & $(0.790)$ & $(0.492)$ \\
\hline \multirow[t]{2}{*}{ Lag of ROA } & 0.130 & - & 0.087 & - \\
\hline & $(0.241)$ & - & $(0.198)$ & - \\
\hline \multirow[t]{2}{*}{ Lag of ROE } & - & $0.787^{* * *}$ & - & $0.722 * * *$ \\
\hline & - & $(0.102)$ & - & $(0.165)$ \\
\hline \multirow[t]{2}{*}{ Environmental } & - & - & $0.821^{* * *}$ & 0.283 \\
\hline & - & - & $(0.262)$ & $(0.179)$ \\
\hline \multirow[t]{2}{*}{ Legal } & - & - & -0.011 & -0.102 \\
\hline & - & - & $(0.189)$ & $(0.131)$ \\
\hline \multirow[t]{2}{*}{ Ethical } & - & - & 0.436 & $0.472 * * *$ \\
\hline & - & - & $(0.339)$ & $(0.156)$ \\
\hline \multirow[t]{2}{*}{ Economic } & - & - & $0.645^{* *}$ & $0.583^{* * *}$ \\
\hline & - & - & $(0.306)$ & $(0.181)$ \\
\hline \multirow[t]{2}{*}{ Philanthropic } & - & - & -0.598 & 0.009 \\
\hline & - & - & $(0.382)$ & $(0.111)$ \\
\hline \multirow[t]{2}{*}{ Years } & $-0.356^{* * *}$ & 0.015 & $-0.509^{* * *}$ & $-0.269 * *$ \\
\hline & $(0.115)$ & $(0.062)$ & $(0.140)$ & $(0.106)$ \\
\hline \multirow[t]{2}{*}{ Constant } & $716.232^{* * *}$ & -31.300 & $1026.163^{* * *}$ & $542.467 * *$ \\
\hline & $(232.074)$ & $(124.751)$ & (281.519) & $(213.381)$ \\
\hline Obs. & 23 & 23 & 23 & 23 \\
\hline R-squared & 0.542 & 0.837 & 0.830 & 0.928 \\
\hline
\end{tabular}

Standard errors are in parentheses. ${ }^{* *} p<0.01,{ }^{* *} p<0.05,{ }^{*} p<0.1$. 


\section{Conclusions and Recommendations}

This study aimed to examine the relationship between CSRD and the financial performance of the Islamic banks in Pakistan. The findings indicate that the overall level of CSRD for the given sample is $51 \%$, which is slightly different from the CSRD reported by a previous study [20]. The prior study shows that Islamic banks in Pakistan disclose around 30.4\% of CSR in their annual reports. This indicates that CSRD increased from 2014 onward. The findings also reveal a significant negative relationship between the CSRD and financial performance of the Islamic banks in Pakistan. Concerning separate dimensions, the legal, philanthropic, and ethical dimensions also have no significant or positive associations with the financial performance of these banks. Though these findings are not in line with most of the established hypotheses $(\mathrm{H} 1, \mathrm{H} 2, \mathrm{H} 3$, and $\mathrm{H} 6)$ of the study and postulations of stakeholder theory, still, these results are compatible with Friedman, who argued that CSRD may cause extra costs to the firms that ultimately decrease their profits. In short, the theory suggests that the greater the level of CSR, the smaller the financial performance of the firm will be. Hence, the results are contrasted with the theoretical argument of stakeholder theory, which posits that CSRD improves firms' financial performance by increasing their goodwill. In addition, Islam supports and encourages carrying out CSR activities, but at the same time discourages their disclosure (CSRD), especially when it is related to the social and philanthropic activities for individuals and society. The discouragement has a rationale that reporting or publicizing these activities may hurt the ego, self-esteem, and respect of the individuals at the receiving end. Because of this, CSRD of the Islamic banks might have created a negative perception in the minds of customers, especially in the cultural context of Pakistan, that could not yield the desired results, i.e., improving firm performance.

Unlike the others, the economic dimension has a significant positive association with financial performance, which may be due to the customers' confidence in the merit and transparency of financial matters of the Islamic banks. The findings might also show the rationale that customers express trust in the profit and loss sharing mechanisms of Islamic banks, as they function per the Shariah principles of Islam. The average percentage score also suggests that priority has been given to the economic dimension in the average CSRD. Similarly, the environmental dimension also shows a significant positive relationship with financial performance, while the ethical dimension shows a significant positive association with the financial performance-the ROE shows a strong commitment of the banking industry towards disclosing information regarding these dimensions, causing a positive impact on the financial performance of the Islamic banking industry. These dimension-wise results support the stakeholder theory, but contradict the Friedman theory.

These results indicate that most of the Islamic banks, as expected, disclosed comparatively high levels of composite CSR practices, but lack a balanced disclosure of the individual dimensions of these practices. It is noted that priority is given to disclosing information related to financial obligations as compared to other dimensions. Except for Bank Al Meezan Limited, the annual reports published by Islamic banks were also found to be non-systematic, as the required information was scattered throughout these reports, making it difficult for the potential customers to access it, which may be one of the reasons for the unexpected results, especially $\mathrm{H} 1, \mathrm{H} 2, \mathrm{H} 3$, and $\mathrm{H} 6$. Being based on the principles of Shariah, Islamic banks are expected to be socially, ethically, and morally responsible, and to publish their CSR at the top to justify their moral and socially friendly nature. These institutions cannot be called true Islamic banks if they do not meet the criteria set by the principles of Shariah.

The standards of the AAOIFI, with which compliance is voluntary, aim to regulate the CSRD in Islamic banks. Likewise, the GRI reporting guidelines for CSRD in conventional banks or other business firms are also voluntary. By merging both the standards of AAOIFI and GRI, this study develops a novel index to standardize and unify the reporting of CSRD according to internationally acceptable standards in the framework of Shariah for Islamic banks. This index may be mandated for increasing CSRD, as the voluntary nature of compliance with both indexes might be a reason for low CSRD. Furthermore, the Islamic banking industry may focus on channels of communication like print and electronic media, along with using simple local languages, so that the messages can be effectively 
communicated to the target customers/stakeholders. The industry may also follow a comprehensive CSR policy that could counter the propaganda and increase its goodwill. The AAOIFI, a regulating authority, may also revisit its standards for CSR and CSRD in light of the new index (Appendix A, Table A1) to meet the upcoming challenges of the Islamic banking industry. In addition, to locate CSR-related information easily, the Islamic banks are also required to publish their annual reports in Urdu and other local languages to minimize the communication gap in countries like Pakistan, where the literacy rate is not high and the general public has a low understanding of the English language.

This study investigated the impact of both the composite CSRD and its dimensions on the financial performance of the Islamic banks in Pakistan from 2012 to 2017. By using the index of this study, studies in the future may work on the data of 2017 onward in Pakistan, as well as on large sample sizes in other countries with Islamic banks. In the future, moderation and mediation of integrated strategies and corporate governance could also be explored in the model of CSRD and financial performance of the Islamic banks. Likewise, for a clearer picture, the qualitative aspect, along with newsletters and websites of the respective banks, could also be considered by future studies. Last but not least, the new green banking regulations of 2017 may also be considered from the perspective of the Islamic banking industry of Pakistan in the future.

Author Contributions: All authors contributed equally. All authors have read and agreed to the published version of the manuscript.

Funding: This research received no external funding.

Conflicts of Interest: The authors declare no conflict of interest.

\section{Appendix A}

Table A1. Comprehensive Corporate Social Responsibility Disclosure Index.

\begin{tabular}{ll}
\hline Dimension of CSRD & \multicolumn{1}{c}{ Sub-Dimensions of CSRD } \\
\hline & - Introduction to greenhouse products \\
- - Controlling measures for the emission of greenhouse gases $\left(\mathrm{CO}_{2}, \mathrm{CO}\right)$ \\
- Energy conservation \\
- Measures for water consumption/availability \\
- Biodiversity \\
- Transportation \\
- Supplier environmental assessment \\
- Conferences on environment-related issues \\
- Amount of donations to environmental protection \\
- Investments in sustainable developmental projects \\
- Investment in environmentally friendly projects \\
- Focus on risk-based corrective actions \\
- Measures for the restoration and protection of natural resources \\
- Stakeholders' involvement in environmental issues \\
- Environmental grievances mechanism \\
- Climate change policy \\
- Any award for environmental achievement \\
- Follow the Shariah and accounting rules \\
- Whether the principles of Shariah are followed \\
- Whether the human rights labor laws are followed \\
- Whether the bank is dealing with legal products \\
- Whether the bank observes anti-money-laundering laws \\
- Provides secure transaction facility to customers \\
- Tax payment \\
- Any internal legal advisory committee \\
- Any legal Shariah committee \\
- Training on anti-corruption and other legal issues \\
\hline
\end{tabular}


Table A1. Cont.

\begin{tabular}{|c|c|}
\hline Dimension of CSRD & Sub-Dimensions of CSRD \\
\hline 3. Ethical & $\begin{array}{l}\text { - Any anti-money-laundering policy } \\
\text { - Whether the transactions are free of Riba } \\
\text { - Whether the fund's sources are disclosed for its customers } \\
\text { - Provides the correct information to its customers } \\
\text { - Prevents corruptions and irregularities in the banking system } \\
\text { - Any internal regulating body dealing with fraud and anti-corruption } \\
\text { - Any internal regulating body dealing with sexual harassment and workplace violence } \\
\text { - Policies regarding sexual harassment and workplace violence } \\
\text { - Non-discriminative policies regarding sex, age, and ethnicity } \\
\text { - Dealing with legal items only } \\
\text { - A proper code of ethics for the accountants } \\
\text { - A proper code of ethics for the internal auditors } \\
\text { - Disciplinary action committee } \\
\text { - Code of ethics for the employees } \\
\text { - Any grievances mechanism regarding ethical issues }\end{array}$ \\
\hline 4. Economic & $\begin{array}{l}\text { - Whether the revenues generated are disclosed } \\
\text { - Employees' wages and benefits are reported } \\
\text { - Whether the paid taxes are reported } \\
\text { - Whether profit and loss statements are reported } \\
\text { - Payments to the equity/capital owners reported } \\
\text { - Any community investment reported } \\
\text { - Economic value distributed in the form of operating cost reported } \\
\text { - Procurement policy } \\
\text { - Any economic Achievement Award } \\
\text { - Any economic award } \\
\text { - Economic grievances mechanism } \\
\text { - International economic appreciation award }\end{array}$ \\
\hline 5. Philanthropic/social & $\begin{array}{l}\qquad \text { Community and Social Development } \\
\text { - Donations for health issues } \\
\text { - Donations for sports activities } \\
\text { - Participating in relief and disaster management issues } \\
\text { - Donations for education } \\
\text { - Microfinance } \\
\text { - Funding other organizations for social activities } \\
\text { - Establishing a comprehensive link with the public industry/society } \\
\text { - Involvement in government-sponsored social activities } \\
\text { - Creating job opportunities } \\
\text { - Job opportunities for special persons } \\
\text { - Women branches } \\
\text { - Amount of zakat paid } \\
\text { - Those who receive the amount of zakat/zakat beneficiaries } \\
\text { - SSB attestation that the amount of zakat has been computed according to sharia } \\
\text { - SSB attestation that the sources and uses of zakat are according to } \\
\text { - Shariah } \\
\text { - Amount of Sadaqah paid } \\
\text { - Sadaqah beneficiaries } \\
\text { - Qard e Hassana paid } \\
\text { - Beneficiaries of Qard e Hassana } \\
\text { - Policy regarding debt } \\
\text { - Amount of debt written off } \\
\text { - Any public policy } \\
\text { - Credit committee } \\
\text { - Whether local communities are taken on board in social activities }\end{array}$ \\
\hline
\end{tabular}


Table A1. Cont.

\begin{tabular}{ll}
\hline Dimension of CSRD & \multicolumn{1}{c}{ Sub-Dimensions of CSRD } \\
\hline - Definition or glossary for a new product \\
- Introduction of SSB-approved new products \\
- Whether the new product is based on the concept of Shariah \\
- Any external or internal communication channel with stakeholders \\
- Regarding product \\
- Zero investment in non-permissible product or services \\
- Market survey and feasibility report \\
- Efforts for research and development promotion \\
- Products with customers' health and safety \\
- Riba-free products \\
- Ensuring the customers' privacy \\
- Whether customers are provided with access to the online banking services \\
- Efforts for a diversified staff \\
- Employees' health and safety \\
- Providing equal employment opportunities \\
- Provide training on Shariah awareness \\
- Provide training on professional skills and challenges \\
- Providing higher education opportunities to employees \\
- Employee appreciation \\
- Employees' safety and protection \\
- Equal remuneration for men and women \\
- Proper promotion mechanism/promotion policy \\
- Remuneration committee \\
- Standard labor practices policy \\
- Employee management interaction \\
- Secure internet facilities for the employees \\
- Grievances mechanism for employees \\
\end{tabular}

Data Source: Authors.

\section{References}

1. Smith, A.; Adam, S. Theory of Moral Sentiments. In Cambridge Texts in the History of Philosophy; Cambridge University Press: Cambridge, UK, 1759; pp. 1-244.

2. Gardiner, L.; Rubbens, C.; Bonfiglioli, E. Research: Big business, big responsibilities. Corp. Gov. 2003, 3, 67-77. [CrossRef]

3. Pearce II, J.A.; Doh, J.P. The high impact of collaborative social initiatives. MIT Sloan Manag. Rev. 2005, 46, 29-39.

4. Dusuki, A.W. What Does Islam Say about Corporate Social Responsibility? Rev. Islam. Econ. 2008, 12, 5-28.

5. Khan, M.M.; Usman, M. Corporate Social Responsibility in Islamic Banks in Pakistan. J. Islam. Bus. Manag. 2016, 6, 179-190.

6. Norafifah, A.; Sudin, H. Perceptions of Malaysian corporate customers towards Islamic banking products and services. Int. J. Islam. Financ. Serv. 2002, 3, 13-29.

7. Peloza, J.; Shang, J. Investing in CSR to Enhance Customer Value. In Director Notes No. 3; The Conference Board of Canada: Ottawa, ON, Canada, February 2011; Volume 3.

8. Quazi, A.; Amran, A.; Nejati, M. Conceptualizing and measuring consumer social responsibility: A neglected aspect of consumer research. Int. J. Consum. Stud. 2016, 40, 48-56. [CrossRef]

9. Jan, A.; Marimuthu, M.; Pisol, M. The nexus of sustainability practices and financial performance: From the perspective of Islamic banking. J. Clean. Prod. 2019, 1, 1-25. [CrossRef]

10. Lodhi, S.; Makki, M. Determinants of Corporate Philanthropy in Pakistan. Pakistan J. Commer. Soc. Sci. 2008, $1,17-24$.

11. Agus, M.; Indrarini, H.; Lee, L.R.; Martinov-Bennie, N.; Soh, D.S.B.; Al, A.; Ahmed, A.; Hossain, M.A.M.S.; Alkhatib, K.; Marji, Q.; et al. Enforcement Rules of the University Act. Int. J. Bus. Soc. Sci. 2012, 4, 1-21. 
12. Aliyu, S.; Hassan, M.K.; Mohd Yusof, R.; Naiimi, N. Islamic Banking Sustainability: A Review of Literature and Directions for Future Research. Emerg. Mark. Financ. Trade 2017, 53, 440-470. [CrossRef]

13. Donaldson, T.; Preston, L.E. The Stakeholder Theory of the Corporation: Concepts, Evidence, and Implications. Acad. Manag. Rev. 1995, 20, 65-91. [CrossRef]

14. Dowling, J.; Pfeffer, J. Organizational Legitimacy: Social Values and Organizational Behavior. Pac. Sociol. Rev. 1975, 18, 122-136. [CrossRef]

15. Suchman, M.C. Managing Legitimacy: Strategic and Institutional Approaches. Acad. Manag. Rev. 1995, 20, 571-610. [CrossRef]

16. Amran, A.; Fauzi, H.; Purwanto, Y.; Darus, F.; Yusoff, H.; Zain, M.M.; Malianna, D.; Naim, A.; Nejati, M. Social Responsibility Disclosure in Islamic Banks: A Comparative Study of Indonesia and Malaysia. J. Financ. Rep. Account. 2017, 15, 99-115. [CrossRef]

17. Haniffa, R.M.; Cooke, T.E. The impact of culture and governance on corporate social reporting. J. Account. Public Policy 2005, 24, 391-430. [CrossRef]

18. Said, R.; Zainuddin, Y.H.; Haron, H. The relationship between corporate social responsibility disclosure and corporate governance characteristics in Malaysian public listed companies. Soc. Responsib. J. 2009, 5, 212-226. [CrossRef]

19. Arshad, R.; Othman, S.; Othman, R. Islamic Corporate Social Responsibility, Corporate Reputation and Performance. Proc. World Acad. Sci. Eng. Technol. 2012, 6, 1070.

20. Farag, H.; Mallin, C.; Ow-Yong, K. Corporate social responsibility and financial performance in Islamic banks. J. Econ. Behav. Organ. 2014, 103, 1-18.

21. Haniffa, R.; Hudaib, M. Exploring the ethical identity of Islamic Banks via communication in annual reports. J. Bus. Ethics 2007, 76, 97-116. [CrossRef]

22. Abdul Rahman, A.; Md Hashim, M.F.A.; Abu Bakar, F. Corporate Social Reporting: A Preliminary Study of Bank Islam Malaysia Berhad ( BIMB ). Issues Soc. Environ. Account. 2010, 4, 18-39. [CrossRef]

23. Belal, A.R.; Abdelsalam, O.; Nizamee, S.S. Ethical Reporting in Islami Bank Bangladesh Limited (1983-2010). J. Bus. Ethics 2015, 129, 769-784. [CrossRef]

24. Ararat, M. A development perspective for "corporate social responsibility": Case of Turkey. Corp. Gov. 2008, 8, 271-285. [CrossRef]

25. Jamali, D.; Mirshak, R. Corporate Social Responsibility (CSR): Theory and Practice in a Developing Country Context. J. Bus. Ethics 2006, 72, 243-262. [CrossRef]

26. Gao, J.; Bansal, P. Instrumental and Integrative Logics in Business Sustainability. J. Bus. Ethics 2013, 112, 241-255. [CrossRef]

27. Bingham, T.; Walters, G. Financial Sustainability Within UK Charities: Community Sport Trusts and Corporate Social Responsibility Partnerships. Int. J. Volunt. Nonprofit Organ. 2012, 24, 606-629. [CrossRef]

28. Aigner, D.J.; Lloret, A. Sustainability and competitiveness in Mexico. Manag. Res. Rev. 2013, 36, 1252-1271. [CrossRef]

29. Carroll, A.B.; Shabana, K.M. The Business Case for Corporate Social Responsibility: A Review of Concepts, Research and Practice. Int. J. Manag. Rev. 2010, 12, 85-105. [CrossRef]

30. SBP. Islamic Banking Bulletin December 2017 Islamic Banking Department State Bank of Pakistan; 2017. Available online: http://www.sbp.org.pk/ibd/bulletin/2017/Dec.pdf (accessed on 8 April 2020).

31. Griffin, J.J.; Mahon, J.F. The Corporate Social Performance and Corporate Financial Performance Debate: Twenty-Five Years of Incomparable Research. Bus. Soc. 1997, 36, 5-31. [CrossRef]

32. Zahid, M.; Rehman, H.U.; Ali, W.; Khan, M.; Alharthi, M.; Qureshi, M.I.; Jan, A. Boardroom gender diversity: Implications for corporate sustainability disclosures in Malaysia. J. Clean. Prod. 2019, 244, 1-24. [CrossRef]

33. Delai, I.; Takahashi, S. Corporate sustainability in emerging markets: Insights from the practices reported by the Brazilian retailers. J. Clean. Prod. 2013, 47, 211-221. [CrossRef]

34. Zahid, M.; Rahman, H.U.; Muneer, S.; Butt, B.Z.; Isah-Chikaji, A.; Memon, M.A. Nexus between government initiatives, integrated strategies, internal factors and corporate sustainability practices in Malaysia. J. Clean. Prod. 2019, 241, 118329. [CrossRef]

35. Greene, W.H. Econometric Analysis, 8th ed.; Pearson Education: London, UK, 2017.

36. Musibah, A.S.; Alfattani, W.S.B.W.Y. The Mediating Effect of Financial Performance on the Relationship between Shariah Supervisory Board Effectiveness, Intellectual Capital and Corporate Social Responsibility, of Islamic Banks in Gulf Cooperation Council Countries. Asian Soc. Sci. 2014, 10, 139-164. [CrossRef] 
37. Saleh, M.; Zulkifli, N.; Muhamad, R. Looking for evidence of the relationship between corporate social responsibility and corporate financial performance in an emerging market. Asia-Pac. J. Bus. Adm. 2011, 3, 165-190. [CrossRef]

38. Rothenberg, S.; Hull, C.E.; Tang, Z. The Impact of Human Resource Management on Corporate Social Performance Strengths and Concerns. Bus. Soc. 2017, 56, 391-418. [CrossRef]

39. Friedman, M. The Social Responsibility of Business Is to Increase Its Profits. New York Times Magazine, 13 September 1970; 122-124.

40. Salzmann, A. Is there a moral economy of state formation? Religious minorities and repertoires of regime integration in the Middle East and Western Europe, 600-1614. Theory Soc. 2010, 39, 299-313. [CrossRef]

41. Amjad, S.M.; Ali, M. Stanford Social Innovation Review; 2018. Available online: https://ssir.org/articles/entry/ philanthropy_in_pakistan\# (accessed on 8 April 2020).

42. Kiarie, M. Corporate citizenship: The changing legal perspective in Kenya. In Proceedings of the Interdisciplinary CSR Research Conference, Nottingham, UK, 22-23 October 2004; International Centre for Corporate Social Responsibility (ICCSR): Nottingham, UK.

43. Chen, K.H.; Metcalf, R.W. The Relationship between Pollution Control Record and Financial Indicators Revisited. Account. Rev. 1980, 55, 168-177.

44. Jaggi, B.; Freedman, M. An examination of the impact of pollution performance on economic and market performance: Pulp and paper firms. J. Bus. Financ. Account. 1992, 19, 697-713. [CrossRef]

45. Mahoney, L.; Roberts, R.W. Corporate social performance, financial performance and institutional ownership in Canadian firms. Account. Forum 2007, 31, 233-253. [CrossRef]

46. Taman, S. The concept of corporate social responsibility in Islamic law. Indiana Int. Comp. Law Rev. 2011, 21, 481-508. [CrossRef]

47. Ullmann, A.A. Data in Search of a Theory: A Critical Examination of the Relationships Among Social Performance, Social Disclosure, and Economic Performance of U.S. Firms. Acad. Manag. Rev. 1985, 10, 540-557.

48. Pava, M.L.; Krausz, J. The association between corporate social-responsibility and financial performance: The paradox of social cost. J. Bus. Ethics 1996, 15, 321-357. [CrossRef]

49. Crane, A.; Matten, D. Questioning the domain of the business ethics curriculum. J. Bus. Ethics 2004, 54, 357-369. [CrossRef]

50. Platonova, E.; Asutay, M.; Dixon, R.; Mohammad, S. The Impact of Corporate Social Responsibility Disclosure on Financial Performance: Evidence from the GCC Islamic Banking Sector. J. Bus. Ethics 2018, 151, 451-471. [CrossRef]

51. Beck, N.; Katz, J.N. Time-series-cross-section data: What have we learned in the past few years? Annu. Rev. Polit. Sci. 2001, 4, 271-293. [CrossRef]

52. Beck, N.; Katz, J.N. What to do (and not to do) with time- series cross-section data. Am. Polit. Sci. Rev. 1995, 89, 634-647. [CrossRef]

53. Hoechle, D. Robust standard errors for panel regressions with cross-sectional dependence. Stata J. 2007, 7, 281. [CrossRef]

54. Rahman, H.U.; Ibrahim, M.Y.; Che-Ahmad, A. Physical characteristics of the chief executive officer and firm accounting and market based performance. Asian J. Account. Gov. 2017, 8, 27-37. [CrossRef]

55. Rahman, H.U.; Rehman, S.; Zahid, M. The impact of boardroom national diversity on firms' performance and boards' monitoring in emerging markets: A case of Malaysia. City Univ. Res. Journa 2018, 18, 1-15.

(C) 2020 by the authors. Licensee MDPI, Basel, Switzerland. This article is an open access article distributed under the terms and conditions of the Creative Commons Attribution (CC BY) license (http://creativecommons.org/licenses/by/4.0/). 
Article

\title{
Toward a Quadruple Bottom Line: Social Disclosure and Financial Performance in the Banking Sector
}

\author{
Francesco Manta ${ }^{1, *}$, Annunziata Tarulli ${ }^{1}$, Domenico Morrone ${ }^{1}$ and Pierluigi Toma ${ }^{2}$ \\ 1 Faculty of Economics and Management, LUM Jean Monnet University, 70010 Casamassima (Ba), Italy; \\ Tarulli.phdstudent@lum.it (A.T.); morrone@lum.it (D.M.) \\ 2 Department of Economics and Management, University of Salento, 73100 Lecce, Italy; \\ pierluigi.toma@unisalento.it \\ * Correspondence: manta.phdstudent@lum.it
}

Received: 6 March 2020; Accepted: 6 May 2020; Published: 14 May 2020

\begin{abstract}
The present study aims to analyze the existence of a possible significant relationship between social disclosure and financial performance in banking institutions. This phenomenon was analyzed by considering the percentage of female executives on boards, and the implementation of the equal opportunity policy when it was applied. We used a sample of 61 banks from European Union countries (between 2015-2017), and sampling was environmental, social, or governance (ESG)-driven in order to capture the effect of non-financial disclosure provided by Bloomberg. A cross-section econometric model was built in order to examine the relationship between the percentage of female directors on boards and the equal opportunity policy. Both the independent variables of banks and performance indicators were adopted as dependent variables. Our study provides empirical evidence that while there is a lack of efficiency and performance when boards are fragmented, the enactments of equal opportunity policies create a good reputation for the firm and the positive performance of staff. The study aims to contribute to the ongoing debate on social sustainability and on the phenomenon of the glass ceiling, and provides political and entrepreneurial implications.
\end{abstract}

Keywords: CSP-CFP relationship; banking sustainability; glass ceiling; board composition; equal opportunity policy

\section{Introduction}

Banking institutions play a crucial role in the accomplishment of the United Nations' Sustainable Development Goals (SDGs) [1]. Their activity goes beyond a mere matter of ecological impact tout-court, being a zero-emission industrial sector-as is considered in several empirical analyses on corporate sustainability [2,3]. Their indirect impact on sustainable activities is, instead, noticeable: for example, they can boost clean energy projects, invest in green bonds, offer green credit funds, and finance virtuous social initiatives [4]. All these practices, as discussed in the literature, enhance the corporate social performance (CSP) of the banking institutions, which has a positive impact on their corporate financial performance (CFP) [5]. Other relevant outcomes are attributed to the increased corporate social responsibility (CSR) practices [6] as an instrument to improve both corporate reputation and firm performance [7].

The impact of banking activity on external stakeholders is significantly positive when CSR commitment occurs, and it is increased by continuous social reporting through the years $[8,9]$. The current literature contains several studies on how banks incentivize sustainable development $[10,11]$. This field of study outlines, in particular, the efforts carried out by financial institutions, as well as concentrating on the single area of action, such as environmental credit risk management, sustainable project finance, impact investing, and banking loans activities $[12,13]$. Recent studies have focused 
on how banks implement their strategies to promote sustainability in an enlarged perspective, while assessing internal operations, too [14].

This is quite an unexplored field, which opens a wide range of questions that ought to be answered. An interesting dimension is provided by the role of environmental, social, or governance (ESG) disclosure, which is the clarification of sustainability strategies carried on by firms-even banking institutions.

In the last few years, new literature in the field of corporate sustainability has emerged, introducing the field of study to new issues regarding the inclusion of corporate governance sustainability. This includes research on the Triple Bottom Line (TBL) concept [15] in the new framework of the Quadruple Bottom Line [16-20]. The long perpetrated financial crisis that occurred in 2007-the consequences of which are still felt in the current economy-showcased several issues, especially regarding social and governance problems [21]. This is because, while banks might only have an indirect effect on the environment, as the financial industry is a zero-emission sector, social and governance issues are critical concerns regarding corporate sustainability in the banking sector. The global financial crisis (GFC) sparked a debate on the role of corporate governance strategies because they had a crucial impact on the catastrophic outcome of the GFC [22,23]. One of the most recently debated issues on corporate governance improvement is gender diversity on boards. As a result, many financial firms have recently begun to adopt gender balance strategies. The EU Commission has approved several directives to satisfy the gender balance for non-executive directors, which should come into force in 2020 for listed companies [24]. The European Parliament has also approved a regulation recommendation for large firms to increase the number of under-represented gender members (usually women) in non-executive roles to at least $40 \%$ of the total directors in order to reduce the existing gender gap. While these are positive examples, such as the Norwegian model [25], the results are far from being satisfactory. This is due to an ongoing debate regarding the real effects of board diversity on corporate governance issues and on operative results. Jensen and Anderson, among others, have stated that more visible diversity is a positive outcome of efficient resource utilization and better innovative product and strategy development, which includes a cross-sectional mix of competences and backgrounds $[26,27]$. Furthermore, regarding social and corporate governance issues, Farag and Mallin argue that a larger presence of women on boards is helpful in the reduction of the phenomenon of the "glass ceiling" [21] and provides higher incomes for women in high directive positions. Moreover, Putnam takes a different position, arguing that the costs of communication and coordination due to diversity could overcome the benefits [28].

The aim of the paper is to investigate the impact of two dimensions of ESG disclosure-specifically, the governance and the social components-by analyzing variables of gender diversity in board composition and the effort of the firm in actively adopting non-discrimination policies on financial performance. We do this using a sample of 61 banks from the 28 countries of the European Union between 2015 and 2017. The result of the empirical analysis shows a negative relationship between diverse board composition and operative result measures, and a positive relationship between equal opportunity policies and return on equity.

The choice of banking sector is related to the strategical importance of the latter in financing sustainable economic development [1-4]. Therefore, it is crucial to investigate whether the banking sector has sought more environmentally sustainable goals since the GFC. The current literature shows that gender diversity in board composition and the adoption of non-discrimination policies are a clear example in this perspective $[29,30]$. Therefore, this contribution could be a further observation regarding the sustainable path of a strategic area.

The theoretical contribution of this paper is consistent with other studies that argue that the cohesion and homogeneity of boards have a positive impact on financial performance in the presence of highly profitable activities. The reason for this is the reduction of assertiveness in the decision-making process. Moreover, it suggests that, according to the results, the social component related to non-discrimination 
policies has a positive impact on market capitalization, implying a positive reaction from the market towards adequate social policies for inclusion.

The paper is composed as follows: in Section 2, we explore the current literature on sustainability strategies in banking and the gender and inclusion policies related to corporate governance strategies. Then, in Section 3, we discuss the methodology and sampling used, matching them with the hypothesis formulation. The final sections, Sections 4-6, consist of an in-depth examination of results, a discussion on the results, the political implications, and the conclusions.

\section{Theoretical Background and Hypotheses Development}

The goal of the present work is to contribute to the analysis of the social and governance dimensions of sustainability, focusing on the bank sector. The intent is to observe if the two aforementioned performances could affect the CFP of banking institutions. Gender diversity and non-discrimination policies are present in the ESG disclosure, indicating the sustainable commitment inside the CSP framework.

The following literature review was developed by taking the main contributions present in the scientific context into account, starting with an overview of the research area from a firm perspective, notwithstanding the industrial sector. Indeed, a specific focus on banks, which has only recently gained much interest $[29,30]$, could not prospect the whole phenomenon in its entirety.

With regard to the CSP, it is important to underline the presence of a full-bodied literature from different decades and, until now, there has not been a convergent definition that can define precise borders [31]. Surely, this difficulty is connected with the different contexts where CSP could be addressed but, taking into account some of the last definitions, it could be represented as a snapshot of a firm's overall social performance at a particular point in time-a summary of the firm's aggregate social posture [32]. In addition, evaluating the strong relationship with CSR, CSP could also be a firm's overall social performance at a specific point in time, which can be ascribed to its investments in CSR over time $[33,34]$. Following the strong debate about CSP, it is simple to comprehend the absence of a univocal perspective on the relationship between Corporate Social Performance (CSP) and Corporate Financial Performance (CFP), too $[35,36]$. In regards to the two concepts, surely, CSP deserves more attention, having more intangible borders. However, even if there is a lack of a common definition/vision, scholars, considering the growing importance of this topic, are concretely involved in this field of research, aiming to highlight all possible dynamics.

Some authors represented the difficult work to make the contributions provided by previous researches comparable [37,38], as well as the theoretical problems in the empirical analysis [39], since it is difficult, for example, to define a standard metric to measure the corporate social performance [40]. Therefore, the need to redefine this topic in accordance with a common outlook is clear [41] when identifying a wide approved methodology [42]. Recent papers have still tried to update this framework, introducing new points of view as the difference among developed and emerging market firms [43], the results coming from different industry contexts [44] or the mediation role of national institutions [45]. The aim of this work is to further contribute to the exploration of the growing dimensions in terms of attention, social performances, indicating gender representation-that is, the percentage of female directors on boards - and the equal opportunity polices provided in the bank sector. This perspective, related to gender composition on the boards, was recently opened to highlight a specific aspect of CSP $[46,47]$. This is applied to the Corporate Sustainability theory regarding all firms. Thus, there are four main hypotheses regarding the relationship between Corporate Social Performance (CSP) and Corporate Financial Performance (CFP):

- Negative relationship: in line with what Milton Friedman asserted, "a company that opts to invest in Social Responsibility would produce significantly higher costs than the profits that can be generated" [48]. Consequently, such "wrong" investments would cause a deterioration in the level of economic and financial indicators; 
- Positive relationship: according to this hypothesis, there would be a direct and growing relationship between CSP and CFP, even if their causal relationship seemed doubtful. It can be argued that good financial performances generate good social performances: in fact, more profitable companies, when allocating profits, would have more resources for programs focused on social responsibility than less profitable enterprises. On the other hand, investing socially also affects the level of reputation, which indirectly generates a return in terms of cash flow. This is confirmed by the work of Barnett and Salomon [49], which suggests that companies with a higher CSR index perform better than those with a lower score [50];

- Mixed relationship: the connection between CSP and CFP may not always be constant over time and can take the form of a "U" or a "U-inverted" depending on the commitment undertaken. The "U" relationship can be explained by the hypothesis that, for a company, the implementation of a Corporate Social Responsibility program could initially generate an increase in costs compared to revenues (and, therefore, a decrease in terms of economic performance-financial), a trend that reverses in the medium to long term. On the contrary, the U-inverted relationship would suggest the existence of an "excellent" level, beyond which, being socially responsible in the long term would not produce any economic advantage; for instance, Wu and Shen and Farag and Mallin stated the existence of a mixed relationship between CSP and CFP in the financial sector $[5,21]$;

- No relationship: according to the latter hypothesis, CSP and CFP should be assumed as two separate variables that are unrelated to each other and, consequently, corporate social responsibility would have no impact on the profitability of companies [51].

Focusing on the bank industry, there is a need to prioritize social and governance dimensions since, as is commonly known, banks are zero-emission firms themselves, so the environmental disclosures might have an indirect impact on the bank's performance by enhancing reputation, social engagement, and green credit line access [4,5]. Governance and social measures, such as diversity and inclusion, are reported to have an impact on the financial performance of banks [52,53]. The importance given to the board composition of banks is justified and proven by several studies: De Andres, for example, underlines some features, such as size and independence, compared to boards in non-financial institutions [54]. Another relevant issue in the field deals with the importance of bank governance strategies and their accountability to other stakeholders: it is argued that bank performance trends have a spillover effect on other banks worldwide [55].

The different composition of boards, carrying various peculiar experiences and backgrounds, has increased in importance among scholars [21,55-58]. In this field, a famous definition by Ingley and Van der Valt describes diversity in boards as the complex of different values, backgrounds, and expertise owned by each member, and this affects the very decision-making process of the board itself [59]. Earlier, Kosnik provided a relevant distinction between board membership and outside board members, arguing that diversity in board members helps to reduce narrow-mindedness on the board's executive proposals: i.e., the decision making process may result in easing the cross-section of different backgrounds [56].

A relevant aspect concerns gender diversity and the existence of a possible effect of the presence of women within the boards of banks. Research on social psychology stresses the relevance of diversity in regard to the existing differences between male and female directors in better applying their skills in some specific fields: women, for example, are likely to have a legal, HR, or public relations background in respect to their male counterparts, who are more focused on operations and marketing [60].

Research in this field focuses on the concept of "value in diversity" and states that the presence of women on boards shall have a positive effect in representing the various interest of shareholders, enhancing discussion [61] and transparency [62].

The phenomenon of the "glass ceiling" is a crucial issue when speaking about female employment, which, of course, reflects its effects at all levels. Women, therefore, are pushed to invest more effort into their work and to gain more capabilities in order to reach higher positions, as they are supposed to be more industrious and talented [63]. 
The empirical testing of board diversity when profiling, in particular, gender diversity has been investigated in several studies [21,55,64-66]. A comprehensive analysis of the literature operated by Terjesen et al. recognizes more than 400 publications on this subject, showing that the degree of the presence of women as directors and its impact on performance has no clear or univocal results [67]. Some of them have a positive relationship, while others show negative effects, giving an undetermined conclusion of the issue.

The diversity-performance nexus has spare and ambiguous outcomes, and a real postulation of the phenomenon has not occurred. This could be due to the discrepancies in sample sizes, periods of time, and industries, in addition to the econometrics problems-e.g., endogeneity [21]. Most of the studies are empirical and depend on a series of variables that might radically influence the results in each specific case. Indeed, very few studies rely on the empirical results obtained by the analysis of financial firms $[21,55]$, and most of them count on the outcomes of studies made on non-financial firms, proving both positive [68,69] and negative effects $[70,71]$.

Indeed, there is not unanimous consent about the positive or negative effects of board gender diversity on financial performance, which turns out to be impacted by several conditions that are arbitrary and country-specific [72]. Therefore, the first hypothesis can be formulated either as affirmative or null. We opted for an affirmative form:

Hypothesis 1 (H1). The percentage of female executives generates a positive effect on the single variables of corporate financial performance.

A parallel but similar approach might be followed when we speak about diversity in terms of ethnicity and disability. Inclusion and non-discrimination policies have become a central topic for many countries, so that regulatory frameworks have been introduced by the government in order to guarantee equal opportunities for every demographic category. Beyond the legal and ethical context, the managerial one must also deal with this relevant issue. There is a massive literature review that applies the concept of inclusion, examining, from different aspects, firms and their performance [73]. Most of the analyses focus on corporate non-financial disclosure, since CSR reporting has a strong relevance for what regards the company's reputation and its corporate social performance [74-77].

Literature has only recently focused on non-financial reporting over the last fifteen years [78,79], and CSR has become a relevant aspect in firm reputation and strategic asset [64]. Moreover, a few studies have focused on the relation between CSP and CFP as result of voluntary non-financial reporting, subordinating reporting to a positive financial performance [78]. The reason for considering the literature on non-financial reporting is due to the nature of the considered variable, since the equal opportunity policy is a parameter that is voluntarily adopted by firms. Beyond the gender diversity aspect, as already disclosed in the previous paragraph, some studies focus on the composition of boards, considering various demographic groups, including nationality [55] and ethnic groups [80,81]. To the best of our knowledge, there is no specific literature on the effect of the adoption of equal opportunity and non-discrimination policies on corporate financial performance. Erhardt et al. argue of the existence of a positive relationship between cultural diversity (as a complex of observable and non-observable features) and organizational performance in US firms [80]. Therefore, our second hypothesis aims to capture the effect of the adoption of equal opportunity policies voluntarily disclosed by banks on the variables of corporate financial performance, so we formulated it as follows:

Hypothesis 2 (H2). The equal opportunity policy generates a positive effect on the single variables of corporate financial performance. 


\section{Materials and Methods}

\subsection{Sampling and Variable Definition}

The methodology adopted to build the analyzed sample can be defined "ESGs-driven"-i.e., driven by the bank's environmental, social, and governance disclosure score presence provided by Bloomberg LP. In fact, the increasing interest in non-financial disclosure by society, the government, and NGOs led companies to shed light on their sustainable practices. However, even though ESG variables have been adopted for more than a decade, the Bloomberg LP database presents missing data for several banks and years. Nevertheless, this study offers new insights into researching the effects of female boardroom participation and the adoption of the equal opportunity policy on the financial performance of banks engaged in non-financial disclosure. The sample identification followed several passages, and data was collected from different databases, using new variables. Therefore, the sample was unique. Using the BankFocus database [82], a first database was set up by looking for all the banks active in the time period of 2011-2017 that belonged to the European Union geographic region. This first database had 5251 active banks. However, it was almost useless for the purpose of the study, because there were no indicators on the BankFocus database that could express the commitment of the banks in terms of sustainability. To address this shortcoming, these indicators were found on the Bloomberg database, obtaining - after eliminating the banks without ESG data-a database made up of 152 active banks that presented ESG data over the reference as a final output [83].

As mentioned above, the dataset, characterized by such a large time period (2011-2017), was missing some data, which proved it, therefore, to be unbalanced. It was concluded that a shorter time period, ranging from 2015 to 2017, could be more significant for the purposes of the analysis. Considering all these facts, the final database was obtained, which appeared to be composed of 61 active banks belonging to the European Union geographic area (28 countries). The distribution of the sample was totally unbiased and not proportional to the total number of banks in each country, and it was interesting to observe the matter of communication of CSR activities.

At this point, some considerations of the sample size were necessary. The sample had the maximum size available for the databases from which the data were extracted [82,83]. In addition, there were two factors that made the sample homogeneous: first, although the European Union geographic area did not have a banking union, it certainly had common rules and exchanges; second, in a fragmented dataset, the two largest shares (i.e., Italy and the United Kingdom) did not exceed $10 \%-15 \%$ of the total. Therefore, they were to be considered low shares. In addition, Italy and the United Kingdom had diametrically opposed behaviours, equilibrating their effects. Lastly, statistical tests were carried out with dummy variables for both countries: the dummy was not significant.

The variables present in the database could be divided into three main categories:

- $\quad$ Corporate Financial Performance variables (i.e., return on average assets (ROAA), return on average equity (ROAE), ln Market Capitalization, Tobin's Q, and ln Net Interest Income), taken as dependent variables;

- Corporate Social Performance variables (percentage of female executives and the equal opportunity policy), taken as independent variables;

- Control variables (e.g., Leverage, Net Interest Margin, Loan Dept, Cost to Income ratio, Coverage, and $\ln$ Total Assets).

Dependent variables were described as follows:

The ROAA (acronym for Return on Average Assets) is an indicator to assess the profitability of a company's assets and is used by banks and financial institutions as a tool to estimate financial performance $[5,51,53,71,84-89]$. ROAA indicates the efficiency of a company in using its resources and is very useful for analyzing similar companies belonging to the same sector. This accounting-based performance measure is able to record the ability of banks to generate income based on the total capital employed: that is, returns generated from the assets financed by the banks $[84,88]$. 
ROAE (acronym for Return on Average Equity), on the other hand, is a profitability indicator aimed at measuring the performance of a company by evaluating the profit obtained on the basis of the money invested in the capital. A high ROAE identifies a favourable situation, in which the company generates more income for each unit of equity $[5,51,53,71,84,88]$.

Market Capitalization represents the assessment made by the market on the value of a company. The capitalization is estimated by multiplying the number of existing shares by the market price of a specific trading day (Schroders). The variable was used in its logarithmic value [53].

For testing the market value of the firm, we used Tobin's $Q$, which is intended as the ratio between current market value and the rate of replacement of the value of the firm $[53,72,86,87,90-93]$. The market value of the firm is the sum of common shareholders' investment in a company, the stocks, and the sum of long and short-term debt. The replacement value of firm assets is the sum of gross property and short-term assets [2]. Tobin's $Q$ reflects the market's expectations for future performances rather than accounting-based measures; thus, it represents a good proxy for the firm's competitive advantages $[69,94,95]$.

The Net Interest Income is calculated as the difference between the revenues generated by the company assets and the charges related to the liabilities. Based on a bank's specific assets and liabilities (i.e., whether at a fixed or variable rate), the Net Interest Income may be more or less sensitive to changes in interest rates $[5,88]$. The variable was used in its logarithmic value.

The independent variables were extracted from the Bloomberg database, and were described as follows:

The Percentage of Female Executives (field ID: ES291, mnemonic: PERCENTAGE_OF_FEMALE_EXECUTIVES) provides the number of female managers as a percentage of the total managers $[53,69,72,85,87,93]$, starting from the end of the tax year where available, or, otherwise, to the last financial year to date. Executives are defined by the company or the individuals who make up the executive committee or management committee/board or equivalent. The field is part of the group of ESG fields (environmental, social, or governance).

The Equal Opportunity Policy (field ID: ES058, mnemonic: EQUAL_OPPORTUNITY_POLICY) variable relates to equal treatment legislation and indicates whether the company has actively committed itself to guarantee the non-discrimination of any demographic group. This may be in the form of an equal opportunity policy as described by the company. The field is part of the group of ESG fields (environmental, social, or governance). Being a dichotomous dummy variable, the field reported ' 1 ' for Yes or ' 0 ' for No [83]. As far as we know, there is no use of this variable in the current literature.

The control variables referred to the financial characteristics of the banks:

Leverage refers to the ratio between the book value of the equity and total liabilities $[53,84]$, detecting the capital adequacy of the bank $[5,96]$.

Net Interest Margin (NIM) refers to the ratio of net interest income to earning assets, which is the sum of total investment earning interest or dividends and net loans [53,71,97], expressed as a percentage. The net interest margin reflects the business the bank engages in. For example, higher margins are associated with banks with more lending operations instead of those that engage in advising and mediating. Hence, this variable is not reflecting performance, but merely revealing the source of the bank's revenues [97].

The Total Asset variable identifies the size of the company and represents a determinant of social and financial performance [98]. The variable is expressed in its logarithmic value (ln Total Asset) $[5,53,84-86]$.

Further control variables were the ones proposed by $\mathrm{Wu}$ and Shen among the bank's main characteristics [5]: Loan Dept-that is, the ratio between net loans and deposits and short-term funding $[86,99]$; Cost to Income ratio, expressed as a percentage of the ratio of total operating expenses to operating revenues [51]; and, lastly, Coverage, calculated as the ratio between loan loss reserves to gross loans [53,84]. 
All the variables are resumed as follows in Table 1.

Table 1. Variable description (own elaboration).

\begin{tabular}{|c|c|c|}
\hline Variables & Description & Source \\
\hline \multicolumn{3}{|l|}{ DEPENDENT VARIABLES } \\
\hline \multicolumn{3}{|l|}{ CFP Variables } \\
\hline ROAA & Return on Average Assets \% & BankFocus \\
\hline ROAE & $\begin{array}{c}\text { (Profit or loss after tax/Total assets) } \times 100 \\
\quad \text { Return on Average Equity \% } \\
\text { (Profit or loss after tax/Total equity) } \times 100\end{array}$ & BankFocus \\
\hline ln Market Capitalization & $\log$ (Market Capitalization) & BankFocus * \\
\hline Tobin's Q & (Market capitalization/Total assets) & BankFocus \\
\hline ln Net Interest Income (expense) & $\begin{array}{l}\log (\text { Net Interest income }) \\
\text { (Total interest income-Total interest expense) }\end{array}$ & BankFocus * \\
\hline \multicolumn{3}{|l|}{$\begin{array}{l}\text { INDEPENDENT VARIABLES } \\
\text { CSP Variables }\end{array}$} \\
\hline Percentage of female executives & $\begin{array}{c}\text { Number of female directors, as percentage of the total } \\
\text { board members }\end{array}$ & Bloomberg \\
\hline Equal opportunity policy & $\begin{array}{l}\text { States if firms are involved in equal opportunity policies, } \\
\text { such as inclusion and non-discrimination }\end{array}$ & Bloomberg \\
\hline CONTROL VARIABLES & & \\
\hline Leverage & (Equity/Liabilities) & BankFocus \\
\hline Net Interest Margin (NIM) \% & (Net interest income (expense)/Total earning assets) $\times 100$ & BankFocus \\
\hline Loan Dept & (Net Loans/Deposits \& Short-Term Funding) & BankFocus * \\
\hline Cost to Income (efficiency) ratio & (Total operating expenses/Operating revenues) $\times 100$ & BankFocus \\
\hline Coverage & (Loan loss reserves/Gross Loans) & BankFocus * \\
\hline ln Total Asset & $\log$ (Total Assets) & BankFocus * \\
\hline
\end{tabular}

\subsection{Econometric Model}

Once we defined the considered variables, we built our econometric models. Even if the study included a timeline of three years, we considered the average value of each variable, being the time period short enough not to register sensible variations during the period. The model, therefore, has been identified as a cross-section analysis, split into five different regression analyses per each hypothesis, resulting in ten different analyses. The model adopted is validated by previous work $[53,86,100]$. A linear regression model was used to test our hypotheses with some modifications (i.e., introducing new variables and different combinations between the independent and control ones).

The first hypothesis ought to be studied according to the following econometric models:

- $\quad$ ROAA $_{i}=\beta_{0}+\beta_{1}$ LEVERAGE $_{i}+\beta_{2}$ NET INTEREST MARGIN $_{i}+\beta_{3}$ LOAN DEPT $_{i}+\beta_{4}$ COST TO INCOME $_{i}+\beta_{5}$ COVERAGE $_{i}+\beta_{6}$ ln TOTAL ASSET $i+\beta_{7}$ Percentage of Female Executives $_{i}+\varepsilon_{i}$

- $\quad$ ROAE $_{i}=\beta_{0}+\beta_{1}$ LEVERAGE $_{i}+\beta_{2}$ NET INTEREST MARGIN $_{i}+\beta_{3}$ LOAN DEPT $_{i}+\beta_{4}$ COST TO INCOME $_{i}+\beta_{5}$ COVERAGE $_{i}+\beta_{6}$ ln TOTAL ASSET $i+\beta_{7}$ Percentage of Female Executives $_{i}+\varepsilon_{i}$

- $\quad$ ln MarketCapitalisation M $_{i}=\beta_{0}+\beta_{1}$ LEVERAGE $_{i}+\beta_{2}$ NET INTEREST MARGIN $_{i}+\beta_{3}$ LOAN DEPT $_{i}+\beta_{4}$ COST TO INCOME $_{i}+\beta_{5}$ COVERAGE $_{i}+\beta_{6} \ln$ TOTAL ASSET $_{i}+\beta_{7}$ Percentage of Female Executives Ex $_{\mathrm{i}}+\varepsilon_{\mathrm{i}}$

- $\quad$ Tobin's $Q_{i}=\beta_{0}+\beta_{1}$ LEVERAGE $_{i}+\beta_{2}$ NET INTEREST MARGIN $_{i}+\beta_{3}$ LOAN DEPT $_{i}+\beta_{4}$ COST TO INCOME $_{i}+\beta_{5}$ COVERAGE $_{i}+\beta_{6} \ln$ TOTAL ASSET $_{i}+\beta_{7}$ Percentage of Female Executives $_{i}+\varepsilon_{i}$

- $\quad$ In Net Interest Income $i=\beta_{0}+\beta_{1}$ LEVERAGE $_{i}+\beta_{2}$ NET INTEREST MARGIN $_{i}+\beta_{3}$ LOAN DEPT $_{i}$

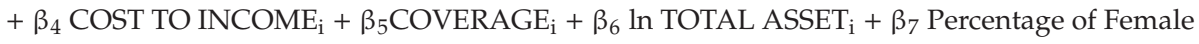
Executives $_{i}+\varepsilon_{\mathrm{i}}$

So as the following ones, built in order to verify Hypothesis 2:

- $\quad$ ROAA $_{i}=\beta_{0}+\beta_{1}$ LEVERAGE $_{i}+\beta_{2}$ NET INTEREST MARGIN $_{i}+\beta_{3}$ LOAN DEPT $_{i}+\beta_{4}$ COST TO INCOME $i+\beta_{5}$ COVERAGE $_{i}+\beta_{6} \ln$ TOTAL ASSET $_{i}+\beta_{7}$ Equal Opportunity Policy $_{i}+\varepsilon_{i}$ 
- ROAE $_{i}=\beta_{0}+\beta_{1}$ LEVERAGE $_{i}+\beta_{2}$ NET INTEREST MARGIN $_{i}+\beta_{3}$ LOAN DEPT $_{i}+\beta_{4}$ COST TO INCOME $_{i}+\beta_{5}$ COVERAGE $_{i}+\beta_{6}$ ln TOTAL ASSET $i+\beta_{7}$ Equal Opportunity Policy $_{i}+\varepsilon_{i}$

- In MarketCapitalisation $i=\beta_{0}+\beta_{1}$ LEVERAGE $_{i}+\beta_{2}$ NET INTEREST MARGIN $_{i}+\beta_{3}$ LOAN DEPT $_{i}+\beta_{4}$ COST TO INCOME $_{i}+\beta_{5}$ COVERAGE $_{i}+\beta_{6} \ln$ TOTAL ASSET $_{i}+\beta_{7}$ Equal Opportunity Policy $_{i}+\varepsilon_{i}$

- $\quad$ Tobin's $Q_{i}=\beta_{0}+\beta_{1}$ LEVERAGE $_{i}+\beta_{2}$ NET INTEREST MARGIN $_{i}+\beta_{3}$ LOAN DEPT $_{i}+\beta_{4}$ COST TO INCOME $i+\beta_{5}$ COVERAGE $_{i}+\beta_{6} \ln$ TOTAL ASSET $_{i}+\beta_{7}$ Equal Opportunity Policy $_{i}+\varepsilon_{i}$

- $\quad \ln$ Net Interest Income $_{i}=\beta_{0}+\beta_{1}$ LEVERAGE $_{i}+\beta_{2}$ NET INTEREST MARGIN $_{i}+\beta_{3}$ LOAN DEPT $_{i}$ $+\beta_{4}$ COST TO INCOME $_{i}+\beta_{5}$ COVERAGE $_{i}+\beta_{6} \ln$ TOTAL ASSET $_{i}+\beta_{7}$ Equal Opportunity Policy $+\varepsilon_{i}$

\subsection{Correlation Matrix}

Table A1 (Appendix A) illustrates the correlation matrix of the variables under study. Overall, the analysis highlighted good direct linear correlations between independent social performance variables and dependent variables in Market Capitalization and Net Interest Income. Furthermore, the independent variable Percentage of Female Executives had a medium/low correlation with the dependent variable ROAE. In detail:

- The independent variable Percentage of Female Executives, on the one hand, was the only one with a direct, albeit modest $(0.25)$ linear correlation with the dependent variable ROAE.

- The independent variable Equity Opportunity Policy, on the other hand, was characterized by small correlations, which were not significant for the purposes of the analysis.

Considering the other dependent variables, there were no relevant significant values.

\section{Results}

Table 2 reports the results relating to Hypothesis 1, which investigated the possible existence of a positive relationship between the independent variable Percentage of Female Executives and the dependent variables relating to financial performance.

Table 2. Hypothesis 1 (H1) test (own elaboration).

\begin{tabular}{|c|c|c|c|c|c|}
\hline & ROAA & ROAE & $\begin{array}{c}\text { ln Market } \\
\text { Capitalization }\end{array}$ & Tobin's Q & $\begin{array}{c}\text { In Net Interest } \\
\text { Income }\end{array}$ \\
\hline Intercept & $\begin{array}{l}2.9760 * * * \\
(0.7370)\end{array}$ & $\begin{array}{c}61.5837 * * * \\
(11.1582)\end{array}$ & $\begin{array}{c}-6.1653 * * * \\
(0.8540)\end{array}$ & $\begin{array}{l}0.4262 * * * \\
(0.1164)\end{array}$ & $\begin{array}{c}-6.1960 * * * \\
(0.8842)\end{array}$ \\
\hline $\begin{array}{l}\text { Percentage of } \\
\text { Female }\end{array}$ & -0.0074 * & -0.0116 & -0.0025 & $-0.0013^{* *}$ & 0.0059 \\
\hline Executives & $(0.0041)$ & $(0.0619)$ & $(0.0047)$ & $(0.0006)$ & $(0.0049)$ \\
\hline Leverage & $\begin{array}{l}0.0728^{* * *} \\
(0.0203)\end{array}$ & $\begin{array}{l}-0.3016 \\
(0.3074)\end{array}$ & $\begin{array}{c}0.0971 * * * \\
(0.0235)\end{array}$ & $\begin{array}{l}0.0068^{* *} \\
(0.0032)\end{array}$ & $\begin{array}{c}0.0976^{* * *} \\
(0.0244)\end{array}$ \\
\hline $\begin{array}{c}\text { Net Interest } \\
\text { Margin (NIM) }\end{array}$ & $0.1322^{* * *}$ & $1.5963 * * *$ & $0.0641^{* *}$ & $0.0288^{* * *}$ & 0.0439 \\
\hline & $(0.0234)$ & $(0.3538)$ & $(0.0271)$ & $(0.0037)$ & $(0.0280)$ \\
\hline Loan Dept & $\begin{array}{c}-0.0038^{* * * *} \\
(0.0011)\end{array}$ & $\begin{array}{c}-0.0698^{* * *} \\
(0.0159)\end{array}$ & $\begin{array}{c}-0.0034^{* * * *} \\
(0.0012)\end{array}$ & $\begin{array}{c}-0.0003 * \\
(0.0002)\end{array}$ & $\begin{array}{l}-0.0004 \\
(0.0013)\end{array}$ \\
\hline Cost to Income & $\begin{array}{c}-0.0186 \text { **** } \\
(0.0035)\end{array}$ & $\begin{array}{c}-0.3548^{* * *} \\
(0.0531)\end{array}$ & $\begin{array}{c}-0.0119 \text { **** } \\
(0.0041)\end{array}$ & $\begin{array}{c}0.0002 \\
(0.0006)\end{array}$ & $\begin{array}{c}-0.0102 * * \\
(0.0042)\end{array}$ \\
\hline Coverage & $\begin{array}{c}-0.1074 \text { *** } \\
(0.0092)\end{array}$ & $\begin{array}{c}-1.1165 \text { *** } \\
(0.1390)\end{array}$ & $\begin{array}{c}-0.0869 * * * \\
(0.0106)\end{array}$ & $\begin{array}{c}-0.0078 * * * \\
(0.0015)\end{array}$ & $\begin{array}{c}0.0088 \\
(0.0110)\end{array}$ \\
\hline In Total Assets & $\begin{array}{c}-0.0678 * \\
(0.0346)\end{array}$ & $\begin{array}{c}-1.1635 * * \\
(0.5240)\end{array}$ & $\begin{array}{c}0.8395 * * * \\
(0.0401)\end{array}$ & $\begin{array}{c}-0.0208^{* * *} \\
(0.0055)\end{array}$ & $\begin{array}{l}1.0844^{* * *} \\
(0.0415)\end{array}$ \\
\hline Observ. & 61 & 61 & 61 & 61 & 61 \\
\hline R-square & 0.8660 & 0.7528 & 0.9140 & 0.8950 & 0.9376 \\
\hline Adj. R-square & 0.8483 & 0.7202 & 0.9027 & 0.8811 & 0.9293 \\
\hline
\end{tabular}

Significance: ${ }^{*} p<0.10 ;{ }^{* *} p<0.05 ;{ }^{* *} p<0.01$; standard error value is in brackets. 
The output of the regressions carried out on the sample identified a negative and significant relationship between the percentage of women holding top positions and two variables of financial performance: ROAA (characterized by low significance with $p$-value less than $10 \%$ and with $\beta=$ -0.0074 ) and Tobin's Q (characterized by an average significance with the $p$-value less than $5 \%$ and with $\beta=-0.0013)$. No further significant relationships emerged with the other dependent variables.

These results showed that $\mathrm{H} 1$ was not confirmed and differed from other contributions in literature. In fact, Carter, Simkins, and Simpson (2003) documented a positive relationship between the gender and ethnic diversity of the board and corporate performance, as proxied by Tobin's Q [85]. In addition, other studies validate this positive relationship [69,84,93,101], finding evidence that is consistent with the idea that the market values workplace diversity. However, the model results did not allow us to foster the major literature in the field, but made us reflect on the reasons behind it. In fact, some explanations of the negative influence of females on ROAA and Tobin's Q may be down to differences in country and organizational culture, family dynamics (that might constrain the board's active participation), gender pay gaps, obstacles in hiring or reaching top management charge for women, etc. These are some suggestions for further investigation.

Moreover, Table 3 reports the results relating to the second hypothesis, in which we investigated the possible existence of a positive relationship between the independent variable Equal Opportunity Policy and the dependent variables relating to financial performance. The use of the dichotomous dummy variable, relating to the adoption of equal opportunity policies, gave a positive outcome for the dependent variable ROAE (characterized by a high significance with a $p$-value lower than $1 \%$ and with $\beta=9.4735$ ). Therefore, equal opportunity policies only influence profitability on invested capital.

Table 3. Hypothesis 2 (H2) test (own elaboration).

\begin{tabular}{|c|c|c|c|c|c|}
\hline & ROAA & ROAE & $\begin{array}{c}\text { ln Market } \\
\text { Capitalization }\end{array}$ & Tobin's Q & $\begin{array}{c}\text { In Net Interest } \\
\text { Income }\end{array}$ \\
\hline Intercept & $\begin{array}{c}2.1768 * * * \\
(0.7290)\end{array}$ & $\begin{array}{c}53.9355 * * * \\
(10.4717)\end{array}$ & $\begin{array}{c}-6.2132 * * * \\
(0.8402)\end{array}$ & $\begin{array}{c}0.3058 * * \\
(0.1176)\end{array}$ & $\begin{array}{c}-5.7088^{* * *} \\
(0.8787)\end{array}$ \\
\hline $\begin{array}{c}\text { Equal } \\
\text { Opportunity } \\
\text { Policy }\end{array}$ & 0.4687 & $9.4735 * *$ & -0.1397 & 0.0521 & -0.1744 \\
\hline Leverage & $\begin{array}{c}(0.2895) \\
0.0825 * * * \\
(0.0202)\end{array}$ & $\begin{array}{l}(4.1591) \\
-0.2162 \\
(0.2915)\end{array}$ & $\begin{array}{c}(0.3337) \\
0.0980 * * * \\
(0.0234)\end{array}$ & $\begin{array}{c}(0.0467) \\
0.0083 * * \\
(0.0033)\end{array}$ & $\begin{array}{c}(0.3490) \\
0.0914^{* * *} \\
(0.0245)\end{array}$ \\
\hline $\begin{array}{c}\text { Net Interest } \\
\text { Margin (NIM) }\end{array}$ & $0.1251^{* * *}$ & $1.4877^{* * *}$ & $0.0651 * *$ & $0.0279^{* * *}$ & 0.0474 \\
\hline & $(0.0237)$ & $(0.3406)$ & $(0.0273)$ & $(0.0038)$ & $(0.0286)$ \\
\hline Loan Dept & $\begin{array}{c}-0.0036 * * * \\
(0.0011)\end{array}$ & $\begin{array}{c}-0.0673 * * * \\
(0.0152)\end{array}$ & $\begin{array}{c}-0.0035^{* * *} \\
(0.0012)\end{array}$ & $\begin{array}{l}-0.0003 \\
(0.0002)\end{array}$ & $\begin{array}{l}-0.0005 \\
(0.0013)\end{array}$ \\
\hline Cost to Income & $\begin{array}{c}-0.0174 * * * \\
(0.0035)\end{array}$ & $\begin{array}{c}-0.3417 * * * \\
(0.0508)\end{array}$ & $\begin{array}{c}-0.0119 * * * \\
(0.0040)\end{array}$ & $\begin{array}{c}0.0004 \\
(0.0006)\end{array}$ & $\begin{array}{c}-0.0109 * * \\
(0.0043)\end{array}$ \\
\hline Coverage & $\begin{array}{c}-0.1045^{* * *} \\
(0.0090)\end{array}$ & $\begin{array}{c}-1.1246 * * * \\
(0.1297)\end{array}$ & $\begin{array}{c}-0.0855^{* * *} \\
(0.0104)\end{array}$ & $\begin{array}{c}-0.0073^{* * *} \\
(0.0015)\end{array}$ & $\begin{array}{c}0.0062 \\
(0.0109)\end{array}$ \\
\hline ln Total Assets & $\begin{array}{l}-0.0635 * \\
(0.0345)\end{array}$ & $\begin{array}{c}-1.3281^{* * *} \\
(0.4955)\end{array}$ & $\begin{array}{c}0.8466^{* * *} \\
(0.0398)\end{array}$ & $\begin{array}{c}-0.0193 * * * \\
(0.0056)\end{array}$ & $\begin{array}{c}1.0772^{* * *} \\
(0.0416)\end{array}$ \\
\hline Observ. & 61 & 61 & 61 & 61 & 61 \\
\hline R-square & 0.8643 & 0.7747 & 0.9139 & 0.8890 & 0.9362 \\
\hline Adj. R-square & 0.8464 & 0.7450 & 0.9025 & 0.8743 & 0.9277 \\
\hline
\end{tabular}

Significance: ${ }^{*} p<0.10 ;{ }^{* *} p<0.05 ;{ }^{* *} p<0.01$; standard error value is in brackets.

According to the results that were previously shown, $\mathrm{H} 2$ was confirmed. To the best of our knowledge, to date, no contribution in literature has used this variable, so there are no previous works capable of validating our study. This makes our results so unique that they will certainly be the subject of future research. 


\section{Discussion}

The debate on diversity has dramatically risen in the last two decades, focusing on both institutional and entrepreneurial concern on social issues. Some disruptive events, such as the financial crisis, have contributed to the boost of policies and strategic decisions regarding these aspects.

This paper aimed to investigate the relationship between gender diversity and financial performance, and the influence of the possible existence of equal opportunity policies within banking institutions in a relatively recent period. The choice, besides the necessity to compose a balanced dataset, was strategic to observe the differences and possible comparisons with previous periods that were temporally closer to the financial crisis. This choice gave the opportunity to settle the consequences of social policies adopted after 2007.

As the analyses conducted show, the impact of the percentage of female executives on boards had a slightly negative effect on ROAA and the Tobin's $Q$. These were the only two variables in which the relationship was significant. It did not have any significant relationship with the others. This result is consistent with the analysis of Farag and Mallin, who observed a decrease in the financial performance of banks when the composition of boards started to have a diffused fragmentation [21]. This is justified as a lack of efficiency in decisional processes, which, of course, condition the pace of the firm (financial or non-financial), impacting negatively on the financial performance. This is particularly evident in the relationship with Tobin's $Q$, which is a measure of the replacement of assets. A decrease or, worse, a lack in efficiency obviously impacts the rate of replacement and the market value of the firm. This is even more evident when dealing with banking institutions, in which the replacement of financial assets happens at a faster pace than any other firm.

The second step of the analysis revealed a very positive relationship between the equal opportunity policy variable and the ROAE. This was a very interesting result, which, of course, had a twofold consideration: on one hand, we observed internally a possible positive effect on operations, as the productivity of employees and their positive effect on process in terms of cross-section decisional processes and strategy composition increased; on the other hand, we observed the possible improvement of the bank's reputation in the market, increasing their return on equity. This is a novelty in literature, according to the extant literature, which qualifies as a relevant contribution to the present study.

The non-significance of the other relationships with the two considered variables gives an interesting perspective: the indicators used in the analyses are probably not the ones influenced by the social dimension of sustainability in financial firms. There are, indeed, numerous indicators that contribute to the debate of non-financial disclosure in all the production sectors in a precious way.

\section{Conclusions}

The aim of the study was to find a relationship between CSP-namely, social and governance sustainability components and CFP in the banking sector. According to the results obtained, H1 has been rejected, as negative significant relationships were found between the percentage of females on boards and ROAA and Tobin's $\mathrm{Q}$, while $\mathrm{H} 2$ has been confirmed as a significant positive relationship between the adoption of equal opportunity policies and the ROAE was found. The research contributed to the study of sustainable behaviour in the banking sector, aiming for the pursuit of the SDGs of the United Nations, with a specific focus on the social and governance disclosure, which is often underestimated in comparison with the conventional aspect of the TBL scheme. Social sustainability has numerous implications both in the firm's theory and governmental political action. The most discussed topic regards the popular "glass ceiling," a wage gap between men and women that, nowadays, must be overcome. Some scholars proved the need for women to make more effort to reach higher positions, so a further step in policy ought to be made in this way, allowing equal salaries between sexes. The impact on the financial performance is crucial for the firm's activity, both on decisional and operative levels. The values collected show, first of all, that many institutions are still far from being involved in equal opportunity policies, so an effort from governments in boosting the adoption of social policies 
is still needed. Based on the results, our study has obtained suggestive results, but a lot could still be done.

Of course, the study has some limitations that might be overcome. First, the study, for lack of data, ought to be completed on a larger sample by selecting other variables from other databases. ESG disclosure is, actually, not a very spread practice, yet, with regard to the banking sector, as observed through the sampling strategy. This, of course, implies different possible outcomes. The sampling strategy may be conducted notwithstanding the existence of the interest of banks in ESG reporting activities, which is itself a relevant deduction. Contrarily, we based our sampling starting from the Bloomberg assessment of ESG disclosure in financial firms. Another limitation is given by the short time interval, which is also linked to the lack of data. Future studies might consider the opportunity to enlarge the sample gradually on both the population and time interval aspects, as the information disclosure on the sustainability aspect improves itself as a good practice on the firm side. Possible future analyses may consider the time effect on the variables.

Author Contributions: Conceptualization, F.M. and A.T.; methodology, P.T.; software, P.T.; validation, P.T., A.T., and F.M.; formal analysis, D.M.; investigation, F.M.; resources, A.T.; data curation, A.T.; writing—original draft preparation, F.M.; writing-review and editing, A.T. and P.T; visualization, F.M.; supervision, D.M.; project administration, F.M. All authors have read and agreed to the published version of the manuscript.

Funding: This research received no external funding.

Acknowledgments: The authors thank Andrea Santaloia for the proof-reading activity.

Conflicts of Interest: The authors declare no conflict of interest. 
Sustainability 2020, 12, 4038

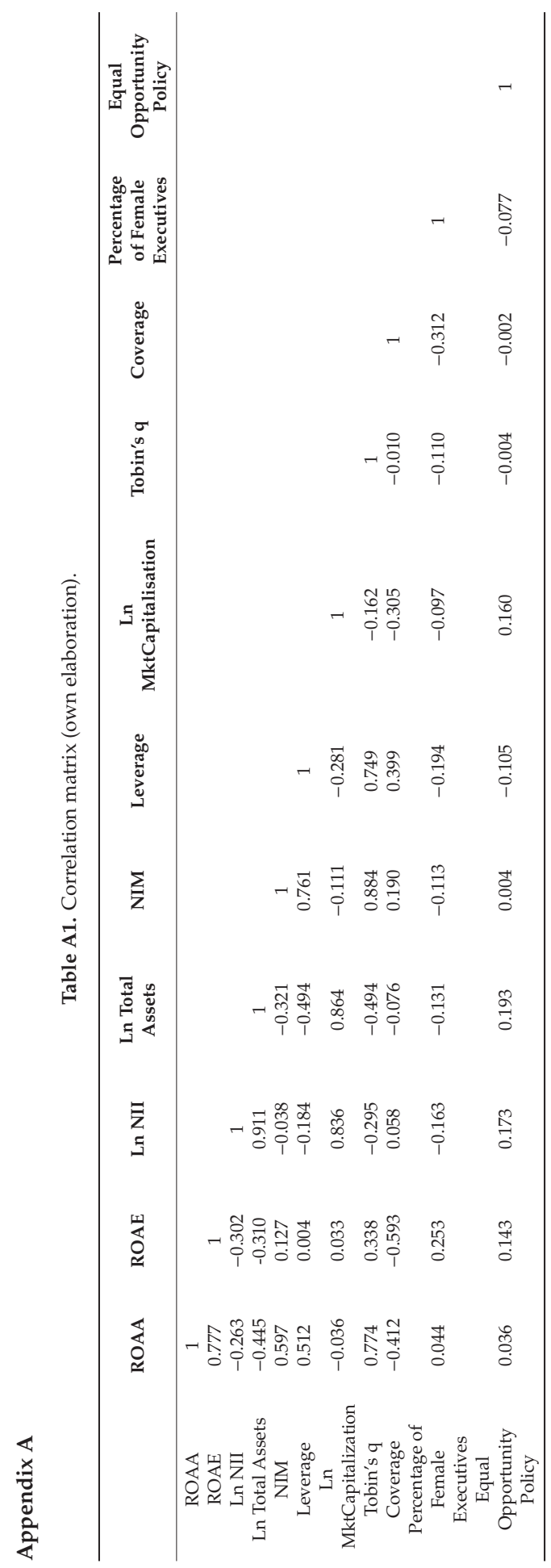




\section{References}

1. Avrampou, A.; Skouloudis, A.; Iliopoulos, G.; Khan, N. Advancing the sustainable development goals: Evidence from leading European banks. Sustain. Dev. 2019, 27, 743-757. [CrossRef]

2. Russo, A.; Pogutz, S. Eco-efficiency vs Eco-effectiveness. Exploring the link between GHG emissions and firm performance. In Academy of Management Proceedings; Academy of Management: Briarcliff Manor, NY, USA, 2009; Volume 2009, pp. 1-6. [CrossRef]

3. Perrini, F.; Russo, A.; Tencati, A.; Vurro, C. Going beyond a long-lasting debate: What is behind the relationship between corporate social and financial performance. EABIS Res. Proj. Work. Pap. 2009. Available online: http://citeseerx.ist.psu.edu/viewdoc/download?doi=10.1.1.542.519\&rep=rep1\&type=pdf (accessed on 28 November 2019).

4. Zimmermann, S. Same but Different: How and Why Banks Approach Sustainability. Sustainability 2019, 11, 2267. [CrossRef]

5. Wu, M.W.; Shen, C.H. Corporate social responsibility in the banking industry: Motives and financial performance. J. Bank. Financ. 2013, 37, 3529-3547. [CrossRef]

6. Dell'Atti, S.; Trotta, A.; Iannuzzi, A.P.; Demaria, F. Corporate social responsibility engagement as a determinant of bank reputation: An empirical analysis. Corp. Soc. Responsib. Environ. Manag. 2017, 24, 589-605. [CrossRef]

7. Forcadell, F.J.; Aracil, E. European banks' reputation for corporate social responsibility. Corp. Soc. Responsib. Environ. Manag. 2017, 24, 1-14. [CrossRef]

8. Buallay, A. Is sustainability reporting (ESG) associated with performance? Evidence from the European banking sector. Manag. Environ. Qual. Int. J. 2019, 30, 98-115. [CrossRef]

9. Nobanee, H.; Ellili, N. Corporate sustainability disclosure in annual reports: Evidence from UAE banks: Islamic versus conventional. Renew. Sustain. Energy Rev. 2016, 55, 1336-1341. [CrossRef]

10. Weber, O.; Remer, S. Social Banks and the Future of Sustainable Finance; Taylor \& Francis: Abingdon, UK, 2011; Volume 64.

11. EFB. Available online: https://www.ebf.eu/priorities/financing-growth/sustainable-finance/ (accessed on 7 April 2020).

12. Meena, R. Green banking: As initiative for sustainable development. Glob. J. Manag. Bus. Stud. 2013, 3, $1181-1186$.

13. Biswas, N. Sustainable green banking approach: The need of the hour. Bus. Spectr. 2011, 1, 32-38.

14. Özçelik, F.; Öztürk, B.A. Evaluation of banks' sustainability performance in Turkey with grey relational analysis. Muhasebe Ve Finansman Dergisi 2014. Available online: http://mufad.org.tr/journal-/attachments/ article/743/11.pdf (accessed on 28 November 2019).

15. Elkington, J. Partnerships from cannibals with forks: The triple bottom line of 21st-century business. Environ. Qual. Manag. 1998, 8, 37-51. [CrossRef]

16. Hawkes, J. The Fourth Pillar of Sustainability: Culture's Essential Role in Public Planning; Common Ground: Melbourne, Australia, 2001.

17. Caust, J. Putting the "art" back into arts policy-making: How arts policy has been "captured" by the economists and the marketers. Int. J. Cult. Policy 2003, 9, 51-63. [CrossRef]

18. Lawler III, E.E. Sustainable effectiveness and organization development: Beyond the triple bottom line. OD Pract. 2014, 46, 65-67.

19. Alibašić, H. Measuring the sustainability impact in local governments using the quadruple bottom line. Int. J. Sustain. Policy Pract. 2017, 13, 37-45. [CrossRef]

20. Budsaratragoon, P.; Jitmaneeroj, B. Measuring causal relations and identifying critical drivers for corporate sustainability: The quadruple bottom line approach. Meas. Bus. Excell. 2019, 23, 292-316. [CrossRef]

21. Farag, H.; Mallin, C. Board diversity and financial fragility: Evidence from European banks. Int. Rev. Financ. Anal. 2017, 49, 98-112. [CrossRef]

22. Kirkpatrick, G. The corporate governance lessons from the financial crisis. OECD J. Financ. Mark. Trends 2009, 1, 61-87. [CrossRef]

23. Erkens, D.H.; Hung, M.; Matos, P. Corporate governance in the 2007-2008 financial crisis: Evidence from financial institutions worldwide. J. Corp. Financ. 2012, 18, 389-411. [CrossRef] 
24. European Commission. Proposal for a Directive of the European Parliament and of the Council on Improving the Gender Balance among Non-Executive Directors of Companies Listed on Stock Exchanges and Related Measures. Brussels, 14.11.2012; COM 2012614 final, 2012/0299 (COD). Available online: https: //eur-lex.europa.eu/legal-content/EN/TXT/?uri=CELEX\%3A52012PC0614 (accessed on 12 December 2019).

25. Mateos de Cabo, R.M.; Gimeno, R.; Nieto, M.J. Gender Diversity on European Banks' Board of Directors. J. Bus. Ethics 2012, 109, 145-162. [CrossRef]

26. Jensen, M.C. The Modern Industrial Revolution, Exit, and the Failure of Internal Control Systems. J. Financ. 1993, 48, 831-880. [CrossRef]

27. Anderson, C.; Reeb, D.M.; Upadhyay, A.; Zhao, W. The Economics of Director Heterogeneity. Financ. Manag. 2011, 40, 5-38. [CrossRef]

28. Putnam, R.D. Pluribus Unum: Heterogeneity and Community in the Twenty-First Century-The 2006 Johan Skytte Prize Lecture. Scand. Political Stud. 2007, 30, 137-174. [CrossRef]

29. Birindelli, G.; Iannuzzi, A.P.; Savioli, M. The impact of women leaders on environmental performance: Evidence on gender diversity in banks. Corp. Soc. Responsib. Environ. Manag. 2019, 26, 1485-1499. [CrossRef]

30. Birindelli, G.; Dell'Atti, S.; Iannuzzi, A.P.; Savioli, M. Composition and activity of the board of directors: Impact on ESG performance in the banking system. Sustainability 2018, 10, 4699. [CrossRef]

31. Wood, D.J. Corporate social performance revisited. Acad. Manag. Rev. 1991, 16, 691-718. [CrossRef]

32. Barnett, M.L. Stakeholder influence capacity and the variability of financial returns to corporate social responsibility. Acad. Manag. Rev. 2007, 32, 794-816. [CrossRef]

33. Orlitzky, M.; Siegel, D.S.; Waldman, D.A. Strategic corporate social responsibility and environmental sustainability. Bus. Soc. 2011, 50, 6-27. [CrossRef]

34. Sila, I. Investigating changes in TQM's effects on corporate social performance and financial performance over time. Total Qual. Manag. Bus. Excell. 2020, 31, 210-229. [CrossRef]

35. Marom, I.Y. Toward a unified theory of the CSP-CFP link. J. Bus. Ethics 2006, 67, 191-200. [CrossRef]

36. Kong, Y.; Antwi-Adjei, A.; Bawuah, J. A systematic review of the business case for corporate social responsibility and firm performance. Corp. Soc. Responsib. Environ. Manag. 2020, 27, 444-454. [CrossRef]

37. Griffin, J.J.; Mahon, J.F. The corporate social performance and corporate financial performance debate: Twenty-five years of incomparable research. Bus. Soc. 1997, 36, 5-31. [CrossRef]

38. Perrini, F.; Russo, A.; Tencati, A.; Vurro, C. Deconstructing the relationship between corporate social and financial performance. J. Bus. Ethics 2011, 102, 59-76. [CrossRef]

39. Wood, D.J.; Jones, R.E. Stakeholder mismatching: A theoretical problem in empirical research on corporate social performance. Int. J. Organ. Anal. 1995, 3, 229-267. [CrossRef]

40. Masip, M. Desperately Seeking a Standard Metric for Corporate Social Performance. In Non-Financial Disclosure and Integrated Reporting: Practices and Critical Issues; Emerald Publishing Limited: Bingley, UK, 2020.

41. Roman, R.M.; Hayibor, S.; Agle, B.R. The relationship between social and financial performance: Repainting a portrait. Bus. Soc. 1999, 38, 109-125. [CrossRef]

42. Callan, S.J.; Thomas, J.M. Corporate financial performance and corporate social performance: An update and reinvestigation. Corp. Soc. Responsib. Environ. Manag. 2009, 16, 61-78. [CrossRef]

43. Ting, I.W.K.; Azizan, N.A.; Bhaskaran, R.K.; Sukumaran, S.K. Corporate Social Performance and Firm Performance: Comparative Study among Developed and Emerging Market Firms. Sustainability 2020, 12, 26. [CrossRef]

44. Tuppura, A.; Arminen, H.; Pätäri, S.; Jantunen, A. Corporate social and financial performance in different industry contexts: The chicken or the egg? Soc. Responsib. J. 2016, 12, 672-686. [CrossRef]

45. Shin, J.Y.; Moon, J.J.; Kang, J. How Do National Institutions Moderate the Relationship between CSP and CFP? In Academy of Management Proceedings; Academy of Management: Briarcliff Manor, NY, USA, 2015; Volume 2015, p. 10995. [CrossRef]

46. Dunn, P.; Sainty, B. The relationship among board of director characteristics, corporate social performance and corporate financial performance. Int. J. Manag. Financ. 2009, 5, 407-423. [CrossRef]

47. Boulouta, I. Hidden connections: The link between board gender diversity and corporate social performance. J. Bus. Ethics 2013, 113, 185-197. [CrossRef] 
48. Friedman, M. The Social Responsibility of Business is to Increase its Profits. N. Y. Time Mag. 1970, 13, $173-178$.

49. Barnett, M.L.; Salomon, R.M. Does it pay to be really good? Addressing the shape of the relationship between social and financial performance. Strateg. Manag. J. 2012, 33, 1304-1320. [CrossRef]

50. Han, J.J.; Kim, H.J.; Yu, J. Empirical study on relationship between corporate social responsibility and financial performance in Korea. Asian J. Sustain. Soc. Responsib. 2016, 1, 61-76. [CrossRef]

51. Soana, M.G. The relationship between corporate social performance and corporate financial performance in the banking sector. J. Bus. Ethics 2011, 104, 133. [CrossRef]

52. Carter, D.A.; D'Souza, F.; Simkins, B.J.; Simpson, W.G. The gender and ethnic diversity of US boards and board committees and firm financial performance. Corp. Gov. Int. Rev. 2010, 18, 396-414. [CrossRef]

53. Bussoli, C.; Conte, D.; Letorri, G.; Barone, M. Does It Pay to Be Sustainable? Evidence from European Banks. Int. J. Bus. Manag. 2019, 14, 128-146. [CrossRef]

54. De Andres, P.; Vallelado, E. Corporate governance in banking: The role of the board of directors. J. Bank. Financ. 2008, 32, 2570-2580. [CrossRef]

55. García-Meca, E.; García-Sánchez, I.M.; Martínez-Ferrero, J. Board diversity and its effects on bank performance: An international analysis. J. Bank. Financ. 2015, 53, 202-214. [CrossRef]

56. Kosnik, R.D. Effects of board demography and directors' incentives on corporate greenmail decisions. Acad. Manag. J. 1990, 33, 129-150.

57. Hillman, A.J.; Cannella, A.A.; Paetzold, R.L. The resource dependence role of corporate directors: Strategic adaptation of board composition in response to environmental change. J. Manag. Stud. 2000, 37, 235-256. [CrossRef]

58. Hillman, A.J.; Cannella, A.A.; Harris, I.C. Women and racial minorities in the boardroom: How do directors differ? J. Manag. 2002, 28, 747-763. [CrossRef]

59. Ingley, C.B.; Van der Walt, N.T. Board configuration: Building better boards. Corp. Gov. 2003, 3, 5-17. [CrossRef]

60. Zelechowski, D.D.; Bilimoria, D. Characteristics of women and men corporate inside directors in the US. Corp. Gov. Int. Rev. 2004, 12, 337-342. [CrossRef]

61. Letendre, L. The dynamics of the boardroom. Acad. Manag. Exec. 2004, 18, 101-104. [CrossRef]

62. Upadhyay, A.; Zeng, H. Gender and ethnic diversity on board and corporate information environment. J. Bus. Res. 2014, 67, 2456-2463. [CrossRef]

63. Eagly, A.H.; Carli, L.L. The female leadership advantage: An evaluation of the evidence. Leadersh. Q. 2003, 14, 807-834. [CrossRef]

64. Farrell, K.A.; Hersch, P.L. Additions to corporate boards: The effect of gender. J. Corp. Financ. 2005, 11, 85-106. [CrossRef]

65. Matsa, D.; Miller, A. A female style in corporate leadership? Evidence from quotas. Am. Econ. J. Appl. Econ. 2013, 5, 136-169. [CrossRef]

66. Goergen, M.; Renneboog, L. Inside the board room. J. Corp. Financ. 2014, 28, 1-5. [CrossRef]

67. Terjesen, S.; Sealy, R.; Singh, V. Women Directors on Corporate Boards: A Review and Research Agenda. Corp. Gov. Int. Rev. 2009, 17, 320-337. [CrossRef]

68. Carter, D.A.; Simkins, B.J.; Simpson, W.G. Corporate governance, board diversity, and firm value. Financ. Rev. 2003, 38, 33-53. [CrossRef]

69. Campbell, K.; Vera, A.M. Gender Diversity in the Boardroom and Firm Financial Performance. J. Bus. Ethics 2008, 83, 435-451. [CrossRef]

70. Ryan, M.K.; Haslam, A.S. The Glass Cliff: Evidence that Women are Over-Represented in Precarious Leadership Positions. Br. J. Manag. 2005, 16, 81-90. [CrossRef]

71. Pathan, S.; Faff, R. Does Board Structure in Banks Really Affect their Performance? J. Bank. Financ. 2013, 37, 1573-1589. [CrossRef]

72. Ferreira, D. Board Diversity: Should We Trust Research to Inform Policy? Corp. Gov. Int. Rev. 2015, 23, 108-111. [CrossRef]

73. Arvidsson, S. Disclosure of non-financial information in the annual report: A management-team perspective. J. Intellect. Cap. 2011, 12, 277-300. [CrossRef] 
74. Bonsón, E.; Bednárová, M. CSR reporting practices of Eurozone companies. Revista De Contabilidad. 2015, 18, 182-193. [CrossRef]

75. Ellerup Nielsen, A.; Thomsen, C. Reporting CSR—What and how to say it? Corp. Commun. Int. J. 2007, 12, 25-40. [CrossRef]

76. Perrini, F. The practitioner's perspective on non-financial reporting. Calif. Manag. Rev. 2006, 48, 73-103. [CrossRef]

77. Tschopp, D.; Huefner, R.J. Comparing the evolution of CSR reporting to that of financial reporting. J. Bus. Ethics 2015, 127, 565-577. [CrossRef]

78. Carnevale, C.; Mazzuca, M.; Venturini, S. Corporate social reporting in European banks: The effects on a firm's market value. Corp. Soc. Responsib. Environ. Manag. 2012, 19, 159-177. [CrossRef]

79. Stolowy, H.; Paugam, L. The expansion of non-financial reporting: An exploratory study. Account. Bus. Res. 2018, 48, 525-548. [CrossRef]

80. Erhardt, N.L.; Werbel, J.D.; Shrader, C.B. Board of director diversity and firm financial performance. Corp. Gov. Int. Rev. 2003, 11, 102-111. [CrossRef]

81. Brammer, S.; Millington, A.; Pavelin, S. Gender and Ethnic Diversity among UK Corporate Boards. Corp. Gov. Int. Rev. 2007, 15, 393-403. [CrossRef]

82. BankFocus Database. Available online: https://banks.bvdinfo.com (accessed on 21 June 2019).

83. Bloomberg Database on ESG. Available online: https://www.bloomberg.com/impact/products/esg-data (accessed on 30 June 2019).

84. Bussoli, C.; Conte, D. The "Virtuous Circle" Between Corporate Social Performance and Corporate Financial Performance in the European Banking Sector. Int. J. Bus. Adm. 2018, 9, 80-92. [CrossRef]

85. Bukar, M.; Ahmed, A. Effect of board of directors' gender diversity on financial performance of deposit money banks in Nigeria. Glob. J. Appl. Manag. Soc. Sci. 2020, 18, 9-19.

86. Adams, R.B.; Ferreira, D. Gender diversity in the boardroom. European Corporate Governance Institute. Financ. Work. Pap. 2004, 57, 30.

87. Ali, S.; Zhang, J.; Naseem, M.A.; Ahmad, F. Moderating Role of Ownership in Relationship between CSRD And Firm Performance. J. Dev. Areas. 2019, 53. [CrossRef]

88. de Koning, C. Reputation, Corporate Social Responsibility, and Financial Performance of Banks. MaRBLe 2018, 1. [CrossRef]

89. Simpson, W.G.; Kohers, T. The link between corporate social and financial performance: Evidence from the banking industry. J. Bus. Ethics 2002, 35, 97-109. [CrossRef]

90. Dowell, G.; Hart, S.; Yeung, B. Do Corporate Global Environmental Standards Create or Destroy Market Value? Manag. Sci. 2000, 46, 1059-1074. [CrossRef]

91. King, A.; Lenox, M.J. Does It Really Pay to Be Green? An Empirical Study of Firm Environmental and Financial Performance. J. Ind. Ecol. 2001, 50, 105-116. [CrossRef]

92. Konar, S.; Cohen, M.A. Does the Market Value Environmental Performance? Rev. Econ. Stat. 2001, 83, 281-289. [CrossRef]

93. Cardillo, G.; Onali, E.; Torluccio, G. Does gender diversity on banks' boards matter? Evidence from public bailouts. J. Corp. Financ. 2020, 101560. [CrossRef]

94. Demsetz, H.; Villalonga, B. Ownership structure and corporate performance. J. Corp. Financ. 2001, 7, $209-233$. [CrossRef]

95. Wernerfelt, B.; Montgomery, C.A. Tobin's q and the importance of focus in firm performance. Am. Econ. Rev. 1988, 246-250.

96. Waddock, S.A.; Graves, S.B. The corporate social performance-financial performance link. Strateg. Manag. J. 1997, 18, 303-319. [CrossRef]

97. Gonenc, H.; Scholtens, B. Responsibility and Performance Relationship in the Banking Industry. Sustainability 2019, 11, 3329. [CrossRef]

98. Ullmann, A.A. Data in search of a theory: A critical examination of the relationships among social performance, social disclosure, and economic performance of US firms. Acad. Manag. Rev. 1985, 10, 540-557.

99. Gangi, F.; Mustilli, M.; Varrone, N.; Daniele, L.M. Corporate Social Responsibility and Banks' Financial Performance. Int. Bus. Res. 2018, 11, 42-58. [CrossRef] 
100. Carnevale, C.; Mazzuca, M. Sustainability report and bank valuation: Evidence from European stock markets. Bus. Ethics A Eur. Rev. 2014, 23, 69-90. [CrossRef]

101. Ellis, K.M.; Keys, P.Y. Stock returns and the promotion of workforce diversity. J. Financ. Econ. 2003, 18, 17-34.

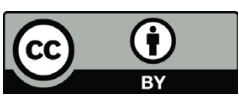

(C) 2020 by the authors. Licensee MDPI, Basel, Switzerland. This article is an open access article distributed under the terms and conditions of the Creative Commons Attribution (CC BY) license (http://creativecommons.org/licenses/by/4.0/). 


\title{
Article \\ European Financial Services SMEs: Language in Their Sustainability Reporting
}

\author{
Esther Ortiz-Martínez * and Salvador Marín-Hernández \\ Department of Accounting and Finance, University of Murcia, 3100 Murcia, Spain; salvlau@um.es \\ * Correspondence: esther@um.es; Tel.: +34-868-887-925
}

Received: 29 August 2020; Accepted: 8 October 2020; Published: 12 October 2020

\begin{abstract}
In this study we concentrate on the segment of small companies in the financial sector in Europe. Services in this sector are developing rapidly and are not necessarily provided only by traditional banks and financial companies. Many nonfinancial companies provide financial services, and this may open the sector to additional risk. In this context, the aspects of both financial and nonfinancial reporting are important and need to be taken into consideration as a whole to provide a complex picture of a particular institution. The goal of this paper is to analyze sustainability reporting according to the Global Reporting Initiative (GRI) by European financial services small and medium-sized enterprises (SMEs). First, we conducted a descriptive analysis of the features of nonfinancial information and its assurance, studying a sample of all European SMEs reporting according to the GRI from 2016 to 2018. Then, we chose only financial services SMEs to apply lexical analysis to their narrative reporting based on a corpus of 102,056 words. We conclude that nonfinancial information does not have the same importance as traditional financial information, and this sustainability reporting only complies with the minimum requirements. Thus, there is still a long way to go in this field.
\end{abstract}

Keywords: European financial services; SMEs; nonfinancial information; sustainable reporting; disclosure; lexical analysis; nonfinancial reporting

\section{Introduction}

Initially, disclosure of nonfinancial information was voluntarily assumed by companies, mainly large global ones. The European Commission decided that the heterogeneity in this field was an inconvenience for transparency and comparability, so it required the compulsory issuance of nonfinancial information by big European groups [1]. Although the transposition of this directive can vary and includes certain flexibility in order to be adopted by each Member State, no state has extended the obligation of issuing this sustainable information to small and medium-sized enterprises (SMEs) [2]. Bearing in mind that most of the companies in Europe are SMEs, it is important to study the nonfinancial information that they provide because disclosure of nonfinancial information is a way to improve companies' transparency and communication of social and ethical practices. The first contribution of this paper is to show which European SMEs are disclosing sustainability reports according to the Global Reporting Initiative (GRI) voluntarily, which will add important knowledge to this field of research traditionally based on large companies.

SMEs are the backbone of the European economy and are traditionally dependent on bank loans for their external financing. The last financial crisis and now the situation generated by COVID-19 have increased both the need for financial resources and the difficulties in accessing it. The European Commission highlights these difficulties and promotes the provision of suitable alternatives to bank loans, so it enacted a specific regulation "to make SMEs more visible to investors and markets more attractive and accessible for SMEs. Regulatory changes will keep the right balance between prudential 
regulation and financing of SMEs, and between investor protection and tailored measures for SMEs" [3]. This sector is also in the spotlight of transparency after the recent crisis and has an additional obligation with society to try to balance the unequal distribution of information [4]. We focused our study on European financial services SMEs that provide sustainability reports according to GRI standards. The development of this sector is linked to economic growth [5], and the effect of the recent crisis on bank credit has increased the importance of other types of financial resources, such as trade credit [6]. Thus, the recent evolution of the financial sector has turned to SMEs to provide these services because their traditional problems in obtaining financial resources can be more easily solved by other SMEs [7]. Although at first sight the small size can seem to be a limitation to operating in the financial sector, it can be an important advantage because specializing as another SME or in retail services in order to provide a more similar service is seen as a positive way to attract SMEs to this sector [7]. Banks and, by extension, financial services companies are expected to approach climate risks and other risks related to sustainability in the same way that they approach any other financial risks [8].

The development of regulations in Europe to require sustainability reporting by financial services companies and obtain financial resources is under discussion, and recently a roadmap of regulation on taxonomy-related disclosures was launched by undertaking the reporting of nonfinancial information included in the European Commission's Action Plan on financing sustainable growth [9]. European financial sector companies have their own regulatory and supervisory bodies that do not depend on their size in terms of national and international financial compliance, although groups of European listed companies are directly regulated by European Union-International Financial Reporting Standards (EU-IFRS). IFRS also include requirements on disclosure as a response to the need for high-quality standards in order to be endorsed in Europe. In this line, in 2018 the European Securities and Markets Authority (ESMA) expanded its supervisory activities to nonfinancial information on environmental, social, and governance (ESG) matters assessing compliance with IFRS, and in 2019 it continued to focus on this disclosure. When speaking specifically about regulation of nonfinancial disclosure, large financial services companies are mainly considered entities of public interest in each Member State, which means that they are compulsorily required to disclose nonfinancial reporting according to Directive 2014/95/EU, although the specific requirements depend on its transposition by each Member State [1]. Hence, financial services SMEs that publish sustainability information do it voluntarily because they are not within the scope of the directive, and this field is not regulated.

Background information on the field of sustainability reporting of financial services SMEs is scarce and far from sufficient to develop requirements about it now when the European Commission is working on a review of nonfinancial reporting. Studying nonfinancial information is also difficult due to its mainly qualitative and narrative nature, which makes the information heterogeneous. Although most companies are using GRI standards, this does not suppose comparable homogeneous information. Hence, it is necessary to look for another type of methodology, such as lexical analysis, which means studying the words used in the narratives of sustainability reports by European financial sector SMEs, and this is the main objective of this study.

There are three main streams of theoretical framework on which this paper is based. The first refers to disclosure of nonfinancial information and global trends in this subject, such as the general use of GRI standards. Background information about the disclosure of nonfinancial information is mainly based on large companies, which are accustomed to listing because they try to inform their stakeholders and cope with the requirements established by the capital markets [10-12]. All global trends in this field have been adopted by large companies, which are globally shaping the features of disclosure with their voluntary reporting [13]. The generally accepted standards of nonfinancial information are GRI standards because "the GRI guidelines seem to fulfil the need for standards when reporting, identifying and implementing sustainable practices in the companies, since the GRI framework has become, de facto, the standard in sustainability reporting around the world" [14]. Reporting according to GRI standards means there is some kind of homogeneous disclosure as well as use of the GRI database [15-22]. 
Another important global trend in nonfinancial information is to verify it externally, or to gain assurance, which is linked to disclosure of these issues [23]. All of these practices have been extensively studied at the level of big companies, but background information on SMEs is scarce. Some studies have tried to obtain differences in disclosure between big companies and SMEs [24]. SMEs have fewer resources to report nonfinancial information [10], which does not mean that they do not behave in a sustainable way or do not have a sustainable culture. Studies have also argued that SMEs adopt better corporate social responsibility (CSR) practices, although they do not issue information about it [25]. Until recently, all sustainable reporting was issued voluntarily, but for a few years the European Union has made some kind of nonfinancial information on large companies compulsory [1], and some SMEs issue this information due to the influence of large companies [26] or because they want to gain a competitive advantage [12].

Currently, important work is being done to advise SMEs on how to voluntarily issue nonfinancial information. This is being done by regulators (such as the European Commission), the regulators' advisors (the European Financial Reporting Advisory Group (EFRAG) advises the European Commission, focusing on disclosure requirements), and professional organizations (the International Federation of Accountants (IFAC) and active organizations representing European SMEs such as the European Federation of Accountants and Auditors for SMEs (EFAA for SMEs) and SMEunited). However, the literature on sustainability reporting by SMEs is scarce and mainly based on a single research method, surveys, which means there is a need for further studies that combine other methods to add additional conclusions about this subject [27]. In this line, we point out the situation of voluntary sustainability reporting according to the GRI by European SMEs, which provides another point of view in a field of research traditionally based on large companies.

Second, there is background information focused on disclosure of financial services companies due to their important role in the economy. This sector has traditionally been a determinant of social issues of companies [28-30] because the information being issued depends on the kind of activity of the firm. Financial services companies are vital agents in the economy, so they are a benchmark for greater transparency [31-33]. They are also under special supervision and regulation in each country, with specific requirements on top of those applied for nonfinancial entities [34], and there can be an effect of the type of market economy on banks' disclosure (coordinated or liberal market economy) [35]. This vital activity and the effects of the recent crisis have increased research on the relationship between social responsibility and profitability in financial services companies and companies operating in other sectors [36-43]. Nowadays, there is also "ethical banking" in comparison to "conventional banking" because it is supposed to be more responsible and issue more information, both financial and nonfinancial, in response to stakeholders [44,45]. Notwithstanding ethical banking, traditional banking is supposed to take care of different aspects of its social responsibility such as consumer satisfaction [46] and the opinions of providers of financial resources [47]. The European Commission is promoting alternative financial plans for SMEs, trying to make it easier for SMEs to access markets [3], while not forgetting investor protection, which also includes sustainable reporting to respond to the increasing pressure to provide nonfinancial information [48].

The third theoretical framework is related to the methodology that we used in this paper: lexical analysis. The area of study, disclosure of nonfinancial information, is complex because it mainly consists of heterogeneous qualitative and narrative information. It is true that most companies are using GRI standards, but this does not mean there is comparable information, as there are different levels of adherence, and the formats of presenting the information can be quite diverse and flexible. Hence, analyzing disclosure implies many problems, which the majority of studies have tried to solve using content analysis or disclosure indices to measure this information (one recent study using indices is [49]), or to check if there is any relationship between disclosure and other features, although there are proven disadvantages when using this methodology [50]. Lexical analysis has been used in research having to do with semantics and language in a variety of fields, such as in [51,52], which strictly refer to language skills, as well as in analyzing qualitative narrative information in the field of economics, 
such as [53], which examined statements by the chairman and CEO in BP plc's Annual Report 2010 [54], which used lexicometric analysis to study a corpus comprising speeches of European Central Bank presidents; [55], which analyzed the results of open-ended interviews in the field of management; and [56], which used lexical analysis to try to extract the sentiments of a group of people to predict the movement of the stock market. Studies using lexical analysis of nonfinancial reporting are scarce, and none has analyzed disclosure by European financial sector SMEs. Mainly they have focused on big firms, such as [57], which conducted lexical analysis of annual reports of Shell plc.; [58], which reviewed previous research on sustainable banks for three periods depending on the financial crisis and used a descriptive bibliometric analysis and a co-word analysis to study the topics in the literature; [59], which applied lexical analysis to environmental disclosure of listed companies; [60], which asserted that the discourse included in the social reports of BP and IKEA was constructed to present the face that the companies wanted to show; and [61], which created two corpora from seven corporate governance reports of listed companies.

In this paper we use lexical analysis to study disclosure of nonfinancial information because it is mainly narrative, and this is a good way to obtain conclusions from the text provided and the words used to compose the narrative. The analysis is based on reporting by European financial sector SMEs, and the background on this field is scarce. Sustainability reporting in the financial sector is mainly inadequate and focused on financial aspects rather than on material issues, as highlighted by the UN when studying sustainability reporting in the financial sector [62]. Only a few of these initiatives of sustainability reporting provide a picture of all sustainability factors of financial companies [62]. In addition, the overwhelming majority of SMEs perceive sustainability reporting as a burden, and it appears that SMEs either do not have the capacity to comply or are reluctant to invest the necessary resources [63], so taking all this together, we propose the following research questions:

Research Question 1. Are European financial sector SMEs preparing their sustainability reports only in accordance with minimum nonfinancial disclosure requirements?

Research Question 2. Are European financial sector SMEs still more influenced by financial terms in their nonfinancial reporting?

The paper is organized as follows: first we describe the methodology, in the next section we discuss the results, and in the final section we wrap up the paper and describe the limitations and future research.

\section{Materials and Methods}

As the first goal of this paper is to point out the situation of sustainability reporting according to GRI voluntarily disclosed by European SMEs, we obtained the sample from the GRI database. Bearing in mind that GRI nonfinancial reporting standards are the most widely used all over the world and that SMEs in Europe are not compelled to issue this information, this database is a suitable resource to get these data. The search tool of the GRI database allows searches for nonfinancial reports according to firm size, and specifically reports issued by SMEs. We made our search on 11 November 2019 with the following criteria: firm size-SMEs; region-Europe; report type-GRI-Standards. Although previous versions of the GRI standards are included in the report type, these are the latest ones, published by GRI on 1 July 2018, replacing the GRI 4 version (https:/www2.globalreporting.org/ standards/g4/Pages/default.aspx). In total, 116 organizations and 157 reports were found. This means that there are firms (or other types of organizations) that issued more than one report because these standards refer to 2016, 2017, 2018, and even 2019. As shown in Table 1, there are many sectors in which SMEs that issue nonfinancial information operate. 
Table 1. Nonfinancial information issued by European small and medium-sized enterprises (SMEs) according to Global Reporting Initiative (GRI).

\begin{tabular}{|c|c|c|c|c|c|c|c|}
\hline & & Frequency & $\%$ & & & Frequency & $\%$ \\
\hline \multirow{34}{*}{ Sector } & Real estate & 16 & 10.2 & \multirow{21}{*}{ Country } & Sweden & 26 & 16.6 \\
\hline & Tourism/leisure & 3 & 1.9 & & Slovenia & 1 & 0.6 \\
\hline & Energy utilities & 3 & 1.9 & & Belgium & 3 & 1.9 \\
\hline & $\begin{array}{c}\text { Food and beverage } \\
\text { products }\end{array}$ & 4 & 2.5 & & Andorra & 1 & 0.6 \\
\hline & Media & 3 & 1.9 & & Poland & 2 & 1.3 \\
\hline & Healthcare services & 7 & 4.5 & & Greece & 5 & 3.2 \\
\hline & Nonprofit services & 15 & 9.6 & & Austria & 5 & 3.2 \\
\hline & $\begin{array}{l}\text { Commercial } \\
\text { services }\end{array}$ & 10 & 6.4 & & Portugal & 3 & 1.9 \\
\hline & Telecommunications & 1 & 0.6 & & Russian & 1 & 0.6 \\
\hline & Textiles and apparel & 6 & 3.8 & & Denmark & 2 & 1.3 \\
\hline & $\begin{array}{l}\text { Forest and paper } \\
\text { products }\end{array}$ & 2 & 1.3 & & United Kingdom & 1 & 0.6 \\
\hline & Agriculture & 4 & 2.5 & & Netherlands & 8 & 5.1 \\
\hline & Conglomerates & 1 & 0.6 & & Norway & 1 & 0.6 \\
\hline & Mining & 2 & 1.3 & & Spain & 38 & 24.2 \\
\hline & Waste management & 8 & 5.1 & & Iceland & 3 & 1.9 \\
\hline & Aviation & 1 & 0.6 & & Germany & 18 & 11.5 \\
\hline & Universities & 1 & 0.6 & & Switzerland & 8 & 5.1 \\
\hline & Construction & 7 & 4.5 & & France & 4 & 2.5 \\
\hline & Energy & 7 & 4.5 & & Italy & 20 & 12.7 \\
\hline & Metal products & 3 & 1.9 & & Finland & 7 & 4.5 \\
\hline & Healthcare products & 6 & 3.8 & & Total & 157 & 100 \\
\hline & $\begin{array}{c}\text { Household and } \\
\text { personal products }\end{array}$ & 4 & 2.5 & \multirow{13}{*}{$\begin{array}{l}\text { Grouped } \\
\text { Sector }\end{array}$} & Real estate & 16 & 10.2 \\
\hline & Logistics & 3 & 1.9 & & Agriculture and mining & 6 & 3.8 \\
\hline & Public agencies & 2 & 1.3 & & Industry & 34 & 21.6 \\
\hline & Consumer durables & 1 & 0.6 & & Services & 38 & 24.2 \\
\hline & Water utilities & 1 & 0.6 & & $\begin{array}{l}\text { Public agencies } \\
\text { and services }\end{array}$ & 6 & 3.8 \\
\hline & $\begin{array}{c}\text { Construction } \\
\text { materials }\end{array}$ & 1 & 0.6 & & Nonprofit services & 15 & 9.6 \\
\hline & Automotive & 3 & 1.9 & & Financial services & 9 & 5.7 \\
\hline & Financial services & 9 & 5.7 & & $\begin{array}{c}\text { Construction and } \\
\text { construction materials }\end{array}$ & 8 & 5.1 \\
\hline & Railroads & 1 & 0.6 & & Energy & 7 & 4.5 \\
\hline & Retailers & 1 & 0.6 & & Other & 18 & 11.5 \\
\hline & Chemicals & 3 & 1.9 & & Total & 157 & 100 \\
\hline & Other & 18 & 11.5 & & - & - & - \\
\hline & Total & 157 & 100 & & - & - & - \\
\hline
\end{tabular}

Second, if we focus on the financial services sector, due to the specific features that we highlighted previously, we see that there are only nine reports to analyze. Hence, there are nine sustainability reports by European financial sector SMEs according to GRI, which supposes an important number of reports according to sector based on the breakdown in Table 1, and a percentage of reports (5.7\%) important in comparing nearly all sectors, with the exception of real estate, nonprofit services, commercial services, 
and others. It was necessary to group the sectors in order to get higher percentages of sustainability reports (grouped sector breakdown in Table 1).

Analyzing the language of these reports to see if they can be investigated more deeply, we find (Table 2) that only four out of nine reports are written in English, and the others are in the mother tongue. Although there is no English financial services SME in the sample, the majority of SMEs use English to prepare this information. It does not seem logical to prepare nonfinancial information according to GRI using the mother tongue in response to the market and stakeholders, but we must bear in mind that we focus on SMEs, and their goals in disclosing this information may not be so global.

Table 2. Nonfinancial information issued by European financial services SMEs according to GRI.

\begin{tabular}{|c|c|c|c|c|c|c|c|}
\hline & & Frequency & $\%$ & & & Frequency & $\%$ \\
\hline \multirow{7}{*}{ Country } & Sweden & 1 & 11.1 & \multirow{4}{*}{ Year } & 2016 & 1 & 11.1 \\
\hline & Iceland & 1 & 11.1 & & 2017 & 4 & 44.4 \\
\hline & Germany & 2 & 22.2 & & 2018 & 4 & 44.4 \\
\hline & Italy & 3 & 33.3 & & Total & 9 & 100 \\
\hline & Finland & 1 & 11.1 & \multirow{2}{*}{ Format of Report } & Pdf & 9 & 100 \\
\hline & Belgium & 1 & 11.1 & & Html & 0 & 0 \\
\hline & Total & 9 & 100 & \multirow{4}{*}{ Adherence Level } & In accordance core & 7 & 77.7 \\
\hline \multirow{6}{*}{$\begin{array}{l}\text { Language } \\
\text { of Report }\end{array}$} & Swedish & 1 & 11.1 & & $\begin{array}{l}\text { In accordance } \\
\text { comprehensive }\end{array}$ & 1 & 11.1 \\
\hline & English & 4 & 66.6 & & GRI referenced & 1 & 11.1 \\
\hline & German & 1 & 11.1 & & Total & 9 & 100 \\
\hline & Italian & 3 & 11.1 & \multirow{3}{*}{ Integrated Report } & Yes & 3 & 33.3 \\
\hline & \multirow{2}{*}{ Total } & \multirow{2}{*}{9} & \multirow{2}{*}{100} & & No & 6 & 66.6 \\
\hline & & & & & Total & 9 & 100 \\
\hline
\end{tabular}

Hence, only four European financial services SMEs issued nonfinancial information according to GRI standards and, fulfilling the methodological requirements, reported in English. We used all the data obtained from the GRI database during this period, so the sample is the whole population of European financial services SMEs that complied with GRI standards from 2016 to 2018 and wrote their reports in English. From the point of view of the lexical analysis methodology, the studied sample has the appropriate size, measured by the size of the corpus (number of words or tokens) compared to previous valid studies $[57,64,65]$.

We used SPSS to analyze the features of the nonfinancial information and its assurance, showing the frequencies in absolute values and percentages. All features were taken from the GRI database. After describing the features of the nonfinancial information issued by European financial services SMEs in English, we studied the narrative discourse of these reports, as this is the best way to analyze qualitative heterogeneous information. Hence, it was necessary to look for another type of methodology, such as lexical analysis, which involves studying the words used in the narrative. The reports are in PDF format in the GRI database, and to do a lexical analysis it is necessary to convert them into TXT files. We used free PDF-to-text software (https://pdftotext.com/es/) to get four TXT files correspondingly organized according to firm. These files made up the corpus for analyzing nonfinancial disclosure. To analyze the narrative reporting, we used another statistical methodology that allowed us to compare the disclosure to obtain the main characteristics of a corpus and find word patterns. The chosen tool was WordSmith Tools 7 software (version 7, Oxford University Press, Oxford, UK), published by Lexical Analysis Software and Oxford University Press since 1996. We used different utilities that this lexical analysis software offers, which are explained in the Results section. 


\section{Results}

\subsection{Features of Nonfinancial Information and Its Assurance of European Financial Services SMEs}

First, $5.7 \%$ of all European SMEs that voluntarily disclosed nonfinancial information according to GRI (9 out of 157) operated in the financial services sector (Table 1). The most important sector in this sample was real estate companies (10.2\%; Table 1), and financial services occupies an important position of nonfinancial information according to sector. The nine financial services companies that issued nonfinancial information came from different EU countries (Table 2). There are two effects to bear in mind. First, sometimes SMEs that need credit have to report on some sustainability aspects to align with banks' sustainability requirements. Second, these SMEs provide financial services, which means they have to report on their own sustainability [63]. As previously pointed out, only four of the nine used the English language to report their nonfinancial information, and five used their mother tongue, although it is supposed that these reports are published for global stakeholders (Table 2).

To get an idea of the importance of this type of SME in Europe, we can highlight that two of the four are asset managers, one in Germany and one in Finland. According to the European Fund and Asset Management Association [65], in 2017 there were 380 asset management companies in Germany (one of the leading European countries with this type of company) and 26 in Finland. Hence, bearing in mind that these numbers are not detailed by company size, we can say that these two SMEs are a good sample to study. The other two European financial services SMEs are a bank in Iceland, a state-owned bank created from an old bank during the last crisis (a national bank, thus its small size), and a provider of financial market infrastructure services in Belgium. The bank's main services are based on consumer, corporate, and private banking; mortgage loans, private equity, wealth management, and credit cards. The German asset manager offers one global investment platform focused on multi-asset alternative credit, real asset debt, and sustainable investments through a digital environment for retail investors. The Belgian provider of financial market infrastructure services acts as an international central securities depository (ICSD) and as the central securities depository (CSD) for some other securities. Retail investors can also have direct accounts in their local CSD. The Finnish asset manager offers asset management solutions and financial advice globally to private investors, institutions, professional athletes, and artists. Finally, the analyzed companies offer a valuable picture of the narrative discourse included in sustainability reports, taking into account particular niches in the financial industry. At the same time, these reports are comparable because all the companies are SMEs operating in the financial services sector, bearing in mind that the sector is one of the most important determinant variables influencing nonfinancial reporting [66-68].

As regards the adherence level, most of the nine European financial services SMEs (80\%) adjust their information to the core level of GRI, which is referred to as the "in accordance" core, and prefer not to prepare integrated reports (Table 2). Thus, it seems as if these companies try to issue nonfinancial information following the minimum established standards as highlighted by the UN when it studies sustainability reporting in the financial sector and says that it is not offering information about all sustainability factors of financial companies [69], even more if we are speaking about SMEs.

Bearing in mind the assurance of this information (Table 3), two-thirds of these financial services companies verified the disclosure externally. The predominant level of assurance is limited/moderate, and the assurance scope is a specified section as defined by GRI. The assurance providers in the analyzed reports were mainly accountants (55.5\%); one-third of verifications were done by one of the Big Four companies, KPMG (33.3\%), and one-third were done following the ISAE 3000 assurance standard. However, the financial services companies did not issue information about this assurance after they verified their nonfinancial information (at least four of them, or $44.4 \%$, did not have this information available; Table 3). 
Table 3. Features of nonfinancial assurance of European financial services SMEs.

\begin{tabular}{|c|c|c|c|c|c|c|c|}
\hline & & Frequency & $\%$ & & & Frequency & $\%$ \\
\hline \multirow{3}{*}{$\begin{array}{c}\text { External } \\
\text { Assurance }\end{array}$} & Yes & 6 & 66.6 & \multirow{3}{*}{$\begin{array}{c}\text { Type of } \\
\text { Assurance } \\
\text { Provider }\end{array}$} & Accountant & 5 & 55.5 \\
\hline & No & 3 & 33.3 & & Not available & 4 & 44.41 \\
\hline & Total & 9 & 100 & & Total & 9 & 100 \\
\hline \multirow{3}{*}{$\begin{array}{c}\text { Level of } \\
\text { Assurance }\end{array}$} & Not available & 4 & 44.4 & \multirow{3}{*}{$\begin{array}{c}\text { Assurance } \\
\text { Scope }\end{array}$} & Not available & 5 & 55.5 \\
\hline & Limited/moderate & 5 & 55.5 & & Specified sections & 4 & 44.4 \\
\hline & Total & 9 & 100 & & Total & 9 & 100 \\
\hline \multirow{5}{*}{$\begin{array}{l}\text { Assurance } \\
\text { Standard }\end{array}$} & Not available & 4 & 44.4 & \multirow{5}{*}{$\begin{array}{l}\text { Assurance } \\
\text { Provider }\end{array}$} & Not available & 4 & 44.4 \\
\hline & ISAE 3000 & 3 & 33.3 & & KPMG & 3 & 33.3 \\
\hline & AA1000AS & 1 & 11.1 & & Deloitte & 2 & 22.2 \\
\hline & National & 1 & 11.1 & & \multirow{2}{*}{ Total } & \multirow{2}{*}{9} & \multirow{2}{*}{100} \\
\hline & Total & 9 & 100 & & & & \\
\hline
\end{tabular}

\subsection{Lexical Analysis of Sustainability Reporting of European Financial Services SMEs}

First, we used the WordList application to obtain the principal characteristics of the text analyzed. The main features are shown in Table 4. Although the companies are in different countries and the reports are from different years, these data are comparable because all are SMEs and operate in the financial services sector. Finally, we analyzed 102,056 words, which are called tokens, and all together are defined as a corpus. The size of the corpus, and thus of the sample, is appropriate to apply lexical analysis (the number of analyzed words or tokens is always bigger than the corpus analyzed in previous valid studies $[57,64,65])$.

Table 4. Principal characteristics of analyzed sustainability reports.

\begin{tabular}{cccccccc}
\hline Corpus/SME & Country & Year & Words (Tokens) & $\begin{array}{c}\text { Types } \\
\text { (Distinct Words) }\end{array}$ & $\begin{array}{c}\text { Type-Token } \\
\text { Ratio (TTR) }\end{array}$ & $\begin{array}{c}\text { Standardized } \\
* * \text { TTR }\end{array}$ & Sentences \\
\hline Corpus & - & - & 102,056 & 7927 & $7.77 \%$ & $40.63 \%$ & 3800 \\
\hline SME1 & Iceland & 2018 & 38,753 & 4214 & $10.87 \%$ & $38.01 \%$ & 1423 \\
\hline SME2 & Germany & 2018 & 29,795 & 3659 & $12.28 \%$ & $42.46 \%$ & 1150 \\
\hline SME3 & Belgium & 2017 & 23,728 & 3570 & $15.05 \%$ & $42.37 \%$ & 725 \\
\hline SME4 & Finland & 2016 & 9780 & 1870 & $19.12 \%$ & $41.37 \%$ & 502 \\
\hline
\end{tabular}

* Types: different words that are not repeated in the text. ${ }^{* *}$ Standardized TTR: TTR that does not depend on different text lengths.

It can be seen that the four companies are in different European countries. There are no big differences between words in the reports of the last three years, except that in 2016 the reports were much briefer than in the following years. This may be due to the early application of GRI standards or to the fact that companies show greater effort "from year to year in giving more information in order to comply with the transparency principle, or at least to give this appearance" [57]. The same can be checked in the different words used in the reports, which are called "types" in this software, and in the type-token ratio (TTR), calculated as different words over total words, which increases when the number of total words decreases (Table 4). However, when the TTR is calculated without considering the extension of the whole text, standardized TTR, the largest number of different words, without repetition, is found in the latter reports, with the exception of the report of the Icelandic financial services company, which seems to repeat words more frequently although the report is the most extensive (more words and more sentences; Table 4). Perhaps more words are used to say the same thing, and the opposite was the case in the 2016 report; fewer words were used to say the important things, which were not repeated. Although, as mentioned, there is value in a reporting narrative, that does not mean it is an extensive report because a sustainability report is not for 
storytelling [70]. Previous studies on the relationship between disclosure length and greater readability, transparency, or complexity were inconclusive [71] and were not focused on financial services SMEs.

The next tool used in the lexical analysis was the word list (results are shown in Table 5). This counts the frequency of words used in the corpus, i.e., how often each word appears in the whole text, and their percentage of use in the text. The position is the ranking of the most frequently used words. We included in Table 5 the most significant frequent words for this analysis (the first position is included as an example). Only the word "risk" appeared in more than $1 \%$ of the cases in the corpus $(1.04 \%)$, in position 8 , followed by "bank" in position 12 and "management" in position 20. To classify these most frequent words, we created three groups: words that are basically related to financial meaning such as "risk", "bank", "management", "financial", "capital", "investment", "business", and "funds"; other words that have to do with the core sense of nonfinancial information, such as "employees", "sustainability", "board", "environmental", "committee", "governance", "pillar", and "GRI"; a group with words related to information and requirements, such as "information", "compliance", "reporting", "disclosures", and "requirement". This classification was based on the assignment of a certain term to a concept, which can be done in specialized languages, as in this case, when analyzing sustainability reporting; for example, the word "meager" is identified as a specialized term in the realm of finance, since it is very commonly used in expressions such as "meager economic recovery" and "meager 10\%" [71]. Although the word "pillar" is included in the financial group, it could also be included in the second group related to nonfinancial aspects, which we called sustainable most frequent words. This is due to the Basel II and III requirements, which ask for reporting on financial and nonfinancial items of these kinds of companies, so it contains both dimensions of the concept, financial and nonfinancial. Although these three groups of most frequent words were made following the assignment of terms to concepts in specialized languages [72], sometimes some words refer to more concepts and the assignment is not so simple.

The following results were obtained from the analysis of the most frequent words, shown in Tables 6-8. The number of occurrences of the search word (hits), occurrences of each word per 1000 words, and their dispersion are calculated. To establish comparisons, it is better to use hits per 1000 words as a homogeneous measurement. As can be seen, "financial" words are used the most: the occurrences per 1000 words were clearly the highest for these kinds of words. The most used was "risk" (10.16 times per 1000 words), followed by "bank", "management", and then a sustainable word, "sustainability" (3.75 times per 1000 words; Table 7) followed by other financial words: "financial", "capital", "investment", "business" (2.40 times per 1000 words), and then "employees", previously included in the group of sustainable words ( 2.29 times per 1000 words) and "GRI" (2.13 times per 1000 words). This means that what counts the most in sustainable reports is the financial information over the nonfinancial information, or at least the typical financial aspects of the business are highlighted more with the use of the language. These companies do not seem to include sustainable words in their vocabulary and, hence, in their culture. Although the four companies are in different countries and operate in different niches of financial services, the results are similar when classifying the most used words.

Analyzing the information on the use of these frequent words considering the four reports separately, we can see that some of the words appear to be used more because they are used very often in some reports, which increases the global frequency in the corpus. This is the case of the words "risk", "bank", and "capital" (20.15, 18.23, 6.80 per 1000 words; Table 6), which occur frequently in the report of the financial services company in Iceland. The word "sustainability" appears as the second most frequent in this group due to its use in the Finnish company's 2016 report, although it is only used in three of the four reports ( 8.10 per 1000 words; Table 7). Something similar happens with the word "employees", whose use increases due to the Finnish company's report (5.36 per 1000 words, Table 7). The case of the word "pillar" deserves some reflection because, although it is a frequent word in the corpus, the detailed analysis of the reports showed that it was only used in two, and essentially only in one because the frequency of use in the other was very low. Thus, "pillar" was exclusively used 
by the financial services company in Iceland in its 2018 report (Table 7). Another example is the term "GRI", which would be expected to appear in all of the reports, given that all are prepared according to GRI standards, yet it did not appear in one report, which is one of the most recent ones (Table 7).

Table 5. Word analysis of sustainability reports.

\begin{tabular}{|c|c|c|c|}
\hline Position & Word & Frequency & $\%$ \\
\hline 1 & The & 5001 & $4.90 \%$ \\
\hline 8 & Risk & 1103 & $1.08 \%$ \\
\hline 12 & Bank & 899 & $0.89 \%$ \\
\hline 20 & Management & 566 & $0.55 \%$ \\
\hline 24 & Financial & 374 & $0.37 \%$ \\
\hline 26 & Capital & 356 & $0.35 \%$ \\
\hline 41 & Investment & 276 & $0.27 \%$ \\
\hline 44 & Business & 261 & $0.26 \%$ \\
\hline 45 & Employees & 248 & $0.24 \%$ \\
\hline 46 & Sustainability & 234 & $0.23 \%$ \\
\hline 52 & Board & 207 & $0.2 \%$ \\
\hline 53 & Information & 206 & $0.2 \%$ \\
\hline 69 & Responsibility & 157 & $0.15 \%$ \\
\hline 73 & Compliance & 153 & $0.15 \%$ \\
\hline 74 & Reporting & 147 & $0.14 \%$ \\
\hline 75 & Disclosures & 147 & $0.14 \%$ \\
\hline 76 & Requirements & 145 & $0.14 \%$ \\
\hline 77 & environmental & 145 & $0.14 \%$ \\
\hline 79 & Committee & 143 & $0.14 \%$ \\
\hline 82 & Governance & 135 & $0.13 \%$ \\
\hline 83 & Pillar & 134 & $0.13 \%$ \\
\hline 84 & GRI & 133 & $0.13 \%$ \\
\hline 86 & Funds & 131 & $0.13 \%$ \\
\hline
\end{tabular}




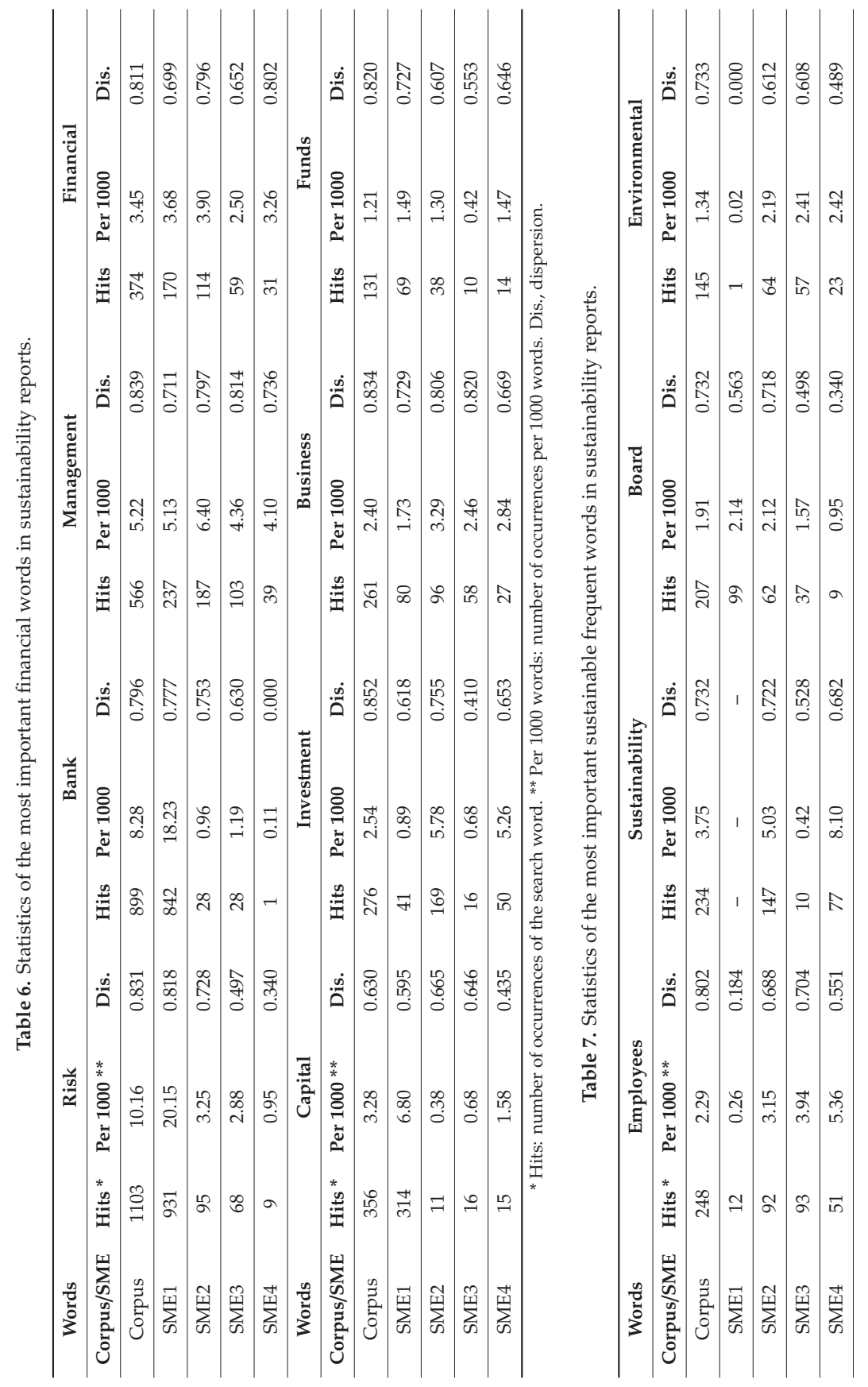




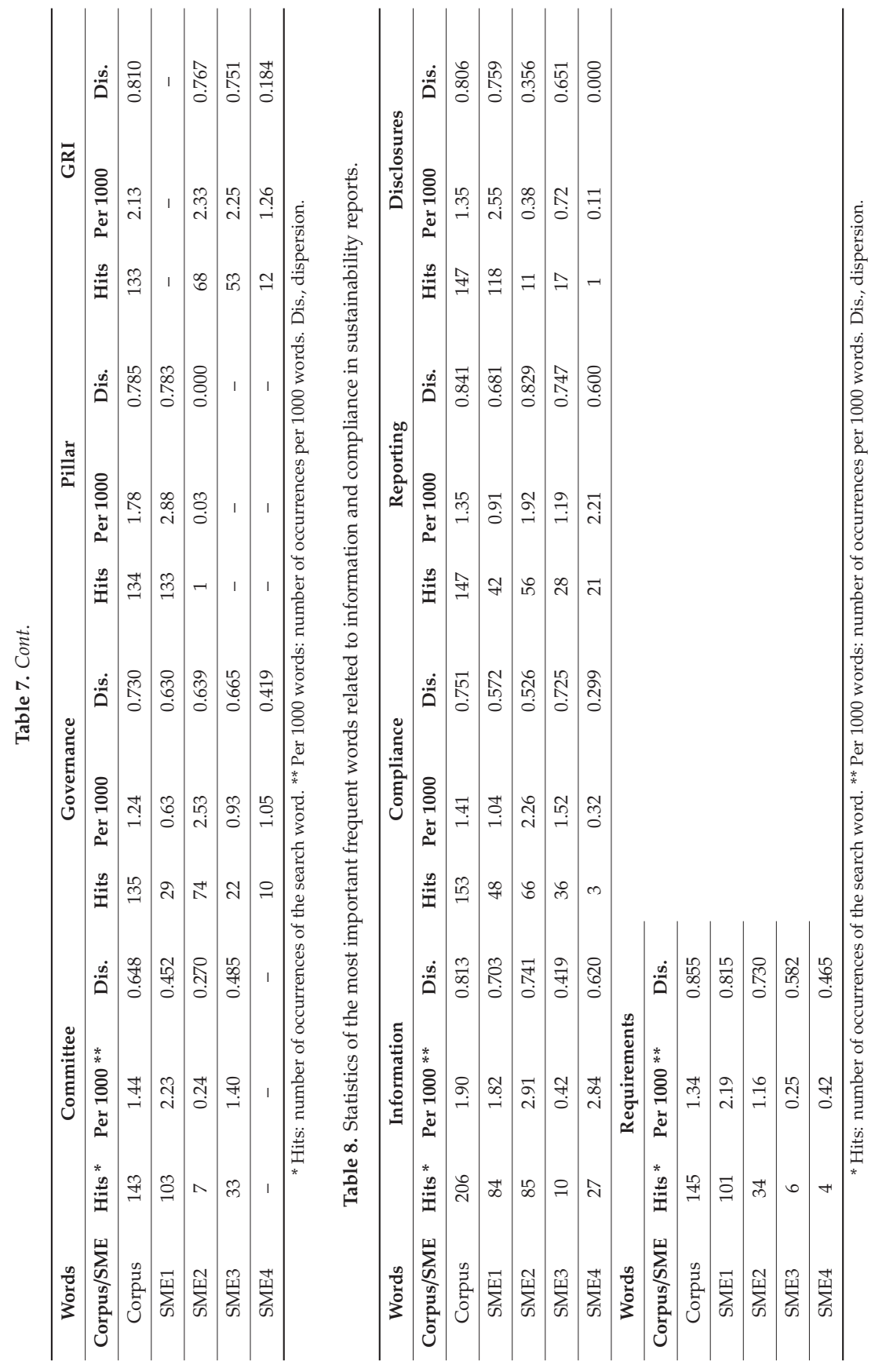


Analyzing Table 8, with the statistics of the most important frequent words related to information and compliance in the sustainability reports, there was one report in which they had less importance, as was previously obtained, that of the Belgian company from 2017. The most used words in the other three reports were those generally obtained as the most frequent words; hence, they follow the general pattern. For example, "information" showed higher frequency per 1000 words in the German and Finnish reports (SME2 and SME4: 2.91 and 2.84, respectively; Table 8) and so on with the other words.

The last three tables of this analysis (Tables 9-11) include the results obtained from the concordance tool of the lexical analysis. The last step is to analyze the most frequent words in their context. This means counting the number of times one word is found in the neighborhood of the chosen word. This tool allows us to discover whether or not the most frequent words are related to the disclosure they supposedly refer to. The method of considering the relationships between certain words and the other words that appear a sentence was used in previous studies, such as [73]. All the tables of concordance include the first eight words with the most important relationships (in the tables, they are in positions from 1 to 8 , and position 1 is always the most frequent word analyzed). In the case of the word "requirements", its position 8 showed very low frequency, and it was not included in Table 11.

Table 9. Concordance of most important financial frequent words in sustainability reports.

\begin{tabular}{ccccccccc}
\hline Position & Word & Total & Word & Total & Word & Total & Word & Total \\
\hline 1. & Bank & 936 & Risk & 1538 & Management & 610 & Financial & 394 \\
\hline 2. & Risk & 254 & Bank & 254 & Risk & 252 & Services & 33 \\
\hline 3. & Arion & 190 & Management & 252 & Asset & 55 & Report & 33 \\
\hline 4. & 2018 & 139 & Credit & 210 & Bank & 53 & Statements & 28 \\
\hline 5. & Disclosures & 104 & 2018 & 160 & Approach & 51 & Risk & 26 \\
\hline 6. & Pillar & 97 & Disclosures & 147 & Capital & 48 & Institutions & 25 \\
\hline 7. & Capital & 64 & Pillar & 118 & With & 38 & Bank & 25 \\
\hline 8. & Management & 53 & Arion & 110 & Senior & 36 & Undertakings & 25 \\
\hline Position & Word & Total & Word & Total & Word & Total & Word & Total \\
\hline 1. & Capital & 450 & Investment & 302 & Business & 279 & Funds & 149 \\
\hline 2. & Bank & 64 & Responsible & 47 & Risk & 36 & Investment & 21 \\
\hline 3. & Risk & 64 & Sustainable & 22 & With & 29 & Bank & 15 \\
\hline 4. & Requirements & 64 & Funds & 21 & Bank & 20 & Pension & 13 \\
\hline 5. & Buffer & 51 & Platform & 21 & Travel & 17 & Sustainable & 12 \\
\hline 6. & Requirement & 50 & Fund & 18 & Units & 17 & Capital & 11 \\
\hline 7. & Management & 48 & Process & 18 & Management & 17 & With & 10 \\
\hline 8. & Adequacy & 32 & Into & 17 & That & 13 & Risk & 10 \\
\hline & $*$ Total: number of times the word was found in the neighborhood of the search word. & &
\end{tabular}


Table 10. Concordance of most important sustainable frequent words in sustainability reports.

\begin{tabular}{|c|c|c|c|c|c|c|c|c|}
\hline Position & Word & Total * & Word & Total & Word & Total & Word & Total \\
\hline 1. & Employees & 260 & Sustainability & 258 & Board & 241 & Environmental & 157 \\
\hline 2. & Time & 19 & Report & 129 & Committee & 53 & Social & 51 \\
\hline 3. & With & 16 & 2018 & 82 & Executive & 44 & Impacts & 15 \\
\hline 4. & That & 15 & Information & 36 & Directors & 42 & Impact & 14 \\
\hline 5. & Have & 15 & Supplementary & 32 & Management & 27 & Group & 12 \\
\hline 6. & Permanent & 15 & Topics & 25 & Risk & 27 & Assessment & 12 \\
\hline 7. & Total & 12 & This & 22 & Bric & 19 & Footprint & 12 \\
\hline 8. & Their & 12 & Clients & 21 & Policy & 17 & Economic & 11 \\
\hline Position & Word & Total & Word & Total & Word & Total & Word & Total \\
\hline 1. & Committee & 203 & Governance & 147 & Pillar & 148 & GRI & 133 \\
\hline 2. & Board & 53 & Corporate & 46 & Risk & 118 & 2017 & 25 \\
\hline 3. & Credit & 40 & Risk & 15 & Disclosures & 105 & Index & 24 \\
\hline 4. & Risk & 25 & Data & 12 & 2018 & 97 & Responsibility & 24 \\
\hline 5. & Management & 24 & Social & 11 & Bank & 97 & With & 19 \\
\hline 6. & Executive & 21 & Policy & 11 & Arion & 94 & Disclosure & 18 \\
\hline 7. & Level & 17 & Body & 11 & Capital & 24 & Reporting & 16 \\
\hline 8. & Arion & 14 & Environmental & 11 & Requirements & 21 & Report & 14 \\
\hline
\end{tabular}

Table 11. Concordance of most important frequent words related to information and compliance in sustainability reports.

\begin{tabular}{|c|c|c|c|c|c|c|}
\hline Position & Word & Total * & Word & Total & Word & Total \\
\hline 1. & Information & 214 & Compliance & 165 & Reporting & 152 \\
\hline 2. & Report & 48 & With & 33 & Risk & 22 \\
\hline 3. & Sustainability & 36 & Risk & 27 & Financial & 22 \\
\hline 4. & Security & 35 & Officer & 19 & Sustainability & 16 \\
\hline 5. & Risk & 31 & Control & 18 & Report & 14 \\
\hline 6. & 2018 & 27 & Regulatory & 14 & Bank & 13 \\
\hline 7. & Supplementary & 26 & Management & 13 & Internal & 12 \\
\hline 8. & Bank & 18 & 2018 & 13 & Period & 11 \\
\hline Position & Word & Total & Word & Total & & \\
\hline 1. & Disclosures & 148 & Requirements & 155 & & \\
\hline 2. & Risk & 148 & Capital & 64 & & \\
\hline 3. & Pillar & 106 & Regulatory & 25 & & \\
\hline 4. & Bank & 104 & With & 21 & & \\
\hline 5. & 2018 & 98 & Bank & 21 & & \\
\hline 6. & Arion & 96 & Risk & 19 & & \\
\hline 7. & Credit & 21 & Buffer & 15 & & \\
\hline 8. & Management & 18 & - & - & & \\
\hline
\end{tabular}


The words that were previously grouped as financial terms in the analysis of the most frequent words are related to the same type of financial words: bank-risk, management-risk, financial-services, capital-bank-risk, business and risk, and funds-investment-bank (all are in position 1, 2, or 3 in Table 9, which means they appear next to each other). The only most frequent financial word included previously that was more frequently related to other sustainable terms was "investment", appearing in the reports with "responsible" and "sustainable" (Table 9).

The most frequent words about sustainable aspects appeared fewer times that the financial ones (Table 10), and the concordance shows the following:

- The word "employees" is not related to other important words.

- The word "sustainability" is linked mainly to "report", due to the requirement to issue sustainable information, and is totally consistent with the results obtained in Table 11.

- The words "committee" and "board", "environmental" and "social", "governance" and "corporate" are found frequently in the same neighborhood, a result that is totally logical.

- The word "pillar" appears in the neighborhood with two other words, "risk" and "disclosures", as is also seen in Table 11 with "disclosures". This result proves that "pillar" is a word that comes from the Basel II and III requirements regarding these aspects.

- Finally, the most important link is found between "GRI", "2017", and "index", as reports include the GRI index to show that they are elaborated according to GRI standards.

The majority of results included in Table 11 go further in the importance of the words "compliance", "requirements", "disclosures", and "risk". According to GRI good practices for SMEs, sustainability reporting has to comply with the following checklist: it describes the sustainable development and draws objective and available information and measures of sustainable development, presents the performance of sustainable conditions and goals and the magnitude of the contribution to (un)sustainability, and describes the relationship between sustainability and long-term organizational strategy, risks, and opportunities [74]. Thus, if we use this lexical analysis to understand whether these financial services SMEs properly developed their sustainability reporting, the obtained results show that although they used some specific words to meet the minimum requirements, the financial dimension of reporting continues to be more important, and the other information is used to increase the length of the report but still does not reflect significant environmental and social impacts. According to previous studies [75], sustainability reporting in financial companies has as the highest priorities those directly related to their business operations.

\section{Discussion}

Our analysis is based on European SMEs included in the GRI database, hence the population of SMEs that voluntarily use GRI standards, although only between 10 and $15 \%$ of sustainability reports in the database from 2017 to 2018 came from SMEs [76]. Then, we focused on European SMEs operating in the financial services sector. Bearing in mind their specific activity, sustainability reports by European financial sector SMEs represent an important percentage of reports in comparison with nearly all other sectors $(5.7 \%)$.

The results obtained from the lexical analysis lead us to think that the answer to our first research question is yes because there is no significant use of symbolic concepts in the narrative discourse in the reports analyzed; hence, there is minimum compliance with nonfinancial requirements. Opposite results were obtained by the authors of [53] after applying a lexicometric analysis to speeches delivered by European Central Bank presidents, although in this case we analyzed sustainability reporting.

Although initially it may be thought that sustainability reports are specific for each company, the broader corpus analysis suggests they were prepared similarly and used the same template [52], even more if it is pointed out that the four companies are in different countries and, although operating in financial services, are focused on different niches. As the sector is a strongly determinant variable of nonfinancial reporting [66-68], the analyzed reports follow the same pattern. Financial services 
companies not only operate in the same sector, but they also have their own regulatory and supervisory bodies. In this case the sector is decisive in following the same financial trend in sustainability information, and as found in KPMG's 2017 survey, financial services companies are in last place in corporate responsibility reporting [77].

These financial services companies are still imbued with traditional financial objectives and information. This means that what counts most in sustainable reports is financial information over nonfinancial, or at least the typical financial aspects of the business in this important sector are highlighted more through the language used. The analysis of the most frequent words in context shows that all financial terms are related to other financial terms. Hence, our second research question is supported. These results are the same as those obtained in previous studies, although in developing countries, based on financial services companies, because it is argued that the most important priorities of these enterprises are those directly related to their business operations [75].

Although a first view of sustainable reporting may show that companies try to exert more effort to increase the extent of their disclosure, the deep lexical analysis of these reports shows that the language used is not so extensive or rich, as some words are repeated many times, which highlights the problem of the lack of content in sustainability information. This shows evidence of the gap that still exists between financial and nonfinancial information and takes us to the same question posed by other researchers: "If it is like this for disclosing firms, what is happening in the case of nondisclosing firms?" [55].

Future research directions depend on an increase in nonfinancial reports, which will make it possible to get a bigger sample, more companies, and a longer period. Currently, the most important limitation is the number of sustainability reports published according to GRI by European financial services SMEs. Another future research project involves using a proper sample of nonfinancial reports to describe and compare financial sector vs. nonfinancial sector SMEs and financial sector SMEs vs. large financial sector companies.

\section{Conclusions}

These financial services SMEs should particularly focus on the proper elaboration and publication of sustainability reporting. There are many initiatives to increase the importance of this type of company in Europe and to move toward more sustainable finance. There is a challenge for these companies, taking into account all of their stakeholders, to give the proper role to nonfinancial information. It is desirable that SMEs, as well as those that operate in the financial services sector due to their essential role in the economy, start issuing nonfinancial information, especially now, when alternatives to traditional bank financing are being promoted for financing SMEs. These results and conclusions have theoretical and practical implications for the importance of sustainability reporting. It may be a burden, but it can also have multiple advantages, such as being an opportunity to create value in the company, differentiate from other companies, improve operational performance, or enhance market reputation, among others. Our contribution with this work is to point out that these financial services SMEs play an important role, and sustainability reporting has to mean there is another way to do business [78]. This study provides an opportunity to improve sustainability disclosure and standards considering the specific features of financial services SMEs. Regulators must take into account the specific features of this type of company in order to adapt the standards and requirements. Sustainability reports must include all relevant topics that reflect the organization's economic, environmental, and social impacts or influence the decisions of stakeholders [74]. The main reasons argued for not having proper sustainability reporting by SMEs are the lack of resources, awareness of sustainability's importance and potential impacts, access to financing, information and skills to elaborate this information, and regulatory requirements [76]. Thus, this is an opportunity for practitioners, academics, and regulators to try to solve these problems from all points of view, theoretical and practical, to make up for this lack of resources according to their different tasks. Now, when the European Commission is working on amending the nonfinancial reporting directive 
through the mission of the European Financial Reporting Advisory Group (EFRAG) and its Project Task Force on nonfinancial reporting standards, it is time to think about these specific features of SMEs and financial services companies to make the process of sustainability reporting easier.

Author Contributions: Conceptualization, E.O.-M. and S.M.-H.; methodology, E.O.-M. and S.M.-H.; software, E.O.-M.; validation, S.M.; formal analysis, E.O.-M. and S.M.-H.; investigation, E.O.-M. and S.M.-H.; resources, E.O.-M. and S.M.-H.; data curation, E.O.-M. and S.M.-H.; writing—original draft preparation, E.O.-M. and S.M.-H.; writing-review and editing, E.O.; visualization, S.M.-H.; supervision, E.O.-M. and S.M.-H. All authors have read and agreed to the published version of the manuscript.

Funding: This research received no external funding.

Conflicts of Interest: The authors declare no conflict of interest.

\section{References}

1. Directive 2014/95/EU of the European Parliament and of the Council of 22 October 2014 Amending Directive 2013/34/EU as Regards Disclosure of Non-Financial and Diversity Information by Certain Large Undertakings and Groups. Available online: https://eur-lex.europa.eu/legal-content/EN/TXT/?uri=CELEX\%3A32014L0095 (accessed on 20 May 2019).

2. Lang, M.; Martin, R. The Trickle down Effect-IFRS and accounting by SMEs. European Federation of Accountants and Auditors for SMEs 2017. Available online: http:/www.efaa.com/cms/upload/efaa_files/pdf/ Publications/Articles/EFAA_Trickle_Down_WEB.pdf (accessed on 10 July 2020).

3. European Commission. Communication from the Commission to the Council, to the European Parliament, to the Committee of the Regions and to the European and Social Committee. An Action Plan to Improve Access to Finance for SMEs 2011. SEC (2011) 1527final. COM (2011) 870 Final. Available online: https: //eur-lex.europa.eu/LexUriServ/LexUriServ.do?uri=COM:2011:0870:FIN:EN:PDF (accessed on 11 July 2020).

4. Azofra Palenzuela, V.; López Iturriaga, F.J. La Asimetría Informativa En Los Mercados Financieros: ¿el Hallazgo De Un Nexo De Unión? An. Estud. Económicos Empresariales 1996, 11, 9-34.

5. Asteriou, D.; Spanos, K. The relationship between financial development and economic growth during the recent crisis: Evidence from the EU. Financ. Res. Lett. 2019, 28, 238-245. [CrossRef]

6. Palacín-Sánchez, M.-J.; Canto-Cuevas, F.-J.; Di-Pietro, F. Trade credit versus bank credit: A simultaneous analysis in European SMEs. Small Bus. Econ. 2018, 53, 1079-1096. [CrossRef]

7. Glisovic, J.; Martínez, M. Financiamiento de Pequeñas Empresas: ¿Qué papel Desempeñan las Instituciones Microfinancieras? Available online: https://www.cgap.org/sites/default/files/CGAP-Focus-Note-FinancingSmall-Enterprises-What-Role-for-Microfinance-Jul-2012-Spanish.pdf (accessed on 25 July 2020).

8. Feridun, M.; Güngör, H. Climate-related prudential risks in the banking sector: A review of the emerging regulatory and supervisory practices. Sustainability 2020, 12, 5325. [CrossRef]

9. European Commission. Roadmap: Commission Delegated Regulation on Taxonomy-Related Disclosures by Undertakings Reporting Non-Financial Information. 2020. Available online: https://ec.europa.eu/info/law/better-regulation/have-your-say/initiatives/12440-Commission-DelegatedRegulation-on-taxonomy-alignment-of-undertakings-reporting-non-financial-information (accessed on 30 July 2020).

10. Baumann-Pauly, D.; Wickert, C.; Spence, L.J.; Scherer, A.G. Organizing corporate social responsibility in small and large firms: Size matters. J. Bus. Ethics 2013, 115, 693-705. [CrossRef]

11. Dincer, C.; Dincer, B. An investigation of Turkish small and medium-sized enterprises online CSR communication. Soc. Responsib. J. 2010, 6, 197-207. [CrossRef]

12. Torugsa, N.A.; O'Donohue, W.; Hecker, R. Capabilities, proactive CSR and financial performance in SMEs: Empirical evidence from an australian manufacturing industry sector. J. Bus. Ethics 2011, 109, 483-500. [CrossRef]

13. Nin Ho, F.; Wang, H.-M.D.; Ho-Dac, N.; Vitell, S.J. Nature and relationship between corporate social performance and firm size: A cross-national study. Soc. Responsib. J. 2019, 15, 258-274. [CrossRef]

14. Ortiz, E.; Marin, S. Global Reporting Initiative (GRI) as recognized guidelines for sustainability reporting by Spanish companies on the IBEX 35: Homogeneity in their framework and added value in the relationship with financial entities. Intang. Cap. 2014, 10, 855-872. [CrossRef]

15. Albers, C.; Günther, T. Disclose or not disclose: Determinants of social reporting for STOXX Europe 600 firms. Z. Plan. Unternehm. 2010, 21, 323-347. [CrossRef] 
16. Berthelot, S.; Coulmont, M.; Serret, V. Do investors value sustainability reports? A Canadian study. Corp. Soc. Responsib. Environ. Manag. 2012, 19, 355-363. [CrossRef]

17. Cuganesan, S.; Guthrie, J.; Ward, L. Examining CSR disclosure strategies within the Australian food and beverage industry. Account. Forum 2010, 34, 169-183. [CrossRef]

18. Etzion, D.; Ferraro, F. The role of analogy in the institutionalization of sustainability reporting. Organ. Sci. 2010, 21, 1092-1107. [CrossRef]

19. Lopatta, K.; Kaspereit, T. The value relevance of corporate sustainability and sustainability reporting in Europe. SSRN Electron. J. 2011. [CrossRef]

20. Levy, D.L.; Brown, H.S.; De Jong, M. The contested politics of corporate governance. Bus. Soc. 2009, 49, 88-115. [CrossRef]

21. Lynch, B. An examination of environmental reporting by Australian state government departments. Account. Forum 2010, 34, 32-45. [CrossRef]

22. Schadewitz, H.J.; Niskala, M. Communication via responsibility reporting and its effect on firm value in Finland. Corp. Soc. Responsib. Environ. Manag. 2010, 17, 96-106. [CrossRef]

23. González Pérez, M.; Ortiz Martínez, E. Información no financiera y su verificación externa: GRI. Rev. Responsab. Soc. Empresa 2017, 27, 85-106.

24. Dias, A.; Rodrigues, L.L.; Craig, R.; Neves, M.E.D. Corporate social responsibility disclosure in small and medium-sized entities and large companies. Soc. Responsib. J. 2019, 15, 137-154. [CrossRef]

25. Ram, M.; Edwards, P.; Gilman, M.; Arrowsmith, J. The dynamics of informality: Employment relations in small firms and the effects of regulatory change. Work Employ. Soc. 2001, 15, 845-861. [CrossRef]

26. Santos, M.J. CSR in SMEs: Strategies, practices, motivations and obstacles. Soc. Responsib. J. 2011, 7, 490-508. [CrossRef]

27. Bikefe, G.; Zubairu, U.M.; Araga, S.; Maitala, F.; Ediuku, E.; Anyebe, D. Corporate Social Responsibility (CSR) by small and medium enterprises (SMEs): A systematic review. Small Bus. Int. Rev. 2020, 4, 16-33. [CrossRef]

28. Griffin, J.J.; Mahon, J.F. The corporate social performance and corporate financial performance debate. Bus. Soc. 1997, 36, 5-31. [CrossRef]

29. Inoue, Y.; Lee, S. Effects of different dimensions of corporate social responsibility on corporate financial performance in tourism-related industries. Tour. Manag. 2011, 32, 790-804. [CrossRef]

30. Ioannou, I.; Serafeim, G. What drives corporate social performance? International evidence from social, environmental and governance scores. J. Int. Bus. Stud. 2012, 43, 834-864. [CrossRef]

31. Khan, C.H.-U.-Z. The effect of corporate governance elements on corporate social responsibility (CSR) reporting. Empirical evidence from private commercial banks of Bangladesh. Int. J. Law Manag. 2010, 52, 82-109. [CrossRef]

32. Jizi, M.; Salama, A.; Dixon, R.; Stratling, R. Corporate governance and corporate social responsibility disclosure: Evidence from the US banking sector. J. Bus. Ethics 2013, 125, 601-615. [CrossRef]

33. Gambetta, N.; García-Benau, M.A.; Zorio-Grima, A. Corporate social responsibility and bank risk profile: Evidence from Europe. Serv. Bus. 2016, 11, 517-542. [CrossRef]

34. Marín, S.; Gras, E.; Ortiz, E. Prudential regulation and financial information in Spanish banks: 1995-2015. Span. J. Financ. Account. Rev. Española Financ. Contab. 2019, 48, 1-23. [CrossRef]

35. Gallego-Alvarez, I.; Pucheta-Martínez, M.C. Environmental strategy in the global banking industry within the varieties of capitalism approach: The moderating role of gender diversity and board members with specific skills. Bus. Strat. Environ. 2020, 29, 347-360. [CrossRef]

36. Platonova, E.; Asutay, M.; Dixon, R.; Mohammad, S. The impact of corporate social responsibility disclosure on financial performance: Evidence from the GCC Islamic banking sector. J. Bus. Ethics 2016, 151, 451-471. [CrossRef]

37. Esteban-Sanchez, P.; De La Cuesta-Gonzalez, M.; Paredes-Gazquez, J.D. Corporate social performance and its relation with corporate financial performance: International evidence in the banking industry. J. Clean. Prod. 2017, 162, 1102-1110. [CrossRef]

38. Wu, M.-W.; Shen, C.-H.; Chen, T.-H. Application of multi-level matching between financial performance and corporate social responsibility in the banking industry. Rev. Quant. Financ. Account. 2016, 49, 29-63. [CrossRef]

39. Al-Malkawi, H.-A.N.; Pillai, R. Analyzing financial performance by integrating conventional governance mechanisms into the GCC Islamic banking framework. Manag. Financ. 2018, 44, 604-623. [CrossRef]

40. Fijalkowska, J.; Zyznarska-Dworczak, B.; Garsztka, P. Corporate social-environmental performance versus financial performance of banks in central and Eastern European Countries. Sustainability 2018, 10, 772. [CrossRef] 
41. Laguir, I.; Marais, M.; El Baz, J.; Stekelorum, R. Reversing the business rationale for environmental commitment in banking: Does financial performance lead to higher environmental performance? Manag. Decis. 2018, 56, 358-375. [CrossRef]

42. Pérez, A.; Salmones, M.D.M.G.D.L.; Liu, M.T. Maximising business returns to corporate social responsibility communication: An empirical test. Eur. Bus. Rev. 2019, 28, 275-289. [CrossRef]

43. San-Jose, L.; Retolaza, J.L.; Gutierrez-Goiria, J. Are ethical banks different? a comparative analysis using the radical affinity index. J. Bus. Ethics 2011, 100, 151-173. [CrossRef]

44. Tse, T. Shareholder and stakeholder theory: After the financial crisis. Qual. Res. Financ. Mark. 2011, 3, 51-63. [CrossRef]

45. Shoenmaker, D.; Werkhoven, D. What Is the Appropriate Size of the Banking System? 2012. No. 28. Available online: https://papers.ssrn.com/sol3/papers.cfm?abstract_id=2158606 (accessed on 25 July 2020).

46. McDonald, L.M.; Rundle-Thiele, S. Corporate social responsibility and bank customer satisfaction: A Research Agenda. Int. J. Bank Mark. 2008, 26, 170-182. [CrossRef]

47. Goss, A.; Roberts, G.S. The impact of corporate social responsibility on the cost of bank loans. J. Bank. Financ. 2011, 35, 1794-1810. [CrossRef]

48. European Commission. Consultation Document Review of the Non-Financial Reporting Directive 2020. Available online: https://ec.europa.eu/info/publications/finance-consultations-2020-non-financial-reportingdirective_en (accessed on 10 July 2020).

49. Amor-Esteban, V.; Galindo-Villardón, P.; García-Sánchez, I.-M. A multivariate proposal for a National Corporate Social Responsibility Practices Index (NCSRPI) for international settings. Soc. Indic. Res. 2018, 143, 525-560. [CrossRef]

50. Ortiz, E.; Clavel, J.G. Índices de revelación de información: Una propuesta de mejora de la metodología. Aplicación a la información sobre recursos humanos incluida en los Informes 20F. Rev. Española Financ. Contab. 2006, 35, 87-113. [CrossRef]

51. Bakhtiar, M.; Weekes, B. Lexico-semantic effects on word naming in Persian: Does age of acquisition have an effect? Mem. Cogn. 2014, 43, 298-313. [CrossRef] [PubMed]

52. Marchenko, O.O. A method for automatic construction of ontological knowledge bases. I. Development of a semantic-syntactic model of natural language. Cybern. Syst. Anal. 2016, 52, 20-29. [CrossRef]

53. D'Northwood, G.; Mundy, J. BP plc 2010—A case of linguistic legitimation? J. Appl. Account. Res. 2017, 18, 480-495. [CrossRef]

54. Morales, A. Uso de la Familia Léxica de Sovereignty en los Discursos de la Presidencia del Banco Central Europeo 2003-2016. Available online: http://hdl.handle.net/10201/53021 (accessed on 20 May 2020).

55. Madeira, A.B.; Lopes, M.; Giampadi, V.; Silveira, J.A.G. Análise proposicional quantitativa aplicada. Á pesquisa em administrasao. Quantitative propositional analysis as applied to business administration research. Análisis proposicional cuantitativo aplicado a la investigación en administración. RAE 2011, 51, 396-410.

56. Sohangir, S.; Petty, N.; Wang, D. Financial sentiment lexicon analysis. In Proceedings of the 2018 IEEE 12th International Conference on Semantic Computing (ICSC), Laguna Hills, CA, USA, 31 January-2 February 2018; pp. 286-289. [CrossRef]

57. Martinez, E.O.; Crowther, D. Is disclosure the right way to comply with stakeholders? The Shell case. Bus. Ethics Eur. Rev. 2007, 17, 13-22. [CrossRef]

58. Nájera-Sánchez, J.-J. A systematic review of sustainable banking through a co-word analysis. Sustainability 2019, 12, 278. [CrossRef]

59. Figueira Marquezau, L.H.; Seibert, R.M.; Bartz, D.; Gomes Barbosa, M.A.; Wickstrom Alves, T. Análise dos Determinantes do disclosure Verde em Relatórios Anuais de Empresas Listadas na BM\&FBOVESPA. Contab. Gest. Gov. Brasilia 2015, 18, 127-150.

60. Fuoli, M. Assessing social responsibility: A quantitative analysis of Appraisal in BP's and IKEA's social reports. Discourse Commun. 2012, 6, 55-81. [CrossRef]

61. Miller, C.V.; Tripp, E.R.; Rasco, M.A. A Linguistic Analysis and Comparison of Hong Kong and US Corporate Governance Reports 2010. Available online: https://digitalcommons.wpi.edu/iqp-all/651 (accessed on 5 April 2020).

62. UN Environment. Sustainability Reporting in the Financial Sector. A Governmental Approach 2017. Available online: https://wedocs.unep.org/handle/20.500.11822/17375 (accessed on 26 April 2020). 
63. GRI. Empowering Small Business. Recommendations for Policy Makers to Enable Corporate Sustainability Reporting for SMEs 2018. Available online: file://C:/Users/UM/Downloads/empowering_small_business_ policy_recommendations\%20(1).pdf (accessed on 22 July 2020).

64. Kaity, M.; Balakrishnan, V. An automatic non-English sentiment lexicon builder using unannotated corpus. J. Supercomput. 2019, 75, 2243-2268. [CrossRef]

65. Kocoń, J.; Miłkowski, P.; Zaśko-Zielińska, M. Multi-level sentiment analysis of PolEmo 2.0: Extended corpus of multi-domain consumer reviews. In Proceedings of the 23rd Conference on Computational Natural Language Learning, Hong Kong, China, 3-4 November 2019; Association for Computational Linguistics: Stroudsburg, PA, USA, 2019; pp. 980-991.

66. Bonsón, E.; Escobar, T. La Difusión Voluntaria de Información Financiera en internet. Un Análisis Comparativo entre Estados Unidos, Europa del Este y la Unión Europea. Rev. Española Financ. Contab. 2004, 33, 1063-1101. [CrossRef]

67. Xiao, J.Z.; Yang, H.; Chow, C.W. The determinants and characteristics of voluntary internet-based disclosures by listed Chinese companies. J. Account. Public Policy 2004, 23, 191-225. [CrossRef]

68. Oyelere, P.; Laswad, F.; Fisher, R. Determinants of internet financial reporting by New Zealand Companies. J. Int. Financ. Manag. Account. 2003, 14, 26-63. [CrossRef]

69. EFAMA. Asset Management in Europe. An Overview of the Asset Management Industry, 11th ed.; EFAMA: Brussels, Belgium, 2019; Available online: https://www.efama.org/Publications/Statistics/Asset\%20Management $\%$ 20Report/AssetManagementReport2019.pdf (accessed on 19 June 2020).

70. Sutton, J. Why There Is Not Role for Storytelling in Your Sustainability Report 2017. Available online: https://sustainablebrands.com/read/marketing-and-comms/why-there-is-no-role-for-storytelling-in-yoursustainability-report (accessed on 27 April 2020).

71. Nazari, J.A.; Hrazdil, K.; Mahmoudian, F. Assessing social and environmental performance through narrative complexity in CSR reports. J. Contemp. Account. Econ. 2017, 13, 166-178. [CrossRef]

72. Moreno-Ortiz, A.; Fernandez-Cruz, J. Identifying polarity in financial texts for sentiment analysis: A corpus-based approach. Procedia Soc. Behav. Sci. 2015, 198, 330-338. [CrossRef]

73. Ito, R.; Izumi, K.; Sakaji, H.; Suda, S. Lexicon creation for financial sentiment analysis using network embedding. J. Math. Financ. 2017, 7, 896-907. [CrossRef]

74. GRI IOE. Small Business Big Impact. SME Sustainability Reporting from Vision to Action. Available online: https://www.ioe-emp.org/fileadmin/ioe_documents/publications/Policy\%20Areas/sustainability/ EN/20171113_Small_business_big_impact___publication_ENGLISH_version.pdf (accessed on 30 July 2020).

75. Kumar, K.; Prakash, A. Examination of sustainability reporting practices in Indian banking sector. Asian J. Sustain. Soc. Responsib. 2019, 4, 2. [CrossRef]

76. Accountancy Europe. SME Risk Management: Sustainability. Factsheet July 2020. Available online: https: //www.accountancyeurope.eu/publications/sme-risk-management-sustainability/ (accessed on 30 July 2020).

77. KPMG. The Road Ahead. The KPMG Survey of Corporate Responsibility Reporting 2017. Available online: https://integratedreporting.org/wp-content/uploads/2017/10/kpmg-survey-of-corporateresponsibility-reporting-2017.pdf (accessed on 20 April 2020).

78. Alonso, A.; Marqués, J.M. Innovación Financiera para una Economía Sostenible; Documentos Ocasionales; Banco de España: Madrid, Spain, 2019.

(C) 2020 by the authors. Licensee MDPI, Basel, Switzerland. This article is an open access article distributed under the terms and conditions of the Creative Commons Attribution (CC BY) license (http://creativecommons.org/licenses/by/4.0/). 


\title{
Sustainable Banking, Market Power, and Efficiency: Effects on Banks' Profitability and Risk
}

\author{
Begoña Torre Olmo, María Cantero Saiz * and Sergio Sanfilippo Azofra
}

Citation: Torre Olmo, B.; Cantero Saiz, M.; Sanfilippo Azofra, S. Sustainable Banking, Market Power, and Efficiency: Effects on Banks' Profitability and Risk. Sustainability 2021, 13, 1298. https://doi.org/ $10.3390 /$ su13031298

\section{Academic Editor:}

Ştefan Cristian Gherghina

Received: 22 December 2020

Accepted: 22 January 2021

Published: 26 January 2021

Publisher's Note: MDPI stays neutral with regard to jurisdictional claims in published maps and institutional affiliations.

Copyright: (c) 2021 by the authors. Licensee MDPI, Basel, Switzerland. This article is an open access article distributed under the terms and conditions of the Creative Commons Attribution (CC BY) license (https:// creativecommons.org/licenses/by/ $4.0 /)$.
Business Administration Department, Faculty of Economics and Business, University of Cantabria, Avd. Los Castros S/N, 39005 Santander, Cantabria, Spain; torreb@unican.es (B.T.O.); sanfilis@unican.es (S.S.A.) * Correspondence: canterom@unican.es

\begin{abstract}
The financial crisis seriously damaged the reputation of the banking sector, as well as its profitability and risk of insolvency, which led many banks to adopt a sustainable approach aimed at balancing long-term goals with short-term performance pressures. This article analyses how sustainable banking practices affect the profitability and the insolvency risk of banks. Moreover, we examine how sustainable strategies determine the effects of market power and efficiency on bank profitability. We used a two-step System-GMM to analyze an unbalanced panel of 1236 banks from 48 countries over the period 2015-2019. We found that sustainable banking practices increased profitability, and market power was an important determinant of profitability among conventional banks, but not among sustainable banks. Higher levels of cost scale efficiency led to greater profitability for both sustainable and conventional banks. However, there was no significant relationship between sustainable banking and insolvency risk. These results indicate that the traditional determinants of bank profitability are not relevant in explaining the superior profits of sustainable banks, which suggests the emergence of a new paradigm related to sustainability among the drivers of bank profitability.
\end{abstract}

Keywords: sustainable banking; market power; efficiency; profitability; risk

\section{Introduction}

During the global financial crisis of 2008, the banking sector focused too much on financial results while disregarding other aspects of business, which led to the banks' failure and seriously damaged their reputation. Banks have attempted to recoup this damaged reputation and restore trust by implementing sustainable business strategies [1,2]. Sustainable practices are aimed at supporting the environment, society, and the economic benefit of the business simultaneously, which can have important effects on bank profitability [3]. Traditionally, the profitability of the banking sector has been explained mainly by two hypotheses [4]. The market power hypothesis considers that greater market concentration, or market power, facilitates the setting of higher profits for customers, which increases windfall profits for banks, while the efficiency hypothesis assumes a positive relationship between efficiency and bank profits.

Some articles have analyzed the profitability of sustainable banks $[1,5,6]$, but none has considered how sustainable banking affects the traditional hypotheses of market power and efficiency. The first contribution of the article is thus to analyze how sustainable practices determine the effects of market power and efficiency on bank profitability. The analysis of these aspects is very important because the financial crisis not only led banks to adopt sustainable activities; it also reduced the profitability of banks, increased the concentration of the banking industry due to mergers and acquisitions, and strengthened the differences between more and less efficient banks because the former could reduce costs, avoid excessive delinquency, and get better financing conditions [7].

Sustainable business models offer competitive advantages for banks, such as better reputation and brand differentiation, which attracts more loyal customers and increases 
market share. However, it is likely that sustainable banks will not exploit their greater market power to impose higher prices on customers, as proposed by the market power hypothesis. Instead, these banks would use other competitive advantages, such as emotional factors or differentiated business cultures and values to capture customers' loyalty and boost profits [8]. We thus propose the following hypothesis:

Hypothesis 1 (H1). The market power hypothesis is less relevant in explaining bank profitability for sustainable banks than for conventional banks.

Conversely, sustainable practices are costly, which can have adverse effects on bank efficiency [9]. Nevertheless, sustainable actions also improve banks' reputation, which lowers their funding costs and gives them access to more investments $[10,11]$. Moreover, these actions also strengthen the sustainability standards of the banking industry, which raises competitors' costs [12]. Therefore, it is likely that the positive effects of sustainable strategies on bank efficiency compensate for the negative ones and, thus, sustainable banks tend to be as efficient as conventional banks. Consequently, we propose the following hypothesis:

Hypothesis 2 (H2). The relevance of the efficiency hypothesis in explaining bank profitability is similar for both sustainable and conventional banks.

Not only can sustainable practices determine the relationship between profitability, efficiency, and market power, but they can also affect banks' insolvency risk: the risk of a bank being unable to fulfil its obligations of repaying its debt. Although studies on the relationship between sustainability and financial performance are relatively numerous, the relationship between sustainability and bank stability has not received enough attention from researchers and remains open to debate even today [13]. The second contribution of this article is thus to analyze how sustainable banking strategies affect insolvency risk. The study of ways to reduce insolvency risk deserves special attention because during the crisis, financial institutions faced huge losses from credit defaults, high levels of uncertainty, and strong funding restrictions $[14,15]$. This is important as insolvency risk not only affects the bank itself, but also may influence the entire financial system [16].

Sustainable strategies can reduce insolvency risk because they improve brand image and attract customers, which lowers reputational risk [11,17]. Sustainable banks also tend to have a greater degree of transparency and higher moral standards, which mitigates adverse selection and moral hazard problems [18]. Moreover, banks with higher funding stability are more prone to invest in sustainable activities $[19,20]$. So, we propose the following hypothesis:

Hypothesis 3 (H3). Sustainable banking practices lead to a reduction in bank risk.

To test Hypotheses 1-3, we performed empirical analysis of a sample of 1236 banks from 48 countries over the period 2015-2019. We defined sustainable banks as those that voluntarily joined the United Nations Principles for Responsible Banking (UNEP Finance Initiative). The analysis was performed using the System-GMM (generalized method of moments) methodology for panel data, which makes it possible to control both unobservable heterogeneity and the problems of endogeneity through the use of instruments [21].

Our results show that sustainable initiatives lead to higher profits. Moreover, conventional banks that operate in more concentrated markets obtain superior profits, whereas this effect is not observed among sustainable banks, and a larger banking concentration does not affect their profitability significantly. On the other hand, higher levels of cost scale efficiency lead to higher profitability for both conventional and sustainable banks. Finally, sustainable strategies do not have a significant impact on insolvency risk. These results show that the traditional determinants of bank profitability are not relevant in explaining 
the superior profits of sustainable banks, which suggests the emergence of a new paradigm related to sustainability among the drivers of bank profitability.

The remainder of the article is structured as follows: Section 2 reviews the previous literature, Section 3 focuses on the empirical analysis and the discussion of the results and Section 4 presents the conclusions, followed by the bibliography and appendices on the procedures followed in calculating the efficiency and scale economies.

\section{Literature Review}

\subsection{Sustainable Banking and the United Nations Principles for Responsible Banking}

Reputation has been always important in banking due to asymmetric information, the qualitative-asset-transformation made by banks and the systemic risk created by the supply of payment and risk management services [22,23]. Since the global crisis of 2008, the banking sector has been especially affected by reputational risk. Several frauds, software failures, and the financial risks of the crisis of 2008 have not helped to improve the negative perceptions among customers and other stakeholders, and have increased skepticism of commercial banks' motives and actions [1,24].

A possible way to improve banks' reputation and restore credibility would be to promote banks' engagement in sustainable activities, which implies integrating environmental protection, social responsibility and financial benefit into management and business operations [25]. Sustainable development has been the priority of many international organizations, but probably one of the most important steps was made in 2015 by the United Nations (UN) with the adoption of Sustainable Development Goals (SDGs) to address several global challenges by the target date of 2030, including the reduction of poverty, inequality, illiteracy, climate change, and environmental degradation, as well as the defending of human rights and dignity.

The banking sector can play a crucial role in achieving these goals because its involvement in sustainable activities has a potential impact on the sustainability of other industries through the lending channel [26,27]. For instance, banks can be directly involved in projects that protect the environment (green finance), orient funds according to the environmental risk of the target companies or promote socially responsible products [28]. Banks can also offer micro-loans and mobile banking to promote financial inclusion and alleviate poverty, or they can provide women's microcredit to contribute to gender equality [3].

Conscious of these aspects, the UN launched the Principles for Responsible Banking (UNEP Finance Initiative), which banks can voluntarily sign, in September 2019. The purpose of this initiative is to increase lending that supports socially and environmentally sustainable economic activities through six principles that signatory banks must implement within four years [29]. The six principles are, first, alignment: banks must align their business strategy to SDGs, the Paris Climate Agreement and relevant national and regional frameworks. Second, impact and target setting: banks must continuously assess the impact of their activity on people and the environment; moreover, banks have to set and publish targets where they have the most significant impacts. Third, clients and customers: banks must develop sustainable practices with clients and customers and enable economic activities that create prosperity for current and future generations. Fourth, stakeholders: to achieve society's goals, banks must responsibly consult, engage, and partner with relevant stakeholders. Fifth, governance and culture: banks must implement effective governance and a culture of responsible banking. Finally, transparency and accountability: banks must periodically review the six principles and be transparent about and accountable for their impacts and contributions to society's goals. The signatories' progress on these principles is reviewed every year and banks that cannot evidence the necessary changes will lose their status as a signatory.

Apart from the previous obligations, the UNEP Finance Initiative also provides several benefits to its signatories [29]. First, the six principles offer unparalleled opportunities for collaboration within the banking sector. Signatories to the Principles for Responsible Banking benefit from the collective expertise of the largest community of sustainable 
bankers globally. By working collaboratively under the auspices of the UN, signatory banks jointly deliver tools, methodology and practical guidance far beyond what any conventional bank could achieve on its own. This collaboration is based on 11 Working Groups composed of representatives from across the signatory banks. Each focuses on a different aspect of implementation, including: impact analysis, knowledge sharing, target setting and progress evaluation. These outputs are uniquely positioned to shape global best practice and influence emerging regional regulation. Moreover, collective initiatives create the space for banks to jointly push beyond current practice and define new standards for sustainability leadership. Second, unlike conventional banks, all signatory banks have access to an individual feedback and support provided by the UNEP Finance Initiative. This takes a look across their business and makes recommendations on steps the banks can take to further progress their implementation of the principles. Third, signatory banks are able to access additional tools and resources for implementation that are not available for conventional banks. For instance, the Communications Toolkit is designed to assist signatories with communicating and promoting the Principles for Responsible Banking, and includes infographics, social media cards, graphics and other materials. On the other hand, the Peer Learning Repository allows peers sharing their approaches to implementing the Principles for Responsible Banking.

In short, banks have opted to become signatories because they recognize that the needs and demands of their clients and stakeholders are shifting. By implementing the Principles for Responsible Banking, banks can create sustainability value for society, as well as serve their business interests. Starting with only 30 founding signatory banks, the UNEP Finance Initiative included 193 banks from 56 countries by October 2020, including top international banks, regional leaders, development banks, and specialized environmental banks. Figure 1a represents the geographical distribution of these banks. More than $50 \%$ of the signatory banks come from Europe, followed by Asia, but with a much lower representation (14\%). The remaining world regions account for about the $30 \%$ of the signatory banks. Africa and South America represent $8 \%$ each; North America and Central America and the Caribbean account for $6 \%$ each; and Oceania contains 3\% of the signatory banks. In terms of the year of joining the initiative, 157 banks representing more than $80 \%$ of the signatories joined the initiative in 2019. During 2020, only 36 banks were added, mainly from Asia and Europe (see Figure 1b).

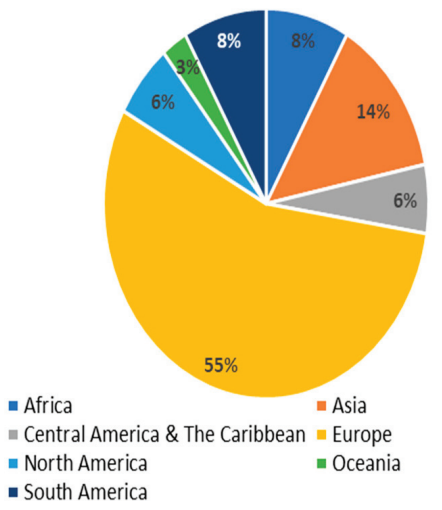

(a)

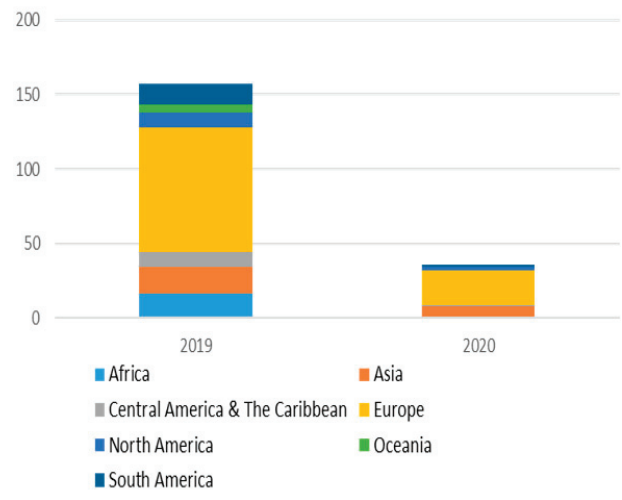

(b)

Figure 1. (a) Geographical distribution of signatory banks of the United Nations (UN) Principles for Responsible Banking; (b) Number of banks by year of signature of the UN Principles for Responsible Banking.

Table 1 shows that more than half of the European signatories come from Norway, Spain, the United Kingdom, France, and Germany; in Asia, more than half of the member banks are headquartered in Japan, South Korea, and China. Most of the African banks 
operate in Nigeria, Egypt, and South Africa; and in South America, signatory banks are concentrated in Ecuador and Brazil. More than $70 \%$ of member banks in North America come from Canada and Mexico, whereas in Central America and the Caribbean, this percentage is represented by Panama, El Salvador, and Costa Rica. In Oceania, only Australian banks have joined the UN initiative.

Table 1. Countries that have joined the UN Principles for Responsible Banking.

\begin{tabular}{|c|c|c|c|}
\hline Region/Country & No. of Banks & Region/Country & No. of Banks \\
\hline EUROPE & 107 & AFRICA & 16 \\
\hline Norway & 18 & Nigeria & 5 \\
\hline Spain & 11 & Egypt & 4 \\
\hline United Kingdom & 9 & South Africa & 3 \\
\hline France & 8 & Kenya & 1 \\
\hline Germany & 8 & Mauritius & 1 \\
\hline Switzerland & 6 & Morocco & 1 \\
\hline Netherlands & 5 & Togo & 1 \\
\hline Turkey & 5 & ASIA & 26 \\
\hline Denmark & 4 & Japan & 7 \\
\hline Finland & 4 & South Korea & 5 \\
\hline Greece & 4 & China & 4 \\
\hline Italy & 4 & Bahrain & 2 \\
\hline Sweden & 4 & Malaysia & 2 \\
\hline Iceland & 3 & Bangladesh & 1 \\
\hline Belgium & 2 & India & 1 \\
\hline Ireland & 2 & Mongolia & 1 \\
\hline Luxembourg & 2 & Myanmar & 1 \\
\hline Russia & 2 & Philippines & 1 \\
\hline Bulgaria & 1 & Thailand & 1 \\
\hline Estonia & 1 & $\begin{array}{l}\text { NORTH } \\
\text { AMERICA }\end{array}$ & 12 \\
\hline Liechtenstein & 1 & Mexico & 5 \\
\hline Portugal & 1 & Canada & 4 \\
\hline Slovenia & 1 & United States & 3 \\
\hline Ukraine & 1 & $\begin{array}{l}\text { SOUTH } \\
\text { AMERICA }\end{array}$ & 16 \\
\hline $\begin{array}{l}\text { CENTRAL AMERICA and THE } \\
\text { CARIBBEAN }\end{array}$ & 11 & Ecuador & 8 \\
\hline Panama & 4 & Brazil & 4 \\
\hline Costa Rica & 2 & Argentina & 2 \\
\hline El Salvador & 2 & Colombia & 1 \\
\hline Dominican Republic & 1 & Paraguay & 1 \\
\hline Nicaragua & 1 & OCEANIA & 5 \\
\hline Trinidad and Tobago & 1 & Australia & 5 \\
\hline
\end{tabular}

\subsection{Sustainable Banking, Market Power, Efficiency, and Profitability}

Joining sustainable initiatives, such as the UNEP Finance Initiative, implies integrating social, environmental, and economic aspects, which can have important effects on banks' profitability. Indeed, many articles have shown that the involvement in sustainable activities improves bank profitability $[1,5,6,30]$. Traditionally, the profitability of the banking sector has been explained through two main theories: the market power hypothesis and the efficiency hypothesis.

The market power hypothesis considers that greater market concentration or market share facilitates setting higher prices to customers, thereby increasing extraordinary profits [4]. This hypothesis has two versions: the structure-conduct-performance (SCP) hypothesis and the relative market power (RMP) hypothesis. The SCP considers that the greatest profits come from highly concentrated markets due to competition concerns and the existence of entrance barriers [31]. The RMP proposes that only banks with significant market share and differentiated products can exercise effective market power [32]. 
The efficiency hypothesis suggests that more efficient banks have lower unit costs, so they can attract more customers, because lower unit costs would make it possible to set lower interest rates for loans and higher interest rates for deposits $[4,33]$. The origin of this greater efficiency could come from superior management skills and production technology (X-efficiency hypothesis) or scale economies (scale-efficiency hypothesis). Both the market power and efficiency hypotheses have found wide empirical support [7,34-38].

Sustainable business models can boost market share because socially and environmentally responsible actions improve reputation, confidence, and customer loyalty $[39,40]$. Consumers of sustainable products and services are more loyal because they not only care about the consumption experience, but also want to form part of a community or wish to belong to a social group when purchasing goods [41]. This loyalty is especially relevant in the financial sector, because competition is normally very intense, and customers have close business relationships with their banks [42].

Bussoli et al. [43] have shown that social initiatives by European financial institutions capture the trust and the loyalty of customers, while Yip and Bocken [44] and AgirreAramburu and Gómez-Pescador [2] have reported the same evidence for the banking industry in Hong Kong and Spain, respectively. Apart from social initiatives, environmental initiatives are also very welcome among customers, and many banks now provide green financial products. Fay [45] has shown that green customers buy more products and spend more when doing so. Mason [46] has argued that green customers are willing to pay a premium price for environmentally friendly products, so banks that finance firms that make such products may indirectly benefit from this green premium. Furthermore, Sun et al. [47] have reported that green banking initiatives strengthen the relationship between corporate social responsibility and consumer loyalty.

According to the market power hypothesis, a larger market share facilitates the setting of higher prices to customers, which increases windfall profits for banks. However, sustainable banks tend not to take direct advantage of their greater market share to impose higher prices for customers. Instead, their competitive advantage is based on emotional factors, such as an appreciated difference in business principles and culture or better scores in non-financial performance indicators than conventional banks [2]. This is because sustainable banks are less concerned with short-term profit-maximization and are rather oriented towards maximizing stakeholder value and client satisfaction by decreasing the harmful effects of economic activities on the environment and society [48].

Matute-Vallejo et al. [8] have found that customers in the banking industry do not perceive a bank's sustainable engagement as an attempt to instrumentalize social issues in a manner ultimately intended to increase prices. The Global Alliance for Banking on Values (GABV) [49,50] has also found evidence that sustainable banks are more profitable because they attract more deposits and provide more loans than conventional banks. However, their returns are more stable, which reinforces their focus on long-term profitability instead of obtaining immediate rents through higher prices. In this regard, as we proposed in our Hypothesis 1 (H1) in the Introduction section of the article, we expect that sustainable banking practices will weaken the market power hypothesis.

Although the relevance of the market power hypothesis may vary across sustainable and conventional banks, in terms of the efficiency hypothesis, however, the differences between both types of banks would be less pronounced. Sustainable strategies still raise concern among bank managers because the fulfilment of sustainable responsibilities could be at the expense of increased costs and reduced efficiency [25]. Sustainable banks can risk losing efficiency if they put too much emphasis on social and environmental investments [9]. Furthermore, trying to satisfy all stakeholders could adversely affect profitability due to inefficient use of resources [51,52].

Conversely, sustainable practices can also be valuable assets that contribute directly to the recovery of bank efficiency. First, a good, strong relationship with all stakeholders can help sustainable banks find more investments and help them access and use resources more efficiently $[10,53]$. Second, sustainability may boost banks' reputation and customer 
loyalty, which in turn would translate into lower funding costs [11,54]. For instance, green bonds have lower yields and superior ratings than conventional bonds because investors reward environmentally responsible actions [55]. Third, sustainable activities can also help banks to improve efficiency in relation to their competitors. If a bank implements these activities, future industry sustainable standards are strengthened, which raises competitors' costs $[12,56]$. Moreover, banks pursuing a proactive sustainable strategy are most likely the ones with greater financial resources and superior management capabilities $[57,58]$. In this regard, sustainable banks can increase motivation and retention, as employees react positively to the opportunity to weave environmental and social dimension into their work [59]. Therefore, it is likely that these positive effects of sustainable activities on bank efficiency offset the negative ones and, thus, sustainable banks would tend to be as efficient as conventional banks. We therefore propose that the efficiency hypothesis is similar across conventional and sustainable banks, as we suggested in our Hypothesis 2 (H2).

\subsection{Sustainable Banking and Risk}

Apart from affecting bank profitability, market share, and efficiency, sustainable activities can also have effects on bank risk. These effects are very important because a healthy banking system is the key to sustainable prosperity, and the security and the soundness of banks can create different external benefits for society [60]. Sustainable strategies can thus lead to a reduction in bank risk, as we proposed in our Hypothesis 3 (H3), for several reasons.

First, by becoming sustainable, banks state that their goal is to link decisively the fulfilment of local community needs with environment protection and sound economic prospects [48]. In achieving this goal, they try to avoid excessive risk taking and better manage risks [61,62]. Rajput and Oberoi [63] have shown that establishing good relationships with the community increases local support and attracts customers, thereby reducing bank risk. Other authors revealed that, by implementing environmentally friendly actions, banks reduce their reputational risk and increase customer loyalty, which leads to higher funding stability $[11,17]$.

Second, a higher level of sustainable activism is associated with higher quality of earnings, a greater degree of transparency and higher moral standards. These factors help banks to mitigate adverse selection and moral hazard problems, which are among the main causes of non-performing loans [18,64]. Saïdane and Abdallah [13] have shown that sustainable banks in Europe are better able to absorb shocks and reduce the risk of insolvency. Moreover, Scholtens and van't Kloose [16] have found that banks with high sustainability scores, especially the social dimension, have lower default risk, as well as lower contribution to financial system risk. Cui et al. [65] have revealed that allocating more green loans to the total loan portfolio reduces the non-performing loan ratio of Chinese banks. Gangi et al. [28], for a sample of 35 countries between 2011 and 2015, have found that banks that are more sensitive to environmental issues also exhibit less risk. The measurement and impact of environmental issues on banking risk has received special attention because crises will increasingly arise from the sheer scale of systemic environmental risks with global effects [66]. Climate-related risks have been identified by the European Central Bank (ECB) as a key risk driver on the Single Supervision Mechanism (SSM) Risk Map for the euro area banking system, and the European Banking Authority (EBA) has been given several mandates to assess how environmental, social, and governance (ESG) risks can be incorporated into the three pillars of prudential supervision [67].

Third, sustainability initiatives normally come from less risky banks. The availability of financial resources incites banks to invest in environmental or social projects, so financial stability is an important condition for investing in responsible activities $[19,20]$. The GABV $[49,50]$ has found that sustainable banks have stronger capital positions and lower levels of return volatility. Furthermore, Chollet and Sandwidi [68] have reported a virtuous circle between sustainability and risk. In this regard, good social and governance 
performance reduces financial risk and thereby reinforces commitment to good governance and environmental practices.

\section{Empirical Analysis}

\subsection{Selection of the Sample}

To test the Hypotheses 1-3 proposed previously, we conducted an empirical analysis, which is reported in this section. To select the sample for the analysis, we started with all of the banks in the S\&P Capital IQ database (S\&P Global Market Intelligence). First, we eliminated banks with no available data. Then, we removed banks with errors in their financial statements or when their values were unreasonable, such as those with negative values for total assets, total liabilities, equity, loans, deposits, interest, and noninterest, as well as operating expenses, investment securities, fixed assets, total employees, and efficiency.

We also excluded banks with data available for less than four consecutive years between 2015 and 2019, and countries without the necessary macroeconomic data. The former condition is essential to test for second-order serial correlation, which is performed to ensure the robustness of the estimates made by System-GMM [21]. Moreover, this sample period covers all of the years since the UN's adoption of SDGs. Finally, to avoid bias and spurious correlations between macroeconomic variables and bank level variables, we removed the countries with fewer than five banks in the sample [69].

The final sample consisted of an unbalanced panel of 1236 banks from 48 countries (Austria, Bangladesh, Belgium, Bolivia, Brazil, Bulgaria, Canada, China, Colombia, Costa Rica, Croatia, the Czech Republic, Denmark, Egypt, France, Germany, Greece, Hong Kong, Hungary, Indonesia, Ireland, Israel, Italy, Latvia, Luxembourg, Malaysia, the Netherlands, Nigeria, Norway, Oman, Pakistan, Peru, the Philippines, Poland, Portugal, Romania, Russia, Saudi Arabia, Serbia, Slovenia, South Africa, Spain, Sweden, Switzerland, Turkey, the United Kingdom, the United States, and Vietnam) between 2015 and 2019 (5915 observations). Table 2 shows the number of banks and observations for each country and the temporary distribution of the sample. The financial information on each bank comes from the S\&P Capital IQ database (Global Market Intelligence). The macroeconomic information comes from the International Monetary Fund database and the World Bank's World Development Indicators.

Table 2. Sample description.

\begin{tabular}{|c|c|c|c|c|c|}
\hline \multicolumn{6}{|c|}{ Panel A: Number of Banks and Observations per Country } \\
\hline Country & No. of Banks & No. of Obs. & Country & No. of Banks & No. of Obs. \\
\hline Austria & 32 & 153 & Luxembourg & 7 & 33 \\
\hline Bangladesh & 11 & 53 & Malaysia & 8 & 39 \\
\hline Belgium & 8 & 39 & Netherlands & 9 & 44 \\
\hline Bolivia & 5 & 24 & Nigeria & 13 & 52 \\
\hline Brazil & 15 & 70 & Norway & 17 & 82 \\
\hline Bulgaria & 8 & 38 & Oman & 5 & 20 \\
\hline Canada & 7 & 34 & Pakistan & 21 & 103 \\
\hline China & 98 & 459 & Peru & 9 & 44 \\
\hline Colombia & 14 & 68 & Philippines & 6 & 29 \\
\hline Costa Rica & 9 & 44 & Poland & 8 & 39 \\
\hline Croatia & 10 & 45 & Portugal & 8 & 39 \\
\hline Czech Republic & 10 & 50 & Romania & 9 & 41 \\
\hline Denmark & 8 & 40 & Russia & 6 & 29 \\
\hline Egypt & 9 & 36 & Saudi Arabia & 12 & 59 \\
\hline France & 81 & 385 & Serbia & 6 & 29 \\
\hline
\end{tabular}


Table 2. Cont.

\begin{tabular}{|c|c|c|c|c|c|}
\hline \multicolumn{6}{|c|}{ Panel A: Number of Banks and Observations per Country } \\
\hline Country & No. of Banks & No. of Obs. & Country & No. of Banks & No. of Obs. \\
\hline Germany & 105 & 500 & Slovenia & 7 & 33 \\
\hline Greece & 6 & 30 & South Africa & 7 & 31 \\
\hline Hong Kong & 9 & 44 & Spain & 20 & 98 \\
\hline Hungary & 6 & 28 & Sweden & 8 & 37 \\
\hline Indonesia & 40 & 193 & Switzerland & 41 & 197 \\
\hline Ireland & 6 & 30 & Turkey & 8 & 38 \\
\hline Israel & 6 & 29 & United Kingdom & 34 & 167 \\
\hline Italy & 41 & 182 & United States & 402 & 1961 \\
\hline Latvia & 11 & 51 & Vietnam & 10 & 46 \\
\hline \multicolumn{4}{|c|}{ Number of total banks and Obs. } & 1236 & 5915 \\
\hline \multicolumn{6}{|c|}{ Panel B: Temporary Disribution of the Sample } \\
\hline & 2015 & 2016 & 2017 & 2019 & Total Obs. \\
\hline No. of Obs. & 1129 & 1236 & 1236 & 1078 & 5915 \\
\hline
\end{tabular}

Obs.: Observations.

\subsection{Profitability Analysis}

\subsubsection{Econometric Model of the Profitability Analysis}

To perform the profitability analysis, we followed Berger [4], who proposed the estimation of the market power and efficiency hypothesis through a single equation. To evaluate these hypotheses for sustainable and conventional banks and to test the differences between both types of banks we proposed the following model:

$$
\begin{gathered}
\mathrm{R}_{\mathrm{i}, \mathrm{t}}=\beta_{0}+\beta_{1} \mathrm{SB}_{\mathrm{i}}+\left(\beta_{2}+\beta_{3} \mathrm{SB}_{\mathrm{i}}\right) \times \mathrm{CONC}_{\mathrm{m}, \mathrm{t}}+\left(\beta_{4}+\beta_{5} \mathrm{SB}_{\mathrm{i}}\right) \times \mathrm{MS}_{\mathrm{i}, \mathrm{t}}+\left(\beta_{6}+\beta_{7} \mathrm{SB}_{\mathrm{i}}\right) \times \mathrm{XEF}_{\mathrm{i}, \mathrm{t}}+ \\
\left(\beta_{8}+\beta_{9} \mathrm{SB}_{\mathrm{i}}\right) \times \mathrm{SEF}_{\mathrm{i}, \mathrm{t}}+\beta_{10} \mathrm{EQUITY}_{\mathrm{i}, \mathrm{t}}+\beta_{11} \mathrm{LOANS}_{\mathrm{i}, \mathrm{t}}+\beta_{12} \mathrm{SIZE}_{\mathrm{i}, \mathrm{t}}+\beta_{13} \Delta \mathrm{GDP}_{\mathrm{m}, \mathrm{t}} \\
+\sum_{\mathrm{t}=1}^{\mathrm{T}} \mathrm{YEAR}_{\mathrm{t}}+\sum_{\mathrm{m}=1}^{\mathrm{M} \mathrm{COUNTRY}_{\mathrm{m}}+\varepsilon_{\mathrm{i}, \mathrm{t}}}
\end{gathered}
$$

The dependent variable $\left(\mathrm{R}_{\mathrm{i}, \mathrm{t}}\right)$ is a measure of the profitability of banks: ROA (return on assets) and ROE (return on equity). ROA is the ratio of net income over total assets and captures the earnings that were generated from invested capital (assets). ROE measures how profitable a bank is for its owners and represents the ratio of net income over shareholder equity. So, ROA only depends on the ability of assets to generate income, whereas ROE also depends on how these assets are financed (the level of equity and debt). These measures are the most widely used in the literature $[4,7,36,70]$.

SB is a dummy variable that serves to capture sustainable banks. It takes the value of 1 for the banks that have signed the UN Principles for Responsible Banking, and 0 otherwise. Many articles have shown that sustainable banks are more profitable because customers reward socially and environmentally responsible actions [1,5]. Therefore, we expect that the variable SB will have a significant and positive coefficient.

CONC is the market concentration. We used the Herfindahl-Hirschman index (HHI), which is the sum of the squared market share, measured in terms of assets, of all of the banks operating in a market [71-73]. For each country, this index was estimated using all of the banks listed in the S\&P Capital IQ database [7,34]. MS is the market share, measured in terms of assets, of bank $i$ at time $t[7,35]$. XEF and SEF are our measures of efficiency in terms of cost. Cost efficiency is the ratio between the minimum cost at which it is possible to attain a given volume of production and the realized cost. Efficiency ranges over the $[0,1]$ interval, and equals 1 for the best-practice bank in the sample [74]. More precisely, $\mathrm{XEF}$ is the cost X-efficiency of bank $\mathrm{i}$ at time $\mathrm{t}$. We estimated the Fourier flexible cost function by applying the stochastic frontier approach (SFA) to measure this variable $[7,75]$ (See Appendix A for a description of the procedure for calculating X-efficiency). SEF is the scale efficiency of bank $i$ at time $t$. We derived the Fourier flexible cost function, with respect to the inputs, to measure this variable $[7,76]$ (See Appendix B for a description of the procedure for calculating scale economies). 
To analyze how sustainable banks determine the effects of market power and efficiency on profitability, in Equation (1) we included the interaction terms between the sustainable banks dummy (SB) and the variables $\mathrm{CONC}, \mathrm{MS}, \mathrm{XEF}$, and SEF $(\mathrm{SB} \times \mathrm{CONC}, \mathrm{SB} \times \mathrm{MS}$, $\mathrm{SB} \times \mathrm{XEF}$, and $\mathrm{SB} \times \mathrm{SEF})$. The effects that $\mathrm{CONC}$ had on the profitability of conventional banks $(S B=0)$ were measured by the coefficient $\beta 2$. In the case of MS, XEF, and SEF, these effects were captured by the coefficients $\beta 4, \beta 6$, and $\beta 8$, respectively. For sustainable banks $(\mathrm{SB}=1)$, the effect of $\mathrm{CONC}$ on profitability was measured by the sum of the coefficients $(\beta 2+\beta 3)$. In the case of MS, XEF, and SEF, this effect was reflected by the sums of the coefficients $(\beta 4+\beta 5),(\beta 6+\beta 7)$, and $(\beta 8+\beta 9)$, respectively.

Conventional banks that operate in more concentrated banking markets or that have a greater market share can obtain non-competitive rents by setting higher prices for customers, so we expect that the coefficients $\beta 2$ and $\beta 4$ will have a positive and significant sign $[4,31]$. Nevertheless, sustainable banks do not normally exploit their greater market share to impose higher prices for clients and their competitive advantage is more based on the emotional factors of their business culture $[2,8]$. Therefore, the sums of the coefficients $(\beta 2+\beta 3)$ and $(\beta 4+\beta 5)$ are expected to be non-significant.

More efficient conventional banks have lower unit costs, so they can attract more customers $[4,33]$. Therefore, we expect that the coefficients $\beta 6$ and $\beta 8$ will have a significant and positive sign. Sustainable practices have both positive and negative effects on efficiency, which is why sustainable banks tend to be as efficient as conventional banks $[9,11]$. As a result, we expect that the sums of the coefficients $(\beta 6+\beta 7)$ and $(\beta 8+\beta 9)$ will have a significant and positive sign also.

EQUITY is the ratio of equity over total assets and serves to capture the risk of insolvency [7]. Banks with lower levels of equity bear higher borrowing costs, which reduces net interest margins and profits [70]. Moreover, banks with higher equity can take advantage of business opportunities more effectively and thus receive a higher return [77]. Therefore, we expect a positive relationship between EQUITY and bank profitability.

The LOANS variable is the ratio of loans to total assets and captures the liquidity risk of the bank and its activity [78,79]. Loans, especially those granted to households and companies, are risky and have a higher expected return than other bank assets such as government securities. Therefore, a positive relationship between LOANS and profitability can be expected [78]. However, another approach suggests that the lower the funds allocated to liquid investments, the higher the profitability obtained [80]. As a result, we can also expect a negative relationship between LOANS and profitability.

SIZE represents the size of the bank and is calculated as the natural logarithm of total assets (deflated) [81,82]. Economies of scale can arise from a larger size, which increases operational efficiency and reduces costs [83]. Therefore, a positive relationship between SIZE and profitability can be expected. Nevertheless, agency costs and bureaucratic expenses tend to be higher in the management of large banks [84]. Consequently, the relationship between SIZE and profitability could also be negative.

$\triangle$ GDP represents the Gross Domestic Product (GDP) per capita growth (annual \%) and captures the economic cycle [38]. Better economic conditions raise the demand for credit, which boosts bank profitability $[77,85]$. Therefore, we expect that the GDP growth will have a significant and positive coefficient. Table 3 provides a summary of the independent variables included in Equation (1) and their expected relationships with profitability.

Finally, year- and country-effect dummies were included to capture year- and countryspecific factors. The error term is $\varepsilon_{i, t}$, and $i=1,2, \ldots, N$ indicates a specific bank $i ; t=1,2$, $\ldots, \mathrm{T}$ indicates a particular year $\mathrm{t}$; and $\mathrm{m}=1,2, \ldots, \mathrm{M}$ indicates a particular country $\mathrm{m}$. Table 4 presents the descriptive statistics of the variables used in the profitability analysis, and Table 5 depicts the correlation between these variables. The software used to evaluate the statistical parameters and the whole empirical models is STATA (version 12). STATA is a program that enables users to analyze, manage, and produce statistical data, and is primarily used by researchers in the fields of economics, biomedicine, and political science. 
Table 3. Summary of the independent variables of the profitability analysis.

\begin{tabular}{ccc}
\hline Variable & Description & Expected Relationship with Profitability (R) \\
\hline SB & Dummy that takes the value of 1 if a bank has signed the & Positive \\
CONC & UN Principles for Responsible Banking, and 0 otherwise & Positive \\
MS & Herfindahl-Hirschman index (HHI) in terms of assets & Positive \\
XEF & Market share in terms of assets & Positive \\
SEF & Cost X-efficiency & Positive \\
SB $\times$ CONC & Scale efficiency with respect to the inputs & Non-significant \\
SB $\times$ MS & Interaction between sustainable banks and market & Non-significant \\
SB $\times$ XEF & concentration & Positive \\
SB $\times$ SEF & Interaction between sustainable banks and cost & Positive \\
EQUITY & Interaction between sustainable banks and scale efficiency & Positive \\
LOANS & Equity/Total assets & Positive/Negative \\
SIZE & Loans/Total assets & Positive/Negative \\
$\Delta \mathrm{GDP}$ & Log (Total assets) & Positive \\
\hline
\end{tabular}

Table 4. Sample statistics of the profitability analysis.

\begin{tabular}{ccccc}
\hline Variable & Mean & Standard Deviation & Minimum & Maximum \\
\hline ROA & 0.0072 & 0.0086 & -0.1173 & 0.1491 \\
ROE & 0.0731 & 0.0786 & -0.9124 & 0.7087 \\
CONC & 0.0792 & 0.0524 & 0.0306 & 0.2914 \\
MS & 0.0261 & 0.0570 & $1.69 \times 10^{-6}$ & 0.4602 \\
XEF & 0.8161 & 0.0579 & 0.3896 & 0.9470 \\
SEF & 0.7455 & 0.0998 & 0.0041 & 0.7813 \\
EQUITY & 0.0996 & 0.0458 & 0.0192 & 0.7450 \\
LOANS & 0.6340 & 0.1596 & 0.0195 & 0.9747 \\
SIZE & 8.9409 & 2.0031 & 3.1179 & 14.7620 \\
$\Delta$ GDP & 2.1572 & 1.9563 & -4.3515 & 23.9855 \\
\hline
\end{tabular}

Table 5. Correlations of the profitability analysis.

\begin{tabular}{ccccccccc}
\hline & CONC & MS & XEF & SEF & EQUITY & LOANS & SIZE & $\Delta$ GDP \\
\hline CONC & 1 & & & & & & & \\
MS & 0.5002 & 1 & & & & & & \\
XEF & -0.0792 & -0.0906 & 1 & & & & & \\
SEF & -0.0137 & -0.2421 & -0.0101 & 1 & & & & \\
EQUITY & 0.0153 & -0.0315 & 0.0301 & 0.1302 & 1 & & \\
LOANS & -0.1249 & -0.1222 & 0.1223 & 0.1928 & -0.0004 & 1 & & \\
SIZE & 0.2204 & 0.4497 & -0.0141 & -0.4382 & -0.2631 & -0.1559 & 1 & \\
SGDP & -0.0486 & -0.0053 & -0.0032 & -0.0051 & -0.0679 & -0.2236 & 0.0350 & 1 \\
\hline
\end{tabular}

\subsubsection{Methodology}

The model in Equation (1) was estimated using a two-step System-GMM with robust errors, which is consistent in the presence of any pattern of heteroscedasticity and autocorrelation. This method allows for controlling the problems of endogeneity and delivers consistent and unbiased estimates by using lagged independent variables as instruments [21]. Additionally, the System-GMM estimator provides stronger instruments and lower bias, by considering both first-differenced and levels equations [86]. This methodology is especially useful in samples that are based on a short time scale and a larger number of countries, as it was our case $[87,88]$. The GDP growth and the year and country dummies were considered exogenous, while the remaining variables were considered endogenous. Based on the Hansen test of the over-identifying restrictions for endogenous variables, in general second 
and third lags were used as instruments. The variables EQUITY in levels and CONC in both levels and differences showed over-identification problems according to the Hansen test. To address this issue, we used third lags for the variables EQUITY and CONC (in levels), and fourth lags for the variable CONC (in differences). The exogenous variables were instrumented by themselves.

The large number of endogenous variables in our estimation means that we had many instruments and could inadvertently overfit our endogenous variables. To reduce this possibility, we collapsed the instruments used in our estimation. With the collapse option, one instrument is created for each variable and lag distance, rather than one for each time period, variable, and lag distance. Bowsher [89] found that the use of too many moment conditions can significantly reduce the power of tests of over-identifying restrictions. The collapse option effectively constrains all of the yearly moment conditions to be the same and reduces the instrument count and the number of moment conditions used in the difference-in-Hansen test of exogeneity instrument subsets, which makes this test more powerful [90,91]. Many articles have collapsed the instruments used in the System-GMM estimation $[69,92,93]$.

Finally, we studied each endogenous variable separately to assess whether the instruments provide significant explanatory power over the endogenous variables, focusing on the F-statistics from the first-stage OLS regressions. We ran two different regressions for each endogenous variable: one for the equations in differences (where the instruments are in levels), and the other for the equations in levels (where the instruments are in differences). For the System-GMM regressions, this test is merely indicative of the strength of the instruments since consistency of the GMM estimates relies on the joint estimation of both the levels and the difference equations. Other articles also calculated the F-statistics to analyze the strength of the instruments for System-GMM estimations [92,94,95].

Table 6 shows the results of this analysis. In general, the F-statistics for the first-stage regressions are significant and higher than 10 , which is the critical value suggested by Staiger and Stock [96] for assessing instrument strength. It implies that the instruments provide significant explanatory power for the endogenous variables.

Table 6. First-stage OLS regressions for System-GMM estimates (profitability analysis).

\begin{tabular}{cccc}
\hline R & F-Statistic & $p$-Value & $\mathbf{R}^{2}$ \\
\hline Panel A. Dependent variable in levels, explanatory & variables (instruments) in differences \\
SB & 254.4 & 0.0000 & 0.9832 \\
CONC & 10.9 & 0.0010 & 0.4071 \\
SB $\times$ CONC & 57 & 0.0000 & 0.9134 \\
MS & 43.6 & 0.0000 & 0.5870 \\
SB $\times$ MS & 58.5 & 0.0000 & 0.7957 \\
XEF & 28.5 & 0.0000 & 0.1375 \\
SB $\times$ XEF & 58.6 & 0.0000 & 0.9858 \\
SEF & 16.3 & 0.0000 & 0.5226 \\
SB $\times$ SEF & 6.5 & 0.0016 & 0.9371 \\
EQUITY & 94 & 0.0000 & 0.1873 \\
LOANS & 13.3 & 0.0000 & 0.1419 \\
SIZE & 1.9 & 0.1456 & 0.4103 \\
Panel B. Dependent variable in differences, explanatory variables (instruments) in levels & 0.9344 \\
$\Delta$ SB & $22,222.9$ & 0.0000 & 0.4108 \\
$\Delta$ CONC & 33.9 & 0.0000 & 0.5180 \\
$\Delta($ SB $\times$ CONC) & 39.8 & 0.0000 & 0.4418 \\
$\Delta$ MS & 67.1 & 0.0000 & 0.4927 \\
$\Delta$ SB $\times$ MS $)$ & 6.9 & 0.0010 & 0.1146 \\
$\Delta$ XEF & 30.1 & 0.0000 & 0.2539
\end{tabular}


Table 6. Cont.

\begin{tabular}{cccc}
\hline $\mathbf{R}$ & F-Statistic & $p$-Value & $\mathbf{R}^{2}$ \\
\hline$\Delta$ SEF & 59.5 & 0.0000 & 0.3644 \\
$\Delta$ (SB $\times$ SEF $)$ & 75.7 & 0.0000 & 0.4049 \\
$\Delta$ EQUITY & 20 & 0.0000 & 0.0739 \\
$\Delta$ LOANS & 42 & 0.0000 & 0.0853 \\
$\Delta$ SIZE & 85 & 0.0000 & 0.2191 \\
\hline
\end{tabular}

\subsubsection{Results of the Profitability Analysis}

Table 7 shows the results of the profitability analysis. In Table 7, model (a), we analyzed ROA, and in Table 7, model (b), we examined ROE. In both models the dummy variable SB shows a significant and positive coefficient, so sustainable banks obtain higher levels of profitability.

Table 7. Results of the profitability analysis.

\begin{tabular}{|c|c|c|c|c|c|c|c|c|}
\hline & \multicolumn{5}{|c|}{ ROA (a) } & \multicolumn{3}{|c|}{ ROE (b) } \\
\hline & Coefficient & $\begin{array}{l}\text { Standard } \\
\text { Error }\end{array}$ & T-Student & $p$-Value & Coefficient & $\begin{array}{l}\text { Standard } \\
\text { Error }\end{array}$ & T-Student & $p$-Value \\
\hline SB & 0.0007 & 0.0002 & 3.14 & $0.002 * * *$ & 0.0086 & 0.0032 & 2.71 & $0.007^{* * *}$ \\
\hline CONC & 0.0357 & 0.0216 & 1.66 & $0.098^{*}$ & 0.5286 & 0.2004 & 2.64 & $0.008^{* * *}$ \\
\hline $\mathrm{SB} \times \mathrm{CONC}$ & -0.0407 & 0.0388 & -1.05 & 0.295 & -0.3207 & 0.3826 & -0.84 & 0.402 \\
\hline MS & 0.0294 & 0.0172 & 1.71 & $0.087 *$ & 0.1422 & 0.1366 & 1.04 & 0.298 \\
\hline $\mathrm{SB} \times \mathrm{MS}$ & -0.0062 & 0.0359 & -0.17 & 0.864 & 0.1472 & 0.2637 & 0.56 & 0.577 \\
\hline XEF & 0.0178 & 0.0166 & 1.08 & 0.282 & 0.0336 & 0.1363 & 0.25 & 0.805 \\
\hline $\mathrm{SB} \times \mathrm{XEF}$ & 0.0002 & 0.0072 & 0.02 & 0.982 & -0.0235 & 0.0725 & -0.32 & 0.746 \\
\hline SEF & 0.0120 & 0.0069 & 1.74 & 0.081 * & 0.1679 & 0.0996 & 1.69 & $0.092 *$ \\
\hline $\mathrm{SB} \times \mathrm{SEF}$ & 0.0036 & 0.0109 & 0.33 & 0.740 & -0.0015 & 0.1004 & -0.02 & 0.988 \\
\hline EQUITY & 0.0427 & 0.0169 & 2.52 & $0.012^{* *}$ & 0.0060 & 0.1713 & 0.04 & 0.972 \\
\hline LOANS & 0.0020 & 0.0044 & 0.46 & 0.646 & -0.0001 & 0.0548 & -0.00 & 0.999 \\
\hline SIZE & -0.0001 & 0.0007 & -0.12 & 0.904 & 0.0066 & 0.0086 & 0.77 & 0.441 \\
\hline$\Delta \mathrm{GDP}$ & 0.0003 & 0.0002 & 2.09 & $0.036^{* *}$ & 0.0030 & 0.0016 & 1.89 & $0.058 *$ \\
\hline LR Test. $\mathrm{SB} \times \mathrm{CONC}$ & -0.0050 & 0.0384 & -0.13 & 0.896 & 0.2078 & 0.4117 & 0.50 & 0.614 \\
\hline LR Test. SB $\times$ MS & 0.0233 & 0.0266 & 0.88 & 0.381 & 0.2894 & 0.2338 & 1.24 & 0.216 \\
\hline LR Test. SB $\times \mathrm{XEF}$ & 0.0180 & 0.0087 & 0.86 & 0.390 & 0.0101 & 0.1614 & 0.06 & 0.950 \\
\hline LR Test. SB $\times$ SEF & 0.0156 & 0.0209 & 1.80 & $0.071 *$ & 0.1664 & 0.0861 & 1.93 & $0.053 *$ \\
\hline CONS & -0.0258 & 0.0181 & -1.42 & 0.154 & -0.1823 & 0.2059 & -0.89 & 0.376 \\
\hline Year dummies & & & Yes & & & & Yes & \\
\hline Country dummies & & & Yes & & & & Yes & \\
\hline M2 & & & & 0.654 & & & & 0.599 \\
\hline Hansen & & & & 0.133 & & & & 0.168 \\
\hline
\end{tabular}

$* * *$ indicates a level of significance of $0.01,{ }^{* *}$ indicates a level of significance of $0.05, *$ indicates a level of significance of 0.1 . LR Test. $\mathrm{SB} \times \mathrm{CONC}$ is the linear restriction test of the sum of the coefficients associated with SB and CONC. LR Test. SB $\times$ MS is the linear restriction test of the sum of the coefficients associated with SB and MS. LR Test. SB $\times$ XEF is the linear restriction test of the sum of the coefficients associated with SB and XEF. LR Test. SB $\times$ SEF is the linear restriction test of the sum of the coefficients associated with SB and SEF. CONS is the regression intercept. M2 is the p-value of the 2nd order serial correlation statistic. Hansen is the $p$-value of the over-identifying restriction test

The variable CONC, which measures the effects of banking concentration on the profitability of conventional banks $(\mathrm{SB}=0)$, has a significant and positive coefficient in Table 7, models (a) and (b). Therefore, conventional banks that operate in more concentrated markets can exercise effective market power and obtain more profitability, as the market power hypothesis suggests. To capture the effects of concentration on the profitability of sustainable banks $(\mathrm{SB}=1)$, we carried out the linear restriction test of the sum of the coefficient associated with $\mathrm{CONC}$ and the coefficient associated with the interaction between SB and CONC (represented in Table 7 by LR Test. SB $\times$ CONC). This linear restriction test is not significant in any of the models, which would support our Hypothesis 1. 
The variable MS, which measures the effects of market share on the profitability of conventional banks ( $\mathrm{SB}=0$ ), is significant and positive in Table 7 , model (a), but not in Table 7, model (b). Conventional banks with higher market share can probably exercise effective market power and obtain more profits, but this evidence is not conclusive across estimations. In any case, market share does not affect the profits that sustainable banks make because the linear restriction test of the sum of the coefficient associated with MS and the coefficient associated with the interaction between SB and MS (represented in Table 7 by LR Test. SB $\times$ MS) is not significant in any of the models.

The variable SEF, which measures the effects of scale efficiency on the profitability of conventional banks ( $S B=0$ ), is positive and significant in Table 7, models (a) and (b). Moreover, the LR Test. SB $\times$ SEF, which captures the previous effect for sustainable banks $(\mathrm{SB}=1)$, is positive and significant in both models, too. Consequently, banks with better scale efficiency are more profitable, regardless of their sustainable orientation, which would support our Hypothesis 2.

Regarding the control variables, the variable $\triangle \mathrm{GDP}$ is significant with a positive sign, so the economic growth boosts bank profitability as other studies suggest $[77,85]$. The variable EQUITY has a significant and positive coefficient in Table 7, model (a), but is not significant in Table 7, model (b), so in our sample, there is no conclusive evidence of the effects of equity on bank profitability.

\subsection{Risk Analysis}

\subsubsection{Econometric Model of the Risk Analysis}

To analyze the relationship between risk and sustainable banking practices, we proposed the following model that is based on the study of Sanfilippo-Azofra et al. [7]:

$$
\begin{aligned}
& Z_{i, t}=\beta_{0}+\beta_{1} S B_{i}+\left(\beta_{2}+\beta_{3} S B_{i}\right) \times C O N C_{m, t}+\left(\beta_{4}+\beta_{5} S B_{i}\right) \times M_{i, t}+\left(\beta_{6}+\beta_{7} S B_{i}\right) \times X E F_{i, t}+ \\
& \left(\beta_{8}+\beta_{9} \text { SB }_{i}\right) \times \text { SEF }_{i, t}+\beta_{10} \text { LOANS }_{i, t}+\beta_{11} \text { SIZE }_{i, t}+\beta_{12} \text { LOANDEP }_{i, t}+\sum_{t=1}^{\mathrm{T}} \text { YEAR }_{t}+ \\
& \sum^{\mathrm{M}=1}{ }_{\mathrm{m}=1} \text { COUNTRY }_{\mathrm{m}}+\varepsilon_{\mathrm{i}, \mathrm{t}}
\end{aligned}
$$

The dependent variable $\left(Z_{i, t}\right)$ is the $\mathrm{Z}$-score, measured as follows:

$$
\mathrm{Z}_{\mathrm{i}, \mathrm{t}}=(\mathrm{ROA}+\mathrm{K} / \mathrm{A}) / \sigma \mathrm{ROA}
$$

where ROA is the return on assets, $\mathrm{K}$ is the equity capital, $\mathrm{A}$ is the total assets, and $\sigma \mathrm{ROA}$ is the standard deviation of ROA. The Z-score is widely used to measure a bank's risk $[7,28,97,98]$; the higher the Z-score, the lower the probability of bankruptcy.

As above, SB is a dummy variable that serves to capture sustainable banks. It takes the value of 1 for the banks that have signed the UN Principles for Responsible Banking, and 0 otherwise. Sustainable banks are more transparent and have more stable returns and higher moral standards, and these characteristics allow them to manage risk more effectively $[13,28]$. As a result, we expect that the variable SB will have a significant and positive coefficient. The variables CONC, MS, XEF, and SEF have the same definitions as in Section 3.2.1.

To analyze how sustainable banks determine the effects of market power and efficiency on risk, in Equation (2) we included the interaction terms between the sustainable banks dummy (SB) and the variables CONC, MS, $\mathrm{XEF}$, and SEF $(\mathrm{SB} \times \mathrm{CONC}, \mathrm{SB} \times \mathrm{MS}, \mathrm{SB} \times$ $\mathrm{XEF}$, and $\mathrm{SB} \times \mathrm{SEF})$. The effects that $\mathrm{CONC}$ had on the risk of conventional banks $(\mathrm{SB}=0)$ were measured by the coefficient $\beta 2$. In the case of MS, XEF, and SEF, these effects were captured by the coefficients $\beta 4, \beta 6$, and $\beta 8$, respectively. For sustainable banks $(\mathrm{SB}=1)$, the effect of CONC on risk was measured by the sum of the coefficients $(\beta 2+\beta 3)$. In the case of MS, XEF, and SEF, this effect was reflected by the sums of the coefficients $(\beta 4+\beta 5)$, $(\beta 6+\beta 7)$, and $(\beta 8+\beta 9)$, respectively.

It is not clear what the expected signs of the coefficients $\beta 2$ and $\beta 4$ will be, nor the sums of the coefficients $(\beta 2+\beta 3)$ and $(\beta 4+\beta 5)$. On the one hand, banks with a larger market share that operate in more concentrated markets can reduce financial instability through the provision of greater capital reserves, which protect them against economic and 
liquidity shocks [99]. Large banks also have a comparative advantage in monitoring loans and can achieve greater diversification of both the loan portfolio and the geographical distribution [100]. On the other hand, a higher concentration can lead to an increase in interest rates on loans, so borrowers will have to undertake riskier projects to repay their loans [101]. Moreover, banks with a higher market share in concentrated markets are usually more protected by governments, which may lead them to take greater risks [102]. Conversely, more efficient banks tend to become more capitalized, which contributes to bank stability. At the same time, less efficient banks may be tempted to take on higher risks to compensate for increased costs and lost returns $[103,104]$. As a result, we expect that the coefficients $\beta 6$ and $\beta 8$, and the sums of the coefficients $(\beta 6+\beta 7)$ and $(\beta 8+\beta 9)$ will have a significant and positive sign.

The variable LOANS is the ratio of loans to total assets and captures the liquidity risk of the bank and its activity $[78,79]$. Because the variable LOANS represents the liquidity risk of the bank, there should be a negative relationship between LOANS and bank risk [105]. Nevertheless, the loan-to-assets ratio is also an indicator of banks' retail orientation. Retail banks are perceived as less risky than non-retail ones, especially during crises. Additionally, banks with higher levels of loans have a lower proportion of securities, which reduces their exposure to other risks, such as sovereign risk [106]. Therefore, we can also expect a positive and significant relationship between the variable LOANS and bank risk.

SIZE represents the size of the bank and is calculated as the natural logarithm of total assets (deflated) [81,82]. Larger banks are likely to have a higher degree of product and loan diversification than smaller banks, which reduces risk [37]. As a result, we can expect a positive relationship between SIZE and bank risk. However, a negative relationship between these two variables can also be expected because a larger size can lead to reduced efficiency in management, less effective internal control and increased organizational complexity, which can lead to higher operational risk [107].

LOANDEP controls for differences in the intermediation ratio and represents the ratio of loans to deposits [108]. When loans exceed the deposit base, banks face a funding gap for which they must access financial markets. Financial markets are more volatile than retail funding, so we expect a negative relationship between LOANDEP and bank risk [109]. Table 8 provides a summary of the independent variables included in Equation (2) and their expected relationships with risk.

Table 8. Summary of the independent variables of the risk analysis.

\begin{tabular}{ccc}
\hline Variable & Description & Expected Relationship with Risk (Z) \\
\hline SB & Dummy that takes the value of 1 if a bank has signed the & Positive \\
CONC & UN Principles for Responsible Banking, and 0 otherwise & Positive/Negative \\
MS & Herfindahl-Hirschman index (HHI) in terms of assets & Positive/Negative \\
XEF & Market share in terms of assets & Positive \\
SEF & Cost X-efficiency & Positive \\
SB $\times$ CONC & Scale efficiency with respect to the inputs & Positive/Negative \\
SB $\times$ MS & Interaction between sustainable banks and & Positive/Negative \\
SB $\times$ XEF & market concentration & Positive \\
SB $\times$ SEF & Interaction between sustainable banks and market share & Positive \\
LOANS & Interaction between sustainable banks and cost X-efficiency & Positive/Negative \\
SIZE & Loans/Total assets & Positive/Negative \\
LOANDEP & Log (Total assets) & Negative \\
\hline
\end{tabular}

Finally, year- and country-effect dummies were included to capture year- and countryspecific factors. The error term is $\varepsilon_{i, t}$, and $\mathrm{i}=1,2, \ldots, \mathrm{N}$ indicates a specific bank $\mathrm{i}$; $\mathrm{t}=1,2, \ldots, \mathrm{T}$ indicates a particular year $\mathrm{t}$; and $\mathrm{m}=1,2, \ldots, \mathrm{M}$ indicates a particular country $\mathrm{m}$. Table 9 presents the descriptive statistics of the variables used in the risk analysis, and Table 10 depicts the correlation between these variables. 
Table 9. Sample statistics of the risk analysis.

\begin{tabular}{ccccc}
\hline Variable & Mean & Standard Deviation & Minimum & Maximum \\
\hline Z & 95.9222 & 196.7297 & 0.1661 & 3975.0530 \\
CONC & 0.0792 & 0.0524 & 0.0306 & 0.2914 \\
MS & 0.0261 & 0.0570 & $1.69 \times 10^{-6}$ & 0.4602 \\
XEF & 0.8161 & 0.0579 & 0.3896 & 0.9470 \\
SEF & 0.7455 & 0.0998 & 0.0041 & 0.7813 \\
LOANS & 0.6340 & 0.1596 & 0.0195 & 0.9747 \\
SIZE & 8.9409 & 2.0031 & 3.1179 & 14.7620 \\
LOANDEP & 7.0419 & 398.6775 & 0.0202 & $30,647.1700$ \\
\hline
\end{tabular}

Table 10. Correlations of the risk analysis.

\begin{tabular}{cccccccc}
\hline & CONC & MS & XEF & SEF & LOANS & SIZE & LOANDEP \\
\hline CONC & 1 & & & & & & \\
MS & 0.5002 & 1 & & & & & \\
XEF & -0.0792 & -0.0906 & 1 & & & & \\
SEF & -0.0137 & -0.2421 & -0.0101 & 1 & & & \\
LOANS & -0.1249 & -0.1222 & 0.1223 & 0.1928 & 1 & & \\
SIZE & 0.2204 & 0.4497 & -0.0141 & -0.4382 & -0.1559 & 1 & 1 \\
LOANDEP & -0.0122 & -0.0046 & 0.0146 & 0.0024 & 0.0020 & 0.0151 & 1 \\
\hline
\end{tabular}

\subsubsection{Methodology}

Like the profitability analysis, the model in Equation (2) was estimated using two-step System-GMM with robust errors [21]. The year and country dummies were considered exogenous, while the remaining variables were considered endogenous. Based on the Hansen test of the over-identifying restrictions for the endogenous variables, in general second and third lags were used as instruments. To avoid over-identification problems based on the Hansen test, we used third and fourth lags for the variable MS in differences. The exogenous variables were instrumented by themselves. We also collapsed the instruments used in our estimation [92,93]. Moreover, we carried out the F-statistics test to assess instrument strength. These results, which are shown in Table 11, reveal that in general, the instruments provide significant explanatory power for the endogenous variables.

Table 11. First-stage OLS regressions for System-GMM estimates (risk analysis).

\begin{tabular}{cccc}
\hline Z & F-Statistic & $p$-Value & $\mathbf{R}^{2}$ \\
\hline Panel A. Dependent variable in levels, explanatory variables (instruments) in differences \\
SB & 255 & 0.0000 & 0.9832 \\
CONC & 40.4 & 0.0000 & 0.4481 \\
SB $\times$ CONC & 57 & 0.0000 & 0.9134 \\
MS & 42.6 & 0.0000 & 0.5859 \\
SB $\times$ MS & 58.4 & 0.0000 & 0.7958 \\
XEF & 30.6 & 0.0000 & 0.1327 \\
SB $\times$ XEF & 58.9 & 0.0000 & 0.9858 \\
SEF & 16.5 & 0.0000 & 0.5247 \\
SB $\times$ SEF & 6.5 & 0.0016 & 0.9371 \\
LOANDEP & 139.1 & 0.0000 & 0.2518 \\
LOANS & 13.5 & 0.0000 & 0.1401 \\
SIZE & 4.6 & 0.0099 & 0.3930 \\
Panel B. Dependent variable in differences, explanatory variables (instruments) in levels & 0.9344 \\
$\Delta$ SB & $22,235.2$ & 0.0000 & 0.4163 \\
$\Delta$ CONC & 92.5 & 0.0000 & 0.5181 \\
$\Delta$ SB $\times$ CONC) & 39.8 & 0.0000 & 0.4725 \\
$\Delta$ MS & 43.5 & 0.0000 & \\
\hline
\end{tabular}


Table 11. Cont.

\begin{tabular}{cccc}
\hline $\mathbf{Z}$ & F-Statistic & $p$-Value & $\mathbf{R}^{2}$ \\
\hline$\Delta(\mathrm{SB} \times \mathrm{MS})$ & 6.9 & 0.0010 & 0.4924 \\
$\Delta \mathrm{XEF}$ & 28.6 & 0.0000 & 0.0937 \\
$\Delta(\mathrm{SB} \times \mathrm{XEF})$ & 87.4 & 0.0000 & 0.2539 \\
$\Delta \mathrm{SEF}$ & 59.3 & 0.0000 & 0.3643 \\
$\Delta(\mathrm{SB} \times \mathrm{SEF})$ & 75.7 & 0.0000 & 0.4049 \\
$\Delta$ LOANDEP & 366.4 & 0.0000 & 0.2561 \\
$\Delta$ LOANS & 42 & 0.0000 & 0.0904 \\
$\Delta$ SIZE & 82.3 & 0.0000 & 0.2020 \\
\hline
\end{tabular}

\subsubsection{Results of the Risk Analysis}

Table 12 shows the results of the risk analysis. Regarding the objective of this analysis, the influence of sustainable banks, the variable SB is not significant, which suggests that sustainable initiatives do not alter bank risk. This does not support our Hypothesis 3.

Table 12. Results of the risk analysis.

\begin{tabular}{ccccc}
\hline & Coefficient & Standard Error & T-Student & $p$-Value \\
\hline SB & 2.1820 & 2.9806 & 0.73 & 0.464 \\
CONC & -181.4364 & 159.8146 & -1.14 & 0.256 \\
SB $\times$ CONC & 241.6333 & 485.7008 & 0.50 & 0.619 \\
MS & -223.2634 & 180.3790 & -1.24 & 0.216 \\
SB $\times$ MS & -169.0902 & 340.5535 & -0.50 & 0.620 \\
XEF & 173.6664 & 145.4064 & 1.19 & 0.232 \\
SB $\times$ XEF & -178.9392 & 120.7129 & -1.48 & 0.138 \\
SEF & -87.7759 & 157.7984 & -0.56 & 0.578 \\
SB $\times$ SEF & 137.3545 & 156.4459 & 0.88 & 0.380 \\
LOANS & 87.1793 & 2.2423 & 1.69 & $0.091 *$ \\
SIZE & 15.7375 & 51.5945 & 1.93 & $0.054 *$ \\
LOANDEP & 0.1084 & 2.2423 & 0.05 & 0.961 \\
LR Test. SB $\times$ CONC & 60.1970 & 474.8923 & 0.13 & 0.899 \\
LR Test. SB $\times$ MS & -392.3537 & 298.9900 & -1.31 & 0.189 \\
LR Test. SB $\times$ XEF & -5.2728 & 139.2918 & -0.04 & 0.970 \\
LR Test. SB $\times$ SEF & 49.5783 & 95.7228 & 0.52 & 0.605 \\
CONS & -133.1983 & 156.7711 & -0.85 & 0.396 \\
Year dummies & & & & \\
Country dummies & & Yes & & 0.442 \\
M2 & & & & 0.102 \\
Hansen & & & & \\
\hline
\end{tabular}

* indicates a level of significance of 0.1. LR Test. SB $\times$ CONC is the linear restriction test of the sum of the coefficients associated with SB and CONC. LR Test. SB $\times$ MS is the linear restriction test of the sum of the coefficients associated with SB and MS. LR Test. SB $\times$ XEF is the linear restriction test of the sum of the coefficients associated with SB and XEF. LR Test. SB $\times$ SEF is the linear restriction test of the sum of the coefficients associated with SB and SEF. CONS is the regression intercept. M2 is the p-value of the 2 nd order serial correlation statistic. Hansen is the p-value of the over-identifying restriction test.

As far as the control variables are concerned, the variable LOANS has a significant and positive coefficient, which denotes that banks with more loans are less exposed to risk [106]. Moreover, the variable SIZE also shows a significant and positive coefficient, so larger banks can achieve greater diversification, which reduces risk [37].

\subsection{Discussion}

This article analyses how sustainable practices affect bank profitability, both directly and through the market power and efficiency hypotheses. Moreover, it examines the impact of sustainable banking on insolvency risk.

Firstly, we find that sustainable banks obtain more profits. These results are in line with other studies that suggest that sustainable banks are more profitable than conventional 
banks. According to these studies, sustainable banks have a better reputation, provide more confidence, and can attract more loyal customers, which is why they earn superior profits $[43,44]$.

Secondly, conventional banks that operate in more concentrated markets make more profits, as proposed by the market power hypothesis. Nevertheless, for sustainable banks, banking concentration does not affect profitability significantly. These results support the evidence of Matute-Vallejo et al. [8], which suggests that banks do not use sustainability as an attempt to instrumentalize social issues in a manner ultimately intended to increase prices. Instead of taking advantage of their market power to set higher prices for customers, sustainable banks would use other attributes to attract clients and earn profits, such as different business culture, lower reputational risk, or compromise with social and environmental values [2].

Thirdly, banks with superior cost scale efficiency are more profitable, regardless of their sustainable orientation, as the efficiency hypothesis suggest. The positive effects of sustainable strategies on efficiency would compensate for the negative ones and, hence, sustainable banks tend to be as efficient as conventional banks. The findings of many previous studies support this idea. On the one hand, Nidumolu et al. [9] reveal that social and environmental compromises are costly, which can reduce efficiency. On the other hand, as Bassen et al. [11] propose, these compromises can also improve the reputation of the banks that acquire them, which reduces their funding costs. Furthermore, Clarkson et al. [12] show that sustainable initiatives strengthen the sustainable standards of the industry, which raises competitors' costs.

Fourthly, our results show that sustainable banking practices do not have a significant impact on insolvency risk. According to García-Benau et al. [110], the financial crisis seriously damaged the reputation and the confidence of banks, which forced them to implement sustainable strategies despite their risks and costs. This aspect, along with the fact that real sustainability concerns have not emerged until recently, could explain why sustainable banks still do not exhibit lower insolvency risk.

\section{Conclusions}

The financial crisis had strongly adverse effects on the image and confidence of the banking sector, which led many banks to implement sustainable business strategies to improve their reputation. These strategies might affect the relationship between market power, efficiency, and profitability, as well as the relationship between sustainable banks and risk. To analyze these changes, we performed an empirical analysis on a sample of 1236 banks from 48 countries over the period 2015-2019. The results of this analysis indicate that sustainable banking practices lead to higher profitability. Moreover, conventional banks that operate in markets with higher concentration are more profitable, as proposed by the market power hypothesis. However, for sustainable banks, market concentration does not affect profits significantly. Higher levels of cost scale efficiency lead to more profitability for both conventional and sustainable banks. There does not appear to be a significant relationship between sustainable banks and risk.

These results have important implications for the implementation of sustainable business models and the research agenda for sustainability in banking. Our results suggest that the traditional determinants of bank profitability are not relevant in explaining the superior profits made by sustainable banks. This suggests the emergence of a new paradigm related to sustainability in the drivers of bank profitability, where intangible competitive advantages such as brand image, customer loyalty, lower reputational risk, or ethical issues could play a key role.

Moreover, sustainable activities still do not affect bank risk, probably because the severe consequences of the financial crisis forced banks to adopt a sustainable approach regardless of their risks. It is possible that sustainable practices will reduce bank risk in the future when banks will have completely restored their image and the confidence lost during the 2008 financial crisis. 
On the other hand, our sample includes banks from many world regions with differences in regulation, which could also determine the relationship between sustainability and the market power and efficiency hypotheses, as well as the relationship between sustainability and credit risk. For instance, regulatory factors and legal requirements can have important effects on bank efficiency and solvency. Additionally, legal impediments to competition can alter the degree of concentration. Further research is therefore needed to fully understand the determinants of profitability and risk among sustainable banks, especially in the long run.

Author Contributions: Conceptualization, B.T.O., S.S.A., M.C.S.; Methodology, S.S.A.; Software, S.S.A., M.C.S.; Validation, B.T.O., S.S.A., M.C.S.; Formal Analysis, B.T.O., S.S.A.; Investigation, B.T.O., S.S.A., M.C.S.; Resources, B.T.O., M.C.S.; Data Curation, S.S.A., M.C.S.; Writing-Original Draft Preparation, M.C.S.; Writing-Review \& Editing, M.C.S.; Visualization, B.T.O., S.S.A., M.C.S.; Supervision, B.T.O., S.S.A.; Project Administration, B.T.O.; Funding Acquisition, B.T.O. All authors have read and agreed to the published version of the manuscript.

Funding: This research was funded by the Santander Financial Institute (SANFI), at the University of Cantabria Foundation for Education and Research in the Financial Sector (UCEIF Foundation).

Data Availability Statement: S\&P Capital IQ database (www.capitaliq.com); International Monetary Fund database (www.imf.org); World Bank's World Development Indicators (https://databank. worldbank.org).

Conflicts of Interest: The authors declare no conflict of interest.

\section{Appendix A}

To estimate cost efficiency, we used the Fourier flexible functional form under the alternative specification. We estimated the efficiency frontier using the stochastic frontier approach (SFA). In addition, we followed the intermediation approach that considers three outputs, three input prices, financial capital (equity) as a correction factor and four environmental variables $[7,74,111-113]$. We also incorporated the time trend as a measure to control for technological progress [114]. Our specification of the cost function is as follows:

$$
\begin{gathered}
\ln (\mathrm{C})=\alpha+\sum_{\mathrm{i}=1}^{3} b_{\mathrm{i}} \ln \left(\mathrm{w}_{\mathrm{i}}\right)+1 / 2 \sum_{\mathrm{i}=1}^{3} \sum_{\mathrm{j}=1}^{3} b_{\mathrm{ij}} \ln \left(\mathrm{w}_{\mathrm{i}}\right) \ln \left(\mathrm{w}_{\mathrm{j}}\right)+\sum_{\mathrm{k}=1}^{3} \gamma_{\mathrm{k}} \ln \left(\mathrm{y}_{\mathrm{k}}\right)+ \\
1 / 2 \sum_{\mathrm{k}=1}^{3} \sum_{\mathrm{n}=1}^{3} \gamma_{\mathrm{kn}} \ln \left(\mathrm{y}_{\mathrm{k}}\right) \ln \left(\mathrm{y}_{\mathrm{n}}\right)+\omega \ln (\mathrm{E})+1 / 2 \psi \ln \left(\mathrm{E}_{\mathrm{i}}\right)^{2}+\tau_{1} \mathrm{~T}+1 / 2 \tau_{2} \mathrm{~T}^{2}+\sum_{\mathrm{i}=1}^{3} \sum_{\mathrm{k}=1}^{3} \rho_{\mathrm{ik}} \\
\ln \left(\mathrm{w}_{\mathrm{i}}\right) \ln \left(\mathrm{y}_{\mathrm{k}}\right) \sum_{\mathrm{i}=1}^{3} \eta_{\mathrm{iE}} \ln \left(\mathrm{w}_{\mathrm{i}}\right) \ln (\mathrm{E})+\sum_{\mathrm{i}=1}^{3} \zeta_{\mathrm{i}} \operatorname{Tln}\left(\mathrm{w}_{\mathrm{i}}\right)+\sum_{\mathrm{k}=1}^{3} \rho_{\mathrm{kE}} \ln \left(\mathrm{y}_{\mathrm{k}}\right) \ln (\mathrm{E})+ \\
\sum_{\mathrm{m}=1}^{3} \sum_{\mathrm{k}=1}^{3} \vartheta_{\mathrm{k}} \operatorname{Tln}\left(\mathrm{y}_{\mathrm{k}}\right)+\sum_{\mathrm{s}=1}^{4} \mu_{\mathrm{k}} \ln \left(\mathrm{v}_{\mathrm{s}}\right)+\sum_{\mathrm{q}=1}^{4}\left[\varphi_{\mathrm{q}} \cos \left(\mathrm{x}_{\mathrm{q}}\right)+\mathrm{w}_{\mathrm{q}} \sin \left(\mathrm{x}_{\mathrm{q}}\right)\right]+\sum_{\mathrm{q}=1}^{4} \sum_{\mathrm{r}=1}^{4}\left[\varphi_{\mathrm{qr}} \cos \left(\mathrm{x}_{\mathrm{q}}+\mathrm{x}_{\mathrm{r}}\right)\right. \\
\left.+\mathrm{w}_{\mathrm{qr}} \sin \left(\mathrm{x}_{\mathrm{q}}+\mathrm{x}_{\mathrm{r}}\right)\right]+\sum_{\mathrm{q}=1}^{4}\left[\varphi_{\mathrm{qqq}} \cos \left(\mathrm{x}_{\mathrm{q}}+\mathrm{x}_{\mathrm{q}}+\mathrm{x}_{\mathrm{q}}\right)+\mathrm{w}_{\mathrm{qqq}} \sin \left(\mathrm{x}_{\mathrm{q}}+\mathrm{x}_{\mathrm{q}}+\mathrm{x}_{\mathrm{q}}\right)\right]+\ln \mathrm{l}+\ln \varepsilon
\end{gathered}
$$

The dependent variable is total cost (interest and non-interest expenses).

Outputs:

1. $\mathrm{y} 1=$ loans.

2. $\quad \mathrm{y} 2=$ securities.

3. $\mathrm{y} 3=$ deposits.

Input prices:

1. $\mathrm{w} 1=$ cost of lendable funds: interest expenses over liabilities (deposits, money market funding and other funding).

2. $\quad \mathrm{w} 2$ = cost of physical capital: defined as the ratio of non-interest expenses and the book value of physical capital.

3. $\quad \mathrm{w} 3=$ cost of labor: operating expenses to total employees.

Fixed netput:

$\mathrm{E}=$ financial capital (equity).

Environmental variables of the country:

1. $\mathrm{v} 1=$ outstanding loans from commercial banks to GDP.

2. $\mathrm{v} 2$ = per capita GDP.

3. $\mathrm{v} 3=$ population density. 
4. $\quad \mathrm{v} 4=$ Herfindahl concentration index to assets.

Time trend:

$\mathrm{T}=$ time trend.

The variables $\mathrm{x}_{\mathrm{q}}, \mathrm{q}=1,2,3,4$ are rescaled values of the variables $\left(\ln _{\mathrm{k}}\right), \mathrm{k}=1,2,3$, and $\ln (\mathrm{E})$ such that $\mathrm{x}_{\mathrm{q}}$ is in the $[0.2 \pi]$ interval, where $\pi$ is the number of radians and not the profits. Moreover, we cut $10 \%$ off each end of the $[0.2 \pi]$ interval such that the $x_{\mathrm{q}}$ span is $[0.1 \times 2 \pi, 0.9 \times 2 \pi]$. This eliminates problems of approximation to the extremes. The formula for $x_{\mathrm{q}}$ is $0.2 \pi-\mu \times \mathrm{a}+\mu \times$ variable, where $\mu \equiv(0.9 \times 2 \pi-0.1 \times 2 \pi) /(\mathrm{b}-\mathrm{a})$, and $[a, b]$ is the range of the variable.

Because the duality theorem requires that the cost function is linearly homogeneous in input prices and continuity requires that the second-order parameters are symmetric, the following restrictions apply to the parameters:

$$
\sum_{i=1}^{3} \beta_{i}=1 ; \sum_{i=1}^{3} \beta_{i j}=0 ; \sum_{i=1}^{3} \rho_{i k}=0 ; \sum_{i=1}^{3} \eta_{i m}=0
$$

The inefficiency term is assumed to be distributed as half-normal.

$$
B_{\mathrm{ij}}=B_{\mathrm{ji}} ; \gamma_{\mathrm{ik}}=\gamma_{\mathrm{ki}}
$$

\section{Appendix B}

We estimated the scale economies by deriving the cost function with respect to the inputs:

$$
\operatorname{SCALE}=\sum_{n=1}^{3}\left(\delta \ln C / \delta \ln y_{i}\right)
$$

This measure was calculated with the mean of the input and output values in various size classes $[7,76]$ and for each of the years analyzed. We considered six intervals: (1) less than $\$ 500 \mathrm{~m}$; (2) between $\$ 500 \mathrm{~m}$ and $\$ 1 \mathrm{bn}$; (3) between $\$ 1$ bn and $\$ 3 \mathrm{bn}$; (4) between $\$ 3 \mathrm{bn}$ and $\$ 5 \mathrm{bn}$; (5) between $\$ 5 \mathrm{bn}$ and $\$ 10 \mathrm{bn}$; and (6) more than $\$ 10 \mathrm{bn}$.

A bank operates under increasing, constant, or decreasing returns to scale when this measure is greater than, equal to, or less than 1 , respectively.

\section{References}

1. Cornett, M.M.; Erhemjamts, O.; Tehranian, H. Greed or good deeds: An examination of the relation between corporate social responsibility and the financial performance of U.S. commercial banks around the financial crisis. J. Bank. Financ. 2016, 70, 137-159. [CrossRef]

2. Agirre-Aramburu, I.; Gómez-Pescador, I. The effects of corporate social responsibility on customer loyalty: The mediating effect of reputation in cooperative banks versus commercial banks in the Basque Country. J. Bus. Ethics 2019, 154, 701-719. [CrossRef]

3. Nosratabadi, S.; Pinter, G.; Mosavi, A.; Semperger, S. Sustainable banking; Evaluation of the European business models. Sustainability 2020, 12, 2314. [CrossRef]

4. Berger, A.N. The profit-structure relationship in banking-tests of market-power and efficient-structure hypotheses. J. Money Credit Bank. 1995, 27, 404-431. [CrossRef]

5. Platonova, E.; Asutay, M.; Dixon, R.; Mohammad, S. The impact of corporate social responsibility disclosure on financial performance: Evidence from the GCC Islamic banking sector. J. Bus. Ethics 2018, 151, 451-471. [CrossRef]

6. Szegedi, K.; Khan, Y.; Lentner, C. Corporate social responsibility and financial performance: Evidence from Pakistani listed banks. Sustainability 2020, 12, 4080. [CrossRef]

7. Sanfilippo-Azofra, S.; Cantero-Saiz, M.; Torre-Olmo, B.; López-Gutiérrez, C. Financial crises, concentration and efficiency: Effects on performance and risk of banks. Financ. Uver 2013, 63, 537-558.

8. Matute-Vallejo, J.; Bravo, R.; Pina, J.M. The influence of corporate social responsibility and price fairness on customer behaviour: Evidence from the financial sector. Corp. Soc. Responsib. Environ. Manag. 2011, 18, 317-331. [CrossRef]

9. Nidumolu, R.; Prahalad, C.K.; Rangaswami, M.R. Why sustainable is now the key driver of innovation? Harv. Bus. Rev. 2009, 87, 56-64.

10. Hambrick, D.C. Some tests of the effectiveness and functional attributes of miles and snow's strategic types. Acad. Manag. J. 1983, 26, 5-26.

11. Bassen, A.; Meyer, K.; Schlange, J. The Influence of Corporate Responsibility on the Cost of Capital. Available online: https: / / papers.ssrn.com/sol3/papers.cfm?abstract_id=984406 (accessed on 25 November 2020).

12. Clarkson, P.; Li, Y.; Richardson, G.; Vasvari, F. Does it pay to be green? Determinants and consequences of proactive environmental strategies. J. Account. Public Policy 2011, 30, 122-144. [CrossRef] 
13. Saïdane, D.; Abdallah, S.B. Sustainability and financial stability: Evidence from European banks. Econ. Bull. 2020, 40, 1769-1780.

14. Bouis, R.; Rawdanowicz, L.; Renne, J.P.; Watanabe, S.; Christensen, A.K. The Effectiveness of Monetary Policy Since the Onset of the Financial Crisis; OECD Economics Department Working Paper No. 1081; OECD Publishing: Paris, France, 2013.

15. Valencia, F. Aggregate Uncertainty and the Supply of Credit. J. Bank. Financ. 2017, 81, 150-165. [CrossRef]

16. Scholtens, B.; Van't Klooster, S. Sustainability and bank risk. Palgrave Commun. 2019, 5, 1-8. [CrossRef]

17. Ruiz, B.; García, J.A.; Revilla, A.J. Antecedents and consequences of bank reputation: A comparison of the United Kingdom and Spain. Int. Mark. Rev. 2016, 33, 781-805. [CrossRef]

18. Lopatta, K.; Buchholz, F.; Kaspereit, T. Asymmetric information and corporate social responsibility. Bus. Soc. 2016, 55, 458-488. [CrossRef]

19. Endrikat, J.; Guenther, E.; Hoppe, H. Making sense of conflicting empirical findings: A meta-analytic review of the relationship between corporate environmental and financial performance. Eur. Manag. J. 2014, 32, 735-751. [CrossRef]

20. Tregidga, H.; Milne, M.; Kearins, K. (Re) presenting sustainable organizations. Account. Organ. Soc. 2014, 39, 477-494. [CrossRef]

21. Arellano, M.; Bond, S. Some tests of specification for panel data: Monte Carlo evidence and an application to employment equations. Rev. Econ. Stud. 1991, 58, 277-297. [CrossRef]

22. Allen, F.; Santomero, A.M. The theory of financial intermediation. J. Bank. Financ. 1997, 21, 1461-1485. [CrossRef]

23. Allen, F.; Santomero, A.M. What do financial intermediaries do? J. Bank. Financ. 2001, 25, 271-294. [CrossRef]

24. Polonskaya, J.; Babenko, M. Best Practice Guide on Sustainable Finance: A Practical Toolkit for Russian Financial Sector; Sustainable Finance Programme Report; WWF-World Wide Fund For Nature: Gland, Switzerland, 2012.

25. Shah, A.A.; Wu, D.; Korotkov, V. Are sustainable banks efficient and productive? A data envelopment analysis and the Malmquist productivity index analysis. Sustainability 2019, 11, 2398. [CrossRef]

26. Scholtens, B. Corporate social responsibility in the international banking industry. J. Bus. Ethics 2012, 86, 159-175. [CrossRef]

27. Weber, O. Environmental credit risk management in banks and financial service institutions. Bus. Strateg. Environ. 2009, 21, 248-263. [CrossRef]

28. Gangi, F.; Meles, A.; D'Angelo, E.; Daniele, L.M. Sustainable development and corporate governance in the financial system: Are environmentally friendly banks less risky? Corp. Soc. Responsib. Environ. Manag. 2019, 26, 529-547. [CrossRef]

29. UNEP Finance Initiative (UNEP FI). Available online: www.unepfi.org (accessed on 18 January 2021).

30. Keffas, G.; Olulu-Briggs, O.V. Corporate social responsibility: How does it affect the financial performance of banks? Empirical evidence from US, UK and Japan. J. Manag. Gov. 2011, 3, 8-26.

31. Demsetz, H. Barriers to entry. Am. Econ. Rev. 1982, 72, 47-57.

32. Shepherd, W.G. Economies of scale and monopoly profits. In Industrial Organization, Antitrust, and Public Policy; Craven, J.V., Ed.; Kluwer Nijhoff: Boston, MA, USA; Springer: Dordrecht, The Netherlands, 1983; pp. 165-204.

33. Peltzman, S. The gains and losses from industrial concentration. J. Law Econ. 1977, 20, 229-263. [CrossRef]

34. Corvoisier, S.; Gropp, R. Bank concentration and retail interest rates. J. Bank. Financ. 2002, 26, 2155-2189. [CrossRef]

35. De Jonghe, O.; Vander Vennet, R. Competition versus efficiency: What drives franchise values in European banking? J. Bank. Financ. 2008, 32, 1820-1835. [CrossRef]

36. Hsieh, M.F.; Lee, C.C. The Puzzle between banking competition and profitability can be solved: International evidence from bank-level data. J. Financ. Serv. Res. 2010, 38, 135-157. [CrossRef]

37. Dietrich, A.; Wanzenried, G. Determinants of bank profitability before and during the crisis: Evidence from Switzerland. J. Int. Financ. Mark. Inst. 2011, 21, 307-327. [CrossRef]

38. Tan, Y.; Floros, C.; Anchor, J. The profitability of Chinese banks: Impacts of risk, competition and efficiency. Rev. Account. Financ. 2017, 16, 86-105. [CrossRef]

39. Gatzert, N. The impact of corporate reputation and reputation damaging events on financial performance: Empirical evidence from the literature. Eur. Manag. J. 2015, 33, 485-499. [CrossRef]

40. Igbudu, N.; Garanti, Z.; Popoola, T. Enhancing bank loyalty through sustainable banking practices: The mediating effect of corporate image. Sustainability 2018, 10, 4050. [CrossRef]

41. Daub, C.H.; Ergenzinger, R. Enabling sustainable management through a new multi-disciplinary concept of customer satisfaction. Eur. J. Mark. 2005, 39, 998-1012. [CrossRef]

42. Ferreira, F.; Jalali, M.; Meiudute-Kavaliauskiene, I.; Viana, B. A metacognitive decision making based-framework for bank customer loyalty measurement and management. Technol. Econ. Dev. Econ. 2015, 21, 280-300. [CrossRef]

43. Bussoli, C.; Conte, D.; Letorri, G.; Barone, M. Does it pay to be sustainable? Evidence from European banks. Int. J. Bus. Manag. 2019, 14, 128-146. [CrossRef]

44. Yip, A.W.; Bocken, N.M. Sustainable business models archetypes for the banking industry. J. Clean. Prod. 2018, 174, 150-169. [CrossRef]

45. Fay, P. Sustainability Gains Consumer Traction as Modo Anticipates Eco 2.0. Available online: Visionmonday.com (accessed on 25 November 2020).

46. Mason, C.F. The economics of eco-labeling: Theory and empirical implications. Int. Rev. Environ. Resour. Econ. 2012, 6, 341-372. [CrossRef] 
47. Sun, H.; Rabbani, M.R.; Ahmad, N.; Sial, M.S.; Cheng, G.; Zia-Ud-Din, M.; Fu, Q. CSR, co-creation and green consumer loyalty: Are green banking initiatives important? A moderated mediation approach from an emerging economy. Sustainability 2020, 12, 10688. [CrossRef]

48. Boitan, I.A. Determinants of sustainable banks' profitability, evidence from EU countries. Financ. Stud. 2015, 19, 21-39.

49. Global Alliance for Banking on Values (GABV). Strong, Straightforward and Sustainable Banking; GABV: Amsterdam, The Netherlands, 2012.

50. Global Alliance for Banking on Values (GABV). Real Banking for the Real Economy: Comparing Sustainable Bank Performance with the Largest Banks in the World; GABV: Amsterdam, The Netherlands, 2013.

51. Aupperle, K.E.; Carroll, A.B.; Hatfield, J.D. An empirical examination of the relationship between corporate social responsibility and profitability. Acad. Manag. J. 1985, 28, 446-463.

52. Ullman, A.A. Data in search of a theory: A critical examination of the relationships among social performance, social disclosure, and economic performance of US firms. Acad. Manag. Rev. 1985, 10, 540-557.

53. Burgstahler, D.; Dichev, I. Earnings management to avoid earnings decreases and losses. J. Account. Econ. 1997, $24,99-126$. [CrossRef]

54. El Ghoul, S.; Guedhami, O.; Kwok, C.; Mishra, D. Does corporate social responsibility affect the cost of capital? J. Bank. Financ. 2011, 35, 2388-2408. [CrossRef]

55. Hachenberg, B.; Schiereck, D. Are green bonds priced differently from conventional bonds? J. Asset Manag. 2018, 19, 371-383. [CrossRef]

56. Hart, S. A natural-resource-based view of the firm. Acad. Manag. Rev. 1995, 20, 986-1014. [CrossRef]

57. Sharma, S.; Vredenburg, H. Proactive corporate environmental strategy and the development of competitively valuable organizational capabilities. Strateg. Manag. J. 1998, 19, 729-753. [CrossRef]

58. Christmann, P. Effects of "best practices" of environmental management on cost advantage: The role of complementary assets. Acad. Manag. J. 2000, 43, 663-680.

59. Pampurini, F.; Quaranta, A.G. Sustainability and efficiency of the European banking market after the global crisis: The impact of some strategic choices. Sustainability 2018, 10, 2237. [CrossRef]

60. Wu, M.; Shen, C. Corporate social responsibility in the banking industry: Motives and financial performance. J. Bank. Financ. 2011, 37, 3529-3547. [CrossRef]

61. Harjoto, M.A.; Laksmana, I. The impact of corporate social responsibility on risk taking and firm value. J. Bus. Ethics 2016, 151, 353-373. [CrossRef]

62. Monti, A.; Pattitoni, P.; Petracci, B.; Randl, O. Does Corporate Social Responsibility Impact Equity Risk? International Evidence. 31 January 2019. Available online: https:// papers.ssrn.com/sol3/papers.cfm?abstract_id=3167883 (accessed on 25 November 2020).

63. Rajput, N.; Oberoi, S. Does corporate social responsibility give long term sustainability and stability? An empirical validation. J Indian Manag. Strategy 2015, 20, 36-40. [CrossRef]

64. Goss, A.; Roberts, G.S. The impact of corporate social responsibility on the cost of bank loans. J. Bank. Financ. 2011, 35, 1794-1810. [CrossRef]

65. Cui, Y.; Geobey, S.; Weber, O.; Lin, H. The impact of green lending on credit risk in China. Sustainability 2018, 10, 2008. [CrossRef]

66. Homer-Dixon, T.; Walker, B.; Biggs, R.; Crépin, A.S.; Folke, C.; Lambin, E.F.; Peterson, G.D.; Rockström, J.; Scheffer, M.; Steffen, W.; et al. Synchronous failure: The emerging causal architecture of global crisis. Ecol. Soc. 2015, 20, 6. [CrossRef]

67. European Central Bank (ECB). Guide on Climate-Related and Environmental Risks. Supervisory Expectations Relating to Risk Management and Disclosure; ECB: Frankfurt, Germany, 2020.

68. Chollet, P.; Sandwidi, B.W. CSR engagement and financial risk: A virtuous cycle? International evidence. Glob. Financ. J. 2018, 38, 65-81. [CrossRef]

69. Sanfilippo-Azofra, S.; Torre-Olmo, B.; Cantero-Saiz, M.; López-Gutiérrez, C. Financial development and the bank lending channel in developing countries. J. Macroecon. 2018, 55, 215-234. [CrossRef]

70. Tregenna, F. The fat years: The structure and profitability of the US banking sector in the precrisis period. Camb. J. Econ. 2009, 33, 609-632. [CrossRef]

71. De Nicoló, G.; Bartholomew, P.; Zaman, J.; Zephirin, M. Bank consolidation, internationalization, and conglomerization: Trends and implications for financial risk. Financ. Mark. Inst. Instrum. 2004, 13, 173-217. [CrossRef]

72. Barth, J.R.; Caprio, G., Jr.; Levine, R. Bank regulation and supervision: What works best? J. Financ. Intermediat. 2004, 13, 205-248. [CrossRef]

73. Beck, T.; Demirgüç-Kunt, A.; Levine, R. Bank concentration, competition and crises: First results. J. Bank. Financ. 2006, 30, 1581-1603. [CrossRef]

74. Maudos, J.; Pastor, J.M.; Pérez, F.; Quesada, J. Cost and profit efficiency in European banks. J. Int. Financ. Mark. Inst. 2002, 12, 33-58. [CrossRef]

75. Kohers, T.; Huang, M.; Kohers, N. Market perception of efficiency in bank holding company mergers: The roles of the DEA and SFA models in capturing merger potential. Rev. Financ. Econ. 2000, 9, 101-120. [CrossRef]

76. Vander Vennet, R. Cost and profit efficiency of financial conglomerates and universal banks in Europe. J. Money Credit Bank. 2002, 34, 254-282. [CrossRef] 
77. Athanasoglou, P.; Brissimis, S.; Delis, M. Bank-specific, industry-specific and macroeconomic determinants of bank profitability. J. Int. Financ. Mark. Inst. 2008, 18, 121-136. [CrossRef]

78. Bourke, P. Concentration and other determinants of bank profitability in Europe, North America and Australia. J. Bank. Financ. 1989, 13, 65-79. [CrossRef]

79. Wheelock, D.C.; Wilson, P.W. Consolidation in US banking: Which banks engage in mergers? Rev. Financ. Econ. 2004, 13, 7-39. [CrossRef]

80. Eichengreen, B.J.; Gibson, H.D. Greek Banking at the Dawn of the New Millennium; Centre for Economic Policy Research: London, UK, 2001.

81. Goldberg, L.G.; Rai, A. The structure-performance relationship for European banking. J. Bank. Financ. 1996, $20,745-771$. [CrossRef]

82. Behr, P.; Schmidt, R.H.; Xie, R. Market structure, capital regulation and bank risk taking. J. Financ. Serv. Res. 2010, 37, 131-158. [CrossRef]

83. Smirlock, M. Evidence on the (non) relationship between concentration and profitability in banking. J. Money Credit Bank. 1985, 17, 69-83. [CrossRef]

84. Pasiouras, F.; Kosmidou, K. Factors influencing the profitability of domestic and foreign commercial banks in the European Union. Res. Int. Bus. Financ. 2007, 21, 222-237. [CrossRef]

85. Bikker, J.A.; Hu, H. Cyclical patterns in profits, provisioning and lending of banks and procyclicality of the new Basel capital requirements. BNL Q. Rev. 2002, 55, 143-175.

86. Blundell, R.; Bond, S. Initial conditions and moment restrictions in dynamic panel data models. J. Econom. 1998, 87, 115-143. [CrossRef]

87. Arellano, M.; Bover, O. Another look at the instrumental variable estimation of error component models. J. Econom. 1995, 68, 29-51. [CrossRef]

88. Nagarajan, N.R.; Teixeira, A.A.C.; Silva, S.T. Ageing population: Identifying the determinants of ageing in the least developed countries. Popul. Res. Policy Rev. 2020, 1-24. [CrossRef]

89. Bowsher, C.G. On testing overidentifying restrictions in dynamic panel data models. Econ. Lett. 2002, 77, 211-220. [CrossRef]

90. Roodman, D.M. How to do xtabond2: An introduction to difference and system GMM in stata. Stata J. 2009, 9, 86-136. [CrossRef]

91. Mehrhoff, J. A Solution to the Problem of Too Many Instruments in Dynamic Panel Data GMM; Discussion Paper Series 1: Economic Studies (2009, 31); Deutsche Bundesbank: Frankfurt, Germany, 2009.

92. Wintoki, M.B.; Linck, J.S.; Netter, J.M. Endogeneity and the dynamics of internal corporate governance. J. Financ. Econ. 2012, 105, 581-606. [CrossRef]

93. Torre-Olmo, B.; Sanfilippo-Azofra, S.; Cantero-Saiz, M. Creditor rights and the bank lending channel of monetary policy. In Corporate Governance in Banking and Investor Protection. From Theory to Practice; CSR, Sustainability, Ethics \& Governance; Díaz-Díaz, B., Idowu, S.O., Molyneux, P., Eds.; Springer International Publishing: Cham, Switzerland, 2018; Chapter 6.

94. Keasey, K.; Martínez, B.; Pindado, J. Young family firms: Financing decisions and the willingness to dilute control. J. Corp. Financ. 2015, 24, 47-63. [CrossRef]

95. Cantero-Sáiz, M.; Sanfilippo-Azofra, S.; Torre-Olmo, B.; López-Gutiérrez, C. Trade credit, sovereign risk and monetary policy in Europe. Int. Rev. Econ. Financ. 2017, 52, 39-54. [CrossRef]

96. Staiger, D.; Stock, J.H. Instrumental variables regression with weak instruments. Econometrica 1997, 65, 557-586. [CrossRef]

97. Laeven, L.; Levine, R. Bank governance, regulation and risk taking. J. Financ. Econ. 2009, 93, 259-275. [CrossRef]

98. Goetz, M.R.; Laeven, L.; Levine, R. Does the geographical expansion of banks reduce risk? J. Financ. Econ. 2016, 120, 346-362. [CrossRef]

99. Boyd, J.H.; de Nicoló, G.; Smith, B.D. Crises in competitive versus monopolistic banking systems. J. Money Credit Bank. 2004, 36, 487-506. [CrossRef]

100. Méon, P.G.; Weill, L. Can mergers in Europe help banks hedge against macroeconomic risk? Appl. Financ. Econ. 2005, 15, 315-326. [CrossRef]

101. Boyd, J.H.; de Nicoló, G. The theory of bank risk taking and competition revisited. J. Financ. 2005, 60, 1329-1343. [CrossRef]

102. Mishkin, S. Financial consolidation: Dangers and opportunities. J. Bank. Financ. 1999, 23, 675-691. [CrossRef]

103. Hughes, J.P.; Mester, L.J. Efficiency in banking: Theory, practice and evidence. In Oxford Handbook of Banking; Berger, A.N., Molyneux, P., Wilson, J.O.S., Eds.; Oxford University Press: Oxford, UK, 2012.

104. Fiordelisi, F.; Marques-Ibanez, D.; Molyneux, P. Efficiency and risk in European banking. J. Bank. Financ. 2011, 35, 1315-1326. [CrossRef]

105. Diamond, D.W.; Rajan, R.G. Liquidity risk, liquidity creation, and financial fragility: A theory of banking. J. Political Econ. 2001, 109, 287-327. [CrossRef]

106. De Bruyckere, V.; Gerhardt, M.; Schephens, G.; Vander Vennet, R. Bank/sovereign risk spillovers in the European debt crisis. J. Bank. Financ. 2013, 37, 4793-4809. [CrossRef]

107. Cetorelli, N.; Hirtle, B.; Morgan, D.; Peristiani, S.; Santos, J. Trends in financial market concentration and their implications for market stability. Econ. Policy Rev. 2007, 13, 33-51.

108. Fries, S.; Taci, A. Cost efficiency of banks in transition: Evidence from 289 banks in 15 post-communist countries. J. Bank. Financ. 2005, 29, 55-81. [CrossRef] 
109. Van den End, J.W. A macroprudential approach to address liquidity risk with the loan-to-deposit ratio. Eur. J. Financ. 2016, 22, 237-253. [CrossRef]

110. García-Benau, A.; Sierra-García, L.; Zorio, A. Financial crisis impact on sustainability reporting. Manag. Decis. 2013, 51, 1528-1542. [CrossRef]

111. Altunbas, Y.; Molyneux, P. Economies of scale and scope in European banking. Appl. Financ. Econ. 1996, 6, 367-375. [CrossRef]

112. Berger, A.N.; Mester, L.J. Explaining the dramatic changes in performance of US banks: Technological change, deregulation, and dynamic changes in competition. J. Financ. Intermediat. 2003, 12, 57-95. [CrossRef]

113. Carbó-Valverde, S.; Humphrey, D.B.; López del Paso, R. Do cross-country differences in bank efficiency support a policy of "national champions"? J. Bank. Financ. 2007, 31, 2173-2188. [CrossRef]

114. Altunbas, Y.; Gardener, E.P.M.; Molyneux, P.; Moore, B. Efficiency in European banking. Eur. Econ. Rev. 2001, 45, 1931-1955. [CrossRef] 
Article

\title{
Non-Parametric Model for Evaluating the Performance of Chinese Commercial Banks' Product Innovation
}

\author{
Luning Shao, Jianxin You, Tao $\mathrm{Xu}$ * and Yilei Shao \\ School of Economics and Management, Tongji University, Shanghai 200092, China; \\ shaoluning@tongji.edu.cn (L.S.); yjx2256@vip.sina.com (J.Y.); 2014shaoyl@tongji.edu.cn (Y.S.) \\ * Correspondence: xutao0709@yeah.net; Tel.: +86-186-2174-4029
}

Received: 16 January 2020; Accepted: 14 February 2020; Published: 18 February 2020

\begin{abstract}
A thorough analysis of commercial banks' product innovation performance is essential to promoting bank product innovation capabilities and sustainable development. In this paper, the product innovation performance of commercial banks is defined as the conversion efficiency of input and output factors. The credit risk of product innovation of banks is considered as an undesirable output and incorporated in the performance evaluation system. Depending on whether there is a synchronous relationship between innovation income and risks, a Fixed Correlation model (FCM) and a Variable Correlation model (VCM) are then constructed based on Data Envelopment Analysis (DEA) method for the evaluation of commercial bank product innovation performance. In addition, an output optimization model of the objective function is also constructed to estimate the target income of commercial banks' product innovation in the FCM and VCM. Finally, the proposed model is applied to Chinese listed commercial banks for estimating the performance and target income of product innovation.
\end{abstract}

Keywords: data envelopment analysis; commercial banks; product innovation; performance evaluation; innovation risk

\section{Introduction}

In recent years, Chinese commercial banks continue to strengthen their capability of innovation and risk management through product innovation, which is also regarded as an important strategy for the improvement of their core competitiveness [1,2]. A thorough analysis of commercial banks' product innovation performance is essential to promoting the banks' competitiveness and sustainable development [3]. Regarding the definition of bank product innovation, Roberts and Amit [4] divide the innovative activities of banks into product innovation, service innovation, process innovation and channel innovation, where product innovation mainly refers to the innovation of corporate and personal banking business; Lerner and Tufano [5] hold that financial innovation of banks includes product and process innovation. Based on the Guidelines for the Financial Innovation of Commercial Banks, issued by the China Banking Regulatory Commission, this paper defines the product innovation of commercial banks as innovations in business and products carried out to meet the demand of customers.

To our best knowledge, the performance of a certain commercial bank product innovation depends on various factors in the innovation process, as examples, R\&D personnel, expenses and income obtained from innovative products [6]. R\&D personnel and expenses could be regarded as input factors in the process of bank product innovation, while income is an output factor. Thus, the product innovation performance of commercial banks could be defined as the conversion efficiency of input and output factors. The DEA method is introduced in this paper to evaluate the performance of Chinese commercial banks' product innovation, since it is a total factor efficiency evaluation method 
that can evaluate the efficiency of decision making units (DMU) with multiple inputs into multiple outputs [7]. As a non-parametric total factor productivity evaluation method, the DEA method can effectively avoid model misspecification. As such, it has been widely used in estimating total-factor efficiencies [8,9].

Although banks can generate more revenue through innovative products [2], it is noted that different from other industries' innovation, financial product innovation also creates potential risks for bank operations. Calmès and Théoret [10], Aktan et al. [11] analyzed the statistics of commercial banks in Canada and Istanbul, respectively, and found that the growth of the innovative products may lead to an increase of risks for commercial banks. Therefore, it is of great significance to consider the impact of product innovation risks when analyzing the performance of commercial banks' product innovation. According to the Core Indicators for the Risk Management of Commercial Banks released by the China Banking Regulatory Commission, risks faced by commercial banks mainly include the liquidity risk, the credit risk, the market risk and the operational risk. Considering the reality of product innovation in Chinese commercial banks, it could be discovered that commission revenue related to loans and quasi-loans are the main source of banks' handling charge income [12], the credit risk can be seen as the major risk involved in the process of product innovation. As such, in this paper, the credit risk is considered as an undesirable output and is incorporated in the performance evaluation system.

As a research on the evaluation of bank product innovation performance, the main contribution of this article lies in the fact that the FCM and VCM are constructed based on DEA for evaluating commercial banks' product innovation performance. To be specific, it assigns a weak disposability setting and a strong disposability setting to undesirable output, according to the relationship between the innovation income and risk. In addition, an output optimization model of the objective function is also constructed to estimate the target income of commercial banks' product innovation in the FCM and VCM. Finally, the proposed model is applied to Chinese listed commercial banks for estimating the performance and target income of product innovation.

The remaining parts of this paper are as follows. Section 2 is a literature review. In Section 3, the DEA-based methodology is introduced to calculate the performance of Chinese commercial banks' product innovation and estimate the target income of product innovation. Section 4 illustrates sampling and data sources, corresponding empirical results, further discussion and suggestions. Conclusion follows in Section 5.

\section{Literature Review}

Performance evaluation is a well-studied subject in the existing literature. In particular, the non-parametric DEA method has been widely used. For example, Vlontzos et al. [13] used DEA to evaluate energy performance and environmental performance. Cai et al. [14] used DEA to analyze the efficiency of China's photovoltaic industry. DEA is also broadly used in studies related to commercial banks. Wang et al. [15] analyzed the efficiency of 16 major Chinese commercial banks during the period 2003-2011 using DEA approach; Liu et al. [16] constructed production possibility sets using the free-disposal axioms and utilized the corresponding DEA model with undesirable intermediate variables to evaluate the efficiency of listed Chinese banks; Ohsato and Takahashi [17] applied a slack-based measure DEA model to evaluate the management efficiency of regional banks in Japan. Undesirable outputs have attracted growing attention from scholars in research on performance evaluation and other bank-related issues. For instance, Wang et al. [15] proposed a DEA model considering undesirable outputs and applied it to the performance evaluation of 26 Chinese commercial banks.

In addition, DEA can also be utilized to discuss the improvement objectives of inputs and outputs while evaluating performance. In existing research, three methodologies are most frequently used. This first involves the investigation of slack variables associated with outputs and is now widely applied in studies where DEA is utilized to evaluate performance [18]; the second estimates potential optimization using an inverse DEA model [19]. Inverse DEA was first developed by Wei et al. [20], 
which estimates inputs/outputs with a given proficiency; the third uses objective functions with specific directions to calculate optimal variables [21].

In studies concerning banks' product innovation, Wenqiang et al. [22] used stochastic frontier analysis to evaluate the efficiency of bank innovation and analyzed the main driving factors for bank product innovation. Lyu [23] investigated the overall innovation and managerial innovation capabilities of listed Chinese banks. There are also scholars who analyze the factors that affect the innovation performance of commercial products. As examples, Rossignoli and Arnaboldi [24] studied relations between innovation, performance and risks of commercial banks in financial crisis. Wen [25] studied the relationship between internet finance and commercial banks' innovation performance; Zeng et al. [26] investigated the impact of financial supervision on product innovation of commercial banks.

It could be found that, in the existing literature, quantitative research on commercial banks' product innovation performance is still scarce and rarely touches on the impact of risks. The current research related to commercial banks' product innovation and risks is mostly built upon the discussion of relations between income structure, non-interest income and commercial banks' profit-making ability. Few studies so far have incorporated risks associated with product innovation into performance evaluation. Thus, this paper proposes a DEA-based non-parametric model to evaluate and analyze commercial banks' product innovation performance, which including the credit risk associated with product innovation.

\section{Methodology}

This section first introduces the input-output process of commercial bank product innovation. Subsequently, a bank product innovation performance evaluation model based on the DEA is constructed. Finally, an optimization model is also established to estimate the target income of bank product innovation.

\subsection{Input and Output Variables}

Before using DEA to evaluate the performance, input and output variables should be determined. There is a wide variety of input/output variables used for the evaluation of commercial banks' performance, which differs according to the objective of the evaluation. It is generally agreed that commercial banks' product innovation income is realized through the input of innovation-related personnel and funds [22].

Considering the reality of Chinese commercial banks' product innovation, Lyu [23] and Wenqiang, Jihui and Hua [22] note that input factors related to commercial banks' product innovation include fixed assets, the number of employees, as well as the handling charge and commission expense, while output factors include the handling charge and commission income. Different from commercial banks' traditional interest income, the handling charge and commission income refer to earnings generated by intermediary services such as consultation, guarantee, escrow services, etc. They can reflect the output of commercial banks' product innovation activity [27]. Similarly, the handling charge and commission expense can reflect the financial input related to commercial banks' product innovation. Given the fact that better-educated employees make a greater contribution to innovation [28,29], employees holding a bachelor's degree or above (educated personnel) are selected to constitute the innovation personnel. Commercial banks' fixed assets, as the basis for bank operation, are treated as another input factor in this study.

Through analyzing the structure of the handling charge and commission income, this study has found that loan-related commissions revenue is the main component of the banks' product innovation income [12]. The related credit risk is therefore included in this study as a major risk. According to the Notice of the China Banking Regulatory Commission on Further Strengthening Credit Risk Management, released in 2016, commercial banks' off-balance-sheet loans should be convertible into risk assets with a conversion coefficient of $100 \%$, which can be regarded as normal commercial loans. According to the Administrative Measures for the Loan Loss Reserves of Commercial Banks, issued 
by the China Banking Regulatory Commission in 2012, commercial banks should create a credit provision tantamount to $1 \%$ of normal quasi-loans. Thus, this paper sets $1 \%$ of commercial banks' off-balance-sheet loans as the anticipated non-performing loans to measure the product innovation risk. Figure 1 shows the process of commercial banks' product innovation factoring in risk impact, where fixed assets $(\mathrm{F})$, product educated personnel $(\mathrm{L})$ and product innovation funds $(\mathrm{K})$ generate product innovation income $(\mathrm{Rt})$ and product innovation credit risk (B).

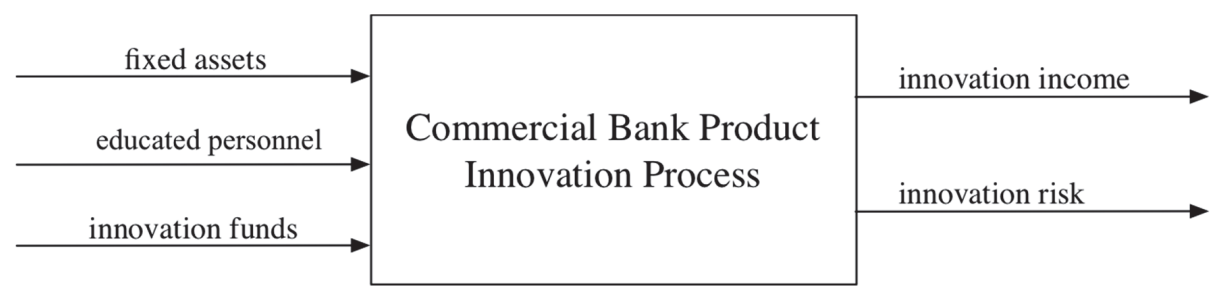

Figure 1. Commercial Bank Product Innovation Process Considering Risk Impact.

\subsection{Models for the Evaluation of Commercial Banks' Product Innovation Performance}

Based on the input and output variables discussed in Section 3.1, commercial banks' product innovation performance is defined as the input-output conversion efficiency, and the DEA model is introduced to evaluate the product innovation performance. Suppose there are n DMUs, noted as $D M U_{j}(j=1,2, \ldots, n)$, a performance evaluation model can be constructed as follows.

$$
\begin{array}{ll} 
& \operatorname{Max} \theta_{i} \\
\text { s.t. } & \sum_{j=1}^{n} \lambda_{j} L_{j} \leq L_{i}, \\
& \sum_{j=1}^{n} \lambda_{j} K_{j} \leq K_{i}, \\
& \sum_{j=1}^{n} \lambda_{j} F_{j} \leq F_{i}, \\
& \sum_{j=1}^{n} \lambda_{j} B_{j}=B_{i}, \\
\sum_{j=1}^{n} \lambda_{j} R_{t j} \geq \theta_{i} R_{t i}, \\
\lambda_{j} \geq 0, j=1,2, \ldots, n .
\end{array}
$$

In Model (1), $\lambda$ is the intensity variable of each $D M U$, and the objective function represents the proxy of each DMU's efficiency. Since Model (1) is an output-oriented DEA method, the range of $\theta_{i}$ is set to be $[1,+\infty]$. In this paper, $\frac{1}{\theta_{i}}$ is used to represent the performance. The value of 1 indicates that the $D M U$ is in DEA efficient, otherwise, the DMU is inefficient.

Additionally, different from the traditional DEA model, Model (1) places an equality constraint on $B_{i}$, the product innovation risk. The equation indicates that undesirable and desirable outputs are correlated [30], which could be regarded as a model with a weak disposability setting [31]. Based on such a setting, it could be understood that the product innovation income of commercial banks and the corresponding credit risk reflect the same trends. The risk will increase with the expansion of product innovation.

On the other hand, as commercial banks' risk management techniques and capability improve, the product innovation risk can be lowered without reducing income. In that case, no synchronous relationship exists between commercial banks' product innovation income and related risk. Based on this assumption, Model (2) is constructed. 
Different from Model (1), Model (2) places an inequality constraint on $B_{i}$ and can be regarded as a DEA model with a strong disposability setting [30]. With this setting, changes of the undesirable output do not affect the desirable output. In other words, the fact that commercial banks' product innovation income and related credit risk change in the same trend is neglected. Therefore, the weak disposability and strong disposability settings represent a product innovation with and without risk management technique optimization, respectively.

$$
\begin{array}{ll} 
& \operatorname{Max} \theta_{i} \\
\text { s.t. } & \sum_{j=1}^{n} \lambda_{j} L_{j} \leq L_{i}, \\
& \sum_{j=1}^{n} \lambda_{j} K_{j} \leq K_{i}, \\
& \sum_{j=1}^{n} \lambda_{j} F_{j} \leq F_{i}, \\
& \sum_{j=1}^{n} \lambda_{j} B_{j} \leq B_{i}, \\
& \sum_{j=1}^{n} \lambda_{j} R_{t j} \geq \theta_{i} R_{t i}, \\
\lambda_{j} \geq 0, j=1,2, \ldots, n .
\end{array}
$$

A strong disposability setting implies that commercial banks manage credit risk through the improvement of risk management techniques and capability. In fact, relevant government agencies in China have already developed policies and carried out reforms to better control risks in the banking sector and maintain financial stability. Major commercial banks have also taken various measures to strengthen their risk management ability. Policy support, together with the development of technologies such as the Internet and big data, has made it possible to build a model based on the strong disposability of credit risk. On the other hand, when a weak disposability setting applies, it can be understood that even with policy support and cooperation between banks and companies, it is still difficult to optimize risk management ability in the short term. With this setting, commercial banks' risk management techniques cannot be optimized within a short period of time, potential credit risk and product innovation income remain in a synchronous relationship.

In this paper, the model that features a synchronous relationship between commercial banks' product innovation income and associated risks is defined as the FCM. In addition, if commercial banks can improve their risk management techniques without any restraint, potential credit risk may also be subject to the influence of these techniques. Therefore, this study also proposes a model with a strong disposability setting, which defined as the VCM.

\subsection{Models for the Estimation of Product Innovation Target Income}

Analyzing the target output of DMUs is crucial for DEA-based performance evaluation. Considering the existence of both desirable and undesirable outputs in this study, an output optimization model of the objective function can be constructed to independently estimate the target income of commercial banks' product innovation. According to the relationship between commercial banks' product innovation income and associated risks, two models-Model (3) and Model (4) - are proposed for the estimation of product innovation target income.

In Model (3), the optimal target can be obtained by calculating the optimal $\eta_{i}^{*}$ and $\lambda_{i}^{*} \cdot \eta_{i}$ is the rate of change of product innovation income and non-performing loans. In this study, the values of product innovation income and potential credit risk cannot be negative (i.e., $\eta_{i}$ must be a positive number). The optimal output obtained through Model (3) can represent the anticipated goals of bank operations. In this study, it can be seen as the target income of commercial banks' product innovation. 


$$
\begin{array}{ll} 
& \operatorname{Max} R_{w i}=R_{t i} \eta_{i} \\
\text { s.t. } & \sum_{j=1}^{n} \lambda_{j} L_{j} \leq L_{i}, \\
& \sum_{j=1}^{n} \lambda_{j} K_{j} \leq K_{i}, \\
& \sum_{j=1}^{n} \lambda_{j} F \leq F_{i}, \\
& \sum_{j=1}^{n} \lambda_{j} B_{j}=\eta_{i} B_{i}, \\
& \sum_{j=1}^{n} \lambda_{j} R_{t j} \geq \eta_{i} R_{t i}, \\
& \eta_{i}, \lambda_{j} \geq 0, j=1,2, \ldots, n . \\
& \operatorname{Max}_{s i}=\hat{R}_{t i} \\
\text { s.t. } \quad \sum_{j=1}^{n} \lambda_{j} L_{j} \leq L_{i}, \\
& \sum_{j=1}^{n} \lambda_{j} K_{j} \leq K_{i}, \\
& \sum_{j=1}^{n} \lambda_{j} F \leq F_{i}, \\
& \sum_{j=1}^{n} \lambda_{j} B_{j} \leq \hat{B}_{i}, \\
& \sum_{j=1}^{n} \lambda_{j} R_{t j} \geq \hat{R}_{t i}, \\
\hat{B}_{i} \leq \delta_{i} \hat{R}_{t i} & \hat{R}_{t i}, \hat{B}_{i}, \lambda_{j} \geq 0, j=1,2, \ldots n .
\end{array}
$$

Model (4) ignores the synchronous relationship between product innovation income and risks. In other words, the growth of commercial banks' product innovation income could also be realized by optimizing risk management techniques. Since credit risk control is an important instrument for commercial banks to realize anticipated goals, the ratio of potential credit risk to product innovation income optimization should be less than the actual rate of risk management technique optimization $\left(\delta_{i}\right)$. The constraint $\hat{B}_{i} \leq \delta_{i} \hat{R}_{t i}$ is therefore placed on Model (4). Other variables and constraints in Model (4) are the same as those in Model (3).

As discussed above, in the VCM, the added value of commercial banks' product innovation income is mainly influenced by risk management techniques and the scale of product innovation; while in the FCM, the latter is the only influential factor. Therefore, the gap between the added values of product innovation income in the VCM and FCM can reflect the profit generated by the optimization of risk management techniques. This is shown by Formulas (5)-(7).

$$
\begin{gathered}
\Delta R_{t i}^{s}=R_{t i}^{s *}-R_{t i}, \\
\Delta R_{t i}^{w}=R_{t i}^{w *}-R_{t i}, \\
\Delta R_{t i}^{c}=\Delta R_{t i}^{s}-\Delta R_{t i}^{w} .
\end{gathered}
$$

In the Formulas (5)-(7), $R_{t i}^{s *}$ is the product innovation target income in the VCM; and $R_{t i}^{w *}$ means the target income in the FCM. $\Delta R_{t i}^{w}$ and $\Delta R_{t i}^{s}$ represent the added values of product innovation income in the FCM and VCM, respectively. As mentioned above, $\Delta R_{t i}^{c}=\Delta R_{t i}^{s}-\Delta R_{t i}^{w}$ could be regarded as the innovation income brought about by optimizing risk management techniques. The ratio $\left(R_{t i}^{*}-R_{t i}\right) / R_{t i}$ in this paper is defined as RII, which means the ratio of product innovation target income increase to actual income. 
To make a clear description, all the acronyms mentioned in this paper are listed in the following nomenclatures.

Nomenclatures

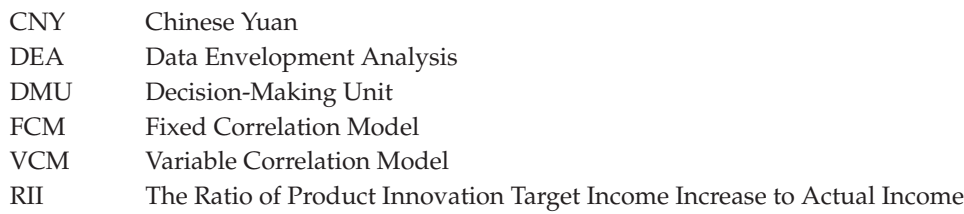

\section{Empirical Analysis}

\subsection{Sampling and Data Source}

In this paper, 25 commercial banks listed in China's stock market were selected as samples. According to the categorization of China's commercial banks, these samples were divided into four groups-state-owned commercial banks, joint-stock commercial banks, urban commercial banks and rural commercial banks-as shown in Table 1. All data were obtained from the annual reports released by these listed commercial banks. Related descriptive statistics are shown in Table 2.

Table 1. Sample Commercial Banks and Categorization.

\begin{tabular}{|c|c|}
\hline Bank Type & Bank Name \\
\hline State-Owned & $\begin{array}{l}\text { Industrial and Commercial Bank of China (ICBC), Agricultural Bank of China (ABC), } \\
\text { Bank of China (BC), China Construction Bank (CBC), Bank of Communications (BCM) }\end{array}$ \\
\hline Joint-Stock & $\begin{array}{c}\text { China Merchants Bank (CMB), Shanghai Pudong Development Bank (SPDB), } \\
\text { China CITIC Bank (CITIC), China Everbright Bank (CEB), Huaxia Bank (HXB), } \\
\text { China Minsheng Bank (CMBC), China Guangfa Bank (CGB), Industrial Bank (IB), } \\
\text { Ping An Bank (PAB), China Zheshang Bank (CZB), Evergrowing Bank Bank (EB), China } \\
\text { Bohai Bank (CBB) }\end{array}$ \\
\hline Urban & $\begin{array}{c}\text { Bank of Ningbo (NBCB), Bank of Jiangsu (JSB), Bank of Hangzhou (HCCB), } \\
\text { Bank of Nanjing (NJCN), Bank of Beijing (BOB), Bank of Shanghai (BOSC), } \\
\text { Bank of Guiyang (GYCB) }\end{array}$ \\
\hline Rural & $\begin{array}{c}\text { Jiangyin Rural Commercial Bank (JYRB), Rural Commercial Bank of Zhangjiagang } \\
\text { (ZJGRB), Wuxi Rural Commercial Bank (WXRB), Changshu Rural Commercial Bank } \\
\text { (CSRB), Wujiang Rural Commercial Bank (WJRB) }\end{array}$ \\
\hline
\end{tabular}

Table 2. Descriptive Statistics.

\begin{tabular}{|c|c|c|c|c|c|c|}
\hline Year & Parameter & Fixed Assets & $\begin{array}{l}\text { No. of Employees } \\
\text { Holding Bachelor's } \\
\text { Degree and above }\end{array}$ & $\begin{array}{c}\text { Handling Charge } \\
\text { and Commission } \\
\text { Expense }\end{array}$ & $\begin{array}{l}\text { Handling } \\
\text { Charge and } \\
\text { Commission } \\
\text { Income }\end{array}$ & $\begin{array}{c}\text { Anticipated } \\
\text { Non-Performing } \\
\text { Loans }\end{array}$ \\
\hline & Unit & $10^{9} \mathrm{CNY}$ & $10^{3}$ & $10^{9} \mathrm{CNY}$ & $10^{9} \mathrm{CNY}$ & $10^{9} \mathrm{CNY}$ \\
\hline \multirow{4}{*}{2013} & Minimum & 0.335 & 0.703 & 0.001 & 0.050 & 0.019 \\
\hline & Maximum & 158.968 & 221.393 & 12.224 & 134.550 & 24.998 \\
\hline & Average & 29.937 & 49.639 & 1.769 & 24.815 & 6.815 \\
\hline & $\begin{array}{l}\text { Standard } \\
\text { Deviation }\end{array}$ & 52.467 & 74.346 & 2.879 & 38.035 & 7.932 \\
\hline \multirow{4}{*}{2015} & Minimum & 0.418 & 0.772 & 0.010 & 0.067 & 0.043 \\
\hline & Maximum & 195.401 & 249.961 & 18.279 & 161.670 & 32.100 \\
\hline & Average & 37.834 & 55.985 & 2.628 & 32.851 & 7.700 \\
\hline & $\begin{array}{l}\text { Standard } \\
\text { Deviation }\end{array}$ & 62.940 & 82.489 & 4.182 & 43.414 & 8.611 \\
\hline \multirow{4}{*}{2017} & Minimum & 0.626 & 1.080 & 0.023 & 0.077 & 0.079 \\
\hline & Maximum & 216.156 & 276.062 & 19.041 & 158.666 & 38.706 \\
\hline & Average & 44.253 & 61.245 & 3.930 & 36.659 & 8.656 \\
\hline & $\begin{array}{l}\text { Standard } \\
\text { Deviation }\end{array}$ & 69.497 & 88.953 & 5.175 & 43.816 & 11.065 \\
\hline
\end{tabular}




\subsection{Product Innovation Performance Analysis}

Based on the data of the 25 commercial banks in 2013, 2015 and 2017, their product innovation performance values in specific years can be obtained through Models (1) and (2). The results are shown in Figure 2. The efficiency change of the four types of commercial banks during the observation period can be found in Figure 3.

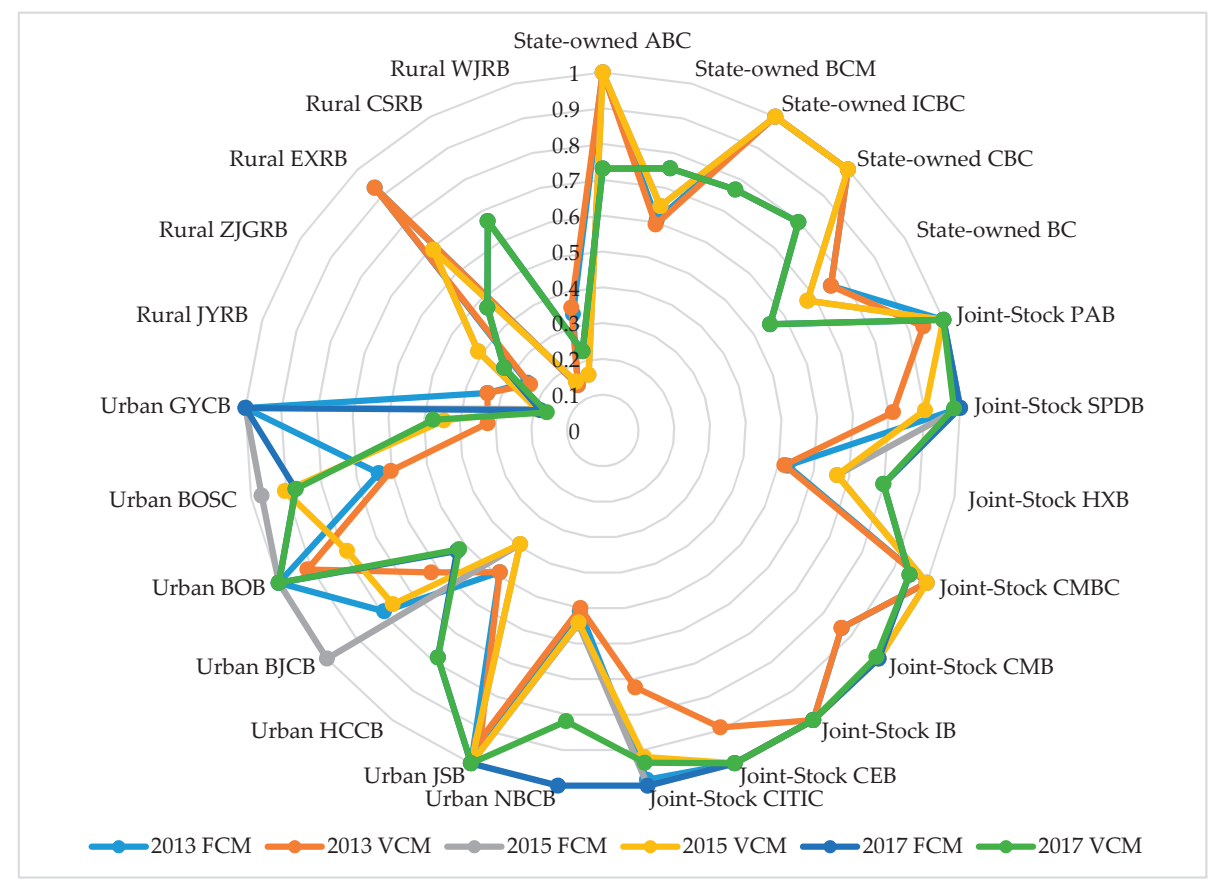

Figure 2. Product Innovation Performance in 2013, 2015 and 2017.

It can be discovered that the average efficiency of the 25 banks was 0.7665 in 2013 in the FCM. The efficiency of joint-stock banks was at the highest level, followed by state-owned banks. Their efficiency values, 0.9218 and 0.8722 , respectively, were higher than those of urban commercial banks $(0.7755)$ and rural commercial banks (0.3996). Among joint-stock banks, five (PAB, SPDB, CMBC, IB and CEB) were efficient in the DEA model; while $\mathrm{HXB}$ was the only one in the group that had an efficiency value (0.5248) lower than the yearly average. During the period, the efficiency value of HXB was the lowest among all joint-stock banks, indicating that its product innovation performance was not yet on par with its counterparts in this group. Among state-owned banks, the BCM and the BC had efficiency values of 0.6067 and 0.7545 respectively. The other banks in this group all had an efficiency value of 1 .

The efficiency values of joint-stock and urban commercial banks were consistently on the rise during the observed period, while those of state-owned banks took on an opposite trend. The efficiency values of the four groups of banks during the observed period in the FCM are shown in Figure 3a. In 2017, the efficiency value of joint-stock banks was 0.9681 and their innovation performance remained in the leading position; whereas urban commercial banks' product innovation efficiency value had been rising for all three years under observation, overtaking that of state-owned banks (0.7215) to reach 0.8836 in 2017. In the VCM, the same conclusions apply. The efficiency value of state-owned banks under this model was slightly higher than that of their joint-stock counterparts in 2013, but assuming a trend similar to the FCM. This can be seen in Figure $3 b$. 


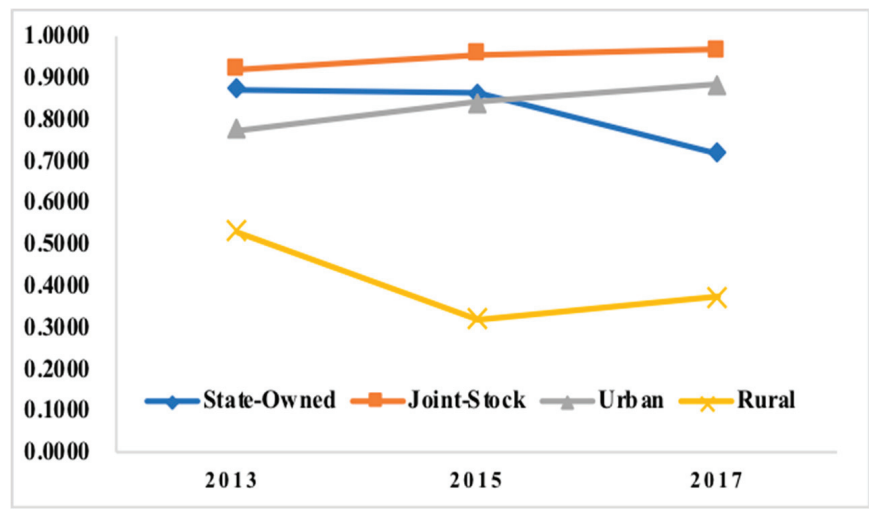

(a)

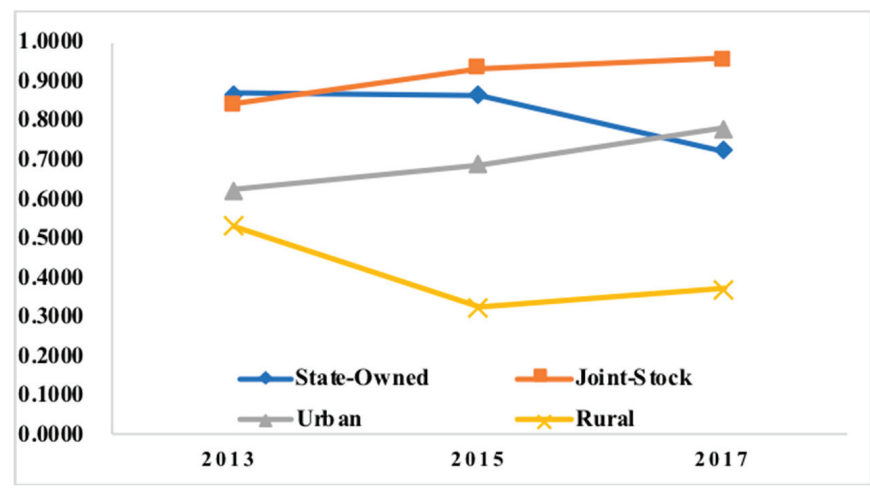

(b)

Figure 3. Innovation Performance changes in the FCM (a) and VCM (b) in 2013, 2015 and 2017.

As mentioned in this article, the difference between the FCM and the VCM is whether to consider the synchronous relationship between credit risk and product innovation income. In order to analyze this relationship, this article presents the scatter plots of commercial bank product innovation revenue and risk in 2013, 2015 and 2017, as shown in Figure 4. The data on the ordinate axis represent product innovation revenue, and the data on the abscissa axis represent anticipated non-performing loans. Obvious linear relationships are observed in the scatter plots below. Therefore, the rationality of the assumptions in the FCM model proposed in this paper is also verified. 


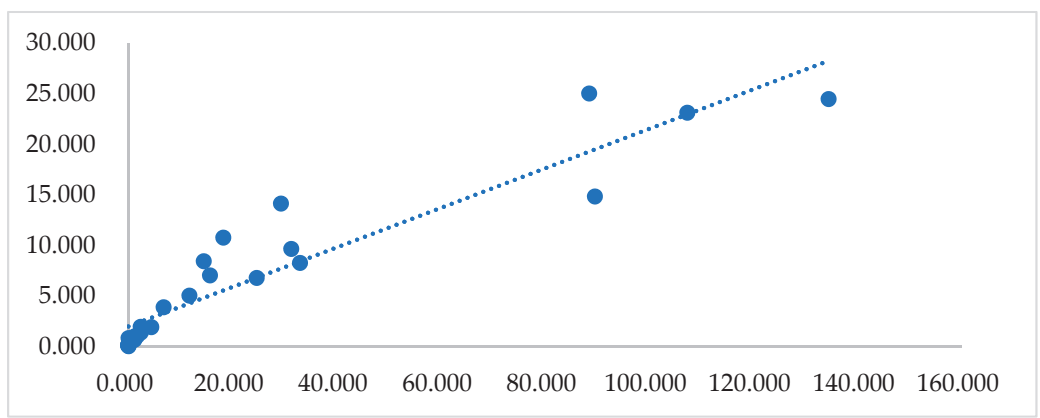

(a)

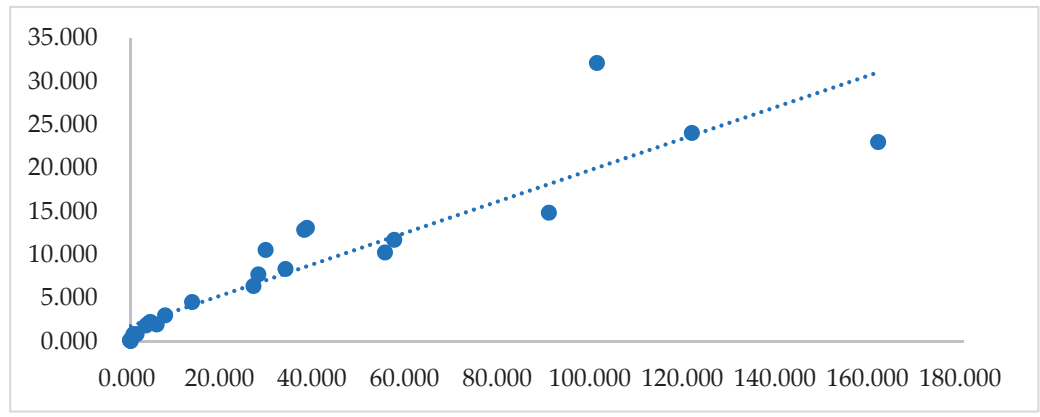

(b)

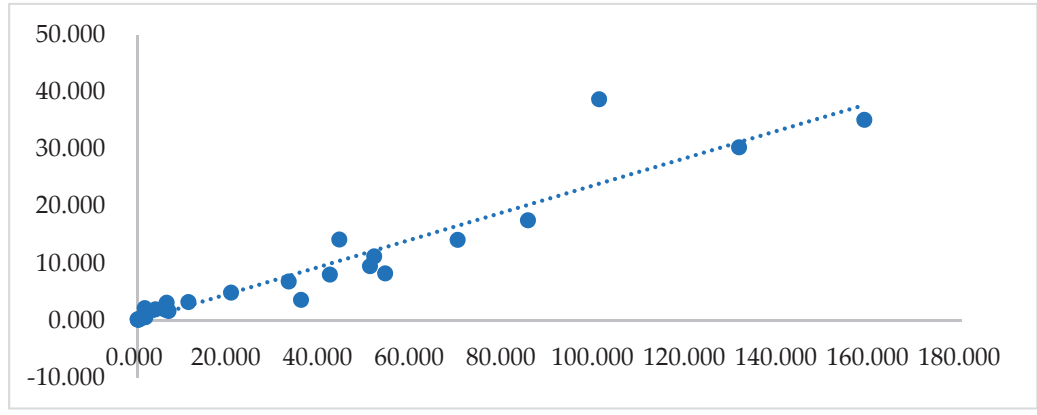

(c)

Figure 4. Relationship between product innovation target income and risk of commercial banks in 2013 (a), 2015 (b), and 2017 (c).

\subsection{Analyzing the Target Income of Commercial Banks' Product Innovation}

Analyzing the target output of DMUs is crucial for DEA-based performance evaluation. In this paper commercial banks' product innovation target income in the FCM and VCM can be obtained by using Model (3), Model (4). Added values of income in the FCM and VCM can be calculated using Formulas (5) and (6), respectively. The results are shown in Table 3.

In Table 3, the 25 selected commercial banks differ significantly in the added value of product innovation income. Since product innovation income changes in the same trend with the associated credit risk, it is found that the optimized product innovation income is lower than the actual income. In terms of income changes, although the values of most state-owned banks were positive, a few still saw a decline in income, e.g., the BCM $(-5.300,-16.441,-2.966)$. This is different from what was 
observed in joint-stock and urban commercial banks. In the VCM, the values of the 25 selected banks' income change were all above 0 , implying that enhancing commercial banks' risk management ability can effectively raise their product innovation income.

Table 3. Added values of income in the FCM and VCM in 2013, 2015 and 2017.

\begin{tabular}{|c|c|c|c|c|c|c|c|}
\hline \multirow{2}{*}{ Type } & \multirow{2}{*}{ DMU } & \multicolumn{2}{|c|}{2013} & \multicolumn{2}{|c|}{2015} & \multicolumn{2}{|c|}{2017} \\
\hline & & $\Delta R_{t i}^{w}$ & $\Delta R_{t i}^{s}$ & $\Delta R_{t i}^{w}$ & $\Delta R_{t i}^{s}$ & $\Delta R_{t i}^{w}$ & $\Delta R_{t i}^{s}$ \\
\hline \multirow{5}{*}{ State-Owned } & ICBC & 10.618 & 29.982 & 108.126 & 130.000 & 39.200 & 74.244 \\
\hline & $\mathrm{CBC}$ & -18.387 & 0.000 & 43.102 & 69.999 & 71.054 & 84.468 \\
\hline & $\mathrm{BCM}$ & -5.300 & 20.112 & -16.441 & 17.588 & -2.966 & 23.977 \\
\hline & $\mathrm{ABC}$ & 37.603 & 50.003 & 90.386 & 100.001 & 116.235 & 126.221 \\
\hline & $\mathrm{BC}$ & 19.887 & 42.935 & -10.462 & 42.791 & 22.661 & 59.785 \\
\hline \multirow{8}{*}{ Joint-Stock } & CEB & -9.070 & 1.907 & 0.000 & 0.000 & -13.895 & 0.000 \\
\hline & HXB & -0.946 & 6.422 & -3.479 & 10.308 & -1.333 & 8.886 \\
\hline & CMBC & -12.470 & 0.002 & -38.745 & 0.000 & -12.337 & 5.689 \\
\hline & РAB & 0.000 & 0.737 & 0.000 & 0.000 & -17.763 & 0.000 \\
\hline & SPDB & 0.000 & 3.366 & 0.000 & 3.201 & -22.272 & 0.886 \\
\hline & IB & -22.065 & 0.004 & -30.398 & 0.000 & -23.944 & 0.002 \\
\hline & $\mathrm{CMB}$ & -8.156 & 4.895 & -27.989 & 0.000 & -30.845 & 0.563 \\
\hline & CITIC & -14.538 & 7.005 & 0.000 & 3.292 & -27.074 & 3.566 \\
\hline \multirow{7}{*}{ Urban } & BOB & -3.125 & 0.434 & 0.000 & 0.918 & -5.661 & 0.000 \\
\hline & GYCB & 0.000 & 0.246 & -0.713 & 2.881 & 0.000 & 1.771 \\
\hline & НССВ & -0.088 & 1.333 & 0.000 & 0.000 & -0.062 & 0.579 \\
\hline & JSB & -0.803 & 0.188 & 0.000 & 1.078 & -2.571 & 0.000 \\
\hline & NJCB & -0.567 & 0.755 & -4.055 & 3.737 & -0.245 & 3.646 \\
\hline & NBCB & -0.253 & 1.797 & -4.837 & 0.617 & -4.450 & 1.415 \\
\hline & BOSC & -0.670 & 1.642 & 0.000 & 2.022 & -0.886 & 1.403 \\
\hline \multirow{5}{*}{ Rural } & CSRB & 0.050 & 0.226 & 0.228 & 0.522 & 0.367 & 0.560 \\
\hline & JYRB & 0.170 & 0.241 & -0.028 & 0.121 & -0.032 & 0.092 \\
\hline & WXRB & 0.276 & 0.312 & 0.356 & 0.413 & 0.294 & 0.464 \\
\hline & WJRB & -0.016 & 0.002 & 0.016 & 0.089 & 0.112 & 0.355 \\
\hline & ZJGRB & 0.046 & 0.157 & 0.034 & 0.215 & 0.120 & 0.410 \\
\hline
\end{tabular}

Figure 5a,b show the RII values in the FCM and VCM, respectively, and Figure 6 shows the average RII values of different types of banks during the observed period. Average RII of four types of commercial banks in 2013, 2015 and 2017 can be found in Table 4. According to Figure 5a, in the FCM, the average rates of change of joint-stock and urban commercial banks' product innovation income were all below 0 , indicating that reducing the scale of product innovation may lead to the reduction of both the income and the credit risk associated with innovation. During the observed period, rural commercial banks had the highest RII. Although the average RII of state-owned banks was lower than that of rural banks, the former was apparently on an upward trajectory. Among rural commercial banks, the RII of WXRB was the highest, standing at 200.27\%, followed by CSRB's $122.20 \%$. Among state-owned banks, $\mathrm{ABC}$ had the greatest RII increase. This indicates that commercial banks can scale up product innovation by strengthening their product innovation capability. 


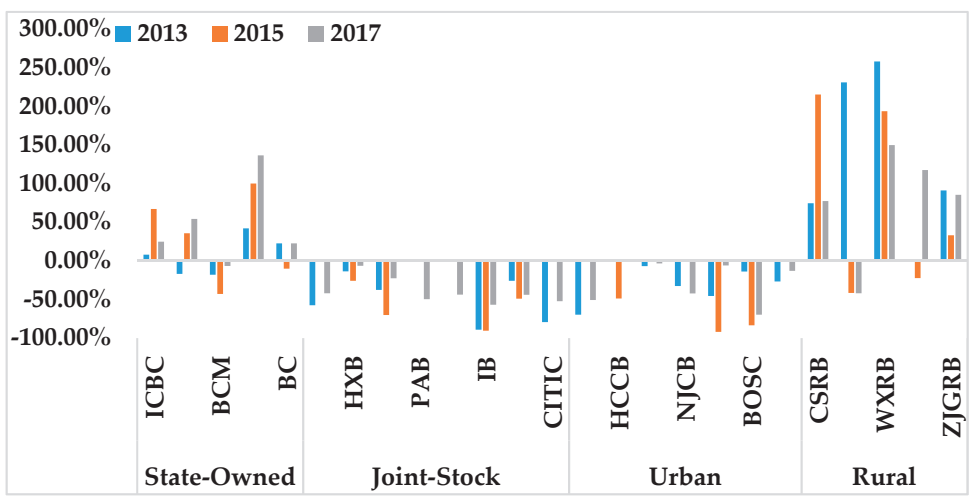

FCM (a)

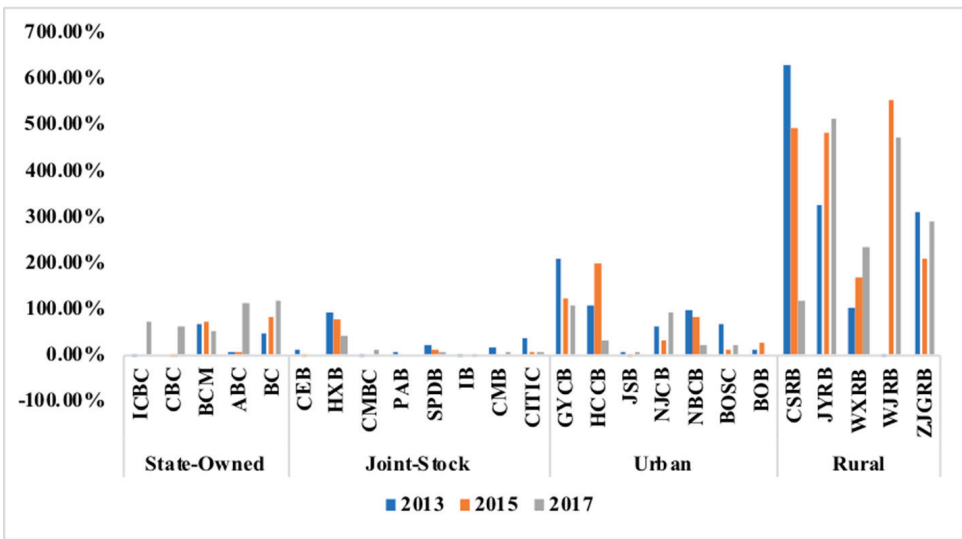

\section{$\operatorname{VCM}(\mathbf{b})$}

Figure 5. RII of each bank in the FCM (a) and VCM (b) in 2013, 2015 and 2017.

Table 4. Average RII of Four Types of Commercial Banks in 2013, 2015 and 2017.

\begin{tabular}{cccccc}
\hline & Type & $\mathbf{2 0 1 3}$ & $\mathbf{2 0 1 5}$ & $\mathbf{2 0 1 7}$ & Average \\
\hline \multirow{2}{*}{ F } & State-Owned & $7.43 \%$ & $29.78 \%$ & $46.18 \%$ & $27.79 \%$ \\
$\mathrm{C}$ & Joint-Stock & $-37.95 \%$ & $-29.46 \%$ & $-39.81 \%$ & $-35.74 \%$ \\
$\mathrm{M}$ & Urban & $-28.03 \%$ & $-32.09 \%$ & $-26.52 \%$ & $-28.88 \%$ \\
& Rural & $130.76 \%$ & $75.47 \%$ & $77.46 \%$ & $94.57 \%$ \\
\hline \multirow{2}{*}{ V } & State-Owned & $23.37 \%$ & $30.84 \%$ & $84.49 \%$ & $46.23 \%$ \\
$\mathrm{C}$ & Joint-Stock & $23.61 \%$ & $12.05 \%$ & $7.93 \%$ & $14.53 \%$ \\
$\mathrm{M}$ & Urban & $80.15 \%$ & $67.96 \%$ & $39.76 \%$ & $62.62 \%$ \\
& Rural & $274.52 \%$ & $381.80 \%$ & $326.43 \%$ & $327.58 \%$ \\
\hline
\end{tabular}

In the VCM, the RIIs of the four groups of banks were all above 0, mainly because the impact of banks' risk management ability was not considered. Rural commercial banks had an average RII of $327.58 \%$ during the observed period, the highest among all four groups, while the average RIIs of urban, state-owned and joint-stock commercial banks were $62.62 \%, 46.23 \%$ and $14.53 \%$, respectively. Therefore, banks with an RII above 0 can increase the scale of product innovation to generate more income, while those with an RII below 0 should properly control the scale of product innovation. 


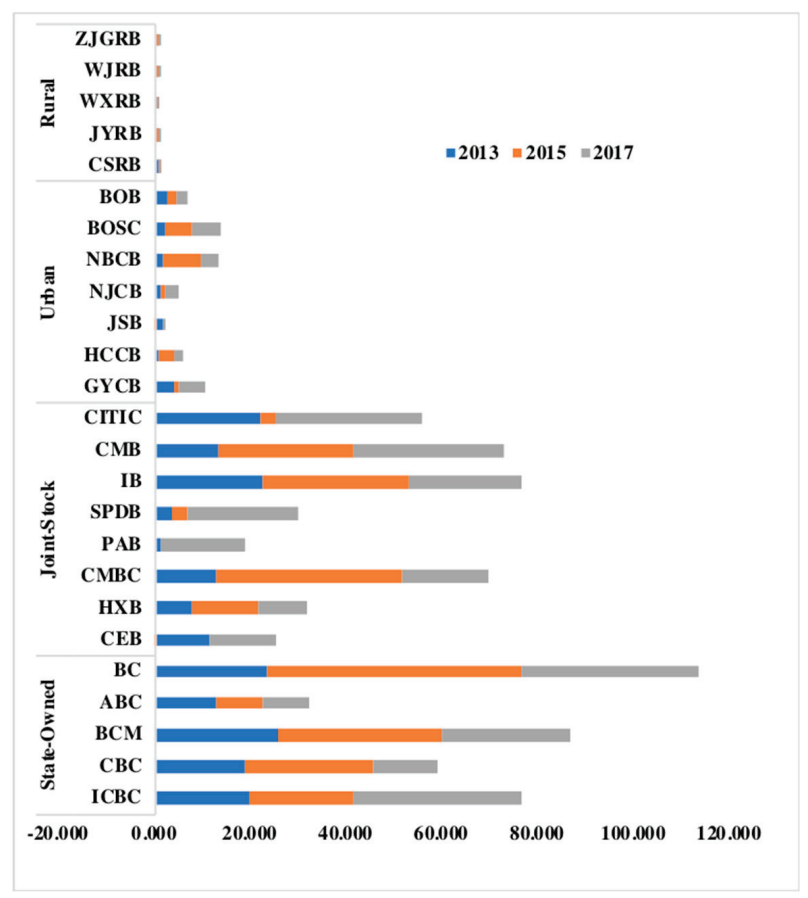

Unit: CNY $10^{9}$

Figure 6. Added-Value of Product Innovation Income after Risk Management Ability Optimization.

\subsection{Findings and Discussions}

This section analyzed the data of 25 selected listed Chinese commercial banks between 2013 and 2017 and discussed their product innovation performance using the proposed DEA-based model. Findings of the empirical analysis are as follows: (1) the four groups of commercial banks differed significantly in their product innovation performance between 2013 and 2017. Among them, joint-stock commercial banks had the best innovation performance, while rural commercial banks had the lowest performance value. (2) During the observed period, the efficiency values of joint-stock and urban commercial banks were consistently on the rise, while those of state-owned banks were on a downward trajectory. (3) Restrained by the existing risk management ability, joint-stock and urban commercial banks need to control the scale of product innovation and subsequently reduce related income to boost performance. Upgrading the risk management ability can effectively lift product innovation income.

According to the research conclusions, the following management suggestions are proposed for the innovation and development of commercial banks: (1) Rural commercial banks should further increase the importance and investment of product innovation, optimize resource allocation, expand the scale of innovative product business, and enhance product innovation capabilities; (2) under the current level of risk, joint-stock commercial banks and city commercial banks need to properly control the scale of product innovation to control product innovation risks; (3) all types of commercial banks should increase their risk management capabilities and use platforms and tools such as the Internet and big data to strengthen their risk management capabilities.

\section{Conclusions}

This study proposes a DEA-based non-parametric model to estimate the performance and target income of Chinese commercial banks' product innovation. The product innovation performance of 
commercial banks is defined as the conversion efficiency of input and output. The credit risk of product innovation of banks is considered as an undesirable output and incorporated in the performance evaluation system. The main contribution of this article lies in the fact that the FCM and VCM are constructed for evaluating commercial banks' product innovation performance. In addition, an output optimization model of the objective function is also constructed to estimate the target income of commercial banks' product innovation in the FCM and VCM. Finally, the proposed model is applied to Chinese listed commercial banks for estimating the performance and target income of product innovation. Some management suggestions have also been put forward to help the sustainable development of commercial banks.

Generally, three further research directions can be drawn from this research. Firstly, the Malmquist index can be introduced in a dynamic analysis of the performance of banks' product innovation. Secondly, it will be interesting to discuss the impact of risk on bank product innovation performance if product innovation risk is uncertain. Thirdly, some suitable methods can be proposed to select data for estimating the performance under the big data environment.

Author Contributions: Conceptualization, L.S. and T.X.; data curation, Y.S.; funding acquisition, J.Y.; methodology, T.X.; supervision, J.Y.; writing-original draft, T.X.; writing-review and editing, L.S. All authors have read and agreed to the published version of the manuscript.

Funding: This research was funded by National Natural Science Foundation of China, grant number 71671125.

Conflicts of Interest: The authors declare no conflict of interest.

\section{References}

1. Norden, L.; Silva Buston, C.; Wagner, W. Financial innovation and bank behavior: Evidence from credit markets. Soc. Sci. Electron. Publ. 2014, 43, 130-145. [CrossRef]

2. Wang, F.; Huang, M.; Shou, Z. Business expansion and firm efficiency in the commercial banking industry: Evidence from the US and China. Asia Pac. J. Manag. 2015, 32, 551-569. [CrossRef]

3. Zhao, J.H.; Min, D.; Mathematics, D.O.; University, L.N. Empirical analysis on the influence factors of commerical bank's intermediary business Innovation-A case of CCB. Technol. Dev. Enterp. 2015, 22, 27.

4. Roberts, P.W.; Amit, R. The Dynamics of Innovative Activity and Competitive Advantage: The Case of Australian Retail Banking, 1981 to 1995. Organ. Sci. 2003, 14, 107-122. [CrossRef]

5. Lerner, J.; Tufano, P. The Consequences of Financial Innovation: A Counterfactual Research Agenda. NBER Work. Pap. 2011, 3, 41-85.

6. Lepetit, L.; Nys, E.; Rous, P.; Tarazi, A. The Provision of Services, Interest Margins and Loan Pricing in European Banking. Ssrn Electron. J. 2006. [CrossRef]

7. Zhu, J.; Price, C.C.; Zhu, J.; Hillier, F.S. Data Envelopment Analysis: A Handbook of empirical Studies and Applications; Springer: Berlin, Germany, 2015; Volume 238, pp. 267-280.

8. Xie, L.; Chen, C.L.; Yu, Y.H. Dynamic Assessment of Environmental Efficiency in Chinese Industry: A Multiple DEA Model with a Gini Criterion Approach. Sustainability 2019, 11, 2294. [CrossRef]

9. Yang, W.X.; Li, L.G. Analysis of Total Factor Efficiency of Water Resource and Energy in China: A Study Based on DEA-SBM Model. Sustainability 2017, 9, 1316. [CrossRef]

10. Calmès, C.; Théoret, R. The impact of off-balance-sheet activities on banks returns: An application of the ARCH-M to Canadian data. J. Bank. Financ. 2010, 34, 1719-1728. [CrossRef]

11. Aktan, B.; Chan, S.-G.; Zikovic, S.; Evrim-Mandaci, P. Off-Balance Sheet Activities Impact on Commercial Banks Performance: An Emerging Market Perspective. Econ. Res. 2013, 26, 117-132. [CrossRef]

12. Chateau, J.P.D. Marking-to-model credit and operational risks of loan commitments: A Basel-2 advanced internal ratings-based approach. Int. Rev. Financ. Anal. 2009, 18, 260-270. [CrossRef]

13. Vlontzos, G.; Niavis, S.; Manos, B. A DEA approach for estimating the agricultural energy and environmental efficiency of EU countries. Renew. Sustain. Energy Rev. 2014, 40, 91-96. [CrossRef]

14. Cai, H.; Liang, L.; Tang, J.; Wang, Q.; Wei, L.; Xie, J. An Empirical Study on the Efficiency and Influencing Factors of the Photovoltaic Industry in China and an Analysis of Its Influencing Factors. Sustainability 2019, 11, 6693. [CrossRef] 
15. Wang, K.; Huang, W.; Wu, J.; Liu, Y.-N. Efficiency measures of the Chinese commercial banking system using an additive two-stage DEA. Omega 2014, 44, 5-20. [CrossRef]

16. Liu, W.; Zhou, Z.; Ma, C.; Liu, D.; Shen, W. Two-stage DEA models with undesirable input-intermediate-outputs. Omega 2015, 56, 74-87. [CrossRef]

17. Ohsato, S.; Takahashi, M. Management Efficiency in Japanese Regional Banks: A Network DEA. Procedia Soc. Behav. Sci. 2015, 172, 511-518. [CrossRef]

18. Bian, Y.; He, P.; Xu, H. Estimation of potential energy saving and carbon dioxide emission reduction in China based on an extended non-radial DEA approach. Energy Policy 2013, 63, 962-971. [CrossRef]

19. Gattoufi, S.; Amin, G.R.; Emrouznejad, A. A new inverse DEA method for merging banks. IMA J. Manag. Math. 2014, 25, 73-87. [CrossRef]

20. Wei, Q.; Zhang, J.; Zhang, X. An inverse DEA model for inputs/outputs estimate. Eur. J. Oper. Res. 2000, 121, 151-163. [CrossRef]

21. Fukuyama, H.; Matousek, R. Modelling bank performance: A network DEA approach. Eur. J. Oper. Res. 2017, 259, 721-732. [CrossRef]

22. Wenqiang, Y.; Jihui, G.; Hua, L. The Internal Driving Force of Commercial Bank Transformation and Upgrading-Based on the Perspective of Innovation Efficiency. Financ. Forum 2017, 22, 13.

23. Lyu, X. The Evaluation of the Innovation Capability of A-Share Listed Banks under the Impact of Internet Banking: Based on Generalized DEA Model of Panel Data. J. Account. Econ. 2016, 23, 253-271.

24. Rossignoli, B.; Arnaboldi, F. Financial innovation: Theoretical issues and empirical evidence in Italy and in the UK. Int. Rev. Econ. 2009, 56, 275-301. [CrossRef]

25. Wen, L. Research on the Relationship between Internet Finance and Commercial Bank's Innovation Performance-Based on the Analysis of MOA Theory. Financ. Theory Pract. 2017, 38, 6.

26. Zeng, W.; Chen, S.; Zhou, Z.B. The Impact of Financial Supervision on Commercial Bank's Product Innovation-the Research Based on Two-stage DEA Model. Chin. J. Manag. Sci. 2016, 24, 1-7.

27. Linyun, C.; Sitai, Y. Research on Intermediary Business and Business Performance of Commercial Banks. Times Financ. 2017, 38, 2.

28. Mottaleb, K.A.; Sonobe, T. What determines the performance of small enterprises in developing countries? Evidence from the handloom industry in Bangladesh. Int. J. Bus. Glob. 2013, 10, 39-55. [CrossRef]

29. Heffernan, S.A.; Fu, X.; Fu, M. The Determinants of Financial Innovation. Soc. Sci. Electron. Publ. 2009. [CrossRef]

30. Yang, H.L.; Pollitt, M. The necessity of distinguishing weak and strong disposability among undesirable outputs in DEA: Environmental performance of Chinese coal-fired power plants. Energy Policy 2010, 38, 4440-4444. [CrossRef]

31. Fare, R.; Grosskopf, S.; Pasurka, C. Effects on relative efficiency in electric power generation due to environmental controls. Resour. Energy 1986, 8, 167-184. [CrossRef]

(C) 2020 by the authors. Licensee MDPI, Basel, Switzerland. This article is an open access article distributed under the terms and conditions of the Creative Commons Attribution (CC BY) license (http://creativecommons.org/licenses/by/4.0/). 

Article

\title{
The Influence of IFRS Adoption on Banks' Cost of Equity: Evidence from European Banks
}

\author{
Sang-Giun Yim \\ School of Finance and Accounting, Kookmin University, Kookmin University, 77, Jeongneung-ro, Seongbuk-gu, \\ Seoul 02707, Korea; yimsg@kookmin.ac.kr; Tel.: +82-2-910-5464
}

Received: 18 February 2020; Accepted: 23 April 2020; Published: 26 April 2020

\begin{abstract}
This study examines how mandatory adoption of International Financial Reporting Standards (IFRS) in European countries affects banks' cost of equity. Supporters of IFRS argue that its adoption improves the quality of accounting information, which in turn decreases the cost of equity. However, banking regulators could intervene in the implementation of new accounting standards to protect the stability of the banking system, which would deteriorate banks' information environment and thereby increase the cost of equity. Using a regression analysis of European listed bank data, I find that banks' cost of equity increases after the adoption of IFRS in countries with strong bank supervisory offices. I also find that strong legal enforcement and additional disclosure requirements jointly reduce banks' cost of equity, but pre-IFRS inconsistencies between local accounting standards and regulatory standards jointly increase banks' cost of equity. This study contributes to the literature on market discipline in banking and has policy implications: The findings suggest that, when implementing new accounting standards, potential conflicts between financial reporting and banking regulations should be considered.
\end{abstract}

Keywords: cost of equity; IFRS adoption; European banks; corporate governance; banking regulation

\section{Introduction}

The 2007 US subprime mortgage crisis shows the importance of the banking system for sustainable economic growth. The adverse effects of this crisis not only impacted the banks and debtors as parties to the mortgage loan contracts, but it also spread across the entire financial system and the real economy. As a result, despite the US government's efforts to stabilize the financial system, real domestic production per capita in the United States decreased by more than 5\% from the fourth quarter of 2007 to the second quarter of 2009. This shows how the soundness of the banking system is critical to sustainable economic growth.

While several government regulations have been adopted to maintain the stability of the banking industry, innovations in financial instruments have been developing quickly, and regulatory bodies are playing catch up with the financial market. Consequently, the role of market discipline is crucial because market mechanisms can adapt more flexibly and promptly to change.

Unlike government regulators, market participants are not authorized to access banks' private information. Therefore, the public information environment is critical for the market discipline of banks. Financial statements are a reliable and comprehensive source of public information. Hence, this study investigates the influence of changes in accounting standards on European banks' financial statements post-International Financial Reporting Standards (IFRS) adoption.

Researchers argue that IFRS adoption improves accounting quality because it requires more disclosure than most local European accounting standards pre-IFRS. They suggest that IFRS adoption improves both earnings quality and the information environment. Consequently, post-IFRS, security trading by foreign investors increased, and equity values increased. These studies mainly focus on the 
impact of IFRS adoption on non-financial firms and equity market characteristics, however, and pay little attention to the banking industry or to the use of accounting information in contracts [1].

IFRS adoption impacts banks differently from non-financial firms because banks possess financial assets. IFRS requires financial assets to be recorded at fair market value, which is a noisy measure of future cash flow. Hence, increased use of this measure post-IFRS could increase the noise in the prediction of cash flow from bank assets, which could increase banks' information risks. Furthermore, unlike the cost of equity for non-financial firms, that for banks could increase post-IFRS.

Furthermore, IFRS as a principle-based accounting system is more flexible than most of the pre-IFRS local accounting standards. In contrast to a rule-based accounting system, a principle-based accounting system allows managers more accounting choices. Thus, accounting information can vary depending on choices made during the preparation of the information. This could enhance decision-making because information selection could be tailored. However, the verifiability of the accounting information could suffer post-IFRS, as the same accounting information can be presented in different ways. Verifiability is critical in contracts [2] because low verifiability provides room for moral hazard regarding debt contracts using accounting information in the debt covenants. Thus, IFRS adoption could reduce the contractibility of accounting information [1]. In sum, although IFRS adoption could improve the information environment for equity markets, it could also have a negative impact on debt markets.

In most countries, the banking industry is regulated by a governmental or a non-governmental organization to protect the stability of the financial system. Should IFRS adoption increase the instability of debt markets, bank supervisors can intervene. When bank supervisors have especially strong power, they have great influence on banks' financial reporting. The bank supervisors' main concern is the stability of financial markets; therefore, if necessary, they could intervene in the financial reporting by managing the law or the implementation of accounting standards, as Skinner [3] reported using a Japanese case. Although the supervisors' intervention stabilizes the lending system of the country, the distortion in the adoption of new accounting standards damages the transparency of the accounting information. Consequently, banks' information risks increase, which increases banks' cost of equity.

Based on the argument above, I hypothesize that IFRS adoption increases banks' cost of equity in countries with strong banking regulations. I also conjecture that IFRS adoption decreases banks' cost of equity in countries with strong investor protection.

Using European listed bank data, I test my hypotheses through a multivariate regression analysis. The results show that IFRS adoption increases banks' cost of equity in countries with strong banking supervision, supporting my conjecture. In examining the effect of additional disclosure requirements, I find that strong legal enforcement and additional IFRS disclosure requirements jointly reduce banks' cost of equity. However, banks' cost of equity is increased by the joint effect of the improvement of comparability by IFRS adoption and banking regulatory power.

This study contributes to the literature in several ways. First, this is one of the few studies that examines how IFRS adoption affects the valuation of the banking sector. Armstrong et al. [4] report that the market reaction of banks' stock prices to IFRS adoption is stronger than that of other industries. Meanwhile, Daske et al. [5] and Li [6] examine the effect of IFRS adoption on market reaction, but they do not examine the banking industry.

Second, this study has policy implications. The importance of market discipline in banking increases as financial instruments become more complex [7]. As seen in the 2007 Mortgage Crisis in the United States, financial instruments have recently been innovated at a rapid pace, and government regulations are not keeping up with the pace of innovation in financial instruments. However, market participants can respond quickly to market innovation, unlike government regulations. Thus, market discipline can supplement government regulation. Since investors rely on public information, high-quality accounting information is important in the market discipline of banks [8]. As this research suggests, in addition to high-quality accounting information, country-level banking governance is necessary for the efficient market discipline of banks. 
Third, this study shows the interaction between the institutional environment of banks and changes in accounting standards. Researchers have pointed out that the institutional environment influences financial reporting [9-11]. Supporting this argument, studies on mandatory IFRS adoption suggest that investor protection facilitates IFRS adoption [6,12]. However, few studies have examined the role of bank regulation in adopting new accounting standards.

The remainder of this paper proceeds as follows. Section 2 summarizes prior studies regarding the effect of IFRS adoption on the cost of equity, institutional environments of the banking industry, and the economic consequences of IFRS adoption. Section 3 documents hypothesis development. Section 4 presents the research design, sample selection, and descriptive statistics. Section 5 documents the results of regression analyses. Section 6 concludes the paper.

\section{Literature Review and Background}

\subsection{The Effect of IFRS Adoption}

Prior studies argue that IFRS adoption improves several aspects of financial reporting, the information environment, and capital markets. Empirical studies find that earnings quality $[13,14]$ and the information environment $[12,15,16]$ are improved following IFRS adoption. Consequently, security trading $[5,17,18]$ and equity valuation $[5,6]$ improve post-IFRS.

Theory expects that the quality of disclosure is negatively related to the cost of equity [19-21], which is backed by empirical evidence [22,23]. Since IFRS adoption improves the transparency of accounting information and the information environment, researchers expect that IFRS adoption decreases the cost of equity. $\mathrm{Li}$ [6] finds evidence supporting this using European non-financial firm data.

However, IFRS adoption also has a negative consequence because it increases a manager's choice of accounting policy, which reduces the contractibility of the accounting information. Supporting this argument, Ball et al. [1] report that IFRS adoption reduces accounting-based debt covenants. This study implies that IFRS adoption is not welcomed by bank regulators because it reduces the contractibility of debt contracts, which results in instability in the financial markets. In addition, the findings of Ball et al. [1] also suggest that banks' risks increase post-IFRS because banks' lending contracts that utilize accounting information in debt covenants become inefficient.

\subsection{The Institutional Environment of Listed Banks}

This study focuses on the equity capital in European listed banks, which are exposed to two different types of institutional environments: Bank supervision and disclosure regulation. Listed banks are regulated by banking supervisory offices. Although the detailed structures of bank supervisory systems vary by country [24], the ultimate goal of supervisory offices is the same, namely, to safeguard the stability of the financing system because the stability of financial markets plays a critical role in the economic growth of the country. As a publicly listed firm, listed banks are also bound to the disclosure requirements of investors, whose main concern is not in protecting the stability of the markets, but in protecting investors' private interests.

The difference in policy objectives between bank regulation and corporate disclosure creates conflicts between accounting policy and bank regulation. Skinner [3] investigates the adoption of deferred tax accounting in Japan in 1998, during which Japanese banks' regulatory capital was insufficient. Thus, to maintain banks' solvency, the Japanese government and bank regulators decided to use a deferred tax asset as regulatory capital. Because maintaining the solvency of banks is more important for the country's economy, the quality of accounting information was sacrificed during the adoption of deferred tax asset accounting. Skinner [1] implies that banking regulations limit or distort the adoption of new accounting standards if the standards negatively affect the solvency of banks. IFRS adoption could necessitate regulatory intervention, as in the case investigated by Skinner [3]. Bischof [25] also pointed out that there are incentives to prevent European bank regulators from introducing new accounting standards 
that affect banks' financial statements, which means that the intervention of bank supervisory offices in the adoption of new accounting standards is not limited to a specific country.

To implement accounting standards, support of institutional environments is necessary [9]. However, as prior studies show [3,25], listed banks face a potential conflict between bank regulation and financial disclosure; therefore, how IFRS adoption influences listed banks is unclear.

Basel II is a set of guidelines that shaped the mandatory adoption of IFRS in European counties. Although replaced by Basel III, Basel II is still useful in understanding the mechanism of the banking regulations. Basel II is based on the following three pillars: (1) Minimum capital requirement that requires safer capital as banks' risky assets increase; (2) review process by a government supervisory office; (3) market discipline that relies on sophisticated investors' monitoring. For the first and second pillars, private information can be required from banks or banks' auditors. Frequently, these two pillars have priority over accounting standards [3,25]. For the third pillar, market discipline penalties include direct penalty by investor activism and indirect penalties through market prices of securities, including stock prices. Due to the high information efficiency of market prices, market discipline can reflect the bank's health information at a rate that bank supervisors cannot follow. This means that market discipline is superior to bank supervisors in reflecting the consequences of financial instruments, which are rapidly becoming increasingly complex as they undergo innovation, on the health of banks. Therefore, the importance of market discipline is in an increasing trend [7].

Banking regulations affect banks' financial reporting. Bank supervisors can require banks to disclose private information found during the review process [26,27]. Furthermore, regulatory capital requirements enhance disclosure by providing timely and extensive information that is not required by accounting standards [28]. Stringent banking regulations could conflict with accounting information in that the regulations safeguard the banking system, whereas the accounting information focuses on capital providers. Moreover, banking regulators could sacrifice the quality of accounting information to stabilize the financial system $[3,28]$ or to avoid rapid changes in the accounting numbers to minimize the negative impact on debt contracts based on accounting information [1,25].

The influence of investor protection is the same for banks and non-financial firms. Strong investor protection provides incentives to managers to provide transparent accounting information [10,11,29]. Consequently, IFRS adoption reduces banks' cost of equity $[6,30,31]$.

\subsection{IFRS Adoption in the Banking Sector}

Compared with the previous local accounting standards, IFRS adoption brought several changes. The two most important changes for this study [2,14] include an increase in fair value measurement and an increase in accounting choices.

As the fair value measure increases, the statement of financial position (balance sheet in US Generally Accepted Accounting Principles terminology) increases in relevance for equity valuation. However, the market volatility included in fair value increases the noise in measuring banks' future cash flows. Even though fair value measures do not directly rely on level 1 inputs, which are market values, level 2 or level 3 inputs of fair value measures do not alleviate the information risk because they discretionary. In sum, extended use of fair value measures increases information risks, which are unfavorable for both investors and bank regulators.

In addition, although the increase in accounting choices enhances the relevance of the statement of financial position to equity valuation, this increase could influence the banking industry negatively. The increase in accounting choices complicates verification of compliance with the debt covenants. This provides opportunities for moral hazard for both parties of the debt contract. The reduction of contractibility of accounting information could have a significant impact on capital markets, which necessitates intervention by banking regulators $[3,25]$. 


\section{Hypothesis Development}

Regarding IFRS adoption and banks' cost of equity, two risks should be considered. The first risk is banks' business risks, which come from operating characteristics; for example, borrowers' credit risks. The second is information risk $[19,20]$. Both risks increase banks' cost of equity.

Because the minimum capital regulation is applied stringently, the regulatory capital ratio efficiently reduces banks' risk [28]. This risk reduction decreases banks' cost of equity. If banks' risk is already lowered by banking regulations, IFRS adoption has little impact on the disclosure of information about banks' risks. Therefore, IFRS adoption has little impact on the cost of equity if capital regulation is strong. Based on this conjecture, I suggest the following hypotheses:

H1: Banks' cost of equity decreases as the minimum capital regulation strengthens.

H2: Strong capital regulation weakens the impact of IFRS adoption on banks' cost of equity.

If banking regulatory agencies have strong power, they can require private information directly from banks or banks' auditors for regulatory actions $[1,28]$. Therefore, bank regulation strength reduces banks' cost of equity because strong banking regulators can monitor and discipline banks.

Banking regulations have priority over financial reporting in most countries; therefore, these regulations could interfere with IFRS adoption if new accounting standards have a negative effect on the banking system. IFRS adoption increases choice among accounting rules; therefore, using accounting information for debt covenants allows for moral hazard for any one of the contracting parties in debt contracts [1]. Several banks' contracts use accounting information for debt covenants; hence, changes in accounting standards could affect banks' existing contracts. Therefore, bank supervisors have the incentive to intervene in the adoption of new accounting standards to prevent potential turmoil, which would interfere with the faithful implementation of IFRS [3,25]. The intervention of bank supervisors increases information risk of banks, which would increase bank supervisors' power. Based on this conjecture, I suggest the following hypotheses:

H3: Banks' cost of equity decreases as the bank supervisors' power strengthens.

H4: IFRS adoption increases banks' cost of equity in the countries with strong banking supervisors.

Market discipline needs a good information environment including high-quality accounting information. Country-level investor protection improves accounting quality by helping faithful financial reporting $[9,29]$, which leads to a reduction in the cost of equity $[11,30,31]$. Thus, in countries with strong investor protection, IFRS adoption reduces banks' cost of equity. In relation to the institutional aspects of the banking sector, I therefore suggest the following hypothesis:

H5: The influence of IFRS adoption on banks' cost of equity is weakened when investor protection is strengthened.

The impact of IFRS adoption varies with the extent of changes that occur in IFRS adoption [32]. In most European countries, IFRS adoption requires more disclosure. Thus, the impact of IFRS adoption increases additional disclosure requirements. Moreover, the impact of IFRS adoption varies with the inconsistencies between IFRS and the local accounting standards implemented before IFRS adoption. Accordingly, I propose the following hypotheses.

H6: The influence of IFRS adoption increases when IFRS adoption requires additional disclosures.

H7: The influence of IFRS adoption increases when inconsistencies exist between IFRS and the local accounting standards implemented before IFRS adoption. 


\section{Research Design}

\subsection{Regression Model}

I use the implied cost of equity as my proxy for expected returns because it has fewer errors than realized-return-based proxies $[30,31,33]$ from information shocks. I average four estimates calculated using the models of Easton [34], Gode and Mohanram [35], Gebhardt et al. [36], and Claus and Thomas [37] to mitigate error in each measurement [30,31].

Studies on the effect of IFRS adoption frequently use a difference-in-differences model using voluntary adopters as the control group. This model controls for the influence that occurs simultaneously with IFRS adoption. However, except the treatment, the control group of the difference-in-differences model should be identical to the treatment group. Furthermore, only three countries have banks that adopted IFRS voluntarily. Most European banks adopt IFRS mandatorily, which means that IFRS adoption was an exogenous event for most European banks. Hence, I do not use the difference-in-differences design.

To test $\mathrm{H} 1$ to H5, I use the following model (1):

$$
\begin{gathered}
\text { COC }=\alpha+\beta_{1} \text { POST }+\beta_{2} \text { ENFORCE }+\beta_{3} \text { OFFICE }+\beta_{4} \text { CAPITAL }+\beta_{5} \text { POST ENFORCE } \\
+\beta_{6} \text { POST }^{*} \text { OFFICE }+\beta_{7} \text { POST }{ }^{*} \text { CAPITAL }+ \text { CONTROLS }+\varepsilon
\end{gathered}
$$

Variable definitions are in the Appendix A. POST is the variable of interest. I include measures for the strength of capital regulation (CAPITAL), the power of bank supervisors (OFFICE), and the efficiency of legal enforcement (ENFORCE) in the regression model. CAPITAL and OFFICE are measured by The Bank Regulation and Supervision Survey 2003 conducted by the World Bank [28,38]. I centered CAPITAL, OFFICE, and ENFORCE by the sample mean of each variable to mitigate multicollinearity problems from biases of spurious correlations [39].

I control firm-level risks using proxies of size, return volatility, financial leverage, total capital ratio, and book-to-price ratio. Size, return volatility, and leverage are measured by the decile rank of each variable to mitigate measurement errors. I include variables to control for cross-listing on the US stock market because investor protection in the US market is stronger than it is in most European countries, but it is not affected by mandatory IFRS adoption. I also control for the annual inflation rate and the indicator variable for the adoption of IFRS 7, which could affect banks. I include the bias and dispersion of analyst forecasts to mitigate the effect of biases and the nonlinearity of the models for the implied cost of equity [37,40]. Many bank-year observations have only one one-year-ahead earnings forecast; hence, I include an indicator variable for the observations to control for potential bias and replace the dispersion of analyst forecasts with zero. I adjust the influence of the firm-level serial correlation using a firm-clustered standard error in all of the regression results in this study [41].

To test $\mathrm{H} 6$ and $\mathrm{H} 7$, I revise model (1) by including additional disclosure requirements $(A D D)$ and inconsistencies between IFRS and the local accounting standards (INC). I use the survey of Nobes [42] to measure $A D D$ and INC. Nobes [42] did not focus on banks; thus, items irrelevant to banks, for example, inventory or plant assets, are included. To avoid potential measurement errors from irrelevant items, I exclude items irrelevant to bank operations from $A D D$ and INC. I centered $A D D$ and INC by their sample means to avoid multicollinearity problems [39]. The following are the models for $\mathrm{H} 6$ and H7, respectively. Model (2) and model (3) are models for testing the effects of ADD and ICC, respectively.

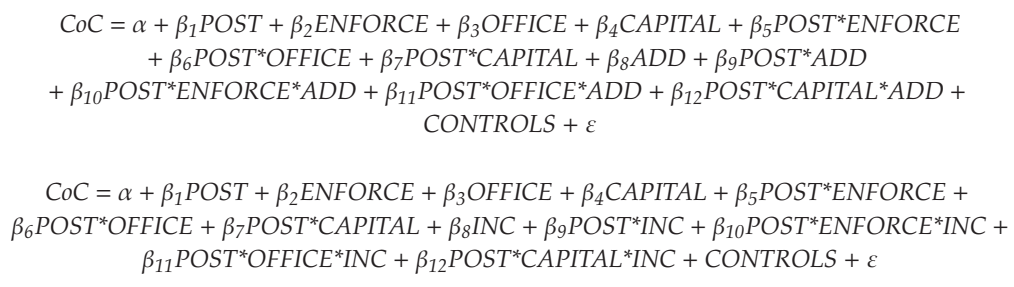




\subsection{Sample Selection}

Mandatory IFRS adoption by the European Union provides the setting for a natural experiment. Therefore, I use data from listed banks of European countries from 1995 to 2009. The observations are required to have the Standard Industry Code between 6020 and 6099 . Analyst forecast data and financial data are obtained from I/B/E/S and Compustat Global, respectively. I match the stock prices and analyst forecasts of seven months after the previous fiscal-year end to make sure that precious accounting information is fully incorporated. Non-positive earnings forecasts were excluded. If three-year-ahead to five-year-ahead analyst forecasts are missing, I fill in missing values using long-term earnings growth rate forecasts. I use the average of a historical three-year payout ratio to calculate the expected dividend payout ratio. If the payout ratio is missing, or smaller (larger) than 0 (1), I use the country-median value instead. I exclude banks that do not have observations both before and after the mandatory IFRS adoption in 2005. I classify years before 2004 as the pre-mandatory adoption period and years from 2005 as the post-mandatory adoption period [6,30,31].

Table 1 presents the composition of the final sample, which has 376 observations from 52 banks in 12 countries having 7 voluntary adopters and 45 mandatory adopters. Among the 376 observations, 52 and 324 observations are obtained from voluntary and mandatory adopters, respectively. Only three countries, namely, Germany, Greece, and Poland, have voluntary adopters. However, voluntary adopters could not provide a good benchmark for difference-in-differences tests, because they are not evenly distributed. The sample selection did not drive this result. By examining the entire Compustat Global database, I confirm that only three countries have banks that voluntarily adopted IFRS. This result implies that IFRS adoption is more like an exogenous event than an endogenous one. Furthermore, this also implies that financial reporting and banking regulations could have conflicting goals.

Table 1. Sample composition.

\begin{tabular}{|c|c|c|c|c|}
\hline \multicolumn{5}{|c|}{ Panel A: Number of observations } \\
\hline & $\begin{array}{l}\text { Voluntary } \\
\text { adopters }\end{array}$ & $\begin{array}{c}\text { Mandatory } \\
\text { adopters }\end{array}$ & $\begin{array}{l}\text { Pre-mandatory } \\
\text { adoption period } \\
\text { (Before 2005) }\end{array}$ & $\begin{array}{c}\text { Post-mandatory } \\
\text { adoption period } \\
\text { (From 2005) }\end{array}$ \\
\hline Belgium & 0 & 11 & 7 & 4 \\
\hline Denmark & 0 & 17 & 8 & 9 \\
\hline Finland & 0 & 6 & 1 & 5 \\
\hline France & 0 & 34 & 16 & 18 \\
\hline Germany & 33 & 4 & 23 & 14 \\
\hline Greece & 7 & 29 & 17 & 19 \\
\hline Ireland & 0 & 21 & 15 & 6 \\
\hline Netherland & 0 & 17 & 10 & 7 \\
\hline Poland & 12 & 28 & 16 & 24 \\
\hline Spain & 0 & 38 & 18 & 20 \\
\hline Sweden & 0 & 37 & 26 & 11 \\
\hline UK & 0 & 82 & 53 & 29 \\
\hline Sum & 52 & 324 & 210 & 166 \\
\hline \multicolumn{5}{|c|}{ Panel B: Number of banks } \\
\hline & \multicolumn{2}{|c|}{ Voluntary adopters } & \multicolumn{2}{|c|}{ Mandatory adopters } \\
\hline Belgium & \multicolumn{2}{|c|}{0} & \multicolumn{2}{|c|}{1} \\
\hline Denmark & \multicolumn{2}{|c|}{0} & \multicolumn{2}{|c|}{3} \\
\hline Finland & \multicolumn{2}{|c|}{0} & \multicolumn{2}{|c|}{1} \\
\hline France & \multicolumn{2}{|c|}{0} & \multicolumn{2}{|c|}{5} \\
\hline Germany & \multicolumn{2}{|c|}{4} & \multicolumn{2}{|c|}{1} \\
\hline Greece & \multicolumn{2}{|c|}{1} & \multicolumn{2}{|c|}{4} \\
\hline Ireland & \multicolumn{2}{|c|}{0} & \multicolumn{2}{|c|}{3} \\
\hline
\end{tabular}


Table 1. Cont.

\begin{tabular}{ccc}
\hline Netherland & 0 & 2 \\
Poland & 2 & 6 \\
Spain & 0 & 5 \\
Sweden & 0 & 4 \\
UK & 0 & 10 \\
\hline Sum & 7 & 45 \\
\hline & Panel C: Number of mandatory adopter observations \\
\hline Belgium & Pre-adoption & Post-adoption \\
Denmark & 7 & 4 \\
Finland & 8 & 9 \\
France & 1 & 5 \\
Germany & 16 & 18 \\
Greece & 2 & 2 \\
Ireland & 14 & 15 \\
Netherland & 15 & 6 \\
Poland & 10 & 7 \\
Spain & 11 & 17 \\
Sweden & 18 & 20 \\
UK & 26 & 11 \\
Sum & 53 & 29 \\
\hline & 181 & 143 \\
\hline
\end{tabular}

\subsection{Descriptive Statistics}

Panel A in Table 2 shows the means of the main variables for regression analyses by country. Means of implied cost of equity are from $10 \%$ to $14 \%$, whereas means of the regulatory capital ratio are larger than $10 \%$ and lower than $14.5 \%$. Only three countries, namely, Germany, Greece, and Poland, have banks that voluntarily adopted IFRS. This implies that, unlike non-financial industries, European banks' IFRS adoption might be regulated by banks [6,25]. Voluntary adopters have a higher regulatory capital ratio than mandatory adopters in the same countries, suggesting the possibility that sound banks choose to adopt IFRS voluntarily to indicate their financial stability. Panel B presents the descriptive statistics for the full sample.

Table 2. Descriptive statistics.

\begin{tabular}{ccccc}
\hline \multicolumn{2}{c}{ Panel A: Country mean value of the cost of equity, market value, and regulatory capital ratio } \\
\hline & $\mathrm{N}$ & CoC & $\begin{array}{c}\text { Market value of } \\
\text { equity }\end{array}$ & $\begin{array}{c}\text { Total regulatory } \\
\text { capital ratio }\end{array}$ \\
\hline Belgium & 11 & 0.1088 & 21,299 & $13.20 \%$ \\
Denmark & 17 & 0.1386 & 10,351 & $11.25 \%$ \\
Finland & 6 & 0.1039 & 2,270 & $12.23 \%$ \\
France & 34 & 0.1282 & 41,695 & $11.00 \%$ \\
Germany & 37 & 0.1086 & 23,640 & $11.57 \%$ \\
(Mandatory adopters) & 4 & 0.1011 & 2,355 & $13.07 \%$ \\
Greece & 36 & 0.1288 & 8,335 & $13.10 \%$ \\
(Mandatory adopters) & 29 & 0.1285 & 8,133 & $13.06 \%$ \\
Ireland & 21 & 0.1228 & 12,645 & $12.29 \%$ \\
Netherland & 17 & 0.1146 & 21,282 & $11.83 \%$ \\
Poland & 40 & 0.1250 & 4,356 & $14.47 \%$ \\
(Mandatory adopters) & 28 & 0.1285 & 4,701 & $14.01 \%$ \\
Spain & 38 & 0.1116 & 36,571 & $11.65 \%$ \\
Sweden & 37 & 0.1017 & 13,381 & $10.44 \%$ \\
UK & 82 & 0.1037 & 109,912 & $13.19 \%$ \\
\hline
\end{tabular}


Table 2. Cont.

\begin{tabular}{|c|c|c|c|c|c|}
\hline \multicolumn{6}{|c|}{ Panel B. Summary statistics of the main variables for the regression analyses } \\
\hline Variable & Mean & STD & $25 \%$ & $50 \%$ & $75 \%$ \\
\hline $\mathrm{CoC}$ & 0.1150 & 0.0306 & 0.0960 & 0.1093 & 0.1270 \\
\hline $\operatorname{SIZE}(=\log T A)$ & 12.5453 & 2.5862 & 10.9217 & 12.2901 & 13.4738 \\
\hline OTC & 0.1649 & 0.3716 & 0 & 0 & 0 \\
\hline $\mathrm{EXCH}$ & 0.1383 & 0.3457 & 0 & 0 & 0 \\
\hline$P P$ & 0.0559 & 0.2299 & 0 & 0 & 0 \\
\hline INFLA & 2.7212 & 2.3848 & 0.69565 & 2.134 & 4.2124 \\
\hline RETVOL & 0.0891 & 0.0592 & 0.0501 & 0.0717 & 0.1087 \\
\hline$L E V$ & 0.9418 & 0.0311 & 0.9312 & 0.9510 & 0.9625 \\
\hline CAP Ratio & 12.2579 & 4.5377 & 10.8 & 11.7 & 13.1 \\
\hline CAPR_DUM & 0.3431 & 0.4754 & 0 & 0 & 1 \\
\hline FBIAS & 0.0081 & 0.0395 & -0.0090 & -0.0010 & 0.0115 \\
\hline$B P R$ & 0.6449 & 0.5156 & 0.3877 & 0.5368 & 0.7352 \\
\hline DISP & 0.0041 & 0.0164 & 0 & 0 & 0.0048 \\
\hline FOLLOW & 3.6170 & 4.1617 & 1 & 1 & 5 \\
\hline
\end{tabular}

Table 3 presents the differences in bank characteristics before and after IFRS adoption. The variables in Table 3 are chosen differently from those in Panel B of Table 2, because the purpose of Table 3 is to present the changes in bank characteristics intuitively. CoC significantly changes after the mandatory IFRS adoption. However, this univariate test does not confirm that the difference is due to IFRS adoption.

Table 3. Differences in bank characteristics before and after the mandatory International Financial Reporting Standards (IFRS) adoption.

\begin{tabular}{ccccccc}
\hline Variable & $\begin{array}{c}\text { Pre-Adoption } \\
\text { (A) }\end{array}$ & $\begin{array}{c}\text { Post-Adoption } \\
\mathbf{( B )}\end{array}$ & $\begin{array}{c}\text { Difference } \\
\mathbf{( B - A )}\end{array}$ & t-Value & $p$-Value & \\
\hline CoC & 0.104 & 0.130 & 0.026 & 7.87 & 0.000 & $* * *$ \\
TA & 243,865 & 581,665 & 337,800 & 5.10 & 0.000 & $* * *$ \\
MKT & 16,309 & 31,747 & 15,438 & 3.64 & 0.000 & $* * *$ \\
RETVOL & 0.089 & 0.084 & -0.005 & -0.72 & 0.470 & \\
BPR & 0.493 & 0.815 & 0.322 & 5.07 & 0.000 & $* * *$ \\
LEV & 0.943 & 0.943 & 0.000 & -0.01 & 0.993 & \\
CAP Ratio & 12.474 & 11.784 & -0.690 & -1.44 & 0.151 & $*$ \\
FBIAS & 0.003 & 0.010 & 0.007 & 1.74 & 0.083 & \\
DISP & 0.005 & 0.003 & -0.001 & -0.68 & 0.497 & $* *$ \\
Follow & 4.039 & 2.902 & -1.137 & -2.48 & 0.014 & $*$ \\
ONEFORECAST & 0.475 & 0.601 & 0.126 & 2.27 & 0.024 & $* *$ \\
\hline
\end{tabular}

$*, * *$, and ${ }^{* * *}$ indicate significance at the $10 \%, 5 \%$, and $1 \%$ levels by two-tailed tests, respectively.

\section{Analysis Results}

\subsection{The Influence of IFRS Adoption and Institutional Environment on the Cost of Equity}

Table 4 documents variables for institutional environments, and Table 5 presents the estimation results of model (1). ENFORCE, OFFICE, and CAPITAL have negative coefficients in both full and partial sample analyses. However, the coefficient on CAPITAL is insignificant in the partial sample analysis. These results imply that investor protection and bank regulation reduce banks' risk in general. 
Table 4. Country characteristics.

\begin{tabular}{|c|c|c|c|c|c|}
\hline \multicolumn{6}{|c|}{ Panel A: Country means of variables } \\
\hline Country & $\begin{array}{c}\text { Legal } \\
\text { enforcement } \\
(E N F O R C E)\end{array}$ & $\begin{array}{l}\text { The index of official } \\
\text { supervisory power of } \\
\text { bank regulators } \\
\text { (OFFICE) }\end{array}$ & $\begin{array}{l}\text { Regulatory } \\
\text { restrictions on } \\
\text { bank capital } \\
(C A P I T A L)\end{array}$ & $\begin{array}{l}\text { Additional disclosure } \\
\text { required by IFRS } \\
\text { adoption for banks } \\
(A D D)\end{array}$ & $\begin{array}{l}\text { Total no. of inconsistencies } \\
\text { between local standardsand } \\
\text { IFRS for banks } \\
\text { (INC) }\end{array}$ \\
\hline Belgium & 9.44 & - & - & 7 & 13 \\
\hline Denmark & 10 & 8 & 2 & 5 & 13 \\
\hline Finland & 10 & 8 & 4 & 7 & 13 \\
\hline France & 8.68 & 7 & 2 & 5 & 15 \\
\hline Germany & 9.05 & 10 & 1 & 6 & 16 \\
\hline Greece & 6.82 & 10 & 3 & 8 & 14 \\
\hline Ireland & 8.36 & 9 & 1 & 0 & 15 \\
\hline Netherland & 10 & 8 & 3 & 2 & 5 \\
\hline Poland & - & - & - & 3 & 14 \\
\hline Spain & 7.14 & 9 & 4 & 8 & 18 \\
\hline Sweden & 10 & 6 & 3 & 4 & 9 \\
\hline UK & 9.22 & 11 & 3 & 0 & 15 \\
\hline \multicolumn{6}{|c|}{ Panel B: Summary statistics of the full sample } \\
\hline Variable & Mean & STD & $25 \%$ & $50 \%$ & $75 \%$ \\
\hline $\mathrm{CoC}$ & 0.1150 & 0.0306 & 0.0960 & 0.1093 & 0.1270 \\
\hline SIZE & 12.5453 & 2.5862 & 10.9217 & 12.2901 & 13.4738 \\
\hline OTC & 0.1649 & 0.3716 & 0 & 0 & 0 \\
\hline $\mathrm{EXCH}$ & 0.1383 & 0.3457 & 0 & 0 & 0 \\
\hline$P P$ & 0.0559 & 0.2299 & 0 & 0 & 0 \\
\hline INFLA & 2.7212 & 2.3848 & 0.69565 & 2.134 & 4.2124 \\
\hline RETVOL & 0.0891 & 0.0592 & 0.0501 & 0.0717 & 0.1087 \\
\hline$L E V$ & 0.9418 & 0.0311 & 0.9312 & 0.9510 & 0.9625 \\
\hline CAP Ratio & 12.2579 & 4.5377 & 10.8 & 11.7 & 13.1 \\
\hline CAPR_DUM & 0.3431 & 0.4754 & 0 & 0 & 1 \\
\hline FBIAS & 0.0081 & 0.0395 & -0.0090 & -0.0010 & 0.0115 \\
\hline$B P R$ & 0.6449 & 0.5156 & 0.3877 & 0.5368 & 0.7352 \\
\hline DISP & 0.0041 & 0.0164 & 0 & 0 & 0.0048 \\
\hline FOLLOW & 3.6170 & 4.1617 & 1 & 1 & 5 \\
\hline
\end{tabular}

Table 5. Basic regression analysis.

\begin{tabular}{|c|c|c|c|c|c|c|}
\hline \multirow[b]{2}{*}{ Parameter } & \multicolumn{3}{|c|}{ (A) Full Sample Period } & \multicolumn{3}{|c|}{ (B) From 2003 to 2006} \\
\hline & Coef & t-Value & & Coef & t-Value & \\
\hline Intercept & 0.0852 & $(14.18)$ & $* * *$ & 0.2003 & $(5.70)$ & $* * *$ \\
\hline POST & 0.0061 & $(2.20)$ & $* *$ & -0.0177 & $(-0.60)$ & \\
\hline ENFORCE & -0.0054 & $(-2.73)$ & $* * *$ & -0.0076 & $(-3.49)$ & $* * *$ \\
\hline OFFICE & -0.0023 & $(-1.81)$ & $*$ & -0.0049 & $(-1.96)$ & * \\
\hline CAPITAL & -0.0078 & $(-3.24)$ & $* * *$ & -0.0021 & $(-0.86)$ & \\
\hline POST $^{*}$ ENFORCE & 0.0010 & $(0.39)$ & & -0.0024 & $(-0.88)$ & \\
\hline POST $^{*}$ OFFICE & 0.0037 & $(2.75)$ & $* * *$ & 0.0044 & $(2.53)$ & $* *$ \\
\hline POST ${ }^{*}$ CAPITAL & -0.0016 & $(-0.50)$ & & 0.0012 & $(0.40)$ & \\
\hline IFRS7 & 0.0226 & $(3.04)$ & $* * *$ & & & \\
\hline SIZE_DEC & -0.0007 & $(-1.43)$ & & -0.0007 & $(-0.64)$ & \\
\hline OTTC & -0.0049 & $(-0.89)$ & & -0.0036 & $(-0.68)$ & \\
\hline $\mathrm{EXCH}$ & 0.0100 & $(3.06)$ & $* * *$ & 0.0082 & $(1.47)$ & \\
\hline INFLA & 0.0023 & $(2.51)$ & $* *$ & 0.0000 & $(0.01)$ & \\
\hline RETVOL_DEC & 0.0000 & $(-0.03)$ & & -0.0006 & $(-0.88)$ & \\
\hline$L E V \_D E C$ & 0.0011 & $(1.56)$ & & 0.0007 & $(0.93)$ & \\
\hline CAPR & -0.0001 & $(-0.83)$ & & 0.0014 & $(1.62)$ & \\
\hline CAPR_DUM & -0.0041 & $(-0.83)$ & & 0.0075 & $(0.70)$ & \\
\hline FBIAS & 0.2182 & $(1.90)$ & $*$ & 0.3136 & $(1.68)$ & \\
\hline DISP & 0.0780 & $(2.72)$ & $* * *$ & 0.2251 & $(0.42)$ & \\
\hline ONEFORECAST & 0.0029 & $(1.29)$ & & 0.0047 & $(1.16)$ & \\
\hline$B P R$ & 0.0188 & $(2.77)$ & $* * *$ & 0.0155 & $(1.84)$ & * \\
\hline \# of OBS & 285 & & & 131 & & \\
\hline ADJ R2 & 0.572 & & & 0.3528 & & \\
\hline
\end{tabular}

$* * *$, and ${ }^{* * *}$ indicate significance at the $10 \%, 5 \%$, and $1 \%$ levels by two-tailed tests, respectively. $t$-values are adjusted by firm cluster. 
The interaction term of POST and OFFICE has positive coefficients, suggesting that banks in countries with strong regulations experience an increase in the cost of equity. Financial reporting and banking regulations conflict regarding IFRS adoption. In this case, banking regulations have priority over financial reporting [26]. Therefore, bank supervisors intervene in the IFRS adoption to suppress the negative impact of IFRS on the banking system, at least temporarily $[3,25]$. The intervention in IFRS adoption reduces the quality of accounting information and increases the uncertainty of banks and the cost of equity. This supports H4. However, the interaction terms of ENFORCE or CAPITAL with POST are insignificant; thus, $\mathrm{H} 2$ and $\mathrm{H} 5$ are not supported. The results are qualitatively consistent with the results for non-financial firms. Listed banks are also exposed to disclosure requirements; therefore, the results should be consistent with prior study [6].

\subsection{The Changes in Disclosure Requirements by IFRS Adoption on Cost of Equity}

Panel A of Table 6 documents the regression result of model (2). In column (A), the sign of the three-way interaction term of ENFORCE shows that legal enforcement facilitates the implementation of additional disclosure requirements by mandatory IFRS adoption, resulting in the decrease in banks' cost of equity. However, the coefficients on the three-way interaction terms of CAPITAL and OFFICE are insignificant. The result of the subsample period test presented in column (B) is qualitatively the same, except that the significance and magnitude are weaker. The results support the conjecture that the institutional environment for investor protection supports the implementation of IFRS adoption because it improves the relevance of accounting information on the equity valuation.

Table 6. The effect of changes in bank disclosures on cost of equity.

\begin{tabular}{|c|c|c|c|c|c|c|}
\hline \multicolumn{7}{|c|}{ Panel A: Effect of additional disclosures } \\
\hline \multirow[b]{2}{*}{ Parameter } & \multicolumn{3}{|c|}{ (A) Full sample period } & \multicolumn{3}{|c|}{ (B) From 2003 to 2006} \\
\hline & Coef & t-Value & & Coef & $\mathrm{t}$-Value & \\
\hline Intercept & 0.0869 & $(10.33)$ & $* * *$ & 0.0794 & $(6.17)$ & $* * *$ \\
\hline POST & -0.0147 & $(-1.53)$ & & -0.0082 & $(-0.82)$ & \\
\hline ENFORCE & -0.0046 & $(-0.97)$ & & -0.0050 & $(-1.03)$ & \\
\hline OFFICE & -0.0023 & $(-1.12)$ & & -0.0031 & $(-1.26)$ & \\
\hline CAPITAL & -0.0081 & $(-2.23)$ & $* *$ & -0.0035 & $(-0.92)$ & \\
\hline$A D D$ & 0.0002 & $(0.08)$ & & 0.0015 & $(0.70)$ & \\
\hline POST $^{*}$ ENFORCE & 0.0163 & $(1.10)$ & & 0.0041 & $(0.38)$ & \\
\hline POST $^{*}$ OFFICE & 0.0009 & $(0.27)$ & & 0.0002 & $(0.05)$ & \\
\hline POST ${ }^{*}$ CAPITAL & -0.0160 & $(-1.49)$ & & -0.0033 & $(-0.36)$ & \\
\hline $\mathrm{POST}^{*} A D D$ & 0.0009 & $(0.25)$ & & -0.0031 & $(-1.04)$ & \\
\hline POST $^{*}$ ENFORCE ${ }^{*} A D D$ & -0.0069 & $(-2.16)$ & $* *$ & -0.0050 & $(-1.71)$ & * \\
\hline POST $^{*}$ OFFICE $E^{*} A D D$ & -0.0026 & $(-1.69)$ & & -0.0001 & $(-0.06)$ & \\
\hline POST $^{*}$ CAPITAL ${ }^{*} A D D$ & 0.0031 & $(1.47)$ & & 0.0019 & (1.09) & \\
\hline IFRS7 & 0.0232 & $(2.81)$ & $* * *$ & & & \\
\hline SIZE_DEC & -0.0011 & $(-1.59)$ & & -0.0005 & $(-0.48)$ & \\
\hline OTC & -0.0038 & $(-0.67)$ & & -0.0030 & $(-0.58)$ & \\
\hline $\mathrm{EXCH}$ & 0.0103 & $(2.96)$ & $* * *$ & 0.0074 & $(1.41)$ & \\
\hline INFLA & 0.0024 & $(2.24)$ & $* *$ & -0.0001 & $(-0.10)$ & \\
\hline RETVOL_DEC & 0.0002 & $(0.37)$ & & -0.0002 & $(-0.28)$ & \\
\hline$L E V \_D E C$ & 0.0009 & (1.35) & & 0.0006 & $(0.77)$ & \\
\hline$\overline{C A P R}$ & -0.0001 & $(-0.68)$ & & 0.0016 & $(1.79)$ & * \\
\hline CAPR_DUM & -0.0049 & $(-0.94)$ & & 0.0089 & $(0.84)$ & \\
\hline FBIAS & 0.2212 & $(1.94)$ & $*$ & 0.3116 & $(1.77)$ & * \\
\hline DISP & 0.0766 & $(2.75)$ & $* * *$ & -0.0595 & $(-0.12)$ & \\
\hline ONEFORECAST & 0.0016 & $(0.71)$ & & 0.0013 & $(0.33)$ & \\
\hline$B P R$ & 0.0186 & $(2.50)$ & $* *$ & 0.0231 & (2.16) & $* *$ \\
\hline No. of OBS & 285 & & & 131 & & \\
\hline ADJ R2 & 0.5772 & & & 0.3757 & & \\
\hline
\end{tabular}


Table 6. Cont.

\begin{tabular}{|c|c|c|c|c|c|c|}
\hline \multicolumn{7}{|c|}{ Panel B. Effect of inconsistencies } \\
\hline \multirow[b]{2}{*}{ Parameter } & \multicolumn{3}{|c|}{ (A) Full sample period } & \multicolumn{3}{|c|}{ (B) From 2003 to 2006} \\
\hline & Coef & t-Value & & Coef & t-Value & \\
\hline Intercept & 0.0882 & $(14.92)$ & $* * *$ & 0.0775 & $(7.01)$ & $* * *$ \\
\hline POST & 0.0073 & $(1.29)$ & & -0.0001 & $(-0.03)$ & \\
\hline ENFORCE & -0.0078 & $(-3.12)$ & $* * *$ & -0.0110 & $(-4.40)$ & $* * *$ \\
\hline OFFICE & -0.0015 & $(-1.04)$ & & -0.0041 & $(-1.43)$ & \\
\hline CAPITAL & -0.0085 & $(-3.87)$ & $* * *$ & -0.0016 & $(-0.63)$ & \\
\hline INC & -0.0013 & $(-2.16)$ & $* *$ & -0.0013 & $(-1.50)$ & \\
\hline POST $^{*}$ ENFORCE & 0.0018 & $(0.50)$ & & -0.0057 & $(-1.54)$ & \\
\hline POST $^{*}$ OFFICE & 0.0031 & (1.85) & * & 0.0061 & $(3.01)$ & *** \\
\hline $\mathrm{POST}^{*}$ CAPITAL & -0.0094 & $(-2.20)$ & $* *$ & -0.0087 & $(-3.41)$ & $* * *$ \\
\hline POST ${ }^{*} I N C$ & -0.0016 & $(-0.83)$ & & -0.0012 & $(-1.01)$ & \\
\hline POST $^{*}$ ENFORCE*INC & 0.0018 & $(1.59)$ & & 0.0011 & $(1.18)$ & \\
\hline POST $^{*}$ OFFICE INC & 0.0009 & $(1.15)$ & & 0.0024 & $(3.43)$ & $* * *$ \\
\hline POST $^{*}$ CAPITAL ${ }^{*} I N C$ & 0.0064 & $(2.04)$ & $* *$ & 0.0051 & (2.93) & $* * *$ \\
\hline IFRS7 & 0.0233 & $(3.12)$ & $* * *$ & & & \\
\hline SIZE_DEC & -0.0010 & $(-1.81)$ & $*$ & -0.0007 & $(-0.61)$ & \\
\hline OTC & -0.0039 & $(-0.76)$ & & -0.0036 & $(-0.83)$ & \\
\hline $\mathrm{EXCH}$ & 0.0108 & $(3.60)$ & $* * *$ & 0.0077 & (1.46) & \\
\hline INFLA & 0.0019 & $(1.96)$ & $*$ & -0.0009 & $(-0.81)$ & \\
\hline RETVOL_DEC & -0.0002 & $(-0.40)$ & & -0.0010 & $(-1.42)$ & \\
\hline$L E V \_D E C$ & 0.0010 & $(1.54)$ & & 0.0008 & $(1.08)$ & \\
\hline CAPR & -0.0001 & $(-0.82)$ & & 0.0016 & $(1.99)$ & * \\
\hline CAPR_DUM & -0.0038 & $(-0.78)$ & & 0.0107 & (1.12) & \\
\hline FBIASS & 0.2151 & $(1.77)$ & $*$ & 0.3305 & (1.77) & * \\
\hline DISP & 0.0752 & $(2.62)$ & $* *$ & 0.1549 & $(0.37)$ & \\
\hline ONEFORECAST & 0.0021 & $(0.95)$ & & 0.0027 & $(0.75)$ & \\
\hline$B P R$ & 0.0193 & $(2.69)$ & $* *$ & 0.0330 & (3.16) & $* * *$ \\
\hline No. of OBS & 285 & & & 131 & & \\
\hline ADJ R2 & 0.5814 & & & 0.4146 & & \\
\hline
\end{tabular}

$*, * *$, and ${ }^{* * *}$ indicate significance at the $10 \%, 5 \%$, and $1 \%$ levels by two-tailed tests, respectively. $\mathrm{t}$-values are adjusted by firm cluster.

Panel B of Table 6 shows the influence of the improved comparability on banks' cost of equity. I use model (3) for this test. INC indicates the differences between IFRS and the pre-IFRS local accounting standards. Therefore, INC also proxies for the improved comparability across countries. Unlike ADD, $I N C$ indicates disclosure requirement changes to the pre-existing accounting standards. Therefore, from the banking regulators' point of view, INC could be a threat to the debt market because it relates to compliance with debt covenants of the pre-existing debt contracts. By contrast, $A D D$ is likely unrelated to the compliance with debt covenants because $A D D$ indicates new disclosure requirements. The items related to $A D D$ were not in the previous accounting standards; hence, those items have little impact on debt covenants. Thus, the effect of bank supervisors' intervention is related to INC, not to $A D D$.

The three-way interaction term of CAPITAL and OFFICE is positive. This means that mandatory IFRS adoption increases the cost of equity in countries with stringent banking regulations and where the pre-existing accounting standards change significantly. As INC increases, bank supervisors' incentive to intervene in the implementation of IFRS increases because the adoption decreases the contractibility of accounting information $[1,3,25]$. Moreover, changes in accounting standards impact the regulatory capital ratio, which potentially impacts the stability of the banking system. As a result of the intervention, accounting standards are implemented to minimize the potential negative influence on the debt markets, which increases information risks. 


\section{Conclusions}

This study examines the effect of mandatory IFRS adoption on European banks' cost of equity. The empirical results of this study show that the impact of IFRS adoption on banks' cost of equity varies depending on institutional aspects. Strong investor protection is helpful in decreasing the cost of equity following IFRS adoption. However, banking regulation increases banks' cost of capital, especially when IFRS adoption has a strong impact on debt contracts. These results show that market monitoring and bank regulation are potentially at odds because of differences in policy objectives. Consequently, the cost of capital is affected differently by IFRS adoption in two institutional aspects.

The results of this study have policy implications. Unlike other industry sectors, the banking sector has a strong regulatory environment. Therefore, the incentives of banking regulators must be considered when designing a disclosure policy for the banking sector. If these incentives are ignored, a disclosure policy can be distorted; hence, the intended results cannot be obtained. Furthermore, this policy can yield results opposite to the intended ones. In addition, although market discipline is an important part of the banking regulatory system, factors that enhance market discipline can easily be weakened by bank supervisors. As market discipline has become more important because of rapid innovations in the finance sector, policy makers should carefully design policies related to the banking system.

This study also has several limitations. First, due to availability, some countries are not included in the analysis, which could cause a selection bias. Second, I incorporate only two aggregate measures of bank regulation, which are not enough to explain every detail of banking regulation. Third, the effects of specific regulatory events that occurred during my sample period are not totally addressed in this study. Fourth, this study focuses only on listed banks. Several banks are unlisted; hence, market discipline on unlisted banks should be addressed in future research settings. Finally, this study does not address the impact of IFRS adoption on several aspects other than stock price; for example, credit allocation activities. These could be examined separately in other studies.

Funding: This research received no external funding.

Acknowledgments: This study is based on one essay of my dissertation. I thank my dissertation chair Woon Oh Jung and committee members Lee-seok Hwan, Jong Hag Choi, Kyung-Ho Park, and Seung Yeon Lim for the guidance and support.

Conflicts of Interest: The author declares no conflict of interest.

\section{Appendix A}

Table A1. Variable definitions.

\begin{tabular}{|c|c|}
\hline Name & Definition \\
\hline$A D D$ & $\begin{array}{c}\text { Increase in disclosure requirements that are not related to assets with a tangible form, e.g., } \\
\text { depreciable assets or inventory [42] }\end{array}$ \\
\hline$B P R$ & Ratio of book value of equity to market value of common shares outstanding \\
\hline CAPITAL & Regulatory restrictions on bank capital from Caprio et al. [38] \\
\hline Capital Ratio & Ratio of the sum of core and supplementary capital to risk weighted assets \\
\hline CAPR & $\begin{array}{c}\text { Ratio of core and supplementary capital to risk weighted assets. Missing value is replaced by } \\
\text { zero }\end{array}$ \\
\hline CAPR_DUM & 1 if CAPR is not available, 0 otherwise \\
\hline $\mathrm{CoC}$ & $\begin{array}{l}\text { Average of four estimates of implied cost of equity calculated by the models of Easton [33], } \\
\text { Gode and Mohanram [34], Gebhardt et al. [35], and Claus and Thomas [36] }\end{array}$ \\
\hline DISP & $\begin{array}{c}\text { Standard variation of one-year-ahead earnings forecasts less actual earnings scaled by the } \\
\text { forecast-period stock price if more than } 1 \text { one-year-ahead earnings forecasts exists, } 0 \\
\text { otherwise }\end{array}$ \\
\hline ENFORCE & $\begin{array}{l}\text { Average of three indices for the efficiency of judicial system, rule of law, and corruption from } \\
\text { La Porta et al. [43] }\end{array}$ \\
\hline
\end{tabular}


Table A1. Cont.

\begin{tabular}{|c|c|}
\hline Name & Definition \\
\hline $\mathrm{EXCH}$ & 1 if a firm trades its shares in major stock markets (NYSE, NASDAQ, or Amex) \\
\hline FBIAS & $\begin{array}{c}\text { One-year-ahead earnings forecast less actual earnings scaled by the forecast-period } \\
\text { stock price }\end{array}$ \\
\hline FOLLOW & The number of analysts following \\
\hline IFRS7 & 1 if the year of an observation is after 2007,0 otherwise \\
\hline INC & $\begin{array}{l}\text { Total number of inconsistencies for banks between local accounting standards and IFRS } \\
\text { measured by Nobes [42] }\end{array}$ \\
\hline INFLA & Inflation rate measured by the wholesale price index \\
\hline LEV & Total liabilities divided by total assets \\
\hline LEV_DEC & Decile of $L E V$ \\
\hline$M K T$ & Market value of equity in million US dollars \\
\hline OFFICE & Index of official supervisory power of bank regulators from Caprio et al. [38] \\
\hline ONEFORECAST & 1 if only one analyst follows, and 0 otherwise \\
\hline OTC & 1 if a firm trades its shares in the US over-the-counter markets, and 0 otherwise \\
\hline POST & 1 if a firm-year observation falls in 2005 or later, and 0 otherwise \\
\hline$P P$ & 1 if a firm trades its shares in a private placement under Rule $144 \mathrm{~A}$ \\
\hline RETVOL & Standard deviation of monthly stock returns for the last 12 months before the fiscal year end \\
\hline RETVOL_DEC & Decile of RETVOL \\
\hline SIZE & Natural $\log$ of the value of total assets in million US dollars \\
\hline SIZE_DEC & Decile of the value of total assets \\
\hline$T A$ & Value of total assets in million US dollars \\
\hline VOLUNT & 1 if the bank adopted IFRS voluntarily, and 0 otherwise \\
\hline
\end{tabular}

\section{References}

1. Ball, R.; Li, X.; Shivakumar, L. Contractibility and Transparency of Financial Statement Information Prepared Uner IFRS: Evidence from Debt Contracts Around IFRS Adoption. J. Account. Res. 2015, 53, 915-963. [CrossRef]

2. Watts, R. Conservatism in Accounting Part I: Explanations and Implications. Account. Horiz. 2003, 17, 207-221. [CrossRef]

3. Skinner, D.J. The Rise of Deferred Tax Assets in Japan: The Role of Deferred Tax Accounting in the Japanese Banking Crisis. J. Account. Econ. 2008, 46, 218-239. [CrossRef]

4. Armstrong, C.S.; Jagolinzer, A.D.; Larcker, D.F. Chief Executive Officer Equity Incentives and Accounting Irregularities. J. Account. Res. 2010, 48, 225-271. [CrossRef]

5. Daske, H.; Hail, L.; Leuz, C.; Verdi, R. Mandatory IFRS Reporting around the World: Early Evidence on the Economic Consequences. J. Account. Res. 2008, 46, 1085-1142.

6. Li, S. Does Mandatory Adoption of International Financial Reporting Standards in the European Union Reduce the Cost of Equity Capital? Account. Rev. 2010, 85, 607-636. [CrossRef]

7. Greenbaum, S.I.; Thakor, A.V. Contemporary Financial Intermediation; Academic Press: Burlington, MA, USA, 2007.

8. Stephanou, C. Rethinking Market Discipline in Banking: Lessons from the Financial Crisis. Policy Research working paper; World Bank: Washington, DC, USA, 2010.

9. Ball, R.; Robin, A.; Wu, J.S. Incentives versus Standards: Properties of Accounting Income in Four East Asian Countries. J. Account. Econ. 2003, 36, 235-270. [CrossRef]

10. Bushman, R.M.; Piotroski, J.D.; Smith, A.J. What Determines Corporate Transparency? J. Account. Res. 2004, 42, 207-252. [CrossRef]

11. Leuz, C.; Nanda, D.; Wysocki, P.D. Earnings Management and Investor Protection: An International Comparison. J. Financ. Econ. 2003, 69, 505-527. [CrossRef]

12. Byard, D.; Li, Y.; Yu, Y. The Effect of Mandatory IFRS Adoption on Financial Analysts' Information Environment. J. Account. Res. 2011, 49, 69-96. [CrossRef]

13. Barth, M.E.; Landsman, W.R.; Lang, M.H. International Accounting Standards and Accounting Quality. J. Account. Res. 2008, 46, 467-498. [CrossRef]

14. Gebhardt, G.; Novotny-Farkas, Z. Mandatory IFRS Adoption and Accounting Quality of European Banks. J. Bus. Financ. Account. 2011, 38, 289-333. [CrossRef] 
15. Chen, C.; Young, D.; Zhuang, Z. Externalities of Mandatory IFRS Adoption: Evidence from Cross-Border Spillover Effects of Financial Information on Investment Efficiency. Account. Rev. 2013, 88, 881-914. [CrossRef]

16. Yip, R.W.Y.; Young, D. Does Mandatory IFRS Adoption Improve Information Comparability? Account. Rev. 2012, 87, 1767-1789. [CrossRef]

17. DeFond, M.; Hu, X.; Hung, M.; Li, S. The Impact of Mandatory IFRS Adoption on Foreign Mutual Fund Ownership: The Role of Comparability. J. Account. Econ. 2011, 51, 240-258. [CrossRef]

18. Florou, A.; Pope, P.F. Mandatory IFRS Adoption and Institutional Investment Decisions. Account. Rev. 2012, 87, 1993-2025. [CrossRef]

19. Diamond, D.W.; Verrecchia, R.E. Disclosure, Liquidity, and the Cost of Capital. J. Financ. 1991, 46, 1325-1359. [CrossRef]

20. Easley, D.; O'Hara, M. Information and the Cost of Capital. J. Financ. 2004, 59, 1553-1583. [CrossRef]

21. Lambert, R.; Leuz, C.; Verrecchia, R.E. Accounting Information, Disclosure, and the Cost of Capital. J. Account. Res. 2007, 45, 385-420. [CrossRef]

22. Botosan, C.A. Disclosure Level and the Cost of Equity Capital. Account. Rev. 1997, 72, 323-349.

23. Botosan, C.A.; Plumlee, M.A. A Re-examination of Disclosure Level and the Expected Cost of Equity Capital. J. Account. Res. 2002, 40, 21-40. [CrossRef]

24. Barth, J.R.; Caprio, G., Jr.; Levine, R. Bank Regulation and Supervision: What Works Best? J. Financ. Intermediat. 2004, 13, 205-248. [CrossRef]

25. Bischof, J. The Effects of IFRS 7 Adoption on Bank Disclosure in Europe. Account. Eur. 2009, 6, 167-194. [CrossRef]

26. Flannery, M.J.; Houston, J.F. The Value of a Government Monitor for U. S. Banking Firms. J. Money Credit Bank. 1999, 31, 14-34. [CrossRef]

27. Flannery, M.J.; Kwan, S.H.; Nimalendran, M. Market Evidence on the Opaqueness of Banking Firms' Assets. J. Financ. Econ. 2004, 71, 419-460. [CrossRef]

28. Beltratti, A.; Stulz, R.M. The Credit Crisis around the Globe: Why Did Some Banks Perform Better? J. Financ. Econ. 2012, 105, 1-17. [CrossRef]

29. Ball, R.; Kothari, S.P.; Robin, A. The Effect of International Institutional Factors on Properties of Accounting Earnings. J. Account. Econ. 2000, 29, 1-51. [CrossRef]

30. Hail, L.; Leuz, C. International Differences in the Cost of Equity Capital: Do Legal Institutions and Securities Regulation Matter? J. Account. Res. 2006, 44, 485-531. [CrossRef]

31. Hail, L.; Leuz, C. Cost of Capital Effects and Changes in Growth Expectations around U.S. Cross-Listings. J. Financ. Econ. 2009, 93, 428-454. [CrossRef]

32. Bae, K.-H.; Tan, H.; Welker, M. International GAAP Differences: The Impact on Foreign Analysts. Account. Rev. 2008, 83, 593-628. [CrossRef]

33. Elton, E.J. Expected Return, Realized Return, and Asset Pricing Tests. J. Financ. 1999, 54, 1199-1220. [CrossRef]

34. Easton, P.D. PE Ratios, PEG Ratios, and Estimating the Implied Expected Rate of Return on Equity Capital. Account. Rev. 2004, 79, 73-95. [CrossRef]

35. Gode, D.; Mohanram, P. Inferring the Cost of Capital Using the Ohlson-Juettner Model. Rev. Account. Stud. 2003, 8, 399-431. [CrossRef]

36. Gebhardt, W.R.; Lee, C.M.C.; Swaminathan, B. Toward an Implied Cost of Capital. J. Account. Res. 2001, 39, 135-176. [CrossRef]

37. Claus, J.; Thomas, J. Equity Premia as Low as Three Percent? Evidence from Analysts' Earnings Forecasts for Domestic and International Stock Markets. J. Financ. 2001, 56, 1629-1666. [CrossRef]

38. Caprio, G.; Laeven, L.; Levine, R. Governance and Bank Valuation. J. Financ. Intermediat. 2007, 16, $584-617$. [CrossRef]

39. West, S.G.; Aiken, L.S. Multiple Regression: Testing and Interpreting Interactions; Sage Publications: Thousand Oaks, CA, USA, 1991.

40. Easton, P.D.; Sommers, G.A. Effect of Analysts' Optimism on Estimates of the Expected Rate of Return Implied by Earnings Forecasts. J. Account. Res. 2007, 45, 983-1015. [CrossRef]

41. Petersen, M.A. Estimating Standard Errors in Finance Panel Data Sets: Comparing Approaches. Rev. Financ. Stud. 2009, 22, 435-480. [CrossRef] 
42. Nobes, C.W. GAAP 2001: A Survey of National Accounting Rules Benchmarked Against International Accounting Standards; Andersen; BDO; Deloitte Touche Tohmatsu; Ernst \& Young; Grant Thornton; KPMG; PriceWaterhouseCoopers: New York, NY, USA, 2001.

43. La Porta, R.; Lopez-de-Silanes, F.; Shleifer, A.; Vishny, R.W. Law and Finance. J. Political Econ. 1998, 106, 1113-1155. [CrossRef]

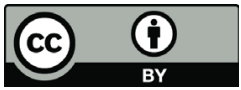

BY
(C) 2020 by the author. Licensee MDPI, Basel, Switzerland. This article is an open access article distributed under the terms and conditions of the Creative Commons Attribution (CC BY) license (http://creativecommons.org/licenses/by/4.0/). 


\title{
Peer-to-Peer Lending and Bank Risks: A Closer Look
}

\author{
Eunjung Yeo ${ }^{1}$ and Jooyong Jun ${ }^{2, *}$ \\ 1 School of Business Administration, Chung-Ang University, Seoul 06974, Korea; ejyeo@cau.ac.kr \\ 2 Department of Economics, Dongguk University, Seoul 04620, Korea \\ * Correspondence: jooyong@dongguk.edu
}

Received: 21 June 2020; Accepted: 25 July 2020; Published: 29 July 2020

\begin{abstract}
This study examined how the expansion of peer-to-peer (P2P) lending affects bank risks, particularly insolvency and illiquidity risks. We compared a benchmark case wherein banks are the only players in the loan market with a segmented market case wherein the loan market is segmented by borrowers' creditworthiness, P2P lending platforms operate only in the low-credit market segment, and banks operate in both low- and high-credit segments. For the segmented market case compared with the benchmark one, we find that, while banks' insolvency risk increases, their illiquidity risk decreases such that their overall risk also decreases. Our results imply that sustainable P2P lending requires an appropriate differentiation of roles between banks and $\mathrm{P} 2 \mathrm{P}$ lending platforms-P2P lending platforms operate in the low-credit segment and banks' involvement in P2P lending is restricted-so that the growth of P2P lending is not adverse for bank stability.
\end{abstract}

Keywords: peer-to-peer lending; bank risk; insolvency risk; illiquidity risk

JEL Classification: G21, G23

\section{Introduction}

Peer-to-peer (P2P) lending-also known as FinTech credit, crowd-finance, or marketplace lending - refers to credit activities through online P2P lending platforms that provide direct matching between investors and borrowers and split loans into payment-dependent notes. (Committee on the Global Financial System (CGFS) of Bank for International Settlements (BIS) provided the differences among P2P lending business models: some simply match lenders and borrowers, while others reflect the loans on their balance sheets [1].) P2P lending often targets borrowers with low- and mid-level credit ratings, a group facing a reduced supply of bank loans since the collapse of the subprime loan markets and the global financial crisis of 2008. P2P lending has also demonstrated its usefulness in financial inclusiveness and as a substitute for bank loans by expanding its range of credit offers to borrowers with low-credit ratings [2] as well as by providing more investment opportunities for small institutions and retail investors [3].

P2P lending has grown dramatically in size and scale over the past decade, drawing attention from both investors and regulatory agencies $[1,3]$. On the one hand, unclear regulations and policy guidelines have sometimes plagued these platforms, hindering the application of new and innovative information technologies that could reduce intermediation costs and improve user experiences. (For example, in 2015, the Financial Supervisory Service of Korea suspended operations of the P2P lending platform " 8 Percent" after concluding that the matching platform should be required to have the same certification as other financial institutions providing credit.) On the other hand, in terms of banking and financial stability, these regulations are reasonable. The lingering effects of the global financial crisis have become the "new normal," and, in reality, P2P lending platforms have at times failed to properly allocate credit. (In May 2016, the LendingClub, one of the best-known P2P 
lending platforms, was accused of providing USD 22 million in loans to underqualified borrowers. Afterwards then-CEO Renaud Laplache and three other directors resigned or were dismissed.)

Direct investments through P2P lending platforms have the following characteristics. First, the notes traded via FinTech platforms are often unsecured [4,5]. Second, P2P lending platforms often subdivide loans into a number of mini-bonds (or notes) and provide aftermarket trading functionality, both of which enhance liquidity. (In some credit markets, wherein raising funds through banks may be difficult, other funding methods are gaining in popularity, such as small-scale divisions of bonds or direct investments. In the UK, for example, small- and medium-sized enterprises use so-called mini-bonds as a means of marketing and financing. These enterprises issue bonds to their customers, who can choose discounted products rather than receiving interest payments [4].) For example, by paying a fee equal to $1 \%$ of the sales price, LendingClub investors can trade their dividend notes in the associated aftermarket (the Note Trading Platform) before they expire. Third, P2P lending platforms typically provide loans for borrowers with low- and mid-level credit ratings. This group has faced a credit gap, or a reduced supply of loans from banks, since the global financial crisis.

Despite its growing popularity, the effects of P2P lending on major bank risks have not been investigated thoroughly. (CGFS [1] provide an expository note about this issue.) Direct investments via P2P lending platforms are supposed to be duration-matched, and they cannot be liquidated until the maturity date. This means that P2P lending is designed not to create a short-term liquidity problem. (In practice, however, some P2P lending platforms adopt more complicated originate-to-distribute approaches. LendingClub is an example: After investors and borrowers are matched, the investment funds raised by LendingClub are transferred to the WebBank (located in Utah, US), which originates from the loan and returns it to LendingClub. LendingClub then divides the loan into "payment-dependent notes" by units of USD 25, and distributes them to investors, the proceeds of which fund specific loans to borrowers. The principal and interest are paid to the loan note holders. Note that, if LendingClub initiated the loan directly, without going through a bank or depository agency, the activity would be considered as an unauthorized shadow banking activity.) Further, notes (of split loans) invested and traded through P2P lending platforms are mainly unsecured bonds (i.e., with no collateral). This implies that the contagious effects of loan defaults would be limited. Still, P2P lending platforms make commissions on initial loan brokerages and exchanges of notes in the associated aftermarkets, while investors mostly bear the risks of borrowers' defaults. (In this sense, P2P lending has some features of an originate-to-distribute model [6]. Phillips [7] uses the features as a basis for criticism of P2P lending.) Thus, P2P lending platforms would be more focused on increasing fee revenues than on proper evaluations of creditworthiness, leading to an increase in the proportion of non-performing loans. To the extent that P2P lending and bank loans act more as substitutes than as complements, competition between banks and P2P lending platforms may hamper banking prudence, given the aforementioned incentives.

Considering these characteristics and the aforementioned gap in the literature, we theoretically analyzed the effects of P2P lending on two major bank risks: (in)solvency risk and (il)liquidity risk. The idea of separating banks' illiquidity and insolvency risks was first introduced by Bagehot [8], who argued that the market itself cannot fully address the problems of an interim liquidity shock. Some researchers have criticized this view e.g., [9], but recent studies such as by Rochet and Vives [10] and Freixas and Ma [11] have supported it. The Bank for International Settlements also supports this view, having introduced the liquidity coverage ratio (LCR) and the net stable funding ratio (NSFR) requirements in Basel III. (LCR requires that a bank should hold adequate stock of unencumbered high-quality liquid assets to meet its liquidity needs for a 30 calendar day liquidity stress scenario [12]. NSFR is defined as the amount of available stable funding relative to the amount of required stable funding. This ratio should be at least $100 \%$ on an ongoing basis [13].)

Finally, while we let P2P lending refer to general lending activities rather than financing with a specific purpose, we want to note the study by Petruzzelli et al. [14], who focus on the 
role of crowdfunding in supporting sustainability-oriented initiatives. They find that in terms of economic importance, P2P lending becomes the most relevant crowd-finance form, (Lending-based crowdfunding collected a global volume of funds about $\$ 25$ billion in 2015 [14].) implying that P2P lending should be an important issue in sustainable finance. The rest of the paper proceeds as follows. Section 2 presents the theoretical background and Section 3 describes the model. Section 4 analyzes the major bank risks-insolvency and liquidity risks-by comparing two cases: in the benchmark case, only banks exist, and in the other case, both banks and P2P platforms exist. Section 5 discusses the effects of competition on bank risks, and the importance of the isolation of P2P lending from the banking sector. Section 6 concludes the paper.

\section{Theoretical Background}

In this study, we compared two cases: (i) the benchmark, in which only banks exist in a single loan market, and (ii) the case wherein the loan market is segmented by borrowers' creditworthiness and P2P lending platforms operate only in the low-credit segment. Our results show that compared with the benchmark case, when P2P lending platforms and banks operate in the low-credit market the (i) insolvency risk of individual banks increases; (ii) illiquidity risk of individual banks decreases; (iii) banks' total credit risk—the sum of both risks-also decreases.

First, regarding insolvency risk, borrowers in the low-credit segment would choose higher-risk, higher-return projects because the interest rate applied to the low-credit market segment would be higher than that applied to the benchmark case, as in Boyd and De Nicolo [15]. As a result, the likelihood of borrowers' defaults on individual bank loans increases in the low-credit segment, leading to higher insolvency risk. Second, regarding illiquidity risk, the proportion of protected deposits in a bank's deposit portfolio would increase with loan market segmentation, as a result of banks substituting for P2P lending platforms. This would lower the level of critical cash flow that would prevent a bank run, resulting in a lower illiquidity risk. Third, in the segmented market case, a bank's combined credit risk is smaller than that in the benchmark case, implying that the decreased illiquidity risk would be great enough to cancel out the increased insolvency risk.

We further investigated the effect of competition and the implication of the separation of P2P lending and banking and find that competition is more likely to reduce the combined credit risk in the segmented market case than in the benchmark case. This result also implies that once banks begin to participate in P2P lending, either directly or indirectly, it would adversely affect the combined risk because it would lessen the competition in the segmented market case. Our results imply that sustainable P2P lending requires an appropriate separation of roles between banks and P2P lending platforms. If $\mathrm{P} 2 \mathrm{P}$ lending platforms and banks are differentiated in their roles for separate market segments, the spread of the former may not pose a significant problem in terms of bank risks. Regulatory agencies, however, would have to limit P2P lending platforms' brokerage of mini-bonds or notes outside their associated aftermarkets. At the same time, they may have to prevent banks or their subsidiaries from joining the trades of split notes in the aftermarkets of P2P lending platforms and let the banks focus on the high-credit market segments and protected deposits business.

Before the mid-2000s, studies on inter-bank competition focused on analyzing the impact of competition on financial stability [16-18]. Often, as competition increases, banks become more risk-seeking (See Carletti [19] for more details on previous studies on bank competition and financial stability). However, recent studies have suggested that this is not necessarily the case $[15,20,21]$. The U-shaped relationship between bank competition and bank failure has been confirmed by both theoretical [15] and empirical analyses [21]. These studies are traditional, homogeneous inter-bank competition analyses, and they do not involve financial institutions that do not follow the deposit-loan model.

More recent studies have investigated the coexistence of P2P lending platforms and banks. Thakor and Merton [22] suggested that banks have a stronger incentive to manage a trust, but P2P lending platforms tend to experience more adverse effects from a loss of trust. De Roure et al. [23] 
found that P2P lenders tend to be bottom fishers, P2P loans are riskier, and the risk-adjusted interest rates for P2P loans are lower than those for bank loans. Tang [24] found that P2P platforms are essentially substitutes for banks and mostly serve the same borrower population, despite their unique potential. Finally, Vallee and Zeng [25] and Balyuk [26] studied the informational role of P2P lending and its relationship with investors and banks, respectively.

A strand of the recent banking literature has adopted global games, which are games of incomplete information wherein each player obtains a private signal about the true state with a small amount of noise, and his/her higher-order beliefs also affect the outcome [27,28]. Goldstein and Pauzner [29] and Rochet and Vives [10] are two well-known global game-based bank run models. Goldstein and Pauzner [29] directly extend the Bryant-Diamond-Dybvig (BDD) model [30,31] by incorporating the actual interim liquidity needs of consumer-depositors. Our study is close to Rochet and Vives [10] and Freixas and Ma [11], who focus on depositors' speculative runs on unprotected bank deposits. Nevertheless, it is distinct because we extend the model to incorporate the situation wherein heterogeneous types of financial institutions co-exist in the market.

In addition to the finance literature, studies such as Cusumano [32], Einav et al. [33], and Sundararajan [34] emphasize the positive aspects of competition in platform economies, which open the chance of entry for small players and enhance efficiency. However, their focus is often the sharing of horizontally diversified, and sometimes idle, "physical" facilities. Due to this difference, there are limitations to applying the implications to the case of P2P lending in the current paper.

To the best of our knowledge, this study is one of the first works, if not the first, to implement a full theoretical analysis of the effects of the competition between P2P lending platform and banks on bank failure risks, specifically in the strand of microeconomic banking literature such as Rochet and Vives [10], Goldstein and Pauzner [29] and Freixas and Ma [11], which consider only homogeneous banks. This study also provides related policy implications that it is necessary for a regulatory authority to supervise the $\mathrm{P} 2 \mathrm{P}$ lending platforms separately from the existing banking sector to promote the sustainable development of alternative lending.

\section{Model}

We follow the basic settings and notations of Freixas and Ma [11], (Freixas and Ma [11] can also be regarded as an extension of the BDD model, which is the de facto standard model and the starting point in the microeconomics of banking.) with modifications, extensions, and clarifications where necessary.

\subsection{Players and Settings}

As per the standard Bryant-Diamond-Dybvig (BDD) model, we consider a one-good, three-period $(t=0,1,2)$ economy wherein all agents are assumed to be risk-neutral. There are two types of investors: depositors who deposit their liquidity in banks, and P2P lenders who lend directly to entrepreneurs (borrowers) via P2P lending platforms and hold these entrepreneurs' loan notes. Similar to the BDD model, depositors are assumed to be homogeneous. At $t=1$, the depositors decide whether to withdraw their deposits early, and the lenders trade notes amongst themselves in the accompanying aftermarket. When depositors withdraw their deposits early at $t=1$, they incur a penalty. (In Rochet and Vives [10], unprotected deposits are mostly wholesale deposits such as certificates of deposit, and early withdrawals stop the rolling over of these deposits.) However, unlike the BDD model, we do not consider any unanticipated consumption needs at $t=1$, which are likely to be covered by protected demand deposits such as checking accounts. We assume that depositors are interested only in the rates of return from their investments, as modeled in Rochet and Vives [10] for example, and that their decisions on the early withdrawal of their deposits solely depend on their speculation on the likelihood of realization of the promised return at $t=2$.

P2P lending platforms do not take deposits; they only match lenders and borrowers and earn fee revenue per match. Loans via P2P lending platforms are split into payment-dependent notes and can be 
traded in the accompanying aftermarkets at $t=1$, similar to that in the (incomplete) market example of Diamond and Dybvig [31]. We assume that trades of notes occur only between P2P lenders, limiting the effects of trades within P2P lending platforms and preventing the "hacking" of the market e.g., [35]. Moreover, we assume that banks cannot identify a borrower's type, default risk, or creditworthiness. However, we assume that P2P platforms, with their new technology, can correctly identify whether a borrower's type is higher or lower than a threshold.

Borrowers are entrepreneurs who are cashless but have long-term and productive, yet potentially risky, projects classified by their type $b \in(0, B]$, with a higher $b$ indicating the safer entrepreneur. Each entrepreneur's project requires a unit of the loan at $t=0$ which is to be paid back with the gross rate of return from the loan $r(>1)$, when the project is completed at $t=2$. There is a threshold type $\hat{B}$ such that $\hat{B}>1 /(x-r)$. Here, $x$ denotes the gross rate of return from an entrepreneur's successful project. Borrowers of $b<\hat{B}$ and $b \geq \hat{B}$ are classified as Group 1 and Group 2, respectively. We assume that there exists a difference in the maximum value of $r$ for Group 1 and for Group 2, respectively, which the borrowers in each group are willing to accept. Banks are supposed to be unable to identify which group a potential borrower belongs to. In contrast, P2P lending platforms, often considered to have more advanced technology, are supposed to correctly identify whether a borrower is in Group 1 or Group 2, although not the exact value of $b$, which creates the possibility of market segmentation.

A bank's portfolio of deposits at $t=0,1+F$, consists of the following: $F$ is the portion of demand deposit, given the amount of loan is normalized as one, in the benchmark case with banks only, and $F^{\prime}$ in the case of P2P lending platforms also operate. (For the remainder of the paper, we use the same approach using the apostrophe.) At $t=2$, the sum of the liquidity reserve and recouped loan with return $D$ (and $\left.D^{\prime}\right), F+D$ (and $F^{\prime}+D^{\prime}$ ), must be delivered to depositors if the bank is solvent where $D>1$ (and $D^{\prime}>1$ ). $F+D$ is the promised, but not all of it is necessarily protected. Note that, although not exactly the same, $F$ is related to the liquidity reserve; a higher value of $F$ implies that the proportion of savings deposits is lower. We assume that there is no equity in the bank's portfolio. For simplicity, we assume that if a bank fails at $t=2$, it returns nothing but $F$ (and $F^{\prime}$ ) to the depositors. As Diamond [36] noted, increased participation in direct financing causes the banking sector to shrink, primarily through the reduced holdings of long-term assets, implying the possibility of $F^{\prime}>F$. Finally, we assume that the size of deposits is less than the demand for loans, causing excess demand for loans.

A P2P lending platform does not have a depository function (i.e., $F=0$ ) and it only matches P2P lenders and borrowers. We assume that all P2P lenders are homogeneous: every P2P lender has an equal share of the loans given to all borrowers such that each P2P lender has the same homogeneous loan portfolio. We also assume that the (average) investment at $t=0$ is normalized as 1 . Thus, a P2P lender's ex-post gross rate of return at $t=2$ is the cash flow generated from successful loans. When banks and credit markets co-exist, we assume that no cross-participation-depositors' purchase of notes or lenders' purchase of loan claims-is allowed at $t=1$. Thus, any transaction that occurs in the secondary markets attached to P2P platforms does not affect the money market. Finally, we assume that all rates are exogenous unless specified.

\subsection{Timing of Game}

At $t=0$, loans are jointly financed by a continuum of investors. For simplicity, a P2P lender is homogeneous and assumed to hold split notes of all types of borrowers' loans, in the same way as (unprotected) deposits are diversified via bank.

At $t=1$, an investor, indexed by $i$, receives a private noisy signal $s_{i}=\theta+\epsilon_{i}$ about a random cashflow generated from the (unit) loan portfolio, denoted by $\theta$. Here, $\epsilon_{i}$ is i.i.d. and follows a probability distribution with zero mean and a small but non-zero standard deviation of $\sigma$. Each depositor who chooses to withdraw his/her deposit early will recover $q D(<D / R$ or $q<1 / R)$ by paying an early withdrawal penalty of $(1-q) D$ where $q \in(0,1)$ is the proportion of a deposit that one can recover from early withdrawal, given that the bank has not failed at $t=1$. Similarly, at $t=1$, 
lenders decide whether to sell or buy the diversified notes in the aftermarket. Both depositors' and P2P lenders' decisions at $t=1$ depend on their observations of private signals.

Provided an early withdrawal of savings deposit (or loan) is requested, the bank should liquidate its long-term financial claims with discount, which generates an expected cash flow of $\theta$ multiplied by the discount factor $\frac{1}{1+\lambda}$ where $\lambda$ is the discount rate. (This can be regarded as the haircut rate of the financial products in the money market. During the repo run in the last global financial crisis of 2007-2008, the average haircut on bilateral repo transactions, except for U.S. Treasuries, rose from zero in early 2007 to almost $50 \%$ at the peak of the crisis in late 2008 [37].) We assume $\frac{1}{1+\lambda} \leq q$, which means that a bank's early liquidation of long-term assets is costlier than a depositor's early liquidation of short-term assets or deposits. If the bank's ex-post cash flow at $t=2$ (i.e., which is the sum of the recovered loan and the value of its remaining assets) is less than the amount to be redeemed, bank failure occurs.

In case of lending via P2P lending platforms, the notes are assumed to be traded within the associated aftermarkets where lenders are randomly matched and trade their notes; if lender $i$ and $j$, whose signals satisfy $s_{i}>s_{j}$ without loss of generality, are matched, then $j$ sells her/his (portfolio of) notes to $i$ at $s_{j}$. (In fact, only a fraction of the notes and not the whole portfolio would be traded in the aftermarkets. This assumption helps to avoid theoretical problems with the measurement from abusing the law of large numbers. This setting also implies that no speculative trade in the sense of Harrison and Kreps [38] would occur.) Thus, the traded notes would be "discounted" proportional to the risk or standard deviation. (For example, if we assume that noise $\epsilon_{j}$ follows $N\left(0, \sigma^{2}\right)$, the amount of the discount can be approximated as $\sigma / \sqrt{3}$.) Note that based on our assumptions, which limit the effects of trades within associated P2P lending platforms, transactions in aftermarkets do not have any spillover effect in the banking sector.

At $t=2$, if the bank is solvent, it delivers the promised amount $F+D$ (and $F^{\prime}+D^{\prime}$ ), and $F$ (and $F^{\prime}$ ) otherwise. For investments via P2P lending platforms, the cash flow generated from loans (excluding non-performing loans) is recovered for an individual lender $i$.

\subsection{Borrowers' Type and Market Segmentation}

Although P2P lending platforms seek to maximize the number of matches between lenders and borrowers, we argue that P2P lending platform eventually match loans only for borrowers in Group 1, and segment the loan market, based on the empirical findings by De Roure et al. [23], Tang [24]. (In this study, we combined the finding from De Roure et al. [23] - P2P lenders tend to be bottom fishers and $\mathrm{P} 2 \mathrm{P}$ loans are riskier, with that from Tang [24] $\mathrm{P} 2 \mathrm{P}$ lending platforms are essential substitutes for banks, as a stylized fact for our setting. We also want to note that [39] observe a similar kind of vertical separation of the hospitality market after the entry of Airbnb. In a separate study, we investigated a condition for this type of endogenous market segmentation to occur. The key idea is that when the loan supply from banks fails to clear the loan demand due to external conditions (e.g., prudence regulation and credit rationing), the P2P lending platform can choose to either (i) compete in both market segments with a single rate, or (ii) let banks cover everyone in the high-credit market and capture the bigger excess loan demand as well as compete only in the low-credit market. In some cases, choosing the latter is better for P2P lending platforms.) Henceforth, we use Market 1 to denote the market segment for low-credit borrowers (Group 1) and Market 2 to denote high-credit borrowers (Group 2). When the loan market is segmented, the gross rate of return from a loan in Market 2, denoted by $r_{2}$, is supposed to be lower than that in Market 1 , denoted by $r_{1}$, namely $r_{1}>r_{2}$.

Similar to the early withdrawal of unprotected deposits, the P2P lending notes can be traded at $t=1$ with a discount proportional to the standard deviation of private signal $\sigma$. Because we assume that investors would not switch between banks and P2P platforms at $t=1$, (For example, without this assumption, depositors of unprotected bank deposits could withdraw early and purchase the notes at $t=1$.) trades in the aftermarkets do not have any influence on the banking sector. Table 1 summarizes the investment characteristics classified by institutional settings, timing, decision, and cash flows. 
Table 1. Timing, decision, and cash flows for different institutional settings.

\begin{tabular}{cccc}
\hline Investment (and Decision) & $\begin{array}{c}\text { Banks Only } \\
\text { (Single Market) }\end{array}$ & $\begin{array}{c}\text { Banks } \\
\text { (Segmented Market) }\end{array}$ & $\begin{array}{c}\text { P2P Platforms } \\
\text { (Low-Credit Segment) }\end{array}$ \\
\hline $\begin{array}{c}\text { Demand deposit } \\
\text { (protected, at } \mathrm{t}=0 \text { ) }\end{array}$ & $F$ & $F^{\prime}$ & 0 \\
\hline $\begin{array}{c}\text { Loan } \\
\text { (unprotected, at } \mathrm{t}=0 \text { ) }\end{array}$ & 1 & 1 & 1 \\
\hline $\begin{array}{c}\text { Investor's choice at } \mathrm{t}=1 \\
\text { Investor's return at } \mathrm{t}=2 \\
\text { (bank failure) }\end{array}$ & $\begin{array}{c}\text { Withdrawal(of } q D) \\
\text { or waiting }\end{array}$ & $\begin{array}{c}\left.\text { Withdrawal(of } q D^{\prime}\right) \\
\text { or waiting }\end{array}$ & $\begin{array}{c}\text { Trades (with discount) } \\
\text { between lenders }\end{array}$ \\
\hline $\begin{array}{c}\text { Investor's return at } \mathrm{t}=2 \\
\text { (bank solvency) }\end{array}$ & $F$ & $F^{\prime}$ & $\begin{array}{c}\text { Cash flow from } \\
\text { performing loans }\end{array}$ \\
\hline
\end{tabular}

\subsection{Cash Flow from Loans}

We adopt the result of the cash flow model by Freixas and Ma [11] which derives the probability of success according to the type of borrower $b$ as follows

$$
\operatorname{Pr}(b)=\left\{\begin{array}{lll}
1 & \text { if } & b \in[1 /(x-r), B] \\
b(x-r) & \text { if } & b \in(0,1 /(x-r)) .
\end{array}\right.
$$

Note that there exists a unique threshold type of entrepreneur that determines whether a loan is risk-free or risky. Assume that $b$ follows a uniform distribution $U(0, B]$ and that $B$ is sufficiently high so that loans would be riskless for a large proportion of borrowers. In the same loan market, (or market segment), banks and P2P lending platforms are assumed to treat borrowers equally. That is, differentiating the rate on loans for each type of borrowers is impossible. The ratio of risk-free to total loans is derived as

$$
\alpha \equiv(B-1 /(x-r)) / B=1-1 /(B(x-r)) .
$$

The greater the value of $\alpha$, the more secure is the loan portfolio.

Equation (2) is the first derivative of $\alpha$ with respect to $r$, represented as

$$
\partial \alpha / \partial r=-1 /\left(B(x-r)^{2}\right)<0,
$$

implying that as the exogenous gross rate of return on loan $r$ increases, the proportion of risk-free loans $\alpha$ decreases.

Let $\gamma$ be the ratio of non-performing loans to risky loans. From a unit loan provided to borrowers, the total cash flow generated referred to as $\theta$, can be expressed as

$$
\theta \equiv \alpha r+(1-r)[0 \cdot \gamma+r \cdot(1-\gamma)]=r-(1-\alpha) r \gamma .
$$

We assume that $\gamma$ follows a uniform distribution $U[0,1]$. (Freixas and Ma [11] show that $\gamma$ follows a uniform distribution between 0 and 1 if entrepreneurs know the exact value of $b$; moreover, $b$ follows a uniform distribution $(0, B]$; and their utility functions are a specific form of the quadratic function. However, we use the result as an exogenous condition due to the symmetric uninformedness of entrepreneur types in our model, and the negative, deterministic correlation between entrepreneur type and the gross rate of return from a project.) Then, the expected value of the ratio of the non-performing loan to the risky loan, $E(\gamma)$, is $1 / 2$. (Consequently, the volatility of the cash flow is determined only by the ratio of risk-free loans, $\alpha$.) and the expected gross rate of return from loans, which is also the expected gross rate of return from investment via P2P lending platforms, is $(1+\alpha) r / 2$. 
Finally, it should be noted that not all of the entrepreneurs would be able to get a loan from banks regardless of their types without P2P lending for the following reasons. First, the canonical credit rationing problem e.g., ref. [40] can occur: all type of borrowers want to get a loan with a given gross rate of return less than $r_{L}$, and some of them are even willing to pay higher rates, but the loan supply is less than the demand. Second, we have assumed that the amount of deposits is not sufficient to cover the entire demand for loans. Note that only one of these two constraints is binding.

\section{Comparison of Risks}

Following Rochet and Vives [10] and Freixas and Ma [11], we consider only speculative runs by depositors and treat (in)solvency risk and (il)liquidity risk separately. We first use the case wherein only banks exist as a benchmark and compare the result with that of the segmented market case with both banks and P2P lending platforms; furthermore, we investigate how individual risks and total credit risk change under different circumstances.

\subsection{Insolvency Risk}

\subsubsection{Benchmark: Only Banks Exist}

Insolvency occurs if the ex-post cash flow $\theta$ from the unit loan is smaller than the total amount of bank deposits $F+D$ that must be paid back at $t=2$. That is if inequality condition,

$$
\theta=r-(1-\alpha) r \gamma \geq F+D,
$$

is not satisfied, the bank can be considered as insolvent. From Equation (4), the critical level of the loan loss for determining solvency, $\gamma_{S R}$, is derived as

$$
\gamma_{S R}=(r-(F+D)) /((1-\alpha) r)
$$

Note that $\gamma$ follows a uniform distribution in $[0,1]$. The (in)solvency risk, or the probability that a bank faces the solvency problem, is denoted by $\rho_{S R}$ and derived as $\rho_{S R} \equiv 1-\gamma_{S R}$. By simple rearrangement in terms of the market gross rate of return from the loan, this is expressed as

$$
\rho_{S R} \equiv 1-\gamma_{S R}=(F+D-\alpha r) /(1-\alpha) r
$$

\subsubsection{Co-Existence of Banks and P2P Lending Platforms}

Now, we investigate the segmented market case of banks and P2P lending platforms co-existing in the low-credit market segment (Market 1) while only banks exist in the high-credit one (Market 2). Unlike a bank, a P2P lending platform itself does not face the problem of insolvency, as the lenders directly take on the default risk of their loans. The cash flow condition for the bank's soundness is now represented as

$$
\hat{\theta}=\frac{\beta \hat{B}}{B}\left[r_{1}-\left(1-\alpha_{1}\right) r_{1} \gamma\right]+\frac{B-\hat{B}}{B} r_{2} \geq F^{\prime}+D^{\prime}
$$

where $\beta$ is the share of applicants for whom banks provide a loan in Market 1, which satisfies

$$
\frac{r_{2}}{r_{1}}=\frac{B-\beta \hat{B}}{B-\hat{B}} \frac{1+\alpha_{1}}{2}
$$

such that the expected cash flows from both a unit loan via banks and via P2P lending are the same. Note that $\alpha_{1}=\left(\hat{B}-1 /\left(x-r_{1}\right)\right) / \hat{B}<\alpha$, and $\alpha_{2}=1$.

From Equation (7), in the segmented market case, the critical level of loan loss, denoted by $\hat{\gamma}_{S R}$, is derived as

$$
\hat{\gamma}_{S R}=\frac{\beta r_{1}+(B-\hat{B}) r_{2} / \hat{B}-B\left(F^{\prime}+D^{\prime}\right) / \hat{B}}{\beta\left(1-\alpha_{1}\right) r_{1}} .
$$


The change in the bank's profit from the benchmark is represented by

$$
\delta(r-(F+D))=\hat{r}-\left(F^{\prime}+D^{\prime}\right)
$$

where $\hat{r}=\frac{\hat{B}}{B} \beta r_{1}+\frac{(B-\hat{B})}{B} r_{2}$, which is supposed to be less than $r$ due to competition, represents the bank's gross rate of return, or revenue, on unit loan from both market segments, and $\delta(<1)$ reflects the decrease in the bank's loan-deposit margin compared with the benchmark case. Given the assumptions and Equation (8), the following inequality

$$
\hat{\gamma}_{S R}=\frac{\delta(r-(F+D))}{\hat{B} / B\left(1-\alpha_{1}\right) \beta r_{1}}=\frac{B \delta r(1-\alpha)}{\hat{B} \beta r_{1}\left(1-\alpha_{1}\right)} \gamma_{S R}=\frac{\delta r\left(x-r_{1}\right)}{\beta r_{1}(x-r)} \gamma_{S R}<\gamma_{S R}
$$

is sufficiently satisfied if $\beta$ is not sufficiently smaller than $\delta$, implying that the impact of P2P lending on banks' profit reduction is greater than that on their market share in the low-credit segment.

To facilitate comparison with the benchmark results, suppose that $F+D=F^{\prime}+D^{\prime}=R$, which means that the future value of the normalized deposit portfolio in the benchmark case and that in the segmented market case are the same. Note that, in this case, the amount of the protected bank deposit, denoted by $F^{\prime}$, is greater than that in the benchmark case (i.e., $F^{\prime}>F$ ) due to the lower rate of return on loan and, consequently, savings deposits. Then, from $\hat{r}-\left(F^{\prime}+D^{\prime}\right)<r-(F+D)+\hat{B}(\beta-1) r_{1} / B$, Equation (9) leads to the following inequality

$$
(1-\delta)(r-(F+D))>(1-\beta) r_{1} \hat{B} / B .
$$

Given that $\hat{B} r_{1} / B>1 / 2$, and $r-(F+D)$, which is the loan-deposit spread, would not be greater than $1 / 2$ in any reasonable case, $1-\delta$ must be greater than $1-\beta$, or $\beta>\delta$. Thus, given that $F+D=F^{\prime}+D^{\prime}=R$, the insolvency risk of a bank, $\hat{\rho}_{S R}=1-\hat{\gamma}_{S R}$, is greater than that in the benchmark, $\rho_{S R}$, which leads to the following proposition.

Proposition 1. When a loan market is segmented by borrowers' capability and when P2P lending platforms and banks operate simultaneously in the low-credit segment, an individual bank's insolvency risk is greater than that in the benchmark case.

\subsection{Liquidity Risk}

\subsubsection{Benchmark: Only Banks Exist}

We now examine the case of bank failure due to insufficient liquidity caused by depositors' early withdrawal. This situation can occur when a bank is forced to liquidate its long-term assets due to the early withdrawal of many depositors at $t=1$, even though in the absence of early withdrawals, the bank would not face a soundness problem and it could repay the debt sufficiently at $t=2$.

Let $q$ be the proportion of a deposit that one can recover from early withdrawal at $t=1$, and let $\lambda$, satisfying $1 /(1+\lambda)<q$ as assumed above, be the discount rate applied to a bank's (long-term) loan sold at $t=1$, which would generate cash flow $\theta$ without the early withdrawal request. The condition that the liquidity problem never occurs at $t=1$ is expressed as

$$
\theta /(1+\lambda)>q D,
$$

implying that the present value of cash flow $\theta$ discounted by $1+\lambda$ is greater than the highest possible recovered amount in early withdrawal. 
Let $L$ be the ratio of depositors who take early withdrawals, or run, at $t=1$. In this case, the level of $L$ at which the bank can survive at $t=1$ but experiences failure at $t=2$ is determined by the following inequality

$$
(1-L) D>\theta-F-L(1+\lambda) q D .
$$

The liquidity risk arises when the deposit to be returned at $t=2$ is greater than the remaining liquidity from the cash flow $\theta$, deducted by the protected deposit $F$, and by the liquidity that has flowed out due to early withdrawal at $t=1, L(1+\lambda) q D$. The probability of each depositor's belief that a bank will not fail at $t=2$ due to illiquidity is the probability that $L$ does not satisfy Equation (10), which is

$$
\operatorname{Pr}\left(L \leq \frac{\theta-F-D}{[(1+\lambda) q-1] D}=L^{*}\right) .
$$

Whether a depositor $i$ chooses to withdraw early at $t=1$ or not is influenced by his/her private signal, $s_{i}=\theta+\epsilon_{i}$, and his/her forecasts about other depositors' behavior, which are reflected by $L$. Note that depositor $i^{\prime}$ s strategy is influenced by other depositors' belief on $L$ upon observing his/her private signal $s_{i}$. Then, ultimately, this depositor must consider the belief on other depositors' beliefs, which violates the common knowledge assumption and corresponds with the setting of a global game [28].

Following convention, we first apply the Laplacian property [28] to our setting: any investor $i$ 's belief about the ratio of early withdrawal $L$ follows $U[0,1]$. Depositors are supposed to use the switching strategy, which is proven to be optimal if the Laplacian Property is satisfied [28]. If depositor $i$ chooses a switching strategy, he/she chooses either to run if the signal is below a certain threshold level or to wait until maturity.

The threshold level of the cash flow for an early withdrawal decision, referred to as $s^{*}$, is determined when the expected value of the early withdrawal at $t=1$ equals that of the maturity withdrawal at $t=2$, or

$$
q D=\operatorname{Pr}\left(\text { survive at } t=2 \mid s=s^{*}\right) \cdot D,
$$

given that $\operatorname{Pr}\left(\right.$ survive at $\left.t=1 \mid s=s^{*}\right)=1$, or $\alpha r>(1+\lambda) q D$. Given that the Laplacian Property is satisfied, in a Perfect Bayesian Equilibrium, the likelihood of other investors' decision to run would behave like a random variable drawn from the uniform distribution of $U[0,1]$. (Moving away from the switching point, this belief may not actually be uniform. However, according to Morris and Shin [28], as long as the payoff advantage of running on the bank is decreasing in $\theta$, the Laplacian action coincides with the equilibrium action.) From the Equation (11), we can infer that

$$
\operatorname{Pr}\left(\text { survive at } t=2 \mid s=s^{*}\right)=\operatorname{Pr}\left(L \leq L^{*}\right)=(\theta-F-D) /([(1+\lambda) q-1] D)
$$

as $L$ follows $U[0,1]$. Note that the probability of solvency at $t=2$ is continuous. Thus, the expected payoff from waiting is also continuous and monotone decreasing in $L$, and thus, monotone increasing in $\theta$. The threshold cash flow level $\theta^{*}$, under which a bank run may occur, is derived as

$$
\theta^{*}=F+D+q[(1+\lambda) q-1] D
$$

Note that $s^{*}$ is uniquely determined, $s^{*}=\theta^{*}$. Let $\underline{\theta}=F+D$, and $\bar{\theta}=F+(1+\lambda) q D$, which satisfy $\underline{\theta}<\theta^{*}<\bar{\theta}$. Then, a depositor has to run for any $L \in[0,1]$ if $\theta<\underline{\theta}$ and wait if $\theta>\bar{\theta}$, which means that the limit dominance property [28] is satisfied. Thus, we can conclude that our setting of the global game satisfies all the required properties in Proposition 2.1 of Morris and Shin [28] for the existence of a unique switching strategy $s^{*}=\theta^{*}$. (While not incorrect, the explanation of the global game model in Freixas and Ma [11] uses the setting of Carlsson and Van Damme [27], where the state variable is an unbounded real number (i.e., $\theta \in \mathbf{R}$ ) and neither upper nor lower dominance exists.) 
Let $\mu=1+q[(1+\lambda) q-1]>1$ for simplicity of notation. If the bank becomes illiquid, despite it being solvent at $t=2$, and a run on the bank would occur, the range of cash flow would be

$$
F+D<\theta \leq F+\mu D
$$

Similar to $\rho_{S R}$, we can define the probability of (il)liquidity risk, $\rho_{L R}$, as

$$
\rho_{L R}=\frac{(\mu-1) D}{(1-\alpha) r}
$$

The total credit risk of a bank, $\rho_{T R}=\operatorname{Pr}\left(\theta<\theta^{*}\right)$, is the sum of the insolvency risk $\rho_{S R}$ and the illiquidity risk $\rho_{L R}$, which is derived as

$$
\rho_{T R}=\frac{(F+\mu D)-\alpha r}{(1-\alpha) r}
$$

\subsubsection{Co-Existence of Banks and P2P Lending Platforms}

Again, we investigate the segmented market case, in which P2P lending platforms enter and operate in the low-credit market segment (Market 1). Considering that loans in the high-credit segment (Market 2) are supposed to be riskless and early withdrawal is not likely to occur, we focus only on Market 1.

Note that the trades of notes in the associated aftermarket at $t=1$ do not influence depositors outside P2P lending platforms. Then, we can adapt Equation (10), which describes the condition for the illiquidity problem for an otherwise solvent bank, for the segmented market case as

$$
(\hat{B} / B)(1-L) D^{\prime} \geq \hat{\theta}-F^{\prime}-L(\hat{B} / B)(1+\lambda) q D^{\prime} .
$$

The threshold cash flow that makes early withdrawal and waiting indifferent without actual insolvency, $\hat{\theta}^{*}$, is then derived as

$$
\hat{\theta}^{*}=F^{\prime}+(\hat{B} / B)(1+q[(1+\lambda) q-1]) D^{\prime}=F^{\prime}+\mu(\hat{B} / B) D^{\prime}
$$

Given the assumptions, we find that the cash flow threshold level $\hat{\theta}^{*}$ is lower than $\theta^{*}$, derived from the benchmark case. The liquidity risk in the segmented market case is derived as

$$
\hat{\rho}_{L R}=\frac{F^{\prime}+\mu(\hat{B} / B) D^{\prime}-\left(F^{\prime}+D^{\prime}\right)}{(\hat{B} / B)\left(1-\alpha_{1}\right) r_{1}}=\frac{(\mu-(B / \hat{B})) D^{\prime}}{\left(1-\alpha_{1}\right) r_{1}}
$$

In the worst case, the cash flow would be generated only from risk-free loans. Given that $B>\hat{B}$, $D^{\prime}<D, \alpha_{1}<\alpha$, and $r<r_{1}$, we derive the following proposition.

Proposition 2. The probability of a bank's (il)liquidity risk is lower when the market is segmented by borrower types and banks compete with P2P platforms than that in the benchmark case, or when $\hat{\rho}_{L R}<\rho_{L R}$.

As in the benchmark case, the total credit risk of a bank in the segmented market case, $\hat{\rho}_{T R}=\operatorname{Pr}\left(\hat{\theta}<\hat{\theta}^{*}\right)$, the sum of the insolvency risk, $\hat{\rho}_{S R}$, and the illiquidity risk, $\hat{\rho}_{L R}$, is derived as

$$
\begin{aligned}
\hat{\rho}_{T R} & =\hat{\rho}_{S R}+\hat{\rho}_{L R}=1-\frac{\delta B(r-(F+D))}{\beta \hat{B}\left(1-\alpha_{1}\right) r_{1}}+\frac{(\mu-(B / \hat{B})) D^{\prime}}{\left(1-\alpha_{1}\right) r_{1}} \\
& <1-\frac{B\left(r-\left(F^{\prime}+D^{\prime}\right)\right)}{\hat{B}\left(1-\alpha_{1}\right) r_{1}}+\frac{(\mu-1) D^{\prime}}{\left(1-\alpha_{1}\right) r_{1}}=\frac{\left(1-\alpha_{1}\right) r_{1}}{\left(1-\alpha_{1}\right) r_{1}}-\frac{B\left(r-\left(F^{\prime}+D^{\prime}\right)\right)}{\hat{B}\left(1-\alpha_{1}\right) r_{1}}+\frac{(\mu-1) D^{\prime}}{\left(1-\alpha_{1}\right) r_{1}},
\end{aligned}
$$


by assuming $\beta>\delta$. The right-hand side of Equation (17) is less than $\rho_{T R}=(F+\mu D-\alpha r) /((1-\alpha) r)$ if the inequality

$$
\frac{\hat{B}}{B}\left(1-\alpha_{1}\right) r_{1}+F^{\prime}+D^{\prime}-r+\frac{\hat{B}}{B}(\mu-1) D^{\prime}<\frac{r_{1}(x-r)}{r\left(x-r_{1}\right)}(F+\mu D-\alpha r)
$$

is satisfied, which can be rewritten as

$$
\frac{r_{1}}{B\left(x-r_{1}\right)}+F^{\prime}+D^{\prime}-r+\frac{\hat{B}}{B}(\mu-1) D^{\prime}<\frac{r_{1}(x-r)}{r\left(x-r_{1}\right)}(F+D-r+(\mu-1) D)+\frac{r_{1}}{\hat{B}\left(x-r_{1}\right)}
$$

Given $A 3, D^{\prime}<D$ and $\hat{B}<B$, we can conclude that the inequality condition of Equation (18) is always satisfied, which leads to Proposition 3

Proposition 3. Given the assumptions, the total credit risk of a bank is lower when the loan market is segmented by borrower types and P2P lending platforms operate in the low-credit market segment than that in the benchmark case.

The insolvency risk rises when the loan market is segmented by credit ratings because banks as well as P2P lending platforms charge higher interest rates in the low-credit segment than they would in the benchmark case, which leads borrowers to choose high-risk, high-return projects, as in Boyd and De Nicolo [15]. In contrast, the decrease in illiquidity risk occurs because the ratio of protected deposits in a bank's portfolio would be higher in the segmented market case. Then, the effect of lowering the cash flow threshold that would trigger a bank run would dominate the effect from the increase in the ratio of risky loans in the low-credit market segment. Note that our model is mainly designed for analyzing the risks of individual institutions; it is not suitable for contagion or systemic risk. Still, our result implies that expecting a minimal impact from P2P lending on contagion and systemic risk in the banking sector is not overstretching. (Freixas and Ma [11] used the same global game approach for the analysis of system risk with strong assumptions about the contagion; it is a simultaneous, non-sequential event that affects only the discount rate.)

Note that our results are mainly derived from the assumptions that (i) P2P lending platforms operate only in the segmented market for borrowers with low-credit ratings while banks operate in both the low- and high-credit market segments; (ii) lending is direct and loans are treated as split notes (non-secured mini-bonds); (iii) only lenders can trade split notes in the associated aftermarket.

\section{Extension}

\subsection{Competition Effects}

Two common effects of competition on the soundness of banks are (i) the risk-shifting effect, which is the result of lower risk-seeking tendencies among borrowers as loan rates decline with intensified competition, and (ii) the buffer-reduction effect, which is the lowered capacity of banks to absorb loan loss as loan-deposit margins decline with intensified competition and deteriorating profitability. The effect of competition on the soundness of banks mainly depends on which effect dominates. As the benchmark for this discussion, we again adopt the results of Freixas and Ma [11], which we summarize as follows.

Considering that the risk-free loan ratio $\alpha$ is also a function of the gross rate of return from a loan $r$, the first derivative of the benchmark insolvency risk $\rho_{S R}$ is as follows:

$$
\frac{\partial \rho_{S R}}{\partial r}=\frac{-1}{(1-\alpha)^{2} r^{2}} \frac{\partial \alpha}{\partial r}\left(r^{2}-x(F+D)\right)
$$


Equation (2) shows that $\alpha$ is monotonically decreasing in $r$. Thus, the insolvency risk $\rho_{S R}$ increase in $r$, or declines as the competition intensifies, only when $r^{2}-x(F+D)>0$, which is a necessary and sufficient condition. In other words, given that all other conditions remain the same, competition in the loan market initially reduces banks' rates of return on loans and contributes to the reduction of insolvency risk. However, once the rate falls below a threshold (or $r^{2}-x(F+D)<0$ ), it leads to decreased buffering capital and increased insolvency risk. The first derivative of the illiquidity risk $\rho_{L R}$ with respect to $r$ in the benchmark case is as follows:

$$
\frac{\partial \rho_{L R}}{\partial r}=(\mu-1) \frac{-D}{(1-\alpha)^{2} r^{2}}\left(\frac{\partial(1-\alpha)}{\partial r} r+(1-\alpha)\right)<0 .
$$

As competition intensifies, the rate of return on loan $r$ decreases and, consequently, the illiquidity risk increases.

Finally, from Equation (14), we conclude that the total credit risk $\rho_{T R}$ increases with respect to $r$ if and only if $r^{2}-x(F+\mu D)>0$. In other words, under the threshold level, $\tilde{r}=\sqrt{x(F+\mu D)}$, the risk-shifting effect no longer dominates the buffer reduction effect, or competition causes the total credit risk to be higher.

Now, we examine the segmented market case. Suppose the rate of return on a loan in Market 2, $r_{2}$, is fixed, and we focus on the rate of return on a loan in Market $1, r_{1}$, and the competition effects in the low-credit market segment between banks and P2P lending platforms. Equation (8) implies that $\hat{\gamma}_{S R}$ monotone decreases in $r_{1}$ in a way that is similar to the benchmark case. That is, the insolvency risk of a bank, $\hat{\rho}_{S R}=1-\hat{\gamma}_{S R}$, decreases, and competition reduces the insolvency risk until $r_{1}$ reaches the threshold level. However, the risk then increases if the interest rate further decreases below the threshold level. From Equation (16), we conclude that competition in Market 1 reduces the illiquidity risk of a bank.

The effect on a bank's total credit risk is similar to that observed in the benchmark case. Instead of the exact threshold rate of return from a loan, we use the approximation derived from Equation (18) to determine the threshold level as

$$
r_{1}^{2}>x_{1}\left(F^{\prime}+(1+\hat{B} / B(\mu-1)) D^{\prime}\right) .
$$

Given that $x_{1}>x$, and $F^{\prime}+(1+\hat{B} / B(\mu-1)) D^{\prime}<F+\mu D$, whether the threshold value of $r_{1}$, $\tilde{r_{1}}=\sqrt{x_{1}\left(F^{\prime}+(1+\hat{B} / B(\mu-1)) D^{\prime}\right)}$, is greater or not than that of the benchmark case $\tilde{r}$ depends on the values of these variables.

Proposition 4 shows that the threshold rate of return on a loan in Market 1 is likely to be lower than that in the benchmark case. That is, the risk-shifting effect-the upside-is likely to dominate the buffer-reduction effect - the downside-for a lower level of threshold rate in the segmented market case than in the benchmark case.

Proposition 4. Given $F+D=F^{\prime}+D^{\prime}$, the threshold rate of Market 1 in the segmented market case, $\tilde{r_{1}}$, is lower than $\tilde{r}$, the threshold rate in the benchmark case (i.e., $\tilde{r_{1}}<\tilde{r}$ ).

Proof. We want to show that $x_{1}\left(F^{\prime}+(1+\hat{B} / B(\mu-1)) D^{\prime}\right)<x(F+\mu D)$. Given that $x_{1} \approx x$, we can rewrite the inequality as

$$
F^{\prime}-F^{\prime}=D-D^{\prime}<\mu D-D^{\prime}-\hat{B}(\mu-1) D^{\prime} / B,
$$

which leads to

$$
\hat{B}(\mu-1) D^{\prime} / B<(\mu-1) D .
$$

As $\hat{B} / B<1$ and $D^{\prime}<D$, we conclude that the inequality holds true. 
Proposition 4 also implies that competition is more likely to reduce the combined credit risk in the segmented market case than in the benchmark case.

\subsection{Implication for the Separation of P2P Lending and Banking}

So far in our analysis, we have strictly limited bank participation in P2P lending and assumed that only individual lenders can buy split notes and trade them in an associated aftermarket. Given the stringent regulations that prohibit shadow banking that includes P2P lending, it is doubtful that P2P lending platforms would be allowed to take deposits or mediate loans for borrowers with high credit ratings. In contrast, banks could use their subsidiaries and invest in and/or trade payment-dependent notes via P2P lending platforms, (For example, as stated in Vallee and Zeng [25], financial institutions like banks could combine their information with that of P2P lending platforms and use this higher-quality information to purchase split notes) or they could even operate their own P2P lending platforms.

Once banks begin purchasing split notes via P2P lending platforms, they would replace the "loans" that the banks would otherwise provide. These could also be used as another source of interim liquidity in the aftermarket, which would be less conspicuous to monitoring authorities than the money market. From the analysis of competition effects in the previous subsection, however, we expect that reduced competition in the low-credit market segment, along with the lax separation of P2P lending and banking, would lead to a higher rate of return on loan $r_{1}$. It would also increase an individual bank's liquidity and total credit risk.

Another possibility is the banks' direct participation in P2P lending. From the perspective (and within the limitations) of our model, unlike banks purchasing split notes via P2P lending platforms, competition in the low-credit market segment (Market 1) would not decrease, although banks would now hold more payment-dependent split notes. If banks choose to buy more notes in the aftermarket after observing their private signals, their liquidity reserves would decrease, which would lead to a higher rate of the haircut in the money market, as suggested by the higher discount rate $\lambda$. If a bank chooses to sell more notes in the aftermarket, the sales themselves would decrease the expected value of the split notes. This would be bad news for the bank, which could, in turn, lead to an increase in the probability of a run on an otherwise solvent bank. In all, allowing banks to participate in P2P lending would counter the purpose of Basel III, which requires stronger prudential regulation of bank liquidity.

\section{Concluding Remarks}

Since the global financial crisis of 2007-2008, direct finance via P2P lending has emerged and rapidly grown as a new vehicle for borrowers without high credit ratings, especially among households and small- and mid-sized enterprises. The growth of P2P lending may have two countervailing effects on banking. One is that banks are less exposed to risky loans and interim liquidity needs, which tend to be better served by P2P lending platforms and their associated aftermarkets. The other is that banks must compete against P2P lending platforms, reducing the liquidity buffers that they need to maintain solvency.

In this study, we investigated the effects of P2P lending on major bank risks: (in)solvency risk and (il)liquidity risk. Specifically, considering the characteristics of direct investments through P2P lending platforms, we compared two cases: (i) the benchmark case, in which only banks exist in a single loan market, and (ii) a segmented market case in which the loan market is segmented by borrowers' creditworthiness, P2P lending platforms operate only in the low-credit segment, and banks operate in both low-and high-credit segments. For the segmented market case, as compared with the benchmark one, we find that while banks' insolvency risk increases, their illiquidity risk decreases such that their overall risk also decreases.

We also find that competition between banks and P2P lending platforms is more likely to reduce the combined credit risk, the sum of (in)solvency, and (il)liquidity risks, in the segmented market case 
than in the benchmark one. This result implies that once banks begin to participate in P2P lending either directly or indirectly, it would create an adverse effect on the combined risk because it would lessen the competition in the segmented market case. In all, sustainable P2P lending requires an appropriate differentiation of roles between the banking sector and P2P lending so that P2P lending platforms focus more on borrowers with low-credit ratings, while banks focus more on the high-credit market segment and protected deposits.

To the best of our knowledge, this study is one of the first works, if not the first, to implement a full theoretical analysis of the effects of the competition between P2P lending platform and banks on bank failure risks, specifically in the strand of microeconomic banking literature such as Rochet and Vives [10], Freixas and Ma [11], Goldstein and Pauzner [29].

Note that our results are valid only if $\mathrm{P} 2 \mathrm{P}$ lending platforms adhere to more primitive, direct forms of financing (e.g., issuing and circulating payment-dependent notes), without handling shadow deposits, derivatives or secured loans. If these platforms expand their business scope and develop more highly leveraged or complex products strongly linked to and affected by other markets and tradings, the implications of the results would be investigated. This is because our assumption that the effects of aftermarket trades of notes stay within the scope of P2P lending platforms would be no longer valid. Finally, we do not fully examine the strategic behaviors of P2P lending platforms in this study. Apart from filling this gap, future studies can (i) empirically investigate how P2P lending platforms affect bank risks under different regulatory frameworks in different economies, and (ii) explore how the role of P2P lending platforms differs from that of banks in advanced economies.

Author Contributions: For this research article, contributing roles are as follows: Conceptualization, E.Y. and J.J.; formal analysis, E.Y. and J.J.; funding acquisition, E.Y.; investigation, J.J.; methodology, J.J.; project administration, E.Y.; writing — original draft, J.J.; writing - review and editing, E.Y. All authors have read and agreed to the published version of the manuscript.

Funding: This research was funded by the Financial Stability Division of Bank of Korea, National Research Foundation of Korea funded by the Ministry of Education (NRF-2018S1A5A2A01035483), and Fulbright Mid-Career Researcher Scholarship.

Acknowledgments: We thank Inho Lee, Takeshi Nakata and, specifically, Yun Woo Park for helpful comments and suggestions.

Conflicts of Interest: The authors declare no conflict of interest. The funders had no role in the design of the study; in the collection, analyses, or interpretation of data; in the writing of the manuscript, or in the decision to publish the results.

\section{Abbreviations}

The following abbreviations are used in this manuscript:

P2P Peer-to-Peer

BDD Bryant-Diamond-Dybvig

\section{References}

1. CGFS. FinTech credit: Market structure, business models and financial stability implications. In Committee on the Global Financial System Report; Bank for International Settlements and Financial Stability Board. 2017. Available online: https:/ / www.bis.org/publ/cgfs_fsb1.htm (accessed on 29 July 2017)

2. Bord, V. M.; Santos, J. A. The Rise of the Originate-to-Distribute Model and the Role of Banks in Financial Intermediation. In Federal Reserve Bank of New York Economic Policy Review; Federal Reserve Bank of New York: New York, NY, USA, 2012; pp. 21-34.

3. Buchak, G.; Matvos, G.; Piskorski, T.; Seru, A. Fintech, regulatory arbitrage, and the rise of shadow banks. Natl. Bureau Econ. Res. 2017, 130, 453-483.

4. Menon, N. Mini-Bonds-So Good Things Come in Small Packates? ReedSmith LLP. 2015. Available online: http:/ / www.structuredfinanceinbrief.com/2015/05/mini-bonds-so-good-things-come-in-smallpackages/ (accessed on 29 July 2017). 
5. Musatov, A.; Perez, M. Shadow banking reemerges, posing challenges to banks and regulators. Econ. Lett. 2016, 11, 1-4.

6. Purnanandam, A. Originate-to-distribute model and the subprime mortgage crisis. Rev. Financ. Stud. 2010, 24, 1881-1915. [CrossRef]

7. Phillips, M. The Incentive Problem at the Heart of Peer-to-Peer Lending. Quartz. 2014. Available online: https:/ / qz.com/310682/the-incentive-problem-at-the-heart-of-peer-to-peer-lending/ (accessed on 29 July 2017).

8. Bagehot, W. Lombard Street: A Description of the Money Market; Scribner, Armstrong \& Company: New York, NY, USA, 1873.

9. Goodfriend, M.; King, R.G. Financial Deregulation, Monetary Policy, and Central Banking; Working paper 88-1; Federal Reserve Bank of Richmond: Richmond, VA, USA, 1988.

10. Rochet, J.C.; Vives, X. Coordination failures and the lender of last resort: Was Bagehot right after all? J. Eur. Econ. Assoc. 2004, 2, 1116-1147. [CrossRef]

11. Freixas, X.; Ma, K. Banking Competition and Stability: The Role of Leverage. Discussion Paper Series no. 2014-048, CentER. 2014. Available online: https://papers.ssrn.com/sol3 / papers.cfm?abstract_id=2488426 (accessed on 29 July 2017).

12. BCBS. Basel III: The Liquidity Coverage Ratio and liquidity risk monitoring tools. Basel Committee on Banking Supervision, Bank for International Settlements. 2013. Available online: https://www.bis.org/ publ/bcbs238.pdf (accessed on 29 July 2017).

13. BCBS. Basel III: The Net Stable Funding Ratio. Basel Committee on Banking Supervision, Bank for International Settlements. 2014. Available online: https://www.bis.org/bcbs/publ/d295.pdf (accessed on 29 July 2017).

14. Petruzzelli, A.M.; Natalicchio, A.; Panniello, U.; Roma, P. Understanding the crowdfunding phenomenon and its implications for sustainability. Technol. Forecast. Soc. Chang. 2019, 141, 138-148. [CrossRef]

15. Boyd, J.H.; De Nicolo, G. The theory of bank risk taking and competition revisited. J. Financ. 2005, 60, 1329-1343. [CrossRef]

16. Besanko, D.; Thakor, A.V. Collateral and Rationing: Sorting Equilibria in Monopolistic and Competitive Credit Markets. Int. Econ. Rev. 1987, 28, 671-689. [CrossRef]

17. Keeley, M.C. Deposit insurance, risk, and market power in banking. Am. Econ. Rev. 1990, 80, 1183-1200.

18. Edwards, F.R.; Mishkin, F.S. The Decline of Traditional Banking: Implications for Financial Stability and Regulatory Policy. NBER Working Paper no. 4993, National Bureau of Economic Research. 1995. Available online: http:/ / www.nber.org/papers/w4993 (accessed on 29 July 2017).

19. Carletti, E. Competition and regulation in banking. Handb. Financ. Intermediation Bank. 2008, 126, 449-482.

20. Allen, F.; Gale, D. Competition and Financial Stability. J. Money Credit Bank. 2004, 36, 453-480. [CrossRef]

21. Martinez-Miera, D.; Repullo, R. Does competition reduce the risk of bank failure? Rev. Financ. Stud. 2010, 23, 3638-3664. [CrossRef]

22. Thakor, R.T.; Merton, R.C. Trust in Lending; NBER Working Paper no.24778; National Bureau of Economic Research: Cambridge, MA, USA, 2018. Available online: http://www.nber.org/papers/w24778 (accessed on 29 July 2020).

23. De Roure, C.; Pelizzon, L.; Thakor, A.V. P2P Lenders Versus Banks: Cream Skimming or Bottom Fishing? SAFE Working Paper No. 206; Goethe University Frankfurt, SAFE-Sustainable Architecture for Finance in Europe: Frankfurt, Germany, 2019.

24. Tang, H. Peer-to-peer lenders versus banks: Substitutes or complements? Rev. Financ. Stud. 2019, 32, 1900-1938. [CrossRef]

25. Vallee, B.; Zeng, Y. Marketplace lending: A new banking paradigm? Rev. Financ. Stud. 2019, 32, 1939-1982. [CrossRef]

26. Balyuk, T. Financial Innovation and Borrowers: Evidence from Peer-to-Peer Lending; Working Paper 2802220; Rotman School of Management: Toronto, ON, Canada, 2018.

27. Carlsson, H.; Van Damme, E. Global games and equilibrium selection. Econometrica 1993, 61, 989-1018. [CrossRef]

28. Morris, S.; Shin, H.S. Global Games: Theory and Applications. Discussion Paper, no.1275r, Cowles Foundation. 2001. Available online: https://papers.ssrn.com/sol3/papers.cfm?abstract_id=284813 (accessed on 29 July 2017). 
29. Goldstein, I.; Pauzner, A. Demand-deposit contracts and the probability of bank runs. J. Financ. 2005, 60, 1293-1327. [CrossRef]

30. Bryant, J. A model of reserves, bank runs, and deposit insurance. J. Bank. Financ. 1980, 4, 335-344. [CrossRef]

31. Diamond, D.W.; Dybvig, P.H. Bank runs, deposit insurance, and liquidity. J. Political Econ. 1983, 91, 401-419. [CrossRef]

32. Cusumano, M.A. How traditional firms must compete in the sharing economy. Commun. ACM 2014, 58, 32-34. [CrossRef]

33. Einav, L.; Farronato, C.; Levin, J. Peer-to-peer markets. Annu. Rev. Econ. 2016, 8, 615-635. [CrossRef]

34. Sundararajan, A. The Sharing Economy: The End of Employment and the Rise of Crowd-Based Capitalism; MIT Press: Cambridge, MA, USA, 2016.

35. Jacklin, C.J. Demand deposits, trading restrictions, and risk sharing. Contract. Arrange. Intertemporal Trade $1987,1,26-47$.

36. Diamond, D.W. Liquidity, banks, and markets. J. Political Econ. 1997, 105, 928-956. [CrossRef]

37. Gorton, G.; Metrick, A. Securitized Banking and the Run on Repo. J. Financ. Econ. 2012, 104, 425-451. [CrossRef]

38. Harrison, J.M.; Kreps, D.M. Speculative investor behavior in a stock market with heterogeneous expectations. Q. J. Econ. 1978, 92, 323-336. [CrossRef]

39. Roma, P.; Panniello, U.; Nigro, G.L. Sharing economy and incumbents' pricing strategy: The impact of Airbnb on the hospitality industry. Int. J. Prod. Econ. 2019, 214, 17-29. [CrossRef]

40. Stiglitz, J.E.; Weiss, A. Credit rationing in markets with imperfect information. Am. Econ. Rev. 1981, $71,393-410$.

(C) 2020 by the authors. Licensee MDPI, Basel, Switzerland. This article is an open access article distributed under the terms and conditions of the Creative Commons Attribution (CC BY) license (http://creativecommons.org/licenses/by/4.0/). 



\title{
Construction and Empirical Research on the Dynamic Provisioning Model of China's Banking Sector under the Macro-Prudential Framework
}

\author{
Xiaofeng Hui ${ }^{1, *}$ and Aoran Zhang ${ }^{2, *}$ \\ 1 School of Economics and Management, Harbin Institute of Technology, Harbin 150001, China \\ 2 Antai College of Economics and Management, Shanghai Jiao Tong University, Shanghai 200030, China \\ * Correspondence: xfhui@hit.edu.cn (X.H.); zhangaoran@sjtu.edu.cn (A.Z.)
}

Received: 5 September 2020; Accepted: 7 October 2020; Published: 15 October 2020

\begin{abstract}
Since the international financial crisis in 2008, to achieve the political goal of financial stability, academic circles, financial industry, and regulatory authorities worldwide have deeply reflected on the current economic regulatory theories and policy adjustment tools through introducing the macroprudential policy. The dynamic provisioning system is a counter-cyclical policy tool in the macro-prudential adjustment framework widely used in the world. This paper uses the binary Gaussian Copula function to combine the measurement method of the default distance in the contingent claims analysis method with the risk warning idea based on the Probit model and proposes the contingent claims analysis (CCA)-Probit-Copula dynamic provisioning model based on nine forward-looking indicators. Based on China's actual conditions, this model solves present problems faced by the current dynamic provisioning system in China, such as insufficient historical credit data reserves of commercial banks, excessive reliance on subjective judgments, and conflicts with the current accounting system. Moreover, this model can put forward corresponding counter-cyclical provisioning requirements according to the influence degree of macro-cyclical factors to different commercial banks' own default risk, which not only takes into account the security and liquidity of commercial banks, but also ensures their profitability and competitiveness. Based on the empirical test of historical data from listed commercial banks in China, it proves that the dynamic provisioning requirements proposed in this model can effectively adjust the overall credit scale of the banking industry in counter-cyclical ways, thereby achieving the policy goals of counter-cyclical adjustment under the macro-prudential framework and maintaining the security of China's financial system and the sustainable development of the macroeconomy.
\end{abstract}

Keywords: dynamic provisioning; macroprudential supervision; counter-cyclical adjustment

\section{Introduction}

For a long time, maintaining the steady growth and sustainable development of the national economy has been the fundamental purpose of macroeconomic policy adjustment and the common pursuit of macroeconomic theory. Since the 1990s, the financial systems of major countries in the world have shown a trend of rapid development and deepening. The development of finance and the improvement of its functions have greatly reduced the financing costs and information costs of the real economy, making finance increasingly the center of the modern economic system. Meanwhile, financial security and stability have also become new key factors that determine the economy's health and sustainable development. Traditional economic adjustment tools have policy objectives that are mainly price stability, economic growth, full employment, and balance of international payments. The key to policy adjustment is to weigh the output target and the price target. However, the introduction of the political goal of financial stability has created a new conflict: when the 
macroeconomy is in a period of low inflation and high growth, it will promote the accumulation of potential financial systemic risks instead. According to Tinbergen's rule and policy comparative advantage theory, major countries generally choose to introduce macro-prudential policies as a supplement to traditional economic adjustment policy tools, which has the effect of promoting sustainable and stable economic development.

Before the international financial crisis in 2007, the conventional wisdom in dealing with financial risk was "monetary policy plus micro-prudential regulation". Micro-prudential regulation believes that systemic risk can be prevented by ensuring the safety of individual financial institutions. In fact, micro-prudence does not guarantee the overall safety of the financial system, but promotes the failure and collapse of the financial system to some extent. On the contrary, macro-prudential policies are intended to examine the prevention, remedy, and distribution of responsibility for systemic risks among financial institutions from the top to bottom with a more macro and holistic perspective, so as to achieve the goal of maintaining the stability and security of the financial system through external review and internal regulation. The starting point of macro-prudence can be considered from horizontal and vertical dimensions. From a horizontal perspective, macro-prudential policies focus on risk contagion among financial institutions; from a vertical perspective, macro-prudential policies are mainly aimed at the pro-cyclical problems in the financial system. In China, an economic system dominated by indirect financing, commercial bank credit is the main financing method for the real economy. Moreover, maintaining the continuity of commercial bank credit is the key to ensuring the sustained and stable development of China's economy. However, the cyclical financial crisis and the pro-cyclicality of bank credit operations have made economic entities' inevitable liquidity difficulties, which have intensified the cyclical crisis of the macro economy. Therefore, counter-cyclical credit adjustment is an inevitable requirement for maintaining the sustainable and stable development of China's economy. Besides, the dynamic provisioning requirements discussed in this paper can be used as a macroprudential tool for counter-cyclical credit adjustment.

Under the micro-prudential framework, banks only focus on the changes of their own present level of risk but lack an overall and forward-looking vision, so they often have the phenomenon of pro-cyclical credit operation. Borio, 2003 [1] argued that Basel II did not prevent the accumulation of risks in the entire financial system, but enhanced the pro-cyclical nature of the bank credit market and even the overall economy. Capital adequacy ratio, the core regulatory indicator in Basel II, has helped prompt this phenomenon. On the one hand, when the economy goes up, the risk weighting of the corresponding asset goes down as the market price of collateral goes up. Under the fixed capital adequacy ratio standard, the existing capital adequacy ratio level will be surplus, which will inevitably prompt most financial institutions to expand their balance sheets by increasing liabilities to avoid being punished by the stock market for perceived lack of leverage. On the other hand, when the economy goes down, as the market price of collateral falls, the risk weighting of the corresponding asset increases, tightening the existing capital adequacy ratio level. Because financial regulators typically require financial institutions in crisis to maintain the required capital adequacy level, financial institutions whose capital adequacy ratios are close to standard levels will choose to sell assets and offset their liabilities in order to scale back their balances.

As an important policy tool for macro-prudential counter-cyclical regulation, a dynamic provisioning ratio requires financial institutions to increase capital provision in the stage of economic upturn, improve the minimum leverage ratio of financial institutions, prevent excessive statement expansion, and increase the foresight of potential risks. During downturns, the dynamic provisioning ratio will be lowered accordingly, which improves the buffer of commercial banks to deal with losses, prevents the rapid contraction of the balance sheets of large-scale financial institutions, and avoids the amplification and contagion of systemic risks. Therefore, the dynamic provisioning requirement can be used as a capital buffer mechanism to smooth the financial cycle and is a powerful tool to increase the effectiveness of macro-prudential policies, maintain the security of the financial system, and promote the sustainability of macroeconomics. Thus, the purpose of this paper is to propose a 
dynamic provisioning model suitable for China's national conditions on the basis of analyzing the limitations of the current dynamic provisioning model in China and to prove the effectiveness of the counter-cyclical adjustment of the model through empirical tests.

\section{Literature Review}

The regulation of capital adequacy ratio has aggravated the pro-cyclical problem among deposit-taking financial institutions. Kashyap et al., 2004 [2] proposed the time-varying capital requirements to this model: the idea is that banks should tolerate higher bankruptcy risks when they are short of capital and tighter credit supply than in booms, which means that banks in distress should be required to meet lower capital adequacy requirements during economic downturns. This thought coincides with the dynamic capital requirement put forward by the Chinese scholar Liu, 2012 [3]. In 2008, Kashyap et al. 2008 [4] proposed to solve the pro-cyclical problem of capital adequacy ratio by issuing contingent convertibles or reverse convertibles. Such financial instruments usually set a threshold value for the issuer's capital or stock market value. When the reference index falls below this threshold value, these bonds will automatically turn into the issuer's stock, thus achieving the purpose of replenishing capital and reducing liabilities. Samuel, Kashyap et al. 2011 [5] proposed an improved solution for PCA, incorporating limits on the amount of capital into the PCA's regulatory indicators so that we can effectively discourage financial institutions from opting to sell assets rather than replenish capital in the event of economic downturns, a surge in risk, or actual losses.

In general, the above methods are all improvements or supplements to the regulatory indicator of capital adequacy ratio. However, if the capital requirements are not "stratified" and the capital adequacy ratio is solely relied on for counter-cyclical adjustment, the expected target is often not achieved. In addition, the existence of moral hazard will further lead to the deviation of policy results and policy objectives.

As a result, Basel III adopts the method of provision dynamic provisioning to carry out counter-cyclical adjustment. Dynamic provisions require financial institutions to increase capital provisions in the stage of economic upturn to improve the foresight of potential risks, and lower the standard of capital provisions in the stage of economic downturn to increase the buffer against losses and prevent the amplification and contagion of risks.

The existing dynamic provisioning model mainly has two forms: the dynamic provisioning model represented by Spain and based on anticipated loan losses, and the dynamic provisioning model represented by Peru and based on a triggering mechanism. In addition, Mexico et al. 2012 [6] transform operational objects from commercial banks to various types of assets in the application of dynamic provisioning systems, but specific modeling ideas continue with the Spanish or Peruvian model.

Academic circles have undertaken a lot of empirical tests on the policy effectiveness of the counter-cyclical adjustment of the dynamic provision system. The research results of Kanagaretnam, et al., 2005 [7] showed that the loan loss provision and provision operation of commercial banks in the uptrend period was more pro-cyclical compared with the downtrend period. Jin et al., 2013 [8] took 1419 banks from different countries and regions as samples. Their study indicated that banks in Asia were more likely to show pro-cyclicality of loan loss provision in the economic downtrend. Balla et al., 2009 [9] substituted the historical data of commercial banks in the United States from 1993 to 2008 into the Spanish dynamic provision model for simulation testing. It was found that, compared with the current US reserve system for loan provision based on occurred or estimable events, the capital provision required in the crisis stage can be extracted at an earlier time, thus smoothing the income of commercial banks and reducing the pro-cyclical nature of commercial bank credit under the framework of dynamic provision. Martha et al., 2014 [10] analyzed the historical credit data of Colombia's commercial banks and pointed out that the counter-cyclical adjustment effect of the dynamic provision system is mainly achieved in two ways: (i) it is effectively suppressed by the excessive credit expansion of commercial banks in the boom, and the credit expansion is mainly due to excessive competition between commercial banks; (ii) the accumulation of provisions during the 
economic boom can show a buffer during the recession. Jimenez et al., 2017 [11] used the historical data of the commercial banks in Spain to prove that dynamic provision can effectively smooth the credit cycle. The study believes that the realization of this mechanism is because the cost of loan loss provision during the economic boom is much less than the cost of capital replenishment and macro-policy adjustment in times of crisis, but the study also stated that while implementing the Spanish dynamic provision system, it should be alert to the possibility of regulatory arbitrage. In addition, Santiago et al., 2010 [12], through analyzing historical experiences of Spain, Colombia, and Peru, believed that only in the process of implementing the dynamic provisioning system, taking into account the policy rules and discretionary decisions, can the policy goal of counter-cyclical regulation be effectively achieved. Meanwhile, the transparency between financial institutions and financial regulators is also a key factor to determine the effect of counter-cyclical regulation. Santiago et al., 2013 [13] also believed that, from a theoretical perspective, the dynamic reserve system could also be regarded as a mechanism to correct disaster myopia, herd behavior, information asymmetry, and short-term behavior of bank managers. In fact, the introduction of the dynamic provision system woul improve the bank managers' awareness of credit risks, so as to properly record and recognize credit risks in advance and reduce the pro-cyclicality of credit provisions. Huang et al., 2014 [14] and Gao et al., 2017 [15], Chinese scholars, proved that the introduction of a forward-looking dynamic provisioning system in China would effectively restrain the cyclical economic fluctuations and the pro-cyclical credit behavior by constructing a new Keynes DSGE model with an independent banking sector. Zhang et al., 2004 [16] believed that, in the light of the experience of countries that already have dynamic provisioning systems, such as Spain, the implementation of the dynamic provisioning system can help to smooth out the cyclical fluctuations in the provision for loan losses and help to enhance the stability of the banking system. However, in the process of introducing the dynamic provisioning system into China's banking supervision system, it is necessary to combine with China's national conditions.

Li, 2009 [17] believed that when the current international dynamic provisioning model is introduced into China's macro-prudential supervision system, there are three difficulties: (i) Provision for losses not yet incurred violated the principle of the current accounting standards that provision can only be made for losses that have occurred or that have been conclusively demonstrated to be occurring; (ii) the subjective factors in the current dynamic provisioning process in the world will give an opportunity to artificially smooth the profits; (iii) China's data reserve on indicators such as long-term loan loss rate of commercial Banks cannot support the direct application of the current international model in China.

Specifically, the basic requirements of both dynamic provisioning models are statistical analysis of historical data on commercial bank loans in a full cycle, both in Spain and Peru, where the non-performing loan ratio has experienced a full cycle of surges and falls. However, China's non-performing loan rate data began to be counted in 2004 and has not yet shown completely cyclical characteristics, and since 2008, China's banking sector non-performing loan rate has been at a historically low level and maintained a relatively stable state. Therefore, it is difficult to put forward an effective dynamic provisioning model through the statistical analysis of the historical data of non-performing loans. Because of this, the China Banking Regulatory Commission (CBRC), in reference to the existing international dynamic provisioning model, proposed the current dynamic provisioning model in China [18]. The model is

$$
\mathrm{GP}=L \times N L R \times(P C R+\delta)-\mathrm{SP}
$$

GP stands for general provisions made in the current period. $L$ represents all loans in the current period. NLR stands for the historical non-performing loan ratio. PCR stands for loan provision coverage in the current period, with a lower limit of $2.5 \%$. $\delta$ is the adjustment factor. SP is a special provision for the current period.

Compared with the dynamic provisioning model implemented in Spain, China's current model is not only based on statistics of historical non-performing loan rates, but also affected by adjustment factor $\delta$ when making loan provisioning. The main reason is that China's commercial banks have insufficient 
historical data reserves for the indicator of non-performing loan ratio, so subjective adjustment factor $\delta$ is needed to help achieve the policy goal of counter-cyclical adjustment.

This model considers the problem of insufficient statistics of historical data in China. Therefore, when determining the historical non-performing loan ratio and provision coverage in the corresponding period, it adopts the five-year moving window period to take the average value and solidifies after a complete economic cycle. However, the non-performing loan rate of the country's commercial banking industry has been at a historically low level and remained relatively stable since 2008 . Therefore, even if the method of moving windows is adopted, it will still be difficult to make the model have forward-looking effects, and it is difficult to truly achieve the policy goal of macro-prudential counter-cyclical supervision. Additionally, as a key parameter to achieve "dynamic" in this model, the adjustment coefficient does not have an exact method to determine its value. Instead, the adjustment, with a certain degree of subjectivity, is based on macroeconomic indicators, the overall risk level of the banking sector, and the financial index deviation of financial institutions. Through empirical analysis, Chen et al., 2015 [19] and Zhang et al., 2016 [20] have found that the provision for loan losses is widely used in China's commercial banking industry to smooth profits. Bushman et al., 2012 [21] argued that forward-looking provisions based on smoothing profits rather than covering future loan losses would significantly increase the risk level taken by banks. In addition, due to the subjective judgmental factors in the model, time lag will occur in the process of adjusting the dynamic provisioning requirements. As a counter-cyclical adjustment tool, the dynamic provision system places more emphasis on time variability and timeliness. The time inconsistency phenomenon may promote economic fluctuations instead. Moreover, the loan provisioning rate based on the current model completely relies on the historical non-performing loan rate, which is contrary to the current accounting system proposing the principle of loan provision based on real or predictable losses.

In order to solve the problem of subjectivity in the dynamic provisioning model, Li et al., 2008 [22] drew on the idea of the credit rating migration matrix adopted by Moody's and applied the Markov chain prediction theory to construct a forward-looking dynamic provisioning model. Moreover, the defects of the original model that could not cover the macroeconomic cyclical fluctuation factors were corrected. The specific method is to measure the credit risk migration matrix during the economic period and recession period, respectively, and introduce the dynamic weighting, which can be adjusted according to macroeconomic changes to construct a weighted migration matrix to indicate dynamic provisioning. However, this method has some limitations: on the one hand, the determination of dynamic weights in this model requires historical data on the change of non-performing loan rate in the complete economic cycle; on the other hand, when this model is used to analyze the changes of credit risks in bank loans, it does not distinguish the macro cyclical factors from the micro individual factors, but all of them are viewed from the cyclical perspective, which weakens the ability of Banks to resist credit risks to some extent. In addition, $\mathrm{Xu}$ et al., 2011 [23] estimated the degree of bank loan default loss and the dynamic law of loan default probability through dynamic random modeling of the return on assets of borrowing enterprises, so as to realize the dynamic and forward-looking provision for loan losses. However, there are two limitations to modeling dynamic provisioning rates in this way: first, the bank's counterparties are not only businesses, but also individuals, peers, and government agencies. In addition, some of the borrowing enterprises are not listed, making it difficult to obtain real and accurate asset return data, so the dynamic provisioning requirements proposed by the model will also be biased. Second, dynamic provisioning requirements are a macro-prudential tool; their role is to inhibit the bank's pro-cyclical operation and offset the financial macro-cyclical changes brought about by the risk. However, taking the return on assets of borrowing enterprises as the dynamic provisioning model indicating variables, the results will be influenced by micro-factors such as the enterprise's own characteristics and business behavior, which makes it difficult to meet the requirements of macro-prudential regulation. 
Therefore, proposing a dynamic provisioning model that is suitable for China's financial system and can avoid subjectivity to a certain extent is important to enrich China's macro prudential "toolbox" and achieve the goal of counter cyclical regulation.

\section{Methods}

\subsection{Construction of Dynamic Provisioning Model}

This paper usds the contingent claims analysis method (CCA) to measure the risk of default by financial institutions due to bankruptcy (hereinafter referred to as default risk). The model was first applied in papers by Gray et al., 2007 [24] and then further extended by Jobst et al., 2010 [25]. The CCA model is a theoretical model based on financial market data and financial institutions' balance sheets to assess the risk of default and can use current data to calculate the probability of default risk. The model can measure the risk of default of individual institutions from a micro level as well as the systemic risk of the whole system at the macro level.

The CCA model, like the B-S-M option pricing formula, assumes the geometric brown movement of asset price $A_{t}$ subject to $\mu_{A}$ as drift rate and $\sigma_{A}$ as volatility. According to mathematical deduction, the following formula can be obtained.

$$
A_{t}=A_{0} \exp \left[\left(\mu_{A}-\frac{\sigma_{A}^{2}}{2}\right) t+\sigma_{A} \sqrt{t} \cdot \varepsilon\right]
$$

where, $\varepsilon \sim \mathrm{N}(0,1)$.

Merton, 1974 [26] argues that a company's stock $E$ can be considered a call option, while the company's total assets $A$ can be considered as the underlying asset of the call option, and the company's liability $B$ can be considered as the execution price. The maturity date of the liability is determined to be $T$. If the total assets of the company $A_{T}>B_{T}$ at the $T$ moment, the total return of the shareholders of the company is $A_{T}-B_{T}$; If the total assets of the company $A_{T}<B_{T}$ at the $T$ moment, the total return of the shareholders of the company is 0 , and the company is in bankruptcy and default.

Additionally, at maturity $T$, the probability of default due to the bankruptcy of the target financial institution is

$$
\begin{gathered}
P\left(A_{T} \leq B_{T}\right)=P\left(A_{0} \exp \left[\left(\mu_{A}-\frac{\sigma_{A}^{2}}{2}\right) T+\sigma_{A} \sqrt{T} \cdot \varepsilon\right] \leq B_{T}\right)=P(\varepsilon \leq-D D)=\Phi(-D D) \\
D D=\frac{\ln \left(\frac{A_{0}}{B_{T}}\right)+\left(\mu_{A}-\frac{\sigma_{A}^{2}}{2}\right) T}{\sigma_{A} \sqrt{T}}
\end{gathered}
$$

It can be found that the $D D$ and the probability of default are inversely variable: the larger the $D D$, the smaller the probability of default, and the smaller the $D D$, the greater the probability of default by the institution, which is the one-to-one correspondence. Therefore, $D D$ can be used as an indicator of the risk of default by financial institutions.

Further observation shows that in addition to the time constant $T$, there are three variables affecting the change of $D D$ : the drift rate of asset return $\mu_{A}$, the volatility of asset return $\sigma_{A}$, and the ratio of the present value of total assets to the maturity date of liabilities $A_{0} / B_{T}$. In addition, $A_{0} / B_{T}$ can represent the leverage ratio of the financial institution to some extent. According to Moody's treatment, the $B_{T}$ value is the sum of the book value of short-term liabilities and 0.5 times the book value of long-term liabilities, so the $B_{T}$ value has a one-to-one correspondence with the total debt level. Additionally, the ratio of $A_{0} / B_{T}$ will be inversely variable to the leverage of the agency at this stage. For convenience, 
the variable $K$ is used below to represent $A_{0} / B_{T}$. The above three influencing factors were used to obtain the partial derivative of $D D$.

$$
\begin{gathered}
\frac{\partial D D}{\partial \sigma_{A}}=-\frac{\ln (K)+\left(\mu_{A}-\frac{\sigma_{A}^{2}}{2}\right) T}{\sigma_{A}^{2} \sqrt{T}}-\sqrt{T}<0 \\
\frac{\partial D D}{\partial \mu_{A}}=\frac{\sqrt{T}}{\sigma_{A}}>0 \\
\frac{\partial D D}{\partial K}=\frac{1}{K \cdot \sigma_{A} \sqrt{T}}>0
\end{gathered}
$$

$D D$ is in the same direction as the drift rate of return on assets $\mu_{A}$, and in the opposite direction as the volatility rate of return on assets $\sigma_{A}$ of the financial institution. The variable $K$ is inversely correlated with the leverage ratio of the institution and positively correlated with the $D D$ of the institution.

According to the "risk neutral" idea proposed by Cox et al., 1976 [27], when applying the B-S-M option pricing formula, all risky assets do not require risk compensation. When calculating the default distance $D D$, most of the relevant studies adopted the idea of "risk neutrality" to replace the return drift rate of assets $\mu_{A}$ with risk-free interest rate $\mathrm{r}$.

Risk-free interest rate $\mathrm{r}$ is affected to some extent by cyclical changes in the macro economy. This paper uses the average of the seven-day fixing repo rate to represent the average of the risk-free interest rate in a year, which is usually in the same direction as the year-on-year level of nominal GDP, as shown in Figure 1.

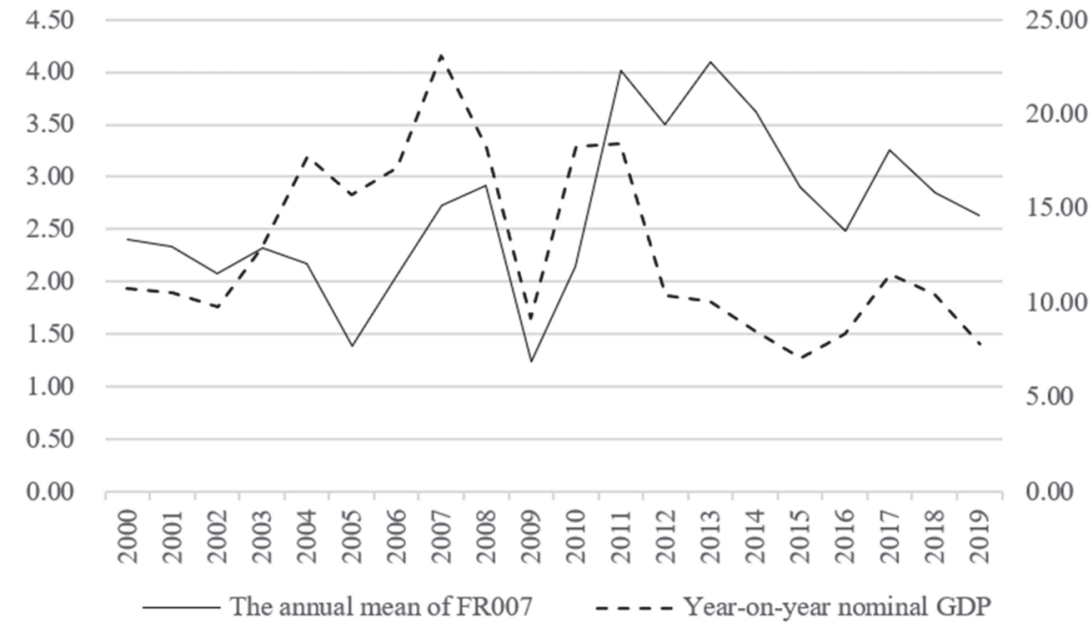

Figure 1. Comparison of the average risk-free interest rate with the year-on-year growth rate of nominal GDP.

This is because the benchmark interest rate level is regulated by monetary policy and is usually equated with the risk-free interest rate, while promoting economic growth and maintaining prices are included in our monetary policy objectives. As one of the common monetary policy rules of central banks, Taylor's Law reflects the influence of these two policy objectives on monetary policy making. It argues that the base rate level is also affected by both the price gap and the output gap, apart from the trend item.

$$
r_{t}=\rho_{0}+\beta_{\mathrm{GDP}}\left(E_{t} \Delta G D P_{t+1}-\Delta G D P_{t+1}^{*}\right)+\beta_{\pi}\left(E_{t} \pi_{t+1}-\pi_{\mathrm{t}+1}^{*}\right)
$$


$\rho_{0}$ represents the trend item. The difference between the expected year-on-year real GDP growth rate and the potential GDP growth rate represents the output gap, and the potential GDP growth rate is obtained from the year-on-year real GDP level processed by the H-P filtering method. The difference between the expected rate of inflation and the target level of monetary policy represents the price gap. The output gap is partly related to the possibility of an expected overheating, and the price gap can be used to measure the level at which expected inflation exceeds policy objectives. When the economy is in an upward cycle, real economic growth rises and is usually accompanied by higher inflation, which is reflected in the increase of output gap and price gap, and leads to the tightening of monetary policy and the rise of benchmark interest rates. Otherwise, it goes down. Therefore, theoretically both $\beta_{\mathrm{GDP}}$ and $\beta_{\pi}$ are positive. In addition, nominal GDP equals the product of the real GDP and GDP deflator, so that the year-on-year growth rate of nominal GDP will also be affected by both real economic growth and inflation level. Therefore, the year-on-year growth level of nominal GDP usually has the same trend as the benchmark interest rate and risk-free interest rate.

According to Sharpe's definition, systemic risk refers to the risk that cannot be eliminated by diversification. Therefore, from a relatively long-term perspective, the volatility of the financial institution's asset return $\sigma_{A}$ and the volatility of the market return $\sigma_{M}$ show a certain degree of the same trend.

From the above analysis, there is a certain correlation between macro-economic cycle changes and financial cycle changes. During the boom, the return on assets of financial institutions $\mu_{A}$ generally rose, while the level of market volatility $\sigma_{M}$ showed a downward trend, which usually promoted the upward trend of the financial cycle. During a recession, the return on assets of financial institutions $\mu_{A}$ generally declines, while the level of market volatility $\sigma_{M}$ tends to rise, usually driving down the financial cycle. However, financial cyclical changes and economic changes are not completely synchronized, and systemic risks do not all come from macroeconomic changes. Factors such as international capital flows, asset pricing bubbles, and even shadow banking may trigger systemic risks. At the same time, the excessive correlation of balance sheets between financial institutions and unreasonable internal incentives have amplified this process. As a result, there may also be increased systemic risks and cyclical downwards in finance during boom period. In addition, failures within the financial system may also contribute to and accelerate the surge in systemic risks when the downturn in the economy leads to a systemic increase. Therefore, when discussing the impact factors of default risk of micro-financial institutions from the perspective of "top-down" macro-prudence, we should consider both macroeconomic fluctuations and internal factors of the financial system.

When the financial cycle goes up, the drift rate of asset return $\mu_{A}$ generally rises, and the volatility of asset return $\sigma_{A}$ is affected by the level of market volatility $\sigma_{M}$, which also has a downward trend, resulting in an increase in the default distance of financial institutions and a decrease in the risk of default. This reduction in the risk of default is usually reflected in a decrease in the risk weighting of the corresponding assets, resulting in an increase in the level of capital adequacy, at which point most financial institutions usually choose to expand their balance sheets by increasing leverage to maximize the value of the company and shareholders' interests. In the process, financial institutions will create a new combination of leverage and default risk.

$$
\left(K^{\prime}, D D^{\prime}\right) \in\left\{(K, D D) \mid K \leq K \leq K^{*}, \mathrm{DD} \leq D D \leq D D^{*}\right\}
$$

The following relationship exists under the condition of risk-neutral pricing.

$$
\mathrm{DD}=\frac{\ln (K)+\left(r^{\prime}-\frac{{\sigma_{A}^{\prime}}_{A}^{2}}{2}\right) T}{\sigma_{A}^{\prime} \sqrt{T}}
$$




$$
D D^{*}=\frac{\ln \left(K^{*}\right)+\left(r^{\prime}-\frac{\sigma_{A}^{\prime 2}}{2}\right) T}{\sigma_{A}^{\prime} \sqrt{T}}
$$

$K^{*}$ and $D D^{*}$ represent, respectively, the original ratio of $A_{0} / B_{T}$ at the time of risk prediction and the correspondingly measured default distance, and $K_{\prime}^{\prime}, D D_{\prime}^{\prime}, r_{\prime}$, and $\sigma_{A}^{\prime}$, respectively, represent the $A_{0} / B_{T}$ ratio, default distance, risk-free interest rate level, and volatility of asset yield after the upward change in the economy. $K$ represents the $A_{0} / B_{T}$ ratio corresponding to the adjustment of the default distance back to the original level when the financial cycle changes upward, which is the lower limit of $K^{\prime}$. When the financial cycle changes upward, DD represents the distance to default when the financial cycle changes downward and the corresponding leverage ratio is not adjusted, namely the lower limit of $D D$.

When there is a cyclical downturn in finance, the drift rate of asset return $\mu_{A}$ usually falls generally, while the volatility of asset return $\sigma_{A}$ tends to rise, at which time the default distance of financial institutions decreases and the risk of default increases. Usually, the risk weight of corresponding assets rises and the capital adequacy ratio drops. In order to meet the regulatory requirements on capital adequacy ratio and reduce the risk of default, most financial institutions sell risky assets and reduce their leverage ratio. In the process, financial institutions will also create a new combination of leverage and default risk.

$$
\left(K^{\prime \prime}, D D^{\prime \prime}\right) \in\left\{(K, D D) \mid K^{*} \leq K \leq \bar{K}, D D^{*} \leq D D \leq \overline{\mathrm{DD}}\right\}
$$

Additionally, there is the following relationship:

$$
\begin{aligned}
\overline{\mathrm{DD}} & =\frac{\ln (\bar{K})+\left(r^{\prime \prime}-\frac{{\sigma^{\prime \prime}}_{A}^{2}}{2}\right) T}{\sigma_{A}^{\prime \prime} \sqrt{T}} \\
\mathrm{DD}^{*} & =\frac{\ln \left(K^{*}\right)+\left(r^{\prime \prime}-\frac{{\sigma^{\prime \prime}}_{A}^{2}}{2}\right) T}{\sigma_{A}^{\prime \prime} \sqrt{T}}
\end{aligned}
$$

$K^{*}$ and DD* still represent, respectively, the original ratio of $A_{0} / B_{T}$ at the time of risk prediction and the correspondingly measured default distance, and $K^{\prime \prime}, D D^{\prime \prime}, r^{\prime \prime}$, and $\sigma_{A}^{\prime \prime}$ represent the $A_{0} / B_{T}$ ratio, default distance, risk-free interest rate level, and volatility of the assets return, respectively, after the downward change in the financial cycle. $\bar{K}$ represents the $A_{0} / B_{T}$ ratio corresponding to the adjustment of the default distance back to the original level after the downward change in the economy, which is the upper limit of $K^{\prime \prime} . \overline{\mathrm{DD}}$ represents the distance to default when the financial cycle changes upward and the corresponding leverage ratio is not adjusted, which is the upper limit of $D D^{\prime \prime}$.

It should be emphasized that the CCA model cannot accurately calculate the change range of $K$, or the adjustment range of leverage ratio, but the model can calculate the range that $K$ can float when the economy changes periodically. The boundary of the value of $K$ in the process of financial cyclical changes is exactly the object that needs supervision.

The core of the so-called counter-cyclical adjustment is that when the systemic risk changes, the financial institutions should not only consider the change of their own default risk during the measurement period, but also increase the forward-looking expectation of the cyclical change of systemic risk, and make comprehensive judgment and adjust the leverage accordingly.

The concept of marginal expected shortfall proposed by Acharya et al., 2016 [28] is adopted to measure the expected loss suffered by individual financial institutions when left-tail extreme events occur in the overall financial system.

$$
M E S_{\alpha}^{i}=-\frac{\partial \sum_{i} y_{i} E\left[r_{i} \mid R \leq-V a R_{\alpha}\right]}{\partial y_{i}}=-E\left[r_{i} \mid R \leq-V a R_{\alpha}\right]
$$




$$
\mathrm{R}=\sum_{i} y_{i} r_{i}
$$

In the formula, $M E S_{\alpha}^{i}$ represents the expected loss of financial institution $i$ when the left-tail extreme event occurs under the $(1-\alpha)$ confidence level. $\mathrm{R}$ represents the rate of return of the overall financial system. $y_{i}$ represents the proportion of financial institution $i$ in the overall financial system. $r_{i}$ represents the rate of return of financial institution $i$.

The higher the $M E S_{\alpha}^{i}$ value, the greater the degree of exposure to systemic risk on behalf of financial institutions, and the greater the degree of loss in the event of a systemic crisis. This potential loss increases the risk of default caused by non-individual factors in micro-financial institutions, which is precisely the object of forward-looking dynamic provisioning.

When putting forward dynamic provisioning requirements for micro-financial institutions and weakening pro-cyclical changes of systemic risks, this paper draws on the idea of a crisis early warning mechanism to enable micro-financial institutions to anticipate the cyclical changes of losses suffered by systematic risks, thus reducing the degree of pro-cyclical operations of financial institutions. First, this paper calculates the historical data of quarter $M E S_{\alpha}^{i}$ of each financial institution and calculates its mean. After that, when the current $M E S_{\alpha}^{i}$ of the financial institution $i$ is below $3 \%$ and, in the next four quarters, the $M E S_{\alpha}^{i}$ rises above 3\%, it is considered that the potential loss of financial institution $i$ due to the influence of systemic risk picks up in the following year, recorded as Event 1 . When the $M E S_{\alpha}^{i}$ of financial institution $i$ is above $5 \%$ at the present stage, and the $M E S_{\alpha}^{i}$ falls below $5 \%$ in the next four quarters, it is considered that the possible losses of financial institution $i$ due to the influence of systemic risks fall in the following year, recorded as Event 2. As the main purpose of this operation is to meet the requirement of increasing counter-cyclicality under macro-prudential conditions, the objective of this paper is to measure the probability of a change in the degree of loss of financial institutions by systemic risk. Event 1 is regarded as a representative event of the pick-up of the loss degree, while Event 2 is regarded as a representative event of the decline of the loss degree. The reason for event setting is detailed in Appendix A.

In this paper, the binary Probit model is used to predict the probability of Event 1 and Event 2 appearing, respectively. The idea of the Logit/Probit model was first proposed by Frankel et al., 1996 [29], namely the FR model. In their paper, they analyzed the factors that caused the currency crisis in developing countries. It is most reasonable to choose quarterly as the frequency of data extraction. This is because, if monthly data is used, when predicting the probability of loss change in the next year, it is equivalent to looking forward 12 units of time. The forecasting period is relatively long, reducing the accuracy of the forecast. If the annual data are used for analysis, there will be few historical data, and the regression results will not be representative. This paper selects the Probit model to build an early warning mechanism, because the Probit model and the default distance in the CCA model are based on the standard normal distribution, which reflects a certain degree of "compatibility". This is conducive to introducing the Probit model into the traditional CCA model to modify, and finally put forward, the dynamic provisioning model.

When analyzing the probability of the MES value of financial institutions to pick up, this paper constructs the dummy variable $Y_{1}$ and stipulates

$$
\begin{aligned}
& Y_{1}=1, M E S_{t} \leq 3 \%, \exists M E S_{j} \geq 3 \%, t+1 \leq j \leq t+4 \\
& Y_{1}=0, \text { else }
\end{aligned}
$$

$M E S_{t}$ represents the $M E S_{\alpha}^{i}$ value of the financial institution $i$ in the $t$ period, representing the expected loss level of financial institution $i$ at the $1-\alpha$ confidence level when a left-tail extreme event occurs in the financial system. 
Set the dummy variable $n . e . d_{1}$ that satisfies the normal distribution, and set a threshold n.e. $d_{1}^{*}$. Let $A$ be linearly dependent on the explanatory variable. Assume that when the dummy variable exceeds the threshold, $Y_{1}=1$. Establish regression model

$$
\text { n.e. } d_{1}=\beta_{0}+\sum \beta_{s} \cdot I_{S}
$$

$I_{S}$ stands for the selected forward-looking indicators.

The probability of n.e. $d_{1}^{*} \leq$ n.e. $d_{1}$ can be calculated by the standard normal cumulative distribution function.

$$
P_{L}^{i}=P\left(Y_{1}=1 \mid \Omega\right)=P\left(\text { n.e. } d_{1}^{*} \leq \text { n.e. } d_{1}\right)=\Phi\left(\beta_{0}+\sum \beta_{s} I_{s}\right)
$$

$P_{L}^{i}$ is the probability of Event 1 .

Similarly, when analyzing the probability of the MES value of financial institutions to decline, this paper constructs the dummy variable $Y_{2}$ and stipulates

$$
\begin{aligned}
& Y_{2}=1, M E S_{t} \geq 5 \% \exists M E S_{j} \leq 5 \%, \mathrm{t}+1 \leq j \leq t+4 \\
& Y_{2}=0, \text { else }
\end{aligned}
$$

Set the dummy variable n.e. $d_{2}$ that satisfies the normal distribution, establish the threshold value n.e. $d_{2}^{*}$, and establish the regression model.

$$
\text { n.e. } d_{2}=\beta_{0}^{\prime}+\sum \beta_{s}^{\prime} \cdot I_{s}
$$

When n.e. $d_{2}^{*} \leq$ n.e. $d_{2}, Y_{2}=1$. Calculate the probability

$$
P_{S}^{i}=P\left(Y_{2}=1 \mid \Omega\right)=P\left(\text { n.e. } d_{2}^{*} \leq \text { n.e. } d_{2}\right)=\Phi\left(\beta_{0}^{\prime}+\sum \beta_{s}^{\prime} \cdot I_{S}\right)
$$

$P_{S}^{i}$ is the probability of Event 2 .

The business activities of financial institutions, especially the credit operations of commercial banks, have pro-cyclical characteristics. The reason is that when financial institutions measure their own bankruptcy risks, they often start from the current economic environment and ignore the cyclical changes in systemic risks that will occur in the future. This reflects the short-sightedness of financial institutions, which leads to the phenomenon of pro-cyclical adjustment of financial institutions' balance sheets. Therefore, the premise of constructing a dynamic provisioning model suitable for China's commercial banking industry is to propose a modified CCA model with a forward-looking mechanism, which can consider the possibility of bankruptcy events in the future when the loss degree caused by systemic risk changes in the future of commercial banks.

$$
\Phi\left(-M D D_{s}\right) \equiv P\left(A_{T} \leq B_{T} \mid Y_{s}=1\right)=\frac{F\left(-D D, \text { n.e. } d_{s}\right)}{\Phi\left(\text { n.e. } d_{s}\right)}
$$

$M D D_{S}$ are defined as the modified default distance, used to reflect changes in the default risk of financial institutions under the condition of forward-looking future systemic risk changes. $F(\cdot, \cdot)$ represents the joint cumulative distribution function. $s=1,2$.

As the theoretical analysis above can determine that the default distance $D D$ and the dummy variable n.e. $d_{s}$ both meet the standard normal distribution, the binary Gaussian Copula function should be introduced for the calculation of their joint cumulative distribution.

$$
\begin{aligned}
F\left(-D D, n . e . d_{S}\right) & =C(U, V) \\
& =\int_{-\infty}^{\Phi^{-1}(U)} \int_{-\infty}^{\Phi^{-1}(V)} \frac{1}{2 \pi \sqrt{1-\rho^{2}}} \exp \left(-\frac{\delta^{2}-2 \rho \delta \eta+\eta^{2}}{2\left(1-\rho^{2}\right)}\right) d \delta d \eta
\end{aligned}
$$




$$
\begin{gathered}
U=\Phi(-D D) \\
V=\Phi(\text { n.e.d })
\end{gathered}
$$

$\Phi^{-1}(\cdot)$ represents the inverse function of the standard normal cumulative distribution. $\rho$ represents the correlation between random variables.

Considering the future rise and fall of the systemic risk level, the upper and lower limits of the $M D D$ value are determined, respectively. When the $D D$ value is higher than the historical average, $M D D$ takes the lower limit. When the $D D$ value is lower than the historical average, $M D D$ takes the upper limit.

In the modified CCA model, it can be found that in addition to measuring their own default risk based on current indicators, financial institutions also consider the possibility of changes in their own default risk due to cyclical changes in systemic risks in the next year. It has narrowed the room for adjustment of the leverage ratio of commercial banks, thus achieving the goal of increasing forward-looking and counter-cyclical regulation.

The counter-cyclical regulation effect of the modified CCA model on the financial system is realized by extracting dynamic provisions. In the research of applying the CCA model, there are two mainstream ways to determine the value of $B_{T}$. One is the treatment method of Moody's, and the other is directly expressed by the level of book total liabilities. However, a large number of existing research conclusions indicate that both calculation results are almost the same. Therefore, this paper adopts Moody's method in calculating the default distance, that is, the sum of the book value of short-term liabilities and 0.5 times the book value of long-term liabilities to represent $B_{T}$. Assuming that the proportion of long-term liabilities of financial institution $i$ in total liabilities is $v$, the relationship between the book value of total liabilities $B$ and $B_{T}$ is:

$$
B_{T}=B \cdot(1-0.5 v)
$$

Then the $K$ value in the modified CCA model has a one-to-one correspondence with the leverage ratio of financial institutions:

$$
L=\frac{K(1-0.5 v)}{K(1-0.5 v)-1}
$$

As the $K$ value and the leverage ratio $L$ have a reverse relationship, the limits of the leverage ratio adjustment can be judged in the process of changes in the default risk of financial institutions.

The requirement of the dynamic provisioning ratio (DPR) of financial institutions is the difference between the leverage ratio obtained by the modified CCA model and the original CCA model. This is because loan provision is regarded as an expense in accounting, decreasing "undistributed profit" and included in the "asset impairment provision" account. According to the requirements of Basel III to calculate the leverage ratio of commercial banks using Tier 1 capital, when the actual level of assets and liabilities remains unchanged, the higher the dynamic provisioning ratio is, the lower the calculated leverage ratio will be. On the contrary, the lower the dynamic provisioning ratio, the higher the calculated leverage ratio. Therefore, when the financial cycle goes up, by increasing the provisioning ratio, the leverage ratio of financial institutions can be reduced, and pro-cyclical balance sheet expansion can be suppressed; when the financial cycle goes down, by reducing the provisioning ratio, it can increase the level of leverage of financial institutions and curb pro-cyclical balance sheet reduction behavior. The dynamic provisioning model constructed in this paper is designed to withdraw loss provisions for the overall assets of commercial banks. The advantage of this design is that it can not only make commercial banks subject to the counter-cyclical adjustment of the dynamic provisioning rate during credit operations, to a certain extent, but also prevent the phenomenon of shadow credit arising from commercial banks' evasion of supervision.

$$
D P R=L_{1}-L_{2}=\frac{K_{1}(1-0.5 v)-1}{K_{1}(1-0.5 v)}-\frac{K_{2}(1-0.5 v)-1}{K_{2}(1-0.5 v)}=\frac{K_{2}^{-1}-K_{1}^{-1}}{1-0.5 v}
$$




$$
\begin{gathered}
K_{1}=\exp \left[\mathrm{DD}^{*} \cdot \sigma_{A} \sqrt{T}-\left(r-\frac{\sigma_{A}^{2}}{2}\right) T\right] \\
K_{2}=\exp \left[M D D_{s}^{*} \cdot \sigma_{A} \sqrt{T}-\left(r-\frac{\sigma_{A}^{2}}{2}\right) T\right]
\end{gathered}
$$

$\mathrm{DD}^{*}$ and $M D D_{S}^{*}$, respectively, represent the default distance and modified default distance of the measure, and $L_{1}$ and $L_{2}$, respectively, represent the leverage adjustment limits calculated by the CCA model and modified CCA model.

When the default distance is lower than the historical average, the DPR value is positive, which means extracting dynamic provisions and restraining the tendency of excessive leverage of financial institutions, that is, preventing the accumulation of potential risks in the upward stage of the financial cycle. When the default distance is higher than the historical average, the $D P R$ value is negative, which means releasing dynamic provisions, preventing large-scale risk aversion of financial institutions, and maintaining the security of the financial system in the downward phase of the financial cycle. From a horizontal perspective, the extraction of the dynamic provisioning rate is related to the degree to which financial institutions are impacted by systemic risks. From a vertical perspective, the dynamic provisioning rate is related to the level of systemic risk and changes in macroeconomic indicators. The model constructed in this paper is dynamic in both horizontal and vertical dimensions and makes up for the shortcoming of the original dynamic provisioning model, which is still pro-cyclical to some extent.

Compared with the traditional dynamic provision model, the dynamic provisioning model constructed in this paper has achieved the following five improvements:

- The model is based on multi-factor indicators, which is helpful to solve the problem of insufficient data reserves when only the historical credit data of commercial banks are used for dynamic provision adjustment.

- The dynamic provisioning rate calculated in this paper is a supplementary provisioning rate that has a corrective effect on the micro-prudential loan provisioning rate based on a five-tier classification method, so it does not cover up the real risk situation of commercial banks in the current period and resolves the conflict with the current accounting system.

- The model excludes subjective factors, so as to avoid the provision behavior of commercial banks based solely on smoothing profits rather than resisting risks.

- The model has different requirements for dynamic provision of different commercial banks, avoiding a one-size-fits-all regulatory model. While maintaining the safety of commercial banks, it also takes into account competitiveness and profitability.

- The model is designed to set aside provisions for the whole assets of commercial banks. The advantage of this design is that it can not only make the credit operation of commercial banks subject to the counter-cyclical regulation through extracting dynamic provisions, but also prevent the phenomenon of regulatory arbitrage of commercial banks and distortion of resource allocation to a certain extent.

\subsection{Selection of Forward-Looking Indicators}

According to the theoretical analysis above, it can be seen from formula (4) that when the leverage ratio of commercial banks remains unchanged, the default risk of commercial banks is influenced by external factors through two channels: volatility of assets and interest rate. Based on previous research results (Behn et al., 2013 [30]; Detken et al., 2014 [31]; Shen Yue et al., 2008 [32]; Ma Jun et al., 2019 [33]), combined with the theoretical analysis in Section 3.1, this paper selects macroeconomic and financial credit indicators. This paper foresees the changes in the default risk of commercial banks from nine aspects: output gap, inflation, unemployment, credit, foreign debt, foreign exchange reserves, foreign trade balance, credit, the stock market, and the real estate market, which enhances the risk 
prediction capabilities of commercial banks and achieves the policy objectives of counter-cyclical adjustment of credit. The specific index setting method is shown in Table 1.

Table 1. Setting method of forward-looking indicators.

\begin{tabular}{|c|c|c|}
\hline Indicator (Quarterly) & Abbreviation & Setting Method \\
\hline Output gap & OG & $\begin{array}{l}\text { The difference between real GDP year-on-year growth rate and } \\
\text { potential GDP year-on-year growth rate }\end{array}$ \\
\hline Inflation & I & Cumulative year-on-year GDP deflator \\
\hline Unemployment rate & UR & Urban unemployment year-on-year growth rate \\
\hline Foreign debt & FD & $\begin{array}{l}\text { The ratio of quarterly increase in foreign debt balance to } \\
\text { nominal GDP }\end{array}$ \\
\hline Foreign exchange reserves & FER & $\begin{array}{c}\text { The ratio of quarterly increase in foreign exchange reserves to } \\
\text { nominal GDP }\end{array}$ \\
\hline Foreign trade balance & FTB & $\begin{array}{c}\text { The ratio of quarterly increase in current account balance to } \\
\text { nominal GDP }\end{array}$ \\
\hline Credit & $\mathrm{C}$ & Domestic non-financial sector credit year-on-year growth rate \\
\hline Stock market & SM & $\begin{array}{l}\text { The ratio of quarterly increase in total market value of A-shares } \\
\text { to nominal GDP }\end{array}$ \\
\hline Real estate market & REM & Cumulative new construction site area year-on-year growth rate \\
\hline
\end{tabular}

The risk level of commercial banks is periodically affected by the macroeconomic output level. Meanwhile, the change of macroeconomic output level will also cause the monetary policy to adjust accordingly, and the adjustment of monetary policy will weaken or even reverse the impact of the cyclical change of macroeconomic output level on the risk level of commercial banks. Therefore, the effect of GDP change on bank default risk in the above two ways should be discussed separately when establishing forward-looking dynamic provisioning indicators. By formula (13), it can be seen that the effect of macroeconomic output on monetary policy is achieved through the expected output gap. Under the conditions of adaptive expectations, the policy makers' judgment on the expected output gap will be largely affected by the current output gap, so this paper selects the current output gap as an indicator to measure the impact of the total output level on the default risk of commercial banks through the transmission of monetary policy. The value of the output gap is equal to the difference between the actual GDP year-on-year growth rate and the potential GDP year-on-year growth rate. The potential GDP year-on-year growth rate is obtained by H-P filtering the actual GDP year-on-year growth rate.

An unemployment indicator to measure the cyclical changes in economic production was chosen. Due to the existence of a natural unemployment rate, the rise of the unemployment rate indicates that the macro economy tends to be depressed, while the decline of the unemployment rate indicates that the macro economy tends to be overheated. As China has long adopted the registered unemployment rate instead of the survey unemployment rate, the statistical unemployment rate is often difficult to measure the accurate unemployment situation in China. The urban unemployment rate is obtained through the census of urban permanent residents, which is more reliable. Therefore, this paper chooses the index of urban unemployment year-on-year growth rate to represent the unemployment situation in China.

In order to meet the quarterly statistical requirements of the forward-looking indicators of the dynamic provisioning model constructed in this paper, the cumulative year-on-year GDP deflator is selected to represent the level of inflation. The expected inflation target announced by China is based on the CPI, and the statistical calibers of the CPI and the GDP deflator are different. Additionally, the expected inflation target is relatively stable. Therefore, this paper does not calculate the inflation gap, but directly uses the current GDP deflator to measure the impact of inflation level on default risk of commercial banks.

The purpose of choosing the three indicators of foreign debt, foreign exchange reserves, and foreign trade balance is to measure the impact of external economic factors on the default risk of Chinese commercial banks. As the three indicators of foreign debt, foreign exchange reserve, and current 
account balance are calculated in USD, the quarter-end value of the USD-CNY reference rate is used to calculate the ratio of current increment to nominal GDP.

In order to exclude the influence of seasonal credit changes, this paper chooses the year-on-year growth rate of domestic non-financial sector credit to represent the change of China's credit scale. At the same time, due to the pro-cyclical changes in the prices of collateral and pledges, which promoted the pro-cyclical operation of bank credit, this paper selects two indicators, the total market value of A-shares and cumulative new construction site area year-on-year growth rate, to forecast the default risk of commercial banks, which will strengthen the counter-cyclicality of commercial bank credit. It is worth emphasizing that the year-on-year growth rate of new construction area can better represent the real estate market. During the boom period, due to the active inventory replenishment operations of real estate companies, the year-on-year growth rate of new construction site area increased; during the downturn, because of the active destocking operations of real estate companies, the year-on-year growth rate of new construction site area decreased.

This paper defines the three indicators of C, SM, and REM as credit forward-looking indicators, and other indicators as economic cyclical indicators. The former reflect the correlation between financial sub-markets, while the latter reflect the impact of cyclical changes in macroeconomic indicators on the financial system.

\section{Empirical Analysis}

\subsection{Study Data}

This paper selected 14 listed commercial banks in China, all of which have completed the A-share listing before 2008. Through the Wind database, this paper obtained the data related to the total liabilities, total assets, and the proportion of long-term liabilities disclosed in the annual reports of these 14 commercial Banks from 2007 to 2019, and regarded them as the assets and liabilities situation at the beginning of the next year. Additionally, according to formula (25), the corresponding execution price $\mathrm{B}_{\mathrm{T}}$ in the CCA model was calculated. In order to correspond with the data disclosed in the annual report, the year-end total market value of common shares of each bank under the CSRC algorithm was obtained through the Wind database, which was used as the total market value at the beginning of next year in turn. In this paper, the seven-day fixed repo rate from 2008 to 2019 was selected as the risk-free interest rate of the corresponding year. This paper assumed that when commercial banks make default risk prediction at the beginning of the year, the beginning level of the seven-day fixed repo rate used in the calculation process represents the risk-free interest rate of the whole year and that the annual volatility of ROA of commercial banks in this year remains the level of the annual volatility in the previous year.

When calculating volatility of ROA, this paper first used the weekly closing price of common shares of each bank in the secondary market to calculate the volatility of logarithmic return and converted it into the corresponding annual volatility. The reason why weekly closing price was chosen to calculate volatility is that after one week of price adjustment, weekly closing price can more reasonably show market information. Therefore, this paper argues that the volatility calculated by weekly closing price can more accurately reflect the risk level of the corresponding stock. The relationship between annual volatility $\sigma_{E}$ and weekly volatility $\sigma$ is

$$
\begin{gathered}
\sigma_{E}=\sqrt{52} \sigma \\
\sigma=\sqrt{\frac{1}{n-1} \cdot \sum_{t=1}^{n}\left(u_{t}-u\right)^{2}} \\
u_{t}=\ln \frac{P_{t}}{P_{t-1}}
\end{gathered}
$$

$P_{t}$ represents the closing price of the stock in week $t . P_{t-1}$ represents the closing price of the stock in week $t-1$. $u_{t}$ represents the logarithmic rate of return in week $t$. $u$ represents the annual average of 
the logarithmic rate of return. $n$ represents the number of trading weeks in a year. It was supposed that the stock price follows logarithmic normal distribution.

Then, formula (31) and the B-S-M option pricing formula were iteratively calculated to output the volatility of ROA under the condition that the error is less than 0.0001 .

$$
\sigma_{E}=\frac{\Phi\left(d_{1}\right) \cdot A_{0}}{E_{0}} \cdot \sigma_{A}
$$

$\sigma_{E}$ represents the volatility of ROE. $\sigma_{A}$ represents the volatility of ROA. $A_{0}$ represents total assets of listed commercial banks at the beginning of the year. $E_{0}$ represents the total market value of the stocks of listed banks at the beginning of the year.

The B-S-M option pricing formula is,

$$
E_{0}=A_{0} \Phi\left(d_{1}\right)-B_{T} e^{-r T} \Phi\left(d_{2}\right)
$$

where $r$ represents the risk-free interest rate. The value of $T$ is 1 , which represents unit time. $B_{T}$ represents the total liabilities of listed banks at the end of the year.

As the above 14 banks all completed the listing before October 2007, this paper used the Wind database to obtain the daily closing price and the total market value of the 14 banks from 9 October 2007 to 31 December 2019. The day-on-day growth rate of Shenwan Bank index was taken as the overall stock return rate of the banking industry, and the tail expected losses of each listed commercial bank from the fourth quarter of 2007 to the fourth quarter of 2019 were calculated, respectively, under the $95 \%$ confidence level according to the method shown in formula (15). The forward-looking indicators for the corresponding quarter were obtained. Descriptive statistics are shown in Table 2.

\subsection{Regression Results}

In this paper, according to the Probit regression model proposed in Section 3.1, the probability of the occurrence of Event 1 and Event 2 was regressed, respectively, and the corresponding parameters were estimated. The heteroscedasticity of random terms is a common phenomenon in the regression of binary discrete models. Therefore, this paper adopted the White correction of robust standard error to heteroscedasticity. In addition, each explanatory variable had a certain theoretical correlation. In order to prevent the existence of multicollinearity, this paper used AIC and SC as the basis and adopted the stepwise regression method. The criterion is to increase the explanatory variable in the model if the AIC value or SC value can be reduced. The regression results are shown in Tables 3 and 4.

\subsection{Discussion}

Through the regression analysis of Event 1 and Event 2, it can be found that the larger the output gap in the current period, the more generally inhibiting the effect on the default risk of the commercial banking industry. Theoretically, this is because the policy makers' judgment on the expected output gap is a weighted average of the historical number of the indicator under the conditions of adaptive expectations. Additionally, the closer the time is, the greater the weight will be applied to the judgment. Therefore, the expected output gap will largely depend on the current output gap level. When the current output gap is large, monetary policy makers will expect that the future economy will have a tendency to overheat, and therefore will raise the level of risk-free interest rates to drive the overall interest rate level upward. According to formula (4), the increase in interest rates will increase the default distance, that is, the default risk of commercial banks has a downward trend. The increase in interest rates will reduce the duration of commercial banks' credit assets, shorten the period required to recover the principal, and reduce the bank's default risk accordingly.

The cumulative year-on-year GDP deflator is significantly negatively correlated with the occurrence probability of Event 1 . It can be understood that when the loss of financial institutions from systemic risks is at a historically low level, the higher the level of inflation, the less likely the loss will rise in the 
next year. This is because the level of systemic risk is low and credit activities generally tend to expand under the upward phase of the financial cycle. The expansion of credit is one of the manifestations of loose monetary policy. Yi et al., 2002 [34] believe that the expansion of monetary policy will cause the stock market to rise before the inflation level in the short term, and the subsequent monetary policy tightening brought by the inflation would bring back the excessively rising stock market in the early stage. It can be seen that when the level of systemic risk is low, the increase in inflation actually inhibits the overheating of the stock market, thereby inhibiting the blind credit expansion that occurred during the overheating stage of the stock market, maintaining the credit quality of commercial banks, and preventing the risk from rising due to the future fall of the stock market. The cumulative year-on-year GDP deflator is also significantly negatively correlated with the occurrence probability of Event 2. It can be understood that when the loss of financial institutions from systemic risks is at a historically high level, the higher the inflation level, the less likely the loss will fall. This is because the level of systemic risk is high, and credit activities generally shrink during the downward phase of the financial cycle. At this time, the tight monetary policy brought by high inflation further suppressed the price of assets in the market, which prompts financial institutions to further sell assets and increases the systemic risk and the volatility of ROA of micro-financial institutions.

Table 2. Descriptive statistics.

\begin{tabular}{|c|c|c|c|c|c|}
\hline Indicators & $\begin{array}{c}\text { Mean } \\
(\%)\end{array}$ & $\begin{array}{c}\text { Maximum } \\
(\%)\end{array}$ & $\begin{array}{l}\text { Minimum } \\
(\%)\end{array}$ & $\begin{array}{c}\text { Median } \\
(\%)\end{array}$ & $\begin{array}{c}\text { Standard Deviation } \\
(\%)\end{array}$ \\
\hline OG & -0.0646 & 2.6092 & -4.4480 & -0.1800 & 1.2016 \\
\hline I & 3.5862 & 9.2100 & -0.9800 & 3.1800 & 3.0763 \\
\hline UR & 1.3456 & 10.9100 & -2.0100 & 0.5500 & 2.8118 \\
\hline $\mathrm{C}$ & 16.1958 & 33.1500 & 10.1900 & 15.1400 & 5.2204 \\
\hline FD & 0.0160 & 0.2900 & -0.0500 & 0.0100 & 0.0471 \\
\hline FER & -0.0307 & 0.0600 & -0.1700 & -0.0200 & 0.0498 \\
\hline FTB & 0.0309 & 0.1200 & -0.0100 & 0.0200 & 0.0280 \\
\hline $\mathrm{SM}$ & 0.0269 & 1.0600 & -1.3100 & 0.0100 & 0.4100 \\
\hline REM & 8.0788 & 34.1000 & -17.2744 & 7.4000 & 11.0717 \\
\hline $\mathrm{MES}_{5 \%}(\mathrm{BOB})$ & 2.8567 & 7.6825 & 0.2424 & 2.6778 & 1.6909 \\
\hline $\mathrm{MES}_{5 \%}(\mathrm{ICBC})$ & 2.3188 & 6.3178 & 0.4141 & 1.8245 & 1.6017 \\
\hline $\mathrm{MES}_{5 \%}(\mathrm{HXB})$ & 3.4414 & 9.0823 & 0.6441 & 3.0618 & 2.0274 \\
\hline $\mathrm{MES}_{5 \%}(\mathrm{CCB})$ & 2.5160 & 7.5438 & -1.1957 & 2.3547 & 1.8034 \\
\hline $\mathrm{MES}_{5 \%}(\mathrm{BCM})$ & 3.1825 & 8.8084 & 0.3155 & 2.8477 & 2.0020 \\
\hline $\mathrm{MES}_{5 \%}(\mathrm{CMBC})$ & 3.0042 & 7.5143 & 0.8844 & 2.4681 & 1.7294 \\
\hline $\mathrm{MES}_{5 \%}(\mathrm{NJCB})$ & 3.3603 & 9.8108 & 0.6306 & 2.8801 & 2.0746 \\
\hline $\mathrm{MES}_{5 \%}(\mathrm{NBBANK})$ & 3.5824 & 8.3472 & 1.1519 & 3.3139 & 1.8716 \\
\hline $\mathrm{MES}_{5 \%}(\mathrm{SPABANK})$ & 3.6243 & 7.8368 & 0.0000 & 3.1213 & 2.0302 \\
\hline $\mathrm{MES}_{5 \%}(\mathrm{SPDB})$ & 3.4216 & 8.2442 & 0.8305 & 2.7384 & 1.8345 \\
\hline $\mathrm{MES}_{5 \%}(\mathrm{CIB})$ & 3.4579 & 7.8659 & 0.7896 & 3.0855 & 1.9586 \\
\hline $\mathrm{MES}_{5 \%}(\mathrm{CMB})$ & 3.2992 & 9.4372 & 0.8803 & 2.8517 & 1.7329 \\
\hline $\mathrm{MES}_{5 \%}(\mathrm{BOC})$ & 2.1903 & 6.5244 & 0.1761 & 1.7219 & 1.4162 \\
\hline $\mathrm{MES}_{5 \%}(\mathrm{CITIC})$ & 3.4881 & 7.4035 & 0.8184 & 3.2361 & 1.8095 \\
\hline $\mathrm{DD}(\mathrm{BOB})$ & 0.9203 & 1.7598 & 0.3859 & 0.7131 & 0.5080 \\
\hline $\mathrm{DD}(\mathrm{ICBC})$ & 1.0059 & 1.6012 & 0.5011 & 0.8989 & 0.4069 \\
\hline $\mathrm{DD}(\mathrm{HXB})$ & 0.6915 & 1.5740 & 0.1645 & 0.5097 & 0.4353 \\
\hline $\mathrm{DD}(\mathrm{CCB})$ & 0.8437 & 1.3817 & 0.4464 & 0.7773 & 0.2990 \\
\hline $\mathrm{DD}(\mathrm{BCM})$ & 0.8511 & 1.5797 & 0.2693 & 0.8324 & 0.4449 \\
\hline $\mathrm{DD}(\mathrm{CMBC})$ & 0.7901 & 1.5887 & 0.2977 & 0.7179 & 0.4198 \\
\hline $\mathrm{DD}(\mathrm{NJCB})$ & 0.7086 & 1.1121 & 0.3419 & 0.7307 & 0.2345 \\
\hline DD(NBBANK) & 0.6362 & 1.0126 & 0.3022 & 0.6199 & 0.2449 \\
\hline DD(SPABANK) & 0.5333 & 1.2552 & 0.0627 & 0.5279 & 0.3037 \\
\hline $\mathrm{DD}(\mathrm{SPDB})$ & 0.7035 & 1.3419 & -0.2586 & 0.6655 & 0.4588 \\
\hline $\mathrm{DD}(\mathrm{CIB})$ & 0.6777 & 1.4472 & 0.0034 & 0.5734 & 0.4535 \\
\hline $\mathrm{DD}(\mathrm{CMB})$ & 0.6393 & 1.0232 & 0.1790 & 0.6745 & 0.2182 \\
\hline $\mathrm{DD}(\mathrm{BOC})$ & 1.0909 & 1.7820 & 0.3374 & 1.1328 & 0.4348 \\
\hline DD(CITIC) & 0.6415 & 1.1214 & 0.2089 & 0.6202 & 0.2989 \\
\hline
\end{tabular}


Table 3. Regression results on the probability of Event 1.

\begin{tabular}{|c|c|c|c|c|c|c|c|c|c|c|}
\hline Banks & c & OG & I & UR & $C$ & FD & FER & FTB & SM & REM \\
\hline BOB & -1.009 & $\begin{array}{c}-0.989 * * \\
(0.017)\end{array}$ & $\begin{array}{c}-0.446^{* *} \\
(0.018)\end{array}$ & - & - & - & - & - & $\begin{array}{l}1.545 * * \\
(0.025)\end{array}$ & $\begin{array}{l}0.053^{*} \\
(0.063)\end{array}$ \\
\hline ICBC & -0.916 & $\begin{array}{c}-0.364 \text { * } \\
(0.080)\end{array}$ & - & - & - & - & - & - & - & $\begin{array}{l}0.043^{* *} \\
(0.039) \\
\end{array}$ \\
\hline HXB & 0.055 & - & - & $\begin{array}{c}-0.281 \text { ** } \\
(0.010)\end{array}$ & - & - & - & - & $\begin{array}{l}0.978^{* *} \\
(0.042)\end{array}$ & - \\
\hline $\mathrm{CCB}$ & 2.832 & - & $\begin{array}{c}-0.370 \text { *** } \\
(0.003)\end{array}$ & - & $\begin{array}{c}-0.169^{* * *} \\
(0.008)\end{array}$ & - & $\begin{array}{c}-19.971^{* * *} \\
(0.008)\end{array}$ & - & - & - \\
\hline $\mathrm{BCM}$ & 6.423 & $\begin{array}{c}-1.652 * * * \\
(0.005)\end{array}$ & - & $\begin{array}{c}-0.326^{*} \\
(0.063)\end{array}$ & $\begin{array}{c}-0.450^{* * *} \\
(0.002)\end{array}$ & - & - & $\begin{array}{c}-21.770 * * \\
(0.038)\end{array}$ & - & $\begin{array}{l}0.049^{*} \\
(0.081)\end{array}$ \\
\hline CMBC & 1.631 & $\begin{array}{c}-0.862 \text { ** } \\
(0.027)\end{array}$ & - & $\begin{array}{c}-0.445^{* *} \\
(0.017)\end{array}$ & $\begin{array}{l}-0.106^{*} \\
(0.073)\end{array}$ & - & - & - & $\begin{array}{l}1.670^{* *} \\
(0.013)\end{array}$ & - \\
\hline NJCB & 0.768 & - & $\begin{array}{c}-0.206^{* *} \\
(0.010)\end{array}$ & $\begin{array}{c}-0.302 * * \\
(0.010)\end{array}$ & - & - & - & - & - & - \\
\hline NBBANK & 3.937 & $\begin{array}{c}-0.794 \text { ** } \\
(0.013)\end{array}$ & - & - & $\begin{array}{c}-0.271^{* * *} \\
(0.004)\end{array}$ & - & - & $\begin{array}{c}-28.101 * * * \\
(0.009)\end{array}$ & - & $\begin{array}{l}0.063 \text { ** } \\
(0.020)\end{array}$ \\
\hline SPABANK & 2.187 & $\begin{array}{c}-0.853^{* * *} \\
(0.002)\end{array}$ & - & - & $\begin{array}{c}-0.216^{* * *} \\
(0.000)\end{array}$ & - & - & - & $\begin{array}{l}1.764^{* *} \\
(0.010)\end{array}$ & $\begin{array}{c}0.095 \\
* * * \\
(0.002)\end{array}$ \\
\hline SPDB & -0.308 & - & - & $\begin{array}{c}-0.210 * \\
(0.055)\end{array}$ & - & - & - & - & - & - \\
\hline $\mathrm{CIB}$ & 3.410 & $\begin{array}{l}-0.811 * \\
(0.068)\end{array}$ & - & $\begin{array}{c}-0.286 * \\
(0.069)\end{array}$ & $\begin{array}{c}-0.267 \text { ** } \\
(0.020)\end{array}$ & - & - & - & - & $\begin{array}{l}0.046^{*} \\
(0.053)\end{array}$ \\
\hline CMB & 0.566 & - & $\begin{array}{c}-0.272 * * * \\
(0.003)\end{array}$ & $\begin{array}{c}-0.336^{*} \\
(0.052)\end{array}$ & - & - & - & - & - & - \\
\hline BOC & 1.871 & - & $\begin{array}{c}-0.301^{* * *} \\
(0.007)\end{array}$ & - & $\begin{array}{c}-0.133^{* * *} \\
(0.038)\end{array}$ & - & $\begin{array}{c}-17.849^{* *} \\
(0.011)\end{array}$ & - & - & - \\
\hline CITIC & 2.673 & - & $\begin{array}{l}-0.147 \text { * } \\
(0.057)\end{array}$ & - & $\begin{array}{c}-0.183^{* * * *} \\
(0.006)\end{array}$ & - & - & - & - & $\begin{array}{l}0.051 \text { ** } \\
(0.018)\end{array}$ \\
\hline
\end{tabular}

$* * *, * * *{ }^{*}$ indicate significance at the $0.01,0.05$, and 0.10 level, respectively.

Table 4. Regression results on the probability of Event 2.

\begin{tabular}{|c|c|c|c|c|c|c|c|c|c|c|}
\hline Banks & OG & $I$ & UR & $\mathrm{C}$ & FD & & FER & FTB & SM & REM \\
\hline ВOB & -1.041 & $\begin{array}{l}0.525^{*} \\
(0.053)\end{array}$ & - & - & - & - & $\begin{array}{c}-12.146^{*} \\
(0.082)\end{array}$ & - & - & $\begin{array}{c}-0.070 * \\
(0.090)\end{array}$ \\
\hline ICBC & -0.512 & - & - & - & $\begin{array}{c}-0.10973^{\text {** }} \\
(0.048)\end{array}$ & - & $\begin{array}{c}-18.604 \text { ** } \\
(0.039)\end{array}$ & - & - & - \\
\hline HXB & -1.363 & - & - & - & - & - & - & $\begin{array}{c}17.058^{* *} \\
(0.018)\end{array}$ & - & - \\
\hline $\mathrm{CCB}$ & -1.740 & - & $\begin{array}{c}-0.137 * \\
(0.098)\end{array}$ & - & - & - & - & $\begin{array}{c}18.986^{* *} \\
(0.017)\end{array}$ & $\begin{array}{c}-1.586 * * \\
(0.050)\end{array}$ & - \\
\hline $\mathrm{BCM}$ & 17.039 & - & - & $\begin{array}{c}40.511^{* * *} \\
(0.000)\end{array}$ & $\begin{array}{c}-18.374^{* * * *} \\
(0.000)\end{array}$ & $\begin{array}{c}-139.812^{* * *} \\
(0.000)\end{array}$ & $\begin{array}{c}-125.262 * * * \\
(0.000)\end{array}$ & $\begin{array}{c}4640.601 * * * \\
(0.000)\end{array}$ & - & $\begin{array}{c}-6.800 \\
* * * * \\
(0.000)\end{array}$ \\
\hline $\mathrm{CMBC}$ & 15.192 & - & - & $\begin{array}{l}2.146^{* * *} \\
(0.023)\end{array}$ & $\begin{array}{c}-1.518^{* * *} \\
(0.014)\end{array}$ & - & $\begin{array}{c}-116.758^{* * *} \\
(0.009)\end{array}$ & - & - & $\begin{array}{c}-0.252 \text { ** } \\
(0.015)\end{array}$ \\
\hline NJCB & -0.455 & $\begin{array}{c}1.212 * * * \\
(0.002)\end{array}$ & $\begin{array}{c}-0.379^{* *} \\
(0.012)\end{array}$ & - & - & $\begin{array}{c}-53.973^{* * *} \\
(0.007)\end{array}$ & $\begin{array}{c}-18.660 * \\
(0.074)\end{array}$ & $\begin{array}{c}27.735^{* *} \\
(0.014)\end{array}$ & $\begin{array}{c}-2.464^{* *} \\
(0.023)\end{array}$ & - \\
\hline NBBANK & -1.235 & - & $\begin{array}{c}-0.289 \\
* * * \\
(0.005)\end{array}$ & - & - & - & - & $\begin{array}{c}38.942 * * * \\
(0.000)\end{array}$ & $\begin{array}{c}-2.147^{* * *} \\
(0.001)\end{array}$ & - \\
\hline SPABANK & -1.335 & - & - & - & - & - & - & $\begin{array}{c}20.222^{* * *} \\
(0.000)\end{array}$ & $\begin{array}{c}-1.474^{* *} \\
(0.024)\end{array}$ & - \\
\hline SPDB & -1.756 & - & - & $\begin{array}{l}0.173^{* *} \\
(0.011)\end{array}$ & - & - & - & $\begin{array}{c}18.484^{* *} \\
(0.015)\end{array}$ & - & - \\
\hline CIB & -1.705 & - & - & $\begin{array}{l}0.173^{* *} \\
(0.011)\end{array}$ & - & - & - & $\begin{array}{c}18.484^{* *} \\
(0.015)\end{array}$ & - & - \\
\hline $\mathrm{CMB}$ & -1.591 & - & - & $\begin{array}{c}48.593^{* * *} \\
(0.000)\end{array}$ & $\begin{array}{c}-20.831^{* * * *} \\
(0.000)\end{array}$ & $\begin{array}{c}-107.995^{* * *} \\
(0.000)\end{array}$ & - & $\begin{array}{c}5558.682 * * * \\
(0.000)\end{array}$ & - & $\begin{array}{l}-6.903 \\
* * * * \\
(0.000)\end{array}$ \\
\hline BOC & 0.255 & - & - & - & $\begin{array}{c}-0.1296^{* *} \\
(0.014)\end{array}$ & $\begin{array}{c}-12.846^{* *} \\
(0.035)\end{array}$ & - & - & - & - \\
\hline CITIC & 1.038 & $\begin{array}{l}0.451 \text { ** } \\
(0.019)\end{array}$ & $\begin{array}{c}-0.231 \text { * } \\
(0.072)\end{array}$ & - & $\begin{array}{c}-0.125 * \\
(0.072)\end{array}$ & - & $\begin{array}{c}-15.914 \text { * } \\
(0.099)\end{array}$ & $\begin{array}{c}17.250 \text { ** } \\
(0.041)\end{array}$ & - & - \\
\hline
\end{tabular}

$* * *, * * *$ indicate significance at the $0.01,0.05$, and 0.10 level, respectively. 
The year-on-year growth rate of urban unemployment has a significant negative correlation with the probability of Event 1 and a significant positive correlation with the probability of Event 2 . This indicates that no matter whether the losses of commercial banks from systemic risks are at a historical high or low level at the present stage, the lower the level of unemployment, the more likely commercial banks will encounter default events triggered by systemic risks in the next year. Conversely, the higher the level of unemployment, the lower the probability that commercial banks will default in the next year. This is because the fluctuation of the unemployment level represents the deviation of the actual unemployment rate from the natural unemployment rate. When the unemployment level is lower, it indicates that the current macro economy has a tendency to overheat, and when the unemployment level is higher, it indicates that the current macro economy is more depressed. As the macro economy is characterized by cyclical changes, commercial banks should put forward higher provision requirements when the level of unemployment is lower, so as to prevent a surge in non-performing loans of commercial banks and an increase in their own default risk due to future economic recessions. In contrast, when the unemployment level is higher, commercial banks should reduce their provision requirements accordingly, so as to adapt to the future economic recovery. It can be seen that the dynamic provisioning model constructed in this article realizes the prospect of cyclical fluctuations in the macro economy due to the inclusion of the unemployment indicator.

Compared with China's current dynamic provisioning model, the model proposed in this paper introduces three forward-looking indicators, the output gap, the cumulative year-on-year GDP deflator, and the year-on-year growth rate of urban unemployment, which make the model more sensitive to fluctuations in macroeconomic cycles while taking into account the credit cycle.

The domestic non-financial sector credit year-on-year growth rate has a significant negative correlation with the occurrence probability of events 1 and 2 . When the financial cycle is downward and the level of systemic risk is high, the expansion of credit will restrain the decline of default risk in the banking industry, further promoting the level of systemic risk in the next year. When the financial cycle goes up and the level of systemic risk is low, the expansion of credit scale will restrain the rise of default risk in the banking industry and maintain a low level of systemic risk. This regression result shows that when the fluctuation of systemic risk occurs before the counter-cyclical credit adjustment policy, the policy will promote systemic risk instead. This further illustrates that counter-cyclical policy adjustments should be forward-looking.

The ratio of the quarterly increase in foreign debt to nominal GDP has a significant negative correlation with the probability of Event 2. This shows that when the level of systemic risk is high, the increase in China's foreign debt will lead to a general increase in the default risk of commercial banks in the next year. This phenomenon is not significant when the systemic risk is low. The main reason for this phenomenon is that there is a huge difference between the foreign debt volume and the treasury bonds volume in China. The increase in the level of foreign debt cannot replace the issuance of treasury bonds, nor can it optimize the debt structure of central finance in China. At the same time, the increase in the volume of foreign debt requires a country to have sufficient foreign exchange reserves as a guarantee, which weakens the country's ability to use foreign reserves to maintain exchange rate stability, and exchange rate fluctuations will increase the default risk of sovereign debt. Gorzelak et al.2019 [35] used panel data regression to analyze developed and developing countries from 1970 to 2012 and found that the default risk of sovereign debt has a significant non-linear positive correlation with the default risk of the private sector. Therefore, when the default risk of foreign debt rises, it will trigger a "spiral rise" in the default probability of sovereign debt and the default probability of the private sector, which will eventually cause the systemic risk to increase sharply, the credit quality of commercial banks to generally deteriorate, and banks default risks to generally increase.

There is a significant negative correlation between the ratio of quarterly increase in foreign exchange reserves to nominal GDP and the occurrence probability of Event 1 and Event 2. Foreign exchange reserves have both advantages and disadvantages for a country's macroeconomic development. On the one hand, the increase in foreign exchange reserves is conducive to enhancing the ability of the central 
bank of China to intervene in the foreign exchange market, meeting the needs of maintaining the stability of exchange rate and blocking the transmission of international economic fluctuations to the country. On the other hand, when a country's foreign exchange reserves are higher than the appropriate scale, it will cause waste of social resources and decline in output. Agarwal 1971 [36], when studying the appropriate scale of foreign exchange reserves of developing countries, proposed that if the foreign exchange held by them that exceeds the appropriate size is used to import production, the underemployment situation in developing countries can be improved, so as to enhance the output level of the country. Therefore, when a country holds excessive foreign exchange reserves, it can be seen as suppressing the country's overall investment returns to a certain extent. As a result, the default risk of China's commercial banks generally rises, and the systemic risk also goes up. Foreign exchange reserves have opposite effects on the default risk of commercial banks from the channels of interest rate and asset volatility, respectively. Through the above results, it can be found that when the level of systemic risk is low, the increase of foreign exchange reserve increment will restrain the increase of default risk of commercial banks in the next year. When the level of systemic risk is high, the increase of foreign exchange reserve increment will keep the default risk of commercial banks at a high level.

The ratio of quarterly increase in current account balance to nominal GDP has a significant negative correlation with the probability of Event 1 and a significant positive correlation with the probability of Event 2, which shows that the foreign trade surplus will bring about a general decline in the default risk of commercial banks in the next year. This is because the increase of current account surplus is conducive to improving China's foreign exchange reserves, reducing the pressure on the central bank to use foreign exchange in adjusting the foreign exchange market and preventing the transmission of external risks to China through the price mechanism.

The ratio of quarterly increase in total market value of A-shares to nominal GDP and cumulative new construction site area year-on-year growth rate has a significant positive correlation with the probability of Event 1 and a significant negative correlation with the probability of Event 2. The reason is that, due to the general rise in stock prices and real estate prices, there is an over-expansion trend in credit that uses listed company stocks as collateral or real estate as collateral, which makes the average credit quality of commercial banks decline. Moreover, the extent of losses caused by systemic risks in commercial banks will generally rise in the next year. Conversely, the general decline in stock prices and real estate prices will inhibit the blind expansion of commercial bank credit and reduce the impact of systemic risks on commercial banks.

The introduction of forward-looking indicators, the ratio of the quarterly increase in foreign debt to nominal GDP, and the ratio of quarterly increase in foreign exchange reserves to nominal GDP allows the dynamic provisioning model to take into account the impact of the external economy on China's economy when making counter-cyclical adjustments. In addition, the introduction of forward-looking indicators, the ratio of quarterly increase in current account balance to nominal GDP, and the ratio of quarterly increase in total market value of A-shares to nominal GDP makes it possible to refer to the driving factors of fluctuations in the credit cycle when calculating the dynamic provision rate and makes the model more forward-looking. The above two aspects reflect the advanced nature of the model proposed in this paper relative to the current model in China.

\subsection{Counter-Cyclical Validity Test}

The dynamic provisioning model can realize the effectiveness of counter-cyclical adjustment, which means that it has the following two functions. First, the loan provision behavior of commercial banks can be adjusted counter-cyclically, and it forms excess provision for non-performing loans in the upward stage of the cycle, the provision which acts as a buffer for the downward stage of the cycle. Second, it can regulate the credit behaviors of commercial banks in a counter-cyclical manner, restrain the excessive expansion of credit in the upward stage of the cycle, and prevent the rapid contraction of credit in the downward stage of the cycle. 
As shown in Table 5, according to formula (24), the correlation coefficients between the default distances of 14 listed commercial banks and their thresholds of Event 1 and Event 2 in the binary Gaussian Copula model are calculated. Then, according to formulas (23) and (27), the dynamic provisioning ratio of the 14 listed commercial banks from 2008 to 2019 is back-tested.

Table 5. The correlation coefficients in the binary Gaussian Copula model.

\begin{tabular}{ccc}
\hline BANK & EVENT 1 & EVENT 2 \\
\hline BOB & 0.373 & -0.367 \\
ICBC & 0.023 & -0.064 \\
HXB & -0.522 & 0.496 \\
CCB & -0.120 & 0.266 \\
BCM & -0.489 & -0.218 \\
CMBC & -0.337 & 0.113 \\
NJCB & -0.354 & -0.044 \\
NBBANK & -0.400 & 0.316 \\
SPABANK & -0.150 & 0.224 \\
SPDB & -0.549 & 0.609 \\
CIB & -0.502 & 0.474 \\
CMB & -0.527 & -0.103 \\
BOC & -0.140 & -0.354 \\
CITIC & -0.185 & -0.083 \\
\hline
\end{tabular}

It is necessary to emphasize that the dynamic provisioning rate provided in this paper is not the total loan loss provision ratio provided by commercial banks during credit operations. It is a supplementary provisioning rate that is additionally set based on a forward-looking view of cyclical systemic risk and has a corrective effect on the micro-prudential loan provision rate based on a five-tier classification method.

As shown in Figure 2, the dynamic provisioning rate based on the model in this paper has a strong counter-cyclical characteristic. Affected by the U.S. financial crisis, the default distances of 14 listed commercial banks in China from 2009 to 2011 were all at a relatively low level, indicating that China's banking industry was also affected during the global financial crisis. At this stage, the dynamic provisioning requirements in this paper are also at a historically low level, releasing credit creation capabilities and helping to supplement the overall economic liquidity. During the period from 2012 to 2013, because the default risk of commercial banks was generally alleviated, the dynamic provisioning rate also increased accordingly, so that the loss reserve coul be accumulated at a lower cost for the subsequent rise of systemic risks. From 2014 to 2016, the supply-side structural reforms and the policy orientation of preventing financial risks worsened the default risk of the country's commercial banks, and the dynamic provisioning rate measured back declined, which can promote the overall economic stability. Since 2017, the default distance of listed commercial banks has been at a historically high level. In order to limit the blind expansion of bank credit, the dynamic provisioning rate level of the commercial banking industry has risen, achieving the characteristics of counter-cyclical adjustment. In addition, this paper has different requirements for dynamic provision of different commercial banks, instead of a one-size-fits-all regulatory model. While maintaining the safety of commercial banks, it also takes into account differences and profitability. 


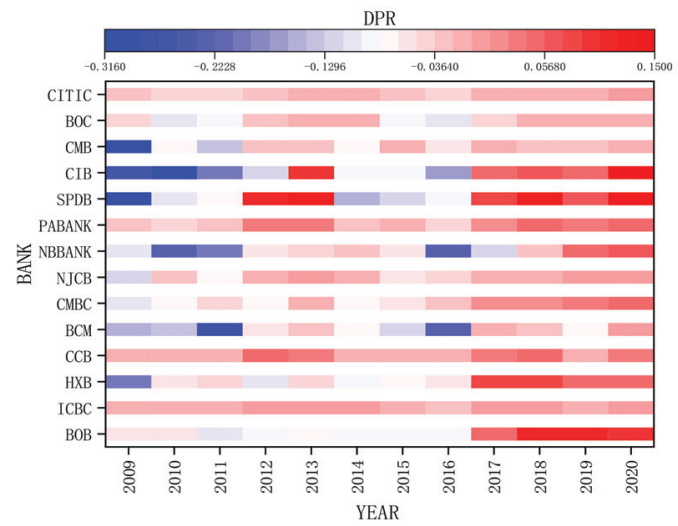

(a)

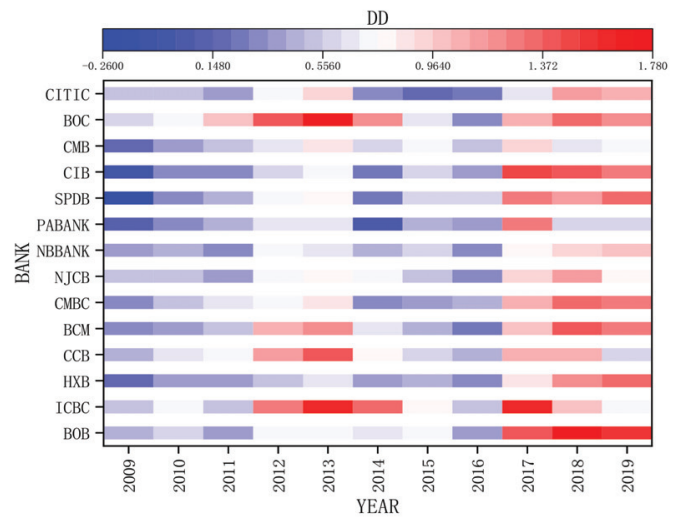

(b)

Figure 2. (a) Dynamic provisioning rate based on the model presented in this paper; (b) default distance of listed commercial banks.

According to the theoretical analysis in Chapter 3, macroeconomic and systemic financial risks are transmitted to the default risk of commercial banks through the two channels of asset return rate and asset volatility in the process of financial cycle changes, thus affecting the bank's leverage ratio adjustment and credit behavior. Therefore, it is possible to simulate the changes of default risk prediction of commercial banks to examine their credit behavior in the economic and financial cycle. After commercial banks are required to take dynamic provision based on the CCA-Probit-Copula model, the fixed index of default risk is changed from the default distance in CCA model to the modified default distance in formula (23). As shown in Figure 3, the modified default distance has a significant improvement in cross-cycle stability compared to the default distance in the CCA model. This indicates that the dynamic provisioning rate in this paper can make the risk prediction of commercial banks appear with less fluctuation, thus making the credit operation more stable and realizing the goal of counter-cyclical regulation of macro-prudential policy. 


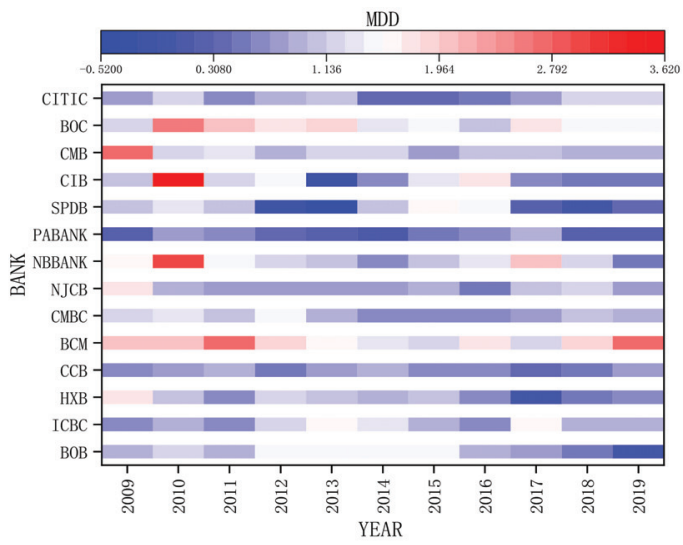

(a)

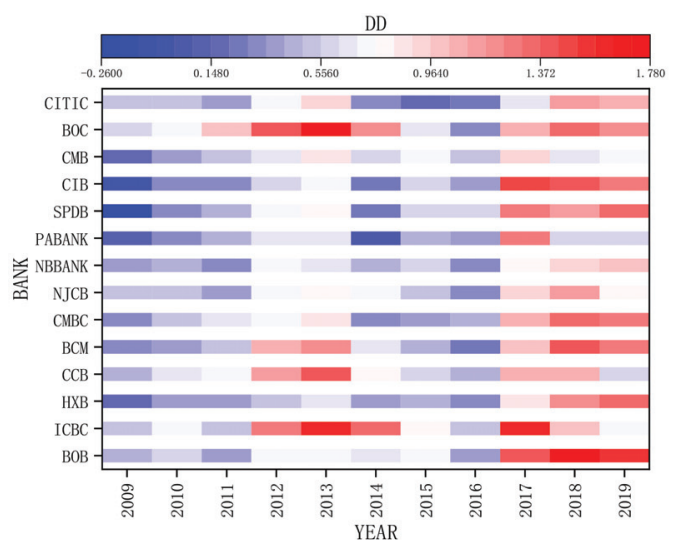

(b)

Figure 3. (a) Modified default distance presented in this paper; (b) default distance in CCA model.

\section{Conclusions}

In China, under an economic system dominated by indirect financing, maintaining the continuity of commercial bank credit is the key to ensuring the sustained development of the national economy. Therefore, counter-cyclical credit adjustment is an inevitable requirement for maintaining the sustainable development of China's economy. Establishing a forward-looking dynamic provisioning system is a key step to improve the macro-prudential supervision system and curb cyclical fluctuations in bank credit. After reading and summarizing relevant literature, a dynamic provisioning model based on the CCA-Probit-Copula model is constructed in this paper to achieve the policy goal of counter-cyclical adjustment of bank credit against the background of China's actual national conditions. The model measures the impact of China's systemic risks on the default risk of commercial banks and provides a counter-cyclical dynamic provisioning rate based on nine forward-looking indicators. According to the historical data of listed commercial banks in China, the empirical test proves that the dynamic provisioning requirements proposed in this model can effectively adjust the overall credit scale of the banking industry in counter-cyclical ways. Therefore, under the macro-prudential framework, 
policy goals of counter-cyclicality can be achieved, maintaining the security of China's financial system and sustainable development of the macroeconomy.

Research conclusions of this paper mainly include the following:

- Both the macroeconomic cyclical factors and the forward-looking factors of credit risk are taken into consideration. The effective way out of such dilemmas as insufficient historical credit data reserves of commercial banks, excessive reliance on subjective judgments, and conflicts with the current accounting system is the CCA-Probit-Copula dynamic provisioning model.

- On the basis of multiple forward-looking indicators, carrying out the CCA-Probit-Copula dynamic provisioning model can make it possible to propose matching differentiated dynamic provisioning requirements in accordance with the degree to which different commercial banks' default risks are affected by macro-cyclical factors. This not only considers the safety and liquidity of commercial banks, but also ensures their profitability and competitiveness.

- The dynamic provisioning rate based on the CCA-Probit-Copula model can respond sensitively to the cyclical changes in the overall commercial banking sector's default risk, which enables banks to accumulate provisions for high-risk periods at lower costs during low-risk periods. Moreover, the continuity and stability of bank credit operations can be significantly improved under the effect of this dynamic provisioning rate, so as to promote the sustainable development of China's economy.

Author Contributions: Conceptualization: X.H. and A.Z.; methodology: X.H. and A.Z.; software: A.Z.; validation: X.H. and A.Z.; formal analysis: X.H. and A.Z.; data curation: X.H. and A.Z.; writing-original draft preparation: X.H. and A.Z.; writing-review and editing: X.H. and A.Z.; funding acquisition: X.H. All authors have read and agreed to the published version of the manuscript.

Funding: This research was funded by Key Program of NSFC, Research on Financial Innovation and Risk Analysis Theory in the Network Big Data Environment (71532004), and Surface Project of NSFC, Research on Financial Crisis Contagion Based on Multifractal Theory (71773024).

Acknowledgments: The authors are grateful to the editors and anonymous reviewers for their valuable comments on earlier versions of the manuscript.

Conflicts of Interest: The authors declare no conflict of interest.

\section{Appendix A}

Because the A-share market has price limits, the daily return rates of listed commercial banks are all between $-10 \%$ and $10 \%$. According to the actual situation of the MES value of 14 listed commercial banks in China selected in this paper, 1\%, 3\%, 5\%,7\%, and 9\% are selected as the boundary values for defining Event 1 and Event 2, respectively. Regression analysis was performed on events with different value methods, and the optimal definition of Event 1 and Event 2 was determined based on the following three principles.

- In the regression analysis of events with different definition methods, the method with the most universally significant parameter estimation is selected.

- In regression analysis, the same forward-looking indicator should indicate the same direction for changes in the default risk of commercial banks, otherwise it will be regarded as a false regression.

- The emergence of extreme values in the regression parameters should be avoided, otherwise the regression results defined by this value method cannot be used to propose the dynamic provisioning ratio.

Due to space limitations, the regression results of other event definition methods are not presented in the paper. Those interested can contact the author's email at zhangaoran@sjtu.edu.cn.

\section{References}

1. Borio, C. Towards a Macroprudential Framework for Financial Supervision and Regulation; BIS: Basel, Switzerland, 2003. 
2. Kashyap, A.K.; Stein, J.C. Cyclical implications of the Basel II capital standards. Econ. Perspect. 2004, 28, 18-31.

3. Liu, Z. Research on the Quantity Selection of Regulatory Capital. Financ. Regul. Res. 2012, 1, 75-87.

4. Kashyap, A.K.; Rajan, R.G.; Stein, J.C. Rethinking capital Regulation. In Proceedings of the Economic Policy Symposium, Jackson Hole, WY, USA, 10 August 2020.

5. Hanson, S.; Kashyap, A.K.; Stein, J.C. A Macroprudential Approach to Financial Regulation. J. Econ. Perspect. 2011, 25, 3-28. [CrossRef]

6. Wezel, T.; Chan-Lau, J.A.; Columba, F. Dynamic Loan Loss Provisioning Simulations on Effectiveness and Guide to Implementation; IMF: Washington, DC, USA, 2012.

7. Kanagaretnam, K.; Lobo, G.J.; Yang, D. Determinants of signaling by banks through loan loss provisions. J. Bus. Res. 2005, 58, 312-320. [CrossRef]

8. Jin, J.Y.; Kanagaretnam, K.; Lobo, G.J.; Mathieu, R. Impact of FDICIA internal controls on bank risk taking. J. Bank. Financ. 2013, 37, 614-624. [CrossRef]

9. Balla, E.; McKenna, A. Dynamic provisioning: A countercyclical tool for loan loss reserves. Econ. Q. 2009, 95, 383-418.

10. López, M.; Tenjo, F.; Zárate, H. Credit Cycles, Credit Risk and Countercyclical Loan Provisions. Ens. Sobre Política Econ. 2014, 74, 9-17.

11. Jiménez, G.; Ongena, S.; Peydró, J.; Saurina, J. Macroprudential Policy, Countercyclical Bank Capital Buffers, and Credit Supply: Evidence from the Spanish Dynamic Provisioning Experiments. J. Polit. Econ. 2017, 125, 2126-2177. [CrossRef]

12. Fernández de Lis, S.; Garcia-Herrero, A. Dynamic Provisioning: Some Lessons from Existing Experiences; Asian Development Bank Institute: Manila, Philippines, 2010.

13. Fernández de Lis, S.; Garcia-Herrero, A. Dynamic Provisioning: A Buffer Rather Than a Countercyclical Tool. Economía 2013, 2, 387-398.

14. Huang, R.; Jiang, H.; Huang, J. Dynamic Provisioning, Financial Risk and Economic Cycle Based on DSGE Model. Mod. Financ. Econ. 2014, 2, 29-41.

15. Gao, J.; Fan, C.; Yang, D. The Synergistic Effect of Chattel Mortgage Financing for Enterprises and Macro-prudential Regulation. J. Financ. Res. 2017, 39, 111-125.

16. Zhang, X.; Yu, L. Spain's Dynamic Provisioning System and Its Enlightenment to China. J. Financ. Res. 2004, 26, 28-35.

17. Li, W. Discussion on Counter-cyclical Policies under the Framework of Macro-prudential Supervision. J. Financ. Res. 2009, 31, 7-24.

18. Li, H.; Hu, Y.; Si, Z. Research on the Implementation of Dynamic Provisioning in China's Banking Industry. China Financ. 2010, 8, 142-151.

19. Chen, C.; Wei, J.; Cao, L. Do China's Commercial Banks Use Loan Loss Provision for Income Smoothing? J. Financ. Res. 2015, 37, 46-63.

20. Zhang, R.; Li, D. An Analysis of Managerial Discretion Behavior Based on Discretionary Loan Loss Provision. Financ. Forum 2016, 12, 30-39.

21. Bushman, R.M.; Williams, C.D. Accounting discretion, loan loss provisioning, and discipline of Banks' risk-taking. J. Account. Econ. 2012, 54, 1-18. [CrossRef]

22. Li, Y.; Lu, J. A Study on Provisioning for Forward- looking Loan Loss in the Banking. Financ. Forum 2008, 4, $42-48$.

23. Xu, Y.; Liu, Q.; Wang, Z. Research on the Appropriateness of Dynamic and Forward-looking Loan Loss Provision. J. Financ. Res. 2011, 33, 100-114.

24. Gray, D.F.; Merton, R.C.; Bodie, Z. A New Framework for Measuring and Managing Macrofinancial Risk and Financial Stability. 2007. Available online: https://www.researchgate.net/publication/43106070 (accessed on 3 February 2015).

25. Jobst, A.A.; Gray, D.F. Systemic CCA-A Model Approach to Systemic Risk. In Proceedings of the Beyond the Financial Crisis: Systemic Risk, Spillovers and Regulation, Dresden, Germany, 28 October 2010.

26. Merton, R.C. Pricing of corporate debt: The Risk Structure of Interest Rates. J. Financ. 1974, 29, 449-470.

27. Cox, J.C.; Ross, S.A. The valuation of options for alternative stochastic processes. J. Financ. Econ. 1976, 3, 145-166. [CrossRef] 
28. Acharya, V.V.; Pedersen, L.H.; Philippon, T.; Richardson, M. Measuring Systemic Risk. Rev. Financ. Stud. 2016, 30, 2-47. [CrossRef]

29. Frankel, J.A.; Rose, A.K. Currency crashes in emerging markets: An empirical treatment. J. Int. Econ. 1996, 41, 351-366. [CrossRef]

30. Behn, M.; Detken, C.; Peltonen, T.A.; Schudel, W. Setting Countercyclical Capital Buffers Based on Early Warning Models: Would it Work; European Central Bank: Frankfurt, Germany, 2013.

31. Detken, C.; Weeken, O.; Alessi, L.; Bonfim, D.; Boucinha, M.M.; Castro, C.; Frontczak, S.; Giordana, G.; Giese, J.; Jahn, N.; et al. Operationalising the Countercyclical Capital Buffer: Indicator Selection, Threshold Identification and Calibration Options; European Systemic Risk Board: Frankfurt, Germany, 2014.

32. Shen, Y.; Qi, L. Index System Design and Monitoring of Chinese Financial Bank Systemic Risks. J. Southwest Univ. Soc. Sci. Ed. 2008, 34, 139-143.

33. Ma, J.; He, X.; Liu, S. A Crisis Warning Model Based on Macro Variables; National Institute of Finance, Tsinghua University: Beijing, China, 2019.

34. Yi, G.; Wang, Z. Monetary Policy and Financial Assets Price. Econ. Res. J. 2002, 48, 13-20.

35. Siwińska-Gorzelak, J.; Brzozowski, M. Sovereign default and the structure of private external debt. Cent. Eur. Econ. J. 2019, 5, 1-9. [CrossRef]

36. Agarwal, J.P. Optimal Monetary Reserves for Developing Countries. Weltwirtschaftliches Arch. 1971, 107, 76-91. [CrossRef]

Publisher's Note: MDPI stays neutral with regard to jurisdictional claims in published maps and institutional affiliations.

(C) 2020 by the authors. Licensee MDPI, Basel, Switzerland. This article is an open access article distributed under the terms and conditions of the Creative Commons Attribution (CC BY) license (http://creativecommons.org/licenses/by/4.0/). 
Article

\title{
Industry-Specific and Macroeconomic Determinants of Non-Performing Loans: A Comparative Analysis of ARDL and VECM
}

\author{
Changjun Zheng ${ }^{1}$, Probir Kumar Bhowmik ${ }^{1, *}$ and Niluthpaul Sarker ${ }^{2}$ \\ 1 School of Management, Huazhong University of Science and Technology, Wuhan 430074, China; \\ zhchjun@hust.edu.cn \\ 2 Department of Accounting and Information Systems, Jagannath University, Dhaka 1100, Bangladesh; \\ niluthpaul@yahoo.com \\ * Correspondence: probir9012@gmail.com
}

Received: 15 December 2019; Accepted: 26 December 2019; Published: 31 December 2019

\begin{abstract}
With the growth of an economy, the banking industry expands and the competitiveness becomes intense with the increased number of banks in the economy. The objective of this research was to discover the influence of industry-specific and macroeconomic determinants of non-performing loans (NPLs) in the entire banking system of Bangladesh. We performed an analysis for the period from 1979 to 2018 by an autoregressive distributed lag (ARDL) model and checked the robustness of the results in the vector error correction (VEC) model. The outcomes of this research suggest that both industry-specific and macroeconomic factors influence NPLs significantly. Among the industry-specific determinants, bank loan growth, net operating profit, and deposit rates negatively impact NPLs with statistical significance while bank liquidity and lending rates have a significant positive affiliation with NPLs. Gross domestic product (GDP) growth and unemployment, among the macroeconomic variables, have a negative connection with NPLs. Whereas, domestic credit and exchange rates have a significant positive association with NPLs. The contribution of this research is that the outcomes found by means of econometric models can be used for predicting and measuring NPLs in upcoming years, not only for Bangladesh but also for developing and emerging economies. Individual banks, as well as the banking sector, by and large, can get a guideline from this research.
\end{abstract}

Keywords: loan expansion; GDP; NPL; ARDL; VECM; Johansen test of co-integration; unit root

JEL Classification: C58; G21; E60

\section{Introduction}

Non-performing loans (NPLs) are a threat to sustainable development for developing countries. NPLs are considered as the major indicator of the financial stability of the banking sector. In developing economies, banks usually take greater risks to increase their market shares. With the chance of higher profit, risk increases, which ultimately results in non-performing loans [1]. NPLs have become a matter of concern for all countries in the world, and as a prerequisite to reinstate the functionality of financial markets, NPLs and its determinants should be addressed carefully [2]. Ex-post credit risk as an element of non-performing loans is one of the key features of the banking system and economic downturn [3,4]. Banks at risk of failing have significant proportions of NPLs in their portfolios of loans before collapse or financial distress [5].

Banks are intertwined and operate with other banks in a competitive industry. Hence, the bad performance of a bank can affect the entire sector and cause performance variability and create fear. Degraded loan quality creates threats of systemic risk, fear and causes drainage of deposits, a hindrance 
to financial intermediation, and finally, slows down the pace of economic growth and development. Non-performing loans play a crucial part in creating a poor performance of banks [6,7]. Banks are restrained from an intermediation role to the real economy and economic growth by NPLs $[8,9]$. NPLs have been termed "financial pollution" for their negative impacts on the economy $[10,11]$. If regulatory authorities implement any policy, the underlying determinants of NPLs should be taken care of first. As per Basel II, a loan unpaid for more than 90 days is considered as uncollectible.

After the global financial crunch of 2007 and 2008 followed by the share market scam in 2010 and 2011 in Bangladesh, the country faced financial turbulence in the economy, and the banking sector went through a transition time. Fifteen new banks have received licenses to operate in the economy in the last 10 years, and 11 banks in the last 5 years. At present, a total of 59 banks are operating in the economy. Hence, there is acute competitiveness in the industry.

After 2010, non-performing loans started to increase rapidly (Figure 1). In 2011, they were 2.70 billion US dollars; in 2012, they were 5.09 billion US dollars, and in 2018, breaking all records, they soared up to 13.20 billion US dollars. For a developing country like Bangladesh, it is a matter of concern and a threat to sustainable development.

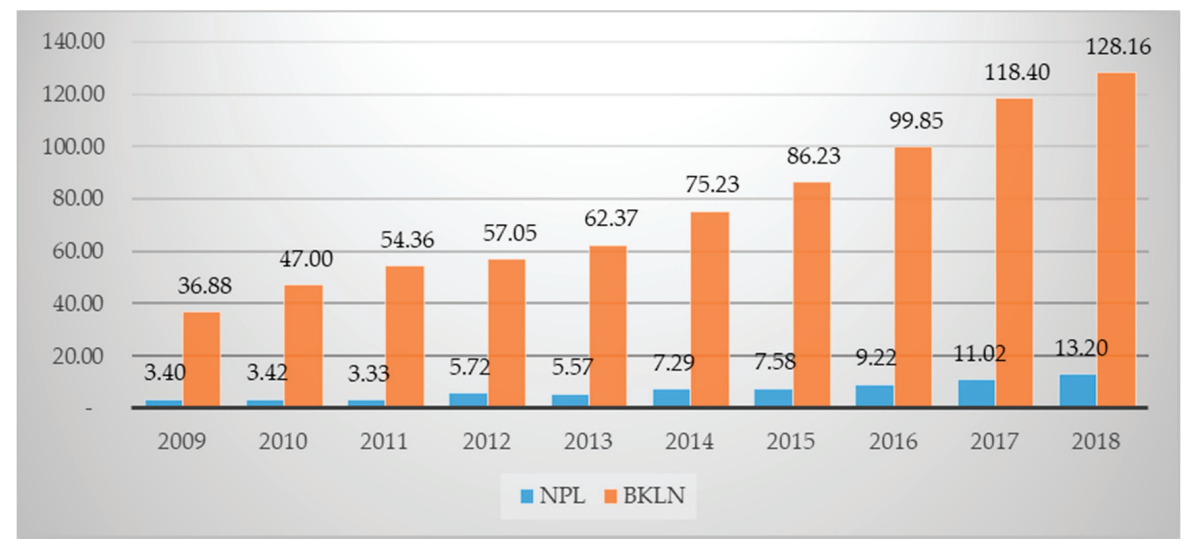

Figure 1. Non-performing loan (NPL) and bank loan (BKLN) growth in Bangladesh (in billion USD); Source: Bangladesh Bank.

The Non-Performing Loan Ratio (NPLR) reached 40.65\% in 1998, which is the highest ever in the history of Bangladesh. Although it gradually came down, this was not enough as it had been $10.30 \%$ in 2018 (Figure 2). Total banking sector NPLs were around 4\% of the total GDP in 2018. This current research examines both industry-specific and macroeconomic components of NPLs of all 59 banks in the economy for the period from 1979 to 2018. In our study, we used data from the whole banking sector using a time series dataset with an annual frequency. This study can be considered as a reference to understand and measure the determinants of NPLs in Bangladesh and for developing countries like Bangladesh. To analyze our dataset, we first used the ARDL model and then by finding co-integration with the variables through the Johansen test of co-integration, we conducted a VEC model. Results found in both the models are analogous, indicating the robustness of the study. To know the stability of the models used in the study, we performed some diagnostic tests. 


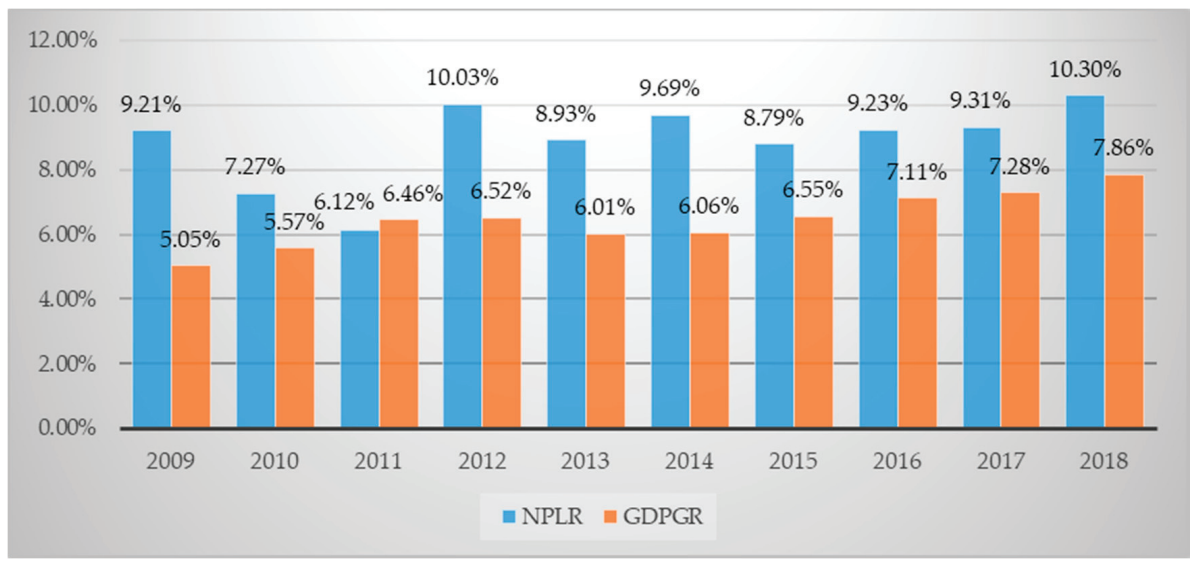

Figure 2. Non-performing loan ratio (NPLR) and gross domestic product growth rate (GDPGR) in Bangladesh; Source(s): Fred and WDI Database.

\section{Theoretical Background}

During our study, we went through many literary works to know the variables, models, and backgrounds on which research was conducted already. We found that factors of NPLs are broadly categorized into two major sources. The macroeconomic sources are GDP and inflation [2,12], unemployment [8], and real interest rates $[13,14]$ and the industry-specific factors are management efficacy $[4,15]$ and bank size [3,5], which may impact the ability to repay loans.

Researchers have found an affiliation between macroeconomic determinants and loan quality, which is a crucial yardstick of the banking sector's health. Previous findings suggest that bad loans decrease with the expansion of the economy. Borrowers have enough income to repay on time. During economic growth, loans are likely to be approved irrespective of the creditworthiness of the customers while during the economic downturn, NPLs tend to increase (Messai and Jouini 2013). Keeton and Morris (1987) studied 2470 commercial banks in the US from 1979 to 1985, which suggested the regional economy and inferior performance of industries had been the key factors for in loan losses. Espinoza and Prasad [16] found relationships of NPLs with economic advancement, risk aversion, and interest rates. NPL used to increase when there is a decreasing trend in economic growth and an increase in risk aversion and interest rates. Louzis, Vouldis et al. [3] looked into types of loans, i.e., consumer, business, mortgage, etc., to find determinants impelling NPLs. They found that macroeconomic variables, such as gross domestic product, interest rates, unemployment, and public debts, can impact the growth of NPLs.

Skarica [17] found that prime sources of NPLs are the economic (GDP) downturn, lack of employment, and the rate of inflation. In a study in France and Germany, it was found that macroeconomic variables influence NPLs [18]. Researchers also found the French economy to be vulnerable to bank-specific factors compared to Germany. Economic expansion and unemployment is positively associated with the reduction of NPLs. Macroeconomic variables, including unemployment and economic development, significantly influence NPLs while industry-specific variables, such as management skill and risk preferences, have consequences on future NPLs [19].

As our quest for literature went on, we found a good number of industry-specific determinants impacting NPLs, i.e., profitability expressed as return on asset (ROA) or return on equity (ROE), capital size expressed as the capital adequacy ratio (CAR), and performance as managerial efficiency. Of these aspects, ROE and ROA have been used as variables to explain managerial efficiency. Weak credit monitoring and poor control over operating expenses led to decreased cost efficiency, which supports the bad management theorem [5]. The bad management theory is also found by [20] 
while applying NPL as technical efficiency. Shreds of evidence were found on the "too big to fail" syndrome in the US banking sector and it was also argued that an increase in income negatively impacts NPLs [21]. Cost efficiency also impacts NPLs. Poor management and moral hazards have been positively associated with variations in NPLs. Managerial efficiency as a proxy to ROA has negative connections with NPLs [22]. Podpiera and Weill [4] used cost efficiency to describe management quality to find an underlying relationship with NPLs. They performed Granger causality tests to show the unconditional connection of inefficiency to NPLs. Louzis, Vouldis et al. [3] using dynamic panel data found management quality along with GDP, unemployment, interest rate, and public debt are the determinants of NPLs. In a very recent study (2019) on the banking system structure of Bangladesh, Barun Kumar Dey [23] found that poor follow-up of loans after disbursement and lack of willingness to write off bad loans are the root causes that cause NPLs to increase. He also argued that NPLs limit lending capacity, the trickle-down effect of which slows down economic growth in the long run. Also, a high level of NPLs leads to higher requirements of loan loss provisioning, which in turn affects ROA and ROE and creates a threat for solvency and liquidity. Finally, NPLs change the nature risk preferences of the managers that leads to a higher cost of funds and less efficiency.

Vardar and Özgüler [24] found the presence of a steady and long-run affiliation between non-performing loans, macroeconomic variables, and bank-specific factors. Inflation and unemployment were found to be positively and significantly associated with NPLs. Bardhan and Mukherjee [25] found results supporting the 'bad management hypothesis' predicting negative future relationships with NPAs (non-performing assets). They used performance as a proxy for managerial efficiency. They also found capital adequacy ratio (CAR) requirements had an impact on the NPAs of banks. According to their research, large banks have more default rates compared to smaller ones.

Rajan, Bardhan, and Mukherjee [25,26] identified that future NPLs are related to past earnings and increases in profit can reduce NPLs. They also explained that managers could manipulate their power to alter credit policies to inflate current earnings, change the terms of the loan, and relax the conditions, which may lead to bad loans. Using the data of 129 Spanish banks from 1993 to 2003 García-Marco and Robles-Fernández [27] found that higher ROEs had been the key reason to boost risk and higher default rates. ROE has positive associations with elevated NPLs [28].

Changes in credit management policy, loan interest rates, fees, and commissions are also other determinants of NPLs. GDP and ROA have a negative impact while unemployment and interest rates have a positive impact on NPLs [14]. In a study in the United States, it was found that elevated interest rates and superfluous lending as internal aspects and economic conditions as external aspects have a significant positive connection to NPLs [29]. Structural differences between countries can create differences in the efficiency of banks as well [30].

Kjosevski [31] conducted sector-wise research and found NPLs of both the enterprise and household were negatively sensitive to profitability, loan growth, and better economic conditions while banks' solvency and unemployment were positively correlated. The authors of [19] examined NPLs determinants in the Eurozone and, like past examinations, found bank-specific and macroeconomic elements had a remarkable impact clarifying variations in NPLs [32,33].

We found researches on Bangladesh covering a research period of 5 to 20 years. A synopsis is given in Table 1. 


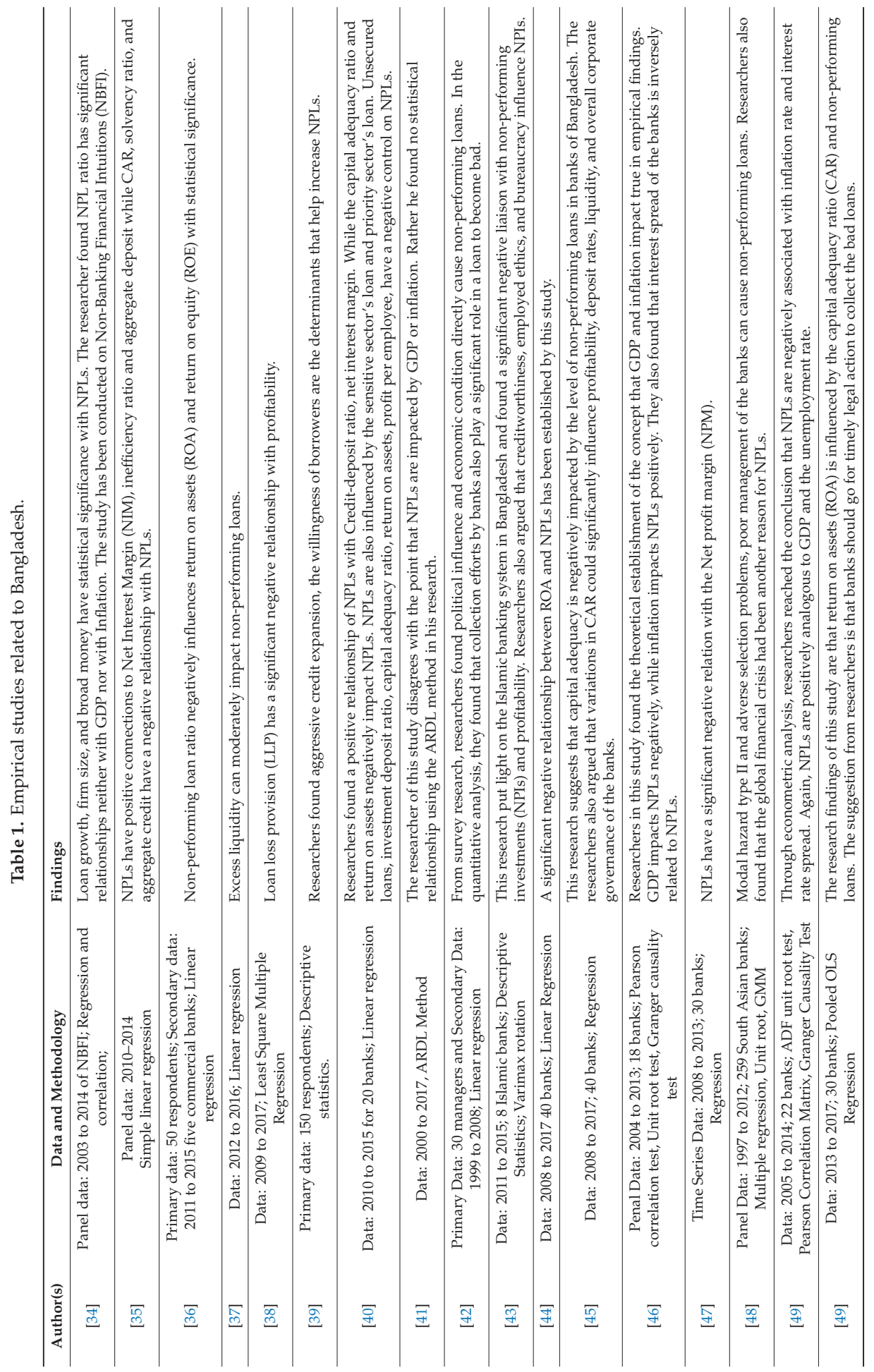




\section{Research Objective, Methodology, and Data}

\subsection{Research Objective}

The purpose of this study was to identify the significance of industry-specific and macroeconomic determinants of non-performing loans (NPLs) of the banking sector. We conducted our study on a developing country and compared the results in autoregressive distributed lag (ARDL) and vector error correction (VEC) model. The findings of this study will help to understand the underlying causes of NPLs in developing economies and help individual banks to take measures to sustain in the competitive industry.

\subsection{Methodology}

\subsubsection{Model Specification}

This paper suggests that NPLs in the economy of Bangladesh depend both on macroeconomic and industry-specific elements. We discuss the functional relationship of the determinants as follows:

$$
N P L R_{t}=f\left(I S_{t}, M E_{t}\right)
$$

where 'NPLR $R_{t}$ (non-performing loan ratio) is the dependent determinants of time $t$; ' $I S_{t}$,' comprises the industry-specific determinants for time $t$; and ' $M E_{t}$ ' contains the macroeconomic determinants causing the banking sector for time $t$.

To evade the hidden multi-collinearity problem, which can ascend from correlated independent variables, we made two different models. Log was used for all variables, and two regression models were developed as:

Model: 1

$$
\begin{aligned}
\operatorname{InNPLR}_{t}=\beta_{0}+ & \beta_{1}(\operatorname{InGDPGR})_{t} \\
& +\beta_{2}(\operatorname{InCPI})_{t}+\beta_{3}(\operatorname{InDOCR})_{t}+\beta_{4}(\operatorname{InUNEM})_{t}+\beta_{5}(\operatorname{InEXR})_{t} \\
& +\varepsilon_{t}
\end{aligned}
$$

Model: 2

$$
\begin{aligned}
\operatorname{InNPLR}_{t}=\alpha_{0}+\quad & \alpha_{1}(\operatorname{InBKLN})_{t} \\
& +\alpha_{2}(\operatorname{InLIQ})_{t}+\alpha_{3}(\operatorname{InNOP})_{t}+\alpha_{4}(\operatorname{InLDR})_{t}+\alpha_{5}(\operatorname{InDPR})_{t}+\varepsilon_{t}
\end{aligned}
$$

where "In" indicates the logarithmic form of the variables under investigation. $\beta_{0}$ and $\alpha_{0}$ are the coefficients of the constant. $\beta_{1}, \beta_{2}, \beta_{3}, \beta_{4}, \beta_{5}, \alpha_{1}, \alpha_{2}, \alpha_{3}, \alpha_{4}$, and $\alpha_{5}$ represent the partial coefficients of the independent variables. Lastly, $\varepsilon_{t}$ represents the stochastic term.

\subsubsection{Unit Root Tests}

We checked the unit root of the series used in this study using the ADF (Augmented Dickey-Fuller) and PP (Philip and Perron). The null hypothesis indicates that the series have a unit root, whereas the alternative hypothesis suggests stationarity. At $\phi=1$, variables have a unit root, and at $\phi<1$, it becomes stationary (Equation (4)). The regression for the ADF test is given below:

$$
\Delta Y_{t}=\Phi Y_{t-1}+\sum_{i=1}^{p} \alpha_{i} Y_{t-1}+\mu_{t}
$$

\subsubsection{ARDL (Autoregressive Distributed Lag) Model}

An autoregressive distributed lag (ARDL) model is an ordinary least square (OLS) used for the time series dataset. ARDL is widely accepted for the co-integration of non-stationary variables 
corresponding to error-correction (EC) dynamics and it also finds a parametric equation in the EC form [50,51]. An important benefit related to the ARDL modeling approach is that it is useful regardless of regressors being (0) or I (1). Again, ARDL permits a large number of lags. Finally, it accepts the development of a dynamic error correction (EC) model that coordinates short-run elements with the long-run stability, thus losing no long-run data [52-54]. The following equation explains the ARDL model:

$$
\Delta Y_{t}=\beta_{0}+\sum_{(i-1)}^{p} \beta_{i} \Delta Y_{\left(t_{-i}\right)}+\sum_{(i-1)}^{p} \beta_{j} \Delta X_{\left(t_{-1}\right)}+\lambda_{1} Y_{(t-1)}+\lambda_{2} X_{(t-1)}+\varepsilon_{t}
$$

\subsubsection{Co-Integration Test}

As all series were stationary at the first differentiation I (1), Johansen co-integration analysis was used to persuade the convergence in the long run (Johansen and Juselius 1990). The Johansen test recommends the existence of co-integration for at least one co-integrating vector.

\subsubsection{Vector Error Correction (Vec) Model}

When there are co-integrations among the variables, VECM can be applied to find long-run equilibrium associations. Co-integration is confirmed by Johansen tests for co-integration. We developed the following models to assess the short-run and long-run coefficients of the variables:

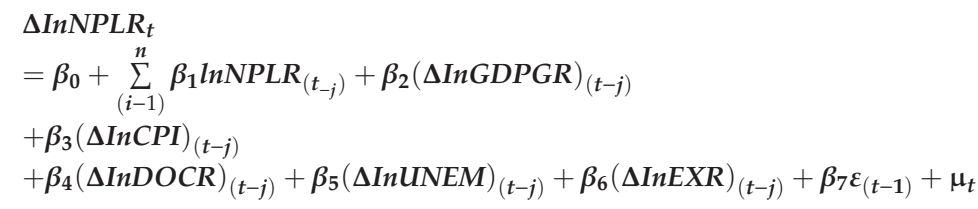

$$
\begin{aligned}
& \Delta \operatorname{InNPLR} \\
& =\alpha_{0}+\sum_{(i-1)}^{n} \alpha_{1} \operatorname{lnNPLR}\left(_{\left(t_{-j}\right)}+\alpha_{2}(\Delta \operatorname{InBKLN})_{(t-j)}\right. \\
& +\alpha_{3}(\Delta \operatorname{InLIQ})_{(t-j)} \\
& +\alpha_{4}(\Delta \operatorname{InNOP})_{(t-j)}+\alpha_{5}(\Delta \operatorname{In} L D R)_{(t-j)}+\alpha_{6}(\Delta \operatorname{InDPR})_{(t-j)}+\beta_{7} \varepsilon_{(t-1)}+\mu_{t}
\end{aligned}
$$

The variation in the independent variables is demonstrated by ' $\Delta$ ', and the error correction term is expressed by ' $\left.\varepsilon_{(t-1)}\right)^{\prime} \cdot \beta_{1}$ and $\alpha_{1}$ are the speed of adjustment by which short and long-run disequilibrium is adjusted. ' $\mu_{t}$ ' is the error term.

\subsection{Data}

Time series data were tested in this paper. We collected data from the Civil, Environmental, and Infrastructure Engineering (CEIE) databases, the World Development Indicators (WDI) databases, and the Bangladesh Bank (the central bank of Bangladesh) databases. We collected data for 40 years, from 1979 to 2018, of all 59 commercial banks for the last 40 years (Table 2).

Table 2. Variable Definition.

\begin{tabular}{ccl}
\hline Variables & Interpretation \\
\hline & InNPLR & $\begin{array}{l}\text { Non-performing loan ratio: Doubtful and bad loans to total loan } \\
\text { ratio }\end{array}$ \\
\hline Macroeconomic Variables & lnGDPGR & $\begin{array}{l}\text { Gross domestic product growth rate: The annual gross domestic } \\
\text { product growth rates of Bangladesh. }\end{array}$ \\
\cline { 2 - 3 } & $\operatorname{lnCPI}$ & $\begin{array}{l}\text { Consumer price index: The weighted average prices of consumer } \\
\text { goods and services. The year 2006 has been considered a base year. }\end{array}$ \\
\hline
\end{tabular}


Table 2. Cont.

\begin{tabular}{|c|c|c|}
\hline \multicolumn{2}{|l|}{ Variables } & \multirow{2}{*}{$\begin{array}{l}\text { Interpretation } \\
\text { Domestic Credit: The aggregate of net dues on the central } \\
\text { government and dues on other segments of the national economy. }\end{array}$} \\
\hline & $\operatorname{lnDOCR}$ & \\
\hline & $\operatorname{lnUNEM}$ & $\begin{array}{l}\text { Rate of unemployment: The annual unemployment rate in } \\
\text { Bangladesh. }\end{array}$ \\
\hline & $\operatorname{lnEXR}$ & $\begin{array}{l}\text { Exchange rates: The annual exchange rates of BDT (currency of } \\
\text { Bangladesh) against USD. }\end{array}$ \\
\hline \multirow{5}{*}{ Industry-specific Variables } & $\operatorname{lnBKLN}$ & $\begin{array}{l}\text { Banking sector gross loan: The annual aggregate loan } \\
\text { disbursement by the entire banking sector of Bangladesh }\end{array}$ \\
\hline & $\operatorname{lnLIQ}$ & $\begin{array}{l}\text { Bank liquidity: The annual liquid asset ratio provided by } \\
\text { Bangladesh Bank. Liquid assets include cash and government } \\
\text { securities. It measures the capacity of banks to meet their } \\
\text { obligations. }\end{array}$ \\
\hline & $\operatorname{lnNOP}$ & $\begin{array}{l}\text { Net operating profit: The annual net operating profit of the entire } \\
\text { banking sector. }\end{array}$ \\
\hline & $\operatorname{lnLDR}$ & $\begin{array}{l}\text { Bank lending rate: The rate at which banks lend to their customers. } \\
\text { Bangladesh bank provides weighted average lending interest rates } \\
\text { of all sorts of loans including short term and long term loans. }\end{array}$ \\
\hline & $\operatorname{lnDPR}$ & $\begin{array}{l}\text { Bank deposit rate: Deposit rates are the weighted average interest } \\
\text { rates banks at which collect funds from its customers for } \\
\text { investment. }\end{array}$ \\
\hline
\end{tabular}

\section{Results and Discussion}

\subsection{Unit Root Test}

Unit root tests (Table 3) for macroeconomic variables with ADF found two macroeconomic variables of $\operatorname{lnGDPGR}$ and $\operatorname{lnEXR}$ found to be stationary at the level I (0) while lnCPI, indoor, and lnUNEM became stationary at first differentiation as indicated by I (1) at the $5 \%$ level of confidence. On the other hand, in PP, only lnGDPGR was stationary at the level I (0); all other variables became stationary, except lnCPI, after first differentiation I (1) at a $5 \%$ confidence level. lnCPI became stationary at first differentiation I (1) with $10 \%$ at the confidence level. Unit root tests (Table 3 ) for industry-specific variables with $\mathrm{ADF}$ found two macroeconomic variables, $\ln \mathrm{NOP}$ (at $10 \%$ confidence level) and $\operatorname{lnDPR}$, to be stationary at the level I (0) while $\ln B N L N, \operatorname{lnLIQ}$, and $\operatorname{lnLDR}$ became stationary at first differentiation as indicated by I (1) at the $5 \%$ level of confidence. On the other hand, in PP, all the variables became stationary after first differentiation I (0).

Table 3. Augmented Dickey-Fuller (ADF) and Philip and Perron (PP) Unit Root Tests.

\begin{tabular}{|c|c|c|c|c|c|c|c|c|c|}
\hline \multirow{3}{*}{\multicolumn{2}{|c|}{ Variables }} & \multicolumn{4}{|c|}{ ADF } & \multicolumn{4}{|c|}{ PP } \\
\hline & & \multicolumn{2}{|c|}{ At the Level } & \multicolumn{2}{|c|}{ First Differentiation } & \multicolumn{2}{|c|}{ At the Level } & \multicolumn{2}{|c|}{ First Differentiation } \\
\hline & & T-Statistics & 0.10 & Test Statistics & 0.10 & T-Statistics & 0.10 & T-Statistics & 0.10 \\
\hline \multirow{3}{*}{ 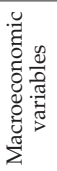 } & $\operatorname{lnGDPGR}$ & $-3.4870 * * *$ & -2.6140 & $-9.335 * * *$ & -2.6160 & $-33.898 * * *$ & -10.4800 & $-63.73 * * *$ & -10.4600 \\
\hline & $\operatorname{lnCPI}$ & -0.1780 & -2.6140 & $-3.232 * *$ & -2.6160 & -0.913 * & -10.4800 & $-11.298^{* * *}$ & -10.4600 \\
\hline & $\ln E X R$ & $-3.5180 * * *$ & -2.6140 & $-4.798 * * *$ & -2.6160 & $-2.269 * *$ & -10.4800 & $-30.731 * * *$ & -10.4600 \\
\hline \multirow{4}{*}{ 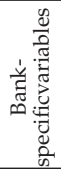 } & $\operatorname{lnBKLN}$ & -0.3000 & -2.6140 & $-5.661 * * *$ & -2.6160 & -0.2920 & -10.4800 & $-32.355^{* * *}$ & -10.4600 \\
\hline & $\operatorname{lnLIQ}$ & -2.4120 & -2.6140 & $-3.213 * *$ & -2.6160 & -8.5110 & -10.4800 & $-29.317 * * *$ & -10.4600 \\
\hline & $\ln N \hat{O P}$ & $-2.763 *$ & -2.6140 & $-5.162 * * *$ & -2.6160 & $-11.782^{*}$ & -10.4800 & $-37.632 * * *$ & -10.4600 \\
\hline & $\operatorname{lnLDR}$ & $-1.951 * * *$ & -2.6140 & $-3.76^{* * *}$ & -2.6160 & -4.6360 & -10.4800 & $-24.115^{* * *}$ & -10.4600 \\
\hline
\end{tabular}




\subsection{ARDL Model}

We constructed two different models to reduce the multi-collinearity problem among the variables. The co-integration relationship was examined among the determinants (i.e., analyzing the zero hypotheses $\left(H_{0}: \lambda=1, \lambda=2 \ldots \lambda_{n}=0\right)$. From the ARDL bounds test, it is apparent that (Table 4$)$ the $\mathrm{F}$ statistics are 30.609 and 15.34 for the first and second models. The F values are significant, and in both models, the F statistics are greater than the upper limit. So, we reject the null hypothesis and agree that there are co-integrations among the determinants. Then, we used Akaike's information criterion (AIC) criterion to choose optimal lag lengths for each model (Table 5). For macroeconomic variables, the AIC selects the ARDL $(4,3,4,3,2,1)$ specification and for industry-specific variables $(3,3,4,1,4,2)$. The reason for using AIC is that AIC provides a smaller standard deviation than the Schwarz information criterion (SIC) when running in a model (Pesaran \& Pesraran, 1997). We tested both long-run associations and short-run dynamics (error correction model) in the ARDL model (Tables 6 and 7). The coefficients were found to have multiple connotations between NPLs and macroeconomic and industry-specific variables.

Table 4. Pesaran/Shin/Smith (2001) ARDL (Autoregressive Distributed Lag) Bounds Test.

\begin{tabular}{cccccccccc}
\hline & & \multicolumn{2}{c}{ At 10\% } & \multicolumn{2}{c}{ At 5\% } & \multicolumn{2}{c}{ At 2.5\% } & At 1\% \\
\hline \multirow{2}{*}{ Category } & F & Lower & Upper & Lower & Upper & Lower & Upper & Lower & Upper \\
Limit & Limit & Limit & Limit & Limit & Limit & Limit \\
\hline Macro-economic & 30.609 & 2.2600 & 3.3500 & 2.6200 & 3.7900 & 2.9600 & 4.1800 & 3.4100 & 4.6800 \\
Industry-specific & 15.337 & 2.2600 & 3.3500 & 2.6200 & 3.7900 & 2.9600 & 4.1800 & 3.4100 & 4.6800 \\
\hline
\end{tabular}

Table 5. VAR (Vector Autoregression) Lag Order Selection Criteria.

\begin{tabular}{cccc}
\hline Lag Rank & & Akaike's Information Criterion (AIC) & Schwarz Information Criterion (SIC) \\
\hline \multirow{2}{*}{ Macroeconomic Variables } & 0 & -13.364 & -13.1001 \\
& 1 & -25.2891 & -23.4417 \\
& 2 & -27.2268 & $-23.7958^{*}$ \\
& 3 & -28.5331 & -23.5186 \\
Industry-specific Variables & 0 & $-29.3804 *$ & -2.64219 \\
& 1 & -2.9061 & -11.1055 \\
& 2 & -12.9529 & -9.95959 \\
& 4 & -13.3905 & -9.39201 \\
& & -14.4065 & $-11.8366^{*}$
\end{tabular}

Table 6. Long-Run coefficients of ARDL Model.

\begin{tabular}{|c|c|c|c|c|c|}
\hline \multicolumn{3}{|c|}{ Macroeconomic } & \multicolumn{3}{|c|}{ Industry-Specific } \\
\hline Determinants & Coefficients & Standard Error & Determinants & Coefficients & Standard Error \\
\hline $\operatorname{lnGDPGR}$ & $-1.396011^{* *}$ & 0.5629 & $\operatorname{lnBKLN}$ & $-0.5203392 * * *$ & 0.0367 \\
\hline $\operatorname{lnCPI}$ & -0.9602321 & 0.7484 & $\operatorname{lnLIQ}$ & $2.669881^{* * *}$ & 0.5103 \\
\hline $\operatorname{lnDOCR}$ & $1.066338^{*}$ & 0.5631 & $\ln N O P$ & $-0.0192367^{* * *}$ & 0.0032 \\
\hline $\operatorname{lnUNEM}$ & $-7.639355^{* * *}$ & 2.0093 & $\ln L D R$ & $3.790614 * * *$ & 0.3349 \\
\hline $\operatorname{lnEXR}$ & $3.756394^{* * *}$ & 1.1450 & $\operatorname{lnDPR}$ & $-0.7667929 * * *$ & 0.1571 \\
\hline Cons & 0.207973 & 0.2722 & Cons & $-3.784955^{* * *}$ & 0.6260 \\
\hline
\end{tabular}

$*, * *$, and ${ }^{* *}$ stand for $10 \%, 5 \%$, and $1 \%$ levels of significance, respectively. 
Table 7. Short-Run coefficients of ARDL Model.

\begin{tabular}{|c|c|c|c|c|c|}
\hline \multicolumn{3}{|c|}{ Macroeconomic } & \multicolumn{3}{|c|}{ Industry-Specific } \\
\hline Determinants & Coefficients & Standard Error & Determinants & Coefficients & Standard Error \\
\hline $\operatorname{lnGDPGR}$ & $0.364553^{* * *}$ & 0.1142 & $\operatorname{lnBKLN}$ & 0.2050954 & 0.1857 \\
\hline $\operatorname{lnCPI}$ & $-5.017027^{* * *}$ & 0.9689 & $\operatorname{lnLIQ}$ & $-2.247147^{* * *}$ & 0.4446 \\
\hline $\operatorname{lnDOCR}$ & -0.279248 & 0.1682 & $\ln \mathrm{NOP}$ & $0.0092824^{* * *}$ & 0.0028 \\
\hline lnUNEM & $2.445047^{* * *}$ & 0.2168 & $\operatorname{lnLDR}$ & $-1.591485^{* * *}$ & 0.3374 \\
\hline $\operatorname{lnEXR}$ & $-0.8860041^{* *}$ & 0.3653 & $\operatorname{lnDPR}$ & 0.2151 & 0.2027 \\
\hline Cons & 0.207973 & 0.2722 & Cons & $-3.784955^{* * *}$ & 0.6260 \\
\hline \multicolumn{3}{|c|}{ R-squared $=0.9618 ;$ Adj. R-squared $=0.8971$} & \multicolumn{3}{|c|}{ R-squared $=0.9338 ;$ Adj. R-squared $=0.8219$} \\
\hline
\end{tabular}

\subsubsection{ARDL Long-Run Results}

Among the macroeconomic variables, the results identified that lnGDPGR has a significant negative effect on the lnNPLR, meaning that as the economy becomes stronger, bad lending decreases. If there is an increase of $1 \%$ in economic growth, non-performing loans will decrease by $1.40 \%$ in the long run in Bangladesh.

$\ln C P I$ also has a negative relationship with $\operatorname{lnNPLR}$, but in this case, the relationship is insignificant in the long run. Domestic credit growth (lnDOCR) and exchange rates (lnEXR) both have significant positive relationships with the bad loan ratio (lnNPLR) while unemployment (lnUNEM) in the country has a significant negative relation with increasing bad loans. With every $1 \%$ increase in both the domestic credit and exchange rates, there is a $1.07 \%$ and $3.76 \%$ increase in non-performing loans, respectively. Surprisingly, with the decrease of non-performing loans by $7.64 \%$, there is a $1 \%$ increase in unemployment.

The long-run results of industry-specific variables show that bank loan growth (lnBKLN) has a negative association with the non-performing loan ratio (lnNPLR). Net operating profit (lnNOP) and deposit rates (lnDPR) also have the same impact over non-performing loans with significant $p$ values, which means that with the growth of bank lending by $0.52 \%$, there will be a decrease of $1 \%$ bad loan, which indicates healthy behavior by the banking sector. NPL reduces bank profitability by $0.02 \%$ when it increases by $1 \%$, and also a $1 \%$ increase in InNPLR reduces the capacity of the banks to provide depositors good returns, which is $0.76 \%$. Finally, a $1 \%$ increase in lending rates (lnLDR) and liquidity (lnLIQ) increase non-performing loans by $3.79 \%$ and $2.67 \%$, respectively.

In both models, the $\mathrm{R}^{2}$, and the adjusted $\mathrm{R}^{2}$ were remarkably good. The $\mathrm{R}^{2}$ and the adjusted $\mathrm{R}^{2}$ for macroeconomic variables are 0.9618 and 0.8971 , respectively, while for industry-specific variables, it is 0.9338 and 0.8219 , respectively, meaning the models fit quite well, which means that the models can explain $96.18 \%$ and $93.38 \%$ of the changes in non-performing loans.

\subsubsection{ARDL Short-Run Results}

The short-run outcomes suggest the growth of GDP has a significant positive influence on lnNPLR. Meaning that if there is a growth of $1 \%$ in GDP in Bangladesh, the non-performing loans of banks will rise by $0.36 \%$. Then, only lnUNEM has a significant positive relation with NPLR. A $1 \%$ increase in unemployment will cause a $2.45 \%$ decrease in bad loans in the short run. The other three variables, $\operatorname{lnCPI}, \ln D O C R$, and lnEXR, affect lnNPLR negatively, with lnDOCR being the only insignificant variable. To be specific, a $1 \%$ increase in all these variables can cause a $5.01 \%, 0.27 \%$, and $0.88 \%$ decrease consecutively in lnNPLR.

The short-run results of industry-specific variables show that bank loan growth (lnBKLN) has an insignificant positive relationship with non-performing loans (lnNPLR). Net operating profit $(\mathrm{lnNOP})$ and deposit rates (lnDPR) also have the same impact over non-performing loans, which 
is statistically significant, while liquidity (lnLIQ) and lending rates (lnLDR) were found to have a statistically significant negative connection with non-performing loans.

\subsection{Co-Integration Test}

We found four co-integration relationships in the first model and for the second model, we found two co-integrating connections. We considered trace statistics to figure out the co-integrating equations at a the $5 \%$ level of significance. The existence of more than one co-integrating equation indicates a long-run convergence of the two models (Table 8).

Table 8. The Johansen Tests for Co-integration.

\begin{tabular}{|c|c|c|c|c|c|c|}
\hline & Max. Rank & Parms & LL & Eigenvalue & T. Statistics & $5 \%$ Critical Value \\
\hline \multirow{7}{*}{ 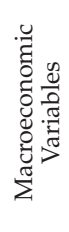 } & 0 & 42 & 485.4188 & & 206.5194 & 94.1500 \\
\hline & 1 & 53 & 527.6884 & 0.8919 & 121.9803 & 68.5200 \\
\hline & 2 & 62 & 553.1712 & 0.7385 & 71.0147 & 47.2100 \\
\hline & 3 & 69 & 570.5570 & 0.5995 & 36.2430 & 29.6800 \\
\hline & 4 & 74 & 581.3974 & 0.4348 & 14.5622 * & 15.4100 \\
\hline & 5 & 77 & 588.6645 & 0.3178 & 0.0281 & 3.7600 \\
\hline & 6 & 78 & 588.6785 & 0.0007 & & \\
\hline \multirow{7}{*}{ 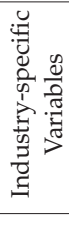 } & 0 & 42 & 273.84 & & 112.7982 & 94.1500 \\
\hline & 1 & 53 & 294.81 & 0.67 & 70.8531 & 68.5200 \\
\hline & 2 & 62 & 308.84 & 0.52 & $42.7962 *$ & 47.2100 \\
\hline & 3 & 69 & 319.77 & 0.44 & 20.9224 & 29.6800 \\
\hline & 4 & 74 & 325.67 & 0.27 & 9.1303 & 15.4100 \\
\hline & 5 & 77 & 330.05 & 0.21 & 0.3664 & \\
\hline & 6 & 78 & 330.24 & 0.01 & & \\
\hline
\end{tabular}

Note: * denotes the number of co-integrating equation(s) at $5 \%$ significance. At ${ }^{*}$ we reject the null hypothesis with a $5 \%$ level of significance.

\subsection{Vector Error Correction (Vec) Model Results}

The VECM was applied to assess the long-run and short-run coefficients (Table 9). We found two lag periods for macroeconomic variables and four lag periods for industry-specific variables using the Schwarz information criterion. We selected the lag length of SIC criterions as it gives better results than AIC criterions. We then calculated the long and short-run coefficients, putting lag length outcomes in the VECM.

Table 9. Vector Error Correction Model (VECM) Results.

\begin{tabular}{|c|c|c|c|c|c|c|c|c|}
\hline \multirow[b]{2}{*}{ Description } & \multicolumn{4}{|c|}{ Macroeconomic Variables } & \multicolumn{4}{|c|}{ Industry-Specific Variables } \\
\hline & Variables & Coefficient & $\begin{array}{l}\text { Standard } \\
\text { Error }\end{array}$ & $\begin{array}{c}\mathrm{T} \\
\text { Statistics }\end{array}$ & Variable & Coefficient & $\begin{array}{l}\text { Standard } \\
\text { Error }\end{array}$ & T Statistics \\
\hline $\begin{array}{c}\text { Speed of } \\
\text { Adjustment }\end{array}$ & $\Delta \operatorname{lnNPLR}$ & $-0.2557821^{* * *}$ & 0.0246683 & -10.37 & $\triangle \operatorname{lnNPLR}$ & -0.1885038 & 0.1307467 & -1.44 \\
\hline \multirow{5}{*}{$\begin{array}{l}\text { Short-run } \\
\text { coefficients }\end{array}$} & $\Delta \operatorname{lnGDPGR}$ & $-0.6820223 * * *$ & 0.0918552 & -7.42 & $\Delta \operatorname{lnBKLN}$ & -0.1901149 & 0.2513614 & -0.76 \\
\hline & $\Delta \operatorname{lnCPI}$ & 0.6937023 *** & 0.1355197 & 5.12 & $\Delta \operatorname{lnLIQ}$ & $0.4885987 * *$ & 0.2136399 & 2.29 \\
\hline & $\triangle \operatorname{lnDOCR}$ & -0.0501226 & 0.1408345 & -0.36 & $\triangle \ln N O P$ & 0.2759852 & 0.2599934 & 1.06 \\
\hline & $\triangle \operatorname{lnUNEM}$ & -0.3287384 & 0.2686674 & -1.22 & $\Delta \operatorname{lnLDR}$ & 0.6160724 * & 0.3157054 & 1.95 \\
\hline & $\Delta \ln E X R$ & 0.2371722 & 0.1514736 & 1.57 & $\triangle \operatorname{lnDPR}$ & $0.7740481^{* * *}$ & 0.2054191 & 3.77 \\
\hline \multirow{5}{*}{$\begin{array}{l}\text { Long-run } \\
\text { coefficients }\end{array}$} & $\operatorname{lnGDPGR}$ & $0.4780902^{* *}$ & 0.2441085 & 1.96 & $\operatorname{lnBKLN}$ & $0.3681242 * * *$ & 0.0323276 & 11.39 \\
\hline & $\operatorname{lnCPI}$ & 0.1832198 & 0.4663795 & 0.39 & $\operatorname{lnLIQ}$ & -0.424397 & 0.3814911 & -1.11 \\
\hline & $\operatorname{lnDOCR}$ & -0.5250594 ** & 0.2479925 & -2.12 & $\ln \mathrm{NOP}$ & $0.0602165^{* * *}$ & 0.0046823 & 12.86 \\
\hline & lnUNEM & $6.997589^{* * *}$ & 0.6446684 & 10.85 & $\operatorname{lnLDR}$ & $-4.923853^{* * *}$ & 0.2398030 & -20.53 \\
\hline & $\operatorname{lnEXR}$ & $-3.293177^{* * *}$ & 0.5921451 & -5.56 & $\operatorname{lnDPR}$ & $2.718319 * * *$ & 0.2358060 & 11.53 \\
\hline
\end{tabular}

$*, * *$, and ${ }^{* *}$ stand for $10 \%, 5 \%$, and $1 \%$ levels of significance, respectively. 
The first model states that $\operatorname{lnNPLR}$ converges to long-run equilibrium with a $25.58 \%$ speed of adjustment every year by the influence of the variables, lnGDPGR, lnCPI, lnDOCR, lnUNEM, and $\operatorname{lnEXR}$. The second model suggests an $18.85 \%$ speed of adjustment in lnNPLR by the influence of $\operatorname{lnBKLN}, \operatorname{lnLIQ}, \operatorname{lnNOP}, \operatorname{lnLDR}$, and $\operatorname{lnDPR}$. The results from both the models recommend that long-run adjustment in the independent variables has substantial influence compared to short-run variables on NPLR. The long-run equations are explained in the following manner:

Model 1:

$$
\begin{aligned}
\operatorname{InNPLR}_{t}=\beta_{0}-\quad & 0.4780902(\operatorname{InGDPGR})_{t} \\
& -0.1832198(\operatorname{InCPI})_{t}+0.5250594(\operatorname{InDOCR})_{t} \\
& -6.997589(\operatorname{InUNEM})_{t}+3.293177(\operatorname{InEXR})_{t}+\varepsilon_{t}
\end{aligned}
$$

Model 2:

$$
\begin{aligned}
\operatorname{InNPLR}_{t}=\alpha_{0}- & 0.3681242(\operatorname{InBKLN})_{t} \\
& +0.424397(\operatorname{InLIQ})_{t}-0.0602165(\operatorname{InNOP})_{t}+4.923853(\operatorname{InLDR})_{t} \\
& -2.718319(\operatorname{InDPR})_{t}+\varepsilon_{t}
\end{aligned}
$$

Model 1: In the case of macroeconomic variables, when lnGDPGR has a negative movement by $1 \%$, non-performing loans $\operatorname{lnNPLR}$ will rise by $0.4780902 \%$. $\operatorname{lnCPI}$ and $\operatorname{lnUNEM}$ have the same negative relationship as $\operatorname{lnGDPGR}$, with $0.1832198 \%$ and $6.997589 \%$, respectively. Meanwhile, domestic credit $\operatorname{lnDOCR}$ and exchange rates $\operatorname{lnEXR}$, if appreciated by $1 \%$, will cause an escalation in non-performing loans (lnNPLR) by $0.5250594 \%$ and $3.293177 \%$ respectively.

Model 2: Among industry-specific variables, when bank lending ( $\operatorname{lnBKLN}$ ) is decreased by $1 \%$, non-performing loans (lnNPLR) will increase by $0.3681242 \%$. Net operating profit (lnNOP) and deposit rates (lnDPR) also have an inverse relationship with $\ln N P L R$. When $\ln N O P$ and $\ln D P R$ decrease by $1 \%, \operatorname{lnNPLR}$ increases by $0.0602165 \%$, and $2.718319 \%$ respectively. On the contrary, at a $1 \%$ increase in banks' liquidity (lnLIQ) and lending rates (lnLDR), bad loan (lnNPLR) is hyped by $0.424397 \%$ and $4.923853 \%$, respectively.

To check if there is any autocorrelation, we performed the Lagrange-multiplier test (Table 10). Both models are free from the autocorrelation problem.

Table 10. VECM Diagnostic Tests (Lagrange-Multiplier Test).

\begin{tabular}{ccccccc}
\hline & \multicolumn{3}{c}{ Industry-Specific Variables } & \multicolumn{3}{c}{ Macroeconomic Variables } \\
\hline Nature of Test & Lag Order & $p$ Value & Interpretation & Lag Order & $p$ Value & Interpretation \\
\hline \multirow{2}{*}{ Auto-correlation test } & Lag 1 & 0.7811 & No & Lag 1 & 0.1264 & No \\
& Lag 2 & 0.6193 & Autocorrelation & Lag 2 & 0.8915 & Autocorrelation \\
\hline
\end{tabular}

\subsection{Robustness of the Study}

The overall stability of the models was examined through a few diagnostic tests of the ARDL model (Table 11). The Durbin-Watson tests (for autocorrelation) suggest that neither the macroeconomic nor the industry-specific variables have autocorrelations among them. Again, for the Jarque-Bera, Breusch-Godfrey (serial correlation test), and White's tests (homoscedasticity test), we cannot reject the zero hypothesis as all the coefficients are not significant, and hence, the models are normal; there is no serial correlation among the variables and the models are free from the heteroscedasticity problem. We checked autocorrelation for VECM and found no autocorrelation problem through the Lagrange-multiplier test. The CUSUM (cumulative sum) was tested to check the model stability (Figures 3 and 4). The model with macroeconomic variables seems okay, with a slight deviation in the middle. Again, the results of VECM are consistent with ARDL estimates as the signs of the coefficients are similar (Table 12). 
Table 11. Diagnostic Tests for ARDL.

\begin{tabular}{cccccc}
\hline \multicolumn{2}{c}{ Tests Detail } & \multicolumn{2}{c}{ Macroeconomic Variables } & \multicolumn{2}{c}{ Industry-Specific Variables } \\
\hline Tests Performed & Nature of Tests & Score $/ p$ Value & Interpretation & Score/ $p$ Value & Interpretation \\
\hline $\begin{array}{c}\text { Durbin-Watson } \\
\text { d-statistic }\end{array}$ & Autocorrelation Test & 2.2850 & $\begin{array}{c}\text { No } \\
\text { Autocorrelation }\end{array}$ & 2.4313 & No Autocorrelation \\
\hline Jarque-Bera test & Normality Test & 0.2483 & Normal & 0.3731 & Normal \\
\hline $\begin{array}{c}\text { Breusch-Godfrey LM } \\
\text { test }\end{array}$ & $\begin{array}{c}\text { Serial Correlation } \\
\text { Test }\end{array}$ & 0.2395 & $\begin{array}{c}\text { No Serial } \\
\text { Correlation }\end{array}$ & 0.0692 & No Serial Correlation \\
\hline White's test & $\begin{array}{c}\text { Homoscedasticity } \\
\text { Test }\end{array}$ & 0.4215 & Homoscedastic & 0.4215 & Homoscedastic \\
\hline
\end{tabular}

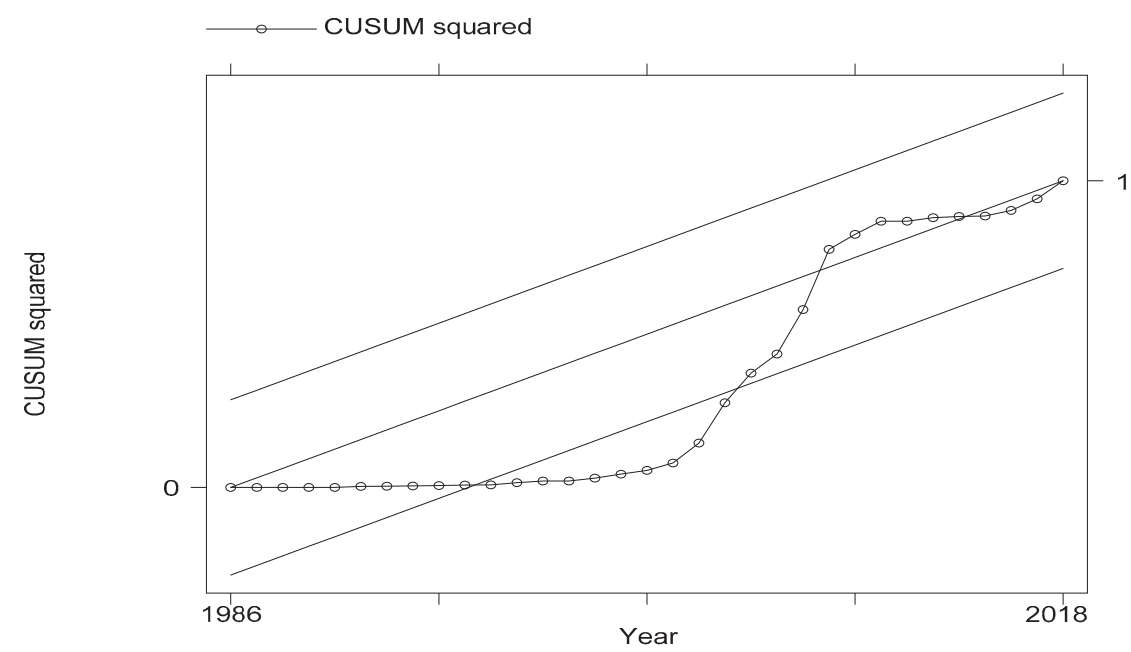

Figure 3. Cumulative Sum (CUSUM) Test for Macroeconomic Variables.

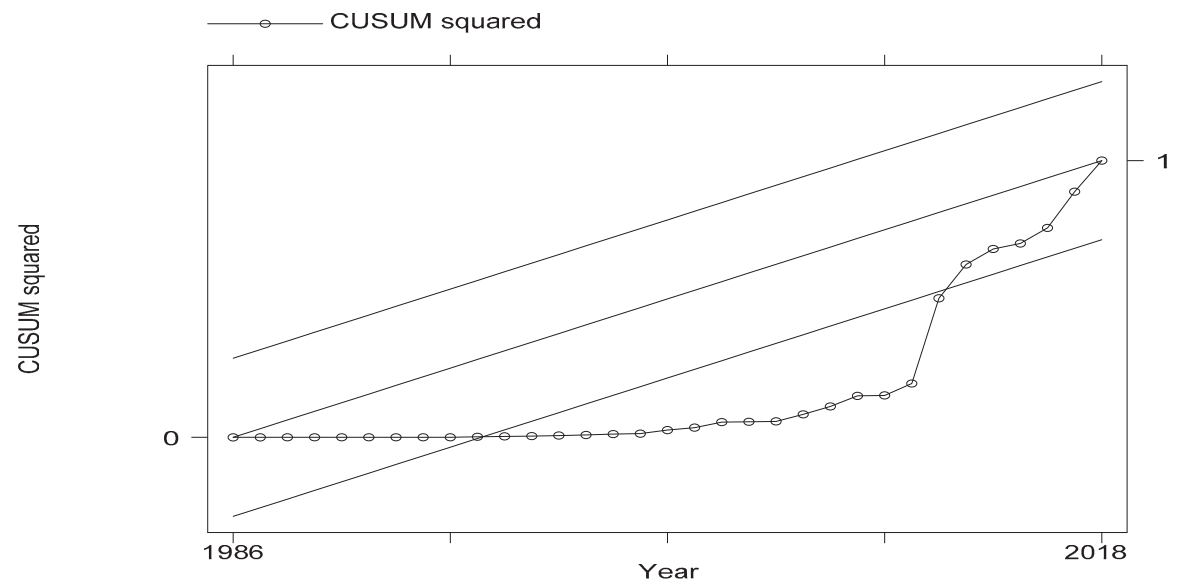

Figure 4. Cumulative Sum (CUSUM) Test for Industry-Specific Variables. 
Table 12. Comparison of ARDL and VECM Coefficients.

\begin{tabular}{|c|c|c|c|c|c|}
\hline \multicolumn{3}{|c|}{ Macroeconomic Variables } & \multicolumn{3}{|c|}{ Industry-Specific Variables } \\
\hline Determinants & $\begin{array}{c}\text { ARDL } \\
\text { Coefficients }\end{array}$ & $\begin{array}{c}\text { VECM } \\
\text { Coefficients }\end{array}$ & Determinants & $\begin{array}{c}\text { ARDL } \\
\text { Coefficients }\end{array}$ & $\begin{array}{c}\text { VECM } \\
\text { Coefficients }\end{array}$ \\
\hline $\operatorname{lnGDPGR}$ & $-1.396011^{* *}$ & $-0.4780902 * *$ & $\ln B K L N$ & $-0.5203392 * * *$ & $-0.3681242 * * *$ \\
\hline $\operatorname{lnCPI}$ & -0.9602321 & -0.1832198 & $\operatorname{lnLIQ}$ & $2.669881 * * *$ & 0.424397 \\
\hline $\operatorname{lnDOCR}$ & 1.066338 * & $0.5250594^{* *}$ & $\ln N O P$ & $-0.0192367 * * *$ & $-0.0602165^{* * *}$ \\
\hline $\ln U N E M$ & $-7.639355^{* * *}$ & $-6.997589^{* * *}$ & $\operatorname{lnLDR}$ & $3.790614^{* * *}$ & $4.923853^{* * *}$ \\
\hline $\operatorname{lnEXR}$ & $3.756394^{* * *}$ & $3.293177^{* * *}$ & $\operatorname{lnDPR}$ & $-0.7667929^{* * *}$ & $-2.718319^{* * *}$ \\
\hline
\end{tabular}

\section{Conclusions}

Throughout the study, we found significant shreds of evidence that our hypothesis of industry-specific and macroeconomic determinants influencing non-performing loans in Bangladesh is being established. To the best of our information, this research is the first to discover the impact of both industry-specific and macroeconomic determinants of NPLs in Bangladesh at a time horizon of 40 years. Also, very few studies, we found, had been conducted comparing the results in ARDL and VECM. Hence, it can be considered a robust study.

Long-run convergences of ARDL show that non-performing loans negatively impact economic growth. That means as the economy advances to good shape, entrepreneurs are more capable of repaying loans. The movement of exchange rates is another important factor, the consequence of which has a positive impact on NPLs. Results show as the exchange rate increases, entrepreneurs have to pay more on their imports causing a reduction in the capacity to repay. Again, with the increase in NPLs, unemployment rises in the short run, which can create instability in the economy as well.

Loan growth in the long run decreases non-performing loans. As the lending horizon has been increasing during the last decade in small and medium enterprises (SMEs) and micro-finances, non-performing loans have decreased proportionately. We may look into this fact in our future research as this is not the focal point of this study. In the short run, NPLs increase with loan growth. Banks' profitability decreases with higher NPLs as banks need to increase the base of loan loss provisions for future losses. This has a spillover effect on the lending interest rates and the deposit rates as well. Lending interest rates increase and deposit rates decrease with the growth of NPLs. Finally, the liquidity of banks needs to be handled carefully so that banks do not become too ambitious and make bad lending. There is a high chance of excess liquidity being wrongly managed by the bankers, as our research found a positive correlation between bad loans and liquidity. Central banks and policymakers can step into this to act as a guide in this regard. Banks may be controlled by implementing contractionary lending policies during an economic downturn and expansionary lending policies during economic growth to ensure their sustainability in the long run. Regulatory bodies may carefully monitor the growth of domestic credit and exchange rate fluctuation to scale down the impact of bad loans in the economy.

The results obtained piloting econometric examination can be used to project fundamental grounds of NPLs in the economy of Bangladesh. It will help policymakers of developing countries like Bangladesh to take enough measures to control NPLs or take precautions against it. The contribution of the current study puts light on future research. For example, future research can be conducted in the developing and emerging economies like Bangladesh.

Author Contributions: Conceptualization: P.K.B.; Methodology, P.K.B.; Formal analysis: P.K.B.; Investigation P.K.B.; Writing original draft preparation: P.K.B.; Writing review and editing: N.S.; Supervision: C.Z. All authors have read and agreed to the published version of the manuscript.

Funding: The research is not funded by any source.

Conflicts of Interest: The authors declare no conflict of interest. 


\section{References}

1. Norton, J.J.; Olive, C.D. Globalization of financial risks and international supervision of banks and securities firms: Lessons from the Barings debacle. Int. Lawyer 1996, 30, 301-344.

2. Klein, N. Non-performing Loans in CESEE: Determinants and Impact on Macroeconomic Performance; International Monetary Fund: Washington, DC, USA, 2013.

3. Louzis, D.P.; Vouldis, A.T.; Metaxas, V.L. Macroeconomic and bank-specific determinants of non-performing loans in Greece: A comparative study of mortgage, business and consumer loan portfolios. J. Bank. Financ. 2012, 36, 1012-1027. [CrossRef]

4. Podpiera, J.; Weill, L. Bad luck or bad management? Emerging banking market experience. J. Financ. Stab. 2008, 4, 135-148. [CrossRef]

5. Berger, A.N.; De-Young, R. Problem loans and cost efficiency in commercial banks. J. Bank. Financ. 1997, 21, 849-870. [CrossRef]

6. Demirgüç-Kunt, A.; Detragiache, E. The determinants of banking crises in developing and developed countries. Staff. Pap. 1998, 45, 81-109. [CrossRef]

7. González-Hermosillo, M.B. Determinants of Ex-Ante Banking System Distress: A Macro-Micro Empirical Exploration of Some Recent Episodes; International Monetary Fund: Washington, DC, USA, 1999.

8. Makri, V.; Tsagkanos, A.; Bellas, A. Determinants of non-performing loans: The case of Eurozone. Panoeconomicus 2014, 61, 193-206. [CrossRef]

9. Yang, C.-C. Reduction of non-performing loans in the banking industry: An application of data envelopment analysis. J. Bus. Econ. Manag. 2017, 18, 833-851. [CrossRef]

10. Barseghyan, L. Non-performing loans, prospective bailouts, and Japan's slowdown. J. Monet. Econ. 2010, 57, 873-890. [CrossRef]

11. Zeng, S. Bank non-performing loans (NPLS): A dynamic model and analysis in China. Mod. Econ. 2012, 3, 100. [CrossRef]

12. Fofack, H.L. Nonperforming Loans in Sub-Saharan Africa: Causal Analysis and Macroeconomic Implications; The World Bank: Washington, DC, USA, 2005.

13. Keeton, W.R.; Morris, C.S. Why do banks' loan losses differ. Econ. Rev. 1987, 72, 3-21.

14. Messai, A.S.; Jouini, F. Micro and macro determinants of non-performing loans. Int. J. Econ. Financ. Issues 2013, 3, 852-860.

15. Matthews, K. Risk management and managerial efficiency in Chinese banks: A network DEA framework. Omega 2013, 41, 207-215. [CrossRef]

16. Espinoza, R.A.; Prasad, A. Nonperforming Loans in the GCC Banking System and Their Macroeconomic Effects; International Monetary Fund: Washington, DC, USA, 2010; pp. 10-224.

17. Škarica, B. Determinants of non-performing loans in Central and Eastern European countries. Financ. Theory Pract. 2014, 38, 37-59. [CrossRef]

18. Chaibi, H.; Ftiti, Z. Credit risk determinants: Evidence from a cross-country study. Res. Int. Bus. Financ. 2015, 33, 1-16. [CrossRef]

19. Dimitrios, A.; Helen, L.; Mike, T. Determinants of non-performing loans: Evidence from Euro-area countries. Financ. Res. Lett. 2016, 18, 116-119. [CrossRef]

20. Partovi, E.; Matousek, R. Bank efficiency and non-performing loans: Evidence from Turkey. Res. Int. Bus. Financ. 2019, 48, 287-309. [CrossRef]

21. Ghosh, A. Banking-industry specific and regional economic determinants of non-performing loans: Evidence from US states. J. Financ. Stab. 2015, 20, 93-104. [CrossRef]

22. Godlewski, C.J. The determinants of multiple bank loan renegotiations in Europe. Int. Rev. Financ. Anal. 2014, 34, 275-286. [CrossRef]

23. Dey, B.K. Managing Nonperforming Loans in Bangladesh. 2019. Available online: https://www.adb.org/ publications/managing-nonperforming-loans-bangladesh (accessed on 26 December 2019).

24. Vardar, G.; Özgüler, I.C. Short Term and Long Term Linkages among Nonperforming Loans, Macroeconomic and Bank-Specific Factors: An Empirical Analysis for Turkey. Ege Akad. Bakış Derg. 2015, 15, 313-326. [CrossRef]

25. Bardhan, S.; Mukherjee, V. Bank-specific determinants of nonperforming assets of Indian banks. Int. Econ. Econ. Policy 2016, 13, 483-498. [CrossRef] 
26. Rajan, R.G. Why bank credit policies fluctuate: A theory and some evidence. Q. J. Econ. 1994, 109, 399-441. [CrossRef]

27. García-Marco, T.; Robles-Fernández, M.D. Risk-taking behaviour and ownership in the banking industry: The Spanish evidence. J. Econ. Bus. 2008, 60, 332-354. [CrossRef]

28. Boahene, S.H.; Dasah, J.; Agyei, S.K. Credit risk and profitability of selected banks in Ghana. Res. J. Financ. Account. 2012, 3, 6-14.

29. Sinkey, J.F.; Greenawalt, M.B. Loan-loss experience and risk-taking behavior at large commercial banks. J. Financ. Serv. Res. 1991, 5, 43-59. [CrossRef]

30. Liu, R. Comparison of Bank Efficiencies Between the US and Canada: Evidence Based on SFA and DEA. J. Compet. 2019, 11, 113-129. [CrossRef]

31. Kjosevski, J.; Petkovski, M.; Naumovska, E. Bank-specific and macroeconomic determinants of non-performing loans in the Republic of Macedonia: Comparative analysis of enterprise and household NPLs. Econ. Res. Ekon. Istraživanja 2019, 32, 1185-1203. [CrossRef]

32. Tanasković, S.; Jandrić, M. Macroeconomic and institutional determinants of non-performing loans. J. Cent. Bank. Theory Pract. 2015, 4, 47-62. [CrossRef]

33. Vogiazas, S.D.; Nikolaidou, E. Investigating the determinants of nonperforming loans in the Romanian banking system: An empirical study with reference to the Greek crisis. Econ. Res. Int. 2011, 2011. [CrossRef]

34. Rifat, A.M. An Analytical Study of Determinants of Non-Performing Loans: Evidence from Non-Bank Financial Institutions (NBFIs) of Bangladesh. J. Bus. Technol. (Dhaka) 2016, 11, 55-67. [CrossRef]

35. Shuman, M.A.R. Effect of Bank Specific Variables on the Non-Performing Loan Ratio: A case study on the Commercial Banks of Bangladesh. In Proceedings of the Annual Banking Conference, Dhaka, Bangladesh, 23-29 November 2015.

36. Parvin, A. Determinants of Problem Loan and Its Effect on the Financial Health: Evidence from Private Commercial Banks of Bangladesh. Proceedings of Welcome Message from Conference Chairs, Omaha, NE, USA, 28-31 September 2017.

37. Amir, M.K. Does excess bank liquidity impact non-performing loan? a study on Bangladeshi economy. Int. J. Bus. Technopreneurship 2019, 9, 287-298.

38. Islam, F.T. Evaluating Loan Loss Provisioning for Non-Performing Loans and Its Impact on the Profitability of Commercial Banks in Bangladesh. Asian Financ. Bank. Rev. 2018, 2, 33-41.

39. Rahman, M.; Hai, A. Factors Affecting Non-Performing Loan (NPL) of Private Commercial Banks in Bangladesh. Amity Glob. Bus. Rev. 2017, 12, 7-14.

40. Rahman, M.A.; Asaduzzaman, M.; Hossin, M.S. Impact of financial ratios on non-performing loans of publicly traded commercial banks in Bangladesh. Int. J. Financ. Res. 2016, 8, 181. [CrossRef]

41. Hasan, M.Z. Macroeconomic Determinants of Non-Performing Loans in Bangladesh: An ARDL Approach. Sci. Res. J. 2019, 7, 84-89.

42. Hasan, K.; Khan, R.S. Management of Non-Performing Loans (NPLs) of Banks in Bangladesh-An Evaluative study. J. Econ. Financ. 2013, 1, 1-15.

43. Rahman, B.; Jahan, N. Non-Performing Loans (NPLs) in Islamic Banks of Bangladesh: An Empirical Study. world Rev. Bus. Res. 2018, 8, 12-23.

44. Islam, M.Z.; Aktar, S.; Hossen, M.A.; Islam, M.S. Non-Performing Loan And Asset Utilization of Banks: Evidence From Bangladesh. Rom. Econ. Bus. Rev. 2018, 13, 31-39.

45. Islam, M.Z.; Islam, M.S. Non-Performing Loan As Eroding Factor of Capital Adequacy: Evidence From Banking Industry In Bangladesh. Rom. Econ. Bus. Rev. 2018, 13, 15-21.

46. Roy, S.; Dey, P.K.; Bhowmik, P. Non-performing loans in private commercial banks of Bangladesh: Macro-economic determinants and impacts. Jahangirnagar J. Bus. Stud. 2014, 4, 47-57.

47. Roy, J. Non-Performing Loan on Profitability: Evidence from Banking Sector of Dhaka Stock Exchange. SSRN Electron. J. 2015, 1, 13. [CrossRef]

48. Islam, M.S.; Nishiyama, S.-I. Non-Performing Loans of Commercial Banks in South Asian Countries: Adverse Selection and Moral Hazard Issues. Asian Econ. Financ. Rev. 2019, 9, 1091. [CrossRef]

49. Mondal, T. Sensitivity of non-performing loan to macroeconomic variables: Empirical evidence from banking industry of Bangladesh. Glob. J. Manag. Bus. Res. 2016, 16, 4-C.

50. Engle, R.F.; Granger, C.W. Co-integration and error correction: Representation, estimation, and testing. Econom. J. Econom. Soc. 1987, 55, 251-276. [CrossRef] 
51. Hassler, U.; Wolters, J. Autoregressive distributed lag models and cointegration. In Modern Econometric Analysis; Springer: Berlin/Heidelberg, Germany, 2006; pp. 57-72.

52. Masih, M.; Hamdan, B. The impact of monetary policy on deposit and lending rates in industrial and developing countries: An application of ARDL approach. J. Int. Financ. Econ. 2008, 8, 114-122.

53. Mallick, H.; Agarwal, S. Impact of real interest rates on real output growth in India: A long-run analysis in a liberalized financial regime. Singap. Econ. Rev. 2007, 52, 215-231. [CrossRef]

54. Shrestha, M.B.; Chowdhury, K. ARDL Modelling Approach to Testing the Financial Liberalisation Hypothesis; Working Paper 05-15; Department of Economics, University of Wollongong: Wollongong, Australia, 2005. Available online: https://ro.uow.edu.au/commwkpapers/121 (accessed on 22 July 2019).

(C) 2019 by the authors. Licensee MDPI, Basel, Switzerland. This article is an open access article distributed under the terms and conditions of the Creative Commons Attribution (CC BY) license (http://creativecommons.org/licenses/by/4.0/). 

Article

\title{
Analysis of Tail Dependence between Sovereign Debt Distress and Bank Non-Performing Loans
}

\author{
Li Liu ${ }^{1}$, Yu-Min Liu ${ }^{1}$ * , Jong-Min Kim ${ }^{2}$, Rui Zhong ${ }^{1}$ and Guang-Qian Ren ${ }^{1}$ \\ 1 Business School, Zhengzhou University, Zhengzhou 450001, China; smile_liliu@163.com (L.L.); \\ rui.zhong@uwa.edu.au (R.Z.); rgq1982@163.com (G.-Q.R.) \\ 2 Division of Science and Mathematics, University of Minnesota-Morris, Morris, MN 56267, USA; \\ jongmink@morris.umn.edu \\ * Correspondence: yuminliu@zzu.edu.cn; Tel.: +86-136-2384-7252
}

Received: 3 January 2020; Accepted: 17 January 2020; Published: 20 January 2020

\begin{abstract}
We investigate the tail dependence between sovereign debt distress and bank non-performing loans (NPLs) using a large sample of developed and emerging countries in recent decades. Considering the feedback loop of sovereign debt and bank loan distress, we use three copula models to analyze the asymmetry of tail dependence structure between sovereign debt exposure and bank NPLs. We use the Gaussian copula marginal regression to control the concurrent impact of other macroeconomic variables. We provide evidence that sovereign debt indicates an important determinant of NPLs. We also find that there is tail dependence between sovereign debt distress and bank NPLs, whereas the tail dependence coefficients vary across countries. Our findings shed light on the influence of fiscal distress on bank loan distress and provide immediate implications for the design of macro prudential and financial policy.
\end{abstract}

Keywords: non-performing loans; sovereign debt distress; tail dependence; gaussian copula regression

JEL Classification: H63 G23

\section{Introduction}

The sovereign debt crises in recent decades highlight the influence of sovereign debt distress on the fragility of bank loans. For example, the Russian government's suspension of debt payments in 1998 triggered a dramatic increase of bank bank non-performing loans (NPLs) in Russian banks. The downgrading of Greece's sovereign debts in 2010 raised the ratio of bank NPLs in Greek and other related banks that hold a significant amount of Greece's sovereign debts. Outside of Europe, a similar influence of sovereign debt distress on the performance of bank NPLs also occurs in Argentina, Ecuador, Pakistan, and Ukraine [1]. In the opposite direction, the banking crisis are also important predictors of sovereign debt crises [2]. There is an increasing amount of literature to investigate this perverse feedback loop of sovereign debt distress and bank distress [3-5]. There are several channels that sovereign credit could have a significant impact on the banking system. First, the euro area is linked by the Eurosystem's collateral framework, the joint monetary policy transmission mechanism, and the shared defalt risk of Eurozone countries through the European Stability Mechanism (ESM) and the European Financial Stability Fund (EFSF) [4]. Sovereign debt impacts the financial sector by influencing the balance sheet of financial institutions, lowering the rating of domestic banks, reducing the value of collateral and increasing their financing costs [6]. All the related literature focus on examining the impact of sovereign default (or crises) on bank default (or crises). Since the actual sovereign (bank) defaults or crises are extreme events and occur rarely in history, the sample size of empirical studies is limited. Meanwhile, there are many concurrent events that occur around sovereign defaults or crises. 
Since the end of 2009, the increase of higher sovereign risk has pushed up the cost and affected the financing structure of some euro area banks. The banks of Greece, Ireland, and Portugal find it difficult to raise large-scale debt and deposits. It is very difficult to isolate the actual impact of sovereign debt distress on bank loan distress from these concurrent events.

In this study, we adopt three copula models to analyze the tail dependence between sovereign debt distress and bank loan performance. Specifically, we use the ratio of government debt to Gross Domestic Product (GDP) to measure sovereign debt exposure and the ratio of non-performing loans to proxy for bank loan performance. The right tail of sovereign debt exposure and bank NPLs reflects the likelihood of sovereign debt and bank loan distress, respectively. In contrast to the related studies [2-5] that use actual sovereign debt defaults (or crises), our measures mitigate the impact of other concurrent events around actual fiscal or financial crises and also significantly increase the sample size in term of time span and countries. In particular, our study covers 25 countries during a period from 2006 to 2017.

First, a Granger causality test was applied to examine the causality between sovereign debt and bank NPLs. We find that most of the significant causality relationship occurs in the first-year lag variables. For instance, the first-year lag of sovereign debt ratio significantly causes bank NPLs in many countries, such as Cyprus, Portugal, Spain, Germany, Slovakia, Denmark, South Africa, etc. Furthermore, we use Kendall's tau as an alternative measure to exhibit the relationship between each pair of countries in our sample. In particular, we divide our countries into two groups: European countries and BRICS countries (Brazil, Russia, India, China and South Africa). We find that the mean of Kendall's tau among the European countries is about 0.4742 , while the mean among the BRICS countries is only 0.0141 . This evidence suggests that geographical location is one of the factors affecting the spillover effects of sovereign debt on bank NPLs.

To analyze the asymmetry of the tail dependence structure between sovereign debt and bank NPLs, we employ three of the most frequently used copula models in finance [7]: Student's $t$-copula (symmetric association of tail dependence), rotated Clayton copula (upper-tail dependence), and Joe copula (upper-tail dependence). We employ these copulas because they are able to analyze the upper tail dependence. Our empirical results suggest that the tail dependence between sovereign debt and bank NPLs varies across countries. Most tail dependence results are consistent across the three copula approaches with slight variation, especially in the $t$ copula. All copula approaches point out that the highest tail dependence between sovereign debt ratio and bank NPLs ratio occurs in Ireland and Croatia. In addition, the tail dependence is high in Denmark, Belgium, Cyprus, Latvia, Austria, and Portugal in contrast to other countries in our sample.

Last, since the bank NPLs ratio is affected by many factors simultaneously, we use the Gaussian copula regression method (GCRM) to isolate the important impact of sovereign debt on bank NPLs from other known determinants. Particularly, we control GDP, inflation rate, government fiscal expenditure and government fiscal revenue. We document significant and positive relation between sovereign debt ratio and bank NPLs ratio in 15 out of 25 countries, which adds more credence to the upper tail dependence between sovereign debt distress and bank non-performing loans in some countries, such as Ireland and Croatia.

This research contributes to the related literature from at least two aspects. First, we use a new method to analyze the upper tail dependence between sovereign debt and bank NPLs. Most closely related literature uses classical regression models to examine the relation between sovereign debt defaults and financial crises [8-11]. In contrast to the classical regression models, copula models have an advantage of analyzing the tail dependence between two distributions. For instance, Reboredo and Ugolini use the CoVaR-copula approach and vine-copula conditional VaR approach to analysis the impact of the European debt crisis on the banking risk in debt markets [12,13]. In this study, we use three alternative copula approaches to explore the tail dependence between sovereign debt ratio and bank NPLs ratio, which deepens the understanding of this relation.

Second, our study enriches the literature on the determinants of bank NPLs by providing new evidence from the aspect of macroeconomic factors. There is a long history and large amount 
of literature to examine the determinants of bank NPLs. Most of the identified determinants are microeconomic factors, mostly bank characteristics, such as cost efficiency [14]), bank's risk management function [15], government ownership [16], bank credit growth [17], etc. Recently, especially after the sub-prime financial crises, a strand of literature has emerged to examine the impact of macroeconomic and policy-related factors on bank non-performing loans, including monetary policy [18], inflation rate [19,20], GDP [10,21,22], fiscal expenditure and revenue [23-26], unemployment rates and housing price index [27], and policy rates [28,29]. Makri et al. reveal strong correlations between NPLs and public debt of Eurozone's banking systems for the period 2000-2008, and fiscal problems may raise bad loans in this region [11]. Ghosh finds that liquidity risk, greater capitalization, greater cost inefficiency, poor credit quality, and banking industry size significantly increase bank non-performing loans. Similarly, inflation, state unemployment rates, and US public debt significantly increase bank non-performing loans [27]. In contrast to previous studies, this paper identifies a new macroeconomic factor, sovereign debt to GDP ratio, which affects bank NPLs ratios. Empirical evidence shows that the impact of sovereign debt ratio on bank non-performing loans varies across countries. Liu et al. find that the government debt and NPLs of EU and BRICS countries increased drastically after the crisis, and crisis countries are contagious [30].

The organization of this paper is as follows: Section 2 describes the econometric methodology in the analysis. Section 3 defines the variables and data descriptions. Section 4 discusses the empirical results. Finally, Section 5 concludes.

\section{Econometric Methodology}

\subsection{Granger Causality Tests}

Granger causality shows that the lagged value of one variable is conducive to predicting another variable [31]. To study the causality relationship between sovereign debt and bank NPLs, we follow the Granger causality test to analyze the existence of a causality relationship. More precisely, we plan to test whether the change of sovereign debt precedes NPLs or, on the contrary, whether NPLs precede the sovereign debt (and even whether these relationships are bidirectional).

Consider two variables, $X_{t}$ and $Y_{t}, X_{t}$ Granger-causes $Y_{t}$ suggested that lags of $X_{t}$ provide useful information to explain present values of $Y_{t}$ and vice versa. Under these conditions, the Granger causality model is as follows:

$$
\begin{aligned}
& X_{t}=\varphi_{1}+\sum_{i=1}^{k} a_{1 i} X_{t-i}+\sum_{j=1}^{k} b_{1 j} Y_{t-j}+\varepsilon_{1 t} \\
& Y_{t}=\varphi_{2}+\sum_{i=1}^{k} a_{2 i} X_{t-i}+\sum_{j=1}^{k} b_{2 j} Y_{t-j}+\varepsilon_{2 t}
\end{aligned}
$$

where $X$ and $Y$ denote NPLs and sovereign debt, interchangeably; $\varphi_{1}$ and $\varphi_{2}$ are the intercepts of the equation; and $k$ is the lag length. $a$ and $b$ represent estimation coefficients, and $\varepsilon$ denotes error terms. This model is suitable for testing the causality relationships between NPLs and sovereign debt during 2006-2017. For each sample country, alternative causal relationship can be found [32]. There is a one-way Granger-causality from $X$ to $Y$ if not all $b_{2 j}$ are zero, but all $a_{1 i}$ are zero. Similarly, there is a one-way Granger-causality from $Y$ to $X$ if not all $a_{2 i}$ are zero, but all $b_{1 j}$ are zero. Additionally, there is a two-way Granger-causality between $X$ and $Y$ if all $b_{2 j}$ and $a_{2 i}$ are not zero. There is no Granger-causality between $X$ and $Y$ if $b_{2 j}$ and $a_{2 i}$ are zero [33].

\subsection{Kendall's Tau Coefficient}

In statistics, Kendall's tau coefficient is a measure of nonlinear dependence between two random variables $X$ and $Y$, which was put forward by Maurice Kendall in 1938. Kendall's tau shows that there 
is a monotonic (but not necessarily linear) relationship between the two variables. A Kendall's tau test is a nonparametric hypothesis test based on the tau correlation coefficient [34].

According to Kendall, suppose a pair of points $\left(X_{i}, Y_{j}\right)$ and $\left(X_{j}, Y_{j}\right)$ are considered to be concordant if $X_{i}<X_{j}$ and $Y_{i}<Y_{j}$ or if $X_{i}>X_{j}$ and $Y_{i}>Y_{j}$, meaning that the pairs are in the same order to each variable. Namely, a higher value of $X$ corresponds to a higher value of $Y$; on the contrary, a lower value of $X$ corresponds to a lower value of $Y$. The pairs are considered to be discordant if $X_{i}<X_{j}$ and $Y_{i}>Y_{j}$ or if $X_{i}>X_{j}$ and $Y_{i}<Y_{j}$, meaning that the values of variables are arranged in opposite directions; in other words, a lower value of $X$ corresponds to a higher value of $Y$, and a higher value of $X$ corresponds to a lower value of $Y[35,36]$. The pairs are tied if $X_{i}=X_{j}$ and/or $Y_{i}=Y_{j}$.

If two random variables $X$ and $Y$ obey joint distribution $H(x, y)$ and two vectors of $\left(X_{i}, Y_{i}\right)$ and $\left(X_{j}, Y_{j}\right)$ are independent, then Kendall's tau is defined by

$$
\tau=P\left[\left(X_{i}-X_{j}\right)\left(Y_{i}-Y_{j}\right)>0\right]-P\left[\left(X_{i}-Y_{j}\right)\left(X_{i}-X_{j}\right)<0\right]
$$

Equation (3) will calculate a value in $[-1,1]$, which is the same as Pearson's correlation. The higher the absolute value of $\tau$, the stronger the correlation between the two variables. Specifically, a positive value indicates that the higher value of one variable is associated with the higher value of another variable, and a negative value is the opposite [37].

\subsection{Copula Function and Tail Dependence}

Copulas were first introduced in the Sklar theorem and further developed by Joe (1997). A copula is a function that relates univariate distribution to one-dimensional marginal multivariate distribution of related variables

$$
H(x, y)=C\left(F_{X}(x), F_{Y}(y)\right)
$$

where $H($.$) is a bivariate function, and F_{X}($.$) and F_{Y}($.$) are cumulative distribution functions of X$ and $Y$. Sklar's theorem says that univariate margins can be separated from the dependence structure, and the dependency structure can be represented by a copula, which is $C$ [38]. A bivariate copula is a function $C:[0,1]^{2} \rightarrow[0,1]$, which has the following properties, that is, $u=F_{X}(x)$ and $v=F_{Y}(y)$ :

(1) The domain of $C(u, v)$ is $[0,1] \times[0,1]$

(2) $\quad C(u, 1)=C(1, u)=u, C(v, 1)=C(1, v)=v, \forall u, v \in[0,1]$

(3) $C(u, v)$ has zero fundamentals and is incremented in two dimensions

As can be seen from the above definition, copulas are a useful way to model dependent random variables. Copulas have some certain properties that are very useful in dependency studies. Firstly, copulas are always constant for strictly increasing the transformation of random variables. Secondly, consistency measurements between widely used random variables, such as Kendall's tau and Spearman's rho, are attributes of copulas. Thirdly, tail dependence is also an attribute of copulas.

Nelsen defines the upper and lower tail dependence coefficients for $\tau^{U} \in[0,1]$ and $\tau^{L} \in[0,1]$ of $(X, Y)[39]$

$$
\begin{aligned}
\tau^{U} & =\lim _{\varepsilon \rightarrow 1} P[U>\varepsilon \mid V>\varepsilon]=\lim _{\varepsilon \rightarrow 1} P[V>\varepsilon \mid U>\varepsilon] \\
\tau^{L} & =\lim _{\varepsilon \rightarrow 0} P[U \leq \varepsilon \mid V \leq \varepsilon]=\lim _{\varepsilon \rightarrow 1} P[V \leq \varepsilon \mid U \leq \varepsilon]
\end{aligned}
$$

The upper (right) and lower (left) tail dependence of a normal copula are equal, which is $\tau^{L}=\tau^{U}=0$, and this means that variables are independent in the extreme of distribution. The most common assumption is the normal copula in finance although it does not have tail dependence. There are many types of copulas that have left or right tail dependence. 


\subsubsection{Student's $t$ Copula}

Similar to the normal distribution, the $t$ distribution is a symmetrical bell-shaped distribution, but its tail is heavier, which means it is more likely to produce values far below its mean [40].

$$
C^{t}(u, v \mid \rho, \lambda)=\int_{-\infty}^{T_{\lambda}{ }^{-1}(u)} \int_{-\infty}^{T_{\lambda}^{-1}(v)} \frac{1}{2 \pi \sqrt{1-\rho^{2}}}\left[1+\frac{s^{2}+r^{2}-2 \rho r s}{\lambda(1-\rho)^{2}}\right]^{-\frac{\lambda+2}{2}} d s d r
$$

where $\lambda$ denotes the degrees of freedom of the $t$ copula, $\rho$ is the coefficient of linear correlation, and $T_{\lambda}^{-1}$ is the inverse of the standard univariate $t$-distribution function with $\lambda$ degrees of freedom. The Kendall's tau of the $t$ copula is $\frac{2 \arcsin \rho}{\pi}$, and

$$
\begin{aligned}
& \tau^{L}=2-2 t_{k+1}\left(\frac{\sqrt{k+1} \sqrt{1-\rho}}{\sqrt{1+\rho}}\right) \\
& \tau^{U}=2-2 t_{k+1}\left(\frac{\sqrt{k+1} \sqrt{1-\rho}}{\sqrt{1+\rho}}\right)
\end{aligned}
$$

where $t_{k+1}\left(\frac{-\sqrt{k+1} \sqrt{1-\rho}}{\sqrt{1-\rho}}\right)$ represents the value of the standard $t$-distribution function with the degree of freedom $k+1$ at $\left(\frac{-\sqrt{k+1} \sqrt{1-\rho}}{\sqrt{1-\rho}}\right)$.

\subsubsection{Clayton Copula}

Clayton proposed one of the first bivariate association models for survival analysis [41]. Especially, the Clayton copula is a popular method for time dependent association data, and it has a lower tail dependence between variables and can fit structural relationships with lower tail dependence well; it is higher for negative events than joint positive events.

$$
C(u, v \mid \theta)=\left(u^{-\theta}+v^{-\theta}-1\right)^{-1 / \theta}
$$

where $\forall \theta \in(0, \infty)$, the Kendall's tau of the Clayton copula is $\frac{\alpha}{2+\alpha}$, and $\tau^{L}=2^{-1 / \alpha}$.

\subsubsection{Joe Copula}

In order to estimate the copula from a bivariate observational data set, Joe proposed the tail dependence concept with copulas [42]. It relates the amount of dependence of the upper-right quadrant tail or the lower-left quadrant tail of a bivariate distribution. The upper tail dependence that can be found by the Joe copula is defined by

$$
C(u, v \mid \theta)=1-\left[(1-u)^{\theta}+(1-v)^{\theta}-(1-u)^{\theta}(1-v) \theta\right]^{1 / \theta}
$$

where $\theta \in[1, \infty)$.

\subsection{Gaussian Copula Regression Method}

Linear regression has been extensively used by statisticians to find the relationship between dependent variables [43]. However, the assumption of linear relationship is too unrealistic and restrictive in real application. Copula regression is more suitable than a linear model when the dependent variable does not follow a normal distribution. Gaussian copula regression has been increasingly popular in longitudinal data analysis, time series, mixed data, and spatial statistics. Copula regression uses various copula models to represent the joint distribution of a pair of continuous and discrete random variables. The marginal can be defined by various parametric distributions. The marginal distributions are fitted to the bivariate joint distribution by maximum likelihood [44,45]. 
To avoid the multicollinearity in regression analysis, we employ the Gaussian copula marginal regression (GCMR) for each country to measure the macroeconomic variables to assess the impact on NPLs.

Consider a vector of $n$ dependent variables $Y_{1}, \ldots, Y_{n}$. Let $F\left(\cdot \mid x_{i}\right)$ be the marginal cumulative distribution of $Y_{i}$ for covariates $x_{i}$. The joint data cumulative distribution function in the Gaussian copula regression is expressed as

$$
\operatorname{Pr}\left(Y_{1} \leq y_{1}, \ldots, Y_{n} \leq y_{n}\right)=\Phi\left(\tau_{1}, \ldots, \tau_{n} ; \mathrm{P}\right)
$$

where $\tau_{i}=\Phi^{-1}\left\{F\left(y_{i} \mid x_{i}\right)\right\}$. For the correlation matrix of $\mathrm{P}, \Phi(\cdot)$ represents the univariate standard normal cumulative distribution function and $\Phi(\cdot ; \mathrm{P})$ denotes the multivariate standard normal cumulative distribution function. More details of the Gaussian copula model are described in Song [46] and Masarotto [47]. In particular, an equivalent formulation of the Gaussian copula is given by

$$
Y_{i}=h\left(x_{i}, \tau_{i}\right)
$$

where $\tau_{i}$ represents a stochastic error. The Gaussian copula regression model assumes that

$$
h\left(x_{i}, \tau_{i}\right)=F^{-1}\left\{\Phi\left(\tau_{i}\right) \mid x_{i}\right\}
$$

and the vector of errors $\tau=\left(\tau_{1}, \ldots, \tau_{n}\right)^{\mathrm{T}}$ follows multivariate normal distribution.

To avoid linearity, normal and independent assumptions, Gaussian marginal distributions for individual predictor variables are used with Gaussian copula functions in this paper.

$$
\begin{aligned}
& \text { NPLs ratio } t=\beta_{0}+\beta_{1} \times \text { government }- \text { to }- \text { GDP ratio }_{t}+\beta_{2} \times \text { Expenditure }_{t}+ \\
& \beta_{3} \times \mathrm{GDP}_{t}+\beta_{4} \times \text { Revenue }_{t}+\mu_{t}
\end{aligned}
$$

where $\mu_{t}$ is the error term, $\mu_{t}=\varphi \mu_{t-1}+\omega_{t}$, and $\omega_{t} \sim \operatorname{iidN}\left(0, \sigma_{\omega}^{2}\right)$ for the GCMR.

\section{Definition of Variables and Data Description}

\subsection{Variables and Data Description}

In this paper, we investigate tail dependence between sovereign debt distress and bank NPLs. The data are comprised of general government gross debt to GDP ratio, bank NPLs, GDP, government fiscal expenditure, government fiscal revenue, and inflation rate which are retrieved from Eurostat and the International Monetary Fund (IMF). Table 1 presents macroeconomic variables in this study and their corresponding sources. We exclude these countries in the sample because data availability problems in some countries, such as Luxembourg, the Netherlands, and Finland. The final sample includes 30 countries, including $25 \mathrm{EU}$ countries and 5 BRICs countries. This paper covers the period of 11 years (2006-2017), which includes both the global financial crisis and European sovereign debt crisis period.

As can be seen from Figures 1 and 2, there are similar fluctuations of two key variables between most sample countries. Meanwhile, the rise of the bank non-performing loan ratio is often accompanied by the expansion of general government gross debt. This feature provides evidence that a dependence of two key variables may exist. 
Table 1. Definition of variables used in this paper.

\begin{tabular}{|c|c|c|}
\hline Variable & Definition & Source \\
\hline $\begin{array}{l}\text { Non-performing loans } \\
\text { (NPLs) }\end{array}$ & $\begin{array}{l}\text { The ratio of non-performing loans to total } \\
\text { loans. }\end{array}$ & $\begin{array}{l}\text { Eurostat, International } \\
\text { Monetary Fund (IMF) }\end{array}$ \\
\hline Sovereign debt & $\begin{array}{l}\text { The general government gross debt to GDP } \\
\text { ratio. }\end{array}$ & Eurostat, IMF \\
\hline $\begin{array}{l}\text { Gross domestic product } \\
\text { (GDP) }\end{array}$ & $\begin{array}{l}\text { GDP has a significant negative impact on } \\
\text { NPLs, because the growth of GDP creates } \\
\text { more jobs, which increases income of } \\
\text { borrowers and reduces NPLs. Therefore, } \\
\text { the level of NPLs will rise when the } \\
\text { economy slows down. }\end{array}$ & IMF \\
\hline Inflation rate & $\begin{array}{l}\text { It is represented by a percentage change in } \\
\text { regional consumer price index }(\mathrm{CPI}) \text { and } \\
\text { low liquidity level is conducive to economic } \\
\text { growth, while high liquidity rate weakens } \\
\text { borrowers' solvency by reducing their real } \\
\text { income, thus increasing NPLs. }\end{array}$ & IMF \\
\hline $\begin{array}{l}\text { Government fiscal } \\
\text { expenditure }\end{array}$ & $\begin{array}{l}\text { Government fiscal expenditure refers to the } \\
\text { funds expended by the government. } \\
\text { Economic growth through fiscal } \\
\text { expenditure and government investment, as } \\
\text { well as more central government deficits } \\
\text { and money supply has been greatly limited } \\
\text { after the economic crisis. Meanwhile, } \\
\text { insufficient fiscal revenue will offset the } \\
\text { growth of tax revenue. When the } \\
\text { government faces a budget deficit, it will } \\
\text { generate public debt. }\end{array}$ & IMF \\
\hline Government fiscal revenue & $\begin{array}{l}\text { Government revenue is the income } \\
\text { available to fund the activities of a } \\
\text { government. High fiscal revenue usually } \\
\text { means the government controls a large } \\
\text { share of financial resources has the ability to } \\
\text { repay bank loans, while fiscal distress } \\
\text { implies that fiscal revenue cannot satisfy } \\
\text { government's expenditures. }\end{array}$ & IMF \\
\hline
\end{tabular}

From Figure 1, it is obvious that the NPLs ratio of the sample countries experienced a huge fluctuation during 2007-2017. After the global financial crisis of 2008, the bank non-performing loan ratio changed significantly for many EU countries such as Greece, Cyprus, Lithuania, Ireland, Latvia, Italy, Croatia, Bulgaria, Hungary, Portugal, Malta, Romania, et al. Meanwhile, the scale of the NPLs ratio expanded significantly when the European sovereign debt crisis emerged. After the debt crisis' peak in 2013, the NPLs ratio started to decrease in most sample countries. One of the important events of the Greek crisis occurred on 18 October 2009 when the Greek government announced that the budget deficit had increased to at least $12 \%$ of the GDP, double the government's estimate. The NPLs ratio of Cyprus and other EU countries rose sharply when the Greek government bonds defaulted, as those countries' banks invested heavily in Greek sovereign debt. Therefore, the economic crisis did spread to countries such as Portugal, Italy, Ireland, Spain, France, and other countries with strong economic strength in the Eurozone. However, the NPLs ratio for the non-crisis countries (Estonia, Sweden, Germany, China, Brazil, South Africa, et al.) remained relatively stable after the outbreak of the crisis. It cannot be ignored that the non-performing loan ratio of the banks in two BRICS countries (India and Russia) has been continuously increasing. 
Figure 2 shows the government-to-GDP ratio for each of the sample countries in the sample. The evolutions of these ratios are very similar; thus, we can distinguish some different periods marked by the global financial risk of 2008 and the European sovereign debt crisis of 2009. It can be seen that the government-to-GDP ratio of most sample countries is lower than the $90 \%$ debt cliff before 2007 . As the global financial crisis deepened, the government-to-GDP ratio began to largely increase in all of the sample countries, especially in Greece, Italy, Portugal, Ireland, and Belgium. By the end of 2017, the government-to-GDP ratio of Greece reached 180.8\%, three times the Eurozone government-to-GDP ratio limit set at $60 \%$. Lately, Belgium, Spain, Cyprus, Slovenia, and the United Kingdom also show large increases. Different from the bank non-performing loan ratio, the government-to-GDP ratio of the BRICS countries such as China, Brazil, and South Africa has grown slowly since 2008. However, the government-to-GDP ratio of Brazil and India has reached above 69\%, higher than some EU countries (Sweden, Slovakia, Lithuania, et al.). Large government debt in many sample countries (developed economics and underdeveloped economics) has become a serious problem.

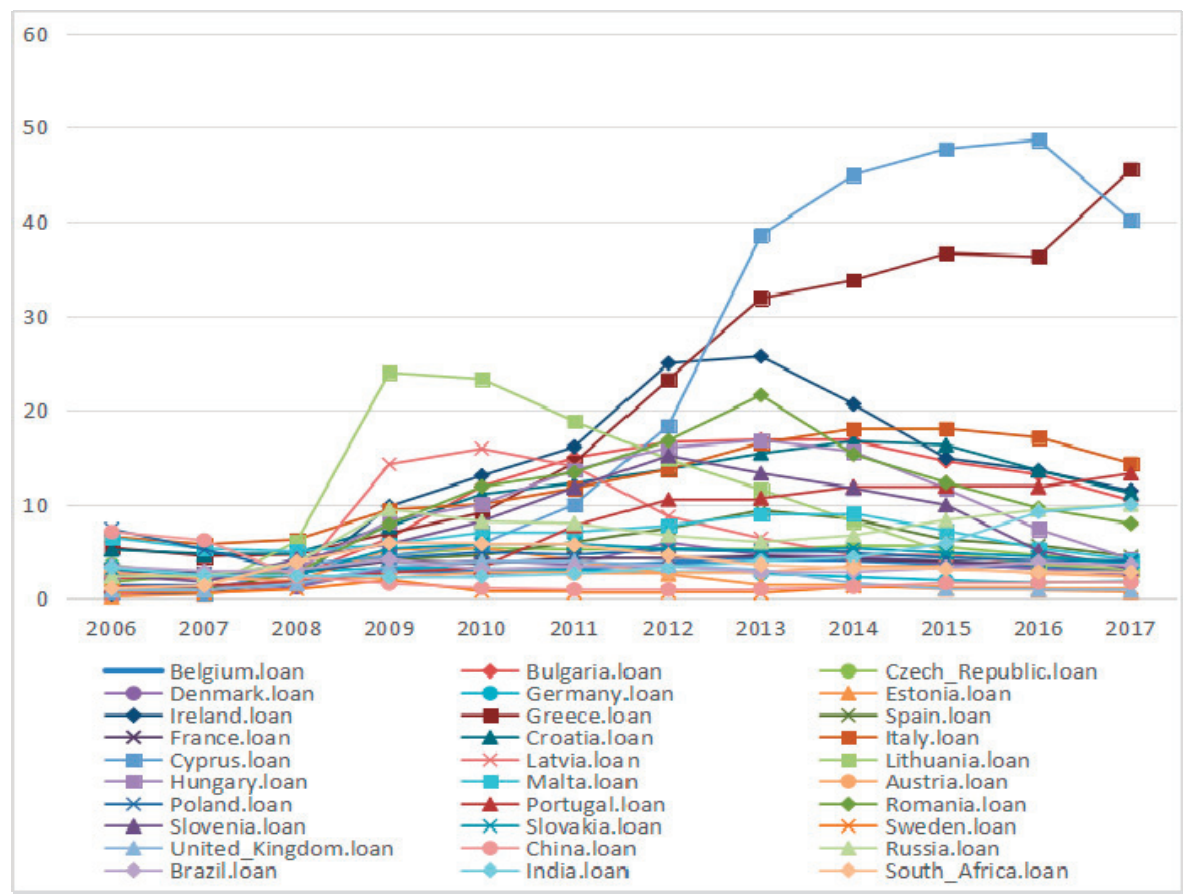

Figure 1. Bank non-performing loans (NPLs) ratio of the sample countries since during 2007-2017. Source: Eurostat; International Monetary Fund. 


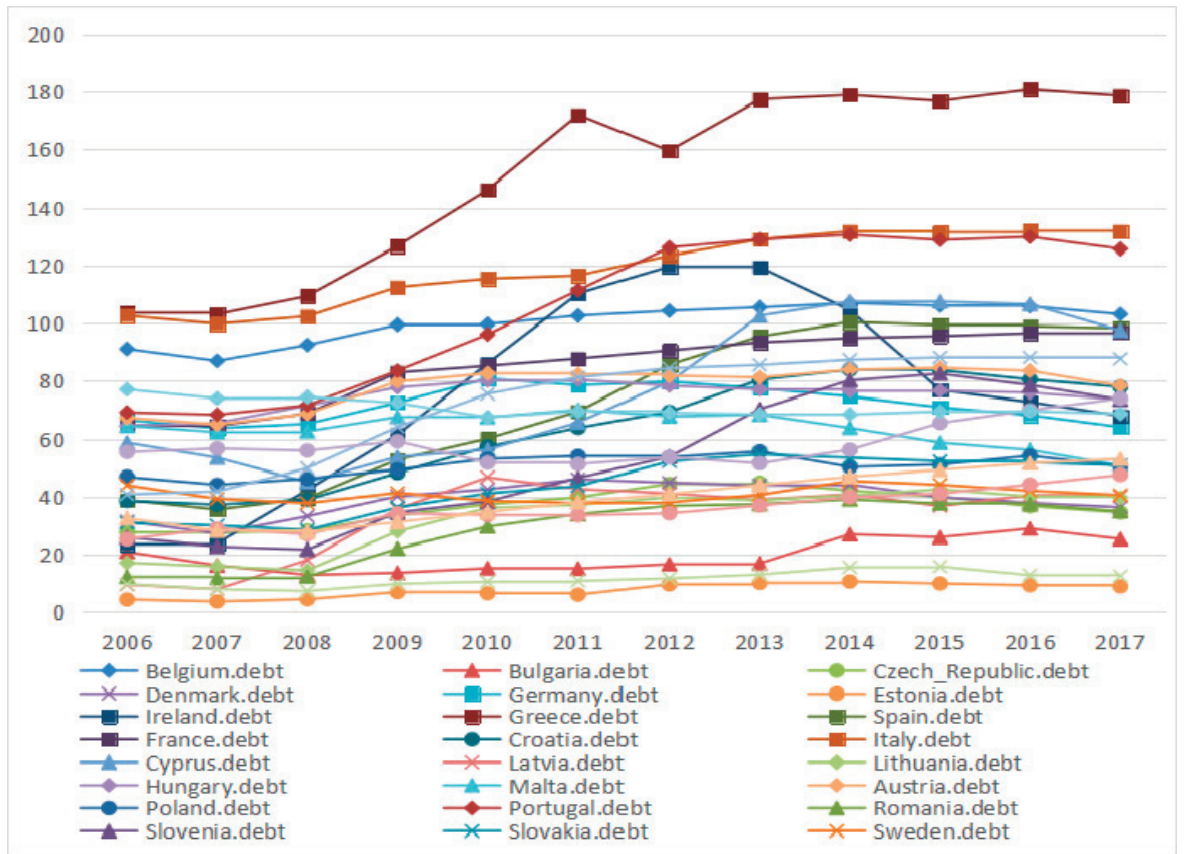

Figure 2. Government-to-gross domestic product (GDP) ratio of the sample countries since during 2007-2017. Source: Eurostat; International Monetary Fund.

\subsection{Descriptive Statistics}

Basic summary descriptive statistics of key variables used in this paper are presented in Tables 2 and 3. The mean is significantly different from zero for the NPLs ratio and government-to-GDP ratio in the sample countries. As shown, the average of some sample countries is higher than other sample countries. The reason is simply that as the European sovereign debt crisis unfolded, some countries with weak competitiveness and loose financial supervision—such as Greece, Cyprus, Ireland, etc.—widened the means in Tables 2 and 3 more speedily than did BRICS countries. Both the minimum/maximum and the standard deviations indicate that there is a notable time series variation in the key variables. For example, the bank non-performing loan ratio for Greece reached a maximum of 45.57 basis points (see Table 2), and the government-to-GDP ratio for Portugal reached a maximum of 130.6 basis points (see Table 3).

In the same time period, the NPLs ratio for Cyprus and the government-to-GDP ratio for Greece reached maximum values of 48.68 basis points and 180.8 basis points, respectively. Meanwhile, the mean values of the key variables are typically very close to the average values. As shown in Table 2, negative values for skewness are more pronounced for the Czech Republic than for the other sample countries, which suggests a bigger probability of large decreases, suggesting that those distributions have long left tails. Meanwhile, there is evidence of positive skewness for Sweden, China, India, Latvia, and Lithuania and therefore distributions with long right tails. Considering that the kurtosis of a normal distribution is generally 3 , Table 2 shows that most the distribution of kurtosis of the NPLs ratio is lower than 3 , suggesting that it does not have a heavy-tailed distribution. 
Table 2. Descriptive statistics for the bank non-performing loan ratio.

\begin{tabular}{|c|c|c|c|c|c|c|c|}
\hline & Mean & Median & Minimum & Maximum & St.D & Skewness & Kurtosis \\
\hline Belgium & 2.9642 & 3.1900 & 1.1600 & 4.2400 & 1.0694 & -0.6117 & 2.0734 \\
\hline Bulgaria & 10.7067 & 12.545 & 2.1000 & 16.8800 & 5.9127 & -0.4996 & 1.6586 \\
\hline $\begin{array}{c}\text { Czech } \\
\text { Republic }\end{array}$ & 4.4858 & 4.8950 & 2.3700 & 5.6100 & 1.1010 & -0.7795 & 2.2255 \\
\hline Denmark & 3.1392 & 3.4800 & 0.4000 & 5.9500 & 1.6898 & -0.3115 & 2.2255 \\
\hline Germany & 2.6633 & 2.7800 & 1.6900 & 3.4000 & 0.5744 & -0.4537 & 1.9127 \\
\hline Estonia & 2.1083 & 1.4300 & 0.2000 & 5.3800 & 1.8157 & 0.8590 & 2.2676 \\
\hline Ireland & 12.7833 & 13.3300 & 0.5300 & 25.7100 & 8.6392 & -0.0637 & 2.0023 \\
\hline Greece & 21.0450 & 18.8500 & 4.5000 & 45.5700 & 15.1776 & 0.2151 & 1.4648 \\
\hline Spain & 5.0642 & 5.1200 & 0.7000 & 9.3800 & 2.7234 & -0.1510 & 2.1743 \\
\hline France & 3.6867 & 3.8700 & 2.7000 & 4.5000 & 0.6312 & -0.3824 & 1.6509 \\
\hline Croatia & 11.0725 & 11.7350 & 4.7500 & 16.7100 & 4.4540 & -0.3116 & 1.6736 \\
\hline Italy & 12.3108 & 12.7450 & 5.7800 & 18.0600 & 4.6595 & -0.1378 & 1.5490 \\
\hline Cyprus & 21.9842 & 14.1800 & 0.6000 & 48.6800 & 20.1756 & 0.2544 & 1.2686 \\
\hline Latvia & 6.6000 & 4.6200 & 0.5000 & 15.9300 & 5.4205 & 0.6585 & 1.9852 \\
\hline Lithuania & 10.0508 & 7.1350 & 1.0000 & 23.9900 & 8.3663 & 0.5788 & 1.8944 \\
\hline Hungary & 9.3150 & 9.1400 & 2.3000 & 16.8300 & 5.4712 & 0.0334 & 1.5220 \\
\hline Malta & 6.5892 & 6.7450 & 4.1000 & 9.05000 & 1.5497 & 0.1544 & 2.0655 \\
\hline Austria & 2.6900 & 2.7250 & 1.9000 & 3.4700 & 0.4563 & 0.1258 & 2.4942 \\
\hline Poland & 4.7175 & 4.7400 & 2.8200 & 7.4000 & 1.0769 & 0.8988 & 4.8279 \\
\hline Portugal & 7.3750 & 9.1250 & 1.3000 & 13.3000 & 4.8475 & 0.1852 & 1.2605 \\
\hline Romania & 10.3367 & 10.7600 & 1.8000 & 21.6000 & 6.1126 & 0.1340 & 2.1850 \\
\hline Slovenia & 7.7317 & 7.0000 & 1.8000 & 15.1800 & 4.5795 & 0.2129 & 1.6299 \\
\hline Slovakia & 4.4883 & 4.9850 & 2.5000 & 5.8000 & 1.2140 & -0.6285 & 1.9133 \\
\hline Sweden & 0.9758 & 0.9000 & 0.6000 & 2.0000 & 0.3941 & 1.4469 & 4.7866 \\
\hline $\begin{array}{l}\text { United } \\
\text { Kingdom }\end{array}$ & 2.1617 & 1.6250 & 0.8100 & 3.9600 & 1.3342 & 0.3073 & 1.3017 \\
\hline China & 2.3125 & 1.6350 & 0.9500 & 7.1000 & 2.0789 & 1.6631 & 4.0742 \\
\hline Russia & 6.8017 & 7.3650 & 2.4000 & 10.0000 & 2.6596 & -0.5731 & 2.0161 \\
\hline Brazil & 3.3600 & 3.3800 & 2.8500 & 4.2100 & 0.4157 & 0.6093 & 2.5971 \\
\hline India & 4.3675 & 3.3350 & 2.3000 & 9.9800 & 2.6547 & 1.2948 & 3.2111 \\
\hline $\begin{array}{l}\text { South } \\
\text { Africa }\end{array}$ & 3.6742 & 3.4350 & 1.1000 & 5.9000 & 1.5988 & -0.0098 & 2.0376 \\
\hline
\end{tabular}

Table 3 reports summary statistics for the general government gross debt of the sample countries. Average means close to zero, which is like the bank non-performing loan ratio. Negative values for skewness are more pronounced for Latvia, Hungary, and Belgium, suggesting that those distributions have long left tails. Meanwhile, there is evidence of positive skewness for Sweden, Brazil, China, and India and therefore of distributions with long right tails. EU countries (except Sweden) have negative values for skewness, whereas the five BRICS countries have opposite results. The distribution of the kurtosis of the government-to-GDP ratio does not comply with the normal distribution generated from Table 3. 
Table 3. Descriptive statistics for the government-to-GDP ratio.

\begin{tabular}{|c|c|c|c|c|c|c|c|}
\hline & Mean & Median & Minimum & Maximum & St.D & Skewness & Kurtosis \\
\hline Belgium & 100.3583 & 102.8500 & 87.0000 & 107.0000 & 6.6701 & -0.8902 & 2.4051 \\
\hline Bulgaria & 19.6333 & 16.8500 & 13.0000 & 29.0000 & 5.7362 & 0.4649 & 1.6080 \\
\hline $\begin{array}{l}\text { Czech } \\
\text { Republic }\end{array}$ & 36.4417 & 37.1000 & 27.5000 & 44.9000 & 6.2432 & -0.2141 & 1.7903 \\
\hline Denmark & 39.0333 & 40.0500 & 27.3000 & 46.1000 & 5.9322 & -0.6277 & 2.2842 \\
\hline Germany & 71.9000 & 71.8000 & 63.7000 & 80.9000 & 6.3577 & 0.0684 & 1.5050 \\
\hline Estonia & 7.6083 & 8.0000 & 3.7000 & 10.7000 & 2.5300 & -0.2885 & 1.5525 \\
\hline Ireland & 75.7500 & 74.8500 & 23.6000 & 119.6000 & 34.0440 & -0.2120 & 1.8718 \\
\hline Greece & 151.1000 & 165.8500 & 103.1000 & 180.8000 & 31.9020 & -0.5597 & 1.6123 \\
\hline Spain & 72.8917 & 77.6000 & 35.6000 & 100.4000 & 26.4605 & -0.2630 & 1.4036 \\
\hline France & 85.1750 & 89.2000 & 64.5000 & 97.0000 & 12.4362 & -0.7907 & 2.0593 \\
\hline Croatia & 63.3833 & 66.6000 & 37.3000 & 84.0000 & 18.6716 & -0.2974 & 1.4865 \\
\hline Italy & 119.0583 & 119.9500 & 99.8000 & 132.0000 & 12.6018 & -0.3452 & 1.5921 \\
\hline Cyprus & 77.8750 & 72.7000 & 45.1000 & 107.5000 & 24.8807 & 0.0977 & 1.2836 \\
\hline Latvia & 33.3000 & 39.5500 & 8.0000 & 46.8000 & 13.3813 & -1.1015 & 2.5721 \\
\hline Lithuania & 32.5500 & 38.0000 & 14.6000 & 42.6000 & 10.6798 & -0.8592 & 1.9943 \\
\hline Hungary & 74.8750 & 76.6500 & 64.5000 & 80.5000 & 5.2343 & -1.0305 & 2.8415 \\
\hline Malta & 63.3583 & 64.1500 & 50.8000 & 70.1000 & 5.7175 & -0.9038 & 2.9411 \\
\hline Austria & 78.3167 & 81.6000 & 65.0000 & 84.6000 & 7.0776 & -1.0123 & 2.3322 \\
\hline Poland & 50.8000 & 50.8500 & 44.2000 & 55.7000 & 3.5868 & -0.4349 & 2.0792 \\
\hline Portugal & 105.8917 & 118.5500 & 68.4000 & 130.6000 & 26.2724 & -0.4422 & 1.4574 \\
\hline Romania & 28.8333 & 34.5000 & 11.9000 & 39.1000 & 11.0311 & -0.7188 & 1.7858 \\
\hline Slovenia & 52.4583 & 50.2000 & 21.8000 & 82.6000 & 23.7567 & -0.0003 & 1.3967 \\
\hline Slovakia & 43.8500 & 47.3000 & 28.5000 & 54.7000 & 10.0848 & -0.4233 & 1.5416 \\
\hline Sweden & 40.8500 & 40.6500 & 37.8000 & 45.5000 & 2.6586 & 0.4120 & 1.8766 \\
\hline $\begin{array}{l}\text { United } \\
\text { Kingdom }\end{array}$ & 72.9333 & 82.9000 & 40.8000 & 88.2000 & 18.7544 & -0.8410 & 2.0280 \\
\hline China & 35.6000 & 34.3000 & 25.4000 & 47.6000 & 6.7618 & 0.1938 & 2.1800 \\
\hline Russia & 11.5417 & 11.3500 & 7.4000 & 15.9000 & 2.6569 & 0.1562 & 2.2124 \\
\hline Brazil & 58.4508 & 56.1300 & 51.2700 & 74.0400 & 7.4771 & 1.0211 & 2.7483 \\
\hline India & 70.7583 & 69.5500 & 67.5000 & 77.1000 & 3.0125 & 0.9404 & 2.5640 \\
\hline $\begin{array}{l}\text { South } \\
\text { Africa }\end{array}$ & 39.9167 & 39.6000 & 27.8000 & 53.1000 & 9.0799 & 0.0783 & 1.5803 \\
\hline
\end{tabular}

\section{Empirical Results and Discussion}

\subsection{Granger Results}

Table 4 reports the $p$-values for Granger causality between NPLs and sovereign debt at various levels of lags in the 30 countries. We observe a bi-directional causality relationship in Cyprus, Italy, Portugal, Romania, Spain, Denmark, Sweden, and South Africa. It cannot be ignored that the bi-directional causal link is mainly found in northern and southern European countries. In those countries, the evidence for bi-directional causality is consistent with the evolution of sovereign debt and NPLs. A substantial increase in the size of sovereign debt occurred in the outbreak of the financial crisis, suggesting a strong interaction between sovereign debt and NPLs.

It can also be observed that unidirectional causality occurs? between NPLs and sovereign debt for Bulgaria, Greece, Malta, Slovenia, Ireland, United Kingdom, Austria, Czech Republic, Germany, Lithuania, Brazil, and India. Our results show that there are several countries for which the null hypothesis of causality between sovereign debt and NPLs cannot be rejected, including Greece, Malta, Slovenia, Ireland, Austria, Czech Republic, Germany, Lithuania, Brazil, and India. The debt ratio rises significantly in the European countries after the recent European debt crisis. Considering the obviously low return on debt accumulation, it seems to have exacerbated the scale of NPLs. Note that Brazil and India are emerging countries with a strong willingness to lend. Nevertheless, we find that bank NPLs 
cannot significantly cause the change of sovereign debt in Bulgaria and the United Kingdom at the conventional level.

A causal relationship exists between sovereign debt and NPLs since the non-causality null hypothesis is rejected in Croatia, Belgium, France, Hungary, Poland, Estonia, Latvia, China, and Russia. Statistical evidence exists against the null hypothesis of an absence of causal relationship between sovereign debts and debt in sample countries, especially in Western Europe, central Europe, and Eastern European countries. It is important to recall that their economic problems have been merged after the economic crisis and sovereign debt crisis.

Table 4. Granger causality test for the lag $k_{i}(i=1,2,3)$.

\begin{tabular}{|c|c|c|c|c|c|c|}
\hline \multirow{2}{*}{ Country } & \multicolumn{3}{|c|}{ Debt $\rightarrow$ NPLs } & \multicolumn{3}{|c|}{ NPLs $\rightarrow$ Debt } \\
\hline & $k=1$ & $k=2$ & $k=3$ & $k=1$ & $k=2$ & $k=3$ \\
\hline Belgium & 0.0690 & 0.0928 & 0.1287 & 0.0621 & 0.06772 & 0.2773 \\
\hline Bulgaria & 0.1033 & 0.4841 & 0.9006 & $0.0085^{* *}$ & 0.0767 & 0.3815 \\
\hline $\begin{array}{c}\text { Czech } \\
\text { Republic }\end{array}$ & $0.0398^{*}$ & 0.0362 * & 0.1691 & 0.1746 & 0.2878 & 0.2525 \\
\hline Denmark & $0.0056^{* *}$ & 0.598 & 0.9068 & $0.0001^{* * * *}$ & 0.0133 * & 0.0907 \\
\hline Germany & $0.0011^{* *}$ & 0.1085 & $0.0445 *$ & 0.0928 & 0.0587 & 0.2920 \\
\hline Estonia & 0.4735 & 0.2668 & 0.1499 & 0.1239 & 0.3308 & 0.1546 \\
\hline Ireland & 0.7105 & 0.0138 * & 0.2595 & 0.2626 & 0.6566 & 0.7956 \\
\hline Greece & $0.0102 *$ & $0.0347^{*}$ & 0.1988 & 0.9357 & 0.5671 & 0.2092 \\
\hline Spain & $0.0028 * *$ & 0.5248 & 0.1932 & 0.0024 ** & 0.0358 * & 0.1492 \\
\hline France & 0.4955 & 0.8559 & 0.6277 & 0.1203 & 0.2864 & 0.7300 \\
\hline Croatia & 0.1952 & 0.1818 & 0.1523 & 0.9109 & 0.8177 & 0.7420 \\
\hline Italy & 0.3479 & 0.0128 * & 0.1527 & 0.1608 & $0.0003^{* * *}$ & 0.2963 * \\
\hline Cyprus & $0.0003^{* * *}$ & 0.5192 & 0.6840 & $0.0042^{* *}$ & 0.0109 * & 0.8223 \\
\hline Latvia & 0.9098 & 0.3147 & - & 0.8794 & 0.3847 & 0.0400 * \\
\hline Lithuania & $0.0089^{* *}$ & $0.0042 * *$ & 0.0638 & 0.1923 & 0.3646 & 0.6983 \\
\hline Hungary & 0.6667 & 0.9697 & 0.6400 & 0.4286 & 0.2949 & 0.3772 \\
\hline Malta & $0.0177^{*}$ & 0.0599 & 0.3195 & 0.02565 & 0.6050 & 0.2901 \\
\hline Austria & 0.01399 * & 0.0352 * & 0.031 * & 0.1153 & 0.3596 & 0.8432 \\
\hline Poland & 0.4803 & 0.6403 & 0.6308 & 0.6490 & 0.2583 & 0.4747 \\
\hline Portugal & $0.0014^{* *}$ & 0.2132 & 0.4841 & $0.0279 *$ & 0.4442 & 0.8346 \\
\hline Romania & $0.0245 *$ & 0.1286 & 0.5888 & $0.036^{*}$ & 0.0515 & 0.3409 \\
\hline Slovenia & 0.4660 & 0.2373 & $0.0443 *$ & 0.8733 & 0.8929 & 0.8374 \\
\hline Slovakia & $0.0089 * *$ & 0.0171 * & 0.1097 & 0.2338 & 0.7354 & 0.7900 \\
\hline Sweden & $0.0044^{* *}$ & 0.3647 & 0.8736 & $0.0052 * *$ & 0.1596 & 0.0232 * \\
\hline $\begin{array}{l}\text { United } \\
\text { Kingdom }\end{array}$ & 0.4964 & 0.6775 & 0.8912 & $0.0009^{* * * *}$ & $0.0268 *$ & 0.4423 \\
\hline China & 0.0948 & 0.0870 & 0.4707 & 0.7309 & 0.7335 & 0.0995 \\
\hline Russia & 0.6297 & 0.5957 & 0.0577 & 0.8246 & 0.6897 & 0.2555 \\
\hline Brazil & 0.2648 & 0.0435 * & 0.3470 & 0.1724 & 0.1267 & 0.3427 \\
\hline India & $0.0074 * *$ & 0.2449 & 0.3934 & 0.8505 & 0.5818 & 0.2473 \\
\hline South Africa & $0.0047^{* *}$ & $0.0022 * *$ & 0.1917 & $0.0094^{* *}$ & 0.0615 & 0.9620 \\
\hline
\end{tabular}

Note: For Debt $\rightarrow$ Loan, H0: Debt does not cause Loan. ${ }^{* * *}, * *$, and ${ }^{*}$ denote rejection of the null hypothesis at the 1 ,

5 , and $10 \%$ significance level, respectively.

Although it is difficult to find commonality of the impact of sovereign debt on bank NPLs across countries, we note that countries with high sovereign debt ratio are usually associated with higher NPLs. An increase in NPLs reflects the deterioration of banks' balance sheets and asset quality, which in turn may reduce banks' leverage or profits. Losses on government bonds weaken banks' balance sheets and increase financing costs. Meanwhile, countries with larger amounts of sovereign debt exhibit a one-way causal relationship between bank NPLs and sovereign debt or bi-directional causality. It is noteworthy that the different characteristics across countries and the heterogeneity in the results point towards caution when making inferences about the relationship between sovereign debt and NPLs. 


\subsection{Kendall's Tau Results}

Kendall's tau shows the correlation between each pair of sample countries. We categorize all pairs of countries into two groups according to the geographical location: European countries and other (BRICS) countries. Table 5 reports the means of Kendall's tau between the government-to-GDP ratio and the bank NPLs for the sample countries. First, within the European group, we calculate the means of Kendall's tau between each country and the other countries and report the results in Panel A. Since sovereign debt crisis occurs in European countries, to easily understand the spillover effect of sovereign debt crisis on the emerging countries, we calculate the means of Kendall's tau between each BRICS country and all European countries and report the results in Panel B. We find that the means of tau within European countries are much higher than the means within BRICS countries.

Table 5. Mean of Kendall's tau for the NPLs ratio and the government-to-GDP ratio.

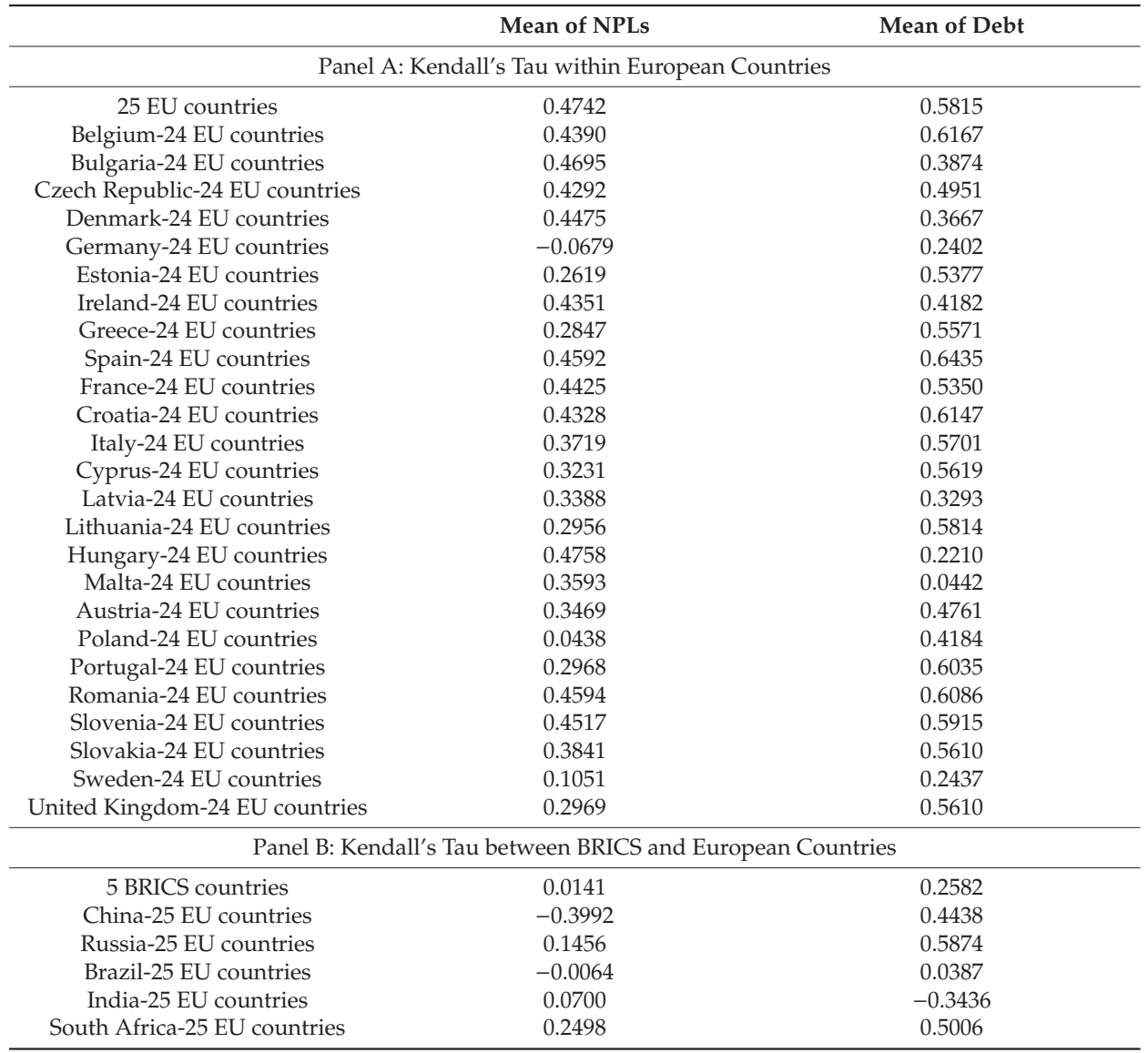

This result is not surprising because there are strong commonalities among European countries, such as currency, geographical location, culture, etc. In particular, the highest means of tau occur in Hungary and Bulgaria, in contrast to other European countries. While in BRICS countries, although the economy grows relatively fast in these countries, the business models and the engines of economy are very different, which leads to a low mean of correlations among these countries. Moreover, we note that the means of tau between each BRICS country and the European countries varies significantly. 
For example, the mean of correlation between South Africa and the European countries is positive but the mean between Brazil and the European countries is negative. The heterogeneity of correlations across countries might be due to the variation of country characteristics, which is out of the scope of this paper. Sovereign risk has a negative spillover effect on bank risk, and failure to fully protect the banking system from the impact of serious domestic sovereignty is a reason to maintain good public finances.

\subsection{Copula Results}

We consider three copula models to analyze the tail dependence between the government-to-GDP ratio and the bank non-performing loan ratio: Student's $t$ copula (symmetric association of tail dependence), rotated Clayton copula (upper-tail dependence), and Joe copula (upper-tail dependence). In terms of tail dependence, these series copula models cover the major combinations of features necessary to capture possible associations between the variables studied, and they are the most commonly used copulas in finance [7].

The estimation results of the three copula models above are shown in Table 6. The $t$-copula detects both upper and lower tail dependence at each sample country. Because of the symmetry of the Student's $t$ distribution, the upper tail coefficient is generally equal to the lower tail coefficient. We find that the highest dependence of upper tails occurs in Ireland, about 0.8778 . The large and positive tail dependence suggests a strong correlation between the extreme expansion of sovereign debt and the sharp increase of bank NPLs. In addition, there are five countries in which the upper tail dependence is greater than 0.5, including Denmark, Ireland, Croatia, Latvia, and Portugal.

Table 6. Tail dependence for different copulas with the NPLs ratio and the government-to-GDP ratio.

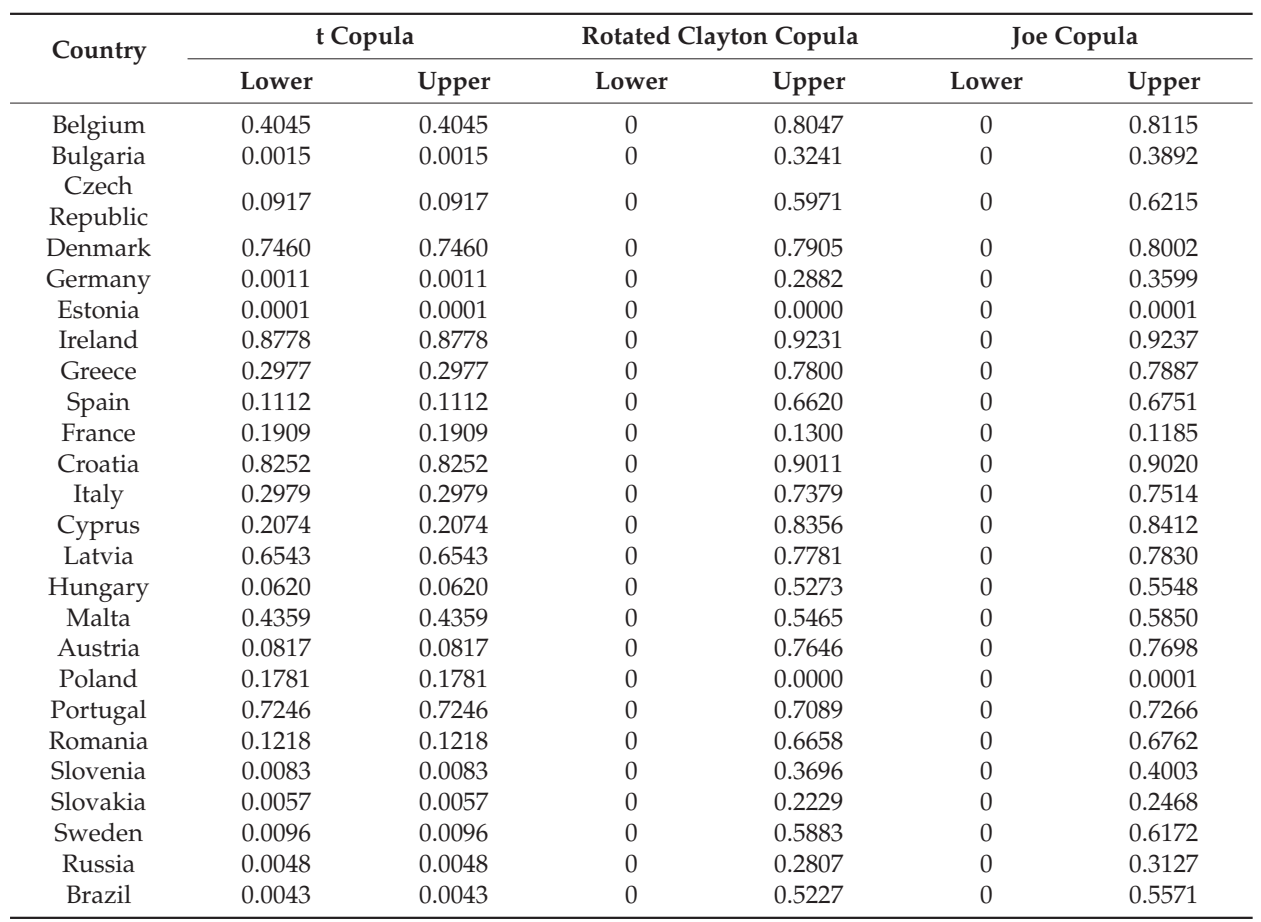

Then, we use the rotated Clayton and Joe copulas as alternative methods to examine the upper tail dependence between sovereign debt ratio and bank NPLs ratio. In contrast to the Student's $t$ 
distribution, the underlying distributions in the rotated Clayton copula and Joe copula focus on the upper tail dependence. According to Table 6, we note that the tail dependence levels in all countries are consistent in the rotated Clayton and Joe copulas but very different from the dependence in the $t$ copula. The highest upper tail dependence occurs in Ireland as well under both the rotated Clayton and Joe copulas. We document 17 out of 25 countries whose value of upper tail dependence is greater than 0.5 using either the rotated Clayton copula or Joe copula which are symmetric copula functions so that those Archimedean copula functions cannot fit asymmetric distributed data well.

\subsection{Gaussian Copula Regression Method Results}

In previous sections, we focused on examining the causality using statistical methods without controlling for the other determinants of bank NPLs. Related literature identifies many factors that drive bank NPLs ratios, at both macro- and micro-levels [14-17,48]. To isolate the impact of other known determinants, we employ the Gaussian copula regression method (GCRM) in this section. Since we use the aggregated level of bank NPLs over total loans, we focus on the macroeconomic variables. Specifically, we control for GDP, inflation rate, government fiscal expenditure, and government fiscal revenue in Gaussian copula regressions.

Because of heterogeneity across countries, as shown in the previous analysis, we perform the Gaussian copula regressions country by country and report regression results in Table 7 . We find positive and significant coefficients for sovereign debt ratio in 17 out of 25 countries, including Cyprus, Greece, Croatia, Malta, Italy, Romania, Portugal, Slovenia, Spain, Ireland, Belgium, Germany, Hungary, Czech Republic, Sweden, Slovakia, and Brazil. These positive and significant coefficients in a majority of the countries provide further support for the positive impact of sovereign debt ratio on bank NPLs ratios. This positive relationship highlights that fiscal stress could be a potential factor that deteriorates bank loan performance. In addition, we also document negative and significant coefficients in several countries including France, the United Kingdom, and South Africa.

Regarding the control variables, their coefficients vary across countries. First, the impact of the GDP growth rate on bank NPLs ratios is mixed. On one hand, positive economic growth for each economy indicates an increase in the wealth of private sector individuals, enterprises, and other institutions, which results in a strong capability of repaying their respective debts and a decrease of bank NPLs ratios. On the other hand, the expansion of the economy is usually associated with credit booming. For instance, the credit bubble before the sub-prime financial crisis. The cheap credit during the expansion of the economy sows the seeds for non-performing loans, which suggests a positive relation between GDP growth and bank NPLs ratio. According to the results in Table 7, we find positive and negative coefficients for GDP growth rate in 7 and 4 countries, respectively, while the coefficients of GDP growth rate are insignificant in other countries.

Second, a high inflation rate is usually accompanied by an expansionary monetary policy. The enlarged monetary base under an expansionary monetary policy increases the supply of loans. Under such circumstance, banks are more likely to adopt an aggressive strategy for lending, which possibly results in a higher level of non-performing loans. Thus, we expect a positive relationship between inflation rate and bank NPL ratio. However, we only document significant and positive coefficients for inflation rate in five countries. On the contrary, we find significantly negative coefficients for inflation in eight countries. One of the possible explanations is that an increase in economic activity leads to enhanced demand for loans, which in turn can cause higher lending rates. In addition, increased economic activity can reduce defaults and increase deposits because it can make business more profitable. However, tightening monetary policy can increase interest rates and make banks be more inclined to attract customers with higher risks and compensate them for the high risk by raising loan interest rates. These results are consistent with the studies by Were and Wambua [49] and Ghosh [27]. 
Table 7. GCMR estimation results of the NPLs ratio to the government-to-GDP ratio.

\begin{tabular}{|c|c|c|c|c|c|c|}
\hline Country & Intercept & Debt & Expenditure & GDP & Revenue & Inflation \\
\hline Bulgaria & $\begin{array}{l}44.8120 * \\
(18.9509)\end{array}$ & $\begin{array}{l}-0.2404 \\
(0.3626)\end{array}$ & $\begin{array}{c}0.4717 \\
(0.5271)\end{array}$ & $\begin{array}{c}0.5576 \\
(0.4915)\end{array}$ & $\begin{array}{l}-1.2776^{*} \\
(0.6131)\end{array}$ & $\begin{array}{l}-1.2742 * \\
(0.6076)\end{array}$ \\
\hline Cyprus & $\begin{array}{l}1.7552 * * * \\
(0.0024)\end{array}$ & $\begin{array}{c}0.7646 * * * \\
(0.0715)\end{array}$ & $\begin{array}{l}-0.7424 \\
(0.5010)\end{array}$ & $\begin{array}{c}0.1576 \\
(0.5022)\end{array}$ & $\begin{array}{l}-0.2369 \\
(0.5877)\end{array}$ & $\begin{array}{l}-0.5485 \\
(0.8323)\end{array}$ \\
\hline Croatia & $\begin{array}{c}53.0771^{* * * *} \\
(0.0004)\end{array}$ & $\begin{array}{c}0.2805^{* * *} \\
(0.0093)\end{array}$ & $\begin{array}{c}0.3155^{* * *} \\
(0.0562)\end{array}$ & $\begin{array}{c}0.0338 \\
(0.0412)\end{array}$ & $\begin{array}{c}-1.0389 * * * \\
(0.062)\end{array}$ & $\begin{array}{c}-0.2666^{* * *} \\
(0.07863)\end{array}$ \\
\hline Greece & $\begin{array}{l}-118.6^{* * *} \\
(0.0065)\end{array}$ & $\begin{array}{l}0.2387^{* * *} \\
(0.0903)\end{array}$ & $\begin{array}{c}0.5013 \\
(0.2686)\end{array}$ & $\begin{array}{l}1.2320^{* * *} \\
(0.3769)\end{array}$ & $\begin{array}{l}1.8230 * * * \\
(0.5232)\end{array}$ & $\begin{array}{l}-0.3670 \\
(0.6392)\end{array}$ \\
\hline Italy & $\begin{array}{c}-76.6442 * * * \\
(0.0014)\end{array}$ & $\begin{array}{c}0.22266^{* * *} \\
(0.02853)\end{array}$ & $\begin{array}{c}0.2701 \\
(0.2545)\end{array}$ & $\begin{array}{l}0.2415^{*} \\
(0.1127)\end{array}$ & $\begin{array}{l}1.0594 * * * \\
(0.2863)\end{array}$ & $\begin{array}{l}-0.3310 \\
(0.2282)\end{array}$ \\
\hline Malta & $\begin{array}{l}28.7748 \text { * } \\
(11.5029)\end{array}$ & $\begin{array}{l}0.3301 * * * \\
(0.0796)\end{array}$ & $\begin{array}{l}-0.0692 \\
(0.2348)\end{array}$ & $\begin{array}{l}0.3674^{* * * *} \\
(0.0684)\end{array}$ & $\begin{array}{c}0.4126 \\
(0.3108)\end{array}$ & $\begin{array}{l}-0.1790 \\
(0.2387)\end{array}$ \\
\hline Portugal & $\begin{array}{c}-4.1232 \\
(12.4124)\end{array}$ & $\begin{array}{l}0.1813^{* * * *} \\
(0.0146)\end{array}$ & $\begin{array}{l}0.3222 * \\
(0.1385)\end{array}$ & $\begin{array}{c}0.0537 \\
(0.1089)\end{array}$ & $\begin{array}{c}0.1857 \\
(0.2245)\end{array}$ & $\begin{array}{l}-0.0917 \\
(0.1744)\end{array}$ \\
\hline Romania & $\begin{array}{l}-12.5478 \\
(20.7407)\end{array}$ & $\begin{array}{l}0.6090 * * * * \\
(0.0893)\end{array}$ & $\begin{array}{l}-1.1359 \\
(0.8139)\end{array}$ & $\begin{array}{l}-0.3779 \\
(0.2783)\end{array}$ & $\begin{array}{l}1.3277^{*} \\
(0.5304)\end{array}$ & $\begin{array}{l}1.1883 \text { ** } \\
(0.4413)\end{array}$ \\
\hline Spain & $\begin{array}{l}-27.9760^{* *} \\
(10.5332)\end{array}$ & $\begin{array}{l}0.0699 * * * \\
(0.0135)\end{array}$ & $\begin{array}{c}0.3601 \\
(0.1946)\end{array}$ & $\begin{array}{l}-0.2669 \\
(0.1958)\end{array}$ & $\begin{array}{l}0.3274 * \\
(0.1546)\end{array}$ & $\begin{array}{c}0.0860 \\
(0.1712)\end{array}$ \\
\hline Slovenia & $\begin{array}{c}-131.3625^{* * * *} \\
(21.3408)\end{array}$ & $\begin{array}{c}0.1401^{* * * *} \\
(0.033)\end{array}$ & $\begin{array}{c}0.1843 \\
(0.1469)\end{array}$ & $\begin{array}{c}-0.4206^{* *} \\
(0.1370)\end{array}$ & $\begin{array}{c}3.0411 * * * \\
(0.5862)\end{array}$ & $\begin{array}{c}0.8356 \\
(0.4637)\end{array}$ \\
\hline Belgium & $\begin{array}{c}-19.6475^{* * *} \\
(0.9114)\end{array}$ & $\begin{array}{c}0.04560 * * * \\
(0.0096)\end{array}$ & $\begin{array}{c}0.2127 * * * \\
(0.0235)\end{array}$ & $\begin{array}{c}0.0205 \\
(0.0221)\end{array}$ & $\begin{array}{l}0.1381 * * \\
(0.0279)\end{array}$ & $\begin{array}{c}-0.1122 * * * \\
(0.0212)\end{array}$ \\
\hline France & $\begin{array}{c}-42.1100 * * * \\
(0.0005)\end{array}$ & $\begin{array}{c}-0.0807^{* * *} \\
(0.0096)\end{array}$ & $\begin{array}{c}0.7195^{* * *} \\
(0.0678)\end{array}$ & $\begin{array}{c}0.0410 \\
(0.0713)\end{array}$ & $\begin{array}{c}0.2384^{* * * *} \\
(0.0697)\end{array}$ & $\begin{array}{c}0.0857 \\
(0.0971)\end{array}$ \\
\hline Ireland & $\begin{array}{c}-9.76100 \\
(5.3245)\end{array}$ & $\begin{array}{c}0.2519^{* * * *} \\
(0.0139)\end{array}$ & $\begin{array}{c}-0.2364^{* * * *} \\
(0.0689)\end{array}$ & $\begin{array}{c}0.0107 \\
(0.0699)\end{array}$ & $\begin{array}{l}0.4172^{*} \\
(0.2016)\end{array}$ & $\begin{array}{l}-1.0583 * \\
(0.4138)\end{array}$ \\
\hline $\begin{array}{l}\text { United } \\
\text { Kingdom }\end{array}$ & $\begin{array}{c}-35.2600 * * * \\
(0.0009)\end{array}$ & $\begin{array}{l}-0.0104 * \\
(0.0051)\end{array}$ & $\begin{array}{c}0.6023 * * * \\
(0.0418)\end{array}$ & $\begin{array}{c}0.0595 \\
(0.0528)\end{array}$ & $\begin{array}{c}0.3763^{* * *} \\
(0.0433)\end{array}$ & $\begin{array}{l}0.00591 \\
(0.0802)\end{array}$ \\
\hline Austria & $\begin{array}{c}-38.1600^{* * * *} \\
(0.0003)\end{array}$ & $\begin{array}{c}0.0000 \\
(0.9981)\end{array}$ & $\begin{array}{c}0.2473^{* * *} \\
(0.0000)\end{array}$ & $\begin{array}{l}0.2690^{* * * *} \\
(0.0275)\end{array}$ & $\begin{array}{c}0.5744^{* * *} \\
(0.0412)\end{array}$ & $\begin{array}{c}-0.0910^{* * *} \\
(0.0469)\end{array}$ \\
\hline $\begin{array}{c}\text { Czech } \\
\text { Republic }\end{array}$ & $\begin{array}{c}23.0463^{* * *} \\
(0.0009)\end{array}$ & $\begin{array}{l}0.2120^{* * *} \\
(0.0147)\end{array}$ & $\begin{array}{c}0.0625 \\
(0.0389)\end{array}$ & $\begin{array}{c}0.0931 * * * \\
(0.0281)\end{array}$ & $\begin{array}{c}-0.7161^{* * *} \\
(0.0456)\end{array}$ & $\begin{array}{c}-0.2335^{* * *} \\
(0.0445)\end{array}$ \\
\hline Germany & $\begin{array}{c}18.3133^{* * * *} \\
(0.0004)\end{array}$ & $\begin{array}{l}0.0187^{*} \\
(0.0090)\end{array}$ & $\begin{array}{c}0.1316^{* * *} \\
(0.0363)\end{array}$ & $\begin{array}{c}-0.0854^{* * *} \\
(0.0225\end{array}$ & $\begin{array}{c}-0.5232 * * * \\
(0.0312)\end{array}$ & $\begin{array}{l}0.2074 * * \\
(0.0780)\end{array}$ \\
\hline Hungary & $\begin{array}{c}-155.4512 \text { **** } \\
(40.5536)\end{array}$ & $\begin{array}{c}0.8237^{* * * *} \\
(0.2018)\end{array}$ & $\begin{array}{l}1.1118^{*} \\
(0.5583)\end{array}$ & $\begin{array}{c}0.5173 \\
(0.3618)\end{array}$ & $\begin{array}{l}1.0447 \\
(0.6036)\end{array}$ & $\begin{array}{c}0.1635 \\
(0.4481)\end{array}$ \\
\hline Poland & $\begin{array}{c}-49.4549 * \\
(19.4889)\end{array}$ & $\begin{array}{c}0.1730 \\
(0.1054)\end{array}$ & $\begin{array}{l}0.5021^{*} \\
(0.1993)\end{array}$ & $\begin{array}{c}0.0908 \\
(0.2431)\end{array}$ & $\begin{array}{c}0.6117 \\
(0.3446)\end{array}$ & $\begin{array}{l}-3.7770 * \\
(0.1628)\end{array}$ \\
\hline Slovakia & $\begin{array}{c}-4.06700 \\
(3.3320)\end{array}$ & $\begin{array}{c}0.0981^{* * *} \\
(0.0171)\end{array}$ & $\begin{array}{c}0.4829 * * * \\
(0.0775)\end{array}$ & $\begin{array}{c}0.0273 \\
(0.0385)\end{array}$ & $\begin{array}{c}-0.4233^{* * *} \\
(0.0788)\end{array}$ & $\begin{array}{c}0.1052 \\
(0.0874)\end{array}$ \\
\hline Denmark & $\begin{array}{c}-21.8500 * \\
(1094)\end{array}$ & $\begin{array}{c}0.0696 \\
(0.0787)\end{array}$ & $\begin{array}{l}0.4173 * \\
(0.1649)\end{array}$ & $\begin{array}{c}0.0754 \\
(0.0830)\end{array}$ & $\begin{array}{l}-0.0008 \\
(0.1549)\end{array}$ & $\begin{array}{l}-0.1979 \\
(0.1464)\end{array}$ \\
\hline Sweden & $\begin{array}{l}-0.0660 \\
(3.0839)\end{array}$ & $\begin{array}{c}0.1284^{* * * *} \\
(0.0226)\end{array}$ & $\begin{array}{c}0.0373 \\
(0.0594)\end{array}$ & $\begin{array}{c}-0.0792^{* * *} \\
(0.0212)\end{array}$ & $\begin{array}{l}-0.1271 * \\
(0.0508)\end{array}$ & $\begin{array}{l}0.3247^{* * *} \\
(0.0950)\end{array}$ \\
\hline Estonia & $\begin{array}{c}-48.8265 * * \\
(18.7886)\end{array}$ & $\begin{array}{c}0.0166 \\
(0.3587)\end{array}$ & $\begin{array}{l}-0.4439 \\
(0.7987)\end{array}$ & $\begin{array}{l}-0.0130 \\
(0.1615)\end{array}$ & $\begin{array}{c}1.6916 \\
(1.0694)\end{array}$ & $\begin{array}{c}0.5242 \\
(0.3737)\end{array}$ \\
\hline Latvia & $\begin{array}{c}-212.5658^{* * * *} \\
(39.9114)\end{array}$ & $\begin{array}{l}-0.1794 \\
(0.0922)\end{array}$ & $\begin{array}{c}3.2445^{* * *} \\
(0.3430)\end{array}$ & $\begin{array}{l}0.6411^{* * * *} \\
(0.1166)\end{array}$ & $\begin{array}{l}2.7942 * * \\
(0.9595)\end{array}$ & $\begin{array}{l}0.6060^{* * * *} \\
(0.1792)\end{array}$ \\
\hline Lithuania & $\begin{array}{c}12.7869 \\
(35.3126)\end{array}$ & $\begin{array}{c}0.1462 \\
(0.1060)\end{array}$ & $\begin{array}{c}2.0778^{* * *} \\
(0.3039)\end{array}$ & $\begin{array}{l}-0.1690 \\
(0.1391)\end{array}$ & $\begin{array}{l}-2.4429^{*} \\
(0.9685)\end{array}$ & $\begin{array}{l}-0.3245 \\
(0.3397)\end{array}$ \\
\hline China & $\begin{array}{l}14.7477 \\
(8.7543)\end{array}$ & $\begin{array}{c}0.1116 \\
(0.1435)\end{array}$ & $\begin{array}{c}0.1928 \\
(0.5110)\end{array}$ & $\begin{array}{l}-0.0441 \\
(0.4064)\end{array}$ & $\begin{array}{l}-0.8561 * \\
(0.3772)\end{array}$ & $\begin{array}{l}0.08932 \\
(0.1556)\end{array}$ \\
\hline Russia & $\begin{array}{l}43.9618 \\
(25.632)\end{array}$ & $\begin{array}{l}-0.1486 \\
(0.1724)\end{array}$ & $\begin{array}{c}0.0552 \\
(0.3749)\end{array}$ & $\begin{array}{l}-0.1515 \\
(0.1686)\end{array}$ & $\begin{array}{c}-1.0344^{* *} \\
(0.3970)\end{array}$ & $\begin{array}{l}-0.1898 \\
(0.1067)\end{array}$ \\
\hline Brazil & $\begin{array}{l}-7.6525 \\
(4.7255)\end{array}$ & $\begin{array}{l}0.0515^{*} \\
(0.0227)\end{array}$ & $\begin{array}{c}0.0048 \\
(0.1067)\end{array}$ & $\begin{array}{c}-0.1513^{* *} \\
(0.0466)\end{array}$ & $\begin{array}{l}0.2473^{* *} \\
(0.0774)\end{array}$ & $\begin{array}{l}-0.0237 \\
(0.0685)\end{array}$ \\
\hline India & $\begin{array}{c}1.2336 \\
(20.9252)\end{array}$ & $\begin{array}{l}-0.2745 \\
(0.1432)\end{array}$ & $\begin{array}{c}1.1337 \\
(0.61111)\end{array}$ & $\begin{array}{l}-0.0997 \\
(0.2197)\end{array}$ & $\begin{array}{l}-0.0520 \\
(-0.5827)\end{array}$ & $\begin{array}{c}-0.8655^{* * *} \\
(0.1773)\end{array}$ \\
\hline South Africa & $\begin{array}{l}4.9088^{* * *} \\
(0.0009)\end{array}$ & $\begin{array}{c}-0.133^{* * * *} \\
(0.0188)\end{array}$ & $\begin{array}{l}1.0070 * * * \\
(0.0887)\end{array}$ & $\begin{array}{l}0.2845^{* * *} \\
(0.1061)\end{array}$ & $\begin{array}{c}-1.04911^{* * *} \\
(0.1153)\end{array}$ & $\begin{array}{l}0.2123 * \\
(0.0845)\end{array}$ \\
\hline
\end{tabular}

Note: * Significance at $10 \%$ level. ${ }^{* *}$ Significance at $5 \%$, level. ${ }^{* * *}$ Significance at $1 \%$ level. Standard errors are in parentheses. 
Government fiscal expenditure and revenue is found to be associated with NPLs. More specifically, the ratio of government fiscal expenditure is negatively correlated with NPLs in Croatia, Portugal, and Ireland and indicates that the rise in government fiscal expenditure decreases the NPLs growth. In contrast, the coefficients for expenditure are positive and statistically significant in Belgium, France, United Kingdom, Austria, Germany, Hungary, Poland, Slovakia, Denmark, Latvia, Lithuania, and South Africa. The implication of these results is that an increase in expenditure stimulates the NPLs growth in the long run. Although the flow of government fiscal expenditure improves productivity, the government should not borrow money to fund it because the resulting increase in public debt would reduce welfare and growth rates. Similarly, there is a significant negative relationship between government fiscal revenue and NPLs in Bulgaria, Croatia, Czech Republic, Germany, Slovakia, Sweden, Lithuania, China, Russia, and South Africa. It can be argued that governments are challenged in the capital markets when accessing loanable funds where the demand for loanable funds far exceeds its supply. Consequently, government fiscal revenue increases capital cost and default risk which increases NPLs. In contrast, revenue is positively significant in Greece, Italy, Romania, Spain, Slovenia, and so on, most of which belong to South and Western Europe. Government fiscal revenue increases (falls) and government spending falls (increases) in good (bad) times. An increase in GDP brings about an increase in government fiscal revenue, which in turn raises the payment capacity of the government and hence reduces NPLs. This relationship highlights that the fiscal problems might lead to a substantial increase in problem loans.

\section{Conclusions}

In this study, we investigate the tail dependence between sovereign debt distress and NPLs using a large sample of developed and emerging countries in recent decades. This paper covers the period of 11 years (2006-2017), which includes both the global financial crisis and European sovereign debt crisis period. Some meaningful results are obtained. The results may have some meaningful implications for policymakers because unsustainable sovereign debt can lead to payment defaults, which will impose more problems on the stability of the region.

According to Granger causality tests, we found a heterogeneity of causality between sovereign debt and bank NPLs across countries. In the majority of countries, we documented a significant causality between government-to-GDP ratio and bank NPLs ratio. We note that countries with a high sovereign debt ratio are usually associated with higher NPLs. An increase in NPLs reflects the deterioration of banks' balance sheets and asset quality, which in turn may reduce banks' leverage or profits. Meanwhile, countries with larger amounts of sovereign debt exhibit a one-way causal relationship between bank NPLs and sovereign debt or bi-directional causality.

Then, we used Kendall's tau as an alternative measure to examine the correlation of sovereign debt and bank NPLs in each pair of countries. We found that the internal correlations within European countries are much higher than within the BRICS countries. This result is not surprising because there are strong commonalities among European countries, the highest means of tau occur in Hungary and Bulgaria. In BRICs countries, although their economic growth is relatively fast, the business models and the engines of economy are very different, resulting in a low average level of correlation between these countries. Moreover, we note that the means of tau between each BRICS country and the European countries varies significantly.

Next, we employed three copula functions to investigate the upper tail dependence between bank NPLs and sovereign debt distress. We found a significant variation of tail dependence across countries. The large and positive tail dependence suggests a strong correlation between the extreme expansion of sovereign debt and the sharp increase of bank NPLs. The higher tail dependence coefficients of these countries imply that bank NPLs is more vulnerable to the expansion of sovereign debt during our sample period.

Finally, we used a Gaussian copula regression method to isolate the impact of sovereign debt ratio on bank NPL ratio by controlling for government expenditure, revenue, GDP growth rate and 
inflation rate. We found a significant and positive relation between sovereign debt ratio and bank NPLs in most of the countries, which adds credence to the positive impact of sovereign debt distress on bank loan crises. We have evidence of the effects of macroeconomic determinants on the increase of NPLs. These results are consistent with Reinhart and Rogoff's [8] empirical studies that bank crises are usually accompanied by a large increase in sovereign debt. Furthermore, government spending tends to be greater than revenues when a financial crisis occurs [50].

This study contributes to the financial literature by investigating the tail dependence between sovereign debt distress and bank NPLs. The results of this study confirm that the contribution of countries with large sovereign debt scale to NPLs has increased significantly since 2008, especially for EU countries. This means that the expansion of sovereign debt by banks is the main determinant of bank NPLs. These results can help financial institutions find out which countries' debts may not be sustainable and which countries' final payment default may bring more problems to the stability of the region. These analyses could also help regulators who are trying to understand the relationship between sovereign debt and bank NPLs, as well as financial institutions that may hold large amounts of sovereign debt.

Therefore, macroprudential policies and sound regulation are also crucial, as a strong strict credit and capital base and liquidity risk management practices are essential to curb the impact of sovereign tensions on banks. Furthermore, the results of this study can also help to establish a better regulatory mechanism and ultimately punish the countries that violate the rules. This study can be expanded by including bank-specific data and macroeconomic variables over a longer period of time. In addition, the examined model could be applied to other developed and underdeveloped countries in addition to the EU and BRICS countries, putting forward a more comprehensive view of factors that affect the NPLs.

Author Contributions: L.L. and Y.-M.L. designed this research and the model, analyzed the data and wrote the paper. J.-M.K., R.Z., and G.-Q.R. obtained inference, analyzed the data, and provided editorial supports. All the authors cooperated to revise the paper. All authors have read and agreed to the published version of the manuscript.

Funding: This research was funded by National Natural Science Foundation of China Grant (nos. U1904211, 71702171, 71672182, U1604262).

Conflicts of Interest: The authors declare no conflict of interest.

\section{References}

1. International Monetary Fund. Sovereign Debt Restructurings and the Domestic Economy Experience in Four Recent cases; Policy Development and Review Department: Washington, DC, USA, 2002.

2. Reinhart, C.M.; Rogoff, K.S. From financial crash to debt crisis. Am. Econ. Rev. 2011, 101, 1676-1706. [CrossRef]

3. Moody's Analysis. European Sovereign Debt and Banking Crises: Contagion, Spillovers and Causality; Moody's Investors Service: New York, NY, USA, 2014.

4. Alter, A.; Beyer, A. The dynamics of spillover effects during the European sovereign debt turmoil. J. Bank Financ. 2014, 42, 134-153. [CrossRef]

5. Angeloni, C.; Wolff, W. Are banks affected by their holdings of government debt? Int. Econ. Rev. 2012, 7, 1-23.

6. Zaghini, A. The Impact of Sovereign Credit Risk on Bank Funding Conditions; CGFS Papers; Bank for International Settlement: Basel, Switzerland, 2011; ISBN 92-9131-879-5.

7. Kleinow, J.; Moreira, F. Systemic risk among European banks: A copula approach. J. Int. Financ. Mark. Inst. Money. 2016, 42, 27-42. [CrossRef]

8. Reinhart, C.M.; Rogoff, K.S. The Aftermath of Financial Crises. Am. Econ. Rev. 2009, 99, 466-472. [CrossRef]

9. Reinhart, C.M.; Rogoff, K.S. Growth in a time of debt. Am. Econ. Rev. 2010, 100, 573-578. [CrossRef]

10. Louzis, D.P.; Vouldis, A.T.; Metaxas, V.L. Macroeconomic and bank-specific determinants of non-performing loans in Greece: A comparative study of mortgage, business and consumer loan portfolios. J. Bank. Finan. 2012, 36, 1012-1027. [CrossRef] 
11. Makri, V.; Tsagkanos, A.; Bellas, A. Determinants of non-performing loans: The case of eurozone. Panoeconomicus 2014, 61, 193-206. [CrossRef]

12. Reboredo, J.C.; Ugolini, A. Systemic risk in European sovereign debt markets: A CoVaR-copula approach. J. Int. Money Finan. 2015, 51, 214-244. [CrossRef]

13. Reboredo, J.C.; Ugolini, A. A vine-copula conditional value-at-risk approach to systemic sovereign debt risk for the financial sector. N. Am. Econ. Financ. 2015, 32, 98-123. [CrossRef]

14. Berger, A.N.; De Young, R. Problem loans and cost efficiency in commercial banks. J. Bank. Financ. 1997, 21, 849-870. [CrossRef]

15. Ellul, A.; Yerramilli, V. Stronger risk controls, lower risk: Evidence from U.S. bank holding companies. J. Financ. 2013, 68, 1757-1803. [CrossRef]

16. Hu, J.L.; Li, Y.; Chiu, Y.H. Ownership and nonperforming loans: Evidence from Taiwan's banks. Dev. Econ. 2010, 42, 405-420. [CrossRef]

17. Vithessonthi, C. Deflation, bank credit growth, and non-performing loans: Evidence from Japan. Int. Rev. Financ. Anal. 2016, 45, 295-305. [CrossRef]

18. Maddaloni, A. Bank risk-taking, securitization, supervision, and low interest rates: Evidence from the euro-area and the u.s. lending standards. Rev. Financ. Stud. 2010, 24, 2121-2165. [CrossRef]

19. Klein, N. Non-Performing Loans in CESEE: Determinants and Impact on Macroeconomic Performance; IMF Working Paper No. 13/72; International Monetary Fund: Washington, DC, USA, 2013.

20. Ozili, P.K. Non-performing loans and financial development: New evidence. J. Risk Financ. 2019, 20, 1526-5943. [CrossRef]

21. Beck, R.; Jakubik, P.; Piloiu, A. Key determinants of non-performing loans: New evidence from a global sample. Open Econ. Rev. 2015, 26, 525-550. [CrossRef]

22. Kuzucu, N.; Kuzucu, S. What Drives Non-Performing Loans? Evidence from Emerging and Advanced Economies during Pre- and Post-Global Financial Crisis. Emerg. Mark. Financ. Trade 2019, 55, 1694-1708. [CrossRef]

23. Kaminsky, G.L.; Reinhart, C.M.; Végh, C.A. When it rains, it pours: Procyclical capital flows and macroeconomic policies. NBER Macroecon. Ann. 2004, 19, 11-53. [CrossRef]

24. Clichici, D.; Tatiana, C. The impact of macroeconomic factors on non-performing loans in the republic of moldova. J. Financ. Monet. Econ. 2014, 1, 73-78.

25. Anastasiou, D.; Louri, H.; Tsionas, E.G. Determinants of non-performing loans: Evidence from euro-area countries. Financ. Res. Lett. 2016, 18, 116-119.

26. Koju, L.M.; Koju, R.; Wang, S.Y. Macroeconomic and Bank-Specific Determinants of Non-Performing Loans: Evidence from Nepalese Banking System. J. Cent. Bank. Theory Prac. 2018, 7, 111-138. [CrossRef]

27. Ghosh, A. Banking-industry specific and regional economic determinants of non-performing loans: Evidence from us states. J. Financ. Stab. 2015, 20, 93-104. [CrossRef]

28. Espinoza, R.A.; Prasad, A. Nonperforming Loans in the GCC Banking System and Their Macroeconomic Effects; IMF Working Papers; International Monetary Fund: Washington, DC, USA, 2010.

29. Us, V. Dynamics of non-performing loans in the Turkish banking sector by an ownership breakdown: The impact of the global crisis. Financ. Res. Lett. 2016, 20, 109-117. [CrossRef]

30. Liu, L.; Liu, Y.M.; Kim, J.M. Sustainable Visual Analysis for Bank Non-Performing Loans and Government Debt Distress. Sustainability 2020, 12, 131. [CrossRef]

31. Granger, C.W.J. Investigating causal relations by econometric models and cross-spectral methods. Econometrica 1969, 37, 424-438. [CrossRef]

32. Miguel, P.; Sansonavarro, M. Granger causality between debt and growth: Evidence from oecd countries. Int. Rev. Econ. Financ. 2015, 35, 66-77.

33. Laszlo, K. Exports and growth: Granger causality analysis on OECD countries with a panel data approach. Econ. Model. 2006, 23, 978-992.

34. Kendall, M.G. A New Measure of Rank Correlation. Biometrika 1938, 30, 81-93. [CrossRef]

35. Anastasopoulos, A.; Segot, T.L. Testing for financial contagion: New evidence from the Greek crisis and yuan devaluation. Res. Int. Bus. Financ. 2018, 45, 499-511. [CrossRef]

36. Fung, W.K.; Hu, Y.Q. Probability and Statistics. In Statistical DNA Forensics: Theory, Methods and Computation; John Wiley \& Sons, Ltd.: Hoboken, NJ, USA, 2008. 
37. Kaminsky, G.L.; Pablo, V.G. Systemic and idiosyncratic sovereign debt crises. J. Eur. Econ. Assoc. 2016, 14, 80-114. [CrossRef]

38. Kim, J.M.; Jung, H. Can asymmetric conditional volatility imply asymmetric tail dependence? Econ. Model. 2017, 64, 409-418. [CrossRef]

39. Nelsen, R.B. An Introduction to Copulas; Springer: New York, NY, USA, 2006.

40. Walpole, R.E.; Myers, R.H. Probability and statistics for engineers and scientists. Technometrics 2006, 74, 348-349. [CrossRef]

41. Clayton, D.G. A model for association in bivariate life tables and its application in epidemiological studies of familial tendency in chronic disease incidence. Biometrika 1978, 65, 141-151. [CrossRef]

42. Joe, H. Multivariate models and dependen dence concepts. Technometrics 1997, 40, 353.

43. He, Y.; Zhang, X.; Zhang, L. Variable selection for high dimensional gaussian copula regression model: An adaptive hypothesis testing procedure. Comput. Stat. Data Anal. 2018, 124, 132-150. [CrossRef]

44. Kim, J.M.; Jung, H. Relationship between oil price and exchange rate by fda and copula. Appl. Econ. 2018, 50, 2486-2499. [CrossRef]

45. Masarotto, G.; Varin, C. Gaussian Copula Regression in R. J. Stat. Softw. 2017, 77, 1-26. [CrossRef]

46. Song, P.X.K. Multivariate Dispersion Models Generated from Gaussian Copula. Scand. J. Stat. 2000, 27, 305-320. [CrossRef]

47. Masarotto, G.; Varin, C. Gaussian Copula Marginal Regression. Electron. J. Stat. 2012, 6, 1517-1549. [CrossRef]

48. Rime, B.; Mathur, I. Capital requirements and bank behaviour: Empirical evidence for Switzerland. J. Bank Financ. 2001, 25, 789-805. [CrossRef]

49. Were, M.; Wambua, J. What factors drive interest rate spread of commercial banks? empirical evidence from Kenya. Rev. Deve. Financ. 2014, 4, 73-82. [CrossRef]

50. Afonso, A.; Jalles, J.T. Fiscal volatility, financial crises and growth. Appl. Econ. Lett. 2012, 19, 1821-1826. [CrossRef]

(C) 2020 by the authors. Licensee MDPI, Basel, Switzerland. This article is an open access article distributed under the terms and conditions of the Creative Commons Attribution (CC BY) license (http://creativecommons.org/licenses/by/4.0/). 


\title{
Macroeconomic Determinants of Nonperforming Loans of Romanian Banks
}

\author{
Teodor Hada ${ }^{1}$, Nicoleta Bărbuță-Mișu ${ }^{2, *}$, Iulia Cristina Iuga ${ }^{3}$ and Dorin Wainberg ${ }^{3,4}$ \\ 1 Department of Finance, “Bogdan Voda” University, 400525 Cluj-Napoca, Romania; teohada@yahoo.com \\ 2 Department of Business Administration, "Dunarea de Jos" University of Galati, 800008 Galati, Romania \\ 3 Department of Finance-Accounting, "1 Decembrie 1918” University of Alba Iulia, 510009 Alba Iulia, \\ Romania; iuga_iulia@yahoo.com (I.C.I.); wainbergdorin@yahoo.com (D.W.) \\ 4 Department of Mathematics, "1 Decembrie 1918" University of Alba Iulia, 510009 Alba Iulia, Romania \\ * Correspondence: Nicoleta.Barbuta@ugal.ro; Tel.: +40-336-130-108
}

Received: 13 July 2020; Accepted: 10 September 2020; Published: 12 September 2020

\begin{abstract}
The banking sector plays an important role in the development of any economy. The performance of the loans in bank portfolios is a critical issue for the banking sector. The increased number of nonperforming loans (NPLs) after the financial crisis of 2008 has questioned the robustness of many banks and the stability of the entire sector. Our study aims to present the most important aspects related to NPLs and to investigate some macroeconomic determinant factors affecting the rate of NPLs in Romania. Based on a set of data for the period 2009-2019, the analysis of NPLs was made using linear regression. The results showed that all selected independent variables (exchange rates of the most used currencies (EUR, USD and CHF), unemployment rate, and inflation rate) have a significant impact on the dependent variable NPL. The study reveals strong correlations between NPLs and the macroeconomic factors studied and that the Romanian economy is clearly connected to the quality of the loan portfolios. Additionally, an econometric analysis of the empirical causes of NPLs shows that the RON-CHF exchange rate has been the main factor in increasing the NPL ratio in the last 5 years in Romania.
\end{abstract}

Keywords: nonperforming loans; macroeconomic factors; econometric model; exchange rate; unemployment rate; inflation rate

\section{Introduction}

The connection between nonperforming loans (NPLs) and bank losses has been analysed by authors from around the world and is considered a very important chapter in banking literature. Rising NPLs are often referred to as the failure of banks to manage credit policy.

In the last two decades, there has been a significant increase in the volume of loans granted by banks [1]. This increase was due to the process of deregulation of financial markets and the development of information technologies in the banking field. These processes have led to improved financial intermediation $[2,3]$.

However, the financial crisis is also the result of the high NPL rate in the banking sector. The financial crisis of 2008 started in the USA and spread all over the world because all countries had trade relations with the USA. That crisis has been labelled as a cause of default on mortgages and loans. Increasing the NPL rate is the main reason for reducing bank revenues and, implicitly, for decreasing profits or recording losses. The reason for the NPL separation is the low repayment capacity of debtors, coupled with a high interest rate. Since 2008, the year of the onset of the global financial crisis, NPL levels have risen significantly.

As the existence of nonperforming loans, being a special category of loans, cannot be ignored, it is necessary to manage and separate this type of loan to a special portfolio of nonperforming loans. 
The negative aspects and impact of these loans affect not only on the bank and its customers but also the economy on a macroeconomic level.

Bank practice has identified a multitude of causes generating nonperforming credits, grouped as follows, depending on the factors generating them:

- Macro level causes: political causes, economic causes, market causes, legislative causes, and competition causes.

- Causes generated by the loan beneficiaries: the weak management of the debtor companies.

- Causes independent of the customer's activity: fraud, takeovers, failure to comply with the provisions of the loan.

- Causes entirely due to the fault of the bank: a mistaken analysis of the customer's situation.

A flexible credit policy may also be the reason for a high volume of national credit, as happened in Romania. The bank sector serves the biggest part of the Romanian economy. The Romanian banks offer a large range of services to companies and individuals: conventional banking services, a variety of instruments for investments, and solutions for specialised financing. As the cornerstone of the national financial system and through its functions, the bank sector has special importance for the Romanian economy. The manner in which the bank sector develops its activity becomes an essential condition for the maintenance of financial stability and the insurance of sustainable economic development.

Therefore, it is clear why the NPL rate is crucial for banks. After the crisis in Romania in 2008, the unemployment rate increased significantly, the level of salaries of employees in state institutions decreased significantly—with a direct impact on NPLs (a large part of employees had contracted bank loans at that time) - and the inflation rate recorded significant changes. The exchange rates of RON-CHF, RON-EURO, and RON-USD almost doubled, affecting the repayment of loans (loans in progress and contracted before 2008) granted by banks in these currencies.

In this context, our study analyses the influence of certain macroeconomic factors from the category of the economic factors (the RON-CHF exchange rate, the RON-EUR exchange rate, the RON-USD exchange rate, the unemployment rate, the inflation rate) on the NPLs in the Romanian banking system. We mention that we chose the EUR, USD and CHF currencies due to their high proportion in Romanian foreign-currency credit granted to individuals and companies. Our paper compares the analysis before the initiation of the process of writing-off the unrecoverable NPLs (in 2014) and after 2014. Thus, the goal of this study is to present the most important aspects related to NPLs and to analyse the sensitivity of NPLs with respect to macroeconomic indicators in Romania. In particular, it uses regression analysis and a time series data set covering around 10 years (in the period 2009-2019) to examine the relationship between the nonperforming loan rate and some key macroeconomic variables that have changed significantly since 2008.

The paper is organised as follows. Section 2 offers a revision of the previous research on NPLs and influencing factors. Section 3 presents the data description and methodology used, including justification of the model used and tests developed. Section 4 shows the interpretation of the results based on the proposed model, compares the results of the models, and highlights similar results found in the literature. Section 5 presents the conclusions of our study, policy implications, and limitations.

\section{Literature Review}

There are many articles that have studied the links between the financial system and the economy. The most important examples are Bernanke and Gertler [4] and Bernanke, Gertler and Gilchrist [5] who developed the concept of the financial accelerator, arguing that credit markets are cyclical and that information asymmetry between creditors and debtors has an effect on amplifying and spreading shocks on the credit market. The Kiyotaki and Moore [6] model showed that if credit markets are imperfect, then relatively small shocks might be sufficient to explain business cycle fluctuations.

Competition has increased in the domestic and European banking markets, being strengthened by the deregulation process [7]. Banks have created permissive lending conditions to attract customers. 
Low interest rates, rising house prices and a stable economic environment characterised the precrisis period. This situation has led to the expansion of credit from both supply and demand. In our paper, we focus on the postcrisis period, characterised by high interest rates, falling house prices, and an unstable economic environment (rising unemployment, rising inflation, declining wages).

Several studies have examined the causes of NPLs and problem loans (e.g., Fernandez de Lis, Pagés and Saurina [8]; Boudriga, Taktak and Jellouli [9]; Espinoza and Prasad [10]).

An important number of studies in the literature on NPLs have focused exclusively on the role of macroeconomic or country-specific causes and have found that they have had the most significant effect. Espinoza and Prasad [10] tried to distinguish the determinants of NPLs for the Gulf Cooperative Council (GCC) banking system. The result of their study was that the NPL ratio increases when economic growth slows and risk aversion decreases, but also when interest rates rise. It is important to note that exchange rates and unemployment were not used as regressors due to the exchange rate regime and low and stable unemployment in the GCC countries.

Nkusu [11] used a methodology similar to that of Espinoza and Prasad [10]. He tested an econometric model that explains NPLs using only macrovariables and found that a worsening of the macroeconomic environment (i.e., a higher unemployment rate) is closely related to the problems of repayment/nonrepayment of loans and improving the macroeconomic environment implies a decrease in nonperforming loans. In recent years, interest in nonperforming loans and their determinants has increased significantly as we encounter more data published at the banking level by each country and at the level of the aggregate banking system. Many NPL studies have been published, whose results reveal important information about the quality of loan portfolios and, in general, the fragility of banks. Many researchers view NPLs as financial pollution with huge effects on both economic development and social life (e.g., Gonzales-Hermosillo [12], Barseghyan [13], Zeng [14]).

In the studies of Baboučak and Jančar [15] for the Czech Republic and Hoggarth, Logan and Zicchino [16] for the United Kingdom, the VAR methodology was used. They found that the important factors influencing financial stability and the quality of the loan portfolio were the dynamics of inflation and interest rates. Baboučak and Jančar [15] found evidence of a positive correlation between NPLs, unemployment rates and consumer price inflation, while GDP growth decreases the NPL rate. They also found that the actual appreciation of the effective exchange rate did not have an exaggerated influence on the NPL ratio. Regarding the Greek banking market, Louzis, Vouldis and Metaxas [17] examined the effect of various macroeconomic factors on NPLs, studying each type of loan in the nine largest Greek banks. The authors found that the real GDP growth rate, unemployment rate and lending rates have a strong negative effect on the NPL level, interpreting them as a sign of poor banking management.

Vogiazas and Nikolaidou [18] investigated the determinants of nonperforming creditors in the Romanian banking sector during the Greek crisis (December 2001-November 2010) and found that inflation and external GDP information are proportional and influence the credit risks of the banking system in the country. Our study is distinguished from the previous ones by investigating the impact of the exchange rate of the most used currencies (EUR, USD and CHF) on the granting of credit in Romania and the impact of unemployment and inflation rates on nonperforming loans after the crisis of 2008 (i.e., in the period 2009-2019, when the effects of the crisis were visible in all sectors of activity and especially on the banking system). We also present the most important determinants used in the literature for studying nonperforming loans, considering that the continuous analysis of the quality of the loans is a repetitive action, with several stages that are more important, namely, the stages before granting the credit, the granting of credit stage and the postgrant stage. Many studies have analysed various factors that can influence NPLs. In the next subsections, we present these factors grouped into the major factors of influence. 


\subsection{NPLs and NPL Data Analytics}

Previous studies have examined the economic determinants of the NPL: "Greater capitalization, liquidity risks, poor credit quality, greater cost inefficiency and banking industry size significantly increase NPLs, while greater bank profitability lowers NPLs" [19]. The following variables significantly impact the NPL level: GDP real growth, share price, exchange rate and interest rate [20]. The assumption is that the macroeconomic variables and also the variables specific to the banks have an impact on the loan quality, depending on the loan category. For example, the NPLs from the Greek bank system can be mainly explained by macroeconomic variables (GDP, unemployment, interest rates, and public debts) and by the quality of the management [17].

Studies from various countries have identified the following factors that determine NPLs: inflation rate, unemployment rate, GDP level, ROA, ROE, liquidity, capital adequacy, size of the bank, volume of the deposits and interest rate [21]. For the saving banks, the GDP, the nonguaranteed loans and the net margins of interest affect NPLs, while for the commercial banks, the factors that affect NPLs are the size of the banks, their capital ratios and the expansion of their branches [7].

Knowledge-sharing processes and innovation processes of Islamic banks are integral parts of the survival and progress of business organisations. Another article conducted an empirical evaluation of the Czech public START program (funded by the European Regional Development Fund), a program that supported new entrepreneurs through zero-interest loans and credit guarantees. The obtained findings could not support the hypothesis of a positive impact of the programme on a firm's performance [22].

A model was created using latent variables of capital adequacy, operations, asset quality, size and profile of the countries in which they were based-this model can predict bank profitability. The study was conducted on the 100 largest banks between 2011 and 2015 [23].

\subsection{NPLs and Macro Level Factors}

Most studies considered macroeconomic factors as factors influencing NPLs.

The real GDP: Some authors have stated a negative relationship between GDP and NPLs [24,25]. Another study uses the data from the USA bank sector and takes into consideration real GDP per capita, inflation and total loans as independent variables, and the NPL ratio as a dependent variable. All the selected independent variables have a significant impact on the dependent variable, but, still, the values of the coefficients are not too high [26].

The economic growth: Another idea showed that NPLs affect the economy by slowing economic growth [27]. A study that analysed the situation in Hong Kong remarked that the NPL ratio grows together with the growth of the nominal interest rate but decreases once the inflation increases with economic growth [28].

The lending rate: Research on Italy found that the lending rate has a negative relationship with NPLs [24].

The unemployment rate: Some studies concluded that NPLs grow when the unemployment rate is high, while [29] showed that the unemployment rate has a negative impact on the quality of the bank loans [24]. NPLs increase when the unemployment rate grows and the debtors are confronted with difficulties related to the return of the loan [25].

The inflation: Inflation is positively connected to NPLs [29], while a lower inflation rate has a positive influence on the debtors' financial conditions and, eventually, on the recovery of the loans, meaning that it presents a positive relationship between the inflation rate and NPLs [30].

The market competition: The economic development of the country results in market growth. Market competition compels enterprises to increase their activity, i.e., to concentrate it [31]. Rahman et al. [32] sustained that taking effective measures to increase bank competition can create a level playing field for other banks and may reduce strict collateral requirements for companies. 
The exchange rate: The high number of NPLs leads to a depreciation of the exchange rate [27] and hence NPLs have, as a result, a depreciation of the exchange rate [29]. At the same time, some authors affirmed that a depreciation of the national currency can lead to more NPLs [33].

The boom/recession/expansion period in the economy: The quality of bank loans of Italian banks is lower during recession periods and higher during expansion periods. The internal factors that influence NPLs are efficiency, the indicator of income from interest to total assets, and the slow growth of loans. The external factors affecting NPLs are the GDP and the interest rates [34].

The governance indicators: The governance indicators are significant factors influencing NPLs [35]. Using techniques for the estimation of data, a study examined the determinant factors of NPLs in the Turkish bank system. The results of the study showed that the determinant factors of NPLs changed after the crisis and that the macroeconomic and political determinant factors have a higher significance [36].

The bank concentration: Bank concentration may reduce NPLs by enhancing market power and boosting bank profits so that high profits can provide a "buffer" against adverse shocks [37]. Çifter [38] examined the effect of bank concentration on nonperforming loans (NPLs) for ten Central and Eastern European (CEE) countries and concluded that the relationship between the concentration of banks and NPLs, with regard to CEE countries, is ambiguous.

\subsection{NPL and Nonspecific Factors}

There is still a group of factors that we have included in the group of nonspecific factors because their influence differs from country to country. This group of factors would be the factors that influence trust in internet banking (such as provided information, e-banking system, a bank's website and bank characteristics). Another factor that falls into this group is perceived value. The results of the studies show that three components of perceived value (economic value, comfort value and emotional value) increase the intention to use banks that are only on the internet [39]. Another study contributed to the specialised literature on the correlation between ecological lending and credit risks and concluded that the institutional pressure of green credit policy has a positive effect on both the environmental performance and financial performance of banks [40]. Some authors combined the two large groups of factors in their studies. They found a positive relationship between GDP growth, inflation and bank performance, whereas a negative relationship between tax burden and performance [41]. The bad-management and moral-hazard hypotheses explain a significant part of NPLs [42].

\section{Data and Methodology}

\subsection{The Dependent and Independent Variables}

As defined in the literature, nonperforming loans are the loans that are delayed for a long period, according to the loan contract. According to Tesfaye [43], any loan that is not recovered in due time is known as nonperforming. The rate of nonperforming loans, according to the ABE definition, is calculated using the following formula: nonperforming exposures from loans and advances/exposures from loans and advances. According to the ABE definition, which was nationally implemented through Order 6/2014 of the National Bank of Romania, nonperforming exposures are the one of the following criteria: (1) there are significant exposures, with over 90 days' delay from the recovery date, and (2) it is considered that lacking a real guarantee, it is improbable for the debtor to integrally return his debts, disregarding the existence of a certain sum or a certain number of delays in payment.

In this study, we used the rate of nonperforming loans (NPLs) from the Romanian bank system as a dependent variable. With regard to the independent variables, we used the following macroeconomic factors: RON-CHF exchange rate (RON_CHF), RON-EUR exchange rate (RON_EUR), RON-USD 
exchange rate (RON_USD), the unemployment rate (UR) and the harmonised index of consumer prices (HICP) inflation rate.

The variables used in this article were selected from the total of possible variables based on the criterion of impact on nonperforming loans of the population, and, moreover, these variables changed significantly during the analysed period compared to the other variables listed above. Thus, following the documentation at a series of banks in Romania, we found that

- the variable unemployment rate influences the outstanding loans of the individuals because the credited persons have fewer possibilities to repay the loan taken due to a lack of income, the unemployment benefits being small in Romania (below 100 euro/month). We have considered this variable in the study because of the consequences of the crisis, which led to more bankruptcies, the reduction of activity in many sectors, followed by staff lay-offs or a reduction of monthly salaries, both from the private and public sectors. This situation increased the unemployment rate and implicitly reduced the income of individuals. In Romania, the majority of active persons used real estate loans, mortgage loans or personal loans for purchasing buildings or other durable goods that were granted in CHF, EUR and USD, and the individuals that were laid off or had their salaries cut found it impossible to reimburse credits and this generated the increase in NPLs;

- the inflation rate influenced the level of outstanding loans by the fact that a high inflation rate reduces the purchasing power of the population, generating the decrease of the population's real income because a great part of the income is used for consumption. Therefore, the reduction of the individuals' incomes leads to a reduction in the ability to repay loans. Thus, inflation can negatively affect the debtor's service capacity [44]. Inflation negatively affects the ability of debtors to repay creditors [11]. We expect a negative impact of inflation on NPLs as a rapid rise in prices exacerbates market frictions, forcing banks to exercise caution in lending [45].

- the RON-EUR, RON-USD and RON-CHF exchange rates significantly reduced the population's income and influenced a decrease in the credit repayment capacity by the fact that during the analysed period, the RON-CHF, RON-EUR, and RON-USD exchange rates increased permanently. The reduction of the population's income was generated by the fact that Romanian individuals received their salaries in RON and had to pay loans granted in EUR, USD and CHF. The increase in the exchange rate of these currencies generated an increase of monthly credit rate, and this situation made it impossible for individuals to pay their debts to banks.

\subsection{Data}

The study used an explanatory analysis and also an econometric analysis based on the data from 2009 until January 2019 in order to investigate the relationship between NPLs and the 5 macroeconomic factors selected and presented in Section 3.1. For each variable, 110 monthly values were considered. The data for our study were taken from the metadata database of the National Institute of Statistics of Romania (www.insse.ro), from the database of the National Bank of Romania (www.bnr.ro), and from the Eurostat database (https://ec.europa.eu/eurostat/data/database). For econometric analysis, we used the statistical package EViews.

A summary table of statistics for these variables is given below (Table 1).

Analysing data presented in Table 1, we found that the average rate of NPLs is $13.04 \%$, the maximum value being $22.52 \%$. Related to the evolution of the exchange rate, we can see that the RON-CHF exchange rate increased by $52.86 \%$ in the period analysed, the RON-EUR exchange rate increased by $14.91 \%$, and the RON-USD exchange rate increased by $50.70 \%$. The average unemployment rate was $6.29 \%$, and the maximum value of the inflation rate was $5.98 \%$.

A graphic representation of the NPL rate with 110 values (calculated monthly, starting at 1 December 2009 until 31 January 2019) is presented in Figure 1. We observe that the trend increases for the period 2009-2014 and decreases between 2015 and 2019. This makes us think that there may be a structural break in the NPL ratio. 
Table 1. Descriptive statistics for the considered variables (Source: authors' estimations).

\begin{tabular}{ccccc}
\hline Variable & Mean & Std. Dev. & Min. & Max. \\
\hline NPL & 13.04 & 4.79 & 4.95 & 22.52 \\
\hline RON_CHF & 3.75 & 0.38 & 2.80 & 4.28 \\
\hline RON_EUR & 4.44 & 0.15 & 4.09 & 4.70 \\
\hline RON_USD & 3.60 & 0.41 & 2.84 & 4.28 \\
\hline UR & 6.29 & 1.09 & 3.70 & 7.90 \\
\hline HICP & 97.62 & 4.90 & 84.03 & 105.98 \\
\hline
\end{tabular}

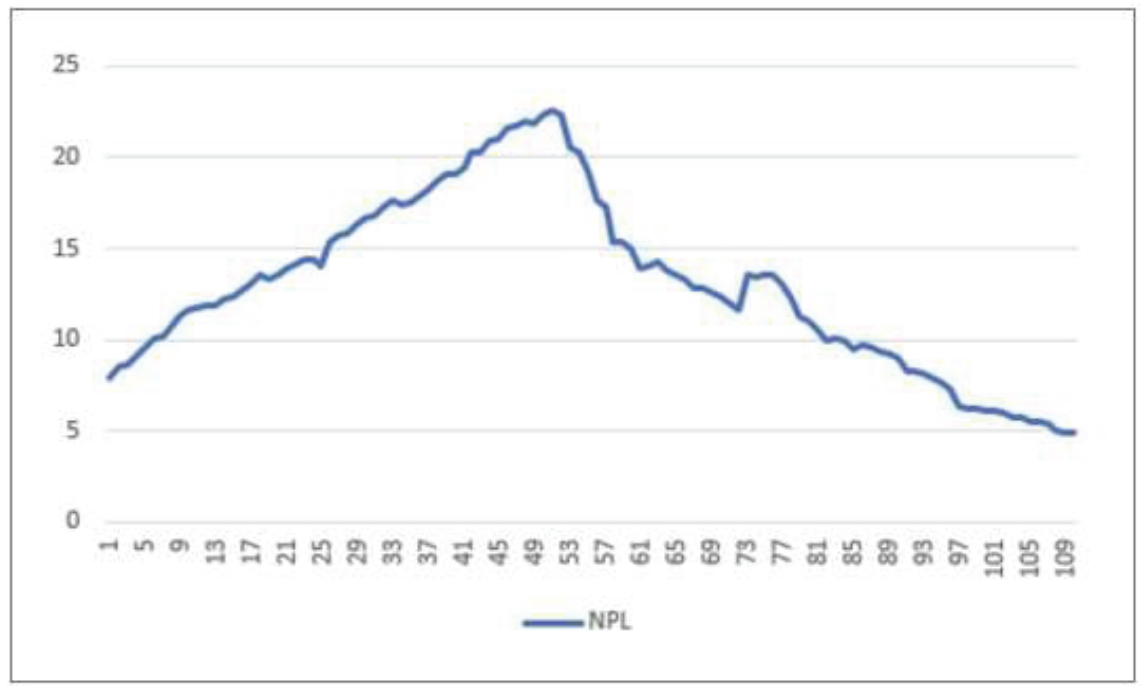

\section{Source: database of the National Bank of Romania (www.bnr.ro)}

Figure 1. The evolution of the NPL rate for the 2009-2019 period.

The novelty element in the general representation of banking activity from 2014 is the initiation of the process of writing-off the uncollectable nonperforming loans, following the recommendations of the National Bank of Romania, a process considered a necessary condition for the sustainable relaunch of credit. The year 2014 registered a significant decrease in nonperforming loans registered in the balance of the banks because of the operations of direct decrease in the value of unrecoverable loans, covered in a high percentage with adjustments for depreciation, that were made at the recommendation of the National Bank of Romania. Considering the limited efficiency of the techniques previously used by commercial banks in order to diminish the number of nonperforming loans-most often restructuration/rescheduling and foreclosure - the National Bank of Romania recommended the cleaning of portfolios in four stages:

- Writing-off the entirely provisioned nonperforming loan (the banks reserved their right to recover the loan).

- The integral forecasting and write-off of loans with a payment delay longer than 360 days.

- The integral forecasting and write-off of loans to companies in insolvency.

- An external audit of the provisions constituted according to IFRS and the guarantees.

The result of these activities was a decrease in the NPL rate from $20.4 \%$ in March to $13.9 \%$ in December 2014 (see Figure 1). 
In our analysis, the dependent variable rate of NPLs is studied by considering as independent variables the exchange rates (RON-CHF, RON-EUR, RON-USD), the unemployment rate (UR) and the inflation rate (HICP), measured in the same statistic interval. As noted on the National Institute of Statistics of Romania website (www.insse.ro), we observe an upward trend of the inflation rate and a downward trend of the unemployment rate during the analysed period (starting on 1 December 2009 until 31 January 2019). From the National Bank of Romania website (www.bnr.ro), we observed an upward trend, with small oscillations for all three exchange rates (RON-CHF, RON-EUR, RON-USD).

The model chosen for studying the influence of the independent variables selected on the NPL rate is the multiple regression model, presented in the form of a linear relation:

$$
y_{i}=\beta_{1} x_{1 i}+\beta_{2} x_{2 i}+\ldots+\beta_{p} x_{p i}+u_{i}
$$

where $i=1, \ldots, n, y_{i}$ represents the values of the explained variable $Y$, and $x_{1 i}, x_{2 i}, \ldots, x_{p i}$ are the values of the independent variables $X_{1}, \ldots, X_{p}$. The coefficients $\beta_{1}, \beta_{2}, \ldots, \beta_{p}$ are the parameters of the regression model, and $u_{i}$ are the values of the residual variable.

\subsection{The Estimation of the Parameters and the Validation of the Regression Model}

In this section, we made a univariate analysis of the series analysing the presence of unit roots through the augmented Dickey-Fuller (ADF) test in order to determine the order of integration of each series.

The results of the augmented Dickey-Fuller test is presented in Table 2.

Table 2. Unit root test (source: authors' estimations).

\begin{tabular}{ccc}
\hline \multicolumn{3}{c}{ Unit Root Test-ADF } \\
\hline \multicolumn{2}{c}{ Ho There is a Unit Root } \\
\hline Variable & $\begin{array}{c}\text { Statistical Value of the } \\
\text { Series in First Differences }\end{array}$ & $\begin{array}{c}\text { Reject H0 } \\
\text { at } \mathbf{9 5 \%}\end{array}$ \\
\hline NPL & -1.931625 & Yes \\
RON_CHF & -1.695445 & Yes \\
RON_EUR & -2.885321 & Yes \\
RON_USD & -2.969274 & Yes \\
UR & -4.433165 & Yes \\
HICP & -1.359764 & Yes \\
\hline
\end{tabular}

Notes: The number of lags was determined according to the Akaike criterion.

From the information provided in Table 2, we conclude that all the variables are first-order integrated, I(1).

\section{Results and Discussion}

\subsection{Interpretation of the Obtained Results}

In this section, we obtain the elements of the multiple regression model, as well as the values of certain indicators and tests for the appreciation of the validity and quality of the equation attached to the model. Therefore, after creating the group formed from the variables presented above, we defined the equation corresponding to the multiple regression model, with the rate of the nonperforming loans (NPLs) as the dependent variable and RON-CHF, RON-EUR, RON-USD, UR and HICP as independent variables, also defining the constant variable $C$, corresponding to the impact of other exogenous variables influencing NPLs, which are not considered in the present analysis. The estimation of the parameters in the equation of the regression model was made using the method of least squares.

The obtained values, representing, at the same time, the coefficients of the variables in the regression model and the results from the tests, are presented in Table 3. 
Table 3. Estimations results (source: authors' estimations).

\begin{tabular}{ccccc}
\hline \multicolumn{2}{c}{ Dependent Variable: NPL } & & & \\
\hline Explanatory Variable & Coefficient & Std. Error & t-Statistic & Prob. \\
\hline RON_CHF & 1.695445 & 1.820228 & 0.931447 & 0.3538 \\
RON_EUR & 15.50740 & 3.957474 & 3.918510 & 0.0002 \\
RON_USD & 5.969274 & 1.460210 & 4.087956 & 0.0001 \\
UR & 4.433165 & 0.333343 & 13.29911 & 0.0000 \\
HICP & 0.339662 & 0.111708 & 3.040627 & 0.0030 \\
C & -101.6536 & 13.38608 & -7.593980 & 0.0000 \\
\hline R-squared & 0.781285 & & & \\
Adjusted R-squared & 0.770770 & & & \\
Prob(F-statistic) & 0.000000 & & & \\
\hline
\end{tabular}

One of the most important assumptions of any time series model is that the underlying process is the same across all observations in the sample. It is, therefore, necessary to analyse carefully the time series data that include periods of violent change (as we observed for the NPL ratio, in Figure 1). A tool that is particularly useful in this regard is the Chow test. The null hypothesis for the test is that there is no breakpoint (i.e., that the data set can be represented with a single regression line). We assumed that there is no structural break between the first five years and the last five years of the period.

As the content of Table 4 confirms, the null hypothesis is rejected, i.e., the regression is not stable over the considered data sets. Because of this structural break, we will estimate the model for the 2009-2014 period (Section 4.3) and 2015-2019 period (Section 4.4) separately.

Table 4. Regression stability test (Chow test; source: authors' estimations).

\begin{tabular}{ccccc}
\hline Score & C.V. & $p$-Value & Stable? & $\mathbf{5 . 0} \%$ \\
\hline 21.813 & 2.461 & $0.00 \%$ & FALSE & \\
\hline
\end{tabular}

\subsection{An Overview of the Period 2009-2019}

From Table 3, we find a linear relationship between NPLs and their explanatory factors, statistically significant at a significance level of $1 \%(\operatorname{Prob}($ F-statistic $)=0.000)$. The sign of each coefficient is the expected one, being positive. If each of the considered macroeconomic components increases, nonperforming loans will also increase. All the variables studied place the level of NPLs at 78.12\% (R-squared $=0.7812)$.

Therefore, based on the values above, we can affirm that the model of linear multiple regression can be accepted for the correlation and interdependence between the NPL rate and the macroeconomic indicators: the exchange rate, the unemployment rate, and inflation. However, as we mentioned before, this regression is not stable, according to the Chow test, and because of that, we have split the 2009-2019 period into two parts and will study each part separately.

In the Coefficient column from the results presented in Table 3, we have the coefficients of the equation of the regression model. The Variable column shows the names of the variables to which the coefficient corresponds. Each parameter estimated in this manner measures the contribution of the independent variable to the dependent variable. Hence, the regression equation is

$$
\begin{gathered}
N P L=1.69 * \text { RON } / C H F+15.50 * R O N / E U R+5.96 * R O N / U S D \\
+4.43 * U R+0.33 * I N F L-101.65
\end{gathered}
$$

Additionally, another method to verify the reliability of the regression parameters is represented by the method of confidence intervals. The confidence intervals are presented in Table 5 . We have intervals with a confidence coefficient of $90 \%$ and $95 \%$. Therefore, we can affirm with a confidence of 
$95 \%$ that the growth of one percent in the unemployment rate leads to the growth of NPLs between $3.77 \%$ and $5.09 \%$.

Table 5. The confidence intervals (source: authors' estimations).

\begin{tabular}{cccccc}
\hline \multicolumn{5}{c}{ Coefficient Confidence Intervals } \\
\hline \multicolumn{5}{c}{$90 \%$ CI } & \multicolumn{2}{c}{$95 \%$ CI } \\
\hline Variable & Coefficient & Low & High & Low & High \\
\hline RON_CHF & 1.695 & -1.325 & 4.716 & 1.914 & 5.305 \\
RON_EUR & 15.50 & 8.939 & 22.075 & 7.659 & 23.355 \\
RON_USD & 5.969 & 3.545 & 8.392 & 3.073 & 8.864 \\
UR & 4.433 & 3.879 & 4.986 & 3.772 & 5.094 \\
INFL & 0.339 & 0.154 & 0.525 & 0.118 & 0.561 \\
C & -101.653 & -123.869 & -79.437 & -128.198 & -75.108 \\
\hline
\end{tabular}

An evaluation obtained for the considered values of this formula is given in Figure 2.

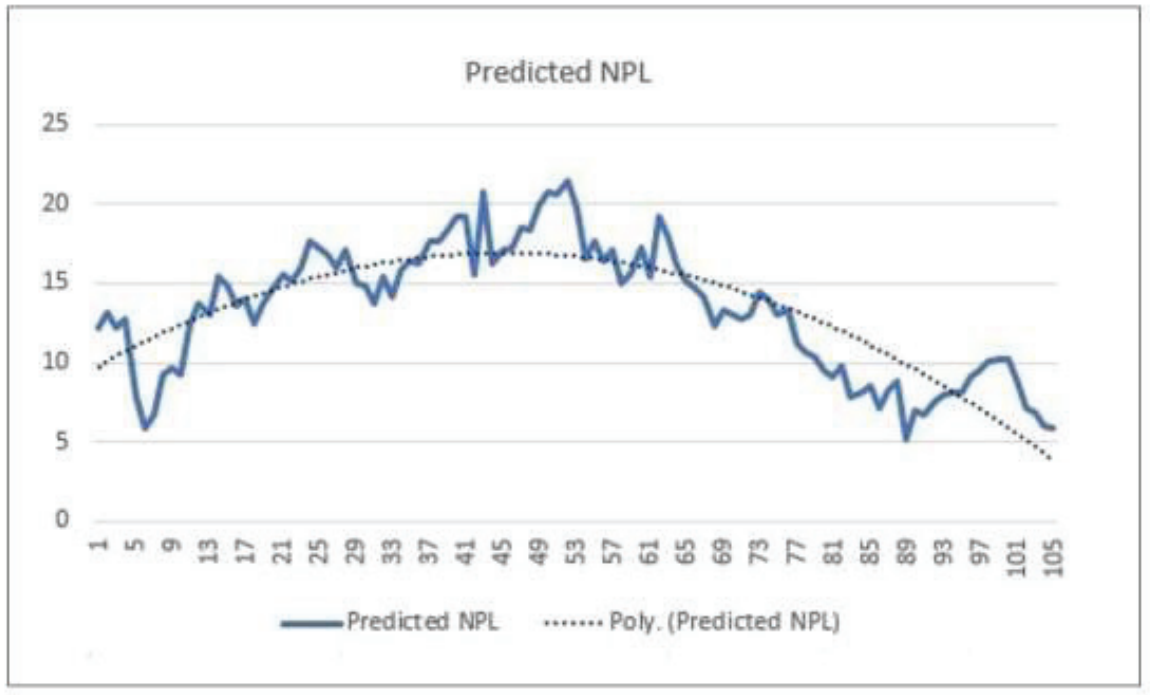

Figure 2. The graphic representation of the regression model for the 2009-2019 period.

As we can see, the trend line for the predicted NPL rate is described by a second-degree polynomial curve. This will sustain a separate study for each of the periods of 2009-2014 and 2015-2019.

\subsection{A Model for the 2009-2014 Period}

As we observed in Figure 1, NPL had an upward trend in the 2009-2014 period. The values of the regression model for this period are given in Table 6 .

Here, we have the elements of the multiple regression model and also the values of certain indicators and tests for the appreciation of the reliability and quality of the equation attached to this model.

Thus, based on the values of these tests, we can affirm that the correlation and interdependence between the NPL and the considered independent variables are represented very well by a model of linear multiple regression. 
Hence, the regression equation is

$$
\begin{gathered}
N P L=1.76 * \text { RON_CHF }+9.50 * \text { RON_EUR }+2.40 * \text { RON_USD } \\
+2.55 * U R+1.54 * I N F L-94.207
\end{gathered}
$$

From here, we can affirm that a growth of one unit in the RON-EUR exchange rate leads to a growth of the NPL rate by $9.5 \%$. Our result is consistent with the study of Farhan et al. [46], who found that unemployment, inflation and exchange rates have a significant positive relationship with NPLs of the Pakistani banking sector. The findings obtained by Bock and Demyanets [27] imply that the exchange rate is one of the main determinants of NPLs.

Table 6. Estimation results for the 2009-2014 period (source: authors' estimations).

\begin{tabular}{ccccc}
\hline \multicolumn{5}{c}{ Dependent Variable: NPL } \\
Explanatory Variable & Coefficient & Std. Error & t-Statistic & Prob. \\
\hline RON_CHF & 1.716 & 1.686 & 1.018 & 0.113 \\
RON_EUR & 9.502 & 2.359 & 4.474 & 0.000 \\
RON_USD & 2.405 & 1.858 & 1.909 & 0.005 \\
UR & 2.550 & 1.602 & 0.913 & 0.265 \\
INFL & 1.547 & 1.087 & 6.270 & 0.000 \\
Const. & -94.207 & 10.566 & -7.950 & 0.000 \\
\hline R-squared & 0.860568 & & & \\
Adjusted R-squared & 0.847893 & & & \\
Prob(F-statistic) & 0.000000 & & & \\
\hline
\end{tabular}

Our results show that a growth of $1 \%$ in the unemployment rate will lead to a growth in the NPL rate by $2.55 \%$. These are in line with the studies of Popa et al. [47], Ghosh [19], Makri et al. [48], Messai and Jouini [49] and Skarica [50]. This result is also reinforced by Louzis et al. [17], who found in their study that NPLs can be explained mainly by macroeconomic variables such as unemployment. The unemployment rate is one of the major determinants of NPLs, as stated by Nkusu [11]. According to Cifter's [38] study, the unemployment rate is the most important macroeconomic factor for NPLs, and a percentage increase in the unemployment rate increases NPLs by 3.61 percentage points for the group of countries analysed by him. Using GMM and quarterly data of Euro-area banks in the 1990-2015 period, Anastasiou et al. [51] found that macrovariables such as unemployment and growth exert a strong influence.

A growth of $1 \%$ in the inflation rate will determine a growth of the NPL rate by $1.54 \%$. This result is similar to the study of Charalambakis et al. [52], who found that the key factors that can explain the movements in NPLs are the unemployment rate and the inflation rate. The results of the study by Donath et al. [53] showed that the variation of NPLs had a positive correlation with inflation as well as unemployment rates, which is the result found in our study.

In Table 7, we have the confidence coefficients intervals of $90 \%$ and $95 \%$ for our model. Hence, we can say, with a confidence of $95 \%$, that an increase of $1 \%$ in the unemployment rate leads to an increase in the NPL rate of between $1.33 \%$ and $3.75 \%$.

In Figure 3, we have the representation of the predicted NPL rate according to (3) for 61 values (calculated monthly, starting on 1 December 2009 until 31 December 2014). Here, the trend line for the predicted NPL rate is an upward linear one. 
Table 7. The confidence intervals (source: authors' estimations).

\begin{tabular}{cccccc}
\hline \multicolumn{5}{c}{ Coefficient Confidence Intervals } \\
\hline \multicolumn{5}{c}{$90 \%$ CI } & \multicolumn{2}{c}{$95 \%$ CI } \\
\hline Variable & Coefficient & Low & High & Low & High \\
\hline RON_CHF & 1.716 & -1.105 & 4.537 & -1.663 & 5.095 \\
RON_EUR & 9.502 & 2.209 & 16.796 & 0.766 & 18.239 \\
RON_USD & 2.405 & -1.297 & 5.513 & -2.682 & 6.127 \\
UR & 2.550 & 1.443 & 3.557 & 1.334 & 3.756 \\
INFL & 1.547 & 1.401 & 1.693 & 1.372 & 1.722 \\
Const. & -94.207 & -113.558 & -74.857 & -117.386 & -71.028 \\
\hline
\end{tabular}

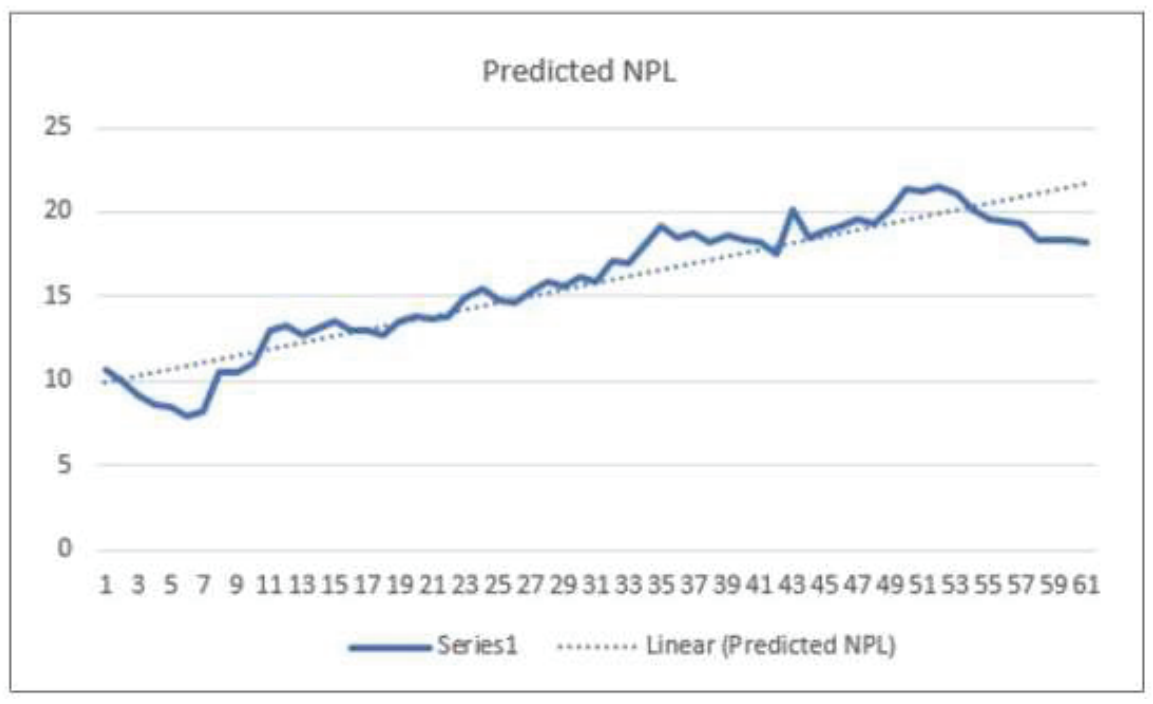

Figure 3. The graphic representation of the regression model for the 2009-2014 period.

\subsection{A Model for the 2015-2019 Period}

We observed in Figure 1 that NPL had an upward trend in the 2009-2014 period. The NPL level started to decrease in June 2014. The novelty element in the general view on the bank activity in 2014 was the initiation of the write-off process for uncollectible NPLs, following the recommendations of the National Bank of Romania to credit institutions. We formulated below the model of multiple regression based only on the data from the period 2015-2019 (the years when the NPL rate decreased) in order to observe if the same independent variables have a stronger impact on the NPL, similar to the previously formulated model.

We used the same techniques as above to study the mentioned period. Hence, in order to formulate the regression model, we defined the rate of nonperforming loans (NPLs) as a dependent variable.

The independent variables that are taken in consideration are the same: the exchange rates (RON-CHF, RON-EUR, RON-USD), the unemployment rate (UR) and the inflation rate (HICP), measured in the same statistic interval (from 1 December 2009 to 31 January 2019).

Using the same technique that we have described above, with the help of the software EViews, we obtained the elements of the multiple regression model and also the values of certain indicators and tests for the appreciation of the reliability and quality of the equation attached to this model. The obtained values, representing the coefficients of the variables in the model of linear multiple regression and, at the same time, the results of the tests on the model, are presented in Table 8. 
Table 8. Estimations results (source: authors' estimations).

\begin{tabular}{ccccc}
\hline \multicolumn{5}{c}{ Dependent Variable: NPL } \\
Variable & Coefficient & Std. Error & t-Statistic & Prob. \\
\hline RON_CHF & 2.224377 & 1.824114 & 1.219429 & 0.2293 \\
RON_EUR & -5.691265 & 3.409805 & -1.669088 & 0.1024 \\
RON_USD & -0.706060 & 1.189802 & -0.593426 & 0.5560 \\
UR & 2.000545 & 0.218424 & 9.159005 & 0.0000 \\
HICP & 0.194019 & 0.075723 & 2.562230 & 0.0140 \\
C & 37.83326 & 15.77087 & 2.398933 & 0.0209 \\
\hline R-squared & 0.954209 & & & \\
Adjusted R-squared & 0.948885 & & & \\
Prob(F-statistic) & 0.000000 & & & \\
\hline
\end{tabular}

We will further present the manner in which we use these values in the study of linear regression with the five considered explanatory variables. The R-squared statistic: In the present case, we can appreciate that $95.4 \%$ of the NPL rate value is explained by the five considered independent variables. S.E. of regression (S): The fact that we have a value of $S=0.69$ in the present case is another confirmation of the fact that the regression model is representative of the relationships between the considered variables. Another confirmation of the obtained model is given by the Fisher test, F-statistic, and its associated probability, Prob(F-statistic). The econometric model of multiple regression using the NPL rate as a dependent variable is a correct one and can be used in the analyses of macroeconomic forecasts. The statistic of the Durbin-Watson test (Durbin-Watson stat): In the present case, the value of the test is 0.85 , corresponding to a positive linear dependence, meaning that a general growth of the values of the independent variables leads to a growth of the NPL rate.

Thus, based on the values of these tests, we can affirm that the correlation and interdependence between the NPL rate and macroeconomic indicators—-the exchange rate, the unemployment rate and inflation-is represented very well in the model of linear multiple regression.

Hence, the regression equation is

$$
\begin{gathered}
N P L=2.22 * R O N / C H F-5.69 * R O N / E U R-0.70 * R O N / U S D \\
+2 * U R+0.19 * I N F L+37.83
\end{gathered}
$$

We observe that the signs of the coefficients are different in this case. This will give us the right to say that the model has not given us consistent estimates and we expect endogeneity for this five-year period of 2015-2019.

An evaluation of this formula, obtained for the values of the independent variables considered for the calculation period, e.g., for 49 values (calculated monthly, starting on 1 January 2015 until 31 January 2019), is represented in Figure 4. We can affirm that for a growth of one unit in the RON-CHF exchange rate, the NPL rate will increase by $2.22 \%$, while a growth of one percent in the unemployment rate will lead to a growth of $2 \%$ in the NPL rate. At the same time, we observe that the influence of the constant variable is important. Therefore, the factors taken into consideration in our analysis have an important impact on the dependent variables, determining its decrease by 37.83 units.

Here, the trend line for the predicted NPL rate is a downward linear one. In order to establish the significance level for each coefficient, we use the values of the Prob. column from Table 9. Another method for the confirmation of the validity of the regression parameters is the method of confidence intervals. We obtained the following intervals.

We obtained, as Table 9 shows, the intervals with a confidence coefficient of $90 \%$ and $95 \%$. Therefore, in the example given, we can affirm with a confidence of $95 \%$ that an increase of $1 \%$ in the inflation rate leads to an increase of the NPL rate between $1.56 \%$ and $2.44 \%$. 


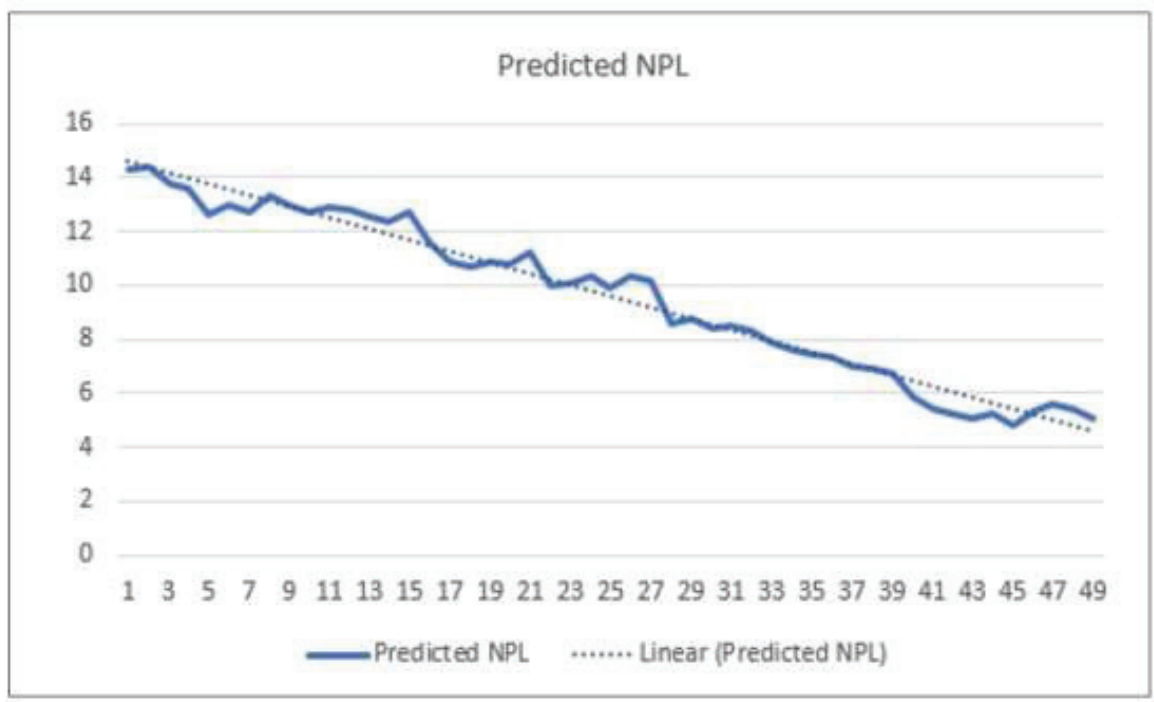

Figure 4. The graphic representation of the regression model for the 2015-2019 period.

Table 9. The confidence intervals (source: authors' estimations).

\begin{tabular}{cccccc}
\hline \multicolumn{5}{c}{ Coefficient Confidence Intervals } \\
\hline \multicolumn{7}{c}{$90 \%$ CI } & \multicolumn{2}{c}{$95 \%$ CI } \\
\hline Variable & Coefficient & Low & High & Low & High \\
\hline RON_CHF & 2.224377 & -0.842087 & 5.290842 & -1.454299 & 5.903054 \\
RON_EUR & -5.691265 & -11.42339 & 0.040859 & -12.56779 & 1.185263 \\
RON_USD & -0.706060 & -2.706201 & 1.294081 & -3.105524 & 1.693405 \\
UR & 2.000545 & 1.633359 & 2.367731 & 1.560051 & 2.441039 \\
HICP & 0.194019 & 0.066724 & 0.321314 & 0.041310 & 0.346728 \\
C & 37.83326 & 11.32131 & 64.34521 & 6.028265 & 69.63825 \\
\hline
\end{tabular}

\subsection{Comparative Analysis for Periods Analysed}

If we compare the influencing factors of the NFL rate analysed in this paper for both periods of 2009-2014 and 2015-2019, we may conclude that

- in the period 2009-2014, an increase in the RON-CHF exchange rate of $1 \%$ leads to an increase in the NPL rate of $1.70 \%$, while, in the period 2015-2019, the same increase leads to an increase in the NPL rate of $2.22 \%$, which shows that after the recommendations of the National Bank of Romania, the credits granted in CHF still remain a generating factor of NPLs in Romania. This is explained by the fact that due to the increase in the RON-CHF exchange rate, many debtors, after paying the monthly rate of the credit for 8-10 years, have a debt higher than the initial value of the credit.

- $\quad$ in the period 2009-2014, an increase in the RON-EUR exchange rate of $1 \%$ leads to an increase in the NPL rate of $9.50 \%$, while in the period 2015-2019, the same increase leads to a decrease in the NPL rate of $5.69 \%$, which shows that after the recommendations of the National Bank of Romania, the RON-EUR exchange rate is not a generating factor of NPLs in Romania.

- in the period 2009-2014, an increase in the RON-USD exchange rate of $1 \%$ leads to an increase in the NPL rate of $2.40 \%$, while in the period 2015-2019, the same increase leads to a decrease of NPL rate with $0.71 \%$, which shows that after the recommendations of the National Bank of Romania, the RON-USD exchange rate is not a generating factor of NPLs in Romania. 
- $\quad$ in the period 2009-2014, an increase in the unemployment rate of $2.55 \%$ leads to an increase in the NPL rate of $2.40 \%$, while in the period 2015-2019, the same increase leads to a decrease in the NPL rate of $2.00 \%$, which shows that after 2014, the unemployment rate still remains a generating factor of NPLs in Romania.

- $\quad$ in the period 2009-2014, an increase in the inflation rate of $1 \%$ leads to an increase in the NPL rate of $1.55 \%$, while in the period 2015-2019, the same increase leads to a decrease in the NPL rate of $0.19 \%$, which shows that after 2014 , the inflation rate is not a generating factor of NPLs in Romania, especially due to the Romanian government's efforts to maintain the inflation rate within the limits recommended by the European Union.

\section{Conclusions}

The present paper identifies several macroeconomic factors influencing the nonperforming loans rate in the Romanian banking system. The results are, in general, comparable to the results from other countries. The econometric analysis of the empirical determinants of the NPL rate presented in this paper shows that the exchange rate and the unemployment rate were the main causes for the growth of NPLs for both analysed periods of 2009-2014 and 2015-2019 (after 2014, what took place was the write-off of uncollectable NPLs at the recommendation of the National Bank of Romania). We applied in the present study an econometric model that helped us to identify the factors influencing the NPL rate in Romania, and we observed strong relations between the NPL rate and various macroeconomic factors. Our results are in general agreement with the literature because, from a macroeconomic perspective, the exchange rate, the unemployment rate and the inflation rate seem to be three supplementary factors affecting the NPL index, showing that the situation of the Romanian economy is clearly connected to the quality of loan portfolios. Related to the causes of nonperforming loans, after a literature review, we can conclude that nonperforming loans depend on several factors. We cannot make a list of all the causes because there are multiple causes, and these depend on macro-level factors and the specificity of each bank and its customers.

The writing-off process was individually transposed by a decrease of the number of banks registering NPL rates above the threshold for high risk, according to the ABE (up to $14 \%$ of the total number of Romanian credit institutions). The foreign currency loans continue to represent approximately $45 \%$ of total loans registered in Romania. An uncontrolled transaction of the exposure of RON to foreign currencies could have dramatic consequences on the situation of the foreign currency of the country and on the stability of the banking sector. The volatility of exchange rates, combined with the impact of the continued cutting of the workforce in Romania, along with the over-indebtedness of a significant part of the population, contribute to a growth of the causes for concern of the customers and the disturbance of the market, generating supplementary legislative and administrative pressure on the banks. In order to rectify the situation, during the last two years, Romanian banks have made new efforts in financial education and, supported by new regulations, mainly changed their position related to RON. The negative effects of COVID-19 on the Romanian economy are associated with expectations of increasing the probability of default in the real sector, as well as expectations of moderation of lending activity. In addition, the risk regarding uncertain and unpredictable legislative framework in the Romanian financial-banking field remains high, having the potential to put pressure on bank solvency and to limit access to the financing of potential borrowers.

The econometric analysis of the empirical causes of the NPL rate presented in this paper shows that the RON/CHF exchange rate has been the main factor in increasing the NPL ratio in the last 5 years in Romania. The coefficient of this explanatory variable is high from an economic point of view, proving that excessive credit in Swiss francs in the period 2006-2008 has significantly affected financial stability. High levels of NPLs are a legacy of the 2008 crisis.

The literature shows that the level of nonperforming loans must be at a low a level as possible because it affects the profitability of banks. For this aspect to become achievable, bank institutions 
must approach a prudent credit policy and create a connected environment between the present economic-financial context and the aspects related to the classification of risk.

Sustainable development needs to be applied in all the fields of activity, including the banking sector. Referring to the present context in the development of the credit system, we can easily observe the fact that credit operations are profitable and risky at the same time. In relation to international experience before the world crisis and to European experience in the recent past, we observed that a global strategy is more efficient in order to solve nonperforming loans. A multilateral strategy for solving nonpayment in the European bank system could combine more attentive supervision, institutional reforms for insolvency and the expansion of markets for the debts in difficulty. These measures need to be supported by an exchange of the fiscal regime and by reforms for the improvement of the access to information.

The problem of nonperforming loans is serious, and the recommended measures need to be applied as soon as possible. Some measures, such as stricter supervision, can be immediately implemented. Other measures, as the judicial reforms and the development of market infrastructure, will take more time to be implemented. As a result of our analysis performed on a period of ten years, 2009 to 2019, we can observe a series of transformations that have taken place in the evolution of nonperforming loans. The greatest challenge in fulfilling of the objectives of the sustainable development of banks is represented, on the one hand, by the understanding of the concept in relation to the business field, and, on the other hand, by the exclusive placement of sustainability within the exclusive responsibility of NGOs and governments. There is a need to understand that bank responsibility does not mean only philanthropic actions and sponsorships; there is more to it. The international bank community has proven, through the examples to be followed, that it understands the importance, necessity and reliability of sustainable development.

The limits of the present research refer to the focus on the influence of macroeconomic factors on the NPL rate without including nonspecific factors, such as the degree of implementation of e-banking (meaning internet banking and mobile banking), perceived value, and green credit policy.

The further directions of research may consist of studying the influence of some less quantifiable factors on the NPL rate, such as trust in banks, the e-banking system, ecological lending, and studying the competitive advantage of the Romanian banks entering into new business niches connected with sustainable development or integrating sustainable development into the banking sector.

Author Contributions: Conceptualization, T.H.; methodology, N.B.-M. and D.W.; validation, I.C.I. and D.W.; formal analysis, I.C.I. and N.B.-M.; investigation, I.C.I. and T.H.; resources, N.B.-M.; writing-original draft preparation, D.W., writing-review and editing, N.B.-M., D.W., and I.C.I. All authors have read and agreed to the published version of the manuscript.

Funding: This work was funded by the project "Excellence, Performance and Competitiveness in Research, Development and Innovation Activities at "Dunarea de Jos" University of Galati" ("EXPERT"), financed by the Romanian Ministry of Research and Innovation in the framework of Programme 1-Development of the National Research and Development System, subprogramme 1.2-Institutional Performance-Projects for Financing Excellence in Research, Development and Innovation, Contract no. 14PFE/17.10.2018.

Acknowledgments: This work was supported by the project "Excellence, Performance and Competitiveness in Research, Development and Innovation Activities at "Dunarea de Jos" University of Galati" ("EXPERT"), financed by the Romanian Ministry of Research and Innovation in the framework of Programme 1-Development of the National Research and Development System, subprogramme 1.2-Institutional Performance-Projects for Financing Excellence in Research, Development and Innovation, Contract no. 14PFE/17.10.2018. We also sincerely thank the anonymous reviewers and editors for their valuable comments and suggestions.

Conflicts of Interest: The authors declare no conflict of interest.

\section{References}

1. Cingolani, M. Finance Capitalism: A Look at the European Financial Accounts. Panoeconomicus 2013, 60, 249-290. [CrossRef]

2. Panopoulou, M. Technological Change and Corporate Strategy in the Greek Banking Industry; Center of Planning and Economic Research: Athens, Greece, 2005. 
3. Rinaldi, L.; Sanchis-Arellano, A. Household Debt Sustainability, What Explains Household Non-Performing Loans? An Empirical Analysis; Working Paper Series 570; European Central Bank: Frankfurt, France, 2006.

4. Bernanke, B.; Gertler, M. Agency Costs, Net Worth, and Business Fluctuations. Am. Econ. Rev. 1989, 79, $14-31$.

5. Bernanke, B.; Gertler, M.; Gilchrist, S. The Financial Accelerator in a Quantitative Business Cycle Framework; Working Paper No. 6455; NBER: Cambridge, MA, USA, 1998.

6. Kiyotaki, N.; Moore, J. Credit chains. J. Political Econ. 1997, 105, 211-248. [CrossRef]

7. Salas, V.; Saurina, J. Credit risk in two institutional regimes: Spanish commercial and savings banks. J. Financ. Serv. Res. 2002, 22, 203-224. Available online: https://link.springer.com/article/10.1023/A:1019781109676 (accessed on 17 May 2020). [CrossRef]

8. Fernandez de Lis, S.; Martinez Pagés, J.; Saurina, J. Credit Growth, Problem Loans and Credit Risk Provisioning in Spain; Banco de Espana Working Paper 18; Bank of Spain: Madrid, Spain, 2000.

9. Boudriga, A.; Taktak, N.; Jellouli, J. Bank Specific, Business and Institutional Environment Determinants of Nonperforming Loans: Evidence from MENA Countries. In Proceedings of the Economic Research Forum 16th Annual Conference, Cairo, Egypt, 9 January 2009.

10. Espinoza, R.A.; Prasad, A. Nonperforming Loans in the GCC Banking System and Their Macroeconomic Effects; Working Paper WP/10/224; International Monetary Fund: Washington, DC, USA, 2010.

11. Nkusu, M. Non-Performing Loans and Macrofinancial Vulnerabilities in Advanced Economies; WP/11/161, IMF Working Papers; IMF: Washington, DC, USA, 2011.

12. Gonzales-Hermosillo, B. Developing indicators to provide early warnings of banking crises. Financ. Dev. 1999, 36, 36-39.

13. Barseghyan, L. Non-performing loans, prospective bailouts, and Japan's slowdown. J. Monet. Econ. 2010, 57, 873-890. [CrossRef]

14. Zeng, S. Bank Non-Performing Loans (NPLS): A Dynamic Model and Analysis in China. Mod. Econ. 2012, 3, 100-110. [CrossRef]

15. Babouček, I.; Jančar, M. Effects of Macroeconomic Shocks to the Quality of the Aggregate Loan Portfolio; Working Paper Series, No. 1; Czech National Bank: Praha, Czech, 2005.

16. Hoggarth, G.; Logan, A.; Zicchino, L. Macro Stress Tests of UK Banks; BIS papers, No. 22; BIS: Basel, Switzerland, 2005.

17. Louzis, D.P.; Vouldis, A.T.; Metaxas, V.L. Macroeconomic and bank-specific determinants of non-performing loans in Greece: A comparative study of mortgage, business and consumer loan portfolios. J. Bank. Financ. 2012, 36, 1012-1027. [CrossRef]

18. Vogiazas, S.; Nikolaidou, E. Investigating the Determinants of Nonperforming Loans in the Romanian Banking System: An Empirical Study with Reference to the Greek Crisis. Econ. Res. Int. 2011, 2011, 1-13. [CrossRef]

19. Ghosh, A. Banking-industry specific and regional economic determinants of non-performing loans: Evidence from US states. J. Financ. Stab. 2015, 20, 93-104. [CrossRef]

20. Beck, R.; Jakubik, P.; Piloiu, A. Key Determinants of Non-performing Loans: New Evidence from a Global Sample. Open Econ. Rev. 2015, 26, 525-550. [CrossRef]

21. Salas, V.; Saurina, J. Deregulation, market power and risk behaviour in Spanish banks. Eur. Econ. Rev. 2003, 47, 1061-1075. [CrossRef]

22. Dvouletý, O. Effects of soft loans and credit guarantees on performance of supported firms: Evidence from the Czech Public Program START. Sustainability 2017, 9, 2293. [CrossRef]

23. Gemar, P.; Gemar, G.; Guzman-Parra, V. Modeling the sustainability of bank profitability using partial least squares. Sustainability 2019, 11, 4950. [CrossRef]

24. Bofondi, M.; Ropele, T. Macroeconomic Determinants of Bad Loans: Evidence from Italian Banks; Questioni di Economia e Finanza (Occasional Papers) No 89; Bank of Italy: Rome, Italy, 2011. Available online: https://www. bancaditalia.it/pubblicazioni/qef/2011_0089/index.html?com.dotmarketing.htmlpage.language=1 (accessed on 3 June 2020).

25. Jiménez, G.; Salas, V.; Saurina, J. Determinants of collateral. J. Financ. Econ. 2006, 81, 255-281. [CrossRef]

26. Saba, I.; Kouser, R.; Azeem, M. Determinants of Non-Performing Loans: Case of US Banking Sector. Rom. Econ. J. 2012, 15, 125-136. 
27. Bock, R.; Demyanets, A. Bank Asset Quality in Emerging Markets: Determinants and Spillovers; Working Paper 12/71; IMF: Washington, DC, USA, 2012. Available online: https://www.imf.org/ \{\}/media/Websites/IMF/ imported-full-text-pdf/external/pubs/ft/wp/2012/_wp1271.ashx (accessed on 3 June 2020).

28. Gerlach, S.; Peng, W.; Shu, C. Macroeconomic Conditions and Banking Performance in Hong Kong SAR: A Panel Data Study; BIS papers No. 22; Bank for International Settlements: Basel, Switzerland, 2005. Available online: https://www.bis.org/publ/bppdf/bispap22x.pdf (accessed on 3 June 2020).

29. Klein, N. Non-Performing Loans in CESEE: Determinants and Impact on Macroeconomic Performance; IMF Working Paper (P/13/72); IMF European Department: Pairs, France, 2013. Available online: https://www.imf.org/en/Publications/WP/Issues/2016/12/31/Non-Performing-Loans-in-CESEEDeterminants-and-Impact-on-Macroeconomic-Performance-40413 (accessed on 17 May 2020).

30. Abid, L.; Ouertani, M.N.; Zouari-Ghorbel, S. Macroeconomic and Bank-specific Determinants of Household's Non-performing Loans in Tunisia: A Dynamic Panel Data. Procedia Econ. Financ. 2014, 13, 58-68. [CrossRef]

31. Ginevičius, R. Determining market concentration. J. Bus. Econ. Manag. 2007, 8, 3-10. [CrossRef]

32. Rehman, R.U.; Zhang, J.; Ahmad, M.I. Political system of a country and its non-performing loans: A case of emerging markets. Int. J. Bus. Perform. Manag. 2016, 17, 241. [CrossRef]

33. Chaibi, H.; Ftiti, Z. Credit risk determinants: Evidence from a cross-country study. Res. Int. Bus. Financ. 2015, 33, 1-16. [CrossRef]

34. Quagliariello, M. Banks' riskiness over the business cycle: A panel analysis on Italian intermediaries. Appl. Financ. Econ. 2007, 17, 119-138. [CrossRef]

35. Anastasiou, D.; Bragoudakis, Z.; Malandrakis, I. Non-Performing Loans, Governance Indicators and Systemic Liquidity Risk: Evidence from Greece. SSRN Electron. J. 2019. [CrossRef]

36. Vuslat, U. The Determinants of Nonperforming Loans before and After the Crisis: Challenges and Policy Implications for Turkish Banks. Emerg. Mark. Financ. Trade 2017, 54, 1-15. [CrossRef]

37. Beck, T.; Demirgüç-Kunt, A.; Levine, R. Bank concentration, competition, and crises: First results. J. Bank. Financ. 2006, 30, 1581-1603. [CrossRef]

38. Çifter, A. Bank concentration and non-performing loans in Central and Eastern European countries. J. Bus. Econ. Manag. 2015, 16, 117-137. [CrossRef]

39. Ahn, S.J.; Lee, S.H. The Effect of Consumers' Perceived Value on Acceptance of an Internet-Only Bank Service. Sustainability 2019, 11, 4599. [CrossRef]

40. Cui, Y.; Geobey, S.; Weber, O.; Lin, H. The impact of green lending on credit risk in China. Sustainability 2018, 10, 2008. [CrossRef]

41. Demirgüç-Kunt, A.; Huizinga, H. Determinants of commercial bank interest margins and profitability: Some international evidence. World Bank Econ. Rev. 1999, 13, 379-408. [CrossRef]

42. Berger, A.; DeYoung, R. Problem loans and cost efficiency in commercial banks. J. Bank. Financ. 1997, 21, 849-870. Available online: https://www.sciencedirect.com/science/article/pii/S0378426697000034 (accessed on 18 June 2020). [CrossRef]

43. Tesfaye, T. Determinants of Banks Liquidity and Their Impact on Financial Performance: Empirical Study on Commercial Banks in Ethiopia. Ph.D. Thesis, Addis Ababa University, Addis Ababa, Ethiopia, 2012.

44. Erdinc, D.; Abazi, E. The Determinants of NPLs in Emerging Europe, 2000-2011. J. Econ. Political Econ. 2014, 1, 112-125.

45. Boyd, J.; Levine, R.; Smith, B. The impact of inflation on financial market performance. J. Monet. Econ. 2001, 47, 221-248. [CrossRef]

46. Farhan, M.; Sattar, A.; Chaudhry, A.; Khalil, F. Economic Determinants of Non-Performing Loans: Perception of Pakistani Bankers. Eur. J. Bus. Manag. 2012, 4, 87-99.

47. Popa, I.D.; Cepoia, C.O.; Anghela, D.G. Liquidity-threshold effect in non-performing loans. Financ. Res. Lett. 2018, 27, 124-128. [CrossRef]

48. Makri, V.; Tsagkanos, A.; Bellas, A. Determinants of non-Performing loans: The case of eurozone. Panoeconomicus 2014, 2, 193-206. [CrossRef]

49. Messai, A.; Jouini, F. Micro and macro determinants of non-performing loans. Int. J. Econ. Financ. Issues 2013, 3, 852-860.

50. Skarica, B. Determinants of non-performing loans in Central and Eastern European countries. Financ. Theory Pract. 2014, 38, 37-59. [CrossRef] 
51. Anastasiou, D.; Louri, H.; Tsionas, M. Determinants of non-performing loans: Evidence from Euro-area countries. Financ. Res. Lett. 2016, 18, 116-119.

52. Charalambakis, E.; Dendramis, Y.; Tzavalis, E. On the Determinants of NPLs: Lessons from Greece; Working Paper; Bank of Greece: Athens, Greece, 2017; ISSN 1109-6691.

53. Donath, L.; Cerna, V.; Oprea, I. Macroeconomic determinants of bad loans in Baltic countries and Romania. SEA Pract. Appl. Sci. 2014, 4, 71-80.

(C) 2020 by the authors. Licensee MDPI, Basel, Switzerland. This article is an open access article distributed under the terms and conditions of the Creative Commons Attribution (CC BY) license (http://creativecommons.org/licenses/by/4.0/). 



\title{
The Effect of Emotional Intelligence on Turnover Intention and the Moderating Role of Perceived Organizational Support: Evidence from the Banking Industry of Vietnam
}

\author{
Ha Nam Khanh Giao ${ }^{1}$, Bui Nhat Vuong ${ }^{1, *}$, Dao Duy Huan ${ }^{2}$, Hasanuzzaman Tushar ${ }^{3}$ and \\ Tran Nhu Quan ${ }^{4}$ \\ 1 Faculty of Air Transport, Vietnam Aviation Academy, Ho Chi Minh City 700000, Vietnam; \\ khanhgiaohn@yahoo.com \\ 2 Vice Rector of Nam Can Tho University, Can Tho 94000, Vietnam; ddhuan51@yahoo.com.vn \\ 3 College of Business Administration, International University of Business Agriculture and Technology, \\ Dhaka 1230,Bangladesh; tushar@iubat.edu \\ 4 Nida Business School-National Institute of Development Administration, Bangkok 10240, Thailand; \\ quantrannhu@gmail.com \\ * Correspondence: nhatvuonga1@gmail.com
}

Received: 17 January 2020; Accepted: 27 February 2020; Published: 1 March 2020

\begin{abstract}
The objective of this study is to investigate the impact of emotional intelligence on turnover intention, noting the mediating roles of work-family conflict and job burnout as well as the moderating effect of perceived organizational support. Survey data collected from 722 employees at banks in Vietnam was analyzed to provide evidence. Results from the partial least squares structural equation modeling (PLS-SEM) using the SmartPLS 3.0 program indicated that there was a negative effect of emotional intelligence on employees' turnover intention; this was mediated partially through work-family conflict and job burnout. Besides, this study indicated that perceived organizational support could decrease work-family conflict, job burnout and turnover intention of employees. It could also moderate the relationship between emotional intelligence and work-family conflict. This negative relationship was stronger for employees who work in a supportive environment. The main findings of this research provided some empirical implications for the Vietnamese banking industry. It implied that organizations in the service industry should try to improve their employees' work-family balance, reduce job burnout and take advantage of these emotional balances and supportive environments to create beneficial outcomes.
\end{abstract}

Keywords: emotional intelligence; work-family conflict; job burnout; employees' turnover intention; perceived organizational support; the Vietnamese banking industry

\section{Introduction}

In recent years, the notion of turnover intention has become a central attraction of research in various fields of managerial disciplines, therefore, prompting more and more executives/managers in different business sectors to take this concept into consideration to effectively manage their employees [1]. Employee turnover can have a variety of negative effects on organizations. For example, according to Allen et al. [2], replacing an employee can cost more than a year's salary for the position being filled. Hausknecht and Trevor [3] noted that turnover results in the loss of both social and human capital. In human services organizations, those negative effects can extend to the clients and the organization it serves. In the 21st century, the concept of job turnover intention is considered as a key concept in management for a successful career of an employee and business survival at all levels, 
predominantly in the service industry $[4,5]$. The particular characteristic of a service industry is "the contact and interaction between service providers (employees) and service acceptors (customers)" that infers that employees in the service industry have become a part of service products. Being a service ambassador, employees play an important role to satisfy customers with proper services. Therefore, understanding employees' emotions and feelings toward work is another recent concern that organizations are struggling to manage. The issue, then, is how individual employees manage their emotions effectively and lessen job turnover intention. Judeh [6] stated that emotional intelligence is a significant factor in interpreting and analyzing human behavior at work. Most successful service organizations understand their people's feelings and always have special concerns about any issues that may threaten the employees. However, it is broadly termed emotional intelligence (EQ) that enables an employee to work together with others toward achieving a common goal. In addition, emotional intelligence will enhance employees' suitable emotions in fulfilling customers' expectations that help to form a positive image of the organization $[4,7]$.

Since joining the World Trade Organization (WTO) in 2007, Vietnam has taken part in significant economic growth in the last decade due to the improvement of the business environment and the high volume of foreign investments. Along with the achievement in the economy, the Vietnamese banking industry has also seen outstanding enlargement and development in terms of scale and service quality [8]. However, the increases in competition and financial innovation have led to extremely rapid expansion which has resulted in banking system problems in the past few years. Eventually, the government-initiated project 254 called "restructuring credit institutions system 2011-2015" was implemented by the Prime Minister in 2012. In response, the State Bank of Vietnam has pushed the commercial banks to merge with the project goal and reduce half of the number of banks. In such an unfavorable condition, employees in this sector have experienced a considerable fluctuation with the highest average voluntary turnover rate compared to other service sectors. As of 2019, the turnover rate was more than $25 \%$ each year [9] and $81 \%$ for turnover intention [10]. Restructuring the banking sector caused not only workforce transition among banks, but also between banking and non-banking sectors. High turnover can lead to compromised client care and increased organizational costs [11]. Service organizations, such as the banking industry, have an added burden with turnover given that they foster individual relationships between their counselors and their clients. When an employee leaves such an organization, a personal relationship with clients is broken. Moreover, the bank incurs the expense of finding and training new employees, and clients can suffer due to discontinuity of care [12]. Additionally, turnover results in decreased efficiency in carrying out job-related responsibilities [13]. Implementing new strategies and achieving organizational goals is hampered by high employee turnover [12]. Consequently, keeping intellectual capital for organizations is a crucial strategy for maintaining sustainable development.

With an increasing interest in employee turnover intention, numerous researches have been conducted to find out the predictors of employee turnover intention and discovered several factors including emotional intelligence (e.g., [14]), work-life conflict (e.g., [15]), job burnout (e.g., [16]), and a few others (e.g., $[14,16])$. Research has shown that emotional intelligence helps the employees to have control of their emotions and to understand the use of social skills that are helpful to the organization [17]. Emotional intelligence in individuals who lead can help organizations to reduce turnover intentions and retain valuable employees [18]. Avey et al. [19] asserted that emotional intelligence is one of the key factors that affect the turnover intention of an employee among other factors. Besides, prior studies have also confirmed that emotional intelligence strongly affects employees who intend to leave their jobs by causing work-family conflict [20] and job burnout [16]. In general, people's emotions change quickly based on the challenges in the workplace and also in family life. The work-family balance will enhance their suitable emotions in responding to customers' expectations that help to form a positive image of their organizations [7]. Hence, understanding an employee's emotions and feelings is a crucial issue for both employees and the organization in the service industry. Moreover, employees are among a company's most valuable assets. Therefore, employers need to understand burnout and its 
causes. Lu and Gursoy [16] pointed out that burnout is one of the best predictors of turnover intention because employees in customer service-based industries have to deal with customer demands, so they are at high risk for job burnout. They also noted that burnout is costly for organizations on two fronts, not only leading to higher turnover rates but also decreasing worker productivity.

Additionally, although there are tangible factors in work environments that have been described as antecedents to work-family conflict and job burnout, theory and empirical findings indicate that the nature of the work environment as sensed by the worker, that is, perceived organizational support, may be an important determinant of work-family conflict and job burnout in employees who work in the banking industry. Perceived organizational support refers to the general belief by an employee that support will be readily available from the organization when stressful situations arise and urgent needs are addressed [21]. Theorists posit that the availability of material aid and emotional support may reduce aversive psychological and psychosomatic reactions (e.g., emotional exhaustion) when stressful situations arise [22]. In supportive work environments, employees treat each other with fairness and respect and engage in effective open communication. These characteristics contribute to win-win solutions for the employee and the organization [21]. Thus, it is plausible that employees who perceive their work environments as supportive will experience work-family conflict and job burnout, and, conversely, bankers who perceive their work environments as unsupportive will experience more job burnout and work-family conflict.

In developed countries, much research has been conducted about the perceptions of subordinates in terms of emotional intelligence, perceived organizational support, work-family conflict, job burnout, and employee turnover intention and their significant mutual relationships [20,23], however, this topic has yet to receive considerable attention from scholars in developing or less developed countries, particularly in Vietnam. An extensive literature review informed that there has been no research conducted to examine the relationship between emotional intelligence and turnover intention of employees in Vietnamese organizations. Moreover, there is no empirical evidence that confirms the relationships of emotional intelligence, perceived organizational support, work-family conflict, job burnout, and turnover intention in one model. Specific to the financial sector, a banker with high emotional intelligence would perform effectively at enhancing customer enthusiasm and reducing customer frustration [24]. So, the need for understanding employee emotional intelligence is strongly considered in this research. Therefore, these twofold gaps have led the researchers to conduct this research to examine the mutual effects of emotional intelligence and perceived organizational support on work-family conflict and job burnout and subsequently explore its impact on the turnover intention of bankers in Vietnamese commercial banks. Besides, the moderating role of perceived organizational support on these relationships will be considered as well.

\section{Literature Review}

\subsection{Emotional Intelligence}

The Emotional Intelligence theory of Bar-On was first introduced in 1985 and was followed by a series of other subsequent developed versions (e.g., [25,26]). Emotional intelligence was found as having an important role in both building and maintaining successful social relationships, predicting specific aspects of situations involving social exchange, and it will either foster or hamper this exchange process [27]. Salovey and Mayer [28] stated that emotional intelligence is "the subset of social intelligence that involves the ability to monitor one's own and others' feelings and emotions, to discriminate among them and to use this information to one's thinking and actions". Besides, Ravichandran et al. [29] defined emotional intelligence as "the ability to recognize, understand, and assess one's own feelings as well as others and use this knowledge in thought and action". In line with this definition, Serrat [30] indicated that "emotional intelligence describes the ability, capacity, skill, or self-perceived ability to identify, assess, and manage the emotions of one's self, of others, and of groups". Possessing high emotional intelligence enables an individual employee to be more 
productive, optimistic, and resilient in both work and family life [31]. Mayer and Salovey [25] have established the scope of emotional intelligence into four dimensions including:

(1) The self-emotions appraisal (SEA): This dimension reflects the ability of a person to understand his/her own emotions and be able to express them properly, then apply the knowledge of those emotions to create beneficial outcomes.

(2) The other emotions appraisal (OEA): This component assesses the ability of an individual to observe and understand other's emotions. A person who has high capability in this dimension will be able to observe other people's emotions and predict other's emotional reactions;

(3) The use of emotion (UOE): This aspect evaluates the ability of an individual to access, generate and use his/her emotions to facilitate personal performance. People who rate highly in this ability will be able to return rapidly to normal psychological states after suffering depression or feeling upset;

(4) The regulation of emotion ( $R O E$ ): This dimension mentions the ability of an individual to regulate his/her emotions to achieve an expected outcome and be able to remain balanced from psychological distress to solve problems.

\subsection{Turnover Intention}

Turnover intention is defined when an individual intends to leave their organization [32,33]. It is inevitable that turnover occurs in every organization in which some of the employees voluntarily leave the organization while others are discharged by the organization. Turnover is classified into two types, i.e., voluntary and involuntary turnover [34]. First, voluntary turnover happens when employees are not fulfilled with their current job and are ready to look for another job in another place. In other words, it is called turnover intention that refers to the desire to voluntarily leave an organization. Second, involuntary turnover happens when employees are fired by their organization. Either voluntary turnover or involuntary turnover creates serious consequences for the organization in today's business world including a number of difficulties in finding a replacement, recruitment, selection, training and development, socialization cost, and perception of service quality by customers $[33,35,36]$. Turnover intention involves a sequence of the process, thinking of leaving, intentions to search, and to leave [37]. Several researchers (e.g., [38,39]) also stated that turnover intention is one of the best predictors of employees' actual quitting.

\subsection{Work-Family Conflict}

The work-family conflict (WFC) refers to an incompatible demand that an individual employee faces difficulty in participating in both work and family roles [40]. Family and work are the inseparable two central areas of an adult's life [41,42]. Both sides assist to shape peoples' roles and define their identity. Greenhaus and Beutell [43] stated that work-family conflict arises from the "simultaneous pressures from both roles which indicate that the relationship between them is a reciprocal one". Disruptive events in either arena may have serious consequences for the individual and the conflict is bi-directional between work and family roles [44]. In other words, conflict on one side will have an impact on the other side, i.e., work stress causes family conflict (WFC) and family stress causes work conflict (FWC). In line with this notion, Boyar et al. [45] also conceptualized work-family conflict into two facets that include "work interfering with family (WIF) and family interfering with work $($ FIW)". Choi and Kim [46] posited that WIF appears when employees' experience at work interferes with their family lives. Conversely, FIW occurs when employees experience stress in family events that interfere with their work-life [47]. Bande, Fernández-Ferrín, Varela, and Jaramillo [23] argued that they are more common and closely associated with job satisfaction, exhaustion, and turnover intention. Moreover, Demerouti et al. [48] propositioned that work-family conflict is a crucial factor that causes job burnout. This can lead to absenteeism and increased turnover intention of an employee [49]. 


\subsection{Job Burnout}

While most people are aware of burnout, there is no specific, generally agreed definition of the term, leaving it to be defined differently in the literature over the years. Freudenberg [50], who is credited with coining the term job burnout, defined it as occurring when a person becomes psychologically worn out and exhausted due to excessive demand that could be internally or externally imposed. Pines et al. [51] viewed burnout as resulting from work tedium where the employee felt distressed and discontented with the job. In the end, the employee experienced a feeling of being emotionally and physically depleted from work. Kahn [52] viewed burnout as a syndrome of negative attitudes towards others and self, which then resulted in negative psychological and physical exhaustion for the person.

Maslach and Jackson [53] defined burnout as "a syndrome of emotional exhaustion and cynicism that occurs frequently among individuals who do people-work of some kind". Burnout is described as consisting of three aspects: emotional exhaustion, depersonalization, and reduced personal accomplishment. Firstly, emotional exhaustion is obtained when staff members feel severe emotional fatigue and feel diminished or have no ambition to work. Secondly, depersonalization is accomplished when employees get away from work and indicate an indifferent and callous attitude at firms. Lastly, reduced personal accomplishment is attained when people feel a lack of competence and successful work accomplishment. According to Maslach et al. [54], burnout has been known to lead to poor physical health. Psychological symptoms can occur, such as negative self-concept, perfectionism, irritability, feeling of being unappreciated, and depression [55].

\section{Hypotheses}

\subsection{Emotional Intelligence and Turnover Intention}

Raza et al. [56] stated that employees' emotional intelligence not only decreases frustration and stress in the workplace but also helps others to have less intention to quit. Optimistic emotions are influential from an individual perception and are indicative of cooperation and fairness within the organization [57]. Pessimistic emotions have negative effects on the organization as well as individuals. Those individuals who are upset have difficulty in assessing others' emotions accurately [58]. Emotional stress results in a lack of confidence, self-esteem, or motivation to reflect these limits. Employees tend to focus more on these negative emotions than they do their work and become disconnected physically and mentally, which results in underperformance and high turnover intention [59]. Emotional intelligence may be a key component to keep employees engaged and understand the emotional reasons for leaving decisions. Employees may use their emotional intelligence to better assess and understand the situation. Thus, emotional intelligence is considered a significant factor in predicting the turnover intention of employees which leads towards actual turnover [60]. There are several proposed theories that support a positive relationship between emotional intelligence and turnover intention: human capital theory, attraction-selection-attrition theory, and job embeddedness theory [61]. As employees continue to work for the same company, they become increasingly motivated to perform well; and, as their interests increasingly align with the company's values, their chances of leaving the company decrease [61]. Prior researches demonstrated a negative association between emotional intelligence and employees' turnover intention $[60,62]$. They stated that employees with higher emotional intelligence have very low intentions to quit. Based on the literature it is hypothesized that:

\section{Hypothesis 1: Emotional intelligence will reduce the turnover intention of bankers.}

\subsection{Emotional Intelligence and Work-Family Conflict}

Emotional intelligence and work-family conflict are two fundamental aspects of service organizations [63]. Both the organization and its employees are responsible for eliminating work-family conflict. Companies have their own policies and procedures to help their staff manage stress, but their employees still burn out. Certainly, individuals hold some responsibilities for regulating their own 
family balance, but they need organizational support. Organizations need to recognize and adapt employees' work and lives to win employee loyalty [64]. According to the content of resource theory, Hobfoll [65] has identified individual differences as resources causing the negative impacts of stressful events on individuals. Individuals who have more personal resources can deal with the loss of other kinds of resources, including resource loss caused by work-family conflict. "Emotional intelligence represents individual differences in the ability and capacity to monitor and recognize one's own and other's emotions and to use this information to regulate one's emotions and actions" [66]. Concerning the role of individuals, researchers have emphasized emotional intelligence is an essential factor in protecting employees from the beginning of the work-family conflict and stress to identify, acknowledge, and manage the emotions. Particularly, Suliman and Al-Shaikh [67] stated that in terms of conflict management, employees with an inflated level of emotional intelligence tended to have effective control with conflict. Indeed, people with high-ability of emotional intelligence tended to suffer less work-family conflict [63]. Accordingly, the following hypothesis is proposed:

Hypothesis 2: Emotional intelligence will reduce the work-family conflict of bankers.

\subsection{Work-Family Conflict and Turnover Intention}

Over the past several years, many researchers have believed that when experiencing work-family conflict, employees have a tendency to quit their job to eliminate the conflict. Employees may leave an organization because of the high stress of being overworked and limited personal time available to spend away from the office [68,69]. They do not want to choose between their personal lives and work, and, if they must, they will choose their personal lives. Employees leave when organizational rules are the cause of intolerable family stress and conflicts [68,69]. Greenhaus et al. [70] proved that being disappointed with family, work, and life leads to withdrawing from work. These studies demonstrated that when job-related retention grows too strong in the organization, one solution that employees can choose is to leave their firms. Allen and Armstrong [71] suggested that work-family conflict may cause employees to leave their jobs because the demands of work lead to frustration in the workplace and the strain from work makes it difficult to fulfill family duties. Employees took the emotions felt in the workplace home, as a result, they find it hard to concentrate on tasks. Similarly, some previous researchers examined and found that WFC has a significant effect on turnover intention $[33,44,45]$. Based on the foregoing review and previous research, it is hypothesized that:

Hypothesis 3: Work-family conflict will increase the turnover intention of bankers.

\subsection{Emotional Intelligence and Job Burnout}

It has been suggested that emotional intelligence enables individuals to control pressure and adapt easily with the challenge to avoid burnout [72]. In relation to job burnout, people who have elevated levels of emotional intelligence deal better with life's challenges and job stresses, which leads to good psychological and physical health [72] and makes them less likely to experience job burnout [73]. The fourth dimension of emotional intelligence enables a person to regulate their emotions quickly and work on emotive information effectively [74]. Regarding this matter, the emotionally intelligent individual helps employees choose appropriate approaches to cope with frustration and make a response more effectively relating to the emotional aspect. Employees with high levels of emotional intelligence can keep away from dysfunctional and angry emotions that would be a consequence of burnout [64]. Individuals with high-ability to manage their emotions would be less likely to experience burnout. Therefore, it could be hypothesized that:

Hypothesis 4: Emotional intelligence will reduce job burnout. 


\subsection{Work-Family Conflict and Job Burnout}

The impact of the work-family conflict was investigated and the findings showed that work-family conflict was strongly influenced by lower job and family satisfaction, greater stress, and higher turnover intention [75]. Experiencing work-family conflict, individuals are subject to burnout that leads to the consequence of a conflict between work and family domains, which seems to result in draining their emotional and physical energy [23,76]. According to Hobfoll [65] in his conservation of resource theory, energy and time are resources that people attempt to maintain, protect, and create. In addition, "during recovery periods when not confronted with an immediate need for resources, individuals attempt to recover and stockpile resources to counter future losses" [76]. Hobfoll [65] perceived that work-family conflict expends an individual's energy and other sources and keeps them from "resource stockpiling" which is likely necessary to fend off other current and future resource demands. For this reason, individuals tend to suffer higher levels of burnout. People with a high level of work-family conflict are susceptible to burnout because conflicts inhibit individuals from accomplishing their work and family obligations. Consequently, work-family conflict could cause job burnout. Thus, the following hypothesis is presented:

Hypothesis 5: Work-family conflict will increase job burnout.

\subsection{Job Burnout and Turnover Intention}

Many researchers have found that job burnout is strongly associated with turnover intention $[77,78]$. Similarly, according to Layne et al. [79], the turnover intention corresponds with stress. Employees with a high level of stress are more likely to leave their organization and seek another opportunity. In addition, burnout will result in lower rates of organizational commitment and higher rates of turnover and turnover intention [80]. Hence, an employee experiencing a higher level of burnout results in a higher level of turnover intentions. Therefore, the following relationship is hypothesized:

Hypothesis 6: Job burnout will increase turnover intention.

\subsection{The Mediating Role of Work-Family Conflict and Job Burnout}

Basically, emotional intelligence is the ability to understand and to regulate one's own emotions effectively, as well as to apply these abilities to help achieve desired outcomes [81]. Normally, people who have high emotional intelligence tend to have good control over their emotions. They won't let negative emotions affect their life, work, and relationship with others. Rather, they know how to use their knowledge about emotions to enhance their interpersonal skills and to help them make good decisions without being affected by emotions. Employees with high emotional intelligence may properly balance the relationship between work and family and reduce job burnout thus resulting in less turnover intention. Previous research revealed the direct relationships between emotional intelligence and work-family conflict, job burnout [82,83], emotional intelligence and employees' turnover intention [60,62,84], work-family conflict, job burnout and employees' turnover intention $[44,60]$. Linking the associations outlined above, the authors argue that work-family conflicts and job burnout are likely to mediate the relationship between emotional intelligence and turnover intention. Based on the foregoing review and previous research, the hypotheses below are proposed:

Hypothesis 7: Work-family conflict mediates the relationship between emotional intelligence and turnover intention of bankers.

Hypothesis 8: Job burnout mediates the relationship between emotional intelligence and turnover intention of bankers. 


\subsection{Perceived Organizational Support}

Perceived organizational support is theoretically defined as the employees' global beliefs about the extent to which the organization values their contributions and cares about their well-being [85]. The individual's perception about the degree to which their organization values their well-being is rooted in the nature of the give-and-take relationship between the workers and their organization [22]. Perceived organizational support theory suggests that when the emotional and social needs of the employee are fulfilled, there are positive outcomes for both the organization and the individual [21,85]. Perceived organizational support is expected to decrease negative psychological and psychosomatic reactions (e.g., burnout) to employees by providing supportive external resources.

According to the theory of perceived organizational support, the employee assigns the organization humanlike characteristics [85]. That is, employees view actions or behaviors by agents of the organizations as actions of the organization itself. Employees view favorable or unfavorable treatment directly by the organization representatives and indirectly through organizational policy as an indication of the extent to which the organization supports them. Employees who believe that their work environment is supportive are more likely to achieve personal and organizational goals, which leads to effectively balancing their work-family. Alternatively, unsupportive work environments foster a win-lose approach [21]. In unsupportive work environments, workers' individual goals are typically incompatible with other workers' goals or even organizational goals so that as one worker moves toward goal attainment, others are less likely to achieve their goals. It is plausible then that the extent to which an organization is perceived to be supportive or non-supportive can influence whether there is a positive outcome for both the employee and the organization and a reduction of work-family conflict as well as job burnout. Perceived organizational support is thought to reduce work-family conflict and job burnout by fostering the perception that material aid and emotional resources will be available when needed to deal with negative situations (e.g., work-family conflict, job burnout, and turnover intention). Besides, some scholars demonstrated that perceived organizational support could decrease work-family conflict (e.g., [86]), job burnout (e.g., [87]), and turnover intention (e.g., [88]). Therefore, the following hypotheses are suggested:

Hypothesis 9: Perceived organizational support reduces the turnover intention of bankers.

Hypothesis 10: Perceived organizational support reduces the work-family conflict of bankers.

Hypothesis 11: Perceived organizational support reduces job burnout of bankers.

\subsection{Moderating Role of Perceived Organizational Support}

Perceived organizational support theorists indicated that perceived organizational support reduces work-family conflict and job burnout because it provides external work environment physical and emotional resources to help employees deal with burnout as well as work-family conflict [86]. Individuals who have high emotional intelligence, work in environments where cooperative (i.e., supportive) values such as fair and respectful treatment of others are supported and are likely to diminish work-family conflict and job burnout [87]. Supportive work environments are characterized by effective open communication, helpfulness, fair and respectful treatment of others, and collaboration to achieve mutual goals leading to win-win solutions [89]. Moreover, the authors state that perceived organizational support could moderate the relationship between emotional intelligence and work-family conflict and job burnout because employees with high emotional intelligence have lower work-family conflict and job burnout levels. However, if the highly emotionally intelligent employees perceived low organizational support, their work-family conflict and job burnout levels could be increased, but if the highly emotionally intelligent employees perceived high organizational support, their work-family conflict and job burnout levels could be decreased as well. Thus, it is plausible that perceived organizational support may moderate or blunt the effects of emotional intelligence leading 
to a decrease in work-family conflict and job burnout. Based on the discussion above, the following hypotheses are proposed:

Hypothesis 12: Perceived organizational support moderates the effect of emotional intelligence on work-family conflict. The negative relationship between EQ and WFC will be stronger for employees who work in a supportive environment.

Hypothesis 13: Perceived organizational support moderates the effect of emotional intelligence on job burnout. The negative relationship between $E Q$ and $J B$ will be stronger for employees who work in a supportive environment.

\subsection{Control Variables}

Some researches (e.g., $[90,91])$ stated that employee demographic variables could be related to turnover intention. For example, Seyrek and Turan [91] argued that "both women and men are confronted with different demands from home, community and workplace in their life and these different groups compete for the person's time and energy. Especially for women, it can be difficult to cope with conflicts arising from playing different roles in workplace and family and this may lead to turnover intention". Although the impacts of individual characteristics of the employee on turnover intentions may differ in different environments, empirical studies in the banking industry context is scanty. Therefore, this study has been conducted exploring control variables (e.g., gender, marital status, age group, income, and educational level) in combination with turnover intention. The following hypotheses can be proposed (Figure 1):

Hypothesis 14: There is a statistically significant relationship between control variables (e.g., gender, marital status, age group, income, and educational level) and turnover intention in the commercial banks of Vietnam.

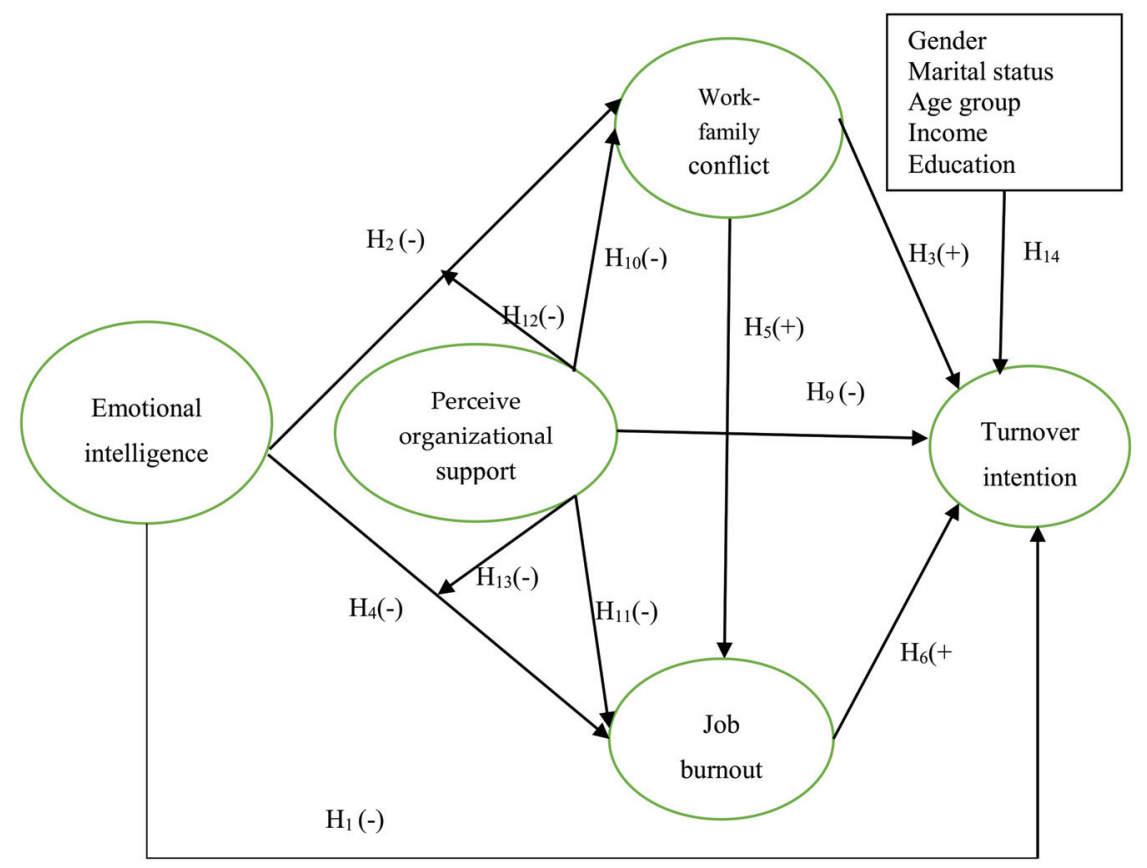

Figure 1. The conceptual model. 


\section{Research Methodology.}

\subsection{Procedure and Sampling Size}

Respondents were the full-time employees of banks in Vietnam. The sample was selected using nonprobability technique-convenience sampling. First of all, the researchers collected a list of commercial banks in Vietnam. Thirty-five commercial banks were chosen to conduct the survey. The researchers contacted the concerned person in charge (i.e., human resource manager) over the phone prior to conducting the survey. The topic and purposes were explained clearly. Ten out of thirty-five banks allowed the researchers to collect data.

Based on the previous studies (e.g., $[74,85,92-94])$, a draft questionnaire was formed. The draft questionnaire was originally developed in the English language. Then the researchers translated the questions into the Vietnamese language and piloted the back-translation with the support of several English language experts. The current study consisted mainly of two stages including qualitative and quantitative research. For qualitative research, the Vietnamese version of the questionnaire was tested by an in-depth interview method in one week with ten employees from three banks to ensure if they understood the questions and revised Vietnamese terms which were unclear due to translation. Based on the comments of respondents, the survey questionnaire was modified properly.

The pilot study was sent to 50 employees working in the Vietnamese banking industry by a convenient method. The participants were asked to provide advice on elements of the survey that were confusing. They also provided recommendations on the wording and any questions they felt uncomfortable answering. Modifications were made to the instrumentation, specifically around grammatical errors and survey logic. The modified instrument was found to be reliable as the minimum Cronbach's Alpha of each factor equals to 0.743 (Table 1). The individual items were deemed to be valid for the research as for each dimension the Cronbach's alpha was above the acceptable threshold of 0.70 and the minimum value of corrected item-total correlation coefficients was higher than 0.3 [95]. Therefore, the reliability of the scales is sufficiently good to test the main survey.

Table 1. The quantitative pilot study analysis of 50 respondents.

\begin{tabular}{cccc}
\hline Variables & $\begin{array}{c}\text { Number of } \\
\text { Items }\end{array}$ & $\begin{array}{c}\text { Cronbach's } \\
\text { Alpha }\end{array}$ & $\begin{array}{c}\text { The Minimum Value of } \\
\text { Corrected Item-Total Correlation }\end{array}$ \\
\hline Self-emotion appraisal & 4 & 0.851 & 0.481 \\
Others' emotion appraisal & 4 & 0.891 & 0.716 \\
Use of emotion & 4 & 0.865 & 0.608 \\
Regulation of emotion & 4 & 0.913 & 0.768 \\
Perceived organizational support & 7 & 0.897 & 0.513 \\
Work interfere with family & 5 & 0.928 & 0.724 \\
Job burnout & 4 & 0.906 & 0.714 \\
Turnover intention & 4 & 0.743 & 0.314 \\
\hline
\end{tabular}

After finishing the main questionnaires, the authors distributed the questionnaires to 10 banks in the chosen sample. A total of 764 completed questionnaires were collected. Among these, 42 questionnaires were found invalid because the respondents answered one choice for all questions. Consequently, there were 722 valid questionnaires usable for further data analysis. Table 2 below shows the diverse information about the demographic profile of respondents. 
Table 2. Statistics description.

\begin{tabular}{|c|c|c|c|}
\hline \multicolumn{2}{|l|}{$N=722$} & \multirow{3}{*}{$\begin{array}{c}\text { Frequency } \\
463 \\
259 \\
\end{array}$} & \multirow{3}{*}{$\begin{array}{c}\text { Percen } \\
64.1 \\
35.9 \\
\end{array}$} \\
\hline & Female & & \\
\hline Gender & Male & & \\
\hline \multirow{2}{*}{ Marital status } & Single & 271 & 37.5 \\
\hline & Married & 451 & 62.5 \\
\hline \multirow{4}{*}{ Age group } & $18-25$ & 140 & 19.4 \\
\hline & $26-35$ & 349 & 48.3 \\
\hline & $36-45$ & 200 & 27.7 \\
\hline & $>45$ & 33 & 4.6 \\
\hline \multirow{4}{*}{ Income ( 1 million $\mathrm{VND} \approx \$ 43.25)$} & Under 10 million VND & 220 & 30.5 \\
\hline & 10-20 million VND & 349 & 48.3 \\
\hline & 20-30 million VND & 117 & 16.2 \\
\hline & Above 30 million VND & 36 & 5.0 \\
\hline \multirow[b]{2}{*}{ Education } & College/University & 581 & 80.5 \\
\hline & Postgraduate & 141 & 19.5 \\
\hline
\end{tabular}

\subsection{Measurement}

All variables in the conceptual model were measured with multiple items, which were developed by prior scholars $[74,85,92-94]$. Particularly, an emotional intelligence scale was measured by 16 items of Wong and Law [74]. Sample items included (Self-emotion appraisal: e.g., "Self-emotion appraisal I have a good sense of why I have certain feelings most of the time"); (Others' emotion appraisal: e.g., "I always know my friends' emotions from their behavior"); (Use of emotion: e.g., "I always set goals for myself and then try my best to achieve them"); (Regulation of emotion: e.g., "I am able to control my temper so that I can handle difficulties rationally"). Perceived organizational support was measured by 7 items of Eisenberger, Huntington, Hutchinson, and Sowa [85]. Sample items for this construct were "The organization really cares about my well-being" and "Help is available from the organization when I have a problem". The work-family conflict scale was measured by 5 items about work interference with family from Netemeyer, Boles, and McMurrian [92]. A sample item for this construct was "The amount of time my job takes up makes it difficult to fulfill family responsibilities". The job burnout scale was measured by 4 items from Lee [93]. Sample items for this construct were "I worry that this job is hardening me emotionally" and "I leave work feeling tired and rundown". Turnover intention scale was measured by 4 items of Vigoda [94]. A sample item for this construct was "Next year I will probably look for a new job outside this organization". All items of these constructs were measured using a 5-point Likert scale ranging from 1 (strongly disagree) to 5 (strongly agree).

\subsection{Partial Least Squares Regression}

The statistical technique chosen to test the stated hypotheses was partial least squares (PLS) path analysis, otherwise known as partial least squares structural equation modeling (PLS-SEM). PLS-SEM is a statistical analysis technique for data exploration within the quantitative research discipline used to measure the observed variables collected from instruments to determine their influence on latent or unobserved variables [96]. Researchers have suggested the use of PLS-SEM due to its effective use as an analysis tool to support prediction models from empirical data [97,98]. Moreover, PLS-SEM is appropriate for analysis when different measurement scales are used in the research model because it allows optimal empirical assessment of a structural model. The use of PLS-SEM data analysis utilizes multi-item observations to measure the area under review as this has shown to be more reliable than using a single-item of observation, as this is shown to provide more accurate reflections on the latent variable. Moreover, PLS-SEM has the capability to calculate p-values through a bootstrapping technique if samples are independent and if the data is not required to be normally distributed $[39,98]$. Therefore, data analysis for this study was performed using PLS-SEM with the SmartPLS 3.0. 


\section{Research Results}

Before performing PLS-SEM estimation for hypotheses testing, the validity and reliability of the multi-item measures should be assessed [99]. Convergent validity is the amount of variance between two or more items that agree when measuring similar constructs and is calculated using factor loadings. Hair, Hult, Ringle, and Sarstedt [98] stated that convergent validity will be suitable when the factor loadings are above 0.5 . In Figure 2, the statistical results showed that all factor loadings were more than the threshold of 0.5. For example, the minimum factor loading for Use of emotion $=0.791$, Regulation of emotion $=0.825$, Self-emotion appraisal $=0.680$, Others' emotion appraisal $=0.834$, Emotional intelligence $=0.609$, Perceived organizational support $=0.632$, Work interference with family $=0.833$, Job burnout $=0.818$, and Turnover intention $=0.604$. Besides, convergent validity will be confirmed when the average variance extracted (AVE) for each of the latent variables is greater than 0.5 [96]. As shown in Table 3 below, AVE values were reported for each of the variables ranging from 0.611 to 0.759 (perceived organizational support and emotional intelligence, respectively). Therefore, all constructs showed good convergent validity.

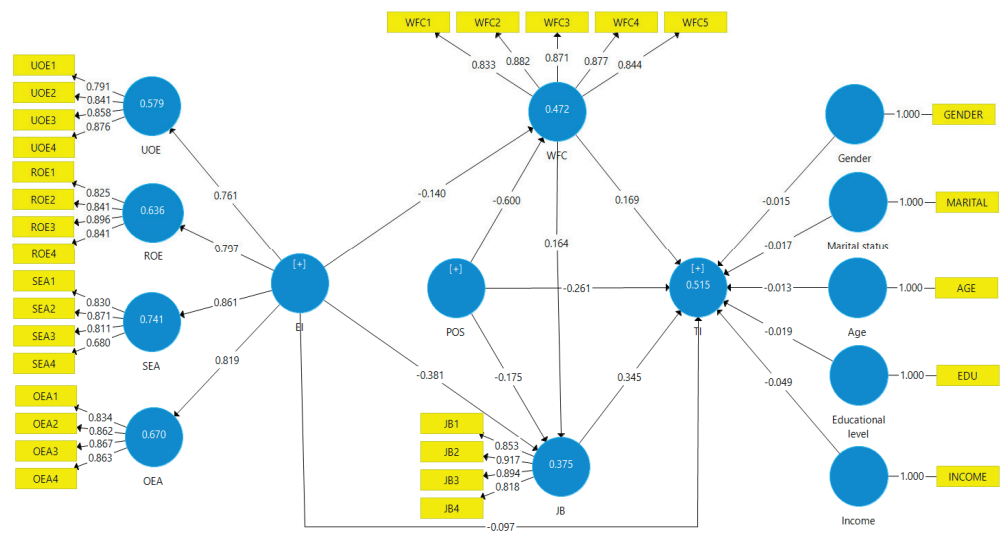

Figure 2. Measurement model.

Additionally, Hair, Hult, Ringle, and Sarstedt [98] recommended that discriminant validity can be shown through the correlation matrix. The square root of a construct's AVE value should be greater than the squared correlation with any other construct "since a construct shares more variance with its associated indicators than it does with any other construct" [96]. Table 2 indicated the correlation matrix of the constructs with the diagonal values. Square roots of AVE of latent constructs which were shown in the parentheses were higher than the correlation coefficient with any variable. For example, the AVE value of Others' emotion appraisal was 0.734 and the square root of its AVE was 0.857 . This value was both higher than the correlation values in its column $(0.069,0.819,0.050,-0.014,0.055$, -0.490 , and 0.106$)$ and its row $(0.362,0.481,0.652,-0.383,0.505$, and -0.267$)$. Therefore, discriminant validity for the constructs was established.

Next, the Cronbach's alpha and composite reliability values were used to assess construct reliability. According to Hair, Hult, Ringle, and Sarstedt [98], Cronbach's alpha and composite reliability values should be 0.7 or greater to be considered reliable in a model. As shown in Table 3 below, Cronbach's alpha and composite reliability values were more than 0.7 . The minimum composite reliability and Cronbach's alpha values were 0.875 and 0.807 , respectively. Furthermore, Hair, Hult, Ringle, and Sarstedt [98] also suggested the rho_A coefficient to measure the reliability for the partial least squares and this value should be greater than 0.7 . According to Table 3, the rho_A values varied from 0.819 to 0.922 . Consequently, the authors can verify that all constructs achieved good reliability. 


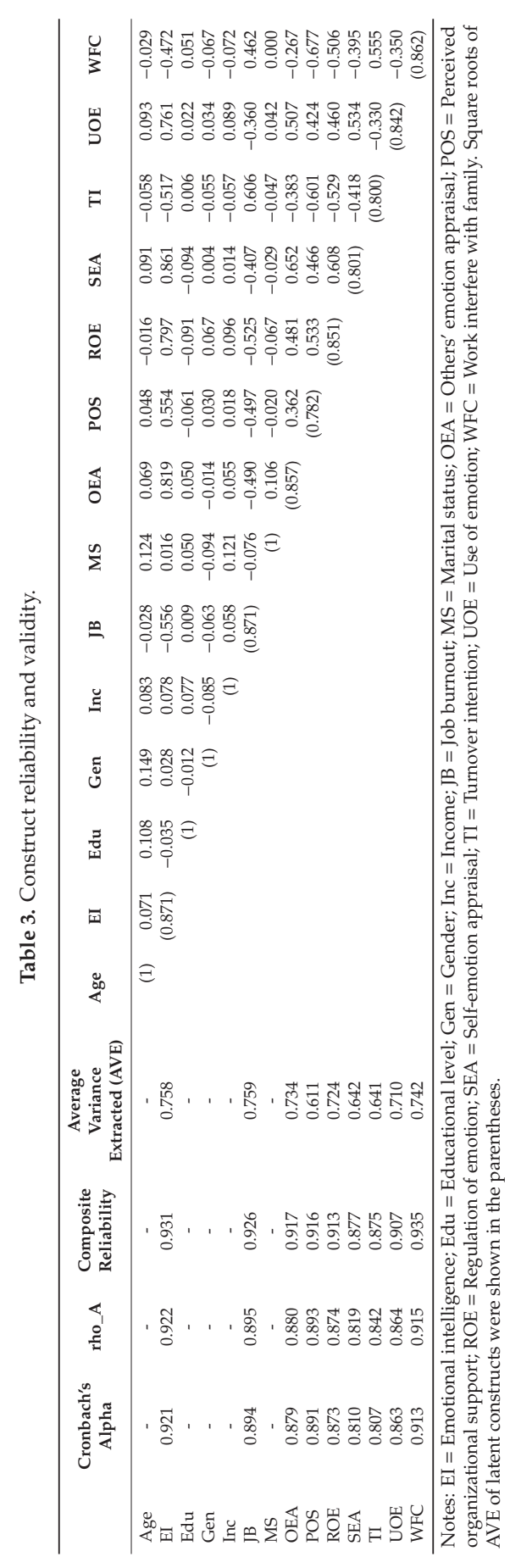


Finally, multicollinearity was assessed for all of the constructs. The variance inflation factor (VIF) indicator was suggested to measure multicollinearity issues. The VIF value should be less than a 5.00 tolerance level $[95,98]$. As shown in Table 4, the maximum inner VIF value of constructs was 2.190. Therefore, the collinearity of the latent variables was not a concern.

Table 4. Multicollinearitystatistic.

\begin{tabular}{cccccccc}
\hline & JB & OEA & ROE & SEA & TI & UOE & WFC \\
\hline Age & & & & & 1.068 & & \\
EI & 1.479 & 1.000 & 1.000 & 1.000 & 1.741 & 1.000 & 1.442 \\
Edu & & & & & 1.024 & & \\
Gen & & & & & 1.054 & & \\
Inc & & & & & 1.065 & & \\
JB & & & & & 1.654 & & \\
MS & & & & & 1.056 & & 1.442 \\
POS & 2.124 & & & & 2.190 & & \\
WFC & 1.896 & & & & 1.964 & & \\
\hline
\end{tabular}

Results from the PLS-SEM analysis are shown in Figure 3. Standardized path coefficients and $\mathrm{p}$-values are reported. The findings are presented as follows:

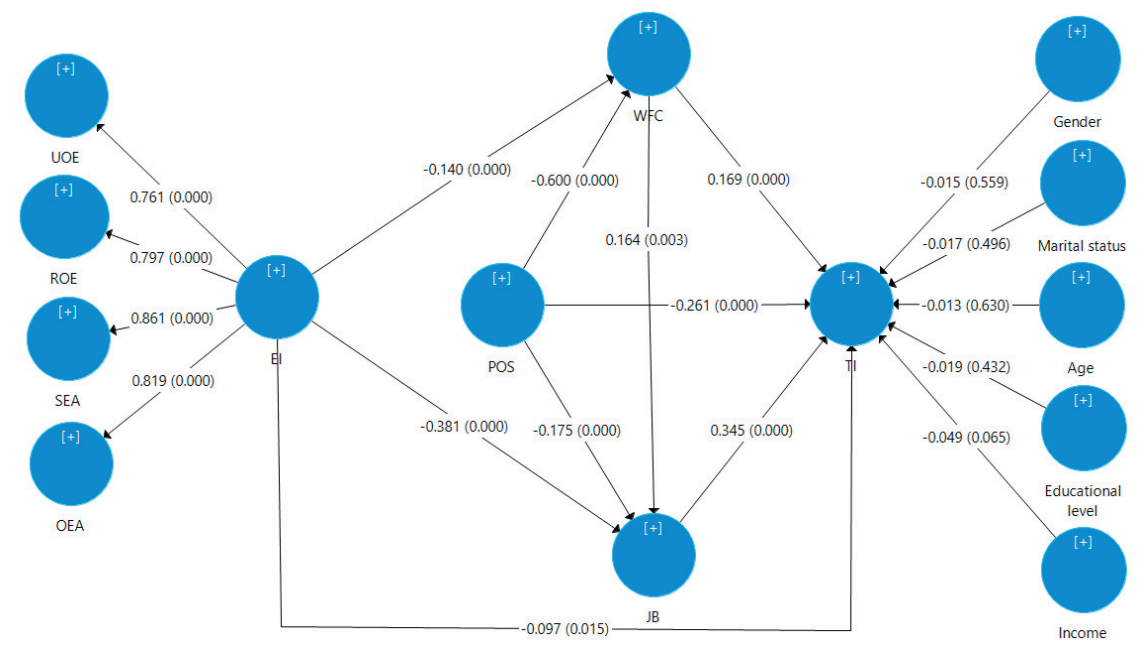

Figure 3. PLS-SEM model.

Hypothesis 1: the result showed that emotional intelligence had a negative and significant relationship with the turnover intention of bankers, $(p$-value $=0.015$ and beta coefficient $=-0.097)$ (Table 5). The results indicated that the more emotional intelligence, the greater the possibility that bankers will have low levels of turnover intention, which was consistent with the findings of the previous study of Akhtar, Shabir, Safdar and Akhtar [62] and Riaz, Naeem, Khanzada and Butt [60]. Emotional intelligence was related to bankers who had the propensity to leave his or her job based on a prolonged period of time being emotionally low regulated by employees' work. Thus, Hypothesis 1 was supported. 
Table 5. Results of the relationship checking of the model's constructs.

\begin{tabular}{|c|c|c|c|c|c|c|c|c|}
\hline Hypothesis & \multicolumn{3}{|c|}{ Relationship } & \multirow{2}{*}{$\begin{array}{c}\text { PathCoefficient } \\
0.761\end{array}$} & \multirow{2}{*}{$\begin{array}{c}\begin{array}{c}\text { Standard } \\
\text { Deviation }\end{array} \\
0.021\end{array}$} & \multirow{2}{*}{$\begin{array}{c}\text { T-Statistics } \\
36.527\end{array}$} & \multirow{2}{*}{$\frac{p \text {-Values }}{0.000}$} & \multirow[t]{2}{*}{ Result } \\
\hline & EI & $\rightarrow$ & UOE & & & & & \\
\hline & EI & $\rightarrow$ & ROE & 0.797 & 0.016 & 50.307 & 0.000 & \\
\hline & EI & $\rightarrow$ & SEA & 0.861 & 0.010 & 89.384 & 0.000 & \\
\hline & EI & $\rightarrow$ & OEA & 0.819 & 0.013 & 64.661 & 0.000 & \\
\hline $\mathrm{H}_{1}$ & EI & $\rightarrow$ & TI & -0.097 & 0.040 & 2.435 & 0.015 & Supported \\
\hline $\mathrm{H}_{2}$ & EI & $\rightarrow$ & WFC & -0.140 & 0.032 & 4.392 & 0.000 & Supported \\
\hline $\mathrm{H}_{3}$ & WFC & $\rightarrow$ & TI & 0.169 & 0.043 & 3.953 & 0.000 & Supported \\
\hline $\mathrm{H}_{4}$ & EI & $\rightarrow$ & JB & -0.381 & 0.030 & 12.527 & 0.000 & Supported \\
\hline $\mathrm{H}_{5}$ & WEC & $\rightarrow$ & JB & 0.164 & 0.054 & 3.019 & 0.003 & Supported \\
\hline $\mathrm{H}_{6}$ & JB & $\rightarrow$ & TI & 0.345 & 0.037 & 9.258 & 0.000 & Supported \\
\hline $\mathrm{H}_{7}$ & POS & $\rightarrow$ & TI & -0.261 & 0.050 & 5.164 & 0.000 & Supported \\
\hline $\mathrm{H}_{10}$ & POS & $\rightarrow$ & WFC & -0.600 & 0.033 & 18.423 & 0.000 & Supported \\
\hline \multirow[t]{4}{*}{$\mathrm{H}_{11}$} & POS & $\rightarrow$ & JB & -0.175 & 0.048 & 3.636 & 0.000 & Supported \\
\hline & Control & ables & & & & & & \\
\hline & Gender & $\rightarrow$ & TI & -0.015 & 0.026 & 0.585 & 0.559 & Not supported \\
\hline & Age & $\rightarrow$ & TI & -0.013 & 0.028 & 0.483 & 0.630 & Not supported \\
\hline \multirow[t]{3}{*}{$\mathrm{H}_{14}$} & Edu & $\rightarrow$ & TI & -0.019 & 0.025 & 0.786 & 0.432 & Not supported \\
\hline & Income & $\rightarrow$ & TI & -0.049 & 0.026 & 1.846 & 0.065 & Supported \\
\hline & $\begin{array}{l}\text { Marital } \\
\text { status }\end{array}$ & $\rightarrow$ & TI & -0.017 & 0.025 & 0.681 & 0.496 & Not supported \\
\hline
\end{tabular}

Hypothesis 2: the result found that emotional intelligence had a negative impact on work-family conflict with a standardized coefficient of -0.140 and $p$-value $=0.000$, which corresponds with many studies (e.g., [63]) which suggested that emotional intelligence is one of the preliminary factors preventing employees from establishing work-family conflict. Subordinates with a good understanding of emotional intelligence would gain feelings of balancing her/his work and family. He or she not only senses that the work being performed is meaningful, but also exhibits the capability to take advantage of work-life balance to have mutual results: completing the job successfully and having a happy family life. Moreover, emotional intelligence helps employees figure out work-family conflicts and helps them to manage their emotions. In terms of conflict management, employees with better emotional intelligence tend to have better effective control with work-family conflict than others. Thus, emotional intelligence (self-emotion appraisal, others' emotions appraisal, use of emotion, regulation of emotion) are important for individual difference effects in regulating emotion in work-family life. Therefore, Hypothesis 2 was supported.

Hypothesis 3: This analysis found that work-family conflict had a positive and significant relationship with the turnover intention of bankers ( $p$-value $=0.000$ and beta coefficient $=0.169)$. It was connected to the studies of Khan, Nazir, Kazmi, Khalid, Kiyani, and Shahzad. [33] and Wang, Lee, and $\mathrm{Wu}$ [44]. Vietnamese bankers with higher work-family conflicts were found to have greater job turnover intentions. With a regression weight of 0.169 , the results showed that bringing conflict from the workplace to employees' homes would likely force them to think of leaving their job. Moreover, in the banking sector, the majority of employees are women, and they may choose to leave an organization voluntarily because of family responsibilities, such as childbearing or child-rearing. Women are generally regarded as the caretakers for an elderly parent as well. As the secondary income earner in the household, a woman's income is characterized traditionally as non-crucial income, which is another common reason identified for turnover. Similarly, from a conventional perspective, women require the flexibility or support from an organization to fulfill family responsibilities. If these requirements cannot be fulfilled by a firm, the employee is more likely to leave voluntarily. Therefore, Hypothesis 3 3 was supported.

Hypothesis 4: The results showed that emotional intelligence had a negative impact on job burnout with the standardized coefficient of -0.381 and the $p$-value $=0.000$ is consistent with research papers (e.g., [64]) which state that emotional intelligence strongly offers individuals control over the work pressures and the ability to adapt easily with challenges to avoid job burnout. In the relationship of emotional intelligence to job burnout, employees who have a moral or intellectual level of emotional intelligence deal better with life's challenges and job stresses, which leads to good psychological 
and physical health and seems to lessen employees' suffering from job burnout. Thus, Hypothesis 4 was supported.

Hypothesis 5: The results showed that work-family conflict had a positive impact on job burnout with the standardized coefficient of 0.164 and $p$-value $=0.003$, which is consistent with the findings of the previous studies of Bande, Fernández-Ferrín, Varela, and Jaramillo [23] and Golden [76]. Employees who experience stress from work-family conflict over a prolonged period of time get drained of energy, which eventually results in job burnout and vice versa. Indeed, the findings also showed that work-family conflict is associated with negative consequences (i.e., burnout) that affect both the work and family. Additionally, high values of work-family conflict may lead to contemporary feelings of emotional exhaustion, reduced personal accomplishment, and depersonalization. Therefore, Hypothesis 5 was supported.

Hypothesis 6: The results showed that job burnout had a positive impact on the turnover intention with the standardized coefficient of 0.345 and $p$-value $=0.000$, which is consistent with the findings of the previous study of Gharakhani and Zaferanchi [78] and Scanlan and Still [77]. Job burnout is related to bankers in the commercial banks propensity to leave his or her job based on a prolonged period of time being emotionally overextended and exhausted by the employees' work. Thus, Hypothesis 6 was supported.

Hypothesis 7: According to Table 6, work-family conflict mediated the relationship between emotional intelligence and turnover intention due to the following reasons: first, the results in Table 5 revealed that the $p$-value for the direct path $\mathrm{EI} \rightarrow \mathrm{TI}$ was $0.015 ; \mathrm{EI} \rightarrow \mathrm{WFC}$ was $0.000 ; \mathrm{WFC} \rightarrow \mathrm{TI}$ was 0.000 , which were statistically significant $(p<0.05)$. Second, the $\mathrm{p}$-value of the indirect effect $(\mathrm{EI} \rightarrow \mathrm{WFC} \rightarrow \mathrm{TI})$ was 0.000 (Table 6) which was statistically significant as well. Hence, the mediating role of work-family conflict exists [95]. Therefore, Hypothesis 7 was supported and this mediation was partial.

Table 6. The result of the mediating effect of work-family conflict and job burnout.

\begin{tabular}{|c|c|c|c|c|c|c|}
\hline Hypothesis & Relationship & Direct Effect & $\begin{array}{c}\text { Indirect } \\
\text { Effect }\end{array}$ & Total Effect & $\begin{array}{l}\text { Mediating } \\
\text { Effect }\end{array}$ & Result \\
\hline $\begin{array}{l}\mathrm{H}_{7} \\
\mathrm{H}_{8}\end{array}$ & $\begin{array}{c}\mathrm{EI} \rightarrow \mathrm{WFC} \rightarrow \mathrm{TI} \\
\mathrm{EI} \rightarrow \mathrm{JB} \rightarrow \mathrm{TI}\end{array}$ & $-0.097^{*}$ & $\begin{array}{l}-0.024^{* * *} \\
-0.131^{* * *}\end{array}$ & $-0.252^{* * *}$ & $\begin{array}{c}\text { Partial } \\
\text { Mediation }\end{array}$ & $\begin{array}{l}\text { Supported } \\
\text { Supported }\end{array}$ \\
\hline
\end{tabular}

Hypothesis 8: According to Table 6, job burnout mediated the relationship between emotional intelligence and turnover intention due to the following reasons: first, the results in Table 5 revealed that the $\mathrm{p}$-value for the direct path $\mathrm{EI} \rightarrow \mathrm{TI}$ was $0.015 ; \mathrm{EI} \rightarrow \mathrm{WFC}$ was $0.000 ; \mathrm{WFC} \rightarrow \mathrm{TI}$ was 0.000 , which were statistically significant $(p<0.05)$. Second, the $\mathrm{p}$-value of the indirect effect $(\mathrm{EI} \rightarrow \mathrm{JB} \rightarrow \mathrm{TI})$ was 0.000 (Table 6) which was statistically significant as well. Hence, the mediating role of job burnout exists [95]. Therefore, Hypothesis 8 was supported and this mediation was partial.

Hypothesis 9: The results showed that perceived organizational support had a negative and significant relationship with the turnover intention of bankers, ( $p$-value $=0.000$ and beta coefficient $=-0.261$ ) (Table 5). The result indicated that the more perceived organizational support, the greater the possibility that bankers will have low levels of turnover intention, which was consistent with the findings of Marchand and Vandenberghe [88]. Thus, Hypothesis 9 was supported.

Hypothesis 10: The results showed that perceived organizational support had a negative and significant relationship with work-family conflict, $(p$-value $=0.000$ and beta coefficient $=-0.600$ ) (Table 5). The result indicated that the more perceived organizational support, the greater the possibility that bankers will have low levels of work-family conflict, which was consistent with the findings of Gurbuz, Turunc, and Celik [86]. Thus, Hypothesis 10 was supported.

Hypothesis 11: The results showed that perceived organizational support had a negative and significant relationship with the job burnout of bankers, $(p$-value $=0.000$ and beta coefficient $=-0.175)$ (Table 5). The results indicated that the more perceived organizational support, the greater the 
possibility that bankers will have low levels of job burnout, which was consistent with the findings of Caesens, Stinglhamber, Demoulin and De Wilde [87]. Thus, Hypothesis 11 was supported.

On the other hand, the findings showed that the component structure of emotional intelligence was a second-order structure. This result was consistent with emotional intelligence concepts [74], which stated that emotional intelligence was composed of four sub-components: self-emotion appraisal, others' emotions appraisal, use of emotion, and regulation of emotion. Regarding the dependency level of each variable to their subscales via arrows, the subscales of use of emotion had the smallest share and others' emotion appraisal had the largest share in stating emotional intelligence.

\subsection{The Moderating Role of Perceived Organizational Support}

Hypothesis 12 predicted that perceived organizational support would moderate the relationship between emotional intelligence and work-family conflict. The study showed that the moderating effect 1 of the interaction between emotional intelligence and perceived organizational support with work-family conflict was negative and statistically significant ( $p$-value $=-0.072$ and beta coefficient $=$ 0.006) (Figure 4). This finding proposed that perceived organizational support negatively moderated the relationship between emotional intelligence and work-family conflict. In other words, the negative relationship between EQ and WFC was stronger for employees who work in a supportive environment (Figure 5). Therefore, Hypothesis 12 is supported.

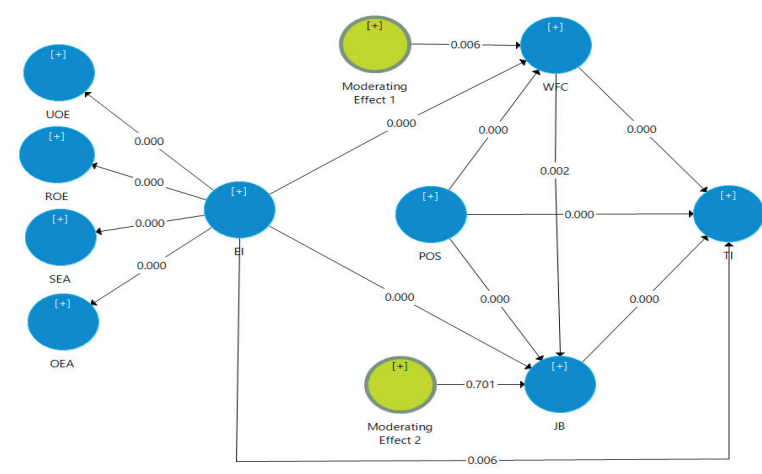

Figure 4. The moderating effect of perceived organizational support.

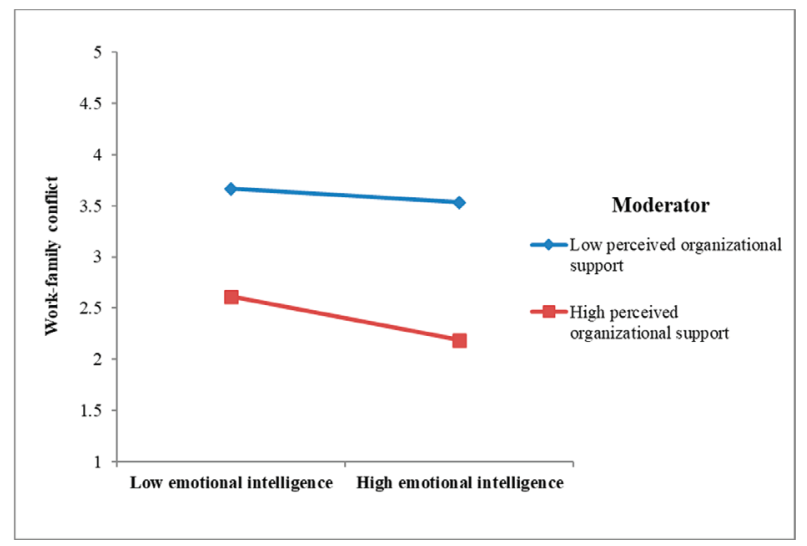

Figure 5. Perceived organizational support (POS) strengthens the negative relationship between emotional intelligence (EQ) and work stress causes family conflict (WFC). 
Hypothesis 13 predicted that perceived organizational support would moderate the relationship between emotional intelligence and job burnout. The study showed that the moderating effect 1 of the interaction between emotional intelligence and perceived organizational support with job burnout was not statistically significant $(p$-value $=0.701)$ (Figure 4$)$. Therefore, Hypothesis 13 was not supported.

Hypothesis 14: The results indicated income negatively related to turnover intention ( $p$-value $=0.065$ ) at the significance level of $10 \%$, which means that bankers who had a high income tended to reduce turnover intention more than other bankers (beta coefficient $=-0.019$ ). This finding was different from some prior results of Seyrek and Turan [91] and Liu, Liu and Hu [90]. However, this study did not find the relationship between turnover intention and gender $(p=0.559 ; \beta=-0.015)$, age $(p=0.630 ; \beta=-0.013)$, educational level $(p=0.432 ; \beta=-0.049)$, and marital status $(p=0.496$; $\beta=-0.017$ ), which was consistent with the findings of Seyrek and Turan [91] and Liu, Liu and $\mathrm{Hu}$ [90].

\subsection{Model Fit}

The coefficient of determination $\left(R^{2}\right)$ is a measure of the model's predictive power. $R^{2}$ is the amount of variance in the endogenous (dependent) latent variables in the structural model explained by the exogenous (independent) constructs connected to it. $R^{2}$ values range from 0 to 1 . The higher the $\mathrm{R}^{2}$ coefficient, the better the construct is explained by the latent constructs in the structural model. The high $R^{2}$ coefficient also reveals that the values of the variables can be well predicted by the PLS path model $[95,98,100]$. The $\mathrm{R}^{2}$ value for the turnover intention was 0.515 which indicated that $51.5 \%$ of the total variation of the endogenous construct turnover intention may be explained by the exogenous construct such as emotional intelligence, perceived organization support, work-family conflict, and job burnout (Figure 2). Moreover, $\mathrm{R}^{2}$ values and the effect for endogenous latent variables in behavioral sciences can be assessed as 0.26 (large effect), 0.13 (moderate effect), and 0.02 (weak effect). Due to the fact that $R^{2}$ values for the turnover intention were greater than 0.26 , the model of this study proved the model-data fit.

\section{Discussion}

Turnover is a costly consequence as recruiting, selecting, and training new members requires additional resources that might negatively affect the performance of a service organization. This study contributes to the existing body of literature supporting the role of emotional intelligence and perceived organizational support in turnover intention. It also focusses on the additional variables of work-family conflict and job burnout having a significant relationship in conjunction with emotional intelligence and perceived organizational support in influencing the turnover intention. Emotional intelligence and perceived organizational support are accounted for $47.2 \%$ and $37.5 \%$ of the variance in work-family conflict and job burnout, respectively. When work-family conflict and job burnout are added as the additional independent variables with emotional intelligence and perceived organizational support, the combination is accounted for $51.5 \%$ of the variance in turnover intention. These numbers may appear to be large; they are very important to banks looking to improve their retention. Being a banker can be an extremely stressful profession, emotionally intelligent bankers are better equipped to work in teams, deal with the job burnout, and interact with their customers. A better understanding of the relationship between emotional intelligence, perceived organizational support, work-family conflict, and turnover intention has the potential to help enhance the workplace as a whole.

An emotionally intelligent banker is more likely to be able to manage her/his tasks properly. Possessing the ability to communicate efficiently, appropriately, and quickly with customers, bankers will have more time for other tasks. It also can increase the accuracy of the banker's work if he or she is better able to understand the needs and wants of the customers in addition to a better understanding of the needs and wants of his/her family. A non-emotionally intelligent banker might struggle to communicate with the customer or misinterpret the customer's needs which can result in the delivery of inappropriate service. A less emotionally intelligent banker may also struggle to interact appropriately with the family members. This could leave the family with the impression that the banker is not caring 
for their loved one which could also leave the family dissatisfied with him/her, leading to an increase in work-family conflict.

Another way emotional intelligence can impact turnover intention is its effect on work-family conflict and job burnout. Employees with higher levels of emotional intelligence are more balanced in their job with family which in turn results in a lower level of job burnout. Emotionally intelligent bankers who can deal with the stressors of the workplace feel more confident and successful, so they have the potential to enjoy their jobs. This would decrease their likelihood of leaving the workplace. They would provide a greater contribution to the overall success of their unit and the bank. Bankers not possessing emotional intelligence would struggle to deal with the stress and demands of the workplace, which may make them more vulnerable to continue their jobs.

Additionally, the recent study of perceived organizational support included plentiful direct causal relations with turnover intention, and it illustrated that elevated employee perceptions of organizational support have been supportive of the reduced intention to quit. Besides, this research found that POS also reduced work-family conflict and job burnout. The negative relationship among POS, work-family conflict and turnover intention was consistent in relation to the previous researches of Marchand and Vandenberghe [88], Gurbuz, Turunc and Celik [86] and Caesens, Stinglhamber, Demoulin and De Wilde [87]. POS were key mechanisms in connecting voluntary turnover among employees. This research found that POS contributed to proactive employees' intent to retain their position in the organization. A positive perception of human resource management practices could lead employees to be less likely to quit as trust could form under a social exchange theory. Perceived organizational support is a belief emanating from the social exchange and the norm of reciprocity. According to organizational support theory, employees exchange valued organizational outcomes for the belief that the organization values their contribution and cares about their well-being as evidenced by tangible support as well as the fulfillment of intangible socio-emotional needs. In other words, employees who feel greater inducements might sense the obligation to repay the organization. Moroever, individuals who have stronger POS might be less likely to seek other jobs or consider turnover.

\section{Conclusions}

Keeping positive and motivated staff is a vital factor for commercial banks and has become a pressing matter for the board of directors. When a banker leaves his/her organization, the organization must absorb the cost of losing an employee such as the cost of recruiting a new employee, which consists of advertising, interviewing, choosing and hiring, and the cost of management activities, which consists of orientation and training. Thus, researchers have examined and proved the effect of emotional intelligence in jobs that required high interaction with others, such as bankers. Particularly, the study examined the effect of the emotional intelligence of commercial bank employees in Vietnam on the turnover intention of employees through the mediation of work-family conflict and job burnout. The findings strongly supported most of the proposed hypotheses. The results of testing have found correlations between a system of variables. The findings showed that emotional intelligence had a negative relationship with work-family conflict, job burnout, and turnover intention. The respondents in this study who had a high level of work-family conflict and job burnout will experience a high level of turnover intention. On the other hand, the high ability of emotional intelligence could lower the level of work-family conflict and job burnout which later could reduce employees' turnover intention.

In terms of emotional intelligence, this research reviewed the definition and dimensions of the emotional intelligence construct and argued its important role in reducing work-family conflict and job burnout issues which also decreased the turnover intention. Due to the importance of this issue, it is strongly recommended to promote the development of emotional intelligence and perceived organizational support to reduce work-family conflict, job burnout, and turnover intention.

Besides, the moderating role of perceived organizational support has not been found in any previous papers about emotional intelligence and turnover intention. Therefore, this study demonstrated the existence of the moderating role of perceived organizational support on these 
relationships. POS could decrease work-family conflict, job burnout, and turnover intention of employees. It could also moderate the relationship between emotional intelligence and work-family conflict. This negative relationship was stronger for employees who work in a supportive environment.

\section{Managerial Implications}

The results of this research study lead to many practical recommendations for both banking practitioners and managers of organizations desirous of improving work-related outcomes.

First of all, hiring employees with high levels of emotional intelligence could have a considerable impact on reducing organizational work-family conflict, job burnout, and turnover intention. Effective retention strategies often begin during the employee recruitment process. When choosing the right employee, the manager should strongly consider the personality, temperament, and capacity of candidates. People who are passionate and active will have strong emotion regulation ability. Thus, during the recruitment process, psychological tests and interviews are suggested methods to determine emotional intelligence. The psychological assessment usually includes a clinical interview, assessment of intellectual functioning (IQ), personality assessment, and behavioral assessment. A personality test is important because it allows the interviewer to thoroughly understand a person and their behavior which includes temperament, personality, interests, attitudes, values, motivation, and other non-cognitive factor characteristics. When interviewing candidates, the interviewer can be flexible and extend the interview to various aspects such as education, knowledge, experience, and achievement. By these approaches, the employer can properly judge the interviewee and select the qualified staff for the organization. In these ways, the organization can hire an employee with high levels of emotional intelligence which can help the organization keep its critical workforce.

Secondly, enhancing training for existing staff is considered. Since practical training can improve individual emotional intelligence levels, organizations may consider implementing Employee Assistance Programs (EAPs) to foster bankers' emotional competence. EAPs have been formed in American companies. EAPs are employee benefit programs that provide professional advice and guidance to help staff with personal problems or work-related conflicts that have a positive impact on reducing work-family conflict and turnover throughout the enterprise. Managers should develop and utilize EAPs in training employees.

Third, perceived organizational support could reduce work-family conflict, job burnout, and turnover intention. Thus, managers of organizations have fresh insight regarding how the delivery of supportive practices to their employees may result in an accretive improvement in organizational outcomes. Specifically, engaging in practices that instill within employees the belief that the organization values their contributions and cares about their well-being may achieve better, stronger outcomes when complemented by related but different organizational practices that increase job satisfaction and decrease work-family conflict, job burnout, and turnover intention to the organization. An employee's belief that the organization is supportive may better explain to management the variance in the levels of worker commitment, which in turn may add insight into how the effect of organizational support is transmitted to outcomes meaningful for organizational strategy execution.

Fourth, emotional intelligence interacts with perceived organizational support upon the intention to quit in a manner such that employees with higher levels of emotional intelligence will experience less work-family conflict and job burnout which will reduce their quitting intention. Management may, therefore, wish to screen potential hires for emotional intelligence, as well as implement training programs that will help employees perceive and better manage their emotions. Of equal importance is the finding that emotional intelligence appears to have an incremental effect upon outcomes as opposed to a basic foundational relation.

Finally, one of the positive ways to reduce the negative effects associated with work-family conflict, job burnout, and turnover intention is to provide a fair work environment. Fairness is a basic element that human beings need and is also a key factor in influencing people's emotions. This will create a pleasant atmosphere, and inspire all people in the organization to build up enthusiasm and be more 
positive. Besides, bankers must know clearly what to do for their customers and establish realistic expectations regarding performance. Managers should always be concerned about their employees and recognize and assist them to deal with problems effectively. A fair atmosphere is beneficial for the employee and the employer; if employees are treated well, then they are more likely to treat customers well. Furthermore, employees will retain positive emotions in the workplace, and the level of work-family conflict, job burnout, and turnover intention will reduce.

\section{Limitations and Recommendations for Future Research}

In this study, there were some limitations. First, this was a cross-sectional study. Future research should test the relations proposed with this study in longitudinal studies using a probability sampling technique, simple random sampling, to increase the generalization of the study. Secondly, multi-culture was another limitation of this project. Although emotional intelligence may be a universal construct, it is believed that the characteristics of the emotional intelligence of individuals may vary across cultures. However, emotional intelligence across cultural boundaries was not mentioned in the literature review. Finally, the survey method was the only method used in this study. Experimental study and field study should be considered in any future research.

Despite these limitations listed above, the present research has practical implications for managers in commercial banks. It is expected to expand the literature on turnover intention in Vietnamese commercial banks and will motivate further research from this scope. Obtaining actual turnover data is much better than turnover intention since there is still a gap between people who just have the intention to leave and those who ultimately leave their organization. This paper mainly studied the relationship between emotional intelligence, perceived organizational support, work-family conflict, and turnover intention. There are also other antecedents that predict turnover such as job satisfaction and employee engagement. These factors should also be involved in investigating the relationship between emotional intelligence and turnover intention.

Author Contributions: H.N.K.G. and B.N.V. proposed the research framework and, together with D.D.H. and T.N.Q. contributed to data collection; B.N.V. and H.T. analyzed the data and wrote the article; B.N.V. contributed to writing and revising article. All authors have read and agreed to the published version of the manuscript.

Funding: This research received no external funding.

Conflicts of Interest: The authors declare no conflict of interest.

\section{References}

1. Li, N.; Zhang, L.; Xiao, G.; Chen, J.; Lu, Q. The relationship between workplace violence, job satisfaction and turnover intention in emergency nurses. Int. Emerg. Nurs. 2019, 45, 50-55. [CrossRef]

2. Allen, D.G.; Bryant, P.C.; Vardaman, J.M. Retaining talent: Replacing misconceptions with evidence-based strategies. Acad. Manag. Perspect. 2010, 24, 48-64.

3. Hausknecht, J.P.; Trevor, C.O. Collective Turnover at the Group, Unit, and Organizational Levels: Evidence, Issues, and Implications. J. Manag. 2011, 37, 352-388. [CrossRef]

4. Hassan, M.; Jagirani, T.S. Employee turnover in public sector banks of Pakistan. Market Forces College of Management Sciences 2019, 14, 119-137.

5. Lee, C.; Chon, K.S. An investigation of multicultural training practices in the restaurant industry: The training cycle approach. Int. J. Contemp. Hosp. Manag. 2000, 12, 126-134. [CrossRef]

6. Judeh, M. Emotional intelligence and retention: the moderating role of job involvement. Int. J. Soc. Behav. Econ. Bus. Ind. Eng. 2013, 7, 656-661.

7. Kusluvan, S. Managing Employee Attitudes and Behaviors in The Tourism and Tourism Industry; Nova Science Publishers: New York, NY, USA, 2003.

8. Leung, S. Banking and financial sector reforms in Vietnam. ESEAN Econ. Bull. 2009, 26, 44-57. [CrossRef]

9. NavigosGroup. Nhân viên ngân hàng thu nhập triệu đồng mỗi tháng vẫn nghỉ việc. Available online: https://news.zing.vn/nhan-vien-ngan-hang-thu-nhap-10-30-trieu-dong-moi-thang-van-nghi-viecpost82.html (accessed on 30 March 2019). 
10. Cafef. Hàng nghìn nhân viên ngân hàng nghỉ việc từ đầu năm đến nay: Nhân sự ngành ngân hàng đang bước vào thời kỳ bị cắt giảm diện rộng? Available online: http://cafef.vn/hang-nghin-nhan-vien-ngan-hang-nghiviec-tu-dau-nam-den-nay-nhan-su-nganh-ngan-hang-dang-buoc-vao-thoi-ky-bi-cat-giam-dien-rong20191017104021499.chn (accessed on 12 December 2019).

11. Ducharme, L.J.; Knudsen, H.K.; Roman, P.M. Emotional exhaustion and turnover intention in human service occupations: The protective role of coworker support. Sociol. Spectr. 2007, 28, 81-104. [CrossRef]

12. Knight, D.K.; Becan, J.E.; Flynn, P.M. Organizational consequences of staff turnover in outpatient substance abuse treatment programs. J. Subst. Abuse Treat. 2012, 42, 143-150. [CrossRef]

13. McNulty, T.L.; Oser, C.B.; Aaron Johnson, J.; Knudsen, H.K.; Roman, P.M. Counselor turnover in substance abuse treatment centers: An organizational-level analysis. Sociol. Inq. 2007, 77, 166-193. [CrossRef]

14. Da Camara, N. Exploring the Relationship between Perceptions of Organizational Emotional Intelligence and Turnover Intentions amongst Employees: The Mediating Role of Organizational Commitment and Job Satisfaction. In New Ways of Studying Emotions in Organizations; Dulewicz, V., Ed.; Emerald Group Publishing Limited: Bentley, UK, 2015; Volume 11, pp. 295-339.

15. Chen, H.; Ayoun, B.; Eyoun, K. Work-Family conflict and turnover intentions: A study comparing China and U.S. hotel employees. J. Hum. Resour. Hosp. Tour. 2018, 17, 247-269. [CrossRef]

16. Lu, A.; Gursoy, D. Impact of job burnout on satisfaction and turnover intention: Do generational differences matter? Journal of Hospitality \& Tourism Research 2013, 40, 210-235.

17. Alfonso, L.; Zenasni, F.; Hodzic, S.; Ripoll, P. Understanding The Mediating Role of Quality of Work Life on the Relationship between Emotional Intelligence and Organizational Citizenship Behaviors. Psychol. Rep. 2016, 118, 107-127. [CrossRef] [PubMed]

18. Mohammad, F.N.; Chai, L.T.; Aun, L.K.; Migin, M.W. Emotional intelligence and turnover intention. Int. J. Acad. Res. 2014, 6, 211-220.

19. Avey, J.M.; Luthans, F.; Jensen, S.M. Psychological capital: A positive resource for combating employee stress and turnover. Hum. Resour. Manag. 2009, 48, 677-693. [CrossRef]

20. O'Boyle, E.H.; Humphrey, R.H.; Pollack, J.M.; Hawver, T.H.; Story, P.A. The relation between emotional intelligence and job performance: A meta-analysis. J. Organ. Behav. 2011, 32, 788-818. [CrossRef]

21. Laschinger, H.K.; Purdy, N.; Cho, J.; Almost, J. Antecedents and consequences of nurse managers' perceptions of organizational support. Nursing Economic 2006, 24, 20-29.

22. Rhoades, L.; Eisenberger, R. Perceived organizational support: A review of the literature. J. Appl. Psychol. 2002, 87, 698-714. [CrossRef]

23. Bande, B.; Fernández-Ferrín, P.; Varela, J.A.; Jaramillo, F. Emotions and salesperson propensity to leave: The effects of emotional intelligence and resilience. Ind. Mark. Manag. 2015, 44, 142-153. [CrossRef]

24. Kidwell, B.; Hardesty, D.M.; Murtha, B.R.; Sheng, S. Emotional intelligence in marketing exchanges. J. Mark. 2011, 75, 78-95. [CrossRef]

25. Mayer, J.D.; Salovey, P. The intelligence of emotional intelligence. Intelligence 1993, 17, 433-442. [CrossRef]

26. Bar-On, R. The Bar-On model of emotional-social intelligence (ESI). Psicothema 2006, 18, 13-25. [PubMed]

27. Reis, D.L.; Brackett, M.A.; Shamosh, N.A.; Kiehl, K.A.; Salovey, P.; Gray, J.R. Emotional Intelligence predicts individual differences in social exchange reasoning. NeuroImage 2007, 35, 1385-1391. [CrossRef] [PubMed]

28. Salovey, P.; Mayer, J.D. Emotional intelligence. Imagin. Cogn. Personal. 1990, 9, 185-211. [CrossRef]

29. Ravichandran, K.; Arasu, R.; Kumar, S.A. The impact of emotional intelligence on employee work engagement behavior: An empirical study. Int. J. Bus. Manag. 2011, 6, 157-169. [CrossRef]

30. Serrat, O. Understanding and Developing Emotional Intelligence. In Knowledge Solutions: Tools, Methods, and Approaches to Drive Organizational Performance; Serrat, O., Ed.; Springer Singapore: Singapore, 2017; pp. 329-339.

31. Krishnaveni, R.; Deepa, R. Emotional intelligence-a soft tool for competitive advantage in the organizational context. ICFAI J. Soft Ski. 2011, 5, 51-62.

32. Tett, R.P.; Meyer, J.P. Job satisfaction, organizational commitment, turnover intention, and turnover: Path analyses based on meta-analytic findings. Pers. Psychol. 1993, 46, 259-293. [CrossRef]

33. Khan, M.R.U.; Nazir, N.; Kazmi, S.; Khalid, A.; Kiyani, T.M.; Shahzad, A. Work-life conflict and turnover intentions: Mediating effect of stress. Int. J. Humanit. Soc. Sci. 2014, 4, 92-100.

34. Dess, G.G.; Shaw, J.D. Voluntary turnover, social capital, and organizational performance. Acad. Manag. Rev. 2001, 26, 446-456. [CrossRef] 
35. Saeed, I.; Waseem, M.; Sikander, S.; Rizwan, M. The relationship of turnover intention with job satisfaction, job performance, leader member exchange, emotional intelligence and organizational commitment. Int. J. Learn. Dev. 2014, 4, 242-256. [CrossRef]

36. Chan, S.H.J.; Ao, C.T.D. The mediating effects of job satisfaction and organizational commitment on turnover intention, in the relationships between pay satisfaction and work-family conflict of casino employees. J. Qual. Assur. Hosp. Tour. 2019, 20, 206-229. [CrossRef]

37. Mobley, W.H. Employee Turnover: Causes, Consequences, and Control; Addison-Wesley publishing: Philippines, PA, USA, 1982.

38. Griffeth, R.W.; Hom, P.W.; Gaertner, S. A meta-analysis of antecedents and correlates of employee turnover: Update, moderate tests, and research implications for the next millennium. J. Manag. 2000, 26, 463-488. [CrossRef]

39. Vuong, B.N.; Giao, H.N.K. The impact of perceived brand globalness on consumers' purchase intention and the moderating role of consumer ethnocentrism: An evidence from Vietnam. J. Int. Consum. Mark. 2020, 32, 47-68. [CrossRef]

40. Karatepe, O.M. The effects of work overload and work-family conflict on job embeddedness and job performance: The mediation of emotional exhaustion. Int. J. Contemp. Hosp. Manag. 2013, 25, 614-634. [CrossRef]

41. Durup, R.J.M. An Integration Model of Work and Family Stress: Comparisons of Models; Dahousie University: Halifax, NS, Canada, 1993.

42. Olorunfemi, D.Y. Family-work conflict, information use, and social competence: a case study of married postgraduate students in the faculty of education, University of Ibadan, Nigeria. Libr. Philos. Pract. 2009, 235, 1-7.

43. Greenhaus, J.H.; Beutell, N.J. Sources and conflict between work and family roles. Acad. Manag. Rev. 1985, 10, 76-88. [CrossRef]

44. Wang, I.A.; Lee, B.W.; Wu, S.T. The relationships among work-family conflict, turnover intention and organizational citizenship behavior in the hospitality industry of Taiwan. Int. J. Manpow. 2017, 38, 1120-1142. [CrossRef]

45. Boyar, S.; Maertz, C.; Person, A.; Keough, S. Work-family conflict: A model of linkages between work and family domain variables and turnover intentions. J. Manag. Issues 2003, 15, 175-190.

46. Choi, H.J.; Kim, Y.T. Work-family conflict, work-family facilitation, and job outcomes in the Korean hotel industry. Int. J. Contemp. Hosp. Manag. 2012, 24, 1011-1028. [CrossRef]

47. Mihelic, K.K.; Tekavcic, M. Work-family conflict: A review of antecedents and outcomes. Int. J. Manag. Inf. Syst. 2014, 18, 15-26. [CrossRef]

48. Demerouti, E.; Bakker, A.B.; Nachreiner, F.; Schaufeli, W.B. The job demands-resources model of burnout. J. Appl. Psychol. 2001, 86, 499-512. [CrossRef] [PubMed]

49. Davidson, M.J.; Cooper, C.L. Shattering the Glass Ceiling, the Woman Manager; Paul Chapman: London, UK, 1992.

50. Freudenberg, H.J. Staff burnout. Journal of Soc. Issues 1974, 1, 159-164. [CrossRef]

51. Pines, A.; Aronson, E.; Kafry, D. Burnout: From Tedium to Personal Growth; Free Press: New York, NY, USA, 1981.

52. Kahn, R.L. Job burnout: Prevention and remedies. Public Welf. 1978, 36, 61-63.

53. Maslach, C.; Jackson, S.E. The measurement of experienced burnout. J. Occup. Behav. 1981, 2, 99-113. [CrossRef]

54. Maslach, C.; Schaufeli, W.B.; Leiter, M.P. Job burnout. Annu. Rev. Psychol. 2001, 52, 397-422. [CrossRef] [PubMed]

55. Toker, S.; Biron, M. Job burnout and depression: unraveling their temporal relationship and considering the role of physical activity. J. Appl. Psychol. 2012, 97, 699-710. [CrossRef] [PubMed]

56. Raza, B.; Ali, M.; Naseem, K.; Moeed, A.; Ahmed, J.; Hamid, M. Impact of trait mindfulness on job satisfaction and turnover intentions: Mediating role of work-family balance and moderating role of work-family conflict. Cogent Bus. Manag. 2018, 5, 1-20. [CrossRef]

57. Webb, K.S. Why emotional intelligence should matter to management: A survey of the literature. SAM Adv. Manag. J. 2009, 74, 32. 
58. Ramesar, S.; Koortzen, P.; Oosthuizen, R.M. The relationship between emotional intelligence and stress management. SA J. Ind. Psychol. 2009, 35, 1-10. [CrossRef]

59. Frost, P.J. Toxic Emotions at Work; Harvard Business School Press: Boston, MA, USA, 2003.

60. Riaz, F.; Naeem, S.; Khanzada, B.; Butt, K. Impact of emotional intelligence on turnover intention, job performance and organizational citizenship behavior with mediating role of political skill. J. Health Educ. Res. Dev. 2018, 6, 250. [CrossRef]

61. Ng, T.; Feldman, D. Organizational tenure and job performance. J. Manag. 2010, 35, 1220-1250. [CrossRef]

62. Akhtar, W.M.; Shabir, A.; Safdar, S.M.; Akhtar, S.M. Impact of emotional intelligence on turnover intentions: The role of organizational commitment and perceive organizational support. J. Account. Mark. 2017, 6, 1-7.

63. Lenaghan, J.A.; Buda, R.; Eisner, A.B. An examination of the role of emotional intelligence in work and family conflict. J. Manag. Issues 2007, 19, 76-94.

64. Carmeli, A. The relationship between emotional intelligence and work attitudes, behavior and outcomes: An examination among senior managers. J. Manag. Psychol. 2003, 18, 788-813. [CrossRef]

65. Hobfoll, S.E. Conservation of resources. A new attempt at conceptualizing stress. Am. Psychol. 1989, 44, 513-524. [CrossRef] [PubMed]

66. Gao, Y.; Shi, J.; Niu, Q.; Wang, L. Work-family conflict and job satisfaction: Emotional intelligence as a moderator. Stress Health 2013, 29, 222-228. [CrossRef]

67. Suliman, A.M.; Al-Shaikh, F.N. Emotional intelligence at work: links to conflict and innovation. Employee Relations 2007, 29, 208-220. [CrossRef]

68. Kaye, B.; Jordan-Evans, S. Love 'Em or Lose 'Em: Getting Good People to Stay; Berrett-Koehler Publishers, Inc: Williston, ND, USA, 2005.

69. Bilal, M.; Rehman, M.Z.; Raza, I. Impact of family friendly policies on employees' job satisfaction and turnover intention: A study on work-life balance at workplace. Interdiscip. J. Contemp. Res. Bus. 2010, 2, 379-395.

70. Greenhaus, J.H.; Parasuraman, S.; Collins, K.M. Career involvement and family involvement as moderators of relationships between work-family conflict and withdrawal from a profession. J. Occup. Health Psychol. 2001, 6, 91-100. [CrossRef]

71. Allen, T.D.; Armstrong, J. Further examination of the link between work-family conflict and physical health: The role of health-related behaviors. Am. Behav. Sci. 2006, 49, 1204-1221. [CrossRef]

72. Taylor, G.J. Low Emotional Intelligence and Mental Illness; Taylor \& Francis: Philadelphia, PA, USA, 2001.

73. Moon, T.W.; Hur, W. Emotional intelligence, emotional exhaustion and job performance. Soc. Behav. Personal. 2011, 39, 1087-1096. [CrossRef]

74. Wong, C.-S.; Law, K. The effects of leader and follower emotional intel- ligence on performance and attitude: An exploratory study. Leadersh. Q. 2002, 13, 243-274. [CrossRef]

75. Aslam, R.; Shumaila, S.; Azhar, M.; Sadaqat, S. Work-family conflicts: Relationship between work-life conflict and employee retention-A comparative study of public and private sector employees. Interdiscip. J. Res. Bus. 2011, 1, 18-29.

76. Golden, T.D. Altering the effects of work and family conflict on exhaustion: Telework during traditional and nontraditional work hours. J. Bus. Psychol. 2012, 27, 255-269. [CrossRef]

77. Scanlan, J.N.; Still, M. Relationships between burnout, turnover intention, job satisfaction, job demands and job resources for mental health personnel in an Australian mental health service. BMC Health Serv. Res. 2019, 19, 62. [CrossRef]

78. Gharakhani, D.; Zaferanchi, A. The effect of job burnout on turnover intention with regard to the mediating role of job satisfaction. Arumshealth 2019, 10, 109-117. [CrossRef]

79. Layne, C.; Hohenshil, T.; Singh, K. The relationship of occupational stress, psychological strain, and coping resources to the turnover intensions of rehabilitation counselors. Rehabil. Couns. Bull. 2004, 48, 19-30. [CrossRef]

80. Khan, F.; Khan, Q.; Naz, A.; Khan, N. Job rotation on job burnout, organizational commitment: A quantitative study on medical staffs Khyber Pakhtunkhwa Pakistan. J. Soc. Sci. Humanit. Stud. 2017, 3, 11-18.

81. Mayer, J.D.; Salovey, P. What is Emotional Intelligence? In Emotional Development and Emotional Intelligence: Educational Implications; Salovey, P., Sluyter, D., Eds.; Basic Books: New York, NY, USA, 1997. 
82. Sergio, R.P.; Dungca, A.L.; Gonzales, J.O. Emotional intelligence, work / family conflict, and work values among customer service representatives: Basis for organizational support. J. East. Eur. Cent. Asian Res. 2015, 2,1-9. [CrossRef]

83. Weinzimmer, L.G.; Baumann, H.M.; Gullifor, D.P.; Koubova, V. Emotional intelligence and job performance: The mediating role of work-family balance. J. Soc. Psychol. 2017, 157, 322-337. [CrossRef]

84. Siddiqui, R.S.; Hasan, A. Relationship between emotional intelligence and employee turnover rate in FMCG organizations. Pak. J. Commer. Social Sci. 2013, 7, 198-208.

85. Eisenberger, R.; Huntington, R.; Hutchinson, S.; Sowa, D. Perceived organizational support. J. Appl. Psychol. 1986, 71, 500-507. [CrossRef]

86. Gurbuz, S.; Turunc, O.; Celik, M. The impact of perceived organizational support on work-family conflict: Does role overload have a mediating role? Econ. Ind. Democr. 2013, 34, 145-160. [CrossRef]

87. Caesens, G.; Stinglhamber, F.; Demoulin, S.; De Wilde, M. Perceived organizational support and employees' well-being: The mediating role of organizational dehumanization. Eur. J. Work Organ. Psychol. 2017, 26, 527-540. [CrossRef]

88. Marchand, C.; Vandenberghe, C. Perceived organizational support, emotional exhaustion, and turnover: The moderating role of negative affectivity. Int. J. Stress Manag. 2016, 23, 350-375. [CrossRef]

89. Kundu Subhash, C. Effects of supportive work environment on employee retention: Mediating role of organizational engagement. Int. J. Organ. Anal. 2017, 25, 703-722. [CrossRef]

90. Liu, B.; Liu, J.; Hu, J. Person-organization fit, job satisfaction, and turnover intention: An empirical study in the Chinese public sector. Soc. Behav. Personal. Int. J. 2010, 38, 615-626. [CrossRef]

91. Seyrek, İ.H.; Turan, A. Effects of individual characteristics and work related factors on the turnover intention of accounting professionals. Int. J. Acad. Res. Account. Financ. Manag. Sci. 2017, 7, 236-244. [CrossRef]

92. Netemeyer, R.G.; Boles, J.S.; McMurrian, R. Development and validation of work-family conflict and family-work conflict scales. J. Appl. Psychol. 1996, 81, 400-410. [CrossRef]

93. Lee, H.J. How emotional intelligence relates to job satisfaction and burnout in public service jobs. Int. Rev. Adm. Sci. 2017, 84, 729-745. [CrossRef]

94. Vigoda, E. Organizational politics, job attitudes, and work outcomes: Exploration and implications for the public sector. J. Vocat. Behav. 2000, 57, 326-347. [CrossRef]

95. Giao, H.N.K.; Vuong, B.N. Giáo Trình Cao Học Phương Pháp Nghiên Cúu Khoa Học Trong Kinh Doanh Cập Nhật SmartPLS; Nhà Xuất Bản Tài Chính: TP. Hồ Chí Minh, Việt Nam, 2019.

96. Fornell, C.; Larcker, D.F. Evaluating structural equation models with unobservable variables and measurement error. J. Mark. Res. 1981, 18, 39-50. [CrossRef]

97. Giao, H.N.K.; Vuong, B.N.; Quan, T.N. The influence of website quality on consumer's e-loyalty through the mediating role of e-trust and e-satisfaction: An evidence from online shopping in Vietnam. Uncertain Supply Chain Manag. 2020, 8. [CrossRef]

98. Hair, J.F.; Hult, G.T.M.; Ringle, C.M.; Sarstedt, M. A Primer on Partial Least Squares Structural Equation Modeling (PLS-SEM); Sage Publication, Inc: Thousand Oaks, CA, USA, 2014.

99. Vuong, B.N.; Suntrayuth, S. The impact of human resource management practices on employee engagement and moderating role of gender and marital status: An evidence from the Vietnamese banking industry. Manag. Sci. Lett. 2020, 10, 1633-1648. [CrossRef]

100. Vuong, B.N.; Hieu, V.T.; Trang, N.T.T. An empirical analysis of mobile banking adoption in Vietnam. Gestão e Soc. 2020, 14, 3365-3393. [CrossRef]

(C) 2020 by the authors. Licensee MDPI, Basel, Switzerland. This article is an open access article distributed under the terms and conditions of the Creative Commons Attribution (CC BY) license (http://creativecommons.org/licenses/by/4.0/). 



\title{
Analyzing the Impacts of Financial Services Regulation to Make the Case That Buy-Now-Pay-Later Regulation Is Failing
}

\author{
Di Johnson ${ }^{1, *}$, John Rodwell ${ }^{2}$ and Thomas Hendry ${ }^{1}$ \\ 1 Griffith Business School, Griffith University, Nathan 4111, Australia; t.hendry@griffith.edu.au
$2 \quad$ School of Business, Swinburne University of Technology, Hawthorn 3122, Australia; jrodwell@swin.edu.au
* Correspondence: di.johnson@griffith.edu.au
}

Citation: Johnson, D.; Rodwell, J.; Hendry, T. Analyzing the Impacts of Financial Services Regulation to Make the Case That Buy-Now-Pay-Later Regulation Is Failing. Sustainability 2021, 13, 1992 https://doi.org/10.3390/su13041992

Academic Editors: Tomás F

Espino-Rodríguez, Andrea Pérez and Ioannis Nikolaou

Received: 29 December 2020

Accepted: 8 February 2021

Published: 12 February 2021

Publisher's Note: MDPI stays neutral with regard to jurisdictional claims in published maps and institutional affiliations.

Copyright: (c) 2021 by the authors. Licensee MDPI, Basel, Switzerland. This article is an open access article distributed under the terms and conditions of the Creative Commons Attribution (CC BY) license (https:// creativecommons.org/licenses/by/ $4.0 /)$.
Abstract: Fee-based Buy-Now-Pay-Later services (BNPL) are becoming widely adopted in many developed countries, including Australia. Across a variety of regulatory approaches there appears to be relatively minimal regulatory coverage of fee-based BNPL. This review applies a results-oriented, behaviourally informed market failure approach to assess the regulatory outcomes of fee-based BNPL. The review makes the case that the impacts of the regulation of fee-based BNPL in Australia demonstrate multiple forms of regulatory failure. The regulatory failure is particularly due to regulatory capture at a broad level and especially in terms of a lack of consumer protections. Consumers may particularly need consideration and protection because understanding the increasing complexity and financial knowledge at the heart of many fintech services is beyond the capability or responsibility of the consumer. Incorporating social and consumer considerations into analyses of regulatory structures can enable analyses of the regulation of fintech and move financial services regulation toward providing more socially useful and sustainable financial services. In the future, a behaviourally informed approach to the regulation of fintech may be beneficial and enhance sustainability.

Keywords: buy-now-pay-later; fintech; regulatory failure; regulation; consumer behaviour

\section{Introduction}

The second machine age, identified as beginning around 1982, created a wave of digital disruption across many industries [1]. This disruption was largely a consequence of the miniaturization of computing, in both size and cost, enabling businesses to leverage computational power to increase business efficiency. The finance industry is particularly affected by digitization because it is a largely quantitative information-based industry, albeit exposed to Moravec's paradox [2,3]. That is, financial calculations are often solved more efficiently by algorithms than humans, although the more nuanced ethical imperatives continue to pose challenges for algorithms. Innovation is further driven by improvements in other technologies, including two at the heart of financial services-data processing and telecommunications [4]. Therefore, the second machine age has created an expanding market supply of algorithmic financial products that require comparatively less human involvement to deliver approximately the same functions to clients. The financial companies that choose to embrace such technology as an integral part of their service or product offering are often referred to as "fintech" companies.

After conducting a systematic review of fintech literature, Milian et al. [5] defined a fintech company as "an innovative company active in the financial industry making use of the availability of communication, the ubiquity of the internet, and the automated processing of information" (p. 18). After reviewing 200 articles containing the word fintech, Schueffel [6] offers an even broader definition: "fintech is a new financial industry that applies technology to improve financial activities" (p. 45). These definitions capture a wide array of financial products and services. However, as technology evolves, certain forms of digitization become the norm and lose their innovative characteristics. For example, in 1983, the Bank of Scotland allowed clients to connect to the internet using their TVs and 
telephones to pay bills and transfer money. At that time, the Bank of Scotland may well have been classified as a fintech company, or at least providing a fintech service, under such definitions. Of course, today almost all banks use the internet to communicate with clients and most are not considered fintech companies. Therefore, it seems the term fintech is better applied to products and services at certain stages in a technological evolution than to companies themselves.

Across many parts of the world, in both established and emerging economies, technology in finance has been revolutionizing the interface between industry, community, and consumers in financial services, with innovation continuing to grow rapidly in recent years. With the opportunities of innovation in this lucrative market comes threats, including of consumer harm and unconscionable conduct in an industry where regulation may not keep pace with innovation. Since 2016, innovation in financial services that enables streamlined consumer spending through innovative payment methods has come under increased scrutiny by financial regulators. However, regulators have come under pressure to intervene sooner in areas where consumer take-up of fintech focused on consumer spending has been very rapid, particularly when the emerging financial services have been designed with features that knowingly or accidently circumvent current consumer protections for credit provision.

Such unfettered approaches to fintech regulation are concerning because history shows that unfettered markets often lead to disastrous social and economic consequences, leading to calls that markets often require government interventions and regulations [7]. Regulations can enhance markets and protect consumers [7]. The outcomes of regulation can be used to assess the efficacy of regulation [8]. Further, evaluating regulation should consider consumer behaviours where such behaviourally informed assessment of regulation takes into account behavioural insights and economic insights about markets [9].

This paper will review a behaviourally informed analysis of regulation for a recent fintech offering, buy now, pay later (BNPL) financial services. The review begins by considering the forms of BNPL financial services, explores the regulatory approaches in countries that have led the take-up of BNPL. Then after setting that context, the review builds an argument that the rapidly growing BNPL consumer payment arrangements, which typically fall out of scope of existing consumer credit protection laws, suffer from regulatory failure and pose a substantial and growing threat of consumer harm. The emerging evidence of consumer detriment in such a rapidly growing fintech offering could reach a point of unrecoverable consumer harm for vulnerable consumer segments unless regulators are able to pre-emptively curb such growing, and arguably foreseeable, consumer detriment.

\section{Traditional vs. Fee-Based BNPL Schemes}

BNPL schemes are offered in several forms; however, in their simplest form it is an agreement between the consumer and lender for the provision of credit to the consumer to purchase goods or services, with the debt being paid off later by the consumer. BNPL schemes can be distinguished from a lay-by agreement where instead a deposit is made to the merchant, who provides the goods or services to the consumer once the full amount is paid. Therefore, a lay-by agreement has no provision of credit; rather, the consumer is purchasing a simple option-to-buy contract from the merchant.

A common type of BNPL scheme is the credit card with a promotional interestfree period in which a consumer enters a credit agreement with a third-party creditor, often at the point of sale, although they can also take the form of a simple loan agreement. The consumer buys the good or service from the merchant with borrowed money and fulfils their contractual obligations (i.e., pays the debt) to the creditor later. In this article, we refer to these types of BNPL schemes as traditional BNPL schemes. These schemes have existed for decades, although they are increasingly taking on a more digital form. For example, a credit card with a promotional period may be accessible as a smartphone application instead of a plastic card. 
On the other hand, it is only relatively recently that BNPL schemes of a similar but not identical form have become increasingly popular. These newer types of BNPL schemes are agreements between the consumer and a third party, whereby the third party purchases the credit sale from the merchant and contractually binds the consumer to pay the third party the amount of the sale, usually in instalments. These arrangements are similar to the long-standing methodology of "factoring of receivables financing" [10,11]. Phelps [12] defines "factoring" as an agreement under which the factor (the financer), assumes the credit and collection function of its client, purchasing their receivables as they arise without recourse for credit losses.

In many cases of BNPL arrangements, consumer payments carry no interest, but instead the consumer incurs fees in addition to the sale amount or if they miss a payment. The third party providing this type of BNPL scheme, as explored later in this article, is not often considered to be providing credit to the consumer. We refer to these types of BNPL schemes as fee-based BNPL schemes. Notably, these schemes are mostly delivered by fintech companies according to the definitions provided earlier. This article largely focuses on fee-based BNPL schemes; however, given the relative novelty of such schemes, we also draw on research relating to traditional BNPL schemes.

In Australia, there has been rapid growth of fee-based BNPL schemes since 2016, with the total amount of credit extended under such schemes doubling from the 2017-18 financial year to the 2018-19 financial year [13]. The growth of fee-based BNPL coincides with decreasing demand for other consumer credit products (traditional BNPL schemes). As of June 2019, there were more than 6.1 million active fee-based BNPL accounts in Australia, representing up to 30 percent of the Australian adult population, with transactions and late payment fees mainly being paid by people aged 18-34 years [13]. The number of transactions increased 90 percent to 32 million in the 2018-19 financial year, and total revenue across six of the main BNPL providers rose 50 percent to $\$ 398$ million in the 2018-19 financial year [13]. The size and growth of fee-based BNPL schemes shows that they are a product line that has a presence in financial services; but, how are fee-based BNPL schemes being regulated? To address that question, we first provide some context about the general approaches to regulation.

\section{Three Approaches to Financial Services Regulation}

With this rapid growth of fee-based BNPL schemes, at least in Australia, we now consider the broader issue of regulation. Financial services regulation should at the very least (a) ensure the stability of the financial system and (b) protect consumers, noting that these two objectives are not exactly parallel to notions of prudential supervision and conduct of business regulation [14]. Three main approaches to financial regulation organization are: institutional, functional, and integrated [15].

Under the institutional approach the supervisory regime is determined by the main line of business conducted by the firm and focuses on the soundness and safety of institutions [16]. The typical arrangement often has different supervisors for each of banking, insurance, and trading markets/securities with each supervisor developing their own techniques and practices that often end up resulting in degrees of inconsistency across fields with differing regulations for similar activities [15].

The functional approach groups similar activities, as a function, and the regulation focuses on how a firm conducts its business and how it behaves toward customers, irrespective of the type of organization conducting that business [16]. The functional approach structures supervision along the functions, or line of the objectives pursued, and thus the potential conflict for different goals, such as between prudential and conduct of business supervision, is made explicit and structurally embedded [15]. Under the functional approach, organizations pursuing the same business should abide by the same rules. The classic functional approach is embodied in the "twin peaks" system raised in the seminal work of Taylor [14] and others, where each peak refers to the objectives of financial stability and consumer protection, often seen to correspond to wholesale versus retail activity [15]. 
Within the functional approach, there could be more peaks/objectives, with arguments for as many as 10 objectives, although the resulting large number of regulators may be unworkable [15].

One of the key weaknesses of the functional approach, particularly for BNPL-the focus of this analysis-is the risk of regulatory capture. Institutional and functional supervisors, often having close contact with the industry, are at risk of being convinced to protect a specific business sector. Similarly, businesses may play off regulators against each other. A potential result of such activities is that some of the resulting regulation may be formed based on intellectual capture that privileges well-resourced interests resulting in collusion between powerful actors and institutionalized rent-seeking [17]. Conversely, a larger supervisor may be less dependent on and more distant from the supervised entities and therefore less prone to capture [15].

Consequently, the third main approach to regulation is the integrated approach. Arguably, key drivers pushing some regulatory systems toward an integrated approach are the difficulties that the institutional approach has with the blurring of lines between traditional financial services activities, such as through the creation of financial conglomerates or the creation of intermediate products (where financial conglomerates are those firms active in several financial markets). These trends in the reality of the market have led to opportunities for regulatory arbitrage. The crux of regulatory arbitrage is how, particularly under an institutional regime, products with identical financial characteristics can be offered to the public under considerably different legal and regulatory regimes and be subject to different safeguards [15].

An integrated approach, with all supervisory functions concentrated in a single entity, may be able to lessen the likelihood of regulatory arbitrage and other weaknesses of the institutional and functional approaches. A single regulator might be more efficient due to shared resources and, in particular, shared information technology systems and support services [16]. A single regulatory entity may also provide economies of scale and scope, especially with respect to the recruitment of staff with appropriate skills and qualifications [16]. However, the integrated approach is not necessarily the pinnacle or best of the regulatory approaches. For example, while the functional distinction between product lines may be eroding in industrial economies, those changes may not be the case in all economies and for many countries there may remain major differences between banks, securities firms, and insurance companies for the foreseeable future [16]. Further, there are profound differences between prudential and conduct-of-business regulation that would make it difficult to combine two such different cultures within one organization [14]. Similarly, for the integrated approach to work well, all of the relevant regulations may need to be detailed and integrated, not just the organizations (building from [15]). Consequently, the movement toward regulatory integration may be a journey that is still ongoing.

\section{BNPL Regulation around the World-The Broader Context of Comparison}

To surface some ideas of the options for regulating fee-based BNPL, we briefly overview the regulations various countries have been applying. The brief summaries below are not meant to be comprehensive, nor absolutely up to date, but rather to show the nature of options being considered around the world and to suggest some patterns occurring in the regulation of fee-based BNPL.

\subsection{United Kingdom}

In the UK, the twin peaks model was adopted in 2013 and consists of two primary bodies; the Prudential Regulation Authority (PRA) and the Financial Conduct Authority (FCA), each charged with their duties of financial stability and consumer protection respectively. Since the global financial crisis (GFC), banking regulation in the UK has generally moved from its previous "light touch" approach toward a much tighter approach [18,19]. Traditional BNPL schemes are regulated under both authorities. More recently, the FCA recommended a series of measures aimed at BNPL schemes that require those schemes to 
provide better information to consumers and not charge backdated interest on repayments made in promotional periods [20]. However, these measures are largely inapplicable to the fee-based schemes that do not charge interest. These fee-based schemes are often heavily promoted to consumers, but also to merchants who are faced with the proposition that failing to offer BNPL schemes to their customers will result in losing a competitive disadvantage [21], and as such, these schemes are rapidly rising in popularity [22]. The lack of aforementioned regulatory oversight has been acknowledged by the FCA who stated that these schemes are "exempt from regulation because they are interest and charge free, and are repayable in no more than a year through 12 or fewer instalments" [23] (p. 20). However, the FCA has announced a review into the unsecured credit market that is expected to address how these providers are, or are failing to be, regulated [24]. On the consumer side, there is a further concern that BNPL terms require standardization to prevent confusion regarding costs [25]. On the merchant side, there are concerns over the risk quality of BNPL offerings and whether the sustainability of the companies offering such schemes will be impacted in less benign credit environments [26]. All in all, newer BNPL schemes in the UK remain largely unregulated with insufficient demand from proponents of increased regulatory oversight. Nonetheless, the upcoming FCA review may go some way to addressing the lack of regulation of these schemes.

\subsection{Canada}

In Canada, the twin peaks model has been adopted in a similar form to the UK. The two primary regulatory bodies charged with financial stability and consumer protection are The Office of the Superintendent of Financial Institutions and the Financial Consumer Agency of Canada (FCAC). Banking regulation in Canada is robust and the simplicity of the twin peaks model was largely responsible for the stability Canada experienced in the GFC compared to the neighbouring United States [27]. Other research has found that Canadian banks tend to be well-capitalized throughout both recessions and expansions [28]. There is also evidence to suggest that Canadian banks might further benefit from diversifying into non-traditional banking activities (i.e., non-interest income) [29]. Although BNPL schemes were not considered, it is plausible that such schemes would also fall under the "feeearning" activities of non-traditional banking. However, despite the comparatively robust regulatory framework in Canada, new fee-based BNPL schemes in the market remain largely unregulated. For example, in offering guidance to consumers about BNPL schemes, the FCAC does not offer any advice concerning those schemes that are not personal loans or credit cards [30]. Such schemes operate in a regulatory blind spot in Canada; however, unlike the UK, there is currently no concrete prospect of increased scrutiny.

\subsection{New Zealand}

New Zealand has also adopted twin peaks regulation of its finance and banking industry, with market conduct and prudential regulation administered by independent bodies. The market conduct regulator of capital markets and financial services is the Financial Markets Authority New Zealand (FMA), along with frontline supervisors. The Reserve Bank of New Zealand (RBNZ) is the prudential regulator of the banking, insurance, and non-bank deposit taker sectors, setting prudential standards and overseeing compliance with these standards [31]. However, New Zealand's Financial Markets Conduct Act 2013 (FMC Act) and financial markets regulatory system excludes regulation of credit contracts. Therefore, BNPL providers are not regulated as part of New Zealand's twin peaks model.

The New Zealand Credit Contracts and Consumer Finance Act 2003 sets the rules for businesses that lend money or provide finance to consumers-for example a cash loan, a home loan or a credit card. However, the New Zealand Credit Contracts and Consumer Finance Act 2003 does not cover BNPL. A possible avenue for review is that New Zealand's Council of Financial Regulators (CoFR) was established to foster high-level cooperation and information sharing between the FMA, RBNZ, the New Zealand Treasury, and the New Zealand Ministry of Business, Innovation and Employment. The CoFR is intended to be a 
forum to consider and address any financial markets regulatory issues, risks, or gaps that arise or are being monitored, including a risk register that helps CoFR and core agencies to prioritize and monitor action on prudential, conduct, and regulatory framework risks.

\subsection{Germany}

Banking regulation throughout Europe is diverse, which is partly attributable to different law traditions, geography, and culture [32-34]. As of 2019, Germany held 25.63 percent of 5981 credit institutions in Europe [35]. The banking regulation model in Germany has been described as "a multi-regulatory framework with strong corporatist elements and with explicit deposit insurance" [36] (p. 203). Germany has a strong publicly-owned banking sector and, compared to regulation in the UK, is considered to be more risk-averse [37]. Germany also has a notably large fintech market with around EUR 17 billion in transactions processed through a fintech platform in 2017 [38]. However, despite the rise of fintech platforms in the region, fee-based BNPL platforms have largely escaped regulatory scrutiny. Again, the lack of scrutiny is mostly due to legal definitions that fail to consider the different attributes of BNPL schemes and have not yet tested whether a BNPL company is defined as a "credit institution" under the German Banking Act. Engaging in a "lending business," which is considered a credit institution activity, is defined as "the granting of money loans and acceptance credits" (Section 1 [39]). Therefore, although BNPL companies are not explicitly exempt (Section 2 [39]), if a BNPL company was considered to be engaged in a lending business, it would require at least a limited license under the Banking Act. The existing regulatory climate therefore provides an opportunity for new BNPL companies to build a market under scarce oversight and expand into traditional lending activities with appropriate licensing later, with one report coining the phrase "Launch Now Comply Later" [40] (p. 25). A nearby precedent for the use of this path was taken by the fintech startup Klarna, when in 2017 it was granted a full banking license in Sweden after operating for several years [41].

\subsection{United States of America (US)}

In the US, the twin peaks model has not been adopted, although it has been considered [42]. Without the simplicity of a federally mandated regulatory system, there is comparatively more complexity regarding the inter-operation of federal and state laws regulating BNPL schemes than other G20 countries [43]. Furthermore, the US has historically taken a private interest micro-prudential approach to regulation although, since the GFC, it has shifted toward a public interest macro-prudential focus more in line with other economically advanced countries [44]. Therefore, both state and federal laws are potentially applicable to BNPL schemes.

Under federal legislation, a company offering a BNPL scheme that either doesn't charge interest or does so requiring payments in less than four instalments will not be considered as a "creditor" $[45,46]$. However, at a state level, particularly in California, three cases against BNPL providers held that BNPL schemes are providing loans, and although not defined as creditors under the Truth in Lending Act for example, nonetheless require a valid state issued license to carry on such practices.

The first of the three cases was The Commissioner of Business Oversight v Sezzle Inc. that concerned whether Sezzle was making loans to Californians without the appropriate license. Sezzle provides consumers with the ability to pay for products or services across four fortnightly repayments after their purchase. Sezzle contended that it was not making loans to consumers but instead purchasing credit sale contracts (which are not subject to Californian loan laws) from merchants. In rejecting this argument, applying mostly common law precedent, the Department of Business Oversight (DBO) found that Sezzle went beyond merely purchasing credit sales contracts, as demonstrated by their active role as a third-party in the transaction-for example, by marketing to consumers before the point of sale. Therefore, the DBO concluded that when considering the substance of the BNPL transaction, it should be considered a loan irrespective of its form. The case of Sezzle 
is important not just because it became a precedent for cases involving two other BNPL providers soon after, but because it serves as an example of a court looking to the substance of a BNPL scheme, not just the form it takes (which is often exempt from regulation) [47]. However, other states are yet to examine the substance of BNPL schemes in the same manner as California, although considering the increasing popularity of BNPL there may be more legal challenges forthcoming $[48,49]$.

The notes above about the regulation of BNPL in selected countries around the world show that while some countries (e.g., Germany, and some states in the US) are starting to consider fee-based BNPL as credit, most of the above jurisdictions are not applying stricter regulations such as the application of credit considerations. Similarly, despite the alleged effectiveness of the functionalist Twin Peaks approach, none of the Twin Peaks countries are yet increasing regulatory intervention, although several have planned reviews of BNPL practices and impacts on consumers. To inform any such reviews of BNPL regulation, they may need to broaden their scope to maintain their relevance for that form of fintech. The analysis below seeks to suggest issues to consider in such reviews, especially consumer issues, by using Australia as an example case.

\section{The Specific Context: BNPL Regulation in Australia}

In analysing the Australian case regarding the regulation of BNPL, this paper first overviews the Australian regulatory environment. The following section then begins to evaluate those regulations from the minimal perspective of avoiding market failure.

Australia was a pioneer of the twin peaks model of financial regulation [50], although one of the stimuli for the changes leading to the current financial services regulatory system in Australia, the Wallis report, proposed four regulators [51]. Each resulting institution is argued to focus exclusively on a particular failure: the Australian Prudential Regulation Authority (APRA)-asymmetric information, the Australian Securities and Investment Commission (ASIC)-consumer protection, the Australian Competition and Consumer Commission (ACCC)—competition weaknesses, and the Reserve Bank of Australia-system stability [16]. The twin peaks nomenclature reflects a focus on prudential supervision for banks and insurance companies in the hands of one institution (APRA) and securities markets supervision in the hands of another (ASIC), both agencies being organized at the federal level but without involvement of the central bank [15] Functional models such as the Twin Peaks model may have some anomalies and illogical ties, but appear to have fewer than the alternatives [14,52]. More broadly, there is no perfect regulatory structure and making a regulatory structure work is largely about identifying the structure's strengths and weaknesses and implementing solutions to address those weaknesses [53].

Fee-based BNPL providers in Australia are generally considered not to be regulated under one of the peaks, namely the National Consumer Credit Protection Act 2009 (National Credit Act). However, BNPL arrangements are regulated as credit under the Australian Securities and Investments Commission Act 2001 (ASIC Act) and are therefore subject to ASIC's product intervention power outlined in Pt 7.9A of the Corporations Act 2001 (Cth) (the Act) which was inserted by the Treasury Laws Amendment (Design and Distribution Obligations and Product Intervention Powers) Act 2019 (Cth) and commenced on 6 April 2019. Thus, ASIC's product intervention power is new and there has been a lag in applying the intervention power in relation to the rapidly growing BNPL market. Further, the benchmarks established in the enactment of the intervention power in terms of the extent of "significant consumer detriment" needed to trigger intervention by ASIC will be a critical signal to BNPL providers and other new product developers in terms of compliance obligations.

The Act also establishes that the extent of ASIC's power reaches beyond product design to include product distribution and related conduct. The application of the design and distribution obligations to financial product providers has been delayed until late 2021 or later, but when they come into effect these new regulatory powers, which focus on 
consumer outcomes and harms, may play an important role in promoting good consumer outcomes to BNPL providers.

Another regulator in Australia related to BNPL is the Reserve Bank of Australia (RBA). In a December 2020 report the RBA determined that merchants cannot pass on the BNPL fee (or surcharge) to customers, which they are able to do for credit card fees, noting however that the decision may need to be reviewed in future. Consequently, one of the risks that BNPL introduces is not just from the customers defaulting on their loans, but with merchants not able to pass on the surcharge of BNPL providers to individual consumers. That cost is passed on to all consumers whether they use BNPL or not [54]. If regulatory provision does not enable a more transparent provision of BNPL services, it may be that consumer action regarding BNPL charges may be an alternative disruptor.

To assess those weaknesses and suggest solutions to Australia's Twin Peaks model, this article will review some of the key market failures arising from new fintech, particularly the case of fee-based BNPL schemes. The theoretical underpinning for public intervention is based on the need to correct market imperfections and unfair distribution of resources [55] The regulatory system can be assessed by evaluating the degree of mismatch between regulatory structure and market reality [14]. Evaluating the regulation of the financial system can thus be considered as an important operationalization of public control over regulation [55] - in this case, the regulation of the financial services industry.

Given the above regulatory context in Australia, how can we evaluate the effectiveness of those regulations for the BNPL form of fintech? To begin, the regulations can be evaluated in terms of their outcomes and resulting behaviour.

\section{Evaluating Regulation in Terms of Results and Behaviour: At a Minimum Avoid Market Failure}

There has been a growing recognition that consumers are fallible in systematic and important ways and that firms have incentives to exploit these shortcomings, particularly in financial services [9]. Thus, financial services regulation should at a minimum (a) ensure the stability of the financial system and (b) protect consumers [14]. That is, the regulation of financial services can be justified on the basis of market failure and government failure [4], sometimes referred to as a market failure approach to regulation assessment and reform [7].

The efficacy of regulation can be assessed in terms of the outcomes of regulations. Evaluating the outcomes taking in to account the regulations' limitations and implementation is considered a necessity for well-designed regulations [7]. Such a results-oriented assessment identifies important hazards and risks (that may need to be the subject of new regulation) or patterns of non-compliance (that may indicate the need to amend existing regulations) [8]. Furthermore, evaluating regulation should consider the nature of human behaviour, as well as how firms may respond to the consumers' behaviours and to the structure of regulation [9]. That is, this paper will apply a behaviourally-informed approach to regulation analysis that examines market failures.

Academically, there are six seminal forms of regulatory failure, of which three appear to be particularly problematic for BNPL. The first form of failure is regulatory capture. The other two key failures impacting BNPL consumers can be considered in general terms, as well as specifically in terms of asymmetric information and the consumer not knowing what is best for themselves.

The extent to which an individual consumer might need protection from these failings will vary by their degree of financial sophistication, the nature of the financial product under consideration, the proportion of an individual's capital being committed to the transaction, and the extent to which there is scope for repeat transactions, enabling the individual to gain in knowledge and experience [14]. Such failures can occur because of: (1) situations of market power brought about because of collusion, concentration, technological conditions or public regulatory conditions, (2) economies of scale, (3) externality (spill over) effects, as in the case of a bank failure generally affecting the confidence of savers in the entire banking system, (4) public good problems, where the marginal costs of a good to the next marginal customer may be low or zero, such as information developed 
by a securities analyst for distribution to clients, (5) information asymmetries, between buyers and sellers of financial products, and (6) individuals who are unable to know their own best interest $[4,55]$. Avoiding these failures reflects an absolute minimum of an operating financial services regulatory regime. Regulatory support for green protocols and social and environmental responsibility policies have been making some progress in Latin America and would represent a proactive approach to fintech regulation [56]. But if the regulatory ecosystem itself is not operating well, it may be difficult to reliably progress to more sustainable goals.

The following sections provide data and summarize the effects of debt and BNPL products in Australia, both generally and for specific forms of failure. To conduct that analysis, the form of failure to do with situations of market power brought about because of collusion, concentration, technological conditions, or public regulatory conditions is covered first and then the failures associated more with the consumer side, both generally and then specifically in terms of asymmetric information and the consumers not knowing their own best interest.

\subsection{Regulation Being Subject to Capture}

The GFC highlighted how regulatory responses in a crisis do not necessarily create systemic stability and that powerful financial actors have been able to intellectually and politically capture regulation in order to make profit [17]. Financial regulation can be said to be captured when a subset of actors, usually powerful elites, are able to strongly influence, if not determine, the regulations to which they may be subject [57]. More specifically, "strong" capture occurs when regulation, in law or application, is directed away from the public interest and toward the interest of the regulated industry [58].

Capture may be more likely in situations where the issues have low political salience, have a technical character (as most fintech does), and where there has been a relatively narrow supply of regulation [17]. In such situations, new products will often start off with a degree of self-regulation of their emerging market. Self-regulation may work when the participants possess approximately equal knowledge, information, and bargaining power, yet transactions involving a professional dealing with a retail client, almost by definition, do not meet these criteria [14]. Then, when the self-regulation structures are largely transmitted across to any later formal regulation, whether in the form of legislation or effect, capture is likely to have occurred [17]. Indicators of capture can be statutory, in terms of the legislation, or by agency, where the behaviour of the agencies could be argued to be supporting industry interest [58]. Both mechanisms of capture are likely to occur when industry-generated self-regulation is the basis of formal regulation. That is, the regulations cease to serve the wider public interest and instead systematically favour specific vested interests [57]. Another indicator of capture could be where a particular fintech product is not regulated by more comprehensive entities, such as credit regulation, where the agency or industry may claim that such regulation could impose significant regulatory costs [17]. Thus, BNPL appears to initially be captured through the agency of the regulators adopting the industry's regulation and then statutory capture by both the resulting formal regulation and by the absence of stricter regulation such as credit regulation. Further, the adoption of the industry-generated regulation may also legitimize and mainstream the new product line, enabling the industry to grow faster.

To a limited degree, regulatory capture can unintentionally lead to some forms of fintech having at least a basic functional utility, such as the case where peer-to-peer (P2P) lending in the UK could be seen to link savers to productive investments [17]. P2P lending occurs when individuals post their borrowing needs and personal profiles on a P2P platform that is then viewed by individual and institutional investors. The investors may then choose to lend through the platform, where the platform may allow the consideration of personal "soft" information (e.g., demographics, context for the loan, investors' values) [59]. The P2P product line went through a phase of self-regulation and then had the government essentially endorse and legitimize that regulation by formalizing it. 
Such minimally "constructive" regulatory capture, as may be the case of P2P in the UK, could be the exception, and its impact will need to be weighed against the reputational value that such regulatory capture provides by legitimizing new forms of fintech. For example, a costly precedent of regulatory capture in California occurred during the 2001 Californian energy crisis, with evidence indicating that Enron played a significant role in manipulating electricity prices, in electricity markets essentially as a fintech, effectively taking advantage of the regulatory prioritization it held above the general public [60]. That is, more discussion needs to occur moving beyond the basic criteria often used by regulators to considerations of how financial services and fintech can be socially useful and that emphasizing social usefulness may be a step forward in thinking about financial services (building from [17]).

In considering BNPL in Australia, a concern is that ASIC has determined a path forward to include a voluntary code of conduct for BNPL providers, suggesting the industry is suited to largely "self-regulation." The intention to adopt self-regulation follows the argument provided by the Australian Finance Industry Association, which is developing the voluntary code, to the 2020 Senate inquiry into financial technology that "even at the peak of financial hardship requests from consumers in March and April 2020, across the BNPL industry the percentage of customers approved for hardship was less than 1 per cent" [61] (p. 216). The draft voluntary Code of Conduct from BNPL providers in Australia received heavy criticism from ASIC in 2020 for its lack of consumer protection when compared to the National Credit Act. Yet in its November 2020 report, ASIC did not call for any immediate new regulation, instead still supporting self-regulation via the code of conduct being developed by the Australian Finance Industry Association, and the potential application of ASIC's delayed design and distribution obligation and new product intervention power [61]. The lack of early intervention by ASIC also suggests a degree of regulatory capture by the BNPL providers. That is, as is typical of regulatory capture, the perspectives of the business community have been well represented, with little representation from others [7].

Of course, BNPL providers have incentives to expend resources defending their market power, along with that spent by smaller BNPL providers attempting to oust them, although those resources could be considered a form of social waste as they could instead be directed to more socially useful purposes [62,63]. Further, although outside of the scope of this article, a theoretical model such as developed by Sadik-Zada and Gatto [64] may be useful for a closer analysis of the incentive structures pertaining to fee-based BNPL schemes that partly drive their efforts.

Fintech companies, such as fee-based BNPL providers, could use their regulatory capture to promote green finance to a greater extent than traditional institutions [65] and this increased reliance on renewable energies could then positively impact sustainability [66], although they have yet to do so in Australia, with the exception of Brighte a BNPL that supports the purchase of solar panels. However, the most concerning aspects of regulatory failure regarding BNPL in Australia are in terms of the impact of BNPL and any resulting debt on consumers. In the short term, the delineation of the detrimental impacts on consumers may help to motivate ASIC to apply their product intervention power, but the specific forms of market failure are also concerning.

\subsection{Consumer Protection Failures: General Consumer Detriment, Asymmetric Information, and Not Knowing Own Best Interests}

Perhaps the main concern with BNPL products is the need to protect consumers, especially given the known ways in which consumers are likely to be fallible [67]. Consequently, we now move to focusing on the consumer side of market failure. At a general level, the Australian regulation should be taking effect, taking action, if there may be significant detriment to consumers caused by a financial product. But what is general detriment and what are examples of the general impact of debt and BNPL?

The benchmark for ASIC's intervention powers of "significant consumer detriment" could be a critical signal to BNPL providers and other new fintech developers in terms of compliance obligations. The term "significant" is not defined in the Act and will depend 
on individual circumstances of the matter [68]. Consumer research has found that the negative consequences for some BNPL users may be significant and went beyond missed or late payment fees. As a starting point, the November 2020 review of BNPL by ASIC [10] detailed that 20 percent of consumers say they had cut back on, or went without, essentials such as meals to make their payments on time, and 15 percent of consumers surveyed said they had taken out an additional loan. Half of the users having these impacts were aged between 19 and 29. Of the consumers who missed repayments, the other payments that were missed were household bills (44\%), credit card payments (32\%), and mortgage payments $(22 \%)$ [13].

Despite these findings, ASIC concluded that there was not sufficient evidence of significant consumer detriment to trigger an intervention. Therefore, early indications are that the consumer detriment benchmarks in relation to BNPL arrangements are likely to be very high, with risk to the market and likely regulatory failure.

Test cases may yet enable ASIC to intervene. In the first use of the intervention power under Pt 7.9A of the Act, delivered by the Federal Court of Australia on 15 April 2020 regarding a payday lender, the Judge presiding concluded that ASIC's power is to be construed broadly, in that the financial product itself or its features do not need to cause the detriment and that the detriment can be caused indirectly by something extraneous to the product, such as the circumstances in which the product is made available [68].

Perhaps a key example of that flow-on impact is the link between BNPL usage and increased credit card debt. ASIC's analysis of users of BNPL shows negative consequences in terms of consistently higher interest charges on credit cards for users who link credit cards to their BNPL providers compared to credit card holders who do not use BNPL providers [13]. Similarly, the inter-relationships between BNPL and credit card debt is also highlighted by recent industry moves such as in the US where major banks such as CapitalOne have barred their users from transferring BNPL debts to them because the banks felt that BNPL transactions were too risky for customers and their banks [69]. Part of the concern of credit card providers about BNPL, which should also be a concern for the regulators, is the impact of indebtedness on consumers.

\subsubsection{General Consumer Considerations, Such as the Effects of Indebtedness on Consumers}

The increasing credit card debt witnessed since the alleged "neoliberal turn" is partly attributable to the phenomenon of new consumerism in which consumers desire to possess more despite not earning more [70]. Instead of government taking on debt to stimulate the economy, a system of privatization that indebted low to middle income individuals arose and has been shown to be unsustainable [71]. By 2019 in Australia, credit card debt had increased about twenty-fold since the Reserve Bank of Australia started reporting outstanding credit card balances in 1985 , reaching a total of $\$ 50.5$ billion [72]. In the case of BNPL services in 2018, over 60 percent of their users are aged 18-34, two in five BNPL users earned under $\$ 40,000,40$ percent were students or worked part-time, and more than four in five consumers who used BNPL planned to do so again [73].

Bad debt rates in BNPL in Australia are four times higher than in Europe. European BNPL bad debts range from 0.2 to 0.35 percent of BNPL sales, whereas in Australia and New Zealand the range is 0.9 to 1.43 percent [37]. In comparison, across Australia's four major banks, bad debt expense in 2019 as a proportion of gross loans was 0.13 percent, a sizeable improvement on the historic average of 0.27 percent over the last 25 years [64] For BNPL users in the US, a concern was that 450,000 or 9 percent of one of the BNPL providers' customers had defaulted between 2016 to 2019, which has major lifestyle issues for these young consumers in the US as their credit history will take seven years to clear, during which time they may be unable to access most lending products, including mobile phones, and may be unable to sign rental or car purchase agreements [74].

Although the increased debt has led to more consumption, it has come at the cost of the mental, and sometimes physical, wellbeing of many individuals. Such mental effects are often described by varying labels such as financial anxiety, financial security, peace of 
mind, or financial satisfaction. These terms are sometimes measured using applicable scales incorporated in surveys or alternatively drawn out by a thematic analysis of interviews. In other cases, they are loosely bundled together, making them difficult to disentangle. There are also the more well-known psychological illnesses such as depression, anxiety, and stress, and although a specific term like "financial depression" is not yet common, depression can nonetheless still be correlated to a person's financial affairs.

For example, Turunen and Hiilamo [75] found that unmet loan payments led to an increase in suicidal thoughts and depression, along with poorer subjective health assessments. O'Neill et al. [76] reported an improvement in perceived health when people paid down or reduced debt in a sample of 3121 people. Increased consumer debt leads to greater cognitive load, leading to compromised financial decision-making, with consumers tending to take more risks, ignoring opportunity costs, and investing fewer cognitive efforts in choice tasks [77]. Over-indebtedness also increased the likelihood of respondents reporting that they had either bad or very bad health in European households [78]. There is also evidence suggesting credit card debt is related to depression, anxiety, stress, or suicide ideation in Asia [79].

Furthermore, these mental effects also appear to be reaching particularly vulnerable segments of society-segments that are the main focus of BNPL usage. For example, young people are more likely to have credit card debt and possess higher levels of financial anxiety [80]. Young adults are a key group of consumers with higher levels of impulsive consumption that is enabled by BNPL and unsustainable [81]. Credit card revolvers, that is those who do not pay the remaining balance each month, are more likely to earn a low income and be less educated $[82,83]$. Credit card debt of at least $\$ 1000$ was associated with being overweight or obese, insufficient physical activity, excess television viewing, infrequent breakfast consumption, fast food consumption, unhealthy weight control, body dissatisfaction, binge drinking, substance use, and violence in a sample of 3206 college students [84]. Similarly, $\$ 1000$ credit card debt has been reported to increase psychological distress in young American adults [85]. Further, mobile phones are taking the place of credit cards themselves and this extra convenience can also induce consumers' willingness to pay [86], which is especially topical for BNPL schemes that rely heavily on smartphone applications. These customer characteristics and relationships with ill health suggest likely problems with BNPL usage, as well as problems for those customers with BNPL and credit cards.

In Australia, there is also a problematic rise in older people seeking financial counselling services, particularly for help managing debts [87]. Moreover, simply possessing a common behavioural bias such as present bias is correlated to increased credit card debt [88]. These effects often lead individuals to seek financial counselling for assistance developing debt repayment plans and negotiating with creditors [89-91].

However, other research has argued that credit card debt can instead have a positive effect by helping young people develop their personal identity and achieve lifestyle goals [92]. Moreover, using credit cards can smooth life transitions and difficulties, which is convenient for affluent people who are less concerned by the debt itself [93]. There is also extant research on the link between credit use and spending behaviour. For example, the credit card effect, whereby consumers will spend more when exposed to certain spending stimuli [94-96], a similar effect to that found for over-consumption facilitated by BNPL [81].

Results such as those above are especially concerning when it is acknowledged that merchants and fintechs are likely to leverage those results and relationships to encourage more consumer spending, which can exacerbate consumer indebtedness and the associated problems mentioned above. Therefore, consumer indebtedness, such as that attributable to BNPL schemes, is often dichotomously interpreted as either positive or negative, depending on whether it is the merchant or consumer concerned. Credit card debt and fee-based BNPL debt are not synonymous, yet comparatively small debts, with or without payment 
schedules, have adverse health effects on consumers, especially those consumers most likely to use BNPL.

The general, practical considerations for consumers in assessing regulatory failure include the direct and indirect effects of indebtedness summarized above. In terms of the more academic considerations of the consumer side of market failure, there are the problems of asymmetric information and when the consumer does not know their own best interests.

\subsubsection{Specific Academic Consumer Considerations: Asymmetric Information and Not} Knowing Own Best Interests

Problems of asymmetric information arise when a party on one side of a transaction has relevant information that the other side does not have [4]. Asymmetric information can present fintech opportunities, as shown by arguments that the rise of microfinance is attributable to information asymmetry that excluded the poor from accessing fair credit-a phenomenon that has ancient origins [97]. But from a behaviourally informed regulation analysis perspective, the key concern is the presence of market failures having detrimental outcomes on consumers.

There are various forms of information asymmetry and particularly relevant are the hidden information problems, including the "lemons" problem of the buyers knowing less about the qualities of the seller's product than does the seller and/or "hidden action" problems of the buyer of services knowing less about the agent's actions than the agent [98] In the hidden-knowledge problems, the agent has and uses information that the principal does not have, and the principal cannot check whether the agent has used that information in the way that best serves the principal's interest [98]. Hidden action primarily concerns how the principal is unable to check on the effort of the agent. For example, a physician may choose actions affecting the welfare of the principal (the patient), where the basis of the relationship is the superior knowledge of the physician. Hence, the patient cannot check to see if the actions of the physician are as diligent as they could be [98].

With consumers in capitalist societies unable to avoid engaging in banking and financial services, consumers must be able to trust the provider of the financial services to have their best interests in mind in the design and delivery of the services. "If the knowledge is considered too complicated or specialist to communicate, then a sector needs to convince the public it is using that knowledge for the benefit of both individuals and the public more generally" [99] (p. 8).

The next academic form of consumer-oriented market failure particularly impacting the customer in the case of BNPL arises when the individual is unable to know their own best interests. Complete information may help to avoid asymmetric information problems, but will not prevent mistaken choices if the individuals do not know their own best interests and may not realize that they should be relying on agents [4]. With the level of knowledge and professional competence required to be successful in finance increasing exponentially, the finance sector cannot validly claim that financial literacy is the responsibility of the customer or client [99].

Both of the above consumer-oriented forms of market failure are exacerbated in the case of BNPL in Australia by a shortage of consumer advocates or financial counsellors who are finding that even though BNPL is a relatively new business model, it is appearing as an increasing component of financial counselling casework, with one survey finding 90 percent of financial counselling clients having BNPL debts [89]. Financial counsellors report that BNPL providers have poor comparative hardship responses (rated at 3.7 out of 10 with 1 being the lowest rating) compared to major banks (7.5 out of 10), non-major banks (5.8 out of 10), and even compared to debt collectors (5.3 out of 10) [100]. An expanded role and increased numbers of financial counsellors may be a quick, fill-in option for consumer advocacy agents in relation to BNPL in the absence of improved consumer protection through regulation, but remediation is usually worse than prevention.

For some fintech products, regulatory capture can be constructive, but in the case of BNPL, it appears to be toxic. Perhaps the main focus of the problems with BNPL are 
regulatory failures impacting consumers. From the arguments above, it appears that for BNPL the Australian regulations do not make the minimum requirement of avoiding failure, especially for consumer-related market failures.

\section{Discussion}

There are a variety of financial services that may fall under the umbrella of being fintech and this paper focuses on BNPL. Some of the options being considered around the world for regulating BNPL range from considering the possibility of treating fee-based BNPL as credit, through to, particularly for some Twin Peaks systems, considering reviews of BNPL. Any such reviews may need to at the least assess the degree of any regulatory capture and the likely impacts on consumers and markets. Further, regulators may also want to consider regulations and actions occurring in other jurisdictions and assess whether such interventions may be useful in their own context (e.g., the interventions occurring in California [47]). In conducting any reviews of fintech regulation, regulators may also want to be proactive and incorporate regulations that facilitate sustainable financial services practices [56].

Across various forms of fintech, there have been arguments that regulatory capture may exist. For P2P in the UK, the regulatory capture may be (minimally) "constructive," but any positive, constructive, impacts of that fintech may be due to the socially useful nature of the fintech rather than regulation [17] and may be the exception. In contrast, our argument above is that the regulatory capture occurring with BNPL in Australia is more the classically destructive form arising from typical regulatory failure and, when also considering the consumer impacts, is likely to be toxic.

The detrimental impacts of BNPL and indebtedness on many consumers are a large source of concerns regarding the impacts of BNPL, both generally and specifically in terms of asymmetric information and the consumer not knowing what is best for themselves. That is, the Australian regulations appear to not even make the minimum threshold of not having substantial market failures evident.

The emerging evidence of consumer detriment for such a rapidly growing fintech offering could generate widespread consumer harm for vulnerable consumer segments unless regulators change to curb such growing and foreseeable consumer detriment. In the immediate term, there is a sliver of hope that, after considering the impacts on relatively vulnerable consumers, ASIC may be motivated to apply their current powers, but the specific forms of market failure are also concerning. The design of policy interventions should make the negative impacts on consumers less likely [7], especially given the likelihood that firms may exploit the above failures $[7,9]$.

Financial services and fintech products impacting consumers will remain an ongoing concern and therefore need vigilant regulation because a key characteristic of debt is that it is rigid, both directly and in terms of required payments. Debt is rigid in that it "is a fixed claim for repayment regardless of the value of the underlying asset" or the debtor's circumstances [101] (p. 418). The rigidity of debt makes it dangerous, especially in declining economic situations. Perhaps the easiest case for demonstrating the rigidity of debt is the case of mortgages. If the value of a mortgaged house declines, any losses concentrate in the homeowners, potentially leading to financial ruin for entire families [102]. Debt rigidity may also occur in terms of any legal obligation for scheduled fixed payments from the debtor to the creditor regardless of the debtor's circumstances or market conditions [101]. Further, as reviewed earlier, BNPL debt and payments particularly impact younger people and can have contagion effects to other forms of credit, as well as impact their wellbeing. The negative effects of unmanageable debt can include poverty, job loss, health problems, and family instability [103]. Any of these outcomes would be detrimental to the consumer and therefore regulatory interventions are likely to be required.

Aggregating the private impacts of excessive debt in a society can lead to systemic failures in national and global economies, as we have seen in the recent global financial crisis, with adverse effects falling disproportionately on persons of limited financial means [101], 
the people who most needed protection. Consumer protection can occur via "general" regulatory action (e.g., by ensuring disclosure, fair contracts terms, best practices relating to disclosure and advertising) and/or defence of consumers' interests, particularly through education and awareness (e.g., [104]) and where specific conflicts arise, through mediation [15]. Future regulation also may want to consider the connection between well-being and regulation, where the externalities of excessive debt should include social elements such as good health, adequate shelter, access to education, and a life free from undue anxiety and fear [103].

Addressing regulatory failures will not only occur through regulatory action or changes. Some elements or portions of the regulatory failures noted above may be addressed through "market" actions. For example, over time, markets may develop institutions and practices (e.g., information-generating entities, certifying agencies) that can ameliorate the problems of asymmetric information, although those activities may involve costs and imperfections that would not be present if the asymmetric information problem were absent [4].

But with the strong incentives for regulatory evasion and arbitrage, regulators should be both proactive and cautious [7]. More specifically, in addressing the market failure problem of individuals' being unaware of their own best interests, regulation interventions may be best approached through, for example, mandated changes in production processes and/or product qualities or types [4]. Addressing the problems of incomplete information and asymmetric information would also use those interventions, but could also include information regulation where sellers attach specified types of information to the goods and services they sell [4].

Evidence of consumer detriment is already mounting across several countries. However, the consumer impact of BNPL also needs to take into account the opportunity cost of directing spending toward discretionary items such as shoes, clothing, and homewares through BNPL arrangements at the cost of a myriad of wealth accumulation strategies for consumers. BNPL providers market their arrangement to merchants, citing increased average sales, including of more expensive items, implying that the BNPL arrangement leads consumers to spend more on discretionary items over time with higher conversion rates at checkout and higher average orders [105]. As such, even for those BNPL users who make all of their payments on time, it may be at the cost of better targeted, more conscious consumerism coupled with wealth accumulation and investment strategies that could lead to a range of more favourable outcomes for consumers and the economy over the longer term.

\section{Conclusions}

This paper has reviewed the results of a behaviourally informed market failure approach to regulatory assessment for the specific fintech of fee-based BNPL, particularly in Australia. The review argues that fee-based BNPL in Australia is mostly characterized by the occurrence of destructive and toxic regulatory capture, along with the detrimental impacts of BNPL and indebtedness on consumers suggest that the Australian regulations do not even make the minimum threshold of not having substantial market failures evident. The ongoing reluctance to incorporate social utility into regulatory consideration is striking given the growth of these alternative forms of finance known as fintech [17]. Consideration of the social context and social consequences of financial services may encourage a richer conversation about financial services and the risks of fuelling the economy with debt-funded consumption [103].

Compelling arguments that the damage caused by events such as the GFC is evidence of the need to have greater social and intellectual heterogeneity in regulatory policy debates have grown and are questioning the social purpose of finance [57]. That is, financial services used to once be part of the social fabric, but by talking only to itself, finance has torn that fabric and now needs to rediscover their social usefulness [17]. 
There have been some moves to incorporate social considerations into financial services, such as the growth of "ethical banking," which have been increasingly legitimized in regulation [106]. At the other extreme, micro-finance initiatives, especially in developing countries, may be a less mainstream example of financial services that have a social value that is growing in recognition [107]. To some extent such changes, although currently small, in the relatively mainstream financial services organizations are a recognition of financial services having a purpose of generating social value. In the fintech space, it could be argued that P2P lending may represent a form of consumer and small business finance that has some purposeful elements of social inclusion, although the social outcomes are still somewhat ambiguous [17].

Yet for an increasing number of BNPL users, and arguably for the financial services system itself, BNPL appears to be generating consumer detriment. A small portion of BNPL companies may be aiming to facilitate socially useful activities, such as the funding of solar panels, but most are not and instead are vehicles of over-consumption [81]. Similarly, forms of fintech have used regulatory failures in other markets, such as energy markets, to manipulate prices for their own benefit, at least temporarily and to the short and longterm detriment of society [60].

Regulations addressing the specific consumer failures noted above tend to require that "unsafe" products and services be banned from markets as a means of providing safety in a society with diverse decision-making capabilities [4]. So, it is in the interest of specific forms of fintech to consider appropriate regulation and reconnect to the social fabric by having social utility. In time, regulators may move beyond relatively reactive approaches to proactively regulating financial services and move on to adopt more sustainable practices that require financial services and fintech services to rethink their businesses and move ahead to more sustainable business models [56].

Fintech is a category of financial services, and if not appropriately regulated, may be associated with regulatory failure. Debt is rigid and can cause consumer harm. When aggregated, unmanageable debt can cause systemic damage. So for their own longevity, regulations should be in place and in effect that enable fintech to have social utility. Applying the calls of [17] to fintech, future research needs to develop systems to assess the social utility of a specific form of fintech in order to contribute to the social fabric and be socially sustainable. Behaviourally informed regulation, with constructive consideration of the nature of human behaviour [9] could lead to a new, more sustainability-enabling approach to financial services regulation.

Author Contributions: Conceptualization, D.J. and J.R.; writing—original draft preparation, D.J., J.R. and T.H.; writing - review and editing, D.J., J.R. and T.H. All authors have read and agreed to the published version of the manuscript.

Funding: This research received no external funding.

Institutional Review Board Statement: Not applicable.

Informed Consent Statement: Not applicable.

Data Availability Statement: Not applicable.

Conflicts of Interest: The authors declare no conflict of interest.

\section{References}

1. Brynjolfsson, E.; McAfee, A. The Second Machine Age: Work, Progress, and Prosperity in a Time of Brilliant Technologies; WW Norton \& Company: New York, NY, USA, 2014.

2. Puschmann, T. Fintech. Bus. Inf. Syst. Eng. 2017, 59, 69-76. [CrossRef]

3. Moravec, H. Mind Children: The Future of Robot and Human Intelligence; Harvard University Press: Cambridge, MA, USA, 1988.

4. White, L.J. International regulation of securities markets: Competition or harmonization? In The Industrial Organization and Regulation of the Securities Industry; University of Chicago Press: Chicago, IL, USA, 1996; pp. 207-242.

5. Milian, E.Z.; Spinola, M.d.M.; de Carvalho, M.M. Fintechs: A literature review and research agenda. Electron. Commer. Res. Appl. 2019, 34, 100833. [CrossRef] 
6. Schueffel, P. Taming the beast: A scientific definition of fintech. J. Innov. Manag. 2017, 4, 32-54. [CrossRef]

7. Stiglitz, J. Regulation and Failure. In New Perspectives on Regulation; Moss, D., Cisternino, J., Eds.; The Tobin Project: Cambridge, MA, USA, 2009; pp. 11-23.

8. Parker, C. Reducing the Risk of Policy Failure: Challenges for Regulatory Compliance; Organisation for Economic Co-Operation and Development: Paris, France, 2000.

9. Barr, M.S.; Mullainathan, S.; Shafir, E. Behaviorally Informed Regulation. In The Behavioral Foundations of Public Policy; Shafir, E., Ed.; Princeton University Press: Princeton, NJ, USA, 2013.

10. Hillyer, W.H. Four centuries of factoring. Q. J. Econ. 1939, 53, 305-311. [CrossRef]

11. Mian, S.L.; Smith, C.W., Jr. Accounts receivable management policy: Theory and evidence. J. Financ. 1992, 47, 169-200. [CrossRef]

12. Phelps, C.W. The Role of Factoring in Modern Business Finance; Commercial Credit, Co.: Baltimore, MD, USA, 1956.

13. Buy Now Pay Later: An Industry Update; Australian Securities and Investments Commission: Brisbane, Australia, 2020.

14. Taylor, M. "Twin Peaks": A Regulatory Structure for the New Century; Centre for the Study of Financial Innovation: London, UK, 1995.

15. Wymeersch, E. The structure of financial supervision in Europe: About single financial supervisors, Twin Peaks and multiple financial supervisors. Eur. Bus. Organ. Law Rev. 2007, 8, 237-306. [CrossRef]

16. Llewellyn, D.T. Institutional Structure of Financial Regulation and Supervision: The Basic Issues. In Proceedings of the World Bank Seminar, Washington, DC, USA, 6-7 June 2006.

17. Rogers, C.; Clarke, C. Mainstreaming social finance: The regulation of the peer-to-peer lending marketplace in the United Kingdom. Br. J. Politics Int. Relat. 2016, 18, 930-945. [CrossRef]

18. Bell, S.; Hindmoor, A. Taming the City? Ideas, structural power and the evolution of British banking policy amidst the great financial meltdown. New Political Econ. 2015, 20, 454-474. [CrossRef]

19. James, S.; Quaglia, L. Why does the United Kingdom (UK) have inconsistent preferences on financial regulation? The case of banking and capital markets. J. Public Policy 2019, 39, 177-200. [CrossRef]

20. Buy Now Pay Later Offers_Feedback on CP18/43 and Final Rules; Financial Counselling Australia: Melbourne, Australia, 2019.

21. GlobalData Retail. Retailers Without ‘Buy Now, Pay Later' Will Pay the Price. Available online: https://www.just-style.com/ comment/retailers-without-buy-now-pay-later-will-pay-the-price_id140156.aspx (accessed on 15 December 2020).

22. Wearn, R. The Rapid Rise of 'Buy Now, Pay Later'. Available online: https://www.bbc.com/news/business-51195759 (accessed on 2 December 2020).

23. Perimeter Report 2019/20; Financial Conduct Authority: London, UK, 2020.

24. Financial Conduct Authority. Christopher Woolard to Chair Review of Unsecured Credit Market Regulation 2020. Available online: https:/ / www.fca.org.uk/news/press-releases/christopher-woolard-chair-review-unsecured-credit-market-regulation (accessed on 11 December 2020).

25. The Money Charity Response to FCA Consultation Paper CP18/43 on Buy Now Pay Later Offers; The Money Charity: London, UK, 2019.

26. The Future of Credit. A European Perspective; Monitor Deloitte: New York, NY, USA, 2019.

27. Bordo, M.D.; Redish, A.; Rockoff, H. Why didn't Canada have a banking crisis in 2008 (or in 1930, or 1907, or ... )? Econ. Hist. Rev. 2015, 68, 218-243. [CrossRef]

28. Guidara, A.; Lai, V.S.; Soumaré, I.; Tchana, F.T. Banks' capital buffer, risk and performance in the Canadian banking system: Impact of business cycles and regulatory changes. J. Bank. Finance 2013, 37, 3373-3387. [CrossRef]

29. Gueyié, J.-P.; Guidara, A.; Lai, V.S. Banks' non-traditional activities under regulatory changes: Impact on risk, performance and capital adequacy. Appl. Econ. 2019, 51, 3184-3197. [CrossRef]

30. FCA Canada. Buy Now, Pay Later Plans. Available online: https://www.canada.ca/en/financial-consumer-agency/services/ loans/buy-now-pay-later.html (accessed on 2 December 2020).

31. Regulatory Charter: Financial Markets Regulatory System; New Zealand Council of Financial Regulators: Wellington, New Zeland, 2020.

32. Stulz, R.M.; Williamson, R. Culture, openness, and finance. J. Finance Econ. 2003, 70, 313-349. [CrossRef]

33. La Porta, R.; Lopez-De-Silanes, F.; Shleifer, A.; Vishny, R.W. Legal determinants of external finance. J. Finance 1997, 52, 1131-1150. [CrossRef]

34. Acemoglu, D.; Johnson, S.; Robinson, J.A. Reversal of fortune: Geography and institutions in the making of the modern world income distribution. Q. J. Econ. 2002, 117, 1231-1294. [CrossRef]

35. Facts and Figures: Banking in Europe 2020; European Banking Federation: Brussels, Belgium, 2019.

36. Bebenroth, R.; Dietrich, D.; Vollmer, U. Bank regulation and supervision in bank-dominated financial systems: A comparison between Japan and Germany. Eur. J. Law Econ. 2009, 27, 177-209. [CrossRef]

37. Leonida, L. Do Basel Accords influence competition in the banking industry? A comparative analysis of Germany and the UK. J. Bank. Regul. 2018, 19, 64-72. [CrossRef]

38. Brandl, B.; Hornuf, L. Where did fintechs come from, and where do they go? The transformation of the financial industry in Germany after digitalization. Front. Artif. Intell. 2020, 3. [CrossRef]

39. Banking Act (Gesetz Uber das Kreditwesen); Deutsche Bundesbank Eurosystem: Frankfurt, Germany, 2014.

40. Global Payments 2020-30 A Quantum Shift in the Next Decade; McLean Roche Consulting Group: Melbourne, Australia, 2020. 
41. Klarna. Klarna-Europe's Newest Bank is Born 2017. Available online: https://www.klarna.com/international/press/klarnaeuropes-newest-bank-is-born/ (accessed on 2 December 2020).

42. Fresh, A.; Bailey, M. What Does International Experience Tell us About Regulatory Consolidation? Pew Economic Policy Group: Philadelphia, PA, USA, 2009.

43. Brean, D.J.S.; Kryzanowski, L.; Roberts, G.S. Canada and the United States: Different roots, different routes to financial sector regulation. Bus. Hist. 2011, 53, 249-269. [CrossRef]

44. Harnay, S.; Scialom, L. The influence of the economic approaches to regulation on banking regulations: A short history of banking regulations. Camb. J. Econ. 2016, 40, 401-426. [CrossRef]

45. Levitin, A. What Is "Credit"? Afterpay, Earnin', and ISAs 2019. Available online: https://protectborrowers.org/what-is-credit/ (accessed on 8 December 2020).

46. Truth in Lending Act (TILA); United States Congress: Washington, DC, USA, 1968.

47. Point-of-Sale Lender QuadPay Agrees to Cease Illegal Loans, Pay Refunds in Settlement with the California Department of Business Oversight; Department of Business Oversight: Sacramento, CA, USA, 2020.

48. Backman, M. Study: Buy Now, Pay Later Services Growing Quickly Among U.S. Consumers. Available online: https://www. fool.com/the-ascent/research/buy-now-pay-later-statistics/ (accessed on 8 December 2020).

49. Franson, M.; Manbeck, P. The Regulation of Marketplace Lending: A Summary of the Principal Issues September 2020 Update; Chapman and Cutler: Chicago, IL, USA, 2020.

50. Lui, A. Financial Stability and Prudential Regulation: A Comparative Approach to the UK, US, Canada, Australia and Germany; Routledge: London, UK, 2017.

51. Treasury Financial System Inquiry Final Report; Commonwealth of Australia: Canberra, Australia, 1997.

52. Sohn, W.; Vyshnevskyi, I. The 'Twin Peaks' model of post-crisis banking supervision. Appl. Econ. Lett. 2017, 24, 571-574. [CrossRef]

53. Carmichael, J. Making the Structural Decision. In Aligning Financial Supervisory Structures with Country Need; Fleming, A., Llewellyn, D.T., Carmichael, J., Eds.; The World Bank: Washington, DC, USA, 2004.

54. Lowe, P. Innovation and Regulation in the Australian Payments System. Available online: https://www.rba.gov.au/speeches/20 20/sp-gov-2020-12-07.html (accessed on 20 December 2020).

55. Di Giorgio, G.; Di Noia, C.; Piatti, L. Financial Market Regulation: The Case of Italy and a Proposal for the Euro Area; The Wharton Financial Institutions Center: Philadelphia, PA, USA, 2000.

56. Mejia-Escobar, J.C.; González-Ruiz, J.D.; Duque-Grisales, E. Sustainable financial products in the Latin America banking industry: Current status and insights. Sustainability 2020, 12, 5648. [CrossRef]

57. Baker, A. Restraining regulatory capture? Anglo-America, crisis politics and trajectories of change in global financial governance. Int. Aff. 2010, 86, 647-663. [CrossRef]

58. Carpenter, D.; Moss, D.A. Preventing Regulatory Capture: Special Interest Influence and How to Limit It; Cambridge University Press: Cambridge, UK, 2013.

59. Morse, A. Peer-to-peer crowdfunding: Information and the potential for disruption in consumer lending. Annu. Rev. Financ. Econ. 2015, 7, 463-482. [CrossRef]

60. Gatto, A.; Busato, F. Evidenze empiriche dalla volatilità dei prezzi elettrici durante la crisi energetica californiana. Cattura del regolatore nel caso Enron? Monet Credito 2019, 72, 29-46.

61. The Senate Select Committee on Financial Technology and Regulatory Technology Interim Report; Commonwealth of Australia: Canberra, Australia, 2020.

62. Tullock, G. The welfare costs of tariffs, monopolies, and theft. Econ Inq. 1967, 5, 224-232. [CrossRef]

63. Tullock, G. Where is the Rectangle? Public Choice 1997, 91, 149-159. [CrossRef]

64. Sadik-Zada, E.R.; Gatto, A. The puzzle of greenhouse gas footprints of oil abundance. Socio Econ. Plan. Sci. $2020,100936$. [CrossRef]

65. Moro-Visconti, R.; Cruz Rambaud, S.; López Pascual, J. Sustainability in fintechs: An explanation through business model scalability and market valuation. Sustainability 2020, 12, 10316. [CrossRef]

66. Sadik-Zada, E.R.; Gatto, A. Determinants of the public debt and the role of the natural resources: A cross-country analysis. FEEM Work. Pap. No. 4 2019. [CrossRef]

67. Barr, M.S.; Mullainathan, S.; Shafir, E. Behaviorally Informed Financial Services Regulation; New America Foundation: Washington, DC, USA, 2008.

68. Cigno Pty Ltd v Australian Securities and Investments Commission; Federal Court of Australia: Sydney, Australia, 2020.

69. Astbury, H. Major US bank bars BNPL, will Australia follow? Available online: https://www.savings.com.au/buy-now-paylater/major-us-bank-bars-bnpl-will-australia-follow (accessed on 12 December 2020).

70. Schor, J. The new politics of consumption. Boston Rev. 1999, 24, 4-9.

71. Crouch, C. Privatised Keynesianism: An unacknowledged policy regime. Br. J. Politics Int. Relat. 2009, 11, 382-399. [CrossRef]

72. Reserve Bank of Australia. C1 Credit and Charge Cards-Seasonally Adjusted Series. Available online: https://www.rba.gov.au/ statistics/tables/xls/c01hist.xlsx (accessed on 26 December 2020).

73. Review of Buy Now Pay Later Arrangements; Report 600; Australian Securities and Investments Commission: Brisbane, Australia, 2018. 
74. Australia Forest for Trees. Seeing the Next Era for Banking in Australia? PricewaterhouseCoopers: Adelaide, Australia, 2019.

75. Turunen, E.; Hiilamo, H. Health effects of indebtedness: A systematic review. BMC Public Health 2014, 14, 489. [CrossRef] [PubMed]

76. O'Neill, B.; Sorhaindo, B.; Xiao, J.J.; Garman, E.T. Financially distressed consumers: Their financial practices, financial well-being, and health. J. Financ. Couns. Plan. 2005, 16, 73-87.

77. Blaywais, R.; Rosenboim, M. The effect of cognitive load on economic decisions. Manag. Decis. Econ. 2019, 40, 993-999. [CrossRef]

78. Angel, S. The effect of over-indebtedness on health: Comparative analyses for Europe. Kyklos 2016, 69, 208-227. [CrossRef]

79. Amit, N.; Ismail, R.; Zumrah, A.R.; Nizah, M.A.M.; Muda, T.E.A.T.; Meng, E.C.T.; Ibrahim, N.; Din, N.C. Relationship between debt and depression, anxiety, stress, or suicide ideation in Asia: A systematic review. Front. Psychol. 2020, 11, 1336. [CrossRef]

80. Drentea, P. Age, debt and anxiety. J. Health Soc. Behav. 2000, 41, 437-450. [CrossRef]

81. Fook, L.A.; McNeill, L. Click to buy: The impact of retail credit on over-consumption in the online environment. Sustainability 2020, 12, 7322. [CrossRef]

82. Stavins, J. Credit card debt and consumer payment choice: What can we learn from credit bureau data? J. Financ. Serv. Res. 2020, 58, 59-90. [CrossRef]

83. Robb, C.A. Financial knowledge and credit card behavior of college students. J. Fam. Econ. Issues 2011, 32, 690-698. [CrossRef]

84. Nelson, M.C.; Lust, K.; Story, M.; Ehlinger, E. Credit card debt, stress and key health risk behaviors among college students. Am. J. Health Promot. 2008, 22, 400-406. [CrossRef] [PubMed]

85. Zhang, Q.; Kim, H. American young adults' debt and psychological distress. J. Fam. Econ. Issues 2018, 40, 22-35. [CrossRef]

86. Boden, J.; Maier, E.; Wilken, R. The effect of credit card versus mobile payment on convenience and consumers' willingness to pay. J. Retail. Consum. Serv. 2020, 52, 101910. [CrossRef]

87. West, R.; Ramcharan, P. The emerging role of financial counsellors in supporting older persons in financial hardship and with management of consumer-directed care packages within Australia. Aust. J. Soc. Issues 2019, 54, 32-51. [CrossRef]

88. Meier, S.; Sprenger, C. Present-biased preferences and credit card borrowing. Am. Econ. J. Appl Econ. 2010, 2, 193-210. [CrossRef]

89. Kim, J.; Garman, E.T.; Sorhaindo, B. Relationships among credit counseling clients' financial well-being, financial behaviors, financial stressor events, and health. J. Financ. Couns. Plan. 2003, 14, 75.

90. Xiao, J.J.; Sorhaindo, B.; Garman, E.T. Financial behaviours of consumers in credit counselling. Int. J. Consum. Stud. 2006, 30, 108-121. [CrossRef]

91. Kim, J.; Garman, E.T.; Sorhaindo, B. Study finds positive financial behaviors increased: Credit counseling, debt management effective. J. Fam. Consum. Sci. 2005, 97, 35.

92. Bernthal, M.J.; Crockett, D.; Rose, R.L. Credit cards as lifestyle facilitators. J. Consum. Res. 2005, 32, 130-145. [CrossRef]

93. Hodson, R.; Dwyer, R.E.; Neilson, L.A. Credit card blues: The middle class and the hidden costs of easy credit. Sociol. Q. 2014, 55, 315-340. [CrossRef]

94. Wong, K.-Y.; Lynn, M. The easy-money effect: Credit card spending and hard-work reminders. J. Consum. Mark. 2017, 34, 541-551. [CrossRef]

95. Wong, K.Y.; Lynn, M. Credit card cue effect. Int. J. Bank Mark. 2019, 38, 368-383. [CrossRef]

96. Feinberg, R.A. Credit cards as spending facilitating stimuli: A conditioning interpretation. J. Cons. Res. 1986, 13, 348-356. [CrossRef]

97. Gatto, A. Historical roots of microcredit and usury: The role of Monti di Pietà in Italy and in the kingdom of Naples in XV-XX centuries. J. Int. Dev. 2018, 30, 911-914. [CrossRef]

98. Arrow, K.J. The Economics of Agency; Stanford University: Stanford, CA, USA, 1984.

99. Kofman, P.; Payne, C. A Matter of Trust: The Practice of Ethics in Finance; Melbourne University Publishing: Melbourne, Australia, 2017.

100. Rank the Banks and Other Creditors 2019; Financial Counselling Australia: Melbourne, Australia, 2020.

101. Linarelli, J. Debt in just societies: A general framework for regulating credit. Regul. Gov. 2020, 14, 409-427. [CrossRef]

102. Leicht, K.T. Borrowing to the brink: Consumer debt in America. In Broke: How Debt Bankrupts the Middle Class; Porter, K., Ed.; Stanford University Press: Stanford, CA, USA, 2012.

103. Porter, K. The damage of debt. Wash. Lee Law Rev. 2012, 69, 979.

104. Recommendation on Principles and Good Practices for Financial Education and Awareness; Organisation for Economic Co-Operation and Development: Paris, France, 2005.

105. Afterpay US Services. For Retailers-Afterpay-Buy Now Pay Later with Afterpay. Available online: https://www.afterpay. com/for-retailers (accessed on 22 December 2020).

106. Guzmán, C.; Savall, T.; Solórzano-García, M. Ethical banking in Spain: Does an organisational identity exist that distinguishes it from conventional banking? J. Soc. Entrep. 2020, 1-28. [CrossRef]

107. Lehner, O.M.; Nicholls, A. Social finance and crowdfunding for social enterprises: A public-private case study providing legitimacy and leverage. Ventur. Cap. 2014, 16, 271-286. [CrossRef] 



\title{
Digital Transformation and Knowledge Management in the Public Sector
}

\author{
Ana Alvarenga ${ }^{1}$, Florinda Matos ${ }^{2, *}$, Radu Godina ${ }^{3}$ and João C. O. Matias ${ }^{4,5}$ \\ 1 Department of Information Science and Technology, Instituto Universitário de Lisboa (ISCTE-IUL), \\ 1649-026 Lisboa, Portugal; arcfa@iscte-iul.pt \\ 2 Centre for Socioeconomic and Territorial Studies (DINÂMIA'CET-ISCTE), Instituto Universitário de \\ Lisboa (ISCTE-IUL), 1649-026 Lisboa, Portugal \\ 3 UNIDEMI, Department of Mechanical and Industrial Engineering, NOVA School of Science and Technology, \\ Universidade NOVA de Lisboa, 2829-516 Caparica, Portugal; r.godina@fct.unl.pt \\ 4 DEGEIT-Departamento de Economia, Gestão, Engenharia Industrial e Turismo, Universidade de Aveiro, \\ Campus Universitário de Santiago, 3810-193 Aveiro, Portugal; jmatias@ua.pt \\ 5 GOVCOPP_Unidade de Investigação em Governança, Competitividade e Políticas Públicas, \\ Universidade de Aveiro, Campus Universitário de Santiago, 3810-193 Aveiro, Portugal \\ * Correspondence: florinda.matos@iscte-iul.pt
}

Received: 26 June 2020; Accepted: 17 July 2020; Published: 20 July 2020

\begin{abstract}
Digitizing public services is, at the moment, an essential necessity for numerous governments around the world. An improved government through digitization will not only have a growing effect on businesses, but it will also be able to intensify citizen engagement and push for economic growth. During the last 10 years more countries have progressively begun to provide digital services to their citizens. Therefore, in order to address this development, the purpose of this paper is to analyze the evolution of the digital government literature in order to describe the aspects of digital transformation in the public sector and how it is related to knowledge management. In this study the methodology is quantitative and it is based on a review and a survey made with the main goal being the estimation from several collected data on how the digital transformation process in the Public Administration takes place and what its relationship is with knowledge management. The review study is based on articles found on Scopus database and it addresses the role that digital government research plays in the theory and practice of knowledge management. In the survey study, 54 employees working for the services of the two governmental areas of the Portuguese Ministry of the Environment were surveyed. The results show that the research on the theme is still at an exploratory stage due to the lack of studies relating digital government to knowledge management effectiveness in the public sector. The results also show that the success of digital government seems to be related with the quality of the organizations' knowledge management, complementing each other for significant improvements in the public sector. In terms of originality, this study aims to contribute and stimulate data-driven discussions regarding the impacts of the digital transformation in the public sector and their relation with the implementation of knowledge management practices. The results offer insights into future research needs.
\end{abstract}

Keywords: digital transformation; knowledge management; digital government; public sector; public administration

\section{Introduction}

Digital transformation is a necessity for the modern enterprise, whether public or private, due to the strength and vertiginous speed with which digitalization has entered and has taken over our lives, which has meant that many organizations have not been able to adapt to it yet. The main and 
most important reason for this state of affairs in organizations is the lack of knowledge or trained personnel, which could allow them to understand how to cope with this change. While many public administration services have made great progress, the full potential of digital adaptation remains untapped. The digital government panorama changes continually to reflect how the government tries to find innovative digital solutions in social, economic, and political areas and how it could transform the decision-making process [1-3].

The current rising necessity of organizational change is altering, through digital transformation, the way governments look at knowledge management practices to address social needs or improve service delivery effectively. Understanding and predicting these changes is extremely important for policymakers, government executives, researchers, and all those who prepare, devise, implement, or evaluate digital government decisions [4].

In [5], three benefits of knowledge management in digital governance were identified: the enhancement of government competence, the increase in quality of government service, and the promotion of a healthy government development. Thus, this supports the idea that the success of digital government depends heavily on knowledge management.

Knowledge management came to the forefront due to the need for public and private organizations to make more rational and effective use of their knowledge [6]. As the authors state in [7], knowledge management "may potentially offer a competitive advantage and help develop knowledge-intensive economies".

Therefore, knowledge management is an important and specific issue in the research context of the public sector. The authors in [8] affirm that "the public sector is influenced by a growing need for: competition, performance standards, monitoring, measurement, flexibility, emphasis on results, customer focus and control". It seems that "knowledge management for government is no longer a choice, but an imperative if economies are to survive in the era of privatization, liberalization, and globalization" [9]. According to the authors in [10], knowledge management "has the potential to greatly influence and improve public sector renewal processes". Indeed, within the public sector, knowledge management "is a powerful facilitator in the current push for greater efficiency in all areas" [11].

Nevertheless, in [10] it is argued that "the development of a knowledge management culture within the public sector is more challenging than in the private sector". The study in [12] supports this argument by highlighting that "organizational goals in public organizations are typically more difficult to measure and more conflicting than in private organizations and are affected differently by political influences".

According to [13], knowledge management has been an object of attention of the academic community, public decision-makers, consultants, and business people since the beginning of the 1990s. A study published in the Journal of Knowledge Management, reports that the importance of knowledge management in the public sector is growing as a research area. It points out that the low level of international cooperation between the authors and the small number of comparative case studies show that the literature is fragmented [14].

Deliberately, systematically, and holistically managing knowledge can increase awareness of the benefits to individuals and organizations. However, there seems to be a lack of knowledge management awareness in the public sector. This can be severely detrimental in the process of digital transformation and in the effective implementation of knowledge management initiatives in organizations seeking to increase performance.

One of the purposes of this paper is to present a structured literature review of the digital government and knowledge management in public administration. In addition, as this article consolidates a body representative of the digital government literature, it can also be used to define and integrate future research in the area. The scientific literature review was carried out in support of an exploratory research, which consisted of analyzing the effect of digital transformation on knowledge management practices in Portuguese Public Administration. 
Thus, the study has the following objectives: to verify if the digital transformation has changed the way the public organization carries out the knowledge management processes and to effectively identify knowledge management practices related to the digital transformation process. Therefore, the research question was: what is the relationship between the implementation of digital transformation and the use of knowledge management practices in public organizations? - and the research hypothesis is: the digital transformation process has an impact on knowledge management practices and, knowledge management, in turn, is a critical factor in the success of digital transformation.

Furthermore, to fulfill the objectives and hypothesis defined by the exploratory research, in the literature review are analyzed several studies in order to understand the definitions, origins, and peculiarities of digital transformation and knowledge management in the public sector. The literature review reveals who has already written and what has been published on the subject, what aspects have already been addressed, and which aspects are least addressed on the research topic.

This paper is composed of several sections: Section 2 presents the literature review methodology and Section 3 addresses the questionnaire methodology; Section 4 presents the literature review results and their analysis. Section 5 presents the results and the analysis of the survey and, finally, in Section 6 a conclusion that offers a future research agenda and limitations is presented.

\section{Literature Review Methodology}

\subsection{The Structured Literature Review}

This article employs a variant of a structured literature review to answer the research question addressed in the introduction. The methodology is similar to other recent reviews of the literature [14-18]. A structured review of the literature critically identifies, selects, and evaluates the research in order to answer a formulated question [19]. Performing a literature review is a formal way of synthesizing available information from available primary studies relevant to a set of research questions. It involves planning a well-thought-out research strategy that has a specific focus and answers those questions.

The literature review follows a clearly defined protocol where the criterion is prominently stated before the review is made. It is a comprehensive and transparent survey based on databases and grey literature that can be replicated and reproduced by other researchers. The review identifies the type of information researched, criticized, and reported within known time frames. Search terms, search strategies (including database names, platforms, search dates), and thresholds are all included in the review. As stated in [20], "greater clarity about the terminology and methods surrounding literature reviews will help researchers identify when and how such revisions can be made".

In this article the methodology of structured literature review is applied in order to share the results of other studies that are within the scope of the research, relate a study to the broader current dialogue in the literature on a topic, filling gaps and expanding previous studies, and finally, provide a framework to establish the importance of the study and an indicator to compare the results of the study with other outcomes.

According to the methodology of structured literature review, several authors $[15,17,18]$ formulated the following main steps:

1. Define the research questions.

2. Write a research protocol for the review.

3. Determine the articles to include and carry out a comprehensive bibliographic search.

4. Develop a coding framework.

5. Code the articles and ensure reliability.

6. Analyze critically and discuss results. 
Therefore, this article presents a comprehensive review of digital government articles published in the Scopus database from 2000 until the beginning of 2019. The following subsections describe the methods applied to the development of the literature review.

\subsection{Research Protocol}

A research protocol provides a step-by-step guide for conducting literature reviews, which may include systematic reviews, scope reviews, and meta-analyses. According to the authors in [21], "it is essential to write a protocol stating the review question, the methods to be used, the types of study and projects that the reviewer intends to find, and by what means and how studies will be evaluated and synthesized".

Therefore, research protocols are essential to ensure high-quality literature reviews. However, defining a protocol comprises many aspects, such as the formulation of research questions, definition of a search strategy and the adequate sources where to find primary studies, specification of the inclusion and exclusion criteria to be used in the selection of studies, and characterization of the process to be used to extract, synthesize, describe, and categorize the selected studies, extracting data and making quality evaluations.

The protocol should contain specific guidelines for identifying and selecting articles relevant to the review as well as outlining review methods for the entire process.

Following these suggestions, a written protocol was developed, describing the identification of the keywords, the source of information, the support tools and the main information searched in the documents. In this way, steps were defined in the research protocol, such as the construction of the collection of articles (Sample I); filtration process; scientometric analysis; content analysis (Sample II), and finally, the construction of gaps and research opportunities. A manual coding procedure was also developed, which indicated which information to recover from each paper, since "manual coding has advantages compared to computer-aided coding because when words with similar meanings like 'human capital' and 'employees' are found, they can be understood in their real sense and encoded accordingly" [15].

Thus, the review protocol is essential to reduce bias in the review process and limit overlap with existing reviews. It also provides an outline for the review process that helps plan and anticipate challenges that may arise during the review.

\subsection{Literature Research}

For the paper selection, a bibliographic research methodology was adopted based on the analysis of the already published literature, in the form of books, articles, and grey literature, which included knowledge management, digital government, and public administration as the primary research areas.

For the identification of the keywords, several attempts and searches were made in advance until the correct constructions could be chosen. More than 15 research builders were researched and interrelated. It was verified that with the term "digital transformation" the research in the databases returns few studies, detecting a gap in the literature. Alternatively, constructions with terms with similar meaning as "e-government" and "Digital Government" were made.

Regarding the search through keywords, it was carried out in January 2019 in the Scopus database, and a manual coding procedure was adopted to ensure that no articles were lost during the research. Based on the data set, the titles, abstracts, and keywords of all articles published in the periods from 2000 to the beginning of 2019 were examined, and articles containing knowledge management and digital government aspects from a public administration perspective were selected. During the search of documents in the database, a low number of results were observed. Only articles published in the English language were selected.

From this research, an initial group of 69 relevant articles was selected and, of these articles, a final group of 30 articles was used, which are depicted in Table 1. 
Table 1. The 30 found articles addressing digital transformation.

\begin{tabular}{|c|c|}
\hline Reference & Title \\
\hline [22] & $\begin{array}{l}\text { A multi-methods study exploring the role of stakeholders in the digital preservation } \\
\text { environment: The case of Ghana. }\end{array}$ \\
\hline [23] & $\begin{array}{l}\text { Preserving the digital heritage of public institutions in Ghana in the wake of } \\
\text { electronic government. }\end{array}$ \\
\hline [24] & $\begin{array}{l}\text { What lessons can be learned from the US archivist's digital mandate for } 2019 \text { and is there } \\
\text { potential for applying them in lower resource countries? }\end{array}$ \\
\hline [25] & The issues and considerations associated with BIM integration. \\
\hline [26] & Transnational digital government research collaborations: Purpose, value, challenges. \\
\hline [27] & $\begin{array}{l}\text { Public sector readiness for digital preservation in New Zealand: The rate of adoption of an } \\
\text { innovation in records management practices. }\end{array}$ \\
\hline [28] & $\begin{array}{l}\text { Information sharing in and across government agencies: The role and influence of scientist, } \\
\text { politician, and bureaucrat subcultures. }\end{array}$ \\
\hline [29] & Technology as a tool of transformation: E-cities and the rule of law. \\
\hline [30] & Document logistics in the public sector: Integrative handling of physical and digital documents. \\
\hline [31] & Digital government and public management research: Finding the crossroads \\
\hline [32] & Archivists 2.0: Redefining the archivist's profession in the digital age. \\
\hline [33] & Government workers say goodbye to paper \\
\hline [34] & $\begin{array}{l}\text { Creating value through managing knowledge in an e-government to constituency } \\
\qquad \text { (G2C) environment }\end{array}$ \\
\hline [35] & Success factors for public sector information system projects: Qualitative literature review \\
\hline [36] & Solon: A holistic approach for modelling, managing, and mining legal sources \\
\hline [37] & $\begin{array}{c}\begin{array}{c}\text { Knowledge brokering in the web } 2.0 \text { era: Empirical evidence of emerging strategies in } \\
\text { government agencies }\end{array}\end{array}$ \\
\hline [38] & $\begin{array}{l}\text { The fourth industrial revolution, agricultural, and rural innovation, and implications for public } \\
\text { policy and investments: A case of India }\end{array}$ \\
\hline [39] & Exploitation and exploration strategies to create data transparency in the public sector \\
\hline [40] & Ensuring interoperability of geographic information in local government and inspire \\
\hline [41] & 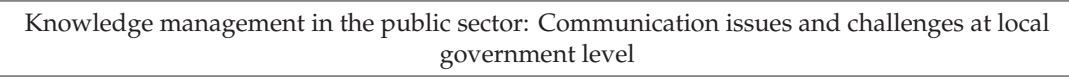 \\
\hline [42] & E-governance in agriculture: Digital tools enabling Filipino farmers. \\
\hline [43] & Digital records keeping to information governance in Estonian local governments \\
\hline [44] & Integrating knowledge management tools for government information \\
\hline [32] & Organizational learning from service innovation in the public sector of Dubai \\
\hline [45] & Case studies on digital government \\
\hline [46] & $\begin{array}{l}\text { Knowledge management system for governance: Transformational approach creating } \\
\text { knowledge as product for governance }\end{array}$ \\
\hline [47] & A conceptual framework for effective appropriation of proactive public e-services \\
\hline [48] & E-government initiatives and information management in two local government authorities \\
\hline [49] & $\begin{array}{c}\text { The e-governance concerns in information system design for effective e-government } \\
\text { performance improvement }\end{array}$ \\
\hline [50] & ICT and PA: A marriage made in heaven? \\
\hline
\end{tabular}

According to [20], "rapid growth literature reviews have resulted in an infinity of terminology to describe approaches that, despite their different names, share certain characteristics, namely, collecting, evaluating, and presenting evidence of available research". 
According to this research, the term "digital transformation" consists of organizational change that uses digital technologies and business models to improve the organization's performance and customer experience. The term e-government consists of the use of information technologies in the internal processes of government, in the delivery of state products and services to both citizens and industry, and in the use of electronic tools and information technologies to approximate government and citizens. The view of e-government as a resource rationalizer seems to be linked to an older, more generalist conception of what digital government is today. For this reason, the search strategy used the terms "Digital Government", "Knowledge Management", and "Public Sector" as keywords.

From the search of those keywords in the Scopus database, 69 results showed up, 39 of which were excluded: 6 because they were in duplicate and 33 because they were outside the scope of the investigation, as it can be seen in Figure 1. The filtering process resulted in sample I, which included 30 articles of studies on digital government, and in sample II, which is composed of 10 articles that were analyzed according to the criterion of the existence of a relationship with knowledge management. In order to obtain sample II, the final 30 selected articles from the databases were filtered using a scientometric analysis, followed by a detailed analysis of the content of the articles by categories, selecting those that were within the scope of the investigation. This sample is composed of 10 articles that contain aspects of knowledge management within the digital government studies.

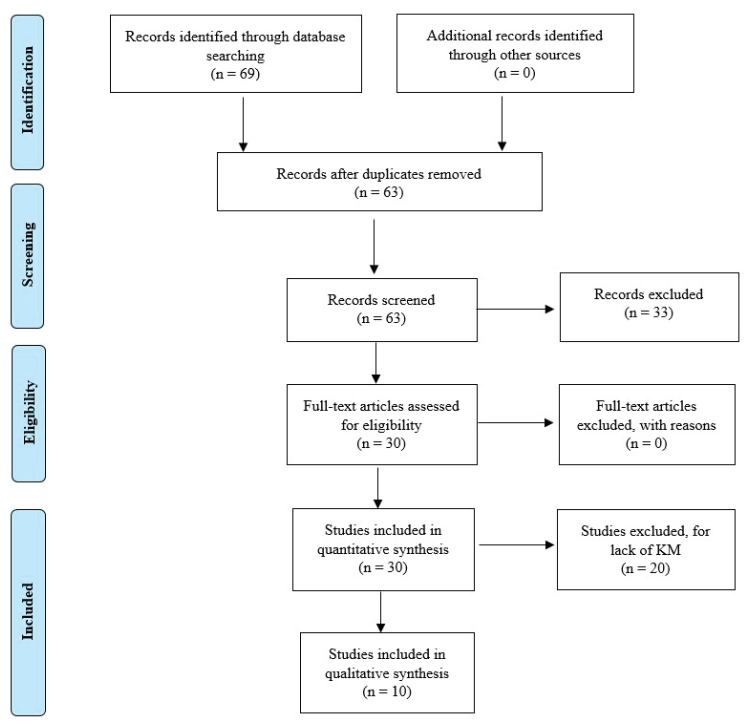

Figure 1. Flow diagram representing the collection of articles in databases and filtering process.

\subsection{Developing a Coding Framework}

The coding framework is based on advanced research frameworks developed by several authors [14-16,18,51]. A formal and systematic approach was adopted by adapting the analytical framework to the data set in order to extract the relevant information. As a result, seven categories were created to systematize the coding, as it can be observed in Table 2 . 
Table 2. Research framework and main results.

\begin{tabular}{|c|c|c|c|}
\hline Category & Variables & Articles & $\%$ \\
\hline \multirow[t]{3}{*}{ Authors, institution, year } & Authors & 61 & \\
\hline & Institution & 40 & \\
\hline & Years & 2000-2019 & \\
\hline \multirow[t]{7}{*}{ Document type } & Conference Paper & 15 & 50.0 \\
\hline & Article & 10 & 33.3 \\
\hline & Review & 2 & 6.7 \\
\hline & Book & 1 & 3.3 \\
\hline & Book Chapter & 1 & 3.3 \\
\hline & Editorial & 1 & 3.3 \\
\hline & Totals & 30 & 100.0 \\
\hline \multirow[t]{6}{*}{ Jurisdiction } & Central government & 19 & 63.3 \\
\hline & State/regional & 2 & 6.7 \\
\hline & Local government & 7 & 23.3 \\
\hline & Public business enterprise (PBE) & 1 & 3.3 \\
\hline & Other & 1 & 3.3 \\
\hline & Totals & 30 & 100.0 \\
\hline \multirow[t]{8}{*}{ Location } & Europe/UK & 14 & 46.6 \\
\hline & Australasia & 1 & 3.3 \\
\hline & North America & 7 & 23.3 \\
\hline & South America & 0 & 0.0 \\
\hline & Africa & 2 & 6.7 \\
\hline & Asia/China & 4 & 13.3 \\
\hline & Other & 2 & 6.7 \\
\hline & Totals & 30 & 100.0 \\
\hline \multirow[t]{9}{*}{ Research method } & Quantitative cross-sectional & 1 & 3.3 \\
\hline & Case study & 7 & 23.3 \\
\hline & Literature review-normative & 3 & 10.0 \\
\hline & Action research & 1 & 3.3 \\
\hline & Qualitative study & 9 & 30.0 \\
\hline & Quantitative study & 2 & 6.7 \\
\hline & Mixed methods & 4 & 13.3 \\
\hline & Other & 3 & 10.0 \\
\hline & Totals & 30 & 100.0 \\
\hline \multirow[t]{4}{*}{ Framework } & No framework-model used & 2 & 6.7 \\
\hline & Applies or considers previous framework-model & 27 & 90.0 \\
\hline & Proposes a new framework-model & 1 & 3.3 \\
\hline & Totals & 30 & 100.0 \\
\hline \multirow[t]{10}{*}{ Theme } & Digital preservation & 3 & 10.0 \\
\hline & Information technology & 8 & 26.7 \\
\hline & knowledge management strategy & 4 & 13.3 \\
\hline & Knowledge innovation & 3 & 10.0 \\
\hline & Management of elements and processes & 3 & 10.0 \\
\hline & Personal and organizational learning & 1 & 3.3 \\
\hline & Organizational culture & 1 & 3.3 \\
\hline & Information management & 6 & 20.0 \\
\hline & Other & 1 & 3.3 \\
\hline & Totals & 30 & 100.0 \\
\hline
\end{tabular}

By looking at Table 2 it is possible to observe that the first category classifies them by journal. The main goal is to analyze the evolution of literature: citation scores were used to measure the impact of articles, authors, and journals.

The second category is a division of the sample by type of document that has been most used in the digital government literature since the year 2004 . 
The third category is jurisdiction based on different levels of government, rather than the broader organizational types found in [15]. In general terms, government jurisdictions are country-specific, while public organizations are comparable across countries. Therefore, by analyzing government jurisdictions, the goal is to understand publication standards and find out if differences in national contexts and data accessibility exist.

The fourth category is the location. Thus, when analyzing a location, the objective is to understand the extent to which the literature supports the development of digital evolution as well as knowledge-intensive economies.

The fifth category is the search method used. Digital government research is still reaching an epistemological consensus among the authors since the main strategies lead to the development of multiple research methods. The goal is to understand what methods have been used in digital government research.

The sixth category is framework-model. This category is derived from [52]. The main objective of the analysis of the framework used is to understand if the literature is proposing new specific models and if it applies or considers the previous framework-models, or if it does not use framework-models for the public sector at all.

The seventh category is the research theme. By analyzing the themes of the selected articles, it was possible to identify areas of interest for other scholars, new research opportunities, and to better understand the scientific dialogue.

After analyzing the articles in sample I and, according to the objective of the development of the review, the category "Focus" used by [14] was removed and the category "Research Theme" was added, giving a clearer information on the evolution and focus of the digital government literature. The classification for this category is similar to that of [52].

\section{Results of the Literature Review and Discussion}

The following subsections present results that attempt to answer the following research questions: the first-research question 1- "What is the evolution and focus of the digital government literature?"; the second-research question 2-“What is the future of research in digital government?"; and, the third,-research question 3- "How does digital government literature relate to knowledge management?".

To do this, gross counts were used, as shown in Table 2. In addition, when issues were found that needed more research and criticism, a more in-depth analysis was conducted based on the combination of the descriptive results, deepening specific questions found in the articles.

\subsection{Authors, Institution, Year}

Analyzing the evolution of articles on digital government in public administration, the results show an increase. The literature search identified 30 relevant articles, of which $73.3 \%$ were published after 2010, suggesting a growing trend. The years included ranged between 2000 and 2019, but in the interval 2000-2003, as well as for the years 2006, 2008, 2013, and 2015, no relevant articles were found for the study as shown in Figure 2. The year that has the highest number of publications is 2018 ( 5 articles) and it is also worth mentioning the years 2017 ( 3 articles) and 2016 (4 articles). This shows, once again, the growing tendency for studies on digital government. Nevertheless, despite the increase in the number of publications per year, the reduced number of documents and a significant shortage of literature about digital government is still evident.

Thus, by observing Figure 2, some of the more recent articles are from 2018 to 2019 [22,31,42,53] and some of the oldest are from 2004 to 2007 [28,33,44]. 


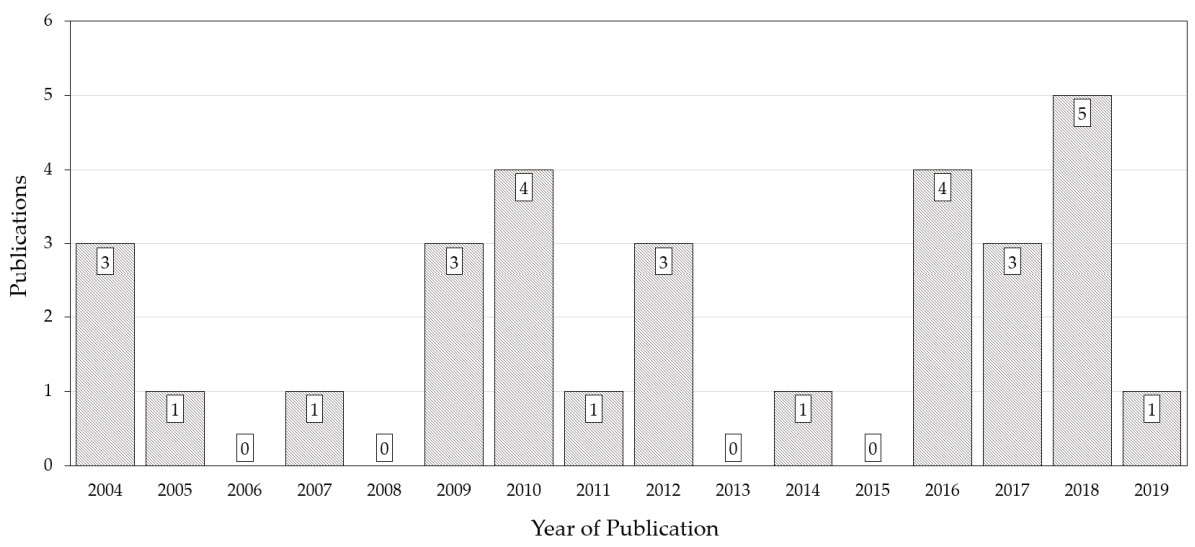

Figure 2. Representation of the total publications by year.

Regarding the analysis of authors, as shown in Table 2, in 30 articles, there are a total of 61 authors/coauthors, showing a significant number of authors who participated in the digital government literature. However, according to Table 1, only two of these authors have more than one publication, showing few dominant authors in the digital government research. The most prolific ones are Kofi Koranteng Adu [22], with two articles published in 2016 and 2018, and Gil-García et al. [31], with two articles published in the years 2011 and 2018.

The main reason for examining these authors and their citations is to verify the superstar effect that sometimes occurs when a small fraction of researchers or institutions produce the highest number of studies and attract a disproportionate number of quotations [54-56]. Although there is a significant fraction of 61 researchers and 40 institutions, there is not a large number of studies led by the same authors or institutions. Thus, in this analysis, the evidence of disproportionately influential individuals was not studied. As an alternative, it opted for the articles with the highest number of publications and their respective authors, according to Table 3.

Table 3. The 12 most cited public sector digital government articles.

\begin{tabular}{ccc}
\hline Paper & Title & Citations \\
\hline$[34]$ & Creating value through managing knowledge in an e-government to constituency & 65 \\
\hline$[$ G2C) environment & $\begin{array}{c}\text { Information Sharing in and Across Government Agencies: The Role and Influence } \\
\text { of Scientist, Politician, and Bureaucrat Subcultures }\end{array}$ & 40 \\
\hline$[44]$ & Integrating knowledge management tools for government information & 25 \\
\hline$[27]$ & $\begin{array}{c}\text { Public sector readiness for digital preservation in New Zealand: The rate of } \\
\text { adoption of an innovation in records management practices }\end{array}$ & 13 \\
\hline$[29]$ & Technology as a tool of transformation: e-Cities and the rule of law & 11 \\
\hline$[43]$ & Digital records keeping to information governance in Estonian local governments & 9 \\
\hline$[32]$ & Archivists 2.0: Redefining the archivist's profession in the digital age & 8 \\
\hline$[45]$ & Case studies on digital government & 6 \\
\hline$[31]$ & Digital government and public management research: finding the crossroads & 4 \\
\hline$[24]$ & What lessons can be learned from the US archivist's digital mandate for 2019 and is & 3 \\
\hline$[23]$ & Preserving the digital heritage of public institutions in Ghana in the wake of & electronic government \\
\hline$[25]$ & The Issues and Considerations Associated with BIM Integration & 3 \\
\hline
\end{tabular}


The article with the most significant number of citations (65) was written by Koh, C.E. et al. [34] and was published in the Journal of Computer Information Systems in 2005. This article, from the University of North Texas, uses as research method a case study about central government focused on information technology and knowledge management. The case study focuses on government agencies due to their challenges in the progression of digitalization, caused by the size and complexity of government structures and the large amount of information these government agencies maintain. Thus, the article proposes that government agencies should go through an evolutionary path as they progress from an introductory digital presence to more complex forms of interaction with constituents. It highlights key facilitators that enable a steady progress by changing how citizens interact with government, increase accessibility to information, and increase efficiency in the public sector.

The article with the second highest number of citations (40), written by Drake, D.B. et al. [28], was published in the Social Science Computer Review in 2004. This article uses an exploratory method and an interdisciplinary study on central government, focusing on issues related to information sharing within and between three public bodies. The study illustrates key points about information sharing among subcultures and some implications for research and practice.

The article written by Prokopiadou, G., et al. [44] has the third highest number of citations (25) and was published in the Government Information Quarterly in 2004. This article uses as research method a qualitative study regarding central government in which it introduces a digital library architecture for the management and delivery of information produced or disseminated through public services. The study notes the lack of advanced information standards and tools and emphasizes public sector challenges such as the presence of fragmented and dispersed information, legislative and administrative diversity, administrative hierarchy, and discrepancies in the implementation of policies at central, regional, and local levels. Furthermore, the study aims to highlight the importance of government information for business transactions, decision-making, and for providing information about organizations to citizens.

The articles with a number of citations ranging between 10 and 15 can be found in $[27,29]$ and were published in Government Information Quarterly and Information Systems: People, Organizations, Institutions, and Technologies, respectively. These articles use, as a qualitative research method, studies about central government and local government, with a focus on digital preservation, information technology, and information and knowledge sharing.

With less than 10 citations, there were seven documents published between 2007 and 2018.

The article of [43], through a qualitative study, provides an overview of the developments in local governments of Estonia in the last 10 years with the objective of introducing the Electronic System of Document and Records Management as the central governance system. This article describes the development of the digital governance model, the first results in terms of implementation of its modules, and other plans on the introduction of information governance in local governments.

In addition, the articles of [24,32], both published in the Records Management Journal, study local and central government in Sweden and in the USA and their focus is on the professional practice of archivists involving information technology and the archivist's digital mandate. The research methods used were mixed and included empirical studies, interviews, literature review, and case studies.

The article in [31], published in the Public Management Review in 2018, is the most recent article appearing in Table 3 of the most cited in sample I. This article analyzes previous studies on the digital government community along with a systematic review of recent articles, published in leading US and European public administration journals, in order to identify and compare the key characteristics of these academic communities, including their top researchers, theories, topics, and methods. From a perspective of public management, digital government could be considered an essential aspect of innovation, coproduction, transparency, and the generation of public value.

From the remaining articles, several research methods were identified, such as case studies, literature review, quantitative cross-sectional, and mixed methods. The studies involve, mostly, central governments and focus on information technology and information management, covering 
a several number of themes, such as project management, which studied the Building Information Modeling (BIM) methods for storing data and asset information using object-oriented modelling of infrastructure [25], digital preservation, and digital community.

Additionally, after the analysis, it was also possible to conclude that six of the documents in Table 3 are conference papers, and some of them were published in the same papers: two articles, written by $[27,44]$, were published in the Government Information Quarterly and another two articles, written by [24,32], were published in the Records Management Journal.

Regarding the summation of the number of citations per year, the years from 2015 to 2019 were considered. It was verified that the number of citations of sample I has a higher incidence in the years 2017 and 2018 with 20 citations in each of the years. In addition, 2019 already has three citations, showing that since 2017 there seems to have been a growing interest in the research of digital government. The years 2015 (14 citations) and 2016 (16 citations) have a similar number of citations. The set of articles contain 73 citations in total since 2015, as it can be seen in Figure 3.

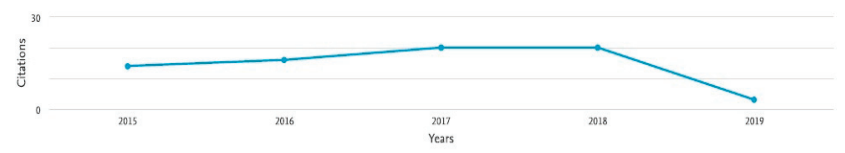

Figure 3. Citations by year (2015-2019) of most cited public sector DG articles.

\subsection{Document Types}

The documents selected in sample I have different types: 15 are conference papers, 10 are articles, 2 are books or book chapters, and 1 is an editorial. As shown in Figure 4, the most significant percentage belongs to conference articles (50\%), followed by articles (33.3\%), both of which show a trend in the type of documents of the digital government literature.

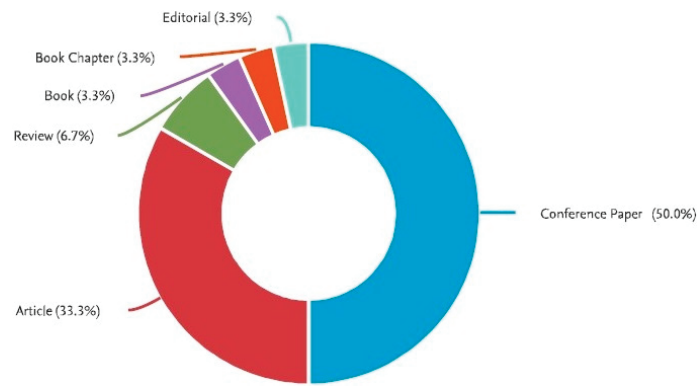

Figure 4. Classification of documents by type.

\subsection{Jurisdiction}

According to Table 2, the main focus of the digital government literature is central governments $(63.3 \%)$, followed by the local governments $(23.3 \%)$. There are also other attributes such as state/regional and public business enterprise (PBE) in $10 \%$ of documents. However, in coding the articles, the lines between what is a central government function and a state/regional function are sometimes blurred or nonexistent because different countries have different structures.

\subsection{Location}

Analyzing the criterion location, the results show that Europe/UK is the most studied region, with 19 articles representing $46.6 \%$ of the studies, followed by the North American region with 7 articles representing $23.3 \%$ of the studies. The Asia/China region, with 4 articles, represents $13.3 \%$ of the sample. No articles were found regarding South America. Digital government research articles include 
various countries, such as the Philippines, Estonia, Australia, China, USA, Greece, India, Ghana, Sweden, Germany, Norway, and New Zealand. According to this analysis, a great variety of countries that study digital government in different contexts can be highlighted. With the emergence of articles from several countries, the possibility of international comparisons regarding differences and common guidelines of digital government research is growing.

The most significant number of articles was identified in the Europe/UK region, covering the years 2009 to 2018, with Sweden being the most analyzed country. The US is also the country that continues to produce more articles regarding the North American region. The results also show that, since 2017, the Asia/China region is growing in published studies $(13.3 \%)$, which may be due to the growing importance of Asia in terms of the global economy. In addition, studies about India are increasing and focus mainly on universities and research centers. Locations like Australia, where one study was found in 2018, South America, which has no studies and Africa, with studies from 2016 and 2018, are under-represented and under-researched. Finally, a study from New Zealand addressing Oceania region was published in 2009. Figure 5 represents the articles published per location. However, nine studies were left out of this classification, due to the fact that they were either theoretical or the location was not disclosed.

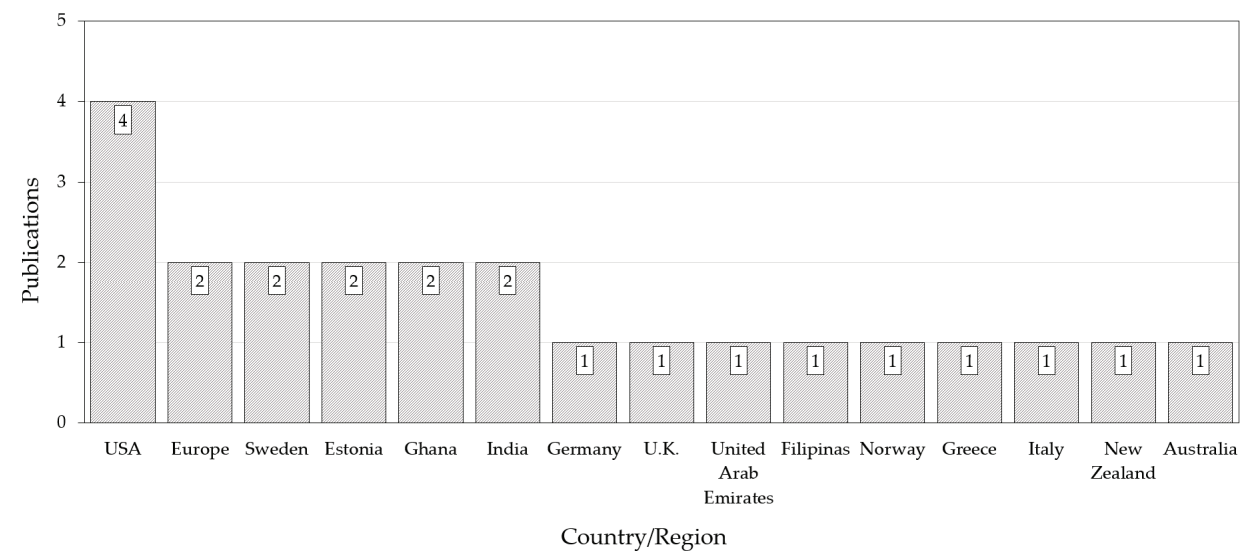

Figure 5. Classification of the published articles by location.

\subsection{Research Methodology}

Qualitative approaches represent $30.0 \%$ of sample I (9 articles) and are the most used and representative approaches in digital government research. The case studies are the second most used approach, with seven articles representing $23.3 \%$ of the sample. In the analysis of the research method of the articles, it was difficult to classify them by specific attributes due to the existence of a mixture of methods. From 2009 until 2018, the articles contained four mixed methods and three other methods, highlighting the existence of a significant fraction of studies that do not use a specific research method.

According to Table 2, approaches such as quantitative cross-sectional and action research represent only $6.7 \%$ of the sample (only 1 article per research method). The quantitative studies represent $6.7 \%$ with two articles, and the literature review represents $10 \%$ with three articles.

\subsection{Framework}

The digital government literature focused mainly on the use of existing frameworks $(90 \%)$. The development of new frameworks concentrated only $3.3 \%$ of the studies and $6.7 \%$ of the articles did not use specific frameworks. Thus, this can be an evidence of the interest of researchers in the issue of digital government. 


\subsection{Themes}

The analysis of the results of the research themes shows that eight articles (26.7\% of the sample) focus on information technology and six articles (20\% of the sample) focus on information management. The third most analyzed issue is the knowledge management strategy, with four articles representing $13.3 \%$ of the sample. The subjects "digital preservation", "knowledge innovation", and "management of elements and processes" have three articles each and together represent $10.0 \%$ of the sample. Less analyzed themes, like "organizational learning" and "organizational culture", represent the remaining $10 \%$ of the studies.

The distribution of themes shows that the topics are scattered. Analyzing the evolution over time, the results show that the theme of "information technology" has been approached between the years 2004 to 2019 with a higher incidence in the articles from the year 2018. This growing trend is due to the importance of information technology in the process of transformation in the public sector. From 2012 until 2017, the research focused more on the theme of "knowledge management strategy".

To complement the themes of the selected articles, the articles of the sample were also analyzed according to the research areas addressed. Table 4 and Figure 6 show that the areas of research "Computer Science" and "Social Sciences" were included 27 times representing 44\% of the sample, followed by "Business, Management and Accounting" and "Decision Sciences", which were included 14 times, representing $28 \%$. The remaining areas were included eight times, representing $18 \%$ of the sample.

Table 4. Documents by subject area.

\begin{tabular}{cc}
\hline Subject Area & Number \\
\hline Computer Science & 15 \\
Social Sciences & 12 \\
Business, Management and Accounting & 8 \\
Decision Sciences & 6 \\
Engineering & 3 \\
Agricultural and Biological Sciences & 1 \\
Chemistry & 1 \\
Earth and Planetary Sciences & 1 \\
Economics, Econometrics and Finance & 1 \\
Mathematics & 1 \\
\hline
\end{tabular}

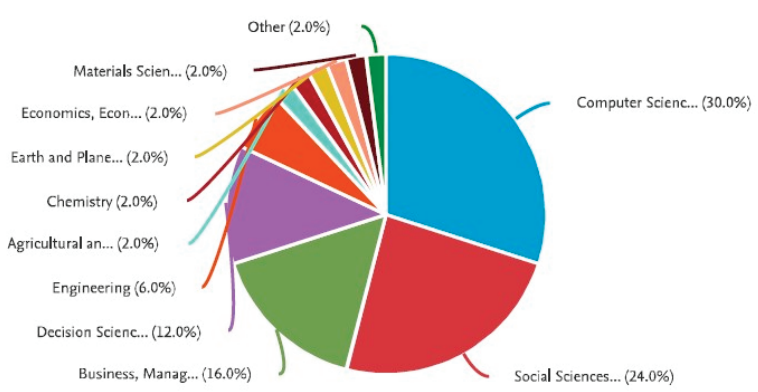

Figure 6. Documents by subject area.

\subsection{Content Analysis (Sample II)}

Sample II, as seen in Table 5, was constructed with 10 studies from the content analysis of sample I, in order to answer the third question in the study-How does digital government literature relate to knowledge management? 


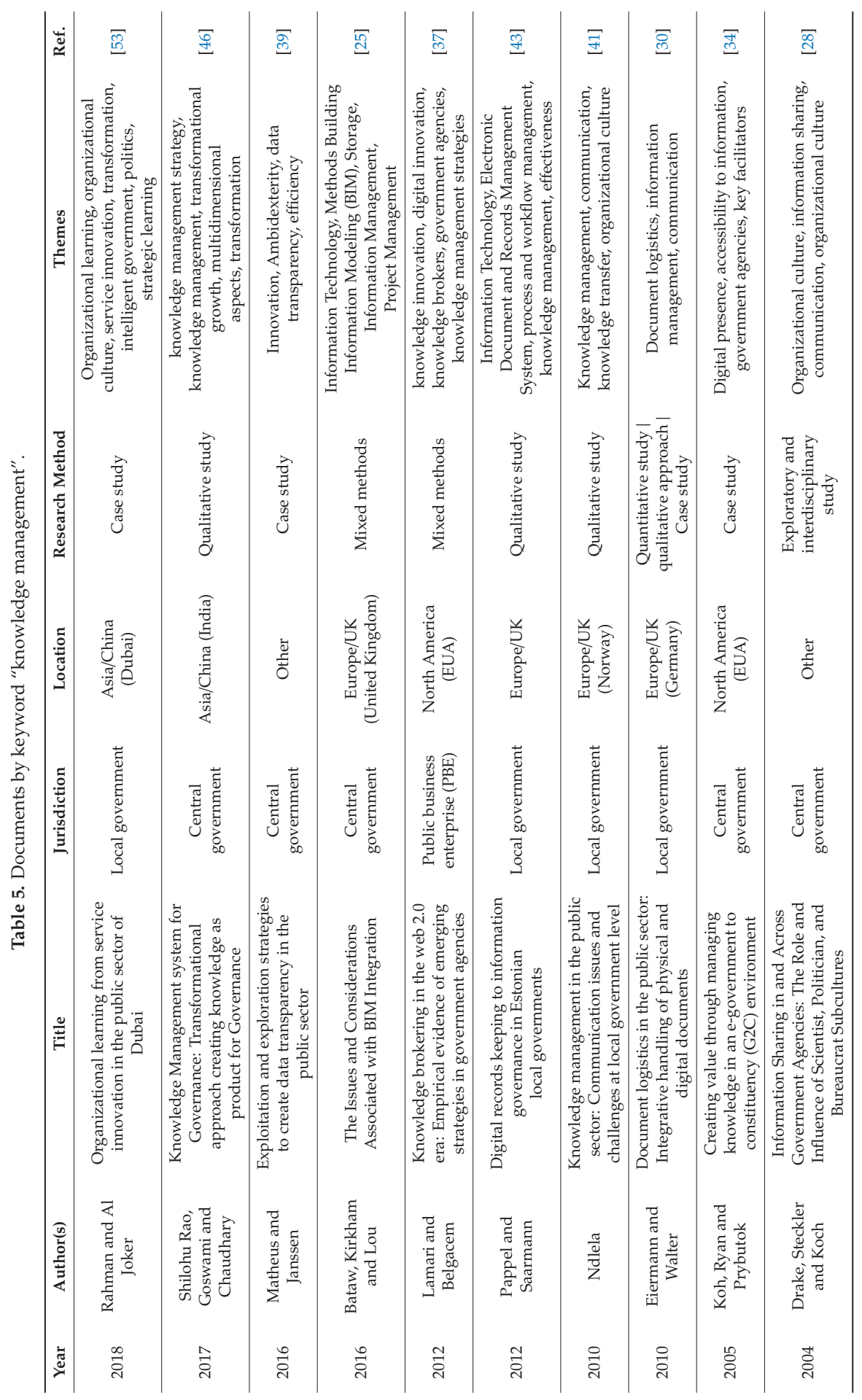


For the article selection, criteria for title and abstract analysis was used along with the application of keyword filtering to knowledge management. The objective was to analyze the content by verifying how knowledge management is present in studies of digital government and how they are related, comparing the main characteristics of knowledge management approach in digital government research, theories, topics, and methods. Their similarities and differences present opportunities for more dialogue between digital government and knowledge management scholars, who can produce synergies to increase the production and dissemination of knowledge.

From this analysis, it was verified that the authors in [53] have published a study that addresses organizational learning and citizen-centered service innovation in the federal and local governments of Dubai. This case is presented in the context of the rapid transformation of the Dubai eGovernment into a smart government that began in 2013. The goal was to outline possible policy and strategic learning more driven by demand and service improvement initiatives.

The authors in [46] have published an article that addresses knowledge management as a phenomenon established and applied in various disciplines for transformational growth. The study focuses on the India Digital Program, launched in 2015, which had the vision of "turning India into a digitally empowered society and knowledge economy". The document highlights the multidimensional aspects of the implementation of knowledge management for digital government, such as the need for knowledge management in a Federal Government system, along with its main objectives, with the main resources moving from structure to implementation.

The article of [39] analyses ambidexterity, which is the ability of an organization to be able to develop new products and innovate while continuing to provide and update its existing services. A case study, to understand better how the combination of exploitation and exploration can enable data transparency, was used.

In [25] the Building Information Modeling (BIM) methods in the UK government are studied as a critical aspect in the notion of "interoperability" between various software applications used in the design process and construction and a common data format for the efficient exchange of information. A mixed methods approach was used: questionnaire analysis and a secondary case study analysis.

The research presented in [37] is based on a representative sample of knowledge brokers from government agencies. The study goes beyond the rhetorical and hermeneutical analyses on this subject, to outline an empirical and factual view of emerging practices and strategies in knowledge intermediation within Québec's government agencies known for their wide use of Web 2.0 platforms and digital innovation.

The authors in [43] conducted a study that provides an overview of developments in local governments in Estonia over the last 10 years intending to introduce the Electronic Records and Records Management System as the central system of governance. It is emphasized that information systems have as their main objective in the public sector to store, manipulate, diffuse, and preserve knowledge to achieve the effectiveness of electronic governance.

In [41] the authors examined the major communication challenges, namely those faced by small municipalities in their efforts to implement knowledge management programs. The study data was extracted from a survey collected in a small municipality of Norway. The article highlights the role of appropriate and inadequate communication behavior patterns for knowledge transfer at local government levels.

In [30] the authors address the current state of document logistics in the public sector and identified current needs and potential trends for the near future using a quantitative study. In addition, a qualitative approach was chosen to further examine the findings of the study, gaining greater insight by conducting a case study with the federal state of Bremen, Germany. The related documents and information are considered an essential basis for communication in the public sector.

In [34] the authors propose that government agencies should go through an evolutionary path as they progress from an introductory digital presence to more complex forms of interaction with constituents. A path of progression is described, and its key facilitators are highlighted. 
Finally, the authors in [28] present an exploratory and interdisciplinary study of issues related to information sharing within and between three public bodies, to illustrate the key points about information sharing among subcultures and some of its implications for research and practice.

After this analysis, it was verified that most of the articles do not present a research approach directly related to knowledge management but approach themes that can indirectly improve knowledge management practices within the public sector. The success of digital government depends on the quality of the organization's knowledge management and how they simultaneously complement each other. There is a lack of studies that relate digital government to the direct or strategic effect of knowledge management effectiveness in the public sector.

\section{Quantitative Research Questionnaire Methodology}

In the first phase of the research, an analysis of the literature was carried out, with the purpose of analyzing the digital transformation process and its relationship with knowledge management in public administration. To support the research hypothesis and meeting what is intended with this research, the choice of the scientific method fell on a quantitative study, which the authors considered more appropriate to answer the problem. Thus, through quantitative research the problem was quantified by generating numerical data, which can be transformed into usable statistics, to understand the behaviors, attitudes, opinions, and other actions of the sample and to generalize the results to a population. Therefore, with this quantitative method, it was intended to verify the effect of digital transformation on knowledge management practices in Portuguese public administration.

\subsection{Sample}

The research was carried out in two governmental areas, the General Secretariat of the Ministry of Environment (SGMAMB) and the Office of the Minister for the Environment and Energy Transition (MATE) belonging to the Ministry of the Environment of the Portuguese Government, which was chosen because it is part of the project Fujitsu's SmartDOCS ${ }^{\circledR}$ in the Portuguese Public Administration, which consists of the implementation and procedural management platform.

In the selection of the target audience, characteristics considered interesting within the scope of this study were analyzed. Collaborators directly involved in the process of implementing the digital transformation were selected, as this is a probabilistic convenience sample.

The target population has a total of 213 employees belonging to the services of the two governmental areas of the Ministry of the Environment, of which 54 employees constitute the sample of the study, which represents $25.35 \%$ of the target population.

At SGMAMB, comprising 113 employees, questionnaires were distributed to 37 employees, and at MATE, comprising 101 employees, questionnaires were distributed to 17 employees, corresponding to a percentage of $33.04 \%$ and $16.83 \%$ of the target population of each of the respective government areas. Questionnaire respondents were asked to indicate their gender, age, educational qualifications, years of work, function, and areas of work, in order to use these elements as characteristics of the sample, as it can be seen in Table 6 .

The sample presented in Table 6 is composed of mainly females $(75.93 \%)$, aged between 35 and 49 years $(48.15 \%)$, and with more than 30 years of work in the studied organization $(33.33 \%)$. The most frequent educational qualifications correspond to secondary education (10th to 12th years, $42.59 \%$ ) and graduation (42.59\%). SGMAMB integrates a greater number of employees $(68.42 \%)$, the "administrative" function is the most frequently performed $(46.30 \%)$, and, finally, the work areas with the highest incidence correspond to the advisory area $(20.37 \%)$ and the administrative support area $(18.52 \%)$. 
Table 6. Research framework and main results.

\begin{tabular}{|c|c|c|c|c|c|c|c|}
\hline \multicolumn{2}{|c|}{ Government Areas } & \multicolumn{2}{|c|}{ SGMAMB } & \multicolumn{2}{|c|}{ MATE } & \multicolumn{2}{|c|}{ Total } \\
\hline & & $\mathrm{Nr}$ & $\%$ & $\mathrm{Nr}$ & $\%$ & $\mathrm{Nr}$ & $\%$ \\
\hline \multirow{2}{*}{ Gender } & Male & 9 & $24.32 \%$ & 4 & $24.53 \%$ & 13 & $24.07 \%$ \\
\hline & Female & 28 & $75.68 \%$ & 13 & $76.47 \%$ & 41 & $75.93 \%$ \\
\hline \multirow{5}{*}{ Age } & From 18 to 24 years & 0 & $0.00 \%$ & 1 & $5.88 \%$ & 1 & $1.85 \%$ \\
\hline & From 25 to 34 years & 0 & $0.00 \%$ & 2 & $11.76 \%$ & 2 & $3.70 \%$ \\
\hline & From 35 to 49 years & 18 & $48.65 \%$ & 8 & $47.06 \%$ & 26 & $48.15 \%$ \\
\hline & From 50 to 64 years & 18 & $48.65 \%$ & 5 & $29.41 \%$ & 23 & $42.59 \%$ \\
\hline & Over 65 years & 1 & $2.70 \%$ & 1 & $5.88 \%$ & 2 & $3.70 \%$ \\
\hline \multirow{8}{*}{ Literary abilities } & 1st to 4th year of EB & 0 & $0.00 \%$ & 0 & $0.00 \%$ & 0 & $0.00 \%$ \\
\hline & 5 th to 6 th year of EB & 0 & $0.00 \%$ & 0 & $0.00 \%$ & 0 & $0.00 \%$ \\
\hline & 7th to 9 th year of EB & 1 & $2.70 \%$ & 0 & $0.00 \%$ & 1 & $1.85 \%$ \\
\hline & High school (10th to 12 th year) & 13 & $35.14 \%$ & 10 & $58.82 \%$ & 23 & $42.59 \%$ \\
\hline & Bachelor & 1 & $2.70 \%$ & 0 & $0.00 \%$ & 1 & $1.85 \%$ \\
\hline & Graduation & 19 & $51.35 \%$ & 4 & $24.53 \%$ & 23 & $42.59 \%$ \\
\hline & masters & 2 & $5.41 \%$ & 2 & $11.76 \%$ & 4 & $7.41 \%$ \\
\hline & PhD/Post Doc & 1 & $2.70 \%$ & 1 & $5.88 \%$ & 2 & $3.70 \%$ \\
\hline \multirow{8}{*}{ Years of work } & Less than 1 year & 0 & $0.00 \%$ & 1 & $5.88 \%$ & 1 & $1.85 \%$ \\
\hline & Between 1 and 5 years & 1 & $2.70 \%$ & 1 & $5.88 \%$ & 2 & $3.70 \%$ \\
\hline & Between 5 and 10 years & 2 & $5.41 \%$ & 2 & $11.76 \%$ & 4 & $7.41 \%$ \\
\hline & Between 10 and 15 years & 4 & $10.81 \%$ & 3 & $17.65 \%$ & 7 & $12.96 \%$ \\
\hline & Between 15 and 20 years & 7 & $18.92 \%$ & 1 & $5.88 \%$ & 8 & $14.81 \%$ \\
\hline & Between 20 and 25 years & 5 & $13.51 \%$ & 2 & $11.76 \%$ & 7 & $12.96 \%$ \\
\hline & Between 25 and 30 years & 6 & $16.22 \%$ & 1 & $5.88 \%$ & 7 & $12.96 \%$ \\
\hline & More than 30 & 12 & $32.43 \%$ & 6 & $35.29 \%$ & 18 & $33.33 \%$ \\
\hline \multirow{6}{*}{ Function } & Administrative & 14 & $37.84 \%$ & 11 & $64.71 \%$ & 25 & $46.30 \%$ \\
\hline & Advisor & 2 & $5.41 \%$ & 4 & $24.53 \%$ & 6 & $11.11 \%$ \\
\hline & Senior Technician & 13 & $35.14 \%$ & 2 & $11.76 \%$ & 15 & $27.78 \%$ \\
\hline & Computer Specialist & 4 & $10.81 \%$ & 0 & $0.00 \%$ & 4 & $7.41 \%$ \\
\hline & Computer Technician & 1 & $2.70 \%$ & 0 & $0.00 \%$ & 1 & $1.85 \%$ \\
\hline & Division Supervisor & 3 & $8.11 \%$ & 0 & $0.00 \%$ & 3 & $5.56 \%$ \\
\hline \multirow{8}{*}{ Areas of job } & Administrative-financial area & 12 & $32.43 \%$ & 0 & $0.00 \%$ & 12 & $22.22 \%$ \\
\hline & Advisory area & 3 & $8.11 \%$ & 8 & $47.06 \%$ & 11 & $20.37 \%$ \\
\hline & Training area & 1 & $2.70 \%$ & 0 & $0.00 \%$ & 1 & $1.85 \%$ \\
\hline & International Relations Area & 4 & $10.81 \%$ & 0 & $0.00 \%$ & 4 & $7.41 \%$ \\
\hline & IT area & 5 & $13.51 \%$ & 0 & $0.00 \%$ & 5 & $9.26 \%$ \\
\hline & Human resources area & 7 & $18.92 \%$ & 0 & $0.00 \%$ & 7 & $12.96 \%$ \\
\hline & Legal Advisory Area & 4 & $10.81 \%$ & 0 & $0.00 \%$ & 4 & $7.41 \%$ \\
\hline & Administrative support area & 1 & $2.70 \%$ & 9 & $52.94 \%$ & 10 & $18.52 \%$ \\
\hline
\end{tabular}

\subsection{Questionnaire}

After the literature review and with a better perception of the state of the art and the importance of digital transformation and knowledge management in public organizations, next is the design phase of the issues that would be the basis of the questionnaires that were made available to a group of employees of the Ministry of the Environment.

The questionnaire focuses on estimating, from the collected data, how the digital transformation process in the Portuguese Public Administration takes place and what its relationship is with knowledge management.

In the elaboration of the questionnaire, an introductory note was added which displays the context of the request for collaboration, the guarantee of anonymity of participation, and the confidentiality of the provided information.

The questionnaire consists of 47 closed-answer questions constructed and organized in two groups allowing the assessment of the perceptions, opinions, attitudes, and behaviors of employees concerning 
the process of digital transformation and concerning knowledge management in the organization. Therefore, the questionnaire structure consists of two parts, the first consisting of seven questions regarding the characterization of the sample and the second with 47 questions regarding digital transformation and knowledge management.

The questions address issues such as the state of knowledge management or how the organization fosters the importance of digital transformation and knowledge management. Questions were also elaborated to show the relationship between digital transformation and knowledge management.

The choice of the most appropriate response format considered its advantages, such as ease of application, process, and analysis; ease and speed in the act of responding; presenting a low possibility of errors and working with several alternatives.

Thus, the answer to this questionnaire is based on a 5-point psychometric scale-the Likert scale. A response rate was applied that varies consecutively using scores from 1 to 5 . The scale used in the questionnaire presents a series of five answer options, of which the respondent must select one of the following:

1. Totally disagree,

2. Disagree,

3. Neither Agree nor Disagree,

4. Agree,

5. Totally agree.

Additionally, in order to safeguard the bias of the collected responses, an option of "0-Don't Know" was created and added.

For the analysis and validation of the items, considering the respective meaning of each of the identified issues, they were structured in two representative groups of each of the identified dimensions:

1. Issues regarding digital transformation

2. Issues related to Knowledge Management practices

The data collection procedure was carried out in June 2019, and the questionnaire was made available in person at the organization's facilities and a response rate of $25.35 \%$ of the target population was obtained.

\subsection{Methods}

The data were treated using descriptive and inferential statistics, using the SPSS program (Statistical Package for the Social Sciences, Version 26.0; SPSS Inc., Chicago, IL, USA) and the effects with $p<0.05$ were considered statistically significant.

In the first phase, the set of collected data was submitted and transformed operationally to a basic uniformly varied descriptive analysis.

The results obtained regarding the dimensions of Minimum, Maximum, Average, Standard Deviation, and Asymmetry regarding the totality of the variables observed in the two groups considered were analyzed: Digital Transformation and Knowledge Management.

The homogeneity of the basic variables of each of the groups of identified questions was analyzed to validate whether they demonstrate significant correlations with each other to proceed with the representation of this set of variables by a single variable, that is, one variable for each one of the groups-calculation of Cronbach's alpha index.

After validating the internal coherence expression of the set of responses for the variables in each group, the average response was calculated for all the variables in that group, in order to present, in a first approximation, the unit value underlying that group.

In addition, the main component analysis was carried out by calculating for each group the main component analysis in order to validate whether, with a variability of approximately $50 \%$, it will make sense to represent the group of variables by the first component. 
Additionally, the linear regression methodologies were applied to verify the existence of relationships between the created average variables.

\section{Result Analysis}

\subsection{Statistical Characterization of Groups of Variables}

After applying basic descriptive analysis methodologies to the two conceptual groups of variables that make up the questionnaire, taking into account their meaning, it was intended to validate the possibility of replacing each of these groups by a single variable, that is, one variable for every group, expressing their meaning.

However, as for the dispersion around the averages, only in exceptional cases does this value exceed 1 , so it is possible to infer a remarkable homogeneity in terms of the obtained responses. The correlations between pairs of variables in the two groups were positive, although some of these values are not significant.

Therefore, it was possible to verify the high values of Cronbach's alpha coefficient $(>0.7)$ for both groups of variables, which could improve if some variables were eliminated. These values are also supported by the percentage of total variance obtained for the global variables of each conceptual group, expressed in the analyzes of the first and second main components. It was also found that in both groups, the first component absorbs a large part of the total variability, as depicted in Table 7.

Table 7. Analysis of internal coherence and variance, explained by the first two main components, for each group.

\begin{tabular}{cccc}
\hline \multirow{2}{*}{ Variable Group } & \multirow{2}{*}{ Cronbach Alfa } & \multicolumn{2}{c}{ \% of Variance } \\
\cline { 3 - 4 } & & 1st CPP & 2nd CPP \\
\hline Digital Transformation & 0.878 & 27.0 & 15.9 \\
Knowledge Management & 0.785 & 27.6 & 19.0 \\
\hline
\end{tabular}

Thus, it was possible to verify that, underlying each of the two groups of variables, there is a variable that these observed variables are manifestations, which can be approximated either by the average value of the variables of each group (in the first approximation) or by the first main component respectively - both are linear combinations of group variables.

Furthermore, for reasons of interpretation, it was chosen to proceed with the representation of groups of variables by calculating the average.

\subsection{Study by Regression of the Relationships Between Groups of Variables}

Therefore, after validating the behavior of each of the groups of variables through a linear combination in order to represent each of the groups, the mean was used to represent the groups.

Thus, in this study it is attempted to estimate by linear regression, the possible linear relationships between the two mean variables representative of the respective groups of questions: DT_med and KM_med, as depicted by Table 8 .

Table 8. Analysis of linear relationships, for each group.

\begin{tabular}{ccccccc}
\hline \multirow{2}{*}{ Model } & \multicolumn{2}{c}{ Explanatory Variables } & \multirow{2}{*}{ Cte. } & $\mathbf{B}_{\mathbf{1}}$ & $\mathbf{B}_{\mathbf{2}}$ & $\mathbf{R}^{\mathbf{2}}$ \\
\cline { 2 - 5 } & KM_med & DT_med & & & & \\
\hline 1 & $\mathrm{X}$ & $\mathrm{X}$ & (N.S) & $0.510(\mathrm{~S})$ & - & 0.66 \\
2 & & & (N.S) & $0.856(\mathrm{~S})$ & - & 0.66 \\
\hline
\end{tabular}

Legend: (N.S.)—Not significant, (S.)—Significant. 
Therefore, it was possible to observe that both Digital Transformation (on average) and knowledge management (on average) present significant values (S.) of the respective coefficients.

The results show that $R^{2}$ values are reasonable, namely: 0.66 when considering the explanatory variable DT_med and also 0.66 when considering the explanatory variable KM_med. The regression model whose objective was to verify whether the model explains knowledge management as a function of Digital Transformation showed reasonable average results in the order of $60 \%$, so it can be concluded that the introduction of digital transformation in the Ministry of the Environment has increased knowledge management.

\subsection{Overall Discussion}

The methodology applied in the exploratory research allowed us to prove the existence of a cause-effect relationship between variables related to digital transformation and variables related to Knowledge Management practices.

Based on the methods of multivariate data analysis, it was possible to validate the hypothesis of the work, in which, in the opinion of the respondents, the Digital Transformation process has a relevant effect on Knowledge Management practices. Furthermore, in turn, it was validated that knowledge management is a critical factor in the success of digital transformation.

For both groups of variables, it was possible to verify a positive asymmetry, meaning that respondents tend to choose high response values, generally above the central value (3), of the chosen Likert response scale-graded from 1 to 5, which corroborates this analysis.

Knowledge management proved to be a critical factor in the success of digital transformation in the public organization. According to literature, knowledge management is the process of creating, capturing, and using knowledge from an organization's intangible assets to improve [57]. Knowledge management, considering it as an intangible and precious asset of an organization, has gained relevance in the strategic positioning of organizations. Within Public Administration, knowledge management "is a powerful facilitator in the current drive for greater efficiency in all areas [11]". In this way, the authors in [10] states that knowledge management "has the potential to greatly influence and improve the renewal processes of the public sector".

Thus, it is concluded that the use of technology combined with the systematic use of knowledge increases efficiency, improves efficiency, and facilitates competence, creativity, and innovation in the studied public organization. In addition, knowledge management proved to be a process of leveraging and articulating the skills and knowledge of employees with the support of information technology [58].

The results of the study show the growing importance of digital government (DG) in the public administration, as measured by the increasing number of published papers and the identification of several key issues. However, there is low specialization because few authors write extensively about the public sector. This lack of cohesive literature is evidenced by the low citation rates.

Furthermore, the low levels of international cooperation between authors contribute to the fragmentation of literature. Some research themes and some geographic areas within the public sector theme are overanalyzed, and others are under-researched. Finally, researchers must rethink methodological approaches to make meaningful contributions to the literature to develop more critical approaches.

\section{Conclusions}

As a field of research, the digital government has emerged from several disciplines, including public administration, knowledge management and innovation, information technology, information management, element and process management, communication and organizational culture, among others. There have been several efforts in the last decade to outline this emerging academic community, assessing the growing body of research represented by new, revised publications each year. 
In this study a review and survey were made with its main focus on estimating, from the collected data, how the digital transformation process in the Public Administration takes place and what its relationship is with knowledge management. The review study aimed to understand the role that digital government research plays in the theory and practice of knowledge management. In the survey study, 54 employees belonging to the services of the two governmental areas of the Portuguese Ministry of the Environment were surveyed.

Knowledge management could provide the overall strategy and techniques for eloquently managing digital government content in order to make knowledge more usable and accessible and keep it current. For the success of digital government, more studies should be carried out using appropriate methods and proposals for new research models, which include the knowledge management approach in the digital government literature. From a perspective of knowledge management, the digital government could be considered an essential aspect of innovation, coproduction, transparency, and the generation of public value.

With the intent to understand the relationship between the implementation of digital transformation and the use of knowledge management practices in public organizations and based on the methods of multivariate data analysis, it was possible to validate the hypothesis of the work, in which, in the opinion of the respondents, the digital transformation process has a relevant effect on knowledge management practices. Furthermore, in turn, it was validated that knowledge management is a critical factor in the success of digital transformation. The regression model disclosed that knowledge management as a function of digital transformation showed a reasonable average outcome in the order of $60 \%$, so it can be concluded that the introduction of Digital Transformation in the Portuguese Ministry of the Environment increased Knowledge Management.

Furthermore, it has been found that the terms used in digital governance studies diverge from other terms that have the same meaning as e-government, which makes bibliographic research challenging. In addition, studies with the term digital transformation are scarce, so digital transformation studies and studies of the terms to be used in the digital government literature may be a possible direction for researchers.

As a result of this study, some research agenda topics were found, such as: studies on knowledge management in the process of digital transformation in public administration; case studies in public organizations that have a high impact on the improvement of public services; studies with methodological approaches that contribute significantly to the digital government literature; structured literature reviews on the topic, including research in more databases in order to perform a more in-depth analysis of the literature of digital government; and international comparative studies.

Several limitations can be highlighted. Firstly, the public sector documents were found only in the Scopus database, which could potentially ignore, involuntarily, some relevant articles on digital government and knowledge management studies. Nevertheless, the selection is a comprehensive and representative sample of the digital government literature.

In addition, this study was based on the analysis and interpretation of results, which can sometimes be subjective. Other researchers using the same data may present different interpretations and conclusions.

Author Contributions: Formal analysis, F.M. and R.G.; supervision, F.M. and J.C.O.M.; writing-original draft, A.A. and F.M.; writing-Review and editing, F.M., R.G. and J.C.O.M. All authors have read and agreed to the published version of the manuscript.

Funding: This work was also financially supported by the research unit on Governance, Competitiveness and Public Policy (UID/CPO/04058/2019), funded by national funds through FCT-Fundacão para a Ciência e a Tecnologia. Radu Godina acknowledges Fundação para a Ciência e a Tecnologia (FCT-MCTES) for its financial support via the project UIDB/00667/2020 (UNIDEMI).

Conflicts of Interest: The authors declare no conflict of interest. 


\section{References}

1. Al-Ruithe, M.; Benkhelifa, E.; Hameed, K. Key issues for embracing the cloud computing to adopt a digital transformation: A study of saudi public sector. Procedia Comput. Sci. 2018, 130, 1037-1043. [CrossRef]

2. Weerakkody, V.; Omar, A.; El-Haddadeh, R.; Al-Busaidy, M. Digitally-enabled service transformation in the public sector: The lure of institutional pressure and strategic response towards change. Gov. Inf. Q. 2016, 33, 658-668. [CrossRef]

3. Omar, A.; Weerakkody, V.; Sivarajah, U. Digitally enabled service transformation in UK public sector: A case analysis of universal credit. Int. J. Inf. Manag. 2017, 37, 350-356. [CrossRef]

4. Lee, J.; Kim, B.J.; Park, S.; Park, S.; Oh, K. Proposing a value-based digital government model: Toward broadening sustainability and public participation. Sustainability 2018, 10, 3078. [CrossRef]

5. Zhou, Z.; Gao, F. E-government and knowledge management. Int. J. Comput. Sci. Netw. Secur. 2007, 7, 285-289.

6. Araújo, R.P.; Mottin, A.P.; Rezende, J.F.D.C. Gestão do conhecimento e do capital intelectual: Mapeamento da produção acadêmica brasileira de 1997 a 2011 nos encontros da ANPAD. Organ. Soc. 2013, 20, 283-301. [CrossRef]

7. Serenko, A.; Bontis, N.; Booker, L.; Sadeddin, K.; Hardie, T. "A scientometric analysis of (1994-2008)”, knowledge management and intellectual capital academic literature. J. Manag. Knowl. 2010, 14, 3-23. [CrossRef]

8. De Angelis, C.T. Models of governance and the importance of KM for public administration. J. Knowl. Manag. Pr. 2013, 14, 1-18.

9. Misra, D.C. Ten guiding principles for knowledge management in e-government in developing countries. In First International Conference on Knowledge Management for Productivity and Competitiveness; National Productivity Council: New Delhi, India, 2007.

10. Edge, K. Powerful public sector knowledge management: A school district example. J. Knowl. Manag. 2005, 9, 42-52. [CrossRef]

11. Mcadam, R.; Reid, R. A comparison of public and private sector perceptions and use of management. J. Eur. Ind. Train. 2000, 24, 317-329. [CrossRef]

12. Amayah, A.T. Determinants of knowledge sharing in a public sector organization. J. Manag. Knowl. 2013, 17, 454-471. [CrossRef]

13. Hislop, D. Knowledge Management in Organizations: Acritical Introduction; Oxford University Press: Oxford, UK, 2013.

14. Massaro, M.; Dumay, J.; Garatti, A. Public sector knowledge management: A structured literature review. J. Knowl. Manag. 2015, 19, 530-558. [CrossRef]

15. Guthrie, J.; Ricceri, F.; Dumay, J. Reflections and projections: A decade of intellectual capital accounting research. Br. Account. Rev. 2012, 44, 68-82. [CrossRef]

16. Dumay, J.; Garanina, T. Intellectual capital research: A critical examination of the thirdstage. J. Intellect. Cap. 2013, 14, 10-25. [CrossRef]

17. Dumay, J. 15 years of the journal of intellectual capital and counting: A manifesto for transformational IC research. J. Intellect. Cap. 2014, 15, 2-37. [CrossRef]

18. Dumay, J.; Cai, L. A review and critique of content analysis as a methodology for inquiring into IC disclosure. J. Intellect. Cap. 2014, 15, 264-290. [CrossRef]

19. Dewey, A.; Drahota, A. Introduction to systematic reviews: Online learning module Cochrane Training. Available online: https://training.cochrane.org/interactivelearning/module-1-introduction-conductingsystematic-reviews (accessed on 16 July 2020).

20. Arksey, H.; O'Malley, L. Scoping studies: Towards a methodological framework. Int. J. Soc. Res. Methodol. 2005, 8, 19-32. [CrossRef]

21. Petticrew, M.; Roberts, H. Systematic Reviews in the Social Sciences: A. Practical Guide; John Wiley \& Sons: Hoboken, NJ, USA, 2008; p. 354.

22. Adu, K.K. A multi-methods study exploring the role of stakeholders in the digital preservation environment: The case of ghana. Electron. Libr. 2018, 36, 650-664. [CrossRef]

23. Adu, K.K.; Ngulube, P. Preserving the digital heritage of public institutions in Ghana in the wake of electronic government. Libr. Hi Tech 2016, 34, 748-763. [CrossRef] 
24. Baron, J.R.; Thurston, A. What lessons can be learned from the US archivist's digital mandate for 2019 and is there potential for applying them in lower resource countries? Rec. Manag. J. 2016, 26, 206-217. [CrossRef]

25. Bataw, A.; Kirkham, R.; Lou, E. The issues and considerations associated with BIM integration. In MATEC Web of Conferences; EDP Sciences: Les Ulis, France, 2016; Volume 66.

26. Dawes, S.S.; Burke, G.B.; Gharawi, M. Transnational digital government research collaborations: Purpose, value, challenges. In Proceedings of the 12th Annual International Digital Government Research Conference on Digital Government Innovation in Challenging Times, College Park, MD, USA, 12-15 June 2011.

27. Dorner, D. Public sector readiness for digital preservation in New Zealand: The rate of adoption of an innovation in records management practices. Gov. Inf. Q. 2009, 26, 341-348. [CrossRef]

28. Drake, D.B.; Steckler, N.A.; Koch, M.J. Information sharing in and across government agencies: The role and influence of scientist, politician, and bureaucrat subcultures. Soc. Sci. Comput. Rev. 2004, 22, 67-84. [CrossRef]

29. Eger, J.M.; Maggipinto, A. Technology as a tool of transformation: E-cities and the rule of law. In Information Systems: People, Organizations, Institutions, and Technologies; AD' Atri, S., Ed.; Physica-Verlag HD: Berlin/Heidelberg, Germany, 2010; pp. 23-30.

30. Eiermann, L.; Walter, S. Document logistics in the public sector: Integrative handling of physical and digital documents. Int. J. Netw. Virtual Organ. 2010, 7, 240-256. [CrossRef]

31. Gil-García, J.R.; Dawes, S.S.; Pardo, T.A. Digital government and public management research: Finding the crossroads. Spec. Issue Digit. Gov. Public 2018, 20, 633-646. [CrossRef]

32. Rahman, M.H.A.A.J. Archivists 2.0: Redefining the archivist's profession in the digital age. Rec. Manag. J. 2012, 22, 98-115.

33. Kammerer, S.C. Government workers say goodbye to paper. DB2 Mag. 2004, 9, 38-40.

34. Koh, C.E.; Ryan, S.; Prybutok, V.R. Creating value through managing knowledge in an e-government to constituency (G2C) environment. J. Comput. Inf. Syst. 2005, 45, 32-41.

35. Kolasa, I. Success factors for public sector information system projects: Qualitative literature review. In Proceedings of the European Conference on e-Government, ECEG, Lisbon, Portugal, 12-13 June 2017; Volume Part F129463, pp. 326-335.

36. Koniaris, M.; Papastefanatos, G.; Anagnostopoulos, I. Solon: A holistic approach for modelling, managing and mining legal sources. Algorithms 2018, 11, 196. [CrossRef]

37. Lamari, M.; Belgacem, I. Knowledge brokering in the web 2.0 era: Empirical evidence of emerging strategies in government agencies. In Proceedings of the 2012 International Conference on Education and e-Learning Innovations, Sousse, Tunisia, 1-3 July 2012.

38. Lele, U.; Goswami, S. The fourth industrial revolution, agricultural and rural innovation, and implications for public policy and investments: A case of India. Agric. Econ. 2017, 48, 87-100. [CrossRef]

39. Matheus, R.; Janssen, M. Exploitation and exploration strategies to create data transparency in the public sector. In Proceedings of the ACM International Conference Proceeding Series, Delft, The Netherlands, 1-3 March 2016; pp. 13-16.

40. Müller, H.; Würriehausen, F. Ensuring interoperability of geographic information in local government and inspire. In Proceedings of the 14th International Multidisciplinary Scientific GeoConference SGEM 2014, Albena, Bulgaria, 17-26 June 2014; Volume 3, pp. 559-566.

41. Ndlela, M.N. Knowledge management in the public sector: Communication issues and challenges at local government level. In Proceedings of the 11th European Conference on Knowledge Management, Famalicão, Portugal, 2-3 September 2010; Volume 2, pp. 711-716.

42. Panganiban, G.G.F. E-governance in agriculture: Digital tools enabling filipino farmers. J. Asian Public Policy 2019, 12, 51-70. [CrossRef]

43. Pappel, I.; Pappel, I.; Saarmann, M. Digital records keeping to information governance in Estonian local governments. In Proceedings of the International Conference on Information Society (i-Society 2012), London, UK, 25-28 June 2012; pp. 199-204.

44. Prokopiadou, G.; Papatheodorou, C.; Moschopoulos, D. Integrating knowledge management tools for government information. Gov. Inf. Q. 2004, 21, 170-198. [CrossRef]

45. Rocheleau, B. Case Studies on Digital Government; IGI Global: Hershey, PA, USA, 2007; ISBN 978-1-59904-177-3.

46. Shilohu Rao, N.J.P.; Goswami, D.; Chaudhary, R. Knowledge management system for governance: Transformational approach creating knowledge as product for governance. In Crowdsourcing and Knowledge 
Management in Contemporary Business Environments; IGI Global: Hershey, PA, USA, 2017; Volume 2, pp. 742-751.

47. Sirendi, R.; Mendoza, A.; Barrier, M.; Taveter, K.; Sterling, L. A conceptual framework for effective appropriation of proactive public e-services. In Proceedings of the 18th European Conference on Digital Government, Santiago, Spain, 25-26 October 2018; Volume 2018, pp. 213-221.

48. Svärd, P. E-Government Initiatives and Information Management in Two Local Government Authorities; Academic Publishing International: Cambridge, MA, USA, 2010; pp. 429-436.

49. Vat, K.H. The E-governance concerns in information system design for effective e-government performance improvement. In Handbook of Research on E-Government Readiness for Information and Service Exchange: Utilizing Progressive Information Communication Technologies; IGI Global: Hershey, PA, USA, 2010; Chapter 3, pp. 48-69.

50. Vivo, M.C.D.; Polzonetti, A.; Tapanelli, P. ICT and PA: A marriage made in heaven? In Proceedings of the European Conference on Information Systems Management, Verona, Italy, 8-10 June 2009; pp. 119-125.

51. Jane Broadbent, J.G. Public sector to public services: 20 years of 'contextual' accounting research. Account. Audit. Account. J. 2008, 21, 129-169. [CrossRef]

52. Alexander Serenko, J.D. Knowledge management journal. Part II: Studying research trends and discovering the Google Scholar Effec. J. Knowl. Manag. 2015, 19, 1335. [CrossRef]

53. Rahman, M.H.; Al Joker, A.S. Organizational learning from service innovation in the public sector of Dubai. In Proceedings of the 15th International Conference on Intellectual Capital, Knowledge Management \& Organisational Learning, Cape Town, South Africa, 29-30 November 2018; Volume 2018, pp. 261-267.

54. Merton, R.K. Social Structure and Social Theory; Free Press: New York, NY, USA, 1968.

55. Merton, R.K. The Matthew Effect in Science, II: Cumulative Advantage and the Symbolism of Intellectual Property. Isis 1988, 79, 606. [CrossRef]

56. Merton, R.K. On market timing and investment performance. I. An equilibrium theory of value for market forecasts. J. Bus. 1981, 54, 363-406.

57. Liao, S. Knowledge management technologies and applications-Literature review from 1995 to 2002. Expert Syst. Appl. 2003, 25, 155-164. [CrossRef]

58. Bennet, A.; Bennet, D. The Partnership between Organisational Learning and Knowledge Management. In International Handbooks on Information Systems; Springer: Berlin/Heidelberg, Germany, 2004.

(C) 2020 by the authors. Licensee MDPI, Basel, Switzerland. This article is an open access article distributed under the terms and conditions of the Creative Commons Attribution (CC BY) license (http://creativecommons.org/licenses/by/4.0/). 
MDPI

St. Alban-Anlage 66

4052 Basel

Switzerland

Tel. +41616837734

Fax +41 613028918

www.mdpi.com

Sustainability Editorial Office

E-mail: sustainability@mdpi.com

www.mdpi.com/journal/sustainability

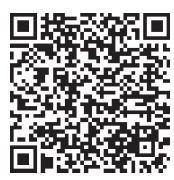





\section{MDPI}

St. Alban-Anlage 66

4052 Basel

Switzerland

Tel: +41 616837734

Fax: +41 613028918 